Rolf Uwe Fülbier

\title{
Konzernbesteuerung nach IFRS
}

IFRS-Konsolidierungsregeln als Ausgangspunkt einer konsolidierten steuerlichen Gewinnermittlung in der EU? 


\section{Rolf Uwe Fülbier}

\section{Konzernbesteuerung nach IFRS}

Die Schaffung einer konsolidierten Körperschaftsteuerbemessungsgrundlage für die grenzüberschreitende Unternehmenstätigkeit innerhalb der EU steht seit dem Jahr 2001 auf der Agenda der EU-Kommission. Dieses ehrgeizige Ziel ist in unterschiedlichen Ausgestaltungsvarianten denkbar und geht mit vielen ungelösten Fragen einher. Eine davon steht im Vordergrund dieser Arbeit: Können die IFRS-Konsolidierungsvorschriften für die Ermittlung dieser Bemessungsgrundlage herangezogen werden? Diese Frage ist von erheblicher Relevanz, weil die Kommission in den eigentlich für völlig andere Zwecke konzipierten IFRS „den einzigen verfügbaren neutralen Ausgangspunkt" für eine konsolidierte steuerliche Gewinnermittlung erkennt. Zudem zählt sie die Ausgestaltung von Konsolidierungsregeln „zu den schwierigsten Aspekten“. Aufbauend auf einem theoretischen Beurteilungsrahmen und unter Berücksichtigung der deutschen und europäischen Rechtssituation wird vor diesem Hintergrund die steuerliche Eignung der IFRS-Konsolidierungsregeln analysiert, um letztlich Ausgestaltungsempfehlungen für den Regulierer zu entwickeln und einen Beitrag zur Steuerrechtsgestaltungslehre zu leisten.

Rolf Uwe Fülbier ist seit 2005 Inhaber des Lehrstuhls für Externes Rechnungswesen an der WHU - Otto Beisheim School of Management, Vallendar. Als Schüler von Bernhard Pellens war er zuvor Wissenschaftlicher Mitarbeiter an den Universitäten Münster und Bochum. Zentrale Arbeitsund Forschungsgebiete liegen im Bereich der Internationalen Rechnungslegung (IFRS und USGAAP), aber auch im Kapitalmarktrecht, Gesellschaftsrecht und Steuerrecht. 2002 hat er das Steuerberaterexamen abgelegt. 


\section{Konzernbesteuerung nach IFRS}




\section{BOCHUMER BEITRÄGE ZUR UNTERNEHMENSFÜHRUNG}

Herausgegeben von

Prof. Dr. Michael Abramovici, Prof. Dr. Dr. h.c. mult. Walther Busse von Colbe,

Prof. Dr. Dr. h.c. Werner H. Engelhardt, Prof. Dr. Roland Gabriel,

Prof. Dr. Gert Laßmann, Prof. Dr. Wolfgang Maßberg, Prof. Dr. Bernhard Pellens,

Prof. Dr. Marion Steven, Prof. Dr. Rolf Wartmann, Prof. Dr. Brigitte Werners

Herausgegeben

vom Direktorium des Instituts für Unternehmensführung

der Ruhr-Universität Bochum

Band 73

\section{PETER LANG}

Frankfurt am Main - Berlin - Bern - Bruxelles - New York - Oxford - Wien 


\title{
Rolf Uwe Fülbier
}

\section{Konzernbesteuerung nach IFRS}

\author{
IFRS-Konsolidierungsregeln \\ als Ausgangspunkt einer konsolidierten \\ steuerlichen Gewinnermittlung \\ in der EU?
}

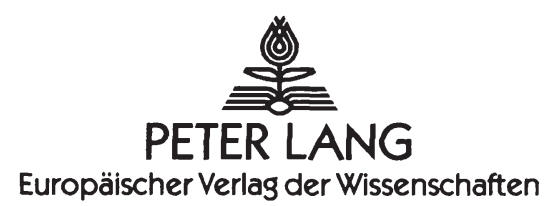




\title{
Bibliografische Information Der Deutschen Bibliothek \\ Die Deutsche Bibliothek verzeichnet diese Publikation in der Deutschen Nationalbibliografie; detaillierte bibliografische \\ Daten sind im Internet über <http://dnb.ddb.de> abrufbar.
}

Open Access: The online version of this publication is published on www. peterlang.com and www.econstor.eu under the international Creative Commons License CC-BY 4.0. Learn more on how you can use and share this work: http://creativecommons.org/licenses/by/4.0.

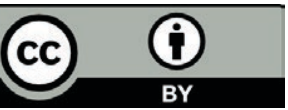

This book is available Open Access thanks to the kind support of ZBW Leibniz-Informationszentrum Wirtschaft.

Gedruckt auf alterungsbeständigem, säurefreiem Papier.

\author{
ISSN $1860-479 X$ \\ ISBN 3-631-55626-8 \\ ISBN 978-3-631-75507-5 (eBook) \\ (c) Peter Lang GmbH \\ Europäischer Verlag der Wissenschaften \\ Frankfurt am Main 2006 \\ Alle Rechte vorbehalten.
}

Das Werk einschließlich aller seiner Teile ist urheberrechtlich geschützt. Jede Verwertung außerhalb der engen Grenzen des

Urheberrechtsgesetzes ist ohne Zustimmung des Verlages

unzulässig und strafbar. Das gilt insbesondere für

Vervielfältigungen, Übersetzungen, Mikroverfilmungen und die Einspeicherung und Verarbeitung in elektronischen Systemen.

Printed in Germany 123467

www.peterlang.de 


\section{Vorwort}

Die vorliegende Arbeit wurde 2005 von der Fakultät für Wirtschaftswissenschaft der Ruhr-Universität Bochum unter dem Titel „Konsolidierte steuerliche Gewinnermittlung nach IFRS? Eine normative Untersuchung der IFRS-Konsolidierungsregeln auf ihre Eignung als Ausgangspunkt einer konsolidierten steuerlichen Gewinnermittlung in der EU“ als Habilitationsschrift angenommen. Damit ist ein Projekt abgeschlossen worden, das 1999 mit der Idee begann, sich mit der spannenden Schnittmenge von IFRSRechnungslegung und steuerlicher Gewinnermittlung auseinanderzusetzen (siehe „Wider die Maßgeblichkeit der International Accounting Standards für die steuerliche Gewinnermittlung“ in: Der Betrieb 1999, S. 1511 ff., zusammen mit Joachim Gassen). Dieses Projekt wurde zusätzlich durch die 2001 neu vorgestellte EU-Strategie zur Unternehmensbesteuerung motiviert, von dem Steuerberater-Examen 2002 begleitet und manchmal, in der "heißen Phase“ 2003 und 2004, sogar in Frage gestellt. Dass es zur Habilitation 2005 und nun zu dieser Veröffentlichung gekommen ist, verdanke ich einer Reihe von Menschen, denen ich (auch) an dieser Stelle ganz herzlich danken möchte.

An erster Stelle steht mein hochgeschätzter akademischer Lehrer Bernhard Pellens, der mich in dieser Zeit, insgesamt sogar über zehn Jahre, geprägt und immer sehr unterstützt und motiviert hat. Für die konstruktive Betreuung auch dieser Habilitationsschrift, die vielen tollen Erfahrungen, Momente und Projekte an seinem Lehrstuhl möchte ich ihm ebenso danken wie für den Spaß und die Begeisterung, die er mir für meinen heutigen Beruf mitgegeben hat. Daneben sei auch Hannes Streim genannt, der sich überaus konstruktiv in die Zweitbetreuung meiner Habilitation eingeschaltet hat. Dafür und für die psychologische Unterstützung während des Habilitationsverfahrens danke ich ihm sehr. Letztlich bin ich der ganzen Bochumer Fakultät, insbesondere Hans Dirrigl, Jochen Hundsdoerfer, Stephan Paul und Dieter Schneider, für die vielen Anmerkungen und Ratschläge während des Verfahrens dankbar.

Großer Dank gebührt auch meinen Kollegen und Freunden, die meine Arbeit in der Endphase sehr sorgfältig durchgearbeitet haben: In der Reihenfolge des Lesens waren dies Andreas Bonse, Thorsten Sellhorn und Joachim Gassen. Wie heißt es doch so schön in ,Apollo 13': „Gentlemen, es war mir eine Ehre, mit Euch zu arbeiten“. Eure Anmerkungen und Kritik sowie Aufmunterungen haben mir sehr geholfen! Ich freue mich schon jetzt auf die vielen gemeinsamen Projekte in der Zukunft.

Natürlich danke ich auch dem gesamten Resthaufen am Lehrstuhl für Internationale Unternehmensrechnung, der während meiner Bochumer Zeit mit mir zusammengearbeitet hat. Mit Euch verbindet mich eine Fülle schöner Erinnerungen, die aufzuzählen hier den Rahmen sprengen würde. Dank an Silke Alves, Kerstin Basche, Nils Crasselt, Karsten Detert, Ralf \& Dirk Jödicke, Stefan Neuhaus, Uwe Nölte, Beate Preuß, Marc Richard, Franca Ruhwedel, Ralf Schremper, Claude Tomaszewski und Markus Weinreis. 
Das Zustandekommen dieser Habilitationsschrift ist zudem maßgeblich gefördert worden durch die Ernst \& Young Stiftung e.V., die mir ein großzügiges Habilitationsstipendium gewährt hat. Hier möchte ich insbesondere Otto H. Jacobs und den gesamten Beirat der Stiftung nennen, denen ich auch für ihre konstruktiven Anmerkungen zu meinem Forschungsprojekt danke. Dank gilt auch dem Accounting, Controlling \& Tax Research Workshop 2004 der Universität Hannover, insbesondere Hans-Jürgen Kirsch und Guido Förster, für Ihre wertvollen Hinweise. Danken möchte ich auch dem Direktorium des ifu - Instituts für Unternehmensführung für die Aufnahme meiner Arbeit in ihre Schriftenreihe und dem Peter Lang-Verlag, hier insbesondere Frau Melanie Sauer, für Ihre gute Betreuung und tollen Konditionen.

Ganz herzlichen Dank gebührt auch Claudia Heymann, die mir hier an der WHU seit Anfang 2005 gekonnt und überaus herzlich den Rücken freihält und dabei noch hervorragende Formatierungsarbeit bei dieser Habilitationsschrift geleistet hat. In der letzten heißen Phase haben auch noch Nils Crasselt (Ruhr-Universität Bochum) und Henrik Pferdehirt (WHU) Teile meiner Arbeit gelesen. Nicht vergessen möchte ich die vielen Bochumer Hilfskräfte, die meine endlosen Kopieraufträge sorgfältig abgearbeitet und meine Literaturarbeit damit entscheidend unterstützt haben.

Was bleibt nach all diesen Danksagungen? Natürlich das Wichtigste: meine Familie! Selbstverständlich steht hier an erster Stelle meine liebe Steffi, die alle Höhen mit mir genossen und alle Tiefen mit mir durchlitten hat - abgesehen davon, dass sie mich tatkräftig beim Korrekturlesen, Literaturverwalten und -sortieren unterstützt hat. Der Dank dafür wiegt umso schwerer, als dass unser erster Sohn Georg im Oktober 2003 geboren wurde und die letzte Habilitationsphase noch sehr geprägt hat. Dem kleinen Scheißer danke ich übrigens für die vielen tollen Ablenkungsmöglichkeiten und die wunderschöne Anfangszeit mit ihm, die ich nie vergessen werde. Unfair wäre es, den zweiten Hosenscheißer, Johann, an dieser Stelle außen vor zu lassen, nur weil er nach Abschluss des Verfahrens geboren wurde. Dank gebührt ihm schon deshalb, dass er akzeptieren musste, seinen Vater in der arbeitsintensiven Startphase an der WHU sehr viel seltener gesehen zu haben als seinerzeit sein älterer Bruder.

Natürlich möchte ich ganz besonders meinen Eltern danken, die unendlich viel an Liebe und Arbeit in mich investiert haben. Mein Vater und meine leider viel zu früh verstorbene Mutter sind wahrscheinlich fürchterlich stolz auf ihren „Herrn Professor“ und können sich sicher sein, dass ich nicht minder stolz auf sie bin! Nicht vergessen möchte ich auch meine Brüder Klaus-Peter und Ulrich, die im Übrigen ebenso wie Steffis Eltern Heide und Fritz an meiner Habilitationsphase teilhatten und mit mir ihrem Ende entgegenfieberten. 


\section{Inhaltsübersicht}

Kapitel I: Einführung 1

1 Problemstellung und Ziel 1

2 Eingrenzung und Gang der Untersuchung 7

Kapitel II: Normative Anforderungen an eine konsolidierte steuerliche $\begin{array}{ll}\text { Gewinnermittlung } & 13\end{array}$

1 Grundprinzip der konsolidierten steuerlichen Gewinnermittlung 13

2 Anforderungen an eine steuerliche Gewinnermittlung $\quad 17$

3 Abgrenzung der rechnungslegenden Einheit 67

4 Zwischenergebnis 107

Kapitel III: Konsolidierte steuerliche Gewinnermittlung als Konsequenz normativer Anforderungen und rechtlicher Nebenbedingungen 111

1 Konsolidierung im Spannungsfeld von Trennungsprinzip und Einheitstheorie 112

2 Gewinnermittlungskonzeption und rechtliche Nebenbedingungen am

Beispiel der deutschen (Steuer-)Rechtsordnung 133

3 Zwischenergebnis $\quad 181$

Kapitel IV: Konsolidierte steuerliche Gewinnermittlung in der EU 183

1 Besteuerung der Unternehmensgruppen auf EU-Mitglied-
staatenebene (de lege lata)

2 Besteuerung der Unternehmensgruppen auf Unionsebene (de lege ferenda) 207

3 Zwischenergebnis 226

Kapitel V: Eignung der IFRS zur Ausgestaltung der steuerlichen

Konsolidierung auf EU-Ebene $\quad 229$

1 Zur Frage der grundsätzlichen Eignung 229

2 Voraussetzungen einer Gruppenbesteuerung und Konsolidierungskreis 254

3 Vorbereitende Maßnahmen (Erstellung der Steuerbilanz II) 293

4 Konsolidierungsmaßnahmen $\quad 302$

5 Ergebnis und Anpassungsvorschläge $\quad 361$

Kapitel VI: Fäizit und Ausblick 
Rolf Uwe Fülbier - 978-3-631-75507-5

Downloaded from PubFactory at 01/11/2019 04:02:44AM 


\section{Inhaltsverzeichnis}

$\begin{array}{ll}\text { Abkürzungsverzeichnis } \quad \mathrm{XV} & \\ & \end{array}$

$\begin{array}{ll}\text { Abbildungsverzeichnis } & \text { XIX }\end{array}$

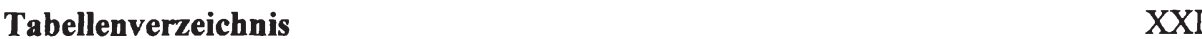

Kapitel I:

Einführung 1

1 Problemstellung und Ziel 1

2 Eingrenzung und Gang der Untersuchung $\quad 7$

\section{Kapitel II:}

Normative Anforderungen an eine konsolidierte steuerliche Gewinnermittlung 13

1 Grundprinzip der konsolidierten steuerlichen Gewinnermittlung 13

2 Anforderungen an eine steuerliche Gewinnermittlung 17

$\begin{array}{ll}2.1 \text { Ökonomische Anforderungen } & 17\end{array}$

$\begin{array}{ll}\text { 2.1.1 Wirtschaftstheoretische Ausgangssituation } & 17\end{array}$

2.1.2 Wirkungsorientierte Effizienzbetrachtung 26

2.1.2.1 Entscheidungsneutralität als ökonomisches Ideal? 26

2.1.2.2 Anforderungen an eine investitionsneutrale

Gewinnermittlung $\quad 30$

2.1.2.3 Anforderungen an eine wettbewerbsneutrale Gewinnermittlung $\quad 37$

2.1.3 Durchführungsorientierte Effizienzbetrachtung 42

2.2 Ethisch-verfassungsrechtliche Anforderungen 47

$\begin{array}{ll}\text { 2.2.1 Verfassungsregeln aus ökonomischer Sicht } & 47\end{array}$

2.2.2 Verfassungsrechtliche Anforderungen am Beispiel des
deutschen Grundgesetzes

2.2.3 Ökonomische Deutung verfassungsrechtlicher Anforderungen: (Un-)Vereinbarkeit von Effizienz und Gerechtigkeit 52

2.2.4 Reinvermögenszugangs- oder -zuwachstheorie zur Messung steuerlicher Leistungsfähigkeit? $\quad 60$

3 Abgrenzung der rechnungslegenden Einheit 67

3.1 Rechnungslegende Einheit als Abbild unternehmerischer Organisation $\quad 68$

3.2 Alternative Sichtweisen unternehmerischer Organisation 70 
3.2.1 Institutionenökonomisches Modell der Unternehmung 70

$\begin{array}{ll}\text { 3.2.1.1 Unternehmung als Vertragsnetzwerk } & 70\end{array}$

3.2.1.2 Parallelen zur evolutorischen Sicht $\quad 77$

3.2.1.3 Schlussfolgerungen für ein ökonomisches Modell der Unternehmung

3.2.2 Rechtsformorientierte Unternehmenssicht

3.3 Modell der Unternehmung als Abgrenzungsleitbild für die steuerliche Gewinnermittlung

$\begin{array}{ll}\text { 3.3.1 Begründungsansätze } & 85\end{array}$

3.3.1.1 Wirkungsorientierte Effizienzbetrachtung $\quad 85$

3.3.1.2 Durchführungsorientierte Effizienzbetrachtung 89

3.3.1.3 Sicht der steuerlichen Leistungsfähigkeit 90

3.3.2 Versuch einer unternehmungsorientierten Abgrenzung 95

3.3.2.1 Schwierigkeit eindeutiger normativer Aussagen 95

3.3.2.2 Nukleus- und ressourcenbasierte Abgrenzung 95

3.3.2.3 Konkretisierung des Vertragskonzepts als Kernproblem der Abgrenzung $\quad 98$

4 Zwischenergebnis

\section{Kapitel III:}

Konsolidierte steuerliche Gewinnermittlung als Konsequenz normativer Anforderungen und rechtlicher Nebenbedingungen

1 Konsolidierung im Spannungsfeld von Trennungsprinzip und Einheitstheorie

1.1 Trennungsprinzip und Einheitstheorie als grundlegende Besteuerungsprinzipien

1.1.1 Trennungsprinzip und Einzelgewinnermittlung 112

1.1.2 Einheitstheorie und Gesamtgewinnermittlung

1.2 Überführung des Trennungsprinzips in die Einheitstheorie durch Konsolidierung

1.3 Parallelen zu den Theorien der rein informationsorientierten

Konzernrechnungslegung

$\begin{array}{ll}1.4 \text { Auswirkungen der Kerngrößenorientierung } & 126\end{array}$

1.4.1 Umfang der Konsolidierungsmaßnahmen 126

1.4.2 Quotenkonsolidierung und Equity-Methode als Alternativen zur Vollkonsolidierung?

2 Gewinnermittlungskonzeption und rechtliche Nebenbedingungen am

Beispiel der deutschen (Steuer-)Rechtsordnung

2.1 Einzelgewinnermittlung und Trennungsprinzip als Grundsatz

2.2 Anrechnungs-, Freistellungs- und organschaftliches Zurechnungsmodell als partielle Ausnahmen

2.3 Berücksichtigung von Unternehmensverbindungen im Konzern 


\subsubsection{Aktienrechtlicher Konzernsachverhalt}

2.3.2 Beschränkte Relevanz des Konzerngedankens in der Rechnungslegung

2.3.2.1 Relevanz des Konzerngedankens in der rein informationsorientierten Konzernrechnungslegung

2.3.2.2 Irrelevanz des Konzerngedankens in der rechtsfolgeorientierten Rechnungslegung

2.4 Annäherung an Einheitstheorie und Konsolidierung in der Mitunternehmerschaft

2.4.1 Transparenzprinzip als Ausgangspunkt

2.4.2 Gewinnermittlung nach dem Transparenzprinzip 151

2.4.3 Vergleich mit der Konsolidierung 154

$\begin{array}{ll}2.5 & \text { Weitere rechtliche Nebenbedingungen } \\ & 160\end{array}$

$\begin{array}{ll}2.5 .1 \text { Gruppenspezifische Nebenbedingungen } & 160\end{array}$

$\begin{array}{ll}\text { 2.5.1.1 Haftungsseparation } & 160\end{array}$

2.5.1.2 Minderheitenproblem und Steuerverteilung trotz Interessenvielfalt 166

2.5.2 Nebenbedingungen bei grenzüberschreitender Tätigkeit 174

3 Zwischenergebnis

\section{Kapitel IV:}

\section{Konsolidierte steuerliche Gewinnermittlung in der EU}

1 Besteuerung der Unternehmensgruppen auf EU-Mitgliedstaatenebene (de lege lata)

1.1 Überblick und Systematisierung

1.2 Rechtsvergleichende Gegenüberstellung existierender

Konsolidierungsvorschriften

1.2.1 Voraussetzungen einer Gruppenbesteuerung und Konsolidierungskreis

1.2.2 Vorbereitende Maßnahmen

1.2.3 Konsolidierungsmaßnahmen im eigentlichen Sinne 196

1.2.3.1 Grundsätzliches Konsolidierungskonzept 197

$\begin{array}{ll}\text { 1.2.3.2 Kapitalkonsolidierung } & 197\end{array}$

1.2.3.3 Schuldenkonsolidierung 200

1.2.3.4 Zwischenergebniseliminierung sowie Betriebsausgaben und -einnahmenkonsolidierung 202

1.2.4 Steuersubjektivität, Haftung und Steueraufteilung 205

2 Besteuerung der Unternehmensgruppen auf Unionsebene (de lege ferenda) 207

2.1 Historische Entwicklung 207

2.1.1 Bemühungen zur Harmonisierung der steuerlichen Gewinnermittlung 
2.1.2 Bemühungen zur Schaffung einer konsolidierten Körperschaftsteuerbemessungsgrundlage

2.2 EU-Strategie zur künftigen Unternehmensbesteuerung

2.2.1 Hintergrund, Ziele und grundsätzliche Konzeption

2.2.2 Konsolidierungsspezifische Fragen

2.2.3 IFRS als möglicher Ausgangspunkt für die Ausgestaltung der steuerlichen Konsolidierung?

\section{Kapitel V:}

Eignung der IFRS zur Ausgestaltung der steuerlichen Konsolidierung auf EU-Ebene

1 Zur Frage der grundsätzlichen Eignung $\quad 229$

1.1 Diskussionsstand in der deutschen Maßgeblichkeitsdebatte 229

1.2 Ergänzende Eignungsanalyse: Systemtauglichkeit unter

Berücksichtigung dynamischer Aspekte

1.2.1 Funktionale Ausrichtung und bilanztheoretisches Leitbild der IFRS

1.2.1.1 Versuch einer Konkretisierung

1.2.1.2 Überprüfung anhand der Anforderungen an die steuerliche Gewinnermittlung

1.2.2 Institutioneller Rahmen der IFRS

1.3 Zwischenergebnis und weiterer Fortgang der Eignungsprüfung 252

2 Voraussetzungen einer Gruppenbesteuerung und Konsolidierungskreis $\quad 254$

2.1 Regulierung auf der Grundlage der IFRS 254

2.1.1 Voraussetzungen einer konsolidierten Rechnungslegung 254

2.1.2 Abgrenzung des Konsolidierungskreises 258

2.2 Eignung für die konsolidierte steuerliche Gewinnermittlung 259

2.2.1 Nukleus- und Ressourcenorientierung 259

2.2.1.1 Grundsatz 259

2.2.1.2 Rechtsformanforderungen $\quad 260$

2.2.1.3 Weltabschlussprinzip 264

2.2.1.4 Obligatorische Aufstellung und Einbeziehung 267

2.2.1.5 Ausnahmen von der Aufstellungs- und Einbeziehungs-
pflicht

2.2.1.5.1 Tannenbaumprinzip und Ausnahmen von der Aufstellungspflicht $\quad 270$

2.2.1.5.2 Ausnahmen von der Einbeziehungspflicht 273

2.2.2 Vertrags- und/oder Verbindungskonzept 275

2.2.2.1 Einfache Stimmrechtsmehrheit 275

2.2.2.2 Weitere Beherrschungssachverhalte 280 
2.2.2.3 Keine weiteren Voraussetzungen neben der Beherrschung

2.3 Stufenkonzept

2.3.1 Regulierung auf der Grundlage der IFRS

2.3.2 Eignung für die konsolidierte steuerliche Gewinnermittlung

3.1 Regulierung auf der Grundlage der IFRS

3.1.1 Einheitliche Bilanzierungsgrundsätze und Stichtagsidentität 293

3.1.2 Währungsumrechnung 294

3.2 Eignung für die konsolidierte steuerliche Gewinnermittlung 297

3.2.1 Einheitliche Bilanzierungsgrundsätze und Stichtagsidentität 297

3.2.2 Währungsumrechnung 299

4 Konsolidierungsmaßnahmen 302

4.1 Konsolidierungskonzeption nach IFRS 302

4.2 Kapitalkonsolidierung 304

4.2.1 Regulierung auf der Grundlage der IFRS 304

4.2.1.1 ,Business Combinations - Phase I' als Stand der Regulierung 304

4.2.1.2 Ausblick auf ,Business Combinations - Phase II' 309

4.2.2 Eignung für die konsolidierte steuerliche Gewinnermittlung 311

4.2.2.1 Erwerbsmethode im Allgemeinen 311

4.2.2.2 Ansatzfragen im Rahmen der Einzelerwerbsfiktion 313

4.2.2.3 Neubewertung und Ergebniswirkungen 323

4.2.2.4 Goodwill-Folgebewertung nach dem ,ImpairmentOnly Approach' 330

4.2.2.5 Berücksichtigung von Minderheiten 336

4.2.2.5.1 Volle Aufdeckung stiller Reserven und Lasten im Rahmen der Neubewertungsmethode $\quad 336$

4.2.2.5.2 ,Full Goodwill Method' , 344

4.2.2.6 ,Fresh Start Method' 349

4.3 Schuldenkonsolidierung 352

4.3.1 Regulierung auf der Grundlage der IFRS 352

4.3.2 Eignung für die konsolidierte steuerliche Gewinnermittlung 354

4.4 Zwischenergebniseliminierung sowie Betriebsausgaben- und -einnahmenkonsolidierung 356

4.4.1 Regulierung auf der Grundlage der IFRS 356

4.4.2 Eignung für die konsolidierte steuerliche Gewinnermittlung 357

5 Ergebnis und Anpassungsvorschläge 361

Kapitel VI:

$\begin{array}{ll}\text { Fazit und Ausblick } & 371\end{array}$ 
Literaturverzeichnis

Rechtsquellenverzeichnis

Rechtsprechungsverzeichnis

447 


\section{Abkürzungsverzeichnis}

$\begin{array}{ll}\text { a.A. } & \text { anderer Ansicht } \\ \text { A.d.V. } & \text { Anmerkung des Verfassers } \\ \text { AAA } & \text { American Accounting Association } \\ \text { Abb. } & \text { Abbildung } \\ \text { ABl.EG } & \text { Amtsblatt der Europäischen Gemeinschaften } \\ \text { ABl.EU } & \text { Amtsblatt der Europäischen Union } \\ \text { Abs. } & \text { Absatz } \\ \text { ACT } & \text { Advance Corporation Tax } \\ \text { AfA } & \text { Absetzung für Abnutzung } \\ \text { AG } & \text { Aktiengesellschaft, Die Aktiengesellschaft (Zeitschrift) } \\ \text { AICPA } & \text { American Institute of Certified Public Accountants } \\ \text { AK } & \text { Arbeitskreis } \\ \text { AktG } & \text { Aktiengesetz } \\ \text { allg. } & \text { allgemein(er) } \\ \text { AO } & \text { Abgabenordnung } \\ \text { APB } & \text { Accounting Principles Board } \\ \text { Art. } & \text { Artikel/article/articulo } \\ \text { Aufl. } & \text { Auflage } \\ \text { BB } & \text { Betriebs-Berater (Zeitschrift) } \\ \text { Bd. } & \text { Band } \\ \text { BewG } & \text { Bewertungsgesetz } \\ \text { BFH } & \text { Bundesfinanzhof } \\ \text { BFHE } & \text { (Sammlung der) Entscheidungen des Bundesfinanzhofs } \\ \text { BFuP } & \text { Betriebswirtschaftliche Forschung und Praxis (Zeitschrift) } \\ \text { BGB } & \text { Bürgerliches Gesetzbuch } \\ \text { BGBl. } & \text { Bundesgesetzblatt } \\ \text { BGH } & \text { Bundesgerichtshof } \\ \text { BiRiLiG } & \text { Bilanzrichtlinien-Gesetz } \\ \text { BMF } & \text { Bundesministerium der Finanzen } \\ \text { BörsG } & \text { Börsengesetz } \\ \text { BörsZulV } & \text { Börsenzulassungs-Verordnung } \\ \text { BStBl. } & \text { Bundessteuerblatt } \\ \text { Buchst. } & \text { Buchstabe } \\ \text { BVerfG } & \text { Bundesverfassungsgericht } \\ \text { BVerfGE } & \text { Entscheidungen des Bundesverfassungsgerichts } \\ \text { bzgl. } & \text { bezüglich } \\ \text { bzw. } & \text { beziehungsweise } \\ \text { c.p. } & \text { ceteris paribus } \\ \text { CCTB } & \text { Common Consolidated Tax Base } \\ \text { DB } & \text { Der Betrieb (Zeitschrift) } \\ \text { DBW } & \text { Die Betriebswirtschaft (Zeitschrift) } \\ & \end{array}$




$\begin{array}{ll}\text { DCF } & \text { Discounted Cash Flow } \\ \text { diesbzgl. } & \text { diesbezüglich(e, er, es, en) } \\ \text { Diss. } & \text { Dissertation } \\ \text { DRS } & \text { Deutscher Rechnungslegungsstandard } \\ \text { DSR } & \text { Deutscher Standardisierungsrat } \\ \text { DStJG } & \text { Deutsche Steuerjuristische Gesellschaft e.V. } \\ \text { DStR } & \text { Deutsches Steuerrecht (Zeitschrift) } \\ \text { DStZ } & \text { Deutsche Steuerzeitung } \\ \text { DSWR } & \text { Datenverarbeitung, Steuer, Wirtschaft, Recht (Zeitschrift) } \\ \text { e.V. } & \text { eingetragener Verein } \\ \text { ED } & \text { Exposure Draft } \\ \text { EG } & \text { Europäische Gemeinschaft(en) } \\ \text { endg. } & \text { endgültig } \\ \text { EStDV } & \text { Einkommensteuer-Durchführungsverordnung } \\ \text { EStG } & \text { Einkommensteuergesetz } \\ \text { EStH } & \text { Hinweise in den Einkommensteuer-Richtlinien } \\ \text { EStR } & \text { Einkommensteuer-Richtlinien } \\ \text { et al. } & \text { et alii } \\ \text { etc. } & \text { et cetera } \\ \text { EU } & \text { Europäische Union } \\ \text { EUCIT } & \text { European Union Company Income Tax } \\ \text { EuGH } & \text { Europäischer Gerichtshof } \\ \text { evtl. } & \text { eventuell } \\ \text { f./ff. } & \text { folgende/fortfolgende } \\ \text { FASB } & \text { Financial Accounting Standards Board } \\ \text { FAZ } & \text { Frankfurter Allgemeine Zeitung } \\ \text { FG } & \text { Finanzgericht } \\ \text { Fn. } & \text { Fußnote } \\ \text { FR } & \text { Finanz-Rundschau (Zeitschrift) } \\ \text { GbR } & \text { Gesellschaft bürgerlichen Rechts } \\ \text { gem. } & \text { gemäß } \\ \text { GewStG } & \text { Gewerbesteuergesetz } \\ \text { GG } & \text { Grundgesetz } \\ \text { GmbH } & \text { Gesellschaft mit beschränkter Haftung } \\ \text { GmbHR } & \text { GmbH-Rundschau (Zeitschrift) } \\ \text { GuV } & \text { Gewinn- und Verlustrechnung } \\ \text { HGB } & \text { Handelsgesetzbuch } \\ \text { Hrsg. } & \text { Herausgeber } \\ \text { hrsg. } & \text { herausgegeben } \\ \text { HST } & \text { Home State Taxation } \\ \text { HTB } & \text { Harmonised Tax Base } \\ \text { i.A.a. } & \text { in Anlehnung an } \\ \text { i.d.R. } & \text { in der Regel } \\ \text { i.d.Zshg. } & \text { in diesem Zusammenhang } \\ & \end{array}$




\begin{tabular}{|c|c|}
\hline i.R.d. & im Rahmen der/des \\
\hline i.S.d. & im Sinne der/des \\
\hline i.V.m. & in Verbindung mit \\
\hline IAS & International Accounting Standard \\
\hline IASB & International Accounting Standards Board \\
\hline IASC & International Accounting Standards Committee \\
\hline IASCF & International Accounting Standards Committee Foundation \\
\hline IDW & Institut der Wirtschaftsprüfer \\
\hline IFRIC & International Financial Reporting Interpretations Committee \\
\hline IFRS & International Financial Reporting Standards \\
\hline IFS & The Institute for Fiscal Studies \\
\hline $\begin{array}{l}\text { IFSt } \\
\text { insb. }\end{array}$ & $\begin{array}{l}\text { Institut „Finanzen und Steuern“ e.V. } \\
\text { insbesondere }\end{array}$ \\
\hline IStR & Internationales Steuerrecht (Zeitschrift) \\
\hline Jg. & Jahrgang \\
\hline Kap. & Kapitel \\
\hline KapAEG & Kapitalaufnahmeerleichterungsgesetz \\
\hline $\mathrm{KGaA}$ & Kommanditgesellschaft auf Aktien \\
\hline KoR & Zeitschrift für kapitalmarktorientierte Rechnungslegung \\
\hline KSt & Körperschaftsteuer \\
\hline KSTG & Körperschaftsteuergesetz \\
\hline KStR & Körperschaftsteuer-Richtlinien \\
\hline lt. & laut \\
\hline m.w.N. & mit weiteren Nachweisen \\
\hline $\max$ & maximal \\
\hline mind. & mindestens \\
\hline Mio. & Million(en) \\
\hline MU & Mutterunternehmen \\
\hline MwSt & Mehrwertsteuer \\
\hline N.F. & Neue Folge \\
\hline NJW & Neue Juristische Wochenschrift (Zeitschrift) \\
\hline No. & Number \\
\hline Nr. & Nummer \\
\hline 0. & oder \\
\hline o.V. & ohne Verfasser \\
\hline OECD & Organization for Economic Cooperation and Development \\
\hline ORDO & Jahrbuch für die Ordnung von Wirtschaft und Gesellschaft (Zeitschrift) \\
\hline Par. & Paragraph(en) \\
\hline PartGG & Partnerschaftsgesellschaftsgesetz \\
\hline PublG & Publizitätsgesetz \\
\hline RFH & Reichsfinanzhof \\
\hline RGBl. & Reichsgesetzblatt \\
\hline RStBl. & Reichssteuerblatt \\
\hline S. & Seite \\
\hline
\end{tabular}




$\begin{array}{ll}\text { s.a. } & \text { siehe auch } \\ \text { Sec } & \text { section(s) } \\ \text { SEC } & \text { Securities and Exchange Commission } \\ \text { SFAC } & \text { Statement of Financial Accounting Concepts } \\ \text { SFAS } & \text { Statement of Financial Accounting Standards } \\ \text { SIC } & \text { Standing Interpretations Committee } \\ \text { sog. } & \text { sogenannt(e) } \\ \text { Sp. } & \text { Spalte } \\ \text { StuB } & \text { Steuern und Bilanzen (Zeitschrift) } \\ \text { StuW } & \text { Steuer und Wirtschaft (Zeitschrift) } \\ \text { SWI } & \text { Steuer und Wirtschaft International (Zeitschrift) } \\ \text { SWK } & \text { Steuer- und WirtschaftsKartei (Zeitschrift) } \\ \text { Tab. } & \text { Tabelle } \\ \text { TEI } & \text { Tax Executive Institute } \\ \text { TU } & \text { Tochterunternehmen } \\ \text { Tz. } & \text { Textziffer } \\ \text { u. } & \text { und } \\ \text { u.a. } & \text { unter anderem } \\ \text { u.U. } & \text { unter Umständen } \\ \text { UM } & \text { Unternehmensbewertung \& Management (Zeitschrift) } \\ \text { UmwStG } & \text { Umwandlungssteuergesetz } \\ \text { URL } & \text { Unified Ressource Locator } \\ \text { US } & \text { United States } \\ \text { US-GAAP } & \text { US-Generally Accepted Accounting Principles } \\ \text { UStG } & \text { Umsatzsteuergesetz } \\ \text { v. } & \text { von, vom } \\ \text { vgl. } & \text { vergleiche } \\ \text { Vol. } & \text { Volume } \\ \text { vs. } & \text { versus } \\ \text { WiSt } & \text { Wirtschaftswissenschaftliches Studium (Zeitschrift) } \\ \text { WISU } & \text { Das Wirtschaftsstudium (Zeitschrift) } \\ \text { WPg } & \text { Die Wirtschaftsprüfung (Zeitschrift) } \\ \text { WPK } & \text { Wirtschaftsprüferkammer } \\ \text { z.B. } & \text { zum Beispiel } \\ \text { z.T. } & \text { zum Teil } \\ \text { ZE } & \text { zahlungsmittelgenerierende Einheit } \\ \text { ZEW } & \text { Zentrum fü Europäische Wirtschaftsforschung GmbH } \\ \text { ZfB } & \text { Zeitschrift für Betriebswirtschaft } \\ \text { ZfbF } & \text { Zeitschrift für betriebswirtschaftliche Forschung } \\ \text { ZfCM } & \text { Zeitschrift für Controlling und Management } \\ \text { ZfhF } & \text { Zeitschrift für handelswirtschaftliche Forschung } \\ \text { ZGR } & \text { Zeitschrift für Unternehmens- und Gesellschaftsrecht } \\ \text { ZHR } & \text { Zeitschrift für das gesamte Handelsrecht und Wirtschaftsrecht } \\ \text { ZIP } & \text { Zeitschrift für Wirtschaftsrecht } \\ & \end{array}$




\section{Abbildungsverzeichnis}

Abb. 1 Gang der Untersuchung 10

Abb. 2 Dreidimensionaler Gerechtigkeitsbegriff 54

Abb. 3 Unternehmung als Netzwerk multilateraler Vertrags-

beziehungen und als nukleusbasiertes Netzwerk bilateraler

Vertragsbeziehungen

Abb. 4 Unternehmung als nukleusbasiertes Netzwerk mit mehreren Subsystemen $\quad 76$

Abb. 5 Sachliche und persönliche Zentraleinheit als Hierarchiespitze 103

Abb. 6 Normative Anforderungen an die konsolidierte steuerliche Gewinnermittlung

Abb. 7 Alternativen zur Erstellung einer steuerlichen

Gesamtgewinnermittlung

Abb. 8 Steuerliche Gewinnermittlung bei der Mitunternehmerschaft nach der Bilanzbündeltheorie

Abb. 9 Steuerliche Gewinnermittlung bei der Mitunternehmerschaft mit einer Personengesellschaft als eigenständiges

Gewinnermittlungssubjekt

Abb. 10 Voraussetzungen einer konsolidierten Gesamtgewinnermittlung

Abb. 11 Gruppenbesteuerungssysteme in der EU zwischen Trennungsprinzip und Einheitstheorie

Abb. 12 „full fair value“-Abschluss

Abb. 13 Steuerlicher Konsolidierungskreis von A unter Zugrundelegung des Stimmrechtskriteriums von IAS 27

Abb. 14

Stufenkonzept nach IFRS

Abb. 15 Zuordnung der Konsolidierungsmethoden zur Einheits- und Interessentheorie 
Rolf Uwe Fülbier - 978-3-631-75507-5

Downloaded from PubFactory at 01/11/2019 04:02:44AM 


\section{Tabellenverzeichnis}

Tab. 1 Gruppenbesteuerungssysteme in den EU-Mitgliedstaaten

Tab. 2 Voraussetzungen einer Gruppenbesteuerung und Abgrenzung des Konsolidierungskreises

Tab. 3 Ausgestaltung der Kapitalkonsolidierung

Tab. 4

Ausgestaltung der Schuldenkonsolidierung

Tab. 5 Ausgestaltung der Zwischenergebniseliminierung sowie Betriebsausgaben- und -einnahmenkonsolidierung 203

Tab. 6 Kapitalkonsolidierungsmethoden im Vergleich 310

Tab. 7 Ertragswertabschreibung auf den Goodwill (Beispielrechnung) 
Rolf Uwe Fülbier - 978-3-631-75507-5

Downloaded from PubFactory at 01/11/2019 04:02:44AM 


\section{Kapitel I}

\section{Einführung}

\section{Problemstellung und Ziel}

Die Harmonisierung der direkten Unternehmensbesteuerung steht seit mehr als vier Jahrzehnten auf der Agenda der Europäischen Union (EU). Nennenswerte Harmonisierungserfolge sind bisher aber nicht zu verzeichnen ${ }^{1}$. Angesichts starker Widerstände von Seiten der Mitgliedstaaten, die sich in ihrer Fiskal-Souveränität bedroht sehen ${ }^{2}$, hat sich die Europäische Kommission auf die Eliminierung steuerlicher Hindernisse beschränkt, die die grenzüberschreitende unternehmerische Tätigkeit innerhalb der EU erschweren und damit der Verwirklichung des europäischen Binnenmarktes entgegenstehen $^{3}$. Letztlich ist die Situation in der EU bei den direkten Unternehmenssteuern weiterhin von einer Koexistenz nationaler Steuerrechtsordnungen geprägt ${ }^{4}$. So bleibt insbesondere auch die steuerliche Gewinnermittlung von den bisherigen Harmonisierungsbestrebungen weitgehend unberührt ${ }^{5}$.

Im Oktober 2001 hat die Europäische Kommission auf der Basis einer umfangreichen, von externen Experten miterstellten Studie („Company Taxation in the Internal Mar$\mathrm{ket}^{\text {"66) }}$ ) eine neue Strategie für den Bereich der direkten Unternehmensbesteuerung bekannt gegeben ${ }^{7}$. Zentrales Anliegen dieser Strategie ist langfristig die Schaffung einer konsolidierten Körperschaftsteuerbemessungsgrundlage für die grenzüberschreitende Unternehmenstätigkeit in der EU. Das zu versteuernde Einkommen einer ganzen Unternehmensgruppe soll hiernach künftig aus einer konsolidierten (Steuer-)Bilanz abgeleitet

1 Vgl. zur Steuerharmonisierung in der EU ausführlich Chetcuti (Corporate Tax Harmonisation, 2001); Hey (Harmonisierung, 1997) S. 67-77; Jacobs (Internationale Unternehmensbesteuerung, 2002) S. 156-192; Lamb (group, 1995) S. 45-50; Mennel/Förster (Steuerrecht im internationalen Vergleich, 2003) Tz. 72-104; Weide (Unternehmenssteuern in der EG, 1996); weiterführend auch Kap. IV.2.

2 Vgl. z.B. o.V. (Towards a common tax base, 2002) S. 5; Roloff (Standortkonkurrenz, 1999) S. 47.

3 Vgl. z.B. Lamb (group, 1995) S. 47; zu den Auswirkungen des europäischen Binnenmarktes auf die Ausgestaltung der nationalen Steuersysteme und die (rechtliche sowie ökonomische Frage der Notwendigkeit der) Steuerharmonisierung in der EU vgl. Dautzenberg (Unternehmensbesteuerung im EG-Binnenmarkt, 1997); Devereux/Pearson (Corporate Tax Harmonisation, 1989); Herzig (Besteuerung der Unternehmen in Europa, 1996); Hey (Harmonisierung, 1997); Jacobs (Internationale Unternehmensbesteuerung, 2002) S. 192-290; Koop (Gewinnbesteuerung, 1993); Lang (Besteuerung in Europa, 1997); Sapusek (Steuerharmonisierung, 1997); Sinn (Tax Harmonization, 1990); Steibert (Einfluss des europäischen Rechts, 2002).

4 Vgl. treffend o.V. (Steuerbasis in EU, 2002) S. 7: „Internationale Konzerne müssen 15 nationale Steuersysteme, rund 100 zwischenstaatliche Doppelbesteuerungsabkommen und zwei EU-Richtlinien beachten“; s.a. EU-Kommission (Steuerumfrage, 2004); Herzig (Steuergestaltung, 1993) S. 1. Durch die Erweiterung der EU am 1.5.2004 auf 25 Mitgliedstaaten hat sich diese Situation noch verschärft.

$5 \mathrm{Vgl}$. zu den bislang weitgehend erfolglosen Bemühungen, die steuerliche Gewinnermittlung in der EU zu harmonisieren, Kap. IV.2.1.

6 Vgl. EU-Kommission (Company Taxation, 2001).

7 Vgl. EU-Kommission (Strategie, 2001); s.a. EU-Kommission (Unternehmensbesteuerung, 2001). 
werden, die auf der Basis eines einzigen Regelwerkes zu erstellen ist ${ }^{1}$. Damit entfiele die bei grenzüberschreitender Unternehmenstätigkeit notwendige Beachtung unterschiedlicher nationaler Gewinnermittlungssysteme. Mit diesem ehrgeizigen Vorhaben entspricht die Europäische Kommission aber nicht nur der Forderung nach einer drastischen Vereinfachung der steuerlichen Gewinnermittlung bei grenzüberschreitender Tätigkeit ${ }^{2}$. Sie wendet sich mit ihren Vorstellungen von einer künftigen Unternehmensbesteuerung auch zwei weiteren, wichtigen Problemfeldern der steuerlichen Gewinnermittlung zu, die - jedes für sich - bereits intensiv diskutiert werden, ohne bisher in ihrer Kombination eine tiefergehende wissenschaftliche Beachtung gefunden zu haben: Dies ist zum einen die Ausrichtung der Unternehmensbesteuerung auf wirtschaftlich zusammenhängende Gruppen rechtlich selbständiger Unternehmen und damit die Einführung einer Art von EU-weiter Konzern- bzw. Gruppenbesteuerung ${ }^{3}$. Bei der Frage, welchem Regelwerk diese steuerliche Gewinnermittlung folgen soll, schlägt die Kommission zum anderen eine Brücke zu den International Financial Reporting Standards (IFRS) ${ }^{4}$ des in London ansässigen International Accounting Standards Board (IASB) und damit zu einem kapitalmarkt- und informationsorientierten Rechnungslegungssystem.

Das erste Problemfeld, die Besteuerung verbundener oder verflochtener Unternehmen, bewegt die wissenschaftliche Diskussion schon seit Jahrzehnten, zumal das wirtschaftlich autonome Unternehmen ,weitgehend der Vergangenheit angehört“s. In Deutschland ist die Entwicklung der handelsrechtlichen Konzernrechnungslegung seit jeher von der Frage begleitet gewesen, ob ein eventuell modifizierter Konzernabschluss nicht auch für steuerliche Zwecke herangezogen werden könne. Überlegungen dieser Art fanden sich schon früh im letzten Jahrhundert ${ }^{6}$, häuften sich zwischenzeitlich im Zuge der

1 Vgl. ausführlich zum Inhalt dieser Strategie Kap. IV.2.2; im Überblick z.B. Devereux (Debating Proposed Reforms, 2004); Oestreicher (Konzernbesteuerung in Europa, 2002) S. 342-348.

2 Vgl. z.B. o.V. (Steuerbasis in EU, 2002) S. 7; diese Forderung hat bereits das Ruding Committee (Report, 1992) S. 193-220 formuliert.

3 Die ,Konzern'-Terminologie ist ein deutsches Spezifikum, weil der ,Konzern' hier umgangssprachlich für eine Unternehmensgruppe steht. Streng genommen beschreibt dieser Begriff nur einen bestimmten aktienrechtlichen Sachverhalt (Kap. III.2.3.1). Im Hinblick auf die von deutschen Rechtskriterien abgekoppelten europäischen Überlegungen zur künftigen Unternehmensbesteuerung wird in dieser Arbeit der neutralere und international gebräuchliche Gruppenbegriff ("group") verwendet.

4 Unter die IFRS sind auch die noch gültigen International Accounting Standards (IAS) zu subsumieren, die vom International Accounting Standards Committee (IASC) als Vorgängerinstitution des IASB von 1973 bis 2001 herausgegeben wurden; vgl. IAS 1.11 (2003).

5 Ordelheide (Konzern, 1986) S. 294, der den hohen Konzernierungsgrad deutscher Aktiengesellschaften empirisch belegt; neuere Erkenntnisse dazu bei Görling (Konzernhaftung, 1998) S. 47-72; Ruhwedel (Eigentümerstruktur, 2003) S. 201-222; Theisen (Konzern, 2000) S. 1-14. In anderen EUMitgliedstaaten sind die Strukturen vergleichbar; vgl. Hommelhoff(Konzernrecht, 1992) S. 121-128.

6 Vgl. u.a. Friedländer (Organtheorie, 1931) Sp. 493-502; Hoffmann (Konzern-Bilanz, 1930) S. 37-46; Oberst (Frage der Konzernbilanz, 1930) S. 225-226; Oberst (Konzernbilanz, 1933) S. 67; RFH v. 26.7.1932 (I D 2/31 u. III D 2/32); später auch Bisani (Konzernbesteuerung, 1962); Bühler (Steuerrecht, 1956) 2. Teil; Bühler (Konzernbesteuerung, 1959); Girnth (Ertragsbesteuerung von Konzernen, 1963). 
Kodifizierung des Aktiengesetzes von $1965^{1}$ und des Bilanzrichtlinien-Gesetzes von $1985^{2}$ und werden bis heute von Ökonomen und Steuerjuristen immer wieder, verstärkt auch mit Bezug auf den grenzüberschreitenden, europäischen Kontext diskutiert ${ }^{3} . \mathrm{Zu}$ einer steuerlichen Anerkennung einer wie auch immer gearteten Konzernrechnungslegung hat dies jedoch nicht geführt ${ }^{4}$, auch wenn Unternehmensverbindungen insbesondere in dem Organschaftskonzept steuerlich nicht völlig ignoriert werden ${ }^{5}$. Neben Deutschland existiert auch in anderen Mitgliedstaaten der EU eine ähnliche Diskussion über die Möglichkeiten und Grenzen einer Gruppenbesteuerung, die in manchen Staaten sogar zu konkreten steuerrechtlichen Konsequenzen geführt hat ${ }^{6}$.

Das zweite Problemfeld, die Verbindung von steuerlicher Gewinnermittlung und informationsorientierter Rechnungslegung nach IFRS, ist erst in den letzten Jahren, mit zunehmender Praxisrelevanz dieses internationalen Rechnungslegungssystems, in den Fokus wissenschaftlicher Untersuchungen gerückt. Ausgangspunkt dieser Untersuchungen ist regelmäßig die Frage, ob sich die handelsrechtliche Entwicklung hin zu einer internationalen Rechnungslegung über die in der EU nicht nur in Deutschland existie-

1 Vgl. zu der hiervon angestoßenen Diskussion über steuerliche Konsequenzen insb. $B F H$ v. 26.7.1967 (I 138/65); Döllerer (Besprechung von Niemann, 1969); Haase (Anerkennung des Konzernabschlusses, 1968); Hübl (Organschaft, 1965); Köhler (Besteuerung von Konzern, 1970) S. 91-189; Mutze (Konzernabschluß, 1971); Niemann (Gewinnrealisierung innerhalb des Konzerns, 1968); Rose (Gegenwartsprobleme, 1966) S. 298-305; Schuhmann (Konzernabschluß, 1962) S. 48-50; von Wallis (Konzernrecht, 1967); kurz auch Birkholz (Aktienrecht, 1966) S. 711; Busse von Colbe (Jahresabschluß des Konzerns, 1960) S. 146, der hier noch eine Schubwirkung für die Konzernbesteuerung vermutet; Pohle (Konzernrecht, 1960) S. 316.

2 Vgl. u.a. Böhm (Konzerngewinn als Grundlage für Dividendenausschüttung und Steuerbemessung, 1979); Harms/Küting (Perspektiven der Konzernbesteuerung, 1982); Küting (Einheitsbesteuerung, 1990); Küting (Rechnungslegung im Umbruch, 1991) S. 19-25; kurz auch Busse von Colbe (Konzernabschluß als Bemessungsgrundlage, 1987) S. 63; Cronos (Anpassung des deutschen Rechts, 1985) S. 1408; Müller (Einfluß des Bilanzrichtlinie-Gesetzes, 1985) S. 245-247; Wentland (Konzembilanz, 1979) S. 29-31.

3 Vgl. u.a. Bauer (Besteuerung deutscher Konzerne, 1987); Beusch (Besteuerung der Konzerne, 1978); Böhm (Konzerngewinn als Grundlage für Dividendenausschüttung und Steuerbemessung, 1979) S. 196-213; Ketterer (Gestaltung der Besteuerung im Konzern, 1997); Krebühl (Konzernbesteuerung, 2003); Mühlschlegel (Gewinnermittlung für Konzerne, 1971); Müller (Konzernbesteuerung, 1991); Oberndorff (Konzernbesteuerung, 1996); Probst (Anteile von Minderheitsgesellschaftern, 1997); Pullen (Körperschaftsbesteuerung, 1994); Rasch (Vorschriften des Steuerrechts, 1972); Richter (Konzernbesteuerung, 2003); Rupp (Ertragsbesteuerung nationaler Konzerne, 1983); Scheffler (Besteuerung von inländischen Konzernen, 1991); Stolk (Behandlung multinationaler Konzerne, 1972); den europäischen, grenzüberschreitenden Kontext explizit berücksichtigend auch Grotherr (Besteuerung nationaler und grenzüberschreitender Konzerne, 1994); Salzberger (Konzernunternehmung, 1994); Scheuchzer (Konzernbesteuerung, 1994); ansatzweise Herzig (Einführung, 2003) S. 27-33; Reis (Körperschaftsbesteuerung des Konzerns, 1996); Senger (Konzernertragsbesteuerung, 1997).

4 Für Busse von Colbe (Konzernabschluß als Bemessungsgrundlage, 1987) S. 63 ist dies „ein unbefriedigender, ja fast schon schizophrener Zustand.“

5 Vgl. dazu näher Kap. III.2.2.

6 Vgl. dazu ausführlich Kap. IV.1. Einen guten Überblick geben z.B. Beusch (Besteuerung der Konzerne, 1978) S. 33-41; Grotherr (Konzernbesteuerungssysteme, 1996). 
rende Maßgeblichkeit ${ }^{1}$ auch mittelbar auf die steuerliche Gewinnermittlung auswirkt und auswirken sollte ${ }^{2}$. Diese Frage hat seit Juli 2002 eine besondere Relevanz erfahren, da die IFRS auf der Basis einer entsprechenden EU-Verordnung ab 2005 als einheitliches Regelwerk für Konzernabschlüsse kapitalmarktorientierter europäischer Unternehmen durchgesetzt worden sind. Durch entsprechende Mitgliedstaatenwahlrechte wird dabei auch die Anwendung der IFRS auf sämtliche sonstigen Konzernabschlüsse und sogar Einzelabschlüsse europäischer Unternehmen ermöglicht ${ }^{3}$. Es ist zu vermuten, dass diese Entwicklung im Bereich der handelsrechtlichen Rechnungslegung hin zu den IFRS nicht ohne Einfluss auf die Kommission bei der Abfassung ihrer Steuer-Strategie

1 Vgl. zu einem Überblick über die Verbindung von handelsrechtlicher Rechnungslegung und steuerlicher Gewinnermittlung in den Mitgliedstaaten der EU Jacobs (Internationale Unternehmensbesteuerung, 2002) S. 104-112; Sigloch (Maßgeblichkeitsprinzip, 2000) S. 163-170; Spengel (IAS und Unternehmensbesteuerung, 2003) S. 30; umfassend auch für die OECD-Staaten $O E C D$ (Relationship between Taxation and Financial Reporting, 1987) S. 9-23, 45; zur Analyse dieser Verbindung in EURecht und -Rechtsprechung Eberhartinger (Ertragsteuerliche Konsequenzen, 2000) S. 193-200.

Vgl. zu dieser Maßgeblichkeitsdebatte, die neben IFRS- auch US-GAAP-Auswirkungen berücksichtigt, u.a. Arbeitskreis Bilanzrecht (Fortentwicklung des deutschen Bilanzrechts, 2002) S. 2378-2381; Arbeitskreis „Externe Unternehmensrechnung “ (IFRS im Einzel- und Konzernabschluss, 2003); Bippus (US-amerikanische Grundsätze, 1998); BMF (Internationalisierung der Rechnungslegung, 2002); Böcking (IAS für Konzern- und Einzelabschluss, 2002) S. 927; Busse von Colbe (Entwicklungsperspektiven, 2002) S. 169-170; Drescher (Zukunft des deutschen Maßgeblichkeitsgrundsatzes, 2002); Eberhartinger (Ertragsteuerliche Konsequenzen, 2000); Eichhorn (Maßgeblichkeitsprinzip, 2001); Euler (Steuerbilanzielle Konsequenzen, 1998); Fülbier/Gassen (Wider die Maßgeblichkeit, 1999); Gröning (Steuerbilanzielle Gewinnermittlung, 2002); Herzig (Internationalisierung, 2000); Herzig (IAS/IFRS, 2004); van Hulle (Reform, 2000) S. 548; Kahle (Europarechtliche Einflüsse, 2001) S. 132 136; Kahle (Internationale Rechnungslegung, 2002) S. 168-222; Kahle (Maßgeblichkeitsgrundsatz, 2002); Kahle (Zukunft der Rechnungslegung, 2003) S. 271; Kirsch (Maßgeblichkeit, 2004); Kußmaul/Klein (Überlegungen zum Maßgeblichkeitsprinzip, 2001) S. 548-549; Müller (Maßgeblichkeitsprinzip, 2001) S. 1861-1862; Niehus (Einzelabschlüsse, 2001) S. 747-748; Oestreicher/Spengel (Anwendung von IAS in der EU, 2001); Oestreicher/Spengel (Maßgeblichkeit der International Accounting Standards, 1999); Oestreicher/Spengel (International Accounting Standards, 1999); Oestreicher/Schmidt/Spengel (Steuerliche Gewinnermittlung, 1999); Pannen (Meßtheoretische Grundprobleme, 2000) S. 241-290; Rahlf (IAS-Bilanzierung und Besteuerung, 2000); Robisch/Treisch (Neuere Entwicklungen, 1997) S. 162-164; Schaffer (Übernahme internationaler Normen, 2000); Schreiber (Gewinnermittlung, 2002) S. 106-107, 114; Schroller (Zukunft des Maßgeblichkeitsgrundsatzes, 2000) S. 367-368; Schulze-Osterloh (Handels- und Steuerbilanz, 2000) S. 602; Selchert (Internationalisierung der Rechnungslegung, 1999); Thiel (Maßgeblichkeit, 1998); Wagner (Aufgabe der Maßgeblichkeit, 1998); Weber-Grellet (Maßgeblichkeitsgrundsatz, 1997) S. 387-389; Zabel (IAS, 2002) S. 922. Die Verbindung von IFRS und steuerlicher Gewinnermittlung wird in anderen EU-Staaten (noch) nicht so intensiv diskutiert; vgl. zu dieser Einschätzung auch EU-Kommission (Konsultationspapier, 2003) S. 12, die diesbezüglich neben Deutschland nur noch das Vereinigte Königreich (von Großbritannien und Nordirland) bzw. dessen Finanzverwaltung anfuhrt; vgl. dazu auch Inland Revenue (Reform of Corporation Tax, 2002) S. 4; Inland Revenue (Pre-Budget Report, 2003) S. 57. Vgl. auch Kap. V.1.1.

3 Vgl. EU-Verordnung Nr. 1606/2002, insb. Art. 4 und 5. Übergangsbestimmungen (Art. 9) sehen unter bestimmten Voraussetzungen eine IFRS-Pflicht erst ab 1. Januar 2007 vor. 
gewesen ist ${ }^{1}$. Mit ihrer dortigen Überlegung, in den IFRS ,in gewissem Maße einen nützlichen Bezugspunkt" ${ }^{\text {"2 }}$ für ein einheitliches steuerliches Regelwerk zu erkennen, geht die Kommission aber über das bisher Diskutierte hinaus, da die IFRS für die steuerliche Gewinnermittlung unmittelbar, ohne Umweg über handelsrechtliche Bilanzen, relevant würden.

Die keineswegs abgeschlossene Diskussion zu beiden Problembereichen zeigt, dass viele offene und interessante Fragen nach wie vor der Klärung bedürfen. Für die vorliegende Arbeit hat aber insbesondere die bisher noch wenig beachtete Verbindung dieser beiden Bereiche ${ }^{3}$ zur wissenschaftlichen Auseinandersetzung angeregt: Die steuerliche Gewinnermittlung auf der Basis konsolidierter Abschlüsse nach IFRS und die damit einhergehende Frage, ob die IFRS für die konsolidierte steuerliche Gewinnermittlung geeignet sein können, ob sie als eigentlich kapitalmarkt- und informationsorientierte Rechnungslegungsregeln in diesem Zusammenhang wirklich einen ,nützlichen Bezugspunkt" liefern. Dabei richtet sich der Fokus auf die bisher kaum untersuchten Konsolidierungsaspekte und weniger auf Ansatz- und Bewertungsfragen, die bis heute die Untersuchungen zur steuerlichen Eignung der IFRS bestimmen ${ }^{4}$. In dieser Arbeit wird folglich der Frage nachgegangen, ob und inwieweit die IFRS in steuerlicher Hinsicht zur Bestimmung und Konkretisierung der Konsolidierungspflicht, der Konsolidierungskreisabgrenzung, der vorbereitenden Maßnahmen und der eigentlichen Konsolidierungstechnik herangezogen werden können.

Die Beschäftigung mit dieser Forschungsfrage ist auch eine regulierungstheoretisch notwendige Konsequenz der EU-Strategie. So hat die Europäische Kommission mit ihrem Vorschlag, die konsolidierte Bemessungsgrundlage auf der Basis eines einzigen Regelwerkes zu ermitteln, mehrere Alternativen der Gewinnermittlung zur Diskussion gestellt: Die einheitliche Orientierung an den nationalen Steuervorschriften im Sitzland der Obergesellschaft bei gegenseitiger Anerkennung derselben (home state taxation, HST), die Entwicklung neuer, „europäischer“ Ermittlungsvorschriften, die (vorerst?)

1 Diese Vermutung stützt sich auf die Äußerungen der EU-Kommission (Strategie, 2001) S. 20-21. Vgl. zu entsprechenden Überlegungen, die Harmonisierung und Internationalisierung der handelsrechtlichen Rechnungslegung auf EU-Ebene auch für die steuerliche Gewinnermittlung in der EU zu nutzen z.B. auch Schreiber (Steuerwettbewerb, 1998) S. 131.

2 EU-Kommission (Strategie, 2001) S. 21.

3 Vgl. zu ersten diesbezilglichen (knappen) Ansätzen Eberhartinger (Ertragsteuerliche Konsequenzen, 2000) S. 261-263; EU-Kommission (Konsultationspapier, 2003) S. 16; Schreiber (Unternehmensbesteuerung, 2004) S. 222-224; bezogen auf den Konsolidierungskreis kurz auch Schneider (IAS als Besteuerungsgrundlage, 2003) S. 302; Spengel (Einheitliche Bemessungsgrundlage, 2004) S. 110; Spengel (Unternehmensbesteuerung in der EU, 2004) S. 145-146.

4 Vgl. stellvertretend für die Dominanz von Ansatz- und Bewertungsfragen die Arbeiten von Eichhorn (Maßgeblichkeitsprinzip, 2001); Gröning (Steuerbilanzielle Gewinnermittlung, 2002); Oestreicher/Spengel (Maßgeblichkeit der International Accounting Standards, 1999). Allerdings weist z.B. Spengel (Unternehmensbesteuerung in der EU, 2004) S. 148 auf die Notwendigkeit hin, Lösungen für die offenen Konsolidierungsfragen zu entwickeln. 
neben die nationalen Vorschriften treten (common consolidated tax base, CCTB) und die EU-weite Harmonisierung der nationalen Vorschriften (harmonised tax base, HTB). Mit einer eigenen europäischen Körperschaftsteuer mit europäischer Steuerverwaltung und -ertragshoheit (EU company income tax, EUCIT) hat die Kommission noch eine vierte Umsetzungsalternative genannt, die allerdings hinsichtlich der Ermittlungsvorschriften der CCTB entspricht ${ }^{1}$. Obwohl der explizite Hinweis auf die IFRS nur im Bereich der CCTB zu finden ist, bleibt auch bei den anderen Umsetzungsalternativen offen, wie denn die Bemessungsgrundlage in konsolidierungstechnischer Hinsicht zu ermitteln ist. Da ein eigenes, vollständiges Gruppenbesteuerungsrecht in den meisten Mitgliedstaaten der EU nicht existiert ${ }^{2}$, fehlen bereits den nationalen Steuervorschriften die benötigten Konsolidierungsregeln. Angesichts der auf nationaler Ebene regelmäßig fehlenden Konsolidierungsregeln und angesichts fehlender Aussagen darüber, in welche Richtung sich eine Harmonisierung im Bereich steuerlicher Konsolidierungsvorschriften bewegen sollte, dürfte sich aber auch die Harmonisierung nationaler Regeln als schwierig erweisen. Die Forschungsfrage dieser Arbeit hat also für sämtliche Umsetzungsalternativen ihre Relevanz ${ }^{3}$. So scheint es verlockend $\mathrm{zu}$ untersuchen, ob die in allen EU-Mitgliedstaaten bekannten und relevanten IFRS geeignete steuerliche Konsolidierungsregeln zur Verfügung stellen können. In diesem Sinne will diese Arbeit auch Ausgestaltungsempfehlungen für den nationalen, insbesondere aber den europäischen Regulierer entwickeln und einen Beitrag zur „Steuerrechtsgestaltungslehre“4 leisten.

Die vorliegende Arbeit hat eine normative Ausrichtung. Zur Beantwortung der formulierten Forschungsfrage bedarf es somit eines normativen Kriteriums, anhand dessen die Eignung der IFRS für steuerliche Konsolidierungszwecke zu beurteilen ist. Schließlich entspricht die normative Fundierung staatlicher Regulierung und ihrer Ausgestaltung einer ordnungspolitischen Grundvoraussetzung des marktwirtschaftlichen Systems. Dies gilt im besonderen Maße für das Steuerrecht, das wie kaum ein anderer Rechtsbereich

Vgl. EU-Kommission (Strategie, 2001) S. 49-50; dazu mehr in Kap. IV.2.2.2.

Vgl. Kap. IV.1.1.

3 Die EU-Kommission (Unternehmensbesteuerung, 2001) S. 5 bemerkt selbst: „Die Konsolidierung auf EU-Ebene ist das Schlüsselelement aller Lösungsansätze.“ Zwei Jahre später fügt sie hinzu: „Die Ausarbeitung von Regelungen für die Konsolidierung zählt zu den schwierigsten Aspekten der Schaffung einer einheitlichen Steuerbemessungsgrundlage" (EU-Kommission (Ergebnisse, 2003) S. 23).

4 Wöhe (Aufgaben der Betriebswirtschaftlichen Steuerlehre, 1983) S. 8, der darunter eine zentrale Teilaufgabe der betriebswirtschaftlichen Steuerlehre versteht, die sich bemühe, ,aus ihren Erkenntnissen praktische Folgerungen für eine zweckmäßige Gestaltung der Steuergesetze zu ziehen und Hilfestellung bei der Auslegung und Reform von Steuergesetzen zu geben“; Schneider (Betriebswirtschaftliche Steuerlehre, 1983) S. 30-37 plädiert i.d.Zshg. für eine ökonomische Analyse des Steuerrechts und hofft dadurch, „eine progressive Problemverschiebung von der nur juristischen (und politischopportunistischen) Regelung von Besteuerungsfragen zu einer ökonomisch begründeten Sicht" einzuleiten; vgl. dazu z.B. auch Salzberger (Konzernunternehmung, 1994) S. 1-2; Theisen (Gewinnerzielungsabsicht, 1988) S. 39-40, der sich, anders als Schneider, für den „Versuch einer kritischen Synthese steuerrechtlicher und steuerbetriebswirtschaftlicher Untersuchungs- und Handlungsrahmen“ (S. 45 [ohne Hervorhebungen des Originals]) einsetzt. 
ein „von fiskalischem Beharrungsvermögen, abgebrochenen Systemansätzen und partikularen Gruppeninteressen geprägtes Material voll innerer Brüche und historischer Verwerfungen"l darstellt. Die verschiedenen Aspekte der hier im Vordergrund stehenden Forschungsfrage machen es indes erforderlich, keinem eindimensionalen Beurteilungskriterium, sondern einem mehrdimensionalen Beurteilungsrahmen zu folgen. Dies wird schon dem in der Schnittmenge von Ökonomie und Recht angesiedelten Untersuchungsgegenstand und dem damit einhergehenden, interdisziplinären Charakter dieser Arbeit geschuldet ${ }^{2}$. Normative Beurteilungskriterien sollen wirtschaftstheoretisch abgeleitet werden, ohne dabei von grundlegenden ethisch-rechtlichen Zwängen zu abstrahieren. Da sich vor diesem Hintergrund ein geeigneter, alle Aspekte berücksichtigender Beurteilungsrahmen nicht unmittelbar anbietet ${ }^{3}$, ist es auch ein notwendiges und wichtiges Ziel dieser Arbeit, einen entsprechenden Rahmen zu entwickeln.

Es ist unbestritten, dass ein mehrdimensionales Beurteilungskriterium nicht immer zu eindeutigen Urteilen führen muss. Dies gilt umso mehr, je spannungsreicher das Verhältnis zwischen den einzelnen Kriterien ist. Dennoch erscheint diese Mehrdimensionalität angesichts der Vielschichtigkeit der Forschungsfrage und angesichts der Heterogenität der normativen Herangehensweise im interdisziplinären wie auch schon im wirtschaftstheoretischen Bereich sinnvoll. Letztlich liegt diesem Vorgehen aber auch die Überzeugung zu Grunde, für komplexe Sachverhalte keine einfachen und klaren Antworten generieren zu können.

\section{Eingrenzung und Gang der Untersuchung}

Die in dieser Arbeit im Vordergrund stehende Forschungsfrage ist in der Schnittmenge zweier Problemfelder angesiedelt. Unter besonderer Fokussierung auf Konsolidierungsaspekte wird untersucht, ob die IFRS für eine konsolidierte steuerliche Gewinnermittlung geeignet sein können. Die grundsätzliche Frage, ob eine wie auch immer definierte Gruppenbesteuerung als solche überhaupt notwendig ist, interessiert dabei nur am Rande. Obwohl Aspekte dieser Frage bei der Herleitung eines normativen Beurteilungsrahmens (Kapitel II) eine gewisse Rolle spielen, wird an der Notwendigkeit einer zusam-

1 Kofler (Steuerstrukturanpassung, 1995) S. 507-508; s.a. Lang (Die einfache und gerechte Einkommensteuer, 1987) S. 7, der einen „Scherbenhaufen des komplizierten, undurchschaubaren Steuerrechts" erkennt, „das von zahlreichen Widersprüchen, Lücken, Privilegien und Sonderlasten durchsetzt ist".

2 Vgl. zur „Notwendigkeit einer verstärkt interdisziplinär orientierten Steuerlehre“ z.B. Theisen (Gewinnerzielungsabsicht, 1988) S. 45; s.a. umfassend und m.w.N. Grotherr (Besteuerung nationaler und grenzüberschreitender Konzerne, 1994) S. 17-22.

3 Vgl. dazu treffend Nobes (Framework for the Taxable Income, 2004) S. 27: „There was no explicit conceptual framework for financial reporting in any country until the last quarter of the twentieth century. There is still no explicit conceptual framework in the context of taxation"; ähnlich TEI (Comments, 2003). 
menhängenden Besteuerung bestimmter Unternehmensgruppen mit Verweis auf bisherige Forschungsergebnisse' nicht grundlegend gezweifelt. Dies gilt erst recht für die Besteuerung des unternehmerischen Einkommens als solches, die hier als Datum angesehen wird ${ }^{2}$.

In der vorliegenden Arbeit steht auch nicht die grundsätzliche Eignung des IFRSSystems für die steuerliche Gewinnermittlung insgesamt im Vordergrund. Allgemeine, von der Konsolidierung losgelöste Fragen von Ansatz und Bewertung werden weitgehend ausgeblendet. Dies gilt gleichermaßen für die Frage nach der steuerlichen Maßgeblichkeit der IFRS. Die grundsätzliche steuerliche Eignung der IFRS wird unter Auswertung bisheriger Forschungsergebnisse zwar kurz analysiert (Kapitel V.1), ehe sich die Untersuchung anschließend auf Konsolidierungsaspekte verengt. Dieser Vorgehensweise liegt die Idee zu Grunde, dass die Untersuchung der IFRS-Vorschriften zur Konsolidierung auch unabhängig von der grundsätzlichen Eignungsfrage einen Sinn ergibt. So wäre es nicht per se ausgeschlossen, dass einzelne, konkrete Konsolidierungsvorschriften aus dem eher kasuistischen Rechnungslegungssystem der IFRS auch in einem steuerlichen Gewinnermittlungssystem verankert werden könnten, selbst wenn die grundsätzliche Eignung der IFRS für die steuerliche Gewinnermittlung insgesamt verneint würde. In der Literatur wird diese Möglichkeit bereits angedeutet ${ }^{3}$ und auch die Europäische Kommission mag dies im Sinn gehabt haben, als sie im Zuge ihrer Strategie zur künftigen Unternehmensbesteuerung in den IFRS einen ,nützlichen Bezugspunkt ${ }^{64}$, später auch einen „Ausgangspunkt für die Debatte ${ }^{65} \mathrm{zu}$ erkennen glaubte. Die in dieser Arbeit im Vordergrund stehende Forschungsfrage ist demnach so zu verstehen, dass sie auf die separierte Eignung einzelner IFRS-Konsolidierungsvorschriften zielt. Hierfür bedarf es für jede der in Frage kommenden Einzelregeln einer eigenen Eignungsprüfung, um zu verhindern, dass Elemente der IFRS - wie bei vergangenen Steu-

1 Vgl. hierzu die in Kap. I.1 angeführte Literatur zur Konzern- bzw. Gruppenbesteuerung.

2 Hierfür mögen gerade aus ökonomischer Sicht weniger die Ergebnisse entsprechender Forschung sprechen, sondern eher eine evolutionär höchst stabile reale Besteuerungspraxis; vgl. Kap. II.3.3.1.

3 Vgl. so insb. Gröning (Steuerbilanzielle Gewinnermittlung, 2002) S. 142; Grotherr (Konzernsteuerrecht, 1995) S. 81; Herzig (Internationalisierung, 2000) S. 111, 114; Herzig/Dautzenberg (Auswirkungen der Internationalisierung, 1998) S. 34; Pannen (Messtheoretische Grundprobleme, 2000) S. 292; Schreiber (Unternehmensbesteuerung, 2004) S. 225; Spengel (IAS und Unternehmensbesteuerung, 2003) S. 34; Spengel (Einheitliche Bemessungsgrundlage, 2004) S. 113; TEI (Comments, 2003) S. 240; differenziert auch Streim/Esser (Bewertungsfragen, 2003) S. 786; s.a. Kap.V.1.3.

4 EU-Kommission (Strategie, 2001) S. 21.

5 EU-Kommission (Ergebnisse, 2003) S. 22. 
erreformen in Deutschland unter dem Schlagwort „Verbreiterung der Bemessungsgrundlage" bereits geschehen ${ }^{1}$ - willkürlich in das Steuerrecht übernommen werden.

Durch die neue EU-Strategie zur künftigen Unternehmensbesteuerung werden auch eine Reihe von weiteren Fragen aufgeworfen, die nicht oder nur am Rande Gegenstand dieser Arbeit sind. Dies betrifft zum einen die grundsätzliche Frage, ob eine Steuerharmonisierung in der EU insbesondere im Bereich der steuerlichen Gewinnermittlung ökonomisch und/oder rechtlich überhaupt sinnvoll und begründet ist. Damit einhergehend unterbleibt auch die tiefergehende Auseinandersetzung mit den von der EU-Kommission zur Diskussion gestellten Umsetzungsalternativen HST, CCTB, HTB und EUCIT. Zum anderen betrifft dies die notwendige Aufteilung der konsolidierten Bemessungsgrundlage auf die einzelnen EU-Mitgliedstaaten, die auf ihren Anteil an dieser Bemessungsgrundlage weiterhin ihre nationalen Steuersätze erheben würden ${ }^{2}$. Die Suche nach einem zweckmäßigen und von allen Beteiligten akzeptierten Zurechnungsmechanismus berührt dabei auch die Frage, ob und wie die insgesamt erhobene Steuerlast innerhalb der Unternehmensgruppe auf die rechtlichen Teileinheiten aufzuteilen ist, an denen eventuell auch Minderheitsgesellschafter beteiligt sind ${ }^{3}$. Diese zentrale Frage der EU-Strategie hat für diese Arbeit nur insoweit Relevanz, wie sich hieraus Konsequenzen für die Beurteilung der Konsolidierungsregeln ergeben können.

Obwohl diese Arbeit eine deutsche Perspektive an vielen Stellen kaum verleugnen kann, versucht sie sich dennoch von den speziellen Besonderheiten der nationalen Steuersysteme zu lösen. Dies betrifft z.B. die Gewerbesteuer in Deutschland, die als Realsteuer den inländischen Gewerbebetrieb belastet und deren Rolle im Rahmen der EUStrategie zur künftigen Unternehmensbesteuerung noch ungeklärt ist. Die vorliegende Arbeit beschränkt sich in diesem Zusammenhang auf die Personensteuern, insbesondere auf die Körperschaftsteuer der Unternehmen. Der Versuch, eine von nationalen Besonderheiten losgelöste Sicht zu vertreten, steht indes in einem Spannungsverhältnis zu dem Anspruch dieser Arbeit, von realen rechtlichen Zwängen nicht zu abstrahieren. Um beide Aspekte dennoch vereinbaren zu können, wird hier nur auf grundlegende Rechtstatbestände abgestellt, die die reale Situation in allen Mitgliedstaaten in der Regel gleichermaßen prägen. Um die nationale Rechtsperspektive dabei nicht völlig zu vernach-

1 Vgl. Herzig (Internationalisierung, 2000) S. 108-111; Herzig (Gestaltung der Konzernsteuerquote, 2003) S. 108-111; Grotherr/Jorewitz (Einflüsse, 2001) S. 144-145. So steht z.B. in der Gesetzesbegründung des Steuerentlastungsgesetzes 1999/2000/2002 unter eben diesem Schlagwort: „Mit der Steuerreform werden die Gestaltungsmöglichkeiten der Unternehmen bei der Gewinnermittlung an internationale Standards angeglichen"; vgl. Deutscher Bundestag (Drucksache 14/23, 1998) S. 127.

2 Angesichts der weiter existierenden nationalen Fiskalsouveränität sollen die Mitgliedstaaten auf die Bemessungsgrundlage, die den bei ihnen steuerlich ansässigen Unternehmen zugeordnet wird, ihre Körperschaftsteuer auf der Grundlage ihrer nationalen Körperschaftsteuersätze erheben.

3 Vgl. hierzu ausführlicher Kap. III.2.5.1.2, IV.2.2.2 und VI; im Überblick z.B. Wellisch (Gewinnaufteilung, 2004). 
lässigen, wird die rechtstatsächliche Situation der steuerlichen Gewinnermittlung in Deutschland an einigen Stellen (Kapitel II.2.2.2 und III.2) exemplarisch auch im Detail beleuchtet. Zudem enthält diese Arbeit einen rechtsvergleichenden Überblick über konkrete steuerrechtliche Regeln einiger ausgewählter EU-Staaten, die für bestimmte Unternehmensgruppen bereits heute eine konsolidierte steuerliche Gewinnermittlung vorsehen (Kapitel IV.1).

Wie in Abb. 1 verdeutlicht, ist die vorliegende Untersuchung in sechs Kapitel gegliedert. Neben einem einführenden und einem zusammenfassenden Kapitel (Kapitel I und VI) verbleiben vier Hauptkapitel, innerhalb derer die Forschungsfrage beantwortet wird.

\begin{tabular}{|c|c|c|c|}
\hline \multicolumn{4}{|l|}{ Kapitel I: Einführung } \\
\hline Kapitel II: & \multirow{2}{*}{\multicolumn{2}{|c|}{$\begin{array}{l}\text { Kapitel IV: } \\
\text { Konsolidierte } \\
\text { steuerliche Ge- } \\
\text { winnermittlung in } \\
\text { der EU }\end{array}$}} & \multirow{3}{*}{$\begin{array}{l}\text { Kapitel V: } \\
\text { Eignung der IFRS } \\
\text { zur Ausgestaltung der } \\
\text { steuerlichen Konsoli- } \\
\text { dierung auf EU-Ebene }\end{array}$} \\
\hline $\begin{array}{l}\text { Normative Anforde- } \\
\text { rungen an eine konso- } \\
\text { lidierte steuerliche } \\
\text { Gewinnermittlung }\end{array}$ & & & \\
\hline \multicolumn{2}{|c|}{$\begin{array}{l}\text { Kapitel III: } \\
\text { Konsolidierung als Konsequenz } \\
\text { normativer Anforderungen und } \\
\text { rechtlicher Nebenbedingungen }\end{array}$} & $\begin{array}{l}\text { Verdeutlichung } \\
\text { an deutscher } \\
\text { (Steuer-)Rechts- } \\
\text { ordnung }\end{array}$ & \\
\hline $\begin{array}{l}\text { Beurteilungsrahmen } \\
\text { der Arbeit }\end{array}$ & \multicolumn{2}{|c|}{$\begin{array}{l}\text { Konkrete Rechtsana- } \\
\text { lyse/Rechtsvergleich }\end{array}$} & Eigentliche Eignungsprüfung \\
\hline \multicolumn{3}{|c|}{ Kapitel VI: Fazit und Ausblick } & \\
\hline
\end{tabular}

Abb. 1: Gang der Untersuchung

Die Entwicklung eines normativen Beurteilungsrahmens ist Gegenstand des zweiten Kapitels. Dieses Kapitel beginnt mit einer kurzen Einführung, in der zunächst die konsolidierte steuerliche Gewinnermittlung in ihren Grundprinzipien erläutert wird (Kapitel II.1). Dem interdisziplinären Anspruch dieser Arbeit folgend, werden anschließend ökonomische und verfassungsrechtlich-ethische Anforderungen an die steuerliche Gewinnermittlung formuliert, auf ihre Bedeutung für die Forschungsfrage dieser Arbeit hin analysiert und $\mathrm{zu}$ einem vorläufigen Beurteilungsrahmen zusammengefügt (Kapitel II.2). Da das hierbei identifizierte Anforderungsprofil erst einmal allgemein auf die steuerliche Gewinnermittlung zielt, kann es den besonderen Aspekten der Konsolidierung noch nicht vollumfänglich genügen. Zu diesem Zweck wird der Beurteilungsrahmen nachfolgend erweitert, um die bis dahin nicht problematisierte Frage nach der rechnungslegenden Einheit in den Vordergrund zu stellen (Kapitel II.3). Um diese Ein- 
heit definieren und abgrenzen zu können, wird hier versucht, ein ökonomisches Modell der Unternehmung zu identifizieren, das anschließend der rechtsformorientierten Unternehmenssicht gegenübergestellt wird. Das zweite Kapitel schließt mit einem kurzen Zwischenergebnis, in dem das entwickelte Anforderungsprofil an die konsolidierte steuerliche Gewinnermittlung noch einmal zusammengefasst wird (Kapitel II.4).

Obwohl das in Kapitel II entwickelte Anforderungsprofil auch der Beurteilung konsolidierungsspezifischer Aspekte dienen soll, ist die Konsolidierung bis dahin noch nicht hinreichend beleuchtet worden. Dieser Aufgabe dient Kapitel III. In einem ersten Schritt wird hier gezeigt, dass die Konsolidierung als ein Versuch verstanden werden kann, eine originär rechtsformorientierte Unternehmenssicht für Zwecke der steuerlichen Gewinnermittlung in das ökonomische Modell der Unternehmung zu überführen (Kapitel III.1). Die Konsolidierung ist vor diesem Hintergrund ein technisches Bindeglied zwischen zwei grundlegenden Besteuerungsprinzipien: dem rechtsform- und unternehmensorientierten Trennungsprinzip und der unternehmungsorientierten Einheitstheorie ${ }^{1}$. Dabei wird deutlich, dass die konsolidierte steuerliche Gewinnermittlung letztlich in einem Spannungsfeld von normativen Anforderungen und rechtlichen Nebenbedingungen angesiedelt ist. Um dieses Spannungsfeld weiter zu konkretisieren, wird in Kapitel III.2 als Beispiel die deutsche Rechtsordnung bemüht. Hierbei geht es aber nicht nur darum, die Abhängigkeit konsolidierungstechnischer Fragen von rechtlichen Zwängen exemplarisch aufzuzeigen. Es geht auch um eine konkrete Beschreibung, wie die BezugsgröBe der steuerlichen Gewinnermittlung in der deutschen Steuerrechtsordnung konkret ausgestaltet worden ist und wie hierbei Trennungs- und Einheitstheorie aufeinanderprallen. Das dritte Kapitel schließt mit einer kurzen Zusammenfassung, in der auch die Konsequenzen für das weitere Vorgehen festgehalten werden (Kapitel III.3).

Das Spannungsverhältnis von Trennungs- und Einheitstheorie wird zwar am Beispiel der steuerlichen Gewinnermittlung in Deutschland verdeutlicht; ein konkretes System der konsolidierten steuerlichen Gewinnermittlung ist dort aber allenfalls in rudimentärer Form gegeben. Das vierte Kapitel weitet deshalb die Rechtsanalyse auf die rechtstatsächliche Situation der konsolidierten steuerlichen Gewinnermittlung in der EU aus. Dies erscheint schon vor dem Hintergrund der europäischen Dimension der hier interessierenden Forschungsfrage gerechtfertigt. Bei dieser Analyse steht die Frage im Vordergrund, ob andere Mitgliedstaaten bereits Erfahrungen mit einer wie auch immer gearteten Konsolidierung im Bereich der steuerlichen Gesamtgewinnermittlung besitzen. Diese Erfahrungen sollen gesammelt werden, um sie später, in Kapitel V, ergänzend zu den normativen Beurteilungskriterien heranzuziehen. Aufbauend auf einem Überblick

1 Die Einheitstheorie wird hier erst einmal als Besteuerungsprinzip verstanden; in Kap. III.1.3 wird das Verhältnis zu der Einheitstheorie beleuchtet, die aus der rein informationsorientierten Konzernrechnungslegung bekannt ist. 
über die diesbezüglichen Vorgehensweisen in den verschiedenen Mitgliedstaaten der EU werden dazu in einem ersten Schritt diejenigen Systeme herausgefiltert und in ihrer Ausgestaltung rechtsvergleichend analysiert, in denen Vorschriften zur steuerlichen Konsolidierung existieren (Kapitel IV.1). Innerhalb des vierten Kapitels werden aber nicht nur die geltenden Konsolidierungssysteme auf Ebene der Mitgliedstaaten beleuchtet. Es geht auch darum, die Strategie der EU-Kommission für eine künftige Unternehmensbesteuerung auf Unionsebene zu untersuchen, innerhalb derer auch eine konsolidierte steuerliche Gewinnermittlung u.U. auf Basis von IFRS-Vorschriften erwogen wird (Kapitel IV.2).

Das fünfte Kapitel greift den konkreten Hinweis der EU-Kommission auf die IFRS als „Bezugspunkt“ bzw. „Ausgangspunkt“ auf und analysiert ausführlich die Eignung der einzelnen Konsolidierungsregeln. Trotz dieser Konzentration auf konsolidierungsspezifische Aspekte soll einfuihrend auf der Basis existierender Untersuchungen und weiterführender eigener Überlegungen die grundsätzliche Eignung der IFRS zur steuerlichen Gewinnermittlung thematisiert werden (Kapitel V.1). Dieser Systemanalyse schließt sich die Einzelanalyse konsolidierungsspezifischer Vorschriften an. Zuerst wird hier untersucht, ob die IFRS-Vorschriften die Voraussetzungen einer Gruppenbesteuerung determinieren und einen steuerlichen Konsolidierungskreis abgrenzen können (Kapitel V.2). Anschließend geht es um die Angleichung der steuerlichen Einzelgewinnermittlungen einbezogener Unternehmen (,,vorbereitende Maßnahmen") und die Frage, ob die entsprechenden IFRS hierzu einen Beitrag leisten können (Kapitel V.3). Die eigentliche Konsolidierung - oder Konsolidierung im engeren Sinne - ist Gegenstand des nachfolgenden Teilkapitels. Hier werden die IFRS-Vorschriften zur Kapitalkonsolidierung, Schuldenkonsolidierung, Aufwands- und Ertragskonsolidierung sowie Zwischenergebniseliminierung auf ihre steuerliche Eignung hin analysiert (Kapitel V.4).

In dem fünften Kapitel wird für jede einzelne Konsolidierungsvorschrift der IFRS analysiert, ob sie den zuvor in Kapitel II definierten Anforderungen genügt und sich innerhalb der in Kapitel III identifizierten rechtlichen Rahmenbedingungen bewegt. Hierbei werden auch die Erfahrungen der „EU-Konsolidierungsstaaten“ ergänzend berücksichtigt, die in Kapitel IV herausgearbeitet worden sind. Das fünfte Kapitel schließt nicht nur mit einer Zusammenfassung der Ergebnisse dieser Einzelanalyse, sondern leitet daraus auch Ausgestaltungsempfehlungen für den europäischen Regulierer ab (Kapitel V.5).

Ein kurzes Fazit und ein Ausblick stehen am Ende dieser Arbeit (Kapitel VI). 


\section{Kapitel II}

\section{Normative Anforderungen an eine konsolidierte steuerliche Gewinn- ermittlung}

Um die Eignung der IFRS für eine konsolidierte steuerliche Gewinnermittlung überprüfen zu können, bedarf es eines Beurteilungsrahmens, der in diesem zweiten Kapitel entwickelt wird. Ausgangspunkt ist hierbei die Frage, welchen normativen Anforderungen eine konsolidierte steuerliche Gewinnermittlung idealiter genügen muss. Diese Frage wird aus ökonomischer wie auch aus ethisch-rechtlicher Perspektive in zwei Schritten beantwortet. In einem ersten Schritt werden die normativen Anforderungen an eine steuerliche Gewinnermittlung im Allgemeinen identifiziert und auf ihre Anwendbarkeit für die in dieser Arbeit im Vordergrund stehende Forschungsfrage hin analysiert (Kapitel II.2). Anschließend ist zu fragen, ob sich aus dem speziellen Konsolidierungsaspekt darüber hinausgehende Anforderungen ergeben, die ebenfalls aus unterschiedlicher Perspektive zu beleuchten sind (Kapitel II.3). Dieses auf zwei Schritten beruhende Vorgehen erscheint vor dem Hintergrund gerechtfertigt, dass normative Anforderungen eben nicht nur aus dem Konsolidierungsaspekt an sich resultieren können, sondern auch aus den grundsätzlichen Rahmenbedingungen der steuerlichen Gewinnermittlung, die bei Ansatz- und Bewertungs- und letztlich auch Konsolidierungsfragen zu beachten sind' Der sich daraus ergebende Beurteilungsrahmen dieser Arbeit wird abschließend noch einmal zusammengefasst (Kapitel II.4).

Dem Kapitel ist eine kurze Einführung vorangeschaltet, in der zunächst die konsolidierte steuerliche Gewinnermittlung in ihrem Grundprinzip erläutert wird (Kapitel II.1).

\section{Grundprinzip der konsolidierten steuerlichen Gewinnermittlung}

Steuern sind öffentlich-rechtliche Abgaben bzw. „Geldleistungen, die nicht eine Gegenleistung für eine besondere Leistung darstellen und von einem öffentlich-rechtlichen Gemeinwesen zur Erzielung von Einnahmen allen auferlegt werden, bei denen der Tatbestand zutrifft, an den das Gesetz die Leistungspflicht knüpft ${ }^{\text {“2 }}$. Diese werden vom Staat bestimmten Gebilden oder Subjekten - den Steuersubjekten - durch gesetzliche Regulierung auferlegt. Steuersubjekte sind damit immer Rechtssubjekte eines Steuergesetzes $^{3}$, gegenüber denen ein (finanzieller) Steueranspruch entsteht, den es in der Höhe

Vgl. hierzu treffend Ordelheide (Konzernerfolg, 1987) S. 292: „Hat man erst die Erfolgskonzeptionen, dann kann man in einigen konsolidierungstechnischen Streitfragen konsistentere Antworten entwickeln".

$2 \S 3$ Abs. 1 AO. Diese Definition aus dem deutschen Steuerrecht soll stellvertretend für sonstige Definitionen angeführt werden, die insb. in anderen europäischen Steuerrechtssystemen zu finden sind.

3 Vgl. zum Gesetzes- bzw. Parlamentsvorbehalt Kap. II.2.2.2. 
zu ermitteln gilt ${ }^{1}$. In einem ersten Schritt ist die Bemessungsgrundlage (Steuerobjekt) ${ }^{2}$ als diejenige zahlenmäßige Maßgröße zu bestimmen, aus der anschließend der Steueranspruch des Staates gegenüber dem Steuersubjekt unter zusätzlicher Berücksichtigung des Steuersatzes abgeleitet wird ${ }^{3}$.

Sofern Steuern nach der jeweiligen (Haupt- )Bemessungsgrundlage differenziert werden, lassen sich Verkehr-, Substanz- und - terminologisch nicht ganz präzise ${ }^{4}-$ Ertragsteuern unterscheiden, wobei letztere in Form der Personensteuern (Einkommen- und Körperschaftsteuer) in dieser Arbeit ebenso im Vordergrund stehen wie die Unternehmen als typische Steuersubjekte derselben. Im Rahmen der Einkommen- und Körperschaftsteuer obliegt es der steuerlichen Gewinnermittlung, ein bestimmtes finanzielles Ergebnis als Bemessungsgrundlage zu ermitteln: den steuerlichen Gewinn ${ }^{5}$.

Die steuerliche Gewinnermittlung ist damit eine Sonderform der Rechnungslegung. Sie dient als solche der standardisierten Aufbereitung und Weitergabe von Informationen ${ }^{6}$.

1 Vgl. zum Steuertatbestand und zum Steuersubjekt aus deutscher Rechtsperspektive Bayer (Steuerlehre, 1997) Tz. 386-392, 457-502; Tipke (Steuerrechtsordnung, Band II, 1993) S. 525-527 m.w.N. Der Begriff des Steuersubjekts wird in den deutschen Einzelsteuergesetzen nicht verwendet, dort wird regelmäßig vom Steuerpflichtigen gesprochen.

2 An dieser Stelle besteht allerdings eine Kontroverse darüber, was genau als Steuerobjekt bzw. Steuergegenstand angesehen werden kann. Eher eine Mindermeinung vertritt hier Bayer (Steuerlehre, 1997) Tz. 503, der i.d.Zshg. abzielt auf „die Verhaltensweise, die Leistung, die Tätigkeit oder die Handlung .., die seitens des Steuerpflichtigen an den Tag gelegt werden muß“; dies kritisierend und - wie wohl die herrschende Meinung - auf den Handlungserfolg abstellend Tipke (Steuerrechtsordnung, Band II, 1993) S. 526-527, der konstatiert: „Niemand wird wegen irgendwelcher Handlungen besteuert, sondern wegen der wirtschaftlichen Ergebnisse seiner Handlungen“ und weiter: „Steuerobjekt der Einkommensteuer und der Körperschaftsteuer ist das Einkommen“ (S. 525) sowie „Gewiß muß die Steuerrechtsfolge an einen Tatbestand anknüpfen. Das kann aber auch in der Weise geschehen, dass die Steuerbemessungsgrundlage in den Vordergrund gestellt" (S. 527) wird.

3 Vgl. zu den Grundlagen des (deutschen) Steuerschuldrechts Bayer (Steuerlehre, 1997) Tz. 1104-1499.

4 Es handelt sich hier eher um „Steuern auf das finanzielle Ergebnis“ (Schneider (Steuerlast, 2002) S. 7), die auf einen wie auch immer definierten Saldo von Ertrag/Einnahmen/Einzahlungen sowie Aufwand/Ausgaben/Auszahlung abstellen.

5 In Abhängigkeit von den nationalen Steuergesetzen zielen Einkommen- bzw. Körperschaftsteuern auf präzise definierte Ergebnisgrößen, die hier der Einfachheit halber als Gewinn bezeichnet werden. In Deutschland ist z.B. zwischen dem aus der Steuerbilanz resultierenden Gewinn und dem letztlich zu ermittelnden ,zu versteuernden Einkommen“ zu differenzieren.

6 Vgl. zu dieser Definition von Rechnungslegung im Allgemeinen z.B. Pellens (Internationale Rechnungslegung, 2001) S 9-10; Pellens/Fülbier/Gassen (Internationale Rechnungslegung, 2004) S. 2-10; Schneider (Rechnungswesen, 1997) S. 1-11. Vgl. zur Information als „zweckorientiertes Wissen“ Wittmann (Information, 1959) S. 14, wobei der Zweck primär in der Entscheidungsrelevanz liegen dürfte, die erstmals wohl Marschak (Information, 1954) betont; eine wissenschaftstheoretische Diskussion und Systematisierung des Informationsbegriffs findet sich bei Bode (Informationsbegriff, 1997); Hopf (Informationen, 1983) S. 6-17; Schneider (Theorie der Unternehmung, 1997) S. 71-78; Wersig (Information, 1971) S. 25-74; Wessling (Information, 1991) S. 11-30. 
Die steuerliche Gewinnermittlung vollzieht sich regelmäßig in einer Steuerbilanz ${ }^{1}$. Letztere wird entweder originär erstellt oder aus einer auch anderen Zwecken dienenden (Handels-)Bilanz ${ }^{2}$ abgeleitet, die für Zwecke der steuerlichen Gewinnermittlung eine vollständige oder auch nur partielle Maßgeblichkeit erfährt. Es ist auch möglich, dass sich die abschließende Bemessungsgrundlage nicht unmittelbar aus der Steuerbilanz selbst, sondern erst durch weitere, ergänzende, außerbilanzielle Korrekturen ergibt. So bezieht sich die steuerliche Gewinnermittlung, z.B. auf Basis deutscher Steuergesetze, streng genommen nur auf die erste, bilanzielle Ermittlungsstufe, um dann in einer zweiten Stufe, außerhalb der Bilanz, z.B. um verdeckte Gewinnausschüttungen, verdeckte Einlagen, Spenden, nicht abziehbare Aufwendungen oder steuerfreie Erträge, korrigiert und in das eigentliche „zu versteuernde Einkommen“ überführt zu werden ${ }^{3}$.

Die folgerichtig auch als „Steuermaßstabsrecht ${ }^{\star 4}$ bezeichnete steuerliche Gewinnermittlung kennzeichnet damit eine Form der Rechnungslegung, die unmittelbar und untrennbar mit einer steuerlichen Rechtsfolge verbunden ist. Sie wird hier deshalb auch als rechtsfolgeorientierte Rechnungslegung bezeichnet, wobei die Rechtsfolge streng genommen nur an den ermittelten Gewinn als einzige Kerngröße gekoppelt ist. Die sonstigen Rechnungslegungsdaten interessieren nur insofern, als dass sich aus ihnen die Ermittlung dieser Größe erkennen und plausibilisieren lässt.

Die hier als Steuersubjekt betrachteten Unternehmen sind mit dem Staat in einem komplexen Geflecht von „Geben und Nehmen“ verbunden". Der Staat fordert von ihnen in diesem Zusammenhang „seinen“ Anteil am unternehmerischen Gewinn und akzeptiert hierbei nur diejenige Bemessungsgrundlage, die nach Maßgabe einer von ihm selbst regulierten Rechnungslegung ermittelt wird. Der Staat ist damit Regulierungssubjekt ${ }^{6}$ der steuerlichen Gewinnermittlung und in Gestalt der Finanzverwaltung (Fiskus ${ }^{7}$ ) auch

1 Die Erstellung einer eigenen Steuerbilanz ist nicht zwingend. In Deutschland z.B. reicht eine mittels Zusätzen oder Anmerkungen an die steuerrechtlichen Vorschriften angepasste Handelsbilanz aus; vgl. $\S 60$ Abs. 2 EStDV.

2 So ist die handelsrechtliche Bilanz z.B. im Rahmen des handelsrechtlichen deutschen Jahres- bzw. Einzelabschlusses nicht nur für die steuerliche Gewinnermittlung maßgeblich. Sie dient auch der (Gewinn-)Ausschüttungsbemessung, Informations- sowie Dokumentationszwecken, geht mit bestimmten Verlustanzeigepflichten einher und hat auch haftungsrechtliche Konsequenzen. Vgl. dazu im Überblick z.B. Coenenberg (Jahresabschluss, 2003) S. 12-19; Pellens/Fülbier/Gassen (Internationale Rechnungslegung, 2004) S. 10-13; Streim (Bilanzierung, 1988) S. 8-24.

3 Vgl. Frotscher (Zweistufige Gewinnermittlung, 2003) S. 230, der in der zweiten „Gewinn“-Ermittlungsstufe die eigentliche Domäne des Steuerrechts erkennt.

4 Bayer (Steuerlehre, 1997) Tz. 1106, der auch von dem „Recht der steuerlichen Wertmaßstäbe“ oder dem ,steuerlichen Bewertungsrecht" spricht (Tz. 1111).

5 Vgl. zu der hier bereits angedeuteten vertragstheoretischen Sicht Kap. II.3.2.1 und II.3.3.2.

6 Vgl. zum Regulierungssubjekt im Rahmen einer Systematisierung des Regulierungsbegriffs ausführlicher Fülbier (Regulierung der Ad-hoc-Publizität, 1998) S. 13-15; Fülbier (Regulierung, 1999) S. 468; Mehnert/Erbsland (Regulierung, 1993) S. 9-12.

7 Vgl. zum Begriff des Fiskus, der den Staat als Träger vermögenswerter Berechtigungen bezeichnet, Rüfner (Fiskus, 1981) insb. S. 302. 
einziger Adressat derselben. Daraus ergibt sich eigentlich eine regulierungstheoretische Idealsituation, die die steuerliche Gewinnermittlung von anderen Formen regulierter Rechnungslegung unterscheidet, die außer dem Staat noch andere Adressatengruppen kennen. Wie in den folgenden Teilkapiteln deutlich wird, stellt diese Idealsituation aber eher ein theoretisches Konstrukt dar und die Realität zeigt, wie schwierig die Deduktion steuerlicher Gewinnermittlungsregeln dennoch ist.

In seiner Funktion als Regulierungssubjekt hat der Staat als legitime institutionalisierte Zwangsgewalt ${ }^{1}$ auch das Recht und die Pflicht, die Steuern einzutreiben. Der aus der Bemessungsgrundlage abgeleitete Steueranspruch begründet ein Steuerschuldverhältnis und führt zu einer Zahlungsverpflichtung, die vom Fiskus im Erhebungsverfahren mit Hilfe hoheitlicher Maßnahmen (Steuerverwaltungsakte) durchgesetzt wird. Als öffentliches (Eingriffs-)Recht geht das Steuerrecht mit unmittelbarem Zwang für die betroffenen Steuersubjekte einher ${ }^{2}$, der in rechtsstaatlichen Demokratien allerdings der abschließenden Kontrolle durch die Finanzgerichtsbarkeit unterliegt ${ }^{3}$.

Bei der bisherigen Betrachtung der steuerlichen Gewinnermittlung ist die Bezugsgröße derselben nicht weiter problematisiert worden. Wie jede Form der Rechnungslegung beziehen sich auch die steuerliche Gewinnermittlung und die von ihr generierten Informationen auf eine bestimmte Bezugsgröße, die als rechnungslegende Einheit bezeichnet werden kann ${ }^{4}$. In diesem Zusammenhang ist bisher nur das einzelne, nicht näher definierte Unternehmen genannt worden ${ }^{5}$. Bei der konsolidierten steuerlichen Gewinnermittlung rückt aber gerade diese Bezugsgröße und die dahinter stehende Frage der rechnungslegenden Einheit in den Vordergrund. Anstelle der bisher dargestellten „Einzelgewinnermittlung“, die sich auf ein einziges Unternehmen im Rechtssinne bezieht, erweitert sich diese rechnungslegende Einheit bei der konsolidierten steuerlichen Gewinnermittlung. Hier umfasst sie mehrere wirtschaftlich zusammenhängende Unternehmen, deren Einzelgewinnermittlungen mittels Konsolidierung in einer bestimmten Art und Weise zusammengefasst werden ${ }^{6}$. Dabei ist keineswegs gesagt, dass die insoweit erweiterte rechnungslegende Einheit auch selbst wiederum ein Steuersubjekt darstellen muss. Theoretisch wäre es denkbar, dass Steueransprüche weiterhin an Unternehmen anknüp-

1 Vgl. Molitor (Staatsversagen, 1991) S. 58 i.A.a. Weber (Wirtschaft und Gesellschaft, 1976) S. 29.

2 Aus Sicht der deutschen Rechtswissenschaft dient öffentliches Recht dem öffentlichen Interesse (Interessentheorie), determiniert ein Unterordnungsverhältnis unter den Staat (Subordinationstheorie) und geht mit Sonderrechten für die Träger hoheitlicher Gewalt einher, die in Deutschland mit den nach Art. 106, 107 GG steuerberechtigten Körperschaften und den nach Art. 108 GG verwaltenden Behörden gegeben sind (Sonderrechtstheorie); vgl. dazu Tipke/Lang (Steuerrecht, 2002) $§ 1 \mathrm{Tz} .10$ m.w.N. 
fen, obwohl sie auf Basis einer abweichenden rechnungslegenden Einheit ermittelt worden sind.

Obwohl der Konsolidierungsaspekt immer mit einer im obigen Sinne erweiterten rechnungslegenden Einheit verbunden ist, gilt dieser Zusammenhang nicht zwingend in umgekehrter Richtung. Die steuerliche Gewinnermittlung einer mehrere Unternehmen umfassenden rechnungslegenden Einheit muss nicht zwingend mit der Konsolidierung einhergehen. Es ist theoretisch denkbar, für diese erweiterte rechnungslegende Einheit eine originäre steuerliche Gewinnermittlung durchzuführen. Diese Form der Einzelgewinnermittlung bezöge sich damit nicht mehr auf ein einzelnes Unternehmen, sondern auf eine Unternehmensmehrzahl, die als Einheit betrachtet wird. Die Konsolidierung kennzeichnet demgegenüber eine bestimmte Form der Zusammenfassung von mindestens zwei Einzelgewinnermittlungen. Die Zusammenfassung mehrerer Einzelgewinnermittlungen ist geradezu das konstituierende Element der konsolidierten steuerlichen Gewinnermittlung. Bei Identität der rechnungslegenden Einheit unterscheiden sich originäre und konsolidierte steuerliche Gewinnermittlung deshalb immer in der technischen Vorgehensweise, nicht aber zwingend im Ergebnis.

\section{Anforderungen an eine steuerliche Gewinnermittlung}

\section{1 Ökonomische Anforderungen}

\subsubsection{Wirtschaftstheoretische Ausgangssituation}

Ökonomische Anforderungen an die steuerliche Gewinnermittlung können nur aus einer bestimmten wirtschaftstheoretischen Perspektive formuliert und analysiert werden. Für undifferenzierte ökonomische Anforderungen als solche erscheint die Wirtschaftstheorie selbst viel zu heterogen. Abgesehen von dem gemeinsamen Erfahrungsobjekt, dem wirtschaftlichen Handeln als Umgang mit knappen Gütern ${ }^{1}$, dürfte eine gemeinsame Basis wirtschaftstheoretischer Sichtweisen allenfalls in ihrer Effizienzorientierung zu erkennen sein. Aber schon bei der Frage, was genau unter Effizienz zu verstehen ist, konkurrieren insbesondere neoklassische Ansätze mit solchen der Neuen Institutionenökonomik, die beide wiederum in einem mehr oder minder starken Spannungsverhältnis zu prozessorientierten, evolutorischen Ansätzen stehen.

Die neoklassische Theorie ist in ihrer ganzen Ausrichtung eine gleichgewichtstheoretische „Allokationstheorie“ ${ }^{“ 2}$. Im Vordergrund stehen Märkte und Preise als ausschließliche Erklärungsprinzipien für die im Vordergrund stehende Allokation und Verteilung knapper Ressourcen zur Erreichung einer optimalen Bedürfnisbefriedigung. Den Höhe-

1 Vgl. zur Wirtschaftswissenschaft aus wissenschaftstheoretischer Sicht z.B. Chmielewicz (Forschungskonzeptionen, 1994); Fülbier (Wissenschaftstheorie, 2004); Schneider (Grundlagen, 1995) S. 1-214.

2 Kunz (Marktsystem, 1985) S. 22. 
punkt neoklassischen Denkens verkörpert das erstmals von Walras formulierte Modell der vollständigen Konkurrenz. In einer gleichgewichtstheoretischen Totalbetrachtung geht dieses statische Modell davon aus, dass sich bei vollkommenen Märkten von jeder beliebigen Verteilung der Erstausstattung aus ein totales Konkurrenzgleichgewicht mit bestimmten Optimalitätseigenschaften einstellt ${ }^{1}$.

Vollkommene Märkte sind jedoch theoretische Konstrukte. Einer Rechnungslegung bedarf es hier nicht, da jeder Marktteilnehmer vollkommen informiert ist. Dies gilt auch für den Staat, so dass sich die steuerliche Gewinnermittlung ebenfalls erübrigt. Der Staat kennt die Bemessungsgrundlage der Unternehmen und kann darauf seine Steuern erheben. Anders als in der Sichtweise der (liberalen) Klassik, in der der Staat nur die marktwirtschaftlichen Rahmenbedingungen zu gewährleisten („Nachtwächterstaat") und nur die hierbei entstehenden Kosten durch Steuern der Allgemeinheit aufzubürden hat, versteht ihn die Neoklassik aber bereits als Helfer im Falle des „Marktversagens“2, das er - wie bei externen Effekten durch Pigou gezeigt ${ }^{3}$ - auch durch Steuern zu beheben vermag. Darin dokumentiert sich ein grundlegender Wandel bei den finanzpolitischen Zielen, da neben fiskalische Besteuerungszwecke auch Lenkungszwecke treten, die zudem, insbesondere im Zuge der Auseinandersetzung mit dem Sozialismus im 19. Jahrhundert, immer stärker auch durch sozialpolitische (distributive) Zwecke ergänzt werden $^{4}$. Der Staat selbst wird jedoch nicht problematisiert, er wird sogar idealisiert, da staatliches Handeln regelmäßig als problemlösend, altruistisch und kostenlos angesehen wird .

1 Vgl. Walras (Éléments d'économie politique, 1874); der erste mathematische Nachweis eines Systems von Gleichgewichtspreisen geht auf Wald (Gleichungssysteme, 1936) zurück; wesentliche Arbeiten existieren dazu auch von Debreu (Equilibrium Existence Theorem, 1952); Arrow/Debreu (Equilibrium, 1954); vgl. zu dieser Entwicklung überblicksartig Arrow (Economic Analysis, 1974). Die Grenzrate der Substitution ist in diesem Gleichgewicht fur alle konsumierenden Wirtschaftssubjekte gleich (Tauschoptimum); ebenso die Grenzrate der Transformation für alle Faktoren (Produktionsoptimum). Zusammengenommen resultiert daraus die Gleichheit der Grenzrate der Transformation zweier Güter im Produktionsbereich mit derjenigen der Substitution derselben Güter im Konsumbereich (Gesamtoptimum). In diesem nach Pareto (Manuale di economia politica, 1906) benannten Zustand der Optimalität kann kein Wirtschaftssubjekt seinen Nutzen bzw. Gewinn durch Gütertausch oder Produktion eines alternativen Güterbündels c.p. weiter erhöhen, ohne eine Nutzen- bzw. Gewinneinbuße bei mindestens einem anderen Wirtschaftssubjekt zu provozieren. Dies wird als Zustand effizienter Produktion und Allokation sowie effizienter Verteilung der produzierten Güter angesehen. Vgl. zur Theorie des Marktversagens Bator (Market Failure, 1958); zu ihren Hauptanwendungsfällen vgl. z.B. Stiglitz/Schönfelder (Finanzwissenschaft, 1989) S. 96-107; Watrin (Staatsversagen, 1986).

3 Vgl. zur Internalisierung externer Effekte bei der Nutzung von Umweltressourcen durch eine später nach ihm benannte Steuer Pigou (Economics of Welfare, 1952) S. 223-226; Stiglitz/Schönfelder (Finanzwissenschaft, 1989) S. 410-411; kritisch Coase (Social Cost, 1960) S. 28-39.

4 Zu finanzpolitischen Zielen im Zeitablauf vgl. Zimmermann/Henke (Finanzwissenschaft, 2001) S. 2-7.

5 Vgl. Demsetz (Information, 1969) S. 2, der i.d.Zshg. von einer "grass is always greener fallacy“ spricht. Vgl. grundlegend zum Staat als „wohlwollendem Diktator" bzw. zum sog. „Staatsversagen“ auch Wolf (Theory of Nonmarket Failure, 1979) oder Molitor (Staatsversagen, 1991); Watrin (Staatsversagen, 1986). 
In ihrer Fortentwicklung hat die neoklassische Theoriewelt auch Abweichungen von dem Marktmodell der vollkommenen Konkurrenz hervorgebracht. Das hohe Abstraktionsniveau der Neoklassik, insbesondere das Ideal vollkommener Märkte, ist aber erst in den Ansätzen der Neuen Institutionenökonomik deutlich heruntergebrochen worden'. Damit bietet sie auch für eine auf Steuern, insbesondere auf die konsolidierte steuerliche Gewinnermittlung bezogene Effizienzbetrachtung einen geeigneten wirtschaftstheoretischen Rahmen. Die (ökonomische) Sichtweise dieser Arbeit wird dabei insbesondere durch die Transaktionskostentheorie ("transaction cost economics"2) und die davon kaum abtrennbare Theorie der Verfügungsrechte ("property rights theory"3) geprägt, die sich durch die folgenden Rahmenbedingungen charakterisieren lassen:

- Es gilt der methodologische Individualismus. Das einzelne Individuum wird hiernach in das Zentrum der Betrachtungen gerückt. Monolithische Aggregate wie z.B. ,Staat', ,Unternehmen' oder ,Haushalt' werden individualisiert ${ }^{4}$.

- Die Prämisse vollkommener Märkte und vollkommener Information wird aufgegeben $^{5}$.

- Begrenzte Rationalität und Opportunismus stellen zentrale Verhaltensannahmen dar. Die Präferenzen der Individuen werden als unvollständig und instabil erachtet; Kostengesichtspunkte rücken in den Vordergrund. In der Abkehr von der strengen Rationalitätsannahme der Neoklassik versucht ein begrenzt rational handelndes Individuum zwar weiterhin, den eigenen Nutzen zu maximieren, kann aber nur noch im Rahmen seiner eingeschränkten kognitiven Fähigkeiten ${ }^{6}$ rational handeln, die sich insbesondere in den begrenzten Kapazitäten zur - keineswegs kostenfreien - Aufnahme und Verarbeitung von Informationen dokumentieren. In ihrer subjektiven, zwangsweise eingeschränkten Sicht handeln die Individuen „intendedly rational, but

1 Eine völlige Abkehr von der neoklassischen Denkwelt ist in den verschiedenen, nicht überschneidungs- und widerspruchsfreien Ansätzen dieser Theorierichtung aber noch nicht vollzogen worden; vgl. dazu z.B. Bonus/Weiland (Welt der Institutionen, 1995) S. 31; Erlei/Leschke/Sauerland (Neue Institutionenökonomik, 1999) S. 44-51; Richter (Institutionenökonomik, 1990) S. 573. Eine gute Übersicht über die verschiedenen Ansätze findet sich bei Erlei/Leschke/Sauerland (Neue Institutionenökonomik, 1999); Richter/Furubotn (Neue Institutionenökonomik, 2003).

2 Diese Bezeichnung geht auf Williamson zurück; vgl. insb. Williamson (Transaction-Cost Economics, 1979); Williamson (Modern Corporation, 1981) S. 1543.

3 Vgl. insb. Furubotn/Pejovich (Property Rights, 1972) S. 1139.

4 Vgl. grundlegend Schumpeter (Nationalökonomie, 1908) S. 88-98. In der konsequenten Anwendung des methodologischen Individualismus unterscheidet sich die neue insb. auch von der ,alten“ Institutionenökonomik; vgl. Richter (Institutionenökonomik, 1990) S. 573. Vgl. bereits zur (weniger konsequenten) Anwendung des methodologischen Individualismus in der Neoklassik Buchanan (Constitution of Economic Policy, 1987) S. 243.

5 Vgl. ausführlich zur Erfassung von Information im Rahmen unterschiedlicher wirtschaftstheoretischer Ansätze Fülbier (Regulierung der Ad-hoc-Publizität, 1998) S. 108-141.

6 Kognitionen umfassen sämtliche (Er-)Kenntnisse und Meinungen, die ein Individuum über seine Umwelt, sich selbst und sein Verhalten hat; vgl. dazu Festinger (cognitive dissonance, 1957) S. 3. 
only limited so"1. Unter der zusätzlichen Annahme opportunistischen Verhaltens geht es den Individuen um die strikte Verfolgung von Eigeninteresse, wenn es sein muss auch unter Anwendung von (Hinter-)List, was Verhaltensweisen wie Lügen und Betrügen beinhaltet ${ }^{2}$.

- Die Rechte der Individuen an einem ökonomischen Gut ${ }^{3}$, genauer: die Beziehungen zwischen den Individuen in Bezug auf die Nutzung (,ius usus'), Veränderung (,ius abusus') und Veräußerung (,ius successionis') knapper Ressourcen sowie die Aneignung ihrer Erträge (,ius usus fructus') werden in Verfügungsrechten konkretisiert ${ }^{4}$. Diese Rechte können absoluter Natur sein und sind dann von jedermann zu beachten (z.B. klassisches Privateigentum) oder sie sind von relativer Natur und wirken nur im Verhältnis zu bestimmten Individuen (z.B. klassisches Schuldverhältnis).

- Die Transaktion als Neuordnung von Verfügungsrechten ${ }^{5}$ avanciert zur Basiseinheit der Analyse ${ }^{6}$. Hinsichtlich der Eigenschaften von Transaktionen kann in die Häufigkeit durchgeführter Transaktionen, die mit der Transaktion verbundene Unsicherheit und die Faktorspezifität differenziert werden? ${ }^{7}$.

- Das Vertragsrecht ist das geeignete Transaktionsmedium. Neben den klassischen und neoklassischen Vertrag als ,juristisches Korollar des Modells des vollkommenen Marktes ${ }^{\text {‘8 }}$, der ex ante sämtliche Leistungen und Gegenleistungen für alle möglichen Eventualitäten über die gesamte Laufzeit vollständig festzulegen vermag, tritt der unvollständige bzw. relationale Vertrag, der insbesondere bei häufigen Transaktio-

1 Simon (Behavior, 1961) S. xxiv, der dabei aber auf satisfizierendes Verhalten abstellt; s.a. Simon (Behavioral Model of Rational Choice, 1955); Simon (Models of Man, 1957) S. 196-279; Wessling (Information, 1991) S. 114-119; in der Anwendung auf die Transaktionskostentheorie vgl. Williamson (Markets, 1975) S. 21-23; Williamson (Economic Institutions, 1985) S. 45-46, der die begrenzte Rationalität als halbstarke Rationalität ansieht und der neoklassischen Maximierung (starke Form) bzw. der organischen (Prozess-)Rationalität (schwache Form) gegenüberstellt; kritisch Schneider (Grundlagen, 1995) S. 265-266.

2 Vgl. Williamson (Markets, 1975) S. 26-30; Williamson (Economic Institutions, 1985) S. 47-49, 64-67. Hierbei können Opportunismus vor Vertragsabschluß (,adverse selection“, ,hidden information“) und nach Vertragsabschluß (,moral hazard“, „,hidden action“) unterschieden werden; im Überblick dazu auch Ricketts (Business Enterprise, 2002) S. 30-35.

3 Vgl. Alchian (Economics of Property Rights, 1977) S. 129-131.

4 Die „property rights“ werden in der deutschsprachigen Literatur auch als ,Handlungsrechte' zurückgehend auf Alchian/Demsetz (Property Rights Paradigm, 1973) S. 17: „socially recognized rights of action“ - oder ,Eigentumsrechte' beschrieben. Vgl. zur Unterteilung der Verfügungsrechte z.B. Bonus/Weiland (Welt der Institutionen, 1995) S. 32-33; Richter (Institutionenökonomik, 1990) S. 575; Schoppe et al. (Theorie der Unternehmung, 1995) S. 139.

5 Vgl. Meyer (Bedeutung des Property Rights-Ansatzes, 1983) S. 35, 38.

$6 \mathrm{Vgl}$. Commons (Institutional Economics, 1934) S. 55-93; Williamson (Modern Corporation, 1981) S. 1543.

7 Vgl. Williamson (Economic Institutions, 1985) S. 52-61; die Faktorspezifität stellt auf die Möglichkeiten alternativer Verwendung transaktionsspezifischer Faktorleistung ab und misst diese i.S.d. Opportunitätsgedankens in Form einer Quasirente, die aus der Differenz der Erträge aus der vorgesehenen Verwendung und aus der nächstbesten Verwendungsalternative bei nicht durchgeführter Transaktion hervorgeht; erläuternd Richter/Furubotn (Neue Institutionenökonomik, 2003) S. 193-196.

8 Richter/Furubotn (Neue Institutionenökonomik, 2003) S. 167. 
nen mit hoher Faktorspezifität als geeignet angesehen wird ${ }^{1}$. Es handelt sich hierbei nicht zwingend um einen Vertrag im strengen Rechtssinne, sondern um ein weiter gefasstes ökonomisches Konzept, das angesichts der getroffenen Annahmen zwangsläufig auf lückenhaften Vereinbarungen basiert. Ex ante ausbedungene Sicherungsund Sanktionsmechanismen geben eine Art von Verfassung vor, in deren Rahmen sich die Vertragsparteien bei unvorhersehbaren Ereignissen im Zuge ständiger Nachverhandungen auch ex post neu arrangieren können.

- Das Handeln der Individuen wird durch die Existenz, Beschaffenheit und Funktionsweise von Institutionen gesteuert, die zielorientierte Systeme von privatvertraglichen sowie rechtlichen Normen und daraus resultierende Verfügungsrechte einschließlich deren Garantieinstrumente darstellen ${ }^{2}$. Die Erforschung dieser Institutionen und damit der ökonomischen Organisation als solcher ${ }^{3}$ ist Gegenstand der Effizienzbetrachtung. Da das ökonomische Organisationsproblem immer auch ein Vertragsproblem ist ${ }^{4}$, findet die Rechts- und Vertragsordnung Eingang in das ökonomische Kalkül. Weil sich diese Ordnung und mit ihr das gesamte Arrangement von Verfügungsrechten unmittelbar auf das volkswirtschaftliche Allokations- und Koordinationsproblem auswirkt, wird ihre Gestaltung - anders als in der Neoklassik, die diese Ordnung als Datum unterstellt - zur wesentlichen Stellschraube effizienzsteigernden Bemühens.

- Transaktionskosten fungieren als Effizienzmaßstab. Dabei orientiert sich die institutionenökonomische Effizienzbetrachtung weniger an theoretisch optimalen Lösungen (,nirvana approach“5), sondern ist eher durch einen komparativen Institutionenvergleich geprägt. Losgelöst von der strengen Optimierung und Quantifizierung der neoklassischen Marginalanalyse und ungeachtet zweifelsohne existierender termino-

1 Vgl. Williamson (Economic Institutions, 1985) S. 68-84, der sich in der dreiteiligen Vertragstypologie (klassischer, neoklassischer und relationaler Vertrag) an Macneil anlehnt; vgl. z.B. Macneil (Contracts, 1978). Der neoklassische Vertrag grenzt sich vom klassischen Vertrag durch die Eigenschaft ab, dass er die Mithilfe Dritter, z.B. der Gerichte, bei der Beilegung von Streitigkeiten vorsieht. Anstelle des relationalen Vertrages wird im Weiteren vom unvollständigen Vertrag gesprochen.

2 Vgl. Richter (Institutionenökonomik, 1990) S. 572; Richter/Furubotn (Neue Institutionenökonomik, 2003) S. 7-8; etwas abgewandelt auch Schneider (Investition, 1992) S. 11, 40; Schneider (Grundlagen, 1995) S. 20-24. Der Institutionenbegriff geht bis auf Schmoller (Grundriß der Allgemeinen Volkswirtschaftslehre, 1900) S. 61-64 und Commons (Institutional Economics, 1934) S. 69-74 zurück. Ergo ist auch die Bezeichnung "Neue Organisationsökonomik" geprägt worden; vgl. Richter/Furubotn (Neue Institutionenökonomik, 2003) S. 39.

4 Vgl. Williamson (Economic Institutions, 1985) S. 20.

5 Demsetz (Information, 1969) S. 1 in seiner Ablehnung insb. neoklassischen Denkens; kritisch allerdings Schneider (Unhaltbarkeit des Transaktionskostenansatzes, 1985) S. 1240-1243; Schneider (Grundlagen, 1995) S. 263-276, der selbiges letztlich auch der Transaktionskostentheorie unterstellt, wenn sie Ineffizienzen im Sinne von Opportunitätskosten über den Vergleich mit der neoklassischen Gleichgewichtslösung zu ermitteln sucht. Zur schwierigen Trennung der Transaktionskosten in Ressourceneinsatz und Wohlfahrtsverlust kurz auch Richter (Neue Institutionenökonomik, 1998) S. 326. 
logischer Abgrenzungs-, Präzisierungs- und Operationalisierungsprobleme ${ }^{1}$ stellen Transaktionskosten ein sinnvolles heuristisches Konzept für den logischen Nachweis der Ungleichheit zweier Zustände $\mathrm{dar}^{2}$. Sie resultieren zu einem großen Teil aus unvollständiger oder ungleich verteilter Information und sind damit gewissermaßen Ausfluss der aufgegebenen Prämisse vollkommener Information. In einer heute üblichen Sichtweise gehen Transaktionskosten über die reinen Kosten der Marktbenutzung hinaus ${ }^{3}$ und beziehen sich auf sämtliche vor, bei oder nach einer Transaktion auch außerhalb des Marktes anfallenden Kosten ${ }^{4}$.

Die steuerliche Gewinnermittlung als Sonderform einer Rechnungslegung ergibt nur auf unvollkommenen Märkten angesichts der dort herrschenden Unsicherheit ${ }^{5}$ einen Sinn. Informationen sind auf diesen Märkten unvollständig und vor allem auch asymmetrisch verteilt. Der Staat hat zwar die hoheitliche Macht, Steuern zu erheben und einzutreiben, ist jedoch über die ,richtige“ Höhe derselben mangels Informationen über den unternehmerischen Gewinn als Zielgröße der Besteuerung schlecht oder gar nicht informiert. Im Idealfall vermittelt nun die steuerliche Gewinnermittlung die gewünschten Informationen, die diese Unsicherheit über den Abbau der asymmetrischen Informationsverteilung reduzieren. Da der Abbau asymmetrischer Informationsverteilungen durch Informationsabgleich ein immanenter Bestandteil nicht nur der steuerlichen Gewinnermittlung, sondern jeder Form der Rechnungslegung ist, kann darin auch ihr „Metazweck ${ }^{“ 6}$ gesehen werden. Die steuerliche Gewinnermittlung wirkt in dieser Hinsicht transaktionskostensenkend, verursacht über den gesetzlich oktroyierten Zwangsvertrag aber auch neue Transaktionskosten, so dass von einer Effizienzsteigerung angesichts gegenläufiger Effekte nicht automatisch auszugehen ist?

1 Vgl. z. B. Schneider (Unhaltbarkeit des Transaktionskostenansatzes, 1985) S. 1241-1243; dazu auch Richter (Institutionenökonomik, 1990) S. 576, 578 sowie Richter/Furubotn (Neue Institutionenökonomik, 2003) S. 65-71, die auch einen kurzen Literaturüberblick über die Versuche der Transaktionskostenmessung aufführen.

2 Vgl. Simon (Rationality, 1978) S. 6-7; Williamson (Comparative Economic Organization 1991) S. 17; Williamson (Economic Institutions 1985) S. 22.

3 Vgl. insb. Coase (Nature of the Firm, 1937) S. 390: „, cost of using the price mechanism“.

4 Vgl. Williamson (Economic Institutions, 1985) u.a. mit der Analogie zu Reibungsverlusten physikalischer Systeme (S. 1-2) oder z.B. von Weizsäcker (Influence of Property Rights, 1984) S. 90, der darunter die Kosten jeder sozialen Koordination versteht. Vgl. zur empirschen Evidenz den Literaturüberblick von Shelanski/Klein (Empirical Research in Transaction Cost Economics, 1995).

5 Der in der Literatur nicht einheitlich benutzte Begriff der Unsicherheit wird hier als Überbegriff für Risiko- und Ungewissheitssituationen auf der Basis vollständiger Entscheidungsmodelle und auch für Entscheidungssituationen auf der Basis unvollständiger Entscheidungsmodelle verwendet; vgl. dazu im Überblick Fülbier (Regulierung der Ad-hoc-Publizität, 1998) S. 109-110 m.w.N.

6 Pellens (Internationale Rechnungslegung, 2001) S. 10; Pellens/Fülbier/Gassen (Internationale Rechnungslegung, 2004) S. 3.

7 Vgl. zur transaktionskostentheoretischen Sicht der Rechnungslegung im Überblick Gassen (Rechnungslegung, 2001) S. 395-397, 403-411. 
Dem methodologischen Individualismus folgend, stehen sich auch nicht mehr die Unternehmen und der Staat als solche gegenüber. Unternehmen oder, aus wirtschaftstheoretischer Sicht terminologisch präziser ${ }^{1}$, Unternehmungen kennzeichnen im Sinne des methodologischen Individualismus abstrakte Konstruktionen vertraglich miteinander verbundener Institutionen und Individuen. Für die an späterer Stelle noch intensiv analysierten Fragen, was denn Unternehmen bzw. Unternehmungen ökonomisch auszeichnet und wie sie letztlich auch für Zwecke einer konsolidierten steuerlichen Gewinnermittlung abzugrenzen sind ${ }^{2}$, vermag die vertragstheoretische Perspektive eine gegenüber der Neoklassik verbesserte Hilfestellung zu geben. Der methodologische Individualismus führt aber auch dazu, dass individuelle Anreize im Zuge der steuerlichen Gewinnermittlung offenkundig werden, wenn unternehmerische Entscheidungsträger, die Manager auf der einen und Bürokraten und Politiker auf der anderen Seite betrachtet werden. Wenn die Vergütung der Manager direkt oder indirekt an Nach-Steuer-Ergebnisse gebunden ist, werden sie im Rahmen ihrer begrenzten Rationalität und unter Einsatz opportunistischer Verhaltensweisen tendenziell versuchen, Steuerzahlungen zu reduzieren oder in die Zukunft zu verlagern (relative Steuerbarwertminimierung ${ }^{3}$ ). Den Politikern und Bürokraten allein Steueraufkommensmaximierung zu unterstellen, ginge hingegen an den vielschichtigen Erkenntnissen der Bürokratietheorie und der Neuen Politischen Ökonomie vorbei ${ }^{4}$. Denkbar wäre hiernach bei den Bürokraten z.B. das Interesse an Steuerkomplexität oder neuen Steuerarten, die u.a. zu Budgetmaximierung, Machterhalt oder innerbehördlichen Karrieremöglichkeiten beitragen. Den auf Wählerstimmen fokussierenden Politikern kann z.B. ebenfalls ein Interesse an Steuerkomplexität unter-

Vgl. dazu Kap. II.3.2.

Vgl. Kap. II.3.3 und V.2.

3 Vgl. z.B. Herzig/Dempfle (Konzernsteuerquote, 2002) S. 4; Schneeloch (Bilanzpolitik, 1990) S. 98. Eine absolute Minimierung scheidet aus, weil dies in letzter Konsequenz mit der Einstellung unternehmerischer Tätigkeit einherginge. Letztlich dokumentiert sich in dieser Zielsetzung eine investitionstheoretische Selbstverständlichkeit, nämlich den Nettoentnahmestrom aus dem Unternehmen zu maximieren und demzufolge die Steuern wie auch alle anderen nichtkonsumtiven Auszahlungen zu minimieren; s.a. Wagner/Dirrigl (Steuerplanung der Unternehmung, 1980) S. 11.

4 Vgl. grundlegend zur Bürokratietheorie u.a. Niskanen (Bureaucracy, 1971); Hilton (Behavior of Regulatory Commissions, 1972); vgl. grundlegend zur Theorie der Neuen Politischen Ökonomie Downs (Theory of Democracy, 1957); McKennzie/Tullock (Modern Political Economy, 1978); zu beiden Ansätzen im Überblick m.w.N. Erlei/Leschke/Sauerland (Neue Institutionenökonomik, 1999) S. 307369; Stiglitz/Schönfelder (Finanzwisenschaft, 1989) S. 141-207; in Anwendung auf die Besteuerung z.B. Brennan/Buchanan (Power to Tax, 1980) S. 17-26. 
stellt werden, um damit z.B. Diskrepanzen zwischen öffentlich kommunizierten und tatsächlichen Zielen zu verschleiern'.

Aus wirtschaftstheoretischer Sicht ließe sich das Problem der Besteuerung aber auch noch aus einer weiteren Perspektive beleuchten: aus Sicht einer evolutorischen, prozessorientierten Theorie, wie sie sich z.B. aus der Österreichischen Schule u.a. um Menger, Böhm-Bawerk, von Mises, von Hayek oder Kirzner ergibt ${ }^{2}$. Typisch ist hier die Ablehnung des als tautologisch kritisierten gleichgewichtstheoretischen Denkens und die Hinwendung zu einer dynamischen, stärker auf Koordinationsaspekte zielenden (Ungleichgewichts-)Analyse evolutorischer Anpassungs- und Wettbewerbsprozesse ${ }^{3}$. Allein diese Prozesse und das sie steuernde marktwirtschaftliche Preissystem ${ }^{4}$ fungieren hier als dezentrales „Entdeckungsverfahren“" ${ }^{65}$ aus dem ungeplante, nicht vorhersehbare Ergebnisse resultieren ${ }^{6}$. In der hier besonders zum Ausdruck kommenden Sicht von Hayeks existiert neben dieser gewachsenen, spontanen Ordnung mit dem Staat eine von Menschen vorsätzlich begründete und damit künstliche Ordnung ${ }^{7}$, die im Idealfall aber selbst wiederum Element der spontanen Ordnung ist und sich auch weitgehend deren Selektionsmechanismen unterwirft ${ }^{8}$. Dies gilt auch für die staatliche Regulierung, die nur Rahmenbedingungen als ,allgemeine, abstrakte Regeln“ (durch) zu setzen hat ${ }^{9}$, da

1 So könnte z.B. vermutet werden, dass Politiker vordergründig kommunizierte Steuersenkungen auf den Steuersatz beziehen, diese aber durch schwer quantifizierbare Erweiterungen der Bemessungsgrundlage zu überkompensieren versuchen und dabei auf die begrenzte Rationalität der Betroffenen vertrauen. Vgl. zu einer ähnlichen Kritik z.B. an einer deutschen Unternehmenssteuerreform Schneider (Steuerlast, 2002) S. V (Vorwort). In einer positiven Theorie der Regulierung dürften damit erste Erklärungsansätze zu dem gegenwärtigen, nicht als befriedigend empfundenen Stand der Steuergesetzgebung generiert sein.

2 Vgl. zur Österreichischen Schule, ihren Hauptvertretern und -werken eingehender Erlei/Leschke/Sauerland (Neue Institutionenökonomik, 1999) S. 31-35; Socher (Österreichische Schule, 2002). Bei Kunz (Marktsystem, 1985) S. 1-9, 62, 145 wird i.d.Zshg. der Begriff der prozessorientierten Evolutions- und Koordinationstheorie benutzt. Vgl. zum Evolutionsbegriff in der Sozialwissenschaft und zum Vorwurf des Sozial-Darwinismus von Hayek (Recht, Band 1, 1980) S. 38-42.

3 Vgl. u.a. von Hayek (Use of Knowledge, 1945) S. 530. Die Zwangsläufigkeit, mit der Gleichgewichtslösungen aus den gesetzten Annahmen resultieren, führt dazu, in der Gleichgewichtstheorie nur noch einen 'Zweig der reinen Logik' zu sehen, der das gesamte wirtschaftliche Geschehen auf eine 'Reihe selbstevidenter Sätze' reduziert; vgl. dazu von Hayek (Wirtschaftstheorie, 1952) insb. S. 51.

4 Vgl. dazu grundlegend von Hayek (Use of Knowledge, 1945).

5 von Hayek (Wettbewerb als Entdeckungsverfahren, 1968) S. 3; von Hayek (Recht, Band 3, 1981) S. 100. Vgl. zum Wettbewerb als dynamischem (Wissensaufdeckungs-)Prozess grundlegend von Hayek (Sinn des Wettbewerbs, 1952); Kirzner (Marktdynamik, 1988) S. 24-47 und vor allem Schumpeter (Capitalism, 1947) S. 81-82.

6 Vgl. von Hayek (Recht, Band 1, 1980) S. 38-42; das Ergebnis evolutionärer Prozesse sei „das Produkt der Handlungen vieler Menschen, aber nicht das Resultat eines menschlichen Entwurfs" (S. 59).

7 Vgl. von Hayek (Recht, Band 1, 1980) S. 59, der die künstliche Ordnung als „taxis“ bezeichnet, die er dem spontanen „,kosmos“ gegenüberstellt; weiterhin von Hayek (Verfassung der Freiheit, 1991) S. 72; ähnlich im Übrigen auch Williamson (Spontaneous and Intentional Governance, 1991).

8 Beide Ordnungen lassen sich aber nicht beliebig „mischen“; vgl. von Hayek (Recht, Band 1, 1980) S. 59, 69-79; von Hayek (Muddle of the Middle, 1983); von Mises (Nationalökonomie, 1940) S. 648.

9 Vgl. insb. von Hayek (Verfassung der Freiheit, 1991) S. 28-29, 161-194. 
jede positive Rechtsetzung nur unter Anmaßung von Wissen (pretence of knowledge ${ }^{1}$ ), quasi „konstruktivistisch“, am Reißbrett entworfen werden kann². Bezogen auf die Besteuerung wird das künstliche Eingreifen in marktwirtschaftliche Prozesse (Lenkungszweck der Besteuerung) deshalb mit ebenso großem Misstrauen betrachtet ${ }^{3}$ wie sozialpolitisch motivierte distributive Besteuerungszwecke, die als ,nivellierender materieller Egalitarismus $^{64}$ das individuelle und eigennutzorientierte Streben nach Wettbewerbsvorteilen konterkarieren.

So bereichernd die evolutorische Perspektive für die Untersuchung von Besteuerungsfragen auch sein kann, so deutlich sind hier die Gemeinsamkeiten mit der Neuen Institutionenökonomik, insbesondere bei der Anerkennung der institutionellen Seite der Ökonomie. Insofern kann es nicht verwundern, dass zentrale institutionenökonomische Rahmenbedingungen in evolutorischer Perspektive gleichermaßen gelten: der methodologische Individualismus, die Verhaltensannahmen der betrachteten Individuen, unvollkommene Märkte, die effizienzbeeinflussende Bedeutung von spontan ${ }^{5}$ oder vorsätzlich begründeten Institutionen und der Vertrag als zentrales Transaktionsmedium. Sogar die Transaktionskosten können als Effizienzmaßstab im Sinne von Prozessfriktionen (Koordinations- und Anpassungskosten ${ }^{6}$ ) dynamisch interpretiert werden ${ }^{7}$, auch wenn sie wegen der immer noch existierenden Quantifizierungsprobleme ${ }^{8}$ weiterhin nur als

1 Vgl. von Hayek (Pretence of Knowledge, 1989).

2 Die Kritik von Hayeks am Konstruktivismus und dessen allgemeinem Begründungsanspruch fußt aus wissenschaftstheoretischer Sicht im kritischen Rationalismus; vgl. z.B. von Hayek (Rationalismus, 1969); von Hayek (Recht Band 1, 1980) S. 47-53; zum Verhältnis von Popper zu von Hayek vgl. Nef (Popper contra Hayek, 1992).

3 Vgl. von Hoyek (Recht, Band 1, 1980) S. 182-184; eindrucksvoll zur allgemeinen Zurückhaltung vor jeder bewussten Lenkung von Hayek (Verfassung der Freiheit, 1991).

4 Winterberger (Hayeks Theorie der Gerechtigkeit, 1992) S. 102; dazu auch von Hayek (Verfassung der Freiheit, 1991) S. 105-124, 296-298; zum Gerechtigkeitsverständnis von Hayeks auch Kap. II.2.2.3.

5 Ähnlich der Theorie der spontanen Ordnung konstatiert z.B. Richter (Neue Institutionenökonomik, 1998) S. 326: „Die institutionelle Struktur ... tendiert dazu, ,sich selbst' so zu entwickeln, daß der Nettoertrag der Transaktionen maximiert wird“.

6 Der Begriff „Koordinationskosten findet sich bei Bössmann (Transaktionskosten, 1982) S. 665; zu dieser auf Koordinations- und Anpassungseffizienz zielenden Terminologie s.a. Fülbier (Regulierung der Ad-hoc-Publizität, 1998) S. 198-199.

7 Vgl. u.a. Casson (The Entrepreneur, 1982) insb. S. 41-218, 247-270, 295-324; Foss (Evolutionary Theories, 1996) S. 13-23; Foss (Evolutionary and Contractual Theories of the Firm, 1997); Kunz (Marktsystem, 1985) S. 108-118; Langlois/Robertson (Firms, 1995) S. 20-45; Streit/Wegner (Transaktionskosten aus evolutorischer Sicht, 1989); Winter (On Coase, 1988) S. 175-179.

8 Das ursprünglich gleichgewichtstheoretische (Opportunitäts-)Konzept der Transaktionskosten (vgl Schneider (Grundlagen, 1995) S. 269-270) erfährt insofern eine Modifizierung, da anstelle des abgelehnten Ideals eines totalen Konkurrenzgleichgewichts nur ein zweiter, quasi optimaler evolutorischer Prozess als Opportunitätsmaßstab in Frage kommt. Da ein optimaler Prozess aber nur unter AnmaBung von Wissen konstruierbar wäre, bleibt die Quantifizierung der Transaktionskosten auch in prozessorientierter Sichtweise problematisch; vgl. Kunz (Marktsystem, 1985) S. 3. 
heuristisches Konzept zum Nachweis von Ungleichheit' oder als „bloße Erklärungen des Prinzips" ${ }^{\text {"2 }}$ taugen. Angesichts des insofern eher komplementären Verhältnisses evolutorischer und institutionenökonomischer Denkwelten ${ }^{3}$ soll die institutionenökonomische Sichtweise den wirtschaftstheoretischen Beurteilungsstandpunkt dieser Arbeit bilden, ohne dabei - im Einzelfall - ergänzende, evolutorische Elemente zu ignorieren ${ }^{4}$.

\subsubsection{Wirkungsorientierte Effizienzbetrachtung}

\subsubsection{Entscheidungsneutralität als ökonomisches Ideal?}

In der Sichtweise der normativen Wirtschaftstheorie sind regulierende Eingriffe des Staates in das marktwirtschaftliche System an den dadurch hervorgerufenen Effizienzwirkungen zu messen. Bei der Frage nach der effizienzorientierten Beurteilung steuerlicher Gewinnermittlungsregeln wird in der Literatur überwiegend auf die Entscheidungsneutralität als konkreteres Beurteilungskriterium verwiesen ${ }^{5}$. Angesichts der Erkenntnis, dass jede Regulierung wieder Ausweichhandlungen der Regulierten nach sich zieht $^{6}$, gilt eine Gewinnermittlung als erstrebenswert, die rechtlich zulässige, aber ineffiziente Anpassungshandlungen (Steuerausweichhandlungen) möglichst zu vermeiden hilft $^{7}$. Entscheidungsneutralität kennzeichnet damit eine Art ökonomisches Ideal ${ }^{8}$, das frei nach dem Motto funktioniert: Wenn der Staat schon in das Marktgeschehen eingreift, dann bitte so, dass wirtschaftliche Dispositionen und aus ihnen resultierende Ergebnisse nicht verzerrt werden. Obwohl man sich dieser normativen „Logik“ intuitiv nur schwer verschließen kann, kennzeichnet die Entscheidungsneutralität ein Konzept, das nur mit erheblichen Einschränkungen und Relativierungen für die Forschungsfrage dieser Arbeit nutzbar gemacht werden kann.

1 Vgl. zu den Vorteilen einer komparativen Vorgehensweise von Hayek (Recht, Band 3, 1981) S. 99; Kunz (Marktsystem, 1985) S. 155.

2 Von Hayek (Theorie komplexer Phänomene, 1972) S. 34, der auch von „Muster-Voraussagen“ spricht.

3 Vgl. z.B. Kunz (Marktsystem, 1985) S. 68; aber auch Williamson (Modern Corporation, 1981) S. 1541; Williamson (Economic Institutions, 1985) S. 46-47.

4 Diese Vorgehensweise würde z.B. der Forderung von Schmidtchen (ökonomische Analyse des Rechts, 1991) entsprechen, eine transaktionskostentheoretisch untermauerte ökonomische Analyse des Rechts durch den Faktor Zeit zu erweitern, bei dem sich ein Rückgriff auf die Österreichische Schule lohne.

5 Vgl. zum Neutralitätspostulat in Finanzwissenschaft u. Betriebswirtschaft stellvertretend m.w.N. Elschen/Hüchtebrock (Steuerneutralität, 1983); Wagner (Neutralität und Gleichmäßigkeit, 1992) S. 2-7.

6 Vgl. Schanze (Hare and Hedgehog, 1995); spezieller zu Steuerausweichhandlungen z.B. Schneider (Steuergerechtigkeit, 1985) insb. S. 349.

7 Vgl. Schneider (Investition, 1992) S. 193; Schneider (Steuerlast, 2002) S. 97. Nach Elschen (Entscheidungsneutralität, 1991) S. 102 habe Schneider erstmals konsequent die grundlegende Bedeutung der Entscheidungsneutralität der Besteuerung für die betriebswirtschaftliche Steuerwirkungslehre herausgestrichen.

8 Vgl. zu dieser Terminologie z.B. Wagner (Neutralität und Gleichmäßigkeit, 1992) S. 3. 
Erst einmal ist festzustellen, dass die Entscheidungsneutralität nicht per se als ökonomisches Ideal für die steuerliche Gewinnermittlung fungieren kann. Anders als bei Fiskalsteuern, die allein zur Finanzierung staatlicher Aufgaben erhoben werden und dabei keine Entscheidungswirkungen entfalten sollen, sind Änderungen des Entscheidungsverhaltens bei den Lenkungssteuern ja gerade beabsichtigt, z.B. um (vermeintlichen) marktwirtschaftlichen Ineffizienzen zu begegnen. Die Entscheidungsneutralität kann hier allenfalls in einer positiven Theorie eine Rechtfertigung erfahren, wenn eine „Messtheorie für Steuerwirkungen“ auf ihr als „methodologischer Vorentscheidung " aufbaut, um Steuervergünstigungen und -benachteiligungen messen und die beabsichtigte Lenkungswirkung auch überprüfen zu können ${ }^{2}$. Nicht nur deswegen werden Lenkungssteuern im weiteren Verlauf dieser Arbeit ausgespart. Auch unabhängig von dem Neutralitätspostulat müsste sich eine normative Analyse der entsprechenden Gewinnermittlungsregeln mit den vielen, oft einzelfallorientierten, nicht immer vollständig bekannten, wirtschaftstheoretisch regelmäßig unterschiedlich begründeten und von einzelstaatlich verfolgten wirtschaftspolitischen Leitbildern kaum loszulösenden Lenkungszwecken auseinandersetzen. Dies kann und soll nicht Gegenstand dieser Arbeit sein. Es verbleiben somit die Fiskalsteuern, bei denen das Ideal der Entscheidungsneutralität aus normativer Sicht überhaupt erst einen Sinn ergibt.

Relativierung erfährt das Konzept der Entscheidungsneutralität aber auch aus wirtschaftstheoretischer Perspektive. Ausgangspunkt der Entscheidungsneutralität ist eine eher neoklassisch geprägte Perspektive, in der Entscheidungswirkungen als allokative Verzerrungen wahrgenommen werden, die zu gesamtwirtschaftlichen Wohlfahrtseinbußen (excess burden) führen ${ }^{3}$. Entsprechend der bereits formulierten Kritik am „nirvana approach"44 werden Wohlfahrtseinbußen also nur im Vergleich zu theoretischen Optimalzuständen ermittelt, unabhängig davon, ob diese in der Realität überhaupt erreichbar sind $^{5}$. Dabei kann die Entscheidungsneutralität nur in einem engen Modellrahmen definiert werden. Gilt ein Steuer(ermittlungs)system hiernach als entscheidungsneutral, wenn sich die Rangfolge der Entscheidungsalternativen der betroffenen Wirtschaftssub-

Schneider (Steuerlast, 2002) S. 100 [beide Zitate].

Vgl. Schneider (Steuerlast, 2002) S. 98-101.

Vgl. dazu m.w.N. Musgrave (Theory of Public Finance, 1959) S. 141: „[T]axes should be as neutral as possible. Unintended interference with the market mechanism may result in an excess burden that should be avoided"; vgl. ebenfalls Musgrave/Musgrave (Public Finance, 1989) S. 279-295. Die soziale Wohlfahrtsfunktion als Maßstab zur Beurteilung von Steuerregulierungen ist deshalb auch zentrales Instrument der finanzwissenschaftlich geprägten (normativen) Theorie der „optimal taxation“; vgl. dazu auch Kap. II.2.1.3. Zum Verhältnis von (einzelwirtschaftlicher) Entscheidungsneutralität und (gesamtwirtschaftlicher) Allokationseffizienz vgl. m.w.N. u.a. Elschen (Entscheidungsneutralität, 1991) S. 99-110; Hundsdoerfer (Einkommenserzielung und Konsum, 2002) S. 16-19.

4 Demsetz (Information, 1969) S. 1, der aus seiner institutionenökonomischen Sichtweise fordert, die Beurteilung einer Marktsituation statt dessen an konkret realisierbaren institutionellen Alternativlösungen zu orientieren (,comparative institution approach").

5 Vgl. dazu bereits Kap. II.2.1.1. 
jekte gegenüber einer Welt ohne Steuern nicht verändert, so wird dabei als restriktive Nebenbedingung vorausgesetzt, dass sich die Steuern nicht auch auf sonstige Bestandteile des Entscheidungsfeldes auswirken, dass Zielgrößen, Handlungsmöglichkeiten, Anfangsausstattung an Mitteln und auch das Ausmaß an Rationalität der Entscheidenden also unverändert bleiben ${ }^{1}$. Informationskosten wie Planungs- oder Suchkosten werden in einer friktionslosen und vollkommen informierten Welt ebenso wenig berücksichtigt wie rechtlich unzulässige Steuerausweichhandlungen (Steuerhinterziehung), da auch opportunistisches Verhalten den Modellprämissen widerspricht.

Das Ideal einer entscheidungsneutralen Besteuerung gilt auch aus institutionenökonomischer Perspektive. Angesichts realitätsnäherer Prämissen gewinnt das Konzept hier aber eine Komplexität, die es für ökonomische Detailanalysen eher unbrauchbar macht, zumindest wenn diese das Ziel haben, konkrete Anforderungen für steuerliche Gewinnermittlungsregeln zu formulieren. Wie im folgenden Abschnitt (Kapitel II.2.1.2.2) gezeigt wird, können derartige Anforderungen - wenn überhaupt - nur in der modelltheoretischen Enge der Neoklassik abgeleitet werden.

Das Ideal der Entscheidungsneutralität kann auch aus prozessorientierter Sicht einen Sinn ergeben. Entsprechend der Schwerpunktverlagerung hin zur Koordinations- oder Anpassungseffizienz von Markt- und Wettbewerbsprozessen dürfte hiernach eine Besteuerung anzustreben sein, die die Zahl und den ökonomischen Charakter abgeschlossener Markttransaktionen unbeeinflusst lässt und Markt- und Wettbewerbsprozesse nicht behindert (Arbitrage- oder Wettbewerbsneutralität ${ }^{2}$ ). Die ergänzende allokative Deutung der Entscheidungsneutralität ist dabei weiterhin möglich. Ausgehend von der Prämisse, dass jede freiwillig zustande gekommene Markttransaktion zu einer einzelwirtschaftlichen Effizienzsteigerung führt ${ }^{3}$, geht mit Markt- und Wettbewerbsprozessen immer auch die Hoffnung auf eine allokationsverbessernde Ressourcenverwendung einher ${ }^{4}$. Eine „Tendenz zum Gleichgewicht“" ${ }^{\text {"S }}$ wird ebenso wenig geleugnet wie die Tat-

1 Vgl. zu diesen idealtypischen Annahmen Schneider (Investition, 1992) S. 193-194; Schneider (Steuerlast, 2002) S. 98.

2 Vgl. z.B. Elschen (Entscheidungsneutralität, 1991) S. 109, 115; Elschen/Hüchtebrock (Steuerneutralität, 1983) S. 257, die unterschiedliche Formen der Wettbewerbsneutralität unterscheiden; Kofler (Steuerstrukturanpassung, 1995) S. 503-507; keineswegs ablehnend, aber dennoch kritisch indes Schneider (Investition, 1992) S. 201-203. Mit der Frage, ob innerhalb einer Wettbewerbsordnung Steuerbemessungsgrundlagen sinnvoll sind, die Allokationseffizienz und Entscheidungsneutralität gewährleisten, beschäftigt sich Schneider (Steuerlast, 2002) S. 255-260.

3 Bei Konsistenz eines Planes einer Einzelperson mit den subjektiven Daten seiner Vertragspartner ist ein individuelles Erwartungsgleichgewicht erreicht, das eine beiden Parteien dienende Markttransaktion ermöglicht; vgl. von Hayek (Wirtschaftstheorie, 1952) S. 52; Windsperger (Gleichgewicht und Wissen, 1983) S. 234-240; dazu auch Elschen (Institutionale oder personale Besteuerung, 1994) S. 210-237; Schneider (Grundlagen, 1995) S. 4.

4 Vgl. Schneider (Grundlagen, 1995) S. 58.

5 Von Hayek (Wirtschaftstheorie, 1952) S. 63. 
sache, dass derartige Koordinationsprozesse in Gleichgewichtsnähe ablaufen können'. Beide Deutungen der Entscheidungsneutralität münden vor diesem Hintergrund in einer Art Rangfolgeneutralität bzw. -invarianz, wonach die Rangfolge bestehender Handlungsalternativen der von der Steuer unmittelbar betroffenen Wirtschaftssubjekte (Steuerpflichtigen) unbeeinflusst bleibt ${ }^{2}$. So dient die entscheidungsneutrale Besteuerung auch nicht der Herstellung allokationseffizienter Optimalzustände, da ein paretooptimaler Effizienzzustand in einer realen Welt ohne Steuern wohl kaum den Ausgangszustand darstellen dürfte. Sinnvoller erscheint statt dessen, auf die Allokationsneutralität abzustellen ${ }^{3}$, die auf eine allgemeine Nichtbeeinflussung der am Markt zustande gekommenen relativen Preise durch die Besteuerung zielt ${ }^{4}$. Als „nicht-nochweitere-Fehllenkung" knapper Ressourcen wird diese durch die Wettbewerbsneutralität als „nicht-noch-weitere-Verzerrung“" von Markt- und Wettbewerbsprozessen ergänzt ${ }^{5}$. Die Relationen der Tauschergebnisse und mit ihnen die Wettbewerbsverhältnisse werden durch eine entscheidungsneutrale Besteuerung nicht beeinflusst ${ }^{6}$. Ob und inwieweit aus einem prozessorientierten Neutralitätsverständnis Konsequenzen für die steuerliche Gewinnermittlung resultieren, wird in Kapitel II.2.1.2.3 untersucht.

Da regulierende Eingriffe des Staates immer an sämtlichen Effizienzwirkungen zu messen sind, ist bei der steuerlichen Gewinnermittlung abschließend zu fragen, ob das Konzept der Entscheidungsneutralität auch unter Einbeziehung sämtlicher wirtschaftstheoretischer Betrachtungsebenen als alleiniges ökonomisches Beurteilungskriterium ausreichend sein kann. Dies ist gleichbedeutend mit der Frage, ob sich die Effizienzbeurteilung der steuerlichen Gewinnermittlung auf die hierdurch hervorgerufenen Steuerwirkungen beschränken soll ${ }^{7}$. Insbesondere aus institutionenökonomischer Perspektive erlangt diese Frage ihre Relevanz, da in einer keineswegs friktionslosen Welt auch an

I Vgl. Kunz (Marktsystem, 1985) S. 68-69, 75-80.

2 Durch den Steuer(entrichtungs)pflichtigen als personalen Bezugspunkt der Entscheidungsneutralität wird die Steuerwirkungsanalyse nur auf diejenigen reduziert, die der rechtlichen Pflicht zur Steuerzahlung unterliegen. Sonstige Marktwirkungen (effektive Steuerinzidenz) werden nicht betrachtet; vgl. dazu Elschen (Entscheidungsneutralität, 1991) S. 104.

3 Vgl. Wagner (Neutralität und Gleichmäßigkeit, 1992) S. 4; in der Deutung ähnlich z.B. Koop (Gewinnbesteuerung, 1993) S. 105; Pannen (Messtheoretische Grundprobleme, 2000) S. 128. Vgl. sehr viel differenzierter zu dem Verhältnis von Entscheidungsneutralität und Allokationseffizienz bzw. -neutralität Elschen (Entscheidungsneutralität, 1991) S. 99-110.

4 Vgl. Musgrave (Theory of Public Finance, 1959) S. 140-157.

5 Die Verwendung beider Neutralitätspostulate findet sich z.B. bei Schneider (Steuerlast, 2002) S. 101; dazu auch Elschen/Hüchtebrock (Steuerneutralität, 1983) S. 257-260.

6 Die Wettbewerbsneutralität wird meist aber ergebnisorientiert interpretiert und müsste in einer eher statischen bzw. komparativ-statischen Gleichgewichtstheorie zu modelltheoretischen Komplikationen führen. In einer so verstandenen Modellwelt hätte ein verfahrensorientiertes Neutralitätsverständnis keine eigenständige Existenzberechtigung, da dort mit den Voraussetzungen und Regeln des Tausches zugleich auch das Tauschergebnis determiniert ist; vgl. Elschen (Institutionale oder personale Besteuerung, 1994) S. 199-202.

7 Die von finanzwissenschaftlicher Seite untersuchte Steuerinzidenz, die eine über den Steuerpflichtigen hinausgehende Steuerwirkungsanalyse betreibt, wird in dieser Arbeit nicht untersucht. 
anderer Stelle Ineffizienzen auftreten können: bei der Durchführung der Besteuerung, die die technische Steuerermittlung an sich, das Festsetzungs- und Erhebungsverfahren beim Fiskus und sämtliche sonstigen Kontroll-, Sanktionierungs- und Durchsetzungsmaßnahmen umfasst ${ }^{1}$. Diese zu vernachlässigen, hieße die Effizienzbetrachtung auf einen Teilaspekt der steuerlichen Gewinnermittlung zu reduzieren. Um dies zu vermeiden, werden die daraus resultierenden Konsequenzen für die steuerliche Gewinnermittlung in Kapitel II.2.1.3 betrachtet.

\subsubsection{Anforderungen an eine investitionsneutrale Gewinnermittlung}

Wenn konkrete Anforderungen an die steuerliche Gewinnermittlung aus dem Ideal der Entscheidungsneutralität abgeleitet werden, geschieht dies regelmäßig auf der Grundlage neoklassisch-allokativer Modelle. Mittels modelltheoretischer Idealisierung erkauft man sich hier konkrete Aussagen zum Preis einer zumindest fragwürdigen normativen Tauglichkeit. Zudem wird die Frage nach der entscheidungs- bzw. allokationsneutralen Ausgestaltung von Ertrag- und hier vor allem Körperschaftsteuer(ermittlungs)systemen nur im Rahmen von einzelwirtschaftlichen Partialmodellen beantwortet, die angesichts der für die Faktorallokation zentralen Bedeutung von unternehmerischen Investitionsentscheidungen insbesondere auf die „Investitionsneutralität“ abstellen ${ }^{2}$. Abgesehen von „entscheidungsfixen“, in der Literatur durchweg abgelehnten Besteuerungssystemen ${ }^{3}$ kann diese Form der Entscheidungsneutralität durch eine Besteuerung finanzieller Zielgrößen erreicht werden, in der die Investitionsalternative mit dem höchsten Bruttoergebnis (vor Steuern) auch zum höchsten Nettoergebnis (nach Steuern) führt ${ }^{4}$. Vor diesem Hintergrund haben sich mit der Besteuerung des kapitaltheoretischen Gewinns (,economic profit" ${ }^{\star 5}$ ) und des Zahlungsüberschusses (Cash-Flow-Besteuerung) zwei

1 Vgl. z.B. Schneeloch (Besteuerung, 2003) S. 40, der die Durchführung der Besteuerung in Ermittlungsverfahren, Festsetzungsverfahren, Erhebungsverfahren, Vollstreckungsverfahren, Rechtsmittelverfahren sowie Straf- oder Bußgeldverfahren unterteilt.

2 Vgl. z.B. Schiele (Unternehmensbesteuerung, 2000) insb. S. 149-171; grundlegend dazu auch Steiner (Gewinnsteuern in Partialmodellen, 1980); weitere Partialbetrachtungen der Entscheidungsneutralität, z.B. der Standortneutralität, Rechtsformneutralität oder Finanzierungsneutralität, werden hier ausgespart; vgl. dazu im systematischen Überblick König (Steuerplanungslehre, 2004) S. 264.

3 In diesem Sinne wären insb. so genannte Pauschal- oder Kopfsteuern (,head tax“) entscheidungsneutral, die aber aus außerökonomischer Perspektive regelmäßig abgelehnt werden; vgl. z.B. Musgrave (Theory of Public Finance, 1959) S. 158; Raab (Öffentliche Transaktionskosten, 1995) S. 148-150; Wagner (Neutralität und Gleichmäßigkeit 1992) S. 4; Wagner/Dirrigl (Steuerplanung der Unternehmung, 1980) S. 16; Wagner/Wissel (Entscheidungsneutralität, 1995) S. 67 sowie Kap. II.2.2. Vgl. indes kritisch zur Entscheidungsneutralität dieser Steuern Schneider (Steuerlast, 2002) S. 264.

4 Vgl. Schneider (Investition, 1992) S. 206; Schneider (Steuerlast, 2002) S. 31, 141, der als „Kernsatz“ der Steuerwirkungslehre formuliert: „Eine Zielgrößenbesteuerung ist entscheidungsneutral"; Wagner/Dirrigl (Steuerplanung der Unternehmung, 1980) S. 17-18; Wagner (Neutralität und GleichmäBigkeit 1992) S. 4.

5 In wörtlicher Übersetzung wird in der deutschen Literatur auch vom „ökonomischen Gewinn“ gesprochen; vgl. kritisch zu diesem Begriff Richter (Investitionsneutrale Besteuerung, 1990) S. 760; Schneider (Investition, 1992) S. 219-220; Schneider (Rechnungswesen, 1997) S. 264. 
Grundmodelle herausgebildet, die die Vorteilhaftigkeitsrangfolge alternativer Investitionsprojekte unter engen modelltheoretischen Prämissen nicht beeinflussen'. Trotz ihrer gleichermaßen investitionsneutralen Wirkung verbinden sich mit diesen beiden GrundGewinnermittlungsmodellen unterschiedliche Vorstellungen über die als ,richtig“ empfundene Steuerbemessungsgrundlage. Mit anderen Worten: Selbst unter Idealbedingungen hat sich die Literatur bis heute nicht darauf einigen können, was genau als finanzielles Ziel ökonomischen Handelns angesehen werden soll: das Einkommen oder der Konsum. Ohne diese schon lang schwelende Grundsatzdiskussion hier nachzeichnen zu wollen ${ }^{2}$, orientiert sich diese Arbeit - soweit es um die Anforderungen an eine investitionsneutrale Besteuerung geht - am Einkommen und folgt damit der vorherrschenden Besteuerungspraxis. Damit steht in den folgenden Ausführungen und insbesondere im weiteren Verlauf der Arbeit der kapitaltheoretischen Gewinn im Vordergrund, auch wenn die Cash-Flow-Besteuerung hier noch kurz skizziert und vom kapitaltheoretischen Gewinn abgegrenzt wird.

Ausgehend von dem Kapitalwert als sinnvollem Entscheidungskriterium finanzieller Vorteilhaftigkeit von Investitionen ${ }^{3}$ vermag eine Besteuerung des kapitaltheoretischen Gewinns die Rangfolge der Kapitalwerte alternativer Investitionen unbeeinflusst zu

1 Vgl. zur Cash-Flow-Besteuerung erstmalig wohl Brown (Business-Income Taxation, 1948); s.a. Musgrave (Theory of Public Finance, 1959) S. 343-345; erläuternd und m.w.N. zu den verschiedenen Varianten Bach (Cash-flow als Bemessungsgrundlage, 1999). Vgl. zum kapitaltheoretischen Gewinn grundlegend u.a. Johansson (Investment Decisions, 1969); Preinreich (Models of Taxation, 1951); Samuelson (Economic Depreciation, 1964); erläuternd z.B. Kahle (Der kapitaltheoretische Gewinn, 1995). Vgl. zur (formaltheoretischen) Gegenüberstellung dieser beiden Systeme und den engen Modellprämissen insb. Elschen/Hüchtebrock (Steuerneutralität, 1983) S. 266-274; König (Ungelöste Probleme einer investitionsneutralen Besteuerung, 1997); Schneider (Investition, 1992) S. 206-251; Schneider (Steuerlast, 2002) S. 103-105; Steiner (Gewinnsteuern in Partialmodellen, 1980), der diese Modelle auch ineinander überführt; vgl. aus finanzwissenschaftlicher Sicht z.B. Sinn (Kapitaleinkommensbesteuerung, 1985) S. 111-129.

2 Vgl. zu dieser Kontroverse z.B. den Sammelband Smekal/Sendlhofer/Winner (Einkommen versus Konsum, 1999); darin insb. Schneider (Einkommensteuer, 1999) und Wagner (konsumorientierte Steuer, 1999); s.a. z.B. Kraft (Steuergerechtigkeit, 1991) S. 41-48; Schneider (Steuerlast, 2002) S. 239-248; Schwinger (Einkommens- und konsumorientierte Steuersysteme, 1992); Siegel (Konsumoder einkommensorientierte Besteuerung, 2000); Wagner (Neutralität und Gleichmäßigkeit, 1992) insb. S. 5-6; für die USA im Überblick McNulty (Vereinigten Staaten, 1989) S. 123-126. Einigkeit besteht darin, dass nicht-monetäre Zielgrößen nicht zu besteuern sind, so dass „nur" fraglich bleibt, was als finanzielle Zielgröße anzusehen ist. Vgl. dazu aus finanzwissenschaftlicher Sicht zusammenfassend Blankart (Öffentliche Finanzen, 2003) S. 292-306.

3 Vgl. ausführlich zum Kapitalwertmodell, seinen Prämissen, der Berücksichtigung von Steuern und der Vorteilhaftigkeit dieses Kriteriums z.B. Steiner (Gewinnsteuern in Partialmodellen, 1980); Wagner (Grundfragen, 1984) S. 207-213; Wagner/Dirrigl (Steuerplanung der Unternehmung, 1980) S. 26-33. 
lassen ${ }^{1}$. Als Bemessungsgrundlage kann der kapitaltheoretische Gewinn in der Periode $\mathrm{t}$ $\left(\mathrm{kG}_{\mathrm{t}}\right)$ bei Vorliegen eines vollkommenen Kapitalmarktes als Verzinsung des Ertragswertes $^{2} \mathrm{zu}$ Periodenbeginn $\left(\mathrm{E}_{\mathrm{t}-1}\right)$ mit dem $\mathrm{zu}$ Grunde liegenden Kapitalmarktgleichgewichtszins (i) berechnet werden:

$$
k G_{t}=E_{t-1} \cdot i
$$

Der Ertragswert ergibt sich hierbei aus dem Ertragswert der Vorperiode, der um den kapitaltheoretischen Gewinn angewachsen ist. Wird in $t$ auch ein Zahlungsüberschuss $\left(\mathrm{N}_{t}\right)$ erwirtschaftet und entnommen, so sinkt der Ertragswert in dieser Höhe:

$$
E_{t}=E_{t-1}+i \cdot E_{t-1}-N_{t}=(1+i) E_{t-1}-N_{t}
$$

Unter Berücksichtigung von Steuern und unter der Voraussetzung, dass steuerliche Konsequenzen auch die Alternativanlagen treffen, in dem die um Steuern geminderte Zahlungsreihe mit einem um den (einheitlichen) Steuersatz s gekürzten Kalkulationszinsfuß $i^{s}=(1-s) i$ abgezinst wird ${ }^{3}$, ergibt sich der Ertragswert nach Steuern:

$$
\begin{aligned}
E_{t}^{s} & =E_{t-1}^{s}+(1-s) i \cdot E_{t-1}^{s}-\left(N_{t}-s\left[N_{t}-A f A_{t}\right]\right) \\
& =\left(1+i^{s}\right) E_{t-1}^{s}-\left(N_{t}-s\left[N_{t}-A f A_{t}\right]\right)
\end{aligned}
$$

Diese Ertragswertberechnung berücksichtigt auch die steuerliche Abzugsfähigkeit einer wie auch immer gemessenen Abschreibung AfA $_{t}$. Um diese zu berechnen folgt aus der Entscheidungsneutralität des Modells $\left(E_{t}=E_{t}^{s}\right.$ ) die Gleichsetzung von (2) und (3):

$$
(1+i) E_{t-1}-N_{t}=\left(1+i^{s}\right) E_{t-1}^{s}-\left(N_{t}-s\left[N_{t}-A f A_{t}\right]\right)
$$

1 Für Entscheidungsneutralität ist die Rangfolgeinvarianz der Kapitalwerte (K) vor und nach Steuern (s) ausreichend $\left(\mathrm{K}_{\mathrm{m}}>\mathrm{K}_{\mathrm{n}} \rightarrow \mathrm{K}_{\mathrm{sm}}>\mathrm{K}_{\mathrm{sn}}\right.$ bei zwei Investitionsprojekten $\mathrm{m}$ und $\mathrm{n}$; anders ausgedrückt: $\mathrm{K}_{\mathrm{s}}=$ $\mathrm{F}(\mathrm{K})$, wobei die Funktion $\mathrm{F}$ streng monoton steigt und streng genommen auch $\mathrm{F}(0)=0$ gelten muss). Die strengere Niveauinvarianz (Kapitalwerte vor und nach Steuern entsprechen einander) ist eine hinreichende, nicht aber notwendige Bedingung investitionsneutraler Steuersysteme. Der kapitaltheoretische Gewinn ist niveauinvariant und erfüllt damit zwangsläufig auch die schwächere Bedingung der Rangfolgeinvarianz. Vgl. dazu Elschen/Hüchtebrock (Steuerneutralität, 1983) S. 265, 270; König (Ungelöste Probleme einer investitionsneutralen Besteuerung, 1997) S. 45-46; König (Wirtschaftliche Effizienz, 1997) S. 133-135; Wagner/Wissel (Entscheidungsneutralität, 1995) S. 67.

2 Vgl. zur Identität von Kapitalwert und Ertragswert in ihrer Wirkung als Vorteilhaftigkeitskriterium bei Investitionsentscheidungen auf vollkommenen Kapitalmärkten Elschen/Hüchtebrock (Steuerneutralität, 1983) S. 267.

3 Dies unterstellt, dass Zinsen der Alternativinvestition besteuert werden und Kreditzinsen bei Kapitalaufnahme abzugsfähig sind; vgl. hierzu ausführlich Wagner/Dirrigl (Steuerplanung der Unternehmung, 1980) S. 30-33. Man spricht deshalb von einer „allgemeinen Gewinnsteuer“, da das betrachtete Investitionsprojekt sowie die Alternativanlage gleichermaßen der Besteuerung unterliegen. Andernfalls $\left(\mathrm{i}^{\mathrm{s}}=\mathrm{i}\right)$ läge eine „diskriminierende“ bzw. heterogene Gewinnsteuer vor; vgl. dazu Elschen/Hüchtebrock (Steuerneutralität, 1983) S. 267. 
woraus sich die $\mathrm{AfA}_{\mathrm{t}}$ nach Auflösung ergibt:

$$
A f A_{t}=N_{t}-i \cdot E_{t-1}=N_{t}-k G_{t}
$$

Während Anfangs- bzw. Anschaffungsauszahlung steuerlich unberücksichtigt bleiben, wird die periodisch anfallende Differenz aus Zahlungsüberschuss $\mathrm{N}_{t}$ und kapitaltheoretischem Gewinn als so genannte Ertragswertabschreibung steuerlich wirksam'. Von dem ursprünglichen Einzahlungsüberschuss verbleibt damit nur noch der Zinsanteil als Steuerbemessungsgrundlage $S_{t}$. Der Ertragswert einer Investition an sich ist steuerfrei gestellt.

$$
S_{t}=N_{t}-A f A_{t}=i \cdot E_{t-1}=k G_{t}
$$

Wie der kapitaltheoretische Gewinn geht auch die Cash-Flow-Besteuerung vom Kapitalwertkalkül aus. Anders als beim kapitaltheoretischen Gewinn, bei dem die Zinsen der Alternativinvestition besteuert werden und Kreditzinsen bei Kapitalaufnahme abzugsfähig sind, liegt aber keine allgemeine Gewinnsteuer vor. Der Kalkulationszinsfuß nach Steuern ist hier mit dem vor Steuern identisch $\left(i^{\mathbf{s}}=i\right)$, weil die Zinsen aus (alternativen) Finanzanlagen steuerlich unberücksichtigt bleiben ${ }^{2}$. Weiteres Charakteristikum der Cash-Flow-Besteuerung ist die steuerliche Abzugsfähigkeit der Anfangsauszahlung I als Sofortabschreibung, so dass in den Folgeperioden die Zahlungsüberschüsse N mangels Periodisierung der Anfangsauszahlung in ungeminderter Höhe besteuert werden ${ }^{3}$. Der Kapitalwert K der Investition sinkt demnach durch die Besteuerung proportional in Höhe des Steuersatzes s, wodurch die notwendige Rangfolgeinvarianz gewährleistet ist ${ }^{4}$.

$$
\begin{aligned}
K_{s} & =-(1-s) I+\sum_{t=1}^{n}(1-s) N_{t}(1+i)^{-t} \\
& =(1-s) K
\end{aligned}
$$

1 Vgl. Samuelson (Economic Depreciation, 1964). Die Ertragswertabschreibung lässt sich auch definieren als Differenz zwischen den Ertragswerten in $t_{0}$ und $t_{1}$ nach Entnahme des Zahlungsüberschusses.

2 Anders als bei der „allgemeinen Gewinnsteuer“ werden bei der hier vorliegenden ,heterogenen Gewinnsteuer" weder Zinseinnahmen noch Zinsausgaben steuerlich berücksichtigt. Dies garantiert wiederum Konsumneutralität, da der künftige Konsum (Sparen) nicht diskriminiert und eine verzerrungsfreie intertemporale Kapitalallokation gewährleistet wird; vgl. Wagner/Wissel (Entscheidungsneutralität, 1995) S. 69; dazu auch König (Wirtschaftliche Effizienz, 1997) S. 160.

3 Durch diese effektive Steuerfreistellung der investiven Mittelverwendung zielt der Steuerzugriff letztlich auf persönliche Konsumausgaben ab; vgl. dazu ausführlicher z.B. Bach (Cash-flow als Bemessungsgrundlage, 1999) S. 86-90, 97-104.

4 Anders als beim kapitaltheoretischen Gewinn liegt damit keine strenge Niveauinvarianz mehr vor. Das Neutralitätskriterium ist allerdings mit der Rangfolgeinvarianz weiterhin gewahrt, die hier durch die proportionale Veränderung sogar enger als notwendig definiert wird, da eine Rangfolgeneutralität selbst bei nicht proportionalen Kapitalwertänderungen möglich ist; vgl. dazu Elschen/Hüchtebrock (Steuerneutralität, 1983) S. 269. 
Bei beiden Grundmodellen ist zu berücksichtigen, dass eine investitionsneutrale Gewinnermittlung und Besteuerung nur in einem engen Modellrahmen möglich ist. Unterstellt wird insbesondere ein Kapitalmarkt im Konkurrenzgleichgewicht, in dem u.a. ein einheitlicher Zins existiert, mögliche Liquiditätsprobleme einfach wegdefiniert und eine sofortige Besteuerung bzw. ein sofortiger Verlustausgleich angenommen werden ${ }^{1}$. Zudem herrscht dort vollkommene Information (Planungssicherheit). Die Einbeziehung von Risiko und Ungewissheit in die investitionsneutralen Systeme ist bisher nur für einfache Modellvarianten geglückt ${ }^{2}$, während Unsicherheit im realen Sinne kaum noch darstellbar sein dürfte ${ }^{3}$.

Vor diesem Hintergrund können in Abhängigkeit von der zwangsläufig notwendigen Vorauswahl einer als „richtig“ empfundenen finanziellen Zielgröße allenfalls TendenzAnforderungen für die inhaltliche Ausgestaltung der steuerlichen Gewinnermittlung abgeleitet werden ${ }^{4}$. Der steuerpflichtige Gewinn eines Jahres hat sich dabei an dem kapitaltheoretischen Gewinn (bzw. Cash-Flow) desselben Jahres zu orientieren. Zu berücksichtigen ist hierbei, dass auch sämtliche kapitalwertgleichen Umperiodisierungen des kapitaltheoretischen Gewinns (bzw. Cash-Flow) die Entscheidungsneutralität erhalten $^{5}$. Interessanterweise fußen beide Gewinnermittlungsmodelle im Grundsatz auf einer

1 Vgl. zu den Prämissen ausführlicher z.B. Schneider (Steuerlast, 2002) S. 104-105, der auch darauf hinweist, dass der Begriff "Verlustausgleich" ungenau ist, da der Verlust insgesamt nicht ausgeglichen, sondern nur in Höhe des Steuersatzes teilkompensiert wird. Da Selbst-, Fremd- und Beteiligungsfinanzierung der gleichen steuerlichen Belastung unterliegen, wird auch Kapitalkostenneutralität garantiert; vgl. Kahle (Der kapitaltheoretische Gewinn, 1995) S. 216.

2 Vgl. z.B. Fane (Neutral Taxation under Uncertainty, 1987); Kahle (Der kapitaltheoretische Gewinn, 1995) S. 217-218; König (Ungelöste Probleme einer investitionsneutralen Besteuerung, 1997) S. 5861; König (Wirtschaftliche Effizienz, 1997) S. 161-167, der unter diesen Modellbedingungen Vorteile bei der Besteuerung des kapitaltheoretischen Gewinns gegenüber der Cash-Flow-Besteuerung erkennt; König (Steuerplanungslehre, 2004) S. 265; Richter (Investitionsneutrale Besteuerung, 1990) S. 760; Schneider (Steuerlast, 2002) S. 148-162.

3 Vgl. Elschen (Entscheidungsneutralität, 1991) S. 103; Schneider (Steuerlast, 2002) S. 102-103; dazu auch Pannen (Messtheoretische Grundprobleme, 2000) S. 129. Aus entscheidungstheoretischer Sicht ist im Rahmen vollständiger Entscheidungsmodelle eine Risikosituation gegeben, wenn die Eintrittswahrscheinlichkeiten möglicher Umweltzustände bekannt sind. Eine Ungewissheitssituation zeichnet sich durch eine unbekannte Wahrscheinlichkeitsverteilung aus. Unsicherheit im realen (weiten) Sinne umfasst daneben auch unvollständige Entscheidungsmodelle, in der die Menge möglicher Umweltzustände, die Menge offen stehender Handlungsalternativen oder auch die individuelle Ziel- und Präferenzstruktur nicht vollständig bekannt sind.

4 Als weiterer Einflussfaktor existiert neben der Steuerbemessungsgrundlage der in dieser Arbeit nicht im Vordergrund stehende Steuersatz; vgl. zu dieser Zweiteilung Wagner/Dirrigl (Steuerplanung der Unternehmung, 1980) S. 34-42.

5 Vgl. bereits Schneider (Einfluß der Besteuerung, 1969) S. 304, der für den kapitaltheoretischen Gewinn feststellt, dass der Barwert der steuerlich wirksamen Abschreibung „,nur" dem Barwert der theoretisch idealen Ertragswertabschreibung zu entsprechen hat. Vgl. auch Elschen/Hüchtebrock (Steuerneutralität, 1983) S. 274; Schneider (Steuerlast, 2002) S. 104; Wagner/Dirrigl (Steuerplanung der Unternehmung, 1980) S. 36-39. So kann z.B. die von Wenger (Gleichmäßigkeit der Besteuerung, 1983), Wenger (Basis für die Einkommensteuer, 1999) u.a. sowie Boadway/Bruce (Neutral Business Tax, 1984) entwickelte zinsbereinigte Einkommensteuer als kapitalwertgleiche Umperiodisierung einer Cash-Flow-Steuer angesehen werden; vgl. Wagner/Wissel (Entscheidungsneutralität, 1995) S. 70. 
zahlungsorientierten Überschussrechnung, die aber beim kapitaltheoretischen Gewinn um eine gewisse Periodisierung ergänzt wird. Für beide Modelle kann festgehalten werden, dass

- Zahlungszu- oder -abflüsse die investitionsneutrale steuerliche Gewinnermittlung prägen und ihr eine Art Barrealisationsprinzip vorgeben,

- das Imparitätsprinzip als Grundsatz der Verlustvorwegnahme nicht existiert und durch einen sofortigen Verlustausgleich ersetzt wird und

- das Periodisierungsprinzip entweder völlig beseitigt (Cash-Flow-Besteuerung) oder durch eine einzige, den Zahlungssaldo korrigierende, kapitaltheoretische Periodisierungsregel (Ertragswertabschreibung) ersetzt wird ${ }^{1}$.

Neben diesen allgemeinen normativen Konsequenzen aus der modelltheoretischen Betrachtung entscheidungsneutraler Gewinnermittlung lassen sich konkrete gewinnermittlungsbedingte Neutralitätsverletzungen (Steuervergünstigungen und Steuerbenachteiligungen) durch den Nachweis entsprechender Abweichungen zwischen einem bestimmten steuerpflichtigen Gewinn und dem aufgezeigten Idealzustand einschließlich dessen kapitalwertgleicher Umperiodisierung identifizieren. Dies geschieht über den Vergleich der Kapitalwerte vor und nach Steuern, wobei Grenzinvestitionsprojekte ${ }^{2}$ die Ausgangsbasis bilden. Kapitalwertdifferenzen weisen dann auf (unerwünschte) Steuerwirkungen im Investitionsbereich hin $^{3}$. Alternativ kann auch eine renditeorientierte Sicht gewählt werden, die die wirtschaftliche (effektive) Grenzsteuerbelastung der rechtlichen (nominalen) gegenüberstellt und bei Abweichungen gewinnermittlungsinduzierte Steuervergünstigungen bzw. -benachteiligungen erkennt ${ }^{4}$. Beim Renditevergleich kommt auch ein messtheoretischer Vorteil des kapitaltheoretischen Gewinns zum Tragen, da nur hier über einen Renditevergleich auf entsprechende Neutralitätsverletzungen geschlossen werden kann ${ }^{5}$. In dem Cash-Flow-System gleichen sich hingegen die Renditen vor und nach Steuern, so dass hier kein „Eichstrich“ zur Beurteilung der wirtschaft-

1 Vgl. Schneider (Investition, 1992) S. 229-230.

2 Der bei vollkommenen Kapitalmärkten stets Null betragende Kapitalwert (Arbitragefreiheit) führt zur Betrachtung von Marginalinvestitionen.

3 Steuerwirkungen sind immer dann zu erwarten, wenn sich die Barwerte der investitionsneutralen und konkret untersuchten Periodisierungsregel unterscheiden. Vgl. zur Messung von Steuerwirkungen via Kapitalwertvergleich ausführlich z.B. Georgi (Investitionsplanung, 1986) S. 6-68; Schiele (Unternehmensbesteuerung, 2000) S. 152-166; Schneider (Investition, 1992) S. 214-250; vgl. in der Anwendung z.B. Gröning (Steuerbilanzielle Gewinnermittlung, 2002) S. 143-235 sowie Kap. V.4.2.2.4.

4 Vgl. zu dieser Vorgehensweise über die Berechnung sog. „Steuerkeile“ (tax wedges) King/Fullerton (Taxation of Income, 1984) S. 7-30; im Überblick z.B. Kahle (Der kapitaltheoretische Gewinn, 1995) S. 216-217; Musgrave/Musgrave (Public Finance, 1989) S. 384; Schiele (Unternehmensbesteuerung, 2000) S. 166-169; Schneider (Investition, 1992) S. 239-241.

5 Bei dem kapitaltheoretischen Gewinn sinkt die Rendite nach Steuern $r_{s}$ proportional zum rechtlichen (tariflichen) Grenzsteuersatz s gegenüber der Vorsteuerrendite $r$ auf $r_{s}=r(1-s)$, so dass die effektive Grenzsteuerbelastung dem Grenzsteuersatz auf Unternehmensebene entspricht $\left[s_{\text {eff }}=\left(r-r_{s}\right) / r=(r-r\right.$ $(1-\mathrm{s})) / \mathrm{r}=\mathrm{s}]$. 
lichen Steuerbelastung realer Rechtsetzung existiert ${ }^{1}$. Die Eignung des kapitaltheoretischen Gewinns als messbarer quantitativer Eichstrich ist allerdings nur für Grenzinvestitionen mit einem Kapitalwert von Null gegeben².

Abschließend bleibt festzuhalten, dass die neoklassisch-allokative Messung gewinner-
mittlungsbedingter Steuerwirkungen nur mit Vorsicht genossen werden kann. Sie ,ist
nur unter den genannten Annahmen der ökonomischen Theorie gültig und bleibt stets an
die Annahmen der Modelle gebunden, innerhalb derer die Neutralität der Besteuerung
nachgewiesen wird““3. Obwohl die Investitions- bzw. Entscheidungsneutralität damit als
generelle Norm für die Steuerrechtsgestaltung ungeeignet erscheint, behält sie ihre
Funktion als Denkhilfe bei. „Selbst wenn man eingestehen muss, dass Investitionsneut-
ralität in der realen Welt ein unerreichbares Ziel ist, muss dies nicht die Aufgabe der
Zielsetzung als solcher bedeuten“4. Für Wagner hat sie immer noch einen logischen,
allerdings keinen allgemeingültigen empirischen Wahrheitsanspruch mehr ${ }^{5}$. Schneider
sieht in ihr ein Bezugsmodell (,Diagnosehilfe“), das für die Steuerwirkungslehre geeig-
net sei, weil es den modellmäßigen Nullpunkt von Steuerwirkungen bezeichne ${ }^{6}$. Für
normative Zwecke kann seiner Meinung nach aber nur ein im modelltheoretischen An-
spruchsgehalt deutlich reduziertes, weit weniger abstraktes Neutralitätspostulat heran-
gezogen werden, das auf die Vermeidung nachgewiesener, einzelfallbezogener Verzer-
rungen individueller Entscheidungen unter Unsicherheit abstellt ${ }^{7}$. In dieser realitätsnä-
heren, einzelwirtschaftlichen, eher heuristischen Deutung könnten dann möglicherweise

Vgl. Schneider (Steuervergünstigungen, 1992) S. 1741; Schneider (Steuerlast, 2002) S. 106.

Vgl. Schneider (Investition, 1992) S. 243; Schneider (Steuervergünstigungen, 1992) S. 1741.

Wagner (Neutralität und Gleichmäßigkeit, 1992) S. 6. Vgl. zur eingeschränkten normativen Tauglichkeit dieser entscheidungsneutralen Messmodelle z.B. auch Jacobs (Entwicklungstendenzen, 2004) S. 252-254; Kahle (Der kapitaltheoretische Gewinn, 1995) S. 217-218; König (Ungelöste Probleme einer investitionsneutralen Besteuerung, 1997) S. 61-62; König (Wirtschaftliche Effizienz, 1997) S. 167168; Pannen (Messtheoretische Grundprobleme, 2000) S. 147-163.

4 Richter (Investitionsneutrale Besteuerung, 1990) S. 761.

5 Vgl. Wagner (Neutralität und Gleichmäßigkeit, 1992) S. 6. Entscheidungsneutrale Steuerrechtssysteme sind auf der Welt empirisch nicht evidente Sachverhalte; vgl. Schneider (Investition, 1992) S. 200.

6 Vgl. Schneider (Investition, 1992) S. 194, 200-203; kritisch dazu Schwinger (Einkommens- und konsumorientierte Steuersysteme, 1992) S. 17-18; s.a. Elschen (Entscheidungsneutralität, 1991) S. 101: „In der Steuerwirkungslehre bildet die Entscheidungsneutralität den „absoluten Nullpunkt“, von dem ausgehend alle Steuerwirkungen sauberer als bislang üblich beschrieben werden können."

7 Vgl. Schneider (Investition, 1992) S. 735-738; Schneider (Steuerlast, 2002) S. 103, der (in Bezug auf die positive Meßtheorie) zudem betont: „.. eine erste, ausbaubedürftige Antwort ist immer noch besser als gar keine Antwort. Heroische Vereinfachungen sind die Muttermilch der Theorie. ... Nach dem gegenwärtigen Erkenntnisstand lassen sich wirtschaftliche Steuerbelastungen nur mittels Modellen aus der Gleichgewichtstheorie (der nicht-evolutorischen Ökonomie) oder anhand von Beispielen berechnen. Hier bessere Eichstriche zu entwickeln, ist eine Aufgabe für die künftige Forschung" (S. 105-106); Elschen (Entscheidungsneutralität, 1991) S. 107; Richter (Investitionsneutrale Besteuerung, 1990) S. 761, der konstatiert: „Die Systemhaftigkeit konkreter steuerlicher Regelungen könnte nur gewinnen, wenn sich die Politiker stets massivem Rechtfertigungsdruck ausgesetzt sähen, sobald sie erkennbar von dem Leitbild investitionsneutraler Besteuerung abwichen“. 
auch Anforderungen an eine investitionsneutrale Gewinnermittlung formuliert und als Deduktionsbasis für entsprechende Gewinnermittlungsregeln akzeptiert werden.

\subsubsection{Anforderungen an eine wettbewerbsneutrale Gewinnermittlung}

In der evolutorischen Wirtschaftstheorie gewinnt der im Rahmen neoklassischer Gleichgewichtsmodelle wegdefinierte Wettbewerb eine zentrale Bedeutung. Das Konzept der Entscheidungsneutralität mutiert hier zu einer Wettbewerbsneutralität, nach der die steuerliche Gewinnermittlung und die auf ihr beruhende Ertragsbesteuerung Marktund Wettbewerbsprozesse nicht verzerren, Wettbewerbsverhältnisse also nicht beeinflussen soll. Dies bedeutet nicht nur, dass Preisbildungsprozesse nicht beeinträchtigt werden, sondern auch, dass relative Marktpreise ebenso unberührt bleiben, wie die Bedingungen, die Marktzugang und Marktabgang determinieren ${ }^{1}$.

Um steuerbedingte Wettbewerbsverzerrungen zu vermeiden, muss eine erste, grundlegende Anforderung an die steuerliche Gewinnermittlung darin liegen, in Markt- und Wettbewerbsprozesse weder asymmetrisch noch willkürlich einzugreifen. Diese Form der Neutralität zielt auf ein gewisses Gleichbehandlungserfordernis, das insbesondere von Juristen zum Anlass genommen wird, die ökonomische Wettbewerbsneutralität in einen engen Bezug zu dem Gerechtigkeits- und Gleichmäßigkeitsgrundsatz zu setzen, der die zentrale ethische Anforderung an die steuerliche Gewinnermittlung beschreibt ${ }^{2}$. Wie später gezeigt wird ${ }^{3}$, ist dieser Bezug aber nur teilweise gerechtfertigt. So kann die Wettbewerbsneutralität nicht mit einer ergebnisorientierten Verteilungsgerechtigkeit, sondern nur mit einer verfahrensorientierten Tauschgerechtigkeit in Einklang gebracht werden. Diese entspringt dem Gerechtigkeitsverständnis von Hayeks, das nicht auf das (allokative) Ergebnis des Wettbewerbs zielt, sondern nur auf die Art und Weise, wie es zustande kommt ${ }^{4}$. Nach der verwandten ${ }^{1}$ Gerechtigkeitslehre von Rawls kann hier auch von Startgerechtigkeit durch wettbewerbliche Chancengleichheit gesprochen werden ${ }^{2}$.

1 Vgl. m.w.N. Elschen (Institutionale oder personale Besteuerung, 1994) S. 275-279, 347-354; s.a. Neumark (Steuerpolitik, 1970) S. 261-282, der allerdings den Begriff der "Wettbewerbsverzerrungen“ als unpräzise kritisiert (insb. S. 264-266).

2 Vgl. stellvertretend Lang (Reform der Unternehmensbesteuerung, 1990) S. 115: „Für Juristen hat die Entscheidungsneutralität der Besteuerung engen Bezug zum Gleichheitssatz, besonders in Gestalt der Wettbewerbsneutralität“; ähnlich auch Hey (Rechtsformneutralität, 2001) S. 164-165 mit Verweis auf das BVerfG; dieser Interpretation von betriebswirtschaftlicher Seite folgend und sie gar als herrschende Meinung beschreibend z.B. Grotherr (Besteuerung nationaler und grenzüberschreitender Konzerne, 1994) S. 57 ebenfalls mit Verweis auf das BVerfG.

3 Vgl. Kap. II.2.2.3

4 Naturereignissen gleich könne ein Prozessergebnis per se weder gerecht noch ungerecht sein. Vgl. u.a. von Hayek (Recht, Band 2, 1981) S. 51-145; vgl. zu von Hayeks Gerechtigkeitsverständnis auch Winterberger (Hayeks Theorie der Gerechtigkeit, 1992). 
Aus einer so verstandenen Wettbewerbsneutralität lassen sich einige grundlegende und nicht überschneidungsfreie Implikationen für die steuerliche Gewinnermittlung ableiten:

- Es gilt der Grundsatz der Allgemeinheit: Aus der Chancengleichheit und Tauschgerechtigkeit resultiert insbesondere die Forderung, dass alle denselben Regeln zu unterliegen haben. Daraus folgt für die steuerliche Gewinnermittlung, dass alle Sachverhalte vollständig ${ }^{3}$ und gleiche Sachverhalte auch gleichermaßen zu erfassen sind ${ }^{4}$.

- Es gilt der Grundsatz der Klarheit und Einfachheit: Angesichts begrenzter Rationalität der Betroffenen ist die steuerliche Gewinnermittlung so klar und einfach wie möglich zu gestalten ${ }^{5}$. Um die marktwirtschaftliche Koordination nicht zu beeinträchtigen und Anpassungsprozesse nicht zu verzögern oder zu verzerren, müssen die (potenziellen) Tauschpartner die steuerlichen Folgen ihres wirtschaftlichen Handelns erkennen und abschätzen können. Eine komplexe Gewinnermittlung steigert nur die Unsicherheit.

- Es gilt der Grundsatz der Willkürfreiheit: Wie die Komplexität steigert auch jede Form der Willkür bei der steuerlichen Gewinnermittlung die Unsicherheit und wirkt damit ineffizient auf Markt- und Wettbewerbsprozesse. Um die bürokratische Willkür zu reduzieren, erscheint eine gesetzliche Kodifizierung der Ermittlungsregeln bei gleichzeitiger Sicherstellung der judikativen Kontrolle geboten ${ }^{6}$. Gegen politische Willkür hilft indes nur das Vertrauen in die Funktionsfähigkeit des demokratischen Systems. Ausdruck der Willkürfreiheit ist letztlich eine gewisse Rechtssicherheit, die

1 Trotz grundsätzlicher Zustimmung zum Gerechtigkeitsverständnis von Rawls steht von Hayek (Recht, Band 2, 1981) S. 119-120 der Chancengleichheit auch kritisch gegenüber, da er gleiche Startchancen wegen kaum zu nivellierender natürlicher Unterschiede zwischen den Individuen für illusorisch hält.

2 Vgl. Rawls (Theorie der Gerechtigkeit, 1979); vgl. zu Verbindungen der Lehre Rawls zur Bibel und zum kategorischen Imperativ (Kant) von Hayek (Grundsätze einer liberalen Gesellschaftsordnung, 1969) S. 115-116; Müller (Schleier des Nichtwissens, 1997) S. 246.

3 Letztlich kann daraus die Forderung nach Erfassung des Totaleinkommens abgeleitet werden, das auch Maßstab der (objektiven) steuerlichen Leistungsfähigkeit ist; vgl. z.B. Lang (Bemessungsgrundlage, 2000) S. 137; vgl. dazu Kap. II.2.2.

4 Im Zuge der Diskussion, ob der (juristische) Gleichmäßigkeitsgrundsatz der ökonomischen Entscheidungsneutralität in Form der Wettbewerbsneutralität entspricht, wird kontrovers diskutiert, ob sich die Gleichbehandlung auf Personen oder auf Handlungsalternativen bezieht; vgl. dazu insb. Schneider (Investition 1992) S. 177; Wagner (Neutralität und Gleichmäßigkeit, 1992) S. 7. Mag die alleinige ökonomische Fokussierung auf Handlungsalternativen bei der Investitionsneutralität aber noch sinnvoll und richtig sein, so dürfte die Gleichbehandlung von Individuen dem evolutorischen Gedanken der Wettbewerbsneutralität (und Chancengleichheit) aber nicht grundlegend widersprechen. Natürlich geht es hier um die Gleichbehandlung von Individuen, allerdings nur in Bezug auf die von ihnen vorgenommenen Handlungen und die ihnen anhaftenden Verhältnisse.

5 Letztlich hat das Ermittlungsprozedere so einfach wie möglich, aber so differenziert wie nötig zu sein; im Idealfall werden die gesetzlichen Ermittlungsregeln aus den übergeordneten Besteuerungsgrundsätzen deduktiv abgeleitet, hierarchisch strukturiert sowie eindeutig und verständlich formuliert; vgl. Schneider (Steuerlast, 2002) S. 279-280, 292-295; Weber-Grellet (Fairneß, 1999) insb. S. 318.

6 Vgl. von Hayek (Recht, Band 3, 1981) S. 59-62, 141-173, der sich vehement gegen ungleiche Behandlung und Willkür wendet und die Gewaltenteilung betont; zur Gewaltenteilung aus ökonomischer Sicht im Überblick Erlei/Leschke/Sauerland (Neue Institutionenökonomik, 1999) S. 443-457. 
die Planbarkeit wirtschaftlicher Transaktionen hinsichtlich ihrer steuerlichen Folgen zu gewährleisten vermag'.

- Es gilt der eingeschränkte Grundsatz der Objektivität: Da auch Steuerpflichtige opportunistisch handeln, muss Willkür bei der Regelanwendung aus Gründen der Chancengleichheit ebenfalls unterbunden werden, so dass ein Mindestmaß an bürokratischer Kontrolle bei der Gewinnermittlung erforderlich ist. Hierbei muss betont werden, dass dies aus evolutorischer Sicht nicht zwingend gegen Wahlrechte bei der steuerlichen Gewinnermittlung spricht. Solange die Steuerpflichtigen gleiche Startchancen besitzen, ihnen diese Wahlrechte also gleichermaßen offen stehen, obliegt es ihrem eigenverantwortlichen Handeln und ihrem individuellen Streben nach Wettbewerbsvorteilen, ob und wie sie sie nutzen und welche Ergebnisse sie dabei erzielen. Während diese Aussage bei expliziten, dem Gesetzeswortlaut unmittelbar zu entnehmenden Wahlrechten ${ }^{2}$ uneingeschränkt gilt, wird die Beurteilung bei impliziten Wahlrechten (Ermessensspielräumen), die eher durch Formulierungsungenauigkeiten, Regulierungslücken und insbesondere auch subjektive Schätzungen bedingt sind $^{3}$, schwieriger. Einerseits wirkt bei impliziten Wahlrechten - viel stärker als bei den expliziten Wahlrechten - der marktwirtschaftliche Selektionsmechanismus, der denjenigen die Identifikation und Nutzung dieser Wahlrechte erlaubt, die entsprechende Informationsvorsprünge und kognitive Fähigkeiten besitzen. Entsprechende Steuerausweichhandlungen sind nicht nur Ausdruck persönlicher Freiheit, sondern fördern auch die „Verwertung von Wissen“ und damit letztlich sogar den Lernprozess der Regulierer, eventuell zum Wohle einer verbesserten Steuergesetzgebung ${ }^{4}$. Andererseits ist aber fraglich, ob hier noch von einer wettbewerbsneutralen steuerlichen Gewinnermittlung gesprochen werden kann. Wenn sich die Tauschpartner nur noch auf diese Form der wettbewerblichen Auseinandersetzung konzentrieren, wird sich derjenige durchsetzen, der das Steuerrecht besser kennt und nicht derjenige, der bessere Chancen im „originären“ (Produkt-)Wettbewerb hätte. Im Bereich des Steuerrechts würden Ressourcen tendenziell aufgebaut und vom originären Produktwett-

1 Vgl. so die Forderung von Rose (Steuergerechtigkeit aus betriebswirtschaftlicher Sicht, 1985) S. 332, 335-339, der dies als wesentlich für die Steuergerechtigkeit ansieht; zum Verhältnis von Rechtssicherheit und Gerechtigkeit auch Tipke (Steuergerechtigkeit, 1981) S. 122-146.

2 Explizite Wahlrechte liegen nach Winnefeld (Bilanz-Handbuch, 2002) C Tz. 660 vor, ,wenn durch Gesetz mehrere Rechtsfolgen zur Auswahl vorgeschlagen werden, von denen eine nach freiem Ermessen bestimmt werden darf."

3 Implizite Wahlrechte ermöglichen gleichfalls eine Auswahl unter mehreren Rechtsfolgen, ohne dass diese im Gesetzeswortlaut ausdrücklich aufgeführt ist. Vgl. zur Abgrenzung expliziter und impliziter Wahlrechte Moxter (Handelsbilanz und Steuerbilanz, 1997) S. 196-197; in anderer Terminologie Schneeloch (Bilanzpolitik, 1990) S. 96-97; zu dieser Problematik z.B. auch Hoffmann/Lüdenbach (Ermessensspielräume, 2003); Scheffler (Zukunft des Maßgeblichkeitsprinzips, 2001) S. 153; Schildbach (Internationale Rechnungslegungsstandards, 1994) S. 702-709.

4 Vgl. Schneider (Steuergerechtigkeit, 1985) insb. S. 355 mit Bezug auf von Hayek (Use of Knowledge, 1945). Allerdings plädiert auch Schneider (Verwertung von Wissen, 2000) S. 39-40 für eine „wahlrechtsfreie" Einkommensbemessung zum Abbau nachteiliger Wissensverteilung. 
bewerb abgezogen. Ob dies unter Gesichtspunkten der Koordinationseffizienz wünschenswert wäre, ist fraglich.

Die insoweit formulierten Anforderungen an eine wettbewerbsneutrale Gewinnermittlung beschränken sich damit auf grundlegende Rahmenbedingungen, ohne dass es zu einer inhaltlichen Konkretisierung der Ermittlungsregeln gekommen wäre. Dies markiert einen zentralen Unterschied zu den Anforderungen, die zuvor aus der Investitionsneutralität abgeleitet worden sind. Unter Verwendung empirisch gehaltvoller Prämissen ist es aus prozessorientierter Sicht nur unter „Anmaßung von Wissen“1 möglich, derart konkrete und wohl auch komplexe Regeln vorsätzlich $\mathrm{zu}$ formulieren. Im evolutorischen Idealfall sollten sich auch diese Regeln als spontane Institutionen aus Markt- und Wettbewerbsprozessen entwickeln. Im Vertrauen in die Funktionsfähigkeit der spontanen Ordnung hat sich z.B. die primäre Orientierung am Einkommen trotz aller Argumente für eine (reine) Konsumbesteuerung weltweit wohl als evolutionär stabil erwie$\operatorname{sen}^{2}$. North spricht hier aus dynamisch-institutioneller Sicht von einer Verlaufs- oder Pfadabhängigkeit (,path dependence“), die das Festhalten an ,altbewährten“ formalen Institutionen (wie steuerlichen Gewinnermittlungsregeln) beschreibt, solange empfindliche Umwälzungen und Erfahrungen keine institutionelle Änderung erzwingen ${ }^{3}$.

Fraglich bleibt nur, wie man den Wettbewerb für die inhaltliche Ausgestaltung der steuerlichen Gewinnermittlungsregeln nutzen kann. Angesichts stark verfestigter Gewinnermittlungssysteme wird das Aufbrechen dieser institutionellen Strukturen um so kostspieliger, je länger sie Bestand haben ${ }^{4}$. Die Lösung mag darin liegen, diese institutionellen Strukturen zueinander in den Wettbewerb zu setzen. Da Gewinnermittlungssysteme regelmäßig auf nationaler Ebene vorliegen, hieße das, den internationalen Wettbewerb zu nutzen und die nationalen Gewinnermittlungssysteme einem „Wettbewerb der Systeme" auszusetzen". Gerade vor dem Hintergrund der Forschungsfrage dieser Arbeit scheint diese Lösung ihren Reiz zu besitzen. Sie spricht eher gegen die wettbewerbsbeschränkende und „vorsätzlich geplante“ Harmonisierung von Gewinnermittlungsregeln

1 Von Hayek (Pretence of Knowledge, 1989); dazu auch Kapitel II.2.1.1.

2 Selbst das Ausnahmemodell Kroatien, dass die „konstruktivistische“ Etablierung einer zinsbereinigten Einkommensteuer nach den Vorstellungen insb. der deutschen Wissenschaftler Lang, Rose, Wagner und Wenger zum Gegenstand hatte (vgl. z.B. Wagner/Wenger (Kroatien, 1996), ist inzwischen deutlich verwässert worden; vgl. z.B. Herz (Gnadenlos einfach, 2001). Neu ist hingegen die „FlatConsumer Tax" in der Slowakei; vgl. dazu Walter (Steuerreform ohne Grenzen, 2003) S. 22.

3 Vgl. North (Institutional Change, 1990) S. 92-104, 112-116; s.a. Erlei/Leschke/Sauerland (Neue Institutionenökonomik, 1999) S. 517-542, insb. S. 526-528; Richter (Neue Institutionenökonomik, 1998) S. 331-332; Streit (Systemwettbewerb, 1996) S. 530. Lang (Konsumorientierung, 1999) S. 144 spricht deshalb treffend von der ,evolutionären Trägheit“ des Steuerrechts.

4 North (Institutional Change, 1990) S. 92 spricht i.d.Zshg. vom "lock-in"-Effekt.

5 Vgl. zum Wettbewerb der Systeme im Überblick Erlei/Leschke/Sauerland (Neue Institutionenökonomik, 1999) S. 371-418, insb. den Literaturüberblick auf S. 383; Kerber (Wettbewerbsordnung für den Systemwettbewerb, 1998); Kiwit/Voigt (Grenzen des institutionellen Wettbewerbs, 1998); Gerken (Wettbewerb der Staaten, 1999); Oberender/Cachej (Wettbewerb der Systeme, 1999). 
auf EU-Ebene und befürwortet statt dessen einen marktwirtschaftlichen Selektionsmechanismus, der im Zeitablauf möglicherweise zu einer Konvergenz der Systeme führt. Die Harmonisierung wird hierdurch ersetzt - mit dem Unterschied, dass das Wissen aller Beteiligten in die prozessuale Auswahlentscheidung mit eingeflossen ist. Auch der Grundsatz der Allgemeinheit wäre gewahrt, da jeder Steuerpflichtige über dieselbe Auswahl bei den Ermittlungssystemen verfügt.

Dieser Systemwettbewerb setzt allerdings u.a. voraus, dass die Mobilität der Produktionsfaktoren gegeben ist und sämtliche, nicht nur steuerliche Hindernisse einer grenzüberschreitenden unternehmerischen Tätigkeit ausgeräumt werden ${ }^{1}$. Ob davon z.B. im europäischen Binnenmarkt trotz dort herrschender Grundfreiheiten auszugehen ist, kann schon angesichts der mit dieser Tätigkeit verbundenen Kosten nicht abschließend beantwortet werden ${ }^{2}$. Dies liegt z.B. auch daran, dass sich in den unterschiedlichen nationalen Steuersystemen divergierende Werturteile zur Kapitalexport- und Kapitalimportneutralität dokumentieren, die Investitionsentscheidungen über Ländergrenzen hinweg verzerren ${ }^{3}$. In diesem Zusammenhang müsste auch untersucht werden, ob ein funktionsfähiger Wettbewerb auf einem „Markt für steuerliche Gewinnermittlungssysteme“ überhaupt zustande käme ${ }^{4}$. Dies wäre schon deshalb notwendig, um den Argumenten gegen einen „unfairen“, „schädlichen“ oder gar ruinösen Steuer(senkungs)wettbewerb (,race to the bottom") begegnen zu können". Da der Systemwettbewerb auch mit nationalen

1 Vgl. zu den Grenzen des Systemwettbewerbs im Überblick Oberender/Cachej (Wettbewerb der Systeme, 1999) S. 579-580; Streit (Systemwettbewerb, 1996) S. 526-531.

2 Vgl. zum Systemwettbewerb aus ökonomischer wie auch juristischer Sicht in Bezug auf die europäische Steuerangleichung mit z.T. völlig unterschiedlichen Ergebnissen und m.w.N. u.a. Becker (Unternehmensbesteuerung als Standortproblem, 1994); Dautzenberg (Unternehmensbesteuerung im EGBinnenmarkt, 1997) S. 17-89; Gerken/Märkt/Schick (Tax Competition in the EU, 2001) S. 246-248; Herzig (Besteuerung der Unternehmen in Europa, 1996); Hey (Harmonisierung, 1997) S. 101-109; Hey (Perspektiven, 2004) S. 204-208; Jacobs (Internationale Unternehmensbesteuerung, 2002) S. 272-290; Koop (Gewinnbesteuerung, 1993) S. 53-123; Lang (Besteuerung in Europa, 1997) S. 885893; Larbig (Perspektiven, 1998); MenckMutén (Europäische Steuerpolitik, 2003) S. 35-54; Schreiber (Steuerwettbewerb, 1998) S. 120-143; Sinn (Tax Harmonization, 1990). Vgl. auch den internationalen Literaturüberblick von Zodrow (Tax Competition, 2003).

3 Während die Kapitalexportneutralität als (Wohn-)Sitzlandneutralität alle Erträge im Standortland des Kapitaleigners gleich besteuert, garantiert dies die im Spannungsverhältnis dazu stehende Kapitalimportneutralität (Quellenlandneutralität) für alle Kapitalerträge im Standortland der Produktion. Vgl. grundlegend Musgrave (Foreign Tax Credit, 1960) S. 84-86; ausführlich abwägend Gandenberger (Kapitalexportneutralität versus Kapitalimportneutraliät, 1983). Vgl. dazu kurz auch Kap. III.2.5.2.

4 Vgl. die bereits zum Systemwettbewerb zitierte Literatur; ergänzend dazu Bracewell-Milnes (Tax Competition, 1999); Sinn (The selection principle, 1997); die Notwendigkeit einer Wettbewerbsordnung für den Systemwettbewerb betonen Gerken (Wettbewerb der Staaten, 1999) S. 75-82; Kerber (Wettbewerbsordnung für den Systemwettbewerb, 1998). Vgl. zur ähnlichen Frage für den Markt für Rechnungslegungssysteme Pellens/Gassen (Bereitstellung von Rechnungslegungssystemen, 1998).

5 So z.B. Hey (Harmonisierung, 1997) S. 104-105; Lang (Besteuerung in Europa, 1997) S. 886-887; Tipke (Resümee, 2000) S. 305; Randzio-Plath (Steuerharmonisierung, 1999) S. 57 mit Verweis auf die diesbzgl. Auffassung der EU-Finanzminister; sowie die Nachweise bei Gerken/Märkt/Schick (Tax Competition in the EU, 2001) S. 248. 
Lenkungs- und/oder Umverteilungszielen kollidieren dürfte, wäre abschließend zu untersuchen, inwieweit dies ökonomisch ${ }^{1}$ und insbesondere auch politisch gewollt ist.

\begin{abstract}
Abschließend bleibt festzuhalten, dass aus der Wettbewerbsneutralität nur grundlegende Anforderungen an die steuerliche Gewinnermittlung abgeleitet werden können. Normative Anforderungen für die inhaltliche Ausgestaltung zu formulieren, ist aus evolutorischer Perspektive problematisch. Eventuell erscheint es hier sinnvoll, den Wettbewerb als Entdeckungsverfahren für diese Aufgabe zu nutzen², auch wenn sich dies eher auf einen internationalen Wettbewerb existierender, nationaler Ermittlungssysteme beschränken dürfte.
\end{abstract}

\title{
2.1.3 Durchführungsorientierte Effizienzbetrachtung
}

Um sämtliche Effizienzaspekte der steuerlichen Gewinnermittlung und einer darauf basierenden Ertragsbesteuerung zu berücksichtigen, scheint eine wirkungsorientierte Effizienzbetrachtung allein nicht auszureichen. Dies gilt insbesondere für die nur unter engen modelltheoretischen Bedingungen mögliche Identifikation gewinnermittlungsbedingter Neutralitätsverletzungen im einzelwirtschaftlichen Investitionskalkül ${ }^{3}$. Unter Beibehaltung der neoklassischen Sichtweise versucht deshalb die eher finanzwissenschaftlich fundierte Theorie der optimalen Besteuerung (,optimal taxation“) gesamtwirtschaftliche Effekte durch Veränderungen gesamtwirtschaftlicher Wohlfahrtsfunktionen abzubilden ${ }^{4}$. Allokationsverzerrende Entscheidungswirkungen wären hier als Teilmenge dieser Wohlfahrtsveränderungen ebenso erfasst wie sämtliche sonstigen Ineffizienzen, die in Folge der Besteuerung auftreten können. Trotz der Kritik an der neoklassischen Wohlfahrtstheorie ${ }^{5}$ zielt diese Erweiterung der Effizienzperspektive bereits

1 Diese Begründung kann nur aus einer anderen wirtschaftstheoretischen Perspektive erfolgen, da Lenkungssteuern in evolutorischer Perspektive eher abgelehnt werden.

2 Im Übrigen wirkt der Systemwettbewerb nicht nur als Entdeckungsverfahren, sondern hinsichtlich der (opportunistisch handelnden) Politiker und Bürokraten auch als Kontrollverfahren; vgl. dazu Streit (Systemwettbewerb, 1996) S. 524-526.

3 Dies dürfte auch für andere neoklassich-allokative Partialmodelle gelten. Die Grenzen entscheidungslogischer Modellanalysen werden z.B. auch dadurch deutlich, dass unvollständige Entscheidungsmodelle oder nicht finanzielle Zielgrößen nicht berücksichtigt werden (können); vgl. Schneider (Investition, 1992) S. 736-737.

4 Vgl. dazu insb. Atkinson/Stiglitz (Design of Tax Structure, 1976); Baumol/Bradford (Optimal Departures, 1970); Diamond/Mirrlees (Optimal Taxation, 1961); im Überblick Stiglitz/Schönfelder (Finanzwisenschaft, 1989) S. 475-502. Vgl. zur „optimal taxation“ auch in Abgrenzung zur ,excess burden-Debatte“ Krause-Junk (Verteilungslehren, 1977) S. 346-348; zu unterschiedlichen Ansichten in der deutschen betriebswirtschaftlichen Steuerlehre zur Vereinbarkeit einzel- und gesamtwirtschaftlicher Kriterien der Steuerrechtsgestaltung Elschen (Entscheidungsneutralität, 1991) S. 106-108 m.w.N.

5 Neben der modelltheoretischen Enge und der typischen Orientierung an nur theoretisch optimalen Lösungen („nirvana approach“; vgl. Kap. II.2.1.1.) wird z.B. auch die schwierige Operationalisierung individueller Nutzenvorstellungen und ihre widerspruchsfrei kaum mögliche Aggregation kritisiert; vgl. z.B. Streit (Wirtschaftspolitik, 1991) S. 17-18; kritisch zur „optimal taxation“ z.B. Elschen (Institutionale oder personale Besteuerung, 1994) S. 267-273. 
in die gewünschte Richtung. Selbst wenn indirekte Folgewirkungen am Markt, wie sie die finanzwissenschaftliche Lehre der Steuerinzidenz zu identifizieren versucht ${ }^{1}$, hier vernachlässigt werden, verbleiben unter Effizienzgesichtspunkten immer noch mehr als nur unmittelbare Entscheidungswirkungen bei den betroffenen Steuersubjekten.

Auf der Basis des institutionenökonomischen Konzepts der Transaktionskosten kann hierzu eine Parallele gezogen werden. So hat die Effizienzbetrachtung steuerlicher Gewinnermittlungsregeln nicht nur die durch Entscheidungsveränderung hervorgerufenen Transaktionskosten $\mathrm{zu}$ berücksichtigen, sondern auch die kostenverursachenden und damit ineffizienten Bestrebungen zur Steuerausweichhandlung bei den Betroffenen (Steuergestaltung bzw. Steuerplanung) sowie sämtliche sonstigen Ineffizienzen, die durch Gewinnermittlungsregeln in einer keineswegs reibungslos funktionierenden Welt mit unvollkommen informierten Individuen entstehen ${ }^{2}$. Damit wird der bislang weitgehend vernachlässigte Prozess der Steuerdurchführung angesprochen, der die Steuergestaltung sowie Steuerermittlung und die damit einhergehenden Planungs- und Informationskosten, Entscheidungs- sowie Durchführungskosten ${ }^{3}$, aber auch die Steuererhebung sowie das gesamte Überwachungs- und Durchsetzungsprozedere umfasst. Von diesem Prozess betroffen sind nicht mehr allein die Steuerpflichtigen, sondern auch die Individuen in den Finanzbehörden und in der Finanzgerichtsbarkeit, die gleichfalls in der einen oder anderen Form mit den Gewinnermittlungsregeln umgehen müssen ${ }^{4}$. In Ergänzung der wirkungsorientierten Effizienzbetrachtung muss für diesen Prozess aus öko-

1 Die finanzwissenschaftliche Lehre von der Steuerinzidenz analysiert das Phänomen marktlicher Steuerüberwälzung. Hiernach wird zwischen einer auf den Steuerschuldner (Steuerpflichtigen) bezogenen formalen Inzidenz und einer auf den effektiv belasteten Steuerträger bezogenen effektiven Inzidenz differenziert; vgl. dazu im Überblick Blankart (Öffentliche Finanzen, 2003) S. 341-362.

2 Werden Transaktionskosten im Sinne von Opportunitätskosten über den Vergleich mit neoklassischen Optimalzuständen ermittelt (vgl. so Schneider (Unhaltbarkeit des Transaktionskostenansatzes, 1985) S. 1242-1243), müsste die auf Transaktionskosten abstellende Betrachtung der Durchführungseffizienz gar der wohlfahrtsökonomischen Theorie der optimalen Besteuerung entsprechen. Dies widerspräche jedoch dem eher heuristischen Umgang mit diesem Effizienzmaßstab (vgl. Kap. II.2.1.1).

3 Letztlich verbergen sich dahinter sämtliche Facetten der Transaktionskosten bei Entscheidungsprozessen, die z.B. Coase (Social Cost, 1960) S. 15 andeutet. Auch i.R.d. Wettbewerbsprozessorientierung ist diese weite Effizienzperspektive in Gestalt der Anpassungs- und Koordinationsfriktionen einer steuerlichen Gewinnermittlung bereits angedeutet worden.

4 In normativen Analysen spielt die Steuerdurchführung im Vergleich zur Steuerwirkung meist nur eine untergeordnete Rolle. Dies scheint sich jedoch in der jüngeren (insb. US-amerikanischen und britischen) Literatur zu ändern; vgl. z.B. Alm („optimal“ tax system, 1996) S. 121-129; IFS (Corporation Tax for the 1990s, 1991) S. 12-13; Nobes (Framework for the Taxable Income, 2004) S. 36-37, 40-41; Slemrod (Tax from Any Angle, 2003) S. 149; Whittington (Tax Policy, 1995) S. 452; vgl. ansatzweise bereits Johnson (All-Purpose Concept, 1954) S. 225, der die „administrative feasibility“ definiert; Musgrave/Musgrave (Public Finance, 1989) S. 278-279, die ,administration cost“ und „,compliance cost" unterscheiden; für den deutschen Raum z.B. Herzig (IAS/IFRS, 2004) S. 23-24; Hundsdoerfer (Einkommenserzielung und Konsum, 2002) S. 34-40, der diesbzgl. auf den vierten allgemeinen Besteuerungsgrundsatz (Verschwendungsvermeidung) von Smith (Wealth of Nations, 1776) verweist. 
nomischer Sicht eine Art Durchführungseffizienz ${ }^{1}$ vorgegeben werden, um die einzelnen Prozessaktivitäten auf ein transaktionskostenminimales Maß zu reduzieren. Dieser Effizienzsicht haben sich sämtliche Steuern, neben den Fiskalsteuern also auch die Lenkungssteuern, zu unterwerfen.

Wird nun versucht, bestimmte Anforderungen an die steuerliche Gewinnermittlung aus dieser Transaktionskostensicht zu formulieren ${ }^{2}$, so lassen sich erhebliche Parallelen zur wettbewerbsprozessorientierten Perspektive erkennen. Dabei werden wirkungsorientierte Koordinationsaspekte gar nicht betrachtet; der Prozess der Steuerdurchführung steht allein im Vordergrund. Trotz nunmehr „durchführungsorientierter“ Argumente sind dafür letztlich gleiche Verhaltensannahmen und ein ähnliches Effizienzverständnis verantwortlich. So dürften auch hier der

- Grundsatz der Klarheit und Einfachheit,

- Grundsatz der Willkürfreiheit und der

- Grundsatz der Objektivität gelten, die, wie noch zu zeigen sein wird, durch den

- Grundsatz der Standardisierung ergänzt werden.

Vor dem Hintergrund herrschender Unsicherheit und begrenzter Rationalität der Betroffenen ist eine klare, einfache, willkürfreie und objektivierte Gewinnermittlung auch zur Steigerung der Durchführungseffizienz von Nöten. Auf Seiten des Steuerpflichtigen reduzieren sich dadurch sämtliche Kosten der Steuergestaltung und -ermittlung und auf Seiten des Fiskus und der Finanzgerichtsbarkeit gilt dasselbe für die Steuererhebung, -überwachung und -durchsetzung ${ }^{3}$. Neben der kostengünstigen Erleichterung der technischen Gewinnermittlung als solcher dürften sich insbesondere auch die Steuerplanungsund -gestaltungsbemühungen reduzieren, die einen wesentlichen Indikator für Transaktionskosten auf der Ermittlungsebene darstellen ${ }^{4}$. Ein klares und einfaches, insbesondere auch objektiviertes Gewinnermittlungssystem schränkt die Menge möglicher Steuerausweichhandlungen ein, seien es nun die realwirtschaftlichen Ausweichhandlungen

1 Vgl. ähnlich z.B. Koop (Gewinnbesteuerung, 1993) S. 103, der aber terminologisch enger von "Erhebungseffizienz" spricht.

2 Aufgrund der Interdependenzen zwischen den Transaktionskostenarten ist die Entwicklung einer exakten, allgemeinen Regel zur simultanen Kostenminimierung eher illusorisch. Statt dessen bietet sich in einem heuristischen Vorgehen an, diejenigen Anforderungen zu identifizieren, die wahrscheinlich mit „vergleichsweise geringeren Transaktionskosten" einher gehen; vgl. Raab (Öffentliche Transaktionskosten, 1995) S. 141, der in Deutschland den Transaktionskostenansatz auf die staatliche Einnahmeerhebung angewendet hat; vgl. auch Schiele (Unternehmensbesteuerung, 2000) S. 116-117.

3 Vgl. zur Forderung nach „simplicity“ und den dadurch hervorgerufenen Kostenwirkungen insb. Alm („optimal“ tax system, 1996) S. 117, 121-131; ähnlich auch Musgrave/Musgrave (Public Finance, 1989) S. 278-279; Nobes (Framework for the Taxable Income, 2004) S. 40-41.

4 Dies trifft letztlich den Inhalt der betriebswirtschaftlichen Steuerlehre, die Schneider (Steuergerechtigkeit, 1985) S. 345 als „Lehre von der vernünftigen Steuerausweichung im Rahmen des gesetzlich Zulässigen" bezeichnet; dazu auch Musgrave/Musgrave (Public Finance, 1989) S. 279; Schiele (Unternehmensbesteuerung, 2000) S. 104. 
oder lediglich Ausweichhandlungen durch Ausnutzung deklaratorischer Gestaltungsmöglichkeiten, die sich vor allem auf die Ausnutzung expliziter wie auch impliziter Wahlrechte beziehen'. Bei der Betrachtung der Steuerausweichhandlungen lassen sich deshalb Wechselwirkungen zwischen wirkungs- und durchführungsorientierter Effizienzbetrachtung erkennen. So lässt eine entscheidungsneutrale Gewinnermittlung kostenverursachende Steuerplanungs- und -gestaltungsaktivitäten im Idealfall völlig obsolet erscheinen ${ }^{2}$ und gewinnt damit auch aus durchführungsorientierter Sicht an Bedeutung. Weil dies allerdings voraussetzt, dass die Steuerpflichtigen die entscheidungsneutrale Wirkung auch erkennen, dürfte eine transparenzfördernde Komplexitätsreduktion ebenfalls durchführungseffizient sein.

Die aufgezeigten Grundsätze gewinnen an zusätzlicher Bedeutung, wenn es um die Berücksichtigung opportunistischer Verhaltensweisen geht. So wird sich die Finanzverwaltung gegen rechtlich unzulässige Steuerausweichhandlungen (Steuerhinterziehung) ${ }^{3}$ der Steuerpflichtigen zu schützen versuchen. Da sich Opportunismus auch im Verzerren von Informationen ausdrückt ${ }^{4}$, dürfte eine klare, einfache, wie auch immer objektivierte und von Manipulationsspielräumen weitgehend befreite Gewinnermittlung die Überwachungs- und Kontrollaktivitäten des Fiskus und nachgelagerte Bemühungen der Finanzgerichtsbarkeit zumindest erleichtern ${ }^{5}$. Dies gilt auch in umgekehrter Richtung. Letztlich befinden sich der Steuerpflichtige und der Staat in einem unvollständigen Vertragsverhältnis, in dem sich beide Seiten vor dem opportunistischen Verhalten der Gegenseite durch kostenverursachende Absicherungsmechanismen zu schützen suchen. Um die im Extremfall prohibitiv teuren Absicherungsbemühungen der von staatlicher Steuerwillkür betroffenen Wirtschaftssubjekte gegen Null zu reduzieren, ist - wie im vorangegangenen Kapitel bereits gefordert - die flankierende Einbettung der steuerlichen Gewinnermittlung in die Kontrollprinzipien einer gewaltenteiligen Demokratie notwendig.

Ein weiteres, wichtiges Instrument zur Transaktionskostenreduktion im Zuge der Steuerdurchführung ist die Standardisierung. Viele, individuell unterschiedliche Gewinner-

1 Vgl. Schiele (Unternehmensbesteuerung, 2000) S. 105-106 oder Schneider (Steuergerechtigkeit, 1985) S. 353, die mit den ,institutionenbildenden Ausweichhandlungen“ eine dritte Kategorie von Steuerplanungs- bzw. -ausweichaktivitäten definieren, in denen es um die rechtliche Qualifikation des finanziellen Grundgeschäfts, z.B. durch Vertrags- oder Rechtsformgestaltung, geht. In der hier gewählten Zweiteilung wird diese Kategorie den realwirtschaftlichen Ausweichhandlungen zugeordnet.

2 Vgl. z.B. Hundsdoerfer (Einkommenserzielung und Konsum, 2002) S. 19-20; Schneider (Steuergerechtigkeit, 1985) S. 353-355; Wagner (Neutralität und Gleichmäßigkeit, 1992) S. 4; ansatzweise auch Nobes (Framework for the Taxable Income, 2004) S. 40.

3 Vgl. stellvertretend für die ökonomische Literatur zur Steuerhinterziehung (tax evasion) Allingham/Sandmo (Income Tax Evasion, 1972); Hundsdoerfer (Steuerhinterziehung, 1996). Vgl. zum Zusammenhang von Steuermoral, Ausweichhandlungen und öffentlich induzierten Transaktionskosten Raab (Öffentliche Transaktionskosten, 1995) S. 256-260; s.a. kurz Kap. II.2.2.3.

4 Vgl. Williamson (Markets, 1975) S. 26-30; Williamson (Economic Institutions, 1985) S. 47-49, 64-67.

5 Kontrollaktivitäten bleiben jedoch notwendig, da auch eine Gewinnermittlung nach den hier formulierten Grundsätzen das völlige Zurückhalten von Informationen nicht verhindern kann. 
mittlungssysteme führen zu Effizienznachteilen: Von Seiten des Fiskus dürften sie nur mit immensen Anstrengungen zu administrieren sein. Auch für die Steuerpflichtigen ergeben sich erhöhte Kosten, z.B. durch die individuelle Schulung von Ermittlungsexperten. Effizienter erscheint deshalb ein standardisiertes Gewinnermittlungssystem, das individuellen Gegebenheiten zwar nicht mehr in Gänze entsprechen kann, dafür aber als eine Art „Kompromiss“" mit deutlichen Kostenvorteilen einhergeht.

Der Effizienzvorteil einer standardisierten Gewinnermittlung ${ }^{2}$ spricht unter Umständen auch gegen den wettbewerbsprozessorientierten Gedanken eines „Wettbewerbs der Systeme" und für eine Harmonisierung nationaler Gewinnermittlungssysteme ${ }^{3}$. Selbst wenn die nationale Steuersouveränität mit nationaler Finanzverwaltung und -gerichtsbarkeit bestehen bleibt und öffentlich induzierte Transaktionskosten ${ }^{4}$ kaum zu reduzieren sind, werden Effizienzvorteile auf Seiten der Steuerpflichtigen offensichtlich. So geht die zum Systemwettbewerb erforderliche Mobilität mit Kosten einher; insbesondere zwingt die grenzüberschreitende unternehmerische Tätigkeit zur kostenintensiven Beachtung unterschiedlicher Rechtsordnungen sowie bilateraler (Doppelbesteuerungs-)Abkommen und motiviert erneut in großem Umfang zu Steuergestaltungs- und -planungsaktivitäten ${ }^{5}$.

Abschließend bleibt festzuhalten, dass die Effizienz steuerlicher Gewinnermittlungsregeln auch aus durchführungsorientierter Sicht betrachtet werden kann. Unter Heranziehung der Transaktionskosten als Effizienzmaßstab ergeben sich Anforderungen an die steuerliche Gewinnermittlung, die in großen Teilen mit denen der wirkungsorientierten Wettbewerbsprozesssicht übereinstimmen und sich insofern verfestigen. Bei der Frage der inhaltlichen Ausgestaltung bleiben diese Anforderungen abstrakt. Allerdings kann auch aus durchführungsorientierter Sicht die effizienzfördernde Wirkung entscheidungsneutraler Gewinnermittlungsregeln nicht geleugnet werden, obwohl diese Erkenntnis angesichts der dort identifizierten Schwierigkeiten, konkrete Aussagen zur inhaltlichen Ausgestaltung abzuleiten, nur bedingt weiterhilft.

1 Walz (Ökonomische Regulierungstheorien, 1993) S. 95, allerdings mit Hinblick auf die gesetzliche Standardisierung des Bilanzrechts.

2 Vgl. überblicksartig zur transaktionskostentheoretischen Sicht der Rechnungslegung im Allgemeinen und zur Frage der Standardisierung Gassen (Rechnungslegung, 2001) S. 395-397, 403-411.

3 So werden Transaktionskosten als Harmonisierungsargument z.B. von Sapusek (Steuerharmonisierung, 1997) S. 31 ins Feld geführt.

4 Vgl. zu diesem Begriff Schiele (Unternehmensbesteuerung, 2000) S. 98-99; von „öffentlichen Transaktionskosten“ spricht Raab (Öffentliche Transaktionskosten, 1995) S. 21-22; von „staatsinduzierten Transaktionskosten“" spricht Vogel (Harmonisierung, 1993) S. 387, der darunter allerdings eine Art Netto-Steuer, d.h. die Differenz zwischen den zu leistenden Abgaben und den empfangenen öffentlichen Gütern versteht.

5 Vgl. z.B. Herzig (Steuergestaltung, 1993); dazu auch Kap. III.2.5.2. 


\subsection{Ethisch-verfassungsrechtliche Anforderungen}

\subsubsection{Verfassungsregeln aus ökonomischer Sicht}

Von Brennan/Buchanan ist die Befürchtung geäußert worden, der vom Eigennutz involvierter Individuen getriebene Fiskus betreibe nach Art des Leviathan eine Steuerund Budgetmaximierung, der die hiervon betroffenen Bürger machtlos ausgesetzt seien'. Diese Befürchtung folgt letztlich institutionenökonomischen Verhaltensannahmen hinsichtlich des Staates. Obgleich „natürliche Grenzen“ durch legale und illegale Abwanderungsoptionen der Steuerpflichtigen weitgehend vernachlässigt werden ${ }^{2}$, leugnen Brennan/Buchanan nicht, dass auch der Leviathanstaat in einer Demokratie rechtsstaatlichen (Mindest-)Regeln zu folgen hat, die der staatlichen Regulierungswillkür gewisse Grenzen setzten ${ }^{3}$. Je nachdem, wieviel Bedeutung dem rechtstaatlich-demokratischen Element beigemessen wird, wandelt sich die Leviathantheorie in eine Theorie der demokratischen Besteuerung, wo die Steuerstruktur in der Verfassung und nur das Steuerniveau von den Wahlberechtigten im laufenden politischen Prozess beschlossen wird ${ }^{4}$.

Steuerliche Gewinnermittlungsregeln sind vor diesem Hintergrund (auch) aus verfassungsrechtlichen Regeln abzuleiten, die für die gesamte Rechtsordnung eine Art Deduktionsbasis liefern. Verfassungsregeln sind demnach Regeln höheren Ranges ${ }^{5}$, deren Existenzberechtigung selbst in einer liberalen ökonomischen Sicht nicht bezweifelt wird, da sie notwendige Spielregeln und Rahmenbedingungen für die spontane, wettbewerbliche Ordnung vorgeben (Wettbewerbsordnung). Der Sinn einer Verfassung liegt deshalb für von Hayek insbesondere darin, individuelle Freiheiten zu garantieren und staatliche Willkür zu reduzieren ${ }^{6}$. Wie in den vorherigen Kapiteln aufgezeigt, ist die Willkürfreiheit gerade im Rahmen der steuerlichen Gewinnermittlung eine zentrale ökonomische

I Vgl. zur sog. Leviathantheorie der Besteuerung Brennan/Buchanan (Power to Tax, 1980) in expliziter Anlehnung (u.a. S. 4, 10) an Hobbes (Leviathan, 1651) Part II; dazu auch Buchanan (Constitutional Economics, 1991) S. 41-42; erläuternd z.B. Blankart (Öffentliche Finanzen, 2003) S. 234-241; Raab (Öffentliche Transaktionskosten, 1995) S. 87-90, 174-199.

2 Diese Anpassungsmöglichkeiten werden bei Brennan/Buchanan (Power to Tax, 1980) nur am Rande betrachtet (z.B. S. 171-173), sind allerdings zentraler Gegenstand der evolutorischen Theorie der Besteuerung; vgl. Blankart (Öffentliche Finanzen, 2003) S. 241, 244-254.

3 Vgl. Brennan/Buchanan (Power to Tax, 1980) insb. S. 2-33, 37-39, die u.a. konstatieren: „All constitutional rules may be interpreted as limiting the potential power" (S. 9 [Hervorhebung aus dem Original übernommen]); so auch Blankart (Öffentliche Finanzen, 2003) S. 234. Vgl. zudem Kofler (Steuerstrukturanpassung, 1995) S. 508, der betont, dass „der Fiskalzweck nicht beliebig, sondern nur nach bestimmten Grundsätzen und Prinzipien, also nach systembildenden und tatbestandsprägenden Grundideen zu erreichen ist."

4 Vgl. Blankart (Öffentliche Finanzen, 2003) S. 241-243, ohne „Steuerstruktur“ und „Steuerniveau“ jedoch weiter zu präzisieren. Vgl. auch Brennan/Buchanan (Power to Tax, 1980) u.a. S. 6-8, 191-192, 202 in der diesbzgl. Auseinandersetzung u.a. mit Wicksell und von Hayek; s.a. Musgrave (Theory of Public Finance, 1959) S. 116-135; Raab (Öffentliche Transaktionskosten, 1995) S. 90-112, 199-238.

5 Vgl. Erlei/Leschke/Sauerland (Neue Institutionenökonomik, 1999) S. 20 mit Verweis u.a. auf Buchanan (Constitutional Economics, 1987); Buchanan (Constitutional Economics, 1991).

6 Vgl. von Hayek (Recht, Band 3, 1981) S. 60-62, 145-173; von Hayek (Verfassung der Freiheit, 1991). 
Forderung, die letztlich nur durch verfassungsrechtliche Rahmenbedingungen zu gewährleisten ist. Verfassungsregeln existieren aber nicht im luftleeren Raum, sondern müssen gesellschaftlich legitimiert und gestützt werden. Wie Buchanan in seiner ökonomischen Theorie der Verfassung betont, erhalten sie ihre Legitimation aus einem demokratischen Konsensverständnis, das die Entstehung von Regeln an die Zustimmung der betroffenen Individuen bindet ${ }^{1}$. Damit entspringen sie einer Art Gesellschaftsver$\mathrm{trag}^{2}$. Die Einstimmigkeitsregel - letztlich Ausdruck des ökonomischen ParetoKriteriums $^{3}$ - kennzeichnet dabei ein theoretisches Ideal, das angesichts unterschiedlicher individueller (Ergebnis-)Wirkungen der jeweils zur Abstimmung stehenden Regeln kaum praktikabel und letztlich zu teuer erscheint ${ }^{4}$. Der gesellschaftliche Konsens stützt sich deshalb realiter auf (qualifizierte) Mehrheitsentscheidungen ${ }^{5}$.

Demokratisch legitimierte Verfassungsregeln sind als Ergebnis einer gesellschaftlichen Konsensentscheidung immer auch Ausdruck gesellschaftlicher Wertvorstellungen, die ökonomischen Effizienzerwägungen entsprechen oder gar entspringen können, aber nicht unbedingt müssen. Auf diese Diskrepanz weisen insbesondere Juristen hin, wenn sie konstatieren, dass die reine Effizienzbetrachtung bei Fragen der Regulierung - und so auch der steuerlichen Gewinnermittlung - die „Multifunktionalität des Rechtswesens" verkürze und der „Komplexität des Rechts“ nicht gerecht werde ${ }^{6}$. Aus diesen, von Effizienzgesichtspunkten weitgehend unabhängigen Wertvorstellungen leiten sich auch grundlegende Besteuerungsprinzipien ab, die gerade aus rechtswissenschaftlicher Sicht die normative Ausgangsbasis zur Deduktion steuerlicher Gewinnermittlungsregeln bil-

1 Vgl. Buchanan (Constitutional Economics, 1987); Buchanan (Constitutional Economics, 1991); dazu auch Brennan/Buchanan (Power to Tax, 1980) S. 2-12; zur Entwicklung der Verfassung als ökonomisches Problem auch Eschenburg (Theorie der Verfassung, 1977) S. 1-22.

2 Parallelen hierzu finden sich bereits in der Aufklärung und der von Rousseau (Du contrat social, 1762) entwickelten Idee vom Gesellschaftsvertrag; vgl. im Überblick zu dieser u.a. auch von Hobbes und Locke geprägten vertragstheoretischen Tradition Vanberg (Markt und Organisation, 1982) S. 39-47. I.d.Zshg. wird (gerade von Juristen) auch Kant (Über den Gemeinspruch, 1793) S. 143-164 (A 231A 270) angeführt, der den ,pactum sociale“ einer Menge von Menschen zur Errichtung einer bürgerlichen Verfassung (pactum unionis civilis) beschreibt.

3 Vgl. Erlei/Leschke/Sauerland (Neue Institutionenökonomik, 1999) S. 20; vgl. zum Pareto-Kriterium Kap. II.2.1.1.

4 Vgl. u.a. Buchanan/Tullock (Calculus of Consent, 1962); dazu auch Eschenburg (Theorie der Verfassung, 1977) S. 46-54, 82-87, 156-161.

5 Vgl. zur Bedeutung der (einfachen) Mehrheitsregel Eschenburg (Theorie der Verfassung, 1977) S. 162-176; qualifizierte Mehrheitsregeln werden durch Behrens (Grundlagen des Rechts, 1986) S. 289 so interpretiert, dass „,den durch sie geschützten Präferenzen eine besondere Intensität beigemessen wird".

6 Fezer (Aspekte einer Rechtskritik, 1986) S. 823 [beide Zitate]. Bezogen auf das Steuerrecht konstatiert Tipke (Steuerrechtsordnung, Band II, 1993) S. 543 moderater: „Da Steuern in einem Rechtsstaat gerecht verteilt werden müssen, gilt das Primat der Ethik. Das heißt nicht, dass die ökonomischen Folgen nicht $\mathrm{zu}$ bedenken wären. Nur kann man grundsätzlich davon ausgehen, dass die gerechte Steuer auch ökonomisch optimal oder jedenfalls dem Gemeinwohl wirtschaftlich nicht abträglicher ist als die ungerechte Steuer". 
den. Im Folgenden soll nun aufgezeigt werden, welche Wertvorstellungen hier gemeint sind, in welchen Besteuerungsprinzipien sich diese ausdrücken und welche Konsequenzen daraus für die steuerliche Gewinnermittlung erwachsen. Ziel der folgenden Ausführungen ist es aber auch, die Gemeinsamkeiten und Unterschiede zur ökonomischen Effizienzsicht herauszuarbeiten. Da diese Ausführungen auf den Bestimmungen einer konkreten Verfassung aufsetzen müssen, wird im Folgenden mangels einer noch nicht ratifizierten europäischen Verfassung ${ }^{1}$ auf das bundesdeutsche Grundgesetz (GG) zurückgegriffen, das als repräsentatives Beispiel für eine demokratisch legitimierte Verfassung angesehen werden kann.

\subsubsection{Verfassungsrechtliche Anforderungen am Beispiel des deutschen Grundge- setzes}

Das Steuerrecht ist in Deutschland Teil der Gesamtrechtsordnung und als solches an die rechtsstaatliche Ordnung, insbesondere an die im Grundgesetz garantierten Grundrechte gebunden. Dieses Rechtsstaatsprinzip (Art. 20 Abs. 3 GG) und der damit einhergehende Zwang zur rechtsstaatlichen Systemhaftigkeit ${ }^{2}$ konkretisiert sich in der notwendigen Beachtung verfassungsrechtlicher Prinzipien, die die „systemtragenden Prinzipien rechtsstaatlichen Steuerrechts ${ }^{\text {(33 }}$ bilden. Nach herrschender Meinung sind in diesem $\mathrm{Zu}-$ sammenhang unter Beachtung (sonstiger) verfassungsrechtlicher Schranken ${ }^{4}$ insbesondere die Gesetzmäßigkeit bzw. Rechtssicherheit (steuerrechtliches Legalitätsprinzip) und die Gleichmäßigkeit der Besteuerung anzuführen ${ }^{5}$.

Das Legalitätsprinzip drückt sich in erster Linie in dem Grundsatz des Gesetzes- bzw. Parlamentsvorbehalts aus. Hiernach dürfen Steuern nur per Gesetz beschlossen werden („nullum tributum sine lege“), da in einem demokratischen Rechtsstaat nur die Legislative, also das Parlament und das hierdurch vertretene Volk, legitimiert ist, sich selbst bestimmte Steuerlasten aufzuerlegen ${ }^{6}$. Daraus folgt auch der Vorrang des Gesetzes, wonach weder die Exekutive z.B. über Verordnungen, noch die Judikative Steuern be-

1 So ist allein in neun EU-Staaten eine Volksbefragung vorgesehen, deren Ausgang z.T. wohl ungewiss ist; vgl. hierzu und zu den Schwierigkeiten bei ablehnenden Voten o.V. (Spanier, 2004); Stabenow (Ein ungewisser Vertrag, 2004).

2 Vgl. dazu grundlegend die Systemlehre von Tipke; vgl. insb. Tipke (Steuerrechtsordnung, Band I, 2000) S. 31-60, 103-468.

3 Tipke/Lang (Steuerrecht, 2002) Überschrift zu § 4 Teil C (Tz. 70-247); dazu auch § 4 Tz. 1-66.

4 Vgl. dazu ausführlicher Kirchhof (Weg zur verfassungsgerechten Besteuerung, 2002) S. 190-200; Tipke/Lang (Steuerrecht, 2002) § 4 Tz. 202-247.

5 Vgl. Tipke (Steuerrechtsordnung, Band I, 2000) S. 118-416; Tipke/Lang (Steuerrecht, 2002) $\$ 4 \mathrm{Tz}$. 13-199; in der Systematisierung etwas abweichend Bayer (Steuerlehre, 1997) Tz. 114-145. Vgl. zu deutlichen Parallelen zu anderen europäischen Verfassungen Hahn (Einfluss des Thomas von Aquin, 2004) S. 171-173.

6 Vgl. Bayer (Steuerlehre, 1997) Tz. 13, 121-122; Tipke/Lang (Steuerrecht, 2002) §4 Tz. 150-160; Walz (Steuergerechtigkeit und Rechtsanwendung, 1980) S. 136-154. 
schließen können. Auch Gewohnheitsrecht ist hierzu nicht in der Lage ${ }^{1}$. Das Legalitätsprinzip betont zudem die Gesetzesbestimmtheit und die in $\S 3$ Abs. $1 \mathrm{AO}$ zum Ausdruck kommende Tatbestandsmäßigkeit der Besteuerung. Die Erhebung von Steuern ist demnach nur zulässig, wenn sie auf konkreten gesetzlichen Tatbeständen beruhen. Hieraus wird gemeinhin die Forderung nach Einfachheit, Eindeutigkeit und Objektivität der Steuervorschriften ${ }^{2}$ und damit auch der steuerrechtlich regulierten Rechnungslegung abgeleitet.

Die Forderung nach Einfachheit, Eindeutigkeit und Objektivität der Steuervorschriften reicht allein aber nicht aus, um Steuervorschriften inhaltlich auszugestalten. Hilfestellung gibt hier die Gleichmäßigkeit der Besteuerung als weiteres systemtragendes Prinzip des Steuerrechts ${ }^{3}$. Dieses Prinzip fußt auf dem allgemeinen Gleichheitsgrundsatz des Art. 3 Abs. 1 GG, aus dem letztlich auch die Vorstellung von Steuergerechtigkeit abgeleitet wird. Hiernach darf (wesentlich) Gleiches nicht willkürlich ungleich bzw. (wesentlich) Ungleiches nicht willkürlich gleich behandelt werden ${ }^{4}$. Dieser Gleichheitsgrundsatz ist jedoch insoweit unbestimmt, als dass Verfassung und Gesetz selbst keinen Vergleichsmaßstab liefern, der die Frage beantworten kann, wann angesichts komplexer realer Sachverhalte und Lebensverhältnisse von Gleichheit bzw. Ungleichheit auszugehen ist. Dabei sind mehrere Konzepte denkbar: das Kopfsteuerprinzip, das eine pro Person gleiche, egalitäre Steuer festlegt ${ }^{5}$, das Äquivalenzprinzip (benefit principle), das Steuern als Gegenwert zu staatlichen Leistungen oder Ausgleich für staatliche Kosten ansieht ${ }^{6}$, und das Leistungsfähigkeitsprinzip (ability-to-pay principle), wonach Steuerlasten auf die Steuerpflichtigen nach Maßgabe ihrer individuellen Leistungsfähigkeit

1 Vgl. Tipke (Steuerrechtsordnung, Band I, 2000) S. 129-130 m.w.N.; Tipke/Lang (Steuerrecht, 2002) $\S 4$ Tz. 160.

2 Einige Autoren leiten den Grundsatz der Einfachheit unmittelbar aus dem Rechtsstaatsprinzip und dem Gebot der Rechtssicherheit ab und sehen ihn als gleichrangig an mit dem Grundsatz der Gesetzmäßigkeit und dem hiervon separierbaren Grundsatz der Tatbestandsmäßigkeit; vgl. Bayer (Steuerlehre, 1997) Tz. 120-126; interpretierend Sellhorn (Steuersatz und Verfassungsrecht, 1998) S. 23, 59.

3 So wird die Gleichmäßigkeit der Besteuerung (insb. auch das u.a. hieraus abzuleitende Leistungsfähigkeitsprinzip) auch als inhaltlicher Besteuerungsgrundsatz den formalen Besteuerungsgrundsätzen (u.a. Tatbestandsmäßigkeit) gegenübergestellt; vgl. Bayer (Steuerlehre, 1997) Tz. 127-130; Sellhorn (Steuersatz und Verfassungsrecht, 1998) S. 23, 65-66.

4 Vgl. m.w.N. insb. zur Rechtsprechung des BVerfG (z.B. BVerfG v. 16.3 .1982 (1 BvR 938/81) S. 133134; BVerfG v. 16.11.1982 (1 BvL 16/75 und 36/79) S. 274) Jacobs (Ertragsteuerbilanz, 1971) S. 12 14; Tipke/Lang (Steuerrecht, 2002) § 4 Tz. 70, 73.

5 Kopfsteuern sind bereits in der Antike erhoben worden und haben bisweilen trotz der Kritik, sie stünden den herrschenden Gerechtigkeitsvorstellungen entgegen, noch in der Gegenwart Relevanz (z.B. „poll taxes“ bis 1966 in den USA oder die „,community charge“ in Großbritannien); vgl. dazu Kraft (Steuergerechtigkeit, 1991) S. 8; Tipke (Steuerrechtsordnung, Band I, 2000) S. 473-475; Walzer (Besteuerung nach dem Leistungsfähigkeitsprinzip, 1986) S. 204. Vgl. auch Kap. II.2.2.3.

$6 \quad$ Vgl. erstmalig wohl Wicksell (Finanztheoretische Untersuchungen, 1896). Parallelen existieren zu der auf Leistung und Gegenleistung zwischen Staat und Bürgern beruhenden Staatsidee von Rousseau (Du contrat social, 1762). 
verteilt werden ${ }^{1}$. Nach Ansicht der Steuerrechtswissenschaft sowie Rechtsprechung, aber auch von Teilen der Ökonomie, entspricht das Leistungsfähigkeitsprinzip am ehesten der herrschenden Vorstellung von Steuergerechtigkeit ${ }^{2}$ und wird deshalb nicht nur in Deutschland, sondern weltweit ${ }^{3}$ als das dominante „Fundamentalprinzip gerechter Besteuerung ${ }^{64}$ angesehen ${ }^{5}$. „Es liefert den rechtsethisch klugen Richtwert, der für die Ordnung des Steuerrechts nicht weniger benötigt wird als die Privatautonomie für die Ordnung des Zivilrechts"6 ${ }^{\text {c6 }}$. Da dieses Fundamentalprinzip aber letztlich immer noch unbestimmt bleibt, existiert bis heute eine kontroverse Diskussion darüber, wie es zu konkretisieren ist.

Fraglich ist insbesondere, an welche Indikatoren bzw. Maßgrößen die Leistungsfähigkeit anknüpfen soll (insb. Einkommen, Vermögen, Konsum ${ }^{7}$ ), wie diese genau zu definieren und vor allem auch zu quantifizieren sind. Nach Ansicht des Bundesverfassungs-

1 Vgl. erstmalig wohl Mill (Principles of Political Economy, 1848), der „ability to pay“ i.S.d. Opferfähigkeit, nicht i.S.d. heute üblichen Lastentragfähigkeit, definiert; zu historischen Vorläufern des Leistungsfähigkeitsprinzips auch Bach (Perspektiven des Leistungsfähigkeitsprinzips, 1991) S. 117-119; Bayer (Steuerlehre, 1997) Tz. 129. Vgl. ausführlich zum Leistungsfähigkeitsprinzip und zur Abgrenzung vom Äquivalenzprinzip Haller (Steuern, 1981) S. 13-45; Kraft (Steuergerechtigkeit, 1991) S. 38-41; Krause-Junk (Verteilungslehren, 1977) S. 334-344; Musgrave (Theory of Public Finance, 1959) S. 61-115; Tipke (Steuerrechtsordnung, Band I, 2000) S. 476-530; Weston (Principles of Justice in Taxation, 1903) S. 160-209. Vgl. kritisch zur Deutung der Leistungsfähigkeit über die in der englischen Übersetzung ausgedrückten Zahlungsfähigkeit Schneider (Steuerlast, 2002) S. 236-237.

2 Vgl. grundlegend zu den Gerechtigkeitsvorstellungen im Steuerrecht und zu dem Leistungsfähigkeitsprinzip als materiellem Gerechtigkeitspostulat Tipke (Steuergerechtigkeit, 1981); Walz (Steuergerechtigkeit und Rechtsanwendung, 1980) insb. S. 44-100, 155-169. Vgl. zur Abgrenzung der individuellen Steuergerechtigkeit von der sozialen Umverteilungsgerechtigkeit Wosnitza/Treisch (Leistungsfähigkeitskonzeptionen, 1999) S. 352-353.

3 Vgl. insb. Tipke (Steuerrechtsordnung, Band I, 2000) S. 488-490 zur verfassungsrechtlichen Fundierung des Leistungsfähigkeitsprinzips in Algerien, Brasilien, Frankreich, Griechenland, Italien, Kroatien, Liechtenstein, Mauretanien, Marokko, Russland, Schweiz, Spanien, Türkei und Ungarn. Hinweise auf Frankreich, Griechenland, Italien und Spanien finden sich auch bei Kofler (Steuerstrukturanpassung, 1980) S. 511; weitere Hinweise z.B. bei Hahn (Einfluss des Thomas von Aquin, 2004) S. 171173; Lang (Bemessungsgrundlage, 2000) S. 129. Vgl. zur Bedeutung des Leistungsfähigkeitsprinzips in den USA bereits Weston (Principles of Justice in Taxation, 1903) S. 171, der konstatiert, dass ,the term ,ability' is the best expression that we have of the ethical basis of distributive justice in taxation". Tipke/Lang (Steuerrecht, 2002) S. 78; Tipke (Steuerrechtsordnung, Band I, 2000) S. 469, 479-498.

5 Vgl. insb. Tipke (Steuergerechtigkeit, 1981) S. 57-58 m.w.N., der konstatiert, dass dieses Prinzip „heute von Finanzwissenschaftlern, Rechtsphilosophen und Steuerrechtlern gleichermaßen anerkannt" ist. Vgl. dazu BVerfG v. 3.11.1982 (1 BvR 620/78, 1335/78, 1104/79 und 363/80) S. 343-344: „Es ist ein grundsätzliches Gebot der Steuergerechtigkeit, daß die Besteuerung nach der (wirtschaftlichen) Leistungsfähigkeit ausgerichtet wird.“ Im Grundgesetz selbst ist das Leistungsfähigkeitsprinzip anders als z.B. in der Weimarer Reichsverfassung - aber nicht kodifiziert. Zum Geltungsanspruch des Leistungsfähigkeitsprinzips (auch in der steuerlichen Gewinnermittlung) vgl. z.B. Kirchhof (Auftrag zur Besteuerung, 1985) S. 319, 322-329; Kofler (Steuerstrukturanpassung, 1980) S. 509, 511; Kraft (Steuergerechtigkeit, 1991) S. 12-21; Moxter (Bilanztheorie, 1984) S. 108; Sellhorn (Steuersatz und Verfassungsrecht, 1998) S. 66-67; Tipke (Steuerrechtsordnung, Band I, 2000) S. 502-505, 511-512; WB Ernst \& Young (Abschaffung des Teilwerts, 2004) S. 3.

6 Tipke/Lang (Steuerrecht, 2002) § 4 Tz. 83.

7 Vgl. Neumark (Steuerpolitik, 1970) S. 135-143, der diese als Leistungsfähigkeitsindikatoren benennt. 
gerichts (BVerfG) ist es die Besteuerung des Einkommens, die im besonderen Maße die Leistungsfähigkeit des einzelnen Steuersubjektes berücksichtigt. Hier wird auf die finanzielle ${ }^{1}$ Leistungsfähigkeit abgestellt, die im Sinne des Lastentragfähigkeitskonzeptes die Fähigkeit des Steuerpflichtigen betont, einen Beitrag zur Finanzierung des staatlichen Finanzbedarfs mittels Geldzahlungen zu leisten². Vorgaben darüber, wie das Einkommen als Indikator und Maßgröße für besteuerungsfähige Leistungsfähigkeit genau zu konkretisieren ist, existieren auf verfassungsrechtlicher Ebene in eher grundlegender Form. So wird Einkommen auf das wirtschaftliche Ergebnis einer Erwerbstätigkeit reduziert $^{3}$, das auf der Basis von Erwerbseinnahmen und -ausgaben zu ermitteln ist (objektives Nettoprinzip) ${ }^{4}$ und das in seiner Gesamtheit (Totalitätsprinzip) ${ }^{5}$, allerdings nicht als Totaleinkommen, sondern periodisch und sukzessiv als Jahreseinkommen erfasst wird (Prinzip der Abschnittsbesteuerung) ${ }^{6}$. Weitergehende verfassungsrechtliche Vorgaben, die insbesondere die inhaltliche Ausgestaltung der steuerlichen Gewinnermittlung konkretisieren, existieren damit nicht.

\subsection{3 Ökonomische Deutung verfassungsrechtlicher Anforderungen: (Un-)Vereinbarkeit von Effizienz und Gerechtigkeit}

Bei einer Gegenüberstellung verfassungsrechtlicher sowie ökonomischer Anforderungen an die steuerliche Gewinnermittlung lassen sich Schnittmengen unmittelbar erkennen. So wird die aus dem Legalitätsprinzip resultierende Forderung nach Einfachheit, Eindeutigkeit und Objektivität der Steuervorschriften auch aus effizienzorientierter Sicht erhoben. Dies gilt ebenfalls für den Gesetzesvorbehalt, der aus ökonomischer Sicht einen Beitrag zur Reduzierung ineffizienter staatlicher Willkür leisten kann ${ }^{7}$.

Anders als beim Legalitätsprinzip sind weitergehende Schnittmengen nur unter größerer Anstrengung zu identifizieren. Im Gegensatz zur (verfassungs-)rechtlichen Perspektive sind ökonomische Vorstellungen stärker effizienz- denn gerechtigkeitsgetrieben und

1 Vgl. kritisch zum Adjektiv „finanziell“ Schneider (Steuerlast, 2002) S. 238.

2 Vgl. z.B. BVerfG v. 22.6.1995 (2 BvL 37/91) S. 135; BVerfG v. 22.6.1995 (2 BvR 552/91) S. 176; auf die „wirtschaftliche“ Leistungsfähigkeit abstellend $B V e r f G$ v. 3.11 .1982 (1 BvR 620/78, 1335/78, $1104 / 79$ und 363/80) S. 343-344; BVerfG v. 28.11.1984 (1 BvR 1157/82) S. 310; BVerfG v. 10.2.1987 (1 BvL 18/81 und 20/82) S. 199-200.

3 Vgl. Bayer (Steuerlehre, 1997) Tz. 518-779.

4 Vgl. Kirchhof (Auftrag zur Besteuerung, 1985) S. 328; Kirchhof (Gutachten, 1988) S. F 20-F 51; s.a. $B V e r f G$ v. 23.1.1990 (1 BvL 4, 5, 6, 7/87). Die terminologische Unterscheidung zwischen Einnahmen und Einzahlungen sowie Ausgaben und Auszahlungen sei nach Schneider (Rechnungswesen, 1997) S. 48-50, 58 allerdings „entbehrlich“.

5 Vgl. Tipke/Lang (Steuerrecht, 2002) § 9 Tz. 1.

6 Vgl. Kirchhof (Auftrag zur Besteuerung, 1985) S. 322, 329; Kirchhof(Gutachten, 1988) S. F 75-F 77; Tipke (Steuerrechtsordnung, Band II, 1993) S. 668-672.

7 Die Regulierungsnotwendigkeit der steuerlichen Gewinnermittlung wird hier nicht als solche in Frage gestellt. Bei der ökonomischen Analyse der steuerlichen Gewinnermittlung steht weniger die Frage im Vordergrund, $o b$ der Staat regulieren soll, sondern „nur", wie er hierbei vorzugehen hat. 
stärker wirkungs- denn wertungsorientiert ${ }^{1}$. Als das Maß sozial ausgewogenen Verhaltens der Menschen unter- und miteinander ${ }^{2}$ ist der häufig strapazierte Gerechtigkeitsbegriff aufgrund höchst subjektiver Vorstellungen von sozialer Ausgewogenheit kaum operationalisierbar. Insofern wenden sich einzelne Ökonomen strikt gegen jede Einbeziehung von wie auch immer gearteten Gerechtigkeitsvorstellungen. Es handele sich gerade im Zusammenhang mit Besteuerungsfragen mehr um „moralische Deckmäntel im Munde von Demagogen, wo sie zur feinen Dirne beliebiger Interessenwünsche erniedrigt würden“"3. Obwohl diese pointiert vorgetragene Sorge vor den Manipulationsspielräumen staatlicher Würdenträger im Namen der Gerechtigkeit nicht unbegründet erscheint, haben sich Teile der ökonomischen Literatur sehr wohl mit Fragen der (Steuer-)Gerechtigkeit beschäftigt und sie aus kritisch-distanzierter Sicht zu beantworten versucht.

Um Gerechtigkeitsfragen im Zuge der steuerlichen Gewinnermittlung analysieren zu können, bedarf es in einem ersten Schritt der Präzisierung des Gerechtigkeitsbegriffs. Auf diesem Wege kann zumindest versucht werden, der Gefahr einer pauschalen und vor allem auch subjektiv-intuitiven Gerechtigkeitssicht nicht völlig zu erliegen. So ist die Gerechtigkeit aus Sicht der ökonomischen Verfassungstheorie nichts anderes als eine von gesellschaftlichen Wertevorstellungen geprägte Regel höheren Ranges. In rechtsstaatlichen Demokratien zielt sie auf einen vorhandenen Konsens innerhalb der normativen Ethik, der im Kern bereits von Aristoteles formuliert wurde: Hiernach hat der Staat als machtvolles soziales Ganzes im Verhältnis zu den dieser Macht unterliegenden Einzelpersonen distributive Gerechtigkeitsvorstellungen (iustitia distributiva) zu beachten. Diese als verhältnismäßige ${ }^{4}$ Gleichheit (ius suum: jedem das Seine) in der staatlichen Behandlung von Einzelpersonen interpretierte Gerechtigkeitsaspekt steht einer kommutativen Tauschgerechtigkeit (iustitia commutativa) gegenüber, die auf das

1 Vgl. zu dieser Gegenüberstellung auch terminologisch ähnlich Wagner (Gegenstand und Methoden, 2004) S. 239-240.

2 Vgl. Bierich (Moral und Effizienz, 1995) S. 187 i.A.a. Platon u. die abendländische Tradition.

3 Elschen (Institutionale oder personale Besteuerung, 1994) S. 184 mit einem integrierten Teilzitat von Mann (Frage der steuerlichen Lastenverteilung, 1926) S. 34, der allerdings von der "feilen“ Dirne spricht. Für Mann ist „[d]ies Glatteis von Subjektivitäten .. als Baugrund wissenschaftlicher Lehrsysteme ungeeignet". Kritisch zur Steuergerechtigkeit auch Rose (Steuergerechtigkeit aus betriebswirtschaftlicher Sicht, 1985) und, sogar aus juristischer Sicht, z.B. Meßmer (Steuergerechtigkeit, 1981) S. 3: „Doch ist der Verdacht nicht von der Hand zu weisen, daß dieses vielen so leicht von der Zunge oder aus der Feder fließende Wort sehr häufig benutzt wird, ohne daß der jeweilige Verwender auch nur versucht hätte, sich eine Vorstellung über den Bedeutungsgehalt jenes so edel klingenden Wortes zu machen". Vgl. auch Ross (Law and Justice, 1959) S. 274: „To invoke justice is the same thing as banging on the table: an emotional expression which turns one's demand into an absolute postulate. That is no proper way to mutual understanding. It is impossible to have a rational discussion with a man who mobilises ,justice", because he says nothing that can be argued for or against. His words are persuasion, not argument".

4 Man spricht hier auch von austeilender, oder, so Tipke (Steuergerechtigkeit, 1981) S. 10 treffender, von zuteilender Gerechtigkeit. 
ausgleichende Verhältnis der gleichberechtigten Einzelpersonen untereinander fokussiert $^{1}$. Dieser dualen Gerechtigkeitsbetrachtung ist später noch die Gesetzesgerechtigkeit (iustitia legalis) hinzugefügt worden, die die Gehorsamspflichten des Einzelnen gegenüber dem Gemeinwesen konkretisiert ${ }^{2}$ (vgl. Abb. 2).

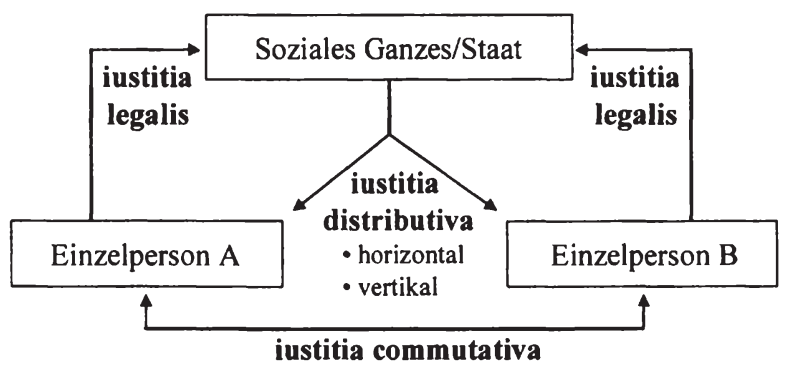

Abb. 2: Dreidimensionaler Gerechtigkeitsbegriff

Aus normativer Sicht werden Gerechtigkeitsfragen also bei jeder Regulierung aufgeworfen, weil der Staat als Regulierungssubjekt und übergeordnetes Machtobjekt mit hoheitlichen Befugnissen in das private, marktwirtschaftliche Verhältnis der Bürger untereinander eingreift. Dies gilt insbesondere für das Steuerrecht, das wie kaum ein anderer regulierter Bereich in der gesellschaftlichen Wahrnehmung mit Gerechtigkeitsvorstellungen verbunden ist ${ }^{3}$. Steuergerechtigkeit ist demnach in ihrer Dreidimensionalität ein zentraler gesellschaftlicher Konsens, der auch bei der Ausgestaltung steuerlicher Gewinnermittlungsregeln zu beachten ist.

Welche konkreten Schlussfolgerungen ergeben sich nun für die steuerliche Gewinnermittlung? Wird mit der steuerlichen Gesetzesgerechtigkeit begonnen, kann aus ihr die Forderung nach einer gesetzeskonformen Gewinnermittlung abgeleitet werden. Diese simple Forderung ist aus ökonomischer Hinsicht nicht unproblematisch, da sie mit der

1 Vgl. Aristoteles (Nikomachische Ethik, 2002) 5. Buch, insb. Kap. 5-7 (1130b5-1132b20); erläuternd dazu auch Radbruch (Rechtsphilosophie, 2003) S. 36-37, der diese beiden Gerechtigkeitsebenen auch dem Privatrecht sowie dem öffentlichen Recht zuordnet.

2 Diese Ebene geht wohl auf Thomas von Aquin zurück, der die Zweiteilung von Aristoteles in eine Dreiteilung überführte; vgl. dazu Hahn (Einfluss des Thomas von Aquin, 2004) insb. S. 169. Als Vorläufer dürfte die Gehorsampflicht gelten, die Platon (Kriton, 1982) Kap. 9-16 mit Bezug auf Sokrates beschreibt. So hat Sokrates das Hilfeangebot seines Freundes Kriton zur Flucht vor der (ungerechten) Todesstrafe wegen der Gesetzesgerechtigkeit abgelehnt.

3 Vgl. hier sehr weitgehend Kofler (Steuerstrukturanpassung, 1995) S. 508: „Indes ist klar, daß der Fiskalzweck nicht beliebig, sondern nur nach bestimmten Grundsätzen und Prinzipien, also nach systembildenden und tatbestandsprägenden Grundideen zu erreichen ist, die allesamt im obersten Prinzip der Gerechtigkeit ihre Wurzel, ihre Begründung und Rechtfertigung zu finden haben." Gemeinhin wird die Steuergerechtigkeit aber auf die distributive Ebene beschränkt; vgl. auch Tipke (Steuergerechtigkeit, 1981) S. 10, Fn. 19 und S. 57, Fn. 90 m.w.N. 
Verhaltensannahme des Opportunismus kollidiert. Ein in ökonomischer Sicht eigennutzorientiert handelndes Individuum, dass aus (begrenzt) rationalen Erwägungen heraus Steuerhinterziehung betreibt ${ }^{1}$, begeht damit aus Sicht gesellschaftlicher Wertvorstellungen eine ethisch verwerfliche Handlung ${ }^{2}$. Nur so ist der wertungsorientierte Vorwurf des „amoralischen“ Verhaltens zu verstehen, der gegenüber opportunistischen Steuerpflichten erhoben wird. Während die Ökonomie nun versucht, Anreize zu illegalen Steuerausweichhandlungen u.a. über entsprechende Anforderungen an die steuerliche Gewinnermittlung zu reduzieren, verlangt die Gesetzesgerechtigkeit die Gehorsamspflicht und das regelkonforme Verhalten als solches und zwar unabhängig davon, wie die Gewinnermittlung inhaltlich ausgestaltet ist ${ }^{3}$. Angesichts der empirischen Relevanz opportunistischen Verhaltens kann dies aber nur funktionieren, wenn die Steuerhinterziehung mit staatlich oktroyierten Kosten, z.B. durch strafrechtliche Sanktionen, einhergeht, um letztlich doch das eigennutzorientierte Anreizverhalten zu beeinflussen.

Dem dreidimensionalen Gerechtigkeitsverständnis folgend sollte den gesetzesgerechten Individuen - quasi im Gegenzug - kommutative und distributive Gerechtigkeit garantiert werden. Dabei wird nicht immer präzise zwischen diesen beiden Ebenen unterschieden. Dies wird auch in der ökonomischen Auseinandersetzung mit dem Gerechtigkeitsbegriff deutlich, in der letztlich auch wieder Effizienzvorstellungen zum Tragen kommen. Deshalb verwundert es nicht, dass die ökonomischen Vorstellungen von Gerechtigkeit wie diejenigen von Effizienz in Abhängigkeit von den jeweils zu Grunde gelegten wirtschaftstheoretischen Sichtweisen variieren ${ }^{4}$. So geht z.B. Posner als Vertreter der Chicago School of Law davon aus, dass Gerechtigkeit über sein eher allokationstheoretisch geprägtes Effizienzverständnis konkretisiert werden könne ${ }^{5}$. Ein eventu-

1 Vgl. so z.B. die Steuerpflichtigen bei Allingham/Sandmo (Income Tax Evasion, 1972), die aus Sicht von Slemrod (Tax from Any Angle, 2003) S. 148 als ,completely amoral“ dargestellt werden.

2 Vgl. relativierend Schneider (Steuerlast, 2002) S. 93-96, der auch aus ethischer Perspektive Ausnahmen von der Gehorsamspflicht identifiziert und die Steuerhinterziehung nicht mehr per se als amoralisch ansieht. Auch gegenüber der legalen und damit „gesetzesgerechten“ Steuerausweichhandlung werden Moralargumente ins Feld geführt, gegen die sich aber Schneider (Steuergerechtigkeit, 1985) ebenfalls verwahrt. Kirchhof (Auftrag zur Besteuerung, 1985) S. 320 fordert z.B. relativierend die "Gefolgschaft gegenüber einer Belastungsidee, nicht bloßen Textgehorsam".

3 Die „iustitia legalis“ des Thomas von Aquin setzt aber ,gerechte Gesetze“ voraus, das „ungerechte Gesetz ist nicht verbindlich"; vgl. so Hahn (Einfluss des Thomas von Aquin, 2004) S. 169-170 m.w.N. Demnach ist Schneider (Steuerlast, 2002) S. 96 zuzustimmen, der die Steuerhinterziehung bei staatlicher Ungerechtigkeit moralisch nicht verurteilt.

4 Vgl. sehr ausführlich zu den in dieser Arbeit nur angerissenen Gerechtigkeitsvorstellungen in Abhängigkeit von differierenden wirtschaftstheoretischen Sichtweisen Elschen (Institutionale oder personale Besteuerung, 1994) S. 182-283.

5 Vgl. z.B. Posner (Recht, 1993) S. 97: „Eine zweite Bedeutung von ,Gerechtigkeit' und vielleicht die gebräuchlichste ist einfach diejenige von ,Effizienz'“; dabei betont er aber auch, dass Fragen der Gerechtigkeit in der Ökonomie letztlich nicht beantwortet werden (S. 86-88); s.a. Elschen (Entscheidungsneutralität, 1991) S. 101. 
elles Spannungsverhältnis zwischen Effizienz und Gerechtigkeit ${ }^{1}$ wird damit ignoriert, denn alles andere sei, so Demsetz, religiös und intuitiv². Obwohl hier Gerechtigkeit nicht weiter differenziert wird, liegt diesen Überlegungen wahrscheinlich ein eher ergebnisorientiertes, distributives Gerechtigkeitsverständnis zu Grunde. So wird z.B. vorgeschlagen, die eher neoklassisch fundierten Anforderungen an eine investitionsneutrale Gewinnermittlung zur Konkretisierung der (distributiven) Gerechtigkeit und mit ihr auch der steuerlichen ${ }^{3}$ Leistungsfähigkeit heranzuziehen ${ }^{4}$. Mit denselben Modellüberlegungen könnten dann investitionsneutrale wie auch gerechte Gewinnermittlungsregeln abgeleitet werden.

Obwohl diese Gleichsetzung ihren Reiz besitzt, da sie ethische Gebote auf ein ökonomisch (halbwegs) fassbares Kriterium reduziert ${ }^{5}$, werden insbesondere aus prozessorientierter Perspektive Zweifel geäußert. So findet sich eine effizienzorientierte Deutung der Gerechtigkeit auch in der evolutorisch-liberalen Sicht von Hayeks. Hiernach bedürfe es allerdings keiner ergebnisorientierten, distributiven (Verteilungs-)Gerechtigkeit, sondern nur der Sicherstellung der verfahrensorientierten, kommutativen Tauschgerechtigkeit, die durch „Regeln gerechten Verhaltens“ sicherzustellen sei ${ }^{6}$. Der kommutative Gerechtigkeitsaspekt erlangt damit als Bestandteil der Wettbewerbsordnung eine zentrale Bedeutung für die wettbewerbliche Freiheitsentfaltung. Eine Konformität von Effizienz und Gerechtigkeit bezieht sich hiernach nur auf kommutative Gerechtigkeitsaspekte $^{7}$. Anforderungen an eine wettbewerbsneutrale Gewinnermittlung können damit unmittelbar auch als kommutative Gerechtigkeitsanforderungen verstanden werden.

1 Vgl. z.B. Bierich (Moral und Effizienz, 1995); Sen (Soziale Gerechtigkeit, 1998); Stiglitz/Schönfelder (Finanzwissenschaft, 1989) S. 59-62.

2 Vgl. Demsetz (Ethics and Efficiency, 1979) insb. S. 98; vgl. zu diesem Zusammenhang Elschen (Institutionale oder personale Besteuerung, 1994) S. 206-208.

3 Im Vergleich zur „finanziellen“ oder auch „wirtschaftlichen“ Leistungsfähigkeit erhält nach Schneider (Steuerlast, 2002) S. 238-239 allein die „steuerliche“ Leistungsfähigkeit als Begriff einen Sinn (in der steuerlichen Betriebswirtschaftslehre). Insofern wird in dieser Arbeit hauptsächlich von steuerlicher Leistungsfähigkeit gesprochen.

4 Vgl. z.B. Richter (Investitionsneutrale Besteuerung, 1990) S. 761; Wagner (Neutralität und Gleichmäßigkeit, 1992) insb. S. 5; relativierend Wagner (Karlsruher Entwurf, 2001) S. 357; s.a. die Literatur bei Schneider (Investition, 1992) S. 244 Fn. 41.

s Vgl. dazu treffend Wagner (Neutralität und Gleichmäßigkeit, 1992) S. 5: „Am sinnvollsten dürfte es daher sein, von der Annahme auszugehen, daß mit der Entfaltung einer Theorie der entscheidungsneutralen Besteuerung ökonomischer Zielgrößen die vergebliche Suche nach den Inhalten einer spezifisch steuerlichen Leistungsfähigkeit beendet werden kann, die auf diese Weise einen ebenso unrühmlichen wie erfolgreichen Abschluß fände, da eine umstrittene Konzeption durch ein klar interpretierbares Konzept ersetzt würde."

6 Vgl. von Hayek (Recht, Band 2, 1981) S. 58-66; von Hayek (Verfassung der Freiheit, 1991) S. 105124, 296-298, für den im Übrigen die Freiheit auch als Moralprinzip fungiert (S. 84-86).

7 Vgl. Elschen (Entscheidungsneutralität 1991) S. 109, 115; Elschen (Institutionale oder personale Besteuerung, 1994) S. 264-279. 
In der totalen Ablehnung distributiver Gerechtigkeit bezieht von Hayek jedoch eine, nicht immer konsequent vertretene ${ }^{1}$ Extremposition. So folgen ihm z.B. Elschen und Schneider in der Anerkennung der verfahrensbezogenen kommutativen Gerechtigkeit, ohne dabei jedoch distributive Gerechtigkeitsvorstellungen auszuklammern ${ }^{2}$. Es gehe hierbei um den Schutzrechtscharakter des Steuerrechts für den einzelnen Staatsbürger, in dem Steuervorschriften die an den Staat abgetretene Besteuerungsmacht begrenzten ${ }^{3}$. Dabei wenden sie sich strikt gegen eine effizienzorientierte Deutung der distributiven Gerechtigkeit. Entscheidungsneutralität könne im besten Fall, unter Ausklammerung sämtlicher modelltheoretischer Schwächen, nur eine Vorstufe distributiver Gerechtigkeit darstellen, indem steuerliche Regeln das zu Verteilende über Nichtverschwendung knapper Ressourcen bzw. Nichtverzerrung von Markt- und Wettbewerbsprozessen maximieren ${ }^{4}$.

Auf distributiven Gerechtigkeitsvorstellungen beruht nun das Verständnis des verfassungsmäßigen Gleichmäßigkeitsgrundsatzes und damit auch der steuerlichen Leistungsfähigkeit. In ethischer Hinsicht ist das Leistungsfähigkeitsprinzip dabei nichts anderes als eine konkrete Bezugsgröße der Verteilungsgerechtigkeit ${ }^{5}$. Aus der Sicht der ökonomischen Verfassungstheorie ist es sogar einzig in der Lage, eine „faire“ Verteilungslösung für erwirtschaftete Kooperationsüberschüsse unter eigennützigen Akteuren sicherzustellen ${ }^{6}$.

An dieser Stelle wird die horizontale Komponente der distributiven Gerechtigkeit (Gleichmäßigkeit als unterschiedslose Besteuerung gleich hoch gemessener Leistungsfähigkeit) von der vertikalen (relativ stärkere Besteuerung einer höheren Leistungsfähigkeit et vice versa) unterschieden. Das Leistungsfähigkeitsprinzip wird von steuerrechtlicher Seite oft auf beide Komponenten bezogen, obwohl sich der verfassungsmä-

1 Vgl. Elschen (Institutionale oder personale Besteuerung, 1994) S. 227 m.w.N.

2 Vgl. Elschen (Institutionale oder personale Besteuerung, 1994) S. 182-279; Schneider (Steuerlast, 2002) S. 231-330; s.a. Schneider (Reform der Unternehmensbesteuerung, 1989) S. 329, dessen Präferenzreihenfolge „Effizienz vor Gerechtigkeit und diese beiden vor Einfachheit der Besteuerung" sich später wohl zu Gunsten der verteilungsgerechten Besteuerung verändert hat, wie das normative Vorgehen z.B. in Schneider (Mängel, 2000); Schneider (IAS als Besteuerungsgrundlage, 2003); Schneider (Rechtsformneutralität, 2004) zeigt; s.a. Gröning (Steuerbilanzielle Gewinnermittlung, 2002) S. 4954; Lang (Reform der Unternehmensbesteuerung, 1990) S. 111-112.

3 Vgl. Elschen (Institutionale oder personale Besteuerung, 1994) S. 243-251 m.w.N.

4 Vgl. Schneider (Steuerlast, 2002) S. 108, 261. Vgl. zur „Kuchenthese“, nach der der Kuchen erst einmal unter Nutzung knapper Mittel möglichst groß gemacht werden soll, ehe er zu verteilen ist Schneider (Investition, 1992) S. 646, 750; Schneider (Rechnungswesen, 1997) S. 255-266.

5 Vgl. Weston (Principles of Justice in Taxation, 1903) S. 171; s.a. Behrens (Grundlagen des Rechts, 1986) S. 102, der Leistungs- und Bedarfsprinzip als zentrale Verteilungsmuster für distributive Gerechtigkeit ansieht.

6 Vgl. Eschenburg (Theorie der Verfassung, 1977) S. 136-155, der die leistungsgerechte Verteilungslösung als theoretische Ideallösung ansieht, dabei aber auch schwerwiegende Bewertungsprobleme bei der praktischen Anwendung erkennt. 
ßige Grundsatz der Gleichmäßigkeit wohl eher auf die horizontale Komponente bezieht $^{\prime}$. So sei der Begriff der steuerlichen Leistungsfähigkeit nach Schneider von einem primär der politischen Sphäre vorbehalten „Umverteilungs-Werturteil “2 zu trennen und „als Maßgröße zu verstehen, über die zum Zwecke der Gleichmäßigkeit der Besteuerung (der horizontalen Gerechtigkeit) empirische Sachverhalte (wie der Gemüseanbau des Bauern, die Spekulation des Devisenhändlers usw.) vergleichbar gemacht werden, und die zugleich einer möglichst weit verbreiteten finanziellen Zielgröße bei einzelwirtschaftlichem Handeln entspricht"“3. Unabhängig davon, welche Gerechtigkeitskomponenten sich im Leistungsfähigkeitsprinzip widerspiegeln, dürfte für diese Arbeit ohnehin mehr die horizontale Komponente interessieren. Während die vertikale Komponente eher tarifliche Fragen zum Gegenstand hat, steht bei der horizontalen die Frage nach der „gerechten“ Bemessungsgrundlage stärker im Vordergrund".

Der Bezug auf Gleichmäßigkeits- bzw. Gerechtigkeitsargumente ist auch international durchaus üblich und steht gerade in normativen Arbeiten als Beurteilungsmaßstab neben der reinen Effizienzbetrachtung ${ }^{5}$ - sogar, wenn dem Leistungsfähigkeitsprinzip als

1 Vgl. z.B. Eberhartinger (Ertragsteuerliche Konsequenzen, 2000) S. 243; Schneider (IAS als Besteuerungsgrundlage, 2003) S. 300; Neumark (Steuerpolitik, 1970) S. 92. Zur Unterscheidung beider Gerechtigkeitsebenen auch Musgrave/Musgrave (Public Finance, 1989) S. 223.

2 Schneider (Steuerlast, 2002) S. 234; ähnlich Neumark (Steuerpolitik, 1970) S. 92. Für von Hayek (Grundsätze einer liberalen Gesellschaftsordnung, 1969) S. 118-121; von Hayek (Recht, Band 2, 1981) S. 99-102 ist die Idee der „Sozialen“ Verteilungsgerechtigkeit mit einer freiheitlichen, durch Rechtsstaat und Marktwirtschaft gekennzeichneten Gesellschaftsordnung gänzlich unvereinbar.

3 Schneider (Steuerlast, 2002) S. 235.

4 Vgl. stellvertretend für viele Eberhartinger (Ertragsteuerliche Konsequenzen, 2000) S. 243-244; aus finanzwissenschaftlicher Sicht auch Blankart (Öffentliche Finanzen, 2003) S. 189-192, der konstatiert: „Was uns das Leistungsfähigkeitsprinzip an handfesten Leitlinien für die Besteuerung bringt, ist vor allem der Grundsatz der horizontalen Gerechtigkeit" (S. 192). Kritisch zur Gleichsetzung von horizontaler und vertikaler Gerechtigkeit mit „gerechter Ermittlung der Bemessungsgrundlage“ bzw. „gerechter Tarifgestaltung" Hundsdoerfer (Einkommenserzielung und Konsum, 2002) S. 24-27. Vgl. grundlegend zur Steuersatzregulierung aus dem Blickwinkel des (Steuer-)Verfassungsrechts Sellhorn (Steuersatz und Verfassungsrecht, 1998).

5 Vgl. z.B. AICPA (Guiding Principles, 2002); Alm („optimal“ tax system, 1996) S. 117-119; Gerken/Märkt/Schick (Tax Competition in the EU, 2001) S. 248-249; IFS (Corporation Tax for the 1990s, 1991) S. 10-11; Nobes (Framework for the Taxable Income, 2004) S. 35-48, der das Gerechtigkeitspostulat zur ranghöchsten Zielsetzung bei der Beurteilung von steuerlichen Gewinnermittlungsregeln kürt; letztlich auch Musgrave (Theory of Public Finance, 1959) S. 157-160. Insofern ist die Berücksichtigung von Gerechtigkeitsargumenten beileibe kein deutsches Phänomen. Vgl. auch RandzioPlath (Steuerharmonisierung, 1999) S. 56, nach der Gerechtigkeit in allen EU-Mitgliedstaaten eine zentrale Anforderung an das Steuerrecht markiert. 
solchem keine große Bedeutung beigemessen wird ${ }^{1}$. Während sich aber die kommutative Gerechtigkeit über prozessorientierte Effizienzgesichtspunkte ökonomischen Herangehensweisen erschließt, ist bei der distributiven Gerechtigkeit fraglich, ob eine ökonomische Analyse des (Steuer-)Rechts neben den Entscheidungs- und sonstigen Effizienzwirkungen auch Verteilungsfolgen einbeziehen soll ${ }^{2}$. In streng effizienzorientierter ökonomischer Sicht ist dies wohl auszuschließen ${ }^{3}$. In einer weiteren Sicht wird aber insbesondere von Schneider gefordert, dass die "ökonomische“ Analyse des Rechts Verteilungsfolgen nicht ausklammern dürfe ${ }^{4}$. Neben der Effizienz sei also auch die Gleichmäßigkeit der Besteuerung als eigenständiges normatives Ziel der steuerlichen Gewinnermittlung zu berücksichtigen, weil „eine Gesellschaft, in der Interessengegensätze möglichst gewaltfrei bereinigt werden sollen, nicht allein unter Effizienzgesichtspunkten geordnet werden kann. ... Deshalb sind ethische Spielregeln vor allem dort ... zu setzen, wo es um die Zumutung von Leistungen ohne Einzelanspruch auf Gegenleistung geht, also insbesondere bei der Besteuerung "55.

1 Vgl. Musgrave (Theory of Public Finance, 1959) S. 160: “...the principle of equality is accepted by many who do not lay much store in the ability-to-pay approach". Die Zurückhaltung in Teilen der ökonomischen Literatur gegenüber dem Leistungsfähigkeitsprinzip wird auch durch Gerechtigkeitsargumente gestützt. Würden statt der dem Leistungsfähigkeitsprinzip innewohnenden Vorstellung eines wohlfahrtsmaximierenden, altruistischen Staates empirisch gehaltvollere Annahmen zum Tragen kommen, müsste das Gerechtigkeitsempfinden durch die Willkür der Staatsverantwortlichen auf der Ausgabenseite konterkariert werden. Vgl. z.B. Littmann (Valet dem Leistungsfähigkeitsprinzip, 1970); interessant auch von Hayek (Recht, Band 1, 1980) S. 183-184; Walz (Steuergerechtigkeit und Rechtsanwendung, 1980) S. 101-119 und allgemeiner Tipke (Steuergerechtigkeit, 1981) S. 171-182, der Steuerverschwendung zwar anprangert, das Leistungsfähigkeitsprinzip aber nicht in Frage stellt. Es scheint aber wenig förderlich, bei einem derart „unvollkommenen“ Staat auf das Äquivalenzprinzip als „Prinzip der gerechten Besteuerung“ abzustellen, da selbiges kaum umsetzbar ist und wegen seiner verteilungspolitischen Zementierung bestehender Verhältnisse selbst wiederum als ungerecht empfunden wird. Vgl. dazu im Überblick Blankart (Öffentliche Finanzen, 2003) S. 187-262; Musgra$v e$ (Theory of Public Finance, 1959) S. 61-89. Einig ist man sich indes in der Verurteilung der ,entscheidungsfixen" und ökonomisch wohl idealen Kopfsteuer, die auch von Ökonomen unter Hinweis auf Gleichmäßigkeits- bzw. Gerechtigkeitsaspekte abgelehnt wird; vgl. dazu bezeichnend Musgrave (Theory of Public Finance, 1959) S. 158: „The head tax, that star performer in efficiency, ranks low on equity grounds; ... Thus, the art of tax policy requires the finding of tax forms that are more or less acceptable on both grounds".

2 Calabresi/Melamed (Property Rules, 1972) S. 1102-1105 haben sogar darauf hingewiesen, dass es Gerechtigkeitsaspekte gibt, die sich weder auf Effizienz-, noch auf Verteilungsgesichtspunkte reduzieren lassen; dazu auch Behrens (Grundlagen des Rechts, 1986) S. 103.

3 Vgl. deshalb z.B. Posner (Recht, 1993) S. 86: „Die Kompetenz des Ökonomen in einer Diskussion über das Rechtssystem ist daher streng begrenzt".

4 Vgl. Schneider (Investition, 1992) S. 646-647, der dazu konstatiert: „Wer nicht unter dem Deckmantel der Ethik in Vorurteilen stecken bleiben will, wird für alternative Rechtssetzungen sowohl die Entscheidungswirkungen als auch die Verteilungsfolgen untersuchen. Alternative Rechtssetzungen im Hinblick auf ihre Entscheidungswirkungen und Verteilungsfolgen zu erforschen, ist Gegenstand einer ökonomischen Analyse des Rechts“.

5 Schneider (Investition, 1992) S. 750. Für die Berücksichtigung (distributiver) Gerechtigkeit in ökonomischen Analysen plädiert insb. auch Sen (Soziale Gerechtigkeit, 1998). 
Obwohl an dieser Stelle nicht abschließend beurteilt werden kann, ob ökonomische Analysen die von der Entscheidungsneutralität losgelöste Gleichmäßigkeit der Besteuerung wirklich berücksichtigen müssen, soll die Konkretisierung dieses Kriteriums im folgenden Kapitel vorangetrieben werden. Da hierdurch die bisher dargestellten Effizienzanforderungen nur eine Ergänzung erfahren, mag dies aus Sicht einer rein effizienzorientierten Betrachtung nicht stören'. Dem gegenüber kann bei dem Versuch ein Zusatznutzen entstehen, ein Kriterium zu konkretisieren, das in der gesellschaftlichen Wahrnehmung wie auch in der steuerrechtlichen Diskussion als zentrale Anforderung an eine ethisch akzeptable und verfassungskonforme Gewinnermittlung angesehen wird. Der verfassungs- und steuerrechtlichen Realität folgend, wird die steuerliche Leistungsfähigkeit als „Ausdruck des allgemeinen Gleichheitssatzes“" dabei ebenso als (evolutionär stabiles) Datum aufgefasst, wie das Einkommen als primäre Maßgröße derselben ${ }^{3}$.

\subsubsection{Reinvermögenszugangs- oder -zuwachstheorie zur Messung steuerlicher Leistungsfähigkeit?}

Sofern die Grundsatzentscheidung für das Einkommen als Maßgröße steuerlicher Leistungsfähigkeit getroffen wurde, reduziert sich das Maßgrößenproblem auf die Definition und Ermittlung desselben. Anders als bei den zumindest unter modelltheoretischen Bedingungen investitionsneutralen und damit zweckadäquaten Gewinnermittlungssystemen hat sich aber auch bei eindeutiger Ausrichtung auf die verfassungsrechtliche Gleichmäßigkeit kein Konsens über die Maßgröße steuerlicher Leistungsfähigkeit herausgebildet ${ }^{4}$. Einerseits hat es der Staat als Regulierungssubjekt und einziger Adressat

1 A.A. indes Wagner (Gegenstand und Methoden, 2004) S. 245-249.

Walz (Steuergerechtigkeit und Rechtsanwendung, 1980) S. 160.

3 Vgl. stellvertretend Herzig (IAS/IFRS, 2004) S. 18; Tipke (Resümee, 2000) S. 308 in einem Rechtsvergleich mehrerer EU-Staaten. Völlig konsistent ist die Ausrichtung am Einkommen bzw. an der Einkommenserzielung realiter aber nicht. So berücksichtigt z.B. das deutsche Steuerrecht vereinzelt Elemente der konsumtiven Einkommensverwendung und ignoriert in Ausnahmefällen Elemente der Einkommenserzielung. Dieses Spannungsverhältnis prägt letztlich auch die unterschiedlichen (theoretischen) Konzeptionen der Einkommensbesteuerung; vgl. dazu z.B. Hundsdoerfer (Einkommenserzielung und Konsum, 2002) insb. S. 3-4, 40-82; Lang (Konsumorientierung, 1999) S. 145-157.

4 Gewinn bzw. Einkommen ist immer zweckabhängig definiert. Vgl. bereits Schmalenbach (Dynamische Bilanz, 1926) S. 86: „Gewinn hat also das zu sein, was wir als Ziel unser Rechnung haben müssen. Und dieses Ziel hinwiederum wird von Zweckmäßigkeitserwägungen bestimmt"; s.a. Ballwieser (Anforderungen, 2001) S. 161; Hundsdoerfer (Einkommenserzielung und Konsum, 2002) S. 40; Pellens/Fülbier (Differenzierung der Rechnungslegungsregulierung, 2000); Wenger (Einkommensteuerliche Periodisierungsregeln, 1985/86) S. 711-734; für die internationale Literatur z.B. Johnson (AllPurpose Concept, 1954). „Richtig“ kann das Einkommen bzw. der Gewinn nur dann sein, wenn es/er einem eindeutig definierten Zweck entsprechend ermittelt ist; vgl. so auch Schneider (Rechnungswesen 1997) S. 96. Einkommen als wirtschaftstheoretischer Begriff ist übrigens nicht mit dem konkreten steuerrechtlich kodifizierten Messergebnis ,Einkommen' zu verwechseln; vgl. Schneider (Steuerlast, 2002) S. 41. Im deutschen Steuerrecht ist das konkrete Messergebnis ,Einkommen' in $\S 2$ Abs. 4 EStG kodifiziert; es wird aus der Summe bzw. dem Gesamtbetrag der Einkünfte ( $\$ 2$ Abs. 3 EStG) abgeleitet und abschließend in das ,zu versteuernde Einkommen' ( $§ 2 \mathrm{Abs} .5 \mathrm{EStG}, \S \S 7 \mathrm{Abs} .1$ und 2, 8 Abs. 1 Satz $1 \mathrm{KStG}$ ) überführt. 
der steuerlichen Gewinnermittlung bisher nicht vermocht, eine konsistente und klare Vorstellung von Gewinn bzw. Einkommen zu entwickeln ${ }^{1}$. Andererseits herrscht auch in der Literatur keine diesbezügliche Einigkeit. Allerdings lassen sich in dieser Kontroverse zumindest zwei grundlegende Konzepte erkennen, die beide für sich den Anspruch erheben, eine steuerliche Gewinnermittlung im Sinne des Leistungsfähigkeitsprinzips zu beschreiben: die Reinvermögenszugangstheorie und die Reinvermögenszuwachstheorie $^{2}$.

Beide Konzepte folgen einer vermögensbasierten Einkommenskonzeption, in der Einkommen in einer Nettobetrachtung über eine (Betriebs-)Vermögensmehrung bei vorausgesetzter nomineller Kapitalerhaltung ${ }^{3}$ gemessen wird. Unterschiede ergeben sich jedoch bei der Frage, was denn überhaupt als Betriebsvermögen anzusehen und wann eine Betriebsvermögensänderung genau verwirklicht ist. Bei der Beantwortung fällt auf, dass sich die beiden Konzepte letztlich in ihrer Interpretation des Realisationsprinzips unterscheiden, das in der Reinvermögenszugangstheorie eher restriktiver und in der Reinvermögenszuwachstheorie eher extensiver ausgelegt wird. So ist nach der Reinvermögenszugangstheorie nur das über abgeschlossene Markttransaktionen mit Dritten „realisierte“ Einkommen relevant, während die Reinvermögenszuwachstheorie zudem auch noch nicht durch derartige Markttransaktionen „realisierte“ Vermögensänderungen einbezieht, sofern diese als „wirtschaftlich verursacht" gelten. Erstere setzt also über Verpflichtungs- und Erfüllungsgeschäft vollzogene Verträge am Markt gegenüber fremden Dritten voraus, die bei letzterer keineswegs notwendig sind. Hier reicht eine

1 Vgl. zu dieser Kritik z.B. Wenger (Einkommensteuerliche Periodisierungsregeln, 1985/86) insb. S. 133-134. Gewinn und Einkommen sind deshalb „offene Rechtsprechungsbegriffe“, die der Rechtssicherheit sicherlich nicht dienen; vgl. Winnefeld (Bilanz-Handbuch, 2002) C Tz. 290, 292.

2 Diese Unterscheidung geht nach Schneider (Rechnungswesen, 1997) S. 246 auf Lion (Einkommensbegriff, 1928) zurück, der in der Analyse des Schanz-Konzeptes u.a. feststellt: „Vermögenszuwachs ist nicht dasselbe wie Vermögenszugang“ (S. 287). Vgl. auch zum Begriff des Reinvermögens Lion (Bilanzsteuerrecht, 1923) S. 2-4, der dies als „Überschuß der Aktivwerte über die Passiva“ definiert (S. 3); nach Schneider (Steuerlast, 2002) S. 44-45 ist es die bewertete, ,in Geld gemessene Menge der einer Wirtschaftseinheit zugeordneten Güter". Beide Theorien haben ihre historischen Wurzeln insb. in den z.T. unterschiedlichen Sichtweisen (vgl. dazu genauer z.B. Hundsdoerfer (Einkommenserzielung und Konsum, 2002) S. 52-65) von Haig (Concept of Income, 1921); Hermann (Staatswirthschaftliche Untersuchungen, 1832) S. 297-326, 336; Schanz (Einkommensbegriff, 1896); Schmoller (Lehre vom Einkommen, 1863) insb. S. 52-53 und Simons (Definition of Income, 1938), in deren Interpretation sich die Reinvermögenszugangstheorie im engeren Sinne (Lehre vom realisierten Reinvermögenszugang) und die Reinvermögenszuwachstheorie herausgebildet haben. Vgl. so z.B. Kraft (Steuergerechtigkeit, 1991) S. 55; Schneider (Steuerbilanzen, 1978) S. 49-50; Schneider (Rechnungswesen, 1997) S. 245-249. Die Begriffsverwendung ist keineswegs einheitlich, zumal weitere z.T. ergänzende, aber auch abweichende Varianten und Konzeptionen existieren. International wird auch vom „Schanz-Haig-Simons-Concept" oder „comprehensive tax base“ gesprochen mit nicht immer eindeutiger Zuordnung zu den deutschen Begriffen; vgl. z.B. Goode (Definition of Income, 1977) S. 7-10; Head (Comprehensive Tax Base, 1982); Shoup (Schanz Concept, 1984) jeweils m.w.N.

3 Vgl. ausführlich zum Problem der Vermögens- bzw. Kapitalerhaltung als Voraussetzung für das Vorliegen von Einkommen Schneider (Steuerbilanzen, 1978) S. 72-101; Schneider (Rechnungswesen, 1997) S. 315-317. 
Art von wie auch immer gemessener Potenzialverbesserung aus, die als Maßstab für die steuerliche Leistungsfähigkeit angesehen wird'. Vor diesem Hintergrund erwachsen auch Unterschiede in der Interpretation von Betriebsvermögen, das einerseits in seiner selbständigen Tauglichkeit für Markttransaktionen definiert wird und andererseits als jedwede Form von wirtschaftlichen Vorteilen oder Lasten, die nicht unbedingt selbst zu Gegenständen des Rechtsverkehrs taugen (müssen) und nur im Rahmen einer Gesamtveräußerung übertragen werden können.

Die Frage nun, ob über abgeschlossene Transaktionen realisierte oder in Potenzialveränderungen ausgedrückte Vermögensänderungen als (besserer) Maßstab für eine veränderte Leistungsfähigkeit anzusehen sind, kann an dieser Stelle noch nicht abschließend beantwortet werden. Letztlich bleibt die steuerliche Leistungsfähigkeit als solche zu unbestimmt, um aus ihr konkrete Anforderungen abzuleiten ${ }^{2}$. Dies mag sich allerdings in einer erweiterten Sichtweise ändern, in der die übergeordnete Gleichmäßigkeit als solche und ergänzend auch das Legalitätsprinzip berücksichtigt werden ${ }^{3}$. Wenn zusätzlich noch Verhaltensannahmen der institutionenökonomischen Analyse einfließen, ergeben sich bestimmte, in ähnlicher Form bereits formulierte Anforderungen an die steuerliche Gewinnermittlung, anhand derer sich beide Konzepte besser bewerten lassen.

Unter dem Gesichtspunkt der Gleichmäßigkeit dürfte es erst einmal sinnvoll sein, alle Personen und Sachverhalte, denen eine steuerliche Leistungsfähigkeit zuerkannt wird, gleichermaßen der Besteuerung zu unterwerfen ${ }^{4}$. Bei dieser schon aus kommutativer Gerechtigkeitsperspektive geforderten Allgemeinheit der Besteuerung steht nun vor allem die Ergebnisorientierung im Vordergrund. Gleiche Bilanzierungssachverhalte müssen hiernach auch zu gleichen Besteuerungsfolgen führen. Da Grund und Höhe der Besteuerung nicht vom Willen des Steuerpflichten abhängig sein dürfen, ist in diesem

1 In einer individuellen Sicht bezieht sich diese einkommensorientierte Potenzialverbesserung nach wie vor auf den Mittelerwerb, d.h. auf die Seite der Wohlstandsentstehung, nicht jedoch auf die Möglichkeiten zur Bedürfnisbefriedigung (Konsum), die auf die Verwendungsseite zielt. Von den insg. vier Alternativen, die sich bei der Abgrenzung von Entstehungs- und Verwendungsseite sowie marktmäßiger Verwirklichung und der Möglichkeit (Potenzial) hierzu ergeben (vgl. Schneider (Steuerlast, 2002) S. 241) werden hier also nur die zwei auf der Entstehungsseite betrachtet.

2 Vgl. stellvertretend Wagner (Neutralität und Gleichmäßigkeit, 1992) S. 4-5; Wagner (konsumorientierte Steuer, 1999) S. 17; Wagner (Neuordnung, 2002) S. 1888; ebenso stellvertretend in der diesbzgl. Kritik Schneider (Steuerlast, 2002) S. 236, 283-284; treffend dazu Herzig (IAS/IFRS, 2004) S. 18: „Das Leistungsfähigkeitsprinzip ist insoweit zwar unbestimmt, jedoch keineswegs unbestimmbar".

3 Sollte hier ein Spannungsverhältnis existieren, ist die Rangfolge dieser Prinzipien mangels Grundgesetzaussage unklar. Kraft (Steuergerechtigkeit, 1991) S. 29-34 räumt dennoch der Gesetzesbestimmtheit in einer Zielabwägung gegenüber dem Leistungsfähigkeitsprinzip nur Nebenbedingungscharakter ein; umfassend zu steuerlichen Zielkonflikten auch Jacobs (Ertragsteuerbilanz, 1971) S. 27-69; Neumark (Steuerpolitik, 1970) S. 382-390.

4 Vgl. Schneider (Gerechtigkeit, 1971) insb. S. 353 Fn. 6 in Abgrenzung von Neumark (Steuerpolitik, 1970) S. 74-121, der den Grundsatz der Allgemeinheit von dem der Gleichmäßigkeit trennt, ohne allerdings Schnittmengen zu leugnen (S. 90-92). 
Zusammenhang auch der Gefahr der „Selbsteinsteuerung“ zu begegnen” ${ }^{1}$. Dies ist nicht nur aus Gleichmäßigkeitserwägungen, sondern auch - wie bereits erläutert - aus dem Postulat der Gesetzesbestimmtheit abzuleiten. Die Gewinnermittlung müsste dazu eindeutig normiert (Eindeutigkeit und Objektiviät) ${ }^{2}$ und auch kontrolliert werden. Dabei sind explizite und implizite Wahlrechte gleichermaßen auszuschließen oder durch geeignete Maßnahmen der Objektivierung weitestgehend einzuschränken. Die Wahl alternativer, gesetzlich frei vorgegebener Rechtsfolgen durch das Steuersubjekt ist also ebenso auszuschließen wie Ermessens-, Gesetzesauslegungs- und Sachverhaltsgestaltungsspielräume. Distributive Anforderung sind an dieser Stelle also eindeutig enger gefasst als kommutative Anforderungen, die explizite Wahlrechte nicht zwingend ausschließen.

Bei Übertragung dieses grob formulierten Anforderungsprofils auf die beiden Einkommenskonzepte dürften sich Vorteile der Reinvermögenszugangstheorie ergeben, die auf der Basis einer Einzelbewertung allein auf den rechtstatsächlich erzielten Mittelerwerb im Sinne einer marktmäßigen Verwirklichung abstellt. Hier wird nur auf existierende, funktionsfähige Märkte und den dort qua Vertragsschluss zwischen zwei oder mehreren unabhängigen Marktparteien festgelegten Marktpreis als objektivierten Maßstab einer Betriebsvermögensänderung vertraut ${ }^{3}$. Dieser Objektivierungsanspruch kann als das Korrektiv unvollkommen handelnder Steuersubjekte aufgefasst werden. Demgegenüber nimmt die Reinvermögenszuwachstheorie in ihrem Streben, Potenzialverbesserungen zu bemessen, mehr oder minder starke Entobjektivierungen bei fehlender Verkehrsfähigkeit und/oder fehlenden Marktpreisen in Kauf. Über die Gesamtbewertung und insbesondere über das unvermeidbare Abgleiten in den Schätzbereich entzieht sich dieses Konzept der intersubjektiven Nachprüfbarkeit und damit letztlich auch dem Gebot der Gesetzesbestimmtheit ${ }^{4}$. Interessanterweise mag sich bei der Reinvermögenszuwachs-

1 Vgl. treffend $B F H$ v. 20.1.1999 (I R 32/98) S. 27: „Im Rahmen des nicht zur Disposition stehenden Steuerrechts kann, abgesehen von gesetzlichen Wahlrechten, Grund und Höhe der Besteuerung nicht vom Willen des Steuerpflichtigen abhängig gemacht werden“; s.a. Schneider (Steuerbilanzen, 1978) S. 31; Schneider (Steuerlast, 2002) S. 279-280.

2 Vgl. Moxter (Bilanztheorie, 1984) S. 111-121.

3 Interessant ist hier die Parallele zur sog. „Markteinkommenstheorie“, die insb. zur Systematisierung der Bemessungsgrundlage nach deutschem Einkommensteuerrecht u.a. von Kirchhof (Gutachten, 1988) und Wittmann (Markteinkommen, 1992) entwickelt worden ist; vgl. hierzu im Überblick und in Abgrenzung von anderen Einkommenskonzeptionen m.w.N. Hundsdoerfer (Einkommenserzielung und Konsum, 2002) S. 67-80; Tipke/Lang (Steuerrecht, 2002) § 8 Tz. 30-35, § 9 Tz. 50-52.

4 Vgl. hierzu z.B. Jacobs (Ertragsteuerbilanz, 1971) S. 27-29; Kraft (Steuergerechtigkeit, 1991) S. 50, 58; Wagner/Wissel (Entscheidungsneutralität, 1995) S. 67-68, die diese Kritik aber z.T. auf die (nicht deckungsgleiche) Konzeption des kapitaltheoretischen Gewinns richten. Fraglich ist auch, inwieweit eine Potenzialzuwachsbesteuerung, die bereits die Möglichkeiten zum Mittelerwerb besteuert, im Extremfall z.B. in Form einer Solleinkommens- oder Fähigkeitsbesteuerung, mit einer Gesellschaftsordnung im Einklang steht, die die individuelle Freiheit zur Lebens- und Daseinsgestaltung grundsätzlich nicht in Frage stellt; vgl. hierzu Kirchhof (Auftrag zur Besteuerung, 1985) S. 325; Schneider (Steuerlast, 2002) S. 240-254. 
theorie über die Ertragswertorientierung eine Annäherung an den kapitaltheoretischen Gewinn ergeben ${ }^{1}$, was möglicherweise der Ansicht Vorschub leistet, diese Theorie bilde eher die steuerliche Leistungsfähigkeit ab, während die Reinvermögenszugangstheorie die Gesetzesbestimmtheit zu Lasten des Leistungsfähigkeitsprinzips überbetone ${ }^{2}$. Unabhängig davon, dass hier distributive Gerechtigkeitsvorstellungen mit effizienzorientierten Anforderungen der Investitionsneutralität vermengt werden, erwächst der Zwang zur eindeutigen, objektiven und einfachen Gewinnermittlung aber auch unmittelbar aus dem Anforderungsprofil der horizontalen Steuergerechtigkeit (Gleichmäßigkeit), so dass Entobjektivierungen nicht nur dem verfassungsrechtlichen Grundsatz der Gesetzesbestimmtheit, sondern zwangsläufig auch der an der Leistungsfähigkeit gemessenen Gleichmäßigkeit der Besteuerung widersprechen ${ }^{3}$.

Die Reinvermögenszugangstheorie begegnet aber nicht nur der Unvollkommenheit agierender Individuen auf Seiten der Steuerpflichtigen. Auch der Zweifel an der Konsequenz und Systemtreue staatlicher Regulierung ist ihr immanent. Damit berücksichtigt sie unter Verwendung realtypischer Verhaltensannahmen, dass gerade das Steuerrecht dem wenig altruistischen Bemühen begrenzt rational und opportunistisch handelnder Bürokraten und Parlamentarier entspringt. Insofern ist zu vermuten, dass die bei der Reinvermögenszuwachstheorie bestehende Gefahr einer Besteuerung „unrealisierter", noch nicht am Markt verwirklichter Gewinne eben nicht durch notwendige Kompensationsmechanismen neutralisiert wird, die eine nominelle Kapitalerhaltung gewährleisten. So fehlt es hinsichtlich des sofortigen Verlustausgleichs im Sinne einer unbeschränkten Verlustsubventionierung durch den Fiskus ebenso an (nationaler wie internationaler) Umsetzungsbereitschaft wie bei der unbeschränkten Liquiditätshilfe für Steuerzahlungen und der Verzinsung eventuell zuviel entrichteter Steuern ${ }^{4}$. Unter der hier auch zu Grunde liegenden Annahme unvollkommener Kapitalmärkte, die Liquiditätsge-

1 Vgl. zu dieser Parallele ansatzweise bereits Kraft (Steuergerechtigkeit, 1991) S. 57-58, insb. Fn. 83, sowie Eichhorn (Maßgeblichkeitsprinzip, 2000) S. 100, Fn. 134. Der kapitaltheoretische Gewinn ist indes nicht mit der Reinvermögenszuwachstheorie identisch; vgl. z.B. Schneider (Investition, 1992) S. 227-229, 244; Schneider (Rechnungswesen, 1997) S. 243-250, 269-272.

2 Vgl. z.B. Eichhorn (Maßgeblichkeitsprinzip, 2001) S. 97-104; Kraft (Steuergerechtigkeit, 1991) S. 55-58.

3 Vgl. ähnlich Kirchhof (Gutachten, 1988) S. F 12-F 39, dessen verfassungsrechtliche Analyse allerdings die Markteinkommenstheorie stützen soll. Indirekt fordert Kirchhof dabei das Prinzip der „Barrealisation“ ein (S. F 16: „Einkommen entsteht im Zusammenwirken der Leistung des Einkommensbeziehers und der Zahlung seines Vertragspartners ..."); s.a. Kirchhof (Auftrag zur Besteuerung, 1985) S. 325, 327; Kröner (Verrechnungsbeschränkte Verluste, 1986) S. 21, der insb. Walz (Steuergerechtigkeit und Rechtsanwendung, 1980) interpretiert; kritisch indes m.w.N. z.B. Hundsdoerfer (Einkommenserzielung und Konsum, 2002) S. 74-80; Jacobs (Ertragsteuerbilanz, 1971) S. 16-29, der den kapitaltheoretischen Gewinn als theoretisch optimalen Ausdruck der Gleichmäßigkeit ansieht, dabei allerdings Verstösse gegen die Rechtssicherheit identifiziert; Tipke/Lang (Steuerrecht, 2002) §8 Tz. 31.

4 So gefordert bei Schneider (Steuerbilanzen, 1978) S. 56-58; Schneider (Rechnungswesen, 1997) S. 248-249; Schneider (IAS als Besteuerungsgrundlage, 2003) S. 301-302; Schneider (Tugend, 2004) S. 295; s.a. Elschen (Institutionale oder personale Besteuerung, 1994) S. 321-328 zur Liquiditätsfrage aus der Gerechtigkeitsperspektive. 
sichtspunkte erst relevant werden lässt, geht Schneider als Befürworter der Reinvermögenszugangstheorie soweit, den ,realisierten“ Vermögenszugang an das Konzept der Barrealisation zu knüpfen. Hiernach setzt „Realisation“ neben der marktlich vollzogenen Lieferung oder Leistung auch den Zugang der korrespondierenden Einzahlung ${ }^{1}$ voraus. Nur so könne sichergestellt werden, dass Steuern als gewinnabhängige Zwangsauszahlungen erst geleistet werden, wenn zuvor die entsprechenden Einzahlungen geflossen und verfügbar sind ${ }^{2}$. Ein derartiges ,reines Realisationsprinzip“" ${ }^{\text {(3) }}$ zielt auf die Ermittlung eines tatsächlich erzielten und entziehbaren Gewinns $a b^{4}$.

Die Ablehnung der Reinvermögenszuwachstheorie und ihrer Ausrichtung an Potenzialveränderungen findet sich auch auf internationaler Ebene. So erteilt z.B. Nobes in einem Versuch, eine gerechte steuerliche Gewinnermittlung zu entwerfen, jeder Neubewertung von Wirtschaftsgütern als Ausdruck von Potenzialveränderungen eine Absage. Statt dessen sei bei dem steuerlichen Einkommen allein auf die marktliche Realisation abzustellen. „On balance, my conclusion is that concepts other than ,sold' are too vague for tax purposes.... The conclusion is that the need for objectivity and certainty argues in favour of the tax system's traditional reliance on transactions and realisation"s. Nobes geht allerdings nicht soweit, auch den tatsächlichen Zahlungsvorgang vorauszusetzen. Mit der stärkeren Orientierung an Zahlungsvorgängen gehen jedoch Objektivierungsvorteile einher, die aus effizienz- wie gerechtigkeitsgetriebener Sicht zu befürworten $\operatorname{sind}^{6}$. Auch führt die Zahlungsorientierung zu einer gewissen Nähe zu den investitions-

1 Obwohl Schneider von Einnahmen spricht, stellt er primär auf Zahlungen ab; vgl. Schneider (Steuerlast, 2002) S. 284-285; vgl. zur untergeordneten Rolle dieser terminologischen Differenzierung Schneider (Rechnungswesen, 1997) S. 48-50, 58.

2 Vgl. Schneider (Sieben Thesen, 1970) S. 1699-1702; Schneider (Realisationsprinzip, 1976) S. 116; Schneider (Steuerbilanzen, 1978) S. 53-71; Schneider (Besteuerung unrealisierter Vermögenswertänderungen, 1986); Schneider (Steuerlast, 2002) S. 284-287; Schneider (Tugend, 2004) S. 303; passend dazu auch Tipke/Lang (Steuerrecht, 2002) § 4 Tz. 102: „Steuerliche Leistungsfähigkeit setzt Liquidität der Steuerzahlung voraus" [Hervorhebung im Original]; grundlegend zur Forderung nach der Barrealisation in der steuerlichen Gewinnermittlung bereits Pohmer (Gewinnrealisation, 1957); s.a. Jacobs (Ertragsteuerbilanz, 1971) S. 122-125; Schneider (Erfolgsermittlung als Rechnungsziel, 1978) in der Auseinandersetzung mit dem strengen Realisationsprinzip von Kosiol (Pagatorische Bilanz, 1976). Die Diskussion um dieses Prinzip wird auch aus Perspektive der Handelsbilanz gefuihrt; vgl. z.B. Leffson (GoB, 1987) S. 258-260; Siegel (Metamorphosen des Realisationsprinzips, 1992) S. 592-595.

3 Schneider (Steuerbilanzen, 1978) S. 60.

4 Vgl. Herzig (Internationalisierung, 2000) S. 113, der ein derartiges Realisationsprinzip als „Eckpfeiler jedweder steuerbilanziellen Gewinnermittlung“" ansieht.

5 Nobes (Framework for the Taxable Income, 2004) S. 40, der zudem konstatiert: "This means that any revaluations of assets should be ignored" (S. 45).

6 Vgl. u.a. Weber-Grellet (Reform des Bilanzsteuerrechts, 1998) S. 1348-1349, der deshalb für eine (Einnahme-)Überschussrechnung als Alternative zur Bilanzierung plädiert, während er selbst noch einige Jahre zuvor für eine ,periodengerechte“ Gewinnermittlung eintrat; vgl. Weber-Grellet (Maßgeblichkeitsschutz, 1994) S. 289. Mit der Orientierung an Zahlungsvorgängen knüpft das so verstandene Konzept des realisierten Reinvermögenszugangs aus deutscher Sicht an das Prinzip der Einnahmeüberschussrechnung gem. §4 Abs. 3 EStG an; vgl. zu Gemeinsamkeiten und Unterschieden Schneider (Steuerbilanzen, 1978) S. 70-71; Schneider (Tugend, 2004) S. 296-304. 
neutralen Konzepten. Vom kapitaltheoretischen Gewinn unterscheidet sie sich „nur“ dadurch, dass die entobjektivierte Ertragswertabschreibung durch die Periodisierung der Anschaffungsauszahlung ersetzt wird. Obwohl das Konzept der Barrealisation für Einzahlungen wie Auszahlungen gleichermaßen gilt, wird die Periodisierung beim abnutzbaren Anlagevermögen ebenso wie die Verlustvorwegnahme (Imparitätsprinzip) solange als Hilfslösung akzeptiert, wie es an dem unbeschränkten Verlustausgleich bzw. zeitlich und betraglich unbeschränkten Verlustrücktrag und -vortrag mit Verzinsung der Ansprüche mangelt'. Dabei werden drohende Manipulationsspielräume in diesem $\mathrm{Zu}$ sammenhang durchaus erkannt. Durch einfache und klar normierte Periodisierungs- und Verlustvorwegnahmeregeln sollten sie soweit wie möglich begrenzt werden, wobei verbleibende Ermessensspielräume risikoneutral, d.h. weder zu vorsichtig, noch zu optimistisch, zu handhaben sind ${ }^{2}$.

Mit dem Konzept des realisierten Reinvermögenszugangs liegt von Schneider eine enge Interpretation des Einkommensbegriffs vor, welche die Einkommens- bzw. Gewinnermittlung von idealtypischen Annahmen löst und an Märkten und Zahlungen objektiviert. Da dies nicht nur verfassungsrechtlichen, sondern in weiten Teilen auch ökonomischen Vorgaben entspricht, erwachsen daraus weitere normative Anforderung an die steuerliche Gewinnermittlung, die abschließend noch einmal kurz aufgeführt werden ${ }^{3}$ :

- Das steuerliche Betriebsvermögen definiert sich über dessen selbständige Tauglichkeit für einzelne Markttransaktionen.

- Das Betriebsvermögen wird einzeln erfasst und bewertet. Das einzeln separierbare Element ist das Wirtschaftsgut.

- Gewinn bzw. Einkommen als Betriebsvermögensänderung ist in seiner Gesamtheit zu erfassen (Totalitätsprinzip, Totaleinkommen ${ }^{4}$ ).

- Es gilt ein eng interpretiertes Realisationsprinzip nach dem Konzept der Barrealisation.

- Einziger „Wertermittlungsgenerator“ ist der Markt und dessen (funktionsfähiger) Preisfindungsmechanismus.

1 Vgl. Schneider (Sieben Thesen, 1970) S. 1701-1704; Schneider (Steuerbilanzen, 1978) S. 62-68; Schneider (Rechnungswesen, 1997) S. 281-284 Schneider (Steuerlast, 2002) S. 287-290; ausführlich zur Periodisierung über Abschreibungen Schneider (Abschreibungsverfahren, 1974); Schneider (Anlagenabschreibung, 1974). Nach Kraft (Steuergerechtigkeit, 1991) S. 80-85 kommen hier letztlich wieder Teilelemente der Reinvermögenszuwachstheorie zum Ausdruck.

2 Vgl. Schneider (Steuerbilanzen, 1978) S. 68-69; Schneider (Steuerlast, 2002) S. 288.

3 Vgl. zu einem ähnlichen Versuch, aus dem Konzept von Schneider einen normativen Beurteilungskatalog abzuleiten Gröning (Steuerbilanzielle Gewinnermittlung, 2002) S. 64-65. Vgl. auch die Parallelen zum Anforderungsprofil von Moxter (Bilanztheorie, 1984) S. 111-121, der der steuerlichen Gewinnermittlung (nach deutschem Recht) eine stark objektivierungsgeprägte „Fortführungsvermögensbilanz" zu Grunde legt, insb. aber das Realisationsprinzip weiter interpretiert.

4 Vgl. auch Lang (Bemessungsgrundlage, 2000) S. 137-146. 
- Es gilt das Prinzip der Abschnittsbesteuerung. Der Gewinnbegriff bezieht sich auf diesen (vergangenen) Zeitabschnitt, der in der Regel das Geschäftsjahr umfasst.

- Das Konzept der Barrealisation gilt für Gewinne wie Verluste gleichermaßen. Eine Vorwegnahme drohender Verluste (Imparitätsprinzip) darf nicht mit Objektivierung verwechselt werden ${ }^{1}$ und sollte nur als zweit- bzw. drittbeste Lösung für die steuerliche Gewinnermittlung akzeptiert werden, wenn ein sofortiger Verlustausgleich nicht existiert und auch nicht durch einen unbeschränkten Verlustrücktrag und -vortrag ersetzt worden ist.

- Bis zur Realisation sind Anschaffungs- und Herstellungsauszahlungen der relevante Wertmaßstab.

- Es gilt der Grundsatz der Periodisierung². Deshalb sind Anschaffungs- und Herstellungsauszahlungen bei abnutzbaren Wirtschaftsgütern auf mehrere Perioden zu verteilen. Die Verrechnung als Betriebsausgabe wird damit auf tatsächlich geleistete Zahlungen beschränkt.

- Der Gleichmäßigkeit und Gesetzesbestimmtheit der Besteuerung folgend gibt es keine Wahlrechte bei der steuerlichen Gewinnermittlung. Dies gilt für explizite, gesetzlich formulierte Wahlrechte und, soweit möglich, auch für implizite Wahlrechte in Form von Ermessensspielräumen.

- Gewinnermittlungsregeln sind insofern eindeutig, klar und so einfach wie möglich formuliert.

\section{Abgrenzung der rechnungslegenden Einheit}

In den bisherigen Ausführungen sind die Anforderungen an die steuerliche Gewinnermittlung im Allgemeinen identifiziert und analysiert worden. Diese Anforderungen gelten somit auch für eine konsolidierte steuerliche Gewinnermittlung. Für sie ist gleichermaßen zu fordern, dass sie im Idealfall Entscheidungsneutralität sowie Durchführungseffizienz gewährleistet und den Verfassungsregeln der Gesetzesbestimmtheit und Steuergerechtigkeit entspricht. Abgesehen davon, dass schon für die inhaltliche Ausgestaltung der Gewinnermittlung im Allgemeinen kein homogener, aufeinander abgestimmter und alle Fragen klärender Beurteilungsrahmen existiert, ist allerdings fraglich, ob das hierzu abgeleitete Anforderungsprofil auch den besonderen Aspekten der Konsolidierung gerecht werden kann. Da die konsolidierte steuerliche Gewinnermittlung definitionsgemäß aus einer Zusammenfassung bestimmter Einzelgewinnermittlungen besteht, fehlt es bisher noch an Erkenntnissen darüber, wer diese singulären Einheiten sind, auf die sich die Einzelgewinnermittlung bezieht, und welche dieser Einheiten in die Konsolidierung einbezogen werden. In diesem Zusammenhang steht die bisher nicht

1 Vgl. Herzig (Internationalisierung, 2000) S. 112.

2 Vgl. zum Vorteil von Periodisierung und Vermögensvergleich gegenüber reinen Zahlungsstromrechnungen Schneider (Tugend, 2004) S. 296-304. 
problematisierte Frage nach dem Besteuerungssubjekt und, damit einhergehend, nach der rechnungslegenden Einheit im Vordergrund.

\subsection{Rechnungslegende Einheit als Abbild unternehmerischer Organisation}

Die steuerliche Gewinnermittlung stellt - wie jede Form der Rechnungslegung - auf eine bestimmte Bezugsgröße ab: die rechnungslegende Einheit. Mit der rechnungslegenden Einheit wird sowohl Subjekt als auch Objekt der Rechnungslegung festlegt, in dem die Fragen beantwortet werden, wer der Rechnungslegende ist und, vor allem, auf wen sich die Rechnungslegungsinformationen beziehen ${ }^{1}$.

Wenn die steuerliche Gewinnermittlung auf einer vermögensbasierten Einkommenskonzeption beruht, sind diesbezügliche Antworten notwendig, um überhaupt über Ansatz und Bewertung entscheiden zu können. So wird mittels der Abgrenzung der rechnungslegenden Einheit bestimmt, welches Vermögen bzw. welche Schulden zu berücksichtigen sind und welche(s) nicht. Diese Abgrenzung bestimmt aber nicht nur Vermögen und Schulden und das hieraus im Saldo als Nettovermögen resultierende Eigenkapi$\mathrm{tal}^{2}$, sondern auch die Zuordnung entsprechender Stromgrößen, wie Betriebseinnahmen und -ausgaben bzw. Aufwendungen und Erträge ${ }^{3}$. Gerade die Ertragsrealisation bei Liefer- und Leistungsbeziehungen beruht auf einer Grenzziehung zwischen „innen“ und „außen“, bei deren Überschreitung - in Abhängigkeit von der konkreten Ausgestaltung des Realisationsprinzips ${ }^{4}$ - ein Umsatz als eingetreten gilt. Im Zuge des Konzepts des realisierten Reinvermögenszugangs ist mit dieser Überschreitung in der Regel ein Wertsprung von den Anschaffungs- und Herstellungsausgaben hin zum erzielten Umsatzerlös verbunden. Über die umsatzbezogene Ertragsrealisation wirkt sich die rechnungslegende Einheit aber auch auf die Periodisierung von Ausgaben aus und damit insgesamt auf Zeitpunkt und Höhe der Gewinn- bzw. Ergebnisrealisation. Wird die Grenze nach

1 Vgl. ähnlich auch Sürken (Abgrenzung der wirtschaftlichen Einheit, 1999) S. 7; grundlegend bereits $A A A$ (Accounting, 1957); AAA (Entity Concept, 1965); Gilman (Accounting Concepts, 1939) S. 25 26, 47-48; später u.a. auch Coughlan (Theory of Accounts, 1965) S. 151-152; Hendriksen/Breda (Accounting Theory, 1992) S. 145-146; Rutherford (Financial Reporting Theory, 2000) S. 170-174.

2 Vgl. Streim (Eigenkapital, 1998) S. 202-204.

3 Streng genommen dürften sich die Aufwendungen und Erträge auf der Basis der deutschen Rechtssituation und Terminologie nur auf die Vorstufe der bilanziellen Gewinnermittlung beziehen, die dann in die steuerrechtlich allein relevanten Betriebseinnahmen und -ausgaben überführt werden.

4 Das Realisationsprinzip legt nur die Art und Weise dieser Überschreitung fest und hat die Grenzziehung an sich nicht zum Gegenstand. Während das Konzept des realisierten Reinvermögenszugangs hier auf das Prinzip der umsatzbezogenen Ertragsrealisation abstellt und selbiges um die Barrealisation erweitert, zielt die Reinvermögenszuwachstheorie auf (u.U. nur fiktive) Marktpreise (NettoveräuBerungspreise), die zwischen den Marktpartnern „innen“ und „außen“ ausgehandelt werden. Vgl. zur Wirkungsweise des Realisationsprinzips z.B. Budde/Förschle (Realisationsprinzip, 1998) S. 595-598. 
,außen“ indes nicht überschritten, handelt es sich um marktferne Lieferungen oder Leistungen ,an sich selbst“, aus denen keine steuerbaren Einnahmen resultieren können'.

Sofern sich die steuerliche Gewinnermittlung nicht auf Individuen, sondern auf unternehmerische Organisationen bezieht, ist die Vorstellung, Präzisierung und Abgrenzung einer rechnungslegenden Einheit untrennbar mit einem bestimmten Verständnis dieser Organisationen verbunden. Gemeinhin wird an dieser Stelle in der betriebswirtschaftlichen Literatur zur Rechnungslegung und Besteuerung nur auf die ,wirtschaftliche' oder ,rechtliche' Einheit verwiesen und damit auf zwei Begriffe, die im besten Fall nur ein unklares Bild von dem jeweils dahinter verborgenen Verständnis erzeugen. Dies liegt einerseits darin begründet, dass es an weitergehenden Definitionen dieser beiden Begriffe und an tiefergehenden Analysen, die über die Identifikation rechtlicher oder wirtschaftlicher (Un-)Selbständigkeit hinausgehen, oft mangelt ${ }^{2}$. Dies könnte aber auch daran liegen, dass in der Rechtswissenschaft, vor allem aber in der Ökonomie, ein klares, konkretes und allgemein akzeptiertes Bild unternehmerischer Organisation nicht existiert $^{3}$. Spannungen sind damit bereits vorprogrammiert, da die steuerliche Gewinnermittlung wie jede Form der Rechnungslegung im Gegensatz dazu auf einer präzisen Vorstellung von einer rechnungslegenden Einheit beruhen muss und schon technisch mit diesbezüglichen Unklarheiten nicht umzugehen vermag. Um sich bei der Definition und Abgrenzung der rechnungslegenden Einheit aber nicht völlig der Gefahr willkürlicher Ad-hoc-Festlegungen auszusetzen, bedarf es trotz aller Schwierigkeiten der Auseinandersetzung mit dem komplexen Phänomen unternehmerischer Organisation.

Aus ökonomischer Sicht versucht die Theorie der Unternehmung Antworten auf die Fragen zu geben, was letztlich eine Unternehmung ausmacht und wie sie abzugrenzen ist $^{4}$. Wie im Folgenden gezeigt wird, ist der Begriff der Unternehmung in diesem $\mathrm{Zu}$ sammenhang bewusst gewählt worden, um die ökonomische Perspektive zu verdeutlichen und um diese auch terminologisch von der rechtsformorientierten Unternehmenssicht zu unterscheiden. Die entsprechenden Erkenntnisse der Theorie der Unternehmung

1 Vgl. Kirchhof(Gutachten, 1988) S. F 24, F 26-F 27.

2 Vgl. so insb. die betriebswirtschaftliche (Lehrbuch-)Literatur zur Konzernrechnungslegung, die, wenn überhaupt, nur den (engeren) aktienrechtlichen Konzernsachverhalt zur begrifflichen Klärung bemüht; vgl. stellvertretend Coenenberg (Jahresabschluss, 2003) S. 513; Baetge/Kirsch/Thiele (Konzernbilanzen, 2002) S. 28 i.V.m. S. 1-7; vgl. früh Schönbucher (konsolidierte Bilanz, 1966) S. 68-75 m.w.N.

3 Zudem wird die analytische Relevanz der Unternehmensgrenzen z.B. von Klein/Crawford/Alchian (Vertical Integration, 1978) S. 326 bezweifelt: "the conventional sharp distinction between markets and firms may have little general analytical importance"; ähnlich auch Jensen/Meckling (Theory of the Firm, 1976) S. 311: ,it makes little or no sense to try to distinguish those things which are ,inside' the firm ... from those things that are ,outside' of it".

4 Das Bild einer Unternehmung wird im Bewusstsein der Öffentlichkeit oftmals auch von soziologischen und psychologischen Aspekten determiniert, die aber im Folgenden - entgegen der Forderung mancher Ökonomen - keine Rolle spielen sollen; vgl. anders z.B. Wagner (Grenzen, 1994) S. 126180. Letztlich sind diese interdisziplinären Annäherungen nach Schneider (Geschichte, 2001) S. 168, 262 immer auch der „Gefahr des Dilettantismus“ ausgesetzt. 
werden im Folgenden aufgearbeitet und anschließend der rechtsorientierten Unternehmenssicht gegenübergestellt. Auf der Basis der dabei gewonnenen Erkenntnisse wird untersucht, welche Perspektive letztlich für die steuerliche Gewinnermittlung als Abgrenzungsleitbild taugt.

\subsection{Alternative Sichtweisen unternehmerischer Organisation}

\subsubsection{Institutionenökonomisches Modell der Unternehmung}

\subsubsection{Unternehmung als Vertragsnetzwerk}

Aus Sicht der institutionenökonomisch geprägten Theorie der Unternehmung ist die Unternehmung eine Organisationsform ökonomischer Aktivität, die nach Aufgabe der engen Dichotomie von Markt und Unternehmung ${ }^{1}$ einen Spezialfall einer NichtmarktOrganisation markiert ${ }^{2}$. Unternehmungen sind damit in erster Linie Organisationen, die in der Terminologie der Neuen Institutionenökonomik Institutionen mit den dazugehörigen Menschen umfassen ${ }^{3}$. Ihre Verbindungen untereinander ist im Wesentlichen vertraglicher Natur ${ }^{4}$. Ähnlich der Gleichgewichtsbildung auf den Märkten wird mittels eines Vertragsgeflechtes ein Interessensausgleich zwischen den beteiligten Individuen erreicht. Eine Unternehmung kann deshalb in einem ersten Schritt nach Jensen/Meckling als Nexus von Vertragsbeziehungen zwischen Individuen verstanden werden .

In der erstmals von Alchian und Demsetz propagierten Sicht, in der eine Unternehmung die organisatorischen Voraussetzungen für die gegenüber der Einzelproduktion überlegene Teamproduktion schafft, handelt es sich bei diesen Individuen um die Ressourcen-

1 Vgl. dazu prägend Coase (Nature of the Firm, 1937).

2 Vgl. North (Institutional Change, 1990) S. 73; Richter/Furubotn (Neue Institutionenökonomik, 2003) S. 318-329.

3 Vgl. Simon (Organizations, 1991); s.a. Richter (Neue Institutionenökonomik, 1998) S. 332-333; Richter/Furubotn (Neue Institutionenökonomik, 2003) S. 10 mit Verweis auf North (Institutional Change, 1990); Schmoller (Grundriß der Allgemeinen Volkswirtschaftslehre, 1900, S. 61; s.a. Kap. II.2.1.1.

4 Dies gilt auch, obwohl alternative Organisationsbeziehungen beschrieben werden, die z.B. auf der weitgehenden Übereinstimmung in den Zielen der Organisationsmitglieder beruhen; vgl. z.B. zur Clan-Organisation u.a. Ouchi (Clans, 1980); zuvor u.a. schon Barnard (Functions of the Executive, 1938) S. 82-83, 86-89, der den "common purpose" als zentrales Organisationselement ansieht. Das hierfür vorausgesetzte Ausmaß an Gemeinschaftsgefühl, an gemeinsamen Werten und Glaubensformen ist jedoch für die in einer Gesellschaft und Unternehmung gelebten Kultur eher untypisch und hat die Bedeutung von Verträgen nicht einschränken können; vgl. Schoppe et al. (Theorie der Unternehmung, 1995) S. 255. Zudem müsste auch hier gefragt werden, ob nicht doch Verträge - allerdings weit entfernt von jenen im Rechtssinne - vorliegen.

5 Vgl. Jensen/Meckling (Theory of the Firm, 1976) S. 310-311. 
eigentümer, die ihre Ressourcen ${ }^{1}$ zur gemeinsamen Nutzung zusammenlegen (Ressourcenpoolung $)^{2}$. Ausgehend von dieser ersten Definition ist die Unternehmung ein mitunter höchst komplexes Geflecht multilateraler Vertragsbeziehungen zwischen den relevanten Individuen oder Aggregationen von Individuen.

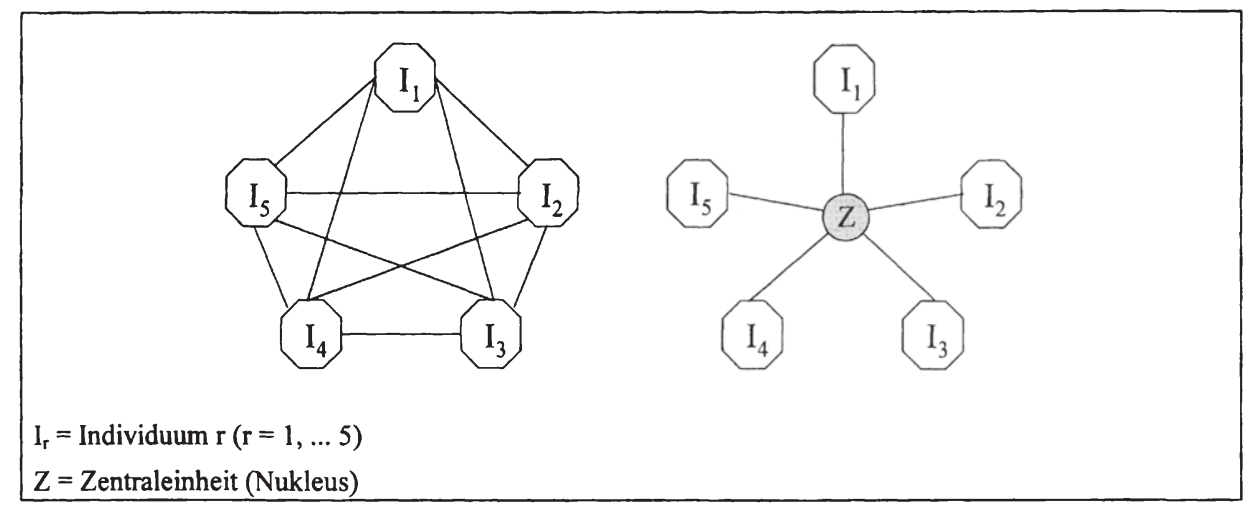

Abb. 3: Unternehmung als Netzwerk multilateraler Vertragsbeziehungen und als nukleusbasiertes Netzwerk bilateraler Vertragsbeziehungen

Auch wenn in diesem Vertragsgeflecht so etwas wie kollektive Interessen der Koalition $^{3}$, „team spirit" ${ }^{\text {“4 }}$ oder gar Unternehmungsidentität ${ }^{5}$ entstehen können, ist die Unternehmung erst einmal nur ein abstraktes Phänomen, bei dem die über Verträge miteinander verbundenen Individuen als einzig kontraktfähige Einheiten im Vordergrund stehen. Coase und später auch Alchian/Demsetz haben aber an dieser Stelle schon die transaktionskostengünstige und damit effiziente Institution einer zentralen Autorität als selbstän-

1 Vgl. z.B. Vanberg (Markt und Organisation, 1982) S. 10-11 m.w.N., der einen sehr weiten Ressourcenbegriff verwendet und darunter materielle und immaterielle Güter subsumiert, die durch übertragbare Mittel ebenso wie unveräußerliche, personengebundene Fähigkeiten und Fertigkeiten ergänzt werden; ähnlich z.B. Valcárcel (Theorie der Unternehmung, 2002) S. 79-86, die finanzielle Ressourcen, tangible und intangible Sach- und Humanressourcen einbezieht.

2 Vgl. Alchian/Demsetz (Economic Organization, 1972) insb. S. 779-781, die allerdings nur von vollständigen Verträgen ausgehen; vgl. Schoppe et al. (Theorie der Unternehmung, 1995) S. 142; zu dem Begriff der Ressourcenpoolung z.B. Penrose (Theory, 1995) S. 24, 149; vgl. zu ressourcenorientierten Modellen der Unternehmung auch Valcárcel (Theorie der Unternehmung, 2002); Vanberg (Markt und Organisation, 1982). Ursprünglich standen der Messkostenansatz und der Transaktionskostenansatz/Governance-Ansatz konkurrierend nebeneinander, bis sie u.a. von Alchian/Woodward (Theory of the Firm, 1987); Klein/Crawford/Alchian (Vertical Integration, 1978) komplementär zueinander ausgestaltet wurden. Vgl. zu dieser Entwicklung z.B. Richter/Furubotn (Neue Institutionenökonomik, 2003) S. 402-413, 496-504. Vgl. zu kollektiven Zielen insb. Cyert/March (Theorie der Unternehmung, 1995) S. 29-49; s.a. Richter/Furubotn (Neue Institutionenökonomik, 2003) S. 410-411 mit Verweis auf Miller (Managerial Dilemmas, 1992).

4 Alchian/Demsetz (Economic Organization, 1972) S.790.

5 Vgl. Wagner (Grenzen, 1994) S. 73, 126-177, der allerdings von "Unternehmensidentität" spricht. 
dig kontraktfähige Einheit angedeutet ${ }^{\prime}$, mittels derer multilaterale in bilaterale Vertragsbeziehungen überführt werden können (Abb. 3). Die ex ante und ex post kostensparende Wirkung bilateraler Verträge ist schon durch ihre von (n-1)n/2 auf $n$ reduzierte Zahl offenkundig ${ }^{2}$.

Die Neue Institutionenökonomik hat die selbständige kontraktfähige Einheit (Zentraleinheit, Nukleus) als effizienten Ausgangspunkt relationaler Vertragsbeziehungen nicht weiter problematisiert; an dieser Stelle setzen - wenn überhaupt - evolutorische Ansätze an. In institutionenökonomischer Sicht wird hier lediglich ein Individuum als Unternehmer (oder Hegemon) angenommen ${ }^{3}$ oder auch eine kontraktfähige Sache, die vereinzelt - als ,pars pro toto“ - mit Unternehmung bezeichnet wird. Um die soeben als Vertragsgeflecht definierte Unternehmung als Gesamtgebilde nicht mit ihrer verselbständigten Zentraleinheit zu verwechseln, soll im Falle einer sachlich verselbständigten Zentraleinheit von dem ,Unternehmen' gesprochen werden. Während der Unternehmer meist in Personalunion auch Ressourceneigentümer ist, stellt das Unternehmen in der Terminologie von Jensen/Meckling nur eine Rechtsfiktion (,legal fiction“) ${ }^{4}$ dar, die den Ressourceneigentümern als effizienzsteigerndes Hilfsmittel dient. Es fungiert als eine Art Ausführungsorgan, das in vertretungstheoretischer Hinsicht gegenüber den Ressourceneigentümern (Prinzipal) die Agentenrolle einnimmt. Streng genommen ist dabei noch zwischen dem Unternehmen als abstrakte Rechtsfiktion und seinen konkreten persönlichen Vertretern, den Managern, zu unterscheiden. Auch kann die Funktion der Zentraleinheit auf die Bewältigung sonstiger Organisationsprobleme ausgeweitet werden, wie Alchian/Demsetz gezeigt haben, die zur Vermeidung von Trittbrettfahrerproblemen innerhalb der Unternehmung eine zentrale Überwachungsinstanz für nötig erachten, hierfür allerdings nur den Eigentümer-Unternehmer als geeignet ansehen ${ }^{5}$.

Bei genauerer Betrachtung der einer Unternehmung zugrunde liegenden Vertragsbeziehungen kann es sich - anders als z.B. bei Alchian/Demsetz, Alchian/Woodward oder

1 Vgl. Coase (Nature of the Firm, 1937) S. 391-392; allerdings hat Coase hier wohl die gesamte Organisation (Unternehmung) gemeint und aus der Zahl deutlich reduzierter Verträge ein Argument für ihre Transaktionskostengünstigkeit (gegenüber dem Markt) abgeleitet. Vgl. zudem Alchian/Demsetz (Economic Organization, 1972) S. 782-783, 791-794.

2 Vgl. auch Kunz (Marktsystem, 1985) S. 111. Im Beispielfall $(\mathrm{n}=5)$ reduziert sich die Zahl der Verträge von zehn auf fünf. Gemessen an der Zahl der Verträge haben multilaterale Vertragskonstruktionen nur bei zwei Individuen Vorteile; bei dreien herrscht Indifferenz und Vorteile für das nukleusbasierte Netzwerk entstehen erst ab vier Individuen.

3 Vgl. bereits Coase (Nature of the Firm, 1937) S. 392, der von "some authority (an 'entrepreneur')" spricht.

4 Vgl. Jensen/Meckling (Theory of the Firm, 1976) S. 310-311; später z.B. auch Casson (The Entrepreneur 1982) S. 215.

5 Vgl. Alchian/Demsetz (Economic Organization, 1972) insb. S. 794. Vgl. aber auch hier bereits Coase (Nature of the Firm, 1937) S. 392, der dem Unternehmer die Aufgabe übertrug, ,to direct the resources". Einen (Literatur-)Überblick über weitere Kritik an Alchian/Demsetz findet sich z.B. bei Valcárcel (Theorie der Unternehmung, 2002) S. 18-21. 
Jensen/Meckling ${ }^{1}$ - nur um unvollständige Verträge handeln, mittels derer die begrenzt rational und opportunistisch handelnden Ressourceneigentümer miteinander verbunden sind. Diese Verträge bilden insbesondere in der Sichtweise von Williamson den geeigneten institutionellen Rahmen bei unsicheren und häufig durchgeführten Transaktionen mit hoher Faktorspezifität. So müssen sich z.B. die Eigentümer unternehmensspezifischen Kapitals oder unternehmensspezifischer Arbeitskraft vor dem Verlust ihrer Quasirenten schützen (,hold-up“-Problematik) ${ }^{2}$. Das Effizienzargument reduzierter Transaktionskosten verkörpert unter diesen Bedingungen auch die Integrationsanreize weg von der Marktorganisation, hin zur Hierarchie und den vereinheitlichten Überwachungs- und Durchsetzungssystemen (,corporate governance structures“), die eine Unternehmung kennzeichnen ${ }^{3}$.

Das Bestehen unvollständiger Verträge deutet aber noch nicht zwingend auf die Existenz einer Unternehmung hin. Diese Verträge stellen nur eine notwendige, aber noch keine hinreichende Existenzbedingung dar. Ist die Unternehmung in der Terminologie von Williamson durch ein vereinheitlichtes Überwachungs- und Durchsetzungssystem gekennzeichnet und damit durch Vereinigung zuvor autonomer Einheiten auf der Basis unvollständiger Verträge entstanden, so können diese Verträge auch weiterhin zwischen autonomen, ansonsten voneinander unabhängigen Organisationen bestehen (hybride Organisationsformen mit sog. zweiseitigen Überwachungs- und Durchsetzungssystemen $)^{4}$. Diese Vertragsbeziehung ist bei häufigen Transaktionen mit weniger spezifischer Faktorspezifität sinnvoll und kennzeichnet z.B. enge, langfristige Geschäftsbeziehungen zwischen zwei Unternehmungen, wo eine zweiseitige Kontrolle ausreicht, um die jeweiligen Quasirenten zu schützen.

Vor diesem Hintergrund steht jedoch die Frage im Raum, wann genau ein unvollständiger Vertrag auf Integration hindeutet. Wann ist die Autonomie des Vertragspartners im ökonomischen Sinne nicht mehr gegeben, wann liegt Vereinigung vor, die auf die Existenz einer Unternehmung hindeutet? Die Antwort lässt sich möglicherweise unter Rückgriff auf die frühere (formale) Vertragstheorie ableiten. Grossman/Hart haben in ihrer Theorie der vertikalen Integration auf der Basis unvollständiger Verträge herausgearbeitet, dass es letztlich auf die Übertragung des Eigentums ankommt, genauer: auf die Ü-

1 Vgl. Alchian/Demsetz (Economic Organization, 1972); Alchian/Woodward (Theory of the Firm, 1987); Jensen/Meckling (Theory of the Firm, 1976), die auf vollständigen Verträgen aufbauen.

2 Vgl. dazu erläuternd z.B. Milgrom/Roberts (Economics, Organization and Management, 1992) S. $307-$ 308; Ricketts (Business Enterprise, 2002) S. 36-38.

3 Vgl. Williamson (Economic Institutions, 1985) S. 72-79. Vgl. z.B. die empirischen Belege in der Übersicht von Shelanski/Klein (Empirical Research in Transaction Cost Economics, 1995) oder auch Ipsen (Erklärungspotential von Williamsons Theorie, 2002), der das Wechselspiel gelöster hold-upProbleme und neu entstehender Agency-Probleme innerhalb der Hierarchie näher betrachtet; erläuternd auch Schuler (Unternehmensgrenzen, 2002) S. 78-94. Vgl. zum hierarchischen Charakter der Unternehmung Casson (Hierarchical, 1994).

4 Vgl. Williamson (Economic Institutions, 1985) S. 75-77 zur „bilateral governance“. 
bertragung der residualen Entscheidungsrechte an den jeweiligen Vermögenswerten (,assets"). Residuale Entscheidungsrechte werden dabei als die Kontrollrechte verstanden, die ex ante nicht explizit vertraglich festgelegt und zugeordnet worden sind ${ }^{1}$. Analog der Denkwelt von Williamson kann die Gefahr opportunistischen Handelns und damit einhergehende Ineffizienzen bei den ex ante getätigten, beziehungsspezifischen Investitionen im Rahmen eines unvollständigen Vertrages nur durch vereinheitlichte Kontrolle überwunden werden. Diese Ineffizienzen drücken sich auch darin aus, dass die Partei ohne residuale Entscheidungs- und Kontrollrechte bei zweiseitiger Kontrolle nur suboptimale Anreize zur Durchführung beziehungsspezifischer Investitionen besitzt, während diese Investitionsanreize bei Integration sehr viel höher sind ${ }^{2}$.

Die Vertragsperspektive wird bei Grossman/Hart durch eine stärkere Berücksichtigung der Vermögenswerte und damit der Ressourcen begrenzt, in dem sich die Unternehmung nur über die Gesamtheit der unter einheitlichem Eigentum stehenden Vermögenswerte definiert. Die Zunahme dieser Werte beschreibt dann die (weitere) Integration über Ausweitung der Unternehmungsgrenzen. Grossman/Hart unterscheiden zwischen genau festgelegten, spezifischen Rechten auf der einen Seite und residualen Rechten, d.h. den Rechten, die eben nicht im Rahmen unvollständiger Verträge festgelegt worden sind, auf der anderen. Wenn es einer Vertragspartei nun zuviel Kosten verursacht, die gewünschte Menge spezieller Entscheidungs- und Kontrollrechte an den Vermögenswerten der anderen Partei vertraglich detailliert festzulegen, kann es für sie optimal sein, die gesamten residualen Rechte zu erwerben. Dieser Erwerb kennzeichnet dann den Übergang des Eigentums ${ }^{3}$. Eigentümer ist damit die Vertragspartei, die die vertraglich nicht spezifizierten Rechte an der Ressourcenverwendung besitzt und damit die eigentliche Kontrolle über die Ressource ausübt.

Obwohl Grossman/Hart allgemein von "assets" sprechen, werden die Ressourcen, die eine Unternehmung determinieren, in der interpretierenden Literatur oft auf das Sachvermögen beschränkt ${ }^{4}$. Diese Beschränkung scheint allerdings eng. So müsste insbeson-

1 Vgl. Grossman/Hart (Costs and Benefits of Ownership, 1986). Williamson lässt in seiner Theorie die Eigentumsfrage indes offen; vgl. Richter/Furubotn (Neue Institutionenökonomik, 2003) S. 405.

2 Vgl. Grossman/Hart (Costs and Benefits of Ownership, 1986) S. 697-709, 716-718; s.a. Hart (Firms, 1995) S. 29-92. Neben dem hier angesprochenen Unterinvestitionseffekt bei der nicht integrierten Struktur ist auch gezeigt worden, dass der Investitionsanreiz bei der integrierten Struktur gar zu wettbewerbspolitisch unerwünschten Überinvestitionseffekten führen kann; vgl. dazu m.w.N. Richter/Furubotn (Neue Institutionenökonomik, 2003) S. 301-302.

3 Vgl. Grossman/Hart (Costs and Benefits of Ownership, 1986) S. 692-695. Ähnlich Jensen/Meckling (Theory of the Firm, 1976) S. 311, die hier aber schon auf die Residualansprüche an den Vermögenswerten und den daraus resultierenden Cash Flows abstellen.

4 Vgl. insb. Hart/Moore (Nature of the Firm, 1990) S. 1121, 1150; Hart (Firms, 1995) S. 56-59; Hart (Theory of the Firm, 1996) S. 35-359, die aber aus der Kontrolle des Sachvermögens die indirekte Kontrolle des Humanvermögens ableiten; s.a. Erlei/Leschke/Sauerland (Neue Institutionenökonomik, 1999) S. 197; Rajan/Zingales (Power, 1998) S. 388; Ricketts (Business Enterprise, 2002) S. 119; Wagner (Grenzen, 1994) S. 40. 
dere auch das Finanzvermögen unter diese Ressourcen subsumiert werden'. Problematischer erscheint indes die Berücksichtigung des immateriellen (Human-)Vermögens. So erscheint es fraglich, ob das Integrationsmerkmal residualer Entscheidungs- und Kontrollrechte auch auf Individuen und deren Handlungen übertragen werden kann. Schließlich lassen sich Fähigkeiten und Wissen einer Person regelmäßig nur durch Handlungen dieser Personen an Dritte ,übermitteln“. Gelänge dies, könnte eine Arbeitgeber-Arbeitnehmer-Beziehung von einer normalen Auftragsbeziehung mit Externen unterschieden werden ${ }^{2}$. Über das Einkaufen residualer Rechte an den Handlungen anderer würden Aktivitäten internalisiert und Unternehmungsgrenzen ebenfalls um diese Form von Humanvermögen erweitert.

In einer Welt, in der Sklavenarbeit geächtet ist, dürften hier allerdings realiter große Abgrenzungsschwierigkeiten verbleiben ${ }^{3}$. Obwohl innerhalb eines hierarchischen Weisungssystems bestimmte Zugriffsrechte auf das Humanvermögen vertraglich fixiert sind, dürften die residualen Entscheidungs- und Kontrollrechte hieran letztlich immer bei den betroffenen Individuen verbleiben ${ }^{4}$. Ökonomisches Eigentum hieran wäre demnach kaum übertragbar, so dass der Ausschluss dieser Form des Humanvermögens aus der ressourcenorientierten Unternehmungsabgrenzung von Grosman/Hart quasi definitionsgemäß vorgegeben worden ist ${ }^{5}$. Eine Ausnahme stellt wohl dasjenige immaterielle Vermögen dar, das von Individuen gelöst und einer Eigentumsübertragung zugänglich gemacht werden kann, wie z.B. dokumentiertes Wissen oder bestimmte Rechte. Dieses Vermögen müsste insofern ebenfalls zu den Ressourcen gezählt werden, die eine Unternehmung determinieren.

Als mittelbare Ressource im Sinne von Grossman/Hart dürfte im Übrigen auch das Unternehmen als vertraglicher Anknüpfungspunkt für weitere Ressourcen gelten ${ }^{6}$. So ist auch vorstellbar, dass ein Unternehmen als sachliche Zentraleinheit das Eigentum an einer anderen sachlichen Zentraleinheit erwirbt. Das Prinzip der Zentraleinheit bleibt

1 Vgl. Holmstrom/Tirole (Theory of the Firm, 1989) S. 74. Das Finanzvermögen dürfte i.S.v. Hart (Firms, 1995) S. 58 auch unter ,nonhuman assets“ subsumiert werden.

2 Vgl. Grossman/Hart (Costs and Benefits of Ownership, 1986) S. 717. Zweifelnd allerdings Wagner (Grenzen, 1994) insb. S. 126-177, der den Grossman/Hart-Ansatz auf das Sachvermögen reduziert und bei humanvermögensintensiven Unternehmungen stärker soziologische und psychologische Sichtweisen einfordert.

3 Vgl. z.B. Klein/Crawford/Alchian (Vertical Integration, 1978) S. 313; Milgrom/Roberts (Economics, Organization and Management, 1992) S. 290, 313.

4 Die Unternehmung (in concreto das Unternehmen als Vertragspartner) verfügt letztlich qua Arbeitsvertrag nur über bestimmte, unmittelbare (Entscheidungs- und Kontroll-)Rechte. Holmstrom/Tirole (Theory of the Firm, 1989) S. 72 bezeichnen Humanvermögen deshalb als "inalienable asset".

5 Vgl. Holmstrom/Tirole (Theory of the Firm, 1989) S. 72; Valcárcel (Theorie der Unternehmung, 2002) S. 72-73. Kritisch hierzu insb. Rajan/Zingales (Power, 1998), die betonen, ,,a firm is more than a simple collection of assets“ (S. 388) und die ihr modifiziertes Abgrenzungskonzept (,access to critical resources") um das Humanvermögen erweitern.

6 Vgl. z.B. Putterman (Ownership, 1993) S. 245: „firm as an ownable asset“. 
damit grundsätzlich gewahrt, nur die organisatorische Struktur der Unternehmung verändert sich. Es existiert damit nicht mehr nur ein zentraler vertraglicher Anknüpfungspunkt innerhalb der Unternehmung, sondern u.U. ${ }^{1}$ mehrere. So kann es durchaus effizienter sein, die Unternehmung in Subsysteme zu zergliedern (,hierarchical decomposition principle ${ }^{\text {" } 2}$ ), denen ihrerseits sachliche Sub-Zentraleinheiten zugeordnet sind (Abb. 4). Es handelt sich auch bei einer Mehrzahl von Zentraleinheiten immer noch um Hilfskonstruktionen mit Vertreter-Charakter, nur mit dem Unterschied, dass mehrstufige Vertretungsbeziehungen entstanden sind. Ein Unternehmer als persönliche Zentraleinheit eignet sich hierbei im Übrigen nur als erwerbende Partei und damit als Hierarchiespitze, da an Individuen selbst kaum Eigentum erworben werden kann.

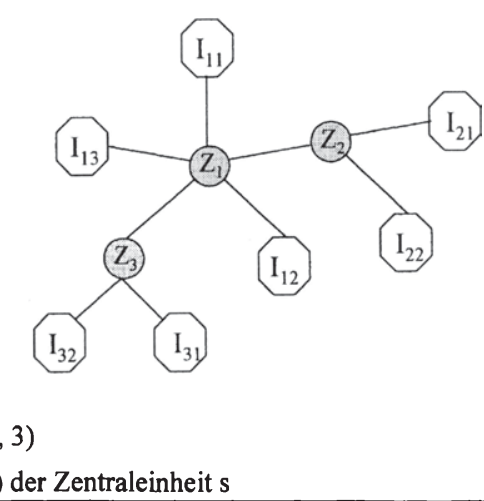

$Z_{s}=$ Zentraleinheit $s(s=1,2,3)$
$I_{s r}=$ Individuum $r(r=1,2,3)$ der Zentraleinheit $s$

Abb. 4: Unternehmung als nukleusbasiertes Netzwerk mit mehreren Subsystemen

Auch wenn Grossman/Hart für die auf bestimmte Ressourcen reduzierte Unternehmungssicht und ihre Beschränkung der Ex-ante Vertragsverhandlungen auf die Festlegung der Eigentümerstruktur kritisiert worden sind ${ }^{3}$ und zudem zwischen Eigentum und Kontrolle nicht stärker differenzieren ${ }^{4}$, haben sie mit der Verteilung der Kontroll- und Entscheidungsrechte an (bestimmten) Vermögenswerten einen Maßstab zur Unterneh-

1 Denkbar wären zwei Fälle: die beiden Zentraleinheiten "verschmelzen" zu einer einzigen kontraktfähigen Einheit oder bleiben als zwei Einheiten bestehen, die dann allerdings in einem hierarchischem Verhältnis zueinander stehen.

2

Williamson (Modern Corporation, 1981) S. 1550; s.a. Milgrom/Roberts (Economics, Organization and Management, 1992) S. 544-552; einen kurzen Literaturüberblick geben z.B. Holmstrom/Tirole (Theory of the Firm, 1989) S. 125-126; empirische Belege zur Effizienz von unternehmenskontrollierten Unternehmen finden sich z.B. bei Kaulmann (Unternehmungstheorie, 1987) S. 90-218.

3 Vgl. dazu m.w.N. z.B. Schweizer (Eigentumsrechte, 2001) S. 37; Valcárcel (Theorie der Unternehmung, 2002) S. 72-73.

4 Vgl. z.B. Valcárcel (Theorie der Unternehmung, 2002) S. 72. Eine diesbezügliche Trennung ist später z.B. von Hart (Firms, 1995) S. 126-209 oder Holmstrom/Tirole (Theory of the Firm, 1989) S. 86-106 in einer Interpretation und Erweiterung des ursprünglichen Modells vollzogen worden. Vgl. zu einigen der vielen Modifikationen, die im Gefolge von Grossman/Hart entstanden sind, Schweizer (Vertragstheorie, 1999) S. 239-281. 
mungsabgrenzung liefern können. Hierbei wird im Übrigen explizit auf residuale Entscheidungs- und Kontrollrechte abgestellt und nicht auf residuale Verfügungsrechte in ihrer vierfachen Ausprägung (Nutzung, Veränderung, Veräußerung sowie Aneignung der Erträge). Obwohl eine große Schnittmenge existieren dürfte, gewinnt diese Betrachtung an Bedeutung, wenn Verfügungsrechte geteilt bzw. „ausgedünnt"1 werden und es eines klaren Abgrenzungskriteriums bedarf. Der in der Literatur unterbreitete Vorschlag, das Grossman/Hart-Modell auf alle residualen Verfügungsrechte auszuweiten ${ }^{2}$, würde dieses klare Kriterium indes nur aufweichen.

\subsubsection{Parallelen zur evolutorischen Sicht}

Das institutionenökonomische Modell der Unternehmung hat auch aus evolutorischer Perspektive Bestand. So wird hier gleichermaßen der Organisationscharakter der Unternehmung anerkannt. Nach von Hayek beruht die Unternehmung auf Organisation bzw. Anordnung, ist aber selbst wieder ein Subsystem des Marktes und damit auch Element der spontanen Ordnung ${ }^{3}$. Nach Nelson/Winter ist sie ein Geflecht organisatorischer Routinen $^{4}$, verstanden als geordnete Menge an beobachtbaren Handlungsabläufen („Unternehmungsprozessen" $)^{5}$. Diese soll als zentrale und regelgeleitete Koordinationsinstitution künftige Handlungsabläufe weniger unsicher machen, in dem den beteiligten Individuen eine vernünftige Planung insbesondere auch der Anpassungsfähigkeit an Fremdereignisse mit unerwarteten Folgen erleichtert wird ${ }^{6}$.

Hinter dieser Sicht einer Unternehmung als „Ort ressourcensparender Komplexitätsreduktion $^{\text {“7 }}$ in einer Umgebung konstitutioneller Unwissenheit ${ }^{8}$ lässt sich eine weitere, deutliche Parallele zu ihrer transaktionskostenreduzierenden Wirkung in der Neuen Institutionenökonomik erkennen. So verwundert es nicht, dass auch in der Evolutorik die Vertragsstruktur der Unternehmung hervorgehoben wird ${ }^{9}$, obgleich diese um eine wis-

1 Vgl. Furubotn/Pejovich (Property Rights, 1972) S. 1146-1148, die von ,attenuation“ sprechen.

2 Vgl. insb. Erlei/Leschke/Sauerland (Neue Institutionenökonomik, 1999) S. 197; dazu auch Valcárcel (Theorie der Unternehmung, 2002) S. 72-73.

3 Vgl. zum Dualismus von spontaner Ordnung und Anordnung von Hayek (Recht, Band 1, 1980) S. 59 , 69-79; ähnlich sogar Williamson (Spontaneous and Intentional Governance, 1991); erläuternd z.B. Vanberg (Markt und Organisation, 1982) S. 88-105.

4 Vgl. Nelson/Winter (Evolutionary Theory, 1982) S. 72-136.

5 Vgl. Schneider (Theorie der Unternehmung, 1997) S. 55.

$6 \mathrm{Vgl}$. Schneider (Investition, 1992) S. 41. Insofern wird auch das Konzept der „bounded rationality“ anerkannt; vgl. so z.B. Winter (On Coase, 1988) S. 173-174.

7 Kunz (Marktsystem, 1985) S. 108.

8 Vgl. Kunz (Marktsystem, 1985) S. 1, 62-133. Vgl. von Hayek (Rechtsordnung, 1969) S. 171, der die „Tatsache unabänderlichen Unwissens konkreter Umstände“ als „konstitutionelle Unwissenheit“ bezeichnet.

9 Vgl. insb. Kunz (Marktsystem, 1985) S. 110; Foss (Evolutionary Theories, 1996) S. 23; implizit auch Schneider (Investition, 1992) S. 42. 
sensorientierte, stärker auf das Humanvermögen fokussierende Interpretation ergänzt wird („organizations know more than what their contracts can say“1). Dies drückt sich insbesondere darin aus, dass ein besonderes Augenmerk auf dem Unternehmer bzw. dem unternehmerischen Element liegt, dessen Erforschung ganz im Gegensatz zur Neuen Institutionenökonomik im Vordergrund steht. Obwohl es auch hier eines zentralen vertraglichen Anknüpfungspunktes bedarf, wird sehr viel stärker die dynamische Funktion des Unternehmers herausgestellt, der in Ungleichgewichtssituationen auf unvollkommenen Märkten Anpassungs- und Wettbewerbsprozesse vorantreibt. Sachliche Zentraleinheiten im Sinne verselbständigter Rechtsfiktionen werden gleichermaßen anerkannt, da das unternehmerische Element hier bei den personellen Vertretern dieser Zentraleinheit angesiedelt wird: den Managern. Ausgehend von Cantillon, der bereits im 18. Jahrhundert in der „Verringerung von Einkommensunsicherheiten“ oder „Suche nach Spekulationsgewinnen“ erste dynamische Aspekte formuliert hat ${ }^{2}$, u.a. über Schumpeters dynamischen (Pionier-)Unternehmer und Kirzners, von Mises oder von Hayeks „Arbitrageur" und „Informationsverwerter"63 hat sich heute eine Lehre dynamischer Unternehmerfunktionen durchgesetzt, die die evolutorische Sichtweise der Unternehmung entscheidend prägt ${ }^{4}$. Schneider sieht deshalb in der Unternehmung eine evolutorische Institution, die Unsicherheit durch das Ausüben von drei bedeutsamen Unternehmerfunktionen reduziert: Neben der reinen Koordinationsaufgabe zum Erhalt der Unternehmung fallen hierunter die Übernahme von Einkommensunsicherheiten anderer und das Erzielen von Arbitrage- bzw. Spekulationsgewinnen ${ }^{5}$.

1 Kogut/Zander (Knowledge of the Firm, 1992) S. 383; ähnlich Foss (Evolutionary Theories, 1996) S. 14; Nelson/Winter (Evolutionary Theory, 1982) S. 59-65; Winter (On Coase, 1988) S. 175: „,business firms are organizations that know how to do things". Interessant auch Vanberg (Markt und Organisation, 1982), der das Problem kollektiven bzw. korporativen Handelns in den Mittelpunkt seiner Untersuchung rückt. Allerdings gibt es die stärkere Fokussierung auf das Humanvermögen auch in der institutionenökonomischen Theorie der Unternehmung; z.B. bei Rajan/Zingales (Power, 1998).

2 Vgl. Schneider (Grundlagen, 1995) S. 35-36; Schneider (Unternehmer, 2001) S. 7; Schneider (Geschichte, 2001) S. 157-161, 511-521 zum Leben und Werk von Cantillon. Schneider (Grundlagen, 1995) S. 14-20, 24-25; Schneider (Theorie der Unternehmung, 1997) S. 47 hat die Verringerung von Einkommensunsicherheiten selbst zum Hauptmerkmal einer Unternehmung und zum Forschungsleitbild der Betriebswirtschaftslehre gekürt.

3 Vgl. u.a. Schumpeter (Theorie der wirtschaftlichen Entwicklung, 1912); von Hayek (Sinn des Wettbewerbs, 1952); von Hayek (Wirtschaftstheorie, 1952); Kirzner (Unternehmertum, 1978); Kirzner (Marktdynamik, 1988); von Mises (Nationalökonomie, 1940).

4 Ein Überblick über die Entwicklung und Fülle dynamischer Unternehmerfunktionen, auch in ihrer Abgrenzung zu den statischen Unternehmerfunktionen, gibt Schneider (Unternehmer, 2001) S. 6-13; vgl. auch Ricketts (Business Enterprise, 2002) S. 53-85; Schoppe et al. (Theorie der Unternehmung, 1995) S. 281-286. Die Verbindung von Unternehmertheorie (Theory of the Entrepreneur) und Theorie der Unternehmung (Theory of the Firm) wurde insb. durch Casson (The Entrepreneur 1982) S. 157324 und letztlich auch Schneider (Theorie der Unternehmung, 1997) vorangetrieben.

5 Vgl. Schneider (Theorie der Unternehmung, 1997) S. 46-59; Schneider (Unternehmer, 2001) S. 9; Schneider (Geschichte, 2001) S. 509-602. Dies entspricht weitgehend herrschender Meinung; vgl. dazu Schoppe et al. (Theorie der Unternehmung, 1995) S. 284-286. 
Klärungsbedarf bleibt aber weiterhin bei der genauen Unternehmungsabgrenzung. Die Grenzen zwischen spontaner Ordnung und Anordnungen erscheinen abstrakt. Ähnlich zu Coase kann diese Grenze in dem Ort invarianter Arten der Komplexitätsreduktion gesehen werden ${ }^{1}$. Während die spontane, ungeplante und zweckunabhängige Ordnung auf evolutionären Marktprozessen beruht und ,das Produkt der Handlungen vieler Menschen, aber nicht das Resultat eines menschlichen Entwurfs ${ }^{\text {"2 }}$ beschreibt, basiert die Anordnung auf vorsätzlicher, bewusster Planung und zentraler Steuerung. Wenn auch Unternehmungsgrenzen weniger normativ als in der Neuen Institutionenökonomik hergeleitet werden (Vorwurf der „Anmaßung von Wissen“"3), sondern sich eher evolutorisch entwickeln und über ihren langfristigen Gebrauch zunehmend verfestigen ${ }^{4}$, bedarf es bei der Anordnung schon vom Wortsinn her einer hierarchischen Struktur, die wie bei Williamson die Möglichkeit auch der Durchsetzung und Überwachung beinhaltet. Derartige Möglichkeiten verlangen (vertraglich) gesicherte Entscheidungs- und Kontrollbefugnisse, die letztlich, ganz im Sinne von Grossman/Hart, die entsprechenden (residualen) Rechte voraussetzen. Bei stärkerer Fokussierung auf die Unternehmerfunktionen könnte die Unternehmungsabgrenzung auch auf dem Kriterium der Einkommensunsicherheiten basieren, wonach die Vertragsparteien zur Unternehmung zählen, die an den Einkommensunsicherheiten beteiligt sind. Obwohl dieses Konzept bei Ausdünnung von Verfügungsrechten einen Abgrenzungsmaßstab zur Verfügung stellt, steht es trotz einer sicherlich hohen Schnittmenge in Konkurrenz zu dem Konzept von Grossman/Hart, das sich auf bestimmte Ressourcen konzentriert und einzig auf residuale Entscheidungs- und Kontrollrechte abstellt. Eine völlig eigenständige, neue Form der Unternehmungsabgrenzung ist der evolutorischen Theorie der Unternehmung damit aber nicht zu entnehmen ${ }^{5}$.

1 Vgl. Kunz (Marktsystem, 1985) S. 111 mit Verweis auf Graf(Muster-Voraussagen, 1978).

2 Von Hayek (Recht, Band 1, 1980) S. 59; ähnlich auch von Hayek (Ergebnisse menschlichen Handelns, 1969) S. 97-107. Für Kunz (Marktsystem, 1985) S. 20-21, existiert neben dieser spontanen noch eine semispontane Ordnung, bei der eine Erklärung mittels der ,invisible hand" nicht mehr ausreicht und einer vertragstheoretischen Ergänzung bedarf.

3 Vgl. von Hayek (Pretence of Knowledge, 1989) S. 3-7. Zur Unmöglichkeit, evolutorische Prozesse voraussagen zu können, vgl. von Hayek (Recht, Band 1, 1980) S. 41.

4 Vgl. Kunz (Marktsystem, 1985) S. 117, der anstelle des Unternehmungsbegriffs aber den des Unternehmens benutzt: „In ihrer Auseinandersetzung mit ihrer ständig sich wandelnden Umwelt werden stets diejenigen Unternehmen (Organisationen) die besten Überlebenschancen haben, die die effizientesten Regeln für die interne Handelnskoordination und Ressourcenallokation herausgefunden haben". In dynamischer Sicht werden sich die Grenzen jedoch ständig weiter verändern, so dass Abgrenzungen nur zeitpunktbezogen möglich sind; vgl. dazu Winter (On Coase, 1988) S. 176, der die Unternehmungsgrenzen mit denen eines Regenwaldes oder einer Mausfamilie vergleicht (,The thing ,knows' ... how to reproduce itself.").

5 Nach Meinung von Foss (Evolutionary Theories, 1996) S. 7 ist die Evolutorik zur Abgrenzung der Unternehmung auch noch nicht in der Lage. 


\subsubsection{Schlussfolgerungen für ein ökonomisches Modell der Unternehmung}

Die Schwierigkeit, eine Unternehmung zu definieren und abzugrenzen, liegt schon in der keineswegs einheitlichen wirtschaftstheoretischen Sichtweise begründet. Wenn hier dennoch der Versuch unternommen wird, gewisse Erkenntnisse zu einem ökonomischen Modell der Unternehmung zusammenzufassen, so geht dies zwangsläufig mit einer Entscheidung zu Gunsten einer dieser wirtschaftstheoretischen Sichtweisen einher. Wie gezeigt, eignet sich noch am ehesten die Neue Institutionenökonomik dazu, ein abgrenzbares Modell der Unternehmung zu zeichnen, das darüber hinaus auch aus evolutorischer Perspektive Bestand haben dürfte. Die dort gewonnenen Erkenntnisse lassen sich in den folgenden Punkten zusammenfassen:

- Die Unternehmung wird als Netzwerk unvollständiger Verträge definiert, wobei persönliche (Unternehmer) oder sachliche Zentraleinheiten (Unternehmen) als zentrale vertragliche Anknüpfungspunkte Effizienzvorteile besitzen.

- Die Vertragsperspektive wird durch eine stärkere Berücksichtigung der Vermögenswerte bzw. Ressourcen erweitert, in dem sich die Unternehmung über die Gesamtheit der unter einheitlichem Eigentum stehenden Vermögenswerte definiert. Ressourceneigentum ergibt sich aus den residualen Entscheidungs- und Kontrollrechten. Mangels Übertragbarkeit dieser Rechte am Humanvermögen ist diese Unternehmungssicht zwangsläufig beschränkt.

- Die Unternehmung wird als Hierarchiesystem, verstanden als vereinheitlichtes Überwachungs- und Durchsetzungssystem, wahrgenommen. Dies entspricht einem vereinheitlichten Kontrollsystem. (,The firm is a unit of control ${ }^{61}$ ).

- Die Unternehmung als Kontrollsystem unterliegt der Logik nach nicht der Kontrolle durch eine andere Unternehmung. Diese andere Unternehmung wäre immer mit in die Unternehmungsgrenzen einzubeziehen. Die Unternehmung ist demnach quasi definitionsgemäß durch ,wirtschaftliche Autonomie“ geprägt ${ }^{2}$.

- Hybride Koordinationsformen basieren zwar ebenfalls auf unvollständigen Verträgen, sind aber durch ein zweiseitiges Kontrollsystem gekennzeichnet. Trotz großer Abgrenzungsschwierigkeiten sind diese Systeme der Unternehmung nicht zuzurechen.

- Die Unternehmung kann ein oder mehrere persönliche oder auch sachliche Zentraleinheiten aufweisen. Diese liefern für die Unternehmung als solche oder auch nur für einzelne Subsysteme der Unternehmung die vertraglichen Anknüpfungspunkte. Da diese Zentraleinheiten über Eigentumsbeziehungen untereinander verknüpft sein müssen, können auf untergeordneter Ebene nur sachliche Zentraleinheiten (Unter-

Casson (The Entrepreneur, 1982) S. 295; s.a. Casson (Hierarchical, 1994).

Vgl. auch Theisen (Konzern, 2000) S. 17, der darin die zentrale Unternehmungseigenschaft erkennt. 
nehmen) in Frage kommen. Sachliche Zentraleinheiten werden durch Manager vertreten.

- Die Unternehmungsabgrenzung bleibt unberührt von sonstigen Vertragsbeziehungen, in die die Unternehmung involviert ist ${ }^{1}$. Nebend den hybriden Kooperationsformen sind dies insbesondere die marktlichen Verträge auf (neo-)klassischer Basis.

\subsubsection{Rechtsformorientierte Unternehmenssicht}

Das ökonomische Modell der Unternehmung spiegelt sich in der Rechtsrealität nur eingeschränkt wider. Hier dominiert statt dessen die rechtsformorientierte Unternehmenssicht, die im Folgenden kurz aus deutscher Perspektive beleuchtet wird. Dabei gewonnene Erkenntnisse dürften auch für andere Rechtsräume typisch sein.

In der deutschen Rechtswissenschaft hat sich für die unternehmerische Organisation der Begriff des Unternehmens durchgesetzt, ohne das damit ein einheitliches Begriffsverständnis einher geht ${ }^{2}$. Der Unternehmensbegriff ist zwar geläufig, bleibt aber letztlich unbestimmt ${ }^{3}$. Das deutsche Unternehmensrecht als dasjenige Rechtsgebiet, das die grundlegenden institutionellen Rahmenbedingungen der Unternehmen zusammenfasst ${ }^{4}$, sei nach Ballerstedt ,rechtspolitisch wie wissenschaftlich so wenig abgeschlossen, daß eine Definition des Begriffs ,Unternehmen' dank ihrer notwendig apodiktischen Formu-

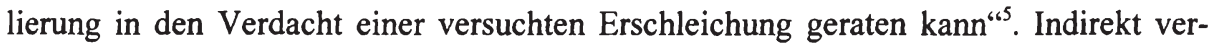
sucht sich Ballerstedt aber doch an einer Definition, wenn er das Unternehmensrecht als „Inbegriff der Rechtsnormen“ beschreibt, „die das Unternehmen als sozialen Verband der in ihm durch Kapitalbeiträge oder personale Leistungen kooperierenden Rechtssubjekte und als Institution der Wirtschaftsverfassung betreffen ${ }^{\text {‘6 }}$.

Diese und andere ${ }^{7}$ Definitionsversuche zeigen auf, dass sich die rechtswissenschaftliche Sicht ökonomischen Erkentnissen keineswegs verschliesst. So wird insbesondere der

1 Dies widerspricht z.B. der weiten (verhaltenswissenschaftlichen) Sicht von Cyert/March (Theorie der Unternehmung, 1995) S. 29-30, die die Unternehmung als Koalition vieler Individuen, wie z.B. Manager, Arbeiter, Anteilseigner, Lieferanten, Kunden, Finanz- und Aufsichtsbehörden, und damit so weit definieren, dass sie selbst die Abgrenzung einer solchen Koalition für unmöglich halten.

2 Vgl. z.B. Schmidt (Gesellschaftsrecht, 2002) S. 494, 935-936.

3 Vgl. Luttermann (Unternehmen, 1998) S. 1; ähnlich auch Kübler (Gesellschaftsrecht, 1999) S. 36-37; allgemein zur Problematik unbestimmter Rechtsbegriffe Tipke (Auslegung, 1986) S. 1.

4 Es handelt sich allerdings um kein abgrenzbares Rechtsgebiet; vgl. insb. zu Unterschieden und Gemeinsamkeiten mit dem Gesellschafts- und Handelsrecht Schilling (Rechtsform, 1977). Vgl. zur Anwendung des Unternehmensbegriffs im Steuerrecht Dornfeld (Steuerfähigkeit, 1966) S. 16-22. Ballerstedt (Unternehmensrecht, 1977) S. 22, der das Unternehmen selbst auch als ,ökonomischsoziales Substrat des Kaufmannsbegriffs" bezeichnet (S. 15).

6 Ballerstedt (Unternehmensrecht, 1971) S. 484.

7 Vgl. den Literaturüberblick zum juristischen Unternehmensbegriff bei Wiedemann (Gesellschaftsrecht, 1980) S. 307; vgl. stellvertretend für nicht-deutsche Sichtweisen Epstein/Freer/Roberts (Business Structures, 2002) S. 135-140; Palmiter (Corporations, 2003) S. 5-7. 
Organisationscharakter anerkannt ${ }^{1}$ und eine, wenn auch nebulöse wirtschaftliche Einheit miteinander in Verbindung stehender Rechtssubjekte identifiziert ${ }^{2}$. Dies verdeutlicht auch die mancherorts vorgenommene Differenzierung in ,Unternehmen' als abstrakte wirtschaftliche Einheit einerseits und ,Unternehmensträger' als Rechtssubjekt und konkreter Bezugspunkt aller Rechte und Pflichten andererseits ${ }^{3}$. Dahinter verbirgt sich letztlich nichts anderes als die Vorstellung von einem nukleusbasierten Netzwerk bilateraler Vertragsbeziehungen, wobei der Unternehmens- oder Rechtsträger die Zentraleinheit markiert. Neben der deutlich engeren Vertragsdefinition, die sich auf Verträge im Rechtssinne beschränkt ${ }^{4}$, liegt der Schwerpunkt rechtswissenschaftlicher Betrachtungen bis heute auf der Zentraleinheit als Unternehmensträger, die es rechtlich auszugestalten, in die Rechtsordnung zu integrieren und angesichts veränderter Umweltbedingungen auch weiterzuentwickeln gilt. Diese starke Fokussierung geht regelmäßig damit einher, das Unternehmen ,rechtstechnisch zu funktionalisieren" ${ }^{\text {"5 }}$, es mit dem Rechtsträger gleichzusetzen und als Rechtssubjekt zu begreifen. In diesem Sinne wird die Unternehmung regelmäßig auf den Unternehmer bzw. das Unternehmen reduziert.

Als diesbezügliche Anküpfungspunkte fungieren die natürliche Person und die juristische Person des Privatrechts. Der Personenbegriff kennzeichnet nach Radbruch einen Gleichheitsbegriff, der dem von kommutativen Gerechtigkeitsvorstellungen getragenen Privatrecht zu Grunde liegt. Mit ihm würden völlig unterschiedliche, persönliche wie auch sachliche Vollsubjekte der Realität in künstlich gleiche Rechtssubjekte transformiert. „Alle Personen, die physischen wie die juristischen sind Geschöpfe der Rechtsordnung. ... Person sein, heißt Selbstzweck sein" ${ }^{\text {“6 }}$. Während die natürliche Person die persönliche Zentraleinheit (Unternehmer) beschreibt, beschreibt die juristische das rechtstechnische Pendant zu der von Jensen/Meckling zutreffend als Rechtsfiktion bezeichneten sachlichen Zentraleinheit ${ }^{7}$. Die juristische Person besitzt unabhängig von hinter ihr stehenden natürlichen Personen (Individuen) uneingeschränkte Rechtsfähigkeit und wird damit zum selbständigen Träger von Rechten und Pflichten ${ }^{8}$. Ihre konkrete Ausgestaltung vollzieht sich in unterschiedlichen Rechtsformvarianten und obliegt dem Gesellschaftsrecht als dem „Recht der privatrechtlichen Personenvereinigungen,

1 Vgl. bereits Isay (Recht am Unternehmen, 1910) z.B. S. 41; s.a. Luttermann (Unternehmen, 1998) S. 3 unter Rückgriff auf ökonomische (und soziologische) Literatur; Wiedemann (Gesellschaftsrecht, 1980) S. 296, 307-311. Vgl. Mülbert (Aktiengesellschaft, 1996) S. 36 mit Bezug auf den Konzern.

2 Vgl. bereits Isay (Recht am Unternehmen, 1910) S. 43-137; beispielhaft zu dem Versuch, die ökonomische Theorie der Unternehmung rechtswissenschaftlich zu beleuchten Easterbrook/Fishel (Corporate Law, 1991); Orts (Legal Theory, 1998).

3 Vgl. Luttermann (Unternehmen, 1998) S. 3-4.

Vgl. Orts (Legal Theory, 1998) S. 267, 291-295.

Luttermann (Unternehmen, 1998) S. 3.

Radbruch (Rechtsphilosophie, 2003) S. 125.

Vgl. Kap. II.3.2.1.1.

Vgl. grundlegend zur juristischen Person Wiedemann (Gesellschaftsrecht, 1980) S. 188-242. 
die zur Erreichung eines bestimmten gemeinsamen Zwecks durch Rechtsgeschäft gegründet werden“1.

Gesellschaftsrechtlich stehen sich in Deutschland und wohl auch weltweit körperschaftlich organisierte Vereine einschließlich deren Sonderformen als verselbständigte Vermögensmassen und individualrechtlich ausgestaltete (Personen-)Gesellschaften gegenüber. Nur die erste Gruppe von Rechtsformen, zu denen insbesondere die Kapitalgesellschaften ( $\mathrm{AG}, \mathrm{GmbH}, \mathrm{KGaA})$ zählen, markiert dabei die Eigenschaft einer juristischen Person $^{2}$. Aus dem ökonomischen Verständnis heraus stellen auch nur sie eine vollwertige sachliche Zentraleinheit als Unternehmen dar. Anders als bei den körperschaftlich organisierten Rechtsformen, stehen bei der zweiten Gruppe, den Gesellschaften im engeren Sinne (Personengesellschaften), die individuellen Gesellschafter als natürliche Personen im Vordergrund, da sie hier die einzigen Rechtssubjekte und damit auch Rechtsträger sind ${ }^{3}$.

Obwohl die juristische Person immer eine vollwertige sachliche Zentraleinheit markiert, tritt das einzelne Individuum hier gegenüber der Körperschaft - in Abhängigkeit von der gesetzlichen und privatvertraglichen Ausgestaltung derselben und dem rechtsphilosophischen Standpunkt des Betrachters - unterschiedlich weit in den Hintergrund. Einen Extremfall markiert die kapitalmarktnotierte Kapitalgesellschaft in der Variante der großen Publikumsgesellschaft. Sie steht besonders in der Gefahr, nur noch als eine von den Interessen der Individuen völlig losgelöste, quasi entpersonalisierte Sach-Institution wahrgenommen zu werden, für die in Deutschland der Begriff des „Unternehmens an sich“ geprägt wurde ${ }^{4}$. Wenn auch die Vorstellung des "Unternehmens an sich" eine in-

Hueck/Windbichler (Gesellschaftsrecht, 2003) § 1 Tz. 1 [ohne Hervorhebungen des Originals].

2 Streng genommen ist der nichtrechtsfähige Verein zwar körperschaftlich organisiert, allerdings keine juristische Person ( $\$ 54$ Satz 1 BGB); dem gegenüber sind rechtsfähige Stiftung und Einmanngesellschaft juristische Personen, ohne Körperschaften zu sein; vgl. dazu weitergehend Kübler (Gesellschaftsrecht, 1999) S. 29, 134-151, 305-318.

3 Die hier vorgenommene (klare) Zweiteilung abstrahiert insofern, als dass z.B. nach deutschem Recht bestimmte Hybridformen existieren. So wird hier z.B. schon der Gesellschaft bürgerlichen Rechts (GbR) nach $\S \S 705$ ff. BGB eine gewisse Rechtsfähigkeit zuerkannt; vgl. $B G H$ v. 29.1.2001 (II ZR 331/00); dazu ausfuhrlich Schmidt (BGB-Außengesellschaft, 2001). Bei den so genannten Personenhandelsgesellschaften (OHG, KG), wird gar von „quasi juristischen Personen“ gesprochen, bei denen eher eine Mixtur aus persönlicher und sachlicher Zentraleinheit vorliegt; vgl. dazu aus steuerrechtlicher deutscher Sicht auch Kap. III.2.4.

4 Vgl. Rathenau (Von kommenden Dingen, 1917) S. 141-143; Rathenau (Vom Aktienwesen, 1918) S. 26-39; Haussmann (Vom Aktienwesen, 1928) Vorwort und S. 27-43; vgl. dazu auch Mestmäcker (Verwaltung, 1958) S. 12-20; Riechers (Unternehmen an sich, 1996); Wiethölter (Aktiengesellschaft im amerikanischen und deutschen Recht, 1961) S. 38-42. 
zwischen zumindest teilweise überholte Extremposition markiert', steht die Rechtswissenschaft dem methodologischen Individualismus ökonomischer Theorieansätze dennoch kritisch gegenüber ${ }^{2}$. Letztlich ist es hier die juristische Person als solche, die als Körperschaft einem ,überindividuellen Zweck“ folgt und die ,aus der Selbständigkeit des Zwecks die Einheit des Wesens" ${ }^{\text {“3 }}$ gewinnt. Dabei ist sich die Rechtsphilosophie letztlich nicht einig, ob sich dieser überindividuelle Zweck vollständig in individuelle Zwecke der vertraglich Beteiligten auflösen lässt („Fiktionstheorie“) oder nicht (u.a. „Lehre von der realen Verbandsperson“, „Theorie vom Zweckvermögen“").

Abschließend kann festgehalten werden, dass die Unternehmung in der Rechtsrealität aus einer stark rechtsträger- und damit rechtsformorientierten Perspektive wahrgenommen wird ${ }^{5}$. Der Fokus liegt auf den Rechtssubjekten, sei es auf natürlichen oder auf juristischen Personen. Diese enge Sicht wird letztlich in der betriebswirtschaftlichen Literatur zur Rechnungslegung und Besteuerung unterstellt, wenn dort von der, ,rechtlichen Einheit" die Rede ist. Um sich auch terminologisch von dem ökonomischen Modell der Unternehmung zu distanzieren, soll der Bezug auf diese rechtsformorientierte Sicht mit dem Begriff des Unternehmens verbunden werden ${ }^{6}$. Dabei schließt die Unternehmens-

1 Vgl. dazu treffend Lutter (Haftung in der Unternehmensgruppe, 1982) S. 253-254: „Denn mühsam genug haben wir gelernt, daß die juristische Person eben kein ,Ding an sich" ist, kein Subjekt mit einem realen, auch für die Rechtsordnung unverrückbaren Sein wie der Mensch, sondern eben eine Kunstform, ein Zweckgebilde der Rechtsordnung, ungemein geeignet als Form dauerhafter Kooperation ebenso wie zur Haftungsbegrenzung, frei von den Schrecken des Todes ebenso wie von den Unbilden eines Menschenschicksals.“ Interessanterweise werden die hinter dieser Rechtsfiktion stehenden Unternehmungsbeteiligten bzw. Vertragspartner hier immer noch nicht explizit erwähnt (dies geschieht einige Sätze später: „...die natürlichen Personen - die wirklich Handelnden, die Adressaten unserer Regeln...“, S. 254); vgl. ähnlich interessant Ballerstedt (Unternehmensrecht, 1977) S. 19-20. Vgl. stellvertretend Orts (Legal Theory, 1998) S. 268, 283-286.

3 Radbruch (Rechtsphilosophie, 2003) S. 126 [beide Zitate], der i.d.Zshg. auf die teleologische Lehre verweist. Zudem konstatiert er: „Man wird freilich hinter der juristischen Person zunächst meistens nichts anderes entdecken als die Vielheit der an ihr beteiligten Einzelmenschen, ihrer Mitglieder, ihrer Organe. Gewiß kann im Einzelfalle hinter einer juristischen Person auch eine soziologische Einheit, eine ,Gemeinschaft' stehen, aber für die Frage nach der, realen' Einheit hinter der juristischen Person ist diese Tatsache gleichgültig. Einheit ist ja niemals Einheit an sich, stets nur Einheit unter einem bestimmten Gesichtspunkte. Die Substrateinheit der juristischen Person muß Einheit unter dem Gesichtspunkte ihres einheitlichen Zweckes sein."

4 Vgl. zu dieser Diskussion Hueck/Windbichler (Gesellschaftsrecht, 2003) § 2 Tz. 7-8; Radbruch (Rechtsphilosophie, 2003) S. 126-127; Wiedemann (Gesellschaftsrecht, 1980) S. 192-196. Vgl. zu parallelen Sichtweisen in der US-amerikanischen corporation-Theorie bereits Wiethölter (Aktiengesellschaft im amerikanischen und deutschen Recht, 1961) S. 196-199 m.w.N.; s.a. Clark (Corporation Law, 1986) S. 675-703 zur „meaning of corporate personality“. Insb. von soziologischer Seite wird die Rechtswissenschaft (wieder) dahin getrieben, in juristischen Personen ,spezifisch kollektive eigene Präferenzen“ zu entdecken, die auf „sozialen Zurechnungsprozessen überpersönlicher Art“ (Walz (Rechtspolitik, 1996) S. 40) beruhen; vgl. Teubner (autopoietisches System, 1989) S. 151-168.

5 Vgl. Schilling (Rechtsform, 1977) S. 548-549 zur Einheit von Unternehmen und Rechtsform auf der Basis der „Formstoff-Methode“, nach der jeder Stoff (Unternehmen) nach (Rechts-)Form verlange.

6 Vgl. zu einer ähnlichen, auf den Konzern bezogenen Begriffsabgrenzung Theisen (Konzern, 2000) S. 17. Die Bezeichnung ,rechtlich selbständiges Unternehmen“ wäre demnach tautologisch. 
sicht die Betrachtung der Rechtsbeziehungen betroffener Rechtssubjekte nicht vollständig aus. Diese Betrachtung beschränkt sich jedoch auf gesetzlich vorgegebene oder im Gesellschaftervertrag (Unternehmensverfassung) festgelegte Rechte und Pflichten der Mitglieder (bei Körperschaften) bzw. Gesellschafter (bei Personengesellschaften), die einerseits ihr Innenverhältnis zueinander oder zur Gesellschaft und das Außenverhältnis gegenüber außen stehenden Dritten regeln. Durch das gesellschaftsrechtliche Ausblenden sonstiger interner Vertragspartner ${ }^{1}$, die Abkehr vom ökonomischen Vertragskonzept hin zu engen gesetzlichen oder satzungsvertraglichen Regeln und die Fokussierung auf das Unternehmen als Rechtssubjekt wird das ökonomische Modell in seiner Komplexität deutlich reduziert, gewinnt aber auch an Operationalität und Rechtssicherheit.

\subsection{Modell der Unternehmung als Abgrenzungsleitbild für die steuerliche Gewinnermittlung}

Das Phänomen unternehmerischer Organisation ist aus ökonomischer Sicht beleuchtet und an der Rechtsrealität gespiegelt worden. Dabei ist deutlich geworden, wie schwierig es bereits ist, eine , wirtschaftliche' oder, rechtliche' Einheit zu definieren oder gar abzugrenzen. Der Versuch, die unterschiedlichen Sichtweisen auf die hier interessierenden Aspekte der konsolidierten steuerlichen Gewinnermittlung zu übertragen, sieht sich deshalb mit einer Kernfrage konfrontiert: Welche Sicht ist für die Zwecke der steuerlichen Gewinnermittlung die ausschlaggebende?

Unter Verwendung der bereits konkretisierten Anforderungen an die steuerliche Gewinnermittlung soll im Folgenden untersucht werden, ob die Abgrenzung der rechnungslegenden Einheit für Zwecke der steuerlichen Gewinnermittlung eher der Vorstellung einer , wirtschaftlichen' oder einer, rechtlichen' Einheit folgen sollte.

\subsubsection{Begründungsansätze}

\subsubsection{Wirkungsorientierte Effizienzbetrachtung}

Die Anforderungen an eine investitionsneutrale Gewinnermittlung entspringen einer einzelwirtschaftlichen Perspektive, in der die rechnungslegende Einheit nicht problematisiert wird. Die naturgemäß auf die bilanzielle Behandlung von Investitionen zielende Investitionsneutralität ${ }^{2}$ mag indes einen Beitrag leisten, wenn es um die Frage geht, wie

1 Eine Ausnahme mag hier die unter bestimmten Voraussetzungen greifende Mitbestimmung darstellen.

2 Durch die Investitionssicht sind die bilanziellen Forderungen der Investitionsneutralität nicht umfassend, sondern fokussieren primär auf bestimmte Ansatz- und Bewertungsfragen der Aktivseite; vgl. so z.B. Schiele (Unternehmensbesteuerung, 2000) S. 150-151. Letztlich gilt, dass potenzielle Bilanzierungsfragen nur über den Bezug zu einem Investitionsprojekt (Marginalinvestition!) zu beantworten sind. Weitere Partialmodelle, wie z.B. die Finanzierungsneutralität, können evtl. ergänzend wirken. 
bestimmte Investitionen in andere Unternehmen (Akquisitionen) in einer konsolidierten Gewinnermittlung abzubilden sind ${ }^{1}$.

Die Anforderungen einer wettbewerbsneutralen Gewinnermittlung steuern allgemeine Rahmenbedingungen bei, die auch bei der Konsolidierung zu beachten sind. Weniger hilfreich sind diese Anforderungen, wenn es darum geht, den Bezugspunkt der steuerlichen Gewinnermittlung unter Gesichtspunkten der Tauschgerechtigkeit zu benennen. Der individualistischen Sichtweise prozessorientierter Ansätze folgend, wird hier primär das Individuum gemeint sein. Streng genommen dürfte die steuerliche Gleichbehandlung aber die Individuen in Bezug auf die von ihnen vorgenommenen Handlungen und die ihnen anhaftenden Verhältnisse betreffen und sich damit letztlich auch auf Sachverhalte beziehen ${ }^{2}$.

Fraglich bleibt der diesbezügliche Stellenwert von unternehmerischen Organisationen als vertraglichen Zusammenschlüssen von Individuen. Mit vereinzeltem Bezug auf die Wettbewerbsneutralität wird in diesem Zusammenhang unter dem Begriff der Rechtsformneutralität diskutiert, ob Unternehmen unabhängig von ihrer Rechtsform den gleichen Besteuerungsregeln unterliegen sollen ${ }^{3}$. Dies ließe sich im Hinblick auf die Unternehmungsabgrenzung erweitern in Richtung einer Organisationsneutralität, die sich in der steuerlichen Gleichbehandlung unterschiedlicher Organisationsformen ausdrückt. $\mathrm{Zu}$ vermeiden sei hiernach, dass die Besteuerung Entscheidungsanreize zur individuellen Organisation verzerre und bestimmte Organisationsformen privilegiere oder gar als Ausdruck eines bestimmten wettbewerbspolitischen Leitbildes - die Konzentration fördere ${ }^{4}$.

Das Ideal der Entscheidungsneutralität scheint vor diesem Hintergrund in der Organisationsneutralität eine weitere, partielle Konkretisierung zu erfahren. Diese ist schnittmengenbehaftet mit der Wettbewerbsneutralität, da es gerade auch im Wettstreit der Organisationen darum geht, die Wirkungen unternehmerischer Tätigkeiten nicht durch organisationsbedingte Steuerkonsequenzen zu verzerren. Interessanterweise könnte diese Art der Organisationsneutralität über die Abschaffung sämtlicher Organisationssteuern erreicht werden. Diese u.a. auch von finanzwissenschaftlicher Seite geforderte Ab-

\footnotetext{
Vgl. dazu Kap. V.4.2.

Vgl. zu dieser Problematik Wagner (Neutralität und Gleichmäßigkeit, 1992) S. 7.

Vgl. z.B. Hey (Rechtsformneutralität, 2001) S. 158-161; zur Rechtsformneutralität vgl. auch die Hinweise in Kap. II.3.3.1.3 und III.2.4.1.

4 Vgl. zum Verständnis eines Wettbewerbs von Institutions- und Organisationstypen Fama/Jensen (Agency Problems, 1983) S. 333; Elschen (Institutionale oder personale Besteuerung, 1994) S. 347 352; s.a. m.w.N. Grotherr (Besteuerung nationaler und grenzüberschreitender Konzerne, 1994) S. 61 64; Köhler (Besteuerung von Konzern, 1970) S. 190-192; Rupp (Ertragsbesteuerung nationaler Konzerne, 1983) S. 38, 40-41.
} 
schaffung der Unternehmungs- bzw. Unternehmenssteuern ${ }^{1}$ dürfte allerdings einer evolutionär höchst stabilen Besteuerungspraxis widersprechen und der Forschungsfrage dieser Arbeit über das Ignorieren der europäischen Besteuerungssituation den Boden entziehen ${ }^{2}$. Wird die Besteuerung des unternehmerischen Einkommen indes nicht in Frage gestellt, kann mittels der Organisationsneutralität eine Besteuerung gerechtfertigt werden, die hinsichtlich des Besteuerungssubjektes eher auf das ökonomische Modell der Unternehmung zielt. Ausgangspunkt dieser Überlegungen ist eine Gegenüberstellung zweier vergleichbarer Unternehmungen, deren einziger (Organisations-)Unterschied darin besteht, dass unternehmerische Bereiche in dem einen Fall rechtlich separiert sind und in dem anderen Fall eben nicht ${ }^{3}$. Um die rechtlich separierte Unternehmung als Unternehmensgruppe nun steuerlich wie die rechtlich nicht separierte Einheitsunternehmung ${ }^{4} \mathrm{zu}$ behandeln, wird unter Verwendung der deutschen Konzernterminologie die Gruppen- bzw. Konzernbesteuerung gerechtfertigt, denn ,[d]em Ziel der Wettbewerbsneutralität der Besteuerung wird sicherlich gerade damit gedient, daß man den Konzern auch konsequent wie ein[e] Einheitsunternehm[ung] behandelt" ${ }^{\text {‘5 }}$.

Unklar ist noch die wirtschaftstheoretische Begründung. Teilweise sind es gar Juristen, die das Abrücken von einer unternehmens- und rechtsformbezogenen Abgrenzung im Sinne der Organisationsneutralität fordern ${ }^{6}$. So ist z.B. fraglich, ob die Organisationsneutralität, wie auch die Investitionsneutralität, auf eine Rangfolgeinvarianz hindeutet. Hiernach bliebe die Rangfolge von Organisationsalternativen - wie die Rangfolge von Investitionsalternativen - von der steuerlichen Gewinnermittlung unbeeinflusst. In diesem Fall läge trotz des ständigen Bemühens der wettbewerblichen Neutralität eher eine allokative, gleichgewichtstheoretische Deutung vor. Die Entscheidung eines Individuums zwischen zwei Organisationsformen solle hiernach nicht durch steuerliche Kon-

1 Vgl. zu dieser Diskussion z.B. Musgrave/Musgrave (Public Finance, 1989) S. 371-375; Stiglitz/Schönfelder (Finanzwissenschaft, 1989) S. 534-565, aber auch Schneider (Gleichmäßigkeit, 1975) jeweils m.w.N.; jüngst wieder für die Abschaffung plädierend Jehnert (Entnahme des Gewinns, 2004) S. 13; s.a. Arlen/Weiss (Theory of Corporate Taxation, 1995) S. 333-335; IFS (Corporation Tax for the 1990s, 1991) S. 8; vgl. auch Kap. II.3.3.1.3.

2 Somit wird die Unternehmensbesteuerung in dieser Arbeit letztlich nicht grundlegend in Frage gestellt, sondern als Datum akzeptiert.

3 Diese Organisationsformen einer Unternehmung i.d.Zshg. als ,sachgerechte Alternativen“ oder zutreffendes „Vergleichspaar" bezeichnend BVerfG v. 20.12.1966 (1 BvR 320/57, 1 BvR 70/63); Rupp (Ertragsbesteuerung nationaler Konzerne, 1983) S. 39; Senger (Konzernertragsbesteuerung, 1997) S. 58.

4 Vgl. zu dieser Terminologie z.B. Schubert/Küting (Unternehmungszusammenschlüsse, 1981) S. 239, die die Einheitsunternehmung als eine Unternehmung definieren, „deren Gliedteile alle rechtlich unselbständig sind".

5 Rupp (Ertragsbesteuerung nationaler Konzerne, 1983) S. 40 [ohne Hervorhebungen des Originals; die hinzugefügten Klammerzusätze dienen der Einpassung in den Text und der Angleichung an die hier verwendetet Terminologie]; ähnlich u.a. Müller (Konzernbesteuerung, 1991) S. 49-51; Scheuchzer (Konzernbesteuerung, 1994) S. 32-40.

6 Vgl. insb. in Bezug auf die Umsatzsteuer stellvertretend Tipke/Lang (Steuerrecht, 2002) § 14 Tz. 127; s.a. $B V \operatorname{erf} G$ v. 20.12.1966 (1 BvR 320/57, 1 BvR 70/63). 
sequenzen verzerrt werden. In prozessorientierter Hinsicht könnte Organisationsneutralität aber auch auf den Wettbewerb der Organisationen und der darin involvierten Individuen untereinander angewendet werden. In diesem Zusammenhang ist fraglich, wie das Neutralitätspostulat genau zu interpretieren ist. Einerseits ist denkbar, dass Organisationsunterschiede und damit einhergehende Wettbewerbsvor- oder -nachteile durch die steuerliche Gewinnermittlung nicht verzerrt werden sollen. Andererseits ist möglich, dass die steuerliche Gewinnermittlung organisatorische Unterschiede berücksichtigt und im Extremfall so kompensiert, dass Wettbewerbsneutralität im Sinne von wettbewerblicher Chancengleichheit und Startgerechtigkeit durch Neutralisierung der organisatorischen Komponente geschaffen wird'. Getreu der Leitlinie, gleiche Sachverhalte auch gleich zu besteuern, würden in diesem Fall nur ,gleichwertige“ Organisationen auch gleich besteuert. Dann wäre allerdings zu fragen, ob eine derartige Gleichwertigkeit z.B. zwischen rechtlich separierten Unternehmungen und Einheitsunternehmungen gegeben ist.

Tendenziell dürfte der ersten Variante zuzuneigen sein, da aktive Wettbewerbspolitik über Besteuerung bzw. steuerliche Gewinnermittlung dem prozessorientierten evolutorischen Denken eher widerspricht. Demnach sollten rechtlich separierte Unternehmungen im Wettbewerb mit Einheitsunternehmungen aufgrund ihrer Organisationsform weder steuerlich bevorzugt oder benachteiligt werden ${ }^{2}$. Das bedeutet jedoch nicht, dass rechtlich separierte Unternehmungen zwingend als Einheitsunternehmung und damit als eigenständiges Steuersubjekt behandelt werden müssen, solange sie nur im steuerlichen Ergebnis wie ein Einheitsunternehmen besteuert werden ${ }^{3}$ : Eine Abtrennung von Steuersubjekt und rechnungslegender Einheit ist deshalb durchaus möglich.

Ein Festhalten an der engen rechtsformorientierten, unternehmensbezogenen Abgrenzung der rechnungslegenden Einheit kann indes in beiden Interpretationsalternativen nicht gerechtfertigt werden. Sollen Organisationsunterschiede steuerlich ignoriert werden, wären allein die Organisations- und damit auch Unternehmungsgrenzen für die rechnungslegende Einheit relevant. Werden organisatorische Unterschiede berücksichtigt, bleibt diese Organisation weiterhin im Blickpunkt. Der einzige Unterschied läge darin, dass die Organisationsunterschiede zu erfassen sind und sich möglicherweise auf Fragen der rechnungslegenden Einheit sowie der steuerlichen Gewinnermittlung aus-

1 Vgl. allerdings Elschen (Institutionale oder personale Besteuerung, 1994) S. 348, der diese Art des steuerlichen "Wettbewerbsausgleichs" mit Hinweis auf die freie Institutionenwahl ablehnt und der ersten Interpretation zuneigt.

2 Vgl. Choate/Mason (Single-Entity Theory, 1994) S. 656; Herzig (Paradigmenwechsel in der Konzernbesteuerung, 2002); Lamb (group, 1995) S. 35; Rupp (Ertragsbesteuerung nationaler Konzerne, 1983) S. 39-42; Salzberger (Konzernunternehmung, 1994) S. 148.

3 Vgl. zu dieser wichtigen Nuance Grotherr (Besteuerung nationaler und grenzüberschreitender Konzerne, 1994) S. 58; Rupp (Ertragsbesteuerung nationaler Konzerne, 1983) S. 40-41. 
wirken. Das hieße jedoch nicht automatisch, dass sich die rechnungslegende Einheit auf die rechtsformorientierte Unternehmenssicht reduziert.

Aus wirkungsorientierter Effizienzsicht gibt es insofern kaum eine Rechtfertigung für eine ausschließlich rechtsformorientierte Unternehmenssicht. Die Abgrenzung der rechnungslegenden Einheit nach Maßgabe ökonomischer Kriterien erscheint sinnvoller. Dabei ist die ökonomische Sicht auch insofern weiter gefasst, als dass sie das Unternehmen als Rechtsträger in seiner Nukleusfunktion durchaus anerkennt, ohne dabei wirtschaftliche Abhängigkeitsbeziehungen zwischen Unternehmen und ihren Vertragspartnern und insofern auch zwischen mehreren Unternehmen auszublenden. Das rechtsformorientierte Unternehmensbild ist primär vom Leitbild der unabhängigen Gesellschaft getragen ${ }^{1}$ und hat deshalb Schwierigkeiten mit der Berücksichtigung unternehmerischer Organisation z.B. in Form mehrerer miteinander verbundener Unternehmen.

\subsubsection{Durchführungsorientierte Effizienzbetrachtung}

In der durchführungsorientierten Effizienzbetrachtung geht es darum, die mit der steuerlichen Gewinnermittlung einhergehenden Prozessaktivitäten auf ihre Effizienz hin zu untersuchen. Dabei ist diejenige Alternative zu präferieren, die mit vergleichsweise geringeren Transaktionskosten einhergeht. Hinsichtlich der Abgrenzung der rechnungslegenden Einheit sind erst einmal klare und einfache Abgrenzungskriterien zu fordern, die von allen Beteiligten eindeutig interpretiert werden können. Möglicherweise ergeben sich daraus Vorteile für die rechtsformorientierte Unternehmenssicht. Weitergehende Aussagen sind schwierig. Allerdings kann die Tendenzaussage getroffen werden, dass eine multiple Gewinnermittlung gegenüber einer zusammengefassten Gewinnermittlung inferior sein dürfte. Wenn eine Unternehmung als Unternehmensgruppe einerseits eine Vielzahl von Ermittlungs-, Erhebungs-, Überwachungs- und Durchsetzungsaktivitäten auslöst, die in einer zweiten Alternative zumindest deutlich reduziert werden, so ist der Transaktionskostenvorteil der zweiten Alternative offenkundig. Da Größe und Abgrenzung der rechnungslegenden Einheit - wie auch Kapitel III zeigen wird - aber nicht zwingend auf Zahl und Ausmaß der Gewinnermittlungsaktivitäten schließen lässt, erscheint eine konkrete Wertung dennoch kaum möglich. Wenn die steuerliche Gewinnermittlung einer rechtlich separierten Unternehmung ökonomischen Abgrenzungskriterien folgen sollte, kann dies zu reduzierten Gewinnermittlungsanstrengungen führen. Zwingend ist dies jedoch nicht ${ }^{2}$.

1 Vgl. z.B. Emmerich/Sonnenschein/Habersack (Konzernrecht, 2001) S. 1, 11.

2 Dafür müssten Annahmen über die konkrete Form der steuerlichen Gewinnermittlung getroffen werden, z.B. ob eine idealtypische oder realtypischen Variante vorliegt oder ob die realtypische Variante noch mit dem Fremdvergleichsgrundsatz verbunden wird; vgl. dazu insb. Kap. III.1.2. 


\subsubsection{Sicht der steuerlichen Leistungsfähigkeit}

Aus der Perspektive der steuerlichen Leistungsfähigkeit bietet sich erst einmal keine unmittelbare Aussage zur Abgrenzung der rechnungslegenden Einheit an. Die in diesem Zusammenhang präferierte Reinvermögenszugangstheorie setzt diese Frage letztlich als schon beantwortet voraus. Insofern muss das Abstraktionsniveau erhöht und direkt auf das Prinzip der steuerlichen Leistungsfähigkeit zurückgegriffen werden.

Fraglich ist in diesem Zusammenhang bereits das Zuordnungssubjekt der Leistungsfähigkeit. Können Unternehmen bzw. Unternehmungen überhaupt Träger steuerlicher Leistungsfähigkeit sein? Mit Bezug auf den Gleichheitsgrundsatz des Art. 3 Abs. 1 GG könnte aus verfassungsrechtlicher Perspektive angeführt werden, dass Grundrechte als Bürger- bzw. Menschenrechte zu begreifen sind und demnach primär auf natürliche Personen abstellen ${ }^{1}$. Nach Maßgabe des Art. 19 Abs. 3 GG werden aber auch inländische juristische Personen als Grundrechtsträger anerkannt, so dass zumindest auch diese Zuordnungssubjekt der steuerlichen Leistungsfähigkeit sein müssten ${ }^{2}$. Demzufolge wären neben den Menschen als natürlichen Personen auch Unternehmen, nicht jedoch Unternehmungen, Träger steuerlicher Leistungsfähigkeit. Damit wäre auch die Einheitlichkeit der Rechtsordnung gewahrt, da natürliche wie juristische Personen gleichermaßen der (Einkommens-)Besteuerung unterliegen können ${ }^{3}$.

1 Vgl. z.B. Dürig (Art. 19 Abs. III, 1977) Tz. 1, der konstatiert, dass Art. 19 Abs. III GG nur „um des Menschen willen“ da sei; ähnlich auch Rüfner (Grundrechtsträger, 2000) Tz. 31: „Es wird also eine eigene Grundrechtssubjektivität der juristischen Person anerkannt, mag auch der Schutz der menschlichen Persönlichkeit und ihrer Freiheit der letzte und eigentliche Zweck aller Grundrechte sein“.

2 Vgl. Tipke/Lang (Steuerrecht, 2002) § 4 Tz. 90-91, die hier lapidar ein „Interesse aller Grundrechtsträger" erkennen, die (objektive) Leistungsfähigkeit aller Unternehmen steuerlich zu erfassen. Vgl. z.B. auch m.w.N. Bayer (Steuerlehre, 1997) Tz. 103-110, 521-522; Birk (Leistungsfähigkeit, 2000) S. 328-329; Hey (Einführung, 1999) S. K 17; Jachmann (Gleichheitsproblem, 2000) S. 16-19; Seer (Verfassungsrechtliche Grenzen, 2000) S. 90-91, 109. Besonders markant auch Schredelseker (Wider eine individualistisch verkürzte Theorie, 1975) S. 326, der mit Bezug auf die BVerfG-Rechtsprechung „Zweifelsfrei“ davon ausgeht, dass der Gleichheitsgrundsatz auf juristische Personen anwendbar sei. Juristischen Personen (und sonstigen steuerrechtsfähigen Gebilden; vgl. dazu Kap. III.2.1) wird allerdings nur die ,objektive' Leistungsfähigkeit zuerkannt, während bei natürlichen Personen eine ,objektive' wie auch eine ,subjektive' Leistungsfähigkeit festgestellt wird; vgl. dazu mit Hinweisen auf die deutsche Verfassungsrechtsprechung z.B. Bayer (Steuerlehre, 1997) Tz. 1157; kritisch dazu Schneider (Steuerlast, 2002) S. 307-311.

3 Vgl. zur Einheitlichkeit der Rechtsordnung, wonach keine Teilrechtsordnung (wie z.B. das Steuerrecht) gegen zentrale Wertungen, Grundsätze und Zielsetzungen anderer Teilrechtsordnungen verstoBen sollte, aus der Perspektive des Steuerrechts Rupp (Ertragsbesteuerung nationaler Konzerne, 1983) S. 83-108; Schredelseker (Wider eine individualistisch verkürzte Theorie, 1975) S. 326, Tipke (Steuerrechtsordnung, Band I, 2000) S. 57-60; Tipke (Steuerrechtsordnung, Band II, 1993) S. 735-738. Für Weber-Grellet (Fairneß, 1999) S. 312-313 ist diese Einheitlichkeit kein Wert an sich und das Steuerrecht „keine Kolonie des Zivilrechts“; zur Emanzipation des Steuerrechts vom Zivilrecht in Fragen der Konzernbesteuerung s.a. BVerfG v. 24.1 .1962 (1 BvR 845/58); Girnth (Ertragsbesteuerung von Konzernen, 1963) S. 127-145. 
Aus einer weniger formalrechtlichen Perspektive werden allerdings Zweifel geäußert, ob Unternehmen eine eigenständige steuerliche Leistungsfähigkeit zugeordnet werden könne. Gerade die stärker ökonomisch orientierte und dem methodologischen Individualismus verhaftete Literatur tut sich schwerer, dem Unternehmen als kontraktfähiger abstrakter Rechtsfiktion völlig unabhängig von den dahinter stehenden Individuen eine eigene Leistungsfähigkeit zu attestieren. Als ethischer Maßstab lasse sich die Leistungsfähigkeit z.B. nach Schneider nur auf Menschen anwenden ${ }^{1}$. Wenn Leistungsfähigkeit als Opferfähigkeit interpretiert wird ${ }^{2}$, ist Unternehmen auch die Fähigkeit zur Nutzeneinbuße im Sinne privater Bedürfnisbefriedigung abzusprechen.

Die steuerliche Leistungsfähigkeit wird heute allerdings eher durch das Lastentragfähigkeitskonzept konkretisiert, das auf die individuelle Fähigkeit zur Finanzierung des staatlichen Finanzbedarfs abstellt. Da dieses nicht wie die Opferfähigkeit an der Mittelverwendung, sondern an der Mittelentstehung anknüpft ${ }^{3}$, erscheint die am Einkommen orientierte Leistungsfähigkeit auch bei juristischen Personen zu greifen ${ }^{4}$. Neumark differenziert deshalb in eine „persönliche (individuelle)“ und „sachliche (generische)" Leistungsfähigkeit ${ }^{5}$, die sich insofern auch auf Unternehmen als sachliche Rechtsträger erstreckt. Eine völlig isolierte Leistungsfähigkeit wird letzteren dennoch mehrheitlich nicht zugestanden. Allerdings wird auch von ökonomischer Seite akzeptiert, dass Unternehmen Einkommen erzielen können, das nicht unmittelbar in individuelles Einkommen transformiert wird (Thesaurierung). Implizit wird in diesem Zusammenhang die Reinvermögenszugangstheorie unterstellt ${ }^{6}$, die sich unter Leistungsfähigkeitsgesichtspunkten als vorteilhaft erweist ${ }^{7}$. Das Unternehmen stellt vor diesem Hintergrund

1 Vgl. Schneider (Steuerlast, 2002) S. 235; ausführlich noch Schneider (Gleichmäßigkeit, 1975) S. 100104; vgl. dazu allerdings die kritischen Anmerkungen von Schredelseker (Wider eine individualistisch verkürzte Theorie, 1975).

Vgl. z.B. wieder Haller (Umstrittene Fragen, 1991) S. 22-25 in der Auseinandersetzung mit Pohmer (Bemerkungen, 1988) S. 138; kritisch insb. Littmann (Valet dem Leistungsfähigkeitsprinzip, 1970). Vgl. Kraft (Steuergerechtigkeit, 1991) S. 40-41.

4 Vgl. Grotherr (Besteuerung nationaler und grenzüberschreitender Konzerne, 1994) S. 52-53. Nach Schredelseker (Wider eine individualistisch verkürzte Theorie, 1975) S. 325 habe sich die ,moderne Finanzwissenschaft ... längst von der utilitaristisch-individualistischen Steuerrechtfertigungslehre gelöst und zu einer höchst pragmatischen Ausfüllung des Begriffs ... gefunden. Sowohl Haushalts- wie Unternehmensbesteuerung haben in diesem System ihren angestammten Platz".

5 Vgl. Neumark (Wirtschafts- und Finanzprobleme, 1961) S. 356-357, 366-368; dazu kritisch Elschen (Institutionale oder personale Besteuerung, 1994) S. 314-320.

6 Der schwierige Balanceakt dieser Argumentation zeigt sich aber z.B. darin, dass Mehrheitsgesellschafter - nicht aber Minderheitsgesellschafter - selbst bei Gültigkeit der Reinvermögenszugangstheorie immer auf die Ausschüttung thesaurierten Einkommens hinwirken können; die Körperschaftsteuer wäre demnach nur noch aus Sicht der Minderheitsgesellschafter als eine Art EinkommensteuerVorauszahlung zu rechtfertigen; vgl. Schneider (Grundzüge der Unternehmensbesteuerung, 1994) S. 176-177; m.w.N. auch Probst (Anteile von Minderheitsgesellschaftern, 1997) S. 68.

7 Vgl. Kap. II.2.2.4. 
neben den Individuen einen ,komplementären Ausgangspunkt“ für die Erfassung steuerlicher Leistungsfähigkeit dar ${ }^{1}$.

Wenn Unternehmen als Zurechnungssubjekt steuerlicher Leistungsfähigkeit erst einmal akzeptiert werden, stellt sich die Frage, ob sich diese Subjekteigenschaft wirklich nur auf die rechtsformorientierte Rechtseinheit beschränken kann - eine Frage, die in der Literatur in diesem Zusammenhang kaum aufgeworfen wird ${ }^{2}$. Wenn die organisatorische Struktur einer Unternehmung eine rechtliche Segmentierung in vergleichsweise abhängige Subsysteme vorsieht, denen ihrerseits Unternehmen als sachliche SubZentraleinheiten zugeordnet sind, erscheint eine isolierte rechtliche Sicht der Leistungsfähigkeit und eine dementsprechend konzipierte steuerliche Gewinnermittlung zu eng. Dies resultiert schon aus der Logik der steuerlichen Leistungsfähigkeit, nach der - wenn sie schon auf Sacheinheiten übertragen wird - die unverbundene Einheitsunternehmung anders $\mathrm{zu}$ behandeln ist als das in eine Unternehmensgruppe integrierte Unternehmen. Einmal handelt es sich um die einzige Zentraleinheit einer qua definitionem wirtschaftlich autonomen Unternehmung, das andere Mal handelt es sich nur um eine Teilmenge einer Unternehmung, der diese Autonomie zwangsläufig fehlt. Eine Gleichbehandlung bedeutet das völlige Negieren der Unternehmungs- und Hierarchiestrukturen, soweit sie sich über Eigentums- und Kontrollbeziehungen manifestiert haben. Sie unterstellt eine fiktive, ökonomisch nicht immer existierende Unabhängigkeit der rechtsfähigen Unternehmen (Fiktion der wirtschaftlichen Selbständigkeit in der Einzelgewinnermittlung ${ }^{3}$ ).

1 Vgl. stellvertretend Kraft (Steuergerechtigkeit, 1991) S. 103-108 m.w.N.; nach dieser wohl vorherrschenden Argumentation stellt die Körperschaftsteuer eine notwendige „Lückensteuer" dar (S. 108); zudem weist sie auf die sich gegenüberstehenden, auch international vertretenen Positionen, die Theorie der getrennten Rechtssubjekte (separate entity theory) einerseits und die Durchgriffstheorie (conduit theory; integration system) andererseits hin; m.w.N. auch Rupp (Ertragsbesteuerung nationaler Konzerne, 1983) S. 100-102; aus internationaler Perspektive Arlen/Weiss (Theory of Corporate Taxation, 1995) S. 328-335. Vgl. weniger kritisch Salzberger (Konzernunternehmung, 1994) S. 78, der konstatiert: „Die Erhebung der Körperschaftsteuer ist bei Verzicht auf eine Einkommenszurechnung zu den Anteilseignern aus Wettbewerbsgründen dringend geboten: Zur Vermeidung einer steuerfreien Gewinnthesaurierung auf der Ebene der Kapitalgesellschaft kann auf die Erhebung einer Körperschaftsteuer nicht verzichtet werden“. Vgl. kritischer, aber dennoch mit Parallelen IFS (Corporation Tax for the 1990s, 1991) S. 9, das in den Unternehmen lediglich einen „,tax collector“ erkennt. Interessanterweise wird in Kap. II.3.3.2.3 eine Argumentation entwickelt, nach der ökonomisches Eigentum an einem Unternehmen unter bestimmten Voraussetzungen bei dessen Vertretern (Managern) liegen und die in diesem Zusammenhang eine zusätzliche Begründung eigenständiger Leistungsfähigkeit eines Unternehmens liefern könnte; vgl. ansatzweise diesen Gedanken formulierend Bach (Perspektiven des Leistungsfähigkeitsprinzips, 1991) S. 128 mit Verweis auf Schanz (Die direkten Steuern Hessens, 1885) S. 317-329, der bereits Ansätze zur Rechtfertigung der (direkten) Besteuerung von Aktiengesellschaften präsentiert; kritisch dazu Schneider (Gleichmäßigkeit, 1975) S. 101.

2 Vgl. die Ausnahmen z.B. bei Grotherr (Besteuerung nationaler und grenzüberschreitender Konzerne, 1994) S. 53-57; Rupp (Ertragsbesteuerung nationaler Konzerne, 1983) S. 30-37; Senger (Konzernertragsbesteuerung, 1997) S. 50-57; aus der Sicht von Mehrheits- und Minderheitsgesellschaftern auch Probst (Anteile von Minderheitsgesellschaftern, 1997) S. 67-71.

3 Vgl. dazu bereits Ordelheide (Konzern, 1986) S. 302. 
Steuerliche Leistungsfähigkeit wird also, wenn überhaupt, primär von der Unternehmung, nicht von dem Unternehmen begründet. Was folgert daraus für die Abgrenzung der rechnungslegenden Einheit? Diese Abgrenzung hat dem Gedanken zusammenhängender, nur in ihrer Gesamtheit wirtschaftlich autonomer Sacheinheiten zu folgen, bei denen die Erfassung steuerlicher Leistungsfähigkeit überhaupt erst einen Sinn ergibt ${ }^{1}$.

Ein weiteres Argument mag aus der Perspektive der übergeordneten Gleichmäßigkeit bzw. horizontalen Gerechtigkeit das Abstellen auf die wirtschaftlich autonome Unternehmung rechtfertigen. Wenn Unternehmen als Subsysteme der Unternehmung die rechnungslegende Einheit bilden, qua definitionem aber keine wirtschaftliche Autonomie besitzen, bieten sie den darüber angesiedelten Entscheidungs- und Kontrollinstanzen, in letzter Instanz der Unternehmungsleitung, profunde Selbsteinsteuerungsmöglichkeiten. Opportunistisch handelnde Individuen innerhalb dieser Leitungsinstanzen, seien es nun Unternehmer oder Manager von Unternehmen, dürften schon aus Flexibilitätsgründen eine engere Abgrenzung der rechnungslegenden Einheit präferieren. Damit erlangen sie die Möglichkeit, innerhalb ihres Entscheidungsbereiches Rechnungslegungsdaten zu gestalten, in dem sie Vermögen und Schulden sowie Lieferungen und Leistungen entsprechend transferieren ${ }^{2}$. Da insbesondere Grenzen der Ertragsrealisation durch die Unternehmung verlaufen, können sie Erträge in den rechnungslegenden Einheiten ihrer Wahl, im Rahmen bestehender Regulierungen ${ }^{3}$ auch zu Konditionen ihrer Wahl, anfallen lassen. Nur eine Übereinstimmung von rechnungslegender Einheit und wirtschaftlichem Einflussbereich dürfte dieser Selbsteinsteuerungsmöglichkeit wirksam begegnen.

Obwohl auch die wirkungsorientierte, auf die Wettbewerbsneutralität zielende Effizienzbetrachtung eher auf die Unternehmung abstellt, existiert hierzu ein wichtiger Unterschied: Während die Organisation einer Unternehmung im Sinne der Organisationsneutralität keine Rolle spielen sollte, dürfte die steuerliche Leistungsfähigkeit der Unternehmung sehr wohl auch durch Aspekte der Organisation bestimmt sein. Dieses Problem wird in der Literatur für die Unternehmensebene unter dem Stichwort „Rechts-

1 Vgl. zu ähnlichen Argumenten z.B. Senger (Konzernertragsbesteuerung, 1997) S. 51-53.

2 Dies dürfte den „Enron-Fall“ markieren, wo insb. Schulden in sog. Zweckgesellschaften (special purpose entities) ausgelagert wurden, die außerhalb der rechnungslegenden Einheit (auch derjenigen der konsolidierten Rechnungslegung!) standen; vgl. dazu auch Kap. V.2. Umgekehrt ist die Interessenlage beim rechtsfolgeberechtigten Fiskus. Dieser dürfte die Übereinstimmung der rechnungslegenden Einheit mit dem Verantwortungs- und Entscheidungsbereich des Rechtsfolgeverpflichteten einfordern.

3 Hier greifen im Wesentlichen nationale und internationale Verrechnungspreisvorschriften nach Maßgabe des Fremdvergleichs; vgl. dazu Kap. III.1.1.1, III.2.1 und III.2.5.2. 
formneutralität" bereits kontrovers diskutiert", während eine entsprechende Erörterung für die Ebene einer Unternehmung (Organisationsneutralität) weitgehend fehlt. Wenn man, wie z.B. Herzig, betont, dass die Steuerbelastung einer Unternehmung nicht von ihrer rechtlichen Organisationsstruktur abhängen solle, sondern vielmehr von ihrer Leistungsfähigkeit ${ }^{2}$, muss auch akzeptiert werden, dass letztere durchaus von ersterer beeinflusst werden kann. Schließlich erachtet es die ökonomische Theorie, z.B. in Gestalt der Transaktionskostenökonomik, als selbstverständlich, dass die organisatorische Struktur der Unternehmung auch Effizienzwirkung entfaltet (,firm structure ... matters ${ }^{63}$ ). Wie in Kapitel III zu zeigen sein wird, kann z.B. rechtliche Separation zu Effizienzunterschieden und damit möglicherweise auch zu einer veränderten Leistungsfähigkeit führen ${ }^{4}$. Unter Leistungsfähigkeitsgesichtspunkten ist eine Organisationsneutralität demnach kaum zu rechtfertigen ${ }^{5}$.

Abschließend kann festgehalten werden, dass die Abgrenzung der rechnungslegenden Einheit nach Maßgabe der steuerlichen Leistungsfähigkeit dennoch eher dem ökonomischen Modell der Unternehmung folgt. Da die Leistungsfähigkeit der Unternehmung aber auch durch Organisationsaspekte determiniert wird, ist deren Berücksichtigung bei Abgrenzungs- und Konsolidierungsfragen durchaus geboten.

Im Folgenden wird nun näher analysiert, wie das aus effizienz- und gerechtigkeitsgetriebener Perspektive präferierte Modell der Unternehmung konkreter in eine rechnungslegende Einheit für Zwecke der steuerlichen Gewinnermittlung überführt werden kann. Weitere Organisationsaspekte finden später auch in Kapitel III Berücksichtigung, wenn untersucht wird, ob und inwieweit konkret existierende rechtliche Rahmenbedingungen das bis dahin geschaffene normative Bild einer steuerlichen Gewinnermittlung relativieren.

1 Die Rechtsformneutralität der Besteuerung wird seit dem 33. Deutschen Juristentag 1924 (ergebnislos) diskutiert; vgl. dazu mit unterschiedlichen Ansichten z.B. Elschen (Institutionale oder personale Besteuerung, 1994) S. 97-99, 129-181; Hey (Rechtsformneutralität, 2001); Pohmer (Verhältnis der Wirtschaftswissenschaft, 1964) S. 61; Ritter (Sicht der Wirtschaft, 1989) S. 321; Schneider (Rechtsformneutralität, 2004); Schreiber (Rechtsformabhängige Unternehmensbesteuerung, 1987); Tipke (Steuergerechtigkeit, 1981) S. 100-101; Tipke/Lang (Steuerrecht, 2002) § 8 Tz. 81-85; Walz (Gutachten, 1980).

2 Vgl. Herzig (Paradigmenwechsel in der Konzernbesteuerung, 2002) S. I.

3 Williamson (Modern Corporation, 1981) S. 1550.

4 Vgl. so auch die Argumentation von Grotherr (Besteuerung nationaler und grenzüberschreitender Konzerne, 1994) S. 58; Senger (Konzernertragsbesteuerung, 1997) S. 51-57, der insofern, ähnlich der Vorgehensweise in Kap. III, Organisations- und Leistungsfähigkeitsunterschiede zwischen Einheitsunternehmung und rechtlich separierter Unternehmensgruppe aufzuzeigen versucht.

5 Fraglich, aber hier nicht problematisiert, ist die Gewichtung dieser eventuell konfligierenden Ziele. 


\subsubsection{Versuch einer unternehmungsorientierten Abgrenzung}

\subsubsection{Schwierigkeit eindeutiger normativer Aussagen}

Abgrenzungsleitbild für Zwecke der steuerlichen Gewinnermittlung ist das ökonomische Modell der Unternehmung. Dieses Modell, das gewissermaßen als Extrakt aus unterschiedlichen ökonomischen Ansätzen herausgefiltert worden ist, erscheint aber aus effizienz- wie gerechtigkeitsgetriebener Sicht noch zu unbestimmt. Notwendig ist hiernach eine zweifelsfreie Abgrenzung, die den Grundsätzen der Klarheit und Einfachheit, aber auch Willkürfreiheit sowie Objektivität zu genügen vermag und die dabei noch standardisierten Vorgaben folgt. An dieser Stelle soll deshalb der Versuch unternommen werden, das Modell in konkretere Abgrenzungsmerkmale zu transformieren.

Dieser Versuch ist aus normativer Sicht nicht unproblematisch. Konkretisierung, Standardisierung und Vereinfachung erscheinen notwendig, dürften aber regelmäßig in einem Spannungsverhältnis zu dem individuellen „,wirtschaftlichen Gehalt“ der unternehmerischen Organisation stehen. Es besteht eine Art „Trade-off“, der nicht beliebig zu Gunsten einer Seite ausgenutzt werden darf. Da allerdings ein übergeordnetes MetaBeurteilungskriterium fehlt, verbleibt die Abwägung zwischen diesen beiden Seiten in einer normativen Grauzone. Diese Grauzone erstreckt sich auch auf die Tatsache, dass unbestimmte Aspekte im ökonomischen Modell der Unternehmung durch mehrere konkretisierende Alternativen ausgestaltet werden können, die den relativ weiten Rahmenbedingungen, wie z.B. Einfachheit und Objektivität, gleichermaßen entsprechen. Eine begründete Auswahl erscheint hier oft schwer möglich. Klare Aussagen werden deshalb zwangsläufig zu Gunsten von Tendenzaussagen zurücktreten.

Eine gewisse Unsicherheit herrscht aber auch, weil der soeben angesprochene wirtschaftliche Gehalt und die damit einhergehende Definition einer Unternehmung angesichts unterschiedlicher Ansätze keine absolute, festgefügte Größe darstellt. Das bedeutet, dass mehr oder minder tragfähige normative Abgrenzungskriterien auf der Basis einer bestimmten Sichtweise gefunden werden können, alternative Kriterien auf der Basis anderer Begründungsansätze aber letztlich nicht auszuschließen sind. Insgesamt resultiert daraus die Feststellung, dass die Konkretisierung des ökonomischen Modells der Unternehmung für Abgrenzungszwecke zwangsläufig unvollkommen bleiben muss.

\subsubsection{Nukleus- und ressourcenbasierte Abgrenzung}

Wird die Unternehmung in ökonomischer Sicht als nukleusbasiertes Geflecht bilateraler Verträge beschrieben ${ }^{1}$, kann der Staat in Gestalt der Finanzbürokratie streng genommen

1 Der Fall multilateraler Vertragsbeziehungen wird hier nicht betrachtet, fällt jedoch gleichfalls unter die Unternehmungsdefinition. 
auch nur das Unternehmen bzw. den Unternehmer und damit juristische bzw. natürliche Personen als Vertragspartner zur Informationsweitergabe verpflichten. Auch die gesetzlich oktroyierten Rechtsfolgen der steuerlichen Gewinnermittlung knüpfen immer an diese konkreten Vertragspartner an. Sie sind die Rechtsfolgeverpflichteten. Sie sind aber auch Informationssammelpunkt innerhalb der Unternehmung, da sie sämtliche Verträge bündeln und damit wohl auch die mit diesen Verträgen einhergehenden Informationen. Den Gesichtspunkten des methodologischen Individualismus folgend, dürfte diese letzte Eigenschaft im Falle des Unternehmens auch weniger das abstrakte Rechtsgebilde, sondern vielmehr dessen Vertreter (Unternehmensleitung, Manager) und Arbeitnehmer betreffen'.

Da es der Unternehmung qua definitionem an Rechtsfähigkeit mangelt, tritt deren kontraktfähige Zentraleinheit zwangsläufig in den Vordergrund. Es dürfte damit vornehmlich als Subjekt der steuerlichen Gewinnermittlung, als Rechnungslegender, in Frage kommen.

Fraglich ist allerdings, ob das Unternehmen - bei Fokussierung auf sachliche Zentraleinheiten - stellvertretend für die gesamte Unternehmung die notwendigen Informationen bereitstellen kann. Wenn die steuerliche Gewinnermittlung unter Leistungsfähigkeitsgesichtspunkten im Sinne eines Nettovermögensvergleichs interpretiert wird, bedeutet dies, das Nettovermögen der Unternehmung vollumfänglich ${ }^{2}$ zu erfassen. Dies kann vom Unternehmen durchaus geleistet werden. Wenn es in seiner Eigenschaft als vertraglicher Anknüpfungspunkt die (residualen) Kontroll- und Entscheidungsrechte über sämtliche Ressourcen der Unternehmung besitzt und auch sämtliche Verpflichtungen bündelt, können Vermögen und Schulden der gesamten Unternehmung hier zentral erfasst werden.

An dieser Stelle zeigt sich die Eignung des Modells von Grossman/Hart ${ }^{3}$. Ihre ressourcenorientierte und damit vergleichsweise enge Sicht der Unternehmung dürfte mit den normativen Anforderungen an die steuerliche Gewinnermittlung durchaus harmonieren. Das unternehmerische Vertragsgeflecht wird hier ausschließlich auf die Verträge reduziert, die das ökonomische Eigentum an Ressourcen manifestieren. Bei der Frage, wer letztlich innerhalb der Unternehmung das Eigentum an den Ressourcen besitzt, rückt wieder das Unternehmen in den Blickpunkt. Seine Existenz als zentraler vertraglicher Anknüpfungspunkt der Unternehmung basiert ja gerade auf den Effizienzvorteilen ge-

1 Komplexe Informationsbeziehungen und -asymmetrien u.a. zwischen den Managern untereinander sowie zwischen ihnen und den sie informationstechnisch unterstützenden Untergebenen sollen hier nicht weiter betrachtet werden.

2 Diese Vollumfänglichkeit ist vor dem Hintergrund des Totalitäts- bzw. Totaleinkommensprinzips zu fordern und ist sowohl aus kommutativen wie distributiven Gerechtigkeitsgesichtspunkten abzuleiten; vgl. Kap. II.2.1.2.3 und II.2.2.4.

3 Vgl. Grossman/Hart (Costs and Benefits of Ownership, 1986) und Kap. II.3.2.1. 
genüber multilateralen Vertragsbeziehungen. So werden durch das Unternehmen auch die Verträge mit den (ursprünglichen) Ressourceneigentümern gebündelt und ökonomisches Eigentum auf das Unternehmen übertragen'. Dabei beschränkt sich das Eigentumskonzept von Grossman/Hart allerdings nur auf bestimmte Ressourcen. Auch wenn - wie gerade evolutorische Ansätze betonen - eine Unternehmung natürlich auch von Handlungen der involvierten Vertragsparteien und ihrem Wissen profitiert, erscheint die vereinfachende Ausklammerung derartiger Vertragsbeziehungen für Abgrenzungszwecke angesichts der Anforderungen an die steuerliche Gewinnermittlung opportun. Im Übrigen dürfte hier eine gewisse Parallele zu einer Gewinnermittlung nach Maßgabe der Reinvermögenszugangstheorie existieren. Sofern es dieser Art von Humanvermögen an der selbständigen Tauglichkeit für Markttransaktionen mangelt, wird es auch dort nicht als Vermögen anerkannt und dem Nettovermögensvergleich nicht zugeführt.

Damit kann erst einmal festgehalten werden, dass die rechnungslegende Einheit in einem ersten Schritt um das Unternehmen aufgebaut werden sollte. Dabei sollten diejenigen Ressourcen mit einbezogen werden, die aufgrund entsprechender Vertragsbeziehungen dem (ökonomischen) Eigentum dieses Unternehmens zuzurechnen sind. Der bisher nicht problematisierte Fall multipler Unternehmen innerhalb einer Unternehmung (Mehrnukleusfall) ist damit bereits erfasst. Jedes Unternehmen fungiert schließlich selbst als mittelbare Ressource bzw. als Anknüpfungspunkt für weitere Ressourcen, an dem gleichfalls Eigentum erworben werden kann. Die rechnungslegende Einheit müsste demnach alle ihr unmittelbar zugerechneten Ressourcen einschließlich weiterer Unternehmen, die dem Ausgangsunternehmen als Subzentraleinheiten zu- bzw. untergeordnet $\operatorname{sind}^{2}$, umfassen. Diese Abgrenzung gilt letztlich für sämtliche, auch indirekte Eigentumsbeziehungen $\mathrm{zu}$ anderen Unternehmen. Ökonomisches Eigentum erlischt nicht, wenn mehrere Unternehmen „dazwischen geschaltet“ $\operatorname{sind}^{3}$.

Das soeben gezeichnete Bild einer rechnungslegenden Einheit geht implizit von einer zentralen Voraussetzung aus: Die rechnungslegende Einheit baut sich immer um die oberste Entscheidungs- und Kontrollinstanz auf. Nur dann ist sichergestellt, dass die in Frage kommenden Ressourcen der Unternehmung auch insgesamt erfasst werden. Andernfalls gilt dies nur für Subeinheiten und damit für Teilmengen der Unternehmung.

1 Die Eigentumsübertragung ist nicht in jedem Vertragsfalle zwingend; zur Unternehmung zählen aber nur die den Unternehmen zugerechneten Ressourcen. Da an Individuen kein Eigentum erworben werden kann, existieren keine Eigentumsbeziehungen zu Ressourcen, die bei den individuellen Ressourceneigentümern verbleiben.

2 Dadurch ergibt sich zwangsläufig eine Art Hierarchie der Zentraleinheiten (Unternehmen).

3 Vorstellbar wären allerdings formalrechtliche oder sonstige Hürden, die sich über die Zahl der Hierarchiestufen hinweg addieren, die der Willensdurchsetzung in Form von Friktionen entgegenstehen und die ökonomische Eigentumsposition letztlich schwächen. Vgl. zu der hier teilweise anwendbaren Diskussion über den Sinn einer Berücksichtigung mittelbarer Beteiligungen i.R.d. finanziellen Eingliederung gemäß $\S 14$ KStG u.a. Rupp (Ertragsbesteuerung nationaler Konzerne, 1983) S. 222-225; Senger (Konzernertragsbesteuerung, 1997) S. 105-107. 
Als derartige Instanz kommt erst einmal das Unternehmen in Frage, das direkt oder indirekt Eigentümer an sämtlichen involvierten anderen Unternehmen ist (Unternehmen als Hierarchiespitze). Darüber kommen nur noch natürliche Personen als „EndEigentümer“ in Frage. Letztlich sind sie die „oberste Kontroll- und Entscheidungsinstanz" der Unternehmung, so dass die rechnungslegende Einheit um sämtliche Unternehmen und Ressourcen zu erweitern ist, die diesen Individuen auch ansonsten zugerechnet werden ${ }^{1}$.

Haben die bisherigen Ausführungen stärker auf die Frage der (Netto-)Vermögenszurechnung fokussiert, so stellt die rechnungslegende Einheit aber auch auf die für die Ertragsrealisation notwendigen Grenze zwischen Unternehmung und Markt ab. Konsequenz der Ressourcenorientierung kann es in diesem Zusammenhang nur sein, auch hier auf die ökonomischen Eigentümer der Unternehmungsressourcen und damit primär auf die zugerechneten Unternehmen abzustellen. Andere Vertragspartner, auch die, die die Ressourcen ursprünglich zur Verfügung gestellt haben, aber z.B. auch die Arbeitnehmer, sind demzufolge dem Markt zuzurechnen.

\subsubsection{Konkretisierung des Vertragskonzepts als Kernproblem der Abgrenzung}

Wie gezeigt, bietet sich für Zwecke der steuerlichen Gewinnermittlung ein nukleus- und ressourcenbasierter Ansatz zur Abgrenzung der rechnungslegenden Einheit an. Dieser Ansatz ist jedoch an einer Stelle noch vergleichsweise unbestimmt. Welchen konkreten Kriterien haben Verträge zu genügen, wenn sie die geforderten Eigentumsbeziehungen innerhalb einer Unternehmung begründen sollen? Letztlich zielt diese Frage auf das Kernproblem der Abgrenzung, da über das Vertragskonzept festgelegt wird, welche Ressourcen und Unternehmen der Unternehmung insgesamt zuzurechnen sind.

Den bisher gewonnenen ökonomischen Erkenntnissen folgend, stehen in diesem Zusammenhang unvollständige Verträge im Vordergrund. Alle vollständigen und damit (neo-)klassischen Verträge sind nicht relevant und kennzeichnen marktliche Vertragsbeziehungen mit externen Dritten. Das Vorliegen unvollständiger Verträge ist notwendig, allerdings nicht hinreichend. Hybride Organisationsformen wie langfristige, enge Geschäftsbeziehungen oder strategische Allianzen² können gleichfalls auf derartigen Vertragsbeziehungen beruhen. Während z.B. Williamson in diesem Zusammenhang zwischen einheitlichen Überwachungs- und Durchsetzungssystemen sowie zweiseitigen

1 Ihre residualen Kontroll- und Entscheidungsrechte können sich auch über andere Zentraleinheiten erstrecken, die aus Sicht des ursprünglich betrachteten „obersten“ Unternehmens nicht mehr zur ursprünglichen Unternehmung gehören. Durch die Berücksichtigung der darüber aufgehängten Individuen wird diese Sicht aber zur Teilmenge der gesamten Unternehmung degradiert. Vgl. differenzierender dazu noch die Ausfuihrungen im nachfolgenden Kap. II.3.3.2.3.

2 Vgl. z.B. Schneider (Theorie der Unternehmung, 1997) S. 429-430 m.w.N. zur schwierigen Unternehmungsabgrenzung bei Vorliegen strategischer Allianzen. 
Kontrollbeziehungen differenziert ${ }^{1}$, erscheint der bereits bemühte Ansatz von Grossman/Hart an dieser Stelle operationaler. Als Integrationsmerkmal stellen sie allein auf das ökonomische Eigentum an bestimmten Ressourcen ab, das sie im Sinne residualer Entscheidungs- und Kontrollrechte verstehen. Übertragen auf das hier im Vordergrund stehende Abgrenzungsproblem wäre ein in Frage kommender (unvollständiger) Vertrag und die anhängenden Ressourcen der rechnungslegenden Einheit immer dann zuzurechnen, wenn diese Rechte innerhalb der Vertragsbeziehung und mit ihnen das ökonomische Eigentum an den Ressourcen auf Seiten der Unternehmung lägen ${ }^{2}$.

Das Eigentumskonzept von Grossman/Hart unterscheidet sich an dieser Stelle durchaus von alternativen Konzepten. Dies wird besonders deutlich, wenn Verfügungsrechte an einer Ressource aufgesplittet werden, so dass sich Teilrechte auf unterschiedliche Vertragspartner verteilen („Ausdünnung ${ }^{63}$ ). Ökonomisches Eigentum kann nun einer Vertragspartei unterstellt werden, ohne dass diese Partei sämtliche der vier Ausprägungen von Verfügungsrechten auf sich vereint. Fraglich ist nur, welche Ausprägung für die Eigentumszurechnung als relevant erachtet wird.

In der älteren Literatur zur Theorie der Verfügungsrechte, aber auch in der evolutorisch geprägten Literatur, wird an dieser Stelle der Vorschlag unterbreitet, nur auf das Recht auf Aneignung der residualen Erträge an der Ressource (,usus fructus' in eingeschränkter Form) abzustellen, was die Übernahme des Residualrisikos mit einschlie $\beta t^{4}$. Eigentümer eines Unternehmens wären dann z.B. in erster Linie die Eigenkapitalgeber, die aber - wie Furubotn gezeigt hat - um alle Eigentümer hochspezifischer Ressourcen, die von der „hold-up“-Problematik betroffen sind (,residual risk bearer“), erweitert werden können, also auch um unternehmensspezifisch spezialisierte Arbeitskräfte ${ }^{5}$. Die Unternehmungsgrenzen würden diese Vertragsbeziehung demnach mit einschließen.

Abgesehen davon, dass das Abstellen auf Residualeinkommen bzw. Residualrisiko mit einer für steuerliche Zwecke wenig operationalen Ausweitung des Ressourcenbegriffs und damit auch der Unternehmungsgrenzen einher geht, scheint sich auch die moderne-

1 Vgl. Williamson (Economic Institutions, 1985) S. 75-79. Bei zweiseitigen Kontrollbeziehungen könnte darauf hingewiesen werden, dass die Vertragspartner weniger „gefangen“ sind als im Rahmen einheitlicher Überwachungs- und Durchsetzungssysteme (Unternehmungen); vgl. ähnlich Richter/Furubotn (Neue Institutionenökonomik, 2003) S. 324.

2 Vgl. die Parallele zu McLure (Unitary Business, 1984) S. 103-108, der das "unitary business" für steuerliche Gewinnermittlungszwecke - allerdings in Anlehnung an Fama/Jensen (Ownership and Control, 1983) und nicht an Grossman/Hart (Costs and Benefits of Ownership, 1986) - über „common ownership and control" abzugrenzen versucht.

3 Vgl. Furubotn/Pejovich (Property Rights, 1972) S. 1146-1148.

4 Vgl. etwa Alchian (Corporate Management, 1969) S. 339-343; s.a. Kap. Il.3.2.1.2 bzgl. der Parallele zur Übernahme von Einkommensunsicherheiten als Unternehmerfunktion.

5 Vgl. Furubotn (Codetermination, 1988) S. 167-170 i.R.d. Analyse mitbestimmter Unternehmungen. 
re Literatur eher an den residualen Entscheidungs- und Kontrollrechten zu orientieren ${ }^{1}$. Auch wenn es hier für effizienter gehalten wird, bei der Gestaltung von Eigentumsverträgen grundsätzlich beide Komponenten zu berücksichtigen, können im Einzelfall Unterschiede erwachsen ${ }^{2}$. So kann es durchaus sein, dass Ressourcen der Unternehmung zugerechnet werden, obwohl residuale Einkommensempfänger außerhalb der Unternehmung verbleiben. Dafür wird jedoch vorausgesetzt, dass die residualen Rechte hinsichtlich der Ressourcenverwendung (,usus', ,abusus' und ,successionis') ${ }^{3}$ bei einem unternehmungsinternen Rechtsträger verbleiben, residuale Entscheidungs- und Kontrollrechte also auf die Ressourcenverwendung und damit letzlich auf Ressourcensteuerung und -koordination fokussieren ${ }^{4}$.

Für Zwecke der steuerlichen Gewinnermittlung dürfte aber auch das solchermaßen eingegrenzte Kriterium residualer Entscheidungs- und Kontrollrechte noch zu unbestimmt sein. Dies liegt bereits an der Weite und fehlenden Objektivierbarkeit des ökonomischen Vertragskonzeptes an sich, aber auch an der Tatsache, dass zur Identifikation residualer Entscheidungs- und Kontrollrechte operationalere Kriterien zu finden sind.

Das ökonomische Vertragskonzept markiert ebenfalls ein Spannungsfeld bei der Abgrenzung der rechnungslegenden Einheit. Einerseits ist die ökonomische Sichtweise einer Unternehmung als steuerlich relevant erachtet worden. Andererseits fehlt es dem ökonomischen Vertragskonzept an Objektivität und Operationalität. So dürfte zumindest tendenziell vermutet werden, dass eine Bewegung weg von dem ökonomischen hin zu dem juristischen Vertragskonzept den steuerlichen Anforderungen eher entgegen $k_{a ̈ m}{ }^{5}$. Dies dürfte dem Charakter einer rechtsfolgeorientierten Rechnungslegung stär-

1 Vgl. z.B. Milgrom/Roberts (Economics, Organization and Management, 1992) S. 289; vgl. zu dieser Einschätzung auch Holmstrom/Tirole (Theory of the Firm, 1989) S. 74; Ricketts (Business Enterprise, 2002) S. 114.

2 Vgl. Hansmann (Ownership, 1988) S. 269-270; Hart (Firms, 1995) S. 63-66, der beide Konzepte eindeutig trennt ("residual income and residual control do not have to be bundled together on a one-toone basis", S. 64), es aber in normativer Sicht für effizienter hält, beides zu verbinden; ähnlich Putterman (Ownership, 1993) S. 245-255; a.A. wohl Holmstrom/Tirole (Theory of the Firm, 1989) S. 74. Für die Zusammenlegung beider Konzepte plädieren auch Milgrom/Roberts (Economics, Organization and Management, 1992) S. 291-293. Vgl. ausführlicher zu diesen beiden Eigentumskonzepten Milgrom/Roberts (Economics, Organization and Management, 1992) S. 289-291; Valcárcel (Theorie der Unternehmung, 2002) S. 68-75, die ein eigenes Abgrenzungskonzept in Abkehr vom Eigentumsbegriff und in Hinwendung zum Mitgliedschaftsstatus (am Ressourcenpool) präsentiert.

3 Vgl. zur Zusammenfassung dieser drei Teilrechte unter den Begriff der ,Ressourcenverwendung' Valcárcel (Theorie der Unternehmung, 2002) S. 50, 70-71.

4 Vgl. ähnlich auch Valcárcel (Theorie der Unternehmung, 2002) S. 51-55, insb. S. 54 in der Auseinandersetzung mit Vanberg (Markt und Organisation, 1982).

5 Vgl. ähnlich, wenn auch nicht mit dem ökonomischen bzw. juristischen Vertragskonzept argumentierend Scheuchzer (Konzernbesteuerung, 1994) S. 240: „Aus Gründen der Rechtssicherheit müssen betriebswirtschaftlich orientierte Begriffsabgrenzungen ... hinter eine durch konkrete rechtliche Merkmale determinierte Umschreibung des steuerlichen Konzernkreises zurücktreten"; Spengel (Einheitliche Bemessungsgrundlage, 2004) S. 110, der „eindeutige rechtliche Kriterien für die Abgrenzung des Konsolidierungskreises“ fordert; Hellerstein/McLure (Company Income Taxation, 2004) S. 203-205. 
ker entsprechen. Gesetzlich erzwungene Rechtsfolgen basieren nicht mehr auf privaten Überwachungs- und Durchsetzungsinstitutionen, sondern bedienen sich regelmäßig der staatlichen Gerichtsbarkeit (Judikative) und der ausführenden, administrativen Gewalt (Exekutive). Vor diesem Hintergrund erscheinen einklagbare Verträge im Rechtssinne von Vorteil, die der verbesserten unternehmungsinternen Durchsetzbarkeit dienen und mittels derer auch der Fiskus jeden Rechtsträger (und Ressourceneigentümer) der Unternehmung separiert belangen könnte ${ }^{1}$. Bei einer rein informationsorientierten Rechnungslegung mag dies anders sein ${ }^{2}$.

Problematisch ist aber auch der Versuch, operationale Kriterien zur Identifikation residualer Entscheidungs- und Kontrollrechte zu finden. Das Abstellen auf das juristische Vertragskonzept allein dürfte für steuerliche Zwecke noch nicht ausreichen. Fraglich ist demnach, welche konkreten Vertragsformen zur „letztinstanzlichen“ Ressourcensteuerung und -koordination berechtigen. Auch wenn die diesbezügliche Antwort von konkreten Rechtsregulierungen abhängt, die hier (noch) nicht betrachtet werden, kann eine Analyse zumindest bestimmter Grundformen durchaus weiterzuhelfen.

Erstes Indiz für die Befähigung zur „letztinstanzlichen“ Ressourcensteuerung und -koordination im Sinne einer Art widerlagbarer Vermutung ist sicherlich das Vorliegen des „rechtlichen“ Eigentums. Rechtliches Eigentum markiert ein absolutes Recht. Beispielhaft formuliert hierzu das deutsche Privatrecht in § 903 BGB, dass der „Eigentümer einer Sache ... mit der Sache nach Belieben verfahren und andere von jeder Einwirkung ausschließen“ kann. Im Regelfall dürfte rechtliches Eigentum deshalb für die vorgenannten Zwecke bereits ausreichen. Diese Vermutung kann jedoch im Falle der schon erwähnten Ausdünnung von Verfügungsrechten durch unterschiedliche Rechtsverträge widerlegt werden. Bezogen auf die zentrale Frage, wie Eigentum an Unternehmen als juristischen Personen zu erlangen ist, ist z.B. vorstellbar, dass residuale Entscheidungsund Kontrollrechte eben nicht bei dem oder den rechtlichen Eigentümern liegen. Sofern hier unterstellt wird, dass im Wesentlichen Stimmrechte Entscheidungs- und Kontrollgewalt manifestieren ${ }^{3}$, fallen - im Unterschied zum Residualeinkommens- bzw. Residu-

1 Diese Feststellung bleibt indes problematisch. Vorstellbar wäre auch, dass zumindest ein Unternehmen als Rechtsträger dem Fiskus als Rechtsfolgeverpflichteten zur Verfügung steht. Träfen sämtliche Rechtsfolgen der Gesamtunternehmung nur dieses Unternehmen, läge es an der Tragbarkeit der ökonomischen Vertragskonstrukte dieses Rechtsträgers, ob die wirtschaftlichen Folgen in der Unternehmung weiter verteilt werden können. Insofern bestünde bereits ein Anreiz auf Seiten des rechtsfolgeverpflichteten Unternehmens und seiner Vertreter, diesbezüglich effektive Überwachungs- und Durchsetzungsinstitutionen zu schaffen. Vgl. zu den Durchführungseffizienzvorteilen rechtlicher Abgrenzungskriterien ansatzweise auch Schreiber (Unternehmensbesteuerung, 2004) S. 223.

2 Vgl. zu diesem Unterschied in der Abgrenzung der rechnungslegenden Einheit zwischen rein informationsorientierter und steuerlich orientierter Rechnungslegung - allerdings eher aus positiver und weniger aus normativer Perspektive - Lamb (group, 1995).

3 Vgl. ebenfalls Reis (Körperschaftsbesteuerung des Konzerns, 1996) S. 232-233; Rupp (Ertragsbesteuerung nationaler Konzerne, 1983) S. 222-223. 
alrisikokonzept - bereits diejenigen Anteilseigner als Eigentümer weg, die zwar Kapitalanteile halten, ohne dass für sie daraus ein Stimmrecht erwächst ${ }^{1}$. Stimmrechte als engeres Indiz für residuale Entscheidungs- und Kontrollrechte müssen sich jedoch auf sämtliche Fragen der letztinstanzlichen Ressourcenverwendung beziehen. Vorgeschaltete, unmittelbare Zugriffsrechte auf diese Ressourcen sind dabei unschädlich.

Die Vorstellung von einer Ressourcensteuerung durch einen ,zentralen Koordinator ${ }^{\text {¿2 }}$ dürfte allerdings kaum durch nur ein einziges Stimmrecht zu realisieren sein. Es stellt sich also die Frage, wie viele Stimmrechte zur Realisation dieser Vorstellung notwendig sind. Die Antwort kann eigentlich nur lauten: so viele, wie zur Entscheidungsdurchsetzung notwendig sind. Im Regelfall dürfte dies die einfache Mehrheit von über $50 \%$ sein. Allerdings variiert diese Quote von den Erfordernissen gesetzlicher und privatvertraglicher Regeln, die für bestimmte Entscheidungen eventuell höhere Stimmrechtsquoten vorsehen ${ }^{3}$. In seiner Wirkung unumstößlich und von diesen Regeln weitgehend unbeeindruckt erscheint deshalb einzig eine 100\%ige Quote. Andererseits dürfte auch eine niedrigere Quote als 50\% in Frage kommen. Angesichts niedrigerer Hauptversammlungspräsenzen ${ }^{4}$ erweisen sich auch Quoten unter 50\% zur Entscheidungsdurchsetzung als durchaus effektiv. Da sich (niedrige) Hauptversammlungspräsenzen indes nicht garantieren lassen, sprechen Standardisierungs- und Objektivierungserfordernisse für eine

1 Ein Abstellen auf die Kapitalbeteiligung ist in der älteren Literatur durchaus üblich, da mit ihr wohl Stimmrechte gleichermaßen assoziiert wurden; vgl. z.B. Hoffmann (Konzern-Bilanz, 1930) S. 33.

2 Vanberg (Markt und Organisation, 1982) S. 18, 169-176 mit Bezug auf das "monokratischhierarchische" Grundmuster der Organisation korporativen Handelns in einem Modell der Ressourcenzusammenlegung. I.d.Zshg. sieht er auch „Herrschaft" und „Macht“, wo „Ressourcen in einen einheitlich disponierten Pool eingebracht", „Dispositionsbefugnisse zentralisiert sind“ (S. 171-172).

3 Vgl. ähnlich Bauer (Besteuerung deutscher Konzerne, 1987) S. 213-214; Grotherr (Besteuerung nationaler und grenzüberschreitender Konzerne, 1994) S. 454-460; Rupp (Ertragsbesteuerung nationaler Konzerne, 1983) S. 222; Salzberger (Konzernunternehmung, 1994) S. 235-236; Senger (Konzernertragsbesteuerung, 1997) S. 147-148.

4 Vgl. für Deutschland z.B. o.V. (Kurs, 2003); o.V. (Stimmabgabe, 2003). 
Mindestquote von $50 \%$ plus einer Stimme (einfache Mehrheit) ${ }^{1}$. Wie bei jeder Standardisierung wird diese Quote den Umständen des Einzelfalls nicht immer gerecht. Dies gilt gleichermaßen für Vertragsvarianten, die alternativ zu Stimmrechten in der Lage sein können, residuale Entscheidungs- und Kontrollrechte zu begründen.
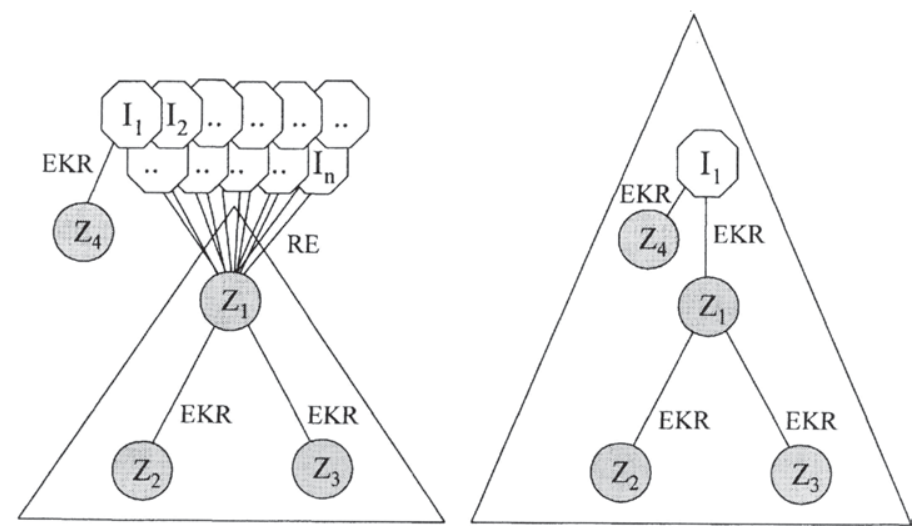

$\mathrm{I}_{\mathrm{r}}=$ Individuum $\mathrm{r}(\mathrm{r}=1, \ldots \mathrm{n})$

$Z_{s}=$ Zentraleinheit $\mathrm{s}(\mathrm{s}=1, \ldots 4)$

EKR $=$ residuale Eigentums- und Kontrollrechte (ökonomisches Eigentum)

$\mathrm{RE}=$ rechtliches Eigentum

Abb. 5: Sachliche und persönliche Zentraleinheit als Hierarchiespitze

Interessant ist es an dieser Stelle, erneut die Eigentumsstruktur desjenigen Unternehmens zu betrachten, das keinem anderen Unternehmen in der Unternehmung eigentumstechnisch zu- bzw. untergeordnet ist. Wurde im vorangegangenen Abschnitt noch betont, dass hinter diesem Unternehmen natürliche Personen als „End-Eigentümer“ ste-

1 Vgl. dies ebenfalls für steuerliche Zwecke als ausreichend erachtend u.a. Hoffmann (Konzern-Bilanz, 1930) S. 33, der hier allerdings nur auf eine Kapitalbeteiligung abstellt; Lechner (Besteuerung von Unternehmensgruppen, 1991) S. 395-396; Schneider (Konzernrechnungslegung als internationale Gewinnsteuerbemessungsgrundlage, 2003) S. 661, der dies als betriebswirtschaftlich nicht befriedigend, aber rechtssicher ansieht; Salzberger (Konzernunternehmung, 1994) S. 235-236, 239-240; Senger (Konzernertragsbesteuerung, 1997) S. 148, 231; relativierend bereits Müller (Konzernbesteuerung, 1991) S. 132, der jede Größe zwischen 50 und 100\% letztlich als willkürlich erachtet, eine einfache Mehrheit aber unter der Voraussetzung eines effizient ausgestalteten Minderheitenschutzes akzeptiert; später allerdings einer 75\%-Mehrheit zuneigend Müller (Voraussetzungen, 1998) S. 45-48; kritisch gegenüber der 50\%-Quote auch McLure (Unitary Business, 1984) S. 103; Schreiber (Unternehmensbesteuerung, 2004) S. 223, der nur auf den Beteiligungsbesitz abstellt. Eine qualifizierte Mehrheit (75\%) fordernd z.B. Bauer (Besteuerung deutscher Konzerne, 1987) S. 211-215, der die Sperrminorität bei einfacher Mehrheit als problematisch erachtet, eine Kombination aus einfacher Mehrheit und Beherrschungsvertrag indes akzeptiert; Beusch (Referat, 1972) S. Q 42; Eberhartinger (Ertragsteuerliche Konsequenzen, 2000) S. 262; Grotherr (Besteuerung nationaler und grenzüberschreitender Konzerne, 1994) S. 454-457, der im EU-Kontext sogar $90 \%$ befürwortet; Krebühl (Konzernbesteuerung, 2003) S. 606; Reis (Körperschaftsbesteuerung des Konzerns, 1996) S. 233-234; Scheuchzer (Konzernbesteuerung, 1994) S. 240-243. 
hen, so muss diese Aussage hier relativiert und präzisiert werden. Dem soeben entwickelten Stimmrechtskonzept folgend, kann den Individuen hinter der sachlichen Hierarchiespitze nicht per se das ökonomische Eigentum zugestanden werden. Wie in Abb. 5 angedeutet, sind hier im Wesentlichen zwei Fälle denkbar.

Vorstellbar ist einerseits der Fall eines sog. „Manager-Unternehmens“, das als Publikumsgesellschaft betrieben wird. Letztlich liegt hier ein Fall ausgedünnter Verfügungsrechte vor, bei dem Teile dieser Rechte eben nicht nur bei den Kapitalgebern (Anteilseignern) sowie Stimmrechtsinhabern liegen, sondern auch bei den Managern. Diese vertreten in streng individualistischer Sichtweise die sachliche Zentraleinheit und nehmen insofern eine Schlüsselrolle ein'. Dabei sind ihnen von (rechtlicher) Eigentümerseite nicht nur umfassende unmittelbare Rechte, z.B. zur Vertretung und Führung des Unternehmens, übertragen worden. Angesichts ihres spezialisierten Wissens und des damit einhergehenden Informationsvorsprungs sowie der Existenz ermessensbehafteter Entscheidungsspielräume erlangen sie darüber hinaus Entscheidungs- und Kontrollbefugnisse. Diese können angesichts zwangsläufig unvollständiger Delegationsverträge durchaus residualen Charakter haben ${ }^{2}$. In Publikumsgesellschaften wird diese Entscheidungs- und Kontrollposition der Manager noch verstärkt, wenn sich die Stimmrechte auf viele Individuen verteilen. Letztere sind angesichts heterogener Informationsstände und Nutzenfunktionen und sonstiger Transaktionskosten im Zuge der Entscheidungsvorbereitung und -findung kaum zu einer einheitlichen (und kompensierenden) Willensbildung in der Lage. Zudem gehen existierende Rechtssysteme oft so weit, die Entscheidungsspielräume dieser Individuen qua Regulierung immer stärker einzuschränken und auf explizite, unmittelbare Rechte zu fixieren ${ }^{3}$. Aber selbst das Interesse an diesen, nicht mehr residualen Rechten ist bei vielen Anteilseignern großer Publikumsgesellschaften begrenzt. Dies wird z.B. nicht nur in theoretischen Untersuchungen zur „free rider"-Problematik bei Publikumsgesellschaften belegt ${ }^{4}$, sondern eindrucksvoll auch in niedrigen Hauptversammlungspräsenzen dokumentiert. Zudem vermögen empirische Untersuchungen z.B. aufzuzeigen, dass Anteilseigner im Interesse der Rendite, im Ide-

1 Dies schließt auch kompliziertere Vertragsstrukturen mit ein, in denen die „obersten“ Manager in Vertragsbeziehung zu untergeordneten Managern stehen, die wiederum in bestimmten Grenzen ermächtigt sind, eigenständig Verträge abzuschließen (,side contracts“); vgl. zu den ,side contracts“ sowie "multiprinciple incentive theory", die das Problem multidimensionaler Prinzipal-Agenten-Beziehungen der Manager zu den (anderen) Vertragspartnern betrachtet, Laffont/Martimort (firm, 1997); einen Literaturüberblick geben hier Holmstrom/Tirole (Theory of the Firm, 1989) S. 120-123. Vgl. zur Schlüsselrolle der Manager auch Williamson (Economic Institutions, 1985) S. 318: „management is centrally implicated in all contracts".

Vgl. Valcárcel (Theorie der Unternehmung, 2002) S. 71-72.

3 Dadurch wechselt der Charakter ihrer Entscheidungs- und Kontrollrechte, die nur noch formaler und unmittelbarer, nicht aber residualer Natur sein dürften. Vgl. dazu eher ratlos aus juristischer Sicht Wiedemann (Gesellschaftsrecht, 1980) S. 125.

4 Vgl. hierzu z.B. den Literaturüberblick bei Ruhwedel (Eigentümerstruktur, 2003) S. 70-74. 
alfall - Fremdkapitalgebern gleich - für eine erfolgsunabhängige „Dividende“, auf ihr Stimmrecht verzichten würden'.

Insofern kann vermutet werden, dass das ökonomische Eigentum an Publikumsgesellschaften und ihren Ressourcen eher bei dem Unternehmen und seinen Vertretern selbst liegt: Die an dieser Stelle oft bemühte Trennung von „Eigentum“ und Kontrolle wäre demnach ökonomisch falsch ${ }^{2}$. Eigentum reduziert sich hier allein auf das rechtliche Eigentumskonzept, das hier - wie oben auch in anderem Zusammenhang dargelegt - zu kurz greift. Die rechtlichen Eigentümer stünden in dem besagten Fall außerhalb der Unternehmung, im Übrigen unabhängig davon, ob sie residuale Einkommensempfänger $\operatorname{sind}^{3}$. Die rechnungslegende Einheit wäre ausgehend von dem Unternehmen als oberster Kontroll- und Entscheidungsinstanz abzugrenzen.

Dennoch ist es möglich, dass auch Individuen als Hierarchiespitze in Frage kommen. Dies wäre der in Abb. 5 dargelegte Alternativfall. Einfachstes Beispiel ist das klassische Eigentümer-Unternehmen, wo der rechtliche Eigentümer auch Manager ist und damit sämtliche Verfügungsrechte in seinen Händen bündelt. Denkbar ist aber auch, dass den Managern eben nicht eine Vielzahl von stimmrechtsbefähigten rechtlichen Eigentümern gegenüber stehen. Sind Stimmrechte in der Hand von einem oder wenigen konzentriert,

1 Vgl. Ernst/Gassen/Pellens (Befragung, 2005), die sich auf die Befragung von 800.000 (!) Aktionären der Deutsche Post AG stützen. Grundlegend ist hier bereits die Untersuchung von Berle/Means (Modern Corporation, 1967), die bei 200 großen „corporations" in den USA etwa 50\% identifizieren, die von den Managern kontrolliert werden; so dass sie hinsichtlich eines Anteilseigners konstatieren: „He becomes simply a supplier of capital on terms less definite than those customarily given or demanded by bondholders; ... he is, in a highly modified sense, not dissimilar in kind from the bondholder or lender of money" (S. 245); vgl. auch den Literaturüberblick bei Arlen/Weiss (Theory of Corporate Taxation, 1995) S. 335. Der Vergleich der Publikumsaktionäre mit Fremdkapitalgebern findet sich aber z.B. schon bei Schanz (Die direkten Steuern Hessens, 1885) S. 318. Einblicke in die empirische Forschung zur Kontrollstruktur einer Unternehmung vermitteln z.B. Ipsen (Erklärungspotential von Williamsons Theorie, 2002) S. 69-72; Kaulmann (Unternehmungstheorie, 1987); Ruhwedel (Eigentümerstruktur, 2003).

2 Vgl. zu ähnlichen Überlegungen Milgrom/Roberts (Economics, Organization and Management, 1992) S. 314-315, die z.B. "normale" Aktionärsrechte als nicht residual einstufen; ansatzweise auch Orts (Legal Theory, 1998) S. 311; Putterman (Ownership, 1993) S. 248-250. Interessanterweise könnte auf diesem Wege die „alte“ juristische Denkweise des „Unternehmens an sich“ (vgl. Kap. II.3.2.2) auch ökonomisch untermauert werden; eine Verbindung, die sich auch bei Berle/Means (Modern Corporation, 1967) S. 309-313 findet. Interessant ist auch die Parallele zur Diskussion, welchen ökonomischen Status Minderheitsgesellschafter im Rahmen z.B. eines Konzernverbunds haben; vgl. dazu z.B. Wentland (Konzernbilanz, 1979) S. 33-44.

3 Vgl. ähnlich auch Valcárcel (Theorie der Unternehmung, 2002) S. 51, 54-55, 69-72. Interessanterweise könnte diese Argumentation auch eine zusätzliche Begründung einer eigenständigen Leistungsfähigkeit eines Unternehmens liefern; vgl. dazu Kapitel II.3.3.1.3. Bereits bei Schanz (Die direkten Steuern Hessens, 1885) S. 317-318 finden sich Überlegungen, die Aktionäre einer AG wirtschaftlich eher als Gläubiger anzusehen und so eine eigenständige (direkte) Besteuerung der AG zu rechtfertigen. Sofern auch Aktiengattungen unterschieden werden, gelten die Aussagen zu Publikumsaktionären in verschärfter Form für Vorzugsaktionäre; vgl. hierzu eindrucksvoll Wenger/Hecker (Vorzugsaktionär als bevorzugtes Plünderungsopfer, 2004). 
dürfte die Abgrenzung wieder anders verlaufen. So werden z.B. in einem auf Grossman/Hart aufbauenden Modell von Hart/Moore die kontrollierenden Anteilseigner aber nicht alle Anteilseigner - mit der Unternehmung identifiziert ${ }^{1}$.

Für Abgrenzungszwecke erscheint es in diesem Zusammenhang aber schwierig, Gruppenbeziehungen zwischen den Anteilseignern zuzulassen. Nicht nur, dass die Vorstellung einer Hierarchiespitze oder eines ,zentralen Koordinators“ mit einer Gruppe hierarchisch gleichwertig nebeneinander stehenden Individuen schwer vereinbar sein dürf$\mathrm{te}^{2}$. Auch dürfte es kaum möglich sein, eine eindeutige Grenze zwischen „wenigen“ und „vielen“ zu ziehen. Zudem kommen nur die Individuen allein und nicht als Gruppe als kontraktfähige Einheit und Rechtsträger in Frage ${ }^{3}$. Möglicherweise erscheint es deshalb für Zwecke der steuerlichen Gewinnermittlung opportun, nur einem einzelnen Individuum, mit Stimmrechtsmehrheit, als oberste Kontroll- und Entscheidungsinstanz einer Unternehmung zu akzeptieren. Diese Instanz, die wieder als „Unternehmer“ anzusehen ist, ist für Zwecke der Ressourcenzurechnung und -abgrenzung wie auch der Ertragsrealisation der Unternehmung zuzurechnen. Sie dürfte dann auch das (verantwortliche) Subjekt der steuerlichen Gewinnermittlung und den Anknüpfungspunkt steuerrechtlicher Rechtsfolgen bilden.

Die gewonnenen Erkenntnisse werden abschließend noch einmal thesenförmig zusammengefasst:

- Die Abgrenzung der rechnungslegenden Einheit für die steuerliche Gewinnermittlung könnte sich an dem ökonomischen Modell der Unternehmung in einer ressourcenorientierten Sichtweise orientieren.

- Diese Sichtweise ist immer auch nukleusbasiert, da Rechtsträger wie Unternehmen und Unternehmer in der Unternehmung letztlich die Ressourcen bündeln. Dabei gilt es, sämtliche Ressourcen dem steuerlichen Nettovermögensvergleich zuzuführen, die im ökonomischen Eigentum der Unternehmung stehen.

- Unternehmen sind selbst wie (mittelbare) Ressourcen zu berücksichtigen. An Unternehmern als natürlichen Personen kann kein ökonomisches Eigentum erworben werden, so dass diese nur als Hierarchiespitze in Frage kommen.

1 Vgl. Hart/Moore (Nature of the Firm, 1990); so interpretierend Wagner (Grenzen, 1994) S. 148. Die Akzeptanz einer natürlichen Person als Hierarchiespitze ist sogar in der juristischen Literatur zu finden; vgl. z.B. Birkholz (Aktienrecht, 1966) S. 712, der dafür auch den Unternehmensbegriff verwendet, sowie Kap. III.2.3.1.

2 Anders allerdings Vanberg (Markt und Organisation, 1982) S. 15-22, der neben „monokratischhierarchischer" auch eine Organisation korporativen Handelns in „genossenschaftlich-demokratischer" Variante anerkennt.

3 Die rechtliche Berücksichtigung einer Gruppe hieße i.S.d. methodologischen Individualismus erneut, eine Rechtsfiktion nach Maßgabe einer juristischen Person bzw. eines Unternehmens zu schaffen. Dadurch wird indes nicht die hier gestellte Frage beantwortet, ob die sich auch dahinter verbergenden, nur einzeln rechtsfähigen Individuen zu berücksichtigen sind oder nicht. 
- Anknüpfungspunkt der Abgrenzung ist die oberste Kontroll- und Entscheidungsinstanz, hinter der sich entweder ein Unternehmen oder ein Unternehmer verbergen kann. Nur sie kann letztlich der Rechtsfolgeverpflichtete sein, wenn die Rechtsfolgen auch wirtschaftlich die gesamte Unternehmung treffen soll.

- Vertragspartner der Unternehmung, die nicht Ressourceneigentümer sind, sind für Rechnungslegungszwecke dem Markt zuzurechnen.

- Für Zwecke der steuerlichen Gewinnermittlung erscheint ein engeres juristisches Vertragskonzept gegenüber einem weiteren ökonomischen Konzept vorteilhafter. Ökonomische Eigentumsbeziehungen werden damit auf diejenigen beschränkt, denen Rechtsverträge zu Grunde liegen.

- Ökonomisches Eigentum manifestiert sich über das Halten residualer Entscheidungs- und Kontrollrechte und damit der Rechte an der Ressourcenverwendung. Es manifestiert sich nicht allein über das Residualeinkommens- bzw. Residualrisikokonzept.

- Bezogen auf das Eigentum an Unternehmen können Stimmrechte als Indiz für residuale Entscheidungs- und Kontrollrechte angesehen werden; eine finanzielle Beteiligung ist dafür nicht zwingend erforderlich. Unter Vereinfachungsgesichtspunkten dürfte das Vorliegen von $50 \%$ plus einer Stimme ein geeignetes Identifikationskriterium darstellen.

\section{Zwischenergebnis}

Im zweiten Kapitel ist ein normativer Beurteilungsrahmen für die konsolidierte steuerliche Gewinnermittlung entwickelt worden. Wie in Abb. 6 aufgezeigt wird, beruht dieser Rahmen auf Kriterien, die auf die steuerliche Gewinnermittlung an sich sowie auf die Identifikation und Abgrenzung der rechnungslegenden Einheit zielen. Erstere sind ökonomisch und ethisch-verfassungsrechtlich fundiert, während letztere insbesondere auf den Erkenntnissen der (institutionen-)ökonomischen Theorie der Unternehmung beruhen.

Der Beurteilungsrahmen ist im Wesentlichen von fünf Wertungsdimensionen geprägt. So hat die steuerliche Gewinnermittlung erst einmal grundsätzlich einem Anforderungsprofil zu folgen, das grob mit der Entscheidungsneutralität (Wirkungsorientierung), sonstigen Effizienzargumenten (Durchführungsorientierung) sowie der Gleichmäßigkeit bzw. Gerechtigkeit umrissen werden kann. Letztere wird zudem durch das verfassungsrechtliche Legalitätsprinzip ergänzt. Um konsolidierungsspezifische Aspekte besser würdigen zu können, sind zudem Erkenntnisse über die unternehmungsorientierte Abgrenzung der rechnungslegenden Einheit generiert und dem normativen Rahmen als weitere Dimension hinzugefügt worden. Diese fünfte Dimension schafft allerdings keine völlig eigenständige Wertungsdimension, sondern fokussiert unter Zuhilfe- 
nahme geeigneter ökonomischer Sichtweisen auf eine andere Frage, bei der die originären Wertungsdimensionen aber weiterhin Bestand haben.

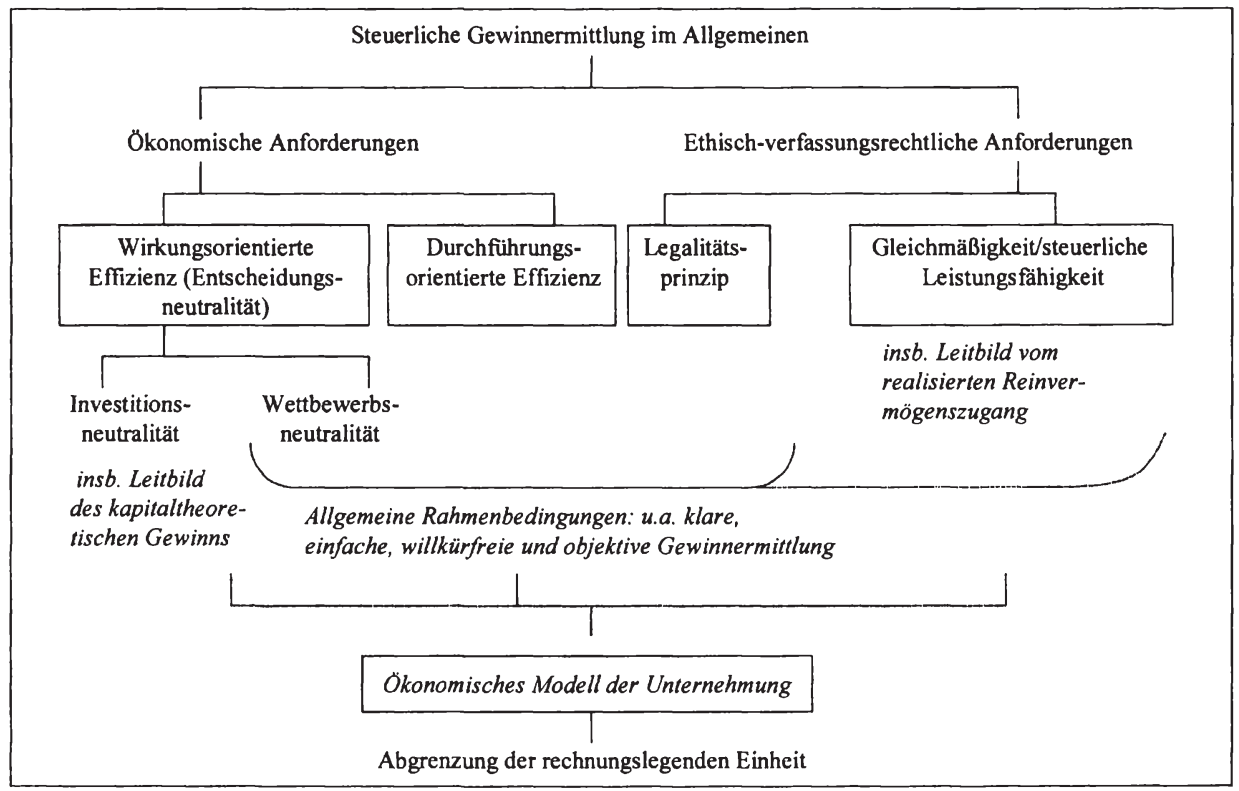

Abb. 6: Normative Anforderungen an die konsolidierte steuerliche Gewinnermittlung

Der insoweit entwickelte Beurteilungsrahmen ist mehrdimensional und wird angesichts seiner durchaus heterogenen Wertungsdimensionen die Forschungsfrage nicht immer eindeutig beantworten können. Dimensionsübergreifende Gemeinsamkeiten sind dennoch unverkennbar. Dies betrifft z.B. die mehr oder minder starke Zahlungsorientierung und die Forderung nach einer klaren, einfachen, willkürfreien und objektiven Gewinnermittlung. Gerade letztere ergibt sich aus wirkungsorientierter (wettbewerbsneutraler) wie durchführungsorientierter Effizienzsicht, aber auch der Sicht des verfassungsrechtlichen Legalitätsprinzips und der gerechtigkeitsgetriebenen steuerlichen Leistungsfähigkeit. In dieser Forderung dokumentiert sich aber auch der wenig konkrete Charakter mancher Beurteilungskriterien, die insbesondere aus der wettbewerbsneutralen oder durchführungseffizienten Perspektive resultieren. Dem kann allerdings in den Worten von Alm entgegnet werden: „In short, the search for a general scheme that specifies, for all countries and all times, the details of an optimal tax system is certain to fail. There are simply too many details that must be known ... . Still, this should not discourage the search for specific tax design - and, especially, tax reform - guidelines that apply to a 
single country at a point in time ... . Such guidelines will necessarily be couched in general terms"'.

Alm ist auch deshalb ein gutes Beispiel, weil er aufzuzeigen vermag, dass mehrere Wertungsdimensionen ökonomischer wie auch ethischer Natur beileibe kein deutsches Phänomen darstellen ${ }^{2}$, auch wenn sie regelmäßig nicht tiefgehender präzisiert werden. So betont Alm zudem: ,taxes must be raised ... in a way that treats individuals fairly (equity), that minimizes interference in economic decisions (efficiency), and that does not impose undue costs on taxpayers or tax administrators (simplicity)"3. In dieser Einschätzung wird er z.B. auch von Whittington unterstützt, der „equity“, „neutrality“ und „administrative effectiveness“ als Besteuerungsprinzipien betont ${ }^{4}$. Ähnliches findet sich u.a. auch bei(m) AICP $A^{5}$, Brazer $^{6}$, Devereux $^{7}$, IFS $^{8}$, Johnson $^{9}$, Mavraganis $^{10}$, Nobes $^{11}$ oder Stiglitz/Schönfelder ${ }^{12}$. Die ökonomische Komponente ist dabei oft nicht auf die allokative Deutung beschränkt. Entweder wird neben der „neutrality“ explizit auch die „simplicity“ oder ,administrative effectiveness“ als Ziel genannt, oder es wird, wie bei Nobes, mit den „minimum total cost“ eine sehr breite Definition der ökonomischen Komponente verwendet. In dieser Breite kommen letztlich die ökonomischen Wertungsdimensionen der vorliegenden Arbeit zum Tragen, die sich z.B. auch in der Forderung „all parties, all taxes and all costs“von Scholes/Wolfson ausdrücken ${ }^{13}$. Dieses für die derzeitige US-amerikanische Steuerliteratur zentrale Motto zielt schließlich darauf

Alm (optimal tax system, 1996) S. 131.

2 Zweifelnd allerdings Wagner (Gegenstand und Methoden, 2004) S. 248: „Deshalb erscheint es als problematisch, wenn Ökonomen sich in der deutschen Steuerreformdiskussion einer [wertungsorientierten] Denkschule anschließen, deren Kategorien sich international etablierten wissenschaftlichen Diskursregeln entziehen" [Klammereinschub hinzugefügt]. Alm (optimal tax system, 1996) S. 117

Vgl. Whittington (Tax Policy, 1995) S. 452.

Vgl. AICPA (Guiding Principles, 2002), die aber insg. zehn Prinzipien definieren; ähnlich (über-)breit z.B. auch Strunk (Ende der Maßgeblichkeit, 2003) S. 398-400.

6 Vgl. Brazer (Report, 1967) S. 671-672, der u.a. ,horizontal and vertical equity“, aber auch die (eher allokativ als Neutralität gedeutete) ,efficiency“ betont.

7 Vgl. Devereux (Debating Proposed Reforms, 2004) S. 80, der "equity" trotz kritischer Sichtweise in seinen vierdimensionalen Bewertungsrahmen (als nachgeordnetes Prinzip) integriert.

8 Vgl. IFS (Corporation Tax for the 1990s, 1991) S. 10, das die Notwendigkeit von "economic efficiency, as evidenced by neutrality", "faimess" und "administrative simplicity" betont und diese Elemente auch definiert.

9 Vgl. Johnson (All-Purpose Concept, 1954) S. 227: "equity among subjects taxed; economic consequences; and administrative feasibility".

10 Vgl. Mavraganis (Tax Harmonization, 1993) S. 222-223 mit neun Kriterien.

11 Vgl. Nobes (Framework for the Taxable Income, 2004) S. 37-41.

12 Vgl. Stiglitz/Schönfelder (Finanzwissenschaft, 1989) S. 408-427 mit fünf Kriterien.

13 Vgl. Scholes/Wolfson (Taxes and Business Strategy, 1992) insb. S. 3, die aber weniger die normativen Rechtsanalytiker als Zielgruppe ansehen, sondern mehr die (betriebswirtschaftlichen) Steuerplaner; vgl. zur Bedeutung auch Shackelford/Shevlin (Empirical tax research, 2001) S. 321-323; Shevlin (Research in Taxation, 1999) S. 431-433; Slemrod (Tax from Any Angle, 2003) S. 146-149. 
$\mathrm{ab}$, die Bandbreite steuerlicher Wirkungen ${ }^{1}$ auf die zumindest direkt betroffenen Parteien (Steuerpflichtige und staatliche Stellen) sowie sämtliche sonstige Kosten zu berücksichtigen $^{2}$.

Insgesamt verbleibt dieses zweite Kapitel aber noch auf einem vergleichbar hohem Abstraktionsniveau. Mit Hinblick auf die eingangs kurz definierte Konsolidierung wird zum Abschluss dieses Kapitels deutlich, dass das Phänomen der Konsolidierung noch nicht erklärt und entsprechende Vorgehensweisen noch nicht konkretisiert werden konnten. Deshalb ist es notwendig, im Folgenden konkrete rechtliche Nebenbedingungen zu berücksichtigen, die in Verbindung mit den normativen Anforderungen eine Konsolidierung überhaupt erst erklären und Hinweise auch zu konkreteren Fragen ihrer Ausgestaltung geben können. Dabei ist durchaus möglich, dass diese Nebenbedingungen normative Anforderungen relativieren und einschränken.

1 Scholes/Wolfson (Taxes and Business Strategy, 1992) S. 2 differenzieren i.d.Zshg. eigentlich zwischen expliziten ("tax dollars paid directly to taxing authorities“) und impliziten Steuern (,taxes that are paid indirectly in the form of lower before-tax rates of return on tax-favored investments").

2 Hierbei berücksichtigen sie neben den wirkungsorientierten Effekten auch sonstige „frictions“, $\mathrm{zu}$ deren Konkretisierung sie Transaktionskosten heranziehen; vgl. Scholes/Wolfson (Taxes and Business Strategy, 1992) S. 7. 


\section{Kapitel III}

\section{Konsolidierte steuerliche Gewinnermittlung als Konsequenz normati- ver Anforderungen und rechtlicher Nebenbedingungen}

Im vorangegangenen Kapitel ist ein normativer Rahmen für die konsolidierte steuerliche Gewinnermittlung entwickelt worden. Dieser Rahmen soll später trotz aller Heterogenität der einzelnen Anforderungskriterien, ihrer theoretischen Schwächen und oft fehlenden Konkretisierung herangezogen werden, um die Ausgestaltung der konsolidierten steuerlichen Gewinnermittlung zu beurteilen. Obwohl dieser Rahmen später auch der Beurteilung konsolidierungsspezifischer Aspekte dient, ist die Konsolidierung an sich noch nicht ausreichend beleuchtet worden. Dieser Aufgabe dient das folgende Kapitel.

In einem ersten Schritt wird aufgezeigt, dass die Konsolidierung als ein Versuch verstanden werden kann, eine originär rechtsformorientierte Unternehmenssicht im Zuge der steuerlichen Gewinnermittlung in das ökonomische Modell der Unternehmung zu überführen (Kapitel III.1). Nur durch diese Überführung erhält das zentrale Definitionsmerkmal der Konsolidierung, die Zusammenfassung von mehreren Einzelgewinnermittlungen, überhaupt erst einen Sinn. Die Konsolidierung wird hier konkret als technisches Bindeglied zwischen zwei grundlegenden Besteuerungsprinzipien, dem rechtsform- und unternehmensorientierten Trennungsprinzip und der unternehmungsorientierten Einheitstheorie, vorgestellt.

In diesem ersten Schritt wird bereits angedeutet, dass die konsolidierte steuerliche Gewinnermittlung in einem Spannungsfeld von normativen Anforderungen und rechtlichen Nebenbedingungen angesiedelt ist. Da die abstrakten normativen Anforderungen bereits im vorangegangen Kapitel präsentiert worden sind, sollen deshalb in einem zweiten Schritt konkrete rechtstatsächliche Restriktionen am Beispiel der nationalen deutschen (Steuer-)Rechtsordnung beleuchtet werden (Kapitel III.2). Hierbei geht es aber nicht nur darum, die Abhängigkeit konsolidierungstechnischer Fragen von rechtlichen Zwängen exemplarisch aufzuzeigen. Es geht auch um eine konkrete Beschreibung, wie die Bezugsgröße der steuerlichen Gewinnermittlung in der deutschen Steuerrechtsordnung ausgestaltet worden ist und wie hierbei Trennungsprinzip und Einheitstheorie aufeinanderprallen.

Das Kapitel schließt mit einer kurzen Zusammenfassung, in der auch die Konsequenzen für das weitere Vorgehen festgehalten werden (Kapitel III.3). 


\section{Konsolidierung im Spannungsfeld von Trennungsprinzip und Einheitstheorie}

\subsection{Trennungsprinzip und Einheitstheorie als grundlegende Besteuerungs- prinzipien}

\subsubsection{Trennungsprinzip und Einzelgewinnermittlung}

Die rechtsformorientierte Unternehmenssicht und das ökonomische Verständnis von einer Unternehmung finden ihren Niederschlag in zwei grundlegenden Besteuerungsprinzipien, die mit jeweils unterschiedlicher Gewichtung in den nationalen Steuerrechtsordnungen zur Anwendung kommen: Das Trennungsprinzip' (separate-entity approach), das ausschließlich auf die rechtliche Unternehmenssicht abstellt, und die Einheitstheorie (single-entity approach), die sich von der rechtlichen Sicht löst und auf eine wie auch immer abgegrenzte ökonomische Einheit zielt.

Weltweit dominant ist wohl das Trennungsprinzip, das auf das rechtsfähige Unternehmen als eigenständiges Steuersubjekt abstellt ${ }^{2}$ und das auch terminologisch in der „Unternehmensbesteuerung" seine Entsprechung findet. Hinter dem Unternehmen steht die Rechtsfigur der juristischen Person, die als eigenständiger Rechtsträger auch Steuersubjekteigenschaft erhalten und der Körperschaftsteuer unterworfen werden kann. Der Dualismus von Einkommen- und Körperschaftsteuer basiert dabei auf der Trennung von menschlich-personaler und sachlich-institutionaler Ebene ${ }^{3}$, die sich in der gesellschaftsrechtlichen Trennung von Gesellschafter- bzw. Mitgliederebene auf der einen und rechtsfähiger Gesellschaftsebene auf der anderen Seite widerspiegelt ${ }^{4}$. Nur durch diese Trennung können steuerrechtsfähige Unternehmen als selbständige Steuersubjekte der Körperschaftsteuer unterworfen und deren Einkommen unabhängig von dem der Anteilseigner ermittelt und besteuert werden. Abgeleitet aus dem Zivilrecht, wo mittels des Trennungsprinzips die Eigenständigkeit der juristischen Person gewahrt wird, haben steuerrechtsfähige Unternehmen somit auch steuerlich eigene Rechte und vor allem auch Pflichten, die nicht Rechte und Pflichten anderer menschlicher oder sachlicher Rechtsträger sein können. So greift erst bei Ausschüttung an die Anteilseigner des steuerrechtsfähigen Unternehmens die zweite Besteuerungsebene (Gesellschafterebene), unabhängig davon, ob es sich bei ihnen wiederum um steuerrechtsfähige Personen handelt. Ökonomische Vorstellungen von einer Unternehmung werden hier im Grundsatz ebenso negiert wie die Existenz von Unternehmensverbindungen, so dass nur das ein-

I Im Zusammenhang mit Unternehmensgruppen spricht die deutsche Literatur auch vom Vielheitskonzept; vgl. z.B. Jacobs/Spengel (Deutschland und Frankreich, 1994) S. 100-101; Rupp (Ertragsbesteuerung nationaler Konzerne, 1983) S. 26.

2 Vgl. zur Dominanz des Trennungsprinzips in den EU-Staaten z.B. Scheuchzer (Konzernbesteuerung, 1994) S. 28; dazu auch die Übersicht in Kap. IV.1.1. Vgl. zur weltweiten Dominanz z.B. Jacobs (Internationale Unternehmensbesteuerung, 2002) S. 291.

3 Vgl. terminologisch ähnlich Elschen (Institutionale oder personale Besteuerung, 1994).

4 Vgl. Kübler (Gesellschaftsrecht, 1999) S. 29, 312; Wiedemann (Gesellschaftsrecht, 1980) S. 198-199. 
zelne Unternehmen zählt und zwar in Abhängigkeit von der Rechtsform, der die jeweilige Rechtsordnung eigene Steuersubjektivität verliehen hat.

Das Trennungsprinzip gibt der steuerlichen Gewinnermittlung auch die rechnungslegende Einheit vor. Das über seine Rechtsform als Körperschaftsteuersubjekt qualifizierte Unternehmen bildet die rechnungslegende Einheit für die steuerliche Gewinnermittlung auf Unternehmens- bzw. Gesellschaftsebene. Für diese Einheiten gestaltet sich die steuerliche Gewinnermittlung als isolierte Einzelgewinnermittlung, unabhängig davon, ob das Unternehmen in eine umfassendere Unternehmungsorganisation eingebunden ist. Vermögen und Schulden nur dieser einzelnen Rechtseinheit werden erfasst. Lediglich Eigenkapitalverflechtungen mit untergeordneten Unternehmen spiegeln sich in dem Beteiligungsansatz als Wirtschaftsgut ${ }^{1}$ wider. Diese Beteiligung ist gewissermaßen Ausdruck des zivilrechtlichen Eigentumsanteils an den Ressourcen (Vermögen und Schulden) des Beteiligungsunternehmens. Für die Einzelgewinnermittlung des Beteiligungsunternehmens ergeben sich hieraus erst einmal keine Konsequenzen. Zudem wird das jeweils andere Unternehmen in der Gewinnermittlung beider Unternehmen hinsichtlich der Ergebnisrealisation weiterhin wie ein fremder Dritter behandelt ${ }^{2}$. Die Grenze zwischen unternehmerischer Organisation und Markt wird dadurch verschoben, bestimmte Organisationsbereiche werden dem Markt zugeordnet.

Das Trennungsprinzip und die hieraus erwachsene Einzelgewinnermittlung gehen letztlich von der Fiktion der wirtschaftlichen Autonomie der steuerrechtsfähigen Unternehmen aus ${ }^{3}$. Probleme ergeben sich immer dann, wenn diese Autonomie realiter nicht existiert. Korrekturmechanismen werden notwendig, die diese Fiktion zu retten versuchen. Zentraler Mechanismus ist hier der sog. Fremdvergleich (dealing at arm's length), der eine Vertragsgestaltung und Bepreisung wie unter fremden Dritten unterstellt. Darin drückt sich der Versuch aus, in der steuerlichen Gewinnermittlung dasjenige Ergebnis zu ermitteln, das sich bei einer selbständigen Einheit ergeben hätte. So gelten Verrechnungspreise von Liefer- und Leistungsbeziehungen dann als angemessen, wenn sie auch

1 Wirtschaftsgüter bezeichnen den steuerrechtlichen Gegenstand der Aktivierung (und Passivierung), ohne diesen hier konkreter eingrenzen oder definieren zu wollen; vgl. zu diesbezgl. normativen Sichtweisen Kap. II.2.1.2.1 und II.2.2.4. Im deutschen Steuerrechtssystem wird der Wirtschaftsgutsbegriff über die BFH-Rechtsprechung anhand der ,selbständigen Bewertbarkeit', ,Objektivität' und ,bilanziellen Greifbarkeit' konkretisiert; vgl. m.w.N. Gruber (BFH-Rechtsprechung, 1991) S. 108137; Knobbe-Keuk (Bilanz- und Unternehmenssteuerrecht, 1993) S. 86-89; Moxter (Bilanzrechtsprechung, 1999) $§ 3$. Oft werden passivierte Schulden als negative Wirtschaftsgüter ebenfalls unter den Begriff des Wirtschaftsguts subsumiert; vgl. z.B. Jacobs (Ertragsteuerbilanz, 1971) S. 91-96.

2 Kritisch dazu bereits Hoffmann (Konzern-Bilanz, 1930) S. 29, der feststellt: „Die wirtschaftliche Einheit des Konzerns als eines Gesamtunternehmens kommt in der gewöhnlichen Bilanz der Obergesellschaft nicht zum Ausdruck"; ebenso Bores (Konsolidierte Erfolgsbilanzen, 1935) S. 20-24.

3 Vgl. Ordelheide (Konzern, 1986) S. 302. 
unter fremden Dritten unter gleichen oder ähnlichen Bedingungen Bestand hätten ${ }^{1}$. Andernfalls werden sie mit den entsprechenden Erfolgswirkungen künstlich korrigiert. Dies dient dem Ziel, eine verursachungsgerechte Gewinnzuordnung innerhalb einer Gruppe miteinander verbundener Unternehmen zu gewährleisten². Mit dieser Vorgehensweise nimmt das jeweilige Steuerrecht Vertrags- und vor allem Abhängigkeitsbeziehungen zwischen Rechtsträgern zumindest wahr und unterstellt, keineswegs zu Unrecht, dass diese zu nicht marktgerechtem Verhalten führen (können). Die künstliche Korrektur dieses Verhaltens beruht aber letztlich auf einer realiter kaum möglichen Ermittlung fiktiver Markttransaktionsbedingungen zwischen unabhängigen Marktparteien in einer ansonsten gleichen Situation. Die damit einhergehenden Schwierigkeiten dokumentieren sich eindrucksvoll in der endlosen Debatte über (künstliche) steuerliche Verrechnungspreise ${ }^{3}$. Diese künstliche Korrektur ist aber auch Ausdruck eines steuerrechtlich oktroyierten Trennungsprinzips, das etwas zu trennen versucht, was insbesondere in ökonomischer Hinsicht gar nicht zu trennen ist. Aus ökonomischer Perspektive ist es ja gerade Sinn und Zweck der Unternehmung als Vertragsgeflecht, den Beteiligten Vorteile gegenüber normalen Markttransaktionen einzuräumen ${ }^{4}$. Insofern wäre in dieser Sichtweise die enge steuerrechtliche Abgrenzung des Steuersubjekts und damit das Trennungsprinzip an sich zu hinterfragen.

\subsubsection{Einheitstheorie und Gesamtgewinnermittlung}

Anders als das Trennungsprinzip knüpft die Einheitstheorie (single-entity approach) an der Unternehmung als Ganzes an und nicht ausschließlich an rechtlich separierten Teileinheiten. Unterschiede zum Trennungsprinzip ergeben sich also immer dann, wenn das einzelne Unternehmen zu einer Gruppe von Unternehmen gehört, die in ihre Gesamtheit eine wirtschaftlich autonome Unternehmung bilden. Sie auch steuerlich als Einheit zu

1 Vgl. umfassender z.B. Kumpf (Steuerliche Verrechnungspreise, 1976) S. 90-99 m.w.N. zur Kodifizierung des Fremdvergleichsgrundsatzes in nationalen Steuersystemen. Vgl. zu dessen Konkretisierung nach Maßgabe international anerkannter Standardmethoden, die insb. in entsprechenden OECDBerichten und -Abkommen ihren Niederschlag gefunden haben, z.B. Baumhoff (Verrechnungspreise, 1986) S. 50-165; Baumhoff (Konzernverrechnungspreise, 1998); Nientimp (Steuerliche Gewinnabgrenzung, 2003) S. 111-144; Scheffler (Besteuerung der grenzüberschreitenden Unternehmenstätigkeit, 2002) S. 315-343; Theisen (Methoden, 1990). Der Fremdvergleichsgrundsatz ist durch innerstaatliche Gewinnkorrekturvorschriften, wie z.B. die verdeckte Gewinnausschüttung, die verdeckte Einlage und auch $\S 1 \mathrm{AStG}$, auszufüllen; vgl. dazu Jacobs (Internationale Unternehmensbesteuerung, 2002) S. 669-685; Rose (Gegenwartsprobleme, 1966) S. 298-300; Wassermeyer (Streitfragen zur grenzüberschreitenden verdeckten Gewinnausschüttung, 1998) Tz. 664-668.

2 Vgl. zu derartigen Rechtfertigungsansätzen z.B. Baumhoff (Verrechnungspreise, 1986) S. 50-52, 89165; Elvidge (Arm's length, 1994); Kumpf (Steuerliche Verrechnungspreise, 1976) insb. S. 102-105.

3 Vgl. zu dieser umfangreichen Diskussion stellvertretend Nientimp (Steuerliche Gewinnabgrenzung, 2003) insb. S. 111-171 m.w.N.

4 Vgl. umfassend Nientimp (Steuerliche Gewinnabgrenzung, 2003) S. 144-160; Schneider (Verrechnungspreise, 2003) S. 53-56; bereits ähnlich z.B. Niemann (Gewinnrealisierung innerhalb des Konzerns, 1968) S. 26-40, 106-108, 162-167; Rasch (Vorschriften des Steuerrechts, 1972) S. G 33-G 54. 
betrachten, ist Ziel der Einheitstheorie, die als „Antithese ${ }^{\text {(6) }}$ zum Trennungsprinzip entwickelt wurde ${ }^{2}$. Die Einheitstheorie folgt damit eher einem ökonomischen Verständnis von unternehmerischer Organisation in seiner Projektion auf die steuerliche Gewinnermittlung. In der Literatur wird sie aber regelmäßig ohne weitere Konkretisierung geliefert. Insofern kann sie auch nicht allein beantworten, wann überhaupt eine unternehmensübergreifende konsolidierte steuerliche Gewinnermittlung vorzunehmen und wie die rechnungslegende Einheit hierbei abzugrenzen ist. Hierfür bedarf es der konkreteren Festlegung auf ein ökonomisches Modell der Unternehmung.

Während beim Trennungsprinzip Steuersubjekteigenschaft und rechnungslegende Einheit zusammenfallen, können diese bei der Einheitstheorie einander entsprechen, müssen es aber nicht. So wird im einheitstheoretischen Idealfall die gesamte Unternehmensgruppe zu einer Art rechtlicher Besteuerungseinheit zusammengefasst und als solche selbst zum Steuersubjekt erhoben. Alternativ ist denkbar, dass die Steuersubjekteigenschaft bei den einzelnen Rechtsträgern verbleibt und sich die rechnungslegende Einheit dennoch über die gesamte Gruppe erstreckt. Letztere ist hier zwar kein Steuersubjekt mehr, aber immer noch Gewinnermittlungsobjekt ${ }^{3}$. Diese Alternative hätte ihren Reiz insbesondere in denjenigen Rechtsordnungen, in denen die Steuersubjektivität einer ganzen Unternehmensgruppe der Einheitlichkeit der Rechtsordnung (zu stark) widerspricht ${ }^{4}$. Die tatsächliche (Steuer-)Rechtsfähigkeit der Gruppe wird hier durch die Fiktion derselben ersetzt, um die Bemessungsgrundlage im Sinne der Einheitstheorie zu erhalten $^{5}$. Da die tatsächliche Steuersubjekteigenschaft weiterhin bei den Unternehmen verbleibt, obliegt es z.B. dem Fiskus, einen Aufteilungsmodus für diese Bemessungsgrundlage zu entwickeln. Diese Aufgabe ähnelt dem schwierigen Unterfangen des Fremdvergleiches und geht zwangläufig mit Elementen der Willkür einher ${ }^{6}$. Alternativ könnten die einzelnen Unternehmen auch gesamtschuldnerisch für die Steuerschuld in

1 Scheuchzer (Konzernbesteuerung, 1994) S. 36.

2 In Deutschland ist dies schon Anfang des 20. Jahrhunderts geschehen; vgl. wohl erstmalig Isay (Recht am Unternehmen, 1910) insb. S. 87-137, der z.B. konstatiert: „Das Wesen einer Filiale beispielsweise wird doch nicht dadurch geändert, daß sie zu einer Aktiengesellschaft erhoben wird" (S. 102) oder „Ich glaube demnach, daß in solchen Fällen trotz Verschiedenheit der beteiligten Rechtssubjekte ein einheitliches, wenn auch zusammengesetztes Unternehmen vorliegt, an dem ein einheitliches subjektives Recht besteht" (S. 104). Die Einheitstheorie ist hier insb. auch i.R.d. sog. Organschaftstheorien diskutiert worden; vgl. dazu früh im Überblick Friedländer (Organtheorie, 1931); Hoffmann (Konzern-Bilanz, 1930) S. 39-42; umfassend und m.w.N. auch Wöhe (Steuerlehre, 1996) S. 77-100. Vgl. beispielhaft zur internationalen Literatur Banks/Fredrickson (Single-Entity Approach, 1997); Choate/Mason (Single-Entity Theory, 1994); Rainey/Sams (Intercompany Transaction, 1995) S. 463-464.

3 Vgl. zu ähnlichen Differenzierungen z.B. auch Jacobs/Spengel (Deutschland und Frankreich, 1994) S. 101; Senger (Konzernertragsbesteuerung 1997) S. 135.

4 Vgl. zu dem Gedanken der Einheitlichkeit der Rechtsordnung bereits Kap. II.3.3.1.3.

5 Vgl. insb. Busse von Colbe et al. (Konzernabschlüsse, 2003) S. 25-26 sowie Kap. III.1.3 zu der identischen einheitstheoretischen Sicht in der rein informationsorientierten Konzernrechnungslegung.

6 Vgl. m.w.N. Mestmäcker (Verwaltung, 1958) S. 308; s.a. Kap. III.2.5, IV, V und VI. 
die Haftung genommen werden, um die Aufteilung der Gesamtunternehmung letztlich selbst zu überlassen ${ }^{1}$.

Unabhängig davon, ob die idealtypische (Steuersubjekt gleich rechnungslegende Einheit) oder eher die realtypische Variante (Steuersubjekt ungleich rechnungslegende Einheit) der Einheitstheorie gilt, liegt letztlich in beiden Fällen eine Art Gesamtgewinnermittlung vor, die als Einzelgewinnermittlung der gesamten Unternehmensgruppe definiert werden kann. Für diese einheitstheoretische Gesamtgewinnermittlung ergeben sich insofern die folgenden Anforderungen²:

- Das der Gruppe zugehörige Betriebsvermögen wird wie bei einem Unternehmen vollständig erfasst. Betriebsvermögensmehrungen werden aber nicht mehrfach erfasst und besteuert. So sind Mehrfachbesteuerungen gruppenintern ausgeschütteter Gewinne nicht möglich. Dies gilt gleichermaßen für Betriebsvermögensminderungen, die als Verluste nicht mehrfach zur Verrechnung kommen.

- Zwischen den Unternehmen einer Gruppe gibt es wie zwischen den Abteilungen innerhalb eines Unternehmens einen unbeschränkten und sofortigen Verlustausgleich.

- Die Unternehmensgruppe ist als solche wie ein Unternehmen abzubilden. Kapitalverflechtungen und insbesondere Liefer- und Leistungsbeziehungen zwischen den Unternehmen einer Gruppe sind deshalb interner Natur (und gelten deshalb als nicht realisiert) und können somit keine Ergebnis- und Steuerwirkung entfalten.

- Der Gewinn der gesamten Gruppe wird wie in einem Unternehmen unter gleichen Bedingungen, insbesondere auf der Basis einheitlicher Regeln und einheitlicher Zeiträume ermittelt.

Sofern dem Trennungsprinzip in Gänze entsprochen und der auf Unternehmen fokussierten Einzelgewinnermittlung gefolgt wird, ist keine der hier genannten Anforderungen aus Sicht einer Unternehmensgruppe erfüllt. Zwischenlösungen mit partiellen Ausnahmen vom Trennungsprinzip sind indes vorstellbar und werden auch realiter praktiziert $^{3}$. Dies gilt insbesondere für den Versuch, über Zurechnungssysteme die Mehrfachbesteuerung ausgeschütteter Gewinne innerhalb einer Gruppe zu vermeiden und einen Verlustausgleich zwischen den betroffenen Unternehmen zu ermöglichen ${ }^{4}$. Allen Anforderungen kann indes nur mit einer Gesamtgewinnermittlung entsprochen werden, die den Gewinn nach der Einheitstheorie auf der Basis einer die gesamte Unternehmensgruppe beinhaltenden rechnungslegenden Einheit ermittelt. Wie dies technisch bewerkstelligt werden kann, wird im Folgenden diskutiert.

1 Vgl. z.B. Herrmann (Reformbedürftiges Konzernsteuerrecht?, 1973) S. 42; dazu auch Kap. III.2.5.

2 Ein Teil dieser Anforderungen ist in der Literatur bereits formuliert worden; vgl. insb. Scheuchzer (Konzernbesteuerung, 1994) S. 39; ansatzweise Niemann (Gewinnrealisierung innerhalb des Konzerns, 1968) S. 106-108, 162-167.

3 Vgl. zum Status Quo in den EU-Mitgliedstaaten Kap. IV.1.1.

4 Vgl. hierzu den konkreten Fall der deutschen (körperschaftsteuerlichen) Organschaft in Kap. III.2.2. 


\section{2 Überführung des Trennungsprinzips in die Einheitstheorie durch Konsoli- dierung}

Wenn die der steuerlichen Gewinnermittlung zu Grunde liegende rechnungslegende Einheit eine Unternehmensgruppe umfassen soll, stellt sich die Frage, wie diese Gesamtgewinnermittlung in technisch-organisatorischer Hinsicht zu erstellen ist. Unter den denkbaren Alternativen sticht als einheitstheoretisch ideale Lösung eine originäre Steuerbilanz für die Unternehmensgruppe hervor'. Diese Form einer Gesamtgewinnermittlung korrespondiert mit der Idealvorstellung einer mit Steuersubjektivität ausgestatteten Unternehmensgruppe, die auch als solche eine originäre Finanzbuchhaltung besitzt, aus der die Steuerbilanz als Einzelgewinnermittlung für die Unternehmensgruppe unmittelbar entwickelt wird. Alle Unternehmen der Gruppe folgen hierbei einem einheitlichen Gewinnermittlungssystem. Korrekturmaßnahmen sind nicht erforderlich, soweit die rechnungslegende Einheit genau der Unternehmensgruppe entspricht. Alternativ kann die steuerliche Gesamtgewinnermittlung aber auch mittelbar aus einer originären Gesamtrechnung abgeleitet werden, die ihrerseits aus der Finanzbuchhaltung der Gruppe entwickelt wird, die aber anderen, insbesondere handels-, gesellschafts- und/oder kapitalmarktrechtliche Zwecken dient.

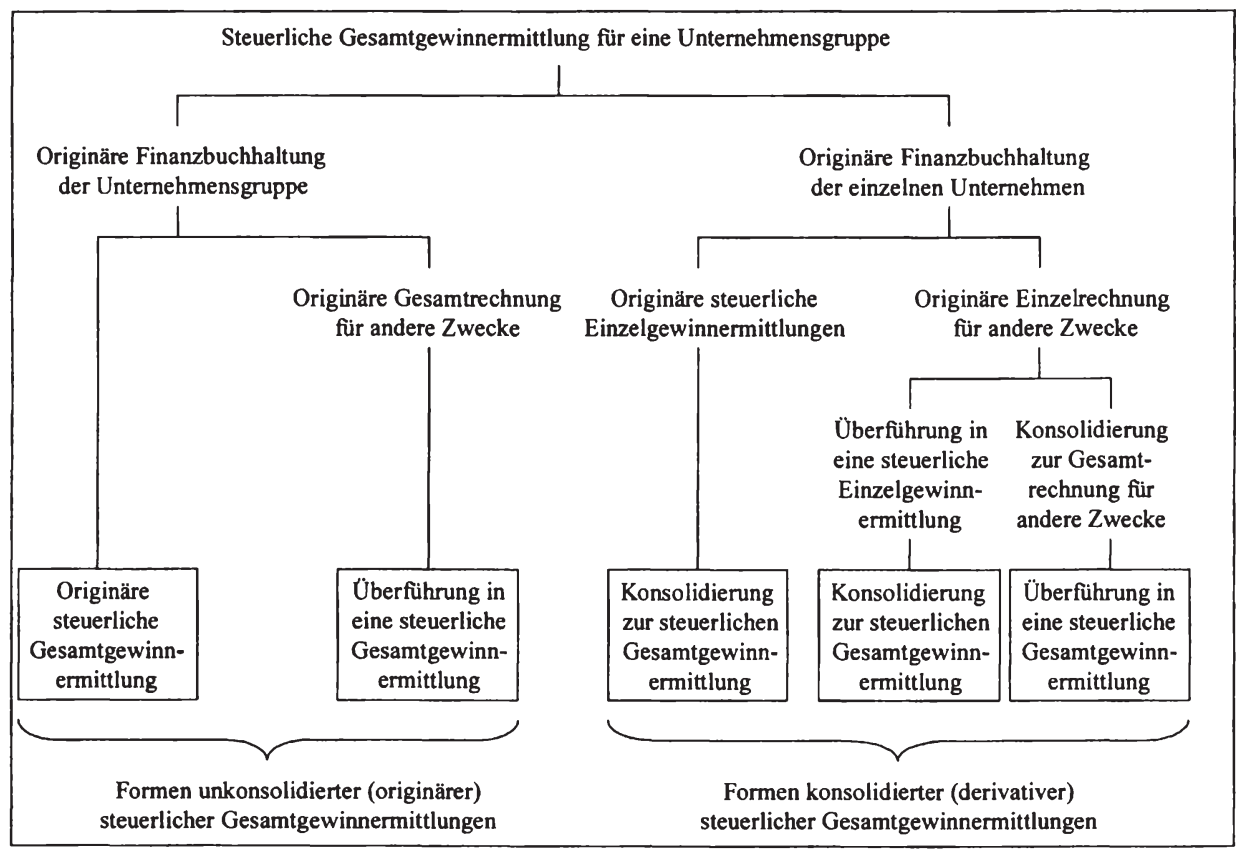

Abb. 7: Alternativen zur Erstellung einer steuerlichen Gesamtgewinnermittlung

1 Vgl. auch Rupp (Ertragsbesteuerung nationaler Konzerne, 1983) S. 74-81; Salzberger (Konzernunternehmung, 1994) S. 155 mit Hinweisen auf Bisani (Konzernbesteuerung, 1962) S. 190; Mühlschlegel (Gewinnermittlung für Konzerne, 1971) S. 103. 
Wie in Abb. 7 verdeutlicht, ergeben sich weitere Erstellungsalternativen ${ }^{1}$. So scheint eine originäre Steuerbilanz für eine Unternehmensgruppe in einer weiterhin unternehmensorientierten Rechtsumgebung wenig realistisch. Dies gilt insbesondere für den Fall, in dem die einheitstheoretische Ideallösung einer mit Steuersubjektivität ausgestatteten Unternehmensgruppe realiter nicht umgesetzt werden kann und durch die Reallösung mit weiterhin steuerrechtsfähigen Unternehmen ersetzt wird. Aber auch in dem Fall, in dem der Gruppe Steuersubjekteigenschaft zugesprochen wird, ohne jedoch die Rechtsträgerstellung der einzelnen Unternehmen in Frage zu stellen, scheint eine originäre Steuerbilanz für eine Unternehmensgruppe weniger durchführungseffizient, wenn - für welchen Zweck und auf welcher Rechtsgrundlage auch immer - die einzelnen Unternehmen auch weiterhin zur Finanzbuchhaltung und zur Einzelgewinnermittlung angehalten werden ${ }^{2}$. Durchführungseffizienter erscheinen deshalb diejenigen Alternativen, die auf den bereits vorhandenen Buchhaltungssystemen und den daraus resultierenden Einzelgewinnermittlungen der Unternehmen aufbauen.

Wenn die steuerliche Gesamtgewinnermittlung auf den Einzelgewinnermittlungen der Unternehmen aufbaut, ergeben sich wiederum unterschiedliche Möglichkeiten der technischen Erstellung. So kann die steuerliche Gesamtgewinnermittlung als derivative Steuerbilanz der Unternehmensgruppe auf den steuerlichen Einzelgewinnermittlungen der Unternehmen, also auf ihren freiwillig oder weiterhin pflichtgemäß zu erstellenden Steuerbilanzen aufbauen. Hierbei kann es sich um Steuerbilanzen handeln, die unmittelbar aus der Finanzbuchhaltung gewonnen oder die mittelbar über Formen der Maßgeblichkeit aus den Einzelabschlüssen für andere Zwecke abgeleitet werden ${ }^{3}$. Diese Steuerbilanzen sind für den Bereich der rechnungslegenden Einheit hinsichtlich ihrer Ermittlungsmethoden zu vereinheitlichen, zusammenzufassen und im Sinne der Einheitstheorie um gruppeninterne Verflechtungen zu korrigieren. Gerade diese Korrektur ist von zentraler Bedeutung, da sie sicherstellt, dass es eben nicht nur um die bloße Zusammenfassung von Bemessungsgrundlagen verschiedener Einheiten geht, sondern um die deri-

1 Vgl. zu ähnlichen Systematisierungen Rupp (Ertragsbesteuerung nationaler Konzerne, 1983) S. 43-44; Salzberger (Konzernunternehmung, 1994) S. 155; Senger (Konzernertragsbesteuerung, 1997) S. 3941.

2 So zeigen schon die bisherigen Erfahrungen mit der rein informationsorientierten Konzernrechnungslegung, dass eine originäre Konzern-Finanzbuchhaltung trotz entsprechender Forderungen in der Literatur (vgl. insb. Lehertshuber (Konzernhandelsbilanz, 1986) S. 181-199; Otte (Konzernbuchführung, 1988) S. 664-665; Pelka (Konzernbuchführung, 1991); Ruhnke (Konzernbuchführung, 1995) S. $107-$ 117) realiter nicht praktiziert wird.

3 So unterscheidet z.B. die OECD hinsichtlich der Verbindung von Tax und Financial Accounting drei Regulierungstypen: Vollständige Trennung der beiden Rechnungslegungen (z.B. USA, Großbritannien, Niederlande), vollständige Identität (z.B. Norwegen) und Ableitung der grundsätzlichen Basis des Tax Accounting aus dem Financial Accounting (z.B. Frankeich, Deutschland, Italien); vgl. OECD (Relationship between Taxation and Financial Reporting, 1987) S. 9. Aber selbst bei den vermeintlichen Trennungssystemen existieren Verbindungen, wie z.B. das Beispiel USA beweist; vgl. hierzu u.a. Dubroff/Cahill/Norris (Tax Accounting, 1983), Haller (Verhältnis, 1988); Kahle (Trennung, 1997); Lischer/Märkl (Conformity, 1997); Schreiber (Bedeutung, 2000). 
vative Ermittlung einer Bemessungsgrundlage für eine einzige rechnungslegende Einheit. Die Konsolidierung bildet hierbei die notwendige Korrekturtechnik, mittels derer alle Verflechtungen zwischen den Unternehmen, die in den so genannten Konsolidierungskreis einbezogen sind, bilanziell so bereinigt werden, dass sie insgesamt dem bilanziellen Bild einer einzigen rechnungslegenden Einheit entsprechen. Im Ergebnis muss eine steuerliche Gewinnermittlung nach dem Konsolidierungsmodell den gleichen Gewinn ermitteln, wie er sich auch aus einer originären Steuerbilanz der Gruppe ergeben würde. Die Konsolidierung überführt damit im Zuge der steuerlichen Gewinnermittlung die originär rechtsformorientierte Unternehmenssicht nach dem Trennungsprinzip in eine eher ökonomisch geprägte Sicht nach der Einheitstheorie, in dem die betroffene Unternehmensgruppe als rechnungslegende Einheit und damit als selbständiges Gewinnermittlungsobjekt behandelt wird.

Als Konsolidierung im engeren Sinne werden also Konsolidierungsmaßnahmen verstanden, die über die reine Addition der Einzelgewinnermittlungsdaten hinausgehen und die im Rahmen einer Kapital-, Schulden-, Aufwands- und Ertrags- bzw. Betriebsausgaben- und -einnahmenkonsolidierung ${ }^{1}$ sowie Zwischenergebniseliminierung durchgeführt werden ${ }^{2}$.

- Die Kapitalkonsolidierung betrifft dabei die Eigenkapitalverflechtungen zwischen den Unternehmen der Gruppe. In ihr werden die Beteiligungsbuchwerte aus den Einzelgewinnermittlungen der „Obergesellschaften“ mit den korrespondierenden Eigenkapitalposten der „Untergesellschaften“ verrechnet.

- In der Schuldenkonsolidierung werden die Fremdkapitalbeziehungen zwischen den Unternehmen der Gruppe und alle damit einhergehenden Konsequenzen bereinigt, indem die daraus resultierenden Bestandspositionen (insb. Forderungen und Schulden) miteinander verrechnet werden.

- In der Zwischenergebniseliminierung werden ergebniswirksame Transaktionen zwischen einbezogenen Unternehmen, die sich in einzelnen Bestandspositionen wertbeeinflussend niedergeschlagen haben, eliminiert.

- In der Aufwands- und Ertragskonsolidierung bzw. Betriebsausgaben- und -einnahmenkonsolidierung wird die Gesamtgewinnermittlung um Betriebsausgaben und -einnahmen korrigiert, die aus Transaktionen zwischen den Unternehmen der Gruppe resultieren. Diese Konsolidierungsmaßnahme zielt demnach nur auf die Korrektur ergebniswirksamer Stromgrößen. Sie geht entweder mit einer anderen Konsolidie-

I Leider bietet sich für diese Art der Stromgrößenkonsolidierung kein allgemeinerer Ausdruck an, der von der (auf Ansatz und Bewertung zielenden) Frage der jeweils verwendeten Stromgrößen abstrahiert. Die hier verwendete Terminologie, entweder aus der rein informationsorientierten Konzernrechnungslegung (Aufwands- und Ertragskonsolidierung) oder in Anlehnung an das deutsche EStG (Betriebseinnahmen und -ausgaben) soll deshalb eher allgemein auf diese Stromgrößen hinweisen.

2 Vgl. zu diesen vier Konsolidierungsmaßnahmen i.e.S. bereits Bores (Konsolidierte Erfolgsbilanzen, 1935) S. 53-162. 
rungsmaßnahme einher, die sich primär auf Bestandsgrößen bezieht (insb. Zwischenergebniseliminierung), oder ist alleine durchzuführen, wenn sich bestimmte Transaktionen nur auf Betriebsausgaben und -einnahmen auswirken'.

Die Konsolidierung im weiteren Sinne umfasst hingegen die Gesamtheit aller Verfahren zur Aufstellung einer Gesamtgewinnermittlung nach der Einheitstheorie, die aus den originären Einzelgewinnermittlungen der einbezogenen Unternehmen abgeleitet wird ${ }^{2}$. Dies umschließt

1. die Prüfung, ob überhaupt eine konsolidierte steuerliche Gewinnermittlung vorzunehmen ist,

2. die Abgrenzung des Konsolidierungskreises,

3. die Vorbereitung bzw. Vereinheitlichung der Einzelgewinnermittlungen der einbezogenen Unternehmen,

4. ihre Zusammenfassung in Form einer Summengewinnermittlung und

5. ihre anschließende Korrektur (Konsolidierung im engeren oder eigentlichen Sinne) nach Maßgabe der Einheitstheorie.

Bisher ist davon ausgegangen worden, dass die derivative Steuerbilanz der Unternehmensgruppe aus den einzelnen Steuerbilanzen der Unternehmen über die Konsolidierung entwickelt wird. Sie kann allerdings auch - wie in Abb. 7 gezeigt - aus einer anderen Zwecken dienenden Gesamtrechnung, in Deutschland z.B. dem handelsrechtlichen Konzernabschluss ${ }^{3}$, abgeleitet werden, der selbst wiederum das Ergebnis einer (handelsrechtlichen) Gewinnermittlung und Konsolidierung ist. Diese anderen Zwecken dienende Gesamtrechnung der konsolidierten steuerlichen Gewinnermittlung zu Grunde zu legen, muss in durchführungsorientierter Sicht nicht zwingend zu Effizienzvorteilen führen. So ist sie erst einmal inhaltlich-materiell in die steuerliche Gewinnermittlung zu überführen, ehe sie um eventuelle Abgrenzungsdifferenzen zum steuerlichen Konsolidierungskreis zu korrigieren ist. Weiterer Anpassungsbedarf kann sich bei den vorberei-

1 Die Abgrenzung der einzelnen Konsolidierungsverfahren ist in der rein informationsorientierten Konzernrechnungslegung nicht einheitlich. Fraglich ist insbesondere, ob die Schuldenkonsolidierung und Zwischenergebniskonsolidierung neben Bestands- auch Stromgrößenkorrekturen beinhalten und wie dann letztlich die Aufwand- und Ertragskonsolidierung abgegrenzt ist. Für die steuerliche Gewinnermittlung hat sich hier noch gar keine einheitliche sowie eigenständige Terminologie herausgebildet.

2 Vgl. die ähnlich weite Definitionen aus der rein informationsorientierten Konzernrechnungslegung von Adler/Düring/Schmaltz (Rechnungslegung, 1995) § 297 Tz. 49: „Gesamtheit aller Methoden und Verfahren zur Entwicklung einer Konzernbilanz aus den Einzelbilanzen“; vergleichbar weit auch Dreger (Konzernabschluß, 1969) S. 17; von Wysocki/Wohlgemuth (Konzernrechnungslegung, 1996) S. 3. Bores (Konsolidierte Erfolgsbilanzen, 1935) S. 5 bezieht sich hier bei der ursprünglichen Begriffsdeutung auf den Sprachgebrauch im Bergbau, wo Konsolidierung ,das Zusammenfassen mehrerer Bergwerke zu einem einzigen bedeutet“"

3 Vgl. hierzu genauer Kap. III.2.3.2.1. 
tenden Maßnahmen und bei den Konsolidierungsmaßnahmen im engeren Sinne ergeben.

Zusammenfassend kann somit festgehalten werden, dass die steuerliche Gewinnermittlung für eine Mehrzahl von Unternehmen entweder auf einer originären Gesamtgewinnermittlung aufbaut oder auf einer derivativen Zusammenfassung von Einzelgewinnermittlungen einbezogener Unternehmen. Von deutlich höherem Realitätsbezug ist wohl der zweite Fall, der in dieser Arbeit auch im Vordergrund steht. Die Zusammenfassung von Einzelgewinnermittlungen wird dabei mittels der Konsolidierung vollzogen, egal nun, ob die derivative Steuerbilanz aus den Steuerbilanzen der Unternehmen oder aus einer bereits konsolidierten, anderen Zwecken dienenden Gesamtrechnung entwickelt wird.

\subsection{Parallelen zu den Theorien der rein informationsorientierten Konzernrech- nungslegung}

Um eine konsolidierte steuerliche Gewinnermittlung in ihrer Ausgestaltung beurteilen zu können, kann die Einheitstheorie als Wertungshülle durch eine bestimmte ökonomische Vorstellung von einer Unternehmung konkretisiert werden. Ergänzend sind sämtliche sonstigen normativen Anforderungen an die steuerliche Gewinnermittlung zu beachten. Möglicherweise können aber auch die Theorien der rein informationsorientierten Konzernrechnungslegung ${ }^{1}$ bei der Ausgestaltung der steuerlichen Konsolidierung dienlich sein. Schließlich sind sie entwickelt worden, um einen „übergeordneten Bezugspunkt für eine sachgerechte Lösung bei Zweifelsfragen im Rahmen der konsolidierten Rechnungslegung ${ }^{“ 2}$ zu schaffen. Im Wesentlichen lassen sich in diesem Zusammenhang zwei Theorien unterscheiden: Die Einheitstheorie (entity theory) und die Interessentheorie (parent company theory), wobei letztere in der Eignertheorie (proprietary theory) noch eine besondere Ausprägung erfährt ${ }^{3}$.

- Im Rahmen der Einheitstheorie wird die Existenz einer wirtschaftlichen Einheit anerkannt, die über die Grenzen eines einzelnen Unternehmens hinausreichen kann.

1 Alternativ finden sich hierfür auch die Bezeichnungen ,Theorien des Konzernabschlusses' oder ,Konsolidierungstheorien' bzw. ,Consolidation Theories'; vgl. im Überblick Sürken (Abgrenzung der wirtschaftlichen Einheit, 1999) S. 103.

2 Coenenberg (Jahresabschluss, 2003) S. 517

3 Vgl. sehr viel ausführlicher zu Inhalt und Abgrenzung dieser Theorien m.w.N. z.B. Childs (Consolidated Financial Statements, 1949) S. 33-35, 48-55; Schönbucher (konsolidierte Bilanz, 1966) S. 95-101; Sürken (Abgrenzung der wirtschaftlichen Einheit, 1999) S. 103-114; Watt/Hammer/Burge (Accounting, 1977) S. 21-31. Nach Bores (Konsolidierte Erfolgsbilanzen, 1935), der sich wohl erstmalig in Deutschland mit diesen beiden Theorien auseinander gesetzt hat, entstammen sie der US-amerikanischen Praxis (S. 129-130). 
Wird sie im Sinne der Fiktion der rechtlichen Einheit interpretiert ${ }^{1}$, bekommt eine als wirtschaftliche Einheit definierte Unternehmensgruppe den Charakter einer fiktiven Rechtsperson und damit die Stellung eines Als-ob-Unternehmens. Die einzelnen Unternehmen gelten innerhalb dieser Fiktion nur noch als rechtlich unselbständige Betriebsstätten. Es kann deshalb nicht ausreichen, die Einzelgewinnermittlungen der einbezogenen Unternehmen bzw. Betriebsstätten lediglich zusammenzufassen. Konsolidierungsmaßnahmen sind notwenig, um Doppelerfassungen und Zwischenergebnisse auszuschließen. Wesentliches Merkmal der Einheitstheorie ist es dabei, dass alle Ressourcen der einbezogenen Unternehmen bzw. Betriebsstätten in vollem Umfang im Rahmen der konsolidierten Rechnungslegung zu erfassen sind (Vollkonsolidierung). Schließlich stehen sie auch vollumfänglich der zentralen Leitungsinstanz zur Verfügung, die in der Unternehmensleitung des Unternehmens an der Gruppenspitze gesehen wird. Die rein informationsorientierte Rechnungslegung hat Auskunft über die Ergiebigkeit der Entscheidungen und Handlungen der fiktiven Rechtsperson zu geben, wobei primär der Gesamtgewinn als Ergiebigkeitsmaß herangezogen wird $^{2}$.

Hinsichtlich der historischen Wurzeln und der inhaltlichen Ausrichtung dürfte bei der Einheitstheorie ein hohes $\mathrm{Ma}$ an Übereinstimmung zu der Einheitstheorie existieren, die auch in der steuerlichen Gewinnermittlung bemüht wird ${ }^{3}$. In ihrer Ausrichtung auf die rein informationsorientierte Konzernrechnungslegung ist die Einheitstheorie aber weiter konkretisiert worden, weil sie dort - anders als in der steuerlichen Gewinnermittlung - eine sehr viel größere rechtstatsächliche Bedeutung erlangt hat. Auch fokussiert sie stärker auf die Stellung der Eigenkapitalgeber. So lautet eine ih-

1 Vgl. insb. Busse von Busse et al. (Konzernabschlüsse, 2003) S. 25-26, 38-44. Im Einklang mit der Literatur (vgl. insb. Adler/Düring/Schmaltz (Rechnungslegung, 1995) § 297 Tz. 40) wird hier die Auffassung vertreten, dass es sich bei dieser Fiktion um eine Interpretation der Einheitstheorie handelt. Andere Interpretationen, die statt dessen - auch in konkretem Bezug auf $\S 297$ HGB - bei der ,wirtschaftlichen Einheit“" verbleiben (vgl. u.a. Adler/Düring/Schmaltz (Rechnungslegung, 1995) § $297 \mathrm{Tz}$. 40), werden hier als weniger konsequent erachtet und nicht weiter verfolgt.

2 Vgl. zu dieser Interpretation z.B. Coenenberg (Jahresabschluss, 2003) S. 1139; Haller (Rechnungslegung in den USA, 1994) S. 114-115.

3 So dürfte z.B. in Deutschland eine gemeinsame Literaturwurzel existieren, die insb. auf Isay (Recht am Unternehmen, 1910) und den Einfluss der Organtheorien der Finanzrechtsprechung (vgl. Kap. III.1.1.2) zurück geht; vgl. grundlegend wohl Bores (Konsolidierte Erfolgsbilanzen, 1935) insb. S. 1427. A.A. wohl Wöhe (Steuerlehre, 1996) S. 67-68, der seine Unterscheidung aber mit der konkreten deutschen handels- und steuerrechtlichen Situation begründet (differenzierter jedoch S. 87-91). Vgl. auch Moonitz (Entity Theory, 1951) S. 1-11 der für die USA die wohl ebenfalls gleiche, von Rechtsprechung und Gesetzgebung geprägte Entwicklungslinie aufzeigt. Die Einheitstheorie ist aber gerade in der US-amerikanischen Sicht nicht nur für die konsolidierte Rechnungslegung entwickelt worden, sondern auch, um die „Zielträger des Jahresabschlusses“ (Coenenberg (Jahresabschluss, 2003) S. 1138) zu identifizieren. In der auf Unternehmen angewendeten Einheitstheorie kommt letztlich das juristische Trennungsprinzip konsequent zum Ausdruck; vgl. z.B. Coughlan (Theory of Accounts, 1965) S. 153-155; Hendriksen/Breda (Accounting Theory, 1992) S. 771; Li (Entity Concept, 1963); Spiller (Basic Concepts, 1966) S. 16-17. Vgl. zu einem Überblick über alle zielträgerorientierte Theorien Haller (Rechnungslegung in den USA, 1994) S. 106-122. 
rer zentralsten Aussagen, dass alle Eigenkapitalgeber im Verhältnis zur fiktiven Rechtsperson auf derselben Stufe stehen, unabhängig davon, welchem Unternehmen der Gruppe sie de jure ihr Kapital zur Verfügung gestellt haben. Daraus ergibt sich ein Kerncharakteristikum der Einheitstheorie, nach dem Mehrheits- und Minderheitsgesellschafter als gleichberechtigte Eigenkapitalgeber zu behandeln sind. Der Minderheitenanteil ist demnach im konsolidierten Eigenkapital und als Teil des Ergebnisses auszuweisen.

- Anders als die Einheitstheorie, die sämtliche Gesellschafter der Gruppe als gleichberechtigte Eigenkapitalgeber der Unternehmensgruppe ansieht, nimmt die Interessentheorie die Gesellschaftersphäre differenzierter wahr. In der Interessentheorie wird die Unternehmensgruppe als (Netto-)Vermögensanlage der Eigner der Obergesellschaft angesehen. Die Rechnungslegung wird deshalb im Interesse und aus Perspektive dieser Eigner erstellt und soll sie über das in dem Gesamtgebilde gebundene Nettovermögen und den daraus resultierenden Gewinn informieren. Es wird gewissermaßen ein erweiterter Abschluss der Obergesellschaft aufgestellt. Die Interessentheorie folgt der Einheitstheorie dabei in der Vorstellung, dass eine unternehmensübergreifende wirtschaftliche Einheit nicht mit Doppelerfassungen und Zwischenergebnissen einhergehen kann. Insoweit bedarf es auch hier der Konsolidierung. In diesem Zusammenhang wird die vollumfängliche Erfassung des Nettovermögens der übrigen Unternehmen einschließlich der vollständigen Zwischenergebniseliminierung (Vollkonsolidierung) ${ }^{1}$ oder auch nur die anteilige Erfassung und Eliminierung (Quotenkonsolidierung) zugelassen. Bei der vollumfänglichen Erfassung - die Begründung ist die der Einheitstheorie, wonach die volle Ressourcenverfügbarkeit aufgrund der hierarchischen Machtstellung der Obergesellschaft gewährleistet ist - werden die Minderheitsgesellschafter aber nicht mehr als Eigner wahrgenommen². Der auf sie entfallende Anteil wird deshalb in der Bilanz nicht mehr dem Eigenkapital zugerechnet und in der Gewinn- und Verlustrechnung als Aufwand berücksichtigt.

In der interessentheoretischen Variante der Eignertheorie wird diese Sichtweise noch konsequenter verfolgt ${ }^{3}$. Hier wird das mehrere Unternehmen umfassende Gesamtgebilde mit dem oder den Eignern der Obergesellschaft geradezu personifiziert. Ein von deren persönlicher Sphäre losgelöstes Nettovermögen existiert hiernach nicht. In dieser noch stärker auf den bzw. die Eigner zugeschnittenen Konzeption interessiert auch nur noch die tatsächlich diese(n/m) Eigner(n) zustehende Nettovermögensent-

1 Diese Variante wird auch als „,modified parent company theory“ bezeichnet; vgl. dazu m.w.N. Sürken (Abgrenzung der wirtschaftlichen Einheit, 1999) S. 110.

2 Diese Sichtweise dürfte insb. mit der „Fiktion der rechtlichen Einheit“ nicht vereinbar sein. Diese Fiktion setzt letztlich die für Rechtsträger typische Trennung von Gesellschafts- und Gesellschaftersphäre voraus, der eine Differenzierung der Eigenkapitalgeber in solche der Obergesellschaft und solche untergeordneter Unternehmen widerspricht.

3 Vgl. insb. Gilman (Accounting Concepts, 1939) S. 48-65 m.w.N.; ähnlich Loch (Proprietary-Theorie, 1994), der in der „normalen“ Interessentheorie noch Elemente der Einheitstheorie erkennt. 
wicklung, die hier nur noch anteilig berücksichtigt wird (Quotenkonsolidierung). Minderheitenanteile werden nicht mehr erfasst und der auf Minderheitsgesellschafter entfallende Transaktionsanteil gilt als mit fremden Dritten realisiert.

Die hier dargestellten Theorien sind letztlich ebenfalls aus der ökonomischen Theorie der Unternehmung abgeleitet. Wie Szyperski anmerkt, trägt ,[d]ie Unternehmungstheorie .. zum Aufbau der Unternehmungsrechnung bei, indem sie dieser ein Bild der Unternehmung in ihrer wirtschaftlichen Situation zum Markt ... vermittelt. ... Der unmittelbare Zusammenhang zwischen Unternehmungstheorie und Rechnungstheorie wird bei der Definition rechnungstheoretischer Grundbegriffe sichtbar, die sich auf wirtschaftstheoretische stützen müssen, wollen sie nicht beziehungslos im Raum stehen "'. Allen diesen Theorien der Konzernrechnungslegung ist gemeinsam, dass sie sich von der rechtsträger- und damit rechtsformorientierten Unternehmenssicht lösen und auf ein wie auch immer geartetes ökonomisches Gebilde zielen, das aber weder genauer konkretisiert noch abgegrenzt wird. Nach Sürken setzen sie eigentlich erst an dem Punkt an, an dem „bereits feststeht, welches rechtlich selbständige Unternehmen zur Erstellung eines konsolidierten Abschlusses verpflichtet ist und welche Unternehmen in den Konsolidierungskreis einzubeziehen sind ${ }^{\text {“2 }}$. Feststellbar ist lediglich, dass die genannten Theorien ebenfalls von einer nukleusbasierten und ressourcenorientierten Sicht der Unternehmung geprägt sind, die auf eine Unternehmensgruppe und das darin gebundene Nettovermögen abstellt. Angesichts der Unterscheidung von Mehrheits- sowie Minderheitsgesellschaftern oder des Abstellens auf eine Anteilsquote wird bei der Verbindung dieser Unternehmen scheinbar vorrangig auf Stimmrechts- und/oder Kapitalbeteiligungsmehrheiten abgestellt ${ }^{3}$.

Die dargestellten Theorien unterscheiden sich insbesondere hinsichtlich der Frage, welche Rolle die Anteilseigner bzw. Eigenkapitalgeber im Verhältnis zur Unternehmung spielen. Letztlich werden hierbei unterschiedliche Organisationsvarianten von Unternehmungen unterstellt. So erinnert die fiktive (und von der Gesellschaftersphäre getrennte) Rechtsperson im Rahmen der Einheitstheorie entfernt an die Vorstellung einer

1 Szyperski (Theorie der Unternehmungsrechnung, 1964) S. 275, der dazu weiter bemerkt, dass „,[d]er fraglos vorhandene Abstand zwischen Wirtschafts- und Rechnungstheoretikern .. nicht durch isolierte, womöglich auseinanderstrebende Entwicklungen, sondern nur durch gemeinsame Bemühungen um eine theoretische Konzeption verringert werden [kann], in der sich die beiden Wissensbereichen zu Grunde liegende Interdependenz widerspiegelt" (S. 276).

2 Sürken (Abgrenzung der wirtschaftlichen Einheit, 1999) S. 104.

3 Diese Feststellung ist aber weniger theorieimmanent, sondern eher praktische Erfahrung in der rein informationsorientierten Rechnungslegung. Eine abschließende Festlegung auf dieses enge, aber objektivierbare und damit rechtssichere Kriterium liegt indes auch dort nicht vor. Dies zeigt bereits die kontroverse und immer noch nicht abgeschlossene Diskussion über Art und Ausgestaltung dieser Verbindung nach US-GAAP und IFRS. Dieser Diskussion ist zu entnehmen, dass man sich zumindest ansatzweise in Richtung eines breiteren, damit aber auch unbestimmteren Vertragskonzeptes zu bewegen scheint; vgl. dazu Sürken (Abgrenzung der wirtschaftlichen Einheit, 1999) sowie Kap. V.2. 
entpersonalisierten Institution nach Art des „Unternehmens an sich“l. Diese in der Rechtswissenschaft nicht völlig aufgegebene Vorstellung ergibt aus ökonomischer Sicht - wenn überhaupt - nur dann einen Sinn, wenn das rechtliche Eigentum zwar auf Seiten der Anteilseigner verbleibt, das „ökonomische Eigentum“ aber auf die Manager der Obergesellschaft übergeht $t^{2}$. Den Gegenpol zur Einheitstheorie markiert die Interessentheorie in der Variante der Eignertheorie, da hier der Eigner als Person und Anteilseigner im Vordergrund steht. Die Unternehmungsorganisation ist damit wohl nicht mehr durch eine sachliche Zentraleinheit (rechtsfähiges Unternehmen) geprägt, sondern durch die persönliche Zentraleinheit, wie sie bei den Unternehmern der Einzel- und Personengesellschaften vorzufinden ist. Während sich Einheits- und Eignertheorie damit unterschiedlichen Unternehmungsorganisationstypen zuordnen lassen, fällt die Zuordnung bei der klassischen Interessentheorie schwerer. Möglicherweise stellt sie auf die Existenz (und Sichtweise) kontrollierender Anteilseigner ab, die einer sachlichen Zentraleinheit zugeordnet sind. Anwendbar ist sie aber auch bei nicht kontrollierenden Anteilseignern sowie persönlichen Zentraleinheiten.

Für die steuerliche Gewinnermittlung ist die Deutung dieser Theorie(variante)n durchaus von Interesse. So erscheint nur die einheitstheoretische Vollkonsolidierung der ökonomischen Vorstellung zu entsprechen, dass die Hierarchiespitze der Unternehmung über die Ressourcen in voller Höhe verfügen kann, da sie allein - im Sinne des „ökonomischen" Eigentums - die diesbezüglichen residualen Entscheidungs- und Kontrollrechte besitzt. Auch ist die Einheitstheorie - anders als die Interessentheorie - dem Grundverständnis des weltweit dominanten Trennungsprinzips rechtssystematisch noch am nächsten. Anstelle der tatsächlichen Rechtsperson wird hier lediglich eine fiktive Rechtsperson der steuerlichen Gewinnermittlung unterworfen ${ }^{3}$. Die jeweilige Gesellschaftersphäre wird in beiden Fällen ausgeblendet, also von dieser (tatsächlichen wie auch fiktiven) Rechtsperson getrennt. Damit überführt die Einheitstheorie die ökonomische Sicht der Unternehmung in bestehende Rechtskonventionen, zumindest soweit es die Behandlung der Gesellschafter einer Rechtsfiktion betrifft ${ }^{4}$. Sie überträgt die rechtliche Unternehmensvorstellung auf eine Gruppe von Unternehmen und wendet den Gedanken der juristischen Person und das damit einhergehende Trennungsprinzip konsequent auf diese Unternehmensgruppe an. Allerdings wird die Gesellschaftersphäre nicht

Vgl. dazu bereits Kap. II.3.2.2 und II.3.3.

2 Vgl. zu dieser Fallkonstellation Kap. II.3.3.2.

3 Da die tatsächliche juristische Person bereits eine Rechtsfiktion darstellt, handelt es sich hierbei demnach um eine doppelte Fiktion: die fiktive juristische Person.

4 Fraglich ist, ob sich diese Aussage ändert, wenn kein Unternehmen bzw. dessen Manager an der Hierarchiespitze der Unternehmung steht. So bleibt unklar, ob die Trennung zur Gesellschaftersphäre im Falle einer natürlichen Person als Hierarchiespitze (partiell) aufgeweicht oder ob die diesbezügliche Grenze - wie bei der Unternehmensgruppe auch - einfach weiter verschoben wird. Alle übrigen (Minderheits-)Gesellschafter sind in jedem Fall der abgetrennten Gesellschaftersphäre zugehörig. Auch relativiert sich dadurch nicht der Sinn der Vollkonsolidierung. 
mehr von der Gesellschaftssphäre, sondern von derjenigen der Unternehmensgruppe abgetrennt. An dieser Konsequenz mangelt es hingegen der Interessentheorie, insbesondere in der Variante der Eignertheorie. Aus Fiskussicht erscheint die einheitstheoretische Gleichbehandlung der Anteilseigner indes folgerichtig, wenn es ihm im Rahmen einer institutionellen Besteuerung wirklich um die Besteuerung der Unternehmensgruppe als wirtschaftlicher Einheit geht. Wird dieser Einheit tatsächlich eine eigenständige steuerliche Leistungsfähigkeit zuerkannt ${ }^{1}$, ist es nur konsequent, einen von der Gesellschaftersphäre unabhängigen steuerlichen Gewinn für diese Einheit zu ermitteln. Alle Gesellschafter haben dann die steuerlichen Konsequenzen in letzter Instanz zu tragen, da sie allesamt, ob nun als Mehrheits- oder Minderheitsgesellschafter, an dem Gebilde beteiligt sind. So wenig, wie sich die Machtverhältnisse bei einem einzelnen Unternehmen mit einem kontrollierenden Anteilseigner auf die steuerliche Gewinnermittlung auswirken, so wenig wirken sie sich dann auch bei einer Gruppe von Unternehmen aus ${ }^{2}$.

So lässt sich abschließend festhalten, dass diese etwas weiterführende Interpretation der Einheitstheorie für die Ausgestaltung der steuerlichen Konsolidierung von Interesse ist ${ }^{3}$ und im Folgenden, in Verbindung mit der originären, ökonomischen Vorstellung von einer Unternehmung, Berücksichtigung findet ${ }^{4}$. Es bedarf allerdings noch der Untersuchung, ob und inwieweit die soeben präsentierten „einheitstheoretischen Konsequenzen“ (komplette Eliminierung gruppeninterner Transaktionen, Vollkonsolidierung) im Rahmen der steuerlichen Gewinnermittlung im vollen Umfang notwendig sind (Kapitel III.1.4). Auch das angesprochene Thema der Minderheitsgesellschafter und ihrer Rolle in der konsolidierten steuerlichen Gewinnermittlung verdient noch weitere Beachtung und wird an späterer Stelle noch einmal aufgegriffen (Kapitel III.2.5.1.2).

\subsection{Auswirkungen der Kerngrößenorientierung}

\subsubsection{Umfang der Konsolidierungsmaßnahmen}

Ein wesentliches Charakteristikum der steuerlichen Gewinnermittlung ist deren ausschließliche Orientierung am Gewinn bzw. Einkommen. Nur an diese Kerngröße ist die konkrete Steuerrechtsfolge geknüpft. Anders als bei der Substanzbesteuerung und auch

1 Vgl. zu dieser problematischen Frage Kap. II.3.3.1.2.

2 Vgl. Pawelzik (Phase II, 2004) S. 680, allerdings ohne Bezug zur steuerlichen Gewinnermittlung.

3 Vgl. die Einheitstheorie in steuerlicher Hinsicht mehr oder minder explizit befuirwortend u.a. Bauer (Besteuerung deutscher Konzerne, 1987) S. 11-40; Bühler (Steuerrecht, 1956) S. 321-328; Girnth (Ertragsbesteuerung von Konzernen, 1963) S. 127-145; Köhler (Besteuerung von Konzern, 1970) S. 9397; Küting (Einheitsbesteuerung, 1990); Mühlschlegel (Gewinnermittlung für Konzerne, 1971) S. 102-107; Oberndorff (Konzembesteuerung, 1996) S. 105-106, 280; Reis (Körperschaftsbesteuerung des Konzerns, 1996) S. 166-170; Rupp (Ertragsbesteuerung nationaler Konzerne, 1983) S. 51.

4 Schon aus Gründen der Durchführungseffizienz spricht erst einmal nichts dagegen, die Erfahrungen der rein informationsorientierten Konzernrechnungslegung furr die konsolidierte steuerliche Gewinnermittlung zu nutzen, sofern dem von normativer Seite ansonsten nichts entgegen steht. 
der rein informationsorientierten Rechnungslegung hat der Ausweis der nach Maßgabe der Einheitstheorie „richtigen“ Höhe des positiven und negativen Betriebsvermögens, der Betriebseinnahmen und -ausgaben für sich gesehen keinen Wert, solange nur die interessierende Kerngröße in diesem Sinne ,richtig“ ermittelt wird. Fraglich ist deshalb, ob sich hieraus Konsequenzen für die steuerliche Konsolidierung ergeben.

Die Antwort kann nur lauten, dass Konsolidierungsmaßnahmen, die über alle Perioden hinweg keinen Einfluss auf die interessierende Kerngröße haben, unnötig sind. Um die Durchführungseffizienz der konsolidierten steuerlichen Gewinnermittlung zu steigern, kann auf diese Konsolidierungsmaßnahmen verzichtet werden. Da der steuerpflichtige Gewinn selbst nicht beeinflusst wird, dürfte dieser Verzicht keine Entscheidungswirkungen hervorrufen und auch unter dem Gesichtspunkt der steuerlichen Leistungsfähigkeit unbedenklich sein. Zu untersuchen ist deshalb, welche Konsolidierungsmaßnahmen periodenübergreifend gewinn- bzw. ergebnisneutral sind. Dabei wird der weite Konsolidierungsbegriff zu Grunde gelegt, der sämtliche Verfahren umfasst, die der Überführung originärer Einzelgewinnermittlungen in eine Gesamtgewinnermittlung nach der Einheitstheorie dienen.

So bedarf es auch in einer kerngrößenorientierten Gewinnermittlung der anfänglichen Prüfung, ob überhaupt eine steuerliche Konsolidierung vorzunehmen ist. Wegen der unmittelbaren Gewinnauswirkungen ist die sich anschließende Abgrenzung des steuerlichen Konsolidierungskreises gleichfalls unverzichtbar. Dies dürfte im Grundsatz auch für die vorbereitenden Maßnahmen gelten, die der Vereinheitlichung der Einzelgewinnermittlungen dienen. Unnötige und damit ineffiziente Vereinheitlichungen sind hier allerdings denkbar. Vereinheitlichungsvorgänge von periodenübergreifender Ergebnisneutralität ergeben sich in erster Linie im Rahmen des Ausweises, sofern hieran keine Bewertungskonsequenzen gebunden sind' ${ }^{\prime}$. Darunter fällt z.B. die Frage, ob ein Sachverhalt brutto auf Aktiv- sowie Passivseite oder nur netto auf der Aktiv- oder Passivseite angesetzt werden soll (Brutto- bzw. Nettoausweis). Bei Ansatz- und Bewertungsfragen fällt es indes schwerer, periodenübergreifende Ergebnisneutralität zu identifizieren. Dafür müsste bei einem Sachverhalt von vornherein feststehen, dass weder zum Zeitpunkt des Ansatzes, noch während der Bilanzzugehörigkeit, noch zum Zeitpunkt des Abgangs Ergebniswirkungen entfaltet werden.

Interessant scheinen in diesem Zusammenhang Ansatz- und Bewertungsvorgänge, die sich zwar auf das Eigenkapital, nicht aber auf das Ergebnis als interessierende Kerngröße auswirken - eine Vorstellung, die im Rahmen einer einkommensteuerlichen Gewinn-

1 Diese Verknüpfung von Ausweis und Bewertung läge z.B. vor, wenn die Zuordnung zum kurz- oder langfristigen Vermögen mit unterschiedlichen Regeln bezüglich der Abschreibungen einhergeht. 
ermittlung auf der Basis eines Betriebsvermögensvergleichs etwas sonderbar erscheint ${ }^{1}$. Eine Betriebsvermögensänderung tangiert in diesem Fall eben nicht den steuerpflichtigen Gewinn. So wäre z.B. vorstellbar, die Wertänderung eines Wirtschaftsgutes in einer gesonderten Eigenkapitalkomponente (Neubewertungsrücklage) zu verbuchen, ohne dabei den steuerpflichtigen Gewinn zu berühren. Derartige Vorgänge - warum sie auch immer in den jeweiligen Gewinnermittlungsregeln vorgesehen sein sollten - könnten aber nur dann im Rahmen der Vereinheitlichung außen vor bleiben, wenn sie periodenübergreifend, also auch bei Bilanzabgang, keine Ergebniswirkung entfalten (z.B. durch ergebnisneutrales Ausbuchen der Neubewertungsrücklage). Dies ginge grundsätzlich mit der Verletzung des Kongruenzprinzips (clean surplus) einher, da die Summe der Periodenergebnisse nicht mehr dem an der Eigenkapitalveränderung gemessenen Totalerfolg entspräche, sofern letzterer unter Ausklammerung sämtlicher Eigenkapitaltransfers mit den Anteilseignern ermittelt würde ${ }^{2}$.

Die Möglichkeit, auf bestimmte Konsolidierungsmaßnahmen wegen ihrer periodenübergreifenden Ergebnisneutralität zu verzichten, bietet sich auch im Bereich der Konsolidierungsmaßnahmen im engeren Sinne. Dies gilt natürlich nicht für die Zwischenergebniseliminierung, deren Ziel es ja gerade ist, den steuerpflichtigen Gewinn als interessierende Kerngröße unmittelbar zu korrigieren. Gemeint sind hier vielmehr diejenigen Konsolidierungsmaßnahmen, die allein der ergebnisneutralen Korrektur von Bestands- oder Stromgrößen dienen. So ist eine Konsolidierung für Zwecke der steuerlichen Gewinnermittlung obsolet, wenn sich positives und negatives Betriebsvermögen, z.B. in Form von Forderungen und Schulden, durch bestimmte Verflechtungen in gleicher Höhe gegenüber stehen ${ }^{3}$. Diese würden im Rahmen einer einzigen rechnungslegenden Einheit zusammengefasst und sich ohnehin im Rahmen eines Betriebsvermögensvergleichs kompensieren. Gleiches gilt für einander in gleicher Höhe gegenüber stehende Betriebseinnahmen und -ausgaben.

Vor diesem Hintergrund gibt es in der konsolidierten steuerlichen Gewinnermittlung keine Notwendigkeit, die Kapital-, Schulden- sowie Betriebsausgaben- und -einnahmenkonsolidierung vollumfänglich nach der Einheitstheorie durchzuführen. Die Konso-

1 Der der deutschen steuerlichen Gewinnermittlung zu Grunde liegende Gewinnbegriff, der sich nach $\S 4$ Abs. 1 EStG aus dem um Kapitalentnahmen und -einlagen korrigierten Bestandsvergleich des Betriebsvermögens zweier aufeinander folgender Zeitpunkte ergibt, entspricht immer dem buchhalterischen Gewinn als Saldo von Aufwendungen und Erträgen innerhalb der durch diese Zeitpunkte determinierten Gewinnermittlungsperiode. Dies schließt „ergebnisneutrale“ Eigenkapitalveränderungen, die nicht auf Entnahmen oder Einlagen beruhen, aus. Vgl. zum steuerrechtlichen Gewinnbegriff auch Knobbe-Keuk (Bilanz- und Unternehmenssteuerrecht, 1993) S. 11-17.

2 Vgl. grundlegend zum Kongruenzprinzip bereits Schmalenbach (Dynamische Bilanz, 1926) S. 96-99; analysierend u.a. Busse von Colbe (Gefährdung des Kongruenzprinzips, 1992); Ordelheide (clean surplus, 1998) S. 516-521; Schildbach (Kongruenz, 1999); vgl. zur theoretischen Fundierung auch die Beiträge im dem Reader von Brief/Peasnell (Clean Suplus, 1996).

3 Vgl. zu dieser Erkenntnis bereits Salzberger (Konzernunternehmung, 1994) S. 241. 
lidierung könnte immer dann entfallen, wenn sie periodenübergreifend ergebnisneutrale Korrekturen umfasst. Davon ist in den folgenden Fällen auszugehen:

- Finanzbeteiligungen an und (anteiliges) Eigenkapital von einbezogenen Unternehmen stehen sich in der Summenbilanz jeweils in gleicher Höhe gegenüber (Kapitalkonsolidierung ist nicht notwendig) ${ }^{1}$.

- Forderungen und Schulden einbezogener Unternehmen stehen sich in der Summenbilanz jeweils in gleicher Höhe gegenüber (Schuldenkonsolidierung ist nicht notwendig).

- Betriebseinnahmen und Betriebsausgaben stehen sich jeweils in gleicher Höhe gegenüber (Betriebsausgaben- und -einnahmenkonsolidierung nicht notwendig) ${ }^{2}$.

Diese Fälle können noch erweitert werden, wenn die Konsolidierung auch Vorgänge beinhaltet, die ergebnisneutral über das Eigenkapital verbucht werden. In diesen Fällen entsprechen sich die jeweiligen Bestandspositionen unter zusätzlicher Einbeziehung der angebuchten Eigenkapitalposition. Wenn diese über alle Perioden hinweg keine Ergebniswirkung entfalten, kann auch hier die steuerliche Konsolidierung unterbleiben.

Notwendig bleibt in jedem Fall die entsprechende Überprüfung der einzelnen Verflechtungen, ob die periodenübergreifende Ergebnisneutralität gegeben ist. Ergebniswirkungen können entweder unmittelbar den Stromgrößendifferenzen entnommen werden oder sie ergeben sich mittelbar über Bestandsdifferenzen und deren Behandlung in der betrachteten Periode sowie in den Folgeperioden. Sollten Differenzen aus der Kompensation gegenläufiger Bestands- oder Stromgrößen - warum auch immer ${ }^{3}$ - über direkte Verbuchung ins Eigenkapital ergebnisneutral behandelt werden, wäre der steuerliche Gewinn als Kerngröße auch nicht betroffen, so dass die Konsolidierungsnotwendigkeit auch entfiele. Wenn sich aber aus ursprünglich ergebnisneutralen Korrekturen in einer Folgeperiode eine Ergebniswirkung ergeben sollte, muss die vorerst ergebnisneutrale Konsolidierung zumindest auf Basis einer Nebenrechnung durchgeführt werden, um Ergebniswirkungen künftig überhaupt erst berechnen zu können. Als Beispiel mag hier die Umbuchung einer Bestandsdifferenz in einen bestimmten Sonderposten angeführt werden, der nicht automatisch (planmäßig), sondern nur fallweise (außerplanmäßig) im Wert verändert bzw. aufgelöst wird. Wie sich an späterer Stelle in dieser Arbeit zeigen wird $^{4}$, haben diese Überlegungen insbesondere bei Eigenkapitalverflechtungen zwischen den Unternehmen und der damit einhergehenden Kapitalkonsolidierung ihre Relevanz.

1 Diese Aussage abstrahiert erst einmal von der Frage, wie insb. das Eigenkapital des einbezogenen Unternehmens zu bewerten ist; vgl. zu dieser Frage sehr viel eingehender Kap. V.4.2.

2 Vgl. so auch Rupp (Ertragsbesteuerung nationaler Konzerne, 1983) S. 64.

3 Der über Durchführungseffizienzargumente hinausgehende normative Sinn einer derartigen Vorgehensweise steht an dieser Stelle nicht zur Diskussion; vgl. dazu eher Kap. V.4.

4 Vgl. Kap. V.4.2.2.4 zum, ,impairment-only approach“. 
Zusammenfassend lässt sich festhalten, dass Konsolidierungsmaßnahmen in der steuerlichen Gewinnermittlung unterlassen werden können, wenn sie periodenübergreifend ohne Ergebniswirkung sind. Dies gilt allerdings nur, soweit diese Unterlassung auch unter Berücksichtigung der notwendigen Identifikation ergebnisneutraler Komponenten gegenüber der Konsolidierung Durchführungseffizienzvorteile aufweist.

Möglicherweise hat die Kerngrößenorientierung der steuerlichen Gewinnermittlung und der dadurch reduzierte Umfang notwendiger Konsolidierungsmaßnahmen dazu geführt, dass die Zwischenergebniseliminierung in der Literatur oft als einzige steuerliche Konsolidierungsmaßnahme genannt oder gefordert wird ${ }^{1}$. Trotz der hervorgehobenen Bedeutung der weiterhin unbeschränkten Zwischenergebniseliminierung erweist sich diese Fokussierung aber dann als zu eng, wenn sie mit der Vernachlässigung sämtlicher sonstiger Ergebniswirkungen einhergeht, die aus den übrigen Konsolidierungsmaßnahmen erwachsen ${ }^{2}$. Nur wenn diese Ergebniswirkungen, wovon nicht auszugehen ist, sämtlich unter die Zwischenergebniseliminierung subsumiert würden, könnte dieser Fokussierung gefolgt werden ${ }^{3}$.

\subsubsection{Quotenkonsolidierung und Equity-Methode als Alternativen zur Vollkonsolidierung?}

Die Kerngrößenorientierung der steuerlichen Gewinnermittlung wirft eine weitere Frage im Rahmen der Konsolidierung auf: Bedarf es in der Gesamtgewinnermittlung wirklich der vollständigen Erfassung sämtlicher Ressourcen der einbezogenen Unternehmen sowie der vollständigen Erfassung sämtlicher Betriebseinnahmen und -ausgaben gegenüber Dritten? Die Antwort auf diese Frage hat möglicherweise Auswirkungen auf die Art der vermögens- und ergebnisrechnerischen Integration der betroffenen Unternehmen in die steuerliche Gesamtgewinnermittlung. Fraglich ist demnach, ob es bei den Unternehmen der Unternehmensgruppe ${ }^{4}$ wirklich der Vollkonsolidierung bedarf, oder ob alternative Einbeziehungsmöglichkeiten existieren, die die steuerliche Kerngrößen-

1 Vgl. z.B. den Literaturüberblick bei Rupp (Ertragsbesteuerung nationaler Konzerne, 1983) S. 44; so z.B. auch Jacobs/Spengel (Deutschland und Frankreich, 1994) S. 101. Hierbei kann primär auf der Basis von Einzelgewinnermittlungen vorgegangen werden, die „nur" hinsichtlich besagter Zwischenergebnisse zu korrigieren sind.

2 Vgl. ähnlich in der Wertung u.a. Niemann (Gewinnrealisierung innerhalb des Konzerns, 1968) S. 147; Rupp (Ertragsbesteuerung nationaler Konzerne, 1983) S. 44.

3 In der Literatur wird alternativ von „Ergebniskonsolidierung“ gesprochen; vgl. z.B. Krebühl (Organschaft, 1995) S. 745; Ritter (Sicht der Wirtschaft, 1989) S. 325. Ob sich dahinter jedoch eine entsprechend weite Interpretation verbirgt, ist mangels konkretisierender Aussagen fraglich.

4 Dieses Teilkapitel bezieht die Frage der Einbeziehungsmethode demnach nur auf Unternehmen, die der Unternehmensgruppe i.S.d. in Kap. II.3 definierten ökonomischen Eigentums voll zuzurechnen sind. Erst an späterer Stelle (Kap. V.2.3) soll die Frage analysiert werden, ob und wie diejenigen Unternehmen i.R.d. konsolidierten steuerlichen Gewinnermittlung erfasst werden, die im Kontinuum zwischen Unternehmung und Markt angesiedelt sind. 
ermittlung nach der Einheitstheorie mit einer höheren Durchführungseffizienz gewährleisten. Schließlich steht hier nicht die vollständige Information über Art und Zusammensetzung sämtlicher Ressourcen(veränderungen) der Gruppe im Vordergrund.

Eine technische Integrationsalternative zur Vollkonsolidierung wäre die Quotenkonsolidierung. Bestands- und Stromgrößen werden hier nur noch quotal berücksichtigt. Das gilt auch für die Eliminierung sämtlicher gruppeninternen Erfolge. Die eher interessenoder eignertheoretisch fundierte Quotenkonsolidierung widerspricht dabei aber nicht nur der auf eine Unternehmensgruppe bezogenen Trennung von Gesellschafts- und Gesellschaftersphäre. Sie nimmt auch eine zu enge Unternehmungsabgrenzung vor, weil sie Teile der einbezogenen Unternehmen dem Markt zurechnet, obwohl über ihre Ressourcen von Seiten der Gruppe insgesamt in voller Höhe verfügt werden kann. Zudem bringt die Quotenkonsolidierung gegenüber der Vollkonsolidierung keine methodische Erleichterung, da weiterhin sämtliche Positionen der Einzelgewinnermittlungen - allerdings unter Berücksichtigung einer Quote - aufsummiert und anschließend den eigentlichen Konsolidierungsmaßnahmen zugeleitet werden.

Eine weitere technische Möglichkeit, Unternehmen in der Gesamtgewinnermittlung zu berücksichtigen, wäre die Equity-Methode. Anders als bei der Voll- und Quotenkonsolidierung basiert diese Methode nicht mehr auf der Zusammenfassung sämtlicher Bestands- und Stromgrößen der jeweiligen Einzelgewinnermittlungen. Da die EquityMethode auch die Vereinheitlichung der betreffenden Einzelgewinnermittlungen wie auch die Aufrechnung sämtlicher gruppeninterner Verflechtungen zumindest nicht zwingend voraussetzt, fehlt es ihr an wesentlichen Definitionsmerkmalen einer Konsolidierung. Deshalb ist zumindest strittig, ob es sich dabei um eine Form der Konsolidierung handelt oder „nur“ um ein Verfahren zur Bewertung von Unternehmensanteilen". Letzteres zielt auf die eigentliche Leistung der Equity-Methode: den Wertansatz von Unternehmensanteilen, ausgehend von ihren Anschaffungskosten, in den Folgeperioden an die Entwicklung des (anteiligen) Eigenkapitals der betreffenden Unternehmen anzupassen. Darin könnte im Übrigen ein Verstoß gegen das Anschaffungswertprinzip der Reinvermögenszugangstheorie vermutet werden, insbesondere wenn letzterer das Prinzip der Barrealisation zu Grunde liegt. Dies trifft allerdings nur aus Sicht des übergeordneten Unternehmens $\mathrm{zu}$, da hier erfolgswirksame Wertänderungen ohne korrespondierende Zahlungen verbucht werden. Für die Unternehmensgruppe als solche gilt dies nicht mehr. Wenn die Unternehmen der Gruppe den realisierten Vermögenszugang in ihrer Einzelgewinnermittlung an das Konzept der Barrealisation knüpfen, sind auch

1 Vgl. zu dieser Diskussion mit unterschiedlichen Ansichten u.a. Busse von Colbe et al. (Konzernabschlüsse, 2003) S. 525-526; Kirsch (Equity-Methode, 1990) insb. S. 9-23, 61-67, 142-144, 155-166; Küting/Zündorf $(\S 312,1998)$ Tz. 7-9; Pellens $(\S 312,2001)$ Tz. 8-9; Schäfer (Equity-Methode, 1982) S. 46-159. 
sämtliche über die Equity-Methode zum Ausdruck kommenden Ergebniswirkungen aus Gruppensicht prinzipiengerecht realisiert worden.

Der Reiz der Equity-Methode für die kerngrößenorientierte steuerliche Gewinnermittlung liegt darin, auf die Zusammenfassung sämtlicher Bestands- und Stromgrößen der jeweiligen Einzelgewinnermittlungen zu verzichten und sich auf die allein interessierenden Nettovermögensänderungen dieser Unternehmen zu konzentrieren. Dies setzt jedoch voraus, dass die Gesamtgewinnermittlung weiterhin der Einheitstheorie entspricht und letztlich kein Unterschied zu der Gewinnhöhe nach Maßgabe der Vollkonsolidierung entsteht. Bei der Equity-Methode als Vollkonsolidierungsersatz wäre es deshalb notwendig, die Einzelgewinnermittlungen vorausgehend $\mathrm{zu}$ vereinheitlichen und sämtliche Konsolidierungsmaßnahmen im engeren Sinne durchzuführen, soweit sie Erfolgswirkung entfalten ${ }^{1}$. Nur unter diesen Bedingungen dürfte die Bezeichnung der Equity-Methode als ,Ein-Zeilen-Konsolidierung (one-line-consolidation) ${ }^{2}$ überhaupt erst einen Sinn ergeben. Ein vollwertiger Vollkonsolidierungsersatz läge damit aber immer noch nicht vor. Wegen ihrer gleichfalls interessentheoretischen Ausrichtung dürfte in der Gewinnhöhe eine Identität nur mit der Quotenkonsolidierung gegeben $\operatorname{sein}^{3}$. Eine weitergehende Modifizierung der Equity-Methode wäre notwendig, in der Nettovermögensänderungen nicht mehr anteilig, sondern in voller Höhe erfasst würden. Dies erstreckte sich auch auf die integrierten Konsolidierungsmaßnahmen. Nur die insoweit deutlich ergänzte und modifizierte Equity-Methode könnte als Vollkonsolidierungsersatz in Frage kommen.

Vor diesem Hintergrund ist es allerdings fraglich, ob Vorteile bei der Durchführungseffizienz gegenüber der Vollkonsolidierung überhaupt noch erzielt würden. Letztlich müssen in entsprechenden Nebenrechnungen sämtliche Konsolidierungsmaßnahmen ergriffen werden, die auch die Vollkonsolidierung unter Berücksichtigung ihres eingeschränkten Konsolidierungsumfangs treffen. Dies gilt sowohl für die Konsolidierung im weiteren wie auch im engeren Sinne, so dass Erleichterungen nicht mehr zu erkennen

1 Da hier weiterhin nur die Unternehmen betrachtet werden, die der Unternehmensgruppe nach Maßgabe des wirtschaftlichen Eigentums voll zugerechnet werden, dürften bei der obersten Leitungsinstanz keine Schwierigkeiten bestehen, diese Maßnahmen durchzuführen und notwendige Informationen von den betreffenden Unternehmen zu erhalten.

2 Vgl. zu diesen und anderen Bezeichnungen m.w.N. Zündorf (Equity-Methode, 1987) S. 24. Der Begriff „einzeilige Konsolidierung“ findet sich insb. auch bei Biener/Berneke (Bilanzrichtlinien-Gesetz, 1986) S. 371. Vgl. treffend Schäfer (Equity-Methode, 1982) S. 185: „Die Konsolidierung findet in einer Nebenrechnung statt und nur ein Wert wird in der Konzernbilanz ausgewiesen.“

3 Vgl. zur Gegenüberstellung von Quotenkonsolidierung und Equity-Methode ausführlich Zündorf (Equity-Methode, 1987). Angesichts der Kerngrößenorientierung ist es unerheblich, dass Bilanzsumme und bestimmte Bilanzverhältnisse (z.B. Eigenkapitalquote) oder auch Betriebseinnahmen wie ausgaben in ihrer Höhe mit ihrem Äquivalent in der Quotenkonsolidierung nicht übereinstimmen. Biener/Berneke (Bilanzrichtlinien-Gesetz, 1986) S. 372 sehen gar eine (Ergebnis-)Übereinstimmung mit der Vollkonsolidierung. 
sind. Auch kann nicht ausgeschlossen werden, dass eine offene Gesamtgewinnermittlung unter Ausschaltung verschiedener Nebenrechnungen dem Fiskus gegenüber und den dort involvierten Individuen mit ihren begrenzten kognitiven Fähigkeiten ein transparenteres Bild der steuerlichen Gewinnermittlung und der dahinter stehenden Leistungsfähigkeit der Unternehmensgruppe vermittelt. Insofern ist die ergänzte und modifizierte Equity-Methode der reduzierten Vollkonsolidierung aus Effizienzgründen wahrscheinlich nicht überlegen.

Abschließend kann festgehalten werden, dass eine ergänzte und modifizierte EquityMethode eine mögliche Alternative zur reduzierten Vollkonsolidierung darstellt, ohne ihr gegenüber allerdings offenkundige Effizienzvorteile aufzuweisen. Die Notwendigkeit steuerlicher Konsolidierungsmaßnahmen bleibt davon unberührt, da beide Alternativen darauf beruhen, Einzelgewinnermittlungen über letztlich gleiche Prüfungs-, Vorbereitungs- und Korrekturverfahren in eine Gesamtgewinnermittlung nach Maßgabe der Einheitstheorie zu überführen. Um die Ausgestaltung der steuerlichen Konsolidierung im Detail analysieren zu können, soll im Folgenden erst einmal am Beispiel der deutschen Rechtsordnung aufgezeigt werden, wie sich das Spannungsverhältnis von unternehmensorientiertem Trennungsprinzip und darüber hinausgehender Einheitstheorie auf ein konkretes Besteuerungssystem auswirkt und welche rechtlichen Nebenbedingungen die Vorstellung einer konsolidierten steuerlichen Gewinnermittlung nach der Einheitstheorie möglicherweise relativieren.

\section{Gewinnermittlungskonzeption und rechtliche Nebenbedingungen am Beispiel der deutschen (Steuer-)Rechtsordnung}

\subsection{Einzelgewinnermittlung und Trennungsprinzip als Grundsatz}

Das deutsche Steuerrecht ist grundsätzlich rechtsträger- und rechtsformorientiert. Anknüpfungspunkt ist immer das steuerrechtsfähige Steuersubjekt. Interessanterweise dehnt das Steuerrecht aber die Steuerrechtsfähigkeit über die zivilrechtliche Rechtsfähigkeit hinaus aus. So können neben der natürlichen und juristischen Person auch zivilrechtlich nicht rechtsfähige Subjekte, wie z.B. nichtrechtsfähige Vereine oder Zweckvermögen, steuerrechtsfähige Steuersubjekte sein. Tipke/Lang sprechen deshalb von 
einer „unabhängigen Sonder-Rechtsfähigkeit“, die theoretisch jedes Subjekt erfassen kann, „das sich dazu eignet, steuergesetzliche Rechte und Pflichten zu übernehmen“1.

Die Differenzierung der personalen Ertragsbesteuerung in Einkommen- und Körperschaftsteuer geht mit der Differenzierung der Steuersubjekte einher. Während erstere die Entstehung der Steuerpflicht an natürliche Personen knüpft ( 1 EStG), zielt letztere rechtsformorientiert auf steuerrechtsfähige Sachsubjekte wie Körperschaften, Personenvereinigungen und Vermögensmassen ab. Nach $\S 1$ Abs. $1 \mathrm{KStG}$ sind hierunter im Wesentlichen die juristischen Personen des Privatrechts zu subsumieren ${ }^{2}$, aber auch die schon angesprochenen nichtrechtsfähigen Vereine, Anstalten, Stiftungen und andere Zweckmögen des privaten Rechts sowie Betriebe gewerblicher Art von juristischen Personen des öffentlichen Rechts. Personengesellschaften wie z.B. die Personenhandels(OHG, KG) sowie BGB-Gesellschaften sind weder nach dem EStG noch nach dem $\mathrm{KStG}$ steuerrechtsfähig und haben deshalb keine Steuersubjektfähigkeit ${ }^{3}$.

Bei Fokussierung auf die steuerrechtsfähigen Sachsubjekte interessiert für Zwecke der steuerlichen Gewinnermittlung allein das über seine Rechtsform als Körperschaftsteuersubjekt qualifizierte Unternehmen. Dieses einzelne Unternehmen bildet die rechnungslegende Einheit für die steuerliche Gewinnermittlung auf Gesellschaftsebene. Im Rah-

1 Tipke/Lang (Steuerrecht, 2002) § 6 Tz. 12 (beide Zitate); dazu auch Bayer (Steuerlehre, 1997) Tz. 459; Dornfeld (Steuerfähigkeit, 1966) S. 23-61. Eine prinzipielle Abkehr von zivilrechtlichen Gegebenheiten ist damit allerdings nicht zu unterstellen; vgl. Tipke/Lang (Steuerrecht, 2002) §17 Tz. 1-2; a.A. wohl Hey (Einführung, 1999) S. K 47, die gerade bei der Unternehmensbesteuerung durch die Abkehr von zivilrechtlich vordefinierten Rechtsformen ein „definitorisches Vakuum“ zu erkennen glaubt. Vgl. zur Emanzipation des Steuerrechts vom Zivilrecht in Fragen der Konzernbesteuerung Girnth (Ertragsbesteuerung von Konzernen, 1963) S. 127-145. Diese Differenzierung ist auch insofern interessant, als dass die fehlende Rechtsfähigkeit, z.B. des aktienrechtlichen Konzerns, einer möglichen Steuersubjektfähigkeit theoretisch nicht entgegen stehen dürfte; vgl. dazu Kap. III.2.3. In diese Richtung geht z.B. auch die Forderung von Kirchhof (Vorschlag zur Reform, 2003) S. 2 nach einer „steuerjuristischen Person“, die de lege ferenda jeden rechtlich fassbaren wirtschaftlichen Organismus verselbstständigen und zu besteuern vermag.

2 Darunter fallen insb. Kapitalgesellschaften, Erwerbs- und Wirtschaftsgenossenschaften, Versicherungsvereine auf Gegenseitigkeit sowie sonstige juristische Personen des privaten Rechts. Vgl. bereits $R F H$ v. 3.7.1935 (VI A 1149/33) S. 1128: „Auf der Anerkennung der Rechtsform der juristischen Person beruht das gesamte Körperschaftsteuerrecht. ... Die wirtschaftliche Betrachtungsweise muß vor diesen Grundsätzen Halt machen“.

3 Hier greift das sog. Transparenzprinzip; vgl. dazu Kap. III.2.4.1. 
men dieser Einzelgewinnermittlung ${ }^{1}$ trägt das Unternehmen die Verantwortung für das Ermittlungsprozedere und hat die steuerlichen Konsequenzen selbst zu tragen. Es gilt das Trennungsprinzip. Ein Verlustausgleich über Unternehmensgrenzen hinweg ist nicht möglich. Er beschränkt sich auf zeitliche Rück- und Vortragsmöglichkeiten innerhalb des Unternehmens ( $\S 8$ Abs. 1 und 4 KStG i.V.m. $§ 10 \mathrm{~d} \mathrm{EStG)})^{2}$. Im Rahmen der Einzelgewinnermittlung ist eine Verlustkompensation allenfalls mittelbar und in der Höhe beschränkt denkbar, wenn ein Unternehmen an einem anderen beteiligt ist und diese Beteiligung in der Steuerbilanz aufgrund nachhaltiger Verluste des Beteiligungsunternehmens einer Teilwertabschreibung unterzogen wird ${ }^{3}$. Mit Einführung des Halbeinkünfteverfahrens ist diese Möglichkeit für körperschaftsteuerpflichtige Unternehmen aber entfallen, da derartige Teilwertabschreibungen den steuerpflichtigen Gewinn nicht mehr mindern dürfen ( $(8 \mathrm{~b}$ Abs. $3 \mathrm{KStG})$.

In diesem Zusammenhang wird deutlich, dass sich Eigenkapitalverflechtungen zwischen Unternehmen in dem Beteiligungsansatz als Wirtschaftsgut in der Steuerbilanz begrenzt widerspiegeln. Hier gilt allerdings nur das Anschaffungswertprinzip ( $\$ 6 \mathrm{Abs}$. 1 Nr. 1, 2 EStG), das insofern dem Trennungsprinzip genügt, als dass die Besteuerungsebene des übergeordneten Unternehmens (Gesellschafterebene) erst bei Ausschüttung durch das untergeordnete Unternehmen angesprochen wird. Zudem erscheint das jeweils andere Unternehmen in der Gewinnermittlung beider Unternehmen hinsichtlich der Ergebnisrealisation weiterhin jeweils wie ein fremder Dritter ${ }^{4}$.

1 Die Körperschaftsteuer bemisst sich wie die Einkommensteuer nach dem zu versteuernden Einkommen ( $\$ 7$ Abs. $1 \mathrm{KStG}$ ), das nach dem Prinzip der Abschnittsbesteuerung über ein Kalender- bzw. Wirtschaftsjahr ( $\$ 7$ Abs. 3 und $4 \mathrm{KStG}$ ) nach den Vorschriften des EStG zu ermitteln ist, soweit dies seiner Natur nach möglich ist und die Vorschriften des $\mathrm{KStG}$ als lex specialis nicht vorgehen $(\S \S 7$ Abs. 2, 8 Abs. 1 Satz $1 \mathrm{KStG}$ i.V.m. $\S \S 2$ ff. EStG). Die gesuchte Einkommensgröße ermittelt sich bei ihnen nicht über eine zahlungsorientierte Einnahmenüberschussrechnung ( $\S 4 \mathrm{Abs}$. $3 \mathrm{EStG}$ ), sondern über einen Betriebsvermögensvergleich ( $§ 4$ Abs. 1, § 5 EStG), der bei Bilanzierungspflichtigen und freiwillig bilanzierenden Unternehme(r)n über das Maßgeblichkeits- ( $\$ 5$ Abs. 1 Satz 1 EStG) sowie Umkehrmaßgeblichkeitsprinzip ( $\$ 5$ Abs. 1 Satz 2 EStG), die zusätzliche Beachtung handelsrechtlicher Vorschriften erzwingt ( $\$ 5$ i.V.m. $§ 4$ Abs. 1 EStG), soweit dem nicht steuerliche Vorschriften entgegenstehen (steuerlicher Bewertungsvorbehalt gemäß $\$ 5$ Abs. 6 EStG). Vgl. zur Maßgeblichkeit im Überblick Knobbe-Keuk (Bilanz- und Unternehmenssteuerrecht, 1993) S. 17-33 und zu seinen Einschränkungen z.B. Scheffler (Reichweite, 2004). Dabei wird der aus dem handelsrechtlichen Einzelabschluss abgeleitete Steuerbilanzgewinn außerhalb der Bilanz i.S.d. $\S \S 8 \mathrm{ff}$. KStG modifiziert und in das zu versteuernde Einkommen überführt.

2 Vgl. dazu genauer (auch zur Mindestbesteuerung durch die Begrenzung der Verlustvortragsverrechnung ab 2004) Herzig/Wagner (Verrechnung von Verlustvorträgen, 2004). Verluste sind streng genommen negatives zu versteuerndes Einkommen.

3 Vgl. zur analogen Situation bei grenzüberschreitender unternehmerischer Tätigkeit Kap III.2.5.2; vgl. zum Teilwert Kap. V.4.2.2; grundlegend zur Beteiligungsbewertung auch Dirrigl (Bewertung von Beteiligungen, 1988).

4 Vgl. zur diesbezüglichen Rechtfertigung z.B. BFH v. 3.2.1971 (I R 51/66); von Wallis (Konzernrecht, 1973) S. 42-46, insb. S. 45. 
Bei der Ergebnisermittlung und -zuordnung ist es getreu dem Trennungsprinzip völlig ohne Bedeutung, ob und wie das Einkommen verteilt bzw. ausgeschüttet wird ( $\$ 8$ Abs. 3 Satz $1 \mathrm{KStG}$ ). Anders als bei der Frage der Steuersubjektivität finden Vertragsbeziehungen des Unternehmens zu seinen Anteilseignern in diesem Zusammenhang aber Berücksichtigung. Auf der Grundlage der Fiktion wirtschaftlich autonomer Unternehmen können sie zu Ergebniskorrekturen führen, wenn sie keine als „marktgerecht“ akzeptierten Konditionen aufweisen. Hierzu gehören insbesondere die verdeckte Gewinnausschüttung ( $\$ 8 \mathrm{Abs} .3 \mathrm{Satz} 2 \mathrm{KStG}, \mathrm{Abschn} .31 \mathrm{ff} . \mathrm{KStR}$ ) und die verdeckte Einlage ( $§ 8$ Abs. 1 KStG i.V.m $\S 4$ Abs. 1 Sätze 1 und 5 EStG, Abschn. 36a KStR) ${ }^{1}$, die immer dann unterstellt werden, wenn bei dem Unternehmen Vermögensminderungen oder verhinderte Vermögensmehrungen auf der einen und (einlagefähige) Vermögensvorteile auf der anderen Seite durch Indizienwürdigung im Rahmen des Fremdvergleichs (dealing at arm's length) identifiziert werden, die letztlich nur durch das Gesellschafterverhältnis mit dem Vertragspartner zu rechtfertigen sind. Damit mutieren zivilrechtlich als Lieferungs- und Leistungsaustausch des Unternehmens qualifizierte Rechtsbeziehungen in steuerlicher Hinsicht zu Ausschüttungen bzw. Einlagen mit der Konsequenz, dass die aus dem Lieferungs- und Leistungsgeschäft resultierende Ergebniswirkung steuerlich zu korrigieren ist.

\subsection{Anrechnungs-, Freistellungs- und organschaftliches Zurechnungsmodell als partielle Ausnahmen}

Das deutsche Steuerrecht kennt auch erste Schritte zur Überwindung des Trennungsprinzips. So sah das von 1977 bis 2000 existierende körperschaftsteuerliche Anrechnungsverfahren zumindest die Vermeidung von Doppelbelastungen bei Gewinnausschüttungen vor. Durch Anrechnung der vom Unternehmen bereits entrichteten Körperschaftsteuer auf die persönliche Einkommensteuerschuld des Anteilseigners wurde der ausgeschüttete Gewinn im Ergebnis nur noch beim Anteilseigner besteuert. Ein konsequent verfolgtes Trennungsprinzip dürfte stattdessen eher mit einem klassischen Doppelbelastungssystem im Einklang stehen, in dem die Gesellschafts- und Gesellschafterebene völlig unabhängig voneinander zu besteuern sind ${ }^{2}$. Das Trennungsprinzip galt aber noch insofern, dass immer noch verschiedene Steuersubjekte weitgehend isoliert voneinander den Gewinn ermittelten, Verluste zwischen den beiden Ebenen nicht ausgeglichen werden konnten und ausländische Anteilseigner inländischer Gesellschaften

1 Zur Charakterisierung der verdeckten Gewinnausschüttung und verdeckten Einlage als Gewinnkorrekturvorschriften vgl. z.B. Wassermeyer (Streitfragen zur grenzüberschreitenden verdeckten Gewinnausschüttung, 1998) Tz. 646-652.

2 Vgl. ähnlich Hey (Einführung, 1999) S. K 23; a.A. wohl Schaumburg (Grundzüge des Konzernsteuerrechts, 1998) S. 7-8. 
vom Anrechnungsverfahren ebenso ausgeschossen waren wie inländische Anteilseigner ausländischer Gesellschaften ${ }^{1}$.

Obwohl das ab 2001 geltende Halbeinkünfteverfahren keine Anrechnung mehr vorsieht und insofern eine Definitivsteuer festlegt, wird das Problem der Doppelbesteuerung auch hier weitgehend vermieden, in dem Gewinnausschüttungen zwischen körperschaftsteuerpflichtigen Steuersubjekten steuerfrei bleiben ( $\S 8$ b Abs. 1 Satz $1 \mathrm{KStG}$ ). Dies ähnelt dem früheren körperschaftsteuerlichen Schachtelprivileg, das bis zur Einführung des Anrechnungsverfahrens 1977 entsprechende Doppelbesteuerungen, allerdings erst bei einer Mindestbeteiligung von $25 \%$, zu vermeiden half ${ }^{2}$. Durch $\S 8 \mathrm{~b}$ Abs. 1 Satz $1 \mathrm{KStG}$ wird der Gewinn, solange er nur im Unternehmensverbund ,durchgeschüttet“" wird, nur einmalig mit der Definitivsteuer belastet. Abgesehen von der weiterhin existierenden Andersbehandlung der Steuerausländer tritt eine Doppelbelastung aber spätestens dann auf, wenn an natürliche Personen als Anteilseigner ausgeschüttet wird, für die eine entsprechende Steuerfreistellung auf die Hälfte der entsprechenden Einnahmen beschränkt ist ( $§ 3 \mathrm{Nr}$. $40 \mathrm{EStG}$ ). Insoweit rückt das Halbeinkünfteverfahren im Vergleich zum Anrechnungsverfahren wieder etwas näher an das Trennungsprinzip heran $^{3}$.

Im Unternehmensverbund können empfangene Gewinnausschüttungen wegen der Freistellung auch nicht zum unternehmensübergreifenden Verlustausgleich beitragen und beteiligungsbezogene Aufwendungen der Obergesellschaft werden zum steuerlichen Abzug nicht mehr zugelassen $(\S 3 \mathrm{c} \text { Abs. } 1 \mathrm{EStG})^{4}$. Korrespondierend zur steuerlichen Freistellung der Veräußerungsgewinne von entsprechenden Unternehmensanteilen ( $\S 8 \mathrm{~b}$ Abs. $2 \mathrm{KStG}$ ) ist auch die mittelbare und ohnehin beschränkte Möglichkeit einer Verlustkompensation über eine Teilwertabschreibung auf aktivierte Unternehmensanteile durch $\S 8$ b Abs. $3 \mathrm{KStG}$ entfallen. Völlig unberührt bleibt hiervon das weiterhin bestehende Anschaffungswertprinzip und die weiterhin isolierte Gewinn- bzw. Einkommensermittlung der betroffenen Steuersubjekte. Interessanterweise wird so etwas ähnliches wie die Equity-Methode allerdings dann angewendet, wenn ein körperschaftsteuerpflichtiges Unternehmen Mitunternehmer einer nicht körperschaftsteuerpflichten Personengesellschaft ist ( $\$ 15$ Abs. 1 Satz 1 Nr. 2 EStG). Da die Personengesellschaft selbst

1 Der letztgenannte Punkt begründet auch europarechtliche Kritik, die mit dem Halbeinkünfteverfahren nicht wirklich entkräftet wurde.

2 Vgl. zuletzt $\S 9$ KStG 1975; dazu ausführlich z.B. Müller (Konzerne, 1975) S. 13-16. Das bis 1996 existierende vermögensteuerliche Schachtelprivileg und das heute noch geltende gewerbesteuerliche Schachtelprivileg sollen hier nicht betrachtet werden; vgl. dazu z.B. Wöhe (Konzernbesteuerung, 1998) S. 357-363. Vgl. schon sehr früh zur partiellen Nähe des Schachtelprivilegs zur „Konzern“Besteuerung Hoffmann (Konzern-Bilanz, 1930) S. 42-46; Oberst (Frage der Konzernbilanz, 1930) S. 225; Oberst (Konzernbilanz, 1933) S. 67.

$3 \mathrm{Vgl}$. zur grundlegenden Diskussion, ob institutionale Unternehmenssteuern auf Ebene der Individuen angerechnet werden sollten oder nicht, z.B. Musgrave/Musgrave (Public Finance, 1989) S. 371-373.

4 Vgl. z.B. Herzig (Paradigmenwechsel in der Konzernbesteuerung, 2002) S. I. 
kein Steuersubjekt darstellt und die „Beteiligung“ an ihr auch nicht als Wirtschaftsgut angesehen wird, hat hier einer Bewertung nach der sog. Spiegelbildmethode entsprechend der Entwicklung des Kapitalkontos zu erfolgen'. Eine Bewertung auch über die Anschaffungskosten hinaus und eine partielle Abkehr vom Trennungsprinzip liegen damit im speziellen Fall der Mitunternehmerbesteuerung vor ${ }^{2}$.

Deutliche Ansätze zur Überwindung des Trennungsprinzips ergeben sich aus dem Organschaftskonzept, dass mit der körperschaftsteuerlichen ( $\S 14-19 \mathrm{KStG})$, gewerbesteuerlichen ( $\$ 2$ Abs. 2 Satz 2 GewStG) und umsatzsteuerlichen Organschaft ( $\$ 2$ Abs. 2 Nr. 2 UStG) drei konkrete steuerrechtliche Ausprägungen besitzt, von denen im Folgenden allein die körperschaftsteuerliche Organschaft ${ }^{3}$ interessiert. Grundgedanke dieser Organschaft ist die unter bestimmten Voraussetzungen mögliche Zusammenfassung einer oder mehrerer Organgesellschaften unter einen Organträger zwecks einer Gewinn- und Verlustverrechnung innerhalb des Organkreises. Von den ursprünglich in der Rechtsprechung entwickelten Organschaftstheorien ${ }^{4}$ hat sich in diesem Zusammenhang nur die Zurechnungstheorie durchsetzen können, wonach das steuerpflichtige Einkommen der untergeordneten Gesellschaften dem Organträger zugerechnet wird ${ }^{5}$, ohne dass diese dadurch der Steuerpflicht entgehen oder gar ihre Steuersubjektivität verlieren. Durch das "Hochschleusen“ haben sie ihr $\mathrm{zu}$ versteuerndes Einkommen abgesehen von der Ausnahme des $\S 16 \mathrm{KStG}$ - lediglich auf Null gesetzt, ohne dass es dabei auf die tatsächliche Gewinnabführung bzw. Verlustübernahme ankäme. Obwohl

1 Vgl. insb. $B F H$ v. 23.7 .1975 (I R 165/73); dazu auch Döllerer (Beteiligung, 1977) S. 87-91; Rupp (Ertragsbesteuerung nationaler Konzerne, 1983) S. 258-259; vgl. zur Bilanzierung von Beteiligungen an Personenhandelsgesellschaften in der Handelsbilanz HFA (Stellungnahme, 1976); Döllerer (Beteiligung, 1977) S. 82-87; vgl. zur Abgrenzung der Spiegelbild- von der Equity-Methode Schäfer (Equity-Methode, 1982) S. 54-68.

2 Vgl. zur Parallele der Mitunternehmerbesteuerung zur Konsolidierung Kap. III.2.4.

3 § 2 Abs. 2 Satz 2 GewStG verweist auf die körperschaftsteuerlichen Organschaftsvoraussetzungen, so dass sich diese beiden ertragsteuerlichen Konzepte in der Ausgestaltung entsprechen.

4 Vgl. dazu früh im Überblick Friedländer (Organtheorie, 1931); Hoffmann (Konzern-Bilanz, 1930) S. 39-42; s.a. Mestmäcker (Verwaltung, 1958) S. 294-302. Gesetzlich erstmals kodifiziert wurde die körperschaftsteuerliche Organschaft im August 1969 durch den damaligen $\S 7$ a KStG; vgl. Herzig (Einführung, 2003) S. 5.

5 Vgl. § 14 Abs. 1 Satz $1 \mathrm{KStG}$; neben der Zurechnungstheorie wird auch die nicht ganz deckungsgleiche Angestelltenhypothese genannt, die ein vom Preußischen Oberverwaltungsgericht entwickeltes, später vom RFH (vgl. $R F H$ v. 11.11.1927 (I A 75/27); $R F H$ v. 18.2.1933 (I A 439/32); $R F H$ v. 25.9.1934/22.1.1935 (I A 401/32)) fortgefuhrtes Verständnis betrifft, wonach die Untergesellschaft als Angestellte der Obergesellschaft fungiert. Vgl. zur Ablehnung der Einheitstheorie durch Gesetzgeber und Rechtsprechung BFH v. 26.7.1967 (I 138/65) S. 743; Rupp (Ertragsbesteuerung nationaler Konzerne, 1983) S. 110-112. Ihre normative Wirkung ist dennoch nicht erloschen, da sie im Zuge von Reformüberlegungen der körperschaftlichen Organschaft durchaus bemüht wird; vgl. z.B. Baetge/Beermann (Eignung der körperschaftsteuerlichen Organschaft, 1998). Interessanterweise hat die Einheitstheorie i.R.d. umsatzsteuerlichen Organschaft eine weitergehende Umsetzung erfahren, da die Organgesellschaften dort ihre Unternehmenseigenschaft verlieren, so dass Innenumsätze zwischen den Gesellschaften des Organkreises nicht mehr steuerbar sind; vgl. § 2 Abs. 2 Nr. 2 UStG; dazu z.B. Herzig (Einführung, 2003) S. 5; Wöhe (Konzernbesteuerung, 1998) Tz. 180. 
die Organschaft damit schon sehr weit geht und das Steuerrecht hier eine ,wirtschaftliche Unternehmenseinheit ${ }^{\text {"1 }}$ nachzuvollziehen versucht, die die Doppelbelastungen ausgeschütteter Gewinne bei Organgesellschaft und Organträger vermeidet und vor allem den innerorganschaftlichen Verlustausgleich ermöglicht, hat sie das Trennungsprinzip nicht in Gänze überwinden können ${ }^{2}$. Alle Unternehmen des Organkreises behalten ihre zivil- und steuerrechtliche Rechtsfähigkeit ${ }^{3}$ und sind weiterhin zur selbständigen und getrennten steuerlichen Gewinnermittlung verpflichtet, nach der die Unternehmen des Organkreises auch untereinander wie fremde Marktteilnehmer behandelt werden ${ }^{4}$. Alle steuerrechtlichen Konsequenzen knüpfen weiterhin an den Unternehmen des Organkreises an, die Organschaft selbst ist weder rechtsfähig noch Steuersubjekt.

Zentrale Organschaftsvoraussetzung ist neben dem wirksamen Gewinnabführungsvertrag die allein auf die Stimmrechtsmehrheit abstellende finanzielle Eingliederung $(\S 14$ Abs. 1 Nr. $1 \mathrm{KStG}$ ). Weitere Eingliederungsvoraussetzungen (wirtschaftliche, organisatorische Eingliederung), die zumindest dezentral organisierten Unternehmensgruppen eher widersprachen und infolgedessen in der Kritik standen ${ }^{5}$, sind inzwischen abgeschafft worden. Zudem ist der Organkreis nur auf inländische Unternehmen ${ }^{6}$ und bestimmte Rechtsformen (Kapitalgesellschaften) bei der Organgesellschaft beschränkt ${ }^{7}$.

Es kann abschließend festgehalten werden, dass das geltende Einkommen- und Körperschaftsteuerrecht in seinem Zwang zur Tatbestandsmäßigkeit und Eindeutigkeit auf steuerrechtsfähige Steuersubjekte abstellt, die regelmäßig, allerdings nicht immer zivilrechtliche Rechtsträger darstellen. Diese Steuersubjekte bilden gleichfalls die rech-

1 Tipke/Lang (Steuerrecht, 2002) §11 Tz. 110.

2 Vgl. z.B. Harms/Küting (Perspektiven der Konzernbesteuerung, 1982) S. 446, die in der Organschaft, neben dem Schachtelprivileg, allenfalls „erste Ansatzpunkte einer Einheitsbesteuerung“ erkennen; ähnlich Herzig (Einführung, 2003) S. 5-6.

3 Vgl. allerdings auch Bühler (Steuerrecht, 1956), nach dem die Rechtsfähigkeit der Organgesellschaften zu etwa neun Zehnteln ausgeschaltet wird.

4 Vgl. ausführlicher Grotherr (Besteuerung nationaler und grenzüberschreitender Konzerne, 1994) S. 83-139, der die Organschaft als „lex imperfecta zur steuerlichen Erfassung der wirtschaftlichen Einheit ,Konzern"“ ansieht; Scheffler (Besteuerung von inländischen Konzernen, 1991) S. 703, 705-706.

5 Vgl. z.B. m.w.N. Reis (Körperschaftsbesteuerung des Konzerns, 1996) S. 126-129; Richter (Konzernbesteuerung, 2003) S. 114-165.

6 Unter restriktiven Voraussetzungen ist lediglich ein ausländischer Organträger gem. § $18 \mathrm{KStG}$ möglich. Zu der Abschaffung des doppelten Inlandsbezugs (früher Sitz und Geschäftsleitung im Inland, heute nur noch letzteres) beim Organträger, der Beibehaltung desselben bei der Organgesellschaft und möglichen Konsequenzen der EuGH-Rechtsprechung zur Gründungs- bzw. Inkorporationstheorie für das Organschaftsrecht vgl. Richter (Konzernbesteuerung, 2003) S. 367-389; s.a. Herzig/Wagner (Zukunft der Organschaft, 2005) S. 3-7 zu Spannungsfeldern zwischen der Organschaftsbesteuerung und gemeinschaftsrechtlichen Vorgaben.

7 Vgl. ausführlich zu den aktuellen Organschaftsvoraussetzungen u.a. Dötsch (Gewinnabführungsvertrag, 2003); Förster (Finanzielle Eingliederung, 2003); Herzig (Einführung, 2003) S. 8-17; Koths (Organträger, 2003); Richter (Konzernbesteuerung, 2003) S. 114-165; s.a. Knobbe-Keuk (Bilanz- und Unternehmenssteuerrecht, 1993) S. 696-721; Wöhe (Konzernbesteuerung, 1998) Tz. 156-180. 
nungslegende Einheit der steuerlichen Gewinnermittlung, auch wenn bestimmte Korrekturverfahren die Auswirkungen des Trennungsprinzips zu reduzieren vermögen. Sie helfen, zumindest die Mehrfachbesteuerung ausgeschütteter Gewinne zu vermeiden (Anrechnungs- und Freistellungsverfahren, Organschaft) und einen Verlustausgleich zwischen den betroffenen Unternehmen zu ermöglichen (Organschaft).

\subsection{Berücksichtigung von Unternehmensverbindungen im Konzern}

\subsubsection{Aktienrechtlicher Konzernsachverhalt}

In Deutschland hat in den zwanziger und frühen dreißiger Jahren des letzten Jahrhunderts eine Diskussion über die rechtliche Berücksichtigung von Unternehmensverbindungen eingesetzt, obwohl derartige Formen der Unternehmenskonzentration bereits seit der Reichsgründung von 1871 ein reales Phänomen darstellten ${ }^{1}$. Für bestimmte Formen von Unternehmensverbindungen entwickelte sich der Konzernbegriff, der schließlich über das AktG 1937 Eingang in das bis heute geltende AktG 1965 fand. Als Teildisziplin des Gesellschaftsrechts entstand das Konzernrecht als Organisationsrecht und als Sonderrecht verbundener Unternehmen ${ }^{2}$. Verbundene Unternehmen werden als organisationsrechtlich miteinander verbundene Rechtsträger definiert ${ }^{3}$, die in Mehrheitsbesitz stehende oder mit Mehrheit beteiligte Unternehmen ( $\$ 16 \mathrm{AktG}$ ), herrschende oder abhängige Unternehmen ( $\S 17 \mathrm{AktG}$ ), wechselseitig beteiligte Unternehmen ( $\$ 19 \mathrm{AktG})$, vertraglich verbundene Unternehmen ( $\$ \S 291,292 \mathrm{AktG}$ ) sowie die zu einem Konzern zusammengefassten und meist in mehrfacher Hinsicht miteinander verbundenen Konzernunternehmen $(\S 18 \mathrm{AktG})$ umfassen. Entsprechende aktienrechtliche Regulierungen lösen sich bewusst vom Leitbild der unabhängigen Gesellschaft. Eine grundlegende Abkehr vom (zivilrechtlichen) Trennungsprinzip wird damit allerdings nicht vollzogen ${ }^{4}$. Auch der Konzern hat keinerlei Rechtsfähigkeit und alle Rechtskonsequenzen treffen die Konzernunternehmen.

Das Konzernrecht ist als Schutzrecht konzipiert. Aus der Konzentration von Unternehmensanteilen in einer Hand, zumal in derjenigen einer (weiteren) juristischen Person, und dem damit einhergehenden Übergang residualer Kontroll- und Entscheidungsrechte begründen sich nach rechtswissenschaftlicher - im Übrigen auch ökonomischer ${ }^{5}-$ Sicht bestimmte Risiken aus der entstehenden Abhängigkeit, die es im Rahmen des Konzern-

1 Vgl. zur Entwicklung der Unternehmenskonzentration in Deutschland und zur Geschichte des Konzernrechts Emmerich/Sonnenschein/Habersack (Konzernrecht, 2001) S. 2-9.

2 Vgl. Mülbert (Aktiengesellschaft, 1996) S. 49. Vgl. zum Verhältnis des Konzernrechts als Organisations- und - wie im weiteren Verlauf erwähnt - als Schutzrecht Schmidt (Konzernunternehmen, 2000).

Vgl. Schmidt (Gesellschaftsrecht, 2002) S. 490.

Vgl. Lutter (Konzerngesellschaftsrecht, 1998) S. 62.

Vgl. stellvertretend Pellens (Aktionärsschutz im Konzern, 1994). 
rechts zu reduzieren gilt ${ }^{1}$. Schutzobjekt sind hierbei insbesondere die individuellen Anteilseigner der betroffenen über- und untergeordneten (Konzern-)Unternehmen ${ }^{2}$. Der Konzern selbst wird gemäß $\S 18 \mathrm{AktG}$ als Zusammenfassung mehrerer rechtlich selbständiger Unternehmen unter einheitlicher Leitung definiert. Als zentrales Tatbestandsmerkmal ist die einheitliche Leitung allerdings unbestimmt und an keine konkreten Voraussetzungen geknüpft ${ }^{3}$. In einer engen Auslegung ist sie nur dann gegeben, wenn die Konzernspitze für sämtliche unternehmerischen Bereiche aller Konzernunternehmen eine einheitliche Planung erstellt und diese auch durchsetzt. In einer weiteren Auslegung reichen hier bereits auf wesentliche Fragen der Geschäftsführung und Finanzplanung reduzierte Leitungsaufgaben aus ${ }^{4}$. Im ökonomischen Verständnis lassen sich in beiden Auslegungsvarianten gewisse Parallelen zu dem Eigentumskonzept von Grossman/Hart erkennen, das auf residualen Kontroll- und Entscheidungsrechten basiert. Konsequenterweise wird der Konzern deshalb von Schmalenbach als eine durch „Beherrschung "s zusammengehaltene Unternehmensgemeinschaft definiert, die nach Busse von Colbe et al. den Charakter einer ,unternehmungsähnlichen wirtschaftlichen Einheit ${ }^{\text {*6 }}$ besitzt.

Der aktienrechtliche Konzern kann durchaus als Versuch verstanden werden, das ökonomische Modell der Unternehmung in die deutsche Rechtsordnung zu übertragen. Vor diesem Hintergrund spricht Theisen insgesamt von einer „Konzernunternehmung “7 , die der nicht-konzerngebundenen und damit rechtlich nicht zergliederten Einheitsunternehmung gegenüber steht. Allerdings hat sie nach Lutter als solche überhaupt keine Rechtsform, ist ,also die Organisationsform des einen Unternehmens, dem selbst Rechtsform und Rechtsfähigkeit fehlen “8. Die Vorstellung des Konzerns als Rechtssubjekt hat sich in der Rechtswissenschaft trotz einzelner anfänglicher Befürworter ${ }^{9}$ nicht

1 Vgl. Emmerich/Sonnenschein/Habersack (Konzernrecht, 2001) S. 8; Schmidt (Gesellschaftsrecht, 2002) S. 487-488, 491-495. Die wichtigsten Schutzvorschriften knüpfen aber weniger an die Konzernzugehörigkeit, sondern an die geringere Hürde der Abhängigkeit an. Vgl. ausführlich zu den konzernspezifischen gesellschaftsrechtlichen Schutzregelungen Streim (Konzernrecht, 2004) S. 49-110.

2 Der Schutzbereich zielt hier letztlich auf die Anteilseigner sämtlicher Unternehmen, die das Aktienrecht als „verbunden“ ansieht ( $§ 15 \mathrm{AktG})$.

3 Vgl. insb. Kropff(Aktiengesetz, 1965) S. 33; Zünd (Einheitliche Leitung, 1988).

$4 \mathrm{Vgl} \mathrm{zu}$ dem engeren und weiteren Konzernbegriff ausführlicher Emmerich/Sonnenschein/Habersack (Konzernrecht, 2001) S. 63-64. Vgl. stellvertretend für die Fülle sonstiger Literatur zur Auslegung dieses Rechtsbegriffs Theisen (Konzern, 2000) S. 34-38.

5 Schmalenbach (Finanzierungen, 1937) S. 135.

6 Busse von Colbe et al. (Konzernabschlüsse, 2003) S. 57.

7 Theisen (Konzem, 2000) S. 127, der soweit geht, diesem betriebswirtschaftlichen Erfahrungsobjekt eigene, originäre Konzernunternehmungsaufgaben zuzuweisen; s.a. Oberndorff (Konzernbesteuerung, 1996) S. 6, der neutraler von „Verbundunternehmung“ spricht; Schubert/Küting (Unternehmungszusammenschlüsse, 1981) S. 239, für die der Konzern als Ganzes die Unternehmung darstellt. Lutter (Organzuständigkeiten, 1985) S. 829 [ohne Hervorhebungen des Originals].

9 Vgl. so wohl erstmals Isay (Recht am Unternehmen, 1910); im historischen Überblick dazu Hommelhoff (Konzernleitungspflicht, 1982) S. 10-12. 
durchgesetzt ${ }^{1}$. Im Gesellschaftsrecht hat der Konzern wegen fehlender Rechtsfähigkeit nicht den Status einer rechtlichen Einheit ${ }^{2}$, auch wenn aus der wirtschaftlichen Verbindung rechtliche Konsequenzen für die einzelnen Unternehmen erwachsen.

Das Konzernrecht differenziert zwischen unterschiedlichen Grundformen des Konzerns. So können Konzerne entweder als Unterordnungs- oder als Gleichordnungskonzerne organisiert sein. Während beim Unterordnungskonzern mehrere abhängige Unternehmen unter der einheitlichen Leitung des herrschenden Unternehmens stehen $(\S 18 \mathrm{Abs}$. 1 Satz 1 AktG), fehlt die Abhängigkeitsbeziehung beim Gleichordnungskonzern, der insofern gleichberechtigte Konzernunternehmen unter einheitlicher Leitung zusammenfasst $(\S 18 \mathrm{Abs} .2 \mathrm{AktG})^{3}$. Da die einheitliche Leitung bei beiden Konzernformen das konstituierende Merkmal darstellt, sind beide, also auch der Gleichordnungskonzern, mit dem ökonomischen Verständnis der Unternehmung als hierarchisches Überwachungs- und Durchsetzungssystem vereinbar. Beim Gleichordnungskonzern sind Hierarchien nicht zu leugnen, wenn sich die Beteiligten freiwillig der einheitlichen Leitung durch eines der beteiligten Unternehmen oder eines speziell hierfür geschaffenen gemeinsamen Leitungsorgans unterstellen. Die Grenze zum Unterordnungskonzern ist jedoch fließend, je nachdem, ob das Leitungsorgan konzernrechtlich als Unternehmen einzustufen ist oder nicht ${ }^{4}$. An Charakter und Stellung des übergeordneten Unternehmens hat sich auch in der Rechtswissenschaft der Streit entzündet, wo genau die Grenzen der Konzernunternehmung verlaufen. Obwohl vom Gesetzgeber wahrscheinlich nicht gewollt, werden inzwischen auch Mehrheitsgesellschafter und damit natürliche Personen oder sogar juristische Personen des öffentlichen Rechts unter bestimmten Voraussetzungen als herrschende Unternehmen qualifiziert und konzernrechtlichen Schutzbestimmungen unterworfen ${ }^{5}$.

Beide Konzernformen, d.h. Unterordnungs- und Gleichordnungskonzen, können auf vertraglicher oder faktischer Grundlage gebildet werden. Während der Vertragskonzern

1 Vgl. treffend dazu Lutter (Aufgabe eines Konzernrechts, 1988) S. 226: „Die Betriebswirtschaftslehre geht also vom Konzern als selbständigem Lebewesen aus, während wir Juristen den Bienenstaat vor uns sehen." Vgl. auch Emmerich/Sonnenschein/Habersack (Konzernrecht, 2001) S. 61, wonach sich die Einheitstheorie bei den Juristen nicht durchsetzen konnte; ähnlich Hommelhoff (Konzernleitungspflicht, 1982) S. 2-35; Mülbert (Aktiengesellschaft, 1996) S. 21, der aber auch Einflüsse der Betriebswirtschaftslehre auf die rechtswissenschaftliche Konzernsicht aufzeigt (S. 36).

2 Vgl. z.B. Mülbert (Aktiengesellschaft, 1996) S. 25, der ein ,gesellschaftsrechtlich eigenständiges Rechtsgebilde ohne eigene Rechtsfähigkeit“ erkennt.

3 Vgl. zu dieser Zweiteilung des $§ 18$ AktG bereits Kropff(Aktiengesetz, 1965) S. 32-34.

4 Vgl. zu der mitunter schwierigen Abgrenzung zum Unterordnungskonzern, wenn das Leitungsorgan als Unternehmen i.S.d. Konzernrechts anzusehen ist, Emmerich/Sonnenschein/Habersack (Konzernrecht, 2001) S. 69-71.

5 Vgl. Emmerich/Sonnenschein/Habersack (Konzernrecht, 2001) S. 31-33; Müller (Konzerne, 1975) S. 9; Streim (Konzernrecht, 2004) S. 1-2; kritisch Schmidt (Konzernunternehmen, 2000) S. 1179-1180; Schmidt (Gesellschaftsrecht, 2002) S. 494-495, 935-939. 
auf Beherrschungsverträgen gemäß $\S 291$ AktG beruht ${ }^{1}$ und die Konzernunternehmen mit ganz bestimmten, stark regulierten Verträgen im Rechtssinne bindet, basiert der faktische Konzern auf allen sonstigen Verbindungsmöglichkeiten, mittels derer die einheitliche Leitung tatsächlich begründet wird. Anders als der eng gefasste Vertragskonzern hat gerade der faktische Konzern in seiner definitorischen Weite das Potenzial, auch ökonomische Vertragsvorstellungen und daraus abgeleitete Unternehmensverbindungen zu berücksichtigen. Die intensitätsmäßig stärkste Verbindungsform zwischen den Konzernunternehmen ist indes die aktienrechtliche Eingliederung gemäß §§ $319 \mathrm{ff}$. $\mathrm{AktG}$, die nur in einem Unterordnungskonzern möglich ist und die sich von der Verschmelzung bzw. Fusion nur noch durch das Aufrechterhalten der rechtlichen Identität des eingegliederten Unternehmens unterscheidet ${ }^{2}$. Nach Lutter kann deshalb bei der Eingliederung bereits de lega lata von einer Einheitsunternehmung gesprochen werden ${ }^{3}$.

Es kann abschließend festgehalten werden, dass das Konzernrecht und der darin definierte Konzern eine Annäherung rechtlicher Vorstellungen an das ökonomische Modell der Unternehmung herbeiführen. Das Recht bleibt zwar konsequent rechtsformorientiert, berücksichtigt jedoch bestimmte Verbindungen zwischen den einzelnen Rechtsträgern und leitet daraus Rechtskonsequenzen ab. Diese Rechtskonsequenzen treffen zwangsläufig nur die rechtsfähigen (Konzern-)Unternehmen und nicht den Konzern selbst, dem es weiterhin an einer eigenen Rechtsfähigkeit mangelt. Offenkundig sind deshalb die Parallelen zur steuerrechtlichen Organschaft, der es gleichfalls an der eigenen Rechtsfähigkeit mangelt und deren Rechtskonsequenzen nur die involvierten Unternehmen treffen. Die steuerliche Wirkung der Organschaft dürfte sicherlich auch Mitursache dafür sein, dass die aktienrechtliche Konzernierung insbesondere durch zusätzlichen Abschluss eines wirksamen ${ }^{4}$ Gewinnabführungsvertrages oftmals mit der steuerlichen Organschaft einhergeht ${ }^{5}$.

1 Der Gewinn- bzw. Ergebnisabfuhrungsvertrag ist gem. § 18 Abs. 1 Satz 2 AktG nicht erforderlich, wenngleich er regelmäßig mit abgeschlossen wird. Zu beachten ist zudem, dass bei einem Gleichordnungskonzern gem. § 291 Abs. 2 AktG streng genommen kein Beherrschungsvertrag vorliegt.

2 Vgl. zu dieser Abgrenzung ausführlicher Schubert/Küting (Unternehmungszusammenschlüsse, 1981) S. 310-331. Interessant ist hierbei auch das sog. „Squeeze-out“ ( $\S 327$ a-f AktG), bei dem die übergeordnete Gesellschaft bei einer Mehrheitsbeteiligung von mind. 95\% den Barankauf der Aktien der restlichen (Minderheits-)Aktionäre beschließen kann; vgl. z.B. Streim (Konzernrecht, 2004) S. 85-87. In ökonomischer Perspektive drängen hier die ökonomischen Eigentümer die residualanspruchsberechtigten juristischen (nicht ökonomischen) Eigentümer des eingegliederten Unternehmens vollends aus dem unternehmerischen Vertragsgeflecht.

3 Vgl. Lutter (Diskussionsbeitrag, 1972) S. Q 56, aber vom „Einheitsunternehmen“ sprechend.

4 Das Steuerrecht verweist hier zwar auf die aktienrechtliche Vorschrift des $\$ 291$ Abs. 1 AktG, geht in seinen Voraussetzungen für die steuerliche Anerkennung jedoch darüber hinaus.

5 Auf die besondere Bedeutung des Körperschaftsteuerrechts für Art und Entwicklung der Unternehmenskonzentration verweisen Emmerich/Sonnenschein/Habersack (Konzernrecht, 2001) S. 19-23. 


\subsubsection{Beschränkte Relevanz des Konzerngedankens in der Rechnungslegung}

\subsubsection{Relevanz des Konzerngedankens in der rein informationsorientierten Konzernrechnungslegung}

Der aktienrechtliche Konzern hallt auch in anderen Gesetzen nach und hat Auswirkungen auf die Regulierung der Rechnungslegung. Offenkundig ist dies bei der Konzernrechnungslegung des Handelsrechts. In den ergänzenden Vorschriften für Kapitalgesellschaften sowie bestimmte Personenhandelsgesellschaften, in denen das HGB in ihrer Haftung beschränkte Unternehmen - gewissermaßen als Korrelat ${ }^{1}$ - mit zusätzlichen Rechnungslegungspflichten belegt, sind die Rechtsgrundlagen für die Erstellung eines Konzernabschlusses zusammengefasst. Getragen vom Konzerngedanken werden hier mehrere Unternehmen unabhängig von ihrer Rechtsform zu einer rechnungslegenden Einheit zusammengefasst, solange zumindest die oberste Gesellschaft, das Mutterunternehmen, als Kapitalgesellschaft (oder dieser gleichgestellten Rechtsform) ${ }^{2}$ firmiert. Für rein informative Abbildungszwecke ${ }^{3}$ hat der Konzernabschluss die Vermögens-, Finanzund Ertragslage der einbezogenen Unternehmen so darzustellen, als ob diese insgesamt ein einziges Unternehmen wären (§297 Abs. 3 Satz 1 HGB). Die handelsrechtliche Konzernrechnungslegung folgt primär der Einheitstheorie, auch wenn interessentheoretische Elemente partiell Berücksichtigung finden ${ }^{4}$.

Problematisch ist die Tatsache, dass sich die handelsrechtliche Abgrenzung der rechnungslegenden Einheit von der aktienrechtlichen Konzernabgrenzung unterscheidet. Deshalb ist der ,Konzernabschluss' als handelsrechtliche Bezeichnung für den Abschluss einer handelsrechtlich abgegrenzten Einheit terminologisch zumindest unpräzise. Abgesehen davon, dass sich die handelsrechtlichen Betrachtungen auf den Unterordnungskonzern beschränken, differiert auch das Verbindungskonzept. Während der aktienrechtliche Konzern hier ausschließlich auf das Merkmal der einheitlichen Leitung abstellt, wird dieses Merkmal in $\S 290$ Abs. 1 HGB noch durch das Beteiligungskriterium des $\S 272$ Abs. 1 HGB ergänzt, worunter eine dauernde Unternehmensverbindung auf der Basis von Anteilsbesitz verstanden wird, die im Zweifel ab einer Anteilsquote

1 Vgl. umfassend Buschmeyer (Publizität als Korrelat, 1993).

2 Obwohl 290 Abs. 1 und 2 HGB die Rechtsform der Kapitalgesellschaft vorschreibt, gelten die Vorschriften zur Konzernrechnungslegung gem. §264a Abs. 1 HGB auch für bestimmte Personenhandelsgesellschaften. Sie gelten in teilweise veränderter Form gem. $\S \S 1-3$ und $11 \mathrm{ff}$. PublG auch für große Unternehmen und gem. $\S \S 340 \mathrm{i}, 341 \mathrm{i}$ HGB für Kreditinstitute und Versicherungsunternehmen sonstiger Rechtsformen.

3 Vgl. stellvertretend Moxter (Bilanzrecht, 1986) S. 109, der „eine (reine) Informationsfunktion“ erkennt. Ähnlich der aktienrechtlichen Ausrichtung ist der Schutzrechtscharakter (Schutz durch Information) insb. für die Gläubiger, Mehr- und Minderheitsgesellschafter wohl ebenfalls offenkundig.

4 Vgl. z.B. Adler/Düring/Schmaltz (Rechnungslegung, 1995) Vorbemerkungen zu $\S \S 290-315$, Tz. 2629; Coenenberg (Jahresabschluss, 2003) S. 517 jeweils auch mit Hinweisen auf partielle Elemente der Interessentheorie im HGB. 
von $20 \%$ zu vermuten ist. Der weiter gefasste aktienrechtliche Konzern wird damit auf die Unternehmen reduziert, die unter der einheitlichen Leitung stehen und an denen zusätzlich eine bestimmte Kapitalbeteiligung gehalten wird.

$\S 290$ Abs. 2 HGB lässt mit dem Control-Konzept in Annäherung an international übliche Vorgehensweisen noch ein weiteres, alternatives Verbindungsmerkmal zwischen zwei Unternehmen zu, das sich trotz großer Schnittmengen von der einheitlichen Leitung unterscheidet ${ }^{1}$. Hiernach beruht die Unternehmensverbindung auf einer von drei möglichen, im Gesetz genannten Voraussetzungen, die von der Mehrheit der Stimmrechte (Nr. 1) über Bestellungs- und Abberufungsrechte bei den Mitgliedern gesellschaftsrechtlicher Führungsorgane bei gleichzeitiger Gesellschafterstellung (Nr. 2) bis hin zu dem Vorliegen eines Beherrschungsvertrages oder satzungsgemäßer Bestimmungen reicht, aus denen das Recht zur Ausübung eines beherrschenden Einflusses unmittelbar abgeleitet wird (Nr. 3). Eine Kapitalbeteiligung ist nicht vorgeschrieben. Die rechtstechnisch einfache Identifizierbarkeit dieser drei Voraussetzungen dürfte gegenüber der einheitlichen Leitung die Rechtssicherheit erhöhen, zumal es auch nicht mehr auf die tatsächliche Beherrschung, sondern nur noch auf die Beherrschungsmöglichkeit ankommt. Auch könnte in dieser Regulierung eine sehr enge, dafür aber konkrete Interpretation residualer Kontroll- und Entscheidungsrechte gesehen werden.

In der handelsrechtlichen Konzernrechnungslegung wird die Abgrenzung der rechnungslegenden Einheit noch zusätzlich präzisiert. Ausgehend von dem Weltabschlussprinzip des $§ 294$ Abs. 1 HGB sind im Grundsatz alle Unternehmen unabhängig von ihrer Rechtsform und ihrem Sitz in diese Einheit einzubeziehen. Unternehmen können jedoch aus der rechnungslegenden Einheit ausgeschlossen werden, wenn das Mutterunternehmen in der Ausübung seiner Vermögens- oder Geschäftsführungsrechte gegenüber dem untergeordneten Unternehmen beschränkt ist, wenn die Einbeziehung zu unverhältnismäßig hohen Kosten oder Verzögerungen führen würde oder wenn die Anteile vom Mutterunternehmen nur zum Zwecke der Weiterveräußerung gehalten werden $(\S 296 \text { Abs. } 1 \mathrm{HGB})^{2}$. Ein Einbeziehungswahlrecht existiert unter Kosten-NutzenErwägungen auch für die Unternehmen, die in ihrer Summe unter Abbildungsgesichtspunkten nur von untergeordneter Bedeutung sind (§ 296 Abs. 2 HGB).

1 Vgl. zur Erläuterung und Abgrenzung dieser beiden Konzepte z.B. Baetge/Kirsch/Thiele (Konzernbilanzen, 2002) S. 82-92; Busse von Colbe et al. (Konzernabschlüsse, 2003) S. 61-63; Coenenberg (Jahresabschluss, 2003) S. 524-527; Siebourg $(\S 290,1998)$ Tz. 16-112; von Wysocki/Wohlgemuth (Konzernrechnungslegung, 1996) S. 32-42.

2 Das vormals in $\S 295$ HGB kodifizierte Einbeziehungsverbot bei abweichender Tätigkeit des Tochterunternehmens ist durch das Bilanzrechtsreformgesetz (Art. 1 Nr. 14 BilReG) 2004 abgeschafft worden; vgl. z.B. Stahlschmidt (Bilanzrechtsreformgesetz, 2004) S. 995. 
Das Handelsrecht folgt bei der Abgrenzung von Unternehmung und Markt dem Stufenkonzept ${ }^{1}$. Dieses sieht reduzierte Formen der Einbeziehung für die Unternehmen vor, bei denen die Einbeziehungskriterien des $\S 290$ HGB (einheitliche Leitung, Control) nicht greifen, die aber noch einer gemeinsamen Führung ( $\S 310$ HGB) oder einem maßgeblichen Einfluss ( $\S 311 \mathrm{HGB}$ ) unterliegen. Während nach $\S 290$ HGB einzubeziehende Unternehmen (Tochterunternehmen) der Vollkonsolidierung ( $\S 300-309$ HGB) und alle sonstigen Unternehmen der Anschaffungswertmethode (§253 Abs. 1 Satz 1 i.V.m. $§ 298$ Abs. 1 HGB) unterliegen, wird für die besagten Unternehmen die Quotenkonsolidierung (Gemeinschaftsunternehmen; $§ 310$ HGB) oder die Equity-Methode (Gemeinschaftsunternehmen, assoziierte Unternehmen; § 311 - 312 HGB) festgeschrieben $^{2}$. Mit diesem Stufenkonzept will der Gesetzgeber wohl dem Umstand Rechnung tragen, dass es sich bei Gemeinschaftsunternehmen sowie assoziierten Unternehmen nicht um „normale“ Marktpartner handelt. Andererseits sind sie aus ökonomischer Sicht auch nicht zur Unternehmung zu zählen, die für diese Arbeit als einheitliches Überwachungs- und Durchsetzungssystems definiert worden ist. Es handelt sich bei diesen Unternehmen vielmehr um hybride Organisationsformen, die weder dem Markt, noch der Unternehmung zuzurechnen sind ${ }^{3}$.

Neben eigenen Vorschriften zur Konzernrechnungslegung beinhaltete das HGB bis 2004 in $§ 292$ a HGB a.F. eine Öffnungsklausel, nach der kapitalmarktorientierte Mutterunternehmen ${ }^{4}$ einen Konzernabschluss und Konzernlagebericht „nach international anerkannten Rechnungslegungsgrundsätzen“ (§ 292a Abs. 2 Nr. 2 a) HGB) alternativ aufstellen konnten. Als international anerkannt galten dabei die US-amerikanischen Generally Accepted Accounting Principles (US-GAAP) sowie die International Financial Reporting Standards (IFRS), die auch die früheren International Accounting Standards (IAS) umfassen ${ }^{5}$. Durch unmittelbar wirksames EU-Recht ist dieses Systemwahlrecht ab 2005 - in bestimmten Ausnahmefällen ab 2007 - aufgehoben und in eine allei-

1 So spricht z.B. Ordelheide (Konzern, 1986) S. 298-299 von mehreren „Stufen“, die den Übergang zum Markt nach abnehmender „Intensität der Gesellschaftsverbindung“ kennzeichnen. Der Begriff „Stufenkonzept" findet sich z.B. bei Busse von Colbe et al. (Konzernabschlüsse, 2003) S. 58-60; Sürken (Abgrenzung der wirtschaftlichen Einheit, 1999) S. 25; Pellens/Fülbier/Gassen (Internationale Rechnungslegung, 2004) S. 696; s.a. Dusemond (Abgrenzung des Konsolidierungskreises, 1994).

2 Vgl. zur Berücksichtigung von Gemeinschaftsunternehmen sowie assoziierten Unternehmen im handelsrechtlichen Konzernabschluss ausführlicher z.B. Adler/Düring/Schmaltz (Rechnungslegung, 1995) $\S \S 310-312$; Baetge/Kirsch/Thiele (Konzernbilanzen, 2002) S. 389-460; Busse von Colbe et al. (Konzernabschlüsse, 2003) S. 499-580; Zündorf(Equity-Methode, 1987).

3 Vgl. Kap. V.2.3.2 zur ausführlichen steuerlichen Beurteilung des Stufenkonzeptes aus Sicht des in Kap. III.3.3 entwickelten Abgrenzungsleitbildes.

4 Gem. § 292a Abs. 1 Satz 1 HGB fällt darunter jedes Mutterunternehmen, das einen organisierten Markt i.S.d. $\S 2$ Abs. 5 WpHG durch von ihm oder einem seiner Tochterunternehmen emittierte Wertpapiere i.S.d. § 2 Abs. 1 Satz 1 WpHG in Anspruch nimmt.

5 Vgl. Deutscher Bundestag (Drucksache 13/9909, 1998) S. 12; bestätigend DRS 1.10; vgl. zu § 292a HGB in seinen weiteren Voraussetzungen ausführlicher Pellens/Bonse/Gassen (Perspektiven, 1998). Im Übrigen werden die IFRS in IAS 1.11 (2003) als Oberbegriff u.a. auch für die IAS verwendet. 
nige Pflicht zur Anwendung der IFRS überführt worden ${ }^{1}$. Diese Pflicht trifft vorerst die Konzernabschlüsse sämtlicher kapitalmarktorientierten europäischen Unternehmen, die damit einem Rechnungslegungssystem zu folgen haben, dass mangels Bezug zu einem wie auch immer gearteten (nationalen) Konzernrecht nur von unternehmensübergreifend konsolidierten Abschlüssen („,consolidated financial statements“) spricht ${ }^{2}$. Da die Konsolidierung nach IFRS erst später in den Mittelpunkt dieser Arbeit rücken wird ${ }^{3}$, sei an dieser Stelle lediglich angemerkt, dass sich hinter den IFRS nicht nur ein alternatives System von Ansatz-, Bewertungs- und Ausweisregeln verbirgt, sondern auch ein eigenes System von Konsolidierungsregeln im weiteren Sinne. Parallelen zur handelsrechtlichen Konsolidierung sind dabei nicht ausgeschlossen, da die handelsrechtliche Regulierung seit der Transformation der 7. EG-Richtlinie (83/349/EWG) auch durch den IFRS immanente anglo-amerikanische Elemente geprägt ist.

Festzuhalten bleibt, dass an Konzernabschlüsse deutscher Unternehmen - seien sie nun auf der Basis von HGB, US-GAAP oder IFRS erstellt - keinerlei unmittelbare Rechtskonsequenzen geknüpft sind. In Analogie zum Aktienrecht wäre allenfalls denkbar, aus der Konzernrechnungslegung erwachsene Rechtsfolgen an ein oder mehrere Unternehmen zu knüpfen, die Teil der rechnungslegenden Einheit sind, z.B. an das Mutterunternehmen. Dies ist aber, bis auf daraus erwachsene Prüfungs- und Offenlegungspflichten ( $\S 316$ - 329 HGB), de lege lata nicht der Fall. Dies gilt nicht nur für das Handels- und Gesellschaftsrecht, sondern insbesondere auch für das Börsenrecht, das die handelsrechtliche Rechnungslegung in börsenrechtliche Publizitätsinstrumente integriert ${ }^{4}$ und mit ihr die dort festgelegte Abgrenzung der rechnungslegenden Einheit. Bei diesen börsenrechtlichen Publizitätsinstrumenten stehen Konzernabschlüsse im Vordergrund, obwohl sie regelmäßig mit den Einzelabschlüssen kombiniert zu veröffentlichen sind. Die Veröffentlichung von Einzelabschlüssen ist unter Informationsgesichtspunkten durchaus von Wert, schon weil sich nur aus ihnen bestimmte Rechtsansprüche ergeben, über deren Grundlage und Höhe es zu informieren gilts.

1 Vgl. EU-Verordnung Nr. 1606/2002.

2 Naturgemäß ist das privatwirtschaftlich organisierte, international ausgerichtete IASB auch nicht in der Lage, konkrete Rechtsformkriterien - etwa vergleichbar denen des HGB - vorzugeben. Hier greifen statt dessen die jeweiligen nationalen Regulierungen und deren Vorstellungen von einem rechtsfähigen Unternehmen. Bei deutschen Unternehmen, auch wenn sie nach IFRS bilanzieren, führt dies zu einer Beibehaltung hiesiger gesellschaftsrechtlicher Rechtsformkriterien.

3 Vgl. Kap. V.

4 Vgl. für den Börsenzulassungsprospekt $\S \S 36$ Abs. 3, 4 und 38 Abs. 1 Nr. 2 BörsG i.V.m. $\S \S 13-47$ BörsZulV, für die jährliche Publizität $\S 44$ Abs. 1 Nr. 3, Abs. 2 BörsG i.V.m. $\S 65$ BörsZulV und für die Zwischenberichterstattung § 44b BörsG i.V.m. $§ \S 53$ - 62 BörsZulV. Obwohl das Erfüllen börsenrechtlicher Publizitätsgebote als Börsenzulassungsvoraussetzung erforderlich ist, soll dies hier nicht als unmittelbare Rechtskonsequenz von Rechnungslegungsdaten verstanden werden.

5 Vgl. zum empirischen Nachweis Pellens (Informationswert, 1989). 


\subsubsection{Irrelevanz des Konzerngedankens in der rechtsfolgeorientierten Rechnungslegung}

Immer dann, wenn aus der Rechnungslegung gesetzliche Rechtsfolgen abgeleitet werden, steht die rechtsformorientierte Unternehmenssicht im Vordergrund, da es gilt, Rechtsfolgen einem rechtsfähigen Rechtssubjekt zuzuordnen. Der Konzerngedanke spielt dann keine Rolle. Dies trifft insbesondere die gesetzliche Erfolgsbeteiligung (Gewinnverwendung) der Gesellschafter bei Personenhandelsgesellschaften ( $\S 120,121$, 167 und 168 HGB) bzw. bei Kapitalgesellschaften ( $\S 57$ Abs. 3, 58; 150 AktG, $\S 278$ Abs. 3 i.V.m. $\S 58$ AktG, $\S 278$ Abs. 2, 286 AktG i.V.m. $\S \S 167,168$ HGB, $§ 29$ Abs. $1 \mathrm{GmbHG})^{1}$, die ausnahmslos am Jahresüberschuss des handelsrechtlichen Einzelabschlusses anknüpft. Aus gesellschaftsrechtlicher Sicht scheint dies vordergründig konsequent, da hier ausschließlich das Innen- und Rechtsverhältnis zwischen der Gesellschaft und den Gesellschaftern geregelt wird und die (einklagbaren) Ansprüche der Anteilseigner gegenüber der sachlichen Zentraleinheit formuliert werden. Allerdings ignoriert das Gesellschaftsrecht die Existenz möglicher Sub-Zentraleinheiten und daraus resultierende Benachteiligungen der Gesellschafter. Vor diesem Hintergrund ist bereits die Forderung erhoben worden, die Gewinnverwendung - wenn sie schon reguliert wird - zumindest an den im Konzernabschluss ermittelten Jahresüberschuss zu koppeln ${ }^{2}$.

Der Konzerngedanke spielt ebenso wenig bei den gesellschaftsrechtlichen Verlustanzeigepflichten gem. $\S 92$ Abs. 1 AktG und $\S 49$ Abs. $3 \mathrm{GmbHG}$ eine Rolle, die bei verlustbedingten Eigenkapitalaufzehrungen ab einer bestimmten Höhe greifen ${ }^{3}$. Darüber hinaus gibt die Rechtsform auch bei aperiodischen Sonderanlässen der Rechnungslegung wie z.B. Gründung, Umwandlung, Auseinandersetzung, Überschuldung oder Liquidation die rechnungslegende Einheit vor ${ }^{4}$.

Es bleibt festzuhalten, dass gesetzliche Rechtsfolgen, die sich aus Rechnungslegungsdaten ableiten, innerhalb der deutschen Rechtsordnung nur an die Daten des unternehmensorientierten Einzelabschlusses geknüpft werden. Unternehmensübergreifende rechnungslegende Einheiten existieren zwar in der Konzernrechnungslegung, sind aber bis-

1 Vgl. erläuternd zum gesellschaftsrechtlichen Anspruch auf Gewinnausschüttung Winnefeld (BilanzHandbuch, 2002) Einf. Tz. 51; zu den Höchst- und Mindestausschüttungsregeln ausführlicher z.B. auch Coenenberg (Jahresabschluss, 2003) S. 14-15.

2 Vgl. insb. Busse von Colbe (Konzernabschluß als Bemessungsgrundlage, 1987); Pellens (Aktionärsschutz im Konzern, 1994) S. 58-64, 128-136, 231-242, 320-325; Pellens (Gewinnverwendung im Konzern, 1995), der die Benachteiligung zudem empirisch belegt. Alternativ zur Verwendung des Konzernergebnisses wird hier auch (weiterhin) das Einzelabschlussergebnis vorgeschlagen, das allerdings unter Anwendung der Equity-Methode zu ermitteln wäre; s.a. Pellens/Gassen/Richard (Ausschüttungspolitik, 2003) S. 324-329.

3 Vgl. Winnefeld (Bilanz-Handbuch, 2002) Einf, Tz. 52-54, 58-59.

4 Vgl. ausführlich dazu Budde/Förschle (Sonderbilanzen, 2002). 
her hinsichtlich darüber hinausgehender unmittelbarer Rechtsfolgen ohne Belang. Die dominante Ausrichtung der steuerlichen Gewinnermittlung am Trennungsprinzip und an der Einzelgewinnermittlung scheint deshalb konsequent. Unabänderlich ist sie jedoch nicht. So lässt das von zivilrechtlichen Gegebenheiten abstrahierende Konzept der Steuerrechtsfähigkeit sogar eine idealtypische Gruppenbesteuerung möglich erscheinen, in der z.B. der aktienrechtliche Konzern de lege ferenda als selbständiges Steuersubjekt der Körperschaftsteuer unterworfen wird.

\subsection{Annäherung an Einheitstheorie und Konsolidierung in der Mitunternehmerschaft}

\subsubsection{Transparenzprinzip als Ausgangspunkt}

Im Zuge der Zweiteilung der Steuersubjekte in natürliche Personen auf der einen und steuerrechtsfähige Sachsubjekte auf der anderen Seite und der daraus resultierenden Differenzierung einkommen- und körperschaftsteuerlicher Tatbestände sind Personengesellschaften bisher weitgehend ausgeklammert worden. Die konkrete Besteuerung der Mitunternehmer einer Personengesellschaft gemäß $\S 15$ Abs. 1 Satz 1 Nr. 2 EStG bietet indes eine Reihe interessanter Parallelen zur Einheitstheorie und zur konsolidierten steuerlichen Gewinnermittlung. Mit diesen, in der Literatur bisher kaum aufgegriffenen Parallelen ${ }^{1}$ geht die Erkenntnis einher, dass die steuerliche Konsolidierung im geltenden deutschen Steuerrecht nicht völlig ohne Relevanz ist.

Personengesellschaften (Gesellschaften im engeren Sinne ${ }^{2}$ ) sind nach zivilrechtlicher Vorstellung Personenvereinigungen, bei denen keine körperschaftliche Verfassung, sondern eine vergleichsweise kleine Zahl von Gesellschaftern im Vordergrund steht. Konsequenterweise mangelt es der Personengesellschaft deshalb selbst an vollwertiger zivilrechtlicher Rechtsfähigkeit. Rechtsträger sind die Gesellschafter, die als solche nach innen und außen im Rechtsverkehr auftreten, gesamthänderisch Eigentümer des Gesellschaftsvermögens sind, ebenso gesamthänderisch für Gesellschaftsschulden haften und mit ihrer fortgesetzten Zugehörigkeit letztlich die gesamte Existenz der Gesell-

1 Vgl. allerdings Groh (Mitunternehmerschaft, 1995); ansatzweise auch Müller (Konzernbesteuerung, 1991) S. 131, 138; Rupp (Ertragsbesteuerung nationaler Konzerne, 1983) S. 107; Senger (Konzernertragsbesteuerung, 1997) S. 228, 235; Söffing (Mitunternehmer, 1994) S. 90-92, der die Besteuerungssituation der Mitunternehmerschaft gar mit der „Einheitstheorie“ umschreibt sowie Döllerer (Steuerbilanz der Personenhandelsgesellschaft, 1974) mit seiner Theorie einer konsolidierten Gesamtbilanz.

2 Personengesellschaften gehen auf den Grundtyp der Gesellschaft bürgerlichen Rechts (GbR) zurück ( $\S 705$ ff. BGB) und umfassen daneben noch die Personenhandelsgesellschaften OHG und KG ( $\S 105 \mathrm{ff} ., 161 \mathrm{ff} . \mathrm{HGB})$, die stille Gesellschaft ( $\S \S 230 \mathrm{ff} . \mathrm{HGB})$ sowie Sondertypen wie z.B. die freiberufliche Partnerschaftsgesellschaft ( $\S 1$ ff. PartGG). Vgl. zur Abgrenzung der Personengesellschaft von der Mitunternehmerschaft Söffing (Mitunternehmer, 1994) S. 70-74. 
schaft determinieren ${ }^{1}$. Das Handelsrecht hat allerdings die Personenhandelsgesellschaften, die $\mathrm{OHG}$ und die KG, in Teilen verselbständigt und einer juristischen Person angenähert. Obwohl die Personenhandelsgesellschaft keine korporative Einheit, sondern einen mitunternehmerischen Verband darstellt, ist sie als solche Kaufmann ( $\$ 6$ Abs. 1 HGB) und kein Zusammenschluss von Kaufleuten. Sie tritt damit unter eigener Firma ( $\S 17$ ff. HGB) auf und ist als Gesellschaft fähig, Trägerin von Rechten und Pflichten zu sein, was sie als „quasi-juristische Person“ qualifiziert. In Folge der jüngeren Rechtsprechung des Bundesgerichtshofes ist wohl auch der GbR eine erweiterte Rechtsfähigkeit zuerkannt worden ${ }^{2}$.

Von der zivilrechtlichen Selbständigkeit nimmt das Steuerrecht kaum Notiz ${ }^{3}$. Personenhandelsgesellschaften und alle übrigen Personengesellschaften sind zumindest für Zwecke der Einkommen- und Körperschaftsteuer keine steuerrechtsfähigen Steuersubjekte ${ }^{4}$. Dies ist insofern erstaunlich, als dass die Steuerrechtsfähigkeit in anderen Fällen fehlender zivilrechtlicher Rechtsfähigkeit als Sonderrechtsfähigkeit dennoch ,vergeben“ wurde 5 . So unterliegt nicht die Personengesellschaft als solche, sondern ihre Gesellschafter als Mitunternehmer der Einkommen- bzw. Körperschaftsteuer ( $§ 15$ Abs. 1 Satz 1 Nr. 2 EStG, $\S 8$ Abs. 1 Satz $1 \mathrm{KStG})$. Ihnen werden die Einkünfte über die einheitliche und gesonderte Gewinnfeststellung gemäß $\S 179$ Abs. 2, 180 Abs. 1 Nr. 2 a) AO zugerechnet und zwar unabhängig davon, ob die Gewinnanteile in der Personengesellschaft verbleiben oder von den Gesellschaftern entnommen werden. Es gilt das so genannte Transparenzprinzip. Während bei einer Kapitalgesellschaft das Trennungsprinzip greift, wonach der Gewinn der Kapitalgesellschaft zunächst der Körperschaftsteuer unterworfen wird und erst bei Ausschüttung (und Verlassen der Gesellschaftssphäre) auf Anteilseignerebene zu versteuern ist, wird der Gewinn der Personengesellschaft nach dem Transparenzprinzip direkt und unmittelbar der Bemessungsgrundlage

1 Vgl. ausführlicher zur grundsätzlichen gesellschaftsrechtlichen Natur der Personengesellschaft z.B. Kübler (Gesellschaftsrecht, 1999) S. 21-22; Schmidt (Gesellschaftsrecht, 2002) S. 1285-1291.

2 Vgl. $B G H$ v. 29.1.2001 (II ZR 331/00); dazu Schmidt (BGB-Außengesellschaft, 2001); zu Personenhandelsgesellschaften ausführlicher Schmidt (Gesellschaftsrecht, 2002) S. 1355-1374; 1529-1557. Von ,relativer Rechtsfähigkeit“ und „Halbrechtsfähigkeit“" spricht Bühler (Steuerrecht, 1956) S. 31.

3 Vgl. dazu insb. BFH v. 11.12.1969 (IV R 92/68). Diese Aussage ist allerdings der Zeit der sog. Bilanzbündeltheorie zuzurechnen und gilt heute nur noch abgeschwächt.

4 Anders ist dies bei der Umsatzsteuer, wo sie unter den weiten Unternehmensbegriff des $\S 2$ Abs. 1 UStG fallen und Steuersubjektfähigkeit besitzen (können). Vgl. zur Steuerrechtsfähigkeit der Personengesellschaft/Mitunternehmerschaft ausführlich und m.w.N. Bayer (Steuerlehre, 1997) Tz. 468; Pinkernell (Einkünftezurechnung bei Personengesellschaften, 2001) S. 62-80.

5 Vgl. Kap. III.2.1. 
des Gesellschafters zugerechnet. Eine steuerliche Trennung zwischen Gesellschaftsund Gesellschafterebene existiert insofern nicht ${ }^{1}$.

Aus ökonomischer Sicht fehlt einer Personengesellschaft demnach die sachliche Zentraleinheit - entweder völlig oder zumindest als vollwertiger vertraglicher Anknüpfungspunkt. Im Vordergrund stehen hier die Gesellschafter. Eine derartige ,personale Gemeinschaft" ansonsten weiterhin selbständig handelnder natürlicher oder juristischer Personen, die sich lediglich im Interesse eines gemeinsamen Einkommenserwerbs vertraglich (ver-)binden, wird nun anders, nämlich ,personal“ (Transparenzprinzip), besteuert als das steuerrechtsfähige Unternehmen, das ,institutional“ (Trennungsprinzip) besteuert wird ${ }^{2}$. Wegen dieser Unterscheidung kann es durchaus sein, dass solchermaßen unterschiedlich organisierte Unternehmungen bei gleichem Gewinn auch unterschiedlich besteuert werden. Dies widerspricht im Übrigen der in der Literatur formulierten, aus dem verfassungsrechtlichen Gleichheitsgrundsatz abgeleiteten Forderung nach rechtsformneutraler Besteuerung ${ }^{3}$. Wegen der Berücksichtigung der Gesellschaftersphäre bei Personengesellschaften können sogar gleichermaßen organisierte Unternehmungen bei gleichem Gewinn unterschiedlich besteuert werden. Diese Ungleichbehandlungen wären aber immer dann zu rechtfertigen, wenn organisatorische und zivilrechtliche Unterschiede auch Unterschiede in der steuerlichen Leistungsfähigkeit der Unternehmungen verkörpern, insbesondere indem sie die individuelle Leistungsfähigkeit der jeweiligen Gesellschafter mit berücksichtigen ${ }^{4}$.

\subsubsection{Gewinnermittlung nach dem Transparenzprinzip}

Mangels entsprechender Anleitung durch die relevante gesetzliche Norm zur Mitunternehmerbesteuerung ( $§ 15$ Abs. 1 Satz 1 Nr. 2 EStG) ist ihre konkrete Ausgestaltung in Fragen der steuerlichen Gewinnermittlung von der Finanzrechtsprechung übernommen worden ${ }^{5}$.

1 Vgl. grundlegend Groh (Trennungs- und Transparenzprinzip, 1998); zur „dogmatischen Konkretisierung“ des Transparenzprinzips vgl. Pinkernell (Einkünftezurechnung bei Personengesellschaften, 2001) S. 130-204.

2 Vgl. zu dieser auch terminologischen Gegenüberstellung Elschen (Institutionale oder personale Besteuerung, 1994) insb. S. 41-47.

3 Vgl. zu dieser umstrittenen Forderung bereits Kap. II.3.3.1.

4 Vgl. auch deshalb kritisch gegenüber der Rechtsformneutralität z.B. Birk (Leistungsfähigkeitsprinzip, 2000) S. 332-336; Pelka (Rechtsformneutralität, 2000); Schneider (Rechtsformneutralität, 2004); damit (kritisch) auseinandersetzend Hey (Rechtsformneutralität, 2001) insb. S. 163; s.a. Kap. II.3.3.1.

5 Vgl. zur Entwicklung der Rechtsprechung Groh (Trennungs- und Transparenzprinzip, 1998) S. 92-94; Pinkernell (Einkünftezurechnung bei Personengesellschaften, 2001) S. 20-44; Schön (Personengesellschaft, 1996) S. 276-281; Söffing (Mitunternehmer, 1994) S. 89-92; Uelner (Mitunternehmergewinn, 1978/79) insb. S. 303-306. 


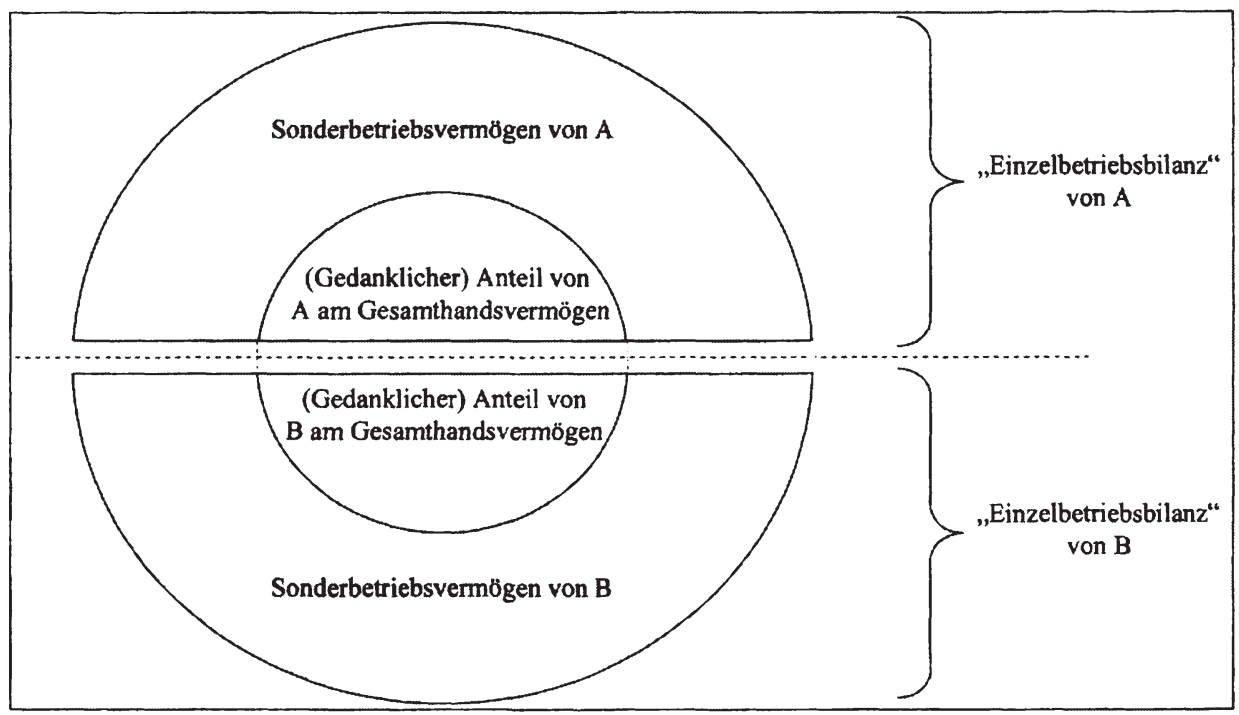

Abb. 8: Steuerliche Gewinnermittlung bei der Mitunternehmerschaft nach der Bilanzbündeltheorie

Bis in die 70er Jahre des letzten Jahrhunderts hinein haben der Reichs- und später der Bundesfinanzhof das Transparenzprinzip kompromisslos umgesetzt. Resultat dieser Umsetzung war die Bilanzbündeltheorie, wonach die Personengesellschaft im Rahmen der Gewinnermittlung völlig negiert wird. In dem Bestreben, die Mitunternehmerbesteuerung der Besteuerung eines Einzelunternehmers gleichzustellen, wird die Personengesellschaft statt dessen als Zusammenfassung von Einzelbetrieben der Gesellschafter angesehen, was sich in der Bündelung der „Einzelbetriebsbilanzen“ für die steuerliche Gewinnermittlung konkretisiert ${ }^{1}$. Neben dem auch zivilrechtlich den Gesellschaftern individuell zugerechneten Sonderbetriebsvermögen wird sogar das Gesamthandsvermögen in der Gewinnermittlung separiert und den Gesellschaftern anteilig zugeteilt (Abb. 8).

Der Kritik der zivilrechtlichen Gesamthandslehre ${ }^{2}$ folgend ist die Personengesellschaft zu Beginn der 1980er Jahre als eigenständiges Subjekt der Gewinnerzielung und -ermittlung in den Vordergrund gerückt ${ }^{3}$. Eine Gesellschaftsbilanz ist etabliert worden, die die Gesellschaftsaktivitäten für den Bereich des Gesamthandsvermögens von denen der Gesellschafter trennt. Damit finden auch Rechtsbeziehungen zwischen Gesellschaft

1 Vgl. dazu m.w.N. von Zezschwitz (Bilanzbündeltheorie, 1970); z.B auch BFH v. 11.12.1969 (IV R 92/68); die BFH-Rechtsprechung bestätigend BVerfG v. 15.7.1969 (1 BvR 457/66).

2 Vgl. grundlegend Flume (Gesamthand, 1972); bestätigend wieder BGH v. 29.1.2001 (II ZR 331/00).

3 Vgl. u.a. $B F H$ v. 10.11 .1980 (GrS 1/79); $B F H$ v. 25.6 .84 (GrS 4/82); Döllerer (Personenhandelsgesellschaften, 1982); später auch $B F H$ v. 3.7.1995 (GrS 1/93). Für Knobbe-Keuk (Bilanz- und Unternehmenssteuerrecht, 1993) S. 363-363 wurde das Ende der Bilanzbündelheorie bereits mit $B F H$ v. 8.1.1975 (I R 142/72) vollzogen. 
und Gesellschaftern steuerliche Berücksichtigung1. Auf Gesellschafterebene werden dann in einem zweiten Schritt das ihrer Vermögenssphäre zugerechnete Sonderbetriebsvermögen und daraus abgeleitete Sonderbetriebsausgaben und -einnahmen erfasst (Abb. 9).

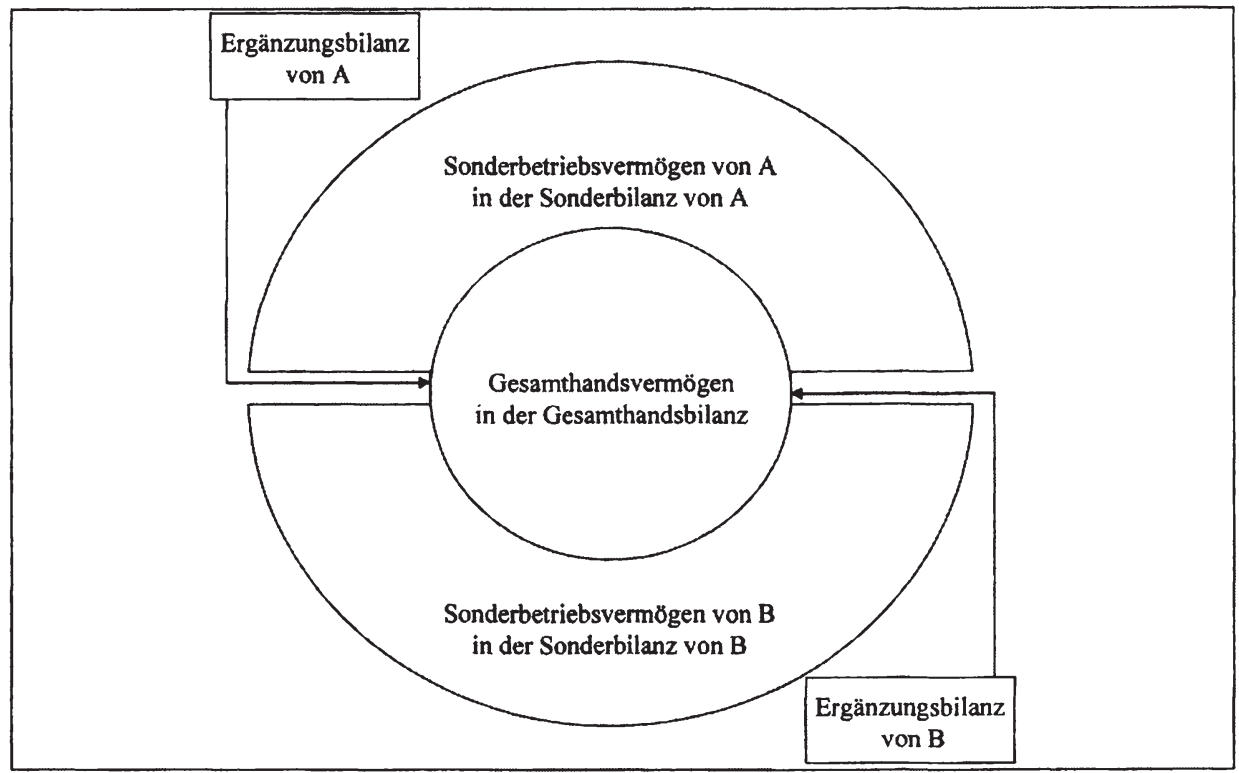

Abb. 9: Steuerliche Gewinnermittlung bei der Mitunternehmerschaft mit einer Personengesellschaft als eigenständiges Gewinnermittlungssubjekt ${ }^{2}$

Unter rein technischen Gesichtpunkten hat sich durch diese formale Korrektur nicht viel geändert. Schon zuvor ist eine Gesellschaftsbilanz als Nebenrechnung geführt worden, um sie dann quotal den Gesellschafterbilanzen zuzurechnen. Aus dieser Neben- ist nun allerdings die Hauptrechnung geworden, deren Gesamthandsgewinn aber weiterhin auf die Gesellschafter $\mathrm{zu}$ verteilen ist ${ }^{3}$. Das Eigenkapital ist in dieser Gesamthandsbilanz aber bereits in die Kapitalkonten der jeweiligen Gesellschafter unterteilt. Der personale Gedanke kommt auch darin zum Ausdruck, dass Sondervorgänge und personenbezogene Regelungen, die das Gesamthandsvermögen betreffen, in der (Wert-)Ergänzungsbilanz der jeweiligen Gesellschafter individualisiert werden ${ }^{4}$.

1 Vgl. Reiss (Gesamthandsbeteiligungen, 1986); Schaumburg (Grundzüge des Konzernsteuerrechts, 1998) Tz. 10.

2 Vgl. zu einer materiell ähnlichen graphischen Gegenüberstellung dieser beiden Sichtweisen Rupp (Ertragsbesteuerung nationaler Konzerne, 1983) S. 16-17.

3 Vgl. Groh (Trennungs- und Transparenzprinzip, 1998) S. 93; Reiss (Gesamthandsbeteiligungen, 1986) S. 234.

4 Vgl. Reiss (Gesamthandsbeteiligungen, 1986) S. 235-238; zu Ergänzungs- und Sonderbilanzen grundlegend Uelner (Ergänzungs- und Sonderbilanzen, 1991). 
Der BFH ist einige Jahre später sogar dazu übergegangen, die Personengesellschaft über ihre zivilrechtliche Stellung hinaus als Steuersubjekt anzusehen, die nach Art des Trennungsprinzips zu besteuern sei ${ }^{1}$. Diese Position hat der BFH aber nach Intervention des Gesetzgebers wieder aufgegeben ${ }^{2}$ und ist zu der Sichtweise zurückgekehrt, die in der Personengesellschaft zwar ein eigenständiges Gewinnermittlungssubjekt, nicht jedoch ein eigenständiges Steuersubjekt erkennt ${ }^{3}$. In dieser heute noch gültigen, vom „Dualismus von Einheit der Gesellschaft und Vielheit der Gesellschafter ${ }^{\measuredangle 4}$ geprägten Sicht der Mitunternehmerbesteuerung wird demnach der Versuch unternommen, Aspekte der Einheitsbetrachtung einer Unternehmung in eine individualisierte Besteuerung der Gesellschafter zu integrieren. Dies geschieht durch ein zweistufiges, additives Gewinnermittlungssystem ${ }^{5}$, das auf der ersten Stufe den Gewinn der Personengesellschaft als solcher mittels einer Gesamthandsbilanz bestimmt und den Gesellschaftern nach dem vereinbarten Gewinnverteilungsschlüssel zurechnet. Hierbei werden Wertkorrekturen der Ergänzungsbilanzen bereits berücksichtigt. In einem zweiten Schritt wird das in den Sonderbilanzen geführte Sonderbetriebsvermögen der jeweiligen Gesellschafter einbezogen, deren Ergebnisse bei der Gewinnfeststellung den Gesellschaftern vorweg zuzurechnen sind ${ }^{6}$. Obwohl in der Zusammenfassung dieser beiden Schritte der Begriff der steuerlichen „Gesamtbilanz der Mitunternehmerschaft" ${ }^{67}$ verwendet wird, ist diese bei einer additiven Gewinnermittlung technisch gesehen überflüssig ${ }^{8}$.

\subsubsection{Vergleich mit der Konsolidierung}

Im Vergleich zur gegenwärtigen Besteuerung von Unternehmensgruppen kann als erste wichtige Parallele festgehalten werden, dass es der Personengesellschaft wie der Unternehmensgruppe an der Steuersubjektivität mangelt. Als steuerrechtsfähige Steuersubjekte stehen in beiden Fällen ihre jeweiligen Gliedteile im Vordergrund, d.h. die einzelnen Mitunternehmer auf der einen Seite und die einzelnen Unternehmen auf der anderen. Eine weitere Parallele lässt sich darin erkennen, dass sowohl die Unternehmens-

\footnotetext{
Vgl. $B F H$ v. 25.6.84 (GrS 4/82); BFH v. 25.2.1991 (GrS 7/89).

Vgl. Groh (Trennungs- und Transparenzprinzip, 1998) S. 93.

Vgl. z.B. BFH v. 3.7.1995 (GrS 1/93).

Schön (Personengesellschaft, 1996) S. 277, 281.

5 Vgl. $B F H$ v. 13.10.1998 (VIII R 78/97); hierzu ausführlicher Pinkernell (Einkünftezurechnung bei Personengesellschaften, 2001) S. 23-27, 116-117, 191-199; Tipke/Lang (Steuerrecht, 2002) $§ 9 \mathrm{Tz}$. 500-502, 526-549 m.w.N.

6 Rechtsgrundlage für die Einbeziehung des Sonderbetriebsvermögens in den Betriebsvermögensvergleich ist nicht $\S 15$ Abs. 1 Satz $1 \mathrm{Nr} .2 \mathrm{EStG}$, sondern $\S 4 \mathrm{Abs}$. $1 \mathrm{EStG}$. Die Buchführungspflicht für Sonderbetriebsvermögen obliegt im Übrigen nicht dem Mitunternehmer, sondern der Gesellschaft; vgl. $B F H$ v. 23.10.1990 (VIII R 142/85); s.a. Söffing (Mitunternehmer, 1994) S. 209.

7 BFH v. 2.12.1997 (VIII R 15/96) S. 483.

8 Vgl. Groh (Mitunternehmerschaft, 1995) S. 389; Knobbe-Keuk (Bilanz- und Unternehmenssteuerrecht, 1993) S. 480. Der „Gesamtgewinn der Mitunternehmerschaft“ ist jedoch Ausgangsbasis für die Ermittlung des Gewerbeertrags.
} 
gruppe als auch die Personengesellschaft als Gewinnerermittlungsobjekte fungieren, ohne eigene Steuerrechtsfähigkeit zu besitzen. Mitunternehmerschaft wie Unternehmensgruppe sind daher vom Dualismus von wirtschaftlicher Einheit und rechtlicher Vielheit geprägt ${ }^{1}$.

Im Rahmen der steuerlichen Gewinnermittlung bildet die Personengesellschaft mitsamt den Mitunternehmern eine Art rechnungslegende Einheit, da die Mitunternehmer von anderen Marktteilnehmern, die ebenfalls Verträge mit der Gesellschaft abschließen, deutlich abgegrenzt werden. Ihr Sonderstatus kommt insbesondere in ihren Sonderbilanzen zum Ausdruck ${ }^{2}$, in denen der Einheit weitere Ressourcen zugerechnet werden. So umfasst das Betriebs(netto)vermögen der rechnungslegenden Einheit neben dem Gesamthandsvermögen auch das Sonderbetriebsvermögen der Mitunternehmer. Obwohl sich letzteres nicht im zivilrechtlichen Gesamthandseigentum befindet, geht das Steuerrecht hier von einer Art ökonomischer Zugehörigkeit zur rechnungslegenden Einheit aus. Interessant erscheint an dieser Stelle die Frage nach der genaueren Abgrenzung dieser Einheit. Diese Frage lässt sich weiter differenzieren in die Frage nach der Qualifikation einer Vertragspartei als Mitunternehmer und in die Frage nach der Qualifikation eines dem Mitunternehmer zivilrechtlich gehörenden Wirtschaftsgutes als Sonderbetriebsvermögen.

Bezüglich der ersten Frage ist auf den Mitunternehmerbegriff abzustellen, der primär an den zivilrechtlichen Gesellschafterbegriff anknüpft, aber trotz weitgehender Übereinstimmung nicht mit diesem identisch ist, da die Mitunternehmerbesteuerung des $\S 15$ Abs. 1 Satz 1 Nr. 2 EStG auch Teilhaber wirtschaftlich vergleichbarer Gemeinschaften betrifft ${ }^{3}$. Als qualifizierende Merkmale eines Mitunternehmertatbestands identifiziert der $\mathrm{BFH}$ neben der rechtlichen, nicht notwendigerweise finanziellen Beteiligung an einer Gesellschaft bzw. Gemeinschaft auch das Mitunternehmerrisiko und die Mitunternehmerinitiative ${ }^{4}$. Ähnlich dem ökonomischen Residualeinkommens- bzw. Residualrisikokonzept trägt das Mitunternehmerrisiko im Regelfall derjenige, der am laufenden Gewinn und Verlust sowie an den stillen Reserven, einschließlich eines etwaig bestehenden (originären) Goodwill ${ }^{5}$, beteiligt ist. Mitunternehmerinitiative bedeutet hingegen

1 Für eine Unternehmensgruppe bzw. einen Konzern ist dieser Dualismus terminologisch bereits von Raiser (Konzernbildung, 1964) S. 54-56; Hommelhoff (Konzernleitungspflicht, 1982) S. 214 und insb. auch Rupp (Ertragsbesteuerung nationaler Konzerne, 1983) S. 11-108 formuliert worden.

2 Vgl. in anderem Zusammenhang Elschen (Institutionale oder personale Besteuerung, 1994) S. 16.

3 Vgl. z.B. Tipke/Lang (Steuerrecht, 2002) §9 Tz. 506; zu Inhalt, Bedeutung und Kritik des Mitunternehmerbegriffs ausführlich Knobbe-Keuk (Bilanz- und Unternehmenssteuerrecht, 1993) S. 381-392; Walz (Steuergerechtigkeit und Rechtsanwendung 1980) S. 251-313.

$4 \mathrm{Vgl} . B F H$ v. 25.6.1984 (GrS 4/82); $B F H$ v. 13.7.1993 (VIII R 50/92); umgesetzt in H 138 (1) EStH ,Mitunternehmerinitiative' und ,Mitunternehmerrisiko'; s.a. Söffing (Mitunternehmer, 1994) S. 52-54.

5 Hier und im weiteren Verlauf der Arbeit wird der Begriff des, Goodwill' dem deutschen Pendant ,Geschäfts- oder Firmenwert' vorgezogen; ersterer müsste auch besser mit ,Geschäftsmehrwert' übersetzt werden; vgl. so bereits Bores (Konsolidierte Erfolgsbilanzen, 1935) S. 66. 
die Beteiligung an oder der Einfluss auf unternehmerische Entscheidungen, was zumindest Stimm- sowie bestimmte Kontroll- und Widerspruchsrechte erfordert und dem ökonomischen Konzept residualer Entscheidungs- und Kontrollrechte ansatzweise ähnelt ${ }^{1}$. Interessanterweise verlangt die Rechtsprechung das Vorliegen beider Merkmale, so dass der Mitunternehmerbegriff enger gefasst ist als der nur auf einem dieser Konzepte beruhende ökonomische Eigentumsbegriff.

Die zweite Frage nach der Sonderbetriebsvermögenseigenschaft eines Wirtschaftsgutes knüpft letztlich an die normale Betriebsvermögensterminologie des Steuerrechts und die Abgrenzung von privater und betrieblicher Vermögenssphäre an. Sonderbetriebsvermögen liegt hiernach vor, wenn ein zur Vermögenssphäre des Mitunternehmers gehörendes Wirtschaftsgut dem Betrieb der Personengesellschaft (Sonderbetriebsvermögen I) oder der Begründung oder Stärkung der Beteiligung des Mitunternehmers an der Personengesellschaft (Sonderbetriebsvermögen II) dient ${ }^{2}$. Es handelt sich um (fiktives) Betriebsvermögen ohne Gewerbebetrieb des zivilrechtlichen Eigentümers ${ }^{3}$. Während die Mitunternehmeridentifikation also eher die personale Zugehörigkeit einer Vertragspartei zu dem (internen) Vertragsgeflecht der Personengesellschaft dokumentiert, grenzt die Identifikation des Betriebsvermögens nun die der Personengesellschaft zur Verfügung stehenden Ressourcen ein.

Die aufgezeigte Vorgehensweise bei der Mitunternehmerbesteuerung zeigt, dass im deutschen Steuerrecht ein weiteres Kriterium zur Abgrenzung einer mehrere Steuerrechtssubjekte umfassenden rechnungslegenden Einheit existiert. Anders als beim körperschaftsteuerlichen Organschaftskreis, der streng genommen noch nicht einmal als rechnungslegende Einheit fungiert, oder auch dem handelsrechtlichen Konsolidierungskreis besitzt sie allerdings einen etwas anderen Fokus: die rechnungslegende Einheit wird hier nicht „von oben nach unten“, sondern „,von unten nach oben“ mit Blick auf die jeweiligen Eigentümer bzw. Mitunternehmer aufgebaut. Diese Unterscheidung wird insbesondere bei einem handelsrechtlichen Mutterunternehmen deutlich, dessen Eigentümer nicht mehr in den Konsolidierungskreis der Konzernrechnungslegung einbezogen werden. Wie bereits beschrieben ${ }^{4}$, wirkt die Einheitstheorie an dieser Stelle wie eine Trennungstheorie für den handelsrechtlich abgegrenzten „Konzern“, da die Konzern-

1 Da gesellschaftsrechtlich immer mehrere Gesellschafter vorgesehen sind, ist aber fraglich, ob der einzelne Gesellschafter überhaupt residuale Rechte im Sinne von Grossman/Hart (Costs and Benefits of Ownership, 1986) besitzen kann.

2 Vgl. R 13 (2) EStR. Je nachdem, ob das Sonderbetriebsvermögen diese Zwecke unmittelbar erfüllt oder nur objektiv dazu geeignet und subjektiv dazu bestimmt ist, kann zwischen notwendigem und gewillkürtem Sonderbetriebsvermögen unterschieden werden. Völlig unerheblich ist hierbei, ob die Nutzungsüberlassung entgeltlich oder unentgeltlich erfolgt. Vgl. zum Sonderbetriebsvermögen ausführlich Söffing (Mitunternehmer, 1994) S. 98-121.

3 Vgl. Knobbe-Keuk (Bilanz- und Unternehmenssteuerrecht, 1993) S. 440.

4 Vgl. Kap. III.1.3. 
sphäre von der seiner Eigentümer getrennt wird. Bei Übertragung der mitunternehmerischen Abgrenzungskonzeption wären diese Eigentümer aber einzubeziehen, wenn sie neben der rechtlichen Eigentümer- bzw. Gesellschafterstellung auch Mitunternehmerrisiko tragen und Mitunternehmerinitiative entfalten und damit de facto Eigentümer im ökonomischen Sinne sind. Gleiches gilt für die Ressourcen, die diesen Eigentümern rechtlich zugeordnet sind, aber den betrieblichen Zwecken des Mutterunternehmens dienen. Die mitunternehmerische Abgrenzungskonzeption und das ihr innewohnende Transparenzprinzip zeichnet damit eine deutliche Parallele zum ökonomischen Modell der Unternehmung, wo z.B. kontrollierende Anteilseigner einer nukleusbasierten (und damit körperschaftlich organisierten) Unternehmung zuzurechnen sind.

Angesichts der bisherigen Erkenntnisse verwundert es nicht, dass sich auch technische Gemeinsamkeiten zwischen dem Transparenzprinzip bei der Mitunternehmerschaft und dem Konsolidierungsmodell ergeben. So hat Döllerer in diesem Zusammenhang in der von ihm entwickelten Theorie einer konsolidierten Gesamtbilanz schon in den 70er Jahren gefordert, im Zuge der Besteuerung einer Mitunternehmerschaft den Rechnungskreis der Gesellschaft mit dem des Gesellschafters zu einer wirtschaftlichen Einheit zusammenzufassen ${ }^{1}$. Neben den bereits aufgezeigten Parallelen bei der Abgrenzung der rechnungslegenden Einheit wird dieser Forderung zumindest hinsichtlich der einheitlichen Ausübung handels- bzw. steuerrechtlicher Bilanzierungswahlrechte innerhalb der Mitunternehmerschaft entsprochen ${ }^{2}$. Auch existiert ein einheitsinterner Verlustausgleich, da Verluste der Gesamthandsbilanz mangels Trennungsprinzip ${ }^{3}$ mit weiteren Einkünften der Gesellschafter saldiert werden ${ }^{4}$.

An der vollständigen Umsetzung von Döllerers Theorie mangelt es jedoch, da die Rechtsbeziehungen zwischen Gesellschaft und Gesellschaftern steuerlich anerkannt und in der heute praktizierten und vom BFH bestätigten Methode der korrespondierenden

1 Vgl. insb. Döllerer (Steuerbilanz der Personenhandelsgesellschaft, 1974); s.a. Döllerer (Personenhandelsgesellschaft, 1978); umfassendere Literaturhinweise finden sich bei Tipke/Lang (Steuerrecht, 2002) $§ 9 \mathrm{Tz}$. 530. Döllerer schlägt vor, die zweistufige Gewinnermittlung zu einer steuerlichen Gesamtbilanz der Mitunternehmerschaft zusammenzufassen; erläuternd dazu Knobbe-Keuk (Bilanz- und Unternehmenssteuerrecht, 1993) S. 479-481; Uelner (Mitunternehmergewinn, 1978/79) S. 301-306, der Döllerer in seinen Forderungen nach einer Gesamtbilanz zwar unterstützt, hier aber eine „strukturierte Gesamtbilanz" vorschlägt, die sich seines Erachtens für Zurechnungszwecke besser eignet (S. 311-320). Vgl. zur neueren Literaturauffassung im Überblick Pinkernell (Einkünftezurechnung bei Personengesellschaften, 2001) S. 45-61.

2 Vgl. hierzu und zu den diesbezüglichen Ausnahmen Söffing (Mitunternehmer, 1994) S. 209-211.

3 Das bei Kapitalgesellschaften bestehende Trennungsprinzip wird für Zwecke des Verlustausgleichs nur durch die Organschaft überwunden, die diesbezüglich eine Gleichstellung mit Einzelunternehmern und Personengesellschaften erreicht; vgl. dazu Scheffler (Besteuerung von inländischen Konzernen, 1991) S. 703.

4 Bei Mitunternehmern, deren Haftung beschränkt ist, z.B. bei Kommanditisten der KG, sind allerdings die Verlustausgleichsbeschränkungen des $§ 15 \mathrm{a}$ EStG zu beachten. 
Gewinnermitlung ${ }^{1}$ nicht herauskonsolidiert werden. So korrespondieren z.B. Forderungen des Mitunternehmers mit Schulden der Gesellschaft, ohne als solche durch eine Schuldenkonsolidierung entfernt zu werden. Dürfte dies im Zuge der Kerngrößenorientierung der steuerlichen Gewinnermittlung ${ }^{2}$ noch unerheblich sein, so ergeben sich aus den Rechtsbeziehungen zwischen Gesellschaft und Gesellschafter aber auch Ergebniswirkungen. Die korrespondierende Gewinnermittlung entspricht im Ergebnis nur dann der konsolidierten, soweit Aufwendungen im Gesamthandsbereich durch korrespondierende Erträge im Sonderbereich neutralisiert werden. Dieser Kompensationsmechanismus ist an den in $\S 15$ Abs. 1 Satz 1 Nr. 2 II. Altern. EStG kodifizierten Sondervergütungstatbestand geknüpft und gilt ansonsten nicht. Die korrespondierende Bilanzierung greift z.B. für den Fall, dass ein Mitunternehmer für sein der Personengesellschaft vermietetes Grundstück eine Miete erhält, aber nicht für den umgekehrten Fall, in dem der Mitunternehmer das Grundstück von der Personengesellschaft mietet ${ }^{3}$. Auch ergeben sich kompensierende Wirkungen nur aus Sicht des jeweils betroffenen Mitunternehmers. Für den oder die anderen Mitunternehmer wirkt das entsprechende Geschäft wie eines mit außen stehenden Marktteilnehmern, da ihr Sonderbereich hiervon unbeeinflusst bleibt. Damit ist festzustellen, dass interne Geschäfte bei der Mitunternehmerschaft im Vergleich zu denen im Konsolidierungsmodell trotz gewisser Parallelen grundsätzlich nicht aus der Sicht einer einzigen rechnungslegenden Einheit betrachtet werden und deshalb zu Ergebniswirkungen führen können.

Um die in den Einzelbilanzen angesetzte Beteiligung im Sinne der Einheitstheorie in die einzelnen Wirtschaftsgüter zu transformieren, bedarf es im Konsolidierungsmodell in technischer Hinsicht der Kapitalkonsolidierung, mittels derer die Eigenkapitalverflechtungen zwischen den einbezogenen Unternehmen eliminiert werden. Ähnliches ergibt sich auch bei der Mitunternehmerschaft ${ }^{4}$. Bei der Erstkonsolidierung entstehende Wertdifferenzen zwischen den Buchwerten der Wirtschaftsgüter und ihren im Sinne der Einzelerwerbsfiktion ermittelten Anschaffungskosten finden ihre Entsprechung in den Ergänzungsbilanzen der Mitunternehmer. Aus Sicht der einzelnen Mitunternehmer können, u.a. durch den Erwerb eines Mitunternehmeranteils, ebenfalls Wertkorrekturen im

$1 \quad B F H$ v. 25.2 .1991 (GrS 7/89); s.a. $B F H$ v. 10.11 .1980 (GrS 1/79); $B F H$ v. 14.11.1985 (IV R 63/83); $B F H$ v. 21.4 .1988 (IV R 80/86); erläuternd zur additiven Gewinnermittlung mit korrespondierender Bilanzierung auch Pinkernell (Einkünftezurechnung bei Personengesellschaften, 2001) S. 193-199.

2 Vgl. dazu Kap. III.1.4.

3 Vgl. ausführlich zu Sonderbetriebseinnahmen, -ausgaben und dem Sondervergütungstatbestand Söffing (Mitunternehmer, 1994) S. 155-180, 200-204; mit Fokus auf die Abgrenzung der Unternehmung bereits Elschen (Institutionale oder personale Besteuerung, 1994) S. 13-19.

4 Vgl. ähnlich Groh (Mitunternehmerschaft, 1995) S 384; Groh (Trennungs- und Transparenzprinzip, 1998) S. 95; ansatzweise Mühlschlegel (Gewinnermittlung für Konzerne, 1971) S. 143-145. 
Verhältnis zur Gesamthandsbilanz entstehen'1. Diese Auf- oder Abstockungsbeträge werden in den Ergänzungsbilanzen individuell erfasst und im Sinne der Folgekonsolidierung auch abgeschrieben bzw. aufgelöst. Gleiches gilt für die hierbei eventuell entstehenden derivativen Firmenwerte, die anzusetzen und abzuschreiben sind ${ }^{2}$.

Interessant ist bei der steuerlichen Gewinnermittlung der Mitunternehmerschaft auch die technische Berücksichtigung von Beteiligungsquoten, mit denen Gesellschafter bzw. Mitunternehmer an der Gesellschaft beteiligt sind. Während das einheitstheoretisch motivierte Konsolidierungsmodell bei Zugehörigkeit zur rechnungslegenden Einheit die Vollkonsolidierung vorsieht, folgt das Transparenzprinzip in Teilen einer Mixtur aus Quoten- und Vollkonsolidierung, in der sich die Interessentheorie oder gar Eignertheorie, möglicherweise aber auch die Einheitstheorie wieder findet. So ist den Mitunternehmern noch bei Gültigkeit der Bilanzbündeltheorie ihr Anteil am Gesamthandsvermögen auf die einzelnen Wirtschaftsgüter herunter gebrochen worden, um diese den jeweiligen Einzelbetrieben quotal zuzurechnen. Dies hat sich durch die heute originär zu erstellende Gesamthandsbilanz geändert, obgleich sich in den separierten Kapitalkonten der Gesellschafter immer noch deren anteiliges Nettovermögen widerspiegelt. Das Sonderbetriebsvermögen wird der rechnungslegenden Einheit allerdings unabhängig von der Beteiligungsquote des jeweiligen Mitunternehmers voll zugerechnet. Eine anteilige Zurechnung ist nur zwingend, wenn das Wirtschaftsgut durch die Personengesellschaft nur anteilig genutzt wird oder nur anteilig im zivilrechtlichen Eigentum des Mitunternehmers steht. Eher der Vollkonsolidierung entspricht auch die korrespondierende Gewinnermittlung bei Vorliegen des Sondervergütungstatbestands. Die korrespondierenden Doppelerfassungen mit umgekehrten Vorzeichen werden in voller Höhe erfasst.

Die im Konsolidierungsmodell bei Unternehmensgruppen eventuell existierenden Minderheiten, deren Kapital- und Ergebnisanteil im Rahmen der Vollkonsolidierung je nach Sicht im Eigenkapital und Ergebnis berücksichtigt werden oder nicht, finden bei der Mitunternehmerschaft allenfalls eine entfernte Entsprechung. Aus Sicht des einzelnen Mitunternehmers könnten die anderen Mitunternehmer eventuell als „QuasiMinderheiten ${ }^{63}$ angesehen werden. Diese Analogie lässt sich allerdings nicht auf die entsprechende Berücksichtigung ihrer Anteile im Eigenkapital oder Ergebnis übertragen. Die mitunternehmerische Gewinnermittlung ist letztlich klar auf den einzelnen

1 Je nachdem, ob die Gesamthandsbilanz zu Teil-, Zwischen- oder Buchwerten (fort-)geführt wird, und je nachdem, ob die Mitunternehmer im Ergebnis eine Buchwertfortführung betreiben oder von Zwischen- oder Teilwerten ausgehen, sind negative oder positive Ergänzungsbilanzen möglich; vgl. erläuternd BMF (Schreiben betr. Umwandlungssteuergesetz, 1998); Knobbe-Keuk (Bilanz- und Unternehmenssteuerrecht, 1993) S. 897-915.

2 Vgl. ansatzweise zu Parallelen zur Konsolidierung bei der Zusammenfügung der Ergänzungsbilanzen mit der Bilanz der Gesellschaft Döllerer (Personenhandelsgesellschaft, 1978) S. 51.

3 Dieser Begriff soll nur die entsprechende Analogie andeuten und ist inhaltlich bedenklich, da die anderen Mitunternehmer auch eine wie auch immer ermittelte Mehrheit bilden können. 
Mitunternehmer ausgerichtet. Eine zusammengefasste Bilanz mit einem Gesamteigenkapital und -ergebnis existiert nicht, so dass ein „Minderheitenanteil“ hieran nur künstlich aus den (unkonsolidierten) Teilmengen der Mitunternehmer berechnet werden müsste. Die klare individuelle Ausrichtung der mitunternehmerischen Gewinnermittlung widerspricht letztlich der Einheitstheorie und ähnelt, wenn überhaupt, der Eignertheorie.

Abschließend kann festgehalten werden, dass die mitunternehmerische Gewinnermittlung einige interessante Parallelen zur Konsolidierung aufweist. Dennoch ist diese Form der steuerlichen Gewinnermittlung ihrer Art nach keine Konsolidierung nach einheitstheoretischen Vorgaben, auch wenn entsprechende Forderungen in der Literatur insbesondere von Döllerer erhoben worden sind. Deutlich wird aber auch hier das Spannungsfeld zwischen rechtlicher Vielheit und wirtschaftlicher Einheit, innerhalb derer auch die konkrete Ausgestaltung der konsolidierten steuerlichen Gewinnermittlung angesiedelt ist.

\subsection{Weitere rechtliche Nebenbedingungen}

Bei den bisherigen Ausführungen ist angeklungen, dass die Besteuerung einer Unternehmensgruppe nach der Einheitstheorie eine Idealvorstellung ist, die realiter auf eine in vielerlei Hinsicht stark rechtsformorientierte Unternehmenssicht trifft. Schon die Konsolidierung im Rahmen der steuerlichen Gewinnermittlung ist nur vor dem Hintergrund zu erklären, dass eine einheitstheoretische Gesamtgewinnermittlung in einer weiterhin vom Trennungsprinzip dominierten Rechtsumgebung wohl nur aus den originären Einzelgewinnermittlungen der einbezogenen Unternehmen abgeleitet werden kann. Aus der rechtsformorientierten Unternehmenssicht resultiert auch die rechtliche Separierung einer Unternehmensgruppe, aus der weitere Rechtskonsequenzen erwachsen. Diese sollen im Folgenden am fortgeführten Beispiel der deutschen Rechtsordnung verdeutlicht und in ihren Konsequenzen für die steuerliche Konsolidierung analysiert werden (Kapitel III.2.5.1). Zudem gilt es, die Existenz nationalstaatlicher Grenzen zu berücksichtigen, die sich ebenfalls auf die rechtstechnische Umsetzung einer derartigen Konsolidierung auswirken können (Kapitel III.2.5.2).

\subsubsection{Gruppenspezifische Nebenbedingungen}

\subsubsection{Haftungsseparation}

Mit den Rechtsformgrenzen eines Unternehmens gehen zivilrechtliche Haftungsgrenzen einher. Diese resultieren aus dem Trennungsprinzip und der damit einhergehenden zivilrechtlichen Selbständigkeit juristischer Personen, die als rechtsfähige Konstrukte nur 
mit ihrem eigenen Vermögen haften ${ }^{1}$. Bei der Kapitalgesellschaft sind deshalb die Anteilseigner aus der Haftung entlassen, solange sie ihrer Einlageverpflichtung entsprochen haben. Innerhalb einer Unternehmensgruppe führt dies zur haftungsrechtlichen Separation entlang der Unternehmensgrenzen. Dabei harmoniert diese Haftungsseparation - wie schon das Trennungsprinzip im Allgemeinen - nicht mit der ökonomischen Vorstellung von einer Unternehmung als autonomer wirtschaftlicher Einheit, deren gesamtes Vermögen für ihre gesamten Schulden haftet. Der Führung rechtlich separierter Unternehmungen steht mit der Haftungsseparation vielmehr ein Gestaltungsinstrument zur Verfügung, um unternehmerische Risiken der gesamten Gruppe durch Verlagerung auf die Vertragspartner des jeweils betroffenen Unternehmens zu begrenzen ${ }^{2}$. Explizit können hier die Gläubiger und Minderheitsgesellschafter angeführt werden ${ }^{3}$. Dieser ökonomisch bedeutsame Effekt rechtlicher Separierung wäre im Rahmen einer ansonsten identischen Einheitsunternehmung nicht zu erzielen. Sind sich die betroffenen Vertragspartner ihrer Risiken bewusst und stehen ihnen funktionierende Selbstschutzmöglichkeiten zur Verfügung, können - müssen aber nicht - aus der Anspruchsseparation im Allgemeinen und aus der Haftungsseparation im Besonderen Effizienzvorteile für die gesamte Gruppe erwachsen ${ }^{4}$. Insofern liegt es nahe, Auswirkungen z.B. auf die Leistungsfähigkeitsbeurteilung zu vermuten.

Fraglich ist nun, ob die zivilrechtliche Trennungstheorie und die damit einhergehende Haftungsseparation Auswirkungen auf die Voraussetzungen und/oder Ausgestaltung der konsolidierten Gesamtgewinnermittlung einer Unternehmensgruppe haben. Problematisch erscheint z.B. die Vorstellung einer unternehmensübergreifenden steuerlichen Verlustverrechnung innerhalb der Unternehmensgruppe. Da (nicht nur) das deutsche Steuerrecht auf dem Grundsatz basiert, dass Verluste steuerlich nur von demjenigen geltend

1 Bei Personengesellschaften ist die Haftungsseparation insoweit nicht gegeben, als dass hier zumindest ein Gesellschafter unbegrenzt haftet.

2 Vgl. bereits Pohmer (Verhältnis der Wirtschaftswissenschaft, 1964) S. 60-63. Klang bei Ordelheide (Konzern, 1986) S. 300-301 noch an, dass die Effizienzwirkungen der Haftungsseparation noch nicht abschließend geklärt sind, so existieren inzw. zumindest ökonomische (agency-theoretische) Analysen z.B. von Debus (Haftungsregelungen, 1990); Schenk (Konzernbildung, 1997) insb. S. 61, 100-111. Vgl. zu den ökonomischen Funktionen der Haftungsseparation, ihren Risiken für bestimmte Vertragspartner der Unternehmung und zum Haftungsmanagement auch Theisen (Konzern, 2000) S. 615-645, der in der aktiven Gestaltung das „Konzernhaftungsmanagement“ erkennt; dazu auch Schenk (Konzernbildung, 1997) S. 139-219.

3 Vgl. Busse von Colbe (Konzernverfassung, 1988) S. 251, der trotz der aktienrechtlichen Pflicht zum Einzelausgleich für schädigende Eingriffe des Mutterunternehmens ( $\S 311,317 \mathrm{AktG})$ in faktischen Konzernen einen „unzureichenden Schutz" dieser Vertragsparteien identifiziert. Vgl. auch Lehertshuber (Konzernhandelsbilanz, 1986) S. 7-78; Theisen (Konzern, 2000) S. 620-621, der Risiken des „Haftungsmanagements“ explizit für Gläubiger über- und untergeordneter Gesellschaften identifiziert.

4 Vgl. Schenk (Konzernbildung, 1997) S. 132-229; stärker die Kosten der Haftungsseparation gegen die Kosten des Haftungsverbunds abwägend Debus (Haftungsregelungen, 1990) S. 41-185; Busse von Colbe (Konzernverfassung, 1988) S. 253, der in freiwilligen Patronatserklärungen ein Indiz für mögliche Vorteile des Haftungsverbundes vermutet. 
gemacht werden können, der sie auch wirtschaftlich trägt ${ }^{1}$, dürfte gerade diese Verlustverrechnung über Haftungsgrenzen hinweg diskussionswürdig sein. Dennoch kann aufgezeigt werden, dass die zivilrechtliche Trennungstheorie der konsolidierten steuerlichen Gewinnermittlung nicht per se widerspricht. Fraglich ist sogar, ob sie vor diesem Hintergrund an bestimmte, zusätzliche Voraussetzungen geknüpft werden sollte.

Rechtsform- sowie Haftungsgrenzen stehen schon deshalb einer konsolidierten steuerlichen Gewinnermittlung nicht entgegen, weil sie durch ein zusätzliches Rechtsgeschäft aufgehoben oder zumindest eingeschränkt werden können. Dies gilt, obwohl die Idee eines unternehmensübergreifenden Haftungsverbunds gerade dem körperschaftlichen Prinzip der auf das eigene Gesellschaftsvermögen begrenzten Haftung grundsätzlich widerspricht. Auch der aktienrechtliche Konzern ist kein Gegenstand eigenständiger Haftungsregeln, weil ein allgemeiner Haftungsdurchgriff dort (noch) ${ }^{2}$ nicht existiert. Durch Abschluss eines Beherrschungs- oder Gewinnabführungsvertrages gemäß $\S 302$ AktG kann allerdings eine Verlustausgleichspflicht und damit ein Haftungsverbund begründet werden. Die rechtlich separierte Unternehmensgruppe wird damit im Bereich der Haftung einer Einheitsunternehmung angenähert, so dass Ordelheide den Vertragskonzern in Abgrenzung zum faktischen Konzern als das unternehmungsnähere Modell bezeichnet $^{3}$. Vor diesem Hintergrund kann der zum Verlustausgleich zwingende Gewinnabführungsvertrag ( $\S 302 \mathrm{AktG}$ ) als wesentliche Organschaftsvoraussetzung gerechtfertigt werden ${ }^{4}$, so dass es auch nicht verwundert, wenn für eine darüber hinausgehende Gruppenbesteuerung gar auf Grundlage einer konsolidierten steuerlichen Gewinnermittlung ein derartiger Haftungsverbund gefordert wird ${ }^{5}$. Zwingend ist dies jedoch nicht.

1 Vgl. sehr viel differenzierter Kröner (Verrechnungsbeschränkte Verluste, 1986) S. 153-339; zur „wirtschaftlichen Identität" als Tatbestandsvoraussetzung der Verlustabzugsberechtigung bei deutschen Körperschaften vgl. auch Orth (§ 8 Abs. 4 KStG, 2003).

2 Die Diskussion zur sog. „Konzernvertrauenshaftung“ deutet jedoch an, dass die in Konzernen konkretisierte Unternehmung auch haftungsrechtlich Anerkennung finden könnte; vgl. m.w.N. Druey (Konzernvertrauen, 2000); Emmerich/Sonnenschein/Habersack (Konzernrecht, 2001) S. 288; Fleischer (Konzernrechtliche Vertrauenshaftung, 1999); Lutter (Haftung in der Unternehmensgruppe, 1982) S. 254-257; Theisen (Konzern, 2000) S. 632-635. Vgl. zur Konzernhaftung allgemein u. umfassend Görling (Konzernhaftung, 1998) S. 73-239. Interessant ist auch die gesellschaftsrechtliche Situation in manchen EU-Staaten: So führt z.B. eine 100\%ige Beteiligung in Belgien, Italien und Großbritannien zur unbeschränkten Haftung des Alleinaktionärs; vgl. Salzberger (Konzernunternehmung, 1994) S. 30-31; zur Haftung der Obergesellschaft im neuen italienischen Konzernrecht vgl. auch Steinhauer (Konzernrecht in Italien, 2004) R 232.

3 Vgl. Ordelheide (Konzern, 1986) S. 300.

4 Vgl. so wohl u.a. Müller-Gatermann (Organschaftsbesteuerung, 1997) S. 464.

5 Der Haftungsverbund als (eine) Anerkennungsvoraussetzung der Einheitsbesteuerung ist bereits auf dem 49. Deutschen Juristentag 1972 gefordert worden; vgl. insb. Beusch (Referat, 1972) S. Q 41Q 42; Flume (Referat, 1972) S. Q 17-Q 19; Lutter (Diskussionsbeitrag, 1972) S. Q 58. 
Einerseits erscheint die auch im Organschaftskonzept zum Ausdruck kommende Konzentration auf dieses spezielle aktienrechtliche Vertragskonzept eher eng'. Eine Verlustübernahmeverpflichtung kann insbesondere auch durch andere aktienrechtliche Instrumente wie den Beherrschungsvertrag oder die noch weiter reichende Eingliederung und die damit einhergehende Begründung einer gesamtschuldnerischen Haftung ( $\$ 322$ AktG) gewährleistet werden ${ }^{2}$. Haftungsgrenzen können aber auch in faktischen Konzernen bzw. bei sonstigen Unternehmensverbindungen, z.B. durch Patronatserklärungen, Liquiditätszusagen, Bürgschaften oder Garantien, aufgehoben werden ${ }^{3}$. Zudem sehen hier $\S \S 311,317$ AktG einen Nachteilsausgleich gegenüber abhängigen Gesellschaften und eventuelle Schadensersatzpflichten des herrschenden Unternehmens vor. Diese dienen aber weniger der haftungsrechtlichen Vereinigung, sondern eher der Begrenzung der Risiken, die für die Vertragspartner der abhängigen Gesellschaft aus der Kombination von nachteiliger Einflussnahme und Haftungsseparation erwachsen. Ähnliche Wirkungen entfaltet auch die Rechtsprechung und das von ihr entwickelte Konstrukt der „qualifizierten" faktischen Unternehmensverbindung. Hier soll die Nachteilszufügung durch eine abgestufte Gleichbehandlung dieser Unternehmensverbindungen mit dem Vertragskonzern kompensiert werden ${ }^{4}$.

Der Gewinnabführungsvertrag wird auch aus anderer Perspektive als Organschaftsvoraussetzung in Frage gestellt. So ist darauf hingewiesen worden, dass das organschaftliche Zurechnungskonzept durch den Gewinnabführungsvertrag im Wesentlichen bereits handelsrechtlich verwirklicht wird ${ }^{5}$. Streng genommen besteht aber eine „Dissonanz von Tatbestand und Rechtsfolge" ${ }^{\text {"6 }}$, da nicht das handelsrechtliche Ergebnis, sondern das zu versteuernde Einkommen Gegenstand der organschaftlichen Zurechnung ist. Für die diesbezüglichen Differenzen greift das Zurechnungskonzept schon jetzt ausschließlich und würde sich bei Abschaffung des Gewinnabführungsvertrags als Organschaftsvo-

1 Die ausschließliche Kopplung der Organschaft an den Gewinnabführungsvertrag kann deshalb wohl nur rechtshistorisch erklärt werden; vgl. z.B. BFH v. 27.11.1956 (I D 1/56 S); s.a. Grotherr (Abschluß eines Gewinnabführungsvertrags, 1995) S. 3.

2 Vgl. Grotherr (Besteuerung nationaler und grenzüberschreitender Konzerne, 1994) S. 468-471; Grotherr (Abschluß eines Gewinnabführungsvertrags, 1995) S. 5-7; Grotherr (Organschaftskonzept, 1998) S. 257.

3 Vgl. Emmerich/Sonnenschein/Habersack (Konzernrecht, 2001) S. 287-290; Lutter (Haftung in der Unternehmensgruppe, 1982).

4 Vgl. dazu ausführlicher Busse von Colbe (Konzernverfassung, 1988) S. 252; Emmerich/Sonnenschein/Habersack (Konzernrecht, 2001) S. 437-442; Görling (Konzernhaftung, 1998) S. 160-216; Lutter (Haftung in der Unternehmensgruppe, 1982) S. 263-267; Theisen (Konzern, 2000) S. 628-632.

5 Vgl. Rupp (Ertragsbesteuerung nationaler Konzerne, 1983) S. 250 sowie Lechner (Besteuerung von Unternehmensgruppen, 1991) S. 394. In diese Richtung weist auch Schneider (Grundzüge der Unternehmensbesteuerung, 1994) S. 162, der Verluste während der Organschaft durch den Gewinnabführungsvertrag als ausgeschlossen und den Verlustausgleich schon darin als verwirklicht ansieht.

6 Müller (Konzernbesteuerung, 1991) S. 23 für die bis 2004 vergleichbare österreichische Organschaftskonzeption. 
raussetzung auf den gesamten (steuerlichen) Verlustausgleich ausdehnen. Die Rechtsfolge könnte damit allein aus dem Zurechnungskonzept begründet werden'.

Der Gewinnabführungsvertrag wird auch dahingehend kritisiert, dass er eine zusätzliche, rechtsgeschäftliche Voraussetzung beschreibt, die der Unternehmungsleitung ein Gestaltungsinstrument in die Hand gibt. Durch Abschluss eines Rechtsgeschäftes bzw. Unterlassen desselben kommt die Zugehörigkeit eines Unternehmens zur Besteuerungseinheit einem Wahlrecht gleich ${ }^{2}$. Unter Gesichtspunkten von Willkürfreiheit und Objektivität scheint dies wenig wünschenswert. Auch dürfte dies dem Gedanken der Entscheidungs- bzw. Organisationsneutralität widersprechen ${ }^{3}$, wenn mögliche Effizienzvorteile rechtlicher Separation der Unternehmung durch einen Vertragskonzern zunichte gemacht werden, dessen formalvertraglicher Charakter allein steuerrechtlich motiviert ist $^{4}$.

Weniger eindeutig erscheint die Wertung aus Sicht der Gleichmäßigkeit und steuerlichen Leistungsfähigkeit. Obwohl Selbsteinsteuerungsmöglichkeiten auch hier verurteilt werden, erscheint es fraglich, ob Unternehmensgruppen unabhängig von ihrer Haftungssituation in der steuerlichen Gewinnermittlung gleich behandelt werden sollten. Ohne zusätzliche Rechtsgeschäfte liegt bei einer Unternehmensgruppe eben keine vollständige Gewinn- und Verlustgemeinschaft nach Vorbild der Einheitsunternehmung vor. Fraglich ist aber, ob eine Leistungsfähigkeitsbeeinflussung über die bloße Möglichkeit der Haftungsseparation gegeben ist, oder ob sie erst eintritt, wenn sich die Unternehmensgruppe der Verlusttragung tatsächlich entzieht ${ }^{5}$. Im letzteren Fall könnte einer bereits bekannten, z.B. in $\S 15$ a EStG kodifizierten Vorgehensweise des Steuerrechts gefolgt werden, die die Verlustverrechnung bei einem beschränkt haftenden Mit-

1 Vgl. Rupp (Ertragsbesteuerung nationaler Konzerne, 1983) S. 250-251; s.a. Grotherr (Abschluß eines Gewinnabführungsvertrags, 1995) S. 10; Grotherr (Organschaftskonzept, 1998) S. 258; Müller (Konzernbesteuerung, 1991) S. 25; Senger (Konzernertragsbesteuerung, 1997) S. 112; Theisen (Konzern, 2000) S. 581.

2 Rupp (Ertragsbesteuerung nationaler Konzerne, 1983) S. 249 sieht hier ein „Mittel der Steuerpolitik im Konzern"; a.A. Grotherr (Abschluß eines Gewinnabführungsvertrags, 1995) S. 3. Schuch (Besteuerung als Unternehmensgruppe, 1998) S. 78-84 hält dieses De-facto-Wahlrecht für sinnvoll.

3 Vgl. ansatzweise Gassner (Besteuerung von Unternehmensgruppen, 1998) S. 16; Müller (Konzernbesteuerung, 1991) S. 50.

4 Vgl. Schenk (Konzernbildung, 1997) S. 229-240; dazu auch Krebühl (Beteiligung an ausländischen Gesellschaften, 1994) S. 500; Krebühl (Organschaft, 1995) S. 744-745; Theisen (Konzern, 2000) S. 580-581; Theisen (Konzernunternehmungslehre, 1988) S. 289; ansatzweise auch Lechner (Besteuerung von Unternehmensgruppen, 1991) S. 393-394; relativierend Debus (Haftungsregelungen, 1990) S. 179-185; Ordelheide (Konzernerfolgskonzeptionen, 1987) S. 983.

5 Vgl. dies vermutend Herzig/Dautzenberg (Steuergestaltung, 1992) S. 7 in der Interpretation von Senger (Konzernertragsbesteuerung, 1997) S. 53; ansatzweise auch Herzig (Steuergestaltung, 1993) S. 7. 
unternehmer auf die Höhe der Haftungseinlage beschränkt ${ }^{1}$. Im Rahmen einer konsolidierten steuerlichen Gewinnermittlung ist hierbei eine Erfolgslokalisation auf Ebene der einzelnen Unternehmen hilfreich, um feststellen zu können, wo genau der Verlust in der Unternehmensgruppe angefallen ist ${ }^{2}$. Angesichts der hier ohnehin angenommenen realtypischen Ausgestaltung des Konsolidierungsmodells, das die Steuerrechtsfähigkeit der Gruppe nur als Fiktion unterstellt und die Steuersubjektivität der einzelnen Unternehmen als gegeben annimmt, erscheint eine, wenn auch verzerrte, Erfolgslokalisation über die vorliegenden Einzelgewinnermittlungen zumindest ansatzweise möglich.

Die Frage, ob die konsolidierte steuerliche Gewinnermittlung an das Vorliegen eines Haftungsverbunds gekoppelt werden sollte, kann damit nicht zweifelsfrei beantwortet werden ${ }^{3}$. Die aufgezeigten Argumente geben allerdings eine gewisse Tendenz vor. Relativ unstrittig ist hierbei, dass eine konsolidierte steuerliche Gewinnermittlung durch die rechtsformorientierte Haftungsseparation nicht generell in Frage gestellt wird. Diese Form der Gewinnermittlung scheint gar bei Nichtvorliegen eines Haftungsverbunds möglich, sofern die Erfolgslokalisation innerhalb der Gruppe als Nebenbedingung formuliert wird ${ }^{4}$. Hierbei ergeben sich allerdings weitere Fragen zu dieser Erfolgslokalisation und einem eventuell notwendigen (zusätzlichen) Schutz der Gläubiger, die im Folgekapitel aufgegriffen und vertieft werden.

1 Vgl. Grotherr (Abschluß eines Gewinnabführungsvertrags, 1995) S. 5, der ansonsten die Gefahr (wieder) entstehender Abschreibungs- bzw. Verlustzuweisungsgesellschaften beschwört; Grotherr (Organschaftskonzept, 1998) S. 260; ansatzweise Müller-Gatermann (Organschaftsbesteuerung, 1997) S. 464. Vgl. allerdings zur Interpretation von $\S 15 \mathrm{a}$ EStG durch den BFH Hempe/Siebels/Obermaier (§ 15a EStG-Abzugsbechränkung, 2004).

2 Bei der Erfolgslokalisation geht es letztlich um die Aufteilung des ermittelten Gesamtgewinns oder -verlusts auf die einzelnen Unternehmen. Die Literatur kennt hierfür auch den Begriff der „Gewinnabgrenzung"; vgl. z.B. Nientimp (Steuerliche Gewinnabgrenzung, 2003) ; Haiß (Gewinnabgrenzung zwischen Betriebsstätten, 1999), die allerdings die Gewinnabgrenzung innerhalb eines international tätigen Unternehmens (zwischen den Betriebsstätten) untersucht. Den Begriff „Erfolgslokalisation“ benutzt z.B. Senger (Konzernertragsbsteuerung, 1997) S. 54, 136 i.R.d. Gesamtgewinnermittlung.

3 Vgl. in der Schlussfolgerung ähnlich Grotherr (Abschluß eines Gewinnabführungsvertrags, 1995) S. 4: „Dieses Problem lässt sich jedoch nicht widerspruchsfrei lösen, so daß hier die Auffassung vertreten wird, daß zumindest eine dauerhafte innerkonzernliche Verlustverrechnung und damit eine Durchbrechung des Trennungsprinzips nur dann in Betracht kommt, wenn dies auch zivilrechtlich vollzogen wird. Insbesondere durch die Pflicht zur Verlustabdeckung kann zivilrechtlich von einem Einheitsunternehmen gesprochen werden, denn die Obergesellschaft kann sich nicht mehr beliebig vom wirtschaftlichen Schicksal der Untergesellschaft lösen"; ansatzweise Grotherr (Besteuerung nationaler und grenzüberschreitender Konzerne, 1994) S. 455. Bezogen auf den Vertragskonzern konstatiert Schildbach (Konzernabschluß als Ausschüttungsbemessungsgrundlage, 1993) S. 58, dass sich die ,auf eine Anspruchseinheit ausgerichtete Lösung des Vertragskonzerns ... vergleichsweise einfach und konsistent mit einer Ausschüttungsregelung verbinden" lässt.

4 Vgl. Senger (Konzernertragsbesteuerung, 1997) S. 66. 


\subsubsection{Minderheitenproblem und Steuerverteilung trotz Interessenvielfalt}

Da die Unternehmensgruppe selbst in der Gestalt des aktienrechtlichen Konzerns keine eigene Rechtsfähigkeit besitzt, hat sie auch als solche keine „eigenen“ Gesellschafter bzw. Anteilseigner. Als direkte Konsequenz der rechtlichen Separierung sind Anteilseigner formalrechtlich nur an den jeweiligen Unternehmen beteiligt und können ihre Ansprüche auch nur gegenüber diesen Rechtsträgern geltend machen. Dabei bietet sich innerhalb einer Unternehmensgruppe auf der Ebene eines jeden Unternehmens die Möglichkeit, weitere Anteilseigner aufzunehmen. Hierbei entstehen Minderheiten, da, wie z.B. in faktischen Konzernen üblich, die finanzielle Beteiligungsmehrheit und mit ihr regelmäßig auch die Stimmrechtsmehrheit bei der jeweils übergeordneten Gesellschaft liegt. Sollte sich die Abgrenzung der Unternehmensgruppe in Abhängigkeit von dem dahinter stehenden ökonomischen Verständnis von einer Unternehmung von dem Kriterium der Kapitalmehrheit oder von der finanziellen Beteiligung insgesamt verabschieden, können ökonomische „Minderheiten“ entstehen, denen trotz ihrer Kapitalmehrheit kein ökonomisches Eigentum mehr zuzurechnen ist. Vorstellbar wäre dies z.B. auch in den Fällen, in denen die einheitliche Leitung gem. $\S 18 \mathrm{AktG}$ bei einer Minderheitsbeteiligung gegeben ist.

In strenger Anwendung der Einheitstheorie dürfte die Gesellschaftersphäre im Rahmen der steuerlichen Gewinnermittlung eigentlich gar nicht interessieren. Das der existierenden Unternehmensbesteuerung zu Grunde liegende Trennungsprinzip wird hier quasi auf die Unternehmensgruppe übertragen, deren Gesamtgewinn als Steuerobjekt zu ermitteln ist. Entgegen der formalrechtlichen Situation werden alle Anteileigner der involvierten Unternehmen gleichermaßen als Anteilseigner der Gruppe behandelt. Dabei gilt die „Fiktion der Interessenhomogenität" ${ }^{\text {"1 }}$ aller Anteilseigner, da ihnen gemeinsam das gesamte Einkommen der Gruppe zusteht. Anders als bei der Einheitsunternehmung führt die rechtliche Separierung in Verbindung mit der definitionsgemäß vorliegenden Hierarchiestruktur in der Unternehmensgruppe aber zu potenziellen Interessenkonflikten zwischen den Mehrheitsgesellschaftern (die übergeordneten Unternehmen der Gruppe) und den Minderheitsgesellschaftern². Während das Mehrheitsinteresse regelmäßig mit dem Gruppeninteresse gleichgesetzt wird ${ }^{3}$, sehen sich die Minderheiten als Anteilseigner abhängiger Unternehmen diversen Konzern- bzw. Gruppenrisiken ausge-

1 Lutter/Rimmelspacher (Einheitstheorie, 1992) S. 487; Probst (Anteile von Minderheitsgesellschaftern, 1997) S. 172.

2 Vgl. insb. Probst (Anteile von Minderheitsgesellschaftern, 1997) S. 30-36; s.a. Prantl (Minderheitenschutz, 1994) S. 1; Wiedemann (Gesellschaftsrecht, 1980) S. 407.

3 Vgl. Probst (Anteile von Minderheitsgesellschaftern, 1997) S. 30, der deshalb auch von einem einheitstheoretischen Mehrheitsprinzip spricht 
setzt ${ }^{1}$, die es für sie zu reduzieren gilt und die sie letztlich auch zum Schutzobjekt aktienrechtlicher Bestimmungen gemacht haben ${ }^{2}$.

In der bisherigen Diskussion zur Konzernbesteuerung ist das Minderheitenproblem als eines der grundlegendsten Argumente gegen eine einheitstheoretische Gruppenbesteuerung angeführt worden ${ }^{3}$. Angesichts verschobener Risiko- und Kompetenzstrukturen bei den abhängigen Unternehmen entstünden dadurch (weitere) Risiken für die Vermögensposition der Minderheiten, die sich insbesondere in einer Überwälzung zu hoher Steuerlasten auf diese Unternehmen konkretisieren könnten. Selbiges gilt aber auch für die Verteilung von z.B. konsolidierungsbedingten Steuervorteilen. An dieser Stelle wird insofern ein Wertungswiderspruch zwischen der aktienrechtlichen Schutzkonzeption auf der einen und einer Besteuerung der Gruppe nach dem ,einheitstheoretischen Mehrheitsprinzip“ auf der anderen Seite vermutet ${ }^{4}$. Mit Verweis auf die Einheitlichkeit der Rechtsordnung wird betont, dass das Steuerrecht den zivilrechtlichen Minderheitenschutz nicht konterkarieren dürfe ${ }^{5}$.

So begründet diese Sorge auch sein mag, so wenig erwächst daraus aber ein grundlegendes Argument gegen eine (voll-)konsolidierte steuerliche Gewinnermittlung. Erst einmal handelt es sich nicht um ein reines Minderheitenproblem. Oft übersehen, tragen auch die Anteilseigner des an der Gruppenspitze stehenden Unternehmens - im Konzern das oberste Mutterunternehmen - ähnliche Risiken ${ }^{6}$ und zwar insbesondere dann, wenn kein kontrollierender Anteilseigner vorliegt und das ökonomische Eigentum in den Händen der Konzern- bzw. Gruppenleitung in Gestalt der Manager des Mutterun-

1 Ordelheide (Konzernerfolgskonzeptionen, 1987) S. 978-980 unterteilt konzerntypische Risiken in Vermögensverlagerungs- u. Zwischengewinnrisiken; s.a. Lehertshuber (Konzernhandelsbilanz, 1986) S. 7-78. Pellens (Aktionärsschutz im Konzern, 1994) S. 46-51 identifiziert für jeden Aktionär Vermögens-, Herrschafts- u. Informationsrechte, die durch Gruppenbildung unterschiedlich stark beeinträchtigt werden. Obwohl Pellens diese Risiken für die Mehrheitsgesellschafter untersucht, dürften sie - in womöglich anderer Form - bei Minderheiten auch vorliegen. Vgl. zudem Orts (Legal Theory, 1998) S. 318-320, der Minderheitenrisiken sogar in dem einzelnen Unternehmen identifiziert.

2 Vgl. hierzu ausführlich und in der Beurteilung der Schutzwirkung auch kritisch Prantl (Minderheitenschutz, 1994) S. 65-148.

3 Vgl. stellvertretend Flume (Referat, 1972) S. Q 20; Lutter (Diskussionsbeitrag, 1972) S. Q 58-Q 59; Rupp (Ertragsbesteuerung nationaler Konzerne, 1983) S. 99-106; Scheffler (Besteuerung von inländischen Konzernen, 1991) S. 712; Scheuchzer (Konzernbesteuerung, 1994) S. 245; kritisch auch zur Vollkonsolidierung trotz Minderheiten EU-Kommission (Konsultationspapier, 2003) S. 16.

4 Vgl. Probst (Anteile von Minderheitsgesellschaftern, 1997) S. 85, 190.

5 Vgl. dazu umfassend m.w.N. Rupp (Ertragsbesteuerung nationaler Konzerne, 1983) S. 89-102.

6 Vgl. allgemein zu Risiken der (Publikums-)Aktionäre des Mutterunternehmens Busse von Colbe (Konzernverfassung, 1988) S. 250-251; Pellens (Aktionärsschutz im Konzern, 1994) S. 52-83; Lehertshuber (Konzernhandelsbilanz, 1986) S. 79-150. Letztlich handelt es sich hier um den klassischen Interessengegensatz bei jedem Unternehmen zwischen Managern und Eigentümern, der insb. agencytheoretisch untersucht wird. Probst (Anteile von Minderheitsgesellschaftern, 1997) S. 32 (m.w.N.) erkennt deshalb ein zweidimensionales Interessenproblem, das einerseits aus der Trennung von Management und Eigentum, andererseits aus der Konzernbildung erwächst; ähnlich auch Pellens (Aktionärsschutz im Konzern, 1994) S. 70. 
ternehmens vermutet werden muss ${ }^{1}$. Auch die schon angesprochenen Gläubiger und sonstige Vertragspartner aller Unternehmen der Unternehmensgruppe tragen gruppenspezifische Risiken ${ }^{2}$ und würden durch die Steuerlastüberwälzungen betroffen. Insofern geht es eher um die Frage, ob und wie die Erfolgs- und damit Steuerverteilung innerhalb einer rechtlich separierten Unternehmensgruppe trotz der heterogenen Vertragspartnergruppen und der dahinter zu vermutenden Interessenvielfalt bewerkstelligt werden $\mathrm{kann}^{3}$.

In einem ersten Schritt kann darauf hingewiesen werden, dass sich diese Frage nicht grundsätzlich stellt, sondern nur in Abhängigkeit von der jeweils vorliegenden Gruppen- und Rechtskonstellation. Würde die Fiktion der rechtlichen Einheit der Unternehmensgruppe de lege ferenda in die Realität überführt und der Gruppe eine eigenständige zivilrechtliche Rechtsfähigkeit zugebilligt, stünde allen Anteilseignern und sonstigen Vertragspartnern die gesamte Unternehmensgruppe als eine einzige Anspruchseinheit gegenüber. Damit ergäbe sich auch rechtlich die Gleichstellung zur Einheitsunternehmung. Realistischer erscheint indes die Vorstellung, analog zu den Ausführungen des vorangegangenen Kapitels, die rechtlich separierte Unternehmensgruppe durch zusätzliche Rechtsgeschäfte in eine zivilrechtliche „Anspruchseinheit" $\mathrm{zu}$ überführen. Dies dürfte bereits de lege lata auf die aktienrechtliche Eingliederung zutreffen ${ }^{4}$. Aber auch der Vertragskonzern dürfte etwaige Verteilungsprobleme durch die Rechtsinstitution der in $\S 304$ AktG kodifizierten Ausgleichsverpflichtung und sonstige Schutzinstrumente

1 Vgl. dazu Kap. II.3.3.2.3. Vgl. zur theoretischen und empirischen Aufarbeitung des Zusammenhangs von Eigentümerstruktur und Erfolg eines Unternehmens Ruhwedel (Eigentümerstruktur, 2003).

2 So formuliert Pellens (Aktionärsschutz im Konzern, 1994) S. 70-83 (m.w.N.) mehrdimensionale Interessenkonflikte, die ausgehend von denjenigen der konzernfreien Aktiengesellschaften durch gruppenspezifische Erweiterungen geprägt sind. Das gilt laut Pellens für klassische Eigner-ManagerKonflikte, Eigner-Gläubiger-Konflikte sowie zusätzlich entstehende Eigner (MU)-Eigner (TU)Konflikte. Vgl. z.B. zu den Schutzinteressen der Gläubiger (im faktischen Konzern) Busse von Colbe (Konzernverfassung, 1988) S. 251-252; vgl. schon sehr früh zu den Risiken der Vertragspartner von Unternehmen einer Unternehmensgruppe Childs (Consolidated Financial Statements, 1949) S. 12-33.

3 Aus steuerlicher Sicht geht es dabei nicht um den vermögensrechtlichen Schutz von Minderheiten und sonstigen Vertragsparteien im Allgemeinen, sondern nur um die Frage, ob diese Vertragsparteien allein durch die konsolidierte steuerliche Gewinnermittlung und die darauf beruhende Einheitsbesteuerung vermögensmäßig geschädigt werden können; vgl. auch Grotherr (Abschluß eines Gewinnabführungsvertrags, 1995) S. 8.

4 So ist die Einheitsbesteuerung insb. für eingegliederte Unternehmen bereits auf dem 49. Deutschen Juristentag 1972 gefordert worden; vgl. Beusch (Referat, 1972) S. Q 42, Q 45; Flume (Referat, 1972) S. Q 19; Lutter (Diskussionsbeitrag, 1972) S. Q 59; dazu auch Herrmann (Reformbedürftiges Konzernsteuerrecht?, 1973) S. 41-43. 
( $\S 300-307$ AktG) deutlich reduzieren ${ }^{1}$. Fraglich bleibt allerdings, wie dieser Ausgleich zu bemessen ist und ob wirklich alle Vertragsparteien gleichermaßen geschützt sind ${ }^{2}$.

Möglicherweise kann die Problematik der Steuerverteilung de lege lata auch anders reduziert werden. So wird z.B. unterstellt, dass eine Unternehmensgruppe ohne Minderheiten naheliegenderweise auch kein diesbezügliches Minderheitenproblem aufweise ${ }^{3}$. In der auf Minderheiten fokussierenden Diskussion bleibt dabei aber die unveränderte Risikosituation der anderen Vertragspartner unberücksichtigt. Eine „Totallösung“ im Sinne einer Angleichung an die Situation des Einheitsunternehmens ergäbe sich wohl nur in dem unrealistischen Fall, dass keines der untergeordneten Tochterunternehmen irgendwelche sonstigen Vertragsbeziehungen unterhielte, also nur das Mutterunternehmen gegenüber Dritten als Vertragspartner aufträte. Damit stellt sich das Problem der Erfolgs- und Steuerverteilung praktisch immer bei faktischen Konzernen oder vergleichbaren Unternehmensgruppen, unabhängig davon, ob Minderheiten beteiligt sind oder nicht.

Es ist also notwendig, das konsolidierte Konzern- oder Gruppenergebnis mit den daraus resultierenden Steuerwirkungen irgendwie den einzelnen Unternehmen und deren Vertragspartnern zuzuordnen. Unter marktwirtschaftlichen Gesichtspunkten spricht erst einmal nichts dagegen, dies der Unternehmensgruppe bzw. ihrer obersten Leitung und den Vertragsbeteiligten dieser Gruppe selbst zu überlassen. Rechtstechnisch könnte dies z.B. mit der Gesamtschuldnerschaft aller Unternehmen des Konsolidierungskreises oder der Steuerschuld der Obergesellschaft verbunden werden. Fraglich ist jedoch, ob hier funktionsfähige Marktmechanismen greifen und die Vertragspartner notwendige Informationen und entsprechende Marktmacht, z.B. in Form sofortiger Ausstiegsoptionen, besitzen. Ein System der gruppeninternen Erfolgslokalisation dürfte an dieser Stelle weiterhelfen, unabhängig davon, ob es der Fiskus zwangsweise vorgibt oder die Beteiligen ,freiwillig“ darauf zugreifen.

Angesichts der nur auf Unternehmen begrenzten Rechtsträgereigenschaft und der nur an sie gekoppelten Vertragsverhältnisse scheint es erst einmal nahe liegend, eine parallele

1 Vgl. z.B. Baetge/Beermann (Eignung der körperschaftsteuerlichen Organschaft, 1998) S. 279, 281; Busse von Colbe (Konzernverfassung, 1988) S. 249; kritischer bereits Voss (Einheitsbesteuerung verbundener Unternehmen, 1973) sowie insb. Flume (Referat, 1972) S. Q 20-Q 21; Herrmann (Reformbedürftiges Konzernsteuerrecht?, 1973) S. 43; Lutter (Diskussionsbeitrag, 1972) S. Q 58-Q 59. De lege ferenda könnte auch die Verlustübertragung von der kompensierenden Leistung einer den künftigen Steuervorteil entsprechenden Ausgleichszahlung abhängig gemacht werden; vgl. Grotherr (Abschluß eines Gewinnabführungsvertrags, 1995) S. 8.

2 Vgl. zweifelnd z.B. Busse von Colbe (Konzernverfassung, 1988) S. 249-251 hinsichtlich der (Publikums-)Aktionäre des Mutterunternehmens.

3 Vgl. z.B. Baetge/Beermann (Eignung der körperschaftsteuerlichen Organschaft, 1998) S. 281; Herrmann (Reformbedürftiges Konzernsteuerrecht?, 1973) S. 40-43; Mühlschlegel (Gewinnermittlung für Konzerne, 1971) S. 105. 
Einzelgewinnermittlung auf Unternehmensebene durchzuführen. In der Literatur wird dies insoweit gefordert, wie Minderheiten betroffen sind ${ }^{1}$ - streng genommen müsste es aber ebenfalls für andere Vertragspartner wie z.B. Gläubiger oder Arbeitnehmer und damit grundsätzlich gelten. An dieser Stelle zeigen sich die Vorteile der realtypischen Lösung einer konsolidierten steuerlichen Gewinnermittlung, die ohnehin auf vorhandene Einzelgewinnermittlungen zugreift. Fraglich ist allerdings, ob diese Einzelgewinnermittlungen weiterhin streng nach dem Trennungsprinzip funktionieren müssen. Dies würde wieder zu dem ökonomisch eher unsinnigen Versuch führen, über den Fremdvergleichsgrundsatz einen Markt zu fingieren, wo gar keiner ist, um auf diese Weise höchst unvollkommen - gruppen- bzw. abhängigkeitsbedingte „Verzerrungen“ auszuschalten. Damit änderte sich auch nichts gegenüber dem bisherigen Verfahren einer Einzelgewinnermittlung nach dem Trennungsprinzip, das als eine Art Schattenveranlagung neben der konsolidierten Gesamtgewinnermittlung auf Gruppenebene durchgeführt würde. Eine doppelte Gewinnermittlung dürfte aber schon unter den Gesichtspunkten der Durchführungseffizienz kaum sinnvoll sein. Ein Kompromiss läge möglicherweise darin, auf die künstliche Ergebniskorrektur nach Maßgabe des Fremdvergleichs zu verzichten - schließlich werden den Minderheitsgesellschaftern vom Gesetzgeber in $\S 58$ Abs. 2 AktG bzw. $\S 29$ Abs. 1 GmbHG auch verzerrungsanfälligere handelsrechtliche Einzelgewinnermittlungen ohne Fremdvergleich zur Bemessung ihrer Ausschüttungsansprüche ,,zugemutet ${ }^{\star 2}$.

Alternativ zu einer realtypischen Variante der einheitstheoretischen Gesamtgewinnermittlung auf Vollkonsolidierungsbasis werden in diesem Zusammenhang auch alternative Gesamtgewinnermittlungssysteme diskutiert. Diese umfassen entweder modifizierte Einzelgewinnermittlungen nach dem Trennungsprinzip, die z.B. auf der Basis eines organschaftsähnlichen Zurechnungsmodells funktionieren und im Hinblick auf beste-

1 Vgl. u.a. Jacobs/Spengel (Deutschland und Frankreich, 1994) S. 101; Lechner (Besteuerung von Unternehmensgruppen, 1991) S. 396, der konstatiert, dass , die Minderheitenprobleme relativ problemlos lösbar sind... Es ist bloß sicherzustellen, dass die Gesamtsteuerschuld der Gruppe möglichst verursachungsgerecht auf die einzelnen Gruppenglieder aufgeteilt wird“; Rupp (Ertragsbesteuerung nationaler Konzerne, 1983) S. 103-104; Scheffler (Besteuerung von inländischen Konzernen, 1991) S. 712; Senger (Konzernertragsbesteuerung, 1997) S. 25, 55; Scheuchzer (Konzernbesteuerung, 1994) S. 244245 .

2 Als Problem wird hier meist nicht der fehlende Fremdvergleichsgrundsatz, sondern die zu enge rechnungslegende Einheit identifiziert; vgl. insb. Böhm (Konzerngewinn als Grundlage für Dividendenausschüttung und Steuerbemessung, 1979) S. 102-195; Busse von Colbe (Konzernabschluß als Bemessungsgrundlage, 1987); Küting (Rechnungslegung im Umbruch, 1991) S. 25-28; Lehertshuber (Konzernhandelsbilanz, 1986) S. 7-199; Schildbach (Konzernabschluß als Ausschüttungsbemessungsgrundlage, 1993); empirische Erkenntnisse beisteuernd Linnhoff/Pellens (Ausschüttungspolitik deutscher Konzerne, 1987) S. 990-994 m.w.N., die dieses Problem jedoch mehr aus der Perspektive der Aktionäre der Muttergesellschaft betrachten; Pellens (Aktionärsschutz im Konzern, 1994) S. 58-64, 128-136, 231-242, 320-325; Pellens (Gewinnverwendung im Konzern, 1995); Pellens/Gassen/Richard (Ausschüttungspolitik, 2003). 
hende Unternehmensverbindungen partiell korrigiert werden ${ }^{1}$. Demgegenüber wird aber auch die Quotenkonsolidierung als mögliche Lösung des Minderheitenproblems diskutiert $^{2}$. Unter regelmäßiger Außerachtlassung anderer Vertragsparteien würde die Quotenkonsolidierung diejenigen Unternehmensanteile, die den Minderheiten zuzurechnen sind, als fremde Dritte behandeln und insbesondere die diesbezüglichen Zwischengewinnanteile als realisiert betrachten. Technisch gesehen unterscheidet sich diese Lösung nicht mehr von der Schattenveranlagung, da auch die Quotenkonsolidierung auf der Einzelgewinnermittlung beruht, die für die Minderheiten ausschlaggebend bleibt. So erhielten die Minderheiten in beiden Varianten auf der Ebene ihrer Rechtseinheit (und letztlich auch die sonstigen Vertragspartner dieser Einheit) ein anteiliges Ergebnis zugewiesen, dass auf der Fiktion einer partiellen wirtschaftlichen Unabhängigkeit ihrer Rechtseinheit beruht ${ }^{3}$. In diese Richtung dürfte auch die um die (normale) EquityMethode ergänzte Einzelgewinnermittlung zielen ${ }^{4}$, die gegenüber der Quotenkonsolidierung sogar durchführungseffizienter sein dürfte.

Die soeben dargestellten Ausgestaltungsalternativen gehen letztlich mit einer mehr oder minder starken Abkehr von der Einheitstheorie einher. Es geht hier insofern um die Grundsatzentscheidung, ob der Fiskus wirklich eine unternehmungsähnliche Unternehmensgruppe als Einheit besteuern möchte und das hierbei ermittelte Gesamtergebnis auch Minderheiten und sonstige Vertragspartner treffen soll. Wird dies verneint, mag eine interessen- oder eignertheoretische Vorgehensweise oder gar eine Hinwendung zu einer modifizierten Einzelgewinnermittlung durchaus sinnvoll sein. Dann verstoßen diese Ausgestaltungsalternativen aber auch gegen das Grundprinzip der bisherigen Un-

1 Vgl. z.B. Scheuchzer (Konzernbesteuerung, 1994) S. 244-257; Theisen (Konzern, 2000) S. 584-585 spricht i.d.Zshg. von einer „einheitstheoretischen Modifikation der Zurechnungstheorie“ (S. 584); ähnlich auch Salzberger (Konzernunternehmung, 1994) S. 228-249, der darin ein „,einheitstheoretisch modifiziertes Trennungsprinzip“ erkennt (S. 228).

2 Befurrwortend (in einer oft auf die Zwischenergebniseliminierung fokussierten Diskussion, in der ansonsten auch unterschiedliche Techniken vorgeschlagen werden) wohl Grotherr (Besteuerung nationaler und grenzüberschreitender Konzerne, 1994) S. 454; Rupp (Ertragsbesteuerung nationaler Konzerne, 1983) S. 278-280; Scheffler (Besteuerung von inländischen Konzernen, 1991) S. 712-713; diese Möglichkeit andeutend auch Müller (Konzernbesteuerung, 1991) S. 127-128, 138. Grotherr (Abschluß eines Gewinnabführungsvertrags, 1995) S. 13 erkennt darin sogar die einhellige Literaturauffassung. Ablehnend und eher für die volle Eliminierung plädierend Bauer (Besteuerung deutscher Konzerne, 1987) S. 208-211; Hellerstein/McLure (Company Income Taxation, 2004) S. 205; Oberndorff (Konzernbesteuerung, 1996) S. 93-95 (relativierend aber S. 69-70); Senger (Konzernertragsbesteuerung, 1997) S. 55-56, 194-196; in upstream- (anteilig) sowie downstream-Lieferungen (voll) differenzierend Probst (Anteile von Minderheitsgesellschaftern, 1997) S. 197-200; vgl. dazu auch (wohl ohne eindeutige Entscheidung) Theisen (Konzern, 2000) S. 585.

3 Vgl. dazu treffend Probst (Anteile von Minderheitsgesellschaftern, 1997) S. 189-190, nach dem die „Existenz der Minderheitsgesellschafter aus gesellschaftsrechtlichen Gründen im Innenverhältnis letztlich eine Revision der einheitstheoretischen Besteuerung durch eine Konzernsteuerumlage" erfordere, „die, will man die Auslösung konzernrechtlicher Nachteilsausgleichs- oder Schadensersatzpflichten vermeiden, auf Basis der Unabhängigkeitsfiktion zu ermitteln ist".

4 Vgl. zu der hier nicht gemeinten modifizierten Variante der Equity-Methode Kap. III.1.4.2. 
ternehmensbesteuerung (Trennungsprinzip), das im Zuge der Gesamtgewinnermittlung nicht mehr im Sinne der „Fiktion der rechtlichen Einheit“" auf eine Unternehmensgruppe übertragen würde'.

Der einheitstheoretischen Gesamtgewinnermittlung auf der Basis vollkonsolidierter Einzelgewinnermittlungen mag indes eine alternative Form der Erfolgslokalisation und Steuerverteilung viel besser entsprechen. So existiert neben der direkten Methode der Erfolgslokalisation über Einzelgewinnermittlungen die alternative Möglichkeit der indirekten Methode ${ }^{2}$. Dem Gedanken der Einheitsbesteuerung folgend, verteilt diese nur das Einkommen der Gruppe und die sich daraus ergebende Steuerlast qua Schlüsselung (formula apportionment) auf die rechtsfähigen Gliedteile der Gruppe ${ }^{3}$. Dem liegt die ökonomische Erkenntnis zu Grunde, dass eine separierte Einzelgewinnermittlung bei ökonomisch verflochtenen und voneinander abhängigen Unternehmen innerhalb einer Unternehmung wenig Sinn ergibt ${ }^{4}$. Vorstellbar wäre dies de lege ferenda z.B. im Rahmen einer einheitlichen und gesonderten Feststellung nach Maßgabe des $\S 179$ Abs. 2 AO, so wie sie auch bei der Mitunternehmerbesteuerung greift ( $\$ 180$ Abs. 1 Nr. 2a) AO). Eventuelle Nachteile bei der ,verursachungsgerechten“ Erfolgslokalisation dürften hier mit Vorteilen bei der Durchführungseffizienz einhergehen. Dafür müsste allerdings ein von allen Vertragsparteien der gesamten Gruppe akzeptierter Verteilungsschlüssel vorliegen. Dies setzt individuelle, privatwirtschaftliche Verhandlungslösungen unter idealtypischen Bedingungen und einen daraus resultierenden Gruppenkonsens voraus. Unter Berücksichtigung von Transaktionskosten kann allerdings eine standardisierte gesetzliche Verteilungslösung Effizienzvorteile aufweisen, zumindest wenn sie mit funktionsfähigen Märkten einher geht, die die jederzeitige Ausstiegsoption für die sich übervorteilt fühlenden Vertragspartner sicher stellt. Der kontrollierende Marktmechnismus einer individuellen Ausstiegsoption ist dabei in jedem Fall einer Ausstiegsoption

1 Insofern widerspricht dies den bisherigen Erkenntnissen in Kap. II.3.3 und III.1.

2 Vgl. zu dieser Unterscheidung ausführlich Haiß (Gewinnabgrenzung zwischen Betriebsstätten, 1999) S. 43-57; Kumpf (Steuerliche Verrechnungspreise, 1976) S. 63-68; kurz auch Rupp (Ertragsbesteuerung nationaler Konzerne, 1983) S. 103 m.w.N.

3 Vgl. kurz zur Funktionsweise dieser Schlüsselung Sunley (Formulary Apportionment, 2002); Weiner (Formulary Apportionment, 2002); s.a. Kap. IV.2.2.2 und Kap. VI. Dies bereits als Lösung für die Beeinträchtigung vermögensrechtlicher Interessen von Minderheitsgesellschaftern m.w.N. andeutend Grotherr (Besteuerung nationaler und grenzüberschreitender Konzerne, 1994) S. 445, der allerdings doch mehr der Quotenkonsolidierung zuzuneigen scheint (S. 454). Diskutiert wird die Verteilung des Konzerngewinns mit Hilfe von Verteilungsschlüsseln auch im Zuge der verwandten Forderung, das Konzernergebnis als Grundlage einer Dividendenausschüttung heranzuziehen; vgl. Böhm (Konzerngewinn als Grundlage für Dividendenausschüttung und Steuerbemessung, 1979) S. 153-172.

4 Vgl. grundlegend McLure (Unitary Business, 1984) S. 91-102; s.a. Mintz/Weiner (Formula Allocation, 2003) S. 698 sowie die in Kap.IV.2.2.2 und VI zitierte Literatur zur "formula apportionment". 
für ganze Unternehmen, z.B. in Form eines steuerlichen Beitrittswahlrechtes ${ }^{1}$, vorzuziehen. Letzteres bietet nicht nur Selbsteinsteuerungsmöglichkeiten für die Unternehmensgruppe, sondern angesichts mehrheitsdominierter Unternehmensorgane auch keinen wirksamen Minderheiten- und sonstigen Vertragsparteienschutz ${ }^{2}$. Selbiges gilt gleichermaßen für ein Einwilligungs- oder Zustimmungserfordernis der betroffenen Unternehmen, das materiell wie ein Wahlrecht wirken dürfte ${ }^{3}$.

Die Bestimmung eines Verteilungsschlüssels wäre für den Gesetzgeber und die dort involvierten, begrenzt rational handelnden Individuen sicherlich mit beträchtlichen Schwierigkeiten verbunden ${ }^{4}$. Ein grundlegender Nachteil gegenüber der direkten Methode der Erfolgslokalisation ist das jedoch nicht, da auch diese angesichts der Willkür des Fremdvergleichs und der Verrechnungspreise keine „richtige“ Erfolgslokalisation gewährleisten kann. Bei der indirekten Schlüsselung wäre darüber hinaus zu prüfen, ob und inwieweit aktien- bzw. gesellschaftsrechtliche Minderheitenschutzvorschriften noch flankierend zur Anwendung kommen (sollten ${ }^{5}$ ). Diese Prüfung entspricht der Vorstellung, dass es letztlich nicht das Ziel des Steuerrechts, sondern, wenn überhaupt, nur des Gesellschaftsrechts sein kann, Vertragsbeteiligte wie Minderheiten oder Gläubiger vor gruppenspezifischen Risiken zu schützen ${ }^{6}$.

Abschließend bleibt festzuhalten, dass die rechtliche Separierung innerhalb einer Unternehmensgruppe zu Interessenkonflikten führt, die über das in einer Einheitsunternehmung bereits vorhandene Maß hinaus gehen können. Aus steuerlicher Sicht ist in diesem Zusammenhang nur die Frage relevant, ob Vermögenspositionen der Vertragspartner durch Gesamtgewinnermittlung und Einheitsbesteuerung beeinträchtigt werden. Dies ist weitgehend auszuschließen, wenn die zivilrechtliche Rechtfähigkeit der Unter-

1 Dieses Wahlrecht fordert z.B. Schuch (Besteuerung als Unternehmensgruppe, 1998) S. 80-83; für die Einheitsbesteuerung als solche ein Wahlrecht fordernd Flume (Referat, 1972) S. Q 19; Herrmann (Reformbedürftiges Konzernsteuerrecht?, 1973) S. 43; Ritter (Sicht der Wirtschaft, 1989) S. 325; Salzberger (Konzernunternehmung, 1994) S. 239-240.

2 A.A. wohl Schuch (Besteuerung als Unternehmensgruppe, 1998) S. 83, der hier auf die gesellschaftsrechtlichen Schranken für die Einflussnahme von Großaktionären vertraut.

3 Vgl. z.B. Müller (Konzernbesteuerung, 1991) S. 133, der einen Antrag der Obergesellschaft und die Einwilligung der einbezogenen Gesellschaften fordert.

4 Vgl. dies andeutend Scheffler (Besteuerung von inländischen Konzernen, 1991) S. 712.

5 So bietet es sich z.B. nach Ordelheide (Konzernerfolgskonzeptionen, 1987) S. 985 an, ,den Minderheitsaktionären [weitere, Anmerkung des Verfassers] Rechte einzuräumen, die sie bei Aufnahme eines Unternehmen in einen Konzernverbund in die Lage versetzen, für sie angemessene Zusagen zu erlangen". Die grundsätzliche Vorteilhaftigkeit individueller, marktlicher Selbstschutzmöglichkeiten gegenüber staatlicher Regulierung betont i.d.Zshg. auch Schenk (Konzernbildung, 1997) S. 228. Allerdings dürfte gerade bei kleineren, regelmäßig auch nicht börsengehandelten Gesellschaften nicht immer die Funktionsfähigkeit z.B. der Eigenkapitalmärkte gegeben sein.

6 Vgl. Reis (Körperschaftsbesteuerung des Konzerns, 1996) S. 232. Die Einheitlichkeit der Rechtsordnung scheint dadurch nicht gefährdet; dies auch deshalb, weil Minderheitenprobleme letztlich schon in dem einzelnen Unternehmen auftauchen (vgl. Orts (Legal Theory, 1998) S. 318-320) und durch die rechtliche Separierung in der Unternehmensgruppe nur verschärft werden. 
nehmensgruppe de lege ferenda vorläge. Dieser Konstellation nähert sich de lege lata nur die Eingliederung, allenfalls der Vertragskonzern an. Bei einem faktischem Konzern oder einer vergleichbaren Unternehmensgruppe, an der u.a. auch Minderheiten vertraglich gebunden sind, bedarf es statt dessen einer Ergebnis- und damit Steuerlastverteilung, die die Vertragspartner weitestgehend vor konsolidierungsbedingten Vermögensschäden schützt. Dies könnte möglicherweise über eine direkte Erfolgslokalisation auf der Grundlage einer wie auch immer relevanten Einzelgewinnermittlung gewährleistet werden. Eine geschlüsselte Einkommens- und Steuerlastverteilung dürfte der einheitstheoretischen Vorstellung einer Gesamtgewinnermittlung indes eher entsprechen, auch wenn dies mit dem Problem verbunden ist, einen geeigneten Verteilungsschlüssel entweder privatwirtschaftlich auf Gruppenebene oder in standardisierter Form gesetzlich festlegen zu müssen. Völlig neu dürfte dieses Problem nicht sein, weil z.B. auch bei der Organschaft die gesamte Steuer im Grundsatz bei dem Organträger anfällt und ebenfalls verteilt werden muss ${ }^{1}$.

\subsubsection{Nebenbedingungen bei grenzüberschreitender Tätigkeit}

Unternehmungen bzw. Unternehmensgruppen sind regelmäßig grenzüberschreitend tätig. Darunter fallen Markttransaktionen mit Vertragspartnern in anderen Staaten (Import- und Exportgeschäfte bzw. Direktgeschäfte) oder die unmittelbare Integration über Staatsgrenzen hinweg (Direktinvestitionen) ${ }^{2}$. Unternehmen einer Unternehmensgruppe können im Falle der Integration über unterschiedliche Staaten verteilt sein und unterliegen demnach auch unterschiedlichen, allenfalls harmonisierten nationalen Rechtsordnungen. Eingeschränkt gilt dies sogar für nicht rechtsfähige Unternehmensteile, wie z.B. Betriebsstätten ${ }^{3}$. Unter Verwendung der Konzernterminologie spricht die deutsche

1 Vgl. zu dieser Parallele Bauer (Besteuerung deutscher Konzerne, 1987) S. 208. Bei der Organgesellschaft werden allerdings Ausgleichszahlungen gem. §16 KStG versteuert; dazu auch Schneider (LAS als Besteuerungsgrundlage, 2003) S. 303.

2 Kombinationen sind ebenfalls denkbar, wenn Transaktionen innerhalb der auf mehrere Staaten verteilten Unternehmensgruppe stattfinden. Jacobs (Internationale Unternehmensbesteuerung, 2002) S. 347, 461 zählt gesellschaftsrechtliche Beteiligungen noch zu den Direktgeschäften, soweit sie nicht auf direktes unternehmerisches Engagement ausgerichtet sind und eine bestimmte Beteiligungsquote nicht übersteigen. Ansonsten läge eine Direktinvestition vor. Vgl. sehr ausführlich zu diesen unternehmerischen Gestaltungsalternativen und ihrer steuerlichen Behandlung Jacobs (Internationale Unternehmensbesteuerung, 2002) S. 345-613, der an dieser Stelle auch den Inbound-Fall (ausländische Tätigkeiten in Deutschland) vom Outbound-Fall (deutsche Tätigkeiten im Ausland) unterscheidet, sowie Scheffler (Besteuerung der grenzüberschreitenden Unternehmenstätigkeit, 2002) S. 155-276.

3 Üblicherweise ist eine Betriebsstätte ein wirtschaftlich teilweise verselbständigter, hauptsächlich materieller Ressourcenpool im Sinne einer festen Geschäftseinrichtung oder Anlage (vgl. § 12 AO), der jedoch die Rechtsträger- bzw. Nukleuseigenschaft fehlt; ein vertraglicher Anknüpfungspunkt liegt damit nicht oder nur sehr eingeschränkt vor. Vgl. zu den Besonderheiten bei der Besteuerung inländischer Betriebsstätten ausländischer Investoren sowie ausländischer Betriebsstätten inländischer Investoren Jacobs (Internationale Unternehmensbesteuerung, 2002) S. 369-423, 479-499; Scheffler (Besteuerung der grenzüberschreitenden Unternehmenstätigkeit, 2002) S. 173-198. 
Literatur im Fall staatenübergreifender Unternehmensgruppen von ,internationalen Konzernen"1, die bei einem in Deutschland domizilierten Mutterunternehmen auch etwas paradox als ,internationale deutsche Konzerne ${ }^{\text {“2 }}$ bezeichnet werden.

Wenn unterschiedliche Staaten von der grenzüberschreitenden Tätigkeit der Unternehmensgruppe betroffen $\operatorname{sind}^{3}$, greift automatisch auch deren steuerliche Souveränität (Steuerautonomie) und deren fiskalisches Interesse. Bei einer auch international eher rechtsträgerorientierten Besteuerungssystematik ${ }^{4}$ unterliegen ausländische Unternehmen (und auch sonstige ausländische Vertragspartner) der Unternehmensgruppe im Grundsatz dem ausländischen Steuerrecht. Für das bisher diskutierte Konzept einer konsolidierten Gesamtgewinnermittlung ergeben sich deshalb erhebliche Konsequenzen.

Das Ausgangsproblem einer grenzüberschreitenden Tätigkeit sind divergierende nationale (Steuer-)Rechtsordnungen, die mit unterschiedlichen Gewinnermittlungs- und Besteuerungssystemen einhergehen. Dies führt bereits auf der Ebene der unternehmensisolierten Einzelgewinnermittlung zu Wirkungen, die die des normalen Trennungsprinzips verstärken und die im Vergleich zu einer rein nationalen Unternehmensgruppe zur Mehr- oder Minderbesteuerung führen ${ }^{5}$. Zentrales Beispiel einer Mehr- bzw. Doppelbesteuerung sind bereits versteuerte Gewinne einer Beteiligungsgesellschaft, die bei der übergeordneten Gesellschaft in einem anderen Staat erneut besteuert werden ${ }^{6}$. Bei der Minderbesteuerung geht es um die zwischenstaatliche Verlagerung von Steuersubstanz in Niedrigsteuerländer oder um die Nutzung von Besteuerungsunterschieden im Rah-

1 So z.B. Theisen (Konzern, 2000) S. 586, der i.d.Zshg. noch einmal „transnationale“ und „,supranationale" Konzerne unterscheidet (S. 6-11).

2 Pullen (Körperschaftsbesteuerung, 1994) S. 9.

3 Wann die Staaten bzw. Steuerhoheiten sich in der Besteuerung für zuständig erachten, hängt von den konkreten Anknüpfungsmomenten ab, an denen die Staaten ein Steuerrechtsverhältnis knüpfen. Diese können bei Personensteuern wie der Einkommen- und Körperschaftsteuer an persönliche Aspekte (Nationalitätsprinzip, Wohnsitz- oder Ansässigkeitsprinzip) oder sachliche Aspekte (Quellen- oder Ursprungsprinzip) anknüpfen. Vgl. dazu ausführlicher Haberstock (Steuerplanung, 1976) S. 12-19; Jacobs (Internationale Unternehmensbesteuerung, 2002) S. 6-8, 291-313; s.a. Bayer (Steuerlehre, 1997) Tz. 1923-1949.

4 Vgl. z.B. Jacobs (Internationale Unternehmensbesteuerung, 2002) S. 291; hierzu ausführlich Kap. IV.

5 Vgl. zur Mehr- bzw. Doppelbesteuerung sowie Minderbesteuerung bei grenzüberschreitender unternehmerischer Tätigkeit und ihren wettbewerbspolitischen Konsequenzen u.a. genauer Gerken/Märkt/Schick (Tax Competition in the EU, 2001) S. 245-246; Haberstock (Steuerplanung, 1976) S. 19-62; Jacobs (Internationale Unternehmensbesteuerung, 2002) S. 3-88; Nientimp (Steuerliche Gewinnabgrenzung, 2003) S. 9-171; Scheffler (Besteuerung der grenzüberschreitenden Unternehmenstätigkeit, 2002) S. 8-21, 57-151, 401-434; mit Fokus auf (internationale) Unternehmenszusammenschlüsse Wöhe (Steuerlehre, 1996) S. 254-320; mit Bezug auf die grenzüberschreitende Gruppenbesteuerung Schneider (IAS als Besteuerungsgrundlage, 2003) S. 302.

6 Diese Form der wirtschaftlichen Doppelbesteuerung kann bei Ausschüttung oder, im Falle der phasengleichen Vereinnahmung, schon bei Thesaurierung greifen. Vgl. zur Abgrenzung der wirtschaftlichen Doppelbesteuerung (vergleichbare Steuer auf dieselben Einkommensteile bei verschiedenen Steuersubjekten) von der rechtlichen (strenge Steuersubjektidentität) z.B. Jacobs (Internationale Unternehmensbesteuerung, 2002) S. 3-4. 
men der gruppeninternen Ergebnis- und Ressourcenabgrenzungen z.B. durch grenzüberschreitende Leasinggeschäfte ${ }^{1}$. Divergierende Systeme sind regelmäßig nicht entscheidungs- und wettbewerbsneutral und führen zu Ausweichhandlungen bei den regulierten Unternehmensgruppen, die Unterschiede in den nationalen Steuersystemen nutzen, um ihre Steuerlast zu reduzieren (Senkung der so genannten „Konzernsteuerquote ${ }^{\text {(22 }}$ ). Dazu kommen erhöhte Transaktionskosten auf Seiten der Unternehmensgruppe und der Fiskalverwaltungen bei der Ermittlung und Administrierung der jeweiligen Einzelgewinne auf der Basis unterschiedlicher Gewinnermittlungs- und Besteuerungssysteme.

Die konsolidierte Gesamtgewinnermittlung und eine darauf aufbauende Einheitsbesteuerung ist hier Lösung und zusätzliches Problem zugleich. Technisch gesehen kann die konsolidierte Gewinnermittlung mit Systemunterschieden in der Einzelgewinnermittlung umgehen, da entsprechende Vereinheitlichungsmaßnahmen der eigentlichen Konsolidierung vorgeschaltet sind (realtypische Variante). Transaktionskosten werden wahrscheinlich ebenso reduziert wie die Möglichkeiten der Mehr- oder auch Minderbesteuerung. Dies setzt allerdings zwingend voraus, dass die steuerlichen Konsequenzen aus der Gesamtgewinnermittlung mit denen der Einzelgewinnermittlung abgestimmt werden, um eine Überlagerung von Einheitsbesteuerung der Gruppe und Einzelbesteuerung der Unternehmen zu vermeiden ${ }^{3}$. Da sich die Unternehmensgruppe im Zugriff mehrerer, nationaler Finanzverwaltungen und mehrerer, unterschiedlicher (Steuer-)Rechtsordnungen befindet, sind deshalb im Grundsatz zwei Alternativen denkbar: Entweder wird das Konzept der Gruppenbesteuerung durch entsprechende Reduzierung des steuerlichen Konsolidierungskreises auf einen einzelstaatlichen Gliedteil der Gruppe beschränkt oder es erwächst die Notwendigkeit eines vollständig abgestimmten Verhaltens zwischen den involvierten Staaten, wie es, wenn überhaupt, nur in supranationalen Staatengemeinschaften wie der EU realistisch erscheint.

Die erste Alternative gibt letztlich den Normalfall der real existierenden Steuerwirklichkeit wieder, in der einzelstaatliche Grenzen die Unternehmensgruppe fiskalisch durchschneiden. In der Konkurrenz um knappes Steueraufkommen haben die autonomen Steuerhoheiten eine verschärfte Form des Trennungsprinzips eingeführt, die nicht mehr

1 Vorstellbar ist, dass der Leasinggegenstand nach dem Steuerrecht des Staates A dem in B ansässigen Leasingnehmer zuzuordnen ist, während das Steuerrecht von B unter denselben Bedingungen eine Zuordnung beim Leasinggeber vorsieht; s.a. Herzig/Dempfle (Konzernsteuerquote, 2002) S. 5-8; Schreiber (Unternehmensbesteuerung, 2004) S. 218-219; zur internationalen Steuerplanung generell Haberstock (Steuerplanung, 1976).

2 Vgl. zur Funktion, Ermittlung, Bedeutung und Kritik der Konzernsteuerquote Hannemann/Peffermann (IAS-Konzernsteuerquote, 2003); Herzig (Gestaltung der Konzernsteuerquote, 2003); Herzig/Dempfle (Konzernsteuerquote, 2002); Müller (Konzernsteuerquote, 2002); vgl. aus internationaler Sicht m.w.N. hinsichtlich diesbezüglicher empirischer Evidenz Lamb (group, 1995) S. 37-38. Die Konzernsteuerquote kann dabei durch Nutzung von Minderbesteuerungspotenzialen oder durch Reduzierung von Mehrbelastungseffekten gesenkt werden.

3 Vgl. zu ähnlichen Befürchtungen Schneider (IAS als Besteuerungsgrundlage, 2003) S. 302. 
nur zwischen Gesellschafts- und Gesellschaftersphäre, sondern auch zwischen In- und Ausland unterscheidet ${ }^{1}$. Dies verdeutlicht sich am Beispiel des Verlustausgleichs, der regelmäßig nach Maßgabe landesspezifischer Vorschriften vollumfänglich nur innerhalb eines Unternehmens und insbesondere auch nur innerhalb der entsprechenden Staatsgrenzen vollzogen werden kann. So ist ein grenzüberschreitender unternehmensinterner Verlustausgleich nach deutschem Steuerrecht gemäß $§ 8$ Abs. 1 KStG i.V.m. $\S 2 \mathrm{a}$ EStG nur eingeschränkt möglich, ein grenzüberschreitender unternehmensübergreifender Verlustausgleich angesichts der auf inländische Gesellschaften beschränkten Organkreiskriterien gar unmöglich ${ }^{2}$.

In Übertragung auf die konsolidierte Gruppenbesteuerung liefe die Einschränkung des Konsolidierungskreises durch fiskalische Grenzen auf eine Art „Inlandsgruppe“ hinaus. Der ökonomisch geprägten Sicht der Unternehmung könnte hierdurch nur zufällig in den Fällen entsprochen werden, in denen keine ausländischen Unternehmen der Gruppe zugehörig sind. Wenn sich die Unternehmensgruppe aber über staatliche Grenzen hinweg erstreckt, träfen sämtliche Argumente gegen eine separierte Besteuerung nach dem Trennungsprinzip, möglicherweise in abgeschwächter Form, auch auf die Inlandsgruppenbesteuerung zu.

Die zweite Alternative setzt indes einen multilateralen Kraftakt voraus. Je nachdem, wie viele nationale Steuerhoheiten von einer Unternehmensgruppe betroffen sind, geht dieser Kraftakt mit der partiellen Aufgabe steuerlicher Souveränität einher und verlangt administrative Lösungen insbesondere bei der wechselseitigen Anerkennung von Steuerbescheiden, bei der Frage des Rechtsschutzes, der Betriebsprüfung sowie der Erklärungs- und Mitwirkungspflichten ${ }^{3}$.

Die Abstimmung beschränkt sich nicht allein auf das Steuerrecht. Gerade vor dem Hintergrund gruppenspezifischer Restriktionen wird deutlich, dass insbesondere auch gesellschaftsrechtliche Rahmenbedingungen grenzüberschreitend vorliegen müssten. So ist z.B. ein Haftungsverbund auf der Basis aktienrechtlicher Konstrukte wie z.B. der Eingliederung oder den Beherrschungs- und Gewinnabführungsverträgen erst einmal nur auf den deutschen Rechtsraum beschränkt. Da Rechtsverhältnisse zwischen den

1 Wie bereits mit Hinweis auf Betriebsstätten angedeutet, berücksichtigen diese fiskalischen Grenzen noch nicht einmal die Grenzen steuerrechtsfähiger Unternehmen, wenn nicht rechtsfähige Gliedteile ebenfalls abgetrennt werden.

2 Vgl. hierzu kritisch Herzig/Wagner (Zukunft der Organschaft, 2005). Eine hier Abhilfe schaffende Verlustrichtlinie ist von der EU-Kommission vorgeschlagen und schließlich 2001 vorerst zurückgezogen worden; vgl. dazu genauer Kap. IV.2.1.2.

3 Vgl. zu administrativen Schwierigkeiten bei einer grenzüberschreitenden Gruppenbesteuerung ansatzweise Raupach (Gemeinschaftsweite Unternehmensbesteuerung, 1997) S. 723. 
Unternehmen wohl nach dem Recht der abhängigen Gesellschaft zu regeln sind ${ }^{1}$, bei Gültigkeit der Sitztheorie also nach dem Recht des jeweiligen Sitzstaates dieser Gesellschaft, bedingt die Einbeziehung ausländischer Unternehmen entweder ein grenzüberschreitendes Aktien- und Konzernrecht oder zumindest eine nationale ausländische Rechtsordnung mit vergleichbaren Rechtskonstrukten. Dies gilt in ähnlichem Maße für die aktienrechtlichen Mechanismen zum Schutz der Vermögenspositionen involvierter Vertragsparteien, wie z.B. der Minderheitengesellschafter, denn vermögensrelevante Gruppenrisiken ergeben sich insbesondere auch durch grenzüberschreitende unternehmerische Tätigkeiten. Selbst innerhalb der EU fehlt es derzeit an den hierfür notwendigen Voraussetzungen. Die neunte gesellschaftsrechtliche Richtlinie (Konzernrechtsrichtlinie) $)^{2}$, die die Einheitsbesteuerung gesellschaftsrechtlich flankieren könnte, ist seit etwa 20 Jahren in der Diskussion, ohne bisher verabschiedet worden zu sein ${ }^{3}$. Auch ein nationales Konzernrecht existiert nur in wenigen EU-Mitgliedstaaten ${ }^{4}$ wie Deutschland, Portugal oder jüngst auch Italien ${ }^{5}$. Grenzüberschreitende Beherrschungs- und Gewinnabführungsverträge sind damit ebenso illusionär ${ }^{6}$, wie weitergehende Konstrukte nach Art z.B. der Eingliederung. Auch die zwischenzeitliche Einführung der Europäischen Aktiengesellschaft (SE) als Ausdruck eines supranationalen, europäischen Gesellschaftstyps ${ }^{7}$ ändert daran vorerst wenig.

1 Vgl. Salzberger (Konzernunternehmung, 1994) S. 28-29 m.w.N.; ansatzweise auch Grotherr (Abschluß eines Gewinnabführungsvertrags, 1995) S. 12.

2 Vgl. zu dem 1984 von der EU-Kommission vorgelegten Vorschlag für eine Konzernrechtsrichtlinie Lutter (neunte Richtlinie, 1985).

3 Vgl. m.w.N. und Hinweisen auch auf weitere gesellschaftsrechtliche Initiativen Behrens (Europäisierung, 1993) S. 133; Grotherr (Abschluß eines Gewinnabführungsvertrags, 1995) S. 12-13; Salzberger (Konzernunternehmung, 1994) S. 48-50; Theisen (Konzern, 2000) S. 76-78, 89; s.a. Kap. IV.2.1.2.

4 Diese Aussage gilt im Hinblick auf die 15 EU-Mitgliedstaaten zum 1.1.2004; vgl. Grotherr (Abschluß eines Gewinnabführungsvertrags, 1995) S. 11; Salzberger (Konzernunternehmung, 1994) S. 49; Theisen (Konzern, 2000) S. 75, der auch weitere, außereuropäische Konzerngesetzgebungen benennt und auf die Tatsache hinweist, dass innereuropäisch oft eine mehr oder weniger ausdifferenzierte Konzernrechtsprechung existiert. Einen Überblick über das Konzernrecht in zehn dieser 15 EU-Staaten gibt der Sammelband von Hommelhoff/Hopt/Lutter (Konzernrecht für Europa, 2001). Ein nationales Konzernrecht existiert aber auch z.B. in Tschechien und damit in (mind.) einem der zum 1. Mai 2004 neu aufgenommenen EU-Mitgliedstaaten; vgl. Sparfeld (Das neue tschechische Konzernrecht, 2002). Vgl. Steinhauer (Konzernrecht in Italien, 2004) S. R 230, R 232.

6 Vgl. z.B. Grotherr (Besteuerung nationaler und grenzüberschreitender Konzerne, 1994) S. 480; Grotherr (Abschluß eines Gewinnabführungsvertrags, 1995) S. 11-12, der zudem darauf hinweist, dass dies auch als möglicher Verstoß gegen Diskriminierungsverbote und Niederlassungsfreiheit angesehen werden könnte; s.a. Hauschka (Entwicklungslinien, 1990) S. 100; Salzberger (Konzernunternehmung, 1994) S. 35-37. Für eine EU-Gruppenbesteuerung ist nach Herzig/Wagner (Zukunft der Organschaft, 2005) S. 9 die Notwendigkeit grenzüberschreitender „Gruppenverträge“ zu prüfen.

7 Vgl. EU-Verordnung Nr. 2157/2001; dazu ausführlich u.a. auch Hauschka (Entwicklungslinien, 1990) S. 94-103; Theisen (Konzern, 2000) S. 80-88; vgl. zur Verträglichkeit des deutschen Konzernrechts mit diesem Statut und der Integrierbarkeit der SE in das deutsche Konzernrecht Hommelhoff (Konzernrecht in der Europäischen Aktiengesellschaft, 2003). 
Die staatenübergreifende Gesamtgewinnermittlung setzt aber auch bei der Steueraufkommensverteilung abgestimmtes Verhalten der involvierten Staaten voraus. Dadurch wird der im Vorkapitel bereits aufgezeigte Interessenkonflikt innerhalb der staatenübergreifenden Unternehmensgruppe noch um die konfligierenden fiskalischen Interessen der betroffenen Steuerhoheiten erweitert. Die Steuerlastverteilung wird noch komplizierter, da sie nun auch den Konsens der um knappes Steueraufkommen konkurrierenden Steuerhoheiten voraussetzt ${ }^{1}$. Gelingt dieser schwierige Konsens, mag der unter Umständen wünschenswerte Wettbewerb der Systeme leiden ${ }^{2}$, hinter dem sich letztlich Verteilungskämpfe um Steueraufkommen verbergen, die einerseits zwischen den Unternehmensgruppen und den jeweiligen nationalen Steuerhoheiten und andererseits aber auch unter den einzelnen Steuerhoheiten geführt werden ${ }^{3}$. Das Problem der Steueraufkommensverteilung hat möglicherweise auch eine ethische Komponente, sofern auf eine Art zwischenstaatlicher Aufteilungsgerechtigkeit („inter-country equity ${ }^{64}$ ) abgestellt wird. Abgesehen davon, dass diese Gerechtigkeitskomponente in distributiver Hinsicht mit dem Gedanken z.B. eines Systemwettbewerbs kollidieren dürfte, lässt sie sich nicht mit dem dieser Arbeit zu Grunde liegenden Gerechtigkeitsverständnis von Aristoteles bzw. Thomas von Aquin vereinbaren ${ }^{5}$. Zudem ist die (Effizienz- wie auch Gerechtigkeits-)Beurteilung der Steueraufkommensverteilung, letztlich die grundsätzliche Beurteilung der grenzüberschreitenden Gruppenbesteuerung als solche ${ }^{6}$, nicht Untersuchungsgegenstand dieser Arbeit. Es bleibt die Feststellung, dass die Frage der Steueraufkommensverteilung bei einer grenzüberschreitenden Gewinnermittlung relevant wird

1 Hey (Einführung, 1999) S. K 25 kommt angesichts dieses Problems zu dem Ergebnis, die inter- bzw. multinationale Konzernbesteuerung sei deshalb noch gänzlich ungelöst. Vgl. bereits zu gegenwärtigen Problemen mit der Steueraufkommensverteilung in der EU Hey (Perspektiven, 2004) S. 198-203.

2 Vgl. Kap. II.2.1.2.3.

3 Vgl. Schneider (IAS als Besteuerungsgrundlage, 2003) S. 299; Schneider (Verrechnungspreise, 2003) S. 55; Schneider (Konzernrechnungslegung als internationale Gewinnsteuerbemessungsgrundlage, 2003) S. 658-660.

4 EU-Kommission (Company Taxation, 2001) S. 421. Vgl. die Gerechtigkeit als Postulat auf Individuen aber auch Jurisdiktionen beziehend Devereux (Debating Proposed Reforms, 2004) S. 80, der aber beides aus normativer Sicht für wenig hilfreich erachtet; Carlson/Galper (Water's Edge, 1984) S. 12; Mavraganis (Tax Harmonization, 1993) S. 223; Schäfer/Spengel (Profit Allocation, 2003) S. 6-7. Devereux/Pearson (Corporate Tax Harmonisation, 1989) S. 77-78 reduzieren diesen Gerechtigkeitsaspekt auf die politische Akzeptanz der betroffenen Staaten, die (eine) Voraussetzung einer grenzüberschreitenden Regulierung sein müsse.

5 So betrifft der dreidimensionale Gerechtigkeitsbegriff des Thomas von Aquin nur das Verhältnis der Individuen untereinander, des Gemeinwesens/Staates zu den Individuen und, umgekehrt, der Individuen zu ihrem Gemeinwesen/Staat, nicht aber der Staaten untereinander; vgl. Kap. II.2.2.3. Auch Schneider (Konzernrechnungslegung als internationale Gewinnsteuerbemessungsgrundlage, 2003) S. 662 fordert i.d.Zshg. eine „gerechte“ Aufschlüsselung des Gruppengewinns, die er aber mit Hinweis auf die auf (natürliche) Personen beschränkte Anwendbarkeit ethischer Normen (S. 665) wohl nur auf die betroffenen Unternehmen und die dahinter stehenden Individuen bezieht.

6 Vgl. hierzu insb. im EU-Kontext EU-Kommission (Company Taxation, 2001) mit vielen offenen Fragen; stellvertretend z.B. auch Devereux (Debating Proposed Reforms, 2004); Devereux/Pearson (Corporate Tax Harmonisation, 1989); Schäfer/Spengel (Profit Allocation, 2003); Sørensen (Company Tax Reform, 2004); Spengel (Internationale Unternehmensbesteuerung, 2003); s.a. Kap. IV.2.2. 
und durch ein wahrscheinlich schwieriges Verfahren der Konsensbildung gelöst werden muss. Für die konsolidierte steuerliche Gewinnermittlung ist nicht wichtig, wie, sondern nur, ob diese Frage überhaupt gelöst werden kann.

Die Verteilung des Steueraufkommens erfolgt bisher auf der Grundlage des Trennungsprinzips und bestehender Grenzen über die jeweiligen Einzelgewinnermittlungen. Dabei spielt die ,verursachungsgerechte“ Erfolgslokalisation nach Maßgabe des auch international gängigen Fremdvergleichsgrundsatzes (dealing at arm's length) und der dahinter stehenden Selbständigkeitsfiktion von Unternehmen und Unternehmensteilen' die zentrale, wenn auch viel kritisierte Rolle ${ }^{2}$. Bei der Gesamtgewinnermittlung einer grenzüberschreitend tätigen Unternehmensgruppe gelten die bereits gewonnenen Erkenntnisse: Entweder behält man die bisherige Einzelgewinnermittlung mit oder ohne Trennungsprinzip als Schattenveranlagung bei (direkte Methode) oder bedient sich der indirekten Methode einer geschlüsselten Steueraufteilung. Wenn hierzu ein Verteilungsschlüssel gefunden wird, der sämtliche Interessen der Unternehmensbeteiligten sowie Staaten zum Ausgleich bringt, erscheinen Vorteile bei der Durchführungseffizienz angesichts des Wegfalls der Schattenveranlagung offenkundig. Möglicherweise bietet sich hier eine Art Finanzausgleich wie zwischen den deutschen Bundesländern an ${ }^{3}$.

Angesichts des hohen Abstimmungsbedarfs auf zwischenstaatlicher Ebene erscheint die zweite Alternative eines multilateralen Kraftakts nur innerhalb eines eng kooperierenden Staatenbündnisses wie z.B. der EU realistisch. Abgestimmtes Verhalten zwischen den Staaten ist zwar weltweit beobachtbar, meist aber auf Lösungen der Doppelbesteuerungsproblematik in Form bilateraler Absprachen („Doppelbesteuerungsabkommen“) beschränkt ${ }^{4}$. Eine grenzüberschreitende Gruppenbesteuerung über Doppelbesteuerungsabkommen zu manifestieren, dürfte schon daran scheitern, dass fremde Staaten nicht ohne kompensierende Zugeständnisse auf ihr Besteuerungsrecht als Sitzstaat verzich-

1 Während das Trennungsprinzip bei Unternehmensgruppen schon im nationalen Kontext zu derartigen Korrekturmaßnahmen zwingt, ist im Falle grenzüberschreitender unternehmerischer Tätigkeit zudem neu, dass diese Maßnahmen hier auch innerhalb ein und desselben Steuersubjekts, also zwischen den verschiedenen Unternehmensteilen und Betriebsstätten greifen. Vgl. zu diesem Problem bereits Rasch (Vorschriften des Steuerrechts, 1972) S. G 68-G 69.

2 Vgl. dazu bereits Kapitel III.1.1.1. Auch die EU-Kommission sieht in dem Fremdvergleichsgrundsatz ein zentrales Investitionshemmnis im Binnenmarkt; vgl. dazu EU-Kommission (Company Taxation, 2001) S. 255-283; EU-Kommission (Strategie, 2001) S. 11.

3 Vgl. zu dieser Parallele bereits Beusch (Referat, 1972) S. Q 45; ähnlich Salzberger (Konzernunternehmung, 1994) S. 179-181; Ende der 1980er Jahre ist ein „Fiscal Clearing“ zur Umverteilung des Steueraufkommens aus der Umsatzsteuer diskutiert worden; vgl. Hansjürgens (Fiscal Clearing, 1990).

4 Vgl. zu den Grundzügen und Rechtsquellen des Internationalen Steuerrechts ausführlicher Bayer (Steuerlehre, 1997) Tz. 1911-1949; vgl. zu der Anwendung auf das konkrete Problem der Doppelbesteuerung bei grenzüberschreitender unternehmerischer Tätigkeit Jacobs (Internationale Unternehmensbesteuerung, 2002) S. 36-84; Salzberger (Konzernunternehmung, 1994) S. 66-70; Scheffler (Besteuerung der grenzüberschreitenden Unternehmenstätigkeit, 2002) S. 57-153. Vgl. zu den entsprechenden Bemühungen auf EU-Ebene Kap. IV.1.1 und IV.2. 
ten $^{1}$. Zudem wäre eine Vielzahl bilateraler Abkommen wenig durchführungseffizient. Die EU verfügt demgegenüber bereits heute, nicht nur im Steuerrecht, über eine Fülle multilateraler Abkommen und deutet die notwendige Einigungsbereitschaft zumindest an. Das abgestimmte Verhalten der betroffenen EU-Mitgliedstaaten ist aber auch hier zwingend erforderlich. Dies betrifft steuerliche und gesellschaftsrechtliche Aspekte, insbesondere aber auch die Frage der Erfolgslokalisation zwecks Steuerlast- bzw. -aufkommensverteilung. Eine entsprechende Basis dürfte nach derzeitigem Rechtsstand noch nicht gegeben sein. Aber selbst wenn dies künftig gelänge, entstünde nur ein größerer, aber kein umfassender Raum der Steuerautonomie, der letztlich keine vollwertige Einheitsbesteuerung aller Unternehmensgruppen sicherstellen könnte. Zwischen den innerhalb und außerhalb der EU angesiedelten Gliedteilen der Unternehmensgruppe verliefen weiterhin fiskalische Grenzen, so dass ein Teil der Gruppe immer noch dritten einzelstaatlichen Steuerhoheiten außerhalb der EU unterläge. Letztlich scheint damit nur eine Kombination aus erster und zweiter Alternative denkbar, bei der aus einer Unternehmensgruppe - wieder mit den Nachteilen von Trennungsprinzip und Fremdvergleich - eine „EU-Gruppe“ herausgeschnitten wird.

\section{Zwischenergebnis}

In Kapitel III ist deutlich geworden, dass eine konsolidierte steuerliche Gewinnermittlung aus dem Spannungsverhältnis normativer Anforderungen und rechtlicher Gegebenheiten resultiert. Über die Konsolidierung wird das rechtsformorientierte Trennungsprinzip in die ökonomisch fundierte Einheitstheorie überführt, nach der Unternehmensgruppen als Einheit institutionell und unabhängig von ihrer Gesellschaftersphäre besteuert werden. Aber auch eine einheitstheoretisch fundierte Gesamtgewinnermittlung bleibt bei gegebener Rechtsrealität immer auch von der rechtlichen Vielheit der Unternehmensgruppe geprägt.

Dem letzten Aspekt hat sich das vorangegangene Kapitel in besonderer Weise gewidmet. Am Beispiel der konkreten deutschen Rechtsordnung ist aufgezeigt worden, dass das rechtsformorientierte Trennungsprinzip die steuerliche Gewinnermittlung dominiert und hiervon allenfalls partielle Ausnahmen existieren. Daran ändern auch der aktienrechtliche Konzerntatbestand und die handelsrechtliche (rein informationsorientierte) Konzernrechnungslegung wenig, die bisher weitgehend ohne materiell-rechtliche Konsequenzen geblieben sind. Interessant erscheint indes die Betrachtung der Mitunternehmerbesteuerung, deren Konzept der steuerlichen Gewinnermittlung durch die feh-

1 Vgl. Herzig/Wagner (Zukunft der Organschaft, 2005) S. 8; Schneider (IAS als Besteuerungsgrundlage, 2003) S. 302; Sørensen (Company Tax Reform, 2004) S. 95. Allerdings könnte ein gegenseitiges Anerkennen der jeweiligen Gruppenbesteuerung eine erste Lösung sein; vgl. dazu auch Kap. V.2.2.1.3. In Kap. III.2.2 und IV.1.1 wird angedeutet, dass mit der Anrechnungs- oder Freistellungsmethode auch unilaterale Maßnahmen existieren, die für den heimischen Fiskus aber mit Aufkommensnachteilen einhergehen; vgl. deshalb kritisch Flume (Referat, 1972) S. Q 8. 
lende Steuersubjektivität der Personengesellschaft in eine gewisse Nähe zur Konsolidierung rückt.

Die rechtliche Vielheit der Unternehmensgruppe geht mit weiteren Konsequenzen einher, die sich auch auf die konsolidierte steuerliche Gewinnermittlung auswirken. Am fortgeführten Beispiel der deutschen Rechtsordnung ist deutlich geworden, dass die rechtlich separierte Unternehmung (Unternehmungsgruppe) im Vergleich zur Einheitsunternehmung mit spezifischen Risiken für die Vertragspartner aller Unternehmen einhergeht. Da es letztlich nicht Ziel des Steuerrechts, sondern, wenn überhaupt, nur des Gesellschaftsrechts sein kann, Vertragsbeteiligte wie z.B. Minderheiten oder Gläubiger vor gruppenspezifischen Risiken zu schützen, muss die Gruppen- bzw. Einheitsbesteuerung auf der Basis einer konsolidierten Gesamtgewinnermittlung „lediglich“ sicherstellen, dass eine gruppeninterne Erfolgslokalisation die Vertragspartner vor zusätzlichen, konsolidierungsspezifischen Vermögensschäden schützt. Hierfür bedarf es entweder einer Schattenveranlagung in Form einer parallelen Einzelgewinnermittlung oder einer indirekten Schlüsselung des konsolidierten Gesamtgewinns und der daraus resultierenden Steuerkonsequenzen auf die Unternehmen der Gruppe. Letztere hat möglicherweise den Reiz, mit der einheitstheoretischen Vorstellung einer Gruppenbesteuerung besser zu harmonieren und dabei noch Vorteile bei der Durchführungseffizienz aufzuweisen.

Zusätzlich zu den gruppenspezifischen Besonderheiten hat die grenzüberschreitende Gesamtgewinnermittlung auch fiskalische Grenzen zu berücksichtigen, die den steuerlichen Konsolidierungskreis territorial beschränken und dem einheitstheoretischen Grundprinzip widersprechen. Wenn der Konsolidierungskreis nicht auf das jeweilige Inland beschränkt werden soll, bedarf es einer weitgehenden, multilateralen Abstimmung der betroffenen Steuerhoheiten, die derzeit selbst über das in der EU vorhandene Ausmaß hinausgeht. Diese Abstimmung schließt eine wie auch immer geartete Aufteilung des Steueraufkommens mit ein, die z.B. ebenfalls über eine indirekte Schlüsselung erfolgen könnte. 


\section{Kapitel IV}

\section{Konsolidierte steuerliche Gewinnermittlung in der EU}

Bisher sind die grundsätzlichen Anforderungen an die steuerliche Gewinnermittlung formuliert (Kapitel II) und mit wichtigen rechtstatsächlichen Nebenbedingungen konfrontiert worden (Kapitel III). Als Ergebnis konnte dabei festgehalten werden, dass die Besteuerung von Unternehmensgruppen im Spannungsfeld von wirtschaftlicher Einheit und rechtlicher Vielheit angesiedelt ist. Dieses Spannungsfeld hat die konsolidierte steuerliche Gewinnermittlung in ihrer Ausgestaltung zu berücksichtigen.

Diese Ausgestaltung der konsolidierten steuerlichen Gewinnermittlung rückt nun in den Mittelpunkt. Bevor jedoch die Eignung der Konsolidierungsvorschriften der IFRS für Zwecke der steuerlichen Gewinnermittlung im Detail analysiert wird (Kapitel V), soll in einem ersten Schritt der Status Quo der Gruppenbesteuerung in den Mitgliedstaaten der EU beleuchtet werden. Dies erscheint schon vor dem Hintergrund der europäischen Dimension der hier interessierenden Forschungsfrage gerechtfertigt ${ }^{1}$. Bei dieser Analyse geltender Besteuerungssysteme soll die Frage im Vordergrund stehen, ob es bereits Erfahrungen mit einer wie auch immer gearteten Gesamtgewinnermittlung im Spannungsfeld normativer Anforderungen und rechtlicher Restriktionen gibt. So ist bisher nur am Beispiel des deutschen Steuerrechts gezeigt worden, dass in der Unternehmensbesteuerung insbesondere in Gestalt der körperschaftsteuerlichen Organschaft zumindest partielle Ausnahmen vom strengen Trennungsprinzip existieren. Um weitere Erkenntnisse für die Ausgestaltung der konsolidierten steuerlichen Gewinnermittlung zu generieren, interessieren dabei insbesondere diejenigen Besteuerungssysteme, die sich noch stärker vom Trennungsprinzip lösen und sich noch mehr der Einheitstheorie bzw. der Einheitsbesteuerung zuwenden. Diese gilt es zu identifizieren und in ihrer Ausgestaltung vorzustellen (Kapitel IV.1), wobei die eigentliche normative Beurteilung dieser Regeln erst in Kapitel $\mathrm{V}$ angesiedelt ist ${ }^{2}$.

Innerhalb des folgenden Kapitels werden aber nicht nur die geltenden Besteuerungssysteme auf Ebene der Mitgliedstaaten identifiziert. Es geht auch darum, die Bestrebungen der EU-Kommission für eine künftige Unternehmensbesteuerung auf der Basis konsoli-

1 Von einer Ausweitung dieser Untersuchung auf außereuropäische Staaten wurde abgesehen. Insbesondere in den USA, aber z.B. jüngst auch in Australien, existieren Gruppenbesteuerungssysteme, die auf einer Art steuerlicher Konsolidierung beruhen; vgl. dazu fur die USA u.a. Riecker (Unitary Taxation, 1997) S. 133-186; Salzberger (Konzernunternehmung, 1994) S. 123-128; Salzberger (Unitary Taxation, 1999); Weber (USA, 1979); Wudernitz (USA, 1996); kurz zur Historie auch Dahlberg (Aggregate vs. Entity, 1987) S. 548-552; für Australien u.a. Addison (Consolidation, 2002); Northeast (group, 2002); Northeast (Coming together, 2003); u.a. auch zu diesen beiden Staaten Endres (Konzernbesteuerung, 2003) S. 462-477.

2 So erfolgt der wertende Abgleich mit dem normativen Rahmen dieser Arbeit unter Kap. V, um gleiche oder ähnliche Sachverhalte nicht an zwei Stellen zu analysieren. 
dierter steuerlicher Gewinnermittlungen im Detail zu beleuchten (Kapitel IV.2). Mit diesem Besteuerungsvorhaben will die EU ihre supranationale Identität nutzen, um grenzüberschreitende Unternehmensgruppen de lege ferenda zumindest auf Unionsebene einer (partiellen) Einheitsbesteuerung zuzuführen.

\section{Besteuerung der Unternehmensgruppen auf EU-Mitgliedstaatenebene (de lege lata)}

\section{1 Überblick und Systematisierung}

Ähnlich der deutschen Situation ist auch das Körperschaftsteuerrecht anderer Mitgliedstaaten der EU (per 1. Januar 2004) ${ }^{1}$ durch mehr oder minder große Abweichungen vom Trennungsprinzip geprägt ${ }^{2}$. Obwohl das Trennungsprinzip und damit die Einzelgewinnermittlung dominiert, gibt es kein nationales Steuersystem, dass das Trennungsprinzip kompromisslos auf Unternehmensgruppen anwendet. Das liegt schon darin begründet, dass in jedem EU-Mitgliedsstaat ein System zur Vermeidung oder Abmilderung der Mehrfachbesteuerung ausgeschütteter Gewinne etabliert worden ist. Dies gilt nicht nur für Gewinnausschüttungen innerhalb der nationalen Grenzen, sondern auch für staatenübergreifende Ausschüttungen. Grundlage hierfür sind entweder bilaterale Doppelbesteuerungsabkommen oder supranationales Recht. So sieht die inzwischen EU-weit in nationales Recht transformierte Mutter-Tochter-Richtlinie von 1990 (90/435/EWG) die Freistellungs- oder (indirekte) Anrechnungsmethode bei Dividendenausschüttungen der Gesellschaften anderer Mitgliedstaaten vor $^{3}$. Angesichts der mit diesen beiden Methoden verbundenen Vorstellung von Entscheidungsneutralität in Bezug auf Kapitalimport(Sitzlandneutralität) bzw. Kapitalexportneutralität (Quellenlandneutralität) ist somit keine Einigung erzielt worden, so dass beide Konzepte in der EU weiterhin aufeinan-

1 Diese Untersuchung bezieht sich auf die 15 Staaten, die zum 1. Januar 2004 Mitglied der EU waren. Die 10 neuen EU-Mitgliedstaaten per 1. Mai 2004 sind nicht mehr berücksichtigt worden; vgl. zu ihrer allgemeinen steuerlichen Situation im Überblick Jacobs et al. (New EU Member States, 2003). Vgl. überblickartig zur historischen Entwicklung der Besteuerungsmodelle in den EU-Staaten Grotherr (Konzernbesteuerungssysteme, 1996) S. 357-358; Lamb (group, 1995) S. 52-56.

3 Vgl. Art. 1 Abs. 1, Art. 4 Abs. 1 der Mutter-Tochterrichtlinie. Während die ausländische Steuer bei der Anrechnungsmethode voll oder teilweise von der Inlandssteuer abgezogen wird, knüpft die Freistellungsmethode nicht beim Steuerbetrag, sondern bei der Bemessungsgrundlage an, in dem sie das ausländische Einkommen von der inländischen Besteuerung voll oder teilweise freistellt. Aus deutscher Sicht greift an dieser Stelle insb. § 8b Abs. $1 \mathrm{KStG}$ als unilaterale Maßnahme, wonach Gewinnausschüttungen auch von ausländischen Körperschaften von der Körperschaftsteuer freistellt werden. Das bisher in allen von Deutschland geschlossenen Doppelbesteuerungsabkommen enthaltene internationale Schachtelprivileg, das ebenfalls - unter bestimmten Voraussetzungen - die Freistellung ausländischer Dividenden vorsieht, hat dadurch an Bedeutung verloren. Vgl. weiterfuihrend u.a. Jacobs (Internationale Unternehmensbesteuerung, 2002) S. 11-35, 84; Scheffler (Besteuerung der grenzüberschreitenden Unternehmenstätigkeit, 2002) S. 57-82, 144-146. Vgl. zum Prinzip der indirekten Steueranrechnung genauer Knobbe-Keuk (Unternehmenssteuerrichtlinien, 1992) S. 337-338. 
derprallen ${ }^{1}$. Auch setzt die in ihrer Wirkung zwangsläufig auf den EU-Raum beschränkte Richtlinie hierbei eine Kapitalbeteiligung von mindestens 20\% (ab 1. Januar 2005) voraus. Den nationalen Regulierungssubjekten ist es aber über Mitgliedstaatenwahlrechte gestattet, die Voraussetzungen einer Unternehmensverbindung $\mathrm{zu}$ modifizieren. So können sie z.B. anstelle der Kapitalbeteiligung auf Stimmrechte abstellen, eine Mindestbeteiligungsdauer vorschreiben oder auch eine weiter reduzierte Quote akzeptieren ${ }^{2}$.

$\mathrm{Zu}$ einer vollumfänglichen Einheitsbesteuerung bedarf es jedoch mehr als nur der Vermeidung der Mehrfachbesteuerung bei Dividendenausschüttungen. Unter Verwendung der in Kapitel III.1 gewonnenen Erkenntnisse unterscheidet sich eine konsolidierte Gesamtgewinnermittlung nach dem Einheitsprinzip insbesondere durch die in Abb. 10 aufgeführten Voraussetzungen von einer isolierten Einzelgewinnermittlung ${ }^{3}$.

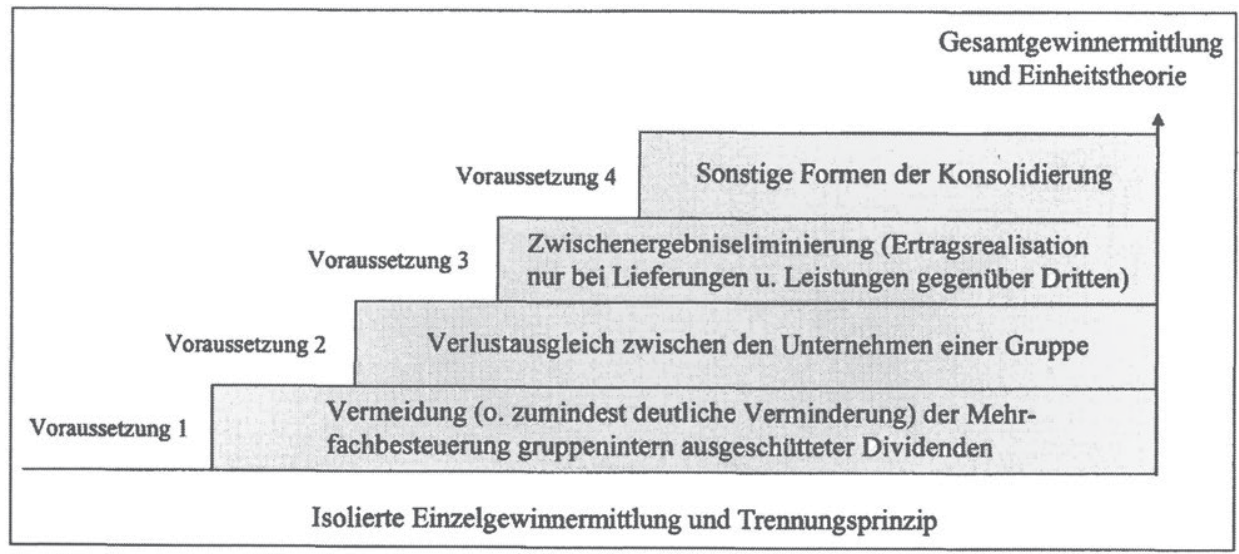

Abb. 10: Voraussetzungen einer konsolidierten Gesamtgewinnermittlung

Unter Verwendung dieses Systems von Voraussetzungen können die Gewinnermittlungssysteme der EU-Mitgliedstaaten systematisiert werden ${ }^{4}$. Wie in Tab. 1 zu erkennen

1 Die Freistellungsmethode entspricht eher der Kapitalimportneutralität, die Anrechnungsmethode der Kapitalexportneutralität; vgl. Gandenberger (Kapitalexportneutralität versus Kapitalimportneutralität, 1983) S. 3; s.a. Kap. II.2.1.2.3. Ihre konkrete Anwendung in der EU verdeutlicht Jacobs (Internationale Unternehmensbesteuerung, 2002) S. 165; Scheuchzer (Konzernbesteuerung, 1994) S. 191-196.

2 Vgl. Art. 1 Abs. 1, Art. 3 Abs. 1 und Abs. 2 der Mutter-Tochterrichtlinie. Auf die Möglichkeit, auch die Beteiligungsquote abzusenken (oder auch mittelbare Beteiligungen mit einzubeziehen), verweisen z.B. Jacobs (Internationale Unternehmensbesteuerung, 2002) S. 164; Knobbe-Keuk (Unternehmenssteuerrichtlinien, 1992) S. 338-339. Vgl. zu den ab Januar 2005 in Kraft tretenden Änderungen dieser Richtlinie Spengel (Unternehmensbesteuerung in der EU, 2004) S. 128-129. Die notwendige Mindestbeteiligungsquote wird ab 1.1.2005 stufenweise herabgesetzt und erreicht am 1.1.2009 10\%.

3 Vgl. ähnlich das nur dreistufige Unterscheidungssystem von Scheuchzer (Konzernbesteuerung, 1994) S. 53; ein komplexeres, aber weniger hierarchisches System benutzt Lamb (group, 1995) S. 38-41.

4 Nach Rheinstein (Rechtsvergleichung, 1987) S. 12 ist die ,übernationale Systematik“ eine wesentliche Teilaufgabe der internationalen Rechtvergleichung. 
ist, verbleibt das Körperschaftsteuerecht von zwei Staaten (Belgien' und Griechenland) bei der ersten Voraussetzung und lässt bis auf die Vermeidung bzw. Verminderung ${ }^{2}$ von Doppel- und Mehrfachbesteuerungen gruppenintern ausgeschütteter Dividenden keine weitergehenden Abweichungen vom Trennungsprinzip zu. In dem Körperschaftsteuerrecht sechs weiterer Staaten (Dänemark, Deutschland, Finnland, Luxemburg, Österreich, Schweden) wird darüber hinaus die Verlustausgleichsmöglichkeit innerhalb der Unternehmensgruppe vorgesehen ${ }^{3}$. Vier Staaten (Dänemark, Deutschland, Luxemburg, Österreich ${ }^{4}$ ) bedienen sich dabei des Zurechnungskonzeptes, in dessen Rahmen das zu versteuernde Einkommen aus den weiterhin isolierten Einzelgewinnermittlungen der Unternehmen sämtlich der Obergesellschaft zugerechnet wird. Die Obergesellschaft wird damit auch Anknüpfungspunkt für die steuerliche Zusammenveranlagung der Gruppe $^{5}$. In Finnland und Schweden existiert hingegen keine Zusammenveranlagung. Die einzeln veranlagten Unternehmen können hier durch Gewährung einer Ausgleichszahlung eigene Verluste auf andere, gewinnerzielende Unternehmen der Gruppe übertragen $^{6}$.

Es verbleiben weitere sieben Staaten (Frankreich, Irland, Italien ${ }^{7}$, Niederlande, Portugal, Spanien, Vereinigtes Königreich ${ }^{8}$ ), deren Gewinnermittlungssysteme über die reine Verlustverrechnung hinausgeht. Drei dieser Staaten beschränken sich dabei auf eine reduzierte Form der Zwischenergebniseliminierung. Im Vereinigten Königreich und in Irland werden - ähnlich der Situation in Finnland und Schweden - gruppenspezifische

1 Allerdings soll in Belgien nach einer Absichtserklärung i.R.d. Steuerreform vom 24.12.2002 über einen Zeitrum von mehreren Jahren eine Gruppenbesteuerung eingeführt werden; vgl. Endres (Konzernbesteuerung, 2003) S. 461. Entsprechende Vorüberlegungen gehen zurück bis in die 1980er Jahre; vgl. Scheuchzer (Konzernbesteuerung, 1994) S. 162.

2 Wie in Deutschland sieht auch das belgische, italienische und französische Abzugssystem nur eine 95\%ige Steuerfreiheit empfangener Dividenden (in Belgien und Frankreich gilt dies auch für inländische Dividenden) und demnach eine wenn auch geringe Doppelbelastung vor; vgl. dazu Jacobs (Internationale Unternehmensbesteuerung, 2002) S. 166-167.

3 Dabei handelt es sich um Verluste, die während der Zugehörigkeit zur Gruppe angefallen sind. Divergierende Sonderregeln existieren für Verluste, die in einem Unternehmen vor dieser Zeit angefallen sind, und für den Verlustrücktrag sowie -vortrag in die Zeit vor oder nach der Gruppenzugehörigkeit; vgl. zu den national unterschiedlichen Sonderregeln FEE (Survey on Group Taxation, 2001) S. 20-24.

4 Auch die ab 2005 neu greifenden Gruppenbesteuerung nach $\S 9 \mathrm{KStG}$ (Österreich) ist - wie die vorherige Organschaft auch - als Zurechnungskonzept ausgestaltet; vgl. hierzu eingehender Ernst \& Young (Gruppenbesteuerung, 2004); Gassner (Gruppenbesteuerung, 2004).

5 Die Zusammenveranlagung geht mit der Abgabe einer gruppenorientierten (gemeinsamen) Steuererklärung meist durch die Obergesellschaft einher. Dies bedeutet jedoch nicht zwingend, dass die anderen Unternehmen nicht ebenfalls Steuererklärungen abgeben müssen.

6 Bei dem leistenden Unternehmen stellt die Ausgleichszahlung eine Betriebsausgabe dar, bei dem empfangenden Unternehmen (Verlustunternehmen) eine Betriebseinnahme; vgl. Grotherr (Konzernbesteuerungssysteme, 1996) S. 359-360, 362, 370.

7 Die italienische „consolidato fiscale“ gilt erst ab 2004; vgl. hierzu weiterführend Dörr (Italien, 2004); o.V. (Italienische Steuergesetzgebung, 2004); s.a. kurz Endres (Konzernbesteuerung, 2003) S. 461.

8 Die Bezeichnung „Vereinigtes Königreich“ soll hier entsprechend der englischsprachigen Vorgabe abkürzend für das „Vereinigte Königreich von Großbritannien und Nordirland“" verwendet werden. 
Ausnahmen vom Trennungsprinzip im Rahmen einer Einzelveranlagung zugelassen. Diese reichen aber über die gruppeninterne Verlustübertragung hinaus und umfassen auch Elemente der Zwischenergebniseliminierung ${ }^{1}$. So können hier Wirtschaftsgüter des Anlagevermögens innerhalb der Unternehmensgruppe steuerneutral zu Buchwerten übertragen werden ${ }^{2}$. Auch das italienische Zurechnungssystem sieht wahlweise steuerliche Neutralität für bestimmte Transaktionen zwischen den Unternehmen der Gruppe vor ${ }^{3}$.

Etwas weiter geht das französische Besteuerungsmodell, das wie das italienische auf einer Zusammenveranlagung beruht. Hiernach wird das isoliert ermittelte Einkommen der Unternehmen erst einmal der Obergesellschaft zugerechnet, ehe Zwischenergebnisse gruppeninterner Lieferungs- und Leistungsbeziehungen anschließend eliminiert werden. Zwischenergebnisse werden also in einem ersten Schritt unter Verwendung des Fremdvergleichsgrundsatzes realisiert, um sie dann in einem zweiten Schritt auf Ebene der Obergesellschaft wieder zu neutralisieren ${ }^{4}$. Während sich interne Leistungsbeziehungen in ihren gegenläufigen Wirkungen regelmäßig auf Gruppenebene neutralisieren, kommt letztlich nur die Lieferungsbeziehung für die Korrektur in Frage. Aus Praktikabilitätsgründen wird die Zwischenergebniseliminierung aber auch hier auf Wirtschaftsgüter des Anlagevermögens beschränkt. Zudem sieht das französische Körperschaftsteuerrecht bestimmte Bereinigungen vor, die in die Richtung einer Schuldenkonsolidierung deuten.

Obwohl sich das französische Besteuerungsmodell schon weit vom Trennungsprinzip entfernt, handelt es sich immer noch um ein Zurechnungskonzept, das aber im Sinne der Einheitstheorie modifiziert worden ist. Eine konsolidierte steuerliche Gewinnermittlung im eigentlichen Sinne findet sich hingegen in Spanien und Portugal. Die Systeme beider Staaten sehen eine konsolidierte steuerliche Gewinnermittlung im realtypischen Sinne vor, bei der die isolierten Einzelgewinnermittlungen zusammengefasst und einer Konso-

1 Dies sind die Steuerfreiheit auf gruppenintern ausgeschüttete Gewinne (group income), die Übertragung von Steuerguthaben auf andere Unternehmen der Gruppe (surrender of ACT), die Verlustverrechnung (group relief), die Übertragung von Reinvestitionsrücklagen auf andere Unternehmen der Gruppe sowie die Zwischenergebniseliminierung bei gruppeninterner Übertragung von Anlagegütern (intra-group transfers of capital assets); vgl. für das Vereinigte Königreich insb. Part IV (Sec. $209 \mathrm{ff}$.), Part VI (Sec. $247 \mathrm{ff}$.) und insb. Part X (Sec. $402 \mathrm{ff}$.) ICTA (Income and Corporation Taxes Act) sowie Sec. $170 \mathrm{ff}$. TCGA (Taxation of Chargeable Gains Act) und für die vergleichbare Situation in Irland insb. Sec. 105 ff. CTA (Corporation Tax Act); dazu u.a. auch Geiger (Großbritannien, 2002); Scheuchzer (Konzernbesteuerung, 1994) S. 105-120.

2 Vgl. Sec. 171 TCGA, Sec. 129-139 CTA; s.a. Geiger (Großbritannien, 2002) S. 399; Holme (Groups of Companies, 1989) S. 629.

3 Vgl. ohne weitere Detailinformationen o.V. (Italienische Steuergesetzgebung, 2004) S. 6-7.

4 Vgl. zur Ergebnisermittlung i.R.d. „nouveau régime de l'intégration fiscale“ Art. 209, 223 A-U (section VIII: groupes de sociétés) CGI (Code Général des Impôts); erläuternd dazu Grotherr (Besteuerung nationaler und grenzüberschreitender Konzerne, 1994) S. 193-216; Scheuchzer (Konzernbesteuerung, 1994) S. 92-99. 
lidierung zugeführt werden. Diese Konsolidierungsmaßnahmen gehen über die Zwischenergebniselimination bei gruppeninternen Lieferungen und Leistungen hinaus und umfassen insbesondere auch die Kapital- sowie die Schuldenkonsolidierung ${ }^{1}$.

\begin{tabular}{|c|c|c|c|c|c|}
\hline & Bezeichnung & Vor. 1 & Vor. 2 & Vor. 3 & Vor. 4 \\
\hline Belgien & - & $\mathrm{X}$ & & & \\
\hline Dänemark & Sambeskatning & $\mathrm{X}$ & $\mathrm{X}$ & & \\
\hline Deutschland & Organschaft & $\mathrm{X}$ & $\mathrm{X}$ & & \\
\hline Finnland & "group contribution“ & $\mathrm{X}$ & $\mathrm{X}$ & & \\
\hline Frankreich & $\begin{array}{l}\text { régime de l'intégration fiscale; } \\
\text { (régime du bénéfice consolidé) }\end{array}$ & $\mathrm{X}$ & $\mathrm{X}$ & $\mathrm{X}^{\mathrm{AV}}$ & $(\mathrm{X})$ \\
\hline Griechenland & - & $\mathrm{X}$ & & & \\
\hline Irland & $\begin{array}{l}\text { group relief; group dividends; } \\
\text { group payments; group gains } \\
\text { relief }\end{array}$ & $\mathrm{X}$ & $\mathrm{X}$ & $\mathrm{X}^{\mathrm{AV}}$ & \\
\hline Italien & $\begin{array}{l}\text { consolidato fiscale naziona- } \\
\text { le/mondiale }\end{array}$ & $\mathrm{X}$ & $\mathrm{X}$ & $(\mathrm{X})$ & \\
\hline Luxemburg & intégration fiscale & $\mathrm{X}$ & $\mathrm{X}$ & & \\
\hline Niederlande & fiscale eenheid & $\mathrm{X}$ & $\mathrm{X}$ & $\mathrm{X}$ & $\mathrm{X}$ \\
\hline Österreich & Gruppenbesteuerung & $\mathrm{X}$ & $\mathrm{X}$ & & \\
\hline Portugal & $\begin{array}{c}\text { regime de tributação pelo lucro } \\
\text { consolidado }\end{array}$ & $\mathrm{X}$ & $\mathrm{X}$ & $\mathrm{X}$ & $\mathrm{X}$ \\
\hline Schweden & „group contribution“ & $\mathrm{X}$ & $\mathrm{X}$ & & \\
\hline Spanien & $\begin{array}{l}\text { régimen de declaratión conso- } \\
\text { lidada }\end{array}$ & $\mathrm{X}$ & $\mathrm{X}$ & $\mathrm{X}$ & $\mathrm{X}$ \\
\hline $\begin{array}{l}\text { Vereinigtes } \\
\text { Königreich }\end{array}$ & $\begin{array}{l}\text { group relief; capital gains } \\
\text { group; group income }\end{array}$ & $\mathrm{X}$ & $\mathrm{X}$ & $\mathrm{X}^{\mathrm{AV}}$ & \\
\hline \multicolumn{6}{|c|}{\begin{tabular}{|l|l|l} 
EU-Mitgliedstaaten zum 1.1.2004 & Vor. $=$ Voraussetzung; $\mathrm{AV}=$ beschrănkt auf das Anlagevermögen
\end{tabular}} \\
\hline
\end{tabular}

Tab. 1: Gruppenbesteuerungssysteme in den EU-Mitgliedstaaten

Quelle: Eigene Rechtsanalyse, auch unter Verwendung von Beusch (Besteuerung der Konzerne, 1978); Dörr (Italien, 2004); Endres (Internationaler Vergleich, 2003); Endres (Konzernbesteuerung, 2003); Ernst \& Young (Gruppenbesteuerung, 2004); FEE (Survey on Group Taxation, 2001); Grotherr (Konzernbesteuerungssysteme, 1996); Grotherr (Besteuerung nationaler und grenzüberschreitender Konzerne, 1994) S. 173-322; Müller (Konzernbesteuerung, 1991) S. 53-120; Reis (Körperschaftsbesteuerung des Konzerns, 1996) S. 185-208; Salzberger (Konzernunternehmung, 1994) S. 109-122; Scheuchzer (Konzernbesteuerung, 1994) S. 55-167.

In die Richtung einer Gesamtgewinnermittlung im idealtypischen Sinne orientiert sich indes das steuerliche Gewinnermittlungssystem in den Niederlanden. Hier wird eine fiktive Fusion unterstellt, so dass Vermögen und Schulden sämtlicher Unternehmen der Gruppe der Obergesellschaft zugerechnet werden und die Geschäfte dieser Unterneh-

1 Vgl. als spanische Regulierungsgrundlage insb. Real Decreto 1414/1977 und Orden de 15 de julio de 1982; zu Portugal insb. Art. 59 IRC (Imposto sobre o Rendimento das Pessoas Colectivas). 
men als solche der Obergesellschaft gelten ${ }^{1}$. Dabei wird nicht mehr explizit eine Einzelgewinnermittlung vorausgesetzt, sondern eine originäre Gesamtgewinnermittlung 2 . Zwischenerfolge werden demnach gar nicht mehr realisiert und brauchen somit auch nicht eliminiert zu werden. Damit ist das Körperschaftsteuerrecht der Niederlande das einzige in der EU, in dem der Fremdvergleichsgrundsatz in der Gruppenbesteuerung keine Rolle mehr spielt. Konsolidierungsschritte bleiben dabei weiterhin für die steuerliche Eröffnungsbilanz der Gruppe oder für die spätere (Des-)Integration einzelner Unternehmen notwendig.

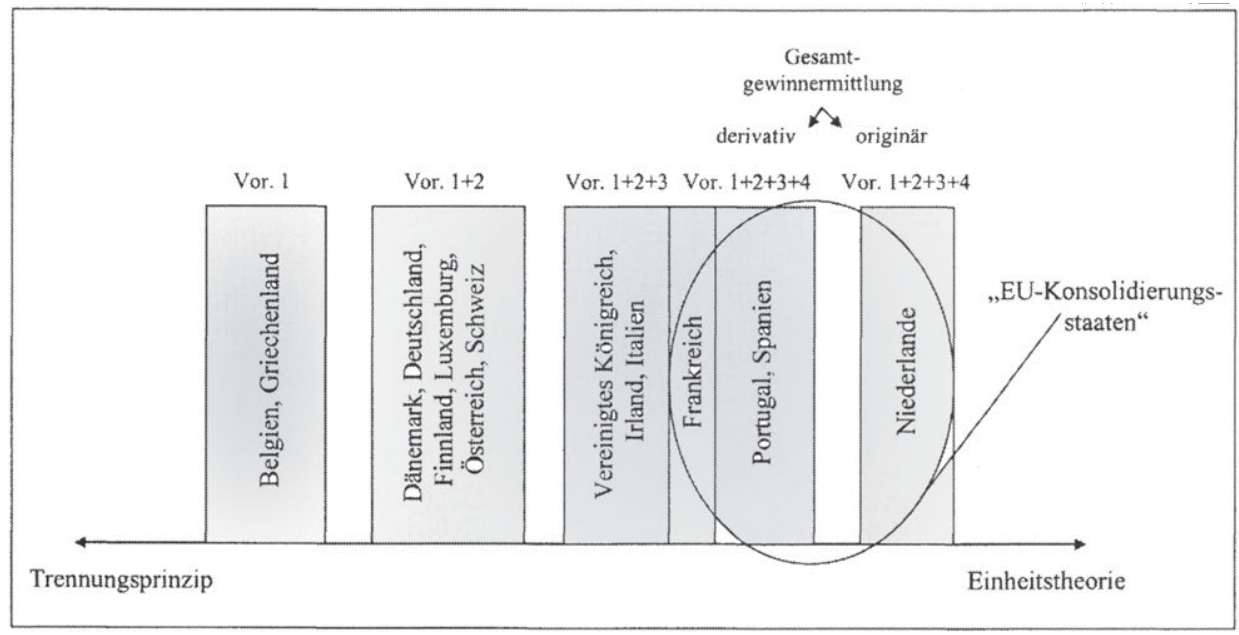

Abb. 11: Gruppenbesteuerungssysteme in der EU zwischen Trennungsprinzip und Einheitstheorie

Wenn abschließend versucht wird, die Gewinnermittlungssysteme der 15 EUMitgliedstaaten nach den jeweils erfüllten Voraussetzungen zusammenzufassen, bietet sich die in Abb. 11 dargestellte Zuordnung an. Hiernach bilden Belgien und Griechenland eine erste Kategorie, die bis auf die Vermeidung oder Verminderung der Doppelbelastung ausgeschütteter Dividenden keinerlei Abweichungen von einer ansonsten isolierten Einzelgewinnermittlung vorsieht. Die zweite Kategorie (Dänemark, Deutschland, Finnland, Luxemburg, Österreich, Schweden) umfasst diejenigen Staaten, deren Kör-

1 Vgl. Art. 15 Par. 1 Satz 1 Wet Vpb (Wet op de vennootschapsbelasting): ,alsof er één belastingpflichtige is, in die zin dat de werkzaamheden en het vermogen van de dochtermaatschappij deel uitmaken van de werkzaamheden en het vermogen van de moedermaatschappij. ... De belastingpflichtigen tezamen worden in dat geval aangemerkt als fiscale eenheid“; sämtliche Regulierungsgrundlagen der „fiscale eenheid“ sind in Art. 15-15aj Wet Vpb zusammengefasst; dazu Geiger (Konzept der fiskalen Einheit, 2002) S. 362; Grotherr (Besteuerung nationaler und grenzüberschreitender Konzerne, 1994) S. 267, 274; Grotherr (Konzernbesteuerungssysteme, 1996) S. 361; Scheuchzer (Konzernbesteuerung, 1994) S. 59.

2 Grotherr (Konzembesteuerungssysteme, 1996) S. 361 spricht hier von einer „originären Konzerngesamtergebnisermittlung"; rechtlich bleibt die Steuersubjektidentität der einbezogenen Unternehmen indes weiterhin erhalten; vgl. Kap. IV.1.2.4. 
perschaftsteuerrecht darüber hinaus einen unternehmensübergreifenden Verlustausgleich innerhalb der Gruppe gewährleistet. Wenn damit auch noch keine Gesamtgewinnermittlung gegeben ist, so kann doch zumindest von einer Art „Verlustausgleichsgemeinschaft" ${ }^{\text {"1 }}$ gesprochen werden. Ein erster Schritt in Richtung Gesamtgewinnermittlung ist dann bei der dritten Kategorie (Irland, Italien, Vereinigtes Königreich) zu beobachten, innerhalb derer Zwischenerfolge zumindest ansatzweise neutralisiert werden. Sehr viel deutlicher ist der Schritt in Richtung Gesamtgewinnermittlung in den französischen, spanischen und portugiesischen Systemen, bei denen insbesondere die beiden letztgenannten als vollständige Konsolidierungsmodelle ausgestaltet sind. Diese vierte Kategorie wird in der Konsequenz nur noch durch die originäre Gesamtgewinnermittlung der „fiscale eenheid“ in den Niederlande übertroffen, die auch eine eigene Kategorie bilden soll.

\subsection{Rechtsvergleichende Gegenüberstellung existierender Konsolidierungs- vorschriften}

Um konkretere Hinweise auf die Ausgestaltung bestehender Konsolidierungsmodelle in der EU zu erhalten, sollen die entsprechenden Vorschriften rechtsvergleichend gegenübergestellt werden. $\mathrm{Zu}$ diesem $\mathrm{Zweck}$ beschränkt sich die nachfolgende Untersuchung auf die Kategorien, die für Unternehmensgruppen auf eine Gesamtgewinnermittlung abstellen (Niederlande, Portugal, Spanien) oder diese zumindest weitgehend nachzubilden versuchen (Frankreich) ${ }^{2}$. Diese vier Staaten werden in Anlehnung an Abb. 11 als „EU-Konsolidierungsstaaten“ bezeichnet. In der Vorgehensweise orientiert sich der nachfolgende Kapitelaufbau an der Schrittabfolge einer Konsolidierung im weiteren Sinne.

\subsubsection{Voraussetzungen einer Gruppenbesteuerung und Konsolidierungskreis}

In einem ersten Schritt wird untersucht, welche Voraussetzungen jeweils kodifiziert worden sind, damit die steuerliche Gesamtgewinnermittlung überhaupt zur Anwendung kommt. Davon kaum zu trennen ist die Frage, wie der Konsolidierungskreis und damit die rechnungslegende Einheit abgegrenzt wird. Die entsprechenden Voraussetzungen zielen insbesondere auf die Art der Unternehmensverbindung, die eine Gruppenbildung oder -zugehörigkeit eines Unternehmens manifestiert. Sie zielen aber auch auf eventuelle Nebenbedingungen, die die Unternehmensgruppe für körperschaftsteuerliche Zwecke

1 Grotherr (Konzernbesteuerungssysteme, 1996) S. 362, der diesen Begriff allerdings auf das Vereinigte Königreich und Irland anwendet.

2 Eine derartige Beschränkung ist bei den Konsolidierungsfragen, bei denen andere Gewinnermittlungssysteme keine Regulierung enthalten, zwangsläufig. Sie soll aber auch für die Frage gelten, die in allen 15 Mitgliedstaaten beantwortet wird: Die Voraussetzung für die Gruppenzugehörigkeit. Hier sollen nur die Einbeziehungsanforderungen der Gesamtgewinnermittlungssysteme interessieren. 
zu erfüllen hat. In Frage kommen hierbei Ansässigkeitsvoraussetzungen betroffener Unternehmen, Anforderungen an ihre Rechtsform oder auch das zusätzliche Einfordern privatvertraglicher Rechtsgeschäfte, wie z.B. Beherrschungs- oder Gewinnabführungsverträge. Zudem ist zu untersuchen, ob die konsolidierte steuerliche Gewinnermittlung verpflichtend oder nur freiwillig von den betroffenen Unternehmen anzuwenden ist sei es hinsichtlich der Gesamtgewinnermittlung als solcher oder der Einbeziehung einzelner Unternehmen.

Als Ergebnis dieser Untersuchung kann festgehalten werden, dass die Beteiligungsquote $^{1}$ als zentrale Voraussetzung einer Unternehmensverbindung dient. Alle vier betrachteten Staaten stellen hierbei auf die herrschaftsrechtliche Machtposition ab, die über Stimmrechte konkretisiert wird. Dabei bedarf es nicht der tatsächlichen, sondern allein der möglichen Stimmrechtsausübung. Zusätzlich wird dazu der vermögensrechtliche Anspruch auf Dividende bzw. Liquidationserlös verlangt, der auf einer Kapitalbeteiligung beruht. Anders als z.B. in Großbritannien und Irland ${ }^{2}$ stellt keiner der vier „Konsolidierungsstaaten" ausschließlich auf den vermögensrechtlichen Anspruch ab, so dass z.B. das Eigentum an stimmrechtslosen Vorzugsaktien völlig unberücksichtigt bleibt.

Bei der Beteiligungshöhe besteht ebenfalls ein Gleichklang der vier EUKonsolidierungsstaaten. Eine sehr hohe Beteiligungsquote von $90 \%$ (Portugal, Spanien) und $95 \%$ (Frankreich, Niederlande) wird vorausgesetzt ${ }^{3}$. Nur im portugiesischen System wird zwischen Kapital- und Stimmrechtsquote differenziert und neben der $90 \%$ igen Kapitalanteilsquote die einfache Stimmrechtsmehrheit für ausreichend erachtet. Die Mindestbeteiligung kann über direkte sowie indirekte Beteiligungen erlangt werden. Dabei ist auch die Zusammenrechnung direkter und indirekter Beteiligungen zulässig ${ }^{4}$.

Eine Mindestbeteiligungsdauer existiert nur in Spanien. Die Gruppenbesteuerung setzt hier eine mindestens zweijährige, ununterbrochene Beteiligung voraus. In den übrigen drei Staaten reicht es aus, wenn die Beteiligungsvoraussetzungen zu Anfang des betreffenden Wirtschaftsjahres bestanden haben.

1 Der Beteiligungsbegriff orientiert sich nicht an der engen Definition des deutschen Handelsrechts (§ 271 Abs. 1 HGB). Statt dessen liegt hier ein allgemeiner Begriff zu Grunde, der - ähnlich z.B. § 16 AktG (allerdings ohne Mehrheitsanforderung) - auf Kapital- und/oder Stimmrechtsanteile abstellt.

2 Vgl. Grotherr (Konzernbesteuerungssysteme, 1996) S. 367.

3 In den Niederlanden war bis 2003 sogar die 100\%-Quote erforderlich, die allerdings durch Rechtsprechung und Verwaltungspraxis in Richtung einer 99\%-Quote abgeschwächt wurde; vgl. Geiger (Konzept der fiskalen Einheit, 2002) S. 362; Scheuchzer (Konzernbesteuerung, 1994) S. 58.

4 Unterschiede liegen hier im Detail. Während es z.B. in Frankreich ausreicht, die Mindestbeteiligungsquote auf jeder Beteiligungs- bzw. Verbindungsstufe einzeln zu erfüllen, verlangen die übrigen Systeme das Vorliegen einer Mindestbeteiligung auch aus Sicht der Obergesellschaft, deren indirekte Beteiligungsquote multiplikativ ermittelt wird. Vgl. dazu Grotherr (Konzernbesteuerungssysteme, 1996) S. 366. 


\begin{tabular}{|c|c|c|c|c|}
\hline & \begin{tabular}{|l|} 
Frankreich \\
(régime de l'inté- \\
gration fiscale) \\
\end{tabular} & Portugal & Spanien & Niederlande \\
\hline $\begin{array}{l}\text { Verbindungskriterium } \\
\text { Mindestbeteiligungsquote } \\
\text { Einbeziehung indirekter } \\
\text { Beteiligungen } \\
\text { Mindestbeteiligungsdauer }\end{array}$ & \begin{tabular}{|l|} 
Kapitalanteile \\
und Stimmrechte \\
$95 \%$ \\
ja \\
nein \\
\end{tabular} & \begin{tabular}{|l|} 
Kapitalanteile \\
und Stimmrechte \\
$90 \% />50 \%$ \\
(Kapital/Stimm- \\
rechte) \\
ja \\
nein \\
\end{tabular} & \begin{tabular}{|l|} 
Kapitalanteile \\
und Stimmrechte \\
$90 \%$ \\
\\
ja \\
2 Jahre \\
\end{tabular} & \begin{tabular}{|l} 
Kapitalanteile \\
und Stimmrechte \\
$95 \%$ \\
\\
ja \\
nein \\
\end{tabular} \\
\hline Sonstiges Rechtsgeschäft & Nein & Nein & Nein & Nein \\
\hline $\begin{array}{l}\text { Unternehmensrechtsform } \\
\text { - Obergesellschaft }\end{array}$ & $\begin{array}{l}\text { KSt-Subjekte } \\
\text { (u.U. best. Be- } \\
\text { triebsstätten u. } \\
\text { Personengesell- } \\
\text { schaften) } \\
\text { analog }\end{array}$ & $\begin{array}{l}\text { Kapitalgesell- } \\
\text { schaften }\end{array}$ & $\begin{array}{l}\text { Aktiengesell- } \\
\text { schaften }\end{array}$ & KSt-Subjekte \\
\hline Ansässigkeit & nur Inland & nur Inla & nur Inland & nur Inland \\
\hline \begin{tabular}{|l|} 
Wahlrecht \\
- Gruppenbesteuerung \\
- Einbeziehung \\
\end{tabular} & $\begin{array}{l}\mathrm{ja} \\
\mathrm{ja}\end{array}$ & $\begin{array}{l}\text { ja } \\
\text { nein }^{\prime}\end{array}$ & $\begin{array}{l}\text { ja } \\
\text { nein }\end{array}$ & $\begin{array}{l}\text { ja } \\
\text { ja }\end{array}$ \\
\hline Antrag & \begin{tabular}{|l|} 
Antrag der Ober- \\
gesellschaft; \\
Zustimmung \\
aller einbezoge- \\
nen Unterneh- \\
men; \\
5 Jahre \\
\end{tabular} & $\begin{array}{l}\text { Antrag der Ober- } \\
\text { gesellschaft; } \\
\text { Zustimmung } \\
\text { aller einbezoge- } \\
\text { nen Unterneh- } \\
\text { men; } \\
3 \text { Jahre } \\
\end{array}$ & $\begin{array}{l}\text { Antrag der Ober- } \\
\text { gesellschaft; } \\
\text { Zustimmung } \\
\text { aller einbezoge- } \\
\text { nen Unterneh- } \\
\text { men; } \\
3 \text { Jahre } \\
\end{array}$ & $\begin{array}{l}\text { Gemeinsamer } \\
\text { Antrag der Ober- } \\
\text { gesellschaft und } \\
\text { aller einbezoge- } \\
\text { nen Unterneh- } \\
\text { men; } \\
\text { nein } \\
\end{array}$ \\
\hline Stufenkonzept & nein & nein & nein & nein \\
\hline
\end{tabular}

Tab. 2: Voraussetzungen einer Gruppenbesteuerung und Abgrenzung des Konsolidierungskreises

Quelle: Eigene Rechtsanalyse, auch unter Verwendung von Endres (Internationaler Vergleich, 2003); Endres (Konzernbesteuerung, 2003); Geiger (Frankreich, 2003); Geiger (Konzept der fiskalen Einheit, 2002); Geiger (Spanien, 2002); Grotherr (Besteuerung nationaler und grenzuberschreitender Konzerne, 1994) S. 173-322; Grotherr (Frankreich, 1995); Grotherr (Konzernbesteuerungssysteme, 1996); Jacobs/Spengel (Deutschland und Frankreich, 1994); Müller (Konzernbesteuerung, 1991) S. 88-91, 97; Salzberger (Konzernunternehmung, 1994) S. 115-122; Scheuchzer (Konzernertragsbesteuerung, 1994) S. 57-102; Selling (Spanische Konzernbesteuerung, 1987); Stieb (Portugal, 2000) Tz. 142.

Weitere Verbindungsmerkmale, wie sie z.B. früher mit der wirtschaftlichen oder organisatorischen Eingliederung im Rahmen der körperschaftsteuerlichen Organschaft in Deutschland bestanden, kommen nicht zur Anwendung. Auch zusätzliche Unternehmensverträge, wie z.B. der Gewinnabführungsvertrag, spielen keine Rolle. Ein Haftungsverbund oder eine Anspruchseinheit muss damit nicht vorliegen. Interessanterwei-

1 Diese Voraussetzung wird in der Literatur widersprüchlich interpretiert; vgl. Grotherr (Besteuerung nationaler und grenzüberschreitender Konzerne, 1994) S. 311 vs. Scheuchzer (Konzernbesteuerung, 1994) S. 83. 
se kommt der Gewinnabführungsvertrag noch nicht einmal in Portugal zur Anwendung, obwohl das dortige Konzernrecht eine derartige Vertragsform kennt ${ }^{1}$.

Andere Verbindungskonzepte als die der Stimmrechts- und Kapitalanteilsmehrheit existieren nicht. Dies gilt auch für Gemeinschaftsunternehmen oder sonstige Beteiligungen, die in der Gruppenbesteuerung nicht zusätzlich, z.B. nach Maßgabe eines Stufenkonzeptes, berücksichtigt werden.

Als Rechtsform der Obergesellschaft kommen in allen vier Staaten nur Körperschaftsteuersubjekte in Frage. Das sind in der Regel Kapitalgesellschaften. Während Spanien und Portugal sich auf letztere beschränken ${ }^{2}$, werden in den Niederlanden weitere Rechtsformen zumindest als Obergesellschaft akzeptiert, die jedoch nicht den Kreis der juristischen Personen verlassen ${ }^{3}$. Lediglich in Frankreich sind auch Personengesellschaften als Obergesellschaft denkbar, sofern sie zur Körperschaftsteuer optiert haben. In Frankreich können - ähnlich $§ 18 \mathrm{KStG}$ in Deutschland - zusätzlich auch inländische Betriebsstätten ausländischer Unternehmen als Obergesellschaft fungieren ${ }^{4}$. Mehrere Obergesellschaften etwa nach Art der früheren „Mehrmütterorganschaft“5 werden in allen vier Konsolidierungsstaaten ausgeschlossen.

Die Rechtsformanforderungen für die einbezogenen Unternehmen der Gruppe sind ana$\log \mathrm{zu}$ denen der Obergesellschaft ausgestaltet. Das zu versteuernde Einkommen der Gruppe verbleibt damit bei allen vier Gruppenbesteuerungssystemen in der körperschaftsteuerlichen Sphäre und wird nicht in den Bereich der Einkommensteuer verlagert $^{6}$ et vice versa.

1 Vgl. Grotherr (Konzernbesteuerungssysteme, 1996) S. 375. Vgl. zur Tatsache, dass der Ergebnisbzw. Gewinnabführungsvertrag eine deutsche und österreichische Besonderheit ist, FEE (Survey on Group Taxation, 2001) S. 6; Grotherr (Konzernbesteuerungssysteme, 1996) S. 369. Mit dem österreichischen Steuerreformgesetz 2005 vom 6. Mai 2004 entfällt dieser Vertrag jedoch für die neu beschlossene Gruppenbesteuerung in Österreich.

2 In Spanien gilt dies - noch enger - nur für Aktiengesellschaften, obwohl GmbH-ähnliche Gesellschaftstypen existieren; vgl. Grotherr (Konzernbesteuerungssysteme, 1996) S. 364.

3 Vgl. Geiger (Konzept der fiskalen Einheit, 2002) S. 361-362.

4 In diesem Fall muss der Staat, in dem die ausländische Gesellschaft steuerlich ansässig ist, ein Doppelbesteuerungsabkommen mit Frankreich abgeschlossen haben; vgl. Geiger (Frankreich, 2003) S. 1337. Dies ergibt sich weniger aus dem Gesetz, sondern entspricht herrschender Auffassung; vgl. Jacobs/Spengel (Deutschland und Frankreich, 1994) S. 102.

5 Vgl. hierzu kurz Kap. V.2.3.2.

6 Vgl. zu dieser Problematik, die z.B. in Deutschland auftritt, wenn „normale“ Personengesellschaften o. Einzelunternehmer Organträger sind, Grotherr (Konzernbesteuerungssysteme, 1996) S. 364. 
In allen vier Staaten wird eine Gruppenbesteuerung auf den inländischen Teil der Unternehmensgruppe beschränkt ${ }^{1}$. Bei dieser „Inlandsgruppe“ muss nicht nur die Obergesellschaft steuerlich im Inland ansässig sein, sondern auch sämtliche Untergesellschaften. Portugal schließt - ähnlich § 14 Abs. 1 Satz $1 \mathrm{KStG}$ in Deutschland - sogar doppelt ansässige Unternehmen vom Konsolidierungskreis aus ${ }^{2}$. Auch die französische Akzep$\operatorname{tanz}$ einer inländischen Betriebsstätte eines ausländischen Unternehmens ist letztlich kein Schritt in Richtung einer grenzüberschreitenden Gesamtgewinnermittlung, sondern im Gegenteil, ein striktes Durchsetzen fiskalischer Grenzen. Interessanterweise findet sich die Berücksichtigung grenzüberschreitender Gruppenstrukturen nur außerhalb der hier betrachteten vier „EU-Konsolidierungsstaaten“. Das (hier nicht betrachtete) französischen System der „,bénéfice consolidé“ sowie der gruppeninterne Verlustausgleich in Dänemark, Italien ${ }^{3}$ sowie Österreich dehnen die Unternehmensgruppe auch auf ausländische Unternehmen aus ${ }^{4}$.

In allen vier Konsolidierungsstaaten gibt es keinen Zwang zur Gruppenbesteuerung. Die Gruppenbesteuerung und die damit einhergehende Gesamtgewinnermittlung stellt eine freiwillige, antragsgebundene ${ }^{5}$ Alternative zur isolierten Einzelgewinnermittlung nach dem Trennungsprinzip dar. Das Wahlrecht erstreckt sich in Frankreich und in den Niederlanden auch auf die Frage, welche Unternehmen in den Konsolidierungskreis einzubeziehen sind ${ }^{6}$. In Portugal und Spanien besteht hingegen eine Einbeziehungspflicht für sämtliche Unternehmen, bei denen die Voraussetzungen vorliegen?

1 Nicht korrekt ist der Hinweis in einigen, z.T. älteren Veröffentlichungen (z.B. Beusch (Besteuerung der Konzerne, 1978) S. 36; Gassner (Besteuerung von Unternehmensgruppen, 1998) S. 17; Selling (Spanische Konzernbesteuerung, 1987) S. 292), dass in Spanien auch ausländische Unternehmen konsolidiert werden könnten; dies dürfte laut Scheuchzer (Konzernbesteuerung, 1994) S. 78 in einer missverständlichen Regulierung des Real Decreto 1414/1977 begründet liegen, die 1982 klargestellt wurde; s.a. Geiger (Spanien, 2002) S. 282; Grotherr (Konzernbesteuerungssysteme, 1996) S. 358. Diese Unternehmen sind mit Geschäftsleitung und Sitz in zwei unterschiedlichen Ländern ansässig. aber nur für die „consolidato fiscale mondiale", nicht für die "consolidato fiscale nazionale". Vgl. Salzberger (Konzernunternehmung, 1994) S. 110-118; zur Gegenüberstellung von „régime du bénéfice consolidé“ und „régime de l'intégration fiscale“ vgl. Scheuchzer (Konzernbesteuerung, 1994) S. 91-99. Vgl. zu der ab 2005 neu greifenden Gruppenbesteuerung nach $\S 9$ KStG (Österreich), die eine auf die Beteiligungshöhe beschränkte Verrechnung ausländischer Verluste zulässt z.B. Ernst \& Young (Gruppenbesteuerung, 2004); Gassner (Gruppenbesteuerung, 2004).

5 Während in Frankreich keine Genehmigungsbedürftigkeit besteht, ist die Zustimmung der Finanzverwaltung in den drei anderen Staaten erforderlich. In den Niederlanden, nicht jedoch in Portugal und Spanien, besteht ein diesbezüglicher Rechtsanspruch.

6 Dieses Wahlrecht liegt durch die Beteiligungsvoraussetzungen und die damit regelmäßig einhergehende Machtverteilung innerhalb der Gruppe bei der Leitung der Obergesellschaft und letztlich nicht bei den Untergesellschaften, auch wenn sie ein Zustimmungsrecht besäßen.

7 Dies gilt, obwohl mit dem Antrag der Obergesellschaft auch die (notariell beglaubigte) Zustimmung der Gesellschafterversammlungen aller einbezogenen Unternehmen vorliegen muss; vgl. z.B. Geiger (Spanien, 2002) S. 279; Grotherr (Konzernbesteuerungssysteme, 1996) S. 370; Grotherr (Besteuerung nationaler und grenzüberschreitender Konzerne, 1994) S. 290-291. 


\subsubsection{Vorbereitende Maßnahmen}

In einem zweiten Schritt wird untersucht, welche vorbereitenden Maßnahmen in den vier Gruppenbesteuerungssystemen vorgeschrieben sind. Sofern die Gesamtgewinnermittlung aus Einzelgewinnermittlungen abgeleitet wird, dienen die vorbereitenden Maßnahmen deren Vereinheitlichung. Die Einzelgewinnermittlungen vor ihrer Zusammenfassung und Konsolidierung zu vereinheitlichen, ist letztlich Ausdruck des Einheitsprinzips. Dies betrifft in concreto Dauer und Abschlussstichtag der periodischen Abschnittsbesteuerung, die der Gewinnermittlung zu Grunde liegende Währung und die Gewinnermittlungsvorschriften.

Die bisherigen Ergebnisse deuten bereits an, dass bestimmte Vereinheitlichungsmaßnahmen nur eine untergeordnete Bedeutung aufweisen. Dies trifft insbesondere die Währungsumrechnung. Bei einer auf „Inlandsgruppen“ beschränkten Gesamtgewinnermittlung ist die Umrechnung kompletter Einzelgewinnermittlungen nicht mehr notwendig. Damit verbleibt das Umrechnungsproblem allein auf der Ebene einzelner, in Fremdwährung getätigter Transaktionen. Diese Form der Fremdwährungsumrechnung betrifft bereits die Einzelgewinnermittlung und ist damit nicht mehr Gegenstand vorbereitender Maßnahmen.

Die Beschränkung des Konsolidierungskreises auf inländische Unternehmen müsste aber auch dazu führen, dass die Vereinheitlichung unterschiedlicher nationaler Gewinnermittlungssysteme entfällt. Die Vereinheitlichung bei den Gewinnermittlungsvorschriften beschränkt sich damit auf die einheitliche Anwendung der inländischen Vorschriften. Da alle vier Gesamtgewinnermittlungssysteme nur auf Körperschaftsteuersubjekte abstellen, dürfte aber auch das Problem unterschiedlicher inländischer Regelsysteme (z.B. für Einkommensteuersubjekte einerseits und Körperschaftsteuersubjekte andererseits) nicht entstehen. Angesichts entsprechender normativer Vorgaben ist darüber hinaus zu vermuten, dass körperschaftsteuerliche Gewinnermittlungsvorschriften - z.B. im Vergleich zu rein informationsorientierten Rechnungslegungsvorschriften - eher wahlrechtsärmer ausgestaltet sind und den Unternehmen deshalb auch weniger Spielraum für eine heterogene Anwendung bieten. Damit kann eigentlich nur die "Gleichschaltung" der steuerlichen Gewinnermittlungsperioden als wesentlicher Gegenstand der vorbereitenden Maßnahmen verbleiben.

Die Ergebnisse der Untersuchung bestätigen die reduzierte Bedeutung der vorbereitenden Maßnahmen. Für alle vier Gruppenbesteuerungssysteme wird vorausgesetzt, dass Dauer und Stichtag der Gewinnermittlungsperioden der einbezogenen Unternehmen 
übereinstimmen'. Weitergehende Vorschriften finden sich hauptsächlich im spanischen Körperschaftsteuerrecht. Hiernach sind die Ansatz- und Bewertungsgrundsätze bei den einbezogenen Unternehmen in Richtung der Vorgehensweise der Obergesellschaft zu vereinheitlichen ${ }^{2}$. Ähnliches gilt auch für Portugal ${ }^{3}$. In Frankreich wird wohl davon ausgegangen dass ein Befolgen der allgemein gültigen Körperschaftsteuergewinnermittlungsregeln zur einheitlichen Anwendung ausreicht ${ }^{4}$. In den Niederlanden ist die gruppeneinheitliche Bilanzierung und Bewertung in einer originären Gewinnermittlung gar zwangsläufig, da die einzelnen Unternehmen der Gruppe wie eine abhängige Betriebsabteilung der Obergesellschaft behandelt werden ${ }^{5}$.

\subsubsection{Konsolidierungsmaßnahmen im eigentlichen Sinne}

Im Rahmen der konsolidierten steuerlichen Gewinnermittlung geht es in einem dritten Schritt um die eigentliche Zusammenfassung der Einzelgewinnermittlungen einbezogener Unternehmen. Diese Zusammenfassung basiert auf der Aufsummierung der Einzelgewinnermittlungen und der anschließenden Korrektur der Summen-Gewinnermittlung zur Beseitigung gruppeninterner Kapital-, Kredit- sowie Liefer- und Leistungsverflechtungen. Diese Korrektur leisten die Konsolidierungsmaßnahmen im eigentlichen Sinne. Kapitalkonsolidierung, Schuldenkonsolidierung, Zwischenergebniseliminierung und Betriebsaugaben und -einnahmenkonsolidierung werden in diesem Zusammenhang gesondert untersucht. Vorangeschaltet ist eine kurze Beschreibung der grundsätzlichen Charakteristika des jeweils angewendeten Konsolidierungskonzeptes.

1 Vgl. Müssener (Niederlande, 2002) Tz. 348; Salzberger (Konzernuntemehmung, 1994) S. 118; Grotherr (Besteuerung nationaler und grenzüberschreitender Konzerne, 1994) S. 212, 281, 304, 315, 578; Grotherr (Frankreich, 1995) S. 412; Müller (Konzernbesteuerung, 1991) S. 97.

2 Vgl. Endres (Konzernbesteuerung, 2003) S. 474; Geiger (Spanien, 2002) S. 280; Scheuchzer (Konzernbesteuerung, 1994) S. 74; Selling (Spanische Konzernbesteuerung, 1987) S. 292, der zudem darauf verweist, dass die Buchführung in der Unternehmensgruppe dem nationalen Kontenplan folgen muss. Hinweise auf eine Währungsumrechnung in Spanien (vgl. z.B. Salzberger (Konzernunternehmung, 1994) S. 119; Selling (Spanische Konzernbesteuerung, 1987) S. 298) lassen sich möglicherweise durch die früher wohl falsche Annahme einer möglichen Einbeziehung ausländischer Unternehmen erklären; vgl. Kap. IV.1.2.1.

3 Vgl. allgemein zur engen Anlehnung des portugiesischen Systems an dasjenige Spaniens Scheuchzer (Konzernbesteuerung, 1994) S. 80; Müller (Konzernbesteuerung, 1991) S. 96, 98; explizit zur Vereinheitlichung Kischel (Übersicht über die direkten Steuern Portugals, 2000) S. 86: „Vorratsbewertungen und Abschreibungen von Gegenständen des Anlagevermögens sind in allen Konzernunternehmen einheitlich durchzuführen“.

4 Vgl. Jacobs/Spengel (Deutschland und Frankreich, 1994) S. 146.

5 Vgl. Beusch (Besteuerung der Konzerne, 1978) S. 34. Als Voraussetzung der „fiscale eenheid“ sieht Art. 15 Par. 3 Wet Vpb aber nicht nur übereinstimmende Perioden (a), sondern u.a. auch gleiche Gewinnermittlungsmethoden (b) als Voraussetzungen vor. 


\subsubsection{Grundsätzliches Konsolidierungskonzept}

Wie bereits unter Kapitel IV.1.1 beschrieben, basieren das portugiesische und das spanische Gruppenbesteuerungssystem auf einer vollständig konsolidierten Gewinnermittlung, die sämtliche Konsolidierungsmaßnahmen umfasst. Dabei schreiben beide Systeme die Methode der Vollkonsolidierung vor und entsprechen diesbezüglich dem $\mathrm{Ge}$ danken der Einheitstheorie. Für diejenigen Unternehmen, die in den steuerlichen Konsolidierungskreis einbezogen werden, ist die Quotenkonsolidierung und EquityMethode explizit ausgeschlossen. Alle anderen Unternehmen, die steuerlich nicht konsolidiert werden, sind wie in der Einzelgewinnermittlung im Grundsatz auf der Basis historischer Anschaffungskosten zu bewerten'.

Das französische Gruppenbesteuerungssystem basiert streng genommen auf einem Zurechnungsmodell, das allerdings über zusätzliche Korrekturmaßnahmen einer vollständig konsolidierten steuerlichen Gewinnermittlung angenähert wird. Hier fehlt es indes an der Aufsummierung der einzelnen Wirtschaftsgüter und deshalb insbesondere auch an der Kapitalkonsolidierung. Die Einzelergebnisse der einbezogenen Unternehmen werden der Obergesellschaft aber unabhängig von der Beteiligungsquote voll zugerechnet $^{2}$, so dass auch die entsprechenden Korrekturen in voller Höhe wirksam werden.

Das niederländische System ist hingegen der idealtypischen Gesamtgewinnermittlung angenähert. So sind verschiedene Konsolidierungsmaßnahmen gar nicht mehr notwendig, da die entsprechende Gewinnermittlung schon originär im Sinne der Einheitstheorie und nicht im Sinne des Trennungsprinzips vollzogen wird. Notwendig bleiben Konsolidierungsmaßnahmen jedoch bei der Aufstellung der Steuer-Eröffnungsbilanz der Gruppe und bei Veränderungen des steuerlichen Konsolidierungskreises. Hierbei greift die Vollkonsolidierung, da die Gesamtgewinnermittlung sämtliche Wirtschaftsgüter der einbezogenen Unternehmen in voller Höhe beinhaltet.

\subsubsection{Kapitalkonsolidierung}

Um Eigenkapitalverflechtungen zwischen den einbezogenen Unternehmen zu neutralisieren, bedarf es der Kapitalkonsolidierung. Ziel ist es, die einbezogenen Unternehmen in der Gesamtgewinnermittlung nur noch mit ihren positiven und negativen Wirtschaftsgütern zu erfassen. Angesichts des Fehlens einer Kapitalkonsolidierung im Zurechnungssystem Frankreichs reduziert sich die Untersuchung der Kapitalkonsolidierung auf die Gruppenbesteuerungssysteme von Portugal, Spanien und den Niederlanden.

Vgl. Selling (Spanische Konzernbesteuerung, 1987) S. 293.

Vgl. Geiger (Frankreich, 2003) S. 1337. 
In den Gruppenbesteuerungssystemen Portugals und Spaniens folgt die Kapitalkonsolidierung in ihrer Grundkonzeption der sog. Erwerbsmethode (purchase method), nach der die Erweiterung der Gruppe um ein Gruppenunternehmen wie der Erwerb eines Bündels einzelner Wirtschaftsgüter behandelt wird. Durch diese Einzelerwerbsfiktion wird den einzelnen Wirtschaftsgütern im Rahmen des Gesamtkaufpreises der jeweilig angenommene Einzel-Anschaffungswert zugeordnet, der zum Erwerbszeitpunkt in der Regel dem jeweiligen Zeitwert entspricht. Dabei wird im Prinzip der sog. Buchwertmethode gefolgt, nach der der Beteiligungsbuchwert erst einmal mit dem anteiligen Eigenkapital verrechnet wird, ehe der hieraus erwachsene Unterschiedsbetrag anschließend durch anteilige ${ }^{1}$ Aufdeckung stiller Reserven bzw. Lasten auf die Wirtschaftsgüter verteilt wird. Der nicht mehr aufteilbare Unterschiedsbetrag ist einem Ausgleichsposten zuzuordnen. Der auf Minderheiten entfallende Anteil des Kapitals wird in der Gruppenbilanz separat ausgewiesen ${ }^{2}$.

Wie die Erstkonsolidierung, so ist auch die Folgekonsolidierung in Spanien und Portugal ergebnisneutral. Zwar werden die Zubuchungen zu den einzelnen Wirtschaftsgütern entsprechend den Amortisierungsregeln dieser Wirtschaftgüter amortisiert. Auch der Ausgleichsposten unterliegt der Amortisation. Allerdings ist diese Amortisation steuerlich ohne weitere Relevanz, weil sie nicht als Betriebsausgabe abzugsfähig ist ${ }^{3}$.

1 Die entsprechende spanische Regel in Orden de 15 de julio de 1982 (segunda parte, norma 7a, 20635 f.) wird von Selling (Spanische Konzernbesteuerung, 1987) S. 293 in einem Beispiel anders interpretiert, da er dort stille Reserven voll aufgedeckt.

2 Vgl. so für Spanien Art. once, catorce Real Decreto 1414/1977 i.V.m. Orden de 15 de julio de 1982 (segunda parte, norma 7a); lt. Salzberger (Konzernunternehmung, 1994) S. 119, Selling (Spanische Konzernbesteuerung, 1987) S. 293-294 erfolgt der Minderheitenausweis getrennt vom Eigenkapital. Vgl. allgemein zur Technik der Buchwertmethode z.B. Baetge/Kirsch/Thiele (Konzernbilanzen, 2002) S. 205-216; Busse von Cole et al. (Konzernabschlüsse, 2003) S. 209-220. Die Unterscheidung zwischen Buchwert- und Neubewertungsmethode wird insb. in Kap. V.4.2.2.5.1 vertieft.

3 Vgl. so für Spanien Art. catorce, quince, 15 Real Decreto 1414/1977 i.V.m. Orden de 15 de julio de 1982 (segunda parte, norma 7a); interessant Selling (Spanische Konzernbesteuerung, 1987) S. 293, der (deshalb?) die aufgedeckten stillen Reserven in seinem Beispiel in der Folgekonsolidierung nicht abschreibt. Vor diesem Hintergrund widersprechen sich wohl die Literaturaussagen zur Folgekonsolidierung bzw. Abschreibung (Grotherr (Konzernbesteuerungssysteme, 1996) S. 373; Scheuchzer (Konzernbesteuerung, 1994) S. 75, 84; Selling (Spanische Konzernbesteuerung, 1987) S. 293). 


\begin{tabular}{|c|c|c|c|}
\hline & \begin{tabular}{|l|} 
Portugal \\
\end{tabular} & Spanien & Niederlande \\
\hline Verrechnungsmethode & $\begin{array}{l}\text { Beteiligungsbuchwert } \\
\text { wird mit dem anteiligen } \\
\text { Eigenkapital zu Buch- } \\
\text { werten verrechnet. } \\
\end{array}$ & $\begin{array}{l}\text { Beteiligungsbuchwert } \\
\text { wird mit dem anteiligen } \\
\text { Eigenkapital zu Buch- } \\
\text { werten verrechnet. } \\
\end{array}$ & $\begin{array}{l}\text { Beteiligungsbuchwert } \\
\text { wird mit dem anteiligen } \\
\text { Eigenkapital zu Buch- } \\
\text { werten verrechnet. } \\
\end{array}$ \\
\hline $\begin{array}{l}\text { Behandlung des Un- } \\
\text { terschiedsbetrages } \\
\text { (UB) }\end{array}$ & $\begin{array}{l}\text { Ergebnisneutrale Auftei- } \\
\text { lung des UB auf die } \\
\text { anteilig aufzudeckenden } \\
\text { stillen Reserven/Lasten } \\
\text { der Wirtschaftsgüter. } \\
\text { Verbleibender Rest-UB } \\
\text { wird einem aktiven/pas- } \\
\text { siven Ausgleichsposten } \\
\text { zugeordnet. }\end{array}$ & $\begin{array}{l}\text { Ergebnisneutrale Auftei- } \\
\text { lung des UB auf die } \\
\text { anteilig aufzudeckenden } \\
\text { stillen Reserven/Lasten } \\
\text { der Wirtschaftsgüter. } \\
\text { Verbleibender Rest-UB } \\
\text { wird einem aktiven/pas- } \\
\text { siven Ausgleichsposten } \\
\text { zugeordnet. }\end{array}$ & $\begin{array}{l}\text { Reine Buchwertfortfuh- } \\
\text { rung, d.h. keine Zuord- } \\
\text { nung des UB auf Wirt- } \\
\text { schaftsguter. Ergebnis- } \\
\text { neutrale Behandlung des } \\
\text { gesamten UB durch Bil- } \\
\text { dung eines aktiven/pas- } \\
\text { siven Ausgleichspos- } \\
\text { tens. } \\
\end{array}$ \\
\hline $\begin{array}{l}\text { Berïcksichtigung von } \\
\text { Minderheiten }\end{array}$ & $\begin{array}{l}\text { Minderheitenanteil an } \\
\text { stillen Reserven/Lasten } \\
\text { wird nicht aufgedeckt; } \\
\text { Minderheitenanteil am } \\
\text { Eigenkapital (zu Buch- } \\
\text { werten) wird separat } \\
\text { ausgewiesen. }\end{array}$ & $\begin{array}{l}\text { Minderheitenanteil an } \\
\text { stillen Reserven/Lasten } \\
\text { wird nicht aufgedeckt; } \\
\text { Minderheitenanteil am } \\
\text { Eigenkapital (zu Buch- } \\
\text { werten) wird separat } \\
\text { ausgewiesen. }\end{array}$ & $\begin{array}{l}\text { Stille Reserven/Lasten } \\
\text { werden überhaupt nicht } \\
\text { aufgedeckt - also auch } \\
\text { nicht der Minderheiten- } \\
\text { anteil . }\end{array}$ \\
\hline Folg & $\begin{array}{l}\text { Ergebnisneutral. } \\
\text { Amortisation der stillen } \\
\text { Reserven/Lasten sowie } \\
\text { des Ausgleichspostens } \\
\text { ist steuerlich nicht ab- } \\
\text { zugsfähig. }\end{array}$ & $\begin{array}{l}\text { Ergebnisneutral. } \\
\text { Amortisation der stillen } \\
\text { Reserven/Lasten sowie } \\
\text { des Ausgleichspostens } \\
\text { ist steuerlich nicht ab- } \\
\text { zugsfähig. }\end{array}$ & $\begin{array}{l}\text { Ergebnisneutral. } \\
\text { Ausgleichsposten wird } \\
\text { eingefroren. }\end{array}$ \\
\hline
\end{tabular}

Tab. 3: Ausgestaltung der Kapitalkonsolidierung ${ }^{1}$

Quelle: Eigene Rechtsanalyse, auch unter Verwendung von Endres (Konzernbesteuerung, 2003); Geiger (Frankreich, 2003); Geiger (Konzept der fiskalen Einheit, 2002); Geiger (Spanien, 2002); Grotherr (Konzernbesteuerungssysteme, 1996); Grotherr (Besteuerung nationaler und grenzüberschreitender Konzerne, 1994) S. 173-322; Jacobs/Spengel (Deutschland und Frankreich, 1994); Salzberger (Konzernunternehmung, 1994) S. 115-122; Scheuchzer (Konzernertragsbesteuerung, 1994) S. 57-102; Selling (Spanische Konzernbesteuerung, 1987); Stieb (Portugal, 2000) Tz. 142.

Die Vorgehensweise in Spanien und Portugal weist Parallelen zu der handelsrechtlichen Kapitalkonsolidierung auf, so wie sie in der 7. EG-Richtlinie (83/349/EWG) festgelegt worden ist, auch wenn die Buchwertmethode dort nur eine mögliche Alternative darstellt. Eine Vorbildfunktion der 7. EG-Richtlinie für die steuerliche Gesamtgewinnermittlung dieser beiden Staaten hat es aber wohl nicht gegeben. So ist das spanische System schon einige Jahre vor der Verabschiedung dieser Richtlinie als Ergebnis einer jahrzehnteübergreifenden Entwicklung kodifiziert worden (1977/1982), während das später etablierte portugiesische System (1987) vom Richtliniengedanken einer wirtschaftlichen Einheit zwar beeinflusst war, sich aber letztlich doch an den konkreten spanischen Regeln angelehnt hat ${ }^{2}$. Insofern verwundert es nicht, dass auch Abweichungen

1 Die Entkonsolidierung ist hier mangels Informationen nicht enthalten. Es kann davon ausgegangen werden, dass jeweils (nur) die ergebnisneutrale Kapitalkonsolidierung wieder rückgängig gemacht wird. Im Falle der „fiscale eenheid" fuhrt das ausscheidendes Unternehmen die Buchwerte fort.

2 Vgl. auch m.w.N. Scheuchzer (Konzernbesteuerung, 1994) S. 72, 80. 
gegenüber der 7. EG-Richtlinie existieren, die sich insbesondere in der Ergebnisneutralität der Kapitalkonsolidierung konkretisieren.

In den Niederlanden ähnelt die Vorgehensweise der Kapitalkonsolidierung eher der früheren deutschen Methode der Kapitalkonsolidierung, die auf der Buchwertfortführung und ergebnisneutralen Verrechnung des Unterschiedsbetrages beruht. Anders als bei der Erwerbsmethode wird das zugegangene Unternehmen bzw. dessen Wirtschaftsgüter also nicht zum Marktwert, sondern zum Buchwert in die Gesamtgewinnermittlung übernommen, wobei der vollständige, nicht aufgeteilte Unterschiedsbetrag als Ausgleichsposten aktiviert bzw. passiviert und während der Gruppenzugehörigkeitsphase nicht aufgelöst wird ${ }^{1}$. Ein Minderheitenanteil wird nicht separat ausgewiesen.

\subsubsection{Schuldenkonsolidierung}

Um die Gesamtgewinnermittlung von gruppeninternen Schuldbeziehungen und sämtlichen damit einhergehenden Konsequenzen zu bereinigen, bedarf es der Schuldenkonsolidierung. Diese findet sich - mehr oder minder umfangreich - in allen vier betrachteten Gruppenbesteuerungssystemen.

In Portugal, Spanien und den Niederlanden werden gruppeninterne Forderungen und Verbindlichkeiten miteinander verrechnet. Ebenso werden Rückstellungen, die sich auf einbezogene Unternehmen beziehen, aufgelöst. In den Niederlanden betrifft dies aber naturgemäß nur den Erstkonsolidierungszeitpunkt, da es der Schuldenkonsolidierung während der Gruppenzugehörigkeitsphase nicht mehr bedarf. Aufrechnungsdifferenzen aus Kreditverhältnissen, die vor der Gruppenzugehörigkeit entstanden sind, werden hier ergebniswirksam aufgelöst ${ }^{2}$. Demgegenüber werden Aufrechnungsdifferenzen in Spanien und Portugal ergebnisneutral in einen Korrekturposten eingestellt und nicht aufgelöst.

1 Vgl. zu dieser im alten Aktiengesetz ( $\$ 331$ AktG 1965) bis zum BiRiLiG festgelegten Konsolidierungsmethode, die so terminologisch von der modifizierten sowie echten angelsächsischen Methode abgegrenzt wurde von Wysocki/Wohlgemuth (Konzernrechnungslegung, 1996) S. 88-91.

2 Vgl. Geiger (Konzept der fiskalen Einheit, 2002) S. 364; eine neutrale Verrechnung erkennt hier allerdings Endres (Konzernbesteuerung, 2003) S. 470-471. 


\begin{tabular}{|l|l|l|l|l|}
\hline & Frankreich & Portugal & Spanien & Niederlande \\
\hline $\begin{array}{l}\text { Konsolidierungs- } \\
\text { maßnahmen }\end{array}$ & $\begin{array}{l}\text { Keine Eliminie- } \\
\text { rung gruppeninter- } \\
\text { ner Schuldbezie- } \\
\text { hungen (Keine } \\
\text { Bestandskorrek- } \\
\text { tur). } \\
\text { Ergebniskorrektur } \\
\text { in bestimmten } \\
\text { Fällen. }\end{array}$ & $\begin{array}{l}\text { Eliminierung } \\
\text { gruppeninterner } \\
\text { Schuldverhältnisse } \\
\text { (Verrechnung ge- } \\
\text { genseitiger Forde- } \\
\text { rungen und Ver- } \\
\text { bindlichkeiten } \\
\text { sowie Rückstel- } \\
\text { lungen). }\end{array}$ & $\begin{array}{l}\text { Eliminierung } \\
\text { gruppeninterner } \\
\text { Schuldverältnisse } \\
\text { (Verrechnung ge- } \\
\text { genseitiger Forde- } \\
\text { rungen und Ver- } \\
\text { bindlichkeiten } \\
\text { sowie Rückstel- } \\
\text { lungen). }\end{array}$ & $\begin{array}{l}\text { Eliminierung } \\
\text { gruppeninterner } \\
\text { Schuldverhältnisse } \\
\text { (Verrechnung ge- } \\
\text { genseitiger Forde- } \\
\text { rungen und Ver- } \\
\text { bindlichkeiten } \\
\text { sowie Rückstel- } \\
\text { lungen). }\end{array}$ \\
\hline $\begin{array}{l}\text { Aufrechnungsdif- } \\
\text { ferenzen (AD) }\end{array}$ & - & $\begin{array}{l}\text { Ergebnisneutrale } \\
\text { Erfassung (und } \\
\text { Vortrag)der AD. }\end{array}$ & $\begin{array}{l}\text { Ergebnisneutrale } \\
\text { Erfassung (und } \\
\text { Vortrag) der AD. }\end{array}$ & $\begin{array}{l}\text { AD aus Kreditver- } \\
\text { hältnissen, die vor } \\
\text { der Gruppenzuge- } \\
\text { hörigkeit entstan- } \\
\text { den sind, werden } \\
\text { ergebniswirksam } \\
\text { aufgelöst. }\end{array}$ \\
\hline
\end{tabular}

Tab. 4: Ausgestaltung der Schuldenkonsolidierung

Quelle: Eigene Rechtsanalyse, auch unter Verwendung von Endres (Konzernbesteuerung, 2003); Geiger (Frankreich, 2003); Geiger (Konzept der fiskalen Einheit, 2002); Geiger (Spanien, 2002); Grotherr (Besteuerung nationaler und grenzüberschreitender Konzerne, 1994) S. 173-322; Grotherr (Frankreich, 1995); Grotherr (Konzernbesteuerungssysteme, 1996); Jacobs/Spengel (Deutschland und Frankreich, 1994); Salzberger (Konzernunternehmung, 1994) S. 115-122; Scheuchzer (Konzernertragsbesteuerung, 1994) S. 57-102; Selling (Spanische Konzernbesteuerung, 1987); Stieb (Portugal, 2000) Tz. 142.

Während die Systeme Portugals, Spaniens und der Niederlande von einer Bestandskorrektur ausgehen und gruppeninterne Forderungen und Verbindlichkeiten miteinander verrechnen, beschränkt sich das französische Zurechnungsmodell auf die Korrektur bestimmter Ergebniswirkungen. So ist das Gruppenergebnis um Wertberichtigungen auf gruppeninterne Forderungen sowie um Zuführungen zu Rückstellungen für ungewisse Verbindlichkeiten gegenüber einbezogenen Unternehmen zu erhöhen, soweit diesen ursprünglichen Betriebsausgaben in den Einzelgewinnermittlungen keine korrespondierenden Erträge gegenüber stehen. Selbiges gilt für einen gruppeninternen Forderungsverzicht, der zu einem außerordentlichen Ertrag (beim Schuldnerunternehmen), nicht aber zu einer Betriebsausgabe (beim Gläubigerunternehmen) geführt hat ${ }^{1}$. Im Falle korrespondierender Betriebseinnahmen und -ausgabenberücksichtigung ist eine Korrektur nicht mehr notwendig, da die kerngrößenorientierte steuerliche Gesamtgewinnermittlung davon unbeeinflusst bleibt. Aufrechnungsdifferenzen aufgrund ungleicher Bestandshöhen werden nicht berücksichtigt ${ }^{2}$.

1 Vgl. Jacobs/Spengel (Deutschland und Frankreich) S. 146; Scheuchzer (Konzernbesteuerung, 1994) S. 97.

2 Es handelt sich eher um kasuistische Einzelregeln, um zu verhindern, dass sich im Gruppenergebnis Verluste eines Unternehmens letztlich zweimal gewinnmindernd auswirken (z.B. als laufende Verluste der Gesellschaft und als Wertberichtigung auf eine Forderung gegenüber dieser Gesellschaft); vgl. Grotherr (Frankreich, 1995) S. 410, 414-415; Grotherr (Konzernbesteuerungssysteme, 1996) S. 373. 


\subsubsection{Zwischenergebniseliminierung sowie Betriebsausgaben- und -einnahmen- konsolidierung}

Soweit die betrachteten Gruppenbesteuerungssysteme ihren Ausgangspunkt in einer Einzelgewinnermittlung nach dem Trennungsprinzip haben, können gruppeninterne Lieferungen und Leistungen Ergebniswirkungen entfalten und zu Zwischenergebnissen führen ${ }^{1}$. Da eine Ertragsrealisation bei Liefer- und Leistungsbeziehungen innerhalb derselben rechnungslegenden Einheit ausgeschlossen ist, bedarf es hiernach der Korrektur. Streng genommen wäre hier zwischen der bestandsorientierten Zwischenergebniseliminierung sowie der Stromgrößenkonsolidierung zu unterscheiden. Während erstere auf den Wertansatz der im Rahmen von Lieferungen oder Leistungen zwischen einbezogenen Unternehmen transferierten Wirtschaftsgüter fokussiert, zielt letztere auf die Korrektur von Betriebseinnahmen sowie -ausgaben, soweit sie auf gruppeninternen Beziehungen beruhen.

In den vier betrachteten Gruppenbesteuerungssystemen und in der interpretierenden Literatur fehlt es jedoch an dieser Differenzierung. Generell wird in diesem Zusammenhang von Zwischenergebniseliminierung gesprochen. Wahrscheinlich liegt dies in der Kerngrößenorientierung der steuerlichen Gesamtgewinnermittlung begründet, die eine Korrektur bei einander in gleicher Höhe gegenüberstehenden Stromgrößen obsolet erscheinen lässt ${ }^{2}$. Dazu passt, dass auftretende Asymmetrien, insbesondere bei gruppeninternen Gewinnausschüttungen, explizit zu korrigieren $\operatorname{sind}^{3}$. In Frankreich ist diese Differenzierung ohnehin nicht relevant, da sich hier die Gesamtgewinnermittlung in einer nur partiellen und außerbilanziellen Ergebnisbereinigung erschöpft ${ }^{4}$.

Die Zwischenergebniseliminierung in Spanien und Portugal kann von der Ergebniswirkung her als Wiederherstellung des Ausgangszustands vor Lieferung und Leistung beschrieben werden. Hier ist das in der Einzelgewinnermittlung realisierte Zwischenergebnis vollständig zu eliminieren ${ }^{5}$. Damit wird dem Einheitsprinzip allerdings nicht gänzlich entsprochen, da sich für die Unternehmensgruppe auch ein anderer historischer Wertansatz als der der Einzelgewinnermittlungen ergeben kann, da z.B. gruppeninterne

Vgl. zu dem Begriff „Zwischenergebnis“ mit Bezug auf das deutsche Handelsrecht genauer Baetge/Kirsch/Thiele (Konzernbilanzen, 2002) S. 318-319.

2 Vgl. bereits Kap. III.1.4; dazu auch Grotherr (Konzernbesteuerungssysteme, 1996) S. 374, der dies aber an die Bedingung gleich hoher Steuersätze und eines gruppeninternen Verlustausgleichs knüpt.

3 Wenn diese nicht schon auf der Ebene der Einzelgewinnermittlung unbeachtlich sind, werden sie gruppenintern von der Besteuerung freigestellt, um Mehrfachbesteuerungen zu vermeiden; vgl. Endres (Internationaler Vergleich, 2003) S. S39; Geiger (Konzept der fiskalen Einheit, 2002) S. 363; Grotherr (Konzernbesteuerungssysteme, 1996) S. 373-374; Scheuchzer (Konzernbesteuerung, 1994) S. 76, 85, 98; Selling (Spanische Konzernbesteuerung, 1987) S. 297.

4 Vgl. Jacobs/Spengel (Deutschland und Frankreich) S. 147-148.

5 Salzberger (Konzernunternehmung, 1994) S. 119 konstatiert allerdings, dass Zwischengewinne in Spanien durch Rücklagenbildung neutralisiert werden. 
Vertriebskosten aus Gruppensicht den Anschaffungs- oder Herstellungskosten hinzuzurechnen wären. Ein gruppendimensionaler Anschaffungs- und Herstellungskostenbegriff findet aber keine Anwendung'.

\begin{tabular}{|l|l|l|l|l|}
\hline & Frankreich & Portugal & Spanien & Niederlande \\
\hline $\begin{array}{l}\text { Zwischenergebnis- } \\
\text { eliminierung } \\
\text { im Anlagevermögen } \\
\text { im Umlaufvermögen }\end{array}$ & $\begin{array}{l}\text { ja } \\
\text { nein }\end{array}$ & $\begin{array}{l}\text { ja } \\
\text { ja }\end{array}$ & $\begin{array}{l}\text { ja } \\
\text { ja }\end{array}$ & $\begin{array}{l}\text { Nicht notwendig } \\
\text { Nicht notwendig }\end{array}$ \\
\hline Vorgehensweise & $\begin{array}{l}\text { Außerbilanzielle } \\
\text { Ergebniskorrektur }\end{array}$ & $\begin{array}{l}\text { Eliminierung } \\
\text { der Zwischen- } \\
\text { ergebnisse } \\
\text { (Zurückdrehen) }\end{array}$ & $\begin{array}{l}\text { Eliminierung } \\
\text { der Zwischen- } \\
\text { ergebnisse } \\
\text { (Zurückdrehen) }\end{array}$ & $\begin{array}{l}\text { Verzicht auf Zwischen- } \\
\text { ergebnisrealisierung } \\
\text { (Buchwertverknüpfung) }\end{array}$ \\
\hline $\begin{array}{l}\text { Vollständige oder } \\
\text { beteiligungsproportio- } \\
\text { nale Eliminierung }\end{array}$ & $\begin{array}{l}\text { Vollständige } \\
\text { Eliminierung }\end{array}$ & $\begin{array}{l}\text { Vollständige } \\
\text { Eliminierung }\end{array}$ & $\begin{array}{l}\text { Vollstăndige } \\
\text { Eliminierung }\end{array}$ & $\begin{array}{l}\text { Keine Ergebnisrealisa- } \\
\text { tion (wirkt wie voll- } \\
\text { ständige Eliminierung) }\end{array}$ \\
\hline
\end{tabular}

Tab. 5: Ausgestaltung der Zwischenergebniseliminierung sowie Betriebausgaben- und -einnahmenkonsolidierung

Quelle: Eigene Rechtsanalyse, auch unter Verwendung von Geiger (Frankreich, 2003); Geiger (Konzept der fiskalen Einheit, 2002); Geiger (Spanien, 2002); Grotherr (Besteuerung nationaler und grenzüberschreitender Konzerne, 1994) S. 173-322; Grotherr (Frankreich, 1995); Grotherr (Konzernbesteuerungssysteme, 1996); Jacobs/Spengel (Deutschland und Frankreich, 1994); Müller (Konzernbesteuerung, 1991) S. 92-93, 98, 101; Salzberger (Konzernunternehmung, 1994) S. 115-122; Scheuchzer (Konzernertragsbesteuerung, 1994) S. 57-102; Selling (Spanische Konzernbesteuerung, 1987); Stieb (Portugal, 2000) Tz. 142.

In dem französischen Zurechnungsmodell beschränkt sich die Zwischenergebniseliminierung - wohl aus Praktikabilitätsgründen - auf die Übertragung von Wirtschaftsgütern des Anlagevermögens ${ }^{2}$. Gerade im Vorratsvermögen erweist sich die Identifikation der entsprechenden Wirtschaftsgüter und die Kenntnis ihrer Gewinnaufschläge als schwierig $^{3}$. In Spanien hat diese Schwierigkeit dazu geführt, dass bei Warenverkäufen von der Zwischenergebniseliminierung abgesehen werden kann, wenn die Waren bei der empfangenen Gesellschaft in die Produktion eingeflossen und weiterverarbeitet worden $\operatorname{sind}^{4}$.

1 Vgl. Salzberger (Konzernunternehmung, 1994) S. 119; Selling (Spanische Konzernbesteuerung, 1987) S. 294; Scheuchzer (Konzernbesteuerung, 1994) S. 75-76; a.A. wohl Geiger (Spanien, 2002) S. 281.

2 Eine Zwischenergebniseliminierung bei Leistungen sowie Lieferungen von Wirtschaftsgütern des Umlaufvermögens existiert wohl nicht. Allerdings müssen hier in der Einzelgewinnermittlung sog. „subventions indirects“ identifiziert werden, die in der Gesamtgewinnermittlung wieder zu neutralisieren sind (Art. 223 B CGI). Obwohl dies nicht als Zwischenergebniseliminierung zu verstehen ist, erlaubt dies - da keine „subventions indirects“ auslösend - zumindest die steuerneutrale gruppeninterne Warenveraußerung zu Selbstkosten; vgl. dazu Geiger (Frankreich, 2003) S. 1340; Grotherr (Frankreich, 1995) S. 409-410; Jacobs/Spengel (Deutschland und Frankreich, 1994) S. 146-149.

3 Vgl. Grotherr (Frankreich, 1995) S. 409; Grotherr (Konzernbesteuerungssysteme, 1996) S. 371; Jacobs/Spengel (Deutschland und Frankreich, 1994) S. 149.

4 Vgl. Selling (Spanische Konzernbesteuerung, 1987) S. 294; Scheuchzer (Konzernbesteuerung, 1994)

S. 76, der dies auch als Vereinfachungsregel ansieht. 
In Frankreich, Portugal und Spanien wird die Zwischenergebniseliminierung bei abnutzbaren Wirtschaftsgütern des Anlagevermögens noch dadurch ergänzt, dass eventuelle Mehrabschreibungen aufgrund überhöhter Wertansätze der Einzelgewinnermittlung neutralisiert, sprich dem Gesamtergebnis wieder hinzugerechnet werden ${ }^{1}$. Auch folgen alle drei Staaten dem Gedanken der Vollkonsolidierung, da Zwischenerfolge voll und nicht beteiligungsproportional neutralisiert werden. So sind auch die auf Minderheitsanteile entfallenden Zwischenerfolge von der Eliminierung betroffen.

In den Niederlanden fehlt es an entsprechenden Korrekturmaßnahmen. Wirtschaftsgüter, die auf gruppeninternen Lieferungen oder Leistungen beruhen, weisen durch Buchwertverknüpfung bzw. Ansatz anfallender Herstellungskosten keine Zwischenergebnisse auf, so dass sich entsprechende Korrekturen erübrigen. Der gruppeninterne Erwerber tritt steuerlich insbesondere auch hinsichtlich der Abschreibungen in die Rechtstellung des Alteigentümers ein. Die Zwischenergebnisberechnung unter Anwendung des Fremdvergleichsgrundsatzes unterbleibt ebenso wie das spätere Korrigieren derselben im Zuge der Konsolidierung ${ }^{2}$. Ein gruppendimensionaler Anschaffungs- und Herstellungskostenbegriff existiert nicht.

Bei Veräußerung der einzelnen Wirtschaftsgüter an eine Partei außerhalb des Konsolidierungskreises ist die komplette Differenz zwischen dem Buchwert und dem erzielten Veräußerungspreis Gegenstand der Ertragsrealisation. Unabhängig davon, ob das Zwischenergebnis bei vorheriger gruppeninterner Lieferung oder Leistung neutralisiert wurde (Frankreich, Portugal, Spanien) oder gar nicht erst angefallen ist (Niederlande) ${ }^{3}$, wird es in diesem Zeitpunkt - in der Regel als Teil der gesamten Wertdifferenz - mit versteuert ${ }^{4}$. Die Gesamtgewinnermittlung im Rahmen der Gruppenbesteuerung wirkt damit wie eine Steuerstundung mit den damit einhergehenden Zins- und Liquiditätsef-

1 Vgl. Geiger (Frankreich, 2003) S. 1339; Geiger (Spanien, 2002) S. 281; Grotherr (Konzernbesteuerungssysteme, 1996) S. 371; Scheuchzer (Konzernbesteuerung, 1994) S. 84-85, 96-97; fur Frankreich (Art. 223 F CGI) sprechen Jacobs/Spengel (Deutschland und Frankreich, 1994) S. 147-149 von ratierlicher „Reintegration“ der neutralisierten Zwischenerfolge in das Gruppenergebnis.

2 Vgl. Grotherr (Besteuerung nationaler und grenzüberschreitender Konzerne, 1994) S. 275; Müller (Konzernbesteuerung, 1991) S. 101; Scheuchzer (Konzernbesteuerung, 1994) S. 62. Da u.U. jedoch eine Nachversteuerungspflicht bei Beendigung der steuerlichen Einheit eintritt, mögen Schwierigkeiten bei der „Nachverfolgung" intern transferierter Wirtschaftsgüter auftreten.

3 Die das niederländische Modell interpretierende Literatur widerspricht sich bei der Frage, ob die ursprünglichen Buchwerte ohne Aufdeckung der stillen Reserven auch nach dem Ausscheiden des gesamten Unternehmens aus dem Konsolidierungskreis fortgeführt werden kőnnen; vgl. dazu Grotherr (Konzernbesteuerungssysteme, 1996) S. 361 vs. Scheuchzer (Konzernbesteuerung, 1994) S. 65.

4 Dem jeweiligen nationalen Steuersystem ist es uberlassen, ob die Unternehmensgruppe Teile oder den gesamten Veräußerungserfolg in eine steuerfreie Reinvestitionsrücklage einstellen kann; vgl. zu diesbezüglichen Hinweisen für Spanien Geiger (Spanien, 2002) S. 282. Konsequenter Ausdruck des Einheitsprinzips ist in diesem Zusammenhang die niederländische Vorgehensweise, die die Übertragung stiller Reserven auf Ersatzwirtschaftsguter innerhalb der Gruppe auch unternehmensubergreifend erlaubt; vgl. Grotherr (Konzernbesteuerungssysteme, 1996) S. 371. 
fekten ${ }^{1}$. In dem französischen Zurechnungsmodell funktioniert dies so, dass das Gruppenergebnis, das in einem ersten Schritt nur den geringeren Ertrag aus der Wertdifferenz der Einzelgewinnermittlung beinhaltet, in einem zweiten Schritt um den zuvor eliminierten und in einer Nebenrechnung mitgeführten Zwischengewinn erhöht wird ${ }^{2}$.

\subsubsection{Steuersubjektivität, Haftung und Steueraufteilung}

Die vier betrachteten Gruppenbesteuerungssysteme weisen weitere Gemeinsamkeiten auch hinsichtlich der steuerrechtlichen Fragen der Steuersubjektivität, Haftung für die Steuerschuld und Steueraufteilung auf. So behalten die Unternehmen der Gruppe in allen Konsolidierungsstaaten als Rechtsträger auch ihre Steuersubjektivität. Der Subjekt-Status der Unternehmensgruppe ist hingegen weniger klar. Während das französische Zurechnungsmodell diese klar verneint, ist die (parallele) Steuersubjektivität der Gruppe in Portugal, Spanien und den Niederlanden strittig ${ }^{3}$.

Zentrale Bezugspunkte für die Steuerwirkungen sind in allen vier Gruppenbesteuerungssystemen die jeweiligen Obergesellschaften. Sie vertreten die Gruppe nicht nur gegenüber der Finanzverwaltung, sondern sind auch der primäre Steuerschuldner. Die übrigen Unternehmen der Gruppe stehen allerdings in einer Art solidarischer Haftung bzw. Gesamtschuldnerschaft, so dass sie vom Fiskus ebenfalls für die volle Steuerschuld in Anspruch genommen werden können oder die Obergesellschaft von ihnen Ausgleichszahlungen verlangen kann ${ }^{4}$. Lediglich in Frankreich haftet die Untergesellschaft nur für den Teil der Steuer, der sich auf der Basis einer Einzelveranlagung ergeben hätte ${ }^{5}$.

Da Minderheiten aufgrund der geforderten (Mindest-)Beteiligungsquote nicht völlig ausgeschlossen sind und gruppenspezifische Risiken für andere Vertragspartner ohnehin bestehen, bedienen sich alle vier Gruppenbesteuerungssysteme eines flankierenden Verfahrens zur Erfolgslokalisation und Steuerverteilung. Dies ist in Frankreich, Spanien und Portugal die parallel durchgeführte Einzelgewinnermittlung auf der Grundlage des

1 Vgl. für die Niederlande Geiger (Konzept der fiskalen Einheit, 2002) S. 364.

2 Dies gilt unter der Annahme stăndig steigender Weiterverkaufspreise; vgl. dazu Jacobs/Spengel (Deutschland und Frankreich, 1994) S. 147-149; Scheuchzer (Konzernbesteuerung, 1994) S. 96-97.

3 Vgl. Geiger (Spanien, 2002) S. 279; Scheuchzer (Konzernbesteuerung, 1994) S. 83; für die Niederlande widersprüchlich Grotherr (Konzernbesteuerungssysteme, 1996) S. 361 und Geiger (Konzept der fiskalen Einheit, 2002) S. 362.

4 Vgl. Geiger (Spanien, 2002) S. 279; Geiger (Frankreich, 2003) S. 1337, Reis (Korperschaftsbesteuerung des Konzerns, 1996) S. 205; Scheuchzer (Konzernbesteuerung, 1994) S. 62, 77, 98.

5 Vgl. Grotherr (Frankreich, 1995) S. 413; Müller (Konzernbesteuerung, 1991) S. 95. 
Fremdvergleichs (Schattenveranlagung), der in den Niederlanden regelmäßig eine geschlüsselte Verteilung des Gesamtgewinns gegenübersteht ${ }^{2}$.

Eine Besonderheit ergibt sich zudem in Portugal. Hier wird die Steuerwirkung aus der Gruppenbesteuerung an eine Art Mindestbemessungsgrundlage gekoppelt, die sich aus der Schattenveranlagung der Unternehmen ergibt. Ein konsolidiertes Gruppenergebnis wird nur dann steuerlich wirksam, wenn es mindestens $65 \%$ der summierten positiven Ergebnisse aus den Einzelgewinnermittlungen der Unternehmen beträgt; andernfalls werden diese $65 \%$ der Steuer unterworfen ${ }^{3}$.

Zusammenfassend bleibt festzuhalten, dass unter den 15 EU-Mitgliedstaaten vier Konsolidierungsstaaten identifiziert werden konnten, deren Gruppenbesteuerungssysteme auf einer Art Gesamtgewinnermittlung beruhen. Die Systeme Frankreichs, Portugals, Spaniens und der Niederlande weisen dabei hinsichtlich ihrer Voraussetzungen, ihrer konsolidierungstechnischen Ausgestaltungen und der steuerlichen Rechtsfolgen deutliche Parallelen auf. Dennoch ergeben sich Systemunterschiede. Während das französische Gruppenbesteuerungssystem über ein Zurechnungsmodell letztlich nicht hinausreicht, kommen das spanische und portugiesische System dem realtypischen Konsolidierungsmodell wohl am nächsten und werden diesbezüglich an (einheitstheoretischer) Konsequenz nur noch von der „fiscale eenheid“ überboten, die sich deutlich der idealtypischen Variante annähert. Fraglich bleibt jedoch, ob die jeweilige konsolidierungstechnische Ausgestaltung für steuerliche Zwecke geeignet ist. Eine derartige Untersuchung auf der Grundlage der normativen Beurteilungskriterien dieser Arbeit wird in Kapitel V vorgenommen, in dem die Erkenntnisse aus diesem EU-Rechtsvergleich bei der Analyse der IFRS-Konsolidierungsregeln ergänzend hinzugezogen werden. Vor dieser Untersuchung richtet sich der Fokus im folgenden Kapitel IV.2 aber erst einmal auf die Bestrebungen der EU, auf Unionsebene eine Form der Gruppenbesteuerung zu etablieren. Diese Bestrebungen bilden letztlich den Ausgangspunkt der in Kapitel V angesiedelten Eignungsanalyse, da erst die EU die IFRS auf Unionsebene als steuerliche Konsolidierungsregeln ,ins Spiel“" gebracht hat.

1 Vgl. Grotherr (Frankreich, 1995) S. 413; Müller (Konzernbesteuerung, 1991) S. 99; Reis (Körperschaftsbesteuerung des Konzerns, 1996) S. 205; Salzberger (Konzernunternehmung, 1994) S. 120; Selling (Spanische Konzernbesteuerung, 1987) S. 292.

2 Vgl. Scheuchzer (Konzernbesteuerung, 1994) S. 63, der allerdings auf die Möglichkeit einer vollwertigen (und sehr viel aufwendigeren!) Schattenveranlagung hinweist; diesbezulglich kritisch Grotherr (Konzernbesteuerungssysteme, 1996) S. 361.

3 Vgl. Scheuchzer (Konzernbesteuerung, 1994) S. 86. 


\section{Besteuerung der Unternehmensgruppen auf Unionsebene (de lege ferenda)}

\subsection{Historische Entwicklung}

\subsubsection{Bemühungen zur Harmonisierung der steuerlichen Gewinnermittlung}

Die Harmonisierung der steuerlichen Gewinnermittlungsvorschriften innerhalb der EU ist eng an die Bemühungen geknüpft, die nationalen Körperschaftsteuersysteme zu harmonisieren. Der erste diesbezügliche Versuch datiert aus dem Jahr 1962, als die Europäische Kommission einen Steuer- und Finanzausschuss zu dieser Frage einsetzte. Der im Juli 1962 nach dem Ausschussvorsitzenden Neumark benannte Abschlussbericht betont bereits die Notwendigkeit eines einheitlichen Körperschaftsteuersystems für den europäischen Wirtschaftsraum. Als potenzieller Gegenstand der Harmonisierung werden hier weniger die Unterschiede in der Gesamtsteuerlast beschrieben, sondern vielmehr die Systemstruktur und die steuerliche Bemessungsgrundlage ${ }^{\prime}$.

In einem Memorandum der Kommission von 1967 wird der Position des NeumarkBerichtes gefolgt. Für Kapitalgesellschaften soll zumindest mittelfristig eine einheitliche Bemessungsgrundlage auf der Basis harmonisierter Gewinnermittlungsregeln eingeführt werden ${ }^{2}$. Obwohl einige Jahre später eine weitere Studie zur Harmonisierung der Körperschaftsteuer von der Kommission in Auftrag gegeben wurde ${ }^{3}$, ist die Frage der steuerlichen Gewinnermittlung erst wieder in den siebziger Jahren aufgegriffen worden. Als das Europäische Parlament einen ersten Richtlinienvorschlag zur Harmonisierung der Körperschaftsteuersysteme vom November $1975^{4}$ annahm, forderte es die Kommission auf, die Gewinnermittlungsvorschriften parallel zu den Systemstrukturen zu harmonisieren und dementsprechende Vorschläge zu unterbreiten ${ }^{5}$.

Im Juli 1978 wurde die Vierte EG-Richtlinie (78/660/EWG) verabschiedet, die über eine versuchte Harmonisierung der handelsrechtlichen Bilanzierungsregeln zumindest mittelbare Auswirkungen auch auf die steuerliche Gewinnermittlung hatte. Diese Auswirkungen trafen insbesondere die Mitgliedstaaten, die das insoweit veränderte Handelsrecht über Formen der Maßgeblichkeit nicht völlig von der steuerlichen Gewinner-

\footnotetext{
Vgl. Europäische Wirtschaftsgemeinschaft (Bericht, 1962).

Vgl. EU-Kommission (Programm, 1967) S. 5, 8.

Vgl. van den Tempel (Körperschaftsteuer, 1971); weiterführend Hey (Harmonisierung, 1997) S. 68.

4 Vgl. Vorschlag einer Richtlinie des Rates zur Harmonisierung der Körperschaftsteuersysteme und der Regelungen der Quellensteuer auf Dividenden; abgedruckt in Deutscher Bundestag (Drucksache 7/3981, 1975) S. 1-7; dieser Vorschlag wurde im Jahr 1990 endgültig zurückgezogen; vgl. Jacobs (Internationale Unternehmensbesteuerung, 2002) S. 271.

5 Vgl. Kreile (Vorentwurf, 1988) S. 2.
} 
mittlung abkoppeln wollten oder konnten'. Vor diesem Hintergrund ist auch die heutige Entscheidungskompetenz des EuGH für das Steuerbilanzrecht in Deutschland zu erklären $^{2}$. Durch europäisches Recht wurde allerdings nicht verbindlich angeordnet, dass die Rechnungslegungsvorschriften der Vierten EG-Richtlinie für die steuerliche Gewinnermittlung aller Mitgliedstaaten maßgeblich sind. Insoweit blieb diese Richtlinie für die steuerliche Gewinnermittlung in einem Teil der europäischen Mitgliedstaaten ohne Auswirkung. Zudem besaßen und besitzen auch die „Maßgeblichkeitsstaaten“ einen mehr oder minder großen Teil eigenständiger und damit nicht harmonisierter steuerlicher Gewinnermittlungsvorschriften, die den handelsrechtlichen Vorschriften ohnehin vorgehen ${ }^{3}$.

Dem Wunsch des Europäischen Parlamentes nach harmonisierten Vorschriften zur steuerlichen Gewinnermittlung kam die Kommission erst im März 1988 entgegen, als sie einen Vorentwurf für eine "Richtlinie des Rates über die Harmonisierung der steuerlichen Gewinnermittlungsvorschriften"4 vorlegte. Hier ging es zum ersten Mal ausschließlich um die Harmonisierung der steuerlichen Bemessungsgrundlage durch Formulierung gemeinsamer Gewinnermittlungsvorschriften. Diese sollten für Unternehmen gelten, die der Einkommen- oder Körperschaftsteuer unterliegen und die zu steuerlichen Zwecken einen Jahresabschluss mit Bilanz sowie Gewinn- und Verlustrechnung gemäß nationalen Vorschriften erstellen. In dem Bestreben, sich auf das "strikt Erforderliche" zu beschränken, schlägt die Kommission hier ein vergleichsweise wenig detailliertes, an die vierte EG-Richtlinie angelehntes, wahlrechtsreduziertes aber nicht wahlrechtfreies Regelsystem vor. Dieses vom Anschaffungswertprinzip geprägte System weist bereits drei Besonderheiten auf, die z.B. das deutsche Bilanzsteuerrecht bis dahin nicht kannte: Auf der Basis unternehmerischer Wahlrechte konnten Aufwendungen zur Schaffung von Firmenwerten, Kundenstamm und Marken aktiviert und über fünf Jahre abgeschrieben werden (Art. 11). Selbiges galt für Forschungs- und Entwicklungsaufwen-

1 Vgl. für Deutschland Fresl (Europäisierung, 2000). Eine mehr oder minder starke Maßgeblichkeit der handelsrechtlichen Rechnungslegung für die steuerliche Gewinnermittlung findet sich innerhalb der EU neben Deutschland in Belgien, Finnland, Frankreich, Griechenland, Italien, Luxemburg, Österreich, Portugal, Spanien und Schweden. Keine Maßgeblichkeit herrscht in den angelsächsisch (geprägten) Mitgliedstaaten wie Dänemark, Irland, den Niederlanden und dem Vereinigten Königreich; vgl. dazu Jacobs (Internationale Unternehmensbesteuerung, 2002) S. 104-112; OECD (Relationship between Taxation and Financial Reporting, 1987) S. 9-23, 45; Sigloch (Maßgeblichkeitsprinzip, 2000) S. 163-170; Spengel (IAS und Unternehmensbesteuerung, 2003) S. 30. Bis auf Estland ist die Maßgeblichkeit indes in allen übrigen neun Mitgliedstaaten, die zum 1. Mai 2004 in die EU neu aufgenommen wurden, unbekannt; vgl. Spengel (Unternehmensbesteuerung in der EU, 2004) S. 117.

2 Vgl. z.B. Baumgartner (Irritationen, 2003); jeweils m.w.N. auch Hey (Perspektiven, 2004) S. $194-$ 198; Jacobs (Internationale Unternehmensbesteuerung, 2002) S. 223; Kahle (Europarechtliche Einflüsse, 2001) S. 128-132; zum sog. ,Tomberger-Urteil“ des EuGH Herzig (Anmerkung, 1996).

3 In Deutschland sind dies insb. die Ermittlungsvorschriften der $\S \S 4 \mathrm{ff}$. EStG, die den handelsrechtlichen Vorschriften gem. $\S 5$ Abs. 6 EStG (steuerrechtlicher Bewertungsvorbehalt) vorgehen.

4 Abgedruckt mit Begründung der Kommission bei Kreile (Vorentwurf, 1988); stärker analysierend Zeitler/Jüptner (Europäische Steuerharmonisierung, 1988). 
dungen zur Schaffung oder Verbesserung von Urheberrechten, gewerblichen Schutzrechten sowie ähnlichen Rechten und Werten (Art. 12). Zudem konnten Aufwandsrückstellungen gebildet werden (Art. 20).

Der Vorentwurf von 1988 wurde jedoch nicht weiter verfolgt. Im April 1990 stellte die Kommission hierzu fest, dass das Ideal einer kompletten Harmonisierung der Unternehmensbesteuerung kaum noch realistisch sei. Wohl im Hinblick auf die starken Widerstände der Mitgliedsstaaten, die ihre Fiskalsouveränität bedroht sahen ${ }^{1}$, wurde nun der Grundsatz der Subsidiarität stärker betont. In der Konsequenz beschränkte die Kommission ihre Bemühungen auf die Maßnahmen, die ihrer Meinung nach zur Vollendung des Binnenmarktes unerlässlich waren ${ }^{2}$. Diese Maßnahmen führten recht bald zu einem konkreten Ergebnis: Mit der Mutter-Tochter-Richtlinie (90/435/EWG), der Fusionsrichtlinie (90/434/EWG) und der Schiedsgerichtskonvention (90/436/EWG) ${ }^{3}$ wurde noch im Jahr 1990 ein Richtlinienpaket verabschiedet, das zwar im Bereich der direkten Steuern punktuell harmonisierend wirkte, ohne dabei jedoch größeren Einfluss auf die Frage der steuerlichen Gewinnermittlung zu haben ${ }^{4}$.

Im Oktober 1990 erteilte die Kommission einer nach ihrem Vorsitzenden Ruding benannten Expertengruppe den Auftrag, die Körperschaftsteuersysteme innerhalb der EU zu analysieren, gegebenenfalls Harmonisierungsbedarf aufzuzeigen und diesbezügliche Lösungen vorzuschlagen. Der Ruding-Ausschuss legte dazu im März 1992 einen engagierten Bericht vor, der auch auf Ergebnissen einer umfangreichen Unternehmensbefragung fußte ${ }^{5}$. Eine Körperschaftsteuerharmonisierung wurde darin für die Funktionsfähigkeit des Binnenmarktes als notwendig angesehen. Harmonisierungsbedarf bestünde insbesondere bei den Gewinnermittlungsvorschriften, deren Angleichung als langfristiges Ziel formuliert wurde. Der Ausschuss schlug deshalb erst einmal vor, den steuerrechtlichen Gewinn an handelsrechtliche Gewinnermittlungsvorschriften zu koppeln. Den Schwierigkeiten vergangener Harmonisierungsbemühungen wurde dabei insofern Rechnung getragen, als dass Gewinnermittlungsvorschriften nur noch den Charakter

1 Vgl. dazu treffend Knobbe-Keuk (Unternehmenssteuerrichtlinien, 1992) S. 337: „Die Finanz- und Steuerhoheit gehört zu den wesentlichen und daher am besten verteidigten Merkmalen staatlicher Souveränität: the power to tax is the power to govern. Dies macht die Harmonisierung besonders schwierig“; vgl. dazu kurz auch Kap. I.

2 Vgl. EU-Kommission (Strategie, 2001) S. 4; s.a. Bundesrat (Drucksache 360/1/90, 1990); Chetcuti (Corporate Tax Harmonisation, 2001) Chapter 3.5.

3 Vgl. erläuternd hierzu u.a. Herzig (Steuergestaltung, 1993); Herzig/Dautzenberg (Steuergestaltung, 1992); Jacobs (Internationale Unternehmensbesteuerung, 2002) S. 162-175; Knobbe-Keuk (Unternehmenssteuerrichtlinien, 1992) S. 336-343.

4 Vgl. zu dieser Einschätzung z.B. Hey (Perspektiven, 2004) S. 194; Spengel (Einheitliche Bemessungsgrundlage, 2004) S. 103.

5 Vgl. Ruding Committee (Report, 1992); dazu u.a. auch Herzig (Besteuerung der Unternehmen in Europa, 1996) S. 126-127; Hey (Harmonisierung, 1997) S. 72-77. 
von Mindeststandards haben sollten, um für alle Mitgliedstaaten eine Art Mindestbemessungsgrundlage zu schaffen.

Die Anbindung steuerrechtlicher Gewinnermittlungsregeln an die Vierte EG-Richtlinie war jedoch problematisch. Keine Zustimmung der Mitgliedstaaten fand die - von deutscher Seite vorgeschlagene - formale Bindung zwischen steuer- und handelsrechtlicher Gewinnermittlung nach Vorbild des deutschen Maßgeblichkeitssystems ${ }^{1}$. Aber selbst eine inhaltliche Anlehnung an die Vierte EG-Richtlinie erschien aufgrund ihrer zahlreichen Mitgliedstaaten- und Unternehmenswahlrechte wenig hilfreich. Der Ausschuss schlug deshalb u.a. vor, bestimmte, hiervon betroffene Bilanzierungsregeln z.B. zu Abschreibungen, immateriellen Wirtschaftsgütern, Leasing, Vorratsbewertung, Rückstellungen oder Pensionsverpflichtungen zu Zwecken der steuerlichen Gewinnermittlung zu überarbeiten. Konkrete und detaillierte Überarbeitungsvorschläge finden sich jedoch kaum. Der Ruding-Ausschuss regte u.a. auch hierzu die Einsetzung einer weiteren Expertengruppe $a^{2}$. Dem Ausschuss schien es dabei weniger um die Harmonisierung in Richtung eines bestimmten Leitbildes zu gehen, sondern eher um die pragmatische Reduzierung von Wahlrechten und innergemeinschaftlichen Regelunterschieden ${ }^{3}$.

Die Reaktionen auf den Ruding-Bericht waren durchwachsen. Insbesondere die Mitgliedsstaaten nahmen eine eher reservierte Haltung ein. In der Beschränkung auf das politisch Machbare gingen sogar der EU-Kommission einige Vorschläge insbesondere auch zur Vereinheitlichung der steuerlichen Gewinnermittlungsvorschriften zu weit. Die Umsetzung blieb somit aus ${ }^{4}$.

Nach 1992 hielten sich die Harmonisierungsbemühungen auf dem Gebiet der direkten Steuern in Grenzen ${ }^{5} .1996$ schlug die Kommission in einem Diskussionspapier eine Reihe kleinerer Maßnahmen vor ${ }^{6}$, die 1997 in einer Mitteilung unter dem (zu) viel versprechenden Titel "Maßnahmenpaket zur Bekämpfung des schädlichen Steuerwettbe-

1 Vgl. Sapusek (Steuerharmonisierung, 1997) S. 257.

2 Vgl. zu den Schlussfolgerungen und Ratschlägen insgesamt Ruding Committee (Report, 1992) S. 193220; dazu kritisch u.a. Koop (Gewinnbesteuerung, 1993) S. 111. Herzig (Besteuerung der Unternehmen in Europa, 1996) S. 128-135.

3 Ähnlich auch die Kritik von Nobes (Framework for the Taxable Income, 2004) S. 29: „The Ruding (1992) Report describes EU differences in tax bases. It makes recommendations (pp. 212-218) concerning the reduction of these differences. These are not based on a framework, however, and seem to be driven more by the motive of harmonisation".

4 Vgl. m.w.N. Jacobs (Internationale Unternehmensbesteuerung, 2002) S. 272; für Spengel (Einheitliche Bemessungsgrundlage, 2004) S. 103 sind deshalb „weitreichende Harmonisierungsvorschläge von vornherein politisch nicht konsensfähig".

5 Vgl. dazu genauer z.B. Chetcuti (Corporate Tax Harmonisation, 2001) Chapter 3.7-3.9.

6 Vgl. EU-Kommission (Steuern, 1996). 
werbs in der Europäischen Union" präzisiert wurden' ${ }^{1}$. Die steuerliche Gewinnermittlung blieb davon aber unberührt.

\subsubsection{Bemühungen zur Schaffung einer konsolidierten Körperschaftsteuerbemes- sungsgrundlage}

Die bisher dargestellten Bemühungen zur Harmonisierung steuerlicher Gewinnermittlungsvorschriften zielten insbesondere auf die Fragen von Ansatz und Bewertung. Obwohl Schnittmengen existieren, sind davon die Bemühungen zur Schaffung einer konsolidierten Körperschaftsteuerbemessungsgrundlage zu trennen. Der erste diesbezügliche Vorstoß der EU-Kommission stammt aus dem Jahr 1969. In diesem Jahr ist der Entwurf einer „Richtlinie des Rates über das gemeinsame Steuersystem für Mutter- und Tochtergesellschaften verschiedener Mitgliedstaaten" ${ }^{\text {"2 }}$ vorgelegt worden. So geht es hier einerseits um die Beseitigung der internationalen Doppelbesteuerung von Gewinnen, die zwischen grenzüberschreitend miteinander verbundenen Unternehmen ausgeschüttet werden. Nach über 20 Jahren ist dieser Teilbereich 1990 in der bereits erwähnten Mutter-Tochter-Richtlinie (90/435/EWG) verabschiedet und inzwischen in das nationale Recht sämtlicher Mitgliedstaaten transformiert worden ${ }^{3}$. Neben der Gewinnausschüttung hat die Kommission weitere 13 Jahre später, im Juni 2003, auch Zins- und Lizenzzahlungen zwischen verbundenen Unternehmen durch die Zins- und Lizenz-Richtlinie $(2003 / 49 / \mathrm{EG})^{4}$ von der Doppelbesteuerung befreit ${ }^{5}$.

Der Richtlinienentwurf von 1969 enthält aber auch Bestimmungen zur Schaffung eines „Systems des konsolidierten Gewinns“. Losgelöst von der rechtlichen Unternehmenssicht basieren diese Bestimmungen auf der Vorstellung, die Körperschaftsbesteuerung stärker auf die wirtschaftliche Einheit zu projizieren. „Das System des konsolidierten Gewinns setzt an die Stelle des engen juristischen Begriffs des Steuerpflichtigen einen umfassenderen, modernen Wirtschaftsbegriff, die „Gruppe von Unternehmen“, die zwar rechtlich unabhängig ist, jedoch eine wirtschaftliche Einheit bildet, die als einziger Steuerpflichtiger gilt ${ }^{\star 6}$. Ausgehend von dieser Vorstellung wird vorgeschlagen, Unternehmen die Möglichkeit zu geben, bei einer Beteiligung von mindestens $50 \%$ eine ge-

1 Vgl. EU-Kommission (Maßnahmenpaket, 1997).

2 Abgedruckt mit Begründung der Kommission in Deutscher Bundestag (Drucksache V/3774, 1969) S. 2-8; erläuternd Debatin (Konzern-Besteuerungs-Richtlinie, 1969).

3 Vgl. Knobbe-Keuk (Unternehmenssteuerrichtlinien, 1992) S. 336-341; s.a. Kap. I, IV.1.1 u. IV.2.1.1.

4 Vgl. dazu ausführlich und kritisch Dautzenberg (Richtlinien, 2004).

5 Letztlich hat diese Richtlinie nur das schon aus den Doppelbesteuerungsabkommen bekannte Prinzip, entsprechende Zahlungen nicht im Quellenstaat, sondern im Empfängerstaat zu besteuern, in das Gemeinschaftsrecht übertragen; vgl. Dautzenberg (Richtlinien, 2004) S. 17.

6 Deutscher Bundestag (Drucksache V/3774, 1969) S. 6, in der Vorschlagsbegründung (S. 5-8). 
meinsame Veranlagung zu wählen. Diese Möglichkeit soll insbesondere auch bei grenzüberschreitenden Unternehmensverbindungen gegeben sein'.

Obwohl so benannt, handelt es sich bei dem „System des konsolidierten Gewinns“ nicht um ein Konsolidierungsmodell. Der Richtlinienentwurf zielt letztlich nur auf die Verlustausgleichsmöglichkeit zwischen den Unternehmen und verbleibt damit auf der zweiten (von vier möglichen) Voraussetzungsebenen einer Gruppenbesteuerung ${ }^{2}$. Die geäußerte Vorstellung, eine wirtschaftliche Einheit als einzigen Steuerpflichtigen besteuern $\mathrm{zu}$ wollen, ist damit nicht konsequent umgesetzt worden ${ }^{3}$. Insbesondere kann von einer einheitlichen, die Unternehmensgruppe umfassenden rechnungslegenden Einheit noch keine Rede sein. So fehlen bereits Hinweise auf eine Vereinheitlichung der Einzelgewinnermittlungen, z.B. auf die Fremdwährungsumrechnung ${ }^{4}$. Es wird ein Zurechnungssystem interessentheoretischer Prägung ohne weitere Konsolidierungsmaßnahmen vorgeschlagen, bei dem die Ergebnisse der isolierten Einzelgewinnermittlungen der Obergesellschaft beteiligungsproportional zugerechnet werden ${ }^{5}$. Terminologisch präziser müsste deshalb eher von einem „System des zusammengerechneten Gewinns" ${ }^{\text {"6 }}$ gesprochen werden.

Das System des konsolidierten Gewinns konnte bereits ein Jahr später als gescheitert angesehen werden. So enthält ein zweiter, modifizierter Richtlinienentwurf der EUKommission von 1970 keine diesbezüglichen Vorschriften mehr ${ }^{7}$. Möglicherweise können die Ursachen dieses Scheiterns in den ungeklärten Verfahrens- und vor allen Dingen Aufteilungsfragen vermutet werden ${ }^{8}$, die insbesondere das fiskalische Interesse der Mitgliedstaaten tangieren. So ist z.B. das Problem der internationalen Doppelbesteue-

1 Vgl. Art. 7 Abs. 1 und 2 des obigen Richtlinienentwurfs. In Abs. 1 wird von „Beteiligung“ gesprochen, so dass nicht eindeutig ist, ob darunter eine Kapital- und/oder Stimmrechtsbeteiligung zu fassen ist. Möglicherweise kann die Tatsache, dass sich die beteiligungsproportionale Ergebniszurechnung nach Kapitalanteilen bemisst (Art. 7 Abs. 2 Buchstabe a)) als Indiz für ein ausschließliches Abstellen auf eine Kapitalbeteiligung gewertet werden.

2 Vgl. Debatin (Konzern-Besteuerungs-Richtlinie, 1969) S. 150; s.a. Abb. 10 in Kap. IV.1.1.

3 Vgl. zu einer ähnlichen Kritik bereits Grotherr (Besteuerung nationaler und grenzüberschreitender Konzerne, 1994) S. 140-144; Reis (Körperschaftsbesteuerung des Konzerns, 1996) S. 209-210; Scheuchzer (Konzernbesteuerung, 1994) S. 225-226; positiver indes Beusch (Besteuerung der Konzerne, 1978) S. 41, der dies als ersten Schritt ansieht, ,um so schrittweise dem Ziel einer echten europäischen transnationalen Besteuerung näherzukommen“"

4 Vgl. so auch Bovermann (Umrechnung, 1988) S. 129.

Vgl. Art. 7 Abs. 2 Buchstabe a) des obigen Richtlinienentwurfs.

Vgl. Bauer (Besteuerung deutscher Konzerne, 1987) S. 197.

7 Der gleich benannte Vorschlag einer Richtlinie ist abgedruckt in Deutscher Bundestag (Drucksache VI/1344, 1970) S. 2-4; der relevante Art. 7 des ersten Entwurfs ist darin nicht mehr enthalten; vgl. auch Beusch (Besteuerung der Konzerne, 1978) S. 40; Scheuchzer (Konzernbesteuerung, 1994) S. 226. Auf eine gewisse Fortführung der Idee des „konsolidierten Gewinns“ in den 1970 bzw. 1975 unterbreiteten Vorschlägen über das Statut der Europäischen Aktiengesellschaft verweist Grotherr (Besteuerung nationaler und grenzüberschreitender Konzerne, 1994) S. 144-150.

$8 \mathrm{Vgl}$. ansatzweise Beusch (Besteuerung der Konzerne, 1978) S. 40 m.w.N. 
rung in dem ursprünglichen Entwurf weitgehend ungelöst geblieben ${ }^{1}$. Das Bemühen um einen grenzüberschreitenden Verlustausgleich hat die Kommission jedoch nicht aus den Augen verloren. 20 Jahre später hat sie erneut eine Initiative in dieser Richtung gestartet und 1990 einen entsprechenden Entwurf einer Verlustrichtlinie (,Vorschlag für eine Richtlinie des Rates über eine Regelung für Unternehmen zur Berücksichtigung der Verluste ihrer in anderen Mitgliedstaaten belegenen Betriebsstätten und Tochtergesellschaften") zur Diskussion gestellt ${ }^{2}$. Bei Vorliegen einer 75\%igen Kapitalbeteiligung, die auch mit einer Stimmrechtsmehrheit einher geht, wird in diesem Entwurf erneut ein grenzüberschreitender Verlustausgleich gefordert. Auch dieser Richtlinienentwurf ist nach weiteren 11 Jahren in der Diskussion von der EU-Kommission 2001 mit Hinweis auf die fehlende Zustimmungsbereitschaft der Mitgliedstaaten zurückgezogen worden ${ }^{3}$. An der Entschlossenheit der Kommission, das Ziel eines grenzüberschreitenden Verlustausgleichs auch weiterhin zu verfolgen, gibt es indes keinen Zweifel ${ }^{4}$.

Trotz aller Bemühungen auf dem Gebiet des Verlustausgleichs sind darüber hinausgehende Anstrengungen der EU-Kommission zur Schaffung einer konsolidierten Körperschaftsteuerbemessungsgrundlage lange nicht $\mathrm{zu}$ beobachten gewesen. Auf gesellschaftsrechtlicher Ebene hat es allerdings den Versuch gegeben, die Akzeptanz des (auch grenzüberschreitenden) Konzernsachverhalts bei allen Mitgliedstaaten materiellrechtlich anzustreben. Der 1984 vorgelegte Entwurf einer neunten gesellschaftsrechtlichen Richtlinie von 1984 (Konzernrechtsrichtlinie) ${ }^{5}$ ist aber weit von einer Umsetzung entfernt und möglicherweise ebenfalls als gescheitert anzusehen ${ }^{6}$. Auf steuerlicher Seite ist dieses gesellschaftsrechtliche Bemühen vorerst auch ohne Widerhall geblieben ${ }^{7}$. Das änderte sich erst 2001, als die EU-Kommission eine neue Strategie für die künftige Unternehmensbesteuerung in der EU vorlegte. Mit dieser Strategie geht die Kommission

1 Vgl. Scheuchzer (Konzernbesteuerung, 1994) S. 225-226, der darauf hinweist, dass die Einzelergebnisse der Unternehmen nach dem Richtlinienentwurf auch weiterhin der Körperschaftsteuer in ihrem Sitzstaat unterliegen (von einem einzigen Steuersubjekt also keine Rede sein kann) und eine klare Abstimmung mit der Gruppenbesteuerung auf der Ebene der Obergesellschaft nicht existiert. Art. 7 Abs. 2 Buchstabe b) des Richtlinienentwurfs führt dazu lediglich auf: „[D]er Betrag der innerstaatlichen Steuer auf die Gewinne der Muttergesellschaft wird vermindert, um die Tatsache zu berücksichtigen, daß die Gesellschaften, deren Gewinne in diese Steuerveranlagung aufgenommen werden, einer Steuer auf diese Gewinne unterliegen“.

2 Abgedruckt in Bundesrat (Drucksache 96/91, 1991); erläuternd z.B. Grotherr (Besteuerung nationaler und grenzüberschreitender Konzerne, 1994) S. 150-168; Jacobs (Internationale Unternehmensbesteuerung, 2002) S. 177-179.

3 Vgl. EU-Kommission (Strategie, 2001) S. 15; EU-Kommission (Ergebnisse, 2003) S. 10.

4 Vgl. EU-Kommission (Ergebnisse, 2003) S. 10-11.

5 Vgl. zu diesem Vorschlag einer Konzernrechtsrichtlinie Lutter (neunte Richtlinie, 1985).

6 Zumindest wird diese Richtlinie nicht weiter verfolgt; vgl. Hommelhoff (Konzernrecht in Europa, 1992); Salzberger (Konzernunternehmung, 1994) S. 50; Schön (Gesellschaftsrecht, 1995) S. 9.

7 Eine Abhängigkeit der konsolidierten steuerlichen Gewinnermittlung von dem Erfolg gesellschaftsrechtlicher Richtlinien, insbesondere der Konzernrechtsrichtlinie und dem Statut einer europäischen Aktiengesellschaft, wird z.B. von Beusch (Besteuerung der Konzerne, 1978) S. 40 und Küting (Einheitsbesteuerung, 1990) S. 490-491 angedeutet. 
weit über das Problem des grenzüberschreitenden Verlustausgleichs hinaus und formuliert zum ersten Mal auch explizit die Idee einer konsolidierten Körperschaftsteuerbemessungsgrundlage. Insbesondere in dieser Hinsicht soll die EU-Strategie im Folgenden näher untersucht werden.

\subsection{EU-Strategie zur künftigen Unternehmensbesteuerung}

\subsubsection{Hintergrund, Ziele und grundsätzliche Konzeption}

Auf der Basis einer umfangreichen Studie "Company Taxation in the Internal Market"1, die von den Kommissionsdienststellen in Zusammenarbeit mit zwei Expertengremien ${ }^{2}$ erstellt worden ist, hat die Kommission im Oktober 2001 der Öffentlichkeit in einer Mitteilung eine neue Strategie für den Bereich der Unternehmensbesteuerung bekannt gegeben $^{3}$. Diese stützt sich auf ein Mandat des Rates, der die Kommission im Juli 1999 beauftragte, die Auswirkungen der unterschiedlichen effektiven Körperschaftsteuerniveaus auf die unternehmerische Standortentscheidung $\mathrm{zu}$ untersuchen. Dabei sollten auch steuerliche Hindernisse für die grenzüberschreitende Unternehmenstätigkeit im EU-Binnenmarkt benannt und entsprechende Lösungen vorgelegt werden ${ }^{4}$.

Für die künftige Regulierung der Unternehmensbesteuerung empfiehlt die EUKommission eine zweigleisige Strategie:

1) Einerseits sollen gezielte Maßnahmen getroffen werden, um einen kurz- und mittelfristigen Beitrag zur Lösung dringender Probleme zu leisten. In diesem Zusammenhang wird vorgeschlagen,

- Orientierungshilfen zum Umgang mit der Rechtsprechung des Europäischen Gerichtshofes $(\mathrm{EuGH}) \mathrm{zu}$ veröffentlichen, um ein allgemeineres Verständnis für dessen Urteile und ihre Auswirkungen auf die Unternehmensbesteuerung zu entwickeln,

- die Mutter-Tochter-Richtlinie (90/435/EWG) und Fusionsrichtlinie (90/434/EWG) zu ergänzen und zu verbessern, um grenzüberschreitende Einkommensströme zwischen verbundenen Unternehmen und grenzüberschreitende Umstrukturierungen noch besser vor steuerlichen Mehrbelastungen zu schützen,

1 Vgl. EU-Kommission (Company Taxation, 2001); dazu auch Kroppen/Rasch (Unternehmensbesteuerung in der Europäischen Union, 2002) S. 498-506.

2 So gab es ein Wissenschaftler- und ein Praktiker-Gremium (first and second panel); unter den sieben Wissenschaftlern fand sich von deutscher Seite Christoph Spengel (damals Universität Mannheim); vgl. EU-Kommission (Company Taxation, 2001) S. 3-4.

3 Vgl. EU-Kommission (Strategie, 2001).

4 Vgl. EU-Kommission (Strategie, 2001) S. 3-4; überaus umfassend zu diesem Thema auch Spengel (Internationale Unternehmensbesteuerung, 2003).

5 Vgl. bereits zu Änderungsvorschlägen für diese Richtlinien vor 2001 Jacobs (Internationale Unternehmensbesteuerung, 2002) S. 175-176. 
- (wieder) eine Lösung für den grenzüberschreitenden Verlustausgleich zu erarbeiten und

- ein gemeinsames Forum zu Verrechnungspreisen einzurichten, um eine EUVersion des OECD-Musterabkommens (und des zugehörigen Kommentars) entwickeln zu können'.

2) Um die identifizierten steuerlichen Probleme systematischer und vor allem auch langfristiger lösen zu können, soll andererseits ein umfassendes Gesamtkonzept erarbeitet werden. Dieses Gesamtkonzept beruht auf der in der Expertenstudie bereits umrissenen Vorstellung, eine einzige, konsolidierte Körperschaftsteuer-Bemessungsgrundlage für die grenzüberschreitende Unternehmenstätigkeit innerhalb der EU zu etablieren ${ }^{2}$.

Insbesondere mit ihrem zweiten Lösungsschritt geht die Kommission noch über die Vorschläge des Ruding-Ausschusses hinaus, der lediglich für eine Harmonisierung verschiedener nationaler Gewinnermittlungsvorschriften plädierte ${ }^{3}$. Auch stellt die Kommission unter Hinweis auf den Subsidiaritätsgrundsatz explizit heraus, dass sie nicht daran denke, Einfluss auf die Körperschaftsteuersätze zu nehmen oder gar einen einheitlichen Regelsteuersatz vorzuschreiben. Trotz erheblicher, in der Basisstudie festgestellter Unterschiede in der effektiven Steuerbelastung innerhalb der EU ${ }^{4}$, soll die Festsetzung der Körperschaftsteuersätze allein in der Verantwortung der Mitgliedstaaten verbleiben. Allerdings wird in einer prozessorientierten Sicht die Hoffnung geäußert, über die mit einer vereinheitlichten Bemessungsgrundlage verbundene Transparenz zu einer Konvergenz der Regelsteuersätze und damit auch zu einer reduzierten Streuung effektiver Steuersätze beizutragen ${ }^{5}$.

Die beiden vorgeschlagenen Lösungsschritte sind auch keineswegs überschneidungsfrei. So konstatiert die EU-Kommission, dass das erste Maßnahmenbündel letztlich auch der langfristigen Schaffung einer konsolidierten Körperschaftsteuer-Bemessungsgrundlage für multinationale Unternehmen bzw. Unternehmensgruppen diene. Das angestrebte Gesamtkonzept vermag die aufgezeigten Probleme schließlich insgesamt zu

1 Vgl. EU-Kommission (Strategie, 2001) S. 11-17; EU-Kommission (Company Taxation, 2001) S. 223305; dazu auch Kroppen/Rasch (Unternehmensbesteuerung in der Europäischen Union, 2002) S. 498506; zu ersten Zwischenergebnissen bei der Realisierung dieser Maßnahmen vgl. EU-Kommission (Ergebnisse, 2003) S. 7-12; zu den inzw. beschlossenen und im Januar 2005 in Kraft getretenen Änderungen Spengel (Unternehmensbesteuerung in der EU, 2004) S. 126-133.

2 Vgl. EU-Kommission (Strategie, 2001) S. 13, 17-23; EU-Kommission (Company Taxation, 2001) S. 14-17, 370-423.

3 Vgl. mehr zu den Unterschieden zwischen Ruding-Bericht und neuer Strategie der EU-Kommission, EU-Kommission (Fragen, 2001); s.a. EU-Kommission (Company Taxation, 2001) S. 16-25.

4 Vgl. EU-Kommission (Company Taxation, 2001) S. 68-222; vgl. unter Einbeziehung aller 25 EUMitgliedstaaten auch Spengel (Unternehmensbesteuerung in der EU, 2004) S. 112-114, 119-123.

5 Vgl. EU-Kommission (Strategie, 2001) S. 8-11; dazu ausfuhrlicher und kritisch Schreiber (Unternehmensbesteuerung, 2004); Sørensen (Company Tax Reform, 2004) S. 104-105. 
lösen. Es gehe sogar über diese Einzelmaßnahmen hinaus, da es ein weiteres, zentrales Hindernis grenzüberschreitender unternehmerischer Tätigkeit zumindest innerhalb der EU zu bewältigen vermag: die Beachtung von 25 (ab Mai 2004, zuvor 15) verschiedenen nationalen Steuersystemen'. Um dies zu erreichen, solle das Gesamtkonzept nicht mehr (allein) auf der Einzelgewinnermittlung rechtlich selbständiger Unternehmen beruhen, sondern (auch) auf der Gesamtgewinnermittlung einer wie auch immer abgegrenzten Unternehmensgruppe. Explizit fordert die Kommission in diesem Zusammenhang,

- das Einkommen der gesamten Gruppe ${ }^{2}$ anhand eines einziges Regelwerks zu berechnen und

- für steuerliche Zwecke konsolidierte Bilanzen zu erstellen, um die potenziellen steuerlichen Wirkungen gruppeninterner Geschäfte auszuschalten ${ }^{3}$.

Schon der Hinweis auf die bisher aufwendige Beachtung der vielen nationalen Steuerund letztlich auch Gewinnermittlungssysteme deutet übergeordnete Ziele der EUStrategie an. Die EU-Kommission formuliert in diesem Zusammenhang ein heterogenes Potpourri, das in Teilen durchaus Parallelen zu den in dieser Arbeit formulierten normativen Leitbildern aufweist. Sie verweist auf

- das Postulat der Entscheidungsneutralität,

- die internationale Wettbewerbsfähigkeit der EU-Unternehmen und auf

- die verursachten Kosten bei der Einhaltung dieser Maßnahmen sowie die eingesparten Kosten bei der Vermeidung steuerlicher Hindernisse für die grenzüberschreitende Tätigkeit ${ }^{4}$.

\footnotetext{
Vgl. EU-Kommission (Strategie, 2001) S. 17-18, 23.

Obwohl die hier zitierte deutsche Fassung von „Konzern“ spricht, soll der neutralere Gruppenbegriff verwendet werden, der in der englischen Fassung dieser Veröffentlichung benutzt wird (,group“).

Vgl. EU-Kommission (Strategie, 2001) S. 18.

Vgl. EU-Kommission (Strategie, 2001) S. 5-6; zu den Kosten EU-Kommission (Steuerumfrage, 2004).
} 
Diese ökonomischen Ziele bleiben allerdings relativ vage'. So wird bereits die Entscheidungsneutralität nicht weiter konkretisiert. Erst an späterer Stelle deutet sich die eher allokationstheoretisch fundierte Sichtweise der Kommission an, die sie in Richtung einer Investitions-, Finanzierungs- und auch Standortneutralität reduziert ${ }^{2}$. Der Hinweis auf die Wettbewerbsfähigkeit europäischer Unternehmen kann wohl eher als Ausdruck eines Lenkungsziels verstanden werden. Dadurch mag sich auch ein gewisses Spannungsverhältnis zum Neutralitätspostulat ergeben. Zudem ist fraglich, ob sich hinter der gleichfalls erhobenen Forderung, dass ,schädliche und für die Wirtschaft nachteilige Formen des Steuerwettbewerbs ${ }^{\text {“3 }}$ beseitigt werden müssen, in prozessorientierter, evolutorischer Hinsicht nicht eher eine wettbewerbsschädliche Einmischung des Regulierers zum Schutze der Unternehmen und des europäischen Wirtschaftsraumes vor Wettbewerb verbirgt ${ }^{4}$. Unmittelbar einleuchtend erscheinen indes die durchführungsorientierten Effizienzargumente, wonach die Beachtung eines einzigen Regelwerkes den Unternehmen(sgruppen) immense Kosteneinsparungen ermöglicht. So ist auch nicht verwunderlich, dass insbesondere Unternehmen das vorgeschlagene Gesamtkonzept einer künftigen Unternehmensbesteuerung befürworten ${ }^{5}$. Schon auf administrativer Ebene dürfte dieses Urteil weniger eindeutig ausfallen, da Umsetzungs- und Anwendungsschwierigkeiten auf Ebene der Finanzverwaltungen wahrscheinlich sind ${ }^{6}$.

Gerechtigkeitsgetriebene Gründe werden von der EU-Kommission für ihre Steuerstrategie nicht explizit genannt. Allerdings verweist sie auf den Zwang, dass die europäische

1 Die Frage, ob diese Ziele mit der EU-Strategie überhaupt erreicht werden können, steht nicht im Vordergrund dieser Arbeit. Die EU-Kommission (Strategie, 2001) zieht sich hier auf den apodiktischen Standpunkt zurück, ihre Strategie ,würde zu größerer Effizienz, Wirksamkeit, Einfachheit und Transparenz der Unternehmenssteuersysteme in der EU beitragen und die Lücken zwischen den einzelstaatlichen Systemen schließen, die jetzt noch Steuervermeidung und Missbrauch Vorschub leisten. Damit würden die Befolgungskosten verringert, die EU könnte die Vorteile des Binnenmarktes voll ausschöpfen, womit die Wettbewerbsfähigkeit der EU-Unternehmen verbessert würde“. (S. 18); umfassende Analysen der EU-Strategie finden sich z.B. bei Menck/Mutén (Europäische Steuerpolitik, 2003); Mintz (European Company Tax Reform, 2002); Mintz (Corporate Tax Harmonization, 2004); Oestreicher (Konzernbesteuerung in Europa, 2002); Sørensen (Harmonise, 2002); Sørensen (Company Tax Reform, 2004); Spengel (Internationale Unternehmensbesteuerung, 2003). Den weiterhin großen Forschungsbedarf angesichts vieler noch offener Fragen betont Gérard (Comprehensive Approaches, 2002) S. 40.

2 Vgl. EU-Kommission (Strategie, 2001) S. 8-10; so interpretierend auch Jacobs (Internationale Unternehmensbesteuerung, 2002) S. 277-278.

3 EU-Kommission (Strategie, 2001) S. 6.

4 Vgl. zu dieser Kritik ansatzweise Schneider (IAS als Besteuerungsgrundlage, 2003) S. 299; diese Frage analysierend Menck/Mutén (Europäische Steuerpolitik, 2003) S. 35-79.

5 Vgl. o.V. (Towards a common tax base, 2002) S. 5; zu den eingesparten Befolgungskosten vgl. EUKommission (Steuerumfrage, 2004)

6 Vgl. z.B. Kap. III.2.5.2; positiver hingegen die Einschätzung der EU-Kommission (Strategie, 2001) S. 20 selbst: „Auch für die Steuerbehörden werden sich erhebliche Vorteile ergeben“ sowie Spengel (Unternehmensbesteuerung in der EU, 2004) S. 135. Vgl. administrative Probleme und Vereinfachungseffekte abwägend Raupach (Gemeinschaftsweite Unternehmensbesteuerung, 1997) S. 723-724. 
Steuerpolitik mit den allgemeinen Zielen der EU-Politik im Einklang stehen müsse ${ }^{1}$. Dadurch bindet sie sich indirekt auch an die ethischen Vorstellungen, die bisher auf einzelstaatlicher Verfassungsebene und möglicherweise künftig in einer EU-Verfassung kodifiziert sind und die als gesellschaftlicher Konsens das Handeln der Regulierungssubjekte ebenfalls bestimmen sollten. Treffend fügt die Kommission deshalb hinzu, dass die künftige Unternehmensbesteuerung in der EU „letztlich Ausdruck einer politischen Entscheidung und einer Abwägung zwischen rein wirtschaftlicher Effizienz und anderen legitimen politischen Zielen"2 sei. Lediglich in der Basisstudie wird mit der zwischenstaatlichen Aufteilungsgerechtigkeit eine Gerechtigkeitsebene thematisiert, nach der eine noch festzulegende Aufteilungsmethode mindestens so „fair" sein solle wie die der bisherigen Einzelgewinnermittlung ${ }^{3}$.

Über die Hintergründe dieser EU-Initiative und über die Frage, warum sie gerade zu diesem Zeitpunkt und in dieser, auf die Bemessungsgrundlage fixierten Form realisiert worden ist, kann nur spekuliert werden. Es scheint, dass die Entwicklung eines gesellschaftsrechtlichen Statuts für die Europäische Aktiengesellschaft (Societas Europaea, SE) und seine endgültige Verabschiedung im Oktober $2001^{4}$ das Ziel eines gemeinsamen Systems der Unternehmensbesteuerung gerade für grenzüberschreitende Tätigkeiten wieder neu belebt hat ${ }^{5}$. Zu vermuten ist außerdem, dass die parallele Entwicklung im Bereich der handelsrechtlichen Rechnungslegung als treibende Kraft gewirkt hat ${ }^{6}$. Obwohl die handelsrechtliche Rechnungslegung mit der Vierten (78/660/EWG) und Siebenten EG-Richtlinie (83/349/EWG) bereits Anfang der achtziger Jahre als formal harmonisiert galt, sah sich die Kommission schon in den neunziger Jahren gezwungen, auf die zunehmende Internationalisierung der Bilanzierungspraxis gerade bei kapitalmarktorientierten europäischen Unternehmen zu reagieren. Im Juni 2000 hat die EUKommission deshalb eine neue Rechnungslegungsstrategie formuliert ${ }^{7}$, die im Juli 2002 Eingang in eine die Mitgliedstaaten unmittelbar bindende EU-Verordnung gefunden hat ${ }^{8}$. Hiernach haben alle kapitalmarktorientierten europäischen ${ }^{9}$ Unternehmen und da-

Vgl. EU-Kommission (Strategie, 2001) S. 6.

EU-Kommission (Strategie, 2001) S. 10.

EU-Kommission (Company Taxation, 2001) S. 421; vgl. zur ,inter-country equity“ Kap. III.2.5.2.

Vgl. EU-Verordnung Nr. 2157/2001; Richtlinie 2001/86/EG; vgl. weiterführend zu den steuerlichen Aspekten der SE z.B. Herzig/Griemla (Societas Europaea, 2002).

5 Vgl. EU-Kommission (Fragen, 2001); EU-Kommission (Unternehmensbesteuerung, 2001); dazu z.B. auch Jacobs (Internationale Unternehmensbesteuerung, 2002) S. 189.

6 Vgl. ähnlich bereits Schreiber (Steuerwettbewerb, 1998) S. 131.

7 Vgl. EU-Kommission (Rechnungslegungsstrategie, 2000); bereits im Dezember 2000 folgte der entsprechende Verordnungsvorschlag.

8 Vgl. EU-Verordnung Nr. 1606/2002; dazu bereits Kap. I und III.2.3.2.1.

9 Kapitalmarktorientierte europäische Unternehmen sind „Gesellschaften, die dem Recht eines Mitgliedstaates unterliegen“ und die „am jeweiligen Bilanzstichtag ihre Wertpapiere in einem beliebigen Mitgliedstaat zum Handel in einem geregelten Markt i.S.d. Artikels 1 Absatz 13 der Richtlinie 93/22/EWG des Rates vom 10. Mai 1993 über Wertpapierdienstleistungen zugelassen“ haben (Art. 4). 
mit alle Unternehmen, deren Wertpapiere in irgendeinem EU-Mitgliedstaat an einem organisierten Markt zum Handel zugelassen sind, für die Geschäftsjahre, die am oder nach dem 1. Januar 2005 beginnen, ihren Konzernabschluss zwingend nach International Financial Reporting Standards (IFRS) ${ }^{1}$ zu erstellen (Art. 4) ${ }^{2}$. Diese einheitliche Ausrichtung auf die IFRS wertet die EU-Kommission selbst als großen Erfolg ${ }^{3}$, der sie möglicherweise auch zu neuen Anstrengungen auf dem schwierigen Feld der direkten Unternehmenssteuern und hier auch der steuerlichen Gewinnermittlung motiviert hat.

\subsubsection{Konsolidierungsspezifische Fragen}

Das in der EU-Strategie zum Ausdruck kommende Gesamtkonzept einer künftigen Unternehmensbesteuerung ist ambitioniert. Dies gilt insbesondere vor dem Hintergrund, dass sich das Gebiet der direkten Unternehmensbesteuerung einer einheitlichen europäischen Regulierung bisher weitgehend entzieht. Möglicherweise handelt es sich bei einer konsolidierten Besteuerung gar um das „Endstadium einer erkennbaren Entwicklungslinie im europäischen Kontext ${ }^{\varsigma 4}$. Dennoch bleibt völlig offen, ob der politische Wille auf der Ebene der Mitgliedstaaten vorhanden ist, etwas derartiges zu realisieren. Dieser Wille dürfte auch davon beeinflusst werden, wie die vielen offenen Ausgestaltungsfragen beantwortet werden und in welcher Form die geplante Grundkonzeption letztlich umgesetzt werden soll.

Zur Systematisierung möglicher Ausgestaltungsfragen ist es sinnvoll, das angestrebte Gesamtkonzept der EU-Strategie in drei Schritte aufzuteilen ${ }^{5}$ :

1) Einzelgewinnermittlung der einzelnen Unternehmen

2) Überführung der Einzelgewinnermittlungen in die Gesamtgewinnermittlung durch Zusammenfassung und Konsolidierung der Einzelergebnisse

3) Aufteilung des Gesamtergebnisses der Unternehmensgruppe auf die einzelnen Unternehmen

1 Die ,alten“ und teilweise noch gültigen International Accounting Standards (IAS) werden gem. IAS 1.11 ebenfalls unter den IFRS-Begriff subsumiert.

2 Für die Einzelabschlüsse kapitalmarktorientierter Unternehmen sowie die Einzel- und Konzernabschlüsse nicht kapitalmarktorientierter Unternehmen hat der europäische Regulierer Mitgliedstaatenwahlrechte formuliert (Art. 5). Mit Art 1 Nr. 20, 29 BilReG hat der deutsche Gesetzgeber dieses Wahlrecht an die Unternehmen weitergegeben, wobei das Wahlrecht für den Einzelabschluss gem. $\S 325$ Abs. 2a, 2b HGB nur für Offenlegungszwecke gilt.

3 Vgl. z.B. EU-Kommission (Finanzdienstleistungen, 2002) S. 5.

4 Grotherr (Konzernbesteuerungssysteme, 1996) S. 358, der diese Entwicklungslinie auf annähernd einhundert Jahre bemisst.

5 Vgl. ähnlich auch Jacobs (Internationale Unternehmensbesteuerung, 2002) S. 279; Spengel (Unternehmensbesteuerung in der EU, 2004) S. 133-134, die beide die realtypische Gesamtgewinnermittlungsvariante unterstellen. 
Hinsichtlich des ersten Schrittes ist bereits fraglich, ob die Einzelgewinnermittlung wie bisher auf der Basis des Trennungsprinzips vollzogen werden soll, um - wie z.B. in Spanien und Portugal - die Gesamtgewinnermittlung dann erst als eine Art Korrekturrechnung hinzuzufügen. Dies würde auch bedeuten, dass die jeweils nationalen Gewinnermittlungsvorschriften weiterhin zur Anwendung kommen. Alternativ wäre vorstellbar, die Einzelgewinnermittlung - mit oder ohne Fremdvergleichsgrundsatz - bereits auf der Basis einheitlicher Vorschriften durchzuführen ${ }^{1}$. Fraglich ist dann allerdings, welche Vorschriften hierbei Verwendung finden sollen.

Hinsichtlich des zweiten Schrittes ist erst einmal zu fragen, was die EU-Kommission genau unter Konsolidierung versteht. Diese Frage ist schon deshalb berechtigt, da der Konsolidierungsbegriff bereits 1969 kursierte, obwohl „nur“ ein Zurechnungssystem zur Ermöglichung eines grenzüberschreitenden Verlustausgleichs gemeint war ${ }^{2}$. Dass diesmal mehr als nur ein Verlustausgleich gemeint sein muss, kann bereits aus der Formulierung abgeleitet werden, dass konsolidierte Steuerbilanzen zu erstellen sind, „um die potenziellen steuerlichen Wirkungen gruppeninterner Geschäfte auszuschalten “3 Zwei Jahre nach Präsentation ihrer Strategie definiert die EU-Kommission sogar den Konsolidierungsbegriff. Leider geschieht dies vergleichsweise ungenau als „Zusammenfassung mehrerer Körperschaften in einer Gruppe. Eine solche Gruppe kann entweder nur auf der Grundlage des rechtlichen Eigentums definiert werden oder auch unter Einbeziehung von Kriterien wie Leitung und Kontrolle“"4. Diese Definition erweckt den Anschein, als würde die Kommission unter Konsolidierung eine Zusammenfassung im weitesten Sinne verstehen, die sowohl die bloße Zurechnung als auch die Konsolidierung im eigentlichen Sinne umfasst. Terminologische Verwirrung stiftet sie, wenn sie letztere auch als „kombinierte Rechnungslegung“ bezeichnet, die sie als „Konsolidierungskategorie“ auffasst, „die über die rechtliche Definition der konsolidierten Gruppe hinausgeht und innerhalb dieser nur diejenigen Körperschaften bzw. Vorgänge erfasst, die wirtschaftlich integriert sind. Die kombinierte Körperschaft („Einheit“) stellt einen einzigen kombinierten Abschluss auf"s. Abgesehen davon, dass es dieser Definition ebenfalls an Präzision mangelt, dürfte zu konstatieren sein, dass der Konsolidierungsbegriff hier nicht allein auf die bloße Zurechnung beschränkt wird. Die letzte Definition

1 Dies nimmt z.B. Jacobs (Internationale Unternehmensbesteuerung, 2002) S. 279 an.

2 Vgl. Kap. IV.2.1.2. Diese Frage wirft z.B. auch Schneider (Konzernrechnungslegung als internationale Gewinnsteuerbemessungsgrundlage, 2003) S. 663-664 auf, der dann für seine weitere Untersuchung eine „echte“ Konsolidierung unterstellt. Interessant ist auch, dass die EU-Kommission bei der Darstellung der Historie entsprechender Initiativen vor der EU-Strategie alle möglichen Berichte, Richtlinien und Richtlinienentwürfe aufzählt, ohne jedoch den entscheidenden Richtlinienentwurf von $1969 \mathrm{zu}$ erwähnen, der zum ersten Mal, zumindest terminologisch, eine konsolidierte steuerliche Gewinnermittlung in die Diskussion einführte; vgl. EU-Kommission (Strategie, 2001) S. 4.

3 EU-Kommission (Strategie, 2001) S. 18.

4 Vgl. EU-Kommission (Ergebnisse, 2003) S. 25.

5 EU-Kommission (Ergebnisse, 2003) S. 25 („combined reporting“ auch in der englische Fassung). 
gibt Anlass zur Vermutung, dass die Kommission ihr Konzept prinzipiell für sämtliche vier Voraussetzungsebenen der Gruppenbesteuerung und damit für sämtliche Konsolidierungsmaßnahmen öffnet ${ }^{1}$.

Wie beim ersten Schritt bleibt auch beim zweiten Schritt die Frage offen, welchen Vorschriften die Konsolidierung folgen soll. Wird der Konsolidierungsbegriff nicht nur auf die Zurechnung beschränkt, ist fraglich, bei welchen Voraussetzungen eine Gruppenbesteuerung überhaupt greift, wie die rechnungslegende Einheit abzugrenzen ist, welche vorbereitenden Maßnahmen notwendig und wie die eigentlichen Konsolidierungsmaßnahmen auszugestalten sind. Die EU-Kommission betont in diesem Zusammenhang, dass die konsolidierte Körperschaftsteuerbemessungsgrundlage einer Unternehmensgruppe nach Maßgabe eines einzigen Regelwerks erstellt werden sollte ${ }^{2}$. Hinsichtlich der Frage, welches Regelwerk dazu herangezogen werden könnte, werden bereits in der Basisstudie vier alternative Lösungsszenarien vorgeschlagen ${ }^{3}$ :

- Home State Taxation (HST): Die Gesamtgewinnermittlung der gesamten Unternehmensgruppe folgt hiernach den Regeln des Sitzstaates, in dem die Obergesellschaft steuerlich ansässig ist ${ }^{4}$.

- Common (Consolidated) Tax Base (CCTB): Die Gesamtgewinnermittlung folgt hiernach einem einheitlichem, neu zu schaffenden Regelsystem, das neben die existierenden einzelstaatlichen Regeln tritt.

- European Union Company Income Tax (EUCIT): Die Gesamtgewinnermittlung folgt hiernach der CCTB-Variante und bietet, streng genommen, hinsichtlich der Frage nach dem Regelwerk keine eigenständige Lösung an. Die berechnete Körperschaftsteuerbemessungsgrundlage wird hier allerdings mit einer eigenen "EUKörperschaftsteuer" belegt.

- Single Compulsory 'Harmonised Tax Base' (HTB): Diese Alternative sieht die Harmonisierung nationaler Gewinnermittlungsvorschriften vor, so dass die Gesamtgewinnermittlung den harmonisierten und insofern vereinheitlichten Regelwerken der Mitgliedstaaten folgen kann.

Ohne an dieser Stelle sämtliche Probleme diskutieren zu wollen, die mit diesen vier Alternativen einhergehen ${ }^{1}$ - die Literatur räumt ohnehin nur den ersten beiden Alterna-

1 Daraus folgt, dass eine vier Ebenen umfassende Gruppenbesteuerung nur eine von mehreren Umsetzungsmöglichkeiten ist; vgl. zu diesen vier Voraussetzungsebenen Abb. 10 in Kap. IV.1.1.

2 Vgl. z.B. EU-Kommission (Strategie, 2001) S. 18.

3 Vgl. EU-Kommission (Company Taxation, 2001) S. 373-378; dazu im Überblick auch Kroppen/Rasch (Unternehmensbesteuerung in der Europäischen Union, 2002) S. 504-506.

4 Die HST-Alternative sollte in Ansätzen bereits in dem 1969 geplanten „System des konsolidierten Gewinns“ eine Rolle spielen; vgl. Scheuchzer (Konzernbesteuerung, 1994) S. 225, 227. Vgl. zur HST ausfuhrlich Lodin/Gammie (Home State Taxation, 2001). 
tiven Umsetzungschancen ein ${ }^{2}$-, wird auch die Frage nach den Konsolidierungsvorschriften nicht abschließend beantwortet. Alle vier Umsetzungsalternativen lassen die Frage offen, nach welchen konkreten Vorschriften insbesondere der zweite (Konsolidierungs-)Schritt zu erfolgen hat. Selbst die HST-Alternative kann diese Frage auf allen vier Ebenen eines Gruppenbesteuerungssystems - wie in Kapitel IV.1 gezeigt - nur für vier Mitgliedstaaten beantworten ${ }^{3}$. Die Ausgestaltung der Konsolidierung bleibt insofern offen. So stellt die EU-Kommission zwei Jahre nach Bekanntgabe ihrer Strategie fest: „Die Ausarbeitung von Regelungen für die Konsolidierung zählt zu den schwierigsten Aspekten der Schaffung einer einheitlichen Steuerbemessungsgrundlage ${ }^{64}$. Klar scheint lediglich, dass sich die Abgrenzung der rechnungslegenden Einheit und der daraus abgeleitete Konsolidierungskreis nur innerhalb der EU-Grenzen vollziehen kann. Ein „Weltabschlussprinzip“, z.B. nach Maßgabe der deutschen handelsrechtlichen Rechnungslegung ( $\$ 294$ HGB), wird es nicht geben. Für Unternehmensgruppen, zu denen auch außereuropäische Gesellschaften gehören, ist damit schon von vornherein keine vollwertige Einheitsbesteuerung mehr möglich ${ }^{5}$.

Ist die letztgenaninte Eingrenzung des Konsolidierungskreises bereits eine Konsequenz rechtlicher Rahmenbedingungen, so gilt dies auch für den dritten Schritt, der Aufteilung des Gesamtergebnisses auf die Unternehmen der Gruppe. Dieser Schritt ist notwendig, um die Steuerwirkungen auf die betroffenen Vertragspartner der Unternehmen bzw. Mitgliedstaaten der EU verteilen zu können. Letztlich konzentriert sich diese Verteilung auf die einzelnen Unternehmen, da auch die Aufkommensverteilung zwischen den Mitgliedstaaten von der EU-Kommission auf der „Mikro-Ebene“, d.h. auf der Ebene der Unternehmen angesiedelt wird ${ }^{6}$. Angesichts der weiter existierenden nationalen Fiskalsouveränität sollen die Mitgliedstaaten auf die Bemessungsgrundlage, die den bei ihnen

1 Vgl. dazu mehr oder weniger ausführlich Giannini (Home State Taxation, 2002); Mintz (Corporate Tax Harmonization, 2004) S. 226-229; Mintz/Weiner (Formula Allocation, 2003); Mors (Roundtable Discussion, 2002); Oestreicher (Konzernbesteuerung in Europa, 2002) S. 347-348; Schneider (Konzernrechnungslegung als internationale Gewinnsteuerbemessungsgrundlage, 2003) S. 663-664; Sørensen (Company Tax Reform, 2004) S. 92-93, 101-103; Spengel (IAS und Unternehmensbesteuerung, 2003) S. 31-32; Spengel (Einheitliche Bemessungsgrundlage, 2004) S. 105-108; Spengel (Unternehmensbesteuerung in der EU, 2004) S. 136-139; Westberg (Consolidated Corporate Tax Bases, 2002).

$2 \mathrm{Vgl}$. insb. Schneider (Konzernrechnungslegung als internationale Gewinnsteuerbemessungsgrundlage, 2003) S. 664, der Alternative 3 (EUCIT) und 4 (HTB) als „Sirenenklänge ferner Zukunftsmusik“ bezeichnet; ähnlich Spengel/Frebel (Neue Initiativen der EU-Kommission, 2003) S. 789. Vgl. z.B. auch zur ablehnenden Haltung der nationalen Finanzminister gegenüber der EUCIT-Alternative o.V. (EUFinanzminister, 2004) S. 11; o.V. (Mehr Verantwortung, 2004) S. 6.

3 Etwas optimistischer Lodin/Gammie (Home State Taxation, 2001) S. 32, die lapidar erklären, dass mit Ausnahme Belgiens, Griechenlands und Italiens jeder Mitgliedstaat seine (mehr oder minder weitgehende) Form der Gruppenbesteuerung anwenden könnte.

4 EU-Kommission (Ergebnisse, 2003) S. 23. Ähnlich auch EU-Kommission (Unternehmensbesteuerung, 2001): „Die Konsolidierung auf EU-Ebene ist das Schlüsselelement aller Lösungsansätze. ... Es handelt sich hier zweifellos um ein großes und komplexes Vorhaben“.

5 Vgl. dazu Kap. III.2.5.2.

6 Vgl. EU-Kommission (Ergebnisse, 2003) S. 24-25. 
steuerlich ansässigen Unternehmen zugeordnet wird, ihre Körperschaftsteuer auf der Grundlage ihrer nationalen Körperschaftsteuersätze erheben. In diesem Zusammenhang thematisiert die Kommission kaum noch die Erfolgslokalisation nach Maßgabe isolierter Einzelgewinnermittlungen. Möglicherweise haben hier durchführungseffizienzorientierte Argumente den Ausschlag gegen eine aufwendige Doppelrechnung gegeben. Statt dessen schlägt die Kommission eine Aufteilung auf der Grundlage der "Wertschöpfung" vor, die sich z.B. aus den Informationen der indirekten Mehrwertbesteuerung ergeben könnte. Vorrangig ist für sie eine indirekte und damit geschlüsselte Verteilung mittels Formelzerlegung (formula apportionment) ${ }^{1}$. Hier allerdings einen Verteilungsschlüssel zu finden, der sämtliche konfligierenden Interessen der Unternehmensbeteiligten sowie Staaten zum Ausgleich bringt, scheint schwierig ${ }^{2}$. Dies gilt auch vor dem Hintergrund, dass Steuerfragen derzeit und im Rahmen der noch zu ratifizierenden EUVerfassung - selbst nach der Osterweiterung der EU auf insgesamt 25 Mitgliedstaaten im Ministerrat nur einstimmig entschieden werden können ${ }^{3}$.

Angesichts der offenen Fragen und der damit einhergehenden Umsetzungsschwierigkeiten erwägt die EU-Kommission diverse Pilotprojekte z.B. für kleinere und mittelgroße Unternehmen oder die europäische Aktiengesellschaft (SE) wohl auf HST-Basis unter teilweiser Ausklammerung von Konsolidierungsmaßnahmen ${ }^{4}$. An dem längerfristigen Ziel, der Schaffung einer konsolidierten Körperschaftsteuerbemessungsgrundlage für alle betroffenen Unternehmen in der EU, hält sie indes fest. In diesem Zusammenhang wartet sie u.a. auch weitere Expertenmeinungen $\mathrm{ab}^{5}$, die sich auch mit dem folgenden Aspekt beschäftigen.

$1 \mathrm{Vgl}$. EU-Kommission (Ergebnisse, 2003) S. 24-28; dazu bereits EU-Kommission (Company Taxation, 2001) S. 407-415; vgl. ausführlicher und befürwortend zur „value added"-Ausrichtung Hellerstein/McLure (Company Income Taxation, 2004) S. 207-218.

2 Dies erkennt auch die EU-Kommission (Ergebnisse, 2003) S. 24-25, die darin ein schwieriges „Schlüsselelement" (S. 25) erkennt und konstatiert: „Dieser Mechanismus soll gerecht, transparent und verwaltungstechnisch möglichst unkompliziert sein. Er muss wirtschaftlichen Erfordernissen genügen und die politische Zustimmung der Mitgliedstaaten finden“. Vgl. dazu kritisch Hellerstein/McLure (Company Income Taxation, 2004) S. 207-217; Mintz/Weiner (Formula Allocation, 2003) S. 698-709; Schröer (Erfolgsabgrenzungsparadigmen, 2004); Sørensen (Company Tax Reform, 2004) S. 93-101; Sunley (Formulary Apportionment, 2002); Weiner (Formulary Apportionment, 2002); Wellisch (Gewinnaufteilung, 2004).

3 Vgl. diese Schwierigkeit ebenfalls betonend Dautzenberg (Richtlinien, 2004) S. 21.

4 Vgl. EU-Kommission (Strategie, 2001) S. 21; EU-Kommission (Summary Report of the Workshop, 2003) Stichwort "The Societas Europaea (SE) - a possible pilot?"; EU-Kommission (Ergebnisse, 2003) S. 20-21, 28-29; EU-Kommission (Sitzlandbesteuerung bei kleinen und mittleren Unternehmen, 2004); EU-Kommission (possible experimental application, 2004); dazu z.B. auch Spengel (Einheitliche Bemessungsgrundlage, 2004) S. 115-117; Spengel (Unternehmensbesteuerung in der EU, 2004) S. 139-143, 149; Spengel/Frebel (Neue Initiativen der EU-Kommission, 2003) S. 789-792.

5 Vgl. EU-Kommission (Ergebnisse, 2003) S. 28-30. 


\subsubsection{IFRS als möglicher Ausgangspunkt für die Ausgestaltung der steuerlichen Konsolidierung?}

Die offene Frage nach einem Regelwerk für die konsolidierte steuerliche Gewinnermittlung hat die EU-Kommission $2001 \mathrm{zu}$ dem Hinweis verleitet, die IFRS könnten hier "in gewissem Maße einen nützlichen Bezugspunkt abgeben"'. An dieser Stelle wird die oben bereits angesprochene Verbindung der neuen EU-Strategie zur Entwicklung der handelsrechtlichen Rechnungslegung in der EU hin zu den IFRS besonders deutlich. Zwar betont die Kommission, dass ,diese Entwicklung keinen unmittelbaren Zusammenhang mit den Steuern“ aufweise, fügt dem jedoch hinzu, dass ,sie doch ganz allgemein zur Entwicklung einer gemeinsamen Besteuerungsgrundlage beitragen “2 könne. Dabei dürfte sich dieser Hinweis nicht nur auf Ansatz- und Bewertungsfragen erstrecken, sondern insbesondere auch auf die Konsolidierung, deren Ausgestaltung bei allen vier Umsetzungsalternativen offen ist. Die spannungsgeladene Bedeutung dieses Hinweises offenbart sich nun darin, dass das Regelwerk des in London ansässigen International Accounting Standards Board (IASB) tatsächlich Ansatz-, Bewertungs- und auch Konsolidierungsregeln enthält, die jedoch fernab der steuerlichen Gewinnermittlungssphäre in einem völlig anderem institutionellen Umfeld für eine rein informationsorientierte Rechnungslegung entwickelt worden sind.

Die EU-Kommission steht mit ihrem Hinweis auf die IFRS nicht alleine da. Schon im Jahr 2000 hat die Vereinigung europäischer Industrieunternehmen UNICE (Union of Industrial and Employers' Confederations of Europe) eine konsolidierte Körperschaftsteuerbemessungsgrundlage für die EU auf der Basis der IFRS gefordert ${ }^{3}$. Wie ernst die Kommission ihren eigenen Hinweis auf die IFRS genommen hat, zeigt die weitere Entwicklung. Schon im April 2002 ist in Brüssel auf Initiative der Kommission eine „European Conference on Company Taxation" abgehalten worden. Steuerexperten aus Wissenschaft und Praxis, Vertreter der Mitgliedstaaten sowie europäischer Institutionen haben hier nicht nur das Vorhaben einer konsolidierten Körperschaftsteuerbemessungsgrundlage im Grundsatz begrüßt, sondern u.a. auch die Rolle der IFRS im Rahmen dieses Vorhabens als künftigen Forschungsgegenstand identifiziert ${ }^{4}$. Im März 2003 hat an diese Frage ein „Workshop on the application of International Accounting Standards

\footnotetext{
EU-Kommission (Strategie, 2001) S. 21.

EU-Kommission (Strategie, 2001) S. 21 [beide Zitate].

Vgl. UNICE (Memorandum, 2000); s.a. Mintz/Weiner (Formula Allocation, 2003) S. 696.

Vgl. EU-Kommission (Conference, 2002). Ein Jahr später konstatiert allerdings die EU-Kommission (Ergebnisse, 2003) S. 22: „Die einheitliche Steuerbemessungsgrundlage für in der EU tätige Unternehmen scheint inzwischen zwar als langfristiges Ziel der EU-Steuerpolitik anerkannt zu sein und weiterhin Unterstützung zu finden, aber sowohl aufseiten der Wirtschaft als auch in den Steuerverwaltungen finden sich noch grundsätzliche Gegner dieses Konzepts. Selbst manchen Befürwortern liegt der Gedanke an eine grenzüberschreitende Konsolidierung für steuerliche Zwecke noch zu fern, als dass man sich zum jetzigen Zeitpunkt damit befassen sollte"[Hervorhebung auch im Original].
} 
(IAS) in 2005 and the implications for the introduction of a consolidated tax base for companies' EU-wide activities“" angeknüpft. Obwohl die Kommission in dem Konsultationspapier zu diesem Workshop bereits klarstellt, dass es gar nicht zwingend darum gehe, IFRS-konforme Abschlüsse unmittelbar als Bemessungsgrundlage heranzuziehen $^{1}$, ist zwischen den Steuerexperten keinerlei Einigung darüber erzielt worden, inwiefern die IFRS für die konsolidierte steuerliche Gewinnermittlung in der EU von Nutzen sein könnten².

Dieser fehlende Konsens erstreckt sich auch auf die Frage der steuerlichen Konsolidierung $^{3}$. Da das Konsolidierungsvorhaben insgesamt als überaus ambitioniert angesehen wird, gibt es sogar Stimmen, die ein zweistufiges Verfahren fordern, das sich erst der Gewinnermittlung an sich (Ansatz und Bewertung) und erst anschließend der schwierigen Frage der Konsolidierung widmet. „As a result there was not very much discussion of the consolidation techniques themselves" ${ }^{64}$.

Nach diesem Workshop hat die EU-Kommission ihr Bestreben keineswegs aufgegeben, bei der Ausgestaltung der konsolidierten steuerlichen Gewinnermittlung auf die IFRS zuzugreifen. Einerseits ist die Kommission hinsichtlich der Konsolidierung ,nach wie vor der Auffassung, dass sie die wirksamste Möglichkeit zur Lösung der steuerlichen Probleme darstellt und langfristig als einer der wesentlichen Aspekte der einheitlichen Steuerbemessungsgrundlage anzusehen ist ${ }^{\text {" }}$. Andererseits bilden die IFRS immer noch „den einzigen verfügbaren neutralen ${ }^{6}$ Ausgangspunkt für die Debatte ${ }^{67}$. Obwohl die Maßgeblichkeit auf EU-Ebene im Zusammenhang mit der EU-Strategie noch in der Diskussion ist ${ }^{8}$, wird nicht mehr angenommen, dass eine konsolidierte IFRS-Bilanz unmittelbar und ohne weitere Modifikationen in die konsolidierte steuerliche Gewinnermittlung übernommen werden kann?. Für die insofern notwendige Suche nach einer steuerspezifischen Konsolidierung dürften die IFRS-Einzelregeln ihre Relevanz als Regulierungsvorbild aber nicht verloren haben. Wird in ihnen ein Ausgangspunkt der Re-

1 Vgl. EU-Kommission (Konsultationspapier, 2003) S. 3: „Ein IAS-konformer Abschluss wäre natürlich allenfalls ein Ausgangspunkt für die Ermittlung einer einheitlichen Steuerbemessungsgrundlage und nicht die Bemessungsgrundlage selbst"; ähnlich auch EU-Kommission (Ergebnisse, 2003) S. 19.

2 Nach der EU-Kommission (Ergebnisse, 2003) S. 19 ,waren die Meinungen geteilt“.

3 Vgl. EU-Kommission (Ergebnisse, 2003) S. 22-23; EU-Kommission (Summary Report of the Workshop, 2003) Stichwort "Consolidation". Der Konsolidierungsaspekt ist von der EU-Kommission (Konsultationspapier, 2003) S. 3-4, 16, 21 zuvor auch explizit angesprochen worden.

4 EU-Kommission (Summary Report of the Workshop, 2003) Stichwort "Consolidation".

5 EU-Kommission (Ergebnisse, 2003) S. 22.

6 Fraglich ist in diesem Zusammenhang, wie dieser Neutralitätsbegriff zu interpretieren ist. Es scheint eher unwahrscheinlich, dass die Kommission die IFRS hier als entscheidungsneutrale Gewinnermittlungsregeln bezeichnet haben könnte.

7 EU-Kommission (Ergebnisse, 2003) S. 22.

8 Vgl. EU-Kommission (Konsultationspapier, 2003) S. 21; EU-Kommission (Ergebnisse, 2003) S. $20-$ 23.

9 Vgl. EU-Kommission (Ergebnisse, 2003) S. 22-23. 
gulierungs- bzw. Ausgestaltungsdebatte erkannt, erfordert dies eine differenzierte, einzelregelorientierte Eignungsprüfung. Folgerichtig betont die EU-Kommission übrigens im Einklang mit den Forderungen des Workshops im Februar 2003 - dass die steuerlichen Möglichkeiten der IFRS eigentlich tiefergehend, anhand zuvor definierter, grundlegender und gemeinsamer Prinzipien der steuerlichen Gewinnermittlung, analysiert werden müssten ${ }^{1}$. Zu einer konsequenten Verfolgung dieses Weges ist sie aber wohl nicht bereit: Dieser Weg, ,nämlich zunächst die steuerlichen Erfordernisse zu definieren, erscheint auf den ersten Blick zwar als geradezu perfekte Lösung, aber es bestünde die Gefahr, dass dies in eine langwierige akademische Diskussion ausartet, die nicht in angemessener Zeit zu einer pragmatischen und funktionsfähigen Lösung führt"s2.

Das nachfolgende Kapitel V dient genau dieser ,akademischen Diskussion“. Dort sollen die einzelnen IFRS auf ihre Eignung für eine konsolidierte steuerliche Gewinnermittlung hin untersucht werden. Dies beschränkt sich auf die hier im Vordergrund stehenden Konsolidierungsregeln. Insbesondere in Kapitel II sind die notwendigen ,steuerlichen Erfordernisse" definiert worden, die dabei als normativer Beurteilungsrahmen Verwendung finden sollen. Berücksichtigung finden auch die rechtlichen Rahmenbedingungen (Kapitel III) und die Erkenntnisse aus dem europäischen Rechtsvergleich (Kapitel IV.1).

\section{Zwischenergebnis}

In diesem vierten Kapitel stand die Frage im Vordergrund, ob es auf europäischer Ebene bereits Erfahrungen mit der Ausgestaltung einer konsolidierten steuerlichen Gewinnermittlung gibt.

Auf der Ebene der Mitgliedstaaten sind in Frankreich, Portugal, Spanien und den Niederlanden vier Gruppenbesteuerungssysteme identifiziert worden, die neben der Vermeidung einer Mehrfachbesteuerung gruppenintern ausgeschütteter Dividenden und dem gruppeninternen Verlustausgleich auch Elemente der Zwischenergebniseliminierung sowie sonstiger Formen der Konsolidierung aufweisen. Trotz der bestehenden Systemunterschiede ergeben sich in diesen vier „Konsolidierungsstaaten“ durchaus Parallelen, die von der Abgrenzung des Konsolidierungskreises über die konsolidierungstechnische Ausgestaltung bis hin zu den Rechtsfolgen reichen. So werden die Gruppenbesteuerungssysteme den Unternehmen in allen vier Staaten als Wahlrecht vorgegeben, in zwei Staaten (Frankreich, Niederlande) erstreckt sich dieses Wahlrecht gar auf die Abgrenzung des Konsolidierungskreises. Letzterer ist zudem auf „Inlandsgruppen“ be-

1 Vgl. EU-Kommission (Summary Report of the Workshop, 2003) Stichwort "The general principles of IAS"; EU-Kommission (Ergebnisse, 2003) S. 20.

2 EU-Kommission (Ergebnisse, 2003) S. 20. 
schränkt und basiert auf der alleinigen Ausrichtung an hohen, auf Stimmrechte und Kapitalanteile zielenden Beteiligungsquote. Auch knüpfen die Rechtsfolgen der Gruppenbesteuerung auch weiterhin an den einzelnen Unternehmen der Gruppe, insbesondere aber an der Obergesellschaft an.

Bei der Konsolidierungstechnik ergeben sich noch die größten Unterschiede. Das französische Zurechnungsmodell begnügt sich letztlich mit der Modifizierung betroffener Einzelgewinnermittlungen, die sich auf die außerbilanzielle Ergebnisbereinigung zum Zwecke einer partiellen Zwischenergebniseliminierung und Schuldenkonsolidierung konzentriert. Eine klassische Konsolidierung in der realtypischen Variante findet sich hingegen in Portugal und Spanien, die der steuerlichen Gesamtgewinnermittlung eine konsolidierte Bestands- und Stromgrößenrechnung zu Grunde legen, die alle Konsolidierungsmaßnahmen umfasst. Das niederländische Modell weist demgegenüber in Richtung einer idealtypischen Variante. Die steuerliche Gewinnermittlung beruht hier eher auf einer originären Gesamtgewinnermittlung, bei der sich die Konsolidierungsmaßnahmen auf die erstmalige Anwendung und Aufhebung der Gruppenbesteuerung und auf Konsolidierungskreisänderungen beschränken. Trotz diverser Abweichungen im Detail ergeben sich bei den Konsolidierungsmaßnahmen aber auch Gemeinsamkeiten. Das betrifft zum einen die eher einheitstheoretische Ausrichtung auf die Vollkonsolidierung, die in zwangsläufig begrenztem Maße selbst für das französische System gilt, in dem gruppeninterne Zwischenergebnisse voll und nicht beteiligungsproportional bereinigt werden. Zum anderen kann festgestellt werden, dass sich die Ergebniswirkungen meist auf die Neutralisierung gruppeninterner Lieferungen und Leistungen beschränken, während sonstige Konsolidierungsvorgänge, insbesondere im Bereich der Kapitalkonsolidierung, eher ergebnisneutral behandelt werden.

In einem zweiten Schritt ist auf Unionsebene untersucht worden, welche Anstrengungen hier insbesondere von Seiten der EU-Kommission existieren, eine konsolidierte steuerliche Gewinnermittlung zu etablieren. Obwohl derartige Anstrengungen identifiziert werden konnten, scheinen sie - wie sämtliche (Harmonisierungs-)Bemühungen im Bereich der direkten Unternehmensbesteuerung - bislang nicht von Erfolg gekrönt. Allerdings strebt die EU-Kommission mit einer 2001 vorgelegten neuen Strategie wiederholt und sehr engagiert ein grenzüberschreitendes Gruppenbesteuerungssystem auf der Basis einer konsolidierten Bemessungsgrundlage an. Bei der Frage, nach welchen Regeln diese Bemessungsgrundlage zu ermitteln ist, hat sie die fernab der steuerlichen Gewinnermittlungssphäre in einem völlig anderen institutionellen und konzeptionellen Umfeld für eine rein informationsorientierte Rechnungslegung entwickelten IFRS als nützlichen „Ausgangspunkt“ benannt. Ob und inwieweit die IFRS dieser Rolle gerecht werden können, wird im nachfolgenden Kapitel untersucht. 
Rolf Uwe Fülbier - 978-3-631-75507-5

Downloaded from PubFactory at 01/11/2019 04:02:44AM 


\section{Kapitel V}

\section{Eignung der IFRS zur Ausgestaltung der steuerlichen Konsolidierung auf EU-Ebene}

Jeder Versuch, die Rechnungslegungsvorschriften der IFRS mit der steuerlichen Gewinnermittlung in Verbindung zu bringen, sollte mit der entsprechenden Eignung der IFRS begründet werden. Dies gilt ebenfalls für den speziellen Aspekt der steuerlichen Konsolidierung. Auch hier ist nachzuweisen, dass eine vollständig oder teilweise nach IFRS durchgeführte Konsolidierung den ökonomischen sowie ethisch-rechtlichen Anforderungen genügt und sich innerhalb der rechtlichen Rahmenbedingungen bewegt. Im Folgenden wird untersucht, ob und inwieweit ein derartiger Nachweis erbracht werden kann.

Trotz der Fokussierung dieser Arbeit auf konsolidierungsspezifische Aspekte soll in einem ersten Schritt vorab die grundsätzliche Eignung der IFRS zur steuerlichen Gewinnermittlung kurz beleuchtet werden. Schließlich ist die Konsolidierung nur ein Bestandteil der steuerlichen Gewinnermittlung, wenn es darum geht, Unternehmensgruppen auf der Basis einer Gesamtgewinnermittlung zu besteuern.

\section{Zur Frage der grundsätzlichen Eignung}

\subsection{Diskussionsstand in der deutschen Maßgeblichkeitsdebatte}

Die Verbindung von steuerlicher Gewinnermittlung und IFRS ist der jüngeren Literatur als Problem nicht fremd. Konsolidierungsspezifische Aspekte spielen dabei jedoch bisher keine nennenswerte Rolle. Auch wird die Diskussion bislang weniger durch die europäische Entwicklung auf dem Gebiet der Unternehmensbesteuerung motiviert. Dies mag schon an der kurzen Zeitspanne liegen, die seit dem Vorschlag der EUKommission verstrichen ist. Wegen der im europäischen Vergleich relativ starken Verknüpfung von Handels- und Steuerbilanz in Deutschland ist hier statt dessen die etwas anders gelagerte - aber verwandte - Frage diskutiert worden, ob sich eine Verbindung von handelsrechtlichem Einzelabschluss und steuerlicher Gewinnermittlung (Maßgeblichkeit) auch bei einer handelsrechtlichen Bilanzierung nach IFRS rechtfertigen ließe. Diese deutsche Maßgeblichkeitsdebatte dürfte auch für andere EU-Staaten typisch sein. 
Schließlich weist die handelsrechtliche Rechnungslegung in der Mehrzahl der EUStaaten Verbindungen zur steuerlichen Gewinnermittlung auf ${ }^{\prime}$.

Unter dem Eindruck einer zunehmend internationalisierten Rechnungslegung ist seit Mitte der neunziger Jahre, spätestens aber mit der Verabschiedung des Kapitalaufnahmeerleichterungsgesetzes 1998 (KapAEG), die Vermutung geäußert worden, die bis dahin auf den handelsrechtlichen Konzernabschluss konzentrierte Entwicklung könne sich über kurz oder lang auch auf den Einzelabschluss und über die Maßgeblichkeit auch auf die steuerliche Gewinnermittlung auswirken. Diese Vermutung hat in Deutschland die ewige Diskussion um den Sinn des Maßgeblichkeitsprinzips ${ }^{2}$ wieder neu belebt. Nach herrschender Meinung wird eine Maßgeblichkeit der IFRS für die steuerliche Gewinnermittlung aber abgelehnt ${ }^{3}$. Obwohl der deutsche Gesetzgeber mit Verabschiedung des Bilanzrechtsreformgesetzes (BilReG) 2004 dieser Meinung vorerst gefolgt ist

1 Eine völlige Trennung von „tax accounting“ und „financial reporting“ ist in Europa nur in Dänemark, Irland, den Niederlanden und in dem Vereinigten Königreich gegeben; vgl. OECD (Relationship between Taxation and Financial Reporting, 1987) S. 9-23, 45; diese Gruppe wird verstärkt durch fast alle der neuen Mitgliedstaaten per 1. Mai 2004, die bis auf Estland keine Maßgeblichkeit kennen; vgl. Spengel (Unternehmensbesteuerung in der EU, 2004) S. 116-118. Vgl. zur Verknüpfung handels- und steuerrechtlicher Gewinnermittlung in anderen Staaten und die dortigen Diskussionen z.B. Pannen (Meßtheoretische Grundprobleme, 2000) S. 241-255; Pocarno/Tran (Relationship, 1998); Wacker (Relative Maßgeblichkeit, 1998) S. 249-252; vgl. z.B. für die britische Sicht Whittington (Tax Policy, 1995). Die Verbindung von IFRS und steuerlicher Gewinnermittlung wird in anderen EU-Staaten noch nicht so intensiv diskutiert; vgl. so die EU-Kommission (Konsultationspapier, 2003) S. 12, die diesbezüglich neben Deutschland nur noch das Vereinigte Königreich bzw. dessen Finanzverwaltung anführt; vgl. dazu Inland Revenue (Reform of Corporation Tax, 2002) S. 2, 4; Inland Revenue (PreBudget Report, 2003) S. 57; Spengel (Einheitliche Bemessungsgrundlage, 2004) S. 112 und Spengel (Unternehmensbesteuerung in der EU, 2004) S. 146, der zudem auf die Absicht in Frankreich, Großbritannien, Österreich und Spanien hinweist, den (handelsrechtlichen) Einzelabschluss für die IFRS zu öffnen, ohne dass daraus allerdings zwingend steuerliche Konsequenzen erwachsen müssen. Rädler (Impact, 2003) S. 466 betont i.d.Zshg., dass die Verbindung zwischen handels- und steuerrechtlicher Rechnungslegung auch die Forschung in vielen EU-Staaten nicht interessiere.

2 Vgl. zu einer umfassenden Aufarbeitung dieser Diskussion Drescher (Zukunft des deutschen Maßgeblichkeitsgrundsatzes, 2002) insb. S. 15-242, 416-605; Schmidt (Maßgeblichkeitsprinzip, 1994); für einen kürzeren Überblick vgl. z.B. Haller (Grundsatz der Maßgeblichkeit, 1992); Hennrichs (Maßgeblichkeitsgrundsatz, 1999); zur Historie Schneider (Entstehung des Maßgeblichkeitsprinzips, 1991).

3 Vgl. zu dieser Einschätzung trotz abweichender Ansicht Spengel (Unternehmensbesteuerung in der EU, 2004) S. 146; eher ablehnend äußern sich u.a. Arbeitskreis Bilanzrecht (Fortentwicklung des deutschen Bilanzrechts, 2002) S. 2380-2381; Böcking (IAS für Konzern- und Einzelabschluss, 2002) S. 927; Busse von Colbe (Entwicklungsperspektiven, 2002) S. 169-170; Euler (Steuerbilanzielle Konsequenzen, 1998) S. 23-24; Fülbier/Gassen (Wider die Maßgeblichkeit, 1999); Herzig (Internationalisierung, 2000) S. 118; Herzig/Bär (Zukunft der steuerlichen Gewinnermittlung, 2003) S. 4-5; Herzig/Hausen (Einnahmenüberschussrechnung, 2004) S. 1; van Hulle (Reform, 2000) S. 548; Kahle (Maßgeblichkeitsgrundsatz, 2002) S. 188; Kußmaul/Klein (Überlegungen zum Maßgeblichkeitsprinzip, 2001) S. 548; Niehus (Einzelabschlüsse, 2001) S. 748 -750; Pannen (Meßtheoretische Grundprobleme, 2000) S. 241-290; Robisch/Treisch (Neuere Entwicklungen, 1997) S. 164; Schneider (Konzernrechnungslegung als internationale Gewinnsteuerbemessungsgrundlage, 2003) S. 669; SchulzeOsterloh (Handels- und Steuerbilanz, 2000) S. 602; Strunk (Ende der Maßgeblichkeit, 2003); Thiel (Maßgeblichkeit, 1998) S. 99-102; Wagner (Aufgabe der Maßgeblichkeit, 1998); Weber-Grellet (Maßgeblichkeitsgrundsatz, 1997) S. 388, 391; Zeitler (Übernahme der IAS, 2003). 
und die fakultative Anwendung der IFRS im Einzelabschluss auf Offenlegungszwecke beschränkt hat (Art. 1 Nr. 29 BilReG, § 325 Abs. 2a, 2b HGB), scheint die Maßgeblichkeitsdiskussion noch nicht abgeschlossen und für die hiervon losgelöste Frage der generellen steuerlichen Eignung der IFRS weiterhin interessant. Neben den ohnehin gegen die Maßgeblichkeit sprechenden Argumenten ${ }^{1}$ sind durch die veränderten Gewinnermittlungsregeln formell-rechtliche und materiell-inhaltliche Bedenken hinzugekommen, die im Folgenden kurz skizziert werden.

Formell-rechtliche Einwände ergeben sich bereits durch das eventuell nicht alle rechnungslegungspflichtigen Unternehmen betreffende Ersetzen traditioneller handelsrechtlicher Gewinnermittlungsvorschriften durch die IFRS. Bei einer lediglich fakultativen Anwendungsmöglichkeit der IFRS im Einzelabschluss würde der Grundsatz der Gleichmäßigkeit der Besteuerung ebenso verletzt wie bei einer nur auf eine bestimmte Unternehmensgruppe beschränkten Anwendungspflicht oder -möglichkeit ${ }^{2}$. Dieser Einwand ist allerdings kein IFRS-spezifischer Nachteil, da er im Rahmen einer geeigneten, alle Unternehmen gleichermaßen betreffenden Regulierung ausgeräumt werden kann. IFRSspezifisch ist indes die Tatsache, dass die IFRS von einem privatwirtschaftlich organisierten Rechnungslegungsgremium, dem IASB in London, entwickelt werden ${ }^{3}$. Mangels Gesetzescharakter der induktiv entwickelten IFRS sei das verfassungsrechtliche Legalitätsprinzip, insbesondere der Grundsatz des Gesetzes- und Parlamentsvorbehalts bei ihnen nicht gewahrt. Die (deduktive) Bestimmung der steuerlichen Bemessungsgrundlage könne nicht in die Hände eines privaten Gremiums mit Sitz im Ausland verlagert werden. Die Tatsache, dass die IFRS durch EU-Verordnung und dort vorgesehene „Anerkennungsmechanismen" (Endorsement) unmittelbar anzuwendendes Recht darstellen ${ }^{4}$, könne diese verfassungsrechtlichen Bedenken wohl nicht völlig ausräumen ${ }^{5}$, ebenso wie dynamische Gesetzesverweise im Steuerrecht. Auch statische Verweise oder gar die vollständige Aufnahme der IFRS ins Steuerrecht lösten das

1 Vgl. z.B. Pannen (Meßtheoretische Grundprobleme, 2000) S. 50-75, 136-138, 191-240; Schneider (Maßgeblichkeit, 1978). Fragen der umgekehrten oder verlängerten Maßgeblichkeit werden in dieser Arbeit ausgeblendet.

2 Vgl. u.a. Kahle (Maßgeblichkeitsgrundsatz, 2002) S. 179; Zeitler (Übernahme der IAS, 2003) S. 1532; mit Bezug auf die EU-Strategie auch Schreiber (Unternehmensbesteuerung, 2004) S. 225.

3 Das IASB ist rechtlich in die International Accounting Standards Committee Foundation (IASCF) eingebunden, die als rechtsfähige Stiftung nach US-amerikanischem Recht in Delaware ansässig ist.

4 Vgl. hierzu ausführlicher Pellens/Fülbier/Gassen (Internationale Rechnungslegung, 2004) S. 89-92.

5 Vgl. m.w.N. Herzig (IAS/IFRS, 2004) S. 31; Zeitler (Übernahme der IAS, 2003) S. 1532-1533; a.A. wohl Oestreicher/Spengel (Anwendung von IAS in der EU, 2001) S. 891-892; Spengel (IAS und Unternehmensbesteuerung, 2003) S. 31; Spengel (Besteuerung, 2004) S. 132; relativierend Spengel (Einheitliche Bemessungsgrundlage, 2004) S. 111; EU-Kommission (Konsultationspapier, 2003) S. 18-19. 
die vollständige Aufnahme der IFRS ins Steuerrecht lösten das Problem schon angesichts des überaus dynamischen Charakters des IFRS-Systems nur unzureichend ${ }^{1}$.

Aus materiell-inhaltlicher Sicht wird regelmäßig auf die Zweckdivergenz zwischen steuerlicher Gewinnermittlung sowie IFRS-Rechnungslegung abgestellt, die die konzeptionelle Rechtfertigungsgrundlage für eine Verknüpfung von handels- und steuerrechtlicher Rechnungslegung erschüttere ${ }^{2}$. Der Zweck der steuerlichen Gewinnermittlung wird in diesem Zusammenhang meist nur ethisch-rechtlich begründet. Hiernach entspreche eine steuerliche Gewinnermittlung nach Maßgabe der steuerlichen Leistungsfähigkeit, die aus der Vorgabe einer gleichmäßigen Besteuerung abgeleitet werde, nicht der kapitalmarkt- und damit rein informationsorientierten Ausrichtung der IFRS, sondern sei ihr, geradezu diametral entgegengesetzt ${ }^{\star 3}$.

Interessant ist allerdings, dass die Zweckdivergenz von einigen Autoren zwar nicht kategorisch geleugnet, als grundsätzliches Argument gegen die Maßgeblichkeit aber nicht akzeptiert wird. So wird auf Gemeinsamkeiten bei dem symmetrischen, nicht imparitätisch verzerrten Periodisierungskonzept und insbesondere bei den Objektivierungsanforderungen verwiesen ${ }^{4}$ und letztlich angedeutet, dass ein nach IFRS ermittelter Gewinn

1 Vgl. insb. Arbeitskreis Bilanzrecht (Fortentwicklung des deutschen Bilanzrechts, 2002) S. 2378-2379; Eberhartinger (Ertragsteuerliche Konsequenzen, 2000) S. 256-260; Herzig (Internationalisierung, 2000) S. 116, 118; Herzig/Hausen (Einnahmenüberschussrechnung, 2004) S. 1; Kahle (Europarechtliche Einflüsse, 2001) S. 135-136; Kahle (Internationale Rechnungslegung, 2002) S. 215-222; Kahle (Maßgeblichkeitsgrundsatz, 2002) S. 186-188; Kahle (Zukunft der Rechnungslegung, 2003) S. 271; Müller (Maßgeblichkeitsprinzip, 2001) S. 1861-1862; Scheffler (Zukunft des Maßgeblichkeitsprinzips, 2001) S. 152; Schreiber (Rechnungslegung im Einzelabschluß, 1999) S. 903; Schulze-Osterloh (Handels- und Steuerbilanz, 2000) S. 602; Zabel (IAS, 2002) S. 922. Vgl. bereits zu den formellrechtlichen Problemen bei der Übernahme der IFRS in das Handelsrecht durch § 292a HGB Heintzen (Verfassungsrechtliche Anforderungen, 2001); Hommelhoff/Schwab (Gesellschaftliche Selbststeuerung, 1998); Kirchhof (private Regelsetzung, 2000).

2 Vgl. stellvertretend Pannen (Meßtheoretische Grundprobleme, 2000) S. 285-290.

3 Arbeitskreis Bilanzrecht (Fortentwicklung des deutschen Bilanzrechts, 2002) S. 2379. Vgl. zu dem Zweckdivergenz-Argument in der Maßgeblichkeitsdebatte u.a. auch Euler (Steuerbilanzielle Konsequenzen, 1998) S. 23; Herzig/Hausen (Einnahmenüberschussrechnung, 2004) S. 1; Kußmaul/Klein (Überlegungen zum Maßgeblichkeitsprinzip, 2001) S. 548; Möhlmann-Mahlau/Gerken/Grotheer (IFRS im Einzelabschluss, 2004) S. 921; Niehus (Einzelabschlüsse, 2001) S. 748; Robisch/Treisch (Neuere Entwicklungen, 1997) S. 164; Weber-Grellet (Maßgeblichkeitsgrundsatz, 1997) S. 387-388.

4 Vgl. (z.T. auch mit Bezug auf die US-Situation das dortige Verhältnis von tax-income und bookincome) Bippus (US-amerikanische Grundsätze, 1998) S. 650; Kahle (Europarechtliche Einflüsse, 2001) S. 134-135; Kahle (Internationale Rechnungslegung, 2002) S. 183-187; Kahle (Zukunft der Rechnungslegung, 2003) S. 271; Oestreicher/Spengel (International Accounting Standards, 1999) S. S. 593-595; Oestreicher/Spengel (Anwendung von IAS in der EU, 2001) S. 892-894; Schreiber (Rechnungslegung im Einzelabschluß, 1999) S. 896; Schreiber (Gewinnermittlung, 2002) S. 114; Spengel (IAS und Unternehmensbesteuerung, 2003) S. 34; regelmäßig wird hierbei auch darauf verwiesen, dass eventuellen Entobjektivierungen - nicht ganz im Sinne einer uneingeschränkten Maßgeblichkeit - durch originäre steuerliche Vorschriften begegnet werden könne. 
möglicherweise auch den Anforderungen steuerlicher Leistungsfähigkeit genüge ${ }^{1}$. Auch wenn diesen Autoren - wie in den folgenden Kapiteln zu zeigen sein wird - im Ergebnis nicht zuzustimmen ist, haben sie dennoch darlegen können, dass ein lapidarer Hinweis auf unterschiedliche Zwecke allein nicht ausreicht, die steuerliche Eignung der IFRS zu diskreditieren, und dass gerade an dieser Stelle eine tiefergehende Auseinandersetzung notwendig ist ${ }^{2}$.

Materielle Kritik richtet sich auch gegen zahlreiche Beurteilungsspielräume im Rahmen der IFRS, die mit den besonderen Objektivierungsanforderungen des Steuerrechts konfligierten ${ }^{3}$. Anderslautende Wertungen ${ }^{4}$ stellen an dieser Stelle wohl nur auf die (wenigen) expliziten, nicht jedoch auf die (vielen) impliziten Wahlrechte in den IFRS $a b^{5}$.

Zudem existieren Befürchtungen, dass eine Maßgeblichkeit der IFRS zu einer erheblichen Steigerung der Gesamtsteuerbelastung führe ${ }^{6}$. Solange sich Unterschiede in pagatorisch abgesicherten Rechnungslegungssystemen bei Gültigkeit des Kongruenzprinzips in einer Totalperiode immer wieder ausgleichen, dürfte es sich hierbei aber „nur“ um Zins- und einmalige Umstellungseffekte handeln ${ }^{7}$. Zinsunabhängige Belastungseffekte auch über eine Totalperiode hinweg sind durch die zunehmende Abkehr der IFRS vom Grundsatz der Kongruenz allerdings nicht mehr auszuschließen ${ }^{8}$. Diese dürften aber eher in umgekehrter Richtung entstehen, da Kongruenzverstöße (noch) mit einer leicht imparitätischen Vorgehensweise einhergehen. Im Wesentlichen geht es in diesem Zusammenhang um die ergebnisneutrale Neubewertung von Sachanlagen oder immateriellen Vermögenswerten, bei denen Wertminderungen unter die (fortgeführten) Buchwerte ergebniswirksam zu erfassen sind, während Wertsteigerungen darüber hinaus aber neutral im Eigenkapital erfasst werden können. Im letzteren Fall muss der insoweit erhöhte

1 Vgl. Oestreicher/Spengel (Replik, 1999) S. 1514; Oestreicher/Spengel (Anwendung von IAS in der EU, 2001) S. 893; Spengel (IAS und Unternehmensbesteuerung, 2003) S. 35; etwas zurückhaltender auch $B M F$ (Internationalisierung der Rechnungslegung, 2002) S. 67-68.

2 Vgl. treffend i.d.Zshg. Herzig/Dautzenberg (Auswirkungen der Internationalisierung, 1998) S. 35, die konstatieren, dass die Internationalisierung der Rechnungslegung die Frage nach der Begründbarkeit der wie auch immer zu gestaltenden steuerlichen Gewinnermittlungsregeln in aller Schärfe aufwirft.

3 Vgl. insb. Arbeitskreis Bilanzrecht (Fortentwicklung des deutschen Bilanzrechts, 2002) S. 2379-2380; gegen IFRS-Wahlrechte wendet sich aus steuerlicher Sicht auch Schneider (IAS als Besteuerungsgrundlage, 2003) S. 300.

4 Vgl. z.B. Oestreicher/Spengel (International Accounting Standards, 1999) S. 594.

5 Vgl. zu dieser Differenzierung der Wahlrechte bereits Kap. II.2.1.2.3.

6 Vgl. Schroller (Zukunft des Maßgeblichkeitsgrundsatzes, 2000) S. 368 mit Bezug auf Oestreicher/Spengel (Maßgeblichkeit der International Accounting Standards, 1999) S. 555-562 bzw. Oestreicher/Spengel (International Accounting Standards, 1999) S. 599, die dies später aber revidieren; vgl. Oestreicher/Spengel (Anwendung von IAS in der EU, 2001) S. 894-902.

7 Vgl. z.B. Biener (Internationalisierung, 1997) S. 348; Eberhartinger (Ertragsteuerliche Konsequenzen 2000) S. 273; Fülbier/Gassen (Wider die Maßgeblichkeit, 1999) S. 1513; Selchert (Internationalisierung der Rechnungslegung, 1999) S. 924-928.

8 Vgl. zu Verletzungen des Kongruenzprinzips unter IFRS insb. Ordelheide (clean surplus, 1998); Schildbach (Kongruenz, 1999). 
Wertansatz im Rahmen der Folgebewertung dennoch ergebniswirksam abgeschrieben werden, während der Eigenkapitalposten ergebnisneutral aufzulösen ist ${ }^{1}$. Damit könnten steuerlich abzugsfähige Betriebsausgaben generiert werden, die nicht mit korrespondierenden Erträgen einhergehen. Die aus ökonomischer wie verfassungsrechtlicher Sicht gebotene Erfassung des Totaleinkommens scheint damit nicht gewährleistet ${ }^{2}$. Den Unternehmen stünde zudem ein kaum akzeptables Selbsteinsteuerungsinstrument zur Verfügung, da diese Art der Neubewertung auch noch als explizites Bewertungswahlrecht ausgestaltet ist.

Etwa seit der Jahrtausendwende wird die Maßgeblichkeitsdebatte auch durch umfassende Studien bereichert, die mögliche Auswirkungen der IFRS-Rechnungslegung auf die steuerliche Gewinnermittlung modelltheoretisch analysieren. So haben Oestreicher/Spengel in einem Gutachten für das deutsche Bundesministerium der Finanzen und weiteren Folgeuntersuchungen die steuerliche Aufkommenswirkung der IFRS im Rahmen eines computergestützten Simulationsmodells untersucht ${ }^{3}$. Im Ergebnis befürworten die Autoren ein Beibehalten des Maßgeblichkeitsprinzips unter der Voraussetzung, dass der Rechtsnormcharakter der Gewinnermittlungsgrundsätze gewahrt werden könne. Bei einer uneingeschränkten Maßgeblichkeit der IFRS errechnen sie gegenüber der derzeit geltenden Situation eine geringere Steuerbelastung deutscher Unternehmen und eine relativ bessere Wettbewerbsposition gegenüber europäischen und USamerikanischen Mitbewerbern ${ }^{4}$.

Auf die Steuerbelastung als primären Beurteilungsmaßstab stützen sich auch weitere Untersuchungen. Während Rahlf in einer computergestützten Veranlagungssimulation bei einer uneingeschränkten Maßgeblichkeit der IFRS eine geringfügig höhere Steuerbelastung errechnet ${ }^{5}$, kommt Schaffer in seiner argumentativen, teils fallstudienartigen

1 Vgl. zu diesbezüglichen Beispielen für IAS 16 und IAS 38 Pellens/Fülbier/Gassen (Internationale Rechnungslegung, 2004) S. 267-270; 293-296.

2 Vgl. Kap. II.2.1.2.3 und II.2.2.2; s.a. Herzig (IAS/IFRS, 2004) S. 19-20, 217-227, der den Grundsatz der Totalgewinngleichheit bei allen steuerlichen Gewinnermittlungsmethoden einfordert.

3 Vgl. Oestreicher/Spengel (Maßgeblichkeit der International Accounting Standards, 1999); dazu auch Oestreicher/Spengel (International Accounting Standards, 1999); Oestreicher/Schmidt/Spengel (Steuerliche Gewinnermittlung, 1999); Oestreicher/Spengel (Anwendung von IAS in der EU, 2001).

4 Vgl. Oestreicher/Spengel (Anwendung von IAS in der EU, 2001) S. 894-902, die sich bei dieser Folgestudie auf den Rechtsstand vom 1.1.2001 stützen. Bei der Vorgängerstudie wird noch eine erhöhte Steuerbelastung deutscher Unternehmen und positive Aufkommenseffekte errechnet, eine Beibehaltung des Maßgeblichkeitsprinzips aber gleichfalls befürwortet. Vgl. zur Kritik an diesen Ergebnissen Fülbier/Gassen (Wider die Maßgeblichkeit, 1999); Oestreicher/Spengel (Replik, 1999); Schneider (IAS als Besteuerungsgrundlage, 2003) S. 303; Schildbach (IAS, 2002) S. 274. Vgl. generell kritisch zu Steuerbelastungsvergleichen z.B. Elschen (Entscheidungsneutralität, 1991) S. 105-106; Schneider (Meßkonzepte zur Steuerbelastung, 1990); zum European Tax Analyzer konkret Niemann/Bachmann/Knirsch (European Tax Analyzer, 2003).

5 Vgl. Rahlf(IAS-Bilanzierung und Besteuerung, 2000) insb. S. 169-174, der allerdings auch das realistischere Szenario einer IFRS-Maßgeblichkeit unter Beachtung des Bewertungsvorbehalts des EStG untersucht und hier keine Abweichungen von der bisherigen Besteuerungssituation feststellen kann. 
Veranlagungssimulation zu dem Ergebnis, dass eine steuerliche Mehrbelastung durch die IFRS (und auch US-GAAP) nicht zu erwarten und das Maßgeblichkeitsprinzip demnach nicht gefährdet sei ${ }^{1}$. Eine Maßgeblichkeit der IFRS (sowie der US-GAAP) sieht Eberhartinger als sehr problembehaftet aber ebenfalls noch möglich an. Auf der Basis einer Untersuchung ausgewählter Aspekte der steuerlichen Gewinnermittlung identifiziert sie bei einer Gewinnermittlung nach IFRS (und US-GAAP) gegenüber der bisherigen österreichischen Gewinnermittlung eine Tendenz zur Vorverlagerung von Gewinnen und damit eine Erhöhung des Steuerbarwertes ${ }^{2}$.

Im Rahmen einer theoretischen Analyse exemplarisch ausgewählter und gegenübergestellter HGB- und IFRS-Vorschriften kommt Eichhorn zu dem Ergebnis, dass die IFRS den Anforderungen der steuerlichen Gewinnermittlung eher genügen ${ }^{3}$. Dabei bedient er sich eines normativen Beurteilungsrahmens, der auf den Anforderungen einer gleichmäßigen und neutralen Besteuerung basieren soll. Während er die ethische Komponente über eine Kombination von Reinvermögenszugangs- und -zuwachstheorie konkretisiert $^{4}$, vollzieht er die wirkungsorientierte ökonomische Beurteilung auf der Grundlage der Investitionsneutralität. Letztere drückt sich darin aus, dass er unter der gebotenen modellmäßigen Vereinfachung die effektiven Grenzsteuerbelastungen beispielhaft ausgewählter Gewinnermittlungsvorschriften mit der Grenzsteuerbelastung des kapitaltheoretischen Gewinns vergleicht.

Methodisch ähnlich nähert sich Gröning der Thematik, stellt dabei allerdings nicht auf die IFRS, sondern allein auf US-GAAP $a^{5}$. Seiner Eignungsanalyse liegt ebenfalls ein ethisch-rechtlich abgeleiteter Beurteilungsrahmen zu Grunde, der sich allerdings an dem realisierten Reinvermögenszugang von Schneider orientiert. Auch Neutralitätseigenschaften werden untersucht. Wie Eichhorn bedient er sich ausgewählter modellgestützter Musterbeispiele, in denen US-GAAP-Gewinne am „Eichstrich“ einer entscheidungsneutralen Gewinnermittlung durch den kapitaltheoretischen Gewinn gemessen werden. Daraufhin kommt er zu dem Ergebnis, dass US-GAAP für Zwecke der steuerlichen Gewinnermittlung nicht taugen - im Übrigen ebenso, wie die handelsrechtlichen Vorschriften - und die Maßgeblichkeit dieses Rechnungslegungssystems für die steuerliche Gewinnermittlung abzulehnen sei.

In einem weiteren Gutachten für das Bundesministerium der Finanzen hat sich auch Herzig mit der Frage beschäftigt, ob Ansatz- und Bewertungsregeln der IFRS der steu-

Vgl. Schaffer (Übernahme internationaler Normen, 2000).

Vgl. Eberhartinger (Ertragsteuerliche Konsequenzen, 2000) insb. S. 237-386.

Vgl. Eichhorn (Maßgeblichkeitsprinzip, 2001).

Vgl. zu einer ähnlichen Kombination bereits Kraft (Steuergerechtigkeit, 1991) S. 61-102.

Vgl. Gröning (Steuerbilanzielle Gewinnermittlung, 2002). Die Berücksichtigung dieser Untersuchung rechtfertigt sich durch die konzeptionelle Nähe der beiden Rechnungslegungssysteme IAS und USGAAP; vgl. dazu z.B. Pellens/Fülbier/Gassen (Internationale Rechnungslegung, 2004) S. 54-69. 
erlichen Gewinnermittlung zu Grunde gelegt werden könnten ${ }^{1}$. Das Gutachten hat allerdings die Aufgabe, die Konzeption einer eigenständigen steuerlichen Gewinnermittlung bei Aufgabe des Maßgeblichkeitsgrundsatzes zu entwickeln. Herzig bedient sich dafür eines mehrdimensionalen Beurteilungsrahmens, der effizienz- wie gerechtigkeitsgetriebenen Kriterien folgt, wobei letztere verfassungsrechtlich begründet und über das Leistungsfähigkeitsprinzip konkretisiert werden. Hieraus leitet er Gewinnermittlungsgrundsätze wie z.B. Klarheit, Wahrheit, Stetigkeit, Vollständigkeit oder Totalgewinngleichheit ab, um bestimmte Konzeptionen im Rahmen eines Betriebsvermögensvergleichs und einer Einnahmen-Überschussrechnung analysieren zu können ${ }^{2}$. In diesem Zusammenhang werden auch die IFRS als mögliches Grundmodell eines Betriebsvermögensvergleichs im Detail untersucht. Bei dieser Einzelregelanalyse spricht Herzig vielen, aber nicht allen Standards die steuerliche Tauglichkeit ab. Insofern erkennt er in Teilmengen der IFRS ,einen geeigneten Referenzpunkt für ein eigenständiges Steuerbilanzrecht $^{63}$.

Es zeigt sich, dass die hier kurz dargestellten Studien insbesondere in Abhängigkeit von den jeweils gewählten Beurteilungskriterien zu keinem einheitlichen Ergebnis gelangen. $\mathrm{Ob}$ die herrschende Meinung in der Maßgeblichkeitsdebatte deshalb durch vereinzelte, anderslautende Ergebnisse erschüttert wird, ist eher zu bezweifeln. Schon die formellrechtlichen Einwände allein dürften ausreichen, die Maßgeblichkeit der IFRS für die steuerliche Gewinnermittlung weiterhin abzulehnen. Dennoch wird die Diskussion durch modelltheoretisch abgesicherte Erkenntnisse bereichert, die der bis dahin eher ethisch-rechtlich geprägten Argumentation mit dem Postulat der Investitionsneutralität einen wichtigen ökonomischen Aspekt hinzufügen. Die Berücksichtigung von Wettbewerbswirkungen steht dabei ebenso oft im Hintergrund wie eine durchführungsorientierte Effizienzbetrachtung. Insofern muss das normative Beurteilungsgerüst genau im Auge behalten werden, um darauf aufbauende Ergebnisse entsprechend interpretieren zu können.

Die Ergebnisse der hier präsentierten Studien basieren zudem auf der Analyse exemplarisch ausgewählter Einzelregeln. Diese beinhalten regelmäßig nur eine Teilmenge der Ansatz- und Bewertungsregeln und können das gesamte IFRS-System nicht vollständig erfassen. Dieser Vorwurf gilt zudem in zeitlicher Hinsicht. Auch eine vollständige Erfassung sämtlicher Ansatz-, Bewertungs- und Konsolidierungsregeln wäre nur zu einem bestimmten Zeitpunkt möglich, so dass die Eignungsprüfung immer nur zeitpunktbezogen bliebe. Eine derartige Statik ist eher unproblematisch, wenn es - wie z.B. im Gutachten von Herzig oder in Kapitel V.2 bis V.5 - um die spezielle steuerliche Eignung

1 Vgl. Herzig (IAS/IFRS, 2004); zusammengefasst in Herzig/Gellrich/Jensen-Nissen (IAS/IFRS, 2004); s.a. die Besprechung von Bohl (Besprechung, 2004).

2 Vgl. Herzig (IAS/IFRS, 2004) S. 14-27.

Herzig (IAS/IFRS, 2004) S. 454. 
ganz konkreter Einzelregeln geht. Die Maßgeblichkeitsdebatte zielt indes auf die Eignung eines ganzen Systems jetzt und in Zukunft. Sie kann deshalb nicht die Dynamik von Rechnungslegungssystemen ignorieren, deren Regeln sich im Zeitablauf verändern und weiterentwickeln. Dies gilt im besonderen Maße für das anglo-amerikanisch geprägte IFRS-System, dessen Konturen sich gerade in dieser Zeit dramatisch verändern ${ }^{1}$. Um den dynamischen Charakter der IFRS stärker berücksichtigen zu können, bedarf es weniger der Analyse einzelner, konkreter Detailregeln. Statt dessen rückt der funktionelle Rahmen des IFRS-Systems und das mittels künftiger Standards angestrebte, bilanztheoretische Leitbild in den Vordergrund. Dabei ist auch der institutionelle Rahmen zu berücksichtigen, innerhalb dessen die Regeln des IASB jetzt und auch künftig entstehen und der insofern zur Abschätzung der Regelentwicklung beiträgt.

Mit der funktionalen Ausrichtung und dem institutionellen Rahmen des IFRS-Systems sollen im Folgenden zwei bisher nicht hinreichend gewürdigte Aspekte analysiert werden. Diese Analyse beruht dabei auf dem Beurteilungsrahmen, der in dieser Arbeit für die steuerliche Gewinnermittlung im Allgemeinen entwickelt worden ist. Da die EUStrategie zur künftigen Unternehmensbesteuerung zeigt, dass es gar nicht des Umwegs über die Handelsbilanz bedarf, um internationale Rechnungslegungsgrundsätze der steuerlichen Gewinnermittlung zu Grunde zu legen ${ }^{2}$, geschieht dies im Rahmen einer von spezifischen Fragen der Maßgeblichkeit losgelösten Betrachtung.

\subsection{Ergänzende Eignungsanalyse: Systemtauglichkeit unter Berücksichtigung dynamischer Aspekte}

\subsubsection{Funktionale Ausrichtung und bilanztheoretisches Leitbild der IFRS}

\subsubsection{Versuch einer Konkretisierung}

Um die IFRS als dynamisches System erfassen und begreifen zu können, bedarf es der Auseinandersetzung mit ihrer grundsätzlichen Zielsetzung und dem bilanztheoretischen Leitbild des IASB. Erstere lässt sich dem Rahmenkonzept (framework) des IASB entnehmen $^{3}$ und mit der ausschließlichen Generierung entscheidungsrelevanter Informati-

1 Vgl. zu dieser Dynamik und zu einem Versuch, künftige Entwicklungslinien dennoch aufzuzeigen Pellens/Fülbier/Gassen (Internationale Rechnungslegung, 2004) S. 853-871.

2 Schon vor Bekanntwerden der EU-Strategie hat insb. Herzig auf diesen Umstand hingewiesen und entsprechende unmittelbare Einflüsse i.R.d. vergangenen Steuerreformen im nationalen Kontext aufgezeigt; vgl. insb. Herzig (Internationalisierung, 2000) S. 108-111; dazu auch Grotherr/Jorewitz (Einflüsse, 2001) S. 131-133, 144-145.

3 Vgl. IASB Framework (Framework for the Preparation and Presentation of Financial Statements) vom 1. April 1989, das vom IASB 2001 übernommen worden ist. In IASB Framework Par. 1-3 wird dessen Status konkretisiert und festgestellt, dass es selbst kein Standard ist und auch keine diesbzgl. Verbindlichkeit erlangt; s.a. Pellens/Fülbier/Gassen (Internationale Rechnungslegung, 2004) S. 98-100. 
onen für interne und externe Unternehmensbeteiligte konkretisieren ${ }^{1}$. Steuerliche Zwecke spielen dabei keine Rolle ${ }^{2}$.

Obwohl das IASB explizit auf alle potenziellen und tatsächlichen Vertragspartner der Unternehmung als Adressaten abstellt ${ }^{3}$, stehen letztlich doch nur die auf organisierten Kapitalmärkten agierenden, anonymen Investoren mit ihren spezifischen Entscheidungsproblemen (Investition oder Desinvestition) im Fokus ${ }^{4}$. Aber selbst mit dieser Fokussierung auf eine bestimmte, von der Zahl her aber kaum begrenzbare Adressatengruppe wird das IASB eine theoretisch einwandfreie Operationalisierung ihrer obersten und einzigen Zielsetzung kaum vornehmen können. Eine normative Begründung für ein allen Individuen gleichermaßen dienendes und damit „richtiges“ Rechnungslegungssystem ist nach Auffassung der ökonomischen Theorie schwierig ${ }^{5}$. Die Zweckoperationalisierung vollzieht sich deshalb eher auf der Basis subjektiver Vorstellungen darüber, welche Informationen ein als repräsentativ angenommener, homogener Investor für seine (Des-)Investitionsentscheidung genau benötigt. Ex post findet diese methodisch angreifbare Informationsauswahl aber eine gewisse Bestätigung, wenn mittels empirischer Kapitalmarktstudien ,nachgewiesen"6 wird, dass die Kapitalmarktteilnehmer auf sie reagieren und sie in ihren Entscheidungen berücksichtigen ${ }^{7}$. In diesem Prozess des ,trial and error" scheint sich bisher herausgestellt zu haben, dass aktuelle und potenzielle In-

1 Vgl. IASB Framework Par. 12-14; die Entscheidungsrelevanz von Informationen hat erstmals Marschak (Information, 1954) betont; zur Information als „,zweckorientiertes Wissen“ vgl. auch Wittmann (Information, 1959) S. 14; zur Informationsdefinition kurz auch Kap. II.1.

2 Wenn die EU-Kommission (Konsultationspapier, 2003) S. 9 i.d.Zshg. betont, dass steuerliche Erfordernisse bei den IFRS „nicht unbedingt“ im Vordergrund stehen, ist das eine Untertreibung, da steuerliche Erfordernisse überhaupt keine Rolle spielen. IASB Framework Par. 9 (f) steht dem nicht entgegen. Der Staat wird dort zwar als Adressat benannt, nicht aber der Fiskus. Letzterer wird in der Literatur folgerichtig als Adressat der IFRS-Rechnungslegung ausgeschlossen; vgl. z.B. Baetge/Schulze (IAS 27, 2002) Tz. 3; ähnlich Schildbach (IAS, 2002) S. 274-275. Vgl. IASB Framework Par. 9.

4 Vgl. IASB Framework Par. 10, wo lapidar erklärt wird: „... As investors are providers of risk capital to the enterprise, the provision of financial statements that meet their needs will also meet most of the needs of other users that financial statements can satisfy"; dazu auch Streim/Bieker/Leippe (Anmerkungen zur theoretischen Fundierung, 2001) S. 179. Diese Ausrichtung erkennt sogar die $E U$ Kommission (Konsultationspapier, 2003) S. 13 an, die mit Hinblick auf das IFRS-Rahmenkonzept zwar den Staat bzw. Fiskus als einen Adressaten benennt, die Informationsbedürfnisse der Investoren aber als dominant ansieht.

5 Vgl. zur Problematik einer normativen Ableitung von Rechnungslegungsregeln bereits im Einpersonenfall grundlegend Demski (General Impossibility, 1973); im Überblick auch Gassen (Datenbankgestützte Rechnungslegungspublizität, 2000) S. 42-44 m.w.N.; Pellens/Fülbier/Gassen (Internationale Rechnungslegung, 2004) S. 15-17.

6 Ein Nachweis im strengen Sinne liegt schon allein wegen der theoretischen Angreifbarkeit empirischer Kapitalmarktstudien nicht vor; vgl. z.B. Schneider (Rechnungswesen, 1997) S. 366-375; Schneider (Verwertung von Wissen, 2000) S. 33-39; s.a. Fülbier (Regulierung der Ad-hoc-Publizität, 1998) S. 158-159 m.w.N.

7 Vgl. hierzu den umfangreichen Literaturüberblick von Bonse (Informationsgehalt, 2004) S. 61-268; zu den Möglichkeiten und Grenzen bei der Nutzung empirischer Kapitalmarktstudien für normative Fragestellungen auch Gassen (Datenbankgestützte Rechnungslegungspublizität, 2000) S. 43-44. 
vestoren diejenigen Informationen präferieren, die sie zur Abschätzung künftiger finanzieller Rückflüsse in Abhängigkeit von ihrer (Des-)Investitionsentscheidung benötigen. Je besser sie dabei in der Lage sind, aus den ihnen präsentierten Daten die Rendite/Risikoprognosen zu erstellen, um so geringer wird ihre subjektive Unsicherheit. Eine derart entscheidungsrelevante Rechnungslegung hat den Adressaten Informationen über künftige Nutzenpotenziale (assets) und künftige Ressourcenabflüsse (liabilities) und deren Veränderung im Zeitablauf zur Verfügung zu stellen ${ }^{1}$. Das Rechnungslegungssystem dient dabei als eine Art Struktur- und Abbildungsmodell für diese Zielgrößenprognose ${ }^{2}$, das bei neuen Informationen kontinuierlich angepasst werden $\mathrm{kann}^{3}$.

Bei dem Streben nach entscheidungsrelevanten Informationen ist das IASB durch das eigene Rahmenkonzept gehalten, Informationen auf zuverlässiger Grundlage zu ermitteln. Das insofern beschriebene Spannungsverhältnis von Entscheidungsrelevanz (relevance) und Zuverlässigkeit (reliability) ${ }^{4}$ führt dazu, dass ,each of the required financial statements is partly a statement of fact and partly an expression of opinion" ${ }^{\text {"5 }}$.Von einigen Autoren ist dies zum Anlass genommen worden, ähnliche Objektivierungsanforderungen wie im Steuerrecht zu vermuten und gar einer Gleichwertigkeit dieser beiden Zielausprägungen das Wort zu reden ${ }^{6}$. Hiervon kann aber keine Rede sein. So ist es weniger das Rahmenkonzept selbst, sondern vielmehr das real beobachtbare Verhalten des IASB, das dieser Gleichwertigkeitsthese widerspricht und das Urteil einer eindeutigen Präferenz zu Gunsten der ,relevance“ stützt ${ }^{7}$.

Schon auf der Basis des Status Quo bestehender IFRS-Regeln ist zu erkennen, dass geschätzte Zahlungspotenziale verstärkt in die Rechnungslegung einfließen (sollen). Hierfür sind die Erwartungen zu berücksichtigen, die sich nicht nur auf mehr oder minder funktionierenden Märkten, sondern auch marktfern, in den Unternehmungen und deren Führungsorganen selbst über das künftige Geschehen bilden. Diese Erfordernis drückt sich besonders plakativ in dem Bewertungskonzept des beizulegenden Zeitwertes (fair value) aus, der deshalb bereits heute, völlig losgelöst von steuerlichen Überlegungen,

Vgl. umfassend IASB Framework Par. 47-84.

2 Empirische Studien haben gezeigt, dass insbesondere Ergebnisgrößen, meist heruntergebrochen auf die „earnings per share“ (EPS), in der Finanzanalyse als wichtiger Indikator für die Aktienbewertung herangezogen werden; vgl. z.B. Booth/Broussard/Loistl (Earnings, 1997); Lev (Usefulness of Earnings, 1989); im Überblick dazu Bonse (Informationsgehalt, 2004) S. 180-191.

Vgl. Pellens/Fülbier (Erfassung immaterieller Werte, 2000) S. 37-39

Vgl. IASB Framework Par. 26-28, 31-32.

Dean/Clarke (Evolving Conceptual Framework, 2003) S. 290.

6 Vgl. u.a. Kahle (Maßgeblichkeitsgrundsatz, 2002) S. 181; Oestreicher/Spengel (International Accounting Standards, 1999) S. 594; Spengel (Einheitliche Bemessungsgrundlage, 2004) S. 113, der konstatiert: „IFRS bieten eine breite Basis an objektivierten Regeln, die für die steuerliche Gewinnermittlung übernommen werden können“.

7 Vgl. in dieser Einschätzung stellvertretend Bieker (Fair Value Accounting, 2005) Kap. 8; Streim/Bieker/Leippe (Anmerkungen zur theoretischen Fundierung, 2001) S. 184, 202. 
heftig kritisiert wird ${ }^{1}$. In diesem Bewertungskonzept kommt die untergeordnete Rolle der ,reliability“ immer dann besonders zum Tragen, wenn angesichts nicht vorhandener oder nicht funktionierender Märkte nicht mehr auf erstbeste Marktwerte zurückgegriffen werden kann ${ }^{2}$. Dies dürfte bei einem großen Teil von Bilanzpositionen der Fall sein. Hier müssen statt dessen ,anerkannte Bewertungsverfahren“ zur Bestimmung der beizulegenden Zeitwerte herangezogen werden, die insbesondere auch die Diskontierung prognostizierter Zahlungsüberschüsse beinhalten ${ }^{3}$. Damit wird verstärkt auf subjektive Schätzungen abgestellt, die zwar von besser informierten, aber dennoch begrenzt rational und vor allem auch opportunistisch handelnden Bilanzerstellern in der Unternehmung stammen und die sich auch durch vermeintlich neutrale Prüfinstanzen nicht wirklich verifizieren lassen ${ }^{4}$.

Die Rechnungslegung nach IFRS ist gegenwärtig noch durch eine Art Mischkonzept gekennzeichnet, die neben (fortgeführten) historischen Anschaffungs- bzw. Herstellungskosten auch die (z.T. fakultative) Verwendung beizulegender Zeitwerte für bestimmte Bilanzposten, wie z.B. immaterielle Vermögenswerte, Sachanlagen, Finanzinstrumente, Agrarprodukte, vorsieht ${ }^{5}$. Aus den schon verabschiedeten oder noch auf der Agenda des IASB stehenden Arbeitsprojekten wird die Tendenz der weiteren Regulierung jedoch ersichtlich. In seinem Streben nach Entscheidungsrelevanz scheint das IASB einem bilanztheoretischen Leitbild zu folgen, das am ehesten mit einer „full fair

1 Vgl. u.a. Ballwieser/Küting/Schildbach (Fair value, 2004); Kley (Fair Value-Bilanzierung, 2001); Schildbach (Zeitwertbilanzierung, 1998); Schildbach (Zeitbewertung, 1999); Schildbach (fair value, 2004); Schneider (Verwertung von Wissen, 2000) S. 28-33; Streim/Bieker/Esser (Fair Values, 2003) S. 469-477; Streim/Bieker/Leippe (Anmerkungen zur theoretischen Fundierung, 2001) S. 197-203. Vgl. zu anderen „Entobjektivierungen“ bereits Schildbach (Internationale Rechnungslegungsstandards, 1994) S. 710-718.

2 Vgl. hierzu die „fair value hierarchy“ in ED ,Fair Value Measurements' des FASB (insb. Par. 14-24), die auch vom IASB z.B. i.R.d. Projekts ,Business Combinations - Phase II' berücksichtigt wird.

3 Vgl. so z.B. IAS 36.5-6, 36.25-32 oder IAS 39.48 i.V.m. IAS 39, Appendix AG69-AG79; s.a. Streim/Bieker/Leippe (Anmerkungen zur theoretischen Fundierung, 2001) S. 197. Expliziter sind noch die Regeln des FASB, vgl. insb. SFAC No. 7, z.B. Par. 1, 17, 25-38; SFAS No. 142, z.B. Par. 23-25; ED ,Fair Value Measurements’. Vgl. zur „marktfernen“ Ermittlung der „fair values“ umfassend Kümmel (Fair Value-Ermittlung mit Barwertkalkülen, 2002). Aber selbst Marktwerte sind bei ,realistischen" (unvollkommenen) Marktbedingungen angreifbar; vgl. Barth/Landsman (Fair Value Accounting, 1995) S. 99-105; Schildbach (fair value, 2004) S. 847-852; plakativ Schneider (Verrechnungspreise, 2003) S. 54: „Angesichts der Unvollkommenheit der Märkte führt ein ,fair value'/gemeiner Wert nicht selten in eine (hundsgemeine) Täuschung ...“.

4 Vgl. u.a. Ballwieser/Küting/Schildbach (Fair value, 2004) S. 535-541; Schildbach (fair value, 2004) S. 849-850; Streim/Bieker/Esser (Fair Values, 2003) S. 474-475. Vgl. zu den Bemühungen des IDW, einen Prüfungsstandard zur Prüfung von Zeitwerten zu entwickeln HFA (Prüfung von Zeitwerten, 2004). Hier wird insbesondere auf eine Systemprüfung abgestellt, die sich auf die organisatorische Ausgestaltung, die Angemessenheit des Bewertungsverfahrens, die Beurteilung der Annahmen und die mathematische Richtigkeit der Berechnungen beschränkt.

5 Vgl. zu diesen und weiteren Beispielen Pellens/Fülbier/Gassen (Internationale Rechnungslegung, 2004) S. 856-857. 
value"-Bilanzierung umschrieben werden kann". Wie in Abb. 12 skizziert, würden dabei alle einzeln identifizierbaren Vermögenswerte und Schulden - bei weiterhin unterstellter Gültigkeit des Einzelbewertungsgrundsatzes ${ }^{2}$ - mit dem beizulegenden Zeitwert bewertet. Neben den Marktwerten kämen dabei auch unternehmensintern ermittelte Ertragswerte $^{3}$ zur Anwendung. Um aus dieser Bilanz idealerweise den Unternehmungsgesamtwert ablesen zu können ${ }^{4}$, müsste auch der selbst geschaffene, originäre Goodwill aktiviert werden, um die Bewertungslücke zwischen Gesamtwert und Summe der Einzelwerte zu schließen.

\begin{tabular}{|c|c|c|c|}
\hline & \multicolumn{2}{|c|}{ Bilanz $_{(t 1)}$} & $\mathrm{GuV}_{(\mathrm{tl}-\mathrm{t} 0)}$ \\
\hline & \multirow{2}{*}{ 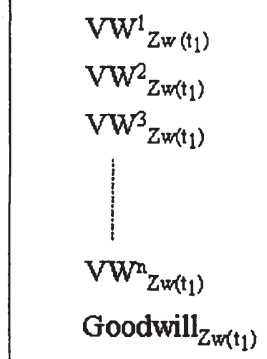 } & $\begin{array}{l}\mathrm{EK}_{\mathrm{Zw}\left(\mathrm{t}_{1}\right)} \\
\left.=U W^{\text {netto }}{ }_{\mathrm{Zw}} \mathrm{t}_{0}\right) \\
+/-\Delta \mathrm{UW}^{\text {netto }}{ }_{\left(\mathrm{t}_{1}-\mathrm{t}_{0}\right)}\end{array}$ & $\begin{array}{l}\Delta \mathrm{VW}^{1} \\
\Delta \mathrm{VW}^{2} \\
\Delta \mathrm{VW}^{\mathrm{m}}\end{array}$ \\
\hline & & $\begin{array}{l}S_{Z w\left(t_{1}\right)}^{1} \\
S_{Z w\left(t_{1}\right)}^{2} \\
S_{Z w\left(t_{1}\right)}^{m_{m}}\end{array}$ & $\begin{array}{l}-\Delta S^{1} \\
-\Delta S^{2} \\
-\Delta S^{m}\end{array}$ \\
\hline & $\sum U_{W} w^{\text {nuto }}{ }_{Z w\left(t_{1}\right)}$ & $\sum U_{W^{b r u t t}}{ }_{Z W\left(t_{1}\right)}$ & $\Delta \mathrm{EK}_{\left(\mathrm{t}_{1}-\mathrm{t}_{0}\right)}=\Delta \mathrm{UW}^{\text {netto }}{ }_{\left(\mathrm{t}_{1}-\mathrm{t}_{0}\right)}$ \\
\hline $\begin{array}{l}V W^{i} \\
S^{j} \\
U W \\
\text { EK } \\
Z w\left(t_{n}\right) \\
\end{array}$ & \multicolumn{2}{|c|}{$\begin{array}{l}\text { Vermögenswert }(i=1, \ldots n) \\
\text { Schuld }(j=1, \ldots m) \\
\text { Unternehmenswert } \\
\text { Eigenkapital } \\
\text { beizulegender Zeitwert im Zeitpunkt } t_{n}(n=0,1)\end{array}$} & \\
\hline
\end{tabular}

Abb. 12: „full fair value“-Abschluss

1 Vgl. zu ähnlichen Annahmen über den Zielpunkt der IFRS-Entwicklung insb. Ballwieser/Küting/Schildbach (Fair value, 2004) S. 544-545; Bieker (Fair Value Accounting, 2005) Kap. 8; Kley (Fair Value-Bilanzierung, 2001) S. 2257-2258; Pellens/Fülbier/Gassen (Internationale Rechnungslegung, 2004) S. 854-858; Streim/Bieker/Esser (Fair Values, 2003) S. 459-469; Streim/Bieker/Esser (Abschied von der Ausschüttungsbilanz, 2004) S. 233-235; in Ansätzen auch Sweeney (fair value, 1998) S. 81; vgl. zu den ähnlichen Leitbild-Vorstellungen des FASB Barth/Landsman (Fair Value Accounting, 1995) S. 97; Willis (Fair Value, 1998).

2 In konsequenter Fortführung der "full fair value“-Bilanzierung steht letztlich auch die traditionelle Abgrenzung der Vermögenswerte in Frage, die sich stärker in Richtung einer Projektabgrenzung entwickeln müsste, die dann auf einer Art „zahlungsmittelgenerierender Einheit“ aufsetzte; vgl. Pellens/Fülbier/Gassen (Internationale Rechnungslegung, 2004) S. 854-856; Streim/Bieker/Esser (Fair Values, 2003) S. 464-468, 471-472; Streim/Bieker/Esser (Abschied von der Ausschüttungsbilanz, 2004) S. 235-238.

3 Der Ertragswertbegriff soll hier als Oberbegriff für sämtliche diskontierten Stromgrößenüberschüsse, also auch für den Discounted Cash Flow (DCF), verstanden werden.

4 Vgl. bereits die Gedanken von Albach (Grundgedanken, 1965) zur „synthetischen Bilanztheorie“. 
Bewertungsänderungen führten nach diesem Leitbild automatisch zu Ergebniswirkungen. Das Realisationsprinzip wäre entsprechend weit interpretiert und von dem juristischen Verkaufsakt mit Leistungserbringung und Gefahrenübergang - geschweige denn Zahlungseingang - losgelöst. Konsequenterweise müssten auch alle Bewertungsänderungen ergebniswirksam über die Gewinn- und Verlustrechnung verrechnet werden. Obwohl derzeit auch hier noch eine Mixtur aus ergebnisneutraler sowie ergebniswirksamer Verrechnung existiert, deuten neue Regulierungsvorhaben bereits in diese Richtung. So zeigt sich insbesondere in dem Projekt „reporting comprehensive income“, dass derartige Wertschwankungen generell ergebniswirksam verbucht und dafür stärker separiert werden sollen ${ }^{1}$. Eine konsequent ergebniswirksame Verrechnung hätte zudem den Effekt, Verstöße gegen das Kongruenzprinzip zu unterbinden. In dem Bestreben, Aufwand und Ertrag über Periodisierung den Perioden ,verursachungsgerecht“ zuzuordnen, ist es heute noch möglich, einen ergebnisneutral zugeschriebenen Wertansatz ergebniswirksam abzuschreiben, die korrespondierende Neubewertungsrücklage aber dennoch ergebnisneutral auszubuchen ${ }^{2}$.

\subsubsection{2 Überprüfung anhand der Anforderungen an die steuerliche Gewinnermittlung}

Die funktionale Ausrichtung der steuerlichen Gewinnermittlung unterscheidet sich von derjenigen der IFRS. Bei der steuerlichen Gewinnermittlung existiert erst einmal keine unbestimmte Adressatenmenge, sondern mit dem Staat nur ein einziger Adressat. Theoretisch zumindest sollte der Staat deshalb in der Lage sein, seine Zweckvorstellungen in einem Rechnungslegungssystem zu operationalisieren ${ }^{3}$. Dem Metazweck der Rechnungslegung folgend ${ }^{4}$ hat der Staat zwar auch ein Informationsbedürfnis, das über die steuerliche Gewinnermittlung zu befriedigen ist. Informationen als entscheidungsrelevantes Wissen sind aber subjektbezogen, da sie sich qua definitionem erst über ihre entscheidungsbeeinflussende Wirkung als Information qualifizieren und insofern niemals losgelöst von dem individuellen Adressaten, dessen Entscheidungssituation und Infor-

1 Vgl. IASB (Comprehensive Income, 2003); s.a. Barker (Reporting Financial Performance, 2004); Pellens/Basche/Crasselt (Ergebnisspaltung, 2004).

2 Dieser Effekt ist gem. IAS 16 und 38 imparitätisch verstärkt, da Wertminderungen unter die fortgeführten historischen Kosten ergebniswirksam verbucht werden; vgl. dazu bereits kritisch Kap. V.1.1.

3 Vgl. Fülbier/Gassen (Wider die Maßgeblichkeit, 1999) S. 1512. Praktisch dürfte diese Vorstellung wohl daran scheitern, dass angesichts des methodologischen Individualismus doch wieder unterschiedliche Vorstellungen der einzelnen Politiker und Bürokraten zum Tragen kommen.

4 Vgl. Pellens (Internationale Rechnungslegung, 2001) S. 9-10. 
mationsstand betrachtet werden können'. Kurz: Eine Information für einen Investor stellt nicht zwingend auch eine Information für den Fiskus dar et vice versa ${ }^{2}$.

Aus wirkungsorientierter Effizienzperspektive muss sich das bilanztheoretische Leitbild der Markt- und Ertragswertbilanzierung erst einmal an den Anforderungen des neoklassisch-allokativen Partialmodells der Investitionsneutralität messen lassen. Zumindest hinsichtlich der Ertragswertbilanzierung ist die Nähe insbesondere zum Konzept des kapitaltheoretischen Gewinns offenkundig - eine Nähe, die zu der Vermutung Anlass gibt, dass die IFRS als steuerliche Gewinnermittlungsregeln tendenziell investitionsneutrale Wirkung entfalten. Entsprechenden Literaturmeinungen u.a. von Oestreicher/Spengel ${ }^{3}$ oder ansatzweise auch von dem deutschen ${ }^{4}$ und britischen Finanzministerium $^{5}$ sowie der EU-Kommission ${ }^{6}$, die in dieser konzeptionellen Nähe zum kapitaltheoretischen Gewinn ein Argument für die steuerliche Eignung der IFRS sehen, ist deshalb erst einmal zuzustimmen. Letztlich geht es in beiden Konzepten um die Schätzung und Abzinsung künftiger Zahlungsflüsse. Trotz der Zahlungsorientierung wird das Periodisierungskonzept dabei nicht völlig beseitigt, da der Zahlungssaldo durch die Ertragswertabschreibung korrigiert wird. Unterschiede könnten allerdings darin vermutet werden, dass der kapitaltheoretische Gewinn tendenziell auf eine Gesamtwertermittlung der rechnungslegenden Einheit konzipiert ist, während das IFRS-Leitbild wohl auf der Stufe einer wie auch immer konkretisierten Einzelbewertung verbleiben dürfte ${ }^{7}$. Die Grenzen sind hier allerdings fließend, da die Idee einer Ertragswertbilanzierung auf Basis traditionell abgegrenzter Vermögenswerte und Schulden nicht immer Sinn ergibt und zumindest partiell in eine Art umfassenderer Projektbewertung überführt werden müsste ${ }^{8}$. Parallelen ergeben sich aber auch bei der symmetrischen, nicht imparitätischen Berücksichtigung von Wertschwankungen, die beide Konzepte prägt. Wenn sich der Steuerge-

1 Vgl. zum Informationsbegriff m.w.N. Kap. II.1; hierzu im Überblick auch Fülbier (Regulierung der Ad-hoc-Publizität, 1998) S. 108-114.

2 Vgl. Wagner (Aufgabe der Maßgeblichkeit, 1998) S. 2076: „Der Fiskus hat anders als Aktionäre keinen Grund, Unternehmenswerte zu prognostizieren, weil er keine Entscheidungen zu treffen hat, für die er solche Informationen benötigt“". Streng genommen ist selbst die Information für einen Investor nicht zwingend eine Information für einen anderen Investor.

3 Vgl. Oestreicher/Spengel (Anwendung von IAS in der EU, 2001) S. 893; differenzierter Spengel (IAS und Unternehmensbesteuerung, 2003) S. 35.

4 Vgl. $B M F$ (Internationalisierung der Rechnungslegung, 2002) S. 67.

$5 \mathrm{Vgl}$. zu den britischen Absichten, die IFRS für steuerliche Zwecke heranzuziehen auch Inland Revenue (Reform of Corporation Tax, 2002) S. 4; Inland Revenue (Pre-Budget Report, 2003) S. 57.

$6 \mathrm{Vgl}$. EU-Kommission (Summary Report of the Workshop, 2003) Stichwort "The general principles of IAS".

7 Vgl. ähnlich Spengel (IAS und Unternehmensbesteuerung, 2003) S. 35; Wagner (Gegenstand und Methoden, 2004) S. 243 allgemeiner bezogen auf die Investitionsneutralität.

8 Vgl. zu dieser Problematik bereits Albach (Grundgedanken, 1965) S. 27 im Rahmen seiner ,synthetischen Bilanztheorie“; s.a. Busse von Colbe (Prognosepublizität, 1968) S. 112-113; Ordelheide (Kaufmännischer Periodengewinn, 1988) S. 292-295; Pellens/Fülbier (Erfassung immaterieller Werte, 2000) S. 63; Streim/Bieker/Esser (Abschied von der Ausschüttungsbilanz, 2004) S. 233-242. 
setzgeber aber - wie zu erwarten - nicht zum sofortigen Verlustausgleich oder noch nicht einmal zum unbeschränkten Verlustrück- bzw. -vortrag durchringt, wird dies allerdings problematisch'.

Der letzte Gedanke zeigt bereits auf, dass das Leitbild der Ertragswertbilanzierung in derselben Kritik steht, die sich auch an der modelltheoretischen Enge investitionsneutraler Konzepte entzündet ${ }^{2}$. So ist die investitionsneutrale Wirkung der IFRS unter Berücksichtigung unvollkommener Information, begrenzter Rationalität und Opportunismus kaum noch realistisch. Unter diesen Bedingungen ist im Übrigen erst die Differenzierung von Markt- und Ertragswerten und die privilegierte Behandlung von Marktwerten als erstbeste Ausprägung beizulegender Zeitwerte zu erklären. Während Markt- und Ertragswerte bei vollkommener Information noch identisch sein dürften, gewinnen Marktwerte bei Aufgabe dieser Idealannahme an Bedeutung. Sofern funktionierende Märkte existieren, werden schließlich sämtliche am Markt verfügbaren Erwartungen der Marktteilnehmer über künftige Zahlungsflüsse und deren Eintrittswahrscheinlichkeiten im Marktpreis aggregiert. Gelöst wäre dadurch aber nicht das Liquiditätsproblem, das eine Kapitalmarktsituation im Ungleichgewicht ohne sofortigen Verlustausgleich prägt.

Bei Ausdehnung der wirkungsorientierten Effizienzbetrachtung auf die Wettbewerbsneutralität wird auch die wirtschaftstheoretische Sichtweise in Richtung empirisch gehaltvoller und damit realitätsnaher Prämissen erweitert. Trotz der Markt- und Wettbewerbsorientierung der koordinationsorientierten Evolutorik können (und sollen) inhaltliche Ausgestaltungsfragen, z.B. hinsichtlich der Sinnhaftigkeit von Markt- oder Ertragswerten, kaum mehr beantwortet werden. Das bilanztheoretische Leitbild der IFRS hat sich hier statt dessen den Rahmenbedingungen der wettbewerbsneutralen Gewinnermittlung zu stellen. Der in diesem Zusammenhang anzuführende Grundsatz der Allgemeinheit, nach der alle denselben Regeln zu unterliegen haben, wäre bereits gewahrt, wenn die IFRS als Gewinnermittlungssystem verpflichtend von allen in Frage kommenden Steuersubjekten anzuwenden wären. Fraglich bleibt indes, ob damit wirklich alle Sachverhalte vollständig und gleiche Sachverhalte auch gleich erfasst würden. Gerade die letzte Anforderung, die mit dem Grundsatz der Willkürfreiheit und Objektivität sowie Klarheit und Einfachheit einher geht, dürfte im Falle einer prospektiven Gewinnermittlung unter Unsicherheit kaum erfüllt sein. Dies trifft hauptsächlich die marktferne Ertragswertbilanzierung, weniger die Marktbewertung. Selbst bei Wegfall aller expliziten Wahlrechte konkretisiert sich in dieser Ertragswertbilanzierung ein einziges, großes implizites Wahlrecht. Willkür kann z.B. bei der Prognose von Zahlungen und ihrer Eintrittswahrscheinlichkeiten oder auch bei der Bestimmung der Zinssätze nicht per se ausgeschlossen werden. Mehr oder minder komplexe Berechnungsmethoden verstärken

Vgl. dazu Kap. II.2.2.4.

Vgl. dazu Kap. II.2.1.2. 
dabei die Intransparenz. Potenzial für eine willkürliche Gewinnermittlung ergäbe sich aber auch auf Seiten der Finanzverwaltung oder auch der Gerichtsbarkeit. Beide könnten unwiderlegbar andere und jeweils wieder verschiedene Erwartungen hinsichtlich der künftigen Zahlungspotenziale besitzen, selbst wenn sie die grundsätzlichen Berechnungsparameter akzeptierten. Dadurch würden wirtschaftliche Transaktionen hinsichtlich ihrer steuerlichen Wirkung schwer planbar.

Vor diesem Hintergrund kann der steuerlichen Gewinnermittlung ein eindeutiger Hang in Richtung ,reliability“ unterstellt werden, während ,relevance“ gegenüber den IFRS klar an Bedeutung verliert ${ }^{1}$. Dies widerspricht indes der bilanztheoretischen Ausrichtung der IFRS. Der Verdacht kostenverursachender Friktionen einer steuerlichen Gewinnermittlung nach IFRS kann dabei auch aus durchführungsorientierter Effizienzperspektive gestützt werden. Die Parallelität durchführungsorientierter und wettbewerbsneutraler Anforderungen fordert schließlich auch hier eine möglichst klare, einfache, vor allem aber willkürfreie und objektive Gewinnermittlung, um die Prozessaktivitäten aller an der steuerlichen Gewinnermittlung Beteiligten auf ein transaktionskostenminimales $\mathrm{Ma} ß \mathrm{zu}$ reduzieren.

Aus institutionenökonomischer Perspektive könnte dem jedoch entgegen gehalten werden, dass es letztlich nicht auf das Erreichen eines Optimalzustandes ankommt (,nirvana-approach“), sondern nur auf eine Verbesserung gegenüber einer Alternative ${ }^{2}$. So könnten relative Vorteile, z.B. in einem bilateralen Vergleich der IFRS mit den existierenden, nationalen Gewinnermittlungssystemen in der EU, nicht kategorisch ausgeschlossen werden ${ }^{3}$. Allerdings kann diese Art der relativen Eignung schon durch die Identifikation eines einzigen Gewinnermittlungssystems mit komparativen Effizienzvorteilen gegenüber den IFRS erschüttert werden. Dass dies möglich ist, wird z.B. mit den Ausführungen zum realisierten Reinvermögenszugang auch in diesem Abschnitt angedeutet.

Aus durchführungsorientierter Perspektive ist allerdings das Standardisierungsargument zu berücksichtigen. Sollten die IFRS die unterschiedlichen steuerlichen Gewinnermittlungssysteme in allen Mitgliedstaaten der EU ersetzen, dürfte ein transaktionskostenre-

1 Vgl. dazu treffend Nobes (Framework for the Taxable Income, 2004) S. 29: „[F]or tax purposes, reliability is likely to be stressed more than relevance to the investor" mit Bezug auf Whittington (Tax Policy, 1995) S. 454, der konstatiert: “.... and it is likely that a method of accounting designed solely to meet the needs of taxation would put greater emphasis on reliability and much less (possible none at all) on relevance to the needs of the investor". Vgl. ansatzweise sogar EU-Kommission (Ergebnisse, 2003) S. 20: "Für steuerliche Zwecke ist jedoch in der Regel ein höheres Maß an Präzision erforderlich“, ähnlich auch Herzig (IAS/IFRS, 2004) S. 33; Kirsch (Maßgeblichkeit, 2004) S. 227.

2 Vgl. Demsetz (Information, 1969) S. 1; dazu auch Kap. II.2.1.1.

3 Den komparativen (Effizienz-)Vergleich mit dem HGB betonen z.B. Eichhorn (Maßgeblichkeitsprinzip, 2001) S. 107-243; Oestreicher/Spengel (International Accounting Standards, 1999) S. 593-595; Oestreicher/Spengel (Replik, 1999) S. 1514-1515; Streim/Esser (Ansatzfragen, 2003) S. 737. 
duzierender Standardisierungseffekt kaum zu leugnen sein. Dies ist aber kein IFRSspezifischer Vorteil, sondern auf jedes System übertragbar, das divergierende nationale Gewinnermittlungssysteme zu ersetzen vermag. Dabei ist nicht davon auszugehen, dass nur die IFRS die alleinige diesbezügliche Eignung besitzen. Standardisierungseffekte können auch an anderer Stelle auftreten. Wenn Unternehmen in der EU ohnehin zur Befolgung der IFRS im Rahmen der rein informationsorientierten Rechnungslegung angehalten werden, lassen sich Einsparpotenziale nicht leugnen, sofern die IFRS auch der steuerlichen Gewinnermittlung zu Grunde lägen ${ }^{1}$.

Außerhalb des effizienzorientierten Betrachtungsrahmens stellt sich als nächstes die Frage, ob die funktionale Ausrichtung der IFRS und ihr bilanztheoretisches Leitbild den gerechtigkeitsgetriebenen Anforderungen an die steuerliche Gewinnermittlung genügen. Diese Frage kann vergleichsweise klar beantwortet werden, wenn das Leistungsfähigkeitsprinzip als Ausdruck der Steuergerechtigkeit akzeptiert und das Einkommen in Form des realisierten Reinvermögenszugangs als Maßgröße steuerlicher Leistungsfähigkeit herangezogen wird. Hiernach interessiert sich der Staat in Gestalt des Fiskus nicht für das prognostizierte künftige Geschehen ${ }^{2}$, sondern nur für den realisierten und damit zwingend auch objektivierten Reinvermögenszugang der abgelaufenen Periode. Das eng an abgeschlossenen Markttransaktionen und Zahlungsvorgängen orientierte Realisationsprinzip verträgt sich nicht mit dem aufgezeigten Leitbild des IASB, das sich ja gerade von dieser engen Interpretation löst und einem sehr weiten, letztlich auch ermessensbehafteten ${ }^{3}$ Realisationsprinzip folgt. Die insofern drohende Einbeziehung der aus Markt- und Zahlungssicht unrealisierten Erträge mag aus dem Blickwinkel einer rein informationsorientierten Rechnungslegung noch tragbar oder gar wünschenswert erscheinen, nicht jedoch aus demjenigen der steuerlichen Gewinnermittlung. Dies gilt nicht nur vor dem Hintergrund damit einhergehender Selbsteinsteuerungsmöglichkei$\operatorname{ten}^{4}$. Auch dürften die notwendigen Kompensationsmechanismen, wie der sofortige Verlustausgleich, unbeschränkte Liquiditätshilfen zur Steuerzahlung und die Verzinsung eventuell zu viel entrichteter Steuern, auch künftig keine Umsetzungschancen besitzen. Vor diesem Hintergrund ist im Übrigen auch die völlige Abkehr vom Imparitätsprinzip abzulehnen, das den Mangel fehlender Kompensationsmechanismen auch

1 Vgl. so z.B. Spengel (Einheitliche Bemessungsgrundlage, 2004) S. 108; Spengel (Unternehmensbesteuerung in der EU, 2004) S. 138, der hier „Vereinfachungs- und Praktikabilitätsgesichtspunkte“ anführt. Ähnliches bereits für einen HGB-Konzernabschluss vermutend Grotherr (Konzernsteuerrecht, 1995) S. 82.

2 Vgl. Fülbier/Gassen (Wider die Maßgeblichkeit, 1999) S. 1512; Schneider (Gewinnermittlung, 1983) S. 1061-1062; Wagner (Aufgabe der Maßgeblichkeit, 1998) S. 2076.

3 Vgl. dazu treffend Schildbach (IAS, 2002) S. 275: „IAS verzichten zudem bewußt darauf, Ermessensspielräume möglichst weitgehend durch punktgenaue, häufig allerdings auch willkürliche Grenzen zu beseitigen. Sie setzen im Gegenteil auf ,professional judgement'“.

4 Vgl. z.B. Streim/Esser (Bewertungsfragen, 2003) S. 784-785, die den ,fair value“ auch deshalb unter Gleichmäßigkeitsgesichtspunkten ablehnen; s.a. Herzig (IAS/IFRS, 2004) S. 48-50. 
angesichts weiterer Einschränkungen beim geltenden Verlustvor- und -rücktrag zumindest abmildert ${ }^{1}$.

In diesem Zusammenhang wird deutlich, dass das Urteil über die vom Staat vorzunehmende Zweckoperationalisierung in Bezug auf die Unternehmungsbesteuerung letztlich wieder von der Wahl der Gewinnermittlungskonzeption beeinflusst wird. So verwundert es nicht, dass die Vertreter der Reinvermögenszugangstheorie (z.B. Schneider, Gröning, Pannen $^{2}$ ) die steuerliche Eignung der IFRS insgesamt verneinen, während diejenigen zu weniger eindeutigen Ergebnissen gelangen, die sich von diesem Verständnis in Richtung der allerdings weniger geeigneten ${ }^{3}$ Reinvermögenszuwachstheorie entfernen (z.B. Oestreicher/Spengel, Eichhorn ${ }^{4}$ ). Aber auch letztere verneinen für Teile der IFRS bereits im gegenwärtigen Stadium die steuerliche Eignung, da diese Teile mit dem Grundsatz der Gesetzesbestimmtheit als unvereinbar angesehen werden. Gemeint ist insbesondere auch die „fair value“-Bilanzierung, deren Behandlung als (kleine) Teilmenge des IFRS-Systems die sich deutlich abzeichnende Entwicklung des gesamten IFRSSystems in diese Richtung leugnet. Die in diesem Zusammenhang geäußert Ansicht, diese einzelnen „unerwünschten Steuerwirkungen“ der IFRS könnten über abweichende Bestimmungen im Steuerrecht analog zu $\S 5$ Abs. $6 \mathrm{EStG}$ neutralisiert werden ${ }^{5}$, greift angesichts des Ausnahmecharakters dieser Vorschrift viel zu kurz. Dem Charakter des aufgezeigten Leitbildes folgend, stellt die vom „reinen Realisationsprinzip“6 sowie Imparitätsprinzip losgelöste Ertrags- bzw. „fair value“-Bewertung ja gerade die Regel dar und müsste demnach gänzlich über einen steuerlichen Bewertungsvorbehalt neutralisiert

1 Vgl. Herzig (Internationalisierung, 2000) S. 113; Herzig (IAS/IFRS, 2004) S. 49; Schneider (Rechnungswesen, 1997) S. 282-287; Schneider (Steuerlast, 2002) S. 290; Schneider (IAS als Besteuerungsgrundlage, 2003) S. 299-301; s.a. Kahle (Maßgeblichkeitsgrundsatz, 2002) S. 186. Vgl. Gröning (Steuerbilanzielle Gewinnermittlung, 2002); Pannen (Messtheoretische Grundprobleme, 2000) und z.B. Schneider (IAS als Besteuerungsgrundlage, 2003).

3 Vgl. Kap. II.2.2.4.

4 Vgl. Eichhorn (Maßgeblichkeitsprinzip, 2001); Oestreicher/Spengel (Anwendung von IAS in der EU, 2001) S. 893; ansatzweise auch BMF (Internationalisierung der Rechnungslegung, 2002) S. 67; relativierend aber Spengel (Besteuerung, 2004) S. 136.

5 Vgl. u.a. Fischer (IAS-Abschlüsse, 2001) S. 106; Kahle (Internationale Rechnungslegung, 2002) S. 187; Kahle (Europarechtliche Einflüsse, 2001) S. 135; Kahle (Maßgeblichkeitsgrundsatz, 2002) S. 181-182; Kahle (Zukunft der Rechnungslegung, 2003) S. 271; Oestreicher/Spengel (Maßgeblichkeit der International Accounting Standards, 1999) S. 563-564; Oestreicher/Spengel (Anwendung von IAS in der EU, 2001) S. 894, die auf die Möglichkeit einer steuerfreien Rücklage verweisen und zudem glauben, der Korrekturaufwand „dürfte sich aber in Grenzen halten“; Spengel (IAS und Unternehmensbesteuerung, 2003) S. 34; Spengel (Besteuerung, 2004) S. 138; Spengel (Einheitliche Bemessungsgrundlage, 2004) S. 113-114, der konstatiert: „Selbstverständlich existieren ... zahlreiche entobjektivierte Regelungen mit unter Umständen großzügigen Ermessensspielräumen. ... Für die Besteuerung ist dies aber nicht störend, da entobjektivierte Regelungen als Anknüpfungspunkt ausscheiden“ (S. 113); Spengel (Unternehmensbesteuerung in der EU, 2004) S. 147; neutraler indes Schreiber (Unternehmensbesteuerung, 2004) S. 225, der zumindest die hohe Veränderungsgeschwindigkeit der IFRS als Problem erachtet.

6 Schneider (Steuerbilanzen, 1978) S. 60. 
und durch ein zwangsläufig eigenständiges und vollumfängliches Steuerbilanzrecht ersetzt werden.

Auch die Diskussion jenseits der deutschen Grenzen zeugt eher von der Ablehnung des aufgezeigten bilanztheoretischen Leitbildes der IFRS für die steuerliche Gewinnermittlung. So ist auf der von der EU-Kommission im März 2003 einberufenen Expertenkonferenz zur Frage der steuerlichen Eignung der IFRS insbesondere die Versteuerung unrealisierter Gewinne mit Nachdruck abgelehnt worden ${ }^{1}$. Da dies das Grundcharakteristikum einer „full fair value"-Bilanzierung darstellt, dürfte die Systemtauglichkeit der IFRS damit auch insgesamt in Frage stehen. So schlussfolgert die EU-Kommission auch an anderer Stelle, dass die Integration des beizulegenden Zeitwerts in die steuerliche Gewinnermittlung ,eine völlige Abkehr von der derzeitigen steuerlichen Praxis“2 wäre. $\mathrm{Zu}$ einem ähnlichen Schluss kommt auch Nobes, der die Frage der steuerlichen Eignung der IFRS auf der Basis eines Beurteilungsrahmens zu beantworten versucht, der auf Durchführungseffizienz und eine gerechte Gewinnermittlung zielt ${ }^{3}$. Da sich letztere auch bei Nobes an einer Art Reinvermögenszugangstheorie orientiert ${ }^{4}$, verneint dieser kategorisch die Eignung der IFRS für die steuerliche Gewinnermittlung ${ }^{5}$.

Abschließend kann festgehalten werden, dass die an ihrem bilanztheoretischen Leitbild analysierte Systemtauglichkeit der IFRS nicht zweifelsfrei gegeben ist. Argumente für die IFRS lassen sich im Wesentlichen nur aus der engen neoklassischen Perspektive einer investitionsneutralen Gewinnermittlung generieren. Abgesehen von gewissen Standardisierungsvorteilen eines für mehrere Zwecke (europaweit) herangezogenen Gewinnermittlungssystems überwiegen aus effizienzorientierter Betrachtungsperspektive ansonsten die Zweifel an der normativen Tauglichkeit der IFRS. Diese fußen insbesondere auf der marktfernen Ertragswertbilanzierung, die sich einer klaren, objektiven und damit auch willkürfreien steuerlichen Gewinnermittlung eher verschließt. Dieses

1 Vgl. EU-Kommission (Summary Report of the Workshop, 2003) Stichwort "The general principles of IAS".

2 EU-Kommission (Konsultationspapier, 2003) S. 14. Ihre Überlegungen zur Verbindung der IFRS mit der steuerlichen Gewinnermittlung scheinen davon dennoch unberührt; vgl. Spengel (Einheitliche Bemessungsgrundlage, 2004) S. 112; Spengel (Unternehmensbesteuerung in der EU, 2004) S. 146.

3 Vgl. Nobes (Framework for the Taxable Income, 2004) S. 35-41.

4 Vgl. Nobes (Framework for the Taxable Income, 2004) S. 40 „Furthermore, taxation could not reasonably be based on the valuations currently used for financial reporting because they are incoherent...Therefore, the tax system would need its own valuation basis. ... That suggests valuation at a market exchange price... The conclusion is that the need for objectivity and certainty argues in favour of the tax system's traditional reliance on transactions and realisation". Ähnlich auch Whittington (Tax Policy, 1995) S. 453, der die steuerliche Gewinnermittlung als "transactions-based“ charakterisiert und die informationsorientierte Rechnungslegung allgemein als ,accruals-based“.

$5 \mathrm{Vgl}$. Nobes (Framework for the Taxable Income, 2004) S. 49-55. Interessant ist indes, dass der britische Fiskus entgegen dieser Meinung die „Nutzung“ der IFRS-Abschlüsse für Zwecke der steuerlichen Gewinnermittlung dennoch erwägt; vgl. Inland Revenue (Reform of Corporation Tax, 2002) S. 4; Inland Revenue (Pre-Budget Report, 2003) S. 57. 
Urteil fällt unter Bezug auf die steuerliche Leistungsfähigkeit und den realisierten Reinvermögenszugang als dessen Maßgröße noch eindeutiger aus.

\subsubsection{Institutioneller Rahmen der IFRS}

Die Zweifel an der grundsätzlichen Eignung der IFRS für Zwecke der steuerlichen Gewinnermittlung lassen sich durch institutionelle Aspekte untermauern. Um der Dynamik des IFRS-Systems gerecht zu werden, sollen die Regelentstehungsmechanismen näher betrachtet werden, aus denen heraus künftige Standards des IASB überhaupt erst erwachsen.

Trotz der regulierungstechnischen Optimalsituation des Staates bei der steuerlichen Gewinnermittlung, bei der er das Regulierungssubjekt und den einzigen Adressaten markiert, fällt ihm die deduktive Operationalisierung seiner Zielvorstellungen schon sichtbar schwer. Für das IASB ergibt sich angesichts der aufgezeigten Adressatenpluralität eine noch problematischere Situation. Der Regelentstehungsprozess (standard setting process, due process) der IFRS sieht neben den Investoren als Kern-Adressaten auch die Einbindung aller übrigen Adressaten, ja der gesamten ,interessierten Öffentlichkeit" vor. Auch die Abschlussersteller sowie -prüfer werden angehalten, sich an diesem Prozess zu beteiligen. Letztlich sollen sich alle aktuellen sowie potenziellen Vertragspartner der rechnungslegenden Unternehmung in den Regelentstehungsprozess einbringen. Dies geschieht entweder durch unmittelbare Mitarbeit im IASB, durch mittelbare Einflussnahme auf organisatorischer sowie finanzieller Ebene oder auch nur durch so genannte Stellungnahmen (comment letters), die in dem Regelentstehungsprozess zu einem konkreten Standardvorschlag des IASB formuliert werden ${ }^{1}$. Das IASB selbst ist letztlich nichts anderes als ein privatwirtschaftlicher Anbieter für Rechnungslegungssysteme, der von den Nachfragern dieses Systems, im Wesentlichen von den Managern der betroffenen Unternehmen, aber auch von den Abschlussprüfern und wichtigen Adressatengruppen, wiederum organisiert und vor allem auch finanziert wird $^{2}$.

Schwer begründbar erscheint, dass anstelle des Staates mit seiner singulären Zielvorstellung nun diese Parteien mit ihren heterogenen Vorstellungen über die Operationalisierung des Gewinn- und Einkommensbegriffs nach Maßgabe ökonomischer Effizienz oder steuerlicher Leistungsfähigkeit entscheiden. Warum sollen sie Regeln der steuerli-

1 Vgl. ausführlicher zu den Möglichkeiten der Einflussnahme (aus deutscher Sicht bezogen auf das IASC als Vorgängergremium des IASB) Pellens/Fülbier/Ackermann (Deutscher Einfluß, 1996); vgl. zum gegenwärtigen Stand des Regelentstehungsprozesses beim IASB Pellens/Fülbier/Gassen (Internationale Rechnungslegung, 2004) S. 84-87.

2 Vgl. hierzu und zu der regulierungstheoretischen Frage, ob ein (rein informationsorientiertes) Rechnungslegungssystem überhaupt durch den Markt allein bereitgestellt werden kann, Pellens/Gassen (Bereitstellung von Rechnungslegungssystemen, 1998). 
chen Gewinnermittlung entwickeln, ohne Adressaten der steuerlichen Gewinnermittlung zu sein?' ${ }^{1}$ Auf Erstellerseite kann dabei durchaus ein Interesse an einer derartigen „Mitarbeit“" vermutet werden. Dies dürfte schließlich die von ihnen angestrebte Selbsteinsteuerung und/oder relative Steuerbarwertminimierung erleichtern. Fraglich ist jedoch, ob die Beteiligung dieser Gruppen dem Grundgedanken des Legalitätsprinzips und hier insbesondere des Parlamentsvorbehalts entspricht. Dies wäre immer dann zu verneinen, wenn nicht mehr allen von der Steuer betroffenen Subjekten der gleiche, parlamentarisch abgesicherte Zugang zur Entscheidungsbildung eingeräumt wird ${ }^{2}$. Abgesehen davon, dass ein privatwirtschaftliches Gremium schon formalrechtlich parlamentarische Entscheidungen nicht nachbilden kann, gibt es aber durchaus Parallelen. Im Parlament, wie im IASB bzw. in der Stiftungsorganisation der International Accounting Standards Committee Foundation (IASCF) werden letztlich Interessen verschiedener Gruppen zum Ausdruck gebracht. Fraglich ist nur, ob die Organisation des IASB im Sinne der ,interest group theory“ oder „capture theory“ stärker noch als bei parlamentarischen Entscheidungen die Möglichkeit bietet, dass kleine, aber gut organisierte Minderheiten über ihre Lobby ein unverhältnismäßiges Gewicht erlangen und bei der Regelgenerierung letztlich nur noch Partikularinteressen dominieren ${ }^{3}$.

Eine Antwort auf diese Frage kann nur auf der Basis von Indizien gegeben werden. So finden sind im IASB selbst - allerdings bei satzungmäßiger Absicherung ihrer Unabhängigkeit - viele (ehemalige) Vertreter großer, internationaler Unternehmungen sowie großer, internationaler Wirtschaftsprüfungsgesellschaften ${ }^{4}$. Auch wenn sich weitere Vertreter in geringerer Zahl z.B. aus der Wissenschaft rekrutieren oder andere Organisationselemente innerhalb der IASCF die Einflussnahmemöglichkeit weiterer Gruppen vorsehen, dürften Großunternehmungen und große Wirtschaftsprüfungsgesellschaften untermauert durch die bisherige historische Entwicklung ${ }^{5}$ - die Arbeit des IASB am stärksten beeinflussen. Ein zentraler Punkt ist in diesem Zusammenhang auch die Finanzierung des IASB getreu dem Motto: „Wes’ Brot ich ess, des’ Lied ich sing”“. Da

1 Diese Frage wird nur unwesentlich durch die Möglichkeit tangiert, dass die (Mitglied-)Staaten oder die EU-Kommission selbst zum weiten Kreis der am Regelentstehungsprozess Beteiligten gehören.

2 Ob dieses ideal-demokratische Allgemeinheitspostulat allerdings in einer parlamentarischen Demokratie realiter existiert, ist fraglich. Vgl. grundlegend zu diesem Allgemeinheitspostulat als parlamentarischem Vollzug eines ,nationalen Allgemeinwillens, der volonté générale“ Walz (Steuergerechtigkeit und Rechtsanwendung, 1980) S. 37-43, 139 m.w.N.

3 Vgl. grundlegend Posner (Taxation by regulation, 1971); Posner (Theories of economic regulation, 1974); Peltzman (Theory of Regulation, 1976); Stigler (The theory of economic regulation, 1971).

4 IASCF Constitution, Par. 22, schreibt vor, dass mind. fünf der 14 IASB-Mitglieder Wirtschaftsprüfer sein sollen und mind. drei Vertreter der Unternehmen (Ersteller). Ihre (formelle) Unabhängigkeit wird insb. in IASCF Constitution, Par. 24, 26, festgeschrieben.

5 Vgl. hierzu im Überblick Pellens/Fülbier/Gassen (Internationale Rechnungslegung, 2004) S. 72-77; so ist das IASC als Vorgängergremium insb. von Wirtschaftsprüfern gegründet und lange Zeit auch beeinflusst worden; erst durch seine Neustrukturierung 2001 ist das IASB rechtlich verselbständigt und von der IFAC (International Federation of Accountants) abgetrennt worden. 
Erträge aus dem zu geringen Stiftungsvermögen der IASCF für das Budget des IASB kaum ausreichen, finanziert sich das IASB über seine Publikationen und insbesondere auch über Spenden und beitragsartige Zuwendungen. Diese werden wiederum primär von den beiden bereits als dominant identifizierten Gruppen geleistet ${ }^{1}$, so dass auch hier eine verstärkte Einflussnahme und die Durchsetzung von Partikularinteressen vermutet werden kann.

Stärker noch als diese institutionellen Vorbehalte wirkt aber ein weiteres Argument der Übertragbarkeit der IFRS in die steuerliche Gewinnermittlung entgegen. Dieses Argument wird allerdings nicht mehr aus der Perspektive der steuerlichen Gewinnermittlung generiert, so dass darin auch keine steuerspezifischen Nachteile offenkundig werden. Durch die Nutzung der IFRS für Zwecke der steuerliche Gewinnermittlung droht vielmehr eine rückwirkende Beeinflussung der ursprünglich rein informations- und kapitalmarktorientierten IFRS. So dürfte angesichts der Dominanz steuerlicher Erwägungen zu erwarten sein, dass von Seiten der Staaten wie auch der betroffenen Steuersubjekte verstärkt Einfluss auf die Regelentstehung genommen wird ${ }^{2}$. Fiskalische Motive treffen dann auf die entgegen gesetzten Motive der Steuersubjekte und die eigentliche funktionale Ausrichtung der IFRS verlöre wahrscheinlich an Bedeutung ${ }^{3}$.

In der EU wäre konkret zu befürchten, dass sich die Mitgliedstaaten und/oder die EUKommission auch unter fiskalischen Motiven verstärkt in den Regelentstehungsprozess der IFRS einschalten, sofern sie sich nicht auf ihr Recht beschränken, im Einzelfall einfach anderslautende, den IFRS vorgehende Regeln analog $\S 5$ Abs. 6 EStG zu kodifizieren. Ähnlich dem nicht immer spannungsfreien, von fiskalischen Motiven aber unbeeinflussten Verhältnis von US-amerikanischer Börsenaufsichtsbehörde SEC (Securities and Exchange Commission) und US-amerikanischem Rechnungslegungsgremium FASB (Financial Accounting Standards Board) wäre vorstellbar, dass bestimmte Arbeitsprojekte von staatlicher Seite initiiert, angetrieben und in eine bestimmte Richtung gelenkt werden. Auch der Einfluss der betroffenen Steuersubjekte wäre dem Informationsziel

1 Vgl. z.B. IASCF (Annual Report 2003, 2004) S. 23, wo diese beiden Gruppen die dort aufgeführten "underwriter" und "supporter" dominieren.

2 Im Extremfall denkbar, auf EU-Ebene aber wohl kaum wahrscheinlich, sind neben Rückkopplungen im Regelentstehungsprozess auch inhaltliche Rückwirkungen nach Vorbild der deutschen Umkehrmaßgeblichkeit. Dies träfe z.B. steuerliche Sonderabschreibungen oder Umstellungseffekte auf IFRS, die nicht direkt, sondern über einen längeren Zeitraum zu versteuern wären und in eine Art Sonderposten mit Rücklageanteil eingestellt würden. Vgl. zu diesen Überlegungen Selchert (Internationalisierung der Rechnungslegung, 1999) S. 927-930 oder auch Herzig (Internationalisierung, 2000) S. 114; Oestreicher/Spengel (Anwendung von IAS in der EU, 2001) S. 894, die über steuerfreie Rücklagen im Zusammenhang mit „unrealisierten" Wertsteigerungen nachdenken.

3 Vgl. Schreiber (Unternehmensbesteuerung, 2004) S. 225, der i.d.Zshg. zu Recht die „steuerliche Deformierung internationaler Rechnungslegungsgrundsätze" vermutet. 
der IFRS kaum dienlich, weil sie den Regelentstehungsprozess sehr viel stärker aus der Perspektive der Steuerbarwertminimierung begleiteten ${ }^{1}$.

Bei aufeinander prallenden Interessen dieser Parteien ist zudem zu befürchten, dass die nationale oder auch europäische (Finanz-)Gerichtsbarkeit im Streitfall gezwungen würde, die IFRS zu deuten ${ }^{2}$. Das alleinige und für ein weltweit einheitliches Regelverständnis unverzichtbare Interpretationsmonopol des International Financial Reporting Interpretation Committee (IFRIC) wäre damit gebrochen oder stünde im besten Fall als $\mathrm{Pa}$ rallelauslegung für rein informationsorientierte Zwecke neben der Gerichtsauslegung. Die bisherige Stoßrichtung der IFRS würde in jedem Falle konterkariert, so dass letztlich die Gefahr bestünde, dass die eigentlichen Schutzbefohlenen der bisherigen IFRSRechnungslegung, die anonymen Investoren und die Funktionsfähigkeit der organisierten Kapitalmärkte ${ }^{3}$, auf der Strecke bleiben.

\subsection{Zwischenergebnis und weiterer Fortgang der Eignungsprüfung}

Vor dem Hintergrund der aus der Maßgeblichkeitsdiskussion gewonnenen Erkenntnisse und wegen der aufgezeigten funktionalen sowie institutionellen Vorbehalte gegen das IFRS-System kann abschließend festgehalten werden, dass die IFRS für die steuerliche Gewinnermittlung insgesamt eher ungeeignet sind. Damit ist nicht nur die Maßgeblichkeit dieses Rechnungslegungssystems für die steuerliche Gewinnermittlung abzulehnen, sondern auch die unmittelbare Ausrichtung der steuerlichen Gewinnermittlung an diesem Gesamtsystem. Im Rahmen der künftigen EU-Strategie ist es insofern notwendig, eigenständige Gewinnermittlungsregeln zu entwickeln, die den wirkungs- und durchführungsorientierten Effizienzkriterien entsprechen und zur Messung der steuerlichen Leistungsfähigkeit taugen. Dies sollte als Chance begriffen werden, der steuerlichen Gewinnermittlung eine einfache, eindeutige, willkürfreie und vor allem auch monofunktionale Rechnungslegung zu Grunde zu legen.

1 Vgl. zu ähnlichen Befürchtungen Herzig/Bär (Zukunft der steuerlichen Gewinnermittlung, 2003) S. 5; Kahle (Zukunft der Rechnungslegung, 2003) S. 271; Schreiber (Gewinnermittlung, 2002) S. 106-107. Nobes (Framework for the Taxable Income, 2004) S. 22 bemerkt treffend, dass die Regelentwicklung letztlich nicht nur der IFRS, sondern auch der steuerlichen Gewinnermittlung behindert würde ("The links between the tax system and financial reporting act as a constraint on the development of both").

2 Vgl. so auch Herzig (IAS/IFRS, 2004) S. 32; Schildbach (IAS, 2002) S. 275. Schon gegenwärtig besteht diese Gefahr, wie das Beispiel des FG Hamburg zeigt, das die IFRS bei der Auslegung der EUBilanzrichtlinie herangezogen hat; vgl. zu Recht kritisch Berndt (FG-Urteil, 2004); vgl. zur Kompetenz (zivilrechtlicher) Gerichte bei der Auslegung der IFRS Schön (Kompetenzen, 2004).

3 Vgl. zu dieser Schutzwirkung der IFRS Pellens/Fülbier/Gassen (Internationale Rechnungslegung, 2004) S. 45-55, 98-118, 792-798, 832-835; zum Anlegerschutz durch Information in seiner dualen, sowohl Individual- als auch Funktionenschutz umfassenden Ausprägung Hopt/Will (Europäisches Insiderrecht, 1973) S. 46-53; Hopt (Kapitalanlegerschutz, 1975) S. 51-52; Koch/Schmidt (Instrumente des Anlegerschutzes, 1981) S. 235-238; im Überblick dazu m.w.N. Fülbier (Regulierung der Ad-hocPublizität, 1998) S. 159-162. 
Natürlich ist es im Rahmen dieser Suche nach geeigneten Gewinnermittlungsvorschriften opportun, einzelne, konkrete Vorschriften innerhalb des Rechnungslegungssystems der IFRS auf ihre diesbezügliche Eignung hin zu untersuchen ${ }^{1}$. Wegen der grundsätzlich fehlenden Eignung des gesamten IFRS-Systems muss aber eine Art von Beweislastumkehr gelten, die besagt, dass eine spezielle IFRS-Regel so lange für steuerliche Zwecke als ungeeignet anzusehen ist, bis das Gegenteil bewiesen wird ${ }^{2}$. Getreu dieser Vorgabe werden im Folgenden konkrete Einzelregeln der IFRS auf ihre steuerliche Eignung hin untersucht. Dabei liegt der Fokus, dem Schwerpunkt dieser Arbeit folgend, auf den einzelnen Konsolidierungsvorschriften und auf der Frage, ob und inwieweit diese Vorschriften bei der künftigen Ausgestaltung einer einheitlichen konsolidierten Körperschaftsteuer-Bemessungsgrundlage auf europäischer Ebene herangezogen werden können. Diese Untersuchung fußt auf den gegenwärtig gültigen Regeln des IASB (Stand: 1 . April 2004). Trotz der Dynamik dieses Regelwerkes erscheint eine statische, zeitpunktbezogene Analyse dabei sinnvoll (und einzig durchführbar), da das Ansinnen der EUKommission auf die Frage zielt, ob einzelne der derzeit existierenden IFRS bei der (Neu-)Regulierung der konsolidierten steuerlichen Gewinnermittlung in der EU berücksichtigt werden können.

Im Rahmen der folgenden, auf Konsolidierungsaspekte beschränkten Einzelfallprüfung konkreter Vorschriften des IFRS-Systems wird die Reihenfolge an den üblichen Aufbau einer Konzernrechnungslegung angelehnt. Hiernach wird zuerst die Pflicht zur Aufstellung konsolidierter Abschlüsse und die damit einhergehende Abgrenzung des Konsolidierungskreises untersucht, ehe die vorbereitenden Maßnahmen und die eigentlichen Konsolidierungsschritte im Mittelpunkt der Eignungsprüfung stehen. Die Vorgehensweise ist dabei bei allen Einzelvorschriften dieselbe: Nach einer kurzen Darstellung der konkreten Vorschrift wird ihre steuerliche Eignung anhand des normativen Beurteilungsrahmens gewürdigt.

1 Vgl. zu dieser grundsätzlich ablehnenden Haltung gegenüber den IFRS, die die Möglichkeit einer selektiven Übernahme von Detailregeln aber dennoch zulässt, bereits Kap. I.2 und die dort zitierte Literatur. I.d.Zshg. ist auch die Bemerkung von Whittington (Tax Policy, 1995) S. 456 treffend: „...business accounting should be no more than a starting point in assessing tax; blindly accepting all accounting standards for this purpose will serve neither the needs of a good tax system nor those of a good system of financial reporting”. Diese „Einzelfall-Eignung“ mag insb. in der gegenwärtigen Phase hier und da noch gegeben sein, in der das IFRS-System als solches noch nicht gänzlich dem beschriebenen bilanztheoretischen Leitbild entspricht.

2 Ein „besonderer Begründungszwang" ergäbe sich nach Grotherr (Konzernsteuerrecht, 1995) S. 83 auch fur entsprechende HGB-Vorschriften. 


\section{Voraussetzungen einer Gruppenbesteuerung und Konsolidierungskreis}

\subsection{Regulierung auf der Grundlage der IFRS}

\subsubsection{Voraussetzungen einer konsolidierten Rechnungslegung}

In der IFRS-Rechnungslegung ergibt sich die Verpflichtung zur konsolidierten Rechnungslegung nach Maßgabe von IAS 27 „Consolidated and Separate Financial Statements" . Hiernach ist ein Unternehmen immer dann zur Aufstellung eines konsolidierten Abschlusses verpflichtet, wenn es einen beherrschenden Einfluss auf mindestens ein weiteres Unternehmen ausüben kann (IAS 27.4 und 27.9). Das Kriterium der Beherrschung (control) ${ }^{2}$ ist demnach das zentrale Verbindungsmerkmal zwischen dem übergeordneten Unternehmen (parent) und den untergeordneten Unternehmen (subsidiaries), die insgesamt eine Unternehmensgruppe bilden (IAS 27.4). In deutschen Übersetzungen werden die beteiligten Unternehmen aus dem terminologischen Verständnis der $§ \S 290$ 315 HGB heraus auch als Mutter- und Tochterunternehmen und die Unternehmensgruppe als Konzern bezeichnet ${ }^{3}$.

Der zentrale Tatbestand der Beherrschung liegt nach IAS 27.4 vor, wenn die Macht bzw. Möglichkeit (power) ${ }^{4}$ besteht, die Geschäftspolitik (financial and operating policies) eines Unternehmens zu bestimmen, um letztlich Nutzen aus dessen Tätigkeit zu ziehen. Ist diese Definition noch vergleichsweise abstrakt, so werden in IAS 27.13 weitere Sachverhalte zur Konkretisierung angeführt. Eine Beherrschungsmöglichkeit ist hiernach widerlegbar zu vermuten, wenn ein (Mutter-)Unternehmen direkt oder indirekt mehr als die Hälfte der Stimmrechte eines (Tochter-)Unternehmens besitzt. Diese Vermutung kann nur widerlegt werden, wenn es trotz dieser Stimmrechtsmehrheit nachweislich an einer Beherrschungsmöglichkeit mangelt.

Neben der Stimmrechtsmehrheit als rechtliche Einflussmöglichkeit sieht IAS 27.13 aber auch vier konkrete Sachverhalte vor, die faktische Einflussmöglichkeiten konstituieren.

1 IAS 27 (revised 2003) ist Ergebnis des im Dezember 2003 abgeschlossenen Improvements-Project. Er ersetzt IAS 27 (revised 2000) „Consolidated Financial Statements and Accounting for Investments in Subsidiaries" und SIC-33 „Consolidation and Equity Method - Potential Voting Rights and Allocation of Ownership Interests“. In dieser Fassung ist IAS 27 für Geschäftsjahre anzuwenden, die am oder nach dem 1. Januar 2005 beginnen, wobei das IASB eine frühere Anwendung begrüßt (IAS 27.IN1, IAS 27.43).

2 In dieser Arbeit wird „control“ in Anlehnung an die „offiziellen“ EU-Übersetzungen mit Beherrschung im Sinne einer Beherrschungsmöglichkeit ins Deutsche übersetzt; vgl. zu alternativen Übersetzungen Baetge/Schulze (IAS 27, 2002) Tz. 11.

3 Vgl. stellvertretend für die Literatur Baetge/Schulze (IAS 27, 2002) Tz. 12-13; Busse von Colbe et al. (Konzernabschlüsse, 2003) S. 60-61. Dies gilt gleichermaßen für die offizielle EU-Übersetzung (i.R.d. „endorsement"-Prozesses) für den inzwischen nicht mehr aktuellen IAS 27 (revised 2000).

4 Der Begriff ,power“ wird in der offiziellen deutschen Übersetzung mit „Möglichkeit“ übersetzt. 
Sofern keine Stimmrechtsmehrheit vorliegt, existiert dennoch eine Beherrschungsmöglichkeit, wenn

a) aufgrund einer vertraglichen Vereinbarung mit anderen Stimmrechtsinhabern über die Stimmrechtsmehrheit verfügt werden kann,

b) aufgrund einer Satzungsbestimmung oder einer vertraglichen Vereinbarung mit dem (Tochter-)Unternehmen die Möglichkeit besteht, dessen Geschäftspolitik zu bestimmen,

c) die Möglichkeit besteht, die Mehrheit der Mitglieder des Vorstands (board of directors) ${ }^{1}$ oder eines vergleichbaren Geschäftsführungs- und Aufsichtsorgans zu bestellen oder abzuberufen und diesem Organ die Beherrschung des Unternehmens obliegt, oder

d) die Möglichkeit besteht, die Stimmmehrheit in dem Geschäftsführungs- und Aufsichtsorgan auszuüben und diesem Organ die Beherrschung des Unternehmens obliegt.

Damit ist eine Stimmrechtsmehrheit nach IAS 27 für ein Beherrschungsverhältnis nicht notwendig. Auch eine Mindestquote für Stimmrechte wird nicht gefordert. Dies gilt auch für Kapitalbeteiligungen. Letztere werden in IAS 27 nicht als Kriterium zur Konkretisierung der Beherrschung aufgeführt, so dass eine Beherrschungsmöglichkeit auch vorliegen kann, wenn das Mutterunternehmen wenig oder kein Eigenkapital des Tochterunternehmens hält ${ }^{2}$.

In diesem Zusammenhang sind weiterführende Konkretisierungen der Beherrschung in Interpretation SIC-12 „Consolidation - Special Purpose Entities“33 zusammengefasst. Hiernach $^{4}$ ist eine Beherrschung unabhängig von Stimmrechts- oder Kapitalanteilsquoten auch dann gegeben, wenn das Mutterunternehmen

a) Nutzen aus der Geschäftstätigkeit eines Unternehmens zieht, welches (nur) zu Gunsten der besonderen Geschäftsbedürfnisse des Mutterunternehmens geführt wird,

b) entweder selbst über die Entscheidungsmacht verfügt, die Mehrheit des Nutzens aus der Geschäftstätigkeit eines Unternehmens zu ziehen, oder durch Vorherbe-

1 Diese Übersetzung ist eigentlich zu eng, da gesellschaftsrechtliche Funktionen des „board of directors" nach deutschem Recht auch vom Aufsichtsrat wahrgenommen werden.

2 Vgl. dies klarstellend auch Interpretation SIC-12.9.

3 SIC-12 ist im Juni 1998 beschlossen worden und gilt seither für alle Berichtsperioden, die am oder nach dem 1. Juli 1999 begannen (SIC-12.11). Die SIC-Interpretationen sind Verlautbarungen des Standing Interpretations Committee (SIC), das im Zuge der Umstrukturierung des IASC 2001 von dem Nachfolgegremium IFRIC (International Financial Reporting Interpretation Committee) abgelöst wurde.

4 Vgl. insb. die Aufzählung in Interpretation SIC 12.10, die im Anhang weiter erläutert wird. 
stimmung („Autopilot“) der Geschäftstätigkeit diese Entscheidungsmacht delegiert hat,

c) wegen der Berechtigung, die Mehrheit des Nutzens aus einem Unternehmen zu ziehen, auch Risiken ausgesetzt ist, die aus dessen Geschäftstätigkeit resultieren oder

d) die Mehrheit der Residual- oder Eigentumsrisiken oder Vermögenswerte hält, um Nutzen aus ihrer Geschäftstätigkeit zu ziehen.

Unternehmen, die in diesem Sinne beherrscht werden, bezeichnet Interpretation SIC-12 als Zweckgesellschaften (special purpose entities). Unter Berücksichtigung der Definition von Tochtergesellschaften in IAS 27.4 sind Zweckgesellschaften als (spezielle) Tochterunternehmen anzusehen. So resultiert auch aus der Existenz mindestens einer Zweckgesellschaft die Verpflichtung zur Aufstellung konsolidierter Abschlüsse ${ }^{1}$. Anders als die in IAS 27.13 aufgeführten Sachverhalte verweist Interpretation SIC-12.10 aber auf den beispielhaften Charakter der hier dargestellten Sachverhalte und fordert in Verbindung mit SIC-12.8 und 12.9 eine wirtschaftliche Betrachtungsweise aller relevanten Faktoren des jeweiligen Einzelfalls.

Die Verpflichtung zur Aufstellung konsolidierter Abschlüsse ist nach IAS 27 rechtsformunabhängig ausgestaltet. Anders noch als in der Vorversion aus dem Jahr 2000, in der konsequent von „enterprises“ die Rede ist, spricht IAS 27 in der gegenwärtigen Fassung allgemeiner von einer ,entity“, für die die bisherige deutsche Übersetzung als 'Unternehmen' etwas zu eng erscheint. Letztlich versteht sich das gesamte IFRS-System allein als Rechnungslegungssystem und damit als rechtsabstrahierendes Teilelement, auf das sich staatliche Regulierungen oder auch privatvertragliche Absprachen bei Rechnungslegungsfragen beziehen können. In der gesetzlichen oder privatvertraglichen Verankerung, nicht aber in den IFRS, müssen z.B. die Voraussetzungen einer IFRSAnwendung und auch die Rechtsnatur der rechnungslegungspflichtigen Subjekte festgelegt werden. Dies geschieht z.B. im Rahmen der 2002 verabschiedeten Verordnung der EU-Kommission, die alle kapitalmarktorientierten europäischen Unternehmen und damit alle Unternehmen, deren Wertpapiere in irgendeinem EU-Mitgliedstaat an einem organisierten Markt zum Handel zugelassen sind, der Verpflichtung unterwirft, zumindest ihre konsolidierten Abschlüsse nach IFRS zu erstellen ${ }^{2}$. Lediglich hinsichtlich der Tochterunternehmen enthält IAS 27.4 eine präzisierende Angabe. Explizit wird dort betont, dass auch Nicht-Kapitalgesellschaften wie z.B. Partnerschaften als Tochterunternehmen in Frage kommen.

1 Obwohl die Stossrichtung von SIC-12 primär auf die Frage der Einbeziehung der Zweckgesellschaften in den Konsolidierungskreis zielt, zeigt der Fußnotenverweis auf SIC-12 innerhalb von IAS 27.13, dass ihre Existenz auch bei der Frage der Aufstellungspflicht zu berücksichtigen ist.

2 Vgl. hierzu Kap. IV.2.2.1. 
Unter restriktiven Bedingungen sieht IAS 27.10 auch eine Befreiung von der Pflicht zur Aufstellung eines konsolidierten Abschlusses vor. Dafür müssen folgende Voraussetzungen kumulativ erfüllt sein:

a) Das Mutterunternehmen ist selbst wieder ein Tochterunternehmen und stellt demnach eine Art Zwischenholding dar. Sofern es nicht im 100\%igen Eigentum ${ }^{1}$ des übergeordneten Unternehmens steht, müssen die anderen Eigentümer (regelmäßig Minderheitsgesellschafter ${ }^{2}$ ) darüber informiert worden und einverstanden sein, dass kein konsolidierter Abschluss aufgestellt wird.

b) Eigen- und Fremdkapitaltitel der Zwischenholding werden an keinem öffentlichen Markt ${ }^{3}$ gehandelt.

c) Die Zwischenholding hat ihre Abschlüsse bei keiner Börsenaufsichtsbehörde zwecks Registrierung irgendeiner Wertpapieremission eingereicht und befindet sich auch in keinem diesbezüglichen Verfahren.

d) Eines der ihr übergeordneten Mutterunternehmen ${ }^{4}$ erstellt konsolidierte $\mathrm{Ab}$ schlüsse nach IFRS, die der Öffentlichkeit auch zugänglich sind.

Sonstige Befreiungsmöglichkeiten, gar aufgrund irgendwelcher Größenkriterien, sind in IAS 27 nicht vorgesehen.

IAS 27 und SIC-12 werden künftig wohl im Rahmen eines neuen Standards zusammengefasst und besser ineinander integriert. Dies ist zumindest das Ziel eines Projektes "Consolidation (including Special Purpose Entities) ${ }^{65}$. Im Rahmen dieses Projektes bestätigt das IASB einmal mehr die zentrale Rolle der Beherrschungsmöglichkeit, die unter Berücksichtigung der Umstände des jeweiligen Einzelfalls zu identifizieren ist. In diesem Zusammenhang stellt es auf drei Kriterien ab, die auf diese Beherrschungsmöglichkeit hindeuten:

- Die Möglichkeit, die strategische Gesamtausrichtung zu beeinflussen und die operative und finanzielle Geschäftspolitik sowie Strategie zu bestimmen (power criterion).

1 IAS 27.10 spricht hier von „wholly-owned subsidiary“. Da eine weitergehende Präzisierung des dabei verwendeten Eigentumsbegriffs fehlt, bleibt dieser vergleichsweise unbestimmt.

2 Regelmäßig dürften in den „,anderen“ (other) Eigentümern Minderheitsgesellschafter vermutet werden. Zwingend ist dies jedoch nicht, da die rechtliche Einflussmöglichkeit nach IAS 27.13 allein auf einer Stimmrechtsmehrheit beruht, die nicht mit einer Kapitalanteilsmehrheit übereinstimmen muss. Bei faktischen Einflussmöglichkeiten bedarf es noch nicht einmal der Stimmrechtsmehrheit; vgl. auch Kap. V.4.2.2.5.1.

3 IAS 27.10 (b) wendet diesen Marktbegriff auf nationale wie ausländische, auf regionale wie überregionale und auf organisierte wie nicht organisierte Märkte an.

4 Konsequenterweise differenziert IAS 27.10 zwischen „the ultimate“ und ,any intermediate parent" und stellt dabei an dieser Stelle auf die oberste Hierarchiespitze der Unternehmung und die in der Hierarchie dazwischen liegenden Unternehmen gleichermaßen ab.

5 Vgl. zu Ziel und Inhalt dieses Projekts die Projektzusammenfassung IASB (Consolidation, 2004); später verändert und stark erweitert in $I A S B$ (Consolidation, revised November, 2004). 
- Die Möglichkeit, Nutzen zu ziehen (benefit criterion).

- Die Möglichkeit, über das „power criterion“ diesen Nutzen(zufluss) zu mehren, zu schützen oder beizubehalten (link) ${ }^{1}$.

Zudem gibt das IASB weitere erläuternde Hinweise, die das bisherige Konzept konkretisieren, aber nicht wesentlich verändern. Dabei steht das Bemühen im Vordergrund, insbesondere die Zweckgesellschaften stärker in ein umfassendes Konsolidierungskonzept zu integrieren ${ }^{2}$.

\subsubsection{Abgrenzung des Konsolidierungskreises}

Im Grundsatz geht IAS 27.12 davon aus, dass sämtliche Tochterunternehmen, die von dem Mutterunternehmen beherrscht werden (können), in den Konsolidierungskreis einzubeziehen $\operatorname{sind}^{3}$. Dieses Einbeziehungserfordernis ist angesichts fehlender Einschränkungen unabhängig von Rechtsform ${ }^{4}$ und Sitz des jeweiligen Tochterunternehmens und kann analog zu handelsrechtlichen deutschen Grundsätzen (§ 294 HGB) als Weltabschlussprinzip charakterisiert werden ${ }^{5}$.

IAS 27 sieht keine Ausnahme von dieser generellen Einbeziehungserfordernis vor. Die in IAS 27.16 nach Abschluss des ,improvements project“ noch enthaltene Ausnahme für temporäre Beherrschungsverhältnisse ist Ende März 2004 mit IFRS 5 „Non-current Assets Held for Sale and Discontinued Operations“ aufgehoben worden ${ }^{6}$. Damit müssen Tochterunternehmen, die nur zum Zwecke der kurzfristigen Weiterveräußerung gehalten werden ${ }^{7}$, zwingend in die Konsolidierung einbezogen werden oder fallen als ,noncurrent asset (or disposal group) as held for sale" unter die Bestimmungen von IFRS $5^{8}$.

1 Mit diesem Kriterium will das IASB insb. Treuhänder vom „control“-Kriterium ausschließen, die zwar „power" besitzen, diese aber nicht zur Mehrung bzw. Sicherung des eigenen Nutzens einsetzen; vgl. dazu IASB (Consolidation, 2004) „The Link“; IASB (Update, June 2004) S. 3. In einer späteren Fassung hat das IASB auf die Überschrift „The Link“ verzichtet; vgl. IASB (Consolidation, revised November, 2004) No. 8c, 17.

2 Vgl. IASB (Consolidation, 2004) “Special Purpose Entities"; IASB (Consolidation, revised November, 2004) No. 41-45.

3 IAS 27.12: „... shall include all subsidiaries of the parent“; in der Definition von „group“ in IAS 27.4 deutet sich diese umfassende Einbeziehung bereits an: „A group is a parent and all its subsidiaries“.

4 Im Gegensatz zum Mutterunternehmen enthält IAS 27.4 eine Negativabgrenzung hinsichtlich der Rechtsnatur des Tochterunternehmens, das nicht auf Kapitalgesellschaften begrenzt wird; vgl. auch Kap. V.2.2.1.2.

5 Vgl. Baetge/Schulze (IAS 27, 2002) Tz. 67; Busse von Colbe et al. (Konzernabschlüsse, 2003) S. 36.

6 Vgl. IFRS 5, Appendix C6; diese Entwicklung zeichnete sich im Vorfeld ab (vgl. IAS 27.BC14).

7 Nach den inzw. aufgehobenen IAS 27.16-18 musste eine Weiterveräußerung innerhalb von zwölf Monaten absehbar sein und das Management aktiv einen Käufer suchen, wobei die Frist auch gewahrt war, wenn der Veräußerungsprozess bereits im Gange und der Vollzug bald zu erwarten war.

8 Die Frage, ob die Behandlung nach IFRS 5 die Konsolidierung ausschließt, ist wohl zu bejahen. Mit Bezug auf IFRS 5.4 ist das (temporäre) Tochterunternehmen als „disposal group“ anzusehen und damit insgesamt als Ganzes (,as a whole“) zu bewerten. 
Auch sonstige Ausnahmen, z.B. aufgrund abweichender Geschäftstätigkeiten, werden in IAS 27.19-20 sowie im Rahmen des Projektes „Consolidation (including Special Purpose Entities)“" explizit verneint ${ }^{1}$.

Es gilt allerdings - wie im gesamten System der IFRS - der Grundsatz der Wesentlichkeit (materiality) und der Wirtschaftlichkeit (balance between benefit and cost). Hiernach kann auf die Einbeziehung derjenigen Tochterunternehmen verzichtet werden, deren Rechnungslegungsdaten für die Vermögens-, Finanz- und Ertragslage sowie die Zahlungsüberschüsse der rechnungslegenden Einheit entweder unwesentlich sind oder nur mit unverhältnismäßig hohen Kosten und zeitlichen Verzögerungen erlangt werden können ${ }^{2}$.

\subsection{Eignung für die konsolidierte steuerliche Gewinnermittlung}

Im Folgenden soll die Eignung der aufgeführten Bestimmungen von IAS 27 für Zwecke der konsolidierten steuerlichen Gewinnermittlung anhand des Beurteilungsrahmens dieser Arbeit analysiert werden. Weil dabei primär Aspekte der rechnungslegenden Einheit und ihrer Abgrenzung im Vordergrund stehen, kommt der diesbezügliche Teil des normativen Anforderungsprofils besonders zur Geltung. Untersucht wird aber auch, inwieweit IAS 27 darüber hinaus in der Lage ist, den rechtlichen Nebenbedingungen der steuerlichen Gewinnermittlung zu genügen. Dabei sollen auch Erkenntnisse aus der rechtsvergleichenden Gegenüberstellung der in der EU existierenden Konsolidierungsvorschriften Berücksichtigung finden ${ }^{3}$.

\subsubsection{Nukleus- und Ressourcenorientierung}

\subsubsection{Grundsatz}

IAS 27 folgt zweifelsohne einer eher ökonomisch geprägten Vorstellung von einer Unternehmung, innerhalb der die rechnungslegende Einheit nicht auf ein einziges Unternehmen (legal entity) beschränkt wird. Statt dessen umfasst sie eine Gruppe von Unternehmen. Diese Erkenntnis vermag nicht zu überraschen, da die konsolidierte Rech-

1 Vgl. neben IAS 27.19-20 auch IASB (Consolidation, 2004) "Exclusions from Consolidation". Ausgeschlossen ist auch die vormals existierende Ausnahme, Tochterunternehmen aus dem Konsolidierungskreis zu entfernen, wenn sie unter erheblichen und langfristigen Beschränkungen tätig sind, die ihre Fähigkeiten zum Finanzmitteltransfer an das Mutterunternehmen wesentlich beeinträchtigen; vgl. IAS 27.13 (b) in der 2000 überarbeiteten Version.

2 Vgl. IASB Framework Par. 29-30, 44; dazu insb. Baetge/Schulze (IAS 27, 2002) Tz. 101-107; Busse von Colbe et al. (Konzernabschlüsse, 2003) S. 123, die allerdings die Gültigkeit des Wirtschaftlichkeitsgebots in diesem Zusammenhang bezweifeln (S. 119-120).

3 Dabei wird die realtypische Variante der Konsolidierung unterstellt, die auf den Einzelgewinnermittlungen aufbaut; vgl. zu entsprechenden Präferenzen auch auf EU-Ebene Spengel (Unternehmensbesteuerung in der EU, 2004) S. 145. 
nungslegung schon per definitionem auf der Zusammenfassung bestimmter Einzelgewinnermittlungen beruht und die rechtsformorientierte Unternehmenssicht der Einzelgewinnermittlung eine dominante Abgrenzungsbasis zur Verfügung stellt. Im Grundsatz entsprechen die Vorschriften in IAS 27 einer nukleus- und ressourcenbasierten Abgrenzungsleitlinie, die auch steuerlichen Zwecken dienen könnte. Anknüpfungspunkt und Einbeziehungsobjekte der konsolidierten Rechnungslegung nach IFRS sind primär die Unternehmen und die ihnen mittelbar oder unmittelbar als Eigentum zugerechneten Ressourcen. Nach IAS 27 einzubeziehende Unternehmen werden als interne Vertragspartner in die rechnungslegende Einheit integriert, während sonstige Vertragsparteien derselben für Rechnungslegungszwecke dem Markt zugerechnet werden.

Folgt IAS 27 damit im Grundsatz dem normativen Abgrenzungsleitbild der konsolidierten steuerlichen Gewinnermittlung, so ergeben sich jedoch einige Besonderheiten und Unterschiede im Detail. Diese sind im Folgenden näher zu untersuchen.

\subsubsection{Rechtsformanforderungen}

Anknüpfungspunkt der Bestimmungen von IAS 27 ist ein Mutterunternehmen (parent), von dem aus die Abgrenzung der rechnungslegenden Einheit vollzogen wird. Fraglich ist, ob IAS 27 in diesem Zusammenhang dem Prinzip der obersten Entscheidungs- und Kontrollinstanz folgt und die Hierarchiespitze der Unternehmung zu treffen versucht. Während dies im Falle eines Unternehmens offensichtlich zutrifft, ist die Situation bei einer natürlichen Person als Unternehmer weniger eindeutig. Dies liegt bereits in der deutschen Übersetzung begründet, die ,parent“ als „Mutterunternehmen“ übersetzt und nicht als „Mutterunternehmer“ o.ä.'. Obwohl die natürliche Person als Anknüpfungspunkt der konsolidierten IFRS-Rechnungslegung in der Literatur meist ausgeklammert wird und in der Praxis kaum eine Rolle spielen dürfte, ist IAS 27 aber durchaus zu ihrer Berücksichtigung in der Lage. So fehlt der Definition von „parent“ in IAS 27.4 jede rechtsformspezifische Eingrenzung, was angesichts des rechtsabstrahierenden Teilmengencharakters der IFRS auch folgerichtig erscheint ${ }^{2}$. Unter einer „entity“ kann insofern auch eine natürliche Person subsumiert werden. Klarer wird diese Tatsache im Übrigen

1 Da Übersetzungen oft - auch unwissentlich - aus einer bestimmten kulturellen Prägung und so auch aus einem bestimmten Rechtsverständnis heraus getätigt werden, könnte an dieser Stelle vermutet werden, dass die Rechtsformvoraussetzungen von $§ 290$ HGB implizit in die deutsche IFRS-Übersetzung übertragen worden sind oder zumindest der Eindruck vorherrschte, dass es sich (deswegen) um ein Unternehmen handeln müsste. Andererseits ist die Unternehmensdefinition dieser Arbeit, die eine eigenständige Rechtsträgerfähigkeit z.B. im Sinne einer juristischen Person unterstellt, nicht mit der deutschen Rechtsterminologie identisch. Letztere kennt sehr wohl das Unternehmen z.B. eines Einzelkaufmanns (z.B. $\S 15$ Abs. 1 Satz 1 Nr. 1 EStG, $\S 1$ Abs. 5, $\S 3$ Abs. 1 Nr. 1 PublG), so dass die Übersetzung von IAS 27.4 vor diesem Rechtshintergrund wieder mehr Sinn ergibt.

2 Vgl. auch Baetge/Schulze (IAS 27, 2002) Tz. 13: „Der IASB möchte offensichtlich mit dieser weichen Formulierung breiten Interpretationsspielraum iSe. möglichst ausgedehnten internationalen Akzeptanz von IAS bieten“. 
in IFRS 3 „Business Combinations“, der seit März 2004 die Bilanzierung von Unternehmenszusammenschlüssen reguliert ${ }^{1}$. Schließlich wird in IFRS 3.12 explizit darauf hingewiesen, dass ,,an entity can be controlled by an individual“2. Letztlich obliegt es aber dem deutschen oder europäischen Steuerrecht, den Rechtscharakter der obersten Entscheidungs- und Kontrollinstanz festzulegen. IAS 27 - und auch IFRS 3 - wäre(n) diesbezüglich wohl nicht der Engpass.

Anders als beim Mutterunternehmen enthält IAS 27.4 jedoch rechtsformspezifische Hinweise zum Tochterunternehmen (subsidiary), das nicht nur als Kapitalgesellschaft, sondern z.B. auch als Personengesellschaft firmieren kann, wenn auch hier eine Beherrschungsmöglichkeit gegeben ist ${ }^{3}$. IAS 27 benutzt wieder den neutralen Begriff der ,entity“, der hiernach eben nicht nur auf Rechtsträger wie natürliche oder juristische Personen beschränkt ist. In Kombination mit dem Weltabschlussprinzip in IAS $27.12 \mathrm{kommt}$ darin das Bestreben der IFRS zum Ausdruck, die Unternehmung - vorausgesetzt, die oberste Entscheidungs- und Kontrollinstanz ist als Anknüpfungspunkt der konsolidierten Rechnungslegung identifiziert worden ${ }^{4}$ - möglichst umfassend abzubilden. Dieses Bestreben ist auch der steuerlichen Gewinnermittlung durchaus zweckdienlich. Einerseits wird dadurch das Vollständigkeitsgebot gestützt, das auch für den Nettovermögensvergleich gilt und das die Auslagerung bestimmter Ressourcen in Personengesellschaften und ihre Ausgrenzung aus dem Konsolidierungskreis zu verhindern sucht ${ }^{5}$. Andererseits dürfte dies auch dazu dienen, die Selbsteinsteuerungsmöglichkeiten der Hierarchiespitze über Rechtsformgestaltung und anschließende Ressourcenverlagerung sowie Ertragsrealisation zu beschränken ${ }^{6}$. Die vollumfängliche Berücksichtigung dient letztlich auch der Organisationsneutralität, nach der Rechtsformunterschiede auf Ebene der Unternehmen zu ignorieren sind.

1 Vgl. hierzu genauer Kap. V.4.2.

2 Weil nach IAS 27.4 feststeht, dass „[a] parent is an entity...“, dürfte die „entity“ nach IFRS 3.12 als Oberbegriff auch Individuen umfassen.

3 Fraglich ist, ob eine Personengesellschaft überhaupt beherrscht werden kann, da es ihnen bereits an der Eigenschaft einer Zentraleinheit mangelt. Letztlich ist der Gesellschafter (Mutterunternehmen) unmittelbarer Eigentümer der dortigen Ressourcen, wobei die diesbezügliche Beherrschungsmöglichkeit bei mehreren Gesellschaftern zumindest problematisch, aber nicht unmöglich erscheint (z.B. bei einer deutschen KG mit nur einem Komplementär, aber mehreren Kommanditisten). Vgl. zu dieser hier nicht weiter vertieften Frage z.B. Grotherr (Besteuerung nationaler und grenzüberschreitender Konzerne, 1994) S. 440.

4 Andernfalls würde nur der Teil der Unternehmung erfasst, der diesem Anknüpfungspunkt unterhalb der eigentlichen Hierarchiespitze als Eigentum mittelbar oder unmittelbar zuzurechnen ist.

5 Vgl. ähnlich auch Senger (Konzernertragsbesteuerung, 1997) S. 145, der i.d.Zshg. vom „Grundsatz der vollständigen Konzernerfassung“ spricht. Indirekt wären die Ressourcen - abgebildet in dem jeweiligen Beteiligungsbuchwert (nur wenn entsprechende Anschaffungskosten vorliegen) - enthalten.

6 Vgl. treffend Baetge/Schulze (IAS 27, 2002) Tz. 13: „... wird der Spielraum zur Sachverhaltsgestaltung durch Rechtsformwahl eingegrenzt..." [ohne Hervorhebungen des Originals]. 
Dessen ungeachtet ist zu konstatieren, dass der EU-Rechtsvergleich und hier insbesondere die steuerrechtlichen Regeln der vier europäischen Konsolidierungsstaaten zeigen, dass Personengesellschaften aus dem Konsolidierungskreis grundsätzlich ausgeschlossen werden '. Darin kommen wohl steuersystematische Schwierigkeiten zum Ausdruck, wenn die Sphären der Einkommensteuer und der Körperschaftsteuer zusammentreffen ${ }^{2}$. So verwundert es nicht, dass - mit Ausnahme Deutschlands und Frankreichs - Personengesellschaften auch nicht als Obergesellschaft in Frage kommen, selbst wenn die Betrachtung um die Gruppenbesteuerungssysteme erweitert wird, die nur einen gruppeninternen Verlustausgleich zulassen. Möglicherweise markiert das französische Modell hier einen Kompromiss, da es immerhin die Personengesellschaften berücksichtigt, die zur Körperschaftsbesteuerung optiert haben ${ }^{3}$. Normativ überzeugen kann dies jedoch nicht, da die Selbsteinsteuerungsmöglichkeit lediglich auf diese Optionsentscheidung verlagert wird und negative Konsequenzen für das Vollständigkeitsgebot und die Organisationsneutralität weiterhin bestehen.

Das Beispiel der körperschaftsteuerlichen deutschen Organschaft erscheint insofern interessanter. So kommen gemäß $\S 14$ Abs. 1 Nr. 2 KStG u.a. unbeschränkt steuerpflichtige natürliche Personen oder nicht steuerbefreite Personenvereinigungen sowie Personengesellschaften i.S. von $\S 15$ Abs. 1 Nr. 2 EStG als Organträger in Frage ${ }^{4}$. Die Organschaft folgt nicht nur der ökonomischen Vorstellung, nach der die oberste Kontrollinstanz der Unternehmung sehr wohl auch aus einer natürlichen Person bestehen kann ${ }^{5}$. Sie dokumentiert zudem, dass eine Einkommensverlagerung zwischen Körperschaft- und Einkommensteuersphäre durchaus möglich ist ${ }^{6}$. In diesen Zusammenhang passt auch, dass der inzwischen allerdings zurückgezogene Entwurf einer EUVerlustrichtlinie von 1990 eher der Wettbewerbs- bzw. Organisationsneutralität zuge-

I Vgl. Kap. IV.1.2.1.

2 Vgl. Grotherr (Konzernbesteuerungssysteme, 1996) S. 364-365; zu dieser Problematik allg. u.a. $O-$ berndorff(Konzembesteuerung, 1996) S. 107-109; Wöhe (Steuerlehre, 1996) S. 76, 107-110.

3 Dies bereits vor dem Hintergrund der Wettbewerbsneutralität diskutierend Grotherr (Besteuerung nationaler und grenzüberschreitender Konzerne, 1994) S. 59, 439.

4 Vgl. zur dieser Auslegung z.B. Haase (Personengesellschaften als Organträger, 2004). Interessant ist, dass der BFH noch 1966 Einzelkaufleuten und Personengesellschaften als Organträger die Anerkennung mit Hinweis auf verletzte fundamentale Grundsätze verweigerte, weil der Gewinn einer Kapitalgesellschaft damit nicht der Körperschaftsteuer, sondern letztlich nur der Einkommensteuer unterworfen werde; vgl. $B F H$ v. 17.11.1966 (I 280/63); erläuternd Wöhe (Steuerlehre, 1996) S. 79.

5 Damit folgt $\S 14 \mathrm{KStG}$ letztlich auch dem deutschen Konzernrecht, das durchaus als Versuch verstanden werden kann, das ökonomische Modell der Unternehmung in die deutsche Rechtsordnung zu übertragen. Hier wird der Unternehmensbegriff ebenfalls sehr weit ausgedehnt und letztlich auch auf natürliche Personen angewendet; vgl. dazu Emmerich/Sonnenschein/Habersack (Konzernrecht, 2001) S. 31-33 und Kap. III.2.3.1. Dies als Ausdruck eines schutzrechtlichen Unternehmensbegriffs interpretierend (,Wer ,Konzerngefahr' in ein Unternehmen hineinträgt, ist ... ,Unternehmen'“) Schmidt (Konzernunternehmen, 2000) S. 1179-1180.

6 Steuertechnische Probleme bei einer Personengesellschaft als Obergesellschaft insb. unter Berücksichtigung von Minderheiten sieht Bauer (Besteuerung deutscher Konzerne, 1987) S. 296-297. 
neigt war und Personengesellschaften von dem Kreis der hiervon erfassten Unternehmen keineswegs ausgeschlossen hat ${ }^{1}$. Bei der notwendigen Abwägung steuersystematischer Einwände und normativer Vorgaben müssen erstere also nicht unbedingt überwiegen $^{2}$. Dabei erscheint es angebracht, die normativen Vorgaben um durchführungsorientierte Effizienzargumente anzureichern, die insbesondere auch die Integrationsfähigkeit dieser Vorgehensweise in die europäische und einzelstaatliche Steuersystematik berücksichtigen.

Mittels der IFRS wird auch die Frage beantwortet, ob rechtlich unselbständige Betriebsstätten dem steuerlichen Konsolidierungskreis zuzurechen sind. Bei einer Betriebsstätte handelt es sich gar nicht mehr um ein Unternehmen im Sinne einer kontraktfähigen Einheit, sondern um eine „normale“ Ressource. Damit fallen Betriebsstätten erst einmal nicht mehr unter die konsolidierte Rechnungslegung und IAS 27, sondern müssen bereits in der Einzelgewinnermittlung desjenigen Rechtsträgers berücksichtigt werden, der das unmittelbare Eigentum an ihr hält ${ }^{3}$. Wie jede andere Ressource auch, sind sie vollumfänglich zu erfassen. Dies ergibt sich bereits aus dem Rahmenkonzept des IASB, das in Par. 38 zur vollständigen Information und damit wohl auch zur vollständigen Erfassung sämtlicher Vermögenswerte und Schulden anhält. Würde lediglich IAS 27 in seiner Eigenschaft als Abgrenzungsregel in die steuerliche Gewinnermittlung übernommen, müsste das ansonsten vorhandene Gewinnermittlungssystem diesen steuerlich wünschenswerten Vollständigkeitsanspruch - modifiziert z.B. nach Maßgabe der Reinvermögenszugangstheorie - gewährleisten.

Sollten Betriebsstätten allerdings einer vollständigen oder partiellen Einzelgewinnermittlung zugeführt worden sein, weil sie z.B. durch fiskalische Grenzen von dem Unternehmen gewinnermittlungstechnisch abgeteilt werden, ist IAS 27 durchaus zur Berücksichtigung dieser Situation in der Lage. Angesichts der rechtsneutralen Definition der „subsidiary“ kann darunter auch eine Betriebsstätte subsumiert werden, die damit ebenfalls der Konsolidierung zugeführt wird. Noch deutlicher wird dies in IFRS 3, der sich definitiv von der Rechtseinheit als Objekt der (Kapital-)Konsolidierung entfernt

1 Vgl. zur Verlustrichtlinie bereits Kap. IV.2.1.2.

2 Auch die Literatur kommt an dieser Stelle zu keinem einheitlichen Ergebnis, dürfte in der Tendenz aber die Einbeziehung der Personengesellschaften eher befürworten; vgl. so Grotherr (Besteuerung nationaler und grenzüberschreitender Konzerne, 1994) S. 59-61, 439-443; Senger (Konzernertragsbesteuerung, 1997) S. 145-146. Salzberger (Konzernunternehmung, 1994) S. 6 hingegen schließt dieses Problem annahmegemäß aus, da er nur Kapitalgesellschaften betrachtet; ähnlich auch Müller (Konzernbesteuerung, 1991) S. 131, der „primär nur unbeschränkt steuerpflichtige Körperschaften in Betracht" zieht. Ob die tatsächliche steuersystematische Ausgestaltung eines europäischen Konsolidierungsmodells nur auf Körperschaftsteuersubjekte begrenzt werden soll, ist letztlich eine politische Entscheidung, die auch Gesichtspunkte der Durchführungseffizienz, z.B. hinsichtlich der steuersystematischen Integration in die nationalen Systeme, zu berücksichtigen hat.

3 Damit ist im Übrigen auch die Ertragsrealisation bei Lieferungs- und Leistungsbeziehungen zwischen diesem Rechtsträger und der Betriebsstätte ausgeschlossen. 
und neben der „entity“ auch auf den sehr viel allgemeineren Begriff der „businesses“ abstellt (,A business combination is the bringing together of separate entities or businesses into one reporting entity“"1).

\subsubsection{Weltabschlussprinzip}

Das in IAS 27.12 festgelegte Weltabschlussprinzip grenzt die rechnungslegende Einheit für eine konsolidierte Rechnungslegung unabhängig von staatlichen bzw. fiskalischen Grenzen ab. Das Vorliegen eines Beherrschungsverhältnisses allein manifestiert die Zuordnung eines wo auch immer angesiedelten Tochterunternehmens zur rechnungslegenden Einheit. Dies entspricht durchaus dem normativen Abgrenzungsleitbild der steuerlichen Gewinnermittlung, zumindest soweit es von fiskalischen Grenzen abstrahiert und eine Welt mit nur einem Fiskus unterstellt. Es entspricht indes nicht den rechtstatsächlichen Gegebenheiten.

Das Weltabschlussprinzip des IAS 27.12 steht deshalb im Widerspruch zur begrenzten Steuersouveränität des europäischen Regulierers. Obwohl nationalstaatliche Grenzen innerhalb der EU für die Abgrenzung des steuerlichen Konsolidierungskreises keine Rolle mehr spielen (sollen), verbleiben auf jeden Fall die Außengrenzen der EU als fiskalische Barriere. Ein steuerlicher Konsolidierungskreis nach Maßgabe von IAS 27.12 würde demnach zur Mehrfachbesteuerung führen, wenn außerhalb der EU angesiedelte Tochterunternehmen weiterhin - wie zu erwarten - der vollen dortigen Steuersouveränität unterliegen ${ }^{2}$.

Eine Mehrfachbesteuerung könnte zwar abgemildert oder verhindert werden, wenn Verfahren zur Vermeidung der Doppelbesteuerung (Anrechnungs- oder Freistellungsmethode) implementiert und/oder bilaterale Vereinbarungen mit den Nicht-EU-Staaten geschlossen würden. Da hierbei allerdings gegenläufige fiskalische Interessen aufeinanderprallen, dürften diese an sich wünschenswerten Alternativen wenig realistisch sein. Dies gilt insbesondere auch vor dem Hintergrund durchführungsorientierter Effizienzargumente. So sind Transaktionskosten bereits offensichtlich, die mit dem multiplen Abschluss oder zumindest der partiellen Neuverhandlung bilateraler Doppelbesteuerungsabkommen einhergehen. Aber auch ohne diese Abkommen wären Effizienznachteile bei der Durchsetzung des Weltabschlussprinzips über unilaterale Maßnahmen erkennbar. Da diejenigen Unternehmen, die außerhalb der EU angesiedelt sind, von mindestens zwei Steuersouveränitäten erfasst würden, trügen sie - und die jeweils betroffenen Fi-

1 IFRS 3.4; die von der „legal entity“ eindeutig abweichende Interpretation von „business“ drückt sich in IFRS 3.5 und Appendix A (Defined terms: business) aus, wo ein „business“ als eine zusammenhängende Menge von Aktivitäten bzw. von Nettovermögen definiert wird. In diese Richtung zielt im Übrigen auch IAS 21.8 mit der rechtsformunabhängigen Definition einer ,foreign operation“.

$2 \mathrm{Vgl}$. zu dieser realistischen Annahme bereits Kap. III.2.5.2. 
nanzverwaltungen - die Last einer Doppelveranlagung. Diese Unternehmen unterlägen wahrscheinlich weiterhin einer traditionellen Vollveranlagung, zu der in einer zweiten Stufe eine komplette Gruppenbesteuerung und die Korrektur der Erstveranlagung hinzukäme. Da diese Korrektur der EU-Steuerhoheit obläge, die die Gruppenbesteuerung zugelassen hätte, trüge auch nur sie die administrativen Mehrkosten der gesamten zweiten Stufe. Abgesehen davon, dass eine vollständige Korrektur ausländischer Mehrbelastungen für die Unternehmensgruppe nicht garantiert werden kann ${ }^{1}$, existiert dabei auch kein kompensierender fiskalischer Anreiz. Die (einseitige) Anrechnungs- oder auch Freistellungsmethode ginge für die EU und die dahinter stehenden Fiski mit keinerlei Aufkommensvorteil einher. Im Gegenteil: Je höher das heimische Steuerniveau, um so stärker ist das fiskalische Bestreben, an den fiskalischen Grenzen in Kombination mit dem Fremdvergleichsgrundsatz festzuhalten, um den gruppenspezifischen Ausweichhandlungen, d.h. der Verlagerung der Ertragsrealisation in Niedrigsteuerstaaten außerhalb der EU, zumindest partiell entgegenzuwirken.

Die Erkenntnisse aus dem EU-Rechtsvergleich bestätigen die Wirkung fiskalischer Grenzen. In den Steuerrechtsordnungen aller vier Konsolidierungsstaaten wird der nationalstaatlichen Steuersouveränität Tribut gezollt. Die Gruppenbesteuerung und mit ihr die Gesamtgewinnermittlung wird auf „Inlandsgruppen“ beschränkt ${ }^{2}$, so dass sich die rechnungslegende Einheit auf eine Teilmenge der grenzüberschreitenden Unternehmensgruppe und ihrer Ressourcen beschränkt. Daran ändert im Übrigen auch das dort weiterhin geltende Welteinkommensprinzip nichts. Hiernach wird das Einkommen der steuerlich im Ausland ansässigen Unternehmen im Sinne des Trennungsprinzips separat ermittelt und der Inlandsgruppe phasengleich oder im Wege der Ausschüttung zugerechnet. Die Nichtberücksichtigung ausländischer Unternehmen im steuerlichen Konsolidierungskreis deutet wohl auch die Schwierigkeiten und Effizienznachteile von unilateralen oder bilateralen Kompensationsmaßnahmen an.

Angesichts rechtstatsächlicher Gegebenheiten erscheint IAS 27.12 als Abgrenzungsregel für Zwecke der konsolidierten steuerlichen Gewinnermittlung kaum durchsetzbar ${ }^{3}$. Dies gilt insbesondere für die konkrete Ausgestaltung des EU-Konsolidierungsmodells. So hat auch die EU-Kommission die gesamte EU-Strategie immer nur auf die ,grenz-

1 Die ausländische Steuer kann die inländische Steuer übersteigen, so dass Freistellungs- und u.U. auch Anrechnungsmethode keine komplette Kompensation ermöglichen.

2 Allerdings mag die Frage, wann ein Unternehmen in den betrachteten vier Staaten steuerlich ansässig ist, variieren. In den Niederlanden fällt darunter z.B. auch eine nach niederländischem Recht gegründete $\mathrm{GmbH}$ (vennootschappen met beperkte aansprakelijheid, BV), die aber effektiv aus dem Vereinigten Königreich geleitet wird; vgl. dazu Müssener (Niederlande, 2002) Tz. 349. Vgl. allg. zur steuerlichen Ansässigkeit Jacobs (Internationale Unternehmensbesteuerung, 2002) S. 6-8, 291-313.

3 Vgl. ähnlich auch Eberhartinger (Ertragsteuerliche Konsequenzen, 2000) S. 262. 
überschreitende Unternehmenstätigkeit in der EU“1 beschränkt und IAS 27.12 schon damit widersprochen ${ }^{2}$. Letztlich geht es im Rahmen dieser Strategie um einen „EUInlandsabschluss", der nur dann dem Weltabschlussprinzip nicht widerspricht, wenn wirklich keine Tochterunternehmen außerhalb der EU existieren. Damit akzeptiert die EU-Kommission die begrenzte Steuersouveränität der EU-Mitgliedstaaten und fordert letztlich eine Kompromisslösung, die die Wirkungen von Trennungsprinzip und Einzelgewinnermittlung nicht vollständig überwinden $\mathrm{kann}^{3}$.

Die abstrakte normative Tauglichkeit von IAS 27.12 ist demgegenüber keineswegs zu leugnen ${ }^{4}$. Allerdings käme sie nur unter veränderten rechtstatsächlichen Rahmenbedingungen zum Tragen. So wäre z.B. vorstellbar, das EU-Konsolidierungsmodell mit einer Art Öffnungsklausel zu versehen, um Tochterunternehmen auch aus Staaten außerhalb der EU steuerlich konsolidieren zu können. Als Voraussetzung müsste mit den betreffenden Staaten z.B. eine entsprechende Übereinkunft erzielt werden, in der sie insbesondere auf fiskalische Hoheitsrechte zu Gunsten der EU verzichten, wenn es um die Besteuerung der (Tochter-)Unternehmen geht, die von der EU aus beherrscht werden ${ }^{5}$. In diesem Fall könnte dem Weltabschlussprinzip von IAS 27.12 mit jedem zusätzlich geschlossenen Abkommen ,etwas mehr“ entsprochen werden.

Um Mutter- und Tochterunternehmen dem EU-Inland - oder einzelnen sonstigen Staaten - überhaupt zurechnen zu können, bedarf es auch einer Antwort auf die Frage, unter welchen Voraussetzungen ein Unternehmen überhaupt wo als steuerlich ansässig gilt. Die IFRS können (und wollen) diese Frage indes nicht beantworten. Abgesehen davon, dass der Sitzstaat des Tochterunternehmens nach Maßgabe des Weltabschlussprinzips nach IAS 27 gar nicht interessiert, greift auch hier wieder der rechtsabstrahierende Teilmengencharakter der IFRS, die sich allein als Rechnungslegungsregeln verstehen.

1 So lautet insb. der Titel der EU-Strategie; vgl. EU-Kommission (Strategie, 2001) S. 1 und z.B. auch S. 19, wo darauf hingewiesen wird, dass Unternehmen „für ihre Tätigkeit innerhalb der EU“ der konsolidierten Körperschaftsteuer-Bemessungsgrundlage unterliegen sollen; vgl. so z.B. auch $E U$ Kommission (Unternehmensbesteuerung, 2001) S. 5.

2 Vgl. dazu EU-Kommission (Konsultationspapier, 2003) S. 16, wo explizit darauf hingewiesen wird, dass Tochterunternehmen außerhalb der EU aus dem Konsolidierungskreis eines IFRS-Abschlusses für Zwecke der konsolidierten steuerlichen Gewinnermittlung nach Maßgabe der EU-Strategie herausgerechnet werden müssten.

3 Vgl. dies bereits aus den rechtlichen Rahmenbedingungen ableitend Kap. III.2.5.2. Vgl. den steuerlichen Konsolidierungskreis im Falle einer fiktiven EU-Konzernbesteuerung ebenfalls nur auf EUTochterunternehmen beschränkend Scheuchzer (Konzernbesteuerung, 1994) S. 243; Salzberger (Konzernunternehmung, 1994), dessen Untersuchung von vornherein auf die ,europäische Konzernunternehmung" fokussiert (S. 6-11).

$4 \mathrm{Vgl}$. zumindest indirekt für eine Art Weltabschlussprinzip plädierend auch Senger (Konzernertragsbesteuerung, 1997) S. 146-147.

5 Vgl. so bereits die Forderung von Grotherr (Besteuerung nationaler und grenzüberschreitender Konzerne, 1994) S. 438. 
Ebenso wie die Rechtsnatur der Hierarchiespitze ist auch die (steuerliche) Ansässigkeit eines Unternehmens in nationalem oder europäischem Recht festzulegen.

\subsubsection{Obligatorische Aufstellung und Einbeziehung}

Eine Rechnungslegung nach IFRS hat eine konsolidierte Rechnungslegung zu sein, wenn die in IAS 27 aufgeführten Voraussetzungen vorliegen ${ }^{1}$. Auch wenn letztlich nur das dahinter stehende nationale oder europäische Rechtssystem eine Pflicht zur (konsolidierten) Rechnungslegung nach IFRS rechtswirksam markieren kann ${ }^{2}$, entspräche IAS 27 damit auch steuerlichen Anforderungen.

Die steuerliche Eignung einer Aufstellungspflicht ergibt sich aus der Ablehnung eines diesbezüglichen Wahlrechts. Ein explizites Wahlrecht zur konsolidierten steuerlichen Gewinnermittlung wäre angesichts der damit einhergehenden Selbsteinsteuerungsmöglichkeiten aus der Perspektive der Steuergerechtigkeit (Gleichmäßigkeit und steuerliche Leistungsfähigkeit) kritisch zu hinterfragen. Auch durchführungsorientierte Effizienzargumente dürften tendenziell gegen ein solches Wahlrecht sprechen ${ }^{3}$, vor allem, wenn es im Zeitablauf in kürzeren Abständen immer wieder unterschiedlich ausgeübt werden kann. Ein Wahlrecht wirkt letztlich hinsichtlich derjenigen Argumente wenig überzeugend, die eine Gruppenbesteuerung per se - z.B. auch im Hinblick auf eine Organisations- und Wettbewerbsneutralität - für sinnvoll erachten ${ }^{4}$.

Für ein solches Wahlrecht wird in der Literatur jedoch angeführt, dass es eine im Vergleich zur Summe der Einzelgewinnermittlungen etwaig höhere Steuerbelastung der Gruppe abfedern könne ${ }^{5}$. Vorgebracht werden auch Vereinfachungsgesichtspunkte ${ }^{6}$ oder die dadurch gewonnene Beibehaltung des Gestaltungsprivilegs für die Unternehmensgruppe ${ }^{7}$. Fraglich ist allerdings, ob diese Argumente aus normativer Sicht über-

1 „A parent, ..., shall present consolidated financial statements ... in accordance with this Standard“ (IAS 27.9).

2 Letztlich ist es sogar der nationale Gesetzgeber, der bzgl. der EU-Verordnung Nr. 1606/2002 festlegt, welche Unternehmen oder Personen konsolidierte Abschlüsse zu erstellen haben und damit unmittelbar der IFRS-Pflicht unterliegen; vgl. so auch EU-Kommission (Kommentare, 2003) S. 7-8.

3 Eindeutig kann allerdings das Urteil aus Sicht der Durchführungseffizienz nicht ausfallen. Den kostenverursachenden Steuerplanungs- und -ausgleichsaktivitäten bei Vorliegen expliziter Wahlrechte stehen schließlich ähnliche Aktivitäten bei entsprechenden Pflichten gegenüber. Dabei erstrecken sich die Ausweichhandlungen im letzten Fall zwangsläufig auch auf gesellschaftsrechtliche Gestaltungen (z.B. über das Variieren der Stimmrechtsquote über oder unter eine geforderte Marke).

4 Vgl. ansatzweise Kap. Il.3.3.1, wobei die Frage nach dem grundsätzlichen Sinn der Gruppenbesteuerung letztlich nicht primärer Untersuchungsgegenstand dieser Arbeit ist.

5 Vgl. Reis (Körperschaftsbesteuerung des Konzerns, 1996) S. 236.

6 Vgl. Gassner (Konzernbesteuerung, 1990) S. 190.

7 Vgl. Herrmann (Reformbedürftiges Konzernsteuerrecht?, 1973) S. 40, 42. Vgl. allg. (z.T. nur in Organschaftszusammenhängen) ein Wahlrecht für die steuerliche (Ergebnis-)Konsolidierung fordernd auch Müller (Konzernbesteuerung, 1991) S. 133; Ritter (Sicht der Wirtschaft, 1989) S. 325. 
zeugen. So fällt es bereits schwer, in der Beibehaltung eines Gestaltungsprivilegs ein Argument zu erkennen, da die Selbsteinsteuerung aus normativer Sicht ja gerade verhindert werden soll ${ }^{1}$. Fragwürdig sind auch Vereinfachungsgesichtspunkte, die die (vereinfachende) Beibehaltung des Status Quo wohl eher überbetonen und sonstige Vereinfachungspotenziale einer Gesamtgewinnermittlung außen vor lassen. Auch das Steuerbelastungsargument erscheint auf den ersten Blick problematisch, weil Belastungswirkungen in beide Richtungen vermutet werden können ${ }^{2}$. Zudem mögen Steuerbelastungsargumente aus lenkungsorientierter bzw. wirtschaftspolitischer Sicht eine gewichtige Rolle spielen, weniger jedoch vor dem Hintergrund der hier zu Grunde liegenden normativen Kriterien.

Ein zentraler Grundsatz wettbewerbsneutraler aber auch gleichmäßiger Besteuerung ist der Grundsatz der Allgemeinheit, wonach sämtliche Unternehmungen der hier in Rede stehenden Verpflichtung gleichermaßen unterliegen sollen. So mag die Wettbewerbsneutralität und Gleichmäßigkeit der Besteuerung zwar im europäischen Kontext durch eine Konsolidierungspflicht in der EU gewahrt sein. Weltweit sähe dies allerdings anders aus, wenn die Konsolidierungspflicht auf die EU beschränkt wäre, ohne dass außerhalb der EU gleichartige Verpflichtungen etabliert würden. Ähnliche Wirkung entfaltete eine Beschränkung des steuerlichen Konsolidierungskreises auf Unternehmen, die in der EU ansässig sind. Hiernach ergeben sich Unterschiede bei der Behandlung von europäisch beherrschten Unternehmensgruppen, je nachdem, ob Tochterunternehmen nur innerhalb oder auch außerhalb der EU ansässig sind. Dieser Verstoß gegen den Grundsatz der Allgemeinheit kann durch ein Wahlrecht zur konsolidierten steuerlichen Gewinnermittlung aber nur eingeschränkt geheilt werden. Die in der EU ansässige Hierarchiespitze einer Unternehmung erlangt so die Möglichkeit, bei eventuell empfundener Benachteiligung gegenüber anderen Unternehmungen mit der Wahl von Trennungsprinzip und Einzelgewinnermittlung zu reagieren. Die konsolidierte steuerliche Gewinnermittlung würde damit nur angewandt, wenn Steuer(belastungs)vorteile gegenüber dem status quo ante gegeben wären. Ein Verstoß gegen den Grundsatz der Allgemeinheit verbleibt aber auch dann, weil diese zusätzliche Option sicherlich nicht allen Unternehmungen auch außerhalb der EU offen steht.

1 Vgl. kritisch gegenüber diesem Argument von Herrmann auch Reis (Körperschaftsbesteuerung des Konzerns, 1996) S. 235.

2 Vgl. insb. Haase (Anerkennung des Konzernabschlusses, 1968) in der Auseinandersetzung mit von Wallis (Konzernrecht, 1967); ausführlich auch Harms/Küting (Perspektiven der Konzernbesteuerung, 1982), die nicht nur temporäre, sondern auch permanente Differenzen der Konzernbesteuerung gegenüber der Einzelgewinnermittlung zu identifizieren glauben. Vgl. zu diesbezüglichen Zweifeln jedoch Kap. V.4.2.2.3. Vgl. auch Grotherr (Besteuerung nationaler und grenzüberschreitender Konzerne, 1994) S. 7-9, der, umgekehrt, aus dem Trennungsprinzip und der additiven Einzelgewinnermittlung Steuerbelastungsnachteile ableitet, wenn er den Steueraufwand aus den Einzelabschlüssen in Relation zum Konzernergebnis häufig als ungewöhnlich hoch ansieht und für die Unternehmensgruppe nicht selten eine ,quasi-konfiskatorische Besteuerung“ identifiziert. 
Neben der Verpflichtung zur konsolidierten Rechnungslegung sieht IAS 27.12 als weitere Verpflichtung vor, sämtliche Tochterunternehmen in den Konsolidierungskreis einzubeziehen. Auch hier existiert kein Wahlrecht und auch hier dürfte normativen steuerlichen Anforderungen erst einmal analog entsprochen werden. Gleichfalls ist fraglich, ob ein Einbeziehungswahlrecht unter Berücksichtigung rechtstatsächlicher Nebenbedingungen gerechtfertigt werden könnte.

Ein Einbeziehungswahlrecht taugte ebenfalls zum Ausgleich etwaiger Belastungsnachteile gegenüber anderen, von der konsolidierten steuerlichen Gewinnermittlung nicht oder nicht vollständig betroffenen Unternehmungen. Allerdings wären die Selbsteinsteuerungsmöglichkeiten des Einbeziehungswahlrechts noch weitreichender als bei einem Aufstellungswahlrecht. Schließlich könnte die oberste Entscheidungs- und Kontrollinstanz der Unternehmung den steuerlichen Konsolidierungskreis durch eigene Entscheidung zwischen der alleinigen Einbeziehung nur der eigenen Rechtseinheit bis hin zur vollständigen Einbeziehung sämtlicher ihr zugerechneten Einheiten beliebig variieren und vom Abgrenzungsleitbild der Unternehmung beliebig abweichen'. Damit umfasst das Einbeziehungswahlrecht letztlich auch das Aufstellungswahlrecht, ohne wesentlich darüber hinausgehende Kompensationswirkungen hinsichtlich des verletzten Grundsatzes der Allgemeinheit zu erzielen.

In der Literatur wird das Einbeziehungswahlrecht indes mit der Existenz von Minderheiten gerechtfertigt. Hierfür sollte die Entscheidung über den Beitritt in den steuerlichen Konsolidierungskreis allerdings den Entscheidungsgremien des betroffenen Unternehmens, nicht der obersten Hierarchiespitze obliegen ${ }^{2}$. Vor dem Hintergrund einer drohenden Benachteiligung bei der Steuerlastverteilung besäßen diese Unternehmen eine Art Ausstiegsoption. Dem steht jedoch gegenüber, dass sich Beherrschung regelmäßig in mehrheitsdominierten Unternehmensorganen konkretisiert, die einen wirksamen Schutz von Minderheiten und sonstigen Vertragsparteien kaum sicherstellen kön$n^{3}{ }^{3}$. Aus diesem Grunde kann ein derartiges Wahlrecht - angesiedelt auf der Hierarchiespitze der Unternehmung oder auch auf Ebene der einzelnen Tochterunternehmen nicht recht überzeugen ${ }^{4}$.

1 Vgl. diesbezüglich steuerliche Gestaltungsmöglichkeiten identifizierend auch Grotherr (Besteuerung nationaler und grenzüberschreitender Konzerne, 1994) S. 482, der dies vergleicht mit „Rosinen aus dem Kuchen zu picken“; Reis (Körperschaftsbesteuerung des Konzerns, 1996) S. 237.

2 Dieses Wahlrecht fordert z.B. Schuch (Besteuerung als Unternehmensgruppe, 1998) S. 80-83.

3 A.A. wohl Schuch (Besteuerung als Unternehmensgruppe, 1998) S. 83, der hier auf die gesellschaftsrechtlichen Schranken für die Einflussnahme von Großaktionären vertraut.

4 Vgl. ablehnend gegenüber einem Einbeziehungswahlrecht auch Grotherr (Besteuerung nationaler und grenzüberschreitender Konzerne, 1994) S. 481-484; Reis (Körperschaftsbesteuerung des Konzerns, 1996) S. 237; Spengel (Unternehmensbesteuerung in der EU, 2004) S. 145. Zu diskutieren wäre eher die Einwilligung der Minderheitsgesellschafter wie letztlich sämtlicher betroffener Vertragsparteien. 
Interessant erscheint an dieser Stelle der Blick auf die konkrete Regulierung der vier europäischen Konsolidierungsstaaten. Dort ist zu beobachten, dass sämtliche vier Steuersysteme ein Aufstellungswahlrecht und immerhin noch zwei (Frankreich und Niederlande) ein Einbeziehungswahlrecht vorsehen ${ }^{1}$. Abgesehen davon, dass sich die rechnungslegende Einheit in diesen Fällen ohnehin nur auf Inlandsgruppen beschränkt, wird das Abgrenzungsleitbild der Unternehmung auch unabhängig von fiskalischen Grenzen zur Illusion. Es handelt sich hier eher um eine von der Hierarchiespitze unter Steueroptimierungserwägungen aus der Unternehmung geschnittene Unternehmensgruppe. Abgesehen von Erklärungsmustern der positiven Regulierungstheorie ${ }^{2}$, wie z.B. Lobbyismus der nach Gestaltungsspielraum strebenden Manager der Unternehmen, sind dafür möglicherweise auch hier nicht betrachtete lenkungsorientierte bzw. wirtschaftspolitische Gründe verantwortlich. Eine gewisse Eingrenzung der Selbsteinsteuerungsmöglichkeiten und eine gewisse Verbesserung der Durchführungseffizienz ist allerdings darin $\mathrm{zu}$ beobachten, dass mehrjährige Mindestzeiträume festgelegt sind, für die die jeweilige Option ausgeübt wird ${ }^{3}$.

\subsubsection{Ausnahmen von der Aufstellungs- und Einbeziehungspflicht}

IAS 27 sieht die Aufstellung konsolidierter Abschlüsse wie auch die Einbeziehung beherrschter Tochterunternehmen als Verpflichtung vor. Teilweise sind jedoch Ausnahmen festgeschrieben.

\subsection{Tannenbaumprinzip und Ausnahmen von der Aufstellungspflicht}

Die Ausnahme von der Aufstellungspflicht in IAS 27.10 trifft lediglich bestimmte Zwischengesellschaften, also Tochterunternehmen, die selbst wiederum Mutterunternehmen sind. Demgegenüber hat die oberste Entscheidungs- und Kontrollinstanz der Unternehmung nach IAS 27 immer einen konsolidierten Abschluss aufzustellen. IAS 27.10 befreit demnach nur Teile der ohnehin in diese rechnungslegende Einheit einbezogenen Unternehmung von der Verpflichtung zur Aufstellung eines konsolidierten (Teil-)Abschlusses. Im Umkehrschluss bedeutet dies, dass IAS 27 jede Zwischengesellschaft im Grundsatz dazu anhält, einen konsolidierten Abschluss für den von ihr be-

I Vgl. über Kap. IV.1.2.1 hinaus auch Müller (Konzernbesteuerung, 1991) S. 123-124, der in den untersuchten EU-Staaten und in den USA kein einziges System mit einer Aufstellungspflicht identifiziert und neben Spanien und Portugal nur noch die USA benennt, die eine Einbeziehungspflicht vorsehen. Vgl. verhalten kritisch hierzu Grotherr (Konzernbesteuerungssysteme, 1996) S. 369-370.

2 Vgl. dazu im Überblick Fülbier (Regulierung, 1999) S. 472-473.

3 So gelten drei- bis fünfjährige Festlegungsfristen insbesondere in Frankreich, Portugal und Spanien; vgl. Kap. IV.1.2.1. Vgl. eine fünfjährige Bindungsfrist flankierend zur „Vermeidung von Manipulationen" bei einem Aufstellungswahlrecht fordernd Reis (Körperschaftsbesteuerung des Konzern, 1996) S. 236; ähnlich Grotherr (Besteuerung nationaler und grenzüberschreitender Konzerne, 1994) S. 451. 
herrschten Teil der Gruppe zu erstellen („Tannenbaumprinzip“'1). Der Zweck dieser Vorgehensweise ergibt sich dabei unmittelbar aus den Voraussetzungen der Befreiungsregel des IAS 27.10: Es ist der Schutz der Minderheitsgesellschafter und aller (anonymen) aktuellen sowie potenziellen Kapitalmarktteilnehmer ${ }^{2}$ durch Information ${ }^{3}$. Abgesehen davon, dass diese Informationsfunktion durch die Gestaltungsmöglichkeiten innerhalb der Gesamtunternehmung in diesem Teilabschluss allenfalls eingeschränkt zum Tragen kommt, stellt sich für die steuerliche Gewinnermittlung die Frage, ob das Tannenbaumprinzip und die diesbezügliche Ausnahme dort überhaupt einen Sinn ergibt.

Dem Gedanken von Einheitsprinzip und Gesamtgewinnermittlung folgend, geht es letztlich darum, die gesamte Unternehmung unter Berücksichtigung steuerlicher Anforderungen in der rechnungslegenden Einheit zu erfassen. Dies geschieht, in dem sie an der obersten Entscheidungs- und Kontrollinstanz in der Unternehmung ansetzt, der alle Ressourcen zugerechnet werden, die direkt oder indirekt in ihrem ökonomischen Eigentum stehen. Nicht an diese oberste Instanz anzuknüpfen hieße, nur Teilmengen dieser Unternehmung abzubilden, was dem Gedanken von Einheitstheorie und Gesamtgewinnermittlung erst einmal widerspricht. Ein Sinn könnte sich - wenn überhaupt - nur aus der auch steuerlich zu berücksichtigenden Minderheitenproblematik ergeben. Sofern berücksichtigt wird, dass hierunter letztlich sämtliche „schutzwürdigen“ Vertragspartner der Tochterunternehmen zu subsumieren sind, könnten Teil-Gesamtgewinnermittlungen nach Maßgabe des Tannenbaumprinzips möglicherweise ihren Beitrag zur notwendigen Erfolgslokalisation in der Unternehmensgruppe und der damit einhergehenden Steuerlastverteilung leisten. Wenn dem aber so wäre, erschiene die in IAS 27.10 enthaltene Beschränkung auf Eigen- und Fremdkapitalgeber zu eng, da andere Vertragspartner der Tochterunternehmen, z.B. Arbeitnehmer, unberücksichtigt blieben.

Fraglich ist jedoch, ob das Tannenbaumprinzip angesichts der bereits entwickelten Lösungsmechanismen $^{4}$ wirklich notwendig ist. Dies müsste verneint werden, wenn die Unternehmensgruppe und die sie umschließende rechnungslegende Einheit über EUrechtliche bzw. gesetzliche oder auch privatrechtliche Konstrukte bereits in eine Anspruchseinheit überführt worden ist. Aber auch wenn keine Anspruchseinheit existiert, erscheint das Tannenbaumprinzip entbehrlich. Das Ziel der Erfolgslokalisation kann

1 Dieser Begriff wird z.B. von Biener (Konzernrechnungslegung, 1983) S. 6 benutzt.

2 Unter die Kapitalmarktteilnehmer werden die in IAS 27.10 indirekt genannten Eigen- und Fremdkapitalgeber subsumiert, die am öffentlichen Kapitalmarkt (,public market (a domestic or foreign stock exchange or an over-the-counter market, including local and regional markets)“) Eigen- oder Fremdkapitaltitel erwerben.

3 Vgl. ansatzweise IAS 27.BC4-BC12; vgl. zur Informationsfunktion im Allgemeinen IASB Framework Par. 9-21, wo bei den Investoren bzw. Eigenkapitalgebern als Adressaten (natürlich) nicht zwischen Mehrheits- und Minderheitsgesellschaftern differenziert wird; vgl. speziell zu Minderheitsgesellschaftern auch Busse von Colbe et al. (Konzernabschlüsse, 2003) S. 69-71.

4 Vgl. dazu Kap. III.2.5. 
schließlich auch mit anderen Instrumenten erreicht werden. Neben der direkten Erfolgslokalisation durch die parallele multiple Einzelgewinnermittlung ist hier insbesondere die indirekte Form der geschlüsselten Erfolgszuordnung zu nennen. Da Einzelgewinnermittlungen der konsolidierten steuerlichen Gewinnermittlung (mit oder ohne Fremdvergleich) ohnehin zu Grunde liegen, scheint eine zusätzliche, kostenverursachende Verpflichtung zur Teil-Gesamtgewinnermittlung nach dem Tannenbaumprinzip kaum notwendig. Ein zusätzlicher Nutzen der Teil-Gesamtgewinnermittlung ist schließlich nicht unmittelbar erkennbar. Einerseits unterliegt sie innerhalb einer Unternehmung denselben Verzerrungen, denen auch die Einzelgewinnermittlung ausgesetzt ist. Beide Gewinnermittlungen erfassen nur Teilmengen der gesamten Unternehmensgruppe, innerhalb der Ressourcenverlagerung und Ertragsrealisation nach dem Willen der Hierarchiespitze möglich sind. Andererseits vermag sie weder der engen juristischen Unternehmenssicht zu entsprechen - die einklagbaren Anspruchsgrundlagen werden über die Einzelgewinnermittlung ermittelt -, noch der weiten ökonomischen Sicht der Unternehmung. Am Beispiel der (Eigen- und Fremd-)Kapitalgeber einer Untergesellschaft kann unschwer gezeigt werden, dass diese ihr Kapital schließlich der gesamten Unternehmung zur Verfügung stellen, weil es letztlich allein der Dispositionsgewalt der Hierarchiespitze unterliegt.

Ein gewisser Nutzen der Teil-Gesamtgewinnermittlung mag allerdings unter expliziter Berücksichtigung des Fremdvergleichs identifiziert werden. Wird dieser als notwendig erachtet, dürften relativ wenige Teil-Gesamtgewinnermittlungen innerhalb einer Unternehmung gegenüber relativ vielen Einzelgewinnermittlungen durchführungseffizienter sein. Dem widerspricht aber der realtypische Charakter der Konsolidierung, dem wohl auch Teil-Gesamtgewinnermittlungen unterworfen wären, die ihrerseits ebenfalls Einzelgewinnermittlungen als Grundlage benötigen ${ }^{1}$. Auch kann an der Notwendigkeit des Fremdvergleichs gezweifelt werden. So könnte - wie bei der Bemessung anderer Anspruchsgrundlagen auch $^{2}$ - auf Einzelgewinnermittlungen ohne Fremdvergleich oder auf die indirekte Form der Erfolgslokalisation zurückgegriffen werden.

Das Tannenbaumprinzip erscheint damit aus Sicht der steuerlichen Gewinnermittlung auch unter Gesichtspunkten der Steuerverteilung entbehrlich. So verwundert es nicht, dass es auch realiter, in den betrachteten vier Konsolidierungssystemen, keine Rolle spielt. Insofern ist auch die Ausnahmeregel des IAS 27.10, die mit ihrer Fokussierung auf Kapitalgeber im Übrigen ohnehin zu eng gestaltet wäre, unter steuerlichen Gesichtspunkten eher obsolet. Im Übrigen erscheint die Ausgestaltung dieser Ausnahme

1 Möglicherweise ist es ein Vorteil, dass Teil-Gesamtgewinnermittlungen (mit Fremdvergleich an den Teilunternehmungsgrenzen) auf Einzelgewinnermittlungen beruhen könnten, die nicht auf Basis eines Fremdvergleichs durchgeführt werden müssten.

2 Vgl. Kap. III.2.5.1.2, wo beispielhaft auf $\S 58 \mathrm{Abs} .2 \mathrm{AktG}$ verwiesen wird. 
als Wahlrecht ${ }^{1}$ unter normativen Gesichtspunkten problematisch, auch wenn die freie Entscheidung sämtlicher Vertragspartner über alternative Wege der Steuerverteilung insbesondere in evolutorischer Sicht ihren Reiz besäß $\mathrm{e}^{2}$.

\subsection{Ausnahmen von der Einbeziehungspflicht}

IAS 27 enthält keine konkrete Ausnahme von der generellen Einbeziehungserfordernis. Dies dürfte erst einmal dem normativen Abgrenzungsleitbild entsprechen, wonach sämtliche Ressourcen vollständig abzubilden sind, wenn sie im ökonomischen Eigentum der konsolidierungspflichtigen Hierarchiespitze stehen. Diesem Vollständigkeitsgebot widersprächen wohl insbesondere Einbeziehungsverbote aufgrund abweichender Tätigkeit ${ }^{3}$, da es in der steuerlichen Gewinnermittlung schlichtweg nicht darauf ankommt, ein „unverzerrtes“ Bild der wirtschaftlichen Lage o.ä. abzugeben ${ }^{4}$.

Fraglich ist allerdings, ob die den IFRS immanenten Grundsätze der Wesentlichkeit und Wirtschaftlichkeit und der hierauf beruhende Ausschluss von Tochterunternehmen aus dem Konsolidierungskreis unter steuerlichen Gesichtspunkten zu rechtfertigen ist. Die Antwort ist schwierig. Erst einmal ist zu konstatieren, dass aus steuerlicher Sicht auch der Wesentlichkeitsgrundsatz nur im Sinne der Wirtschaftlichkeit bzw. Durchführungseffizienz gedeutet werden kann. Ein eigenständiger Wesentlichkeitsgrundsatz, der auf die jeweilige Bedeutung für ein zu vermittelndes Bild zielt, dürfte der steuerlichen Gewinnermittlung eher fremd $\operatorname{sein}^{5}$. Insofern zielen Wesentlichkeits- und Wirtschaftlichkeitsgrundsatz unisono auf die Beachtung der Durchführungseffizienz. Ein darauf beruhender Ausschluss von Tochterunternehmen aus dem Konsolidierungskreis müsste demnach mit Vorteilen bei der Durchführungseffizienz einhergehen, die allerdings mit einem Verstoß gegen das normative Abgrenzungsleitbild erkauft werden. Da beide Grundsätze zudem gewisse Freiheitsgrade bei der jeweiligen Auslegung zulassen ${ }^{6}$, er-

1 Vgl. dazu IAS 27.10: „A parent need not ...“ sowie noch deutlicher IAS 27.11: „A parent that elects in accordance with paragraph 10 ...".

2 Zur Verhinderung des auf von Hayek (Pretence of Knowledge, 1989) zurückgehenden Vorwurfs der „Anmaßung von Wissen“ wäre es demnach dem Markt überlassen, entsprechende Varianten der Erfolgslokalisation hervorzubringen. Eine dieser Varianten könnte dann auch die Teil-Gesamtgewinnermittlung darstellen.

3 Vgl. ähnlich auch Reis (Körperschaftsbesteuerung des Konzerns, 1996) S. 237, die hier die Einheitstheorie als normatives Leitbild bemüht; Schneider (IAS als Besteuerungsgrundlage, 2003) S. 302.

4 Entsprechende Argumente konnten bereits bei $\S 295 \mathrm{HGB}$ a.F. nicht recht überzeugen und führten letztlich auch zur Abschaffung dieser Regel (Art. 1 Nr. 14 BilReG).

5 A.A. wohl Spengel (Einheitliche Bemessungsgrundlage, 2004) S. 113 und Spengel (Besteuerung, 2004) S. 137, der diesen Grundsatz für die Besteuerung als ,nicht störend“ empfindet.

6 Vgl. Wolz (Wesentlichkeitsgrenzen, 2004). Nach Busse von Colbe et al. (Konzernabschlüsse, 2003) S. 120 dürfte der Grundsatz der Wirtschaftlichkeit gar nicht zur Anwendung kommen, da sorgfältig geschätzte Angaben immer noch informativer seien als der Ausschluss von der Konsolidierung. Schätzungen sind in der steuerlichen Gewinnermittlung insb. wegen der damit einhergehenden Selbsteinsteuerungsmöglichkeiten problematisch. 
scheint ihre Übertragung in die steuerliche Gewinnermittlung - wenn überhaupt - nur bei zusätzlicher Konkretisierung opportun' ${ }^{1}$.

Rechtssicher konkretisierte Vereinfachungsregeln, wie sie z.B. auch in den nationalen Steuersystemen enthalten sind ${ }^{2}$, fehlen allerdings in IAS 27. Möglicherweise hätte der vormals in IAS 27.16-18 aufgeführte Ausnahmetatbestand bei Weiterveräußerungsabsicht eine derartige Vereinfachungsregel markieren können. So konnte diese Regel auch weniger im Hinblick eines normativen Abgrenzungsleitbildes gerechtfertigt werden. Mit Rückgriff z.B. auf die Transaktionskostentheorie von Williamson ${ }^{3}$ konnte allenfalls in der Tendenz vermutet werden, dass ökonomische Vorstellungen von Integration auf der Basis unvollständiger Verträge bei hoher Faktorspezifität und häufig wiederkehrenden Transaktionen eher für eine gewisse Langfristigkeit der Vertragsbeziehung sprechen und nicht unbedingt mit einer konkret belegbaren Verkaufsabsicht harmonieren. Der Vorteil dieser Ausnahmeregel lag statt dessen in der gesteigerten Durchführungseffizienz. Bei der in diesem Zusammenhang genannten Maximal-Haltefrist von zwölf Monaten zwischen Erwerb und Weiterveräußerung wären - bei der üblichen Abschnittsbesteuerung von einem Jahr - nur eine, maximal zwei Besteuerungsperioden betroffen gewesen. Um sich für diesen vergleichsweise kurzen Zeitraum das gesamte Prozedere der Erst-, Folge- und Entkonsolidierung zu sparen, hätten die inzwischen aufgehobenen IAS 27.16-18 als kostensparende Vereinfachungsregel gewirkt. Lediglich die schnelle und rechtssichere Überprüfung der Ausnahmevoraussetzungen, insbesondere der Weiterveräußerungsabsicht, schien noch verbesserungsfähig ${ }^{4}$.

Bei Rückgriff auf die sonstigen Ansatz- und Bewertungsregeln der IFRS zeigt sich allerdings die Problematik einer auf Konsolidierungsaspekte reduzierten Betrachtung. Sollten nämlich die Voraussetzungen von IFRS 5 vorliegen, greift dieser Standard für die in Weiterverkaufsabsicht erworbenen Unternehmen, für die sich das umfangreiche Konsolidierungsprozedere insofern ebenfalls erübrigt.

1 Vgl. diese Grundsätze deshalb generell ablehnend z.B. Grotherr (Besteuerung nationaler und grenzüberschreitender Konzerne, 1994) S. 353-354; Grotherr (Konzernsteuerrecht, 1995) S. 93-94, der sich allerdings auf (die weitgehend inhaltsgleiche) handelsrechtliche Sicht bezieht; kritisch auch Rädler (Impact, 2003) S. 467; a.A. wohl Spengel (Unternehmensbesteuerung in der EU, 2004) S. 147, der aber ebenfalls eine EU-weit einheitliche Konkretisierung fordert. Eine Ausklammerung der Unternehmen von untergeordneter Bedeutung aus dem steuerlichen Konsolidierungskreis fordert aus Vereinfachungsgesichtspunkten auch Senger (Konzernertragsbesteuerung, 1997) S. 150, 232 m.w.N. (die allerdings oft für ein generelles Einbeziehungswahlrecht plädieren). Im deutschen Steuerrecht gibt es durchaus klare Einzel-Vereinfachungsregeln im Bereich von Ansatz und Bewertung; vgl. z.B. $\S 6$ Abs. 2 EStG zur Sofortabschreibung geringwertiger Wirtschaftsgüter. Vgl. dazu Kap. II.2.1.1 und II.3.2.1.

4 Vgl. z.B. die Kritik von Baetge/Schulze (IAS 27, 2002) Tz. 91 an der Weiterveräußerungsabsicht als „subjektives, schwer zu überprüfendes Merkmal“. 


\subsubsection{Vertrags- und/oder Verbindungskonzept}

Die Beherrschungsmöglichkeit ist als das zentrale Verbindungskonzept von IAS 27 identifiziert worden. Dabei geht es im Sinne des sog. „power-Kriteriums“ um die Macht bzw. Möglichkeit, die Finanz- und Geschäftspolitik eines Unternehmens zu bestimmen, um Nutzen aus dessen Tätigkeit zu ziehen (IAS 27.4) ${ }^{1}$. Da dieses Beherrschungskonzept auch der konsolidierten steuerlichen Gewinnermittlung das zentrale Abgrenzungsmerkmal vorgeben würde, ist es im besonderen Maße auf seine Nähe zum normativen Abgrenzungsleitbild zu untersuchen.

\subsubsection{Einfache Stimmrechtsmehrheit}

Das Kernproblem bei der Abgrenzung des steuerlichen Konsolidierungskreises liegt in der Bestimmung ökonomischer Eigentumsbeziehungen. Trotz aller normativen Schwierigkeiten, diese eindeutig zu konkretisieren, hat sich die Orientierung an residualen Entscheidungs- und Kontrollrechten hierbei als vorteilhaft erwiesen ${ }^{2}$. IAS 27 geht mit dieser Orientierung durchaus konform. Abgesehen von der terminologischen Nähe von Beherrschungs- bzw. control-Konzept und (residualen) Entscheidungs- und Kontrollrechten, unterstützt auch das auf hierarchische ${ }^{3}$ Machtausübung ausgerichtete „power criterion" diese normative Vorstellung. Die Machtausübung zielt hierbei mit der Finanzund Geschäftspolitik auf zentrale Bereiche der Unternehmensführung, die wohl auch die Möglichkeit zur Ressourcensteuerung und -koordination umfassen dürften. Bei ausgedünnten Verfügungsrechten ist die entsprechende Definition allerdings nicht hinreichend trennscharf, da sie letztlich auch das Residualeinkommens- und -risikokonzept mit einbezieht (,..to obtain benefits from its activities"). Dieser umfassendere Ansatz wird künftig wohl noch verstärkt, wenn das „benefit criterion“ im Rahmen des Projektes „Consolidation (including Special Purpose Entities)“ explizit neben das ,power criterion" gestellt wird".

Der Eignungsprüfung dienlicher erscheint indes die Auseinandersetzung mit den Kriterien, die in IAS 27 zur Konkretisierung des Beherrschungskonzeptes angeführt werden. So dokumentiert sich in der primär angeführten Stimmrechtsmehrheit eine Präferenz zu Gunsten der residualen Entscheidungs- und Kontrollrechte, für die das Halten von Kapi-

1 Vgl. ausführlich auch zum US-amerikanischen Pendant von „control“ und „power“ und deren Abgrenzung von handelsrechtlichen deutschen Vorschriften Sürken (Abgrenzung der wirtschaftlichen Einheit, 1999).

2 Vgl. Kap. II.3.2.1 und II.3.3.2.

3 Insofern wird hier auch dem hierarchischen Abgrenzungsleitbild der steuerlichen Gewinnermittlung gefolgt, in der andere Konstruktionen, wie z.B. der aktienrechtliche Gleichordnungskonzern ( $\S 18$ Abs. 2 AktG), keine Berücksichtigung finden. Im Übrigen greift IAS 27 nicht für Gleichordnungskonzerne; vgl. Baetge/Schulze (IAS 27, 2002) Tz. 12.

4 Vgl. IASB (Consolidation, 2004); IASB (Consolidation, revised November, 2004) No. 8, 14-16. 
talanteilen allein nicht ausreichend sein kann. Die einfache Stimmrechtsmehrheit taugt dabei durchaus als standardisierte und im Übrigen auch rechtssichere Vorgabe für ein steuerliches Abgrenzungskriterium' ${ }^{1}$. Zudem beschränkt IAS 27 das Beherrschungskonzept nicht auf diese einfache Stimmrechtsmehrheit. Da letztere als widerlegbare Vermutung auf die Beherrschungsmöglichkeit hindeutet, kann dieser Vermutung im Einzelfall auch widersprochen werden. Dies dürfte z.B. der Fall sein, wenn wesentliche Entscheidungen per Gesetz ${ }^{2}$ oder Satzung nur auf der Basis qualifizierter Mehrheiten beschlossen werden können. Das Konzept der widerlegbaren Vermutung erscheint deshalb steuerlich sinnvoll, da es den Grundsatz markiert und dort durchführungseffiziente Standardisierungsvorteile generiert, Ausnahmen jedoch zulässt. Der Rechtssicherheit dienlich ist die Beweislastumkehr im Ausnahmefall, weil so die betroffenen Unternehmen bei vorliegender Stimmrechtsmehrheit dem Fiskus das Nichtvorliegen der Beherrschungsmöglichkeit nachweisen müssen. Grundsatz wie Ausnahme sind damit klar und nachprüfbar belegt. Das Zulassen von Ausnahmen zur verbesserten Annäherung an das normative Abgrenzungsleitbild scheint deshalb trotz der damit einhergehenden Zusatzkosten opportun.

Das Indiz der einfachen Stimmrechtsmehrheit zielt - wie schon die Definition der Beherrschung an sich - auf die Möglichkeit der beherrschenden Einflussnahme, nicht auf deren tatsächliche Ausübung. Dies wird im Übrigen noch dadurch untermauert, dass IAS 27.14 und 27.15 dazu anhalten, auch potenzielle Stimmrechte zu berücksichtigen, die z.B. aus jederzeit in Aktien wandelbaren Schuldverschreibungen resultieren ${ }^{3}$. Abgesehen davon, dass die Möglichkeit der Beherrschung über bestimmte Indizien, wie z.B. einfache Stimmrechtsmehrheiten, einfacher und rechtssicherer nachgewiesen werden kann als die tatsächliche Beherrschung ${ }^{4}$ und zudem auch weniger Selbsteinsteuerungs-

1 Vgl. bereits Kap. II.3.3.2.3; zustimmend im Kontext der neuen EU-Strategie auch Spengel (Unternehmensbesteuerung in der EU, 2004) S. 145.

$2 \mathrm{Zu}$ nennen sind hier insb. aktienrechtliche deutsche Zustimmungserfordernisse (Dreiviertelmehrheit des anwesenden Grundkapitals) bei einem Beherrschungs- oder Gewinnabführungsvertrag ( $\$ 293$ Abs. 1 Satz 2 AktG) oder einer Eingliederung ( 319 Abs. 2 Satz 2 AktG). Daraus jedoch ein grundsätzliches, EU-weites Erfordernis einer qualifizierten Mehrheit (auch des Kapitalanteils?) abzuleiten (vgl. so z.B. Grotherr (Besteuerung nationaler und grenzüberschreitender Konzerne, 1994) S. $454-$ 460; dazu auch Kap. II.3.3.2), erscheint fraglich. Nicht nur, dass es in anderen EU-Mitgliedsstaaten an vergleichbaren Gesetzen fehlt, auch dürfte diese formalrechtliche Position über die des ökonomischen Eigentums auf der Basis residualer Entscheidungs- und Kontrollrechte hinausgehen.

3 Vgl. IAS 27.14: „... The existence and effect of potential voting rights that are currently exercisable or convertible, including potential voting rights held by another entity, are considered when assessing whether an entity has the power to govern the financial and operating policies of another entity ..."

4 Vgl. so ansatzweise auch Scheuchzer (Konzernbesteuerung, 1994) S. 239. 
möglichkeiten eröffnet ${ }^{1}$, dürfte sie auch eher mit dem Konzept residualer Entscheidungs- und Kontrollrechte harmonieren, die das hier interessierende ökonomische Eigentumskonzept manifestieren.

Bei der Berechnung der einfachen Stimmrechtsmehrheit gibt IAS 27 keine konkrete Leitlinie vor. In IAS 27.13 wird lediglich konstatiert, dass direkte wie indirekte Beteiligungsverhältnisse gleichermaßen akzeptiert werden. Dies erscheint folgerichtig, da die Finanz- und Geschäftspolitik eines Unternehmens auch bei indirekter Stimmrechtsmehrheit beherrscht werden kann. Obwohl Berechnungsvorschriften in IAS 27 fehlen, dürfte das Wesen der dort definierten Beherrschung bestimmten Berechnungsmethoden allerdings widersprechen. So ist insbesondere das multiplikative Verknüpfen von Stimmrechtsquoten bei mehrstufigen Unterordnungsverhältnissen nicht mit diesem Wesen und auch nicht mit dem steuerlichen Abgrenzungsleitbild und der dahinter stehenden nukleus- sowie ressourcenbasierten Vorstellung einer hierarchisch strukturierten Unternehmung vereinbar ${ }^{2}$. Beherrschung nach IAS 27 oder im Sinne residualer Entscheidungs- und Kontrollrechte kennzeichnet letztlich eine binäre Funktion mit nur zwei möglichen Ausprägungen: Entweder liegt sie vor oder sie liegt nicht vor ${ }^{3}$. Ist ein Tochterunternehmen also selbst wieder Mutterunternehmen und damit Zwischengesellschaft, so muss der Stimmrechtsbesitz dieses Unternehmens dem übergeordneten Mutterunternehmen voll zugerechnet werden. Umgekehrt muss der Stimmrechtsbesitz eines Unternehmens, das sich nicht als Tochterunternehmen qualifiziert, obwohl auch an ihm Stimmrechte gehalten werden, vollständig aus der Berechnung ausgeklammert werden ${ }^{4}$. Beispielhaft sei dies an Abb. 13 verdeutlicht ${ }^{5}$.

1 Das Kriterium der tatsächlichen Beherrschung schafft letztlich wieder eine Art Gestaltungsprivileg und Einbeziehungswahlrecht. Die oberste Hierarchieinstanz kann hier bei jedem Tochterunternehmen nahezu beliebig zwischen (engerer) tatsächlicher und (weiterer) potenzieller Einflussnahme wechseln. Demgegenüber neutralisiert das unmittelbare Abstellen auf das weitere Kriterium der potenziellen Einflussnahme diese Wahlentscheidung. Vgl. dennoch kritisch zum Kriterium der rechtlichen Beherrschungsmöglichkeit Schreiber (Unternehmensbesteuerung, 2004) S. 223, der hier in Anlehnung an McLure (Unitary Business, 1984) auf die (tatsächliche), „ökonomische Integration“ abstellt.

2 Vgl. ähnlich bereits in seiner Auseinandersetzung mit dem organschaftlichen Kriterium der finanziellen Eingliederung Rupp (Ertragsbesteuerung nationaler Konzerne, 1983) S. 224. Die Berechnung der Beteiligungsquote zum Zwecke der Konsolidierungskreisabgrenzung darf indes nicht mit der evtl abweichenden Berechnung für die Kapitalkonsolidierung verwechselt werden; vgl. zu diesem Unterschied z.B. Dusemond/Weber/Zündorf $(\S 301,1998)$ Tz. 273.

3 Vgl. so auch Oberndorff(Konzernbesteuerung, 1996) S. 95; McLure (Unitary Business, 1984) S. 107.

4 Selbst wenn hier gegenteilig argumentiert werden sollte, eine Stimmrechtsmehrheit also unter Berücksichtigung dieses Anteilsbesitzes ermittelt würde, müsste das Konzept der widerlegbaren Vermutung greifen, da eine Beherrschung über eine nicht beherrschte Zwischengesellschaft unmöglich erscheint.

5 Problematischer erscheint indes die Frage, wie ein „dazwischen“ geschaltetes Unternehmen außerhalb der EU zu behandeln wäre; vgl. dazu Grotherr (Besteuerung nationaler und grenzüberschreitender Konzerne, 1994) S. 449-450. Unter normativen Gesichtspunkten müsste es, obgleich außerhalb des Konsolidierungskreises liegend, bei der Stimmrechtsquotenberechnung wohl hinzuzählen. 


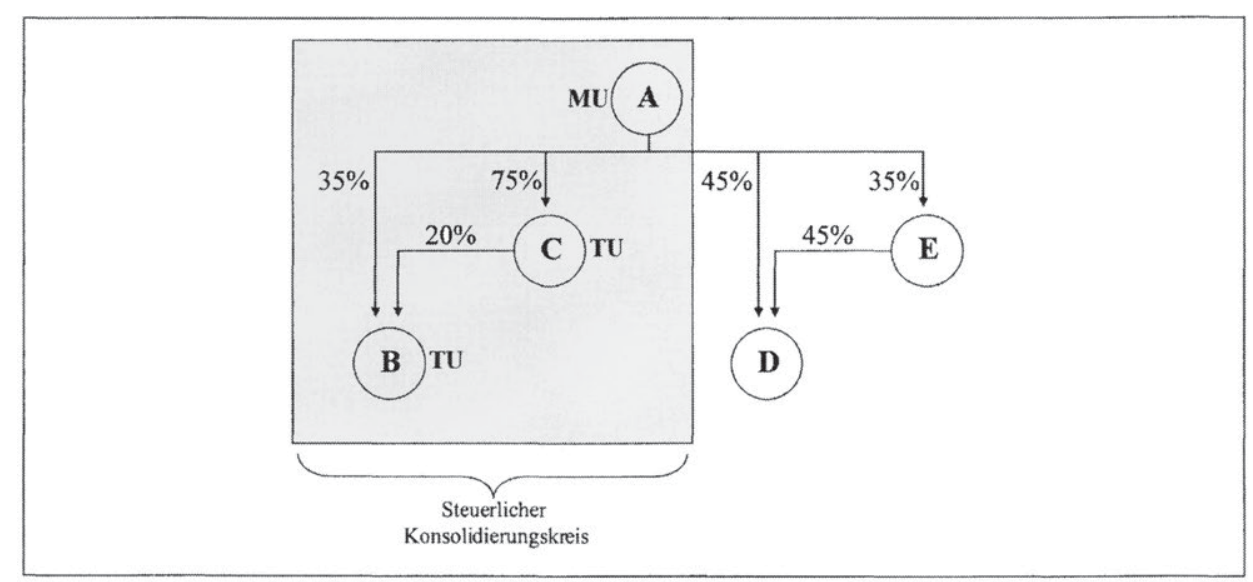

Abb. 13: Steuerlicher Konsolidierungskreis von A unter Zugrundelegung des Stimmrechtskriteriums von IAS 27

Die vollständige Ausklammerung der Beteiligungsverhältnisse von nicht beherrschten Unternehmen (vgl. z.B. Unternehmen $\mathrm{E}$ in Abb. 13), an denen das Mutterunternehmen eine (Minderheits-)Beteiligung hält, kann allerdings kontrovers diskutiert werden. Im seltenen Einzelfall mögen Situationen denkbar sein, in denen das kollektive Entscheidungsverhalten mehrerer Minderheitsgesellschafter selbst wiederum als beherrschender Einfluss einer dahinter stehenden Partei wahrgenommen wird. Eine Beurteilung dieser Situationen hängt aber letztlich von den konkreten Bedingungen des Einzelfalls ab (z.B. konkrete rechtliche Möglichkeiten der Minderheitsgesellschafter, „Stabilität“ des kollektiven Einflusses). In der um Klarheit und Eindeutigkeit bemühten steuerlichen Sicht kann es deshalb nicht ausreichen, auf die Existenz dieser Ausnahmen zu verweisen; zur generellen Modifikation der gefundenen Abgrenzungsleitlinie taugen sie nicht.

Als Zwischenergebnis kann festgehalten werden, dass die in IAS 27.13 festgelegte Konzeption der einfachen Stimmrechtsmehrheit für Zwecke der steuerlichen Konsolidierungskreisabgrenzung durchaus geeignet erscheint und als Teilelement steuerlicher Abgrenzungsmerkmale fungieren könnte. Diese Eignung dokumentiert sich zumindest teilweise in den entsprechenden Bestimmungen der betrachteten vier nationalen Konsolidierungssysteme innerhalb der EU. Stimmrechte bilden auch dort das zentrale Verbindungsmerkmal bei der Abgrenzung einer Unternehmensgruppe ${ }^{1}$. Allerdings wird dies in zweierlei Richtungen relativiert. Einerseits kombinieren diese Systeme das herrschaftsrechtliche Stimmrechtskriterium mit einem vermögensrechtlichen Kriterium, der Beteiligung am dividendenberechtigten Nennkapital. Andererseits reicht eine einfache Stimmrechtsmehrheit nicht aus; statt dessen werden sehr hohe Quoten von $90 \%$ und mehr gefordert. 
Das kumulative Abstellen auf Stimmrechte und Kapitalanteile kennzeichnet dabei ein idealtypisches und deshalb auch sehr enges Eigentumskonzept, das die gesamte Bandbreite möglicher Verfügungsrechte voraussetzt. Residuale Entscheidungs- und Kontrollrechte werden - wie z.B. auch im Mitunternehmerbegriff der bundesdeutschen Finanzrechtsprechung ${ }^{1}$ - durch das Residualeinkommens- oder -risikokonzept ergänzt. Die Möglichkeit, dass ökonomische Eigentumsbeziehungen trotz ausgedünnter Verfügungsrechte bestehen können, wird hier für Zwecke der steuerlichen Konsolidierung negiert. Die Tendenz zu einer überaus engen Abgrenzung des steuerlichen Konsolidierungskreises drückt sich aber auch in den hohen Stimmrechtsquoten aus. Durchweg $90 \%$ und mehr zu verlangen, erscheint angesichts des normativen Abgrenzungsleitbildes nicht immer notwendig und in der konkreten Höhe auch willkürlich ${ }^{2}$. Schließlich könnte auch die widerlegbare Vermutung einer Beherrschung bei einer einfachen Stimmrechtsmehrheit im Ausnahmefall berücksichtigen, dass z.B. unternehmensindividuelle Herrschaftsrestriktionen bestehen, die eine höhere Stimmrechtsquote notwendig machen.

Die im Vergleich zu IAS 27 engere Abgrenzung des steuerlichen Konsolidierungskreises in den vier europäischen Konsolidierungsstaaten zeugt davon, dass letztere den Fehler, ein Unternehmen in den Konsolidierungskreis einzubeziehen, das der Unternehmensgruppe ökonomisch nicht zuzurechnen ist (Einbeziehung trotz Nicht-Zugehörigkeit), minimieren. Dabei nehmen sie billigend in Kauf, dass der Fehler, ein Unternehmen aus dem Konsolidierungskreis auszuschließen, das der Unternehmensgruppe ökonomisch zuzurechnen ist (Ausschluss trotz Zugehörigkeit), deutlich ansteigt. Die Konzeption von IAS 27 scheint demgegenüber ausgewogener, da es hier darum geht, beide Fehler gleichberechtigt zu minimieren. Dem steuerlichen Abgrenzungsleitbild dürfte dies eher entsprechen, da es seine Vorteile hinsichtlich wirkungsorientierter Neutralitätsaspekte wie auch der steuerlichen Leistungsfähigkeit nur dann voll entfaltet, wenn im Idealfall beide Fehler nicht auftreten. Vor dem Hintergrund von Durchführungseffizienz wie auch Rechtssicherheit dürfte die Ausweitung des steuerlichen Konsolidierungskreises durch eine abgesenkte Stimmrechtsquote allein keinen Nachteil entfalten. Dieser ergäbe sich erst in Kombination mit dem Prinzip der widerlegbaren Vermutung. Aber auch dieser Nachteil scheint - wie bereits ausgeführt - vertretbar.

Die hohe Mindestquote in den vier Konsolidierungsstaaten mag aber auch auf den Versuch hindeuten, das Minderheitenproblem möglichst nicht auftreten zu lassen. Da dieses Problem allerdings nicht konsequent gelöst wird, indem mittels einer 100\%igen Quote sämtliche Minderheiten ausgeschlossen werden, und gruppenspezifische Risiken für andere Vertragspartner ohnehin bestehen, bedienen sich alle vier Gruppenbesteuerungs-

1 Vgl. zu dem auf Mitunternehmerinitiative und Mitunternehmerrisiko abstellenden Mitunternehmerkonzept Kap. III.2.4.

2 Vgl. z.B. Lechner (Besteuerung von Unternehmensgruppen, 1991) S. 395, der zu Recht darauf hinweist, dass alle Werte zwischen $50 \%$ und $100 \%$ letztlich willkürlich gewählt sind. 
systeme eines flankierenden Verfahrens zur Erfolgslokalisation und Steuerverteilung. Während in Frankreich, Spanien und Portugal parallel eine vollwertige Einzelgewinnermittlung durchgeführt wird, steht in den Niederlanden die geschlüsselte Erfolgslokalisation im Vordergrund ${ }^{1}$. Das immer bestehende Problem der Steuerverteilung muss also letztlich nicht über Mindestquoten gelöst werden, sondern über Verfahren der Erfolgslokalisation.

\subsubsection{Weitere Beherrschungssachverhalte}

Die einfache Stimmrechtsmehrheit ist in IAS 27.13 das zuerst genannte, allerdings nicht einzige Indiz, das auf einen beherrschenden Einfluss hindeutet. Auch wenn keine einfache Stimmrechtsmehrheit vorliegt, kann eine Beherrschungsmöglichkeit nach IAS 27.13 gegeben sein. Damit öffnet IAS 27 das Standardisierungselement der einfachen Stimmrechtsmehrheit in beide Richtungen: Trotz Vorliegen derselben kann, wie im Vorkapitel diskutiert, eine Beherrschung ausgeschlossen werden. Demgegenüber kann trotz Nicht-Vorliegens der Stimmrechtsmehrheit eine Beherrschung durchaus gegeben sein. In diese Richtung wirkt neben IAS 27 vor allem auch Interpretation SIC-12 sowie weiterführende Überlegungen des IASB im Rahmen des Projektes „Consolidation (including Special Purpose Entities)“.

Diese Öffnung des Beherrschungskonzeptes auch für Situationen, in denen keine Stimmrechtsmehrheit vorliegt, folgt dem ökonomischen Modell der Unternehmung. So sind natürlich Situationen vorstellbar, in denen residuale Entscheidungs- und Kontrollrechte auch ohne Stimmrechtsmehrheit vorliegen können. Diese im steuerlichen Konsolidierungskreis abzubilden, dürfte im Sinne der Organisationsneutralität und steuerlichen Leistungsfähigkeit sein $^{2}$. Andererseits wird dadurch der Standardisierungsvorteil des Stimmrechtskriteriums weiter aufgeweicht. Dies führt zu einer Verkomplizierung des Abgrenzungskriteriums und damit zwangsläufig zu Einbußen bei der Durchführungseffizienz und Rechtssicherheit.

Eine Beurteilung dieser zusätzlichen Beherrschungssachverhalte kann aus steuerlicher Sicht nur unter großen Schwierigkeiten vorgenommen werden, weil die gegenläufigen Wirkungen kaum operationalisiert und gegeneinander abgewogen werden können. Es lässt sich allerdings erkennen, dass IAS 27.13 im Zuge der Öffnung hinsichtlich Durchführungseffizienz und Rechtssicherheit den einzig akzeptablen Weg einschlägt: Die Öffnung wird auf lediglich vier vergleichsweise klar abgegrenzte Sachverhalte begrenzt. Nach IAS 27.13 können nur diese vier Sachverhalte neben der Stimmrechtsmehrheit

Vgl. Kap. IV.1.2.4.

2 Die Begründung ist die übliche: Die Organisationsneutralität bedingt eine vollständige Ressourcenerfassung der Unternehmung; zudem garantiert nur diese, dass Selbsteinsteuerungsmöglichkeiten reduziert werden, weil die Grenze der Ertragsrealisation nicht zu eng gezogen ist. 
eine Beherrschung manifestieren, so dass nicht mehr zu prüfen und Willkür weitestgehend ausgeschlossen ist. Dabei zählt der erste Sachverhalt, nach dem sich einfache Stimmrechtsmehrheiten - generell oder im Einzel(abstimmungs)fall - auch unter Berücksichtigung von vertraglichen Konstruktionen mit anderen Eigentümern ergeben können, streng genommen noch zum Konzept der einfachen Stimmrechtsmehrheit und dessen genauer Ermittlung. Damit verbleiben satzungsmäßige oder vertragliche Bestimmungen, die eine Beherrschung determinieren (b), die wie auch immer begründete Möglichkeit, die Leitungsgremien der betroffenen Unternehmen personell in ihrer Mehrheit zu bestimmen (c) oder dort zumindest die Stimmrechtsmehrheit ausüben zu können (d). Diese drei zusätzlichen Sachverhalte dürften jeder für sich geeignet sein, ökonomische Eigentumsbeziehungen zu manifestieren. Dies gilt im besonderen Maße für Sachverhalt (b), unter den nach deutschem Aktienrecht u.a. auch Beherrschungsverträge und zweifelsohne auch Eingliederungen zu subsumieren sind ${ }^{1}$. Hinsichtlich der Sachverhalte (c) und (d) ist noch vorauszusetzen, dass die hier im Fokus stehenden Leitungsgremien wirklich residuale Entscheidungs- und Kontrollrechte besitzen. IAS 27.13 (c) und (d) verlangen deshalb auch folgerichtig, dass ,control of the entity is by that board or body".

Bei der Ableitung des normativen Abgrenzungsleitbildes ist die Vorteilhaftigkeit des juristischen Vertragskonzeptes für die steuerliche Gewinnermittlung als rechtsfolgeorientierte Rechnungslegung herausgearbeitet worden ${ }^{2}$. Während das Stimmrechtskriterium - auch unter Berücksichtigung von IAS 27.13 (a) - dieser Vorgabe noch entspricht, sieht dies bei den drei weiteren Beherrschungssachverhalten anders aus. Einklagbare Verträge im Rechtssinne werden nur in dem zweiten Sachverhalt in IAS 27.13 (b) explizit gefordert (,...under a statute or an agreement“). Sachverhalt (c) und (d) stellen demgegenüber nur allgemein auf eine entsprechende Machtstellung (,,power to...") ab, ohne in irgendeiner Weise zu konkretisieren, wie diese begründet wird. Für Zwecke der steuerlichen Konsolidierung scheint IAS 27.13 an dieser Stelle zu unbestimmt.

Probleme aus dem Nebeneinander von Stimmrechtsmehrheit und weiteren Beherrschungssachverhalten können sich auch in der Gefahr dokumentieren, dass ein und dasselbe Unternehmen als Tochterunternehmen für mehrere Mutterunternehmen in Frage kommt ${ }^{3}$. Auch wenn dieser Fall theoretisch nie eintreten dürfte - greift ein zusätzlicher Beherrschungssachverhalt, müsste die Beherrschungsvermutung über Stimmrechts-

1 Vgl. i.d.Zshg. z.B. Reis (Körperschaftsbesteuerung des Konzerns, 1996) S. 234, die diese beiden Rechtsinstitute explizit als Verbindungskonzept für Zwecke der steuerlichen Konsolidierung akzeptiert; Bauer (Besteuerung deutscher Konzerne, 1987) S. 214-215 akzeptiert den Beherrschungsvertrag allerdings nur in Kombination mit der einfachen Stimmrechtsmehrheit.

2 Vgl. Kap. II.3.3.2.

3 Vgl. diese Gefahr i.Zshg. mit IAS/US-GAAP andeutend Eberhartinger (Ertragsteuerliche Konsequenzen, 2000) S. 262; ansatzweise auch Lechner (Besteuerung von Unternehmensgruppen, 1991) S. 394, der deshalb kategorisch für eine Mehrheitsbeteiligung plädiert. 
mehrheit konsequenterweise widerlegt werden - sind Kontroll- und Abstimmungsmaßnahmen gerade von Seiten der Finanzverwaltung erforderlich, um Doppel- oder Mehrfachberücksichtigungen auszuschließen. Aus durchführungsorientierter Sicht wären demnach weitere Ineffizienzen zu beklagen.

Die Problematik zusätzlicher Beherrschungssachverhalte beschränkt sich nicht allein auf IAS 27.13. Das Beherrschungskonzept wird auch durch Interpretation SIC-12 erweitert. Hier werden weitere Beherrschungsmöglichkeiten definiert, die über die in IAS 27.13 festgelegten Sachverhalte hinausgehen. Dabei fällt bereits auf, dass diese sehr viel stärker noch als IAS 27.4 auf das Residualeinkommens- bzw. Residualrisikokonzept abstellen. Der eher duale Charakter der ursprünglichen Beherrschungsdefinition in IAS 27.4 wird damit deutlich einseitiger interpretiert. Abgesehen davon, wird das Beherrschungskonzept noch weiter ausgeweitet und verkompliziert. Dies könnte durch eine höhere Einzelfallgenauigkeit gerechtfertigt werden, um ökonomische Eigentumsbeziehungen noch besser bei der Abgrenzung des Konsolidierungskreises berücksichtigen zu können. Klarer wird dies noch im Rahmen des Projektes „Consolidation (including Special Purpose Entities)“ formuliert, wo die Tendenz zur Ausweitung und vor allem auch Verallgemeinerung des Beherrschungskonzeptes auch mit dem expliziten Hinweis auf einen - steuerlich nicht unbedingt förderlichen - „principles-based“-Ansatz untermauert wird ${ }^{1}$.

So sehr die steuerliche Berücksichtigung von Zweckgesellschaften der Organisationsneutralität und steuerlichen Leistungsfähigkeit dienen dürfte, so stark sind auch die Vorbehalte insbesondere hinsichtlich der Klarheit, Einfachheit und Objektivität, so wie sie aus Sicht der ökonomischen Wettbewerbsneutralität und Durchführungseffizienz, aber auch des verfassungsrechtlichen Legalitätsprinzips gefordert werden. Während IAS 27.13 noch einen vergleichsweise konkreten Sachverhaltskatalog vorgelegt hat, beruht die zusätzliche Öffnung des Beherrschungskonzeptes in SIC-12 auf sehr viel abstrakteren Formulierungen. In ihnen kommt unzweifelhaft das Bestreben zum Ausdruck, Sachverhalte im Sinne der „relevance“ möglichst ihrer wirtschaftlichen Natur entsprechend zu berücksichtigen. Die Abkehr von der „reliability“ ist dabei offenkundig. Die bereits problematisierte Abwägung zweier gegenläufiger Wirkungen stellt sich damit erneut. Nur scheinen diesmal, im Vergleich zu IAS 27.13, die Nachteile aus wirkungssowie durchführungsorientierter Sicht und auch vor dem Hintergrund der Gesetzesbestimmtheit sehr viel offensichtlicher.

Abschließend kann festgehalten werden, dass das Verbindungskonzept von IAS 27 unter Einbeziehung von SIC-12 die Vorteile der Standardisierung zu realisieren sucht,

Vgl. IASB (Consolidation, 2004) „Special Purpose Entities“, in den USA wird die Berücksichtigung der Zweckgesellschaften in der steuerlichen Gesamtgewinnermittlung bereits diskutiert; vgl. Carman (SPEs, 2002). 
indem es erst einmal auf eine Stimmrechtsmehrheit abzielt, wenn es darum geht, Beherrschung zu konkretisieren. Letztlich werden diese Vorteile aber preisgegeben, weil sich die Beherrschung auch in anderen Sachverhalten ausdrücken kann. Zu differenzieren ist hierbei zwischen den vergleichsweise klar abgrenzbaren Sachverhalten des IAS 27.13, die möglicherweise noch einen tragfähigen Kompromiss für die konsolidierte steuerliche Gewinnermittlung markieren. Erweiterungen durch Interpretation SIC-12 und mögliche künftige IASB-Vorschriften, die zudem sehr viel stärker durch das Residualeinkommens- und Residualrisikokonzept getragen werden, erscheinen aus steuerlicher Sicht weniger akzeptabel.

Der abschließende Blick auf die konkreten steuerrechtlichen Regulierungen in den vier europäischen Konsolidierungsstaaten scheint diese Sicht zu bestätigen. Dort ist eindeutig erkennbar, dass neben der Stimmrechts- bzw. Kapitalanteilsmehrheit keine weiteren Beherrschungssachverhalte anerkannt werden. Die Standardisierungsvorteile einer klaren Ausrichtung auf ein objektiv messbares und einfach zu administrierendes Kriterium scheinen hier den Ausschlag zu geben, auch wenn dafür insbesondere - wie schon angesprochen - ein hoher „Fehler der fälschlichen Ausschließung“ (Ausschluss trotz Zugehörigkeit) in Kauf genommen wird ${ }^{1}$. Dies wird auch an anderer Stelle bestätigt. So wurde auch im Rahmen des körperschaftsteuerlichen Organschaftsrechts in Deutschland die auslegungsbedürftige organisatorische und wirtschaftliche Eingliederung abgeschafft, so dass das Organschaftsverhältnis nunmehr allein auf der finanziellen Eingliederung (Stimmrechtsmehrheit) und einem Gewinnabführungsvertrag beruht (§14 Abs. 1 $\mathrm{KStG})^{2}$.

\subsubsection{Keine weiteren Voraussetzungen neben der Beherrschung}

Das Verbindungskonzept von IAS 27 stellt allein auf die Beherrschung ab. Darüber hinausgehende Verbindungsmerkmale werden in IAS 27 oder anderswo im System der IFRS nicht gefordert. Daraus folgt, dass der Konsolidierungskreis nach IFRS z.B. nicht

1 Demgegenüber könnte bei SIC-12 und den weiteren Regulierungsbemühungen des IASB die beidseitig ausgewogene Fehlerbegrenzung hinterfragt und eine einseitige Minimierung dieses AusschlieBungsfehlers vermutet werden. Dies erscheint nicht abwegig angesichts der Bestrebungen des IASB (und FASB), „off balance sheet activities“ der Unternehmungen vor dem Hintergrund entsprechender Unternehmenskrisen (Enron etc.) in die Bilanz zu ziehen.

2 Parallelen zu dem Verbindungskonzept von IAS 27 finden sich auch außerhalb des Steuerrechts, z.B. in dem Konzept der einheitlichen Leitung ( $\$ 18$ AktG, $§ 290$ Abs. 1 HGB), das sich nur unter Schwierigkeiten auf konkrete Sachverhalte reduzieren lässt. Die Rechtsunsicherheit dieses Kriteriums stand seit jeher in der Diskussion, zumal es hier auch um die (schwerer nachweisbare) tatsächliche Ausübung geht; vgl. z.B. Adler/Düring/Schmaltz (Rechnungslegung, 1995) §290 Tz. 12-16; Siebourg (§ 290, 1998) Tz. 17-18; im Überblick auch Sürken (Abgrenzung der wirtschaftlichen Einheit, 1999) S. 29-38; für die steuerliche Konsolidierung aus Gründen der Rechtssicherheit ablehnend Grotherr (Konzernsteuerrecht, 1995) S. 86. Das in $\S 290$ Abs. 2 HGB enthaltende „Control-Konzept“ hat ebenfalls Ähnlichkeiten mit IAS 27, ist durch seine abschließend auf drei klar abgegrenzte Sachverhalte beschränkte Konzeption indes sehr viel enger und rechtssicherer ausgestaltet. 
mit einem Haftungsverbund einhergehen muss. Aktienrechtliche Vertragsgestaltungen wie z.B. Gewinnabführungs- oder Beherrschungsverträge ( $\$ 291 \mathrm{AktG}$ ) oder auch Eingliederungen ( $\$ 319 \mathrm{AktG}$ ) sind zwar durchaus geeignet, eine Beherrschung im Sinne von IAS 27.13 (b) zu begründen. Zwingend sind sie allerdings nicht, da auch andere Sachverhalte diese Eignung besitzen.

Wird der Vorstellung gefolgt, dass eine Einheitsbesteuerung und eine damit einhergehende Gesamtgewinnermittlung nur bei einer Unternehmensgruppe möglich sein soll, die - wie das Einheitsunternehmen - keine Haftungsseparation zulässt ${ }^{1}$, reicht das Verbindungskonzept von IAS 27 hierfür nicht aus. Wenn diese Vorstellung allerdings dahingehend relativiert wird, dass die hieraus erwachsende Leistungsfähigkeitsbeeinflussung nicht allein von der bloßen Möglichkeit der Haftungsseparation abhängt, sondern von der tatsächlichen Verlustentziehung ${ }^{2}$, mag IAS 27 in seiner Konzeption bereits genügen. Dies hätte zumindest den Vorteil, mit der zusätzlichen Vertragsvoraussetzung kein weiteres Gestaltungsinstrument zur Selbsteinsteuerung etablieren zu müssen. Zudem müsste dieses Instrument im grenzüberschreitenden, europäischen Kontext nicht völlig neu geschaffen werden, weil es zumindest derzeit an den nationalen sowie europarechtlichen Voraussetzungen hierfür mangelt ${ }^{3}$. Wird allerdings kein Haftungsverbund vorausgesetzt, wäre sicherzustellen, dass die Erfolgslokalisation in der Unternehmensgruppe auf direktem oder indirektem Wege funktioniert und/oder Verlustverrechnungen in ihrer Höhe auf die jeweiligen Haftungseinlagen beschränkt werden ${ }^{4}$.

Auch ein weiteres Problem rechtlicher Separation würde durch IAS 27 nicht wirklich gelöst: die Steuerverteilung in der Unternehmensgruppe. Eine zivilrechtliche Anspruchseinheit ist eben keine zwingende Voraussetzung der Konsolidierung nach IFRS. Aber auch für Zwecke der steuerlichen Konsolidierung sind zusätzliche Rechtsgeschäfte zur Begründung dieser Anspruchseinheit nicht in jedem Fall erforderlich ${ }^{5}$. Dies bedingt allerdings ebenfalls eine funktionierende Erfolgslokalisation, um die Vertragspartner weitestgehend vor konsolidierungsbedingten Vermögensschäden zu schützen.

IAS 27 könnte indes vorgeworfen werde, Interessenkonflikte innerhalb der Unternehmensgruppe zu verstärken. Bezogen auf das Teilproblem der Minderheiten könnte dieser Vorwurf darauf gründen, dass einfache Stimmrechtsmehrheiten für eine Einbeziehung bereits ausreichen oder, angesichts der weiteren Beherrschungsmöglichkeiten

1 Vgl. stellvertretend Beusch (Referat, 1972) S. Q 41-Q 42; Flume (Referat, 1972) S. Q 17-Q 19; Lutter (Diskussionsbeitrag, 1972) S. Q 58; dazu auch Kap. III.2.5.1.1.

2 Vgl. Senger (Konzernertragsbesteuerung, 1997) S. 53 mit Hinweis auf Herzig/Dautzenberg (Steuergestaltung, 1992) S. 7; dazu auch Kap. III.2.5.1.1.

3 Vgl. ähnlich Grotherr (Besteuerung nationaler und grenzüberschreitender Konzerne, 1994) S. $477-$ 479; Salzberger (Konzernunternehmung, 1994) S. 238-239; dazu auch Kap. III.2.5.2.

4 Vgl. Kap. III.2.5.1.1.

5 Vgl. Kap. III.2.5.1.2. 
noch extremer, auch „ökonomische Minderheiten“ trotz mehrheitlichem Stimmrechtsanteil an die Gruppe gebunden werden. Dieser Vorwurf ist allerdings insoweit zu relativieren, dass auch sehr viel höhere Stimmrechts- (und Kapitalanteils-)quoten bis hin zu $100 \%$ das zu Grunde liegende Problem etwaig benachteiligter Vertragspartner innerhalb einer rechtlich separierten Unternehmensgruppe nicht lösen. Lediglich auf der Basis des deutschen Aktienrechts könnte argumentiert werden, dass zusätzliche Rechtsgeschäfte durch eine qualifizierte Mehrheit entbehrlich werden. Eine qualifizierte, allerdings auf Kapitalanteile abstellende Hauptversammlungsmehrheit definiert schließlich die formalrechtliche Position, um Gewinnabführungs- und Beherrschungsverträge sowie Eingliederungen beschließen zu können ( $§ 293$ Abs. 1 Satz 2, 319 Abs. 2 Satz 2 AktG) ${ }^{1}$. Diese formalrechtliche Position begründet so eine Art potenzieller Anspruchseinheit. Fraglich ist jedoch, ob es ausreicht, die qualifizierte Mehrheit, die sich angesichts der aktienrechtlichen Vorgaben auf den Kapitalanteil erstrecken müsste, grundsätzlich als Verbindungsmerkmal einzufordern. Dies ist schon deshalb zu bezweifeln, da andere EUStaaten die entsprechenden Rechtsinstitute nicht einmal kennen ${ }^{2}$, so dass eine vergleichbare formalrechtliche Position dort auch nicht geschaffen werden kann. Zudem ist eine gesellschaftsrechtliche Angleichung an dieser Stelle oder gar eine Etablierung grenzüberschreitender Vertragskonstruktionen nach der bislang gescheiterten Verabschiedung der neunten gesellschaftsrechtlichen Richtlinie von 1984 (Konzernrechtsrichtlinie) $)^{3}$ wohl nicht zu erwarten. Insofern handelt es sich eher um eine "deutsche“ Argumentation, die nicht auf europäische Zusammenhänge übertragbar ist und die letztlich auch daran leidet, dass die grundsätzliche Notwendigkeit einer zivilrechtlichen Anspruchseinheit für Gruppenbesteuerungszwecke nicht erwiesen ist ${ }^{4}$.

Interessant erscheint an dieser Stelle wieder der Blick auf die vier nationalen Konsolidierungssysteme in der EU. So sieht keines dieser vier Systeme zusätzliche Rechtsgeschäfte zur Begründung eines Haftungsverbundes bzw. einer Anspruchseinheit vor. Obwohl in allen vier Staaten sehr hohe Stimmrechts- und Kapitalanteilsquoten vorgeschrieben sind, fällt es angesichts der dort meist fehlenden gesetzlichen Grundlagen schwer, darin ein kompensierendes Element zu erkennen. Statt dessen wird in allen diesen Staaten eine Erfolgslokalisation in der einen oder anderen Weise gewährleistet. Daraus abgeleitete Lösungen für das Problem der Haftungsseparation, z.B. über eine

Vgl. zu der Frage der Anteilsquote bereits Kap. II.3.3.2.

Vgl. Kap. III.2.5.2.

Vgl. zu dieser Richtlinie Kap. III.2.5.2 und Kap. IV.2.1.2.

Vgl. dazu treffend Lechner (Besteuerung von Unternehmensgruppen, 1991) S. 396: „Daß die Minderheitenprobleme relativ problemlos lösbar sind, zeigen nicht zuletzt das amerikanische Beispiel und andere Beispiele... Es ist bloß sicherzustellen, dass die Gesamtsteuerschuld der Gruppe möglichst verursachungsgerecht auf die einzelnen Gruppenglieder aufgeteilt wird“; dazu auch Kap. III.2.5.1. 
einlagengedeckelte Verlustverrechnung o.ä., sind allerdings nicht erkennbar ${ }^{1}$. Dafür sieht das Steuerecht dieser vier Staaten noch eine Art Zustimmungserfordernis der in die Gruppenbesteuerung einbezogenen Unternehmen vor ${ }^{2}$. Ob sich dahinter ein wirksamer Schutz aller betroffenen Vertragsparteien vor steuerinduzierten Vermögensverlagerungsrisiken verbirgt, mag jedoch schon vor dem Hintergrund bezweifelt werden, dass gerade auch die jeweiligen Leitungsorgane der betroffenen Unternehmen der Beherrschung des Mutterunternehmens ausgesetzt $\operatorname{sind}^{3}$.

\subsection{Stufenkonzept}

\subsubsection{Regulierung auf der Grundlage der IFRS}

Die Rechnungslegung nach IFRS basiert auf dem Stufenkonzept ${ }^{4}$. In Abhängigkeit von der jeweils identifizierten Verbindungsintensität werden Unternehmen in der Rechnungslegung und in der rechnungslegenden Einheit unterschiedlich berücksichtigt (Abb. 14).

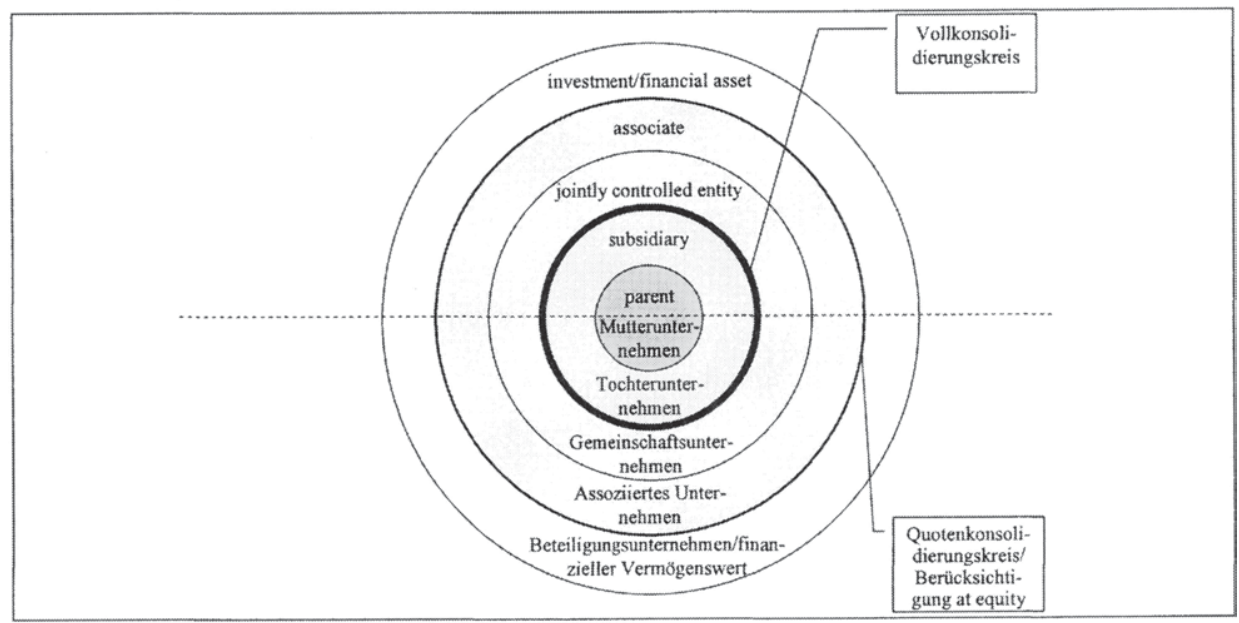

Abb. 14: Stufenkonzept nach IFRS

Quelle: In Anlehnung an Pellens/Fülbier/Gassen (Internationale Rechnungslegung, 2004) S. 126.

1 In Portugal gibt es eine abgewandelte, nicht an der Höhe des eingelegten Kapitals orientierte Beschränkung der Bemessungsgrundlage, die sich an den Einzelveranlagungen der einbezogenen Unternehmen orientiert; vgl. IV.1.2.4. Außerhalb der vier Konsolidierungsstaaten existiert eine derartige Verlustausgleichsbeschränkung aber z.B. in der ab 2005 in Österreich greifenden Gruppenbesteuerung in Bezug auf ausländische Unternehmen der Gruppe; vgl. z.B. Ernst \& Young (Gruppenbesteuerung, 2004) S. 11-13. Letztlich kann die gesellschaftsrechtliche Haftungssituation bei faktischen Unternehmensverbindungen in den EU-Mitgliedstaaten hier aber nicht abschließend beurteilt werden.

2 Ein klassisches Einbeziehungswahlrecht existiert aber nur in Frankreich und in den Niederlanden, während in Spanien und Portugal hier wohl eher ein formaler Pflichtakt vorliegt; vgl. Kap. IV.1.2.1. Vgl. Kap. III.2.5.1.2.

4 Vgl. hierzu bereits Kap. III.2.3.2.1. 
Die höchste Intensitätsstufe wird durch Beherrschung erzielt. Ein beherrschtes Unternehmen qualifiziert sich als Tochterunternehmen und wird im Weg der Vollkonsolidierung berücksichtigt (IAS 27.11-36). Demgegenüber definiert IAS 31 „Interests in Joint Ventures"1 auch Gemeinschaftsunternehmen (jointly controlled entities ${ }^{2}$ ), die unter gemeinschaftlicher Beherrschung durch mindestens zwei Parteien stehen (IAS 31.3, 31.24-29). Gemeinschaftsunternehmen sind nach IAS 31.30 per Quotenkonsolidierung zu berücksichtigen. Alternativ sieht IAS 31.38 hierfür auch die Equity-Methode vor ${ }^{3}$, die nach IAS 28 „Investments in Associates“ ${ }^{4}$ auch als Standardmethode zur Berücksichtigung assoziierter Unternehmen vorgesehen ist (IAS 28.13) ${ }^{5}$. Assoziierte Unternehmen (associates) sind nach IAS 28.2 alle Unternehmen ${ }^{6}$, auf die ein maßgeblicher Einfluss (significant influence) ausgeübt werden kann. Der maßgebliche Einfluss ist nach IAS 28.2 und IAS 28.6-10 als Macht bzw. Möglichkeit definiert, an den geschäftspolitischen Entscheidungen eines Unternehmens mitzuwirken. In der Intensitätsstufe ist der maßgebliche Einfluss eindeutig unter der Möglichkeit der Beherrschung bzw. gemeinschaftlichen Beherrschung angesiedelt ${ }^{7}$. Wenn kein maßgeblicher Einfluss ausgeübt wird, sind Unternehmen, an denen Kapitalanteile erworben worden sind, als ,normale" (Beteiligungs-)Unternehmen zu behandeln. Sie sind als finanzieller Vermögenswert nach Maßgabe von IAS 39 entweder als „avaliable for sale financial assets“ oder als „financial instruments at fair value through profit or loss“ zum beizulegenden Zeitwert zu bilanzieren ${ }^{8}$.

1 IAS 31 (revised 2003) ist Ergebnis des im Dezember 2003 abgeschlossenen Improvements-Project. Er ersetzt IAS 31 (revised 2000) „Financial Reporting of Interests in Joint Ventures” und ist für Geschäftsjahre anzuwenden, die am oder nach dem 1. Januar 2005 beginnen, wobei das IASB eine frühere Anwendung begrüßt (IAS 31.IN1, IAS 31.58-59).

2 Das Gemeinschaftsunternehmen (jointly controlled entity) tritt nach LAS 31.7 neben die gemeinschaftlich geführten Tätigkeiten (jointly controlled operations) und die Vermögenswerte unter gemeinschaftlicher Führung (jointly controlled assets) und ist damit eine von drei Ausprägungen eines ,joint venture".

3 Vgl. zu den hier nicht weiter thematisierten Anwendungsausnahmen IAS 31.1-2, 31.42-45.

4 IAS 28 (revised 2003) ist ebenfalls Ergebnis des im Dezember 2003 abgeschlossenen ImprovementsProject. Er ersetzt IAS 28 (revised 2000) „Accounting for Investments in Associates“, SIC-3 „Elimination of Unrealised Profits and Losses on Transactions with Associates“, SIC-20 „Equity Accounting Method - Recognition of Losses" und SIC-33 "Consolidation and Equity-Method - Potential Voting Rights and Allocation of Ownership Interests". In dieser Fassung ist IAS 28 für Geschäftsjahre anzuwenden, die am oder nach dem 1. Januar 2005 beginnen, wobei das IASB eine frühere Anwendung begrüßt (IAS 28.IN1, IAS 28.41-43).

5 Vgl. zu den hier nicht weiter thematisierten Anwendungsausnahmen IAS 28.1, 28.13 (a)-(c).

6 Auch an dieser Stelle ist - in Analogie zu IAS 27.4 (vgl. Kap. V.2.2.1.2) - der Unternehmensbegriff zu eng, da IAS 28.2 allgemeiner von einer „entity“ spricht, die beispielsweise auch Personengesellschaften bzw. Partnerschaften umfassen kann.

7 Vgl. so auch IAS 28.2: „... but is not control or joint control over those policies“.

8 Vgl. IAS 28.19. Wenn die Ausnahme nach IAS 28.13 (a) greift, schreibt IAS 28.14 auch direkt die Bilanzierung als ,held for trading "vor, eine Kategorie von Finanzinstrumenten, die in IAS 39 (revised 2003) in ,financial instruments at fair value through profit or loss“ ihre Entsprechung findet. 
Das dargestellte Stufenkonzept gilt nach IFRS ausschließlich für den konsolidierten bzw. „höchstaggregierten“1 Abschluss. Sofern der Einzelabschluss nicht den „höchstaggregierten" Abschluss darstellt, wird hier sogar die Equity-Methode gemäß IAS 28.34 explizit ausgeschlossen². Der Begriff des Stufenkonzeptes gibt Aufschluss darüber, dass die rechnungslegende Einheit nach IFRS nicht abrupt zwischen Markt und Unternehmung unterscheidet. Während Tochterunternehmen der rechnungslegenden Einheit mit ihren Ressourcen voll zugerechnet werden und hinsichtlich der Ertragsrealisation vollumfänglich als „innen“ gelten, gilt dies bei quotenkonsolidierten Gemeinschaftsunternehmen nur noch in Höhe der zu Grunde liegenden Quote. Gemeinschaftsunternehmen sind damit partiell auch als Markt zu charakterisieren.

Bei assoziierten Unternehmen greift mit der Equity-Methode eine Methode, die nach IAS 28 über ein reines Bewertungsverfahren hinaus geht und stark in Richtung eines (einzeiligen) Konsolidierungsverfahrens ausgestaltet ist ${ }^{3}$. So verlangen IAS 28.26-27 auch hier die Vereinheitlichung der Bilanzierungsgrundsätze, der Währung ${ }^{4}$ sowie, wenn möglich, die Angleichung der Bilanzstichtage (IAS 28.24). Zudem sieht IAS

1 Unter dem „höchstaggregierten“ Abschluss ist der Abschluss zu verstehen, in den sämtliche Tochterunternehmen, Gemeinschaftsunternehmen und assoziierte Unternehmen nach Maßgabe der gültigen IFRS auf der Basis der Voll- bzw. Quotenkonsolidierung bzw. Equity-Methode einbezogen sind. Das ist nicht nur ein konsolidierter Abschluss, sondern auch ein Abschluss, in dem assoziierte Unternehmen at equity berücksichtigt werden. Dies beinhaltet z.B. auch den Abschluss eines Untemehmens, das wirtschaftlich völlig autonom ist und weder Tochter- noch Gemeinschaftsunternehmen ,"übergeordnet" ist, das aber einen maßgeblichen Einfluss auf ein assoziiertes Unternehmen ausübt. Dieses assoziierte Unternehmen wäre dann nach IAS 28 in diesem „höchstaggregierten“ Abschluss at equity zu berücksichtigen.

2 In der alten Fassung von IAS 28 (revised 2000) gab es an dieser Stelle noch ein Wahlrecht, das aber im Zuge des Improvements-Project aufgehoben wurde. Der Begriff des Einzelabschlusses (separate financial statements) beschränkt sich dabei allerdings nach IAS 28.4 auf die Abschlüsse eines Unternehmens, das ansonsten auch in einen „höchstaggregierten“ Abschluss einbezogen ist. Damit ist der Abschluss eines wirtschaftlich völlig autonomen Unternehmens, das auch keinen beherrschenden oder maßgeblichen Einfluss auf ein anderes Unternehmen ausübt (Einzelunternehmung), kein Einzelabschluss mehr im Sinne von IFRS. Mit anderen Worten: der „höchstaggregierte“ Abschluss ist nie ein Einzelabschluss; auch nicht, wenn das Unternehmen als rechtliche Einheit identisch mit der wirtschaftlichen Einheit ist. Interessant ist diese Unterscheidung schon deshalb, weil nur in den so definierten Einzelabschlüssen nach IAS 27.37 ein Wahlrecht besteht, Tochterunternehmen, Gemeinschaftsunternehmen und assoziierte Unternehmen alternativ zu IAS 39 auch zu historischen Kosten zu bewerten. Vgl. auch die Verweise in IAS 28.35 und IAS 31.46. Im Übrigen weisen IAS 27.38, IAS 28.36 und IAS $31.47 \mathrm{zu}$ Recht darauf hin, dass die IFRS nicht regeln (können), welche Unternehmen öffentlich verfügbare Einzelabschlüsse aufzustellen haben.

$3 \mathrm{Vgl}$. auch IAS 28.20: „Many of the procedures appropriate for the application of the equity method are similar to the consolidation procedures described in IAS 27. Furthermore, the concepts underlying the procedures used in accounting for the acquisition of a subsidiary are also adopted in accounting for the acquisition of an investment in an associate." Vgl. zu der Abgrenzung von Konsolidierungs- und Bewertungsverfahren bereits Kap. III.1.4.2.

4 Dieses Erfordernis ergibt sich eher aus dem Gesamtzusammenhang sowie aus IAS 21.3 (b); vgl. grundlegend zur Währungsumrechnung bei Anwendung der Equity-Methode (nach HGB) Pellens (Anwendung der Equity-Methode, 1990). 
28.22 eine partielle Zwischenergebniseliminierung vor ${ }^{1}$. Typisch für die EquityMethode ist bereits die der Kapitalkonsolidierung angenäherte Vorgehensweise in IAS 28.23. Damit können auch assoziierte Unternehmen nicht vollständig dem Markt zugerechnet werden ${ }^{2}$, auch wenn sich die Ressourcenerfassung auf den fortgeschriebenen Beteiligungsansatz beschränkt und Konsolidierungsverfahren wie die Schuldenkonsolidierung in IAS 28 nicht explizit angesprochen werden.

Völlig außerhalb der rechnungslegenden Einheit stehen letztlich nur die „normalen“ Beteiligungsunternehmen. IAS 39 legt für diese Unternehmen lediglich das Bewertungsverfahren fest. Konsolidierungsverfahren sind hierfür nach IFRS, auch ansatzweise, nicht vorgesehen.

\subsubsection{Eignung für die konsolidierte steuerliche Gewinnermittlung}

Es ist fraglich, ob das Stufenkonzept nach IFRS Eingang in die konsolidierte steuerliche Gewinnermittlung finden sollte ${ }^{3}$. Wenn die Abgrenzung der rechnungslegenden Einheit auf Erkenntnissen der ökonomischen Theorie basiert, so ist auch dort zu konstatieren, dass eine exakte Grenze zwischen der Unternehmung und dem Markt nicht existiert. Dies liegt schon in den Schwierigkeiten der ökonomischen Theorie begründet, ein zweifelsfreies Abgrenzungskonzept zur Verfügung zu stellen. Dies liegt aber auch an der Existenz komplexer Hybridformen zwischen der Unternehmung und dem Markt. Zwischen der vereinheitlichten Kontrolle durch Integration und dem damit einhergehenden Erwerb ökonomischen Eigentums und der reinen Markttransaktion zweier unabhängiger Vertragspartner gibt es schließlich Zwischenformen mit unterschiedlich starker Bindungsintensität.

Das dieser Arbeit zu Grunde liegende Abgrenzungsleitbild ist aber letztlich der Versuch, die Unternehmung nicht nur vom Markt, sondern auch von den dazwischen liegenden Hybridformen abzugrenzen. Die nukleus- und ressourcenbasierte Abgrenzung auf der Grundlage residualer Entscheidungs- und Kontrollrechte trägt diesem Leitbild Rechnung. Hier wird nur eine Stufe, der Vollkonsolidierungskreis, als Bild der Unternehmung in Form der rechnungslegenden Einheit anerkannt. Zentrales Verbindungskriterium ist dabei die Frage des ökonomischen Eigentums. In seinem binären Charakter

1 Im Zuge des Improvements-Project ist die frühere Interpretation SIC-3 „Elimination of Unrealised Profits and Losses on Transactions with Associates" in IAS 28.33 integriert worden.

2 Vgl. z.B. auch Ordelheide (Konzern, 1986) S. 299, der konstatiert, dass in der Equity-Methode die „Ambivalenz zwischen Markt und Unternehmung besonders deutlich zum Ausdruck" komme.

3 In Abgrenzung zu Kap. III.1.3.4.2 soll kurz angemerkt werden, dass es hier nicht um die Frage geht, ob Unternehmen der Unternehmensgruppe qua Quotenkonsolidierung oder at equity einzubeziehen sind. Hier geht es statt dessen um die Frage, wie die Unternehmen, die außerhalb der hierarchisch strukturierten und auf ökonomischem Eigentum basierenden Unternehmensgruppe stehen, zu berücksichtigen sind. 
kann dieses Eigentum entweder vorliegen oder aber nicht vorliegen. Ein „bisschen“ Eigentum gibt es nicht ${ }^{1}$. Bereits bei Gemeinschaftsunternehmen mangelt es deshalb an residualen Entscheidungs- und Kontrollrechten, da selbige nur gemeinschaftlich mit anderen Institutionen ausgeübt werden können ${ }^{2}$. Dies widerspricht im Übrigen auch dem hier vertretenen hierarchischen Bild der Unternehmung. Dem dahinter stehenden Abgrenzungsverständnis folgend, darf dieses Gemeinschaftsunternehmen nicht mehr der rechnungslegenden Einheit zugerechnet werden. Diese Argumentation gilt dann natürlich erst recht für assoziierte Unternehmen ${ }^{3}$, auf die lediglich ein maßgeblicher Einfluss ausgeübt wird, der gar nicht mehr im Sinne des ökonomischen Eigentums gedeutet werden kann.

Die Abgrenzung des steuerlichen Konsolidierungskreises allein auf diese binäre Form der Abgrenzung festzulegen, bedarf allerdings der weiteren Begründung. Schließlich versuchen die IFRS als rein informationsorientierte Rechnungslegungsregeln, Hybridformen abzubilden, und die diesbezügliche Rechnungslegungsforschung treibt diese Entwicklung gar noch voran ${ }^{4}$. Eine Begründung aus der Perspektive der steuerlichen Gewinnermittlung gestaltet sich indes nicht einfach. Aus wirkungsorientierter Effizienzsicht könnte gar für ein Stufenkonzept angeführt werden, dass es letztlich um die steuerliche Gleichbehandlung unterschiedlicher Organisationsformen im Allgemeinen geht und sich diese Organisationsformen nicht zwingend auf Unternehmungen reduzieren lassen. Überaus problematisch erscheint dann allerdings eine Grenzziehung, da Hybridformen letztlich kontinuierlich in reine Markttransaktionen übergehen. Die Stufenkonzeption nach IFRS erscheint hier mehr oder weniger willkürlich.

Noch schwieriger erscheint die Rechtfertigung des Stufenkonzeptes aus der Sicht der steuerlichen Leistungsfähigkeit. So ist es bereits problematisch, dieses Konzept zu „entindividualisieren“ und auf Unternehmen bzw., noch weitergehender, auf Unternehmensgruppen als Ausdruck einer Unternehmung zu übertragen ${ }^{5}$. Hier konnte allerdings noch argumentiert werden, eine qua definitionem wirtschaftlich autonome Einheit als Zurechnungsobjekt identifizieren zu wollen. Implizit ist die steuerliche Leistungsfähigkeit damit an wirtschaftliche Unabhängigkeit und Autonomie gekoppelt, die eine Ab-

1 An dieser Stelle sei allerdings auf die Diskussion in Kap. V.2.2.2.1 und auf seltene Ausnahmemöglichkeiten im Einzelfall verwiesen.

2 Vgl. in Argumentation und Ergebnis ähnlich Oberndorff (Konzernbesteuerung, 1996) S. 94-95; siehe auch Kap. V.2.2.2.1. I.d.R. wird in der Literatur auch akzeptiert, dass über das Stufenkonzept nicht die wirtschaftliche Einheit, sondern die Einflußsphäre derselben aufgezeigt wird; vgl. m.w.N. Dusemond (Abgrenzung des Konsolidierungskreises, 1994) S. 1733.

3 Vgl. Oberndorff(Konzernbesteuerung, 1996) S. 98.

4 Bestrebungen zur verbesserten Abbildung hybrider Konstruktionen in der rein informationsorientierten Rechnungslegung finden sich z.B. bei Kasperzak (Netzwerkorganisationen, 2004), der allerdings auf enger definierte Netzwerke fokussiert, und Schmidt (Kooperationsformen, 2003), jeweils m.w.N.

5 Vgl. zu dieser Diskussion Kap. II.3.3.1. 
grenzung der Unternehmung von Hybridformen unterstützt. Die steuerliche Leistungsfähigkeit dieser Unternehmung wird dabei natürlich auch von ihrer Einbettung in hybride Vertragskonstruktionen bestimmt. Dies kann allerdings als Rechtfertigung für die entsprechende Ausdehnung des Zurechnungsobjektes der steuerlichen Leistungsfähigkeit nicht ausreichen ${ }^{1}$.

Argumente gegen das Stufenkonzept und für eine binäre Abgrenzung der rechnungslegenden Einheit ergeben sich aus Sicht der effizienz- wie gerechtigkeitsgetriebenen Forderung nach Einfachheit, Eindeutigkeit und Objektivität der Steuervorschriften. So ist bereits angedeutet worden, dass allein die Grenzziehung der über die Unternehmung hinausgehenden Organisation unter diesen Gesichtspunkten kaum beherrschbar erscheint - auch wenn die Stufenfestlegung der IFRS hier eine gewisse Standardisierung erreicht. Selbst wenn dieses Problem ausgeklammert wird, verbleiben Abstimmungsprobleme im Rahmen der steuerlichen Gewinnermittlung im Hinblick auf die sich hieraus ergebenden Rechtsfolgen. Gälte das Stufenkonzept nach IFRS in der steuerlichen Gewinnermittlung, würden Unternehmen, zu denen zwar enge vertragliche Beziehungen bestehen, die jedoch nicht allein der Entscheidungs- und Kontrollgewalt der obersten Instanz unterliegen, in die Gefahr der Doppel- und auch Mehrfachbesteuerung geraten. Einerseits wären diese Unternehmen als hybride Vertragspartner qua Quotenkonsolidierung oder Equity-Methode in die Gesamtgewinnermittlung einzubeziehen und trügen somit ihren Teil zum zu versteuernden Einkommen der Gruppe bei. Andererseits könnten diese Unternehmen entweder selbst der Ertragsbesteuerung unterworfen sein oder, als Teil einer Unternehmensgruppe im ökonomischen Eigentum eines fremden Mutterunternehmens, auch in die dortige Gesamtgewinnermittlung einbezogen werden ${ }^{2}$.

Die Abstimmung der jeweiligen Besteuerungsfolgen erscheint komplex. So wäre auch eine Vollkonsolidierung der Tochterunternehmen nach dem Einheitsprinzip kaum noch vorstellbar, wenn der Gewinn dieser Unternehmen auch anderweitig - wenn auch nur

1 Vgl. ansatzweise auch Schneider (IAS als Besteuerungsgrundlage, 2003) S. 302. Die steuerliche Leistungsfähigkeit einer Unternehmung wird z.B. auch durch die Häufigkeit und Güte seiner Markttransaktionen beeinflusst, ohne dass hier eine entsprechende Ausweitung der rechnungslegenden Einheit ernsthaft erwogen wird.

2 Wahrscheinlich ist nur eine Kombinationsbesteuerung als Tochterunternehmung und als assoziiertes Unternehmen. Angesichts seiner Definition erscheint eher unwahrscheinlich, dass ein Gemeinschaftsunternehmen gleichzeitig auch als Tochterunternehmen oder assoziiertes Unternehmen angesehen werden kann. Unmöglich ist dies jedoch nicht. Wenn z.B. zwei Untemehmen A und B an dem Unternehmen C jeweils $49 \%$ der Stimmrechte halten, während die restlichen $2 \%$ bei einem weiteren Unternehmen D liegen, so kann letzterem immer noch ein maßgeblicher Einfluss im Sinne von IAS 28.7 zuwachsen. Dabei sind Inkonsistenzen in der Beurteilung auf den jeweiligen Seiten kaum auszuschließen, da unterschiedliche Einschätzungen der eigenen und jeweils anderen Bindungsintensitäten realiter zumindest möglich sind. Die etwaige Existenz potenzieller Stimmrechte sowie von Stimmrechtsverhältnissen losgelöster Einflussmöglichkeiten dürfte diese Möglichkeit nicht unwahrscheinlicher machen. Selbiges gilt im Hinblick auf SIC-12 und die damit einhergehende Möglichkeit, Tochterunternehmen auch ohne Stimmrechts- bzw. Kapitalanteil beherrschen zu können. 
partiell - der Besteuerung zugeführt würde. Letztlich liefe dies eher auf eine generelle Quotenkonsolidierungspflicht auch für beherrschte Tochterunternehmen hinaus. Aber selbst dann erscheinen der Abstimmungsbedarf und die gesteigerte Komplexität der steuerlichen Gewinnermittlung beträchtlich. So müsste eine neue Form der quotalen Ergebnisberücksichtigung auch das nicht beherrschte Unternehmen in seiner Einzelgewinnermittlung treffen, wenn es z.B. als assoziiertes Unternehmen in eine Gesamtgewinnermittlung einer anderen Unternehmung partiell integriert wird. Der ausgewiesene Einzelgewinn müsste zumindest in einen nicht zu versteuernden (da in der Gesamtgewinnermittlung versteuerten) und in einen zu versteuernden (da nicht in der Gesamtgewinnermittlung erfassten) Teil differenziert werden. Genauerer Klärung bedarf hier auch die Abstimmung von Quotenkonsolidierung und Equity-Methode. Zudem sieht letztere nach IAS 28.29-30 im Regelfall eine Begrenzung der Verlustverrechnungsmöglichkeiten auf den fortgeführten Beteiligungsbuchwert vor ${ }^{1}$, was unter steuerlichen Gesichtspunkten wenig sachgerecht erscheint ${ }^{2}$.

Obwohl das Abstimmungsproblem theoretisch lösbar erscheint, dürfte der damit offenkundig einhergehende Abstimmungsbedarf aus durchführungseffizienter Sicht kaum tragbar sein. Dabei ist noch nicht einmal berücksichtigt, dass Unternehmen - darunter nach IAS 28 auch assoziierte Unternehmen - bei Einbeziehung in mehrere Gesamtgewinnermittlungen multiple Anstrengungen unternehmen müssen, um ihre Gewinnermittlung (jeweils) zu vereinheitlichen und Konsolidierungsmaßnahmen (jeweils) durchzuführen $^{3}$. Aber selbst wenn die Equity-Methode als „normales“ Bewertungsverfahren begriffen würde, widerspräche sie zumindest dem gerechtigkeitsgetriebenen Konzept des realisierten Reinvermögenszugangs, das zur Bewertung außerhalb der rechnungslegenden Einheit stehender Unternehmensbeteiligungen wohl nur historische Anschaffungskosten zulassen dürfte ${ }^{4}$.

Das Stufenkonzept nach IFRS erscheint vor diesem Hintergrund für Zwecke der konsolidierten steuerlichen Gewinnermittlung eher ungeeignet ${ }^{5}$. Dieses Ergebnis wird im Übrigen durch die Situation in den vier europäischen Konsolidierungsstaaten gestützt. Auch dort gibt es keinerlei Berücksichtigung irgendwelcher Zwischenformen in der

1 IAS 28.30 sieht nur unter restriktiven Bedingungen den Ansatz einer Verbindlichkeit vor.

2 Vgl. Oberndorff (Konzernbesteuerung, 1996) S. 101-102, der zudem auch die Abstimmung der Einzelgewinnermittlung mit der Equity-Methode in der Gesamtgewinnermittlung problematisiert (S. 99100); Senger (Konzernertragsbesteuerung, 1997) S. 181-182.

3 An dieser Stelle ist bereits nach IFRS zu fragen, inwieweit noch dem Grundsatz der Wirtschaftlichkeit entsprochen würde.

4 Letztlich handelt es sich hierbei um eine Bewertungsfrage, die unter Berücksichtigung aller normativen Kriterien analysiert werden müsste, ohne hier im Vordergrund zu stehen; vgl. dazu Kap. III.1.4.2.

5 Vgl. zum selben Ergebnis kommend auch Reis (Körperschaftsbesteuerung des Konzerns, 1996) S. 238-239, die allerdings auf das handelsrechtliche deutsche Stufenkonzept fokussiert und - bis auf den Verweis auf Einheitstheorie bzw. Einheitsbesteuerung, der angeblich widersprochen würde - keine weitere Argumentation bemüht. 
Gesamtgewinnermittlung. Hier wird statt dessen einer klaren binären Abgrenzung gefolgt. Weil das zu Grunde liegende Abgrenzungskonzept in diesen Staaten zudem sehr eng ausgestaltet ist, verläuft die Grenze zum Markt tendenziell sogar innerhalb der Unternehmung, so wie sie sich z.B. nach dem Abgrenzungsleitbild dieser Arbeit ergeben würde. Nur mit der sog. Mehrmütterorganschaft konnte eine gewisse Parallele zu dem Phänomen eines Gemeinschaftsunternehmens hergestellt werden. Diese bis 2003 in Deutschland existierende Form der Organschaft war möglich, wenn sich mehrere Personen, Personenvereinigungen oder Unternehmen zu einer Gesellschaft bürgerlichen Rechts (GbR, §§ 705 ff. BGB) zusammenschlossen, sofern diese u.a. zur einheitlichen Willensbildung und -durchsetzung gegenüber einer Organgesellschaft in der Lage war'. Hierbei handelte es sich jedoch um kein Gesamtgewinnermittlungssystem, sondern nur um ein reines Zurechnungssystem. Wie ansonsten auch, sah dieses System im Falle der Mehrmütterorganschaft eine volle Zurechnung an die GbR vor, auf deren Ebene erst eine einheitliche und gesonderte Gewinnfeststellung gemäß $\S 179,180$ AO vorgenommen wurde, so dass im Ergebnis eine beteiligungsproportionale Verlustverrechnung möglich erschien. Mit einem Stufenkonzept hat das wenig zu tun. Zudem findet die Mehrmütterorganschaft in der EU nur im Vereinigten Königreich und in Irland ein gewisses Pendant, nicht jedoch in den vier identifizierten Konsolidierungsstaaten ${ }^{2}$.

\section{Vorbereitende Maßnahmen (Erstellung der Steuerbilanz II)}

\subsection{Regulierung auf der Grundlage der IFRS}

\subsubsection{Einheitliche Bilanzierungsgrundsätze und Stichtagsidentität}

Konsolidierte Abschlüsse nach IFRS müssen nach IAS 27.28 auf der Basis einheitlicher Bilanzierungsgrundsätze erstellt werden ${ }^{3}$, die zwangsläufig den IFRS entsprechen. Deshalb sind die Einzelabschlüsse der einbezogenen Unternehmen gegebenenfalls anzupassen, wenn sie ursprünglich anderen Bilanzierungsgrundsätzen folgen (IAS 27.29). Die Einheitlichkeit der Grundsätze bezieht sich auch auf eine etwaige Wahlrechtsausübung, so dass Bilanzierungswahlrechte der IFRS bei gleichartigen Sachverhalten auch einheitlich auszuüben sind ${ }^{4}$. Unter Verwendung des deutschen Terminus technicus wird so aus der Handelsbilanz I eine angepasste Handelsbilanz II, die anschließend der Addition zur

1 Vgl. zur Mehrmütterorganschaft z.B. genauer R 52 Abs. 6 KStR 1995; vgl. zu deren Abschaffung sowie Ersatzlösungen Jonas (Abschaffung, 2003); Raupach/Burwitz (Abschaffung, 2003); Schroer/Starke (Abschaffung der Mehrmütterorganschaft, 2003).

2 Vgl. Grotherr (Besteuerung nationaler und grenzüberschreitender Konzerne, 1994) S. 564-565; Grotherr (Konzernbesteuerungssysteme, 1996) S. 365.

3 Vgl. IAS 27.28: „... shall be prepared using uniform accounting policies for like transactions and other events in similar circumstances“. Unter ,accounting policies“ sind nach Baetge/Schulze (IAS 27, 2002) Tz. 121 sämtliche Ansatz-, Bewertungs- und Ausweismethoden zu subsumieren.

4 Vgl. Baetge/Schulze (IAS 27, 2002) Tz. 122, die neben dieser sachlichen Einheitlichkeit mit Rückgriff auf das Rahmenkonzept auch die zeitliche Stetigkeit für notwendig erachten. 
Summenbilanz und der eigentlichen Konsolidierung zu Grunde gelegt wird. Lediglich in den Fällen, in denen der Grundsatz der Wesentlichkeit (materiality) oder Wirtschaftlichkeit (balance between benefit and cost) greift, darf diese Anpassung unterbleiben ${ }^{1}$.

Die Einzelabschlüsse der einbezogenen Unternehmen sollen nach IAS 27.26-27 auch denselben Berichtszeitraum und Abschlussstichtag aufweisen. Bei abweichenden Stichtagen ist die Handelsbilanz II des Tochterunternehmens über einen Zwischenabschluss auf den Stichtag des Mutterunternehmens hin anzupassen. Nur wenn dies kaum durchführbar (impracticable) erscheint, nimmt IAS 27.26 von der Verpflichtung zur Aufstellung eines Zwischenabschlusses Abstand. In diesem Fall beschränkt sich die Anpassungsverpflichtung auf wesentliche Transaktionen oder Ereignisse der Zwischenzeit. Diese Erleichterung greift allerdings nur, wenn die Stichtagsdifferenz drei Monate nicht überschreitet (IAS 27.27).

\subsubsection{Währungsumrechnung}

Eine weitere zentrale Maßnahme zur Vereinheitlichung der Einzelabschlüsse stellt die Währungsumrechnung dar. Eine solche Währungsumrechnung ist auch innerhalb der EU vonnöten, sobald sich eine Unternehmensgruppe über die Grenzen der Euro-Zone erstreckt. Regeln zur Währungsumrechnung finden sich insbesondere ${ }^{2}$ in IAS 21 „The

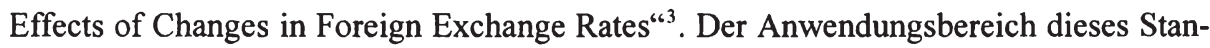
dards geht dabei über die vorbereitenden Maßnahmen im Vorfeld der Konsolidierung hinaus. Er umfasst auch die Umrechnung der in Fremdwährung getätigten EinzelTransaktionen ${ }^{4}$. Dieser Aspekt soll hier allerdings nicht primär interessieren. Bei der währungsraumüberschreitenden Konsolidierung sind Regeln zur Umrechnung der Fremdwährungsabschlüsse im Rahmen der vorbereitenden Maßnahmen zwingend erforderlich. Nur dieser in IAS 21 regulierte Aspekt der Währungsumrechnung steht hier im Vordergrund der Untersuchung.

1 Vgl. IASB Framework Par. 29-30, 44; dazu z.T. Baetge/Schulze (IAS 27, 2002) Tz. 126. Der in IAS 27.21 (revised 2000) noch vorgesehene Ausnahmetatbestand einer „mangelnden Durchführbarkeit“ ist in der jetzigen Fassung indes entfallen.

2 Der in IAS 29 „Financial Reporting in Hyperinflationary Economies“ geregelte Sonderfall der Hochinflationswährung soll hier nicht weiter behandelt werden.

3 IAS 21 (revised 2003) ist Ergebnis des im Dezember 2003 abgeschlossenen Improvements-Project. Er ersetzt den gleichlautenden IAS 21 (revised 1993) sowie SIC-11 „Foreign Exchange - Capitalisation of Losses Resulting from Severe Currency Devaluations", SIC-19 "Reporting Currency - Measurement and Presentation of Financial Statements under IAS 21 and IAS 29" und SIC-30 "Reporting Currency - Translation from Measurement Currency to Presentation Currency". In dieser Fassung ist IAS 21 für Geschäftsjahre anzuwenden, die am oder nach dem 1. Januar 2005 beginnen, wobei das IASB eine frühere Anwendung begrüßt (IAS 21.IN1, IAS 21.58-62).

4 Dieser Einzel- wie konsolidierte Abschlüsse betreffende Aspekt der Währungsumrechnung wird als „foreign currency transactions“ bezeichnet und ist in IAS 21.20-37 geregelt. Die hier festgelegte Zeitbezugsmethode hat aber auch Relevanz für die Umrechnung von Fremdwährungsabschlüssen. 
IAS 21 folgt bei der Einbeziehung von Fremdwährungsabschlüssen dem Konzept der funktionalen Währung. Dieses Konzept sieht in einem ersten Schritt vor, die funktionale Währung des betrachteten Tochterunternehmens ${ }^{1}$ zu bestimmen. In Abhängigkeit von dieser Bestimmung wird dann entweder die Zeitbezugs- oder die modifizierte Stichtagskursmethode zur Umrechnung des Fremdwährungsabschlusses herangezogen.

Die funktionale Währung ist nach IAS 21.8 die Währung desjenigen Wirtschaftsraumes, in der das Tochterunternehmen seine überwiegende Geschäftstätigkeit abwickelt. IAS 21.9-11 geben hier eine Reihe von Indizien vor, die darauf hinweisen, ob dies die Währung der gesamten rechnungslegenden Einheit ist (Berichtswährung der Unternehmensgruppe im konsolidierten Abschluss, presentation currency) oder eine davon abweichende Währung, die regelmäßig der Landeswährung des Tochterunternehmens entspricht. Im Grundsatz gilt, dass ein im ausländischen Ansässigkeitsstaat weitgehend selbständig agierendes Tochterunternehmen (,with a significant degree of autonomy“) eine von der Berichtswährung der Unternehmensgruppe abweichende funktionale Währung hat. Demgegenüber stimmen diese beiden Währungen überein, wenn das Tochterunternehmen eher als „verlängerter Arm“ der Gruppenspitze agiert und damit vergleichsweise wenig Autonomie besitzt ${ }^{2}$.

Der Fremdwährungsabschluss des selbständig agierenden Unternehmens wird auf der Grundlage einer modifizierten Stichtagskursmethode umgerechnet. Danach sind alle Vermögenswerte und Schulden zum Stichtagskurs von der funktionalen Währung in die Berichtswährung der Unternehmensgruppe umzurechnen (IAS 21.39(a)). Aufwand und Ertrag müssen indes zum Kurs des Transaktionszeitpunktes umgerechnet werden (IAS 21.39(b)), wobei IAS 21.40 hier aus Praktikabilitätsgründen die Verwendung von Durchschnittskursen erlaubt ${ }^{3}$. Die Umrechnung des Eigenkapitals ist in IAS 21 nicht explizit geregelt. Festgelegt ist nur, dass Umrechnungsdifferenzen ergebnisneutral im Eigenkapital zu erfassen sind (IAS 21.39(c)) und in ihrer Periodenveränderung in einer Überleitungsrechnung separat ausgewiesen werden (IAS 21.52(b)). Das in der Berichtsperiode erwirtschaftete Periodenergebnis wird dabei als Residualgröße umgerechneter Aufwendungen und Erträge in die Bilanz übernommen. Offen bleibt indes die Umrechnung der sich nicht auf die laufende Periode beziehenden Eigenkapitalbestandteile. In

1 Streng genommen bezieht sich die Währungsumrechnung gemäß IAS 21.3 (b) nicht nur auf Tochter-, sondern auch auf Gemeinschafts- sowie assoziierte Unternehmen (ja sogar, vgl. z.B. IAS 21.8 und 11, auf Betriebsstätten). Angesichts der tendenziell fehlenden steuerlichen Relevanz des Stufenkonzeptes (vgl. Kap. V.2.3.2) wird hier aber vereinfachend auf Tochterunternehmen abgestellt.

2 Vor der Überarbeitung von IAS 21 Ende 2003 wurden diese beiden Sachverhalte als „foreign entities“ und „foreign operations“ explizit gegenübergestellt; seitdem spricht IAS 21 nur noch übergreifend von „foreign operations“; die entsprechende Unterscheidung findet sich noch indirekt in IAS 21.11; vgl. IAS 21.IN9. Allerdings gehen die in IAS 21.9 genannten Kriterien in Zweifelsfällen It. IAS 21.BC9 den in IAS 21.10-11 genannten prinzipiell vor.

3 Bei stark schwankenden Wechselkursen wird die Verwendung von Durchschnittskursen in IAS 21.40 allerdings als ungeeignet erachtet. 
der Vorversion von IAS 21 ist diesbezüglich noch vorgeschrieben worden, diese Bestandteile mit den Kursen umzurechnen, die aus Gruppensicht zum Zeitpunkt ihres Zugangs galten, oder, vereinfachend, die im Vorjahr vorhandenen Eigenkapitalbestandteile aus dem umgerechneten Vorjahresabschluss zu übernehmen. Dies ist nach gegenwärtigem Stand wohl weiterhin möglich. Alternativ ist aber auch ihre Umrechnung zum Stichtagskurs denkbar ${ }^{1}$.

Um den Fremdwährungsabschluss eines unselbständigen Tochterunternehmens in die funktionale Währung (Berichtswährung) umzurechen, sieht IAS 21 mit der Zeitbezugsmethode ein alternatives Verfahren vor. Dieses beruht letztlich auf den gleichen Grundsätzen, die auch für die Umrechnung einzelner Fremdwährungstransaktionen gelten, denn als solche werden sämtliche Transaktionen des Tochterunternehmens auch behandelt: Hiernach ist der Fremdwährungsabschluss so in die funktionale Währung zu transformieren, als wären die einzelnen Transaktionen originär in dieser Währung verbucht und bilanziert worden (IAS 21.34). IAS 21.21 verlangt diesbezüglich im Erstbewertungs- bzw. Transaktionszeitpunkt die Umrechnung zum aktuellen Kassakurs. An den Folgestichtagen greift die Zeitbezugsmethode nach IAS 21.23-34, die die Währungsumrechnung äquivalent zur Folgebewertung fortführt ${ }^{2}$. Bei der Umrechnung ist danach zu differenzieren, ob monetäre oder nicht-monetäre Posten betroffen sind $^{3}$. Während erstere mit dem Stichtagskurs umzurechnen sind, erfolgt die Umrechnung der nicht-monetären Posten in Abhängigkeit davon, ob sie zu historischen Werten oder zum beizulegenden Zeitwert bewertet werden. Dem Prinzip des Zeitbezugs folgend werden erstere zum historischen Wechselkurs des Transaktionszeitpunktes umgerechnet. Letzteren liegt hingegen der Wechselkurs desjenigen Zeitpunktes zu Grunde, in dem der beizulegende Zeitwert bestimmt worden ist. Im Regelfall ist das der Bilanzstichtagskurs (IAS 21.23). Wird der Buchwert eines nicht-monetären Postens auf eine außerordentliche Wertminderung (impairment) überprüft, so hat der z.B. nach IAS 36 „Impairment of Assets" notwendige Wertminderungstest auch die Wechselkursentwicklung zu berücksichtigen (IAS 21.25) ${ }^{4}$.

Die Behandlung der Umrechnungsdifferenzen orientiert sich gleichermaßen an dieser Systematik. Die aus monetären Positionen abgeleiteten Umrechnungsdifferenzen sind

1 Vgl. Küting/Wirth (Umrechnung, 2003) S. 380. Vgl. zur modifizierten Stichtagskursmethode nach IAS 21 auch Oechsle/Müller/Doleczik (IAS 21, 2002) Tz. 69-93 (insb. Tz. 70); Pellens/Fülbier/Gassen (Internationale Rechnungslegung, 2004) S. 612-615 jeweils mit vertiefenden Beispielen.

2 Vgl. zum „Äquivalenzprinzip“ insb. Busse von Colbe (Umrechnung der Jahresabschlüsse, 1972) S. 311-313, 327-330.

3 Vgl. hierzu auch IAS 21.16, der monetäre Posten charakterisiert und mit Beispielen konkretisiert.

4 Vgl. ausfuihrlicher zu der hier nur knapp dargestellten Zeitbezugsmethode nach IAS 21.23 Oechsle/Müller/Doleczik (IAS 21, 2002) Tz. 55-68; Pellens/Fülbier/Gassen (Internationale Rechnungslegung, 2004) S. 603-611 jeweils mit vertiefenden Beispielen; vgl. grundlegend zu dieser Methode Busse von Colbe (Umrechnung der Jahresabschlüsse, 1972); Lorensen (Temporal Principle, 1972). 
ergebniswirksam zu behandeln (IAS 21.28). Bei Differenzen aufgrund nicht-monetärer Positionen kommt es darauf an, ob diese Positionen selbst ergebnisneutral oder ergebniswirksam behandelt werden. Analog verhält es sich mit den korrespondierenden Umrechnungsdifferenzen (IAS 21.30) ${ }^{1}$.

\subsection{Eignung für die konsolidierte steuerliche Gewinnermittlung}

Im Folgenden soll der Frage nachgegangen werden, ob die vorbereitenden Maßnahmen nach IFRS für Zwecke der konsolidierten steuerlichen Gewinnermittlung taugen. In einem ersten Schritt wird versucht, diese Frage für die Vereinheitlichung der Bilanzierungsgrundsätze und Stichtage zu beantworten (Kapitel V.3.2.1). Anschließend werden die Bestimmungen von IAS 21 zur Währungsumrechnung untersucht (Kapitel V.3.2.2).

\subsubsection{Einheitliche Bilanzierungsgrundsätze und Stichtagsidentität}

Die Vereinheitlichung der Bilanzierungsgrundsätze ist ebenso Ausfluss der Einheitstheorie wie die Stichtagsidentität. Da die steuerliche Gesamtgewinnermittlung als Einzelgewinnermittlung der gesamten Unternehmensgruppe definiert worden ist, muss der Gewinn dieser Gruppe und der darauf basierenden rechnungslegenden Einheit auch unter gleichen Bedingungen, insbesondere auf der Basis einheitlicher Regeln und einheitlicher Zeiträume, ermittelt werden ${ }^{2}$. So basiert schon das Prinzip der rechnungslegenden Einheit nicht nur auf einer Grenzziehung nach außen, sondern auch auf einer einheitlichen Gewinnermittlung im Inneren. Schließlich würde auch eine Einheitsunternehmung für unterschiedliche Betriebsabteilungen keine unterschiedlichen Regeln oder Gewinnermittlungszeiträume verwenden können. Wenn eine Gruppenbesteuerung auf der Basis einer Gesamtgewinnermittlung gewollt ist, kann eine Andersbehandlung kaum gerechtfertigt werden. Die diesbezüglichen Normen von IAS 27 gehen demnach mit Anforderungen an die konsolidierte steuerliche Gewinnermittlung vollauf konform.

Die Notwendigkeit einer „Steuerbilanz $\mathrm{II}^{\text {“ }}$ ist damit immer dann gegeben, wenn keine einheitlichen Bilanzierungsgrundsätze angewendet worden sind oder unterschiedliche Besteuerungsabschnitte existieren ${ }^{3}$. Letzteres würde wohl auch dem Prinzip der Abschnittsbesteuerung widersprechen, wonach das Einkommen der Unternehmensgruppe für eine vom Fiskus fest definierte und natürlich einheitliche Besteuerungsperiode zu

1 Der in IAS 21.32 geregelte Sonderfall eines „net investment in a foreign operation“ wird hier nicht betrachtet.

2 Vgl. dazu auch Kap. III.1.

3 Vgl. Oberndorff (Konzernbesteuerung, 1996) S. 110; Reis (Körperschaftsbesteuerung des Konzerns, 1996) S. 240-241; hinsichtlich der Stichtagsidentität auch Grotherr (Konzernsteuerrecht, 1995) S. 8990; Mühlschlegel (Gewinnermittlung für Konzerne, 1971) S. 107-108. 
ermitteln und zu versteuern ist ${ }^{1}$. Ein auf die konsolidierte steuerliche Gewinnermittlung übertragenes Vereinheitlichungsgebot hätte hier auch den Vorteil, dass die Stichtagsidentität nicht alternativ als Einbeziehungsvoraussetzung festgeschrieben werden müss$t^{2}$. Dies würde nur zusätzliche Selbsteinsteuerungsmöglichkeiten schaffen, da eventuell existierende Freiheitsgrade bei der Wahl des Besteuerungsabschnitts zur Beeinflussung des Konsolidierungskreises genutzt werden könnten. Die mit der Aufstellung von Zwischenabschlüssen einhergehende Mehrarbeit dürfte ohnehin zu einer (freiwilligen) Vereinheitlichung der Stichtage innerhalb der Gruppe führen ${ }^{3}$.

Die Steuerbilanz II sollte allerdings nicht der Neuausübung von Wahlrechten dienen. Die Existenz von Wahlrechten ist aus Sicht normativer steuerlicher Anforderungen schon generell schwer zu rechtfertigen. Deshalb sind sie bereits in der Steuerbilanz I und somit auch in der Steuerbilanz II und insbesondere noch in jeweils unterschiedlicher Ausübung abzulehnen ${ }^{4}$.

Die im Rahmenkonzept oder, bei der Frage der Stichtage, in IAS 27.26 legitimierten Abweichungen von dem Vereinheitlichungsgebot zielen letztlich allesamt auf den Grundsatz der Wesentlichkeit bzw. Wirtschaftlichkeit. Die Frage der diesbezüglichen steuerlichen Eignung kann - wie bereits skizziert ${ }^{5}$ - nur unter Abwägung mit durchführungsorientierten Effizienzargumenten beantwortet werden. Eine eindeutige Antwort erscheint auch hier kaum möglich. Zumindest bedarf es der zusätzlichen Konkretisierung der entsprechenden Ausnahmetatbestände, um eine objektive und rechtssichere Handhabung in der steuerlichen Konsolidierung zu gewährleisten.

Die Regulierungen der vier EU-Konsolidierungsstaaten stützen die steuerliche Notwendigkeit eines Vereinheitlichungsgebotes, so wie es letztlich auch in IAS 27 zum Ausdruck kommt. Bei den dort nur gebildeten „Inlandsgruppen“ wird die Einheitlichkeit regelmäßig vorausgesetzt oder, wie in Spanien, explizit auch für Bilanzierungsgrundsätze vorgeschrieben. In allen vier Gruppenbesteuerungssystemen müssen die Dauer und

1 Vgl. Kirchhof (Auftrag zur Besteuerung, 1985) S. 329; vgl. Kap. II.2.2.2.

2 Vgl. dies fordernd z.B. Senger (Konzernertragsbesteuerung, 1997) S. 149. Wahrscheinlich ist dies auch eine Voraussetzung der vier EU-Konsolidierungsstaaten; vgl. so auch Müller (Konzernbesteuerung, 1991) S. 133-134. Diese Diskussion würde sich mit einer etwaigen Harmonisierung der Besteuerungsperioden in der EU, z.B. in Richtung des Kalenderjahres, indes erübrigen.

3 Vgl. so bereits Busse von Colbe (Jahresabschluß des Konzerns, 1960) S. 147.

4 Vgl. Reis (Körperschaftsbesteuerung des Konzerns, 1996) S. 240-241; a.A. wohl Salzberger (Konzernunternehmung, 1994) S. 163-165. Ohne die Neuausübung von Wahlrechten wäre die von Grotherr (Konzernsteuerrecht, 1995) S. 93 geforderte Maßgeblichkeit der steuerlichen Einzelgewinnermittlungen für die Gesamtgewinnermittlung wegen eines ansonsten fehlenden (Konzern-)Bilanzzusammenhangs zumindest dann gewahrt, wenn in beiden Rechnungen dasselbe Gewinnermittlungssystem zum Tragen käme. Davon ist angesichts der unterschiedlichen EU-Systeme allerdings nicht auszugehen.

5 Vgl. bereits Kap. V.2.2.1.5.2 
der Stichtag der Gewinnermittlungsperioden der einbezogenen Unternehmen zudem übereinstimmen ${ }^{1}$.

\subsubsection{Währungsumrechnung}

Durch die wohl zwingende Beschränkung des steuerlichen Konsolidierungskreises auf die EU ist das Währungsumrechnungsproblem zum gegenwärtigen Zeitpunkt zwar begrenzt, aber, wohl auch mittelfristig, immer noch vorhanden. Da der Rechtsraum der EU über denjenigen der „Maastricht-“ bzw. „Euro-Staaten“ hinausreicht, sind neben dem Euro auch Fremdwährungen, wie z.B. das britische Pfund oder die dänische Krone, möglich. Insofern bedarf die grenzüberschreitende steuerliche Gesamtgewinnermittlung auch in der EU einer Form der Fremdwährungsumrechnung für die betreffenden Einzelgewinnermittlungen ${ }^{2}$.

Fraglich ist, ob das in IAS 21 festgelegte Konzept der funktionalen Währung mit der modifizierten Stichtagskursmethode und der Zeitbezugsmethode auch für steuerliche Zwecke tragfähig ist. In diesem Zusammenhang fällt bereits auf, dass das Konzept der funktionalen Währung und die dahinter stehende Vorstellung unterschiedlicher Autonomiegrade bei Tochterunternehmen nicht unmittelbar mit der hier entwickelten ökonomischen Sicht der Unternehmung harmoniert. Dies betrifft das ,weitgehend selbständig agierende“ Tochterunternehmen, das eher ein Fremdkörper in einer hierarchischen Gruppenstruktur zu sein scheint und bei dem schon die Zugehörigkeit zum steuerlichen Konsolidierungskreis in Frage steht ${ }^{3}$. Dem könnte allerdings entgegen gehalten werden, dass ein gewisser, auch größerer Autonomiegrad einer sachlichen Subzentraleinheit keineswegs mit der Vorstellung residualer Eigentums- und Kontrollrechte kollidiert. Residuale Rechte dieser Art zu besitzen, bedeutet auch, sie nicht und schon gar nicht in operativen Belangen ausüben zu müssen. Gleiches gilt für das mit dieser Vorstellung harmonierende Konzept der Beherrschungsmöglichkeit, das in IAS 27 festgelegt ist und - wie bereits diskutiert ${ }^{4}$ - auch für steuerliche Zwecke geeignet sein dürfte.

Fraglich ist jedoch, ob es aus steuerlicher Sicht einer Differenzierung hinsichtlich der Umrechnungsmethoden bedarf, wenn letztlich alle einbezogenen Unternehmen im ökonomischen Eigentum der Hierarchiespitze stehen und nur der Grad ihrer tatsächlichen Beherrschung variiert. In der Grundkonzeption folgt IAS 21 der Vorstellung, dass das relativ autonome Tochterunternehmen über die modifizierte Stichtagskursmethode in

\footnotetext{
Vgl. Kap. IV.1.2.2.

Vgl. ansatzweise auch Reis (Körperschaftsbesteuerung des Konzerns, 1996) S. 241; Salzberger (Konzernunternehmung, 1994) S. 165, der allerdings auf die abnehmende Relevanz durch die europäische Währungsunion verweist.

3 Vgl. ähnlich bereits Busse von Colbe/Ordelheide (Konzernabschlüsse, 1993) S. 143-144; McLure (Unitary Business, 1984) S. 104-105.

4 Vgl. Kap. V.2.2.2.
} 
seiner bereits in der funktionalen Währung abgebildeten finanziellen Struktur unverändert, über eine modifizierte Lineartransformation' in die Berichtswährung der Gruppe überführt werden soll. Demgegenüber wirkt die Zeitbezugsmethode insbesondere in ihrer Ausrichtung am Äquivalenzprinzip ${ }^{2}$ wie ein Bewertungsvorgang hinsichtlich der Fremdwährungstransaktionen im Tochterunternehmen ${ }^{3}$, so dass sie in IAS 21.20-34 konsequenterweise auch für Einzeltransaktionen (foreign currency transactions) vorgeschrieben ist.

Sofern die Frage nach der steuerlichen Eignung dieser beiden Methoden vorerst zurückgestellt wird, bleiben bereits Zweifel an dem Sinn dieser Methodenpluralität in IAS 21. Diese Zweifel begründen sich schon aus der Einschätzung, dass trotz der in IAS 21.9-14 festgelegten Kriterien letztlich die Hierarchiespitze der Unternehmensgruppe über die funktionale Währung des jeweiligen Tochterunternehmens bestimmt. Einerseits sind die festgelegten Kriterien vergleichsweise unbestimmt ${ }^{4}$. Andererseits kann die Hierarchiespitze den tatsächlichen Beherrschungsgrad leicht variieren, so dass der Selbsteinsteuerung durch Methodenwahl bei der Währungsumrechnung Tür und Tor geöffnet werden. Aber auch unter Ausblendung des Selbsteinsteuerungsvorwurfs kann die Methodenpluralität nicht recht überzeugen, da sie letztlich nur über den jederzeit veränderbaren tatsächlichen Beherrschungsgrad gerechtfertigt wird. Wenn demgegenüber - wie in IAS 27 - nur auf die binär zu beantwortende Frage der Beherrschungspotenziale abgestellt würde, könnte die nicht immer einfache Bestimmung der funktionalen Währung entfallen, da es ohnehin nur noch einer Umrechnungsmethode bedürfte. Dies ginge auch mit einem Vorteil bei der Durchführungseffizienz einher.

Bei der Frage, welche der in IAS 21 vorgesehenen Methoden für Zwecke einer steuerlichen Gesamtgewinnermittlung geeignet sein können, ist zu beurteilen, ob es einer Lineartransformation oder eines Bewertungsvorgangs bedarf. Letzterer ist mit der Zeitbezugsmethode verbunden ${ }^{5}$. Dabei steht diese Methode eher für bewertungstechnische Konsequenz als für eine eigene originäre Bewertungsregel, da die Umrechnungskurse letztlich „nur" dem Zeitbezug der Gewinnermittlungsposten und damit originären Bewertungsregeln folgen ${ }^{6}$. Insofern wäre auch vorstellbar, diese Methode z.B. mit dem

1 Vgl. insb. von Wysocki (Weltbilanzen, 1973) S. 692, der eine „lineare Transformation von Systemen kardinaler Meßwerte" identifiziert.

2 Vgl. Busse von Colbe (Umrechnung der Jahresabschlüsse, 1972) S. 311-313, 327-330.

3 Vgl. insb. Lorensen (Temporal Principle, 1972) S. 49.

4 Vgl. Busse von Colbe et al. (Konzernabschlüsse, 2003) S. 187-188, die hier zu Recht ein ,verstecktes Wahlrecht" erkennen.

5 So zeigt sich an dieser wie auch an späterer Stelle die schwer trennbare Verzahnung von Ansatz, Bewertung und Konsolidierung bzw. ihren vorbereitenden Maßnahmen. Vgl. hierzu insb. die Diskussion i.R.d. Kapitalkonsolidierung in Kap. V.4.2.2.

6 Über diesen Zeitbezug wird z.B. eine am Anschaffungswert- und Niederstwertprinzip orientierte Umrechnung gewährleistet; alternativ könnte sie aber auch der „full fair value“-Bilanzierung entsprechen. 
Konzept des realisierten Reinvermögenszugangs zu kombinieren - eine Vorstellung, die bei der Stichtagskursmethode nicht funktioniert. Auch spricht einiges dafür, dass die Zeitbezugsmethode einheitstheoretisch konsequent(er) verfährt, da sie die Unternehmen wie Betriebsabteilungen behandelt, deren Transaktionen wie in einer Einheitsunternehmung umgerechnet würden. Die Einhaltung gültiger Bewertungsregeln auch bei der Währungsumrechnung über die Zeitbezugsmethode wird sogar von der deutschen Finanzrechtsprechung gefordert ${ }^{1}$. In Abstimmung z.B. mit dem Konzept des realisierten Reinvermögenszugangs müsste der Realisationszeitpunkt der Währungsumrechnung zur Vermeidung unrealisierter Erträge angepasst werden. Gleiches gilt für die imparitätische Vorwegnahme von Währungsverlusten ${ }^{2}$.

Die Zeitbezugsmethode geht aber auch mit einem nicht unerheblichen Komplexitätsgrad einher, der aus durchführungseffizienter Sicht zu berücksichtigen ist. Diesbezüglich kann die modifizierte Stichtagskursmethode als Lineartransformation klare Effizienzvorteile aufweisen ${ }^{3}$, die sich im Übrigen für die reine Variante dieser Methode ${ }^{4}$ noch verstärken. Die fehlenden Vorschriften zur Eigenkapitalumrechnung erscheinen dabei wenig hinderlich, da sie die kerngrößenorientierte steuerliche Gewinnermittlung ohnehin nicht tangieren. Dafür fehlt es dieser Methode aber an Bewertungskonsequenz. Zudem geht diese Methode und die mit ihr verbundene Vorstellung einer von der Hierarchiespitze akzeptierten Form einer gewissen tatsächlichen Autonomie an der ökonomischen Natur der zuvor abgegrenzten Unternehmensgruppe vorbei. Aus Sicht der kon-

1 Vgl. insb. BFH v. 13.9.1989 (IR 117/87). In diesem Urteil hat der BFH für die Umrechnung der unmittelbar zuzurechnenden Abschlüsse ausländischer Personengesellschaften zwar ein Methodenwahlrecht vorgegeben, die Umrechnung aber an die Befolgung gültiger Bilanzierungsgrundsätze gebunden, so dass eigentlich nur die Zeitbezugsmethode zur Anwendung kommen kann; vgl. zu dieser Interpretation Busse von Colbe/Ordelheide (Konzernabschlüsse, 1993) S. 139, 141, 146; neutraler Haiß (Gewinnabgrenzung zwischen Betriebsstätten, 1999) S. 317-353, die bei der Übernahme eines in Fremdwährung erstellten Betriebsstättenabschlusses letztlich doch der (modifizierten) Stichtagskursmethode zuneigt. Zudem zeigt sie empirisch auf, dass letztere in der Praxis mit $78 \%$ gegenüber der Zeitbezugsmethode (mit 22\%) dominiert (S. 337); empirische Befunde zur Währungsumrechnung in der handelsrechtlichen Konzernrechnungslegung liefern z.B. Gelhausen/Mujkanovic (Auswertung, 1995). Vgl. zu weiteren Hinweise auf die Finanzrechtsprechung Jacobs (Internationale Unternehmensbesteuerung, 2002) S. 659; zur Methodenabwägung in der kommentierenden Steuerliteratur m.w.N. Bovermann (Umrechnung, 1988) S. 144-155 mit Hinweisen auch auf andere EU-Staaten (S. 157-195).

2 Vgl. deshalb eher kritisch Jacobs (Internationale Unternehmensbesteuerung, 2002) S. 659-661.

3 Vgl. ähnlich Haiß (Gewinnabgrenzung zwischen Betriebsstätten, 1999) S. 325, 336, 340, die die Einfachheit auch als zentrales Motiv für die praktische Relevanz dieser Methode identifiziert. Hinsichtlich der fehlenden Bewertungskonsequenz ist es für sie ausreichend, wenn der Fremdwährungsabschluss an sich (und nicht auch noch die Umrechnung) geforderten Bewertungsgrundsätzen entspricht.

4 Vgl. zu weiteren Gründen für diese Variante u.a. von Wysocki (Weltbilanzen, 1973) S. 691-693. 
solidierten steuerlichen Gewinnermittlung ist auch nach Sinn und Eignung ergebnisneutral verbuchter Umrechnungsdifferenzen zu fragen ${ }^{1}$.

$\mathrm{Zu}$ der Frage der Fremdwährungsumrechnung von Einzelgewinnermittlungen liegen Erkenntnisse auf europäischer Ebene nicht vor, da sich alle vier Konsolidierungsstaaten bei der Gruppenbesteuerung auf „Inlandsgruppen“ beschränken ${ }^{2}$. Insofern kann zu IAS 21 abschließend nur festgehalten werden, dass das Konzept der funktionalen Währung steuerlich nicht recht überzeugt und wohl in Richtung eines Methodenmonismus abgeändert werden müsste. Theoretisch konsequent erscheint hierfür die Zeitbezugsmethode, deren höhere Komplexität gegenüber der Stichtagskursmethode jedoch kaum zu leugnen ist.

\section{Konsolidierungsmaßnahmen}

\subsection{Konsolidierungskonzeption nach IFRS}

Angesichts verbleibender Zweifel an der Eignung des Stufenkonzeptes für Zwecke der konsolidierten steuerlichen Gewinnermittlung beschränkt sich die folgende Betrachtung auf einen steuerlichen Konsolidierungskreis, der nur diejenigen Ressourcen der Unternehmensgruppe umfasst, die in dem vollständigen ökonomischen Eigentum der Hierarchiespitze stehen. In Bezug auf das IFRS-Konsolidierungskonzept geht es also um die Einbeziehung von Tochterunternehmen, die - wie bereits aufgezeigt - auch rechtlich unselbständige Einheiten umfassen können, die einer eigenen Einzelgewinnermittlung unterliegen (subsidiaries, separate entities, businesses ${ }^{3}$ ).

IAS 27 folgt hier dem Konzept der Vollkonsolidierung ${ }^{4}$. Nach entsprechender Vereinheitlichung der Einzelabschlüsse sind diese Tochterunternehmen ,line by line by adding together like items of assets, liabilities, equity, income and expenses ${ }^{655} \mathrm{zu}$ einem Summenabschluss zusammenzufassen. Anschließend greifen die eigentlichen Konsolidie-

1 So hat z.B. Ordelheide (Nominalkapitalerhaltung durch die Währungsumrechnung, 1994) S. 799-807 aufgezeigt, dass die ergebniswirksame Behandlung der (bilanziellen) Umrechnungsdifferenz eine notwendige und hinreichende Voraussetzung der (Konzern-)Einlageerhaltung ist. Er fordert deshalb auch für die steuerliche Gewinnermittlung eine ergebniswirksame Verrechnung (S. 816-817). Vgl. ebenfalls kritisch zur ergebnisneutralen, das Kongruenzprinzip verletzenden Differenzverrechnung Bernhard (Währungsumrechnung und Kongruenz, 2001); Busse von Colbe et al. (Konzernabschlüsse, 2003) S. 172; ansatzweise auch Busse von Colbe (Konzernabschluß als Bemessungsgrundlage, 1987) S. 75; a.A. wohl Jacobs (Internationale Unternehmensbesteuerung, 2002) S. 660-661.

2 Wenn ausländische Unternehmen im dänischen Zurechnungsmodell oder im französischen ,bénéfice consolidé" berücksichtigt werden, orientiert sich die Umrechnung der zugerechneten Ergebnisbestandteile aber eher an Stichtagskursen; vgl. Bovermann (Umrechnung, 1988) S. 162, 166-167.

3 Das sind die diesbezüglich in IAS 27 und IFRS 3 verwendeten Begriffe. Wie in den vorherigen Ausführungen auch, wird dafür regelmäßig der Begriff des Tochterunternehmens benutzt.

4 Vgl. insb. IAS 27.22-25.

5 IAS 27.22 . 
rungsmaßnahmen, wie die Kapital- und Schuldenkonsolidierung, Zwischenergebniseliminierung sowie Aufwands- und Ertragskonsolidierung, so dass unter Rückgriff auf Abb. 10 in Kapitel IV.1.1 sämtliche vier Voraussetzungen einer konsolidierten Gesamtgewinnermittlung erfüllt werden. Unabhängig von der Beteiligungs- oder Stimmrechtsquote werden die Einzelabschlusspositionen in dem Summenabschluss voll erfasst und, sofern auf gruppeninternen Transaktionen beruhend, im Rahmen etwaiger Konsolidierungsmaßnahmen auch in voller Höhe eliminiert'. Minderheitenanteile am NettoBetriebsvermögen und Ergebnis werden dabei separat im Eigenkapital (IAS 27.22(c)) bzw. in der Gewinn- und Verlustrechnung (IAS 27.22(b)) berücksichtigt.

IAS 27.22 folgt mit dieser Form der Vollkonsolidierung in weiten Teilen der Einheitstheorie (,consolidated financial statements present financial information about a group as that of a single economic entity ${ }^{“ 2}$ ). Besonders deutlich kommt dies in dem Ausweis der Minderheitenanteile im Eigenkapital zum Ausdruck ${ }^{3}$. Mehrheits- wie Minderheitsgesellschafter werden dort als gleichberechtigte Eigenkapitalgeber der Unternehmensgruppe betrachtet, auch wenn weiterhin ein separater Ausweis verlangt wird ${ }^{4}$. Selbiges gilt für die Gewinn- und Verlustrechnung. Der Minderheitenanteil wird dort nicht als Aufwand aufgefasst, sondern eher als eine Art Gewinnverteilungskomponente. Die Umsetzung der Einheitstheorie ist allerdings nicht immer konsequent. Wie die folgenden Ausführungen zeigen, folgen die Konsolidierungsmaßnahmen im großen Ganzen, nicht jedoch in jedem Detail der Einheitstheorie.

Vgl. insb. IAS 27.24-25.

IAS 27.22; ähnlich auch IAS 27.4.

3 Diese Ausweisregel ist erst durch das Improvements Project 2003 in IAS 27 eingeflossen. Zuvor mussten die Minderheitenanteile separat vom Eigenkapital und von den Schulden ausgewiesen werden (,mezzanine Präsentation“). Nunmehr vollzieht das IASB eine klarere Hinwendung zur Einheitstheorie. Es stellt explizit heraus, dass ,a minority interest is not a liability of a group because it does not meet the definition of a liability" (IAS 27.BC24). "Rather the Board noted that a minority interest represents the residual interest in the net assets of those subsidiaries held by some of the shareholders of the subsidiaries within the group, and therefore meets the Framework's definition of equity" (IAS 27.BC26). Auch in der Literatur ist eine verstärkte einheitstheoretische Ausrichtung des IASB erkannt worden; vgl. z.B. Busse von Colbe (Einheitstheorie für den Konzernabschluss, 2004). Eine „einheitstheoretische Kehrtwende" möchte allerdings Pawelzik (Phase II, 2004) S. 693 darunter nicht verstehen, weil er die einheitstheoretische Ausrichtung der IFRS schon seit der Grundsatzentscheidung für die Vollkonsolidierung als feststehend erachtet.

4 In konsequenter Fortführung der Einheitstheorie wäre noch nicht einmal das notwendig; vgl. so auch Baetge/Kirsch/Thiele (Konzernbilanzen, 2002) S. 14. 


\subsection{Kapitalkonsolidierung}

\subsubsection{Regulierung auf der Grundlage der IFRS}

\subsubsection{1 'Business Combinations - Phase I' als Stand der Regulierung}

Die Kapitalkonsolidierung wird in IFRS 3 „Business Combinations“ geregelt. Dieser im März 2004 herausgegebene Standard schließt eine erste Phase des gleichnamigen Projekts ab, innerhalb dessen das IASB insbesondere IAS 22 als Vorgängerregel vollständig aufgehoben und durch IFRS 3 ersetzt hat ${ }^{1}$. IFRS 3 reguliert, wie zuvor IAS 22, die bilanzielle Abbildung von Unternehmenszusammenschlüssen (business combinations). Diese liegen nach IFRS 3.4 immer dann vor, wenn separierte (Unternehmens-)Einheiten (,separate entities or businesses“) ${ }^{2}$ zu einer rechnungslegenden Einheit zusammengeschlossen werden, weil ein (Mutter-)Unternehmen als Käufer die bereits in IAS 27 definierte Beherrschung ${ }^{3}$ über mindestens ein (Tochter-) Unternehmen erlangt ${ }^{4}$. Unter einem Unternehmenszusammenschluss versteht IFRS 3.5 nicht nur das mittelbare Wachstum über den Beteiligungs- bzw. Stimmrechtserwerb (share deal), sondern auch das unmittelbare Wachstum über den Erwerb der entsprechenden Wirtschaftsgüter (asset deal). Letzteres beinhaltet neben der Verschmelzung (Fusion) auch die Fälle, in denen sich der Erwerb nur auf abgrenzbare Teilbereiche eines Unternehmens (businesses) bezieht ${ }^{5}$.

In IFRS 3 hat sich das IASB mit der Erwerbsmethode (purchase method) auf eine einzige Methode der Kapitalkonsolidierung festgelegt (IFRS 3.14). Die in IAS 22 noch vorgesehene Interessenzusammenführungsmethode (pooling of interests method) im Falle eines aktientauschbasierten Zusammenschlusses zweier in etwa gleich großer Unter-

1 IFRS 3 wurde am 31. März 2004 herausgegeben und ist seit diesem Datum auch anzuwenden (IFRS 3.78). Mit IFRS 3 werden IAS 22 „Business Combinations“ sowie SIC-9 „Business Combinations Classification either as Acquisitions or Unitings of Interests", SIC-22 "Business Combinations Subsequent Adjustment of Fair Value Values and Goodwill Initially Reported" und SIC-28 "Business Combinations - 'Date of Exchange' and Fair Value of Equity Instruments" ersetzt (IFRS 3.IN1 und IFRS 3.86-87).

2 Obwohl in der (offiziellen) deutschen Übersetzung (IAS 22) von Unternehmenszusammenschlüssen gesprochen wird, ist IFRS 3 - wie bereits IAS 27 - nicht nur auf Unternehmen im Sinne selbständiger Rechtsträger festgelegt. Der hier relevante „,business“-Begriff wird in IFRS 3, Appendix A näher definiert; vgl. dazu auch Hommel/Benkel/Wich (IFRS 3, 2004) S. 1267-1268. Der Einfachheit halber wird im Folgenden dennoch, wie in den Vorkapiteln auch, auf den Unternehmensbegriff abgestellt.

3 IFRS 3.19 und IFRS 3, Appendix A, definieren „,control“ fast wortgleich, ergänzen den „entity“Begriff allerdings noch durch den „business“-Begriff, so dass sich das Spektrum der beherrschten Objekte tendenziell erweitert.

4 Der Einfachheit halber werden die deutschen Begriffe Mutter- und Tochterunternehmen hier beibehalten, obwohl sie angesichts von Terminologie und Anwendungsbereich in IAS 27 und IFRS 3 sowie der darauf gestützten Erwägungen in Kap. V.2.2.1.2 eher zu eng umrissen sind.

5 IFRS 3.5 sieht auch weitere Differenzierungen z.B. nach Art der Gegenleistung vor; vgl. dazu ausführlicher Pellens/Fülbier/Gassen (Internationale Rechnungslegung, 2004) S. 624-626. 
nehmen ist damit ersatzlos entfallen ${ }^{1}$. Die Erwerbsmethode bildet die durch Beherrschungsausweitung erforderliche Erweiterung der rechnungslegenden Einheit wie den Erwerb eines Investitionsgutes $\mathrm{ab}^{2}$. IFRS 3.16-23 verlangt in diesem Zusammenhang, bei allen Unternehmenszusammenschlüssen einen Erwerber als beherrschende Instanz zu identifizieren. Dieser Erwerber wird regelmäßig als Mutterunternehmen im Sinne von IAS 27 angesehen, der ein Tochterunternehmen wie ein Investitionsgut erwirbt ${ }^{3}$.

Die Erwerbsmethode basiert auf der Einzelerwerbsfiktion. Hiernach wird der Erwerb des Tochterunternehmens bilanziell wie der einzelne Erwerb sämtlicher Vermögenswerte und Schulden desselben abgebildet ${ }^{4}$. IFRS 3.36 verlangt deshalb, dass zum Erwerbszeitpunkt $^{5}$ die nach IFRS 3.24-35 ermittelten Kosten des Unternehmenszusammenschlusses ${ }^{6}$ auf diese einzelnen Positionen aufgeteilt werden (allocating the cost of a business combination). Im Ergebnis sind alle Vermögenswerte und Schulden des Tochterunternehmens, die den IFRS-Ansatzkriterien genügen ${ }^{7}$, separat zu ihren beizulegenden Zeitwerten zu erfassen. Anzusetzen sind insbesondere auch immaterielle Vermögenswerte und sogar Eventualschulden (contingent liabilities), sofern auch ihr beizulegender Zeitwert verlässlich messbar ist ${ }^{8}$. Dies gilt jeweils unabhängig davon, ob sie in

1 Vgl. so auch IFRS 3.IN3 und IN9, mit Begründung in IFRS 3.BC50-BC53. Vgl. zu der ,pooling of interest method" nach IAS 22 z.B. Sellhorn (Goodwill Impairment, 2004) S. 15-18, 23-24.

2 Vgl. Busse von Colbe et al. (Konzernabschlüsse, 2003) S. 203-204; Ordelheide (Konzernerfolg, 1987) S. 294.

3 Vgl. IFRS 3.6: „A business combination may result in a parent-subsidiary relationship in which the acquirer is the parent and the acquiree a subsidiary of the acquirer" [Hervorhebungen im Original]. Dies ist nach IFRS 3.7 allerdings nicht zwingend, da auch nur ein Unternehmensteil, z.B. ein Geschäftsbereich, erworben werden kann, so dass keine „parent-subsidiary relationship“ entsteht, IFRS 3 aber dennoch Anwendung findet. Im Folgenden wird vom Regelfall der ,parent-subsidiary relationship“ ausgegangen. Zu beachten ist zudem, dass IFRS 3.21 i.V.m. IFRS 3.B1-B15 den Fall der „,reverse acquisition" regelt, wonach das juristisch gesehen erworbene Unternehmen die Beherrschungsmacht erlangt und für bilanzielle Zwecke als Erwerber angesehen wird; vgl. ausführlicher Küting/Müller/Pilhofer (Reverse Acquisitions, 2000).

4 Vgl. zur Einzelerwerbsfiktion u.a. Busse von Colbe et al. (Konzernabschlüsse, 2003) S. 219; Ordelheide (Kapitalkonsolidierung, 1984) S. 240; Ordelheide (Anschaffungskostenprinzip, 1986) S. 493; von Wysocki/Wohlgemuth (Konzernrechnungslegung, 1996) S. 93-95.

5 Vgl. zum ,acquisition date“ IFRS 3.39, wo unabhängig vom rechtlichen Kaufzeitpunkt auf die Erlangung der Beherrschungsmöglichkeit abgestellt wird $(, \ldots$ the date on which the acquirer effectively obtains control of the acquiree").

6 Gemäß IFRS 3.24 sind dies die am Akquisitionszeitpunkt ermittelten beizulegenden Zeitwerte der entsprechenden Positionen (,... assets given, liabilities incurred or assumed...“) bzw. der korrespondierenden Eigenkapitalinstrumente, die diesbezüglich vom Käufer zum Erwerb der Beherrschung emittiert worden sind, sowie sämtliche sonstige Kosten, die dem Zusammenschluss direkt zugeordnet werden können.

7 Ergänzend und auch überschneidend $\mathrm{zu}$ den allgemeinen Ansatzkriterien des Rahmenkonzeptes und einzelner IFRS (insb. IAS 38) verlangt IFRS 3.37 einen wahrscheinlichen künftigen Nutzenzu- bzw. -abfluss auf Käuferseite sowie die verlässliche Messbarkeit der entsprechenden beizulegenden Zeitwerte.

8 IFRS 3.45-46 verweisen explizit auf die in IAS 38 festgeschriebenen Ansatzkriterien für immaterielle Werte, insb. auf das Kriterium der Identifizierbarkeit, das Separierbarkeit oder eine vertragliche oder gar gesetzliche Grundlage erfordere (IAS 38.12). 
dem Einzelabschluss des betroffenen Tochterunternehmens zuvor angesetzt worden sind (IFRS 3.44). Bei Restrukturierungsrückstellungen ist IFRS 3 an dieser Stelle restriktiver: Diese dürfen nur passiviert werden, wenn sie bereits beim Tochterunternehmen im Einklang mit IAS 37 angesetzt waren (IFRS 3.41(a)) ${ }^{1}$. Der nach der „cost allocation“ verbleibende, nicht mehr aufteilbare Rest der Kosten des Unternehmenszusammenschlusses ist nach IFRS 3.36 und 3.51 als Goodwill anzusetzen. Sollte indes der Wertansatz der separat identifizierbaren Vermögenswerte und (Eventual-)Schulden diese Kosten übersteigen, schreibt IFRS 3.56 eine wiederholte Identifikations- und Bewertungsphase vor, nach der ein sich weiterhin ergebender Differenzbetrag sofort ergebniswirksam zu verrechnen ist.

IFRS 3 folgt mit dieser Vorgehensweise der Neubewertungsmethode, da stille Reserven oder Lasten in den entsprechenden Vermögenswerten oder Schulden unabhängig von der Existenz etwaiger Minderheitsgesellschafter vollständig aufgedeckt werden. In der handelsrechtlichen Terminologie wird die vereinheitlichte Handelsbilanz II damit in eine zum Erwerbszeitpunkt neu bewertete Handelsbilanz III überführt ${ }^{2}$. Eine nur anteilige Aufdeckung im Sinne der Buchwertmethode, die nach IAS 22 noch zulässig war und dort sogar das bevorzugte Benchmark darstellte ${ }^{3}$, ist mit IFRS 3 abgeschafft worden. In seinem Bestreben, stille Reserven und Lasten konsequent aufzudecken, geht IFRS 3 mit den Vorschriften zur „,cost allocation“ auch deutlich über das Bisherige hinaus. Dabei kommen sogar Eventualschulden als stille Lasten zum Ansatz, die nach IAS 37 „Provisions, Contingent Liabilities and Contingent Assets“ eigentlich nicht angesetzt werden dürfen ${ }^{4}$.

In der Folgekonsolidierung werden die Wertansätze der Vermögenswerte und Schulden entsprechend der für sie vorgesehenen Folgebewertungsverfahren fortgeführt. Im Falle z.B. abnutzbarer Vermögenswerte betrifft dies die planmäßige Abschreibung der im Erstkonsolidierungszeitpunkt ermittelten beizulegenden Zeitwerte oder deren kontinuierliche Neubewertung. Hierbei gelten die entsprechenden Einzelstandards. Außerplan-

Vgl. Pellens/Fülbier/Gassen (Internationale Rechnungslegung, 2004) S. 655.

Vgl. zu dieser Terminologie z.B. Busse von Colbe et al. (Konzernabschlüsse, 2003) S. 210.

An dieser Stelle galt nach IAS 22 ein Wahlrecht, wobei die Buchwertmethode die bevorzugte Alternative (benchmark treatment) und die Neubewertungsmethode nur die zweitbeste Alternative (allowed alternative treatment) darstellte.

4 Der Anwendungsbereich von IAS 37 ist diesbezüglich 2004 beschränkt worden, so dass IFRS 3 als Spezialnorm IAS 37 vorgeht; vgl. IFRS 3.C14. Durch die Voraussetzung der verlässlichen Messbarkeit des beizulegenden Zeitwertes entfällt allerdings eine der in IAS 37.4 genannten Fälle einer Eventualschuld, bei der die Höhe der Verpflichtung nicht ausreichend verlässlich geschätzt werden kann. Damit verbleiben in der konsolidierten Bilanz diejenigen Eventualschulden, die insbesondere hinsichtlich ihrer Eintrittswahrscheinlichkeit und/oder der Wahrscheinlichkeit des Ressourcenabflusses die Ansatzkriterien einer Rückstellung deutlich verfehlen (nicht wahrscheinlich, nur möglich). 


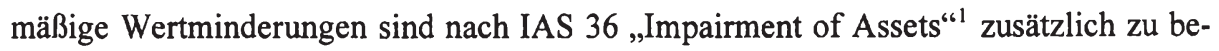
rücksichtigen. Lediglich für Eventualschulden legt IFRS 3 mangels originärer Vorschriften eine eigene Fortführungsregel fest ${ }^{2}$. Im Falle immaterieller Vermögenswerte ist $\mathrm{zu}$ berücksichtigen, dass diejenigen Werte mit einer unbestimmten Nutzungsdauer (indefinite useful life) lediglich auf eine Wertminderung zu überprüfen und gegebenenfalls außerplanmäßig abzuschreiben sind. Diese Vorschrift ist im Zuge der Verabschiedung von IFRS 3 neu in IAS 38 ,Intangible Assets“" eingefügt worden und kann letztlich als Konsequenz der in IFRS 3 neu festgelegten Goodwillbilanzierung nach Maßgabe des ,impairment-only approach“ angesehen werden ${ }^{4}$. Der nach IFRS 3.36 und 3.51 als (immaterieller) Vermögenswert ${ }^{5}$ anzusetzende Goodwill ist hiernach nicht mehr wie noch in IAS 22 - planmäßig abzuschreiben. Statt dessen ist er mindestens einmal jährlich auf seine Werthaltigkeit zu überprüfen und eventuell außerplanmäßig abzuschreiben (IFRS 3.54-55).

Die Goodwillbilanzierung nach Maßgabe des ,impairment-only approach“ richtet sich nach IAS 36 (IFRS 3.55). Hiernach muss der Goodwill (wie alle anderen Vermögenswerte und Schulden) in einem ersten Schritt zuvor identifizierten zahlungsmittelgenerierenden Einheiten (ZGE) zugeordnet werden (allocating goodwill to cash-generating units). Diese Einheit ist nach IAS 36.6 die ,smallest identifiable group of assets that generates cash inflows that are largely independent of the cash inflows from other assets or groups of assets". Sie soll einerseits nicht höher aggregiert sein als ein Segment nach IAS 14 „Segment Reporting“ und andererseits die niedrigste Organisationsebene innerhalb der rechnungslegenden Einheit repräsentieren, für die das Management den (Teil-)Goodwill für Steuerungszwecke ermittelt und überwacht (IAS 36.80) ${ }^{6}$. Bei Hinweisen auf mögliche Wertminderungen, mindestens jedoch einmal jährlich, ist der Goodwill der ZGE auf Werthaltigkeit zu testen. Hierfür muss der Buchwert (carrying

1 IAS 36 (revised 2004) ist am 31. März 2004 zusammen mit IFRS 3 und LAS 38 in einer neu überarbeiteten Version herausgegeben worden und auch seit diesem Datum anzuwenden; vgl. IAS 36.IN1, IN3, IAS 36.138-141.

2 Vgl. IFRS 3.48, der auf den Betrag abstellt, der sich nach IAS 37 ergeben würde, oder, sofern höher, auf den ursprünglich angesetzten Betrag, der nach Maßgabe von IAS 18 „Revenue“ um kumulierte Amortisationen reduziert worden ist.

3 Vgl. insb. IAS 38.107-108, wo bezüglich des Impairment-Tests wieder auf IAS 36 verwiesen wird. IAS 38 (revised 2004) ist am 31. März 2004 zusammen mit IFRS 3 und IAS 36 in einer neu überarbeiteten Version herausgegeben worden und auch seit diesem Datum anzuwenden.

4 Vgl. z.B. IAS 36.IN3, IAS 38.IN2-IN4. Vgl. zur Goodwillbilanzierung nach IFRS 3, ihrer Entwicklung, ausgehend von der US-amerikanischen Goodwillbilanzierung nach SFAS 141 und 142, sowie ihrer Verbindung zur Folgebewertung immaterieller Werte nach IAS 38 u.a. Bieker/Esser (ED 3, 2003); Bieker/Esser (IFRS 3, 2004); Brücks/Wiederhold (IFRS 3, 2004) S. 180-183; Pellens/Sellhorn (Goodwill-Bilanzierung nach US-GAAP, 2001); Pellens/Sellhorn (Goodwill-Bilanzierung, 2001).

5 IFRS 3.51(a) bezeichnet den Goodwill explizit als "asset".

6 Der Hinweis auf eine Art "management approach" fällt auch in IAS 36.82: “... a level that reflects the way an entity manages its operations and with which the goodwill would naturally be associated. Therefore, the development of additional reporting systems is typically not necessary". 
amount) der ZGE einschließlich Goodwill mit dem erzielbaren Betrag (recoverable amount) derselben verglichen werden. Letzterer entspricht nach IAS 36.6 dem beizulegenden Zeitwert abzüglich etwaiger Verkaufskosten ${ }^{1}$ oder, sofern höher, dem Nutzungswert (value in use) des Goodwill. Während ersterer auf einen (Netto-)Transaktionspreis zu Marktbedingungen zielt (IAS 36.25-29), muss letzterer aus diskontierten künftigen Cash-Flows abgeleitet werden (IAS 36.6 und 36.30-32) ${ }^{2}$. Nur wenn der auf diesem Wege ermittelte erzielbare Betrag den Buchwert unterschreitet, fällt ein Wertminderungsaufwand in Höhe dieser Differenz an (IAS 36.88-90). Dieser Wertminderungsaufwand mindert den Buchwert der Vermögenswerte der ZGE und zwar zuerst denjenigen des Goodwill, bevor die anderen Werte gegebenenfalls anteilig abgeschrieben werden (IAS $36 \cdot 104^{3}$ ). Eine spätere Wertaufholung des Goodwill ist ausgeschlossen (IAS 36.124) ${ }^{4}$.

Der nach IFRS 3 zu ermittelnde Goodwill beschränkt sich auf den erworbenen Goodwill. IAS 36.91 stellt klar, dass auch im Fall von Minderheiten, die an der ZGE beteiligt $\operatorname{sind}^{5}$, nur der vom Mutterunternehmen erworbene Goodwill berücksichtigt wird und nicht der insgesamt vom Mutterunternehmen beherrschte. Damit bleibt der auf Minderheiten entfallende Goodwill außer Ansatz. Da der erzielbare Betrag der ZGE allerdings den Minderheitenanteil mit umfasst, verlangt IAS 36.92 für Zwecke des Werthaltigkeitstests eine proportionale Aufstockung des Goodwill-Buchwerts, ehe er dem erzielbaren Betrag gegenübergestellt wird. Die etwaig ermittelte Wertminderung ist dann allerdings wieder aufzuteilen, weil letztlich nur der dem Mutterunternehmen zuzurechnende Anteil als Wertminderungsaufwand berücksichtigt wird (IAS 36.93).

Die Entkonsolidierung ist zumindest teilweise in IAS 27 reguliert. Nach IAS 27.30 ist der Erfolg aus der Veräußerung des Tochterunternehmens durch Vergleich des Veräußerungserlöses mit dem Buchwert des Tochterunternehmens - unter zusätzlicher Berücksichtigung zwischenzeitlich ergebnisneutral verrechneter Umrechnungsdifferenzen aus der Währungsumrechnung - zum Veräußerungszeitpunkt zu ermitteln. Der Buch-

1 In der vorherigen Fassung von IAS 36 (1998) wurde an dieser Stelle der Begriff des Nettoveräußerungspreises (net selling price) verwendet, der diesen Sachverhalt etwas korrekter beschreibt. Abgrenzungsprobleme zwischen dem beizulegenden Zeitwert und Nutzungswert dürften offenkundig sein.

2 Vgl. ergänzend für ZGE auch IAS 36.74-79.

3 Die Grenzen dieser anteiligen Abschreibung werden in IAS 36.105 abgesteckt. So ist es ökonomisch auch wenig sinnvoll, z.B. die Kasse unter ihren Barwert, der wohl dem „fair value“ sowie „value in use" entsprechen würde, zu bewerten.

4 IAS 36.125 weist darauf hin, dass diese Wertaufholung wohl nur aus einem zwischenzeitlich neu generierten originären Goodwill stammen könne und deshalb - angesichts des diesbezuglichen Ansatzverbotes in IAS 38.48 - nicht berücksichtigt werden könne.

5 Minderheitsgesellschafter einer ZGE sind denkbar, wenn die ZGE einem Unternehmen oder einer klar abgegrenzten Gruppe von Unternehmen entspricht, an denen Minderheiten beteiligt sind. Werden die Grenzen der ZGE völlig unabhängig von denjenigen dieser Unternehmen gezogen, wird die Zuordnung der Minderheitenanteile verkompliziert. Denkbar ist z.B. eine proportionale Zuordnung nach Maßgabe der jeweils zugerechneten Unternehmensteile. 
wert des Tochterunternehmens enthält auch den ihm zuzuordnenden Teil des Goodwills (IAS 36.86) ${ }^{1}$.

\subsubsection{Ausblick auf 'Business Combinations - Phase II'}

IFRS 3 gilt nach Meinung des IASB in der im März 2004 vorgelegten Fassung noch nicht als abschließend. Die zweite Projektphase („Business Combinations (Phase II) Application of the Purchase Method“) wird kurz- bis mittelfristig zu einer Modifizierung dieses Standards führen ${ }^{2}$. In dieser zweiten Phase versucht das IASB in Zusammenarbeit mit dem US-amerikanischen Financial Accounting Standards Board (FASB) harmonisierte Vorgaben für die Erwerbsmethode zu entwickeln. Dabei wollen sich IASB wie FASB konsequent(er) an dem beizulegenden Zeitwert als Arbeitsprinzip orientieren $^{3}$. Zwei mögliche Konsequenzen sollen an dieser Stelle eingehender betrachtet werden:

Bereits in der gegenwärtig geltenden Fassung wird der Goodwill nach IFRS 3 für Zwecke des Werthaltigkeitstests in einer Nebenrechnung um die Anteile der Minderheitsgesellschafter erhöht. Diese abgeschwächte Variante der ,full goodwill method“ gewinnt in den Überlegungen der zweiten Projektphase an Konsequenz. Hiernach soll auch der in der konsolidierten Bilanz berücksichtigte Goodwill voll zum beizulegenden Zeitwert angesetzt werden und somit den Minderheitenanteil mit umfassen. Diese konsequentere Form der „full goodwill method“4 bedingt allerdings ein Verfahren zur Ermittlung des gesamten Goodwill einschließlich des Minderheitenanteils. Hierbei ergeben sich zwei Möglichkeiten: Einerseits ist denkbar, von dem bereits erworbenen Goodwill auszugehen, der auf den Gesamt-Goodwill über eine Division durch die Beteiligungsquote line-

1 Vgl. dazu ausführlicher Baetge/Schulze (IAS 27, 2002) Tz. 187-200; Pellens/Fülbier/Gassen (Internationale Rechnungslegung, 2004) S. 673-674.

2 Vgl. IASB (Business Combinations (Phase II), 2004) S. 1-2; IASB (Project Timetable, 2004) mit Hinweis auf Fertigstellung in 2005, woran jedoch gezweifelt werden kann. Neben Phase I und II wird dabei noch das Projekt "Business Combinations: Scope of IFRS 3" verfolgt.

3 Vgl. IASB (Business Combinations (Phase II), 2004) S. 2: "The working principle: In a business combination the total amount to be recognised by the acquirer should be the fair value of the net assets over which it obtains control". Vgl. zur Sicht des FASB FASB (Business Combinations, 2004); FASB (Noncontrolling Interests, 2004); Osborne (Purchase Accounting Issues, 2001).

4 Busse von Colbe et al. (Konzernabschlüsse, 2003) S. 210 sprechen hier von der „reinen“ Neubewertungsmethode, Ordelheide (Kapitalkonsolidierung, 1984) S. 273-274 diskutiert diesen Sachverhalt i.R.d. „Ganzheitsmethode“. Interessanterweise vermutet Küting (Kapitalkonsolidierung, 1995) S. 196 schon für die HGB-Konzernrechnungslegung, dass einige Unternehmen den Minderheitenanteil beim Goodwill hochgerechnet und den Goodwill dann insgesamt ergebnisneutral gegen das Eigenkapital und den Anteil anderer Gesellschaften verrechnet haben. Die rechtliche Basis hierzu verneinen indes Busse von Colbe/Chmielewicz (Bilanzrichtlinien-Gesetz, 1986) S. 337. 
ar hochgerechnet wird. Die Alternative löst sich hingegen von den Erwerbskosten und versucht den Gesamt-Goodwill über Bewertungsverfahren unmittelbar zu ermitteln ${ }^{1}$.

\begin{tabular}{|l|c|c|c|c|c|c|}
\hline & \multicolumn{3}{|c|}{$\begin{array}{c}\text { Aufdeckung stiller Reserven } \\
\text { und Lasten }\end{array}$} & \multicolumn{2}{c|}{ Aufdeckung des Goodwill } \\
\cline { 5 - 8 } & \multirow{2}{*}{ MU } & \multicolumn{2}{|c|}{ TU } & MU & \multicolumn{2}{|c|}{ TU } \\
\cline { 6 - 8 } & & $\mathrm{Me}$ & $\mathrm{Mi}$ & & $\mathrm{Me}$ & $\mathrm{Mi}$ \\
\hline pooling of interests method & - & - & - & - & - & - \\
\hline Buchwertmethode & - & $\mathrm{x}$ & - & - & $\mathrm{x}$ & - \\
\hline Neubewertungsmethode & - & $\mathrm{x}$ & $\mathrm{x}$ & - & $\mathrm{x}$ & - \\
\hline full goodwill method & - & $\mathrm{x}$ & $\mathrm{x}$ & - & $\mathrm{x}$ & $\mathrm{x}$ \\
\hline fresh start method & $\mathrm{x}$ & $\mathrm{x}$ & $\mathrm{x}$ & $\mathrm{x}$ & $\mathrm{x}$ & $\mathrm{x}$ \\
\hline MU= Mutterunternehmen, TU=Tochterunternehmen, Me=Mehrheitsanteil; Mi=Minderheitenanteil & \\
\hline
\end{tabular}

Tab. 6: Kapitalkonsolidierungsmethoden im Vergleich

Quelle: In Anlehnung an Pellens/Basche/Sellhorn (Full Goodwill Method, 2003) S. 2.

Abgesehen von der Tatsache, dass Minderheitenanteile beim Goodwill aufgedeckt werden, entspricht die "full goodwill method“, wie in Tab. 6 verdeutlicht, ansonsten der „normalen“ Neubewertungsmethode. Durch die Berücksichtigung der Minderheitenanteile bei sämtlichen stillen Reserven und Lasten des Tochterunternehmens, einschließlich des Goodwill, wird das erworbene Tochterunternehmen nun vollständig zu beizulegenden Zeitwerten in die konsolidierte Bilanz übernommen.

Kann die „full goodwill method“ damit noch als Ausprägung der Erwerbsmethode angesehen werden, so geht die ebenfalls diskutierte „fresh start method“2 darüber hinaus. Bei dieser Methode wird ein Unternehmenszusammenschluss so abgebildet, dass nicht nur die Vermögenswerte und (Eventual-)Schulden der neu in die rechnungslegende Einheit aufgenommenen Unternehmen zum beizulegenden Zeitwert angesetzt werden, sondern die aller bisher darin enthaltenen Einheiten, also auch des Mutterunternehmens. Sämtliche Vermögenswerte und Schulden des daraus resultierenden konsolidierten Abschlusses werden damit zum beizulegenden Zeitwert bewertet, einschließlich des Goodwills der gesamten in der rechnungslegenden Einheit zusammengefassten Unternehmensgruppe. Die „fresh start method“ impliziert damit eine Abkehr von dem Gedanken der Erwerbsmethode, die letztlich den Kauf eines Investitionsgutes abzubilden versucht. In dem Anwendungsbereich ergeben sich statt dessen Parallelen zu der ebenfalls in Tab. 6 aufgeführten ,pooling of interests method“. So wird dieses Verfahren insbesondere für die Fälle diskutiert, bei denen sich zwei oder mehrere Unternehmen

1 Vgl. IASB (Business Combinations (Phase II), 2004) S. 3, 15; IASB (Purchase Method Procedures, 2004) S. 23-24: dazu auch $F A S B$ (Business Combinations, 2004) S. 23-24, 75 (mit Bezug auf einen „proposed SFAS“ (par. 49) und eine ,implementation guidance“ (par. A79-A81)); Pellens/Basche/Sellhorn (Full Goodwill Method, 2003) S. 2-3.

2 Diese Methode wird z.B. von Busse von Colbe et al. (Konzernabschlüsse, 2003) S. 198-201 „Neugründungsmethode“, von Ordelheide (Konzernerfolg, 1987) S. 300 „new entity method“ genannt. 
zusammenschließen, ohne dass dabei ein Erwerber bzw. Erworbener identifiziert werden kann ${ }^{1}$.

\subsubsection{Eignung für die konsolidierte steuerliche Gewinnermittlung}

\subsubsection{Erwerbsmethode im Allgemeinen}

Wenn die in einer rechnungslegenden Einheit zusammengefasste Unternehmensgruppe in der steuerlichen Gesamtgewinnermittlung im Sinne der Einheitstheorie wie eine einzige Unternehmung abgebildet werden soll, müssen einbezogene Unternehmen mit ihren einzelnen Wirtschaftsgütern erfasst werden. Dabei dürfen Mehrfacherfassungen des eingesetzten Eigenkapitals nicht auftreten. Die Erwerbsmethode garantiert beides und folgt darin der Einheitstheorie. Der auf den Zeitpunkt der Akquisition, genauer: der Erlangung der Beherrschungsmöglichkeit (IFRS 3.39), abstellende Erstkonsolidierungszeitpunkt erscheint dabei konsequent. Dass sie zudem - anders z.B. als in der Vorgängerregel des IAS 22 - die einzig anwendbare Methode der Kapitalkonsolidierung ist, dürfte steuerlich im Hinblick auf eine Wahlrechts- bzw. Selbsteinsteuerungsfreiheit erwünscht sein ${ }^{2}$.

In ihrer Abbildungswirkung fingiert die Erwerbsmethode die Identität zur Verschmelzung bzw. verschmelzenden Umwandlung ${ }^{3}$. Da der Anwendungsbereich von IFRS 3 sowohl ,share deal" als auch ,asset deal" umfasst ${ }^{4}$, ist als Teilmenge des ,asset deal“ auch der tatsächliche rechtliche Vollzug eines Verschmelzungsvorgangs erfasst. Allerdings zeigt sich schon an dieser Stelle ein gravierendes Abstimmungsproblem, weil der primär die Einzelgewinnermittlung betreffende ,asset deal“ seit jeher in den nicht harmonisierten (Umwandlungs-)Steuergesetzen der Mitgliedstaaten reguliert ist. Solange dieses Abstimmungsproblem ungelöst bleibt, dürfte es sinnvoll sein, sich im Folgenden

1 Vgl. in Ansätzen IASB (Business Combinations (Phase II), 2004) S. 1; IFRS 3.BC42, BC48(d), BC49; s.a. Osborne (Purchase Accounting Issues, 2001) S. 3; zur „fresh start method“ u.a. Krawitz/Klotzbach (Fresh-Start-Methode, 2000); Pellens/Sellhorn (Fresh Start Methode, 1999).

2 Vgl. zu der Kritik aus steuerlicher Sicht an dem Wahlrecht zwischen Erwerbsmethode und Interessenzusammenführungsmethode in IAS 22 EU-Kommission (Konsultationspapier, 2003) S. 16.

3 Vgl. z.B. Wöhe (Steuerlehre, 1996) S. 88; dies analysierend Bauer (Besteuerung deutscher Konzerne, 1987) S. 220-228. Bei der Fokussierung auf die Gesamtgewinnermittlung wäre die vollständige Wirkungsidentität mit einem Verschmelzungsvorgang nur gegeben, wenn anschließend wirklich der idealtypischen Variante einer (originären) Gesamtgewinnermittlung gefolgt würde. Statt dessen wird das Ergebnis über die realtypische Variante simuliert, die weiterhin auf Einzelgewinnermittlungen aufbaut. Vgl. ähnlich z.B. Rupp (Ertragsbesteuerung nationaler Konzerne, 1983) S. 62; Reis (Körperschaftsbesteuerung des Konzerns, 1996) S. 242, die deshalb auch die Anwendung der Verschmelzungsvorschriften des (deutschen) UmwStG verneinen.

4 Vgl. IFRS 3.5; vgl. dazu Pellens/Fülbier/Gassen (Internationale Rechnungslegung, 2004) S. 624-626. 
ausschließlich auf den „share deal“ und den Fall der ,parent-subsidiary relationship“l im Rahmen der konsolidierten Gesamtgewinnermittlung zu beschränken.

Auch beim ,share deal“ orientiert sich die Erwerbsmethode an der Parallele zum ,asset deal“" und unterstellt den Erwerb eines (Teil-)Betriebs bzw. einer Betriebsstätte zum Stichtag der Erstkonsolidierung ${ }^{2}$. Mit dieser Parallele wird der Organisationsneutralität der Besteuerung insofern entsprochen, als dass beide Formen des externen Unternehmungswachstums in der steuerlichen Gewinnermittlung gleichgestellt werden ${ }^{3}$. Eine Gleichstellung mit dem unternehmungsinternen Wachstum, bei dem ein rechtstatsächlicher Akquisitions- (und Objektivierungs-)vorgang fehlt, ist indes nicht gegeben.

Die in IFRS 3 vorgesehene Erwerbsmethode wirkt als Konsolidierungsmethode, weil sie Mehrfacherfassungen des Eigenkapitals über die Verrechnung des Beteiligungsbuchwertes und des anteiligen Eigenkapitals aus den jeweiligen Einzelgewinnermittlungen unterbindet. Wegen der Einzelerwerbsfiktion geht es hier aber auch darum, die erworbenen Wirtschaftsgüter aus der Perspektive der rechnungslegenden Einheit anzusetzen und zu bewerten und diesbezügliche Ansatz- und Bewertungsdifferenzen zu den Einzelgewinnermittlungen zu schließen. Dies gilt für den Zeitpunkt der Erstkonsolidierung, für jeden Zeitpunkt der Folgekonsolidierung und sogar für die Entkonsolidierung. Bei letzterer wird aus Sicht des konsolidierten Abschlusses korrespondierend zur Einzelerwerbsfiktion bei der Erstkonsolidierung die Veräußerung jedes einzelnen Wirtschaftsgutes einschließlich Goodwill fingiert ${ }^{4}$. Die Erwerbsmethode nach IFRS 3 ist demnach kaum trennbar von dem grundsätzlichen Ansatz- und Bewertungsverständnis der IFRS. Streng genommen stehen deshalb mit der Erwerbsmethode auch Ansatz und Bewertung nach IFRS auf dem Prüfstand.

1 Vgl. IFRS 3.6, der mit IAS 27 und dem dortigen Abgrenzungsmodell einer durch Beherrschung (control) verbundenen Unternehmensgruppe korrespondiert.

2 Vgl. Busse von Colbe et al. (Konzernabschlüsse, 2003) S. 203-204, ohne explizites Abstellen auf den „share deal“. Für Reis (Körperschaftsbesteuerung des Konzerns, 1996) S. 242-243 ist diese Parallele sinnvoller als die zum Verschmelzungsvorgang.

3 Vgl. auch Schreiber (Unternehmensbesteuerung, 2004) S. 223, der die „Gleichstellung von Beteiligung und Betrieb“ auch steuerlich als „folgerichtig“ erachtet; s.a. Küting (Einheitsbesteuerung, 1990) S. 492-496, der konstatiert: „Die Purchase Methode führt ... dazu, dass ökonomisch und realwirtschaftlich zu gleichen Ergebnissen führende Wachstumswege auch bilanziell gleich behandelt werden" (S. 496). Eine unterschiedliche Behandlung nach derzeitigem (deutschen) Steuerrecht sei hiernach „nicht sachgerecht“. Grotherr (Besteuerung nationaler und grenzüberschreitender Konzerne, 1994) S. 550 (m.w.N.) weist i.d.Zshg. aber auf die Möglichkeit bestimmter steuergestalterischer Maßnahmen beim Beteiligungserwerb hin (sog. Kombinationsmodell), die zu einem vergleichbaren steuerlichen Ergebnis führen können.

4 Die Literatur spricht hier von der einheitstheoretisch konsequenten „Fiktion des Einzelabgangs“; vgl. z.B. Busse von Colbe et al. (Konzernabschlüsse, 2003) S. 275; Pfaff/Ganske (Ent- und Übergangskonsolidierung, 2002) Sp. 655; von Wysocki/Wohlgemuth (Konzernrechnungslegung, 1996) S. 149. 
Angesichts der bereits aufgezeigten Zweifel an der steuerlichen Eignung der Ansatzund Bewertungsregeln der IFRS ist diese Verflechtung aus steuerlicher Sicht problematisch. Schließlich kommen für die im Sinne der Einzelerwerbsfiktion erworbenen Wirtschaftsgüter Ansatz- und Bewertungsregeln zum Tragen, die insbesondere in ihrer weiteren Entwicklung in Richtung einer „full fair value“-Bilanzierung den normativen Anforderungen an die steuerliche Gewinnermittlung kaum genügen'. Um IFRS 3 und die dort festgeschriebene Erwerbsmethode nicht von vornherein abzulehnen, wird die weitere Analyse von IFRS 3 unter der schwierigen, IFRS 3 auch inhaltlich tangierenden Annahme fortgeführt, dass alternative, steuerlich geeignete Ansatz- und Bewertungsregeln zum Einsatz kommen. Dabei wird hier der Versuch unternommen, Ansatz- und Bewertungsfragen auszuklammern, soweit sie auch in der originären Einzelgewinnermittlung zur Anwendung kommen. Statt dessen beschränkt sich diese Untersuchung auf wichtige Bilanzierungsaspekte, die erst aus der konsolidierten steuerlichen Gewinnermittlung erwachsen.

Das Minderheitenproblem wird in diesem Zusammenhang vorerst ausgeklammert. Dafür braucht nur unterstellt zu werden, dass das betreffende Tochterunternehmen zu $100 \%$ erworben wird. An späterer Stelle finden Minderheiten in der Kapitalkonsolidierung gesondert Berücksichtigung ${ }^{2}$.

\subsubsection{Ansatzfragen im Rahmen der Einzelerwerbsfiktion}

Eine spezifische Besonderheit der „,cost allocation“ nach IFRS 3.36-37 ist der Ansatz von Vermögenswerten und Schulden unabhängig davon, ob diese in der Einzelgewinnermittlung des erworbenen Tochterunternehmens angesetzt sind ${ }^{3}$. In steuerlicher Sicht würde also der Ansatz von Wirtschaftsgütern ermöglicht, die in der Steuerbilanz II ursprünglich nicht enthalten sind. Vorausgesetzt, die Steuerbilanz II ist fehlerfrei und damit vollständig aufgestellt, kann dies nur über den „dazwischen“ liegenden Akquisitionsvorgang gerechtfertigt werden ${ }^{4}$. So ist dieser Vorgang in normativer Hinsicht durchaus geeignet, die Ansatzfähigkeit eines vorher noch nicht existierenden Wirtschaftsgutes mit $\mathrm{zu}$ begründen. Entweder handelt es sich - bei Fokussierung auf positive Wirtschaftsgüter - um eine neu getätigte Investition, die es im Sinne des kapitaltheoretischen Gewinns zu periodisieren gilt, oder im Sinne der Reinvermögenszugangstheorie um ein Wirtschaftsgut, das sich erst über den Markt- und Preismechanismus als „Wert-

\footnotetext{
Vgl. Kap. V.1; kritisch auch Hommel/Benkel/Wich (IFRS 3, 2004) S. 1268-1271.

Vgl. Kap. V.4.2.2.5.

Vgl. explizit IFRS 3.44: „They might also include assets and liabilities not previously recognised in the acquiree's financial statements".

4 So auch ansatzweise die Begründung in IFRS 3.44 (,... because they did not qualify for recognition before the acquisition"); s.a. Hommel/Benkel/Wich (IFRS 3, 2004) S. 1269-1273, die dies bei Akquisitionen als deutliche Begriffsausweitung der "assets" und „,iabilities“ interpretieren, z.B. im Hinblick auf das Weglassen des probable-Kriteriums beim Ansatz immaterieller Vermögenswerte.
} 
ermittlungsgenerator" konkretisiert. In beiden Fällen ist das Wirtschaftsgut mit den Anschaffungsauszahlungen in der konsolidierten Bilanz zu aktivieren ${ }^{1}$. Dies setzt allerdings voraus, dass der Investitions- bzw. Wirtschaftsgutcharakter durch künftige Zahlungsrückflüsse (und Kenntnis derselben!) bzw. selbständige Tauglichkeit für einzelne Markttransaktionen gegeben ist. Gerade aus objektivierungsgetriebener steuerlicher Sicht erscheint dabei überaus problematisch, dass der Markt- und Preismechanismus letztlich nur für die Gesamttransaktion, z.B. den Beteiligungserwerb, greift, nicht jedoch für das einzelne Wirtschaftsgut. Die Aufteilung der Gesamttransaktion auf einzelne Wirtschaftsgüter vollzieht sich damit außerhalb marktlicher Objektivierung - zumindest insoweit, wie eine separate marktliche Objektivierung im Rahmen der Einzelgewinnermittlung zuvor auch nicht existierte. Es kommt hinzu, dass der Kaufpreis eines Unternehmens nach herrschender Meinung einzig und allein einer Gesamtbewertung entspringt und eben nicht über die aggregierten Einzelwerte der Wirtschaftsgüter ermittelt wird $^{2}$.

Eine Besonderheit der konsolidierten Rechnungslegung nach IFRS ist zudem, dass die Kaufpreisaufteilung im Rahmen der „,cost allocation“ nach IFRS 3.37(c) zum Ansatz von Eventualschulden führt. Eventualschulden sind nach IAS 37.10 definiert als mögliche (possible) und damit nicht wahrscheinliche (probable) Verpflichtungen ${ }^{3}$ oder als Verpflichtungen, deren Höhe nicht ausreichend verlässlich geschätzt werden kann. Obwohl das IAS 37.27 widersprechende Ansatzgebot im Rahmen der Kapitalkonsolidierung durch IFRS 3.37(c) gezwungenermaßen auf die erstgenannte Teilmenge beschränkt wird, ist diese Vorgehensweise auch ${ }^{4}$ aus steuerlicher Sicht zu hinterfragen ${ }^{1}$.

1 I.R.d. kapitaltheoretischen Gewinns basiert dies auf der Annahme der Marginalinvestition, weil die Anfangsauszahlung zu Beginn der Zahlungsreihe nur bei einem Kapitalwert von Null dem eigentlich zu aktivierenden Ertragswert entspricht.

2 Vgl. stellvertretend Dusemond/Weber/Zündorf $(\S 301,1998)$ Tz. 72-73, nach denen Unternehmensakquisitionen auf Ertragswertverfahren beruhen, aber nur das Substanzwertverfahren die für die Erwerbsmethode notwendigen Informationen bereitstellt. Die Differenz zweier Bewertungsverfahren dokumentiert sich insb. im Goodwill als Restgröße; vgl. Esser (Goodwillbilanzierung, 2003) S. 8-12.

3 Hierbei wird streng genommen ein zweidimensionaler Wahrscheinlichkeitsbegriff zu Grunde gelegt, der sich entweder auf das Vorliegen einer Verpflichtung (bedingte Verpflichtung im Sinne einer Abhängigkeit von unsicheren, nicht beeinflussbaren künftigen Ereignissen) oder auf den künftigen Ressourcenabfluss bezieht.

4 Letztlich dürften sich auch aus rein informationsorientierter Perspektive Zweifel an der Ansatzfähigkeit von Eventualschulden im konsolidierten Abschluss ergeben, zumal - imparitätisch - auf ein korrespondierendes Ansatzgebot bei Eventualforderungen vorerst verzichtet wird. Vgl. dazu Hommel/Benkel/Wich (IFRS 3, 2004) S. 1271-1272; Watrin/Strohm/Struffert (Aktuelle Entwicklungen, 2004) S. 1455; Zülch (IFRS 3, 2004) S. 335; a.A. wohl Küting/Wirth (IFRS 3, 2004) S. 173. Wenig weiterführend sind die entsprechenden Erläuterungen des IASB; vgl. z.B. IASB (Business Combinations Phase I, 2003) S. 4-5; IASB (Business Combinations (Phase II), 2004) S. 5-6, wo auch die künftige Aktivierung der Eventualforderungen erwogen wird. 
So läge ein Verstoß gegen die Einheitstheorie und damit auch die Organisationsneutralität der Besteuerung vor, wenn dieses Ansatzgebot im Rahmen der Erstkonsolidierung nicht für die Einheitsunternehmung gälte, die Eventualschulden gegen Entgelt übernommen hätte ${ }^{2}$. Damit wird allerdings wieder eine allgemeine Ansatz- und Bewertungsfrage aufgegriffen, die derzeit nur in den unterschiedlichen europäischen Steuerrechtssystemen beantwortet wird. Nach deutschem Steuerrecht dürfte der Ansatz wohl auch bei entgeltlichem Erwerb ausscheiden ${ }^{3}$. Die IFRS wären an dieser Stelle einheitstheoretisch nur dann konsequent, wenn die entgoltene Risikoübernahme auch in der nichtkonsolidierten Rechnungslegung z.B. nach IAS 39 als Finanzschuld (financial liability) zu passivieren wäre ${ }^{4}$.

Ein Kernelement der Erwerbsmethode nach IFRS 3 ist die Aktivierung des verbleibenden positiven Unterschiedsbetrages als Goodwill. Dieser Unterschiedsbetrag kann sich nur im Erwerbsfall ergeben, da die Anschaffungskosten bei Gründung eines Tochterunternehmens dem anteiligen Eigenkapital entsprechen ${ }^{5}$. Bleibt das bereits angesprochene, sich auch auf den ersten Wertansatz des Goodwill auswirkende Objektivierungsproblem der marktfernen „cost allocation“ außen vor, scheint die Aktivierung der dem Goodwill zugeordneten Anschaffungsauszahlungen durchaus Sinn zu ergeben. Wie schon erwähnt, sollten Wirtschaftsgüter aus steuerlicher Sicht auch in der konsolidierten Bilanz mit den Anschaffungsauszahlungen aktiviert werden. Dies gilt - unter der Annahme

1 Letztlich handelt es sich hier um eine „klassische“ Ansatzfrage, die z.B. nach Maßgabe des kapitaltheoretischen Gewinns oder der steuerlichen Leistungsfähigkeit analysiert werden könnte. Obwohl im Modell des kapitaltheoretischen Gewinns kapitalwertgleiche Umperiodisierungen über vorweggenommene Auszahlungen die Investitionsneutralität erhalten können, erfassen die restriktiven Modellbedingungen nicht die Unsicherheit als Kerncharakteristikum der Eventualschuld. Eine sinnvolle Deutung erscheint innerhalb dieses Modellrahmens kaum möglich. Die Rechtfertigung der gerechtigkeitsgetriebenen Reinvermögenszugangstheorie erwächst indes aus einer weniger abstrakten und damit unvollkommenen Welt. Fehlt es z.B. an den geforderten Verlustverrechnungsmöglichkeiten, hat hier die imparitätische Verlustvorwegnahme als Hilfslösung ihren Sinn. Darin mag möglicherweise ein negatives Wirtschaftsgut gesehen werden, das aber anders als vergleichsweise „sichere“ Schulden den Nachteil hat, mit einem deutlich größeren $\mathrm{Maß}$ an Ermessenspielraum einherzugehen und so der Möglichkeit zur Selbsteinsteuerung Vorschub zu leisten. Dieser Nachteil wird durch den Akquisitions- und Objektivierungsvorgang auf Ebene des gesamten Tochterunternehmens nur unwesentlich gemindert, weil sich dieser Vorgang nicht ohne Objektivitätseinbußen auf Einzelpositionen herunter brechen lässt. Vgl. (aus anderer Sicht) ähnlich kritisch Hommel/Benkel/Wich (IFRS 3, 2004) S. 1271-1272; Gröning (Steuerbilanzielle Gewinnermittlung, 2002) S. 233-235, der allerdings auf Rückstellungen nach US-GAAP fokussiert.

2 Kraft (Steuergerechtigkeit, 1991) S. 63 schließt bedingte Forderungen und Verpflichtungen aus Sicht der Reinvermögenszugangstheorie als Wirtschaftsgüter mit der Begründung aus, dass es ihnen an der selbständigen (Rechts-)Verkehrsfähigkeit mangele. Angesichts der Bandbreite inzwischen z.B. als Derivate handelbarer Chancen und Risiken kann dieser Ansicht nicht gefolgt werden.

3 Ein Ansatz der erworbenen Eventualschuld dürfte weder als Verbindlichkeit, noch als Rückstellung und auch nicht als Rechnungsabgrenzungsposten in Frage kommen.

4 Dann wären die separaten Ansatzvorschriften in IFRS 3 allerdings redundant, so dass Zweifel an dem Ansatz in der nicht-konsolidierten Rechnungslegung verbleiben. Auch IAS 37.27-30 enthalten keinen Hinweis, dass eine entgeltliche Übernahme an dem Ansatzverbot etwas ändert.

5 Vgl. Busse von Colbe et al. (Konzernabschlüsse, 2003) S. 218. 
einer Marginalinvestition - für die Konzeption des kapitaltheoretischen Gewinns und auch für die Reinvermögenzugangstheorie.

Beim Goodwill ist jedoch fraglich, ob in steuerlicher Hinsicht überhaupt ein Wirtschaftsgut vorliegt ${ }^{1}$. Obwohl IFRS 3.51(a) konstatiert, dass der Goodwill als Vermögenswert zu aktivieren sei, sind Zweifel schon wegen des apodiktischen Charakters dieser Aussage sowie der Unterschiede zwischen der ,asset“-Definition nach IFRS und der eines steuerlichen Wirtschaftsgutes angebracht ${ }^{2}$. Kaum weiterführend ist hier die Betrachtung im Modell des kapitaltheoretischen Gewinns. So handelt es sich bei der zu beobachtenden Anschaffungsauszahlung unter vollkommener Information entweder um eine Investition, die mit künftig sicheren und bekannten Zahlungsrückflüssen einhergeht, oder nicht. Da in einer derartigen Modellwelt kein überhöhter Kaufpreis gezahlt würde, kann eigentlich immer nur der erste Fall vorliegen. Der Goodwill wäre demnach immer ein Wirtschaftsgut und enthielte diejenigen Teile der im Kaufpreis ausgedrückten (und sicher eintretenden) Ertragserwartungen, die nicht im neubewerteten Eigenkapital des Tochterunternehmens abgebildet sind ${ }^{3}$. Die gerade auch für den Goodwill charakteristische Unsicherheitsdimension bleibt aber außen vor, so dass eine sinnvolle Deutung innerhalb dieses Modellrahmens kaum möglich erscheint.

Eher geeignet erscheint hier die Reinvermögenzugangstheorie. Hiernach sind Wirtschaftsgüter aufgrund separierter marktlicher Objektivierung entstanden und zeichnen sich durch ihre selbständige Tauglichkeit für einzelne (künftige) Markttransaktionen aus $^{4}$. Selbst wenn Ersteres dem Goodwill zuerkannt würde, verbleiben große Zweifel an Letzterem. Auch wenn sich die Literatur über die Natur des Goodwill bislang nicht einigen konnte ${ }^{5}$, dürfte Einigkeit zumindest hinsichtlich dieser Zweifel bestehen. Eine selbständige Verkehrsfähigkeit wird dem Goodwill nicht zugebilligt ${ }^{6}$. Es gibt allerdings Ansätze in der Literatur, die in dem Goodwill keine monolithische Größe erkennen, sondern unterschiedliche wirtschaftliche Komponenten mit unterschiedlichem wirt-

1 Vgl. zu der Diskussion über die Wirtschaftsguteigenschaft des Goodwill aus (steuerrechtlicher) deutscher Sicht mit Hinweisen auf die Finanzrechtsprechung z.B. Wöhe (Bilanzierung und Bewertung des Firmenwertes, 1980) S. 100-103; s.a. m.w.N. Esser (Goodwillbilanzierung, 2003) S. 6-9; Reis (Körperschaftsbesteuerung des Konzerns, 1996) S. 246-247. Vgl. zu dieser nicht konsolidierungsspezifischen Frage z.B. Eberhartinger (Ertragsteuerliche Konsequenzen, 2000) S. 266-267; Eichhorn (Maßgeblichkeitsprinzip, 2001) S. 107-124; Herzig (IAS/IFRS, 2004) S. 61-147.

3 Vgl. zu dieser Interpretation auch Busse von Colbe et al. (Konzernabschlüsse, 2003) S. 218-219.

4 So stellt Kraft (Steuergerechtigkeit, 1991) S. 63 bei der Ansatzkonzeption der Reinvermögenszugangstheorie explizit auf die Rechtsposition der Wirtschaftsgüter bzw. ihre ,rechtliche Entstehung“ ab und lässt dabei nur Sachen bzw. rechtlich geschützte Immaterialgüter sowie Rechte (Rechtsgegenstände 1. und 2. Ordnung) gelten.

5 Vgl. z.B. den Literaturüberblick bei Dusemond/Weber/Zündorf $(\S 301,1998)$ Tz. 79-81; unter Einbeziehung auch internationaler Quellen Sellhorn (Goodwill Impairment, 2004) S. 10-15.

6 Vgl. stellvertretend Schneider (Gerechtigkeit, 1971) S. 378. 
schaftlichem Gehalt. Zu erwähnen sind hier insbesondere die Ansätze von Wöhe ${ }^{1}$, Johnson/Petrone ${ }^{2}$, Henning/Lewis/Shaw ${ }^{3}$ oder Sellhorn ${ }^{4}$. Nach Sellhorn wäre hier beispielsweise der Going-Concern-Goodwill, der Synergien-Goodwill, der RestrukturierungsGoodwill, der Strategie-Goodwill und die erworbene Flexibilität zu unterscheiden ${ }^{5}$. Auch das $I A S B$ differenziert den Goodwill und stellt insbesondere auf die ersten beiden Komponenten ab, die es als „core goodwill“" bezeichnet ${ }^{6}$. Zusätzlich berücksichtigt es noch diejenige Komponente des Unterschiedsbetrages, die den aus Erwerbersicht schlichtweg überhöhten Preis aufgrund fehlender, falscher oder schlecht verarbeiteter Information sowie schlechter Verhandlungsführung umfasst - angesichts unvollkommener Information und Opportunismus bei den am Akquisitionsprozess beteiligten Individuen ein durchaus realistisches Szenario, das jedoch nicht unter den (Kern-)Goodwill subsumiert wird.

Die Goodwillseparierung führt hinsichtlich der Frage der Wirtschaftsguteigenschaft aber kaum weiter. Sämtlichen Einzelkomponenten mangelt es letztlich an der selbständigen Verkehrsfähigkeit. Diese ist dem Goodwill allenfalls für eine Teilmenge des Going-Concern-Goodwill zuzubilligen. Als originärer Goodwill des erworbenen Unternehmens ${ }^{7}$ beinhaltet dieser möglicherweise auch nicht in der Einzelgewinnermittlung angesetzte wirtschaftliche Werte, die einzeln verkehrsfähig wären, ohne dort bislang erfasst worden zu sein ${ }^{8}$. Dieser Fall scheint dem Gedanken von IFRS 3 und der dort festgelegten „cost allocation“ allerdings zu widersprechen und dürfte zumindest theoretisch kaum auftreten.

Im Goodwill zeigt sich letztlich überdeutlich der Unterschied zwischen einer rein informationsorientierten Rechnungslegung und einer steuerlichen Gewinnermittlung, die sich an der Reinvermögenszugangstheorie orientiert. In kaum einer anderen Position konkretisiert sich die Diskrepanz zwischen künftigen Nutzenpotenzialen und selbständig verkehrsfähigen Wirtschaftsgütern so stark. Dies gilt gleichermaßen für die Objektivierungserfordernisse der Reinvermögenszugangstheorie, die in der rein informations-

Vgl. Wöhe (Bilanzierung und Bewertung des Firmenwertes, 1980) S. 91-100.

Vgl. Johnson/Petrone (Goodwill, 1998) S. 294-296.

Vgl. Henning/Lewis/Shaw (Components, 2000) S. 375-376, 379 mit Bezug auf Johnson/Petrone und APB Opinion No. 16. In dieser empirischen Untersuchung werden unterschiedliche Kapitalmarktreaktionen auf Goodwillkomponenten identifiziert.

4 Vgl. Sellhorn (Ansätze zur bilanziellen Behandlung des Goodwill, 2000) S. 889-890, der diese Separation auf den Erkenntnissen von Wöhe und Johnson/Petrone aufbaut.

5 Vgl. Sellhorn (Ansätze zur bilanziellen Behandlung des Goodwill, 2000) S. 889-890.

Vgl. IFRS 3.BC130-135 sowie IFRS 3.BC93.

7 Vgl. Sellhorn (Ansätze zur bilanziellen Behandlung des Goodwill, 2000) S. 889.

8 Da die Einzelgewinnermittlungen nicht zwingend den IFRS folgen müssen, ist an dieser Stelle unerheblich, ob und unter welchen Bedingungen diese Werte nach IAS $38 \mathrm{zu}$ aktivieren wären. Vgl. zu der Definition rechtlich ungeschützter ,wirtschaftlicher Werte“ und ihrer Eigenschaft, Objekt von Rechtsgeschäften sein zu können, von Keitz (Immaterielle Güter, 1997) S. 6-7. 
orientierten Rechnungslegung geringer ausgeprägt sind ${ }^{1}$ und deshalb einen Goodwill mit seinen einzelnen Komponenten zum Ansatz kommen lassen. Hinzuzufügen ist aber auch, dass kaum eine andere Position so stark von der normativen Ausrichtung der steuerlichen Gewinnermittlung abhängt wie der Goodwill. Wegen der grundsätzlichen Irrelevanz marktlicher Realisation und Objektivierung könnte der Goodwill, oder zumindest manche seiner Komponenten, als wirtschaftlicher Vorteil durchaus dem Reinvermögen im Sinne der Reinvermögenzuwachstheorie zugerechnet werden. Dies wäre unabhängig davon, ob dieser wirtschaftliche Vorteil als Nutzenpotenzial letztlich nur im Rahmen einer Unternehmensveräußerung übertragen werden könnte ${ }^{2}$. Aber selbst wenn einige der Goodwill-Komponenten auch aus steuerlicher Sicht die Eigenschaft eines Wirtschaftsgutes besäßen, wäre es aus durchführungsorientierter Effizienzsicht nicht unbedingt opportun, diese schwierige Goodwill-Separierung und die damit einhergehende partielle Aktivierung auch vorzunehmen. Einfacher und weniger ermessensbehaftet erschiene in diesem Fall eine Konvention, die für den Goodwill entweder eine Aktivierung in voller Höhe oder aber eine sofortige Aufwandsverrechnung vorsähe.

Fraglich ist in diesem Zusammenhang, wie der Goodwill einheitstheoretisch aus der Sicht der Einzelgewinnermittlung einer Einheitsunternehmung zu würdigen ist. Anders als der originäre (selbst geschaffene) Goodwill müsste es sich auch hier um einen derivativen (erworbenen) Goodwill handeln. Weil der Fall eines isolierten Goodwillkaufs, wie soeben erläutert, angesichts seiner fehlenden Verkehrsfähigkeit aber von vornherein ausscheidet, hilft diese Analogie kaum weiter. Es bleiben damit nur ,asset deals“, bei denen Bündel von Wirtschaftsgütern zu einem über den addierten Einzel(zeit)werten liegenden Kaufpreis erworben werden. Da der zu analysierende ,share deal“" diesen ,asset deal" über die Erwerbsmethode aber gerade zu fingieren versucht, entsprechen sich die normativen Überlegungen. Der einzige Unterschied liegt darin, dass der ,asset deal“" als Problem der Einzelgewinnermittlung in den nationalen Steuerrechtssystemen regelmäßig reguliert sein dürfte. $\mathrm{Ob}$ sich hieraus der möglicherweise durchführungseffiziente Hinweis ergeben sollte, in der konsolidierten Rechnungslegung gleichermaßen zu verfahren, ist schon deshalb fraglich, weil so wahrscheinlich völlig unterschiedliche nationale Regulierungen zum Tragen kommen ${ }^{3}$.

Der Unterschiedsbetrag zwischen dem neubewerteten Eigenkapital und dem Beteiligungsbuchwert muss nicht zwangsläufig positiv sein. Deshalb stellt sich auch die Frage,

1 Vgl. hiezu bereits Kap. V.1.2.1.

2 Vgl. zu dieser Deutung der Reinvermögenszuwachstheorie Kraft (Steuergerechtigkeit, 1991) S. 57 und Kap. II.2.2.4.

3 Vgl. kritisch zur Vorbildwirkung des (deutschen) UmwStG für steuerliche Konsolidierungsregeln z.B. Bauer (Besteuerung deutscher Konzerne, 1987) S. 220-227; Reis (Körperschaftsbesteuerung des Konzerns, 1996) S. 242; Rupp (Ertragsbesteuerung nationaler Konzerne, 1983) S. 62. I.R.d. EU-Strategie wäre diese Überlegung auch allenfalls bei der HST-Alternative relevant. 
ob die unmittelbare ergebniswirksame Verrechnung eines negativen Unterschiedsbetrages nach IFRS 3.56(b) den steuerlichen Anforderungen genügt. Zu erwähnen ist dabei, dass die ergebniswirksame Verrechnung schon innerhalb von IFRS 3 nicht unbedingt konsequent erscheint ${ }^{1}$ - abgesehen davon, dass sich bereits der Sinn einer zuvor zwingend zu wiederholenden „cost allocation“ (reassessment) nach IFRS 3.56(a) nicht recht erschließt ${ }^{2}$. Ebenso apodiktisch wie der Goodwill in IFRS 3.51(a) als ,,asset" bezeichnet wird, erscheint bei einem negativen Unterschiedsbetrag die implizite Verneinung des Schuldcharakters. So ist durchaus vorstellbar, dass sich ungünstige künftige Entwicklungen zwar im Kaufpreis, aber noch nicht im neubewerteten Eigenkapital niedergeschlagen haben (badwill) ${ }^{3}$. Ihre sofortige Ertragsverrechnung widerspräche insbesondere einer periodengerechten und damit auch paritätischen Gewinnermittlung.

Aus steuerlicher Sicht sind die Analogien zum Goodwill unübersehbar. Hier wie dort dürfte die Eigenschaft als (negatives) Wirtschaftgut im Rahmen der Reinvermögenszugangstheorie bezweifelt werden ${ }^{4}$. Auch ist der negative Unterschiedsbetrag mit seiner Unsicherheitsdimension im Modellrahmen der investitionsneutralen Besteuerung kaum sinnvoll zu interpretieren. Wie beim Goodwill erscheint die gedankliche Aufspaltung des negativen Unterschiedsbetrages in seine wirtschaftlichen Komponenten möglich, aus durchfürungseffizienter sowie gerechtigkeitsgetriebener Sicht aber nicht geboten. Im Übrigen wäre dann mit Verweis auf die einheitstheoretisch gültigen Regeln der steuerlichen Einzelgewinnermittlung zu bezweifeln, ob im Falle eines „badwill“ eine Art Aufwandsrückstellung angesetzt werden könnte. Bei einem glücklichen und vor allem günstigen „lucky buy“ ergäben sich sogar Zweifel an der Einhaltung des Realisationsprinzips ${ }^{5}$. So wird anstelle einer die (zu niedrigen) Anschaffungs- oder Herstellungskosten üblicherweise übersteigenden Mehrzahlung bei Weiterveräußerung des Unternehmens eine unter den marktfern (als „richtig“) bewerteten Anschaffungs- oder

1 Vgl. z.B. $A A A$ (Business Combinations, 2004) S. 60.

2 Das IASB sieht in dem negativen Unterschiedsbetrag wohl hauptsächlich einen „Fehler“; vgl. IFRS 3.57; Küting/Wirth (IFRS 3, 2004) S. 177; Zülch (IFRS 3, 2004) S. 337; sehr viel differenzierter IFRS 3.BC143-156. Vgl. dennoch kritisch zur erneuten Überprüfung Pellens/Fülbier/Gassen (Internationale Rechnungslegung, 2004) S. 637.

3 Vgl. zu den möglichen Interpretationen negativer Unterschiedsbeträge („Geschäftsminderwerte") bereits Bores (Konsolidierte Erfolgsbilanzen, 1935) S. 65-66; s.a. z.B. Baetge/Kirsch/Thiele (Konzernbilanzen, 2002) S. 243-244; Busse von Colbe et al. (Konzernabschlüsse, 2003) S. 239; Dusemond/Weber/Zündorf $(\S 301,1998)$ Tz. 149 sowie IFRS 3.BC146-150.

$4 \mathrm{Vgl}$. zu dieser Frage, allerdings mit Bezug auf die handels- und steuerrechtliche deutsche Einzelgewinnermittlung und unter weniger stringentem Bezug auf die Reinvermögenszugangstheorie, ausführlich Bachem (Berücksichtigung negativer Geschäftswerte, 1993) m.w.N.; für die Gesamtgewinnermittlung Bauer (Besteuerung deutscher Konzerne, 1987) S. 246-249; Reis (Körperschaftsbesteuerung des Konzerns, 1996) S. 247. Über die Meinung der deutschen Finanzrechtsprechung informiert $\mathrm{Ba}$ chem (Berücksichtigung negativer Geschäftswerte, 1993).

5 Vgl. Bauer (Besteuerung deutscher Konzerne, 1987) S. 246-247, der aber nicht die engere Interpretation der „Barrealisation“ verwendet; zustimmend Salzberger (Konzernunternehmung, 1994) S. 172. 
Herstellungskosten liegende Minderzahlung bei Anschaffung desselben als Ertrag im Zuge der Erstkonsolidierung angesehen.

Interessant erscheint an dieser Stelle die Betrachtung derjenigen europäischen Konsolidierungsstaaten, die eine Kapitalkonsolidierung durchführen (Niederlande, Portugal, Spanien). Obwohl diese drei Steuersysteme den Beteiligungsbuchwert mit dem Eigenkapital des erworbenen Unternehmens verrechnen, kann eine Zuordnung des hierbei identifizierten Unterschiedsbetrages auf Wirtschaftsgüter nur in Portugal und Spanien beobachtet werden. Nur in diesen beiden EU-Staaten existiert eine Erwerbsmethode auch für steuerliche Zwecke. In den Niederlanden bleibt dieser Unterschiedsbetrag en bloc bestehen, so dass von einer Einzelerwerbsfiktion gar nicht mehr gesprochen werden kann. Dies entspricht der früher aktienrechtlich kodifizierten „,deutschen Methode“"1 und hat partielle Ähnlichkeiten mit der ,pooling of interests method“, bei der ein Unterschiedsbetrag allerdings ergebnisneutral mit dem Eigenkapital verrechnet wird. Auch in Portugal und Spanien wird der nach Aufteilung verbleibende positive oder negative Unterschiedsbetrag in der konsolidierten Bilanz belassen und dort explizit als konsolidierungstechnischer Ausgleichsposten, also nicht als Wirtschaftsgut, gekennzeichnet. Abgesehen davon, dass ein derartiger Ausgleichsposten einheitstheoretisch kaum zu rechtfertigen ist, scheint in diesen Staaten eine vereinfachende Konvention im Umgang mit dem Unterschiedsbetrag aus der Kapitalkonsolidierung gefunden worden zu sein. Damit dürfte sie zumindest durchführungseffizienten Anforderungen gerecht werden ${ }^{2}$.

Es kann abschließend festgehalten werden, dass die Erwerbsmethode nach IFRS 3 und die ihr innewohnende Einzelerwerbsfiktion in ihrer einheitstheoretischen Konsequenz für steuerliche Konsolidierungszwecke geeignet erscheint. Dem stehen allerdings erhebliche Zweifel gegenüber, die vor dem Hintergrund der marktfernen „cost allocation“ unter effizienz- wie gerechtigkeitsgetriebenen Objektivierungserfordernissen erwachsen. Diese Zweifel betreffen die Vermögenswerte und (Eventual-)Schulden, die im Rahmen der Erstkonsolidierung erstmalig angesetzt werden. Diese Zweifel betreffen aber auch die bilanzielle Behandlung des verbleibenden positiven oder negativen Unterschiedsbetrags. Das Spannungsverhältnis zwischen Einheitstheorie und Objektivierung lässt sich wohl nicht auflösen. Wenn damit aber festgestellt wird, dass eine eindeutige normative Wertung der Ansatzfragen im Rahmen der Einzelerwerbsfiktion kaum möglich erscheint, greift die in Kapitel V.1.3 formulierte Beweislastumkehr. Hiernach ist eine spezielle IFRS-Regel für steuerliche Zwecke solange als ungeeignet anzusehen, bis

1 Vgl. zu dieser im alten Aktiengesetz ( $\$ 331$ AktG 1965) bis zum BiRiLiG festgelegten Konsolidierungsmethode, die so terminologisch von der modifizierten sowie echten angelsächsischen Methode abgegrenzt wurde von Wysocki/Wohlgemuth (Konzernrechnungslegung, 1996) S. 88-91; zu dieser Parallele bereits Rupp (Ertragsbesteuerung nationaler Konzerne, 1983) S. 61-62.

2 Natürlich spielen im Einzelfall andere Regulierungsmotive eine Rolle, die in einer positiven (nicht normativen) Analyse zu identifizieren wären. Vorstellbar ist z.B., dass der Gesetzgeber aus fiskalischem Interesse eine sofortige Aufwandsverrechnung eines Goodwills ablehnt. 
das Gegenteil bewiesen wird. Dieser Beweis konnte hier nicht zweifelsfrei erbracht werden. Möglicherweise dokumentiert sich diese Erkenntnis auch in den körperschaftsteuerlichen Regulierungen der EU-Konsolidierungsstaaten, die anders als IFRS 3 einer vergleichsweise einfachen und klaren Konvention folgen.

Aus den vorangegangenen Ausführungen ergeben sich weitere Konsequenzen. So ist an mehreren Stellen die einheitstheoretische Notwendigkeit angedeutet worden, die steuerliche Kapitalkonsolidierung mit der steuerlichen Einzelgewinnermittlung abzustimmen und zu verzahnen. Nur so lässt sich die Organisationsneutralität der Besteuerung überhaupt gewährleisten. Dies betrifft nicht allein den Anwendungsbereich von IFRS 3 auch für ,asset deals“ sowie Ansatz- und Bewertungsaspekte, sondern insbesondere auch die hier angesprochenen Fragen, wie mit positiven oder negativen Unterschiedsbeträgen in der Einzelgewinnermittlung verfahren wird oder wie entgeltlich erworbene Eventualschulden (und letztlich auch -forderungen) dort behandelt werden. Daraus folgt die Erkenntnis, dass Konsolidierungsregeln eben nicht „so einfach“ als Zusatzregulierung neben den weiterhin existierenden und nicht harmonisierten einzelstaatlichen Ansatzund Bewertungsregeln etabliert werden können'

Zudem existieren technische Schwierigkeiten. Sie resultieren teilweise aus der soeben angesprochenen Verzahnung mit der heterogenen einzelstaatlichen Einzelgewinnermittlung, auf der eine realtypische Gruppenbesteuerung schließlich aufsetzt ${ }^{2}$. Zum Teil betreffen sie aber auch Sonderprobleme, die nicht oder nur zum Teil in den IFRS geregelt sind. Angesichts ihres speziellen Charakters werden diese im Folgenden nur kurz angesprochen:

- Im Fall des erstmaligen Übergangs auf eine konsolidierte steuerliche Gewinnermittlung muss die steuerliche Erstkonsolidierung auf schon bestehende Gruppenstrukturen angewendet werden. Angesichts möglicher Einführungsprobleme bedarf es hierfür eventuell steuerlicher Übergangsregeln ${ }^{3}$.

- Wird ein Beherrschungsverhältnis durch mehrere, hintereinander geschaltete Anteilserwerbe realisiert, besteht das Problem divergierender Zeitwerte und unterschiedlich hoher stiller Reserven. IFRS 3 löst dieses Problem zumindest über die klare Festlegung des Erstkonsolidierungszeitpunktes (Erlangung der Beherrschungsmöglichkeit, IFRS 3.39, 3.59), wobei der Erwerbsvorgang für die Goodwillermitt-

1 Vgl. zu dieser Notwendigkeit bereits Eberhartinger (Ertragsteuerliche Konsequenzen, 2000) S. 262.

2 Vgl. ebenfalls Spengel (Einheitliche Bemessungsgrundlage, 2004) S. 110, der das Problem in der fehlenden Harmonisierung der nationalen Steuerrechtsordnungen sieht.

3 Vgl. dies fordernd Bauer (Besteuerung deutscher Konzerne, 1987) S. 297-299; Grotherr (Besteuerung nationaler und grenzüberschreitender Konzerne, 1994) S. 556; Krebühl (Konzernbesteuerung, 2003) S. 607; Salzberger (Konzernunternehmung, 1994) S. 174; sehr kritisch Rupp (Ertragsbesteuerung deutscher Konzerne, 1983) S. 58-61, der die Erwerbsmethode auch deshalb für steuerliche Zwecke insgesamt in Zweifel zieht. 
lung dennoch in seine einzelnen Tranchen zu zerlegen ist (IFRS $3.58^{1}$ ). Fraglich ist insbesondere, ob hier für steuerliche Zwecke, gerade bei vielen Erwerbstranchen, vereinfachende Konventionen sinnvoller sind ${ }^{2}$.

- Zusätzliche Anteilserwerbe bereits vollkonsolidierter oder zwischenzeitliche Teilveräußerungen weiterhin vollkonsolidierter Tochterunternehmen sind in der Gesamtaber auch Einzelgewinnermittlung zu verbuchen. Das Vorgehen ist in den IFRS nicht explizit geregelt. In der konsolidierten Rechnungslegung müsste in konsequenter Anwendung der Einheitstheorie nur eine ergebnisneutrale Eigenkapitaltransaktion zwischen Mehrheits- und Minderheitsgesellschaftern abgebildet werden, die aber nur bei Gültigkeit der „full goodwill method“ konsequent umsetzbar wäre ${ }^{3}$. Zu klären sind insbesondere auch die korrespondierenden Ergebniswirkungen in der Einzelgewinnermittlung.

- Fraglich ist, wie nachträgliche Wertkorrekturen zu behandeln sind, die die ursprüngliche „cost allocation“ später in Frage stellen. IFRS 3.62 sieht hier innerhalb einer zwölfmonatigen Anpassungsfrist eine ergebnisneutrale Korrektur der Erstkonsolidierung vor, als ob die endgültigen Wertansätze bereits im Erwerbszeitpunkt bekannt gewesen $\operatorname{seien}^{4}$.

- Die Gliederung des steuerlichen Eigenkapitals ist insbesondere dann komplexer als in einer IFRS-Bilanz, wenn das verwendbare Eigenkapital mit unterschiedlicher Körperschaftsteuer belastet ist. Etwaig bestehende Anrechnungspotenziale - in Deutschland z.B. für eine Übergangszeit auch nach Einführung des Halbeinkünfteverfahrens gegeben - müssten wohl im Eigenkapital und bei der Kapitalkonsolidierung berücksichtigt werden ${ }^{5}$.

- Fraglich ist, wie mit Verlustvorträgen zu verfahren ist, die vor der Gruppenzugehörigkeit entstanden sind. Offen sind auch steuerliche Verrechnungsmöglichkeiten von Verlustvorträgen aus der Konsolidierungsphase in der Nachkonsolidierungsphase.

1 In der Gegenüberstellung der Teil-Anschaffungskosten jeder Erwerbstranche (cost of each exchange transaction) und dem dann geltenden beizulegenden Zeitwert des neu erworbenen Nettovermögens ergibt sich (eventuell) für jede einzelne Tranche ein Goodwill; vgl. Pellens/Fülbier/Gassen (Internationale Rechnungslegung, 2004) S. 661-662.

2 Vgl. für Vereinfachungen plädierend Bauer (Besteuerung deutscher Konzerne, 1987) S. 233-234; ansatzweise Salzberger (Konzernunternehmung, 1994) S. 173 m.w.N. Nach Oberndorff (Konzernbesteuerung, 1996) S. 28 steht die Kapitalkonsolidierung im Fall des sukzessiven Erwerbs (immer) konzeptionell in einem „unauflöslichen Dilemma“.

3 Vgl. Busse von Colbe (Einheitstheorie für den Konzernabschluss, 2004) S. 52-56, 60; Pellens/Fülbier/Gassen (Internationale Rechnungslegung, 2004) S. 662-663; sehr ausführlich auch $\mathrm{Pa}$ welzik (Phase II, 2004) S. 685-690.

4 Vgl. hierzu ausführlicher Pellens/Fülbier/Gassen (Internationale Rechnungslegung, 2004) S. 664.

5 Vgl. differenzierter dazu Senger (Konzernertragsbesteuerung, 1997) S. 212-214. Weitere Probleme können sich u.a. aus der Fortführung etwaiger nationaler Eigenkapitalgliederungen ergeben, insb. auch, wenn neben Kapital- auch Personengesellschaften involviert sind; vgl. Bauer (Besteuerung deutscher Konzerne, 1987) S. 234-243, 278-280. 
Auch ergibt sich hierbei Abstimmungsbedarf mit den existierenden einzelstaatlichen Regeln zur Nutzung von Verlustvorträgen ${ }^{1}$.

- Fraglich ist, wie mit steuerfreien Rücklagen, in Deutschland z.B. gemäß $\S 6 \mathrm{~b}$ EStG oder Abschnitt 35 EStR, im Rahmen der Kapitalkonsolidierung zu verfahren ist. Plausibel erscheint die Lösung, hier den Nach-Steuer-Anteil zum Eigenkapital zu rechnen ${ }^{2}$.

\subsubsection{Neubewertung und Ergebniswirkungen}

Wird die Erwerbsmethode nach IFRS 3 der steuerlichen Konsolidierung trotz der bisher aufgezeigten Bedenken zu Grunde gelegt, werden auch die in den entsprechenden Einzelgewinnermittlungen enthaltenen Wirtschaftgüter im Rahmen der Kaufpreisallokation neu bewertet. Das heißt nichts anderes, als dass stille Reserven und Lasten aufgedeckt und die ursprünglichen Buchwerte für die konsolidierte Bilanz angepasst werden. Diese Neubewertung steht der „Maßgeblichkeit“ der Einzelgewinnermittlung für die Gesamtgewinnermittlung entgegen, die sich nur in einer Buchwertverknüpfung konkretisieren würde. Dies gilt aber nur insoweit, wie ein ,push down“ der als neu bewerteten und als „richtig“ empfundenen Werte in die Einzelgewinnermittlung unterbleibt ${ }^{3}$. Dieser „Maßgeblichkeit“ der Einzel- für die Gesamtgewinnermittlung wird allerdings auch schon zuvor, im Rahmen der vorbereitenden Maßnahmen, widersprochen. Auch die Neubewertung entspringt der einheitstheoretischen Sichtweise, nach der unter Zugrundelegung der Einzelerwerbsfiktion „Gruppenanschaffungskosten“ zu identifizieren sind ${ }^{4}$. Es liegt in der Natur einer Anschaffung, dass sich die gezahlten Anschaffungskosten für ein Wirtschaftgut von den vorherigen Buchwerten unterscheiden können.

Aus steuerlicher Sicht ist diese Vorgehensweise im Sinne der Erwerbsmethode konsequent. Wie bereits angeklungen, lässt sich die Erstbewertung zu neu ermittelten An-

1 Vgl. hierzu ausführlicher Grotherr (Besteuerung nationaler und grenzüberschreitender Konzerne, 1994) S. 569-577; s.a. Bauer (Besteuerung deutscher Konzerne, 1987) S. 243; Salzberger (Konzernunternehmung, 1994) S. 173; Senger (Konzernertragsbesteuerung, 1997) S. 215.

2 Vgl. Reis (Körperschaftsbesteuerung des Konzerns, 1996) S. 243-244. Köhler (Besteuerung von Konzern, 1970) S. 145 schlägt vor, diese Positionen bei der Kapitalkonsolidierung nicht zu verrechnen und statt dessen unverändert in die steuerliche Gesamtgewinnermittlung zu übernehmen. Vgl. zu der auf den Sonderposten mit Rücklagenanteil zielenden Diskussion i.R.d. handelsrechtlichen deutschen Konzernrechnungslegung Dusemond/Weber/Zündorf $(\S 301,1998)$ Tz. 58-61.

3 Hierbei läge streng genommen wohl der umgekehrte Fall, die Maßgeblichkeit der Gesamtgewinnermittlung für die Einzelgewinnermittlung, vor. Vgl. zum ,push down accounting“, das sich in der Konzernrechnungslegung allerdings auf die Handelsbilanz II beschränken dürfte z.B. Jeter/Chaney (Advanced Accounting, 2001) S. 239-244.

4 Vgl. insb. Ordelheide (Anschaffungskostenprinzip, 1986) S. 493. Nach Bauer (Besteuerung deutscher Konzerne, 1987) S. 218 werde der Gedanke der wirtschaftlichen Einheit hierbei über den Grundsatz der Maßgeblichkeit (des Einzelabschlusses für den Konzernabschlusses) gestellt; s.a. Mühlschlegel (Gewinnermittlung für Konzerne, 1971) S. 117-167; ablehnend Rupp (Ertragsbesteuerung nationaler Konzerne, 1983) S. 74-78, der insb. den fehlenden Bilanzzusammenhang bemängelt. 
schaffungskosten durchaus rechtfertigen. Eine unterschiedliche Behandlung der Wirtschaftsgüter in der Einzel- und Gesamtgewinnermittlung ist aus Sicht jeweils unterschiedlich abgegrenzter rechnungslegender Einheiten korrekt, da aus Sicht nur einer dieser Einheiten ein - wenn auch fingierter - Einzelerwerbsvorgang stattgefunden hat. Bei der hierbei implizit zu Grunde gelegten Reinvermögenszugangstheorie wäre ein „push down accounting“ in die steuerliche Einzelgewinnermittlung demgegenüber eher abzulehnen'.

Problematisch ist die ebenfalls im Vorkapitel geäußerte Kritik an der „cost allocation“, bei der stille Reserven und Lasten vergleichsweise marktfern und damit willkürbehaftet aufgedeckt werden ${ }^{2}$. So zeigen die in IFRS 3.B16 und 3.B17 enthaltenen Hinweise zur Bewertung des erworbenen Nettovermögens auf, dass der beizulegende Zeitwert als zentraler Wertmaßstab wenn möglich durch Marktwerte (market values), wenn nötig aber auch durch geschätzte Werte auf der Basis von Barwertverfahren (fair values to be estimated using present value techniques) zu konkretisieren ist. Diese Bewertung ist nicht nur unter den restriktiven Modellbedingungen einer investitionsneutralen Besteuerung konsequent. Auch in der Reinvermögenszugangstheorie besteht kein Zweifel an der Ansatzfähigkeit gezahlter Markt- oder Zeitwerte. Hier verbleibt allerdings das schon angesprochene Problem, dass sich die Aufteilung der Gesamttransaktion auf einzelne Wirtschaftsgüter letztlich außerhalb marktlicher Objektivierung vollzieht. Damit offenbart auch die Wertbeimessung für die bereits in der Einzelgewinnermittlung erfassten Wirtschaftsgüter ein hohes $\mathrm{Ma} ß$ an Selbsteinsteuerungsmöglichkeiten. Anreize opportunistisch handelnder Manager, stille Reserven im Sinne der Steuerbarwertminimierung möglichst bei Wirtschaftsgütern mit eher kürzeren Abschreibungsdauern anfallen zu lassen, sind offensichtlich. Diese Erkenntnis hat wohl Oberndorff dazu verleitet, die konsolidierungstechnische Neubewertung unter Gesichtspunkten willkürlicher Ergebnisbeeinflussung als ,inakzeptabel“ abzulehnen ${ }^{3}$.

Möglicherweise mag an dieser Stelle weiterhelfen, dass dieses in der Neubewertung zum Ausdruck kommende Objektivierungsproblem auch eine zentrale Wertkategorie im deutschen Steuerrecht prägt, ohne dass diese Kategorie dadurch an rechtstatsächlicher Bedeutung eingebüßt hätte: den Teilwert ${ }^{4}$. Dieser ist nach $\S 6$ Abs. 1 Nr. 1 Satz 3 EStG

1 Ein eindeutig ablehnendes Urteil scheint aber kaum möglich, wenn die Einzelerwerbsfiktion als eine Form marktlicher Objektivierung akzeptiert wird. Dann gäbe es immerhin eine marktliche Objektivierung, wenn auch nur auf aggregierter Ebene und aus Sicht einer anderen rechnungslegenden Einheit.

2 Vgl. so auch Pellens/Fülbier/Gassen (Internationale Rechnungslegung, 2004) S. 657; allgemeiner, dafür mit Bezug auf steuerliche Fragen Reis (Körperschaftsbesteuerung des Konzerns, 1996) S. 246.

3 Vgl. Oberndorff (Konzernbesteuerung, 1996) S. 61-68, insb. S. 65; ähnlich auch Reis (Körperschaftsbesteuerung des Konzerns, 1996) S. 246, die ebenfalls ,eine willkürliche Zuordnung der stillen Reserven zu einzelnen Wirtschaftsgütern als unzulässig“ ansieht.

4 Vgl. zu dieser Parallele in Ansätzen bereits Dusemond/Weber/Zündorf (\$ 301, 1998) Tz. 74; Grotherr (Besteuerung nationaler und grenzüberschreitender Konzerne, 1994) S. 557; ansatzweise bereits Mühlschlegel (Gewinnermittlung für Konzerne, 1971) S. 143-145. 
sowie $§ 10$ Satz 2 BewG als Betrag definiert, ,den ein Erwerber des ganzen Unternehmens im Rahmen des Gesamtkaufpreises für das einzelne Wirtschaftsgut ansetzen würde $^{\text {"1 }}$. Hier wird ebenfalls der Annahme gefolgt, dass eine Gesamtbewertung in Einzelbewertungen aufgespaltet werden kann. Objektivierungsprobleme sind dabei offensichtlich. Wahrscheinlich ergeben sich gegenüber der konsolidierungstechnischen Neubewertung sogar zusätzliche Objektivierungsnachteile, weil der tatsächliche Kauf des Unternehmens bei der Teilwertermittlung noch nicht einmal nötig ist. Möglicherweise kann daraus zumindest aus deutscher Sicht in einer komparativen Betrachtung die Erkenntnis abgeleitet werden, dass die steuerliche Konsolidierung nach der Erwerbsmethode bei dem Aspekt der Neubewertung zumindest nicht hinter das Objektivierungsniveau bestehender steuerrechtlicher Regeln zurückfällt. Ein überzeugendes Argument ist das angesichts der ebenfalls existierenden Kritik am Teilwertkonzept ${ }^{2}$ allerdings nicht.

Der Erwerbsfiktion wird im Zuge der Erstkonsolidierung nach IFRS 3 auch insofern gefolgt, als dass der Erwerbsvorgang an sich erst einmal ergebnisneutral ist. Dies ist einheitstheoretisch konsequent, wenn - wovon mit Ausnahme der Cash-Flow-Besteuerung auszugehen ist - der Kauf eines Investitionsobjektes auch in der Einzelgewinnermittlung keine Ergebniswirkung entfaltet. Diese Neutralität gilt nicht nur für jeden fingierten Einzelerwerb, sondern - mit Ausnahme der sofortigen Verrechnung des negativen Unterschiedsbetrages - auch für die Erstkonsolidierung als solche. Ergebniswirkung entfaltet hingegen die Folgekonsolidierung. Die gesamte Differenz zwischen Kaufpreis und einzelnen Wirtschaftsgütern der Einzelgewinnermittlung zu Buchwerten (im Saldo gleich dem Buchwert des Eigenkapitals) wird nach Maßgabe der jeweils geltenden Bewertungsregeln periodisiert ${ }^{3}$. Dabei ist die Periodisierung mit Ausnahme derjenigen des verbleibenden positiven oder negativen Unterschiedsbetrages letztlich kein spezifisches Konsolidierungsproblem und insofern auch nicht in IFRS 3 geregelt. Es handelt sich hier um eine ,normale“ Bewertungsfrage, bei der eine steuerliche Gesamtgewinnermittlung - analog zu IFRS 3 - auf das ansonsten geltende (nationale) Steuerrecht zurückgreifen müsste. An dieser Stelle reicht dabei die Erkenntnis aus, dass das Phänomen der Periodisierung normativen Vorgaben durchaus entspricht, zumindest soweit diese die Cash-Flow-Besteuerung nicht umfassen ${ }^{4}$.

1 Die beiden genannten Paragraphen enthalten wortgleiche Definitionen mit der Ausnahme, dass $\S 6$ Abs. $1 \mathrm{Nr}$. 1 Satz 3 EStG nicht von einem „Unternehmen“, sondern von einem „Betrieb“ spricht.

2 Vgl. zu dieser Kritik umfassend z.B. Schneider (Gerechtigkeit, 1971) S. 377-378; WB Ernst \& Young (Abschaffung des Teilwerts, 2004).

3 Vgl. Busse von Colbe et al. (Konzernabschlüsse, 2003) S. 204; letztlich werden die gesamten Anschaffungskosten in der konsolidierten Bilanz periodisiert, da auch der Buchwert der übernommenen Wirtschaftsgüter der Periodisierung unterliegt.

4 Die steuerliche Eignungsprüfung von Bewertungsregeln ist nicht Gegenstand dieser Arbeit. Sofern sich diese Prüfung auf die IFRS beziehen sollte, lässt es diese Arbeit bei den Ausführungen in Kap.V.1 und den dortigen Literaturangaben bewenden. 
Die ergebniswirksame Kapitalkonsolidierung wird aus steuerlicher Perspektive aber aus einem anderen Grund kritisiert. Dabei fokussiert diese Kritik meist auf den Fall eines positiven Unterschiedsbetrages aufgrund existierender stiller Reserven in den zu aktivierenden Wirtschaftsgütern einschließlich Goodwill. Werden diese Wirtschaftgüter im Zuge der Erstkonsolidierung höher bewertet, entsteht ein höheres Abschreibungspotenzial bzw. ein niedrigerer Veräußerungsgewinn bei deren Abgang ${ }^{1}$. Hier, so lautet der Vorwurf z.B. von Rupp ${ }^{2}$ und Grotherr $^{3}$, werde das steuerliche Betriebsvermögen durch Aufdeckung stiller Reserven ergebnis- und damit steuerneutral erhöht, während die Abschreibungen in den Folgeperioden ergebniswirksam und damit steuermindernd wirkten $^{4}$. Insofern komme es durch die erneute Schaffung von Abschreibungspotenzial zu ungerechtfertigten Steuervorteilen, die es durch die Besteuerung der aufgedeckten stillen Reserven zu vermeiden gälte ${ }^{5}$.

Im Grundsatz widerspricht diese Kritik der einheitstheoretischen Einzelerwerbsfiktion. Aus Sicht der rechnungslegenden Einheit wird ein Bündel von Investitionsgütern zu (insgesamt) marktgerechten Preisen erworben. Die beim Erstansatz aufzudeckenden stillen Reserven zu versteuern, liefe dem Prinzip des ergebnisneutralen Erwerbsvorgangs entgegen. Bei jedem Erwerbsvorgang ist schließlich zu unterstellen, dass die Veräußerer, also die ehemaligen Anteilseigner des Tochterunternehmens, die stillen Reserven über den Verkaufspreis realisieren. Somit ist Bauer erst einmal zuzustimmen, der sich diesbezüglich fragt, wieso der Erwerber die angeschafften und vom Veräußerer bereits versteuerten stillen Reserven nochmals versteuern sollte ${ }^{6}$.

In diesem Zusammenhang ist allerdings ein wichtiger Aspekt zu beachten. So vermögen die Kritiker der Erwerbsmethode steuerlich problematische Fallkonstellationen aufzuzeigen, in denen stille Reserven durch den Veräußerer eben nicht zu versteuern sind. Das deutsche Körperschaftsteuerrecht kann hier mit der steuerlichen Freistellung entsprechender Veräußerungsgewinne gemäß $§ 8 \mathrm{~b}$ Abs. $2 \mathrm{KStG}$ als Beispiel angeführt

1 Da abnutzbare und nicht abnutzbare Wirtschaftsgüter existieren, muss diese Aussage auf planmäßige wie außerplanmäßige Abschreibungen bezogen werden.

2 Vgl. Rupp (Ertragsbesteuerung nationaler Konzerne, 1983) S. 59-60.

3 Vgl. Grotherr (Besteuerung nationaler und grenzüberschreitender Konzerne, 1994) S. 553-556.

4 Ähnlich kritisch wohl Lechner (Besteuerung von Unternehmensgruppen, 1991) S. 392; ansatzweise auch Schreiber (Unternehmensbesteuerung, 2004) S. 224.

5 Sofern es hier um die „Veräußerungsgewinnbesteuerung im Betriebsvermögen des erworbenen Unternehmens“ geht, liegt evtl. eine Parallele zum „push down accouting“ vor. Diese Variante träfe zwar nicht unmittelbar die Gesamtgewinnermittlung, kollidiert aber wahrscheinlich mit der Reinvermögenszugangstheorie aus Sicht des erworbenen Unternehmens, mit den Besteuerungsfolgen in der Gesellschaftersphäre und deshalb wohl auch mit dem Trennungsprinzip bei einzelnen Unternehmen.

6 Vgl. Bauer (Besteuerung deutscher Konzerne, 1987) S. 232; dem explizit zustimmend Reis (Körperschaftsbesteuerung des Konzerns, 1996) S. 245-246; Salzberger (Konzernunternehmung, 1994) S. 167; die ergebniswirksame Kapitalkonsolidierung ebenfalls für steuerliche Zwecke begrüßend Krebühl (Konzernbesteuerung, 2003) S. 607; Küting (Einheitsbesteuerung, 1990) S. 496; Mühlschlegel (Gewinnermittlung für Konzerne, 1971) S. 133-150. 
werden. Auch sind Asymmetrien in der Wertentwicklung zwischen dem Betriebsvermögen der veräußerten (Kapital-)Gesellschaft und der Kapitalbeteiligung an ihr denkbar, so wie sie z.B. durch steuerliche Sonderabschreibungen hervorgerufen werden ${ }^{1}$. Obwohl die einheitstheoretische Konsequenz der Erwerbsmethode dadurch gar nicht tangiert wird, erhebt sich einmal mehr die bereits angesprochene Notwendigkeit, die steuerliche Konsolidierung mit den betroffenen nationalen Steuersystemen abzustimmen $^{2}$, zu einer fundamentalen Nebenbedingung. Je geringer also die Erfolgsaussichten einer derart schwierigen Abstimmungsaufgabe sind - schließlich geht es hier (wieder) um die partielle Harmonisierung der direkten Unternehmensbesteuerung in der EU desto stärker dürfte die konkrete steuerliche Tauglichkeit der Erwerbsmethode leiden.

Im Übrigen kann auch die Abkopplung aufgedeckter stiller Reserven (abzüglich stiller Lasten) vom Kaufpreis zu Asymmetrien führen. Dies ist z.B. dann gegeben, wenn das erworbene und neu bewertete Eigenkapital den Kaufpreis übersteigt. In diesem Fall wäre das neu geschaffene Abschreibungspotenzial höher als der zu versteuernde Veräußerungsgewinn. Da IFRS 3 keinerlei „Anschaffungskostenrestriktion“ beinhaltet, so wie sie z.B. die handelsrechtliche deutsche Konzernrechnungslegung bis 2002 vorsah $^{3}$, ist dieser Fall durchaus realistisch. Die ergebniswirksame Verrechnung des negativen Unterschiedsbetrages nach IFRS 3.56(b) wirkt hier allerdings als Korrelat. Die Differenz zwischen dem zu geringen Veräußerungsgewinn und den aufgedeckten stillen Reserven (abzüglich stiller Lasten) wird hiernach sofort als Ertrag der Steuer zugeführt. Vor diesem Hintergrund scheint die sofortige ergebniswirksame Verrechnung des negativen Unterschiedsbetrages steuerlich konsequent.

1 Vgl. Grotherr (Besteuerung nationaler und grenzüberschreitender Konzerne, 1994) S. 554-555; Rupp (Ertragsbesteuerung nationaler Konzerne, 1983) S. 60, die beide auf die Sonder-AfA abstellen. Sonder-AfA sind deshalb interessante Beispiele, weil sie den jeweiligen Buchwert, nicht jedoch den ökonomischen Wert eines Wirtschaftsgutes bzw. des Eigentumsrechtes daran zu reduzieren vermögen. Reis (Körperschaftsbesteuerung des Konzerns, 1996) S. 246 fügt dem noch hinzu, dass eine Beteiligung auch im Privatvermögen gehalten werden kann und bei einer Veräußerung $\S \S 17,23$ EStG nicht zwingend greifen müssen.

2 Bauer (Besteuerung deutscher Konzerne, 1987) S. 233 verweist allerdings zu Recht auf die Gefahr, die steuerliche Behandlung des Erwerbers im Einzelfall mit derjenigen des Veräußerers zu verknüpfen. Abgesehen davon, dass die steuerliche Situation des Veräußerers nicht immer zu ermitteln sei, mögen Asymmetrien z.B. auch deshalb existieren, weil der Veräußerer steuerlich privilegiert werde. Dies betreffe z.B. die Steuerfreiheit von Veräußerungsgewinnen im Privatvermögen (in der vorherigen Fußnote bereits angedeutet) oder Stundungs- und Erleichterungseffekte, wie sie das deutsche Steuerrecht z.B. in $\S \S 6 \mathrm{~b}, 16,34 \mathrm{EStG}$ kenne.

3 Die in $\S 301$ Abs. 1 Satz 4 HGB a.F. enthaltene Klausel, nach der das neubewertete (anteilige) Eigenkapital nicht mit einem Betrag angesetzt werden dürfe, der die Anschaffungskosten des Mutterunternehmens für die Anteile an dem einbezogenen Tochterunternehmen überschreitet, ist 2002, wahrscheinlich zur Angleichung an internationale Rechnungslegungsstandards, aufgehoben worden. Zuvor hat der Deutsche Standardisierungsrat (DSR) diese Abschaffung bereits vorgeschlagen; vgl. dazu Fülbier (Bilanzierung von Unternehmenserwerben im Konzernabschluss, 2000) S. 1343. 
Um die Ergebniswirkungen der Kapitalkonsolidierung umfassend zu würdigen, muss neben der Erst- und Folgekonsolidierung immer auch die Entkonsolidierung berücksichtigt werden. Durch die Folge- und Entkonsolidierung wird im konsolidierten Abschluss gewährleistet, dass der Ergebnisbeitrag des Tochterunternehmens in der Gesamtgewinnermittlung insgesamt demjenigen für die Einzelgewinnermittlung des Mutterunternehmens entspricht (identische Totalerfolgskonzeption) ${ }^{1}$. Dies dürfte auch für die IFRS gelten, sofern die knappe Vorschrift zur Entkonsolidierung in IAS 27.30 in diese Richtung interpretiert wird. Die in der Literatur Z.B. von Harms $/ \mathrm{Küting}^{2}$ formulierte Behauptung, die ergebniswirksame Kapitalkonsolidierung führe z.B. über die Abschreibung des Goodwill gegenüber einer allein auf der Basis des Trennungsprinzips angesiedelten Einzelgewinnermittlung zu permanenten Steuermindereinnahmen, ist deshalb zumindest zweifelhaft. Spätestens beim Ausscheiden des Tochterunternehmens aus dem Konsolidierungskreis dürfte sich der Totalerfolg von Einzel- und Gesamtgewinnermittlung entsprechen, so dass „lediglich“ Periodisierungsunterschiede verbleiben ${ }^{3}$. Aber selbst wenn Steuerbelastungsunterschiede im Vergleich $\mathrm{zu}$ nationalen, auf der Trennungstheorie beruhenden Steuersystemen existieren sollten, stehen sie außerhalb des hier entwickelten Beurteilungsrahmens und müssen z.B. unter lenkungsorientierten bzw. wirtschaftspolitischen Gesichtspunkten separat beurteilt werden.

Interessant erscheint auch hier wieder die Gegenüberstellung mit der europäischen Konsolidierungsrealität. Wie bereits aufgezeigt, kommen nur noch Portugal, Spanien und die Niederlande als Vergleichsländer in Frage. Dabei folgt das niederländische Körperschaftsteuerrecht eher der früheren ,deutschen“ Methode der Kapitalkonsolidierung und damit einer in jeder Hinsicht ergebnisneutralen Variante. Dort liegt im Zuge der Erstkonsolidierung eine reine Buchwertverknüpfung vor, bei der stille Reserven (oder Lasten) nicht aufgedeckt und in den Folgeperioden demzufolge auch nicht abgeschrieben werden. Stattdessen wird der gesamte Unterschiedsbetrag ohne weitere Aufteilung in

1 Vgl. Busse von Colbe et al. (Konzernabschlüsse, 2003) S. 206-209, 269-287; s.a. Baetge/Herrmann (Probleme der Endkonsolidierung, 1995) S. 225.

2 Vgl. Harms/Küting (Perspektiven der Konzernbesteuerung, 1982) insb. S. 451.

3 Vgl. so auch Bauer (Besteuerung deutscher Konzerne, 1987) S. 298-299. Folgendes Beispiel mag (auf der Grundlage der deutschen (Einzel-)Gewinnermittlungsregeln) diese Totalerfolgsidentität beleuchten: Ein Mutterunternehmen (MU) erwirbt für 200 Geldeinheiten (GE) das Tochterunternehmen (TU). In der bisherigen Bilanz von TU wird nur ein Grundstück zu $100 \mathrm{GE}$ und Eigenkapital in gleicher Höhe ausgewiesen. In der Erstkonsolidierung wird der Unterschiedsbetrag auf stille Reserven von $50 \mathrm{GE}$ im (ansonsten wertkonstanten) Grundstück und auf einen verbleibenden Goodwill von $50 \mathrm{GE}$ aufgeteilt. Letzterer wird in der Folgekonsolidierung komplett abgeschrieben. Anschließend wird TU wieder für $200 \mathrm{GE}$ verkauft. Das TU hatte in der Zwischenzeit weder Gewinne noch Verluste erwirtschaftet. In der Einzelgewinnermittlung von MU sind zwei Szenarien denkbar: die Finanzbeteiligung ist durch Bildung von originärem Goodwill über die Jahre unverändert mit $200 \mathrm{GE}$ fortgeführt worden oder sie hat sich kontinuierlich über Teilwertabschreibungen auf $150 \mathrm{GE}$ reduziert. Im ersten Fall wird kein steuerlicher Gewinn, im zweiten Fall einer von $50 \mathrm{GE}$ realisiert. Der Totalerfolg liegt in beiden Fällen bei Null. Nichts anderes ergibt sich in der Gesamtgewinnermittlung, wo der Goodwillabschreibung von $50 \mathrm{GE}$ ein Ergebnis aus der Entkonsolidierung von $50 \mathrm{GE}$ gegenüber steht. 
der konsolidierten Steuerbilanz bis zur Entkonsolidierung' eingefroren. Diese Vorgehensweise ist insofern interessant, als dass das niederländische Gruppenbesteuerungssystem in seiner idealtypischen Ausgestaltung konsequent der Einheitstheorie folgt, in punkto Kapitalkonsolidierung aber die Maßgeblichkeit von Einzel- und Gesamtgewinnermittlung auf Kosten der Einheitstheorie (über-)betont ${ }^{2}$. Möglicherweise kann dies als Indiz dafür angesehen werden, dass die einheitstheoretische Konsequenz einer ergebniswirksamen Neubewertung gegenüber den in der steuerlichen Gewinnermittlung dominanten Argumenten der Objektivierung, Einfachheit und Klarheit unterliegt.

Die Gruppenbesteuerungssysteme in Portugal und Spanien folgen indes der Erwerbsmethode und scheinen einheitstheoretisch konsequenter. Die Wirtschaftsgüter werden hier neu bewertet, so dass nur der verbleibende Restunterschiedsbetrag als aktivischer oder passivischer Ausgleichsposten verbleibt. Der ergebnisneutralen Erstkonsoliderung folgt aber keine ergebniswirksame Folgekonsolidierung. Stille Reserven bzw. Lasten sowie Konsolidierungsausgleichsposten werden in den Folgeperioden steuerlich nicht wirk$\mathrm{sam}^{3}$. So wird auch hier der Einheitstheorie nicht in letzter Konsequenz entsprochen. Angesichts der Kerngrößenorientierung der steuerlichen Gewinnermittlung hat das Aufdecken stiller Reserven und Lasten keine Bedeutung, da es an einer entsprechenden Ergebniswirkung mangelt. Im Ergebnis unterscheiden sich die Gruppenbesteuerungssysteme von Portugal und Spanien damit nicht von dem niederländischen Pendant. Aus durchführungsorientierter Effizienzperspektive erscheint das niederländische System sogar im Vorteil, weil es die im Ergebnis nutzlose Aufdeckung stiller Reserven und Lasten unterlässt ${ }^{4}$.

Dass alle drei Systeme keine ergebniswirksame Kapitalkonsolidierung zulassen, kann auch als Indiz dafür gelten, dass die Integration der Konsolidierungsregeln in bestehende Steuersysteme schon auf rein nationaler Ebene überaus schwierig ist, insbesondere wenn es darum geht, die Dominanz und „Maßgeblichkeit“ der Einzelgewinnermittlun-

1 Da die Niederlande der idealtypischen Variante folgt, ist der Konsolidierungsbegriff insbesondere im Zusammenhang mit einer Folgekonsolidierung problematisch. Die Notwendigkeit einer Erst- und Entkonsolidierung bleibt davon jedoch unberührt.

2 Ebenfalls kritisch gegenüber der „,deutschen“ Methode aus steuerlicher Sicht Salzberger (Konzernunternehmung, 1994) S. 167.

3 Ergebnisneutral schwankt auch eine Konsolidienungsrücklage im Eigenkapital in Abhängigkeit von Eigenkapitalveränderungen, die sich zwischenzeitlich im Vergleich zum Erstkonsolidierungszeitpunkt ergeben; vgl. dazu mit Beispielen Selling (Spanische Konzernbesteuerung, 1987) S. 293.

4 Während das niederländische System die ergebnisneutrale Kapitalkonsolidierung zumindest als bloße Transformationstechnik benötigt, um die Einzelgewinnermittlung in eine idealtypische Gesamtgewinnermittlung zu überführen, bleibt ihr Sinn im portugiesischen und spanischen Steuersystem eher unklar. Da es in der steuerlichen Gewinnermittlung angesichts ihrer Kerngrößenorientierung letztlich überhaupt keiner ergebniswirksamen Kapitalkonsolidierung bedarf (vgl. so auch Grotherr (Besteuerung nationaler und grenzüberschreitender Konzerne, 1994) S. 557), wirkt ihre Existenz und insbesondere auch die Aufdeckung stiller Reserven wenig konsequent. Unweigerlich entsteht der Eindruck, als sei man dort „auf halber Strecke stehen geblieben“. 
gen zu durchbrechen. Das konsequentere niederländische System hat zudem den Vorteil, die kostenintensive sowie marktferne und damit ermessensbehaftete ,cost allocation“ überhaupt nicht zu benötigen. Die Buchwertverknüpfung kommt der Durchführungseffizienz gerade bei häufigen Konsolidierungskreisänderungen ${ }^{1}$, aber auch den effizienz- wie gerechtigkeitsgetriebenen Objektivierungsanforderungen natürlich entgegen. $\mathrm{Ob}$ diese offensichtlichen Vorteile die entsprechenden Einbußen bei der einheitstheoretischen Konsequenz und der dadurch auch nicht mehr gewahrten Organisationsneutralität kompensieren, sei dahingestellt.

Abschließend bleibt festzuhalten, dass die ergebniswirksame Kapitalkonsolidierung nach IFRS 3 wieder in dem bereits aufgezeigten Spannungsverhältnis von konsequenter Einheitstheorie auf der einen und Objektivitätsanforderungen, ergänzt um Durchführungseffizienz, auf der anderen Seite angesiedelt ist. Obwohl damit nicht zweifelsfrei ausgeschlossen werden kann, dass diese Form der Kapitalkonsolidierung für Zwecke der steuerlichen Konsolidierung geeignet ist, greift hier wieder die Beweislastumkehr und die Erkenntnis, dass eine zweifelsfreie Begründung ihrer steuerlichen Eignung ebenso fehlt. Zudem ist die Existenzberechtigung der ergebniswirksamen Kapitalkonsolidierung in der steuerlichen Gesamtgewinnermittlung an die zentrale Nebenbedingung einer erfolgreichen Abstimmung mit dem sonstigen (nationalen) Steuerrecht insbesondere zur Veräußerungsgewinnbesteuerung geknüpft.

\subsubsection{Goodwill-Folgebewertung nach dem ,Impairment-Only Approach'}

In der konsolidierten Bilanz nach IFRS sind die im Zuge der „cost allocation“ angesetzten und neu bewerteten Vermögenswerte und (Eventual-)Schulden nach Maßgabe der jeweils originären Bewertungsregel fortzuführen. Ausnahmen existieren für diejenigen Positionen, die als Konsequenz der Kapitalkonsolidierung nur in konsolidierten Bilanzen erscheinen. So formuliert IFRS 3.48 eine eigene Bewertungsregel für Eventualschulden, da eine solche in IAS 37 nicht existiert. Ähnlich verhält es sich mit dem Goodwill. Da der Ansatz eines originären Goodwill in IAS 38.48 ausgeschlossen ist, erhält der aus der Kapitalkonsolidierung erwachsene derivative Goodwill in IFRS 3.5455 und IAS 36.65-108 sowie IAS 36.124-125 ebenfalls eigene Bewertungsregeln. Damit handelt es sich um ein Bewertungsproblem mit konsolidierungsspezifischen Ursachen, das im Folgenden auf seine steuerliche Eignung hin zu untersuchen ist. Die Grenze zwischen diesem Problem der Folgekonsolidierung und einem ,normalen“ Bewertungsverfahren ist aber fließend, weil die Goodwill-Folgebewertung seit der Umsetzung

1 Vgl. Grotherr (Besteuerung nationaler und grenzüberschreitender Konzerne, 1994) S. 556, 558; ansatzweise auch Bauer (Besteuerung deutscher Konzerne, 1987) S. 218-219, der einen „beachtlichen Mehraufwand" erkennt. 
von 'Business Combinations - Phase I' derjenigen immaterieller Vermögenswerte mit unbestimmter Nutzungsdauer entspricht ${ }^{1}$.

Wird der Goodwill in der konsolidierten steuerlichen Gewinnermittlung z.B. qua Konvention angesetzt ${ }^{2}$, stellt sich die Frage, ob der in IFRS 3 und IAS 36 festgelegte ,impairment-only approach" für steuerliche Zwecke geeignet ist. Dabei kann sogar eine gewisse Wechselwirkung zwischen dieser Art der Goodwill-Folgebewertung und der zuvor aufgeworfenen Ansatzfrage beobachtet werden. Trotz großer Zweifel könnte der Ansatz des Goodwill qua Konvention erleichtert werden, wenn er in Kombination mit einem Werthaltigkeitstest gesehen wird, der relativ schnell und, wenn es sein muss, in voller Höhe als Korrekturmechanismus greift. Ob allerdings die diesbezügliche Funktionsfähigkeit gegeben ist und ob die Periodisierung des Goodwill über Wertminderungen auch steuerlichen Zwecken genügen kann, wird im Folgenden zu beantworten sein.

Die Periodisierung von Anschaffungsauszahlungen ist den normativen Leitbildern der steuerlichen Gewinnermittlung, mit Ausnahme der Cash-Flow-Besteuerung, immanent. Unterschiede bestehen allerdings darin, welche Form der Periodisierung jeweils für wünschenswert gehalten wird. Um eine investitionsneutrale Gewinnermittlung im Modell des kapitaltheoretischen Gewinns zu gewährleisten, wird der ursprünglich angesetzte Ertragswert einer Investition von Periode zu Periode um die Ertragswertabschreibung reduziert. Um die steuerliche Bemessungsgrundlage zu erhalten, wird der positive Zahlungssaldo der entsprechenden Folgeperioden um diese Abschreibung reduziert, so dass letztlich nur der kapitaltheoretische Gewinn verbleibt. Wenn nun der Investitionscharakter des Goodwill nicht mehr in Zweifel gezogen wird und der Werthaltigkeitstest nach IAS 36 unter identischen Modellprämissen durchgeführt werden kann, ist die Parallele zwischen dem Wertminderungsaufwand nach IAS 36.104 und der Ertragswertabschreibung offenkundig. Dies sei an einem kleinen Beispiel verdeutlicht:

Im Rahmen der Erstkonsolidierung verbleibt nach IFRS 3.36 ein Unterschiedsbetrag von $75.000 \mathrm{~T} €$, der gemäß IFRS 3.51 als Goodwill in der konsolidierten Bilanz angesetzt wird. Es werden goodwillbezogene Zahlungsrückflüsse in den vier Folgeperioden von 28.000 T€ $\left(\mathrm{t}_{1}\right), 24.000 \mathrm{~T} €\left(\mathrm{t}_{2}\right), 20.000 \mathrm{~T} €\left(\mathrm{t}_{3}\right)$ und $17.171 \mathrm{~T} €\left(\mathrm{t}_{4}\right)$ erwartet. Unter Berücksichtigung eines Kapitalmarktgleichgewichtszinses von $8 \%$ ergibt sich für diese

1 So werden „intangible assets“ mit „indefinite useful lives“ nicht mehr planmäßig abgeschrieben, sondern dem Wertminderungstest nach IAS 36 unterzogen; vgl. IAS 38.88, 38.107-108.

2 Die Goodwill-Folgebewertung wird hier analysiert, weil die für die konsolidierte Rechnungslegung spezifischen IFRS auf ihre steuerliche Eignung zu prüfen sind. Diese Prüfung kann nicht von vornherein mit dem Argument „erschlagen“ werden, dass der steuerliche Ansatz des Goodwill kategorisch abzulehnen sei. Für die Untersuchung der Goodwill-Folgebewertung soll es ausreichen, dass die Ansatzfrage, z.B. mit Hinweis auf vereinfachende Konventionen, nicht zweifelsfrei zu verneinen ist. 
Marginalinvestition ein Kapitalwert von Null ${ }^{1}$. Der zu Anfang $\left(\mathrm{t}_{0}\right)$ aktivierte Ertragswert entspricht demnach den Anschaffungsauszahlungen für den Goodwill. Um Investitionsneutralität zu gewährleisten, darf in jeder Folgeperiode nur der kapitaltheoretische Gewinn mit dem einheitlichen Steuersatz (s) von 50\% besteuert werden. Dieser ergibt sich als Verzinsung des Ertragswertes der Vorperiode bzw. als Differenz von Zahlungszufluss und Ertragswertabschreibung. Wie in Tab. 7 gezeigt, hat somit auch der veränderte Zahlungsrückfluss unter Berücksichtung der Steuerwirkungen einen Kapitalwert von Null $^{2}$.

\begin{tabular}{|l|r|r|r|r|r|r|}
\hline Periode & $\mathrm{t}_{0}$ & $\mathrm{t}_{1}$ & $\mathrm{t}_{2}$ & $\mathrm{t}_{3}$ & $\mathrm{t}_{4}$ & Kapitalwert \\
\hline $\begin{array}{l}\text { Zahlungsüberschuss vor } \\
\text { Steuern (i=0,08) }\end{array}$ & -75.000 & 28.000 & 24.000 & 20.000 & 17.171 & 0 \\
\hline Ertragswert & 75.000 & 53.000 & 33.240 & 15.900 & 0 & \\
\hline Ertragswertabschreibung & 0 & 22.000 & 19.760 & 17.340 & 15.900 & \\
\hline $\begin{array}{l}\text { Kapitaltheoretischer } \\
\text { Gewinn }\end{array}$ & 0 & 6.000 & 4.240 & 2.660 & 1.272 & \\
\hline Steuer (s=0,5) & 0 & 3.000 & 2.120 & 1.330 & 636 & \\
\hline $\begin{array}{l}\text { Zahlungsüberschuss } \\
\text { nach Steuern }\left(\mathrm{i}_{\mathrm{s}}=0,04\right)\end{array}$ & -75.000 & 25.000 & 21.880 & 18.670 & 16.535 & 0 \\
\hline
\end{tabular}

Tab. 7: Ertragswertabschreibung auf den Goodwill (Beispielrechnung)

Nichts anderes passiert unter den gegebenen Modellbedingungen im Rahmen eines Werthaltigkeitstests. Dafür sei hier vereinfachend angenommen, dass sich die Vorgehensweise von IAS 36 unmittelbar auf den Goodwill bezieht und nicht auf eine ZGE. Der ursprüngliche Erstansatz von $75.000 \mathrm{~T} €$ (carrying amount) ist in der ersten Periode $\left(t_{1}\right)$ auf seine Werthaltigkeit zu testen. Hierfür wird der erzielbare Betrag (recoverable amount) benötigt, wobei der beizulegende Zeitwert abzüglich etwaiger Verkaufskosten im Falle vollkommener Information dem Nutzungswert entspricht. Verkaufskosten spielen dabei keine Rolle, da sie in einer friktionslosen Welt nicht existieren - abgesehen davon, dass sich der Goodwill, wie aufgezeigt, zum separierten Verkauf gar nicht eignet. Der erzielbare Betrag in $t_{1}$ entspricht somit dem Ertragswert von $53.000 \mathrm{~T} \epsilon$, so dass sich im Vergleich zum Buchwert ein Wertminderungsaufwand in Höhe von 22.000T€ ergibt. Dieser entspricht der Ertragswertabschreibung. Für die Perioden $t_{2}$ bis $t_{4}$ gilt dies analog. Wenn der Wertminderungsaufwand als Betriebsausgabe und die Zahlungszu-

1 Investitions- bzw. Entscheidungsverzerrungen einer steuerlichen Gewinnermittlung würden sich insofern in einer Kapitalwertänderung bei der Berücksichtigung von Steuern dokumentieren; vgl. dazu z.B. Schiele (Unternehmensbesteuerung, 2000) S. 158-159 sowie Kap. II.2.1.2.2.

$2 \mathrm{Vgl}$. ähnlich in dieser beispielorientierten Vorgehensweise bei der Identifikation investitionsneutraler Abschreibungsmethoden im Sachanlagevermögen Gröning (Steuerbilanzielle Gewinnermittlung, 2002) S. 156-160. 
flüsse als Betriebseinnahme behandelt werden, wird im Ergebnis wiederum nur der kapitaltheoretische Gewinn besteuert, so dass eine investitionsneutrale Gewinnermittlung gegeben ist. Weil der Ertragswert der Investition in den Goodwill erhalten bleibt, ist über diese Periodisierung qua Wertminderungsaufwand das „entscheidungsneutrale Ausmaß der Innenfinanzierung aus Aufwandsverrechnung “ ${ }^{1}$ erreicht.

Die Beschränkung des Werthaltigkeitstests auf den Goodwill ist im Übrigen modellimmanent. Nach IAS 36.97-98 besteht eine vorrangige Pflicht, zuerst die in der ZGE enthaltenen Vermögenswerte auf ihre Werthaltigkeit zu prüfen, so dass unter den gegebenen Prämissen nur die Goodwillkomponente für residuale Wertkorrekturen verantwortlich sein kann. Andernfalls wäre die erst den Goodwill betreffende Zuteilungsreihenfolge der ZGE-Wertminderung auch kaum zu rechtfertigen. Unter den gegebenen Modellbedingungen ist auch das Wertaufholungsverbot des IAS 36.124 konsequent, da es eine Wertaufholung unter vollkommener Information gar nicht geben kann. Selbst die Marginalinvestition lässt sich rechtfertigen, da der Goodwill ja nicht aus einer gruppeninternen und damit marktfernen Transaktion resultiert, sondern aus einer unter fremden Dritten, die bei vollkommenen Märkten keine Überrendite verspricht.

Damit kann festgehalten werden, dass der Werthaltigkeitstest nach IAS 36 unter den Modellbedingungen des kapitaltheoretischen Gewinns in geradezu idealer Weise einer investitionsneutralen Gewinnermittlung entspricht. Das Problem besteht aber darin, dass es realiter an eben diesen Modellbedingungen mangelt. Dadurch wird die normative Aussagekraft dieser Wertung natürlich deutlich relativiert. An dieser Stelle greift wieder die Reinvermögenszugangstheorie, deren Stärke ja gerade in der Berücksichtigung entsprechender Unvollkommenheit liegt. Der normative Fokus wird dabei allerdings von der Investitionsneutralität hin zur gerechtigkeitsgetriebenen Perspektive steuerlicher Leistungsfähigkeit verschoben.

Sofern die Reinvermögenszugangstheorie konsequent am Prinzip der Barrealisation festhielte, müsste hier streng genommen auf jedes Periodisierungsprinzip verzichtet werden. Damit wäre bereits der Ansatz des Goodwill abzulehnen und mit ihm jede Periodisierung der auf ihn entfallenden Anschaffungsauszahlungen. Angesichts fehlender diesbezüglicher Voraussetzungen (u.a. sofortiger Verlustausgleich, im Zeitablauf konstanter Steuersatz ${ }^{2}$ ), der nicht unproblematischen Vermengung gerechtigkeitsgetriebe-

1 Schneider (Steuerlast, 2002) S. 287, 107. Vor dem Hintergrund der in dieser Arbeit verwendeten Terminologie müsste hier anstelle von ,Entscheidungsneutralität' eher von ,Investitionsneutralität' und anstelle von ,Aufwandsverrechnung' von ,Verrechnung der Anschaffungsauszahlungen als Betriebsausgaben' gesprochen werden.

2 Schneider (Steuerlast, 2002) S. 287 fügt hinzu, dass der Verzicht auf das Periodisierungsprinzip auch das Anstreben vertikaler Gerechtigkeit ausschließe, wenn diese über einen teilweise (direkt-)progressiven Tarif erreicht werden solle; s.a. Schneider (Tugend, 2004) S. 303. 
ner Sichtweisen mit wirtschaftspolitischen Überlegungen ${ }^{1}$ und des Versuchs, sich den Anforderungen einer investitionsneutralen Gewinnermittlung zumindest anzunähern, kann die Periodisierung aber auch in diesem Kontext befürwortet werden ${ }^{2}$. Dadurch kommt es jedoch zu einem Dilemma: Die Periodisierung wird einerseits als Hilfslösung akzeptiert, obwohl andererseits die Erkenntnis vorherrscht, dass unter den Bedingungen unvollkommener Information und fehlender Planungssicherheit kein „ökonomisch richtiges" Abschreibungsverfahren existieren könne ${ }^{3}$. Im Ergebnis wird deshalb eine Konvention präferiert, die zumindest den effizienz- wie gerechtigkeitsgetriebenen Grundsätzen der Klarheit, Einfachheit und Objektivität genügt. Nach dieser, insbesondere von Schneider vertretenen Auffassung solle die Abschreibung ,nach dem Satz vom mangelnden Grunde als gleichmäßige Periodenbelastung ${ }^{64}$ über ein normiertes Durchschnittsverfahren bemessen werden ${ }^{5}$.

Der ,impairment-only approach“ nach IFRS 3 und IAS 36 dürfte diesen Anforderungen widersprechen. Das gilt bereits für den damit einhergehenden Komplexitätsgrad und den dafür notwendigen personellen Ressourceneinsatz ${ }^{6}$, der z.B. ein normiertes Durchschnittsverfahren aus durchführungsorientierter Effizienzsicht deutlich überlegen erscheinen lässt. Das Kernargument gegen den ,impairment-only approach“ resultiert aber aus der realitätsfernen Prämisse vollkommener Information. Nur die sichere Kenntnis künftiger Zahlungen führt im Ergebnis dazu, dass sich die Höhe des Wertminderungsaufwands als Ertragswertabschreibung nach dem ex ante schon bekannten Gewinn bemisst. In der Realität dürfte es eher umgekehrt sein. Hier fließt die unter Unsicherheit bemessene Abschreibung in die Gewinnermittlung ein, aus der sich der Gewinn ex post ergeben soll ${ }^{7}$. In anderen Worten: Die unvollkommene Information der Bilanzierenden, aber auch der Kontrollierenden, wird immer dazu führen, dass die Prognoseproblematik die Bestimmung des Wertminderungsaufwands erschwert. Angesichts begrenzter Rationalität und Opportunismus geht dies insbesondere auch mit erheblichen

1 Das Festhalten an der Periodisierung über Abschreibungen hätte demnach seine wirtschaftspolitische Berechtigung, solange die ansonsten wegfallende Finanzierungsfunktion der Abschreibungen nicht anderweitig kompensiert wird. Vgl. so insb. Schneider (Steuerlast, 2002) S. 287-288.

3 Vgl. Schneider (Steuerlast, 2002) S. 288. „Ökonomisch richtig“ wird hier wohl im Sinne von „verursachungsgerecht" gedeutet. Ein verursachungsgerechtes Abschreibungsverfahren könne aber nicht abgeleitet werden, ohne den korrespondierenden Gewinn als bekannt vorauszusetzen bzw. gegen das Anschaffungswertprinzip zu verstoßen; vgl. dazu Schneider (Abschreibungsverfahren, 1974); Schnei$\operatorname{der}$ (Anlagenabschreibung, 1974).

4 Schneider (Anlagenabschreibung, 1974) S. 402.

5 Vgl. Schneider (Abschreibungsverfahren, 1974) S. 375; Schneider (Anlagenabschreibung, 1974) S. 405; Schneider (Steuerlast, 2002) S. 288; Schneider (Tugend, 2004) S. 303-304.

6 Vgl. u.a. Protzek (Impairment Only-Ansatz, 2003) S. 501 m.w.N.; Saelzle/Kronner (impairment-onlyAnsatz, 2004) S. S 164.

7 Vgl. Schneider (Abschreibungsverfahren, 1974) S. 375. 
Ermessens- und Selbsteinsteuerungsspielräumen einher ${ }^{1}$, die aus wettbewerbsneutraler, durchführungseffizienter sowie verfassungsrechtlich-ethischer Sicht für die steuerliche Gewinnermittlung abzulehnen sind. So ist es geradezu ein Kerncharakteristikum des Werthaltigkeitstests von IAS 36, dass er auf einer Fülle ermessensbehafteter Entscheidungen beruht ${ }^{2}$. Dies betrifft bereits die Identifikation und Abgrenzung der ZGE (IAS 36.66-73) und setzt sich in der Frage fort, wie der Goodwill aus der Erstkonsolidierung diesen ZGE zuzuordnen ist (IAS 36.80-87) ${ }^{3}$. Selbst die Festlegung des Zeitpunkts, zu dem der Werthaltigkeitstest durchzuführen ist, dürfte nicht ermessensfrei sein, da verbindliche testauslösende Indikatoren nicht definiert sind ${ }^{4}$. Das Ermessen gipfelt aber gewissermaßen in der Ermittlung des erzielbaren Betrages, insbesondere in der oft notwendigen Prognose künftiger Zahlungsüberschüsse, der Festlegung geeigneter Kalkulationszinsfüsse und der rechnerischen Berücksichtigung der Unsicherheit (IAS 36.25-57, Appendix A). Auch die IAS $36 \mathrm{zu}$ entnehmenden Objektivierungsbemühungen in Form der vielen Detailregeln können das Ermessen, das vielen dieser Entscheidungen letztlich inhärent ist, nicht wesentlich reduzieren.

Die steuerliche Eignung des ,impairment-only approach“ wird aus der Sicht der Reinvermögenszugangstheorie durch ein weiteres Argument relativiert. Da der Werthaltigkeitstest auf Ebene der ZGE durchgeführt wird, kommt es selbst unter theoretischen Idealbedingungen $\mathrm{zu}$ keiner Wertberichtigung, wenn die Wertminderung des erworbenen Goodwill mindestens in gleicher Höhe durch einen neu geschaffenen originären Goodwill in der ZGE kompensiert wird. Die Nichtberücksichtigung der eigentlich anfallenden Wertminderung verstößt nicht nur gegen das Leitbild der investitionsneutralen Gewinnermittlung und die wie auch immer geartete Periodisierungsnotwendigkeit in Verbindung mit der Reinvermögenszugangstheorie. Sie verstößt vor allem gegen das

1 Vgl. selbige mit gewissen Analogien auch bei der Anlagenabschreibung nach US-GAAP identifizierend Gröning (Steuerbilanzielle Gewinnermittlung, 2002) S. 149-153, der hier ein implizites Wahlrecht der Verlustvorwegnahme erkennt.

2 Vgl. dazu (in Teilen bezogen auch auf die nicht identische, jedoch wesensverwandte Vorgehensweise nach US-GAAP) Esser (Goodwillbilanzierung, 2003) S. 221-250; Hommel (Goodwillbilanzierung, 2001) S. 1945-1948; Kirsch (Asset Impairment, 2004) S. 137-139; Pellens/Sellhorn (Goodwill-Bilanzierung, 2001) S. 1685-1689; Protzek (Impairment Only-Ansatz, 2003) S. 497-499; Richter (Goodwill nach SFAS No. 141 und SFAS No. 142, 2004) insb. S. 247-253; Saelzle/Kronner (impairment-onlyAnsatz, 2004) S. S 162-S 163; Watts (Conservatism, 2003) S. 217-218; Wüstemann/Duhr (ED 3, 2003); Zülch (IFRS 3, 2004) S. 338-339; sehr ausführlich und m.w.N. Sellhorn (Goodwill Impairment, 2004) S. 163-204; vgl. zu Unterschieden zwischen der US-GAAP- und IFRS-Vorgehensweise z.B. Lüdenbach/Hoffmann (Goodwill-Impairment, 2004).

3 Letztere Frage ist schon deshalb interessant, weil im Goodwill immer auch schwer aufteilbare Verbundwirkungen enthalten sind. Andererseits scheint diese Allokation auch aus steuerlicher Sicht notwendig, wenn der Goodwill auf Minderheiten zugeteilt und nicht als etwas gruppeneigenes betrachtet werden soll.

4 Vgl. z.B. IAS 36.88: „..shall be tested for impairment, whenever there is an indication that the unit may be impaired, .." oder IAS 36.96: "... may be performed at any time during an annual period, provided the test is performed at the same time every year. Different cash-generating units may be tested for impairment at different times. ..." 
Ansatzverbot eines originären Goodwill ${ }^{1}$, das der Reinvermögenszugangstheorie und dem dort herrschenden Verständnis eines Wirtschaftsgutes und im Übrigen auch dem Ansatzverbot in IAS 38.48 widerspricht. Im Modell des kapitaltheoretischen Gewinns konnte dieses Problem einfach ausgeklammert werden. Zahlungen zum Aufbau des originären Goodwill müssten hiernach wieder als eigenständige Investition betrachtet und beurteilt werden. Unter realitätsnäheren Bedingungen dürfte diese Trennung indes schwierig und der Ansatz eines originären Goodwill kaum vermeidbar sein. Da schon der Ansatz eines zumindest erworbenen (derivativen) Goodwill mit der Reinvermögenszugangstheorie nur schwerlich in Einklang zu bringen ist, gilt dies erst recht für den originären Goodwill, der, von einer selbständigen Verkehrsfähigkeit ganz zu schweigen, noch nicht einmal zwingend mit irgendwelchen Auszahlungen in Verbindung gebracht werden muss.

Im Ergebnis lässt sich festhalten, dass der „impairment-only approach“ den Anforderungen einer investitionsneutralen steuerlichen Gewinnermittlung unter restriktiven Modellbedingungen vollauf entspricht. Aus dieser Perspektive wäre es nur konsequent, eine derartig ideale Bewertungsmethodik auch auf andere Wirtschaftsgüter und damit in die Einzelgewinnermittlung zu übertragen, wie es im IFRS-System in IAS 38.107-108 bereits ansatzweise der Fall ist. Die investitionsneutrale Wirkung des " impairment-only approach" ist allerdings den gleichen Kritikpunkten ausgesetzt, die das Modell des kapitaltheoretischen Gewinns als solches betreffen. Werden reale (Markt-)Unvollkommenheiten berücksichtigt, relativiert sich die zuvor aufgezeigte Eignung deutlich. So sollte die als Hilfslösung anerkannte Periodisierung aus Sicht der gerechtigkeitsgetriebenen Reinvermögenszugangstheorie einer klaren, einfachen und objektiven Konvention folgen. Der Werthaltigkeitstest nach IAS 36 dürfte diesem Leitbild eher widersprechen.

\subsubsection{Berücksichtigung von Minderheiten}

\subsection{Volle Aufdeckung stiller Reserven und Lasten im Zuge der Neubewer- tungsmethode}

In den bisherigen Ausführungen ist das Minderheitenproblem ausgeklammert worden. Das soll sich im Folgenden ändern. Wenn Tochterunternehmen nur anteilig erworben werden, sind Minderheiten in der Kapitalkonsolidierung zu berücksichtigen. Schon an

1 Vgl. zu dieser Kritik an der Vermengung von derivativem und originärem Goodwill bereits Hommel (Goodwillbilanzierung, 2001) S. 1948; Pellens/Sellhorn (Goodwill-Bilanzierung, 2001) S. 1685-1686; dieses Problem ist grundsätzlich mit einem Werthaltigkeitstest beim Goodwill verbunden, unabhängig davon, auf welcher Ebene dieser Test durchgeführt wird; vgl. so schon Fülbier (Bilanzierung von Unternehmenserwerben im Konzernabschluss, 2000) S. 1344; Sellhorn (Ansätze zur bilanziellen Behandlung des Goodwill, 2000) S. 890; jüngst wieder $A A A$ (Business Combinations, 2004) S. 60, die deshalb für eine planmäßige Abschreibung des Goodwill plädieren. 
dieser Stelle zeigt sich eine Eigenart der Minderheitenberücksichtigung. Der Minderheitenanteil bezieht sich allein auf die finanzielle Beteiligung bzw. den Kapitalanteil' ${ }^{1}$, obwohl das Beherrschungskonzept von IAS 27 und SIC-12 selbst nicht auf den Kapitalanteil abstellt. So kann es im Extremfall dazu kommen, dass z.B. eine Zweckgesellschaft nach SIC-12 trotz eines „Minderheitenanteils“2 von 100\% vom Mutterunternehmen beherrscht wird. Diese Vorgehensweise scheint aber korrekt, weil es hier letztlich um zwei verschiedene Fragen geht: Mit dem Beherrschungskonzept wird die Frage beantwortet, ob überhaupt ökonomisches Eigentum vorliegt. Diese Frage kann - wie bereits ausgeführt $^{3}$ - nur binär mit ja oder nein beantwortet werden und führt entweder zur Vollkonsolidierung oder zu keiner Einbeziehung in den Konsolidierungskreis. Die zweite Frage zielt anschließend ,nur“ noch auf die konsolidierungstechnische Berücksichtigung des Kapitalanteils, der realiter von Minderheiten gehalten wird, sowie auf den Ergebnisanteil, der ihnen zuzuordnen ist ${ }^{4}$.

Nach IFRS 3.36 sind sämtliche Tochterunternehmen, auch diejenigen, an denen Minderheiten beteiligt sind, nach der Neubewertungsmethode zu konsolidieren. Dies ist eine vergleichsweise konsequente Umsetzung einheitstheoretischer Vorstellungen. Die Vermögenswerte und Schulden werden vollständig zu beizulegenden Zeitwerten in der konsolidierten Bilanz angesetzt, so dass stille Reserven und Lasten auch in Höhe des Minderheitenanteils aufgedeckt werden. Da die oberste Entscheidungs- und Kontrollinstanz der Unternehmensgruppe über sämtliche Ressourcen vollständig verfügen kann, wäre z.B. die Buchwertmethode mit einer nur anteiligen Berücksichtigung stiller Reserven und Lasten ein Rückfall in die Interessentheorie. Auf der Passivseite der konsolidierten Bilanz ist es ebenso konsequent, den Minderheitenanteil im Eigenkapital nach IAS 27.33 auszuweisen, da Mehrheits- wie Minderheitsgesellschafter als gleichberechtigte Eigenkapitalgeber zu behandeln sind.

Fraglich ist, ob die Neubewertungsmethode in ihrer Berücksichtigung der Minderheiten auch für steuerliche Konsolidierungszwecke geeignet ist. Mag die einheitstheoretische Konsequenz eher dafür sprechen, so existieren aber auch Zweifel und zwar unabhängig von den generellen Bedenken gegenüber der Erwerbsmethode. Diese Zweifel konzent-

1 Vgl. z.B. bezeichnend die Definition von „minority interest“" in IFRS 3, Appendix A: „That portion of the profit or loss and net assets of a subsidiary attributable to equity interests that are not owned, directly or indirectly through subsidiaries, by the parent" [Hervorhebungen vom Verfasser]; wortgleich auch IAS 27.4.

2 Busse von Colbe et al. (Konzernabschlüsse, 2003) S. 209 oder auch von Wysocki/Wohlgemuth (Konzernrechnungslegung, 1996) S. 118 verwenden hier den neutraleren Begriff der „Anteile anderer Gesellschafter“. Mit ähnlicher Begründung schlägt bereits Moonitz (Entity Theory, 1951) S. 76 ,outside interest" vor. In dieser Arbeit wird indes der IFRS-Terminologie (,minority interest“) gefolgt.

3 Vgl. Kap. V.2.3.

4 Würde der Minderheitenanteil z.B. nur über Stimmrechtsquoten bemessen, wäre das wahrscheinlich eine Vermengung dieser zwei Ebenen. Wenn aus Stimmrechten wirklich eine Minderheitenberechtigung abgeleitet würde, wäre letztlich die Vollkonsolidierung als solche zu hinterfragen. 
rieren sich auf das Kerncharakteristikum der Neubewertungsmethode, die stillen Reserven und Lasten vollständig aufzudecken, obwohl diese durch den bzw. die Mehrheitsgesellschafter letztlich nur anteilig erworben und bezahlt worden sind. Daraus lassen sich Verstöße gegen das Anschaffungswertprinzip und die Pagatorik ableiten' .

Der Vorwurf, die Neubewertungsmethode verstoße gegen Anschaffungswertprinzip und Pagatorik, ist aus normativer Perspektive für die steuerliche Eignung der Neubewertungsmethode problematisch. Wenn in dieser Arbeit konkretere Anforderungen an die steuerliche Gewinnermittlung abgeleitet werden konnten, so zielten sie sämtlich in Richtung einer starken Zahlungsorientierung. Nichts anderes verbirgt sich hinter einer pagatorischen Rechnung, die auf Zahlungsvorgängen aufbaut und sich insbesondere von kalkulatorischen Größen distanziert. Dabei ist zu gewährleisten, dass das Gesamtergebnis der Rechnungslegung in der Totalperiode der Summe aller Zahlungsüberschüsse entspricht ${ }^{2}$. Wenn eine wie auch immer geartete Periodisierung für die steuerliche Gewinnermittlung akzeptiert wird, gilt Ähnliches auch für das Anschaffungswertprinzip. Hiernach sind Wirtschaftsgüter mit den Zahlungen anzusetzen, die das Unternehmen für ihre Anschaffung oder Herstellung geleistet bzw. erhalten hat ${ }^{3}$.

So verstößt die Neubewertungsmethode gegen das Anschaffungswertprinzip, soweit die Wertansätze der neu bewerteten Vermögenswerte und Schulden in der Erstkonsolidierung Minderheitenanteile beinhalten ${ }^{4}$. Das führt gleichermaßen zu pagatorischen Verwerfungen. Obwohl IFRS 3 zumindest ergebnisneutrale Verrechnungen und damit zusätzliche Verwerfungen unterbindet, ist der Gleichklang von Zahlungsüberschuss und Ergebnis in der Totalperiode nicht gewährleistet. Wenn Minderheiten beteiligt sind, entsprechen die Auszahlungen für den Kauf des Unternehmens (abzüglich späterer Verkaufseinzahlungen) nicht den Abschreibungen sowie Auflösungsbeträgen in der Erstund Folgekonsolidierung.

Streng genommen sind hier aber mehrere pagatorische Ebenen $\mathrm{zu}$ unterscheiden: Aus Sicht der erwerbenden Unternehmensgruppe und rechnungslegenden Einheit umfasst

1 Vgl. hierzu z.B. Ordelheide (Kapitalkonsolidierung, 1984) S. 241; Ordelheide (Anschaffungskostenprinzip, 1986); vgl. m.w.N. gerade zur älteren Literatur dieser keineswegs neuen Diskussion sowie zu weiteren Argumenten Küting (Problematik des Ausgleichspostens, 1984) S. 553-560; aus steuerlicher Sicht Bauer (Besteuerung deutscher Konzerne, 1987) S. 287.

2 Vgl. dazu grundlegend Kosiol (Pagatorische Bilanz, 1976) insb. S. 113-317; zum Terminus ,pagatorisch" auch S. 351-359.

3 Vgl. dazu grundlegend Kosiol (Pagatorische Bilanz, 1976) insb. S. 345-389. Das Anschaffungswertprinzip in seiner Wirkung für die Folgebewertung (Wertobergrenze) wird hier nicht betrachtet.

4 Auch hier gilt gleichermaßen, dass positive und negative Unterschiedsbeträge nicht als technisches Residuum fungieren und nicht den Ausgleich zwischen dem Kaufpreis und dem Saldo sämtlicher Vermögenswerte und Schulden garantieren. Wenn dem so wäre, könnte der Wert dieses Residuums ebenfalls als Anschaffungsaus- bzw. -einzahlung interpretiert werden und das Anschaffungswertprinzip wäre gewahrt. 
die pagatorische Abweichung sämtliche Minderheitenanteile an den Vermögenswerten und Schulden, also an ihren Buchwerten sowie stillen Reserven und Lasten. Über jeden pagatorischen Zweifel erhaben wäre aus dieser Perspektive nur die Quotenkonsolidierung, denn auch die Buchwertmethode nimmt im Rahmen der Vollkonsolidierung den auf Minderheiten entfallenden Buchwert in die konsolidierte Bilanz auf, ohne dass er durch die Anschaffungsauszahlung für den anteiligen Unternehmenskauf gedeckt wäre. An dieser Stelle greift nun die zweite pagatorische Ebene, die den Einzelabschluss des erworbenen Unternehmens mit berücksichtigt. Sofern die Buchwerte dort pagatorisch abgesichert, also tatsächlich bezahlt worden sind, kann diese Absicherung in die konsolidierte Bilanz hineinwirken und gilt damit auch für den Minderheitenanteil. Auf dieser zweiten Ebene ist die pagatorische Absicherung aber schon weniger fundiert. In der Terminologie der (deutschen) Konzernrechnungslegung konstatieren Busse von Colbe et al. deshalb zu Recht, dass man nicht übersehen sollte, dass diese Zahlungen ,nicht vom Konzern geleistet wurden. Diese Zahlungen wurden zum Teil weit vor dem Erwerbszeitpunkt der Mehrheitsbeteiligung geleistet und damit vor dem Zeitpunkt des Zugangs dieser Vermögensgegenstände zum Konzernabschluss. Es sind Poolingwerte und keine Purchasewerte" .

Die der Neubewertungsmethode immanente Abkopplung von Zahlungen ist unbestreitbar. Dennoch ist fraglich, welche genauen Konsequenzen sich daraus für die steuerliche Eignung ergeben. Ein schlagendes Argument dürfte daraus nicht abzuleiten sein. So akzeptiert z.B. Kosiol als Befürworter der pagatorischen Bilanz die Sach-oder Realeinlage, bei der Gesellschafter Real(wirtschafts)güter gegen Kapitalanteile in ein Unternehmen einlegen können. Hier werde ,in der Regel ein realisiert-pagatorischer Wert durch Vereinbarung festgelegt und damit unterstellt ${ }^{6 / 2}$. Selbiges dürfte auch für die steuerliche Gewinnermittlung gelten. In der Denkwelt des kapitaltheoretischen Gewinns wie der der Reinvermögenszugangstheorie kann die Sacheinlage dem Ansatz des entsprechenden Wirtschaftsgutes nicht entgegenstehen, insbesondere dann nicht, wenn eine klare und eindeutige Wertzuordnung möglich ist. So ist die Sacheinlage z.B. auch im deutschen Steuerrecht eine Selbstverständlichkeit ${ }^{3}$.

Die Analogie zur Sacheinlage bei der Einheitsunternehmung mag auch bei der Beurteilung der Neubewertungsmethode im Rahmen der Kapitalkonsolidierung hilfreich sein ${ }^{4}$. So kann hier qua Annahme unterstellt werden, dass die Minderheiten ihren Anteil an

1 Busse von Colbe et al. (Konzernabschlüsse, 2003) S. 211.

2 Kosiol (Pagatorische Bilanz, 1976) S. 380 [Hervorhebungen im Original fehlen], der hinzufugt, dass hier letztlich nur ein Zahlungsvorgang antizipiert werde („Vorratsausgabe“), so dass sich die „unterstellte Vorratsausgabe für das eingebrachte Wirtschaftsgut .. zwanglos in das pagatorische Bewertungssystem einbeziehen" lasse.

3 Vgl. hierzu im Überblick z.B. Hiort (Einlagen, 2004) S. 15-21.

4 Vgl. so auch Busse von Colbe et al. (Konzernabschlüsse, 2003) S. 211; Ordelheide (Konzernerfolg, 1987) S. 299-300; jüngst wieder Pawelzik (Phase II, 2004) S. 678. 
den stillen Reserven und Lasten zu dem Zeitpunkt, zu dem der Mehrheitsgesellschafter die Beherrschungsmöglichkeit erlangt, über eine Sacheinlage in die konsolidierte Bilanz bzw. Unternehmensgruppe einbringen. Weil sie ihren Anteil an den Wirtschaftsgütern einlegen, erhöht sich - einheitstheoretisch konsequent - auch der im Eigenkapital ausgewiesene Minderheitenanteil. Konsequenterweise führt demnach die Entkonsolidierung zu einer Entnahme des Minderheitenanteils aus der Gruppe.

Die Kernfrage der Sacheinlage ist allerdings die Wertbeimessung ${ }^{1}$. Im Idealfall liegen hier objektivierte Marktwerte vor, wie sie die Neubewertungsmethode letztlich nachzubilden versucht. Interessant ist hierbei der Vergleich mit der Buchwertmethode. Auch dort wird letztlich im Zuge der Vollkonsolidierung unterstellt, dass die Minderheiten mangels jedweder Zahlung eine derartige Sacheinlage leisten, die aber lediglich auf den aus der Einzelgewinnermittlung stammenden Buchwertanteil beschränkt ist.

Letztlich steht damit wieder das Objektivierungsproblem im Vordergrund. So ist es nicht von der Hand zu weisen, dass die Minderheiten ihren Anschaffungswertanteil tatsächlich nicht selbst bezahlen und bestimmen. Immerhin werden die auf sie entfallenden Anteile aber rechnerisch aus dem Akquisitionsvorgang der Mehrheitsgesellschafter abgeleitet. Darin könnte eine Art pagatorische Fiktion ${ }^{2}$ und eine gewisse Objektivierung gesehen werden ${ }^{3}$. Objektivierungsprobleme treten letztlich aber auch bei der Buchwertmethode auf. Bei Erwerb des ökonomischen Eigentums kann auch dort nicht unterstellt werden, dass der Erwerber (Mehrheitsgesellschafter) die Ressourcen des Tochterunternehmens streng anteilig erwirbt. Dies würde eine lineare Funktion zwischen Beteiligungsquote und Kaufpreis - im Übrigen auch zwischen Beteiligungsquote und Wertansatz der einzelnen Wirtschaftsgüter ${ }^{4}$ - unterstellen, die realiter kaum realistisch ist. Da der Erwerber weiß, dass er mit dem ökonomischen Eigentum die volle Verfügungsgewalt über die Ressourcen des Tochterunternehmens erlangt, dürfte ein überproportionaler Kaufpreis wahrscheinlich sein ${ }^{5}$. Dieses Phänomen ist unter dem Stichwort „Kon-

1 Vgl. dazu bereits Kosiol (Pagatorische Bilanz, 1976) S. 998: „Bei der Sachgründung tritt die Frage der Bewertung auf. Da den eingebrachten Realgütern keine tatsächlichen Ausgaben gegenüberstehen, kommen unterstellte (fiktive) Ausgaben als Anschaffungswerte infrage. Pagatorisch handelt es sich dabei um den Tagesbeschaffungswert im Zeitpunkt der Einbringung".

2 Küting (Problematik des Ausgleichspostens, 1984) S. 559 spricht hier von der Fiktion, „daß der Konzern im Falle des Erwerbs aller Anteile tatsächlich bereit gewesen wäre, die bei der Untergesellschaft gebildeten und bislang auf Minderheiten anteilig entfallenden stillen Reserven zu bezahlen“.

3 Vgl. Ordelheide (Kapitalkonsolidierung, 1984) S. 274, der konstatiert, dass die Wertheraufsetzung auf einer ermessensfreien Hochrechnung basiere, die mit keiner zusätzlichen Entobjektivierung verbunden sei; ähnlich auch Schindler (Kapitalkonsolidierung, 1986) S. 192, der soweit geht, einen Verstoß gegen das pagatorische Prinzip zumindest mittelbar zu bezweifeln.

4 Vgl. hierzu kritisch Küting/Zündorf(Ermittlung der Minderheitenanteile, 1985) S. 1172.

5 Mit Bezug auf die von Küting (Problematik des Ausgleichspostens, 1984) S. 559 formulierte pagatorische Fiktion ist sogar anzunehmen, dass die Unternehmensgruppe nicht nur fiktiv bereit gewesen wäre, die Minderheitenanteile an den stillen Reserven mit zu bezahlen, sondern dies im Regelfall, für einen mehr oder minder großen Teil davon, auch tatsächlich tut. 
trollprämie“" auch empirisch nachweisbar ${ }^{1}$. Die streng beteiligungsproportionale Aufdeckung stiller Reserven und Lasten dürfte damit von ähnlichen „Informationsdefiziten“ betroffen sein wie ihre Vollaufdeckung. Dies liegt im Übrigen auch daran, dass das Problem der marktfernen Einzelwertzumessung im Rahmen der „cost allocation“ beide Methoden gleichermaßen trifft ${ }^{2}$.

Als Zwischenergebnis kann nur Bauer zugestimmt werden, der ein generelles „Informationsdefizit" bei der Existenz von Minderheiten identifiziert, so dass „eine theoretisch einwandfreie Lösung des Problems von vornherein unmöglich" ${ }^{\text {"3 }}$ sei. Vor diesem Hintergrund dürfte aber die kategorische Ablehnung der Neubewertungsmethode für Zwecke der steuerlichen Konsolidierung und die diesbezügliche Befürwortung der Buchwertmethode ${ }^{4}$ ebenfalls nicht überzeugen. Wenn theoretische einwandfreie Lösungen nicht vorliegen, bedarf es in steuerlicher Hinsicht einer praktikablen Konvention. Diese hat zumindest den effizienz- wie gerechtigkeitsgetriebenen Grundsätzen der Einfachheit, Klarheit und Objektivität zu entsprechen. Wird die Erwerbsmethode an sich trotz aufgeführter Bedenken nicht in Frage gestellt, dürfte die Neubewertungsmethode hierfür eine gewisse Eignung besitzen. Sie ist einheitstheoretisch konsequenter als die Buchwertmethode $^{5}$, ohne deutlich weniger objektiv oder technisch schwieriger zu erscheinen.

Die einheitstheoretische Konsequenz der Neubewertungsmethode ist in steuerlicher Hinsicht wichtig. Wenn der konsolidierte Abschluss für Minderheiten irgendeine steuerliche Konsequenz haben soll, ist nicht einzusehen, dass dort Ergebnisse berechnet werden, die bestimmte Minderheitenanteile nicht enthalten. Leugnet man aber die Relevanz des konsolidierten Abschlusses für Minderheiten, wäre die konsequente Alternative zur

1 Vgl. z.B. Claessens et al. (Effects of Large Shareholdings, 2002); Nenova (Voting Rights and Control, 2003). Treffend formuliert bereits Schönbucher (konsolidierte Bilanz, 1966) S. 139a: „Meist sind die mit dem Beteiligungserwerb verbundenen Ertragsaussichten für die Obergesellschaft relativ größer als für die Minderheitsaktionäre, da die Obergesellschaft in der Lage ist, die Untergesellschaft ihren eigenen unternehmerischen Zwecken dienstbar zu machen“.

2 So ist für Schindler (Kapitalkonsolidierung, 1986) S. 193 die Ermittlung der stillen Reserven das eigentliche Objektivierungsproblem, nicht die Frage, ob diese dann voll oder anteilig aufgedeckt werden.

3 Bauer (Besteuerung deutscher Konzerne, 1987) S. 287; ähnlich bereits Ordelheide (Konzernerfolg, 1987) S. 299-300, der hier zu Recht auf das Aufeinanderprallen einheits- und interessentheoretischer Standpunkte abstellt und konstatiert: „Die zufriedenstellende Verwirklichung solcher interessentheoretischer Zielsetzungen im einheitstheoretischen Konzernabschluß erscheint mir bisher wie die Entwirrung eines gordischen Knotens" (S. 300).

4 Vgl. Bauer (Besteuerung deutscher Konzerne, 1987) S. 286-288, der aber zumindest konstatiert, dass auch das dadurch erzielte Ergebnis theoretisch nicht einwandfrei sei; ohne tiefergehende Begründung Grotherr (Modell der Besteuerung nationaler und grenzüberschreitender Konzerne, 1994) S. 552; Senger (Konzernertragsbesteuerung, 1997) S. 228.

5 Diejenigen, die die Neubewertungsmethode für Zwecke der steuerlichen Konsolidierung befürworten, wie z.B. Reis (Körperschaftsbesteuerung des Konzerns, 1996) S. 244-245; Salzberger (Konzernunternehmung, 1994) S. 171, beschränken sich meist auf dieses Argument. 
Neubewertungsmethode nicht die Buchwertmethode, sondern die Quotenkonsolidierung ${ }^{1}$. „Eine Vollkonsolidierung ohne Einheitstheorie gibt es daher nicht" ${ }^{\star 2}$. Die steuerliche Eignung der Neubewertungsmethode hängt damit entscheidend von dieser theoretischen Ausrichtung der konsolidierten steuerlichen Gewinnermittlung ab.

Aus einheitstheoretischer Perspektive ist sogar fraglich, wozu überhaupt ein Minderheitenausweis im steuerlichen Eigenkapital und Ergebnis taugt. Wenn die rechtliche Unternehmensvorstellung und das damit einhergehende Trennungsprinzip konsequent auf eine Gruppe von Unternehmen angewendet wird, interessiert die Gesellschaftersphäre eigentlich nicht mehr. Das mag sich allerdings ändern, wenn aus dem Minderheitenanteil, insbesondere dem Ergebnisanteil, die auf Minderheiten entfallende Steuerlast abgeleitet wird ${ }^{3}$. Die diesbezügliche Eignung ist allerdings gering, da es sich hier um einen hochaggregierten Posten handelt, der kaum Aufschluss über die an einem bestimmten Tochterunternehmen beteiligten Minderheiten gibt. Zudem enthält dieser Posten - wie in Kapitel V.4.4 zu zeigen sein wird - keinerlei Minderheitenanteil an den Zwischenergebnissen, da die Zwischenergebniseliminierung einheitstheoretisch konsequent verfährt, indem sie Zwischenergebnisse unabhängig vom Minderheitenanteil immer in voller Höhe eliminiert.

Der unmittelbare Rückgriff auf die Einzelgewinnermittlungen im Sinne einer direkten Erfolgslokalisation ist allerdings ebenfalls problematisch. Gegenüber den Minderheitenanteilen in der konsolidierten Gewinnermittlung ergeben sich in den Einzelgewinnermittlungen nach dem Trennungsprinzip Ergebnis- (und Eigenkapital-)Diskrepanzen, die auf eine Benachteiligung der Mehrheits- oder Minderheitsgesellschafter hindeuten können ${ }^{4}$. Völlig unwichtig erscheint der Kapital- und Ergebnisausweis der Minderheiten aber insbesondere dann, wenn die Steuerlast der Gruppe mittels indirekter Erfolgslokalisation auf die einzelnen Unternehmen verteilt wird. Konsequent wäre in diesem Fall nur eine Neubewertungsmethode, die - anders als nach IFRS vorgesehen - den Minderheitenausweis gänzlich vernachlässigen könnte. Diese Lösung hätte auch den Charme,

1 Interessentheoretisch wäre es deshalb konsequent, die Quotenkonsolidierung zu fordern. Vgl. so (oft ohne interessentheoretischen Bezug) wohl Grotherr (Besteuerung nationaler und grenzüberschreitender Konzerne, 1994) S. 454; Grotherr (Abschluß eines Gewinnabführungsvertrags, 1995) S. 13; Müller (Konzernbesteuerung, 1991) S. 127-128, 138; Rupp (Ertragsbesteuerung nationaler Konzerne, 1983) S. 278-280; Scheffler (Besteuerung von inländischen Konzernen, 1991) S. 712-713; vgl. hierzu auch die Literaturbasis und Argumentation in Kap. III.2.5.1.2 zur Minderheitenproblematik.

2 Pawelzik (Phase II, 2004) S. 679.

3 Vgl. in diesem Zusammenhang allerdings ablehnend Oberndorff (Konzembesteuerung, 1996) S. 6970, der mit einer z.T. interessentheoretischen Argumentation jede steuerliche Bedeutung eines konsolidierten Abschlusses für Minderheitsgesellschafter verwirft.

4 Vgl. dazu auch Kap. V.4.4.2 sowie die Ausführungen des AK „Immaterielle Werte im Rechnungswesen" der Schmalenbach-Gesellschaft für Betriebswirtschaft e.V. auf dem 58. Deutschen Betriebswirtschafter Tag in Berlin am 28.9.2004, der insb. die weit verbreitete Vorgehensweise der Unternehmen kritisierte, die Minderheitenanteile vereinfacht der HB I zu entnehmen. 
das technisch schwierige Problem zu lösen, das verwendbare steuerliche Eigenkapital auf Minderheiten aufteilen zu müssen ${ }^{1}$.

Zwei weitere Aspekte seien in diesem Zusammenhang noch betrachtet. Der erste Aspekt zielt auf mögliche Parallelen der Kapitalkonsolidierung zur Mitunternehmerbesteuerung im deutschen Steuerrecht. Gewisse Parallelen sind - wie bereits aufgezeigt ${ }^{2}$ - offenkundig. So wird auch nach dem Transparenzprinzip eine Art Kapitalkonsolidierung durchgeführt, wenn z.B. ein neuer Gesellschafter in die Mitunternehmerschaft (Personengesellschaft) eintritt. Hierbei werden stille Reserven bzw. Lasten und sogar Firmenwerte aufgedeckt. Hilfestellungen oder gar eindeutige Empfehlungen für die konsolidierte steuerliche Gewinnermittlung lassen sich daraus allerdings kaum ableiten ${ }^{3}$. Einerseits fehlt es dem Mitunternehmerkonzept an einheitstheoretischer Konsequenz, andererseits kann dort im Hinblick auf Mitgesellschafter nicht wirklich von Minderheiten gesprochen werden. Außerdem sieht der für die Einbringung in eine Personengesellschaft maßgebliche $\S 24$ UmwStG mehrere Vorgehensweisen als Wahlrecht vor. Bei einer Einbringung zu Buchwerten gemäß $§ 24$ Abs. 2 UmwStG wird den Altgesellschaftern eigentlich nur das garantiert, was bei Buchwert- wie Neubewertungsmethode für das Mutterunternehmen selbstverständlich ist, nämlich die Buchwertfortführung. Bei einer Gesamthandsbilanz zu Zwischen- ${ }^{4}$ oder Teilwerten wird dies in der Regel über negative Ergänzungsbilanzen erreicht. Im Ergebnis werden also nur die stillen Reserven anteilig aufgedeckt, die auf einen neu eintretenden und eine Bareinlage leistenden Gesellschafter entfallen. Mit der Buchwertmethode hat dies allenfalls entfernt etwas zu tun 5 . $\S 24$ Abs. 2 UmwStG sieht aber auch die Einbringung zu höheren (Zwischen-)Werten vor, die die Teilwerte allerdings nicht überschreiten dürfen. Eine Einbringung zu Teilwerten, bei der sämtliche stille Reserven und Lasten einschließlich Firmenwert aller Beteiligten aufgedeckt werden, verabschiedet sich indes von dem Gedanken der Erwerbsmethode. Hier kann statt dessen eine interessante Parallele zu der ,fresh start method“ beobachtet werden.

Vgl. zu diesem Problem ausführlich Bauer (Besteuerung deutscher Konzerne, 1987) S. 289-293.

Vgl. Kap. III.2.4.3.

Vgl. so auch Oberndorff (Konzernbesteuerung, 1996) S. 69.

4 Selbst wenn nach $\S 24$ Abs. 2 UmwStG die Einbringung zu Buchwerten gewählt wurde, kann die Gesamthandsbilanz der Personengesellschaft zu Zwischenwerten (zwischen Buch- und Teilwerten) aufgestellt werden, um dort die Kapitalkonten der Gesellschafter im richtigen Verhältnis zueinander auszuweisen. Korrigierend treten dann positive und negative Ergänzungsbilanzen hinzu.

5 Vgl. dennoch Senger (Konzernertragsbesteuerung, 1997) S. 228-229, der eine Parallele zur Buchwertmethode erkennt und sie auch deshalb für steuerliche Konsolidierungszwecke befürwortet. Der Vergleich hinkt jedoch, da z.B. bei Einbringung von (Teil-)Betrieben o.ä. keiner der Beteiligten stille Reserven aufdecken muss. Zudem fällt es schwer, hier Minderheiten zu erkennen. Diese lägen nur vor, wenn ein Anteil eingebracht würde, an dem auch ein weiterer Gesellschafter beteiligt wäre - ein Fall, der in der individuellen, personenbezogenen Mitunternehmerbesteuerung gar nicht eintreten kann. Fraglich ist deshalb auch, ob der Erwerbsvorgang im Konsolidierungsmodell mit dem Einbringungsvorgang überhaupt vergleichbar ist. 
Der zweite Aspekt zielt auf den Rechtsvergleich mit den europäischen Konsolidierungssystemen. Obwohl mit dem portugiesischen und spanischen System immerhin noch zwei Staaten der Erwerbsmethode folgen, ist die Frage nach der verwendeten Methodik hinsichtlich der Minderheiten müßig. Bei einer grundsätzlich ergebnisneutralen Kapitalkonsolidierung ist es für eine kerngrößenorientierte steuerliche Gewinnermittlung ohne Belang, ob stille Reserven sowie Lasten beteiligungsproportional oder voll aufgedeckt werden. So hilft auch der Hinweis nicht weiter, dass hier die volle Aufdeckung nach Art einer ergebnisneutralen Neubewertungsmethode vorgeschrieben ist ${ }^{1}$. Durchführungseffizient wäre es in diesem Fall, wie bei der früheren „deutschen“ Methode überhaupt keine stillen Reserven und Lasten mehr aufzudecken.

\subsubsection{2 ,Full Goodwill Method'}

Bei den bisherigen Ausführungen ist die Neubewertungsmethode als einheitstheoretisch konsequent bezeichnet worden, weil sie den Minderheitenanteil an den stillen Reserven und Lasten berücksichtigt. Dies gilt allerdings nicht für den verbleibenden Unterschiedsbetrag, der nach IFRS 3.51(a) als Goodwill zu aktivieren oder, sofern negativ, nach IFRS 3.56(b) ummittelbar als Ertrag zu verrechnen ist. Minderheitenanteile sind darin nicht enthalten. Lediglich im Rahmen des Werthaltigkeitstestes wird der Goodwill nach IAS 36.92 aus systematischen Gründen um etwaige Minderheitenanteile aufgestockt. Einheitstheoretisch wirklich konsequent erscheint deshalb das Bestreben des IASB, die „full goodwill method“ in der nächsten Phase des „Business Combinations“Projekts umzusetzen. Dann wird auch der in der Bilanz ausgewiesene Goodwill um den Minderheitenanteil erhöht. Korrespondierend steigt auch das Eigenkapital um diesen Anteil.

Fraglich ist auch hier, ob die „full goodwill method“ für Zwecke der steuerlichen Konsolidierung geeignet ist. Die einheitstheoretische Konsequenz ist dabei unbestritten. Weil die Minderheiten an sämtlichen Bilanzpositionen partizipieren, dürfte die ,full goodwill method", wie in Abb. 15 aufgezeigt, die einheitstheoretisch sinnvollste Methode der Vollkonsolidierung unter der Erwerbsfiktion sein ${ }^{2}$.

1 Dies ist zumindest den Beispielen von Selling (Spanische Konzernbesteuerung, 1987) S. 293-294 zu entnehmen.

2 Vgl. zu dieser einheitstheoretischen Forderung bereits Moonitz (Entity Theory, 1951) S. 59-63. 

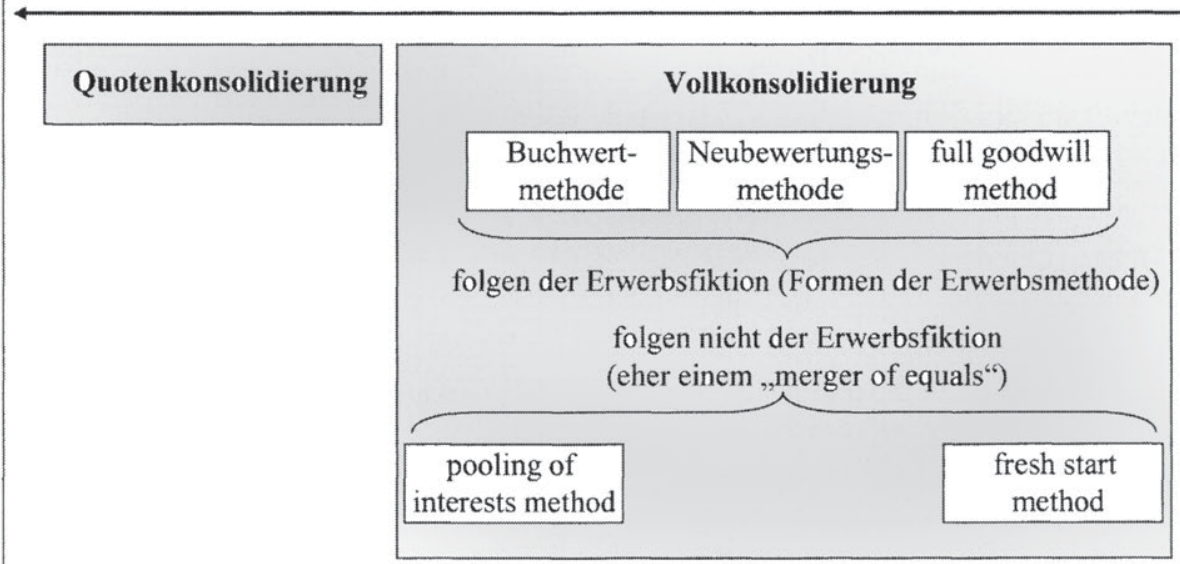

Abb. 15: Zuordnung der Konsolidierungsmethoden zur Einheits- und Interessentheorie

Quelle: In Anlehnung an Pellens/Basche/Sellhorn (Full Goodwill Method, 2003) S. 1; Pellens/Fülbier/Gassen (Internationale Rechnungslegung, 2004) S. 640.

Wie der Neubewertungsmethode kann aber auch der ,full goodwill method“ vorgeworfen werden, gegen Pagatorik und Anschaffungswertprinzip zu verstoßen. So ist die Aufstockung des Goodwill um Minderheitenanteile nicht zahlungsbasiert. Der Goodwill verliert seine Eigenschaft als „Kaufpreisrest“". Die Qualifikation als „Kaufpreisrest“" macht dabei deutlich, dass es in der ,cost allocation“ nach IFRS 3 letztlich darum geht, den Kaufpreis aufzuschlüsseln (purchase price allocation). Der Goodwill wirkt hier eher als Residuum und bezeichnet nicht zwingend die Differenz zwischen dem Substanzwert des Tochterunternehmens (Teilreproduktionswert) und dem höheren Ertragswert ${ }^{2}$. Der residuale Charakter bezieht sich dabei aber nur auf den Mehrheitsanteil, so dass er schon im Rahmen der Neubewertungsmethode pagatorische Verwerfungen insgesamt nicht verhindert ${ }^{3}$. Im Rahmen der "full goodwill method“ verliert der Goodwill indes völlig seinen residualen Charakter und wird unabhängig davon als eigenständig zu er-

Busse von Colbe et al. (Konzernabschlüsse, 2003) S. 205.

Vgl. Busse von Colbe et al. (Konzernabschlüsse, 2003) S. 205.

3 Ein „vollständiger Kaufpreisrest", der als technisches Residuum den Ausgleich zwischen Kaufpreis bzw. Gesamtanschaffungsauszahlung und dem Saldo der neu und vollständig bewerteten Vermögenswerte und Schulden (neu bewertetes Eigenkapital) garantiert, würde die Neubewertungsmethode von pagatorischen Verstößen befreien. Wenn der Wert dieses Residuums ebenfalls als Anschaffungsaus- bzw. -einzahlung interpretiert würde, wäre auch das Anschaffungswertprinzip gewahrt. Da sich der Goodwill wie auch der verbleibende negative Unterschiedsbetrag nur auf die Differenz von Beteiligungsbuchwert (cost of a business combination) und anteiligem neubewerteten Eigenkapital beziehen, funktionieren sie nicht wirklich als residualer „Kaufpreisrest“. Deshalb unterscheidet sich z.B. die Goodwillhöhe bei der Neubewertungsmethode nicht von derjenigen bei der Buchwertmethode. 
mittelnder Wert aufgefasst. Der Verstoß gegen Pagatorik und Anschaffungswertprinzip ist offenkundig'.

Das zuvor schon angeführte Sacheinlageargument gilt allerdings auch hier ${ }^{2}$. Dazu wird angenommenen, dass die Minderheiten auch ihren Anteil am Goodwill per Sacheinlage in die konsolidierte Bilanz der Unternehmung einlegen. Im Unterschied zur Vorgehensweise der Neubewertungsmethode steht die „full goodwill method“ aber vor der Aufgabe, den Goodwill eigenständig und nicht mehr als Residuum bewerten zu müssen. Abgesehen davon, dass es nach den bisherigen Plänen des IASB nicht konsistent erscheint, die Minderheiten nicht auch am negativen Unterschiedsbetrag zu beteiligen ${ }^{3}$, bleibt insbesondere die Bewertung des Minderheitenanteils und mit ihr die des GesamtGoodwill problematisch.

Das IASB selbst gibt zwei Wege zur Ermittlung des Gesamt-Goodwill vor. Entweder kann der Gesamt-Goodwill aus dem bisherigen „Mehrheits-Goodwill“ über Division durch die Beteiligungsquote proportional hochgerechnet werden ${ }^{4}$ oder er ergibt sich über eine originäre Unternehmensbewertung als Differenz des hierbei ermittelten Wertes und des gesamten neubewerteten Eigenkapitals. Die zweite Ermittlungsmethode mag theoretisch konsequenter erscheinen, unterliegt aber letztlich ähnlich schwerwiegenden Kritikpunkten, die aus steuerlicher Sicht auch gegen den ,impairment-only approach" sprechen ${ }^{5}$. Ermessensspielräume und Selbsteinsteuerungspotenziale sind unverkennbar. Diesbezüglich hat die proportionale Hochrechnung des verbleibenden positiven Unterschiedsbetrages deutliche Vorteile. Zudem wäre sie einfacher und deshalb auch durchführungseffizienter. Auch ist anzunehmen, dass diese Methode bereits in IAS 36.92 gemeint ist, wo der Gesamt-Goodwill für die abgeschwächte Variante der „full

1 Verstöße gegen die Pagatorik bei der „full goodwill method“ erkennen auch Pellens/Basche/Sellhorn (Full Goodwill Method, 2003) S. 3-4; ähnlich auch Busse von Colbe (Einheitstheorie für den Konzernabschluss, 2004) S. 57; ansatzweise bereits Salzberger (Konzernunternehmung, 1994) S. 170-171. Neutral bis ablehnend bereits aus handelsrechtlicher Sicht Dusemond/Weber/Zündorf $(\S 301,1998)$ Tz. 103, 135; Küting/Zündorf (Ermittlung der Minderheitenanteile, 1985) S. 1170; von Wysocki/Wohlgemuth (Konzernrechnungslegung, 1996) S. 124; Weber/Zündorf $(\S 307,1998)$ Tz. 9 m.w.N.

2 Vgl. Kap. V.4.2.2.5.1 sowie Pawelzik (Phase II, 2004) S. 682.

3 Vgl. zu dieser Kritik Busse von Colbe (Einheitstheorie für den Konzernabschluss, 2004) S. 51, 58; Pellens/Basche/Sellhorn (Full Goodwill Method, 2003) S. 4. Die asymmetrische Vorgehensweise des IASB dürfte darin begründet liegen, dass der negative Unterschiedsbetrag hauptsächlich als „Fehler“ angesehen wird; vgl. IFRS 3.57; Küting/Wirth (IFRS 3, 2004) S. 177; kommentierend dazu $A A A$ (Business Combinations, 2004) S. 60.

4 Vgl. dazu bereits Childs (Consolidated Financial Statements, 1949) S. 99, der ein Beispiel bemüht, wonach ein Goodwill als „Kaufpreisrest“ von 20.000 \$ bei einer $80 \%$ igen Beteiligung einen GesamtGoodwill von $25.000 \$(20.000 \$ / 0,8)$ ergibt.

5 Vgl. Kap. V.4.2.2.4; so, allerdings nicht aus steuerlicher Sicht, auch Pellens/Basche/Sellhorn (Full Goodwill Method, 2003) S. 4. Nach Busse von Colbe (Einheitstheorie für den Konzernabschluss, 2004) S. 47-48 erinnere die diesbezügliche Überlegung des IASB, den „fiktiven fairen Preis“ zu finden ,an den Verkehrswert oder Gemeinen Wert im deutschen Recht, wenn nicht sogar an den Gerechten Preis des Mittelalters“; ähnlich bereits Schneider (Verwertung von Wissen, 2000) S. 29. 
goodwill method“ im Rahmen des Werthaltigkeitstest auf ZGE-Ebene „by grossing up“ zu ermitteln ist.

Das Problem der proportionalen Aufstockung liegt jedoch woanders: Wie im Vorabschnitt bereits erläutert, steht der Kaufpreis für ein Unternehmen schon allein durch die nachweisbare Existenz gezahlter „Kontrollprämien“ in keinem linearen Zusammenhang zur Beteiligungsquote'. Ein proportionales Aufstocken würde diese Linearität jedoch implizieren. Das IASB erkennt diese Problematik bereits selbst, weil sie diese Ermittlungsmethode zwar gegenüber der originären Unternehmensbewertung präferiert, ihre Anwendung aber davon abhängig machen will, dass diese Prämie auch bekannt und quantifizierbar ist. Letzteres dürfte aber unter steuerlichen Objektivierungserfordernissen kaum möglich sein ${ }^{2}$.

Des weiteren ist zu fragen, ob der Goodwill angesichts seiner darin enthaltenen Komponenten wirklich anteilig den Minderheiten zusteht. Wenn hier nach Sellhorn ein Synergie-Goodwill, Strategie-Goodwill oder gar ein Flexibilitätsbestandteil identifiziert wird $^{3}$, liegt statt dessen die Vermutung nahe, dass allein oder überwiegend die Mehrheit von diesen Vorteilen profitiert, insbesondere dann, wenn sie nicht in dem Tochterunternehmen selbst, sondern z.B. bei dem Mutterunternehmen anfallen ${ }^{4}$. Auch das würde bedeuten, dass ein Goodwill überproportional stark von der Mehrheit genutzt wird und sich deshalb auch überproportional stark im Kaufpreis niederschlägt. Ein beteiligungsproportionales Aufstocken liefe dem zuwider. Eine rechtssichere Quantifizierung dieser Effekte scheint aber unmöglich.

Weitere, technische Probleme dürften entstehen, selbst wenn das Ermittlungsproblem gelöst wäre. Im Zusammenspiel mit dem ,impairment-only approach“ nach IAS 36 ist z.B. offensichtlich, dass die unternehmensunabhängige Abgrenzung der ZGE zu Minderheitenverschiebungen führen kann. Als Beispiel mag angeführt werden, dass eine aus

1 Vgl. dazu bereits Childs (Consolidated Financial Statements, 1949) S. 99, der u.a. auf die Kontrollprämie verweist und treffend konstatiert: „For example, the goodwill arising from the acquired subsidiary's contribution to the welfare of the enterprise is seldom proportional to the percentage of stock owned“. Zweifel daran, dass „ein entsprechend höherer Betrag bei Erwerb sämtlicher Anteile gezahlt worden wäre", äußert auch die Kommission Rechnungswesen (Stellungnahme, 1985) S. 273; ähnlich Küting (Kapitalkonsolidierung, 1995) S. 196; Schönbucher (konsolidierte Bilanz, 1966) S. 139-140. Vgl. dies relativierend Pawelzik (Phase II, 2004) S. 683.

2 So bezweifelt dies Busse von Colbe (Einheitstheorie für den Konzernabschluss, 2004) S. 49, 58-60 bereits für eine rein informationsorientierte Rechnungslegung.

3 Vgl. Sellhorn (Ansätze zur bilanziellen Behandlung des Goodwill, 2000) S. 889-890; s.a. Kap. V.4.2.2.2.

4 Vgl. so für akquisitionsbedingte Synergien Pellens/Basche/Sellhorn (Full Goodwill Method, 2003) S. 4; ansatzweise auch Schindler (Kapitalkonsolidierung, 1986) S. 192-193. In einer Unternehmensgruppe verkompliziert sich dieses Lokalisationsproblem, je nachdem, wo letztlich diese Vorteile konkret realisiert werden und welche Minderheiten dabei jeweils betroffen sind. Denkbar sind damit auch Querverlagerungen zwischen verschiedenen Minderheiten. 
zwei Tochterunternehmen bestehende ZGE einen Goodwill besitzt, der aus der Akquisition des einen Unternehmens stammt. Unter der Annahme, dass unterschiedlich hohe Minderheitenanteile an den beiden Tochterunternehmen beteiligt sind, würde z.B. ein Goodwilltransfer von dem einen zum anderen Unternehmen die Werthaltigkeit des Gesamt-Goodwill auf ZGE-Ebene zwar erhalten ${ }^{1}$ und eine Wertminderung nicht auslösen. $\mathrm{Ob}$ das IASB aber berücksichtigt hat, dass ein entsprechender Transfer das Anteilsverhältnis von Mehrheit und Minderheit im Eigenkapital verändert hat ${ }^{2}$, ist fraglich.

Für die steuerliche Gewinnermittlung wäre dieser Effekt nur dann ohne Relevanz, wenn die Steuerlastverteilung ausschließlich über eine indirekte Erfolgslokalisation vonstatten ginge und eine Separierung von Eigenkapital und Ergebnis in Mehr- und Minderheitenanteil nicht mehr notwendig erschiene. Unter diesen Bedingungen dürfte die „full goodwill method" sogar mit Vorteilen bei der Durchführungseffizienz einhergehen, da sie das angesprochene Problem der Erst- und Folgebewertung des Goodwill bei Minderheiten löst. Diesbezügliche Vorteile ergeben sich z.B. auch bei der Erfassung von sukzessiven $\mathrm{Zu}$ - oder Verkäufen mehrerer Beteiligungstranchen ${ }^{3}$. In Abhängigkeit von dem gefundenen Schlüssel könnte sogar das soeben angesprochene Problem disproportionaler Goodwillnutzung gelöst werden, wenn Minderheiten wie Mehrheiten am Gesamtergebnis der Gruppe partizipieren.

Abschließend bleibt festzuhalten, dass mit der „full goodwill method“ die wohl einheitstheoretisch konsequenteste Variante der Erwerbsmethode vorliegen dürfte. Dem stehen jedoch erhebliche normative Bedenken gegenüber. Diese gehen über diejenigen Bedenken hinaus, die hinsichtlich der Neubewertungsmethode oder auch der ,pagatorisch fundierten" Goodwillbilanzierung nach IFRS 3 formuliert worden sind. So sind es insbesondere große Objektivierungsschwierigkeiten im Rahmen der Gesamt-GoodwillErmittlung, die - ganz im Sinne der hier geltenden Beweislastumkehr - eher gegen ihre steuerliche Eignung sprechen.

1 An dieser Stelle ergeben sich sogar Vorteile der „full goodwill method“ gegenüber der Neubewertungsmethode, so dass Pellens/Basche/Sellhorn (Full Goodwill Method, 2003) S. 4 konstatieren, dass sich die „Favorisierung der Full Goodwill Method möglicherweise nicht als konzeptionell gewollte Überzeugungstat, sondern als pragmatische Behelfslösung herausstellen" könnte. Diese Vorteile beziehen sich z.B. auch auf die einheitstheoretische Erfassung von sukzessiven Zu- oder Verkäufen mehrerer Beteiligungstranchen, die Busse von Colbe (Einheitstheorie für den Konzernabschluss, 2004) S. 52-56 und erstmalig wohl Moonitz (Entity Theory, 1951) S. 63 beschreibt.

2 Vgl. zu diesen Gedanken bereits Pellens/Sellhorn (Minderheitenproblematik beim Goodwill Impairment Test, 2003) S. 405-407.

3 Vgl. zu derartigen Vorteilen z.B. Busse von Colbe (Einheitstheorie für den Konzernabschluss, 2004) S. 52-56; Pawelzik (Phase II, 2004) S. 684; erstmalig wohl Moonitz (Entity Theory, 1951) S. 63. 


\subsubsection{6 ,Fresh Start Method'}

Das „Business Combinations“-Projekt stützt einmal mehr die These, dass sich das gesamte IFRS-Regelwerk in Richtung einer ,full fair value“-Bilanzierung fortentwickelt ${ }^{1}$. Ist schon in der "full goodwill method" ein weiterer Schritt in Richtung „Fair ValueLand“2 gesehen worden, so wird dieser Schritt in der „fresh start method“ an Konsequenz noch überboten ${ }^{3}$. Hier werden - wie bereits in Tab. 6 skizziert - nun sämtliche stillen Reserven und Lasten in der konsolidierten Bilanz (ergebnisneutral) aufgedeckt, also auch diejenigen aller anderen konsolidierten Unternehmen einschließlich des Mutterunternehmens. Dies betrifft auch den Goodwill.

Die steuerliche Eignung dieser Methode kann allerdings nur auf den Anwendungsfall bezogen werden, von dem auch das IASB in seinen Überlegungen ausgeht. Ausgangspunkt der „fresh start method“ ist die Erkenntnis, dass sich die in IFRS 3 als ausschließliche Methode der Kapitalkonsolidierung vorgesehene Erwerbsmethode nicht für alle denkbaren Anwendungsfälle gleichermaßen eignet. Dies gilt insbesondere für die Fälle, in denen die Identifikation eines Käufers auch unter Berücksichtigung von IFRS 3.1723 kaum möglich erscheint. Als bestes Beispiel gilt hierfür der mehr oder minder gleichberechtigte und durch Anteilstausch beglichene Zusammenschluss zweier (Mutter-)Unternehmen im Sinne eines „merger of equals“. Bis zur Abschaffung des IAS 22 2004 griff an dieser Stelle der Anwendungsbereich der ,pooling of interests method“, die beide „Fusionspartner“ insofern gleichberechtigt behandelte, als dass sämtliche Vermögenswerte und Schulden im Sinne einer Buchwertfortführung in die konsolidierte Bilanz übernommen und insofern keine stillen Reserven und Lasten (einschließlich Goodwill) aufgedeckt wurden. Seit der Verabschiedung von IFRS 3 muss nun aber auch ein ,merger of equals“ über die dann sicherlich schwierige Identifikation eines Erwerbers auf der Grundlage der Erwerbsmethode (Neubewertungsmethode) bilanziert werden.

Die Erwerbsmethode wird erst einmal durch das normative Abgrenzungsleitbild einer hierarchisch strukturierten Unternehmung gestützt. Da Integration mit der Übertragung ökonomischen Eigentums im Sinne residualer Entscheidungs- und Kontrollrechte gleichgesetzt wird, erscheint die Anwendung der Erwerbsmethode immer dann sinnvoll, wenn eine bereits bestehende Entscheidungs- und Kontrollinstanz in ihrer Funktion auch nach dem Zusammenschluss bestehen bleibt. Sie zu identifizieren und mit ihr das erwerbende Unternehmen ist letztlich Ziel von IFRS 3.17-23. Weniger zielführend er-

Vgl. hierzu das in Kap. V.1.2.1.1 entwickelte Leitbild der IFRS.

Busse von Colbe (Einheitstheorie für den Konzernabschluss, 2004) S. 57.

Vgl. so auch Pellens/Basche/Sellhorn (Full Goodwill Method, 2003) S. 4, die die „full fair value method" als finalen Endpunkt des IASB-Regulierungsprozesses bezeichnen und damit der in Kapitel V.1.2.1.1 entwickelten Leitbildidee zustimmen. 
scheint die Erwerbsfiktion jedoch im Falle eines Zusammenschlusses, in dem sich eine neue oberste Kontrollinstanz in gleichberechtigter Form erst aus den alten Instanzen ergibt $^{1}$. Für diese Fälle, in denen die Verschmelzungsfiktion wieder an Gewicht gewinnt, wird die „fresh start method“ erwogen (vgl. auch Abb. 15) ${ }^{2}$.

Aus steuerlicher Sicht hat die "fresh start method“ ebenfalls ihren Reiz. Der aufgezeigte Anwendungsbereich ist nicht wirklich sinnvoll über die Erwerbsmethode abzubilden. Einheitstheoretisch konsequenter erscheint hier die "fresh start method", weil sich die deutliche Parallele zur Neugründung einer Einheitsunternehmung anbietet. So ist in ökonomischer Perspektive nicht der Erwerb eines zusätzlichen Teilglieds (Unternehmen) durch eine bestehende Unternehmung gegeben, sondern die Vereinigung zweier Unternehmungen zu einer neuen. Der Gedanke der "fresh start method“, dass sämtliche Buchwerte im Neugründungszeitpunkt den Marktwerten entsprechen, scheint aus normativer Perspektive nur folgerichtig. Anders als z.B. in der ,pooling of interests method" geben diese Buchwerte im Neugründungszeitpunkt die Ertragswerte bzw. Anschaffungsauszahlungen wieder. Aufgrund der einheitlichen Bewertungsbasis werden $\mathrm{zu}$ diesem Zeitpunkt sämtliche Eigentümeranteile - damit auch Minderheiten- und Mehrheitenanteile am Eigenkapital - im Verhältnis zueinander korrekt ausgewiesen ${ }^{3}$. Aus der Perspektive der Erwerbsfiktion lässt sich diese Vorgehensweise - wenn überhaupt - nur mit einigen Verrenkungen rechtfertigen: So könnte unterstellt werden, dass die Alteigentümer ihre Anteile an die neue Unternehmung verkaufen und den Verkaufspreis in Form von Anteilen an der neuen Unternehmung erhalten. Die neu entstandene Hierarchiespitze kauft gewissermaßen beide Unternehmungen ${ }^{4}$.

Die steuerlichen Bedenken sind mit dieser Begründung aber schon angerissen. Streng genommen liegen eben keine klassischen Anschaffungsauszahlungen vor ${ }^{5}$. Eine marktliche Objektivierung gibt es aber sehr wohl. Die Entscheidungs- und Kontrollinstanzen

1 In streng individualistischer Sicht kann dies allerdings nur realisiert werden, wenn eine Personengruppe von mindestens zwei Individuen als Instanz anerkannt wird.

2 Vgl. IFRS 3.BC 42, 48-49; zur Historie und Wirkungsweise der „fresh start method“ Krawitz/Klotzbach (Fresh-Start-Methode, 2000); Pellens/Sellhorn (Fresh Start Methode, 1999).

$3 \mathrm{Vgl}$. Ordelheide (Konzernerfolg, 1987) S. 299-300. Bei der Erwerbsmethode hat die auf erworbene Unternehmen beschränkte Neubewertung tendenziell zu einer Übergewichtung des Minderheitenanteils geführt, weil das Eigenkapital der bisherigen rechnungslegenden Einheit weiterhin zu Buchwerten fortgeführt wird. Ein konzeptioneller Nachteil der Erwerbsmethode ist darin jedoch nicht zu erkennen. Dies gilt zumindest, soweit die Reinvermögenszugangstheorie akzeptiert wird, wonach Wirtschaftsgüter grundsätzlich bei Erwerb zu Anschaffungskosten (= Marktwert) in eine ansonsten zu Buchwerten geführte Bilanz aufgenommen werden.

4 Vgl. Pellens/Sellhorn (Fresh Start Methode, 1999) S. 2126, 2131-2132. Zutreffen dürfte dies z.B. auf den Zusammenschluss Daimler-Benz AG und Chrysler Corp.; vgl. Bruns (Pooling of Interests, 1999) S. 831-833; Krawitz/Leukel (Unternehmensfusionen, 2001) S. 101-103. Eine Personenidentität zwischen alten und neuen (ökonomischen) Eigentümern kann dabei nicht ausgeschlossen werden.

5 Nach Pellens/Sellhorn (Fresh-Start-Methode, 1999) S. 2132 lägen pagatorisch nicht abgesicherte Wertgrößen nur dann vor, wenn obige Fiktion von der kaufenden Hierarchiespitze nicht zuträfe. 
der zwei Altunternehmungen haben sich über den Markt als fremde Dritte auf entsprechende Austauschverhältnisse und damit Marktpreise geeinigt. Diese Markttransaktion objektiviert insofern auch die zwangsläufig notwendigen Unternehmensbewertungen, die nun von zwei im Interessengegensatz stehenden Marktparteien akzeptiert werden. Der Vorwurf entsprechender Ermessens- und Selbsteinsteuerungsmöglichkeiten wird dadurch - ganz anders als z.B. im Fall eines Werthaltigkeitstests nach IAS 36 oder bei der Ermittlung eines Gesamt-Goodwill - deutlich relativiert.

Hinsichtlich drohender Selbsteinsteuerungsmöglichkeiten liegt die Gefahr eher woanders: Es scheint überaus schwierig, den Anwendungsbereich der „fresh start method“ anhand operationaler Kriterien klar von demjenigen der Erwerbsmethode abzugrenzen ${ }^{1}$. Dies ist aber notwendig, um zu verhindern, dass die Hierarchiespitze einer Unternehmensgruppe den Erwerb eines Unternehmens nicht zur Aufdeckung sämtlicher stillen Reserven und Lasten nutzen kann et vice versa ${ }^{2}$. Zudem verbleiben auch bei der ,fresh start method" zwei bereits analysierte Kernprobleme der Erwerbsmethode nach IFRS 3: das marktferne Herunterbrechen der Unternehmenswerte auf einzelne Wirtschaftsgüter mit der Gefahr gezielter steuerbarwertminimierender Zuordnung und die notwendige Abstimmung mit den einzelstaatlichen Vorschriften zur Veräußerungsgewinnbesteuerung, die bei der ,fresh start method“ naturgemäß die Gesellschaftersphären beider Unternehmen betrifft.

Letztlich können die Fragen der konkreten Ausgestaltung in dem frühen Stadium der bisherigen Planungen mangels entsprechender Hinweise des IASB nicht abschließend analysiert werden. Das gilt im Übrigen auch für offene Fragen, wie z.B. mit verbleibenden Unterschiedsbeträgen verfahren wird ${ }^{3}$. Zudem gibt es aus steuerlicher Sicht ein mögliches Korrektiv für das Abgrenzungsproblem. Wenn es im Rahmen der „fresh start method" gestattet sein wird, im Zuge der Erstkonsolidierung stille Reserven und Lasten ergebnisneutral aufzudecken und in der Folge ergebniswirksam abzuschreiben, wird eine vorangeschaltete Veräußerungsgewinnbesteuerung bei den Alteigentümern ${ }^{4}$ getreu der Fiktion ihres Verkaufs an die neue Hierarchiespitze - unumgänglich sein. Diese aus rein informationsorientierter Sicht nicht erforderliche Rechtskonsequenz dürfte das Ausnutzen bestehender Ermessensspielräume beschränken. Das Problem wird

1 Vgl. so auch das IASB selbst in IFRS 3.BC48; Pellens/Sellhorn (Fresh-Start-Methode, 1999) S. 2131.

2 Diese Gefahr kann im Extremfall dazu führen, dass eine (große) Unternehmensgruppe de facto jederzeit die Möglichkeit hat, stille Reserven und Lasten aufzudecken, wenn sie dafür nur irgendein anderes Unternehmen zu kaufen braucht.

3 Der Logik von IFRS 3 und IAS 36 würde eine ergebnisneutrale Verrechnung allerdings widersprechen. Zudem ginge sie wieder mit starken Ermessensspielräumen einher, weil der ergebnisneutral zu verrechnende Betrag letztlich willkürbehaftet ist; vgl. so auch Pellens/Sellhorn (Fresh-Start-Methode, 1999) S. 2131.

4 Steuertechnische Fragen, wo genau dieser Veräußerungsgewinn anfallen sollte, werden hier jedoch nicht weiter betrachtet. 
damit aber nicht vollständig neutralisiert. Schließlich bleibt im umgekehrten Fall, in der eigentlich die „fresh start method“ zur Anwendung kommen müsste, ein klarer Selbsteinsteuerungsanreiz zu Gunsten der Erwerbsmethode, bei der die Buchwertfortführung (und damit die Nichtbesteuerung) für den ,erwerbenden“ Teil garantiert ist.

Zusammenfassend kann festgehalten werden, dass die „fresh start method“ auch steuerlich für ganz bestimmte, klar zu definierende Anwendungsfälle erst einmal sinnvoll erscheint. Interessant ist dabei aus deutscher Perspektive der Hinweis, dass im Umwandlungssteuerrecht eine Parallele zur „fresh start method" bereits existiert. Zumindest im Wortlaut sehen $\S \S 3,11,20$ und $24 \mathrm{UmwStG}$ die Möglichkeit einer beidseitigen und damit vollständigen Teilwertbewertung (einschließlich Firmenwert bzw. Goodwill) in der Übertragungs- bzw. Eröffnungsbilanz bei einer Verschmelzung oder Vermögensübertragung vor" ${ }^{1}$. Die mit der "fresh start method“ einhergehenden Objektivierungsprobleme dürften damit zumindest nicht völlig neu sein. Theoretisch sind sie bei der „fresh start method“" sogar geringer, da dort zwei Unternehmungen qua definitionem als wirtschaftlich autonome Marktpartner die Bedingungen des Zusammenschlusses aushandeln. Rechtliche Verschmelzungsvorgänge finden hingegen oft auch innerhalb einer Unternehmung und damit fern marktlicher Objektivierung statt ${ }^{2}$. Es verbleiben allerdings Selbsteinsteuerungspotenziale bei dem marktfernen Herunterbrechen der zwei (objektivierten) Gesamtwerte auf einzelne Wirtschaftsgüter, so wie sie im Prinzip schon aus der Erwerbsmethode bekannt sind. Wie bei der Erwerbsmethode existiert auch die Notwendigkeit, einzelstaatliche Vorschriften zur Veräußerungsgewinnbesteuerung mit der „fresh start method“ abzustimmen.

\subsection{Schuldenkonsolidierung}

\subsubsection{Regulierung auf der Grundlage der IFRS}

Zur Aufstellung einer konsolidierten Bilanz nach IFRS bedarf es nach IAS 27 auch der Schuldenkonsolidierung. So müssen nach IAS 27.24 gruppeninterne Transaktionen und daraus resultierende Abschlusspositionen und Ergebnisse in voller Höhe eliminiert wer-

1 Vgl. zu dieser Analogie ansatzweise auch Krawitz/Klotzbach (Fresh-Start-Methode, 2000) S. $1167-$ 1168, 1171. Der Wortlautverweis soll andeuten, dass die deutsche Finanzverwaltung bei $\S \S 3,11$ UmwStG mit Hinweis auf den Maßgeblichkeitsgrundsatz ein Bewertungswahlrecht verneint und den Buchwertansatz für zwingend erachtet; vgl. BMF (Schreiben betr. Umwandlungssteuergesetz, 1998) Tz. 03.01, 11.01 .

2 Dabei können sich die Anwendungsfälle der „fresh start method“ mit denen des UmwStG durchaus überschneiden, wenn nicht nur zwei Unternehmensgruppen zusammen geführt werden, sondern die beiden Mutterunternehmen auch rechtlich verschmelzen. Alternativ wäre aber auch die Neugründung einer (Holding-)Gesellschaft vorstellbar, die Anteile an den weiterhin bestehenden zwei ehemaligen Mutterunternehmen im Wege eines ,share deal“ übernimmt. 
den ${ }^{1}$. Gruppeninterne Forderungen und Schulden sind unabhängig von der jeweiligen Beteiligungsquote miteinander zu verrechen. Dies gilt auch für alle ähnlichen Positionen und die mit ihnen im Zusammenhang stehenden Wertberichtigungen und Disagien ${ }^{2}$. Es verbleiben nur solche Forderungen und Schulden in der konsolidierten Bilanz, die auf Kreditgeschäften mit fremden Dritten beruhen.

Entsprechen sich gruppeninterne Forderungen und Schulden, ist die Eliminierung dieser Bestandspositionen ohne Auswirkung auf das Eigenkapital und Ergebnis. Entsprechen sie sich nicht, ergeben sich zwangsläufig Differenzen. Mit Verweis auf die Grundregel des IAS 27.24 müssen Differenzbeträge zwischen Bestandspositionen wie Korrekturposten zum Eigenkapital wirken ${ }^{3}$. Nur der jeweils periodenbezogene Anteil wirkt sich auf das laufende Ergebnis aus und muss insoweit auch dort eliminiert werden ${ }^{4}$. Der auf die Vergangenheit entfallende Rest ist ergebnisneutral zu korrigieren. Differenzen in den Beständen entsprechen somit immer der kumulierten Ergebnisveränderung aus der Schuldenkonsolidierung bzw. der damit einhergehenden Betriebseinnahmen- und -ausgabenkonsolidierung ${ }^{5}$.

Da Schulden (liabilities) nach IFRS auch Rückstellungen umfassen, sind im Rahmen der Schuldenkonsolidierung auch gruppeninterne Rückstellungen zu neutralisieren. Da Schulden im IFRS-System nur gegenüber Dritten bestehen können ${ }^{6}$, kommt eine Übernahme in die konsolidierte Bilanz auch als Aufwandsrückstellungen nicht in Frage. Aus der in IAS 27.22 festgelegten Einheitstheorie folgt im Übrigen, dass auch Anhangangaben aufgrund von Eventualschulden und -forderungen (IAS 37.28 und 37.34) entfallen, soweit sie zwischen den Unternehmen der Gruppe bestehen ${ }^{7}$.

Der im IFRS-System grundsätzlich gültige Wesentlichkeits- und Wirtschaftlichkeitsvorbehalt gilt auch im Rahmen der Schuldenkonsolidierung. Hiernach kann auf die

1 Vgl. IAS 27.24: „Intragroup balances, transactions, income and expenses shall be eliminated in full“. Eigentlich beschränkt sich der "consolidation"-Begriff auf die Kapitalkonolidierung (IAS 27.22), während IAS 27.22-25 ansonsten terminologisch auf „elimination“ abstellt.

2 Die Frage, ob (Dis-)Agien nach IFRS (Effektivzinsmethode, IAS 39) überhaupt (noch) angesetzt werden, interessiert an dieser Stelle nicht. Im Vordergrund steht die Konsolidierung nach IFRS, die i.S.d. EU-Strategie nicht zwingend auch auf IFRS- Ansatz- und Bewertungsregeln aufsetzen müssen.

3 Vgl. Busse von Colbe et al. (Konzernabschlüsse, 2003) S. 359.

4 Konkret bleibt die Behandlung der Aufrechnungsdifferenzen nach IAS 27 ungeregelt. Unter den Gesichtspunkten von Einheitstheorie und periodengerechter Ergebnisermittlung ist anzunehmen, dass Differenzen in der Entstehungsperiode ergebniswirksam behandelt werden, so dass in den Folgeperioden nur die weitere Veränderung ergebniswirksam und die jeweiligen Anfangsbestände (Stand der Vorperiode) ergebnisneutral zu erfassen sind; vgl. dazu Baetge/Schulze (IAS 27, 2002) Tz.145-147; allgemeiner auch $\mathrm{Fa \beta}$ (Unterschiedsbeträge, 1990) S. 1305.

5 Vgl. Busse von Colbe et al. (Konzernabschlüsse, 2003) S. 359-361.

6 Vgl. IAS 37.14, 17, 20; zur Definition der ,liability“ auch IASB Framework Par. 49, 60-64.

7 Vgl. ansatzweise Baetge/Schulze (IAS 27, 2002) Tz. 131, 137. 
Schuldenkonsolidierung in Fällen von untergeordneter Bedeutung oder zu hoher Kosten verzichtet werden ${ }^{1}$.

\subsubsection{Eignung für die konsolidierte steuerliche Gewinnermittlung}

Die Schuldenkonsolidierung nach IAS 27 folgt einer einheitstheoretischen Ausrichtung und dürfte damit grundsätzlich auch steuerlichen Erfordernissen entsprechen. Soll die rechnungslegende Einheit eine Unternehmensgruppe umfassen, sind gruppeninterne Schuldverhältnisse wie innerbetriebliche Verrechnungsposten zu behandeln und zu eliminieren. Konsequent erscheint auch weiterhin die Vollkonsolidierung, d.h. die Eliminierung der entsprechenden Positionen in voller Höhe, selbst wenn Minderheiten beteiligt sind.

Aufgrund der Kerngrößenorientierung bedarf es in der steuerlichen Gewinnermittlung aus durchführungseffizienter Sicht aber nur eines Teils der Schuldenkonsolidierung. Wenn sich Bestandspositionen in gleicher Höhe gegenüberstehen, ist ihre Verrechnung im Rahmen der steuerlichen Konsolidierung nicht erforderlich. Die Erfordernis greift bei Aufrechnungsdifferenzen, die nicht nur durch unterschiedlich bewertete Forderungen und Schulden entstehen, sondern z.B. auch durch gruppeninterne Rückstellungen, denen überhaupt keine korrespondierenden Positionen eines anderen Unternehmens der Gruppe gegenüber stehen. Regelmäßig dürften hierbei, in Abhängigkeit von den konkreten steuerrechtlichen Einzelgewinnermittlungsregeln, passivische Differenzbeträge zu vermuten sein, weil die aggregierten Passivposten in einer Unternehmensgruppe höher als die korrespondierenden Aktivposten sind. Grund derartiger Asymmetrien sind nicht nur imparitätische Einflüsse, sondern z.B. auch aktivische Forderungsabschläge aufgrund keiner oder einer zu geringen Verzinsung oder eines Disagios sowie Wertberichtigungen auf Forderungen oder die schon angesprochenen Rückstellungen ohne korrespondierende Gegenposition ${ }^{2}$. Diese passivischen Differenzbeträge deuten darauf hin, dass die rechtlich separierte Unternehmensgruppe gegenüber der Einheitsunternehmung zumindest zeitweilig das Gruppeneinkommen reduzieren und dadurch Steuervorteile erlangen kann ${ }^{3}$. Dies ist z.B. vor dem Hintergrund der Organisationsneutralität schwer zu rechtfertigen.

Die ergebniswirksame Schuldenkonsolidierung nach IFRS stellt das hierfür technisch notwendige Korrekturverfahren zur Verfügung. Die aus gruppeninternen Kreditbezie-

Vgl. IASB Framework Par. 29-30, 44; dazu insb. Baetge/Schulze (IAS 27, 2002) Tz. 150-152.

Vgl. so auch Kap. III.1.2; Busse von Colbe et al. (Konzernabschlüsse, 2003) S. 355-358. Da hier allgemein auf Ansatz- und Bewertungsregeln Bezug genommen wird, ist es unerheblich, dass z.B. Forderungsabschläge aufgrund eines Disagios im IFRS-System (IAS 39) eher nicht existieren.

3 Vgl., allerdings ohne Zeitbezug, Grotherr (Besteuerung nationaler und grenzüberschreitender Konzerne, 1994) S. 544. In der Totalperiode dürfte bei Gültigkeit des Kongruenzprinzips kein Unterschied zwischen der Summe der Einzelgewinnermittlungen und der Gesamtgewinnermittlung entstehen. 
hungen erwachsenen Bestandspositionen sind zu verrechnen, wobei die Differenzen, soweit sie auf das laufende Periodenergebnis entfallen, in der Betriebseinnahmen- sowie -ausgabenkonsolidierung zu eliminieren sind, während der auf frühere Perioden entfallende Teil konsequenterweise im Eigenkapital korrigiert wird. Aus steuerlicher Sicht scheint es dabei abseits aller Ansatz- und Bewertungsfragen auch keine sonstigen normativen Bedenken zu geben. Auch der obligatorische Charakter der Schuldenkonsolidierung ist steuerlich gerechtfertigt. In durchführungseffizienter Perspektive dürften ohnehin eher die zeitlichen (,unechten“) Differenzen problematisch sein, die ein streng abgestimmtes Verhalten innerhalb der Unternehmensgruppe bei der Verbuchung von Schuldverhältnissen erforderlich machen'.

Problematisch ist allerdings die Gültigkeit des Wesentlichkeits- und Wirtschaftlichkeitsgrundsatzes. Abzuwägen ist hier die einheitstheoretische Konsequenz mit der durchführungsorientierten Effizienz. Angesichts der bereits angedeuteten Freiheitsgrade bei der Auslegung dieser Grundsätze ${ }^{2}$, erscheint ihre Anwendung auf die Schuldenkonsolidierung nur unter zusätzlicher Konkretisierung möglich ${ }^{3}$.

In der EU ist die Schuldenkonsolidierung den Steuersystemen der Konsolidierungsstaaten nicht fremd. In Portugal und Spanien werden gruppeninterne Kreditbeziehungen eliminiert, wobei die Aufrechnungsdifferenzen ergebnisneutral behandelt werden. Damit ist die Schuldenkonsolidierung in den Gruppenbesteuerungssystemen dieser beiden Staaten steuerlich ohne Relevanz und - ähnlich wie bei der Kapitalkonsolidierung - aus durchführungseffizienter Hinsicht generell zu hinterfragen. Konsequenter erscheint hier das französische System. Als Zurechnungsmodell verzichtet es auf die Eliminierung der Bestandspositionen, korrigiert aber zumindest teilweise die Ergebniswirkungen gruppeninterner Kreditbeziehungen. Demgegenüber ist das niederländische Gruppenbesteuerungssystem in seiner einheitstheoretischen Konsequenz sogar IAS 27 voraus. Wegen seiner idealtypischen Ausgestaltung ist hier „nur“ das Problem der erstmaligen Schuldenkonsolidierung zu lösen ${ }^{4}$, während gruppeninterne Kreditbeziehungen in den Folgeperioden gar nicht mehr erfasst werden. Für die realtypische Variante der Gesamtgewinnermittlung scheint IAS 27 aber auch vor diesem Hintergrund geeignet.

Vgl. Ackermann/Maj (Intercompany Reconciliation, 2002).

Vgl. Kap. V.2.2.1.5.2; dazu auch Baetge/Schulze (IAS 27, 2002) Tz. 150-152.

Vgl. diesen Grundsätzen deshalb generell ablehnend gegenüberstehend z.B. Grotherr (Besteuerung nationaler und grenzüberschreitender Konzerne, 1994) S. 353-354, 547-548, der sich allerdings auf (die weitgehend inhaltsgleiche) handelsrechtliche Sicht bezieht.

4 Nach Geiger (Konzept der fiskalen Einheit, 2002) S. 364 werden eventuelle Aufrechnungsdifferenzen aus Kreditverhältnissen, die im Erstkonsolidierungszeitpunkt zwangsläufig vor der Gruppenzugehörigkeit entstanden sind, ergebniswirksam aufgelöst. Über diese Vorgehensweise ließe sich aus einheitstheoretischer Sicht streiten. Sinnvoller scheint eher eine ergebnisneutrale Eigenkapitalverrechnung; vgl. so z.B. Busse von Colbe et al. (Konzernabschlüsse, 2003) S. 374, die aber einheitstheoretische Schwierigkeiten bei der genauen Eigenkapitalpositionszuordnung zugeben. IAS 27 sieht für dieses Problem keine explizite Lösung vor. 


\subsection{Zwischenergebniseliminierung sowie Betriebsausgaben- und einnahmen- konsolidierung}

\subsubsection{Regulierung auf der Grundlage der IFRS}

Die Zwischenergebniseliminierung sowie Betriebsausgaben- und einnahmen- bzw. Aufwands- und Ertragskonsolidierung fußen auf derselben Vorschrift, die auch zur Schuldenkonsolidierung anhält. IAS 27.24 wird dabei durch IAS 27.25 ergänzt. Hier wird explizit vorgeschrieben, dass Zwischenergebnisse aus den Bestandspositionen der Bilanz herauszukonsolidieren sind. Selbiges gilt für Aufwendungen und Erträge, die aus gruppeninternen Transaktionen erwachsen'. Tiefergehende technische Details sind in IAS 27 nicht enthalten.

Zwischenergebniseliminierung sowie Aufwands- und Ertragskonsolidierung folgen nach IAS 27.24-25 der Vollkonsolidierung, so dass Zwischenergebnisse und gruppeninterne Aufwendungen und Erträge immer in voller Höhe zu eliminieren sind. Dies gilt auch für den Fall, in dem Minderheiten beteiligt sind, sowie für jede Art von gruppeninterner Lieferung und Leistung. So sind „upstream-“ und „downstream“-Geschäfte in dieser Beziehung gleich zu behandeln.

Durch die Zwischenergebniseliminierung ist zu gewährleisten, dass die Vermögenswerte, die auf gruppeninternen Lieferungen oder Leistungen beruhen, in der konsolidierten Bilanz mit einem Wert angesetzt werden, der den einheitlichen Bilanzierungsvorschriften genügt, die für die Unternehmensgruppe als rechnungslegende Einheit nach IAS 27.28 gelten. Dabei können sich die ursprünglichen Wertansätze aus dem Einzelabschluss (Handelsbilanz II) des liefernden bzw. leistenden Unternehmens gegenüber denjenigen in der konsolidierten Bilanz verändern, weil aus Gruppensicht weitere aktivierungspflichtige Kosten hinzugekommen sind. Somit sind „Gruppen-Anschaffungs- bzw. Herstellungskosten“" anzusetzen, deren Ermittlung sich in Abhängigkeit von den jeweils betroffenen Vermögenswerten aus den Einzelvorschriften anderer Standards ergibt (z.B. IAS 2 zu Vorräten, IAS 16 zum Sachanlagevermögen, jeweils unter Berücksichtigung von IAS 23 zur Behandlung von Fremdkapitalzinsen) $)^{2}$.

Die Aufwands- und Ertragskonsolidierung zielt indes auf die Korrektur der Stromgrößen in der Summen-GuV. Sie hat zu gewährleisten, dass die konsolidierte GuV ab-

1 Vgl. IAS 27.25: „Intragroup balances and transactions, including income, expenses and dividends, are eliminated in full. Profits and losses resulting from intragroup transactions that are recognised in assets, such as inventory and fixed assets, are eliminated in full".

2 Vgl. so auch Baetge/Schulze (IAS 27, 2002) Tz. 154-156. In Analogie zur Schuldenkonsolidierung müssten Unterschiedsbeträge aus der Zwischenergebniseliminierung auch nach Vorjahresdifferenzen und laufende Differenzen differenziert werden, um sie ergebnisneutral bzw. -wirksam zu korrigieren; vgl. so auch $F a ß$ (Unterschiedsbeträge, 1990) S. 1306-1310. 
schließend nur noch Aufwendungen und Erträge beinhaltet, die aus Transaktionen mit fremden Dritten resultieren.

Zwischenergebniseliminierung sowie Aufwands- und Ertragskonsolidierung fallen wie andere Konsolidierungsschritte zuvor auch - unter den allgemeinen Wesentlichkeits- und Wirtschaftlichkeitsvorbehalt. Nach diesen Grundsätzen ist auf diese speziellen Konsolidierungsmaßnahmen zu verzichten, wenn sie für die Informationswirkung des konsolidierten Abschlusses unwesentlich sind oder wenn sie nur mit unverhältnismäßig hohen Kosten durchführbar sind ${ }^{1}$.

\subsubsection{Eignung für die konsolidierte steuerliche Gewinnermittlung}

Die Zwischenergebniseliminierung sowie Aufwands- und Ertragskonsolidierung ist auch Kernbestandteil einer steuerlichen Konsolidierung und einer daraus erwachsenen Gesamtgewinnermittlung. Fraglich ist nur, ob die spezielle IFRS-Regulierung für steuerliche Zwecke geeignet ist.

In ihrer einheitstheoretischen Ausrichtung ist IAS 27.24-25 konsequent. Dies betrifft die Vorgehensweise der Volleliminierung unabhängig von der Beteiligungsquote der Minderheiten, die eben nicht als ,außenstehende“ Marktteilnehmer behandelt werden. Deshalb ist es auch folgerichtig, nicht zwischen „upstream-“" und „downstream"-Geschäften zu differenzieren, weil dies innerhalb des steuerlichen (Voll-)Konsolidierungskreises schlichtweg unerheblich wäre ${ }^{2}$. So unterbleibt auch der diesbezügliche Minderheitenausweis im Eigenkapital oder Ergebnis. Minderheitenanteile werden nur auf die Kapital- oder Ergebnisbestandteile berechnet, die - abgesehen von Eigenkapitaltransfers mit den Gesellschaftern - mit Dritten erwirtschaftet worden sind.

An dieser Stelle zeigt sich, dass eine einheitstheoretisch geprägte Vollkonsolidierung auch unter Berücksichtigung des Minderheitenausweises nicht ohne weiteres in eine Quotenkonsolidierung überführt werden kann. Einmal mehr ${ }^{3}$ konkretisieren sich darin auch die Konsequenzen für die Frage der Erfolgslokalisation. So lässt sich der Gewinnanteil der jeweiligen Minderheiten aus der konsolidierten Gewinnermittlung selbst gar nicht mehr ableiten. Dieser letztlich interessentheoretische Anspruch kollidiert mit der

1 Vgl. Baetge/Schulze (IAS 27, 2002) Tz. 167-168, die an dieser Stelle allerdings - im Gegensatz zu ihren Ausführungen zur Schuldenkonsolidierung und ohne weitere Begründung - nur auf den Grundsatz der Wesentlichkeit verweisen.

2 Insofern wird zwischen „upstream-“ und „downstream"-Geschäften auch nur außerhalb der Vollkonsolidierung, i.R.d. Quotenkonsolidierung sowie Equity-Methode differenziert; vgl. z.B. Busse von Colbe et al. (Konzernabschlüsse, 2003) S. 510-513, 555-559.

3 Vgl. hierzu insb. Kap. V.4.2.2.5. 
einheitstheoretisch konsequenten Vollkonsolidierung ${ }^{1}$, die nicht nur Zwischenergebnisse in voller Betragshöhe eliminiert, sondern auch nicht mehr zwischen ,upstream-“ und „downstream"-Geschäften differenziert. Da auch die originäre Einzelgewinnermittlung (Steuerbilanz I) als Alternative nicht unproblematisch ist, müsste das um Zwischenergebnisse bereinigte, konsolidierte Ergebnis letztlich wieder auf die einbezogenen Unternehmen zugerechnet werden - in eine Art Steuerbilanz IV ${ }^{2}$. Dies erscheint aber gegenüber der indirekten Methode insbesondere hinsichtlich der Durchführungseffizienz von Nachteil. Die indirekte Methode könnte statt dessen, ganz im Sinne von Vollkonsolidierung und Einheitstheorie, auf den Minderheitenausweis verzichten. Die „korrekte“ Ermittlung desselben auf der Basis einer direkten Methode harmoniert demgegenüber besser mit der interessentheoretisch geprägten Quotenkonsolidierung.

Einheitstheoretisch konsequent ist darüber hinaus, dass die Formulierung in IAS 27.24 sämtliche gruppeninternen Transaktionen zwischen den Unternehmen der Gruppe und daraus resultierende Bestandspositionen sowie Stromgrößen erfasst. Damit wird eine nicht zu rechtfertigende Beschränkung auf bestimmte Rechtsbeziehungen, z.B. Lieferungen und Leistungen nur zwischen Mutter- und Tochterunternehmen, verhindert. Selbiges gilt auch für die Beschränkung auf Rechtsbeziehungen mit bestimmten, z.B. „marktunüblichen“ Transaktionsbedingungen. Selbiges gilt zudem für die Einengung der Zwischenergebniseliminierung nur auf bestimmte Wirtschaftsgüter, wie z.B. Anlagegegenstände oder Vorräte. Wird das Realisationsprinzip im Sinne des Konzepts des realisierten Reinvermögenszugangs gedeutet, kann es einzig und allein bei Markttransaktionen (mit Dritten) greifen, völlig unabhängig davon, welche Transaktionen und Wirtschaftsgüter jeweils betroffen sind.

Wie bei der Schuldenkonsolidierung auch, stellt die Zwischenergebniseliminierung sowie Aufwands- und Ertragskonsolidierung nach IFRS letztlich das technisch notwendige Korrekturverfahren zur Verfügung, um die Wirkungen gruppeninterner Transaktionen innerhalb einer rechnungslegenden Einheit zu neutralisieren. Dabei geht die IFRSVorgehensweise über das steuerlich notwendige Ausmaß hinaus. Aus durchführungseffizienter Sicht ist eine Betriebseinnahmen- und -ausgabenkonsolidierung nicht erforderlich, wenn sich Stromgrößen in betraglich gleicher Höhe, aber mit unterschiedlichen Vorzeichen, gegenüber stehen. Steuerlich notwendig ist demgegenüber die Korrektur jeglicher Ergebniswirkung gruppeninterner Transaktionen, so wie sie ebenfalls durch

1 Vgl. hierzu bereits die übertragbare Argumentation und Literatur aus Kap. V.4.2.2.5.1, insb. Ordelheide (Konzernerfolg, 1987) S. 300.

2 Diese träte neben die „normale“ Einzelgewinnermittlung (Steuerbilanz I), die für Konsolidierungszwecke vereinheitlicht (II) und neu bewertet wird (III). 
IAS 27.24 obligatorisch vorgeschrieben ist ${ }^{1}$. Im Prinzip wirkt diese Korrektur wie eine temporäre (nicht endgültige ${ }^{2}$ ) Steuerbefreiung bis zur Realisierung durch entsprechende Außenumsätze, durch Liquidation oder durch Ausscheiden des betreffenden Unternehmens aus dem Konsolidierungskreis.

Wegen der Beschränkung dieser steuerlichen Eignungsprüfung auf Konsolidierungsmaßnahmen sind eher technische Aspekte der Zwischenergebniseliminierung sowie Aufwands- und Ertragskonsolidierung nach IFRS nicht von Interesse. Es handelt sich hierbei größtenteils um technische Schwierigkeiten, die im Rahmen einer steuerlichen Konsolidierung bei der Korrektur steuerlicher Einzelgewinnermittlungen auftreten und die durchaus, z.B. bei mehrstufigen Lieferungen, beträchtlich sein können ${ }^{3}$. Da sich die Einzelgewinnermittlungen auf national unterschiedliche steuerrechtliche Ansatz- und Bewertungsregeln beziehen, können diese Schwierigkeiten weder verallgemeinert, noch losgelöst von diesen Regeln analysiert werden. Diese technischen Schwierigkeiten stellen den in IAS 27.24 festgelegten Konsolidierungsgrundsatz aber nicht in Frage und berühren insofern auch nicht seine steuerliche Eignung.

IAS 27 ist möglicherweise vorzuwerfen, technische Details nicht zu regulieren. Dies könnte problematisch sein, wenn daraus z.B. Ermessensspielräume und Selbsteinsteuerungspotenziale oder Nachteile bei der Durchführungseffizienz erwachsen. Andererseits wird der allgemeinen Regulierung zur Zwischenergebniseliminierung sowie Aufwandsund Ertragskonsolidierung in IAS 27.22 eine klare einheitstheoretische Vorgabe flankierend zur Seite gestellt. Unter Rückgriff auf diese Vorgabe müsste sich ein Großteil der Ausgestaltungsfragen, die sich in Bezug auf das jeweilige nationale Gewinnermittlungsrecht ergeben, eindeutig beantworten lassen. Selbst wenn einige wenige dieser Fragen unbeantwortet bleiben ${ }^{4}$, dürfte daraus kein grundsätzlicher Mangel abgeleitet werden, sondern, wenn überhaupt, die Notwendigkeit kleinerer regulatorischer Ergänzungen.

1 Vgl. zu Argumenten, die für eine fakultative Ergebniskorrektur sprechen könnten, Grotherr (Besteuerung nationaler und grenzüberschreitender Konzerne, 1994) S. 502. Mit einem rechtssicher ausgestalteten Wirtschaftlichkeitsgrundsatz, der eben nicht als Option konzipiert ist, mag diesen Argumenten aber z.T. begegnet werden.

2 Der temporäre Charakter setzt allerdings voraus, dass der Besteuerungszugriff innerhalb des Konsolidierungskreises gewährleistet ist. Vor dem Hintergrund der EU-Strategie bedarf es der Konsolidierungskreisbegrenzung auf die EU mit aufeinander abgestimmter Steuerhoheit der Mitgliedstaaten.

3 Vgl. dazu z.B. Busse von Colbe et al. (Konzernabschlüsse, 2003) S. 387-390, 416-428.

4 Vgl. z.B. Busse von Colbe et al. (Konzernabschlüsse, 2003) S. 384, 391, die auch unter Rückgriff auf die Einheitstheorie eine eindeutige Definition der Anschaffungs- und Herstellungskosten aus Sicht der Unternehmensgruppe als rechnungslegender Einheit für schwer möglich erachten, wenn z.B. Kosten entstanden sind, die bei einer Einheitsunternehmung nicht hätten entstehen können. 
Hinsichtlich der steuerlichen Eignung des Grundsatzes der Wesentlichkeit und Wirtschaftlichkeit kann auf bisherige Erkenntnisse verwiesen werden ${ }^{1}$. Bei der Zwischenergebniseliminierung sowie Aufwands- und Ertragskonsolidierung dürfte der durchführungsorientierte Effizienzvorteil derartiger Grundsätze aber möglicherweise schwerer wiegen, weil hier unter realtypischen Bedingungen eine exakte Ermittlung gruppeninterner Ergebniswirkungen kaum noch möglich erscheint. Dies liegt auch darin begründet, dass die Gruppen-Anschaffungs- oder -Herstellungskosten regelmäßig derivativ aus den Kalkulationen der Einzelgewinnermittlungen abgeleitet werden müssen ${ }^{2}$.

Auch in den vier nationalen Gesamtgewinnermittlungssystemen der EU existiert die mehr oder minder umfangreiche Notwendigkeit zur Zwischenergebniseliminierung, ohne dass hier - wohl im Hinblick auf die Kerngrößenorientierung der steuerlichen Gewinnermittlung - zwischen der Bestandsgrößen- sowie Stromgrößenkorrektur streng unterschieden wird. Da das niederländische Ermittlungssystem Zwischenergebnisse erst gar nicht anfallen lässt und sich das französische Zurechnungssystem hier auf das Anlagevermögen beschränkt, sind deutlichere Parallelen zur IFRS-Vorgehensweise nur in Spanien und Portugal zu entdecken. In diesen beiden Systemen ist das in der Einzelgewinnermittlung realisierte Zwischenergebnis in voller Höhe zu eliminieren. Weil damit „nur“ der Status quo ante wieder hergestellt wird und es insofern an einem gruppendimensionalen Anschaffungs- und Herstellungskostenbegriff mangelt, ist die Vorgehensweise einheitstheoretisch weniger konsequent, möglicherweise aber durchführungseffizienter.

Abschließend kann festgehalten werden, dass die in IAS 27 festgelegte Zwischenergebniseliminierung sowie Aufwands- und Ertragskonsolidierung für steuerliche Konsolidierungszwecke durchaus geeignet erscheinen. Aus steuerlicher Sicht kann es möglicherweise sinnvoll sein, bestimmte durchführungseffiziente Vereinfachungen zu erwägen, die zwar zu Lasten der einheitstheoretischen Konsequenz gehen, die sich aber auch als Ausdruck eines entsprechend konkretisierten Wirtschaftlichkeitsgrundsatzes interpretieren lassen.

Vgl. Kap. V.2.2.1.5.2 und V.4.3.2.

2 Vgl. so auch Busse von Colbe et al. (Konzernabschlüsse, 2003) S. 392-416, 424-425; aus steuerlicher Perspektive Grotherr (Besteuerung nationaler und grenzüberschreitender Konzerne, 1994) S. 528-530, der die Komplexität einer korrekten Zwischenergebniseliminierung z.B. an den Schwierigkeiten bei der Ermittlung der Mengen- und Wertkomponente gruppeninterner Lieferungen und Leistungen beschreibt. Aus Wirtschaftlichkeitserwägungen befürwortet er gerade bei Handelswaren und Vorräten angesichts der hohen Umschlagshäufigkeit einen Verzicht auf die steuerliche Zwischenergebniseliminierung (S. 499, 502). 


\section{Ergebnis und Anpassungsvorschläge}

Die vorangegangene Analyse hat verdeutlicht, dass die IFRS durchaus als „Ausgangspunkt ${ }^{* 1}$ einer eigenständigen steuerlichen Konsolidierung dienen können. Insoweit ist der diesbezüglichen These der EU-Kommission zuzustimmen ${ }^{2}$. $\mathrm{Zu}$ betonen ist jedoch, dass sich diese Zustimmung allein auf die hier untersuchten Konsolidierungsvorschriften bezieht.

Die vorangegangene Analyse hat darüber hinaus gezeigt, dass die IFRS auch nicht mehr als einen Ausgangspunkt für die steuerliche Konsolidierung darstellen können. Schon terminologisch bedeutet dies, dass ein regulatorischer Prozess zur Entwicklung eigenständiger steuerlicher Konsolidierungsregeln allenfalls zu Beginn bei den IFRS aufsetzen kann. Jede Aussage darüber, wie weit sich der anzustrebende Endpunkt vom Ausgangspunkt entfernt, fehlt. Letztlich kann also jedes Regelsystem einen Ausgangspunkt einer eigenständigen steuerlichen Konsolidierung darstellen. Wenn also, wie im Folgenden gezeigt wird, die Anpassungsmaßnahmen einen Großteil der untersuchten Einzelregeln betreffen, stellt sich aus durchführungseffizienter Sicht die Frage, ob die IFRS wirklich der Ausgangspunkt zur Entwicklung einer eigenständigen steuerlichen Gesamtgewinnermittlung sein sollen. Möglicherweise könnte bei einem alternativen System ein geringerer Anpassungsbedarf festgestellt werden.

Im Folgenden soll der Anpassungsbedarf für die IFRS aus steuerlicher Sicht explizit aufgezeigt werden. Er leitet sich unmittelbar aus den Ergebnissen der vorangegangenen Eignungsanalyse ab. In den Fällen, in denen große Zweifel an der steuerlichen Eignung einer konkreten Konsolidierungsregel nach IFRS verbleiben - im Sinne der Beweislastumkehr also keine steuerliche Eignung vorliegt - , wird allgemein auf einen diesbezüglichen Anpassungsbedarf hingewiesen. In welche Richtung sich die jeweilige Anpassung zu vollziehen hat, wird, soweit möglich, skizziert ${ }^{3}$. Im Rahmen dieser Ausgestaltungsempfehlungen wird aber auch oft genug auf die normative Schwierigkeit eindeutiger Aussagen verwiesen.

Voraussetzung einer konsolidierten Rechnungslegung und Abgrenzung des Konsolidierungskreises

- Bei den Voraussetzungen einer konsolidierten Rechnungslegung und bei der Abgrenzung des Konsolidierungskreises folgen die IFRS im Grundsatz dem dieser Ar-

EU-Kommission (Ergebnisse, 2003) S. 22.

$2 \mathrm{Zu}$ einem ähnlichen Ergebnis (trotz anderer Argumentation) kommt Spengel (Einheitliche Bemessungsgrundlage, 2004) S. 113-117 und Spengel (Unternehmensbesteuerung in der EU, 2004) S. 147, der sich allerdings auf die gesamten IFRS und auf den Einzelabschluss fokussiert.

3 Mehr als eine mögliche Lösungsskizze kann an dieser Stelle nicht vorgenommen werden, da viele der hier angesprochenen Fragen wiederum eigenständige Untersuchungen nach sich ziehen müssten. 
beit zu Grunde liegenden normativen Abgrenzungsleitbild der konsolidierten steuerlichen Gewinnermittlung. Anknüpfungspunkt und Einbeziehungsobjekte sind primär Unternehmen und die ihnen mittelbar sowie unmittelbar zugerechneten Ressourcen.

- Mutter- und Tochterunternehmen werden in IAS 27.4 nicht rechtsformspezifisch eingegrenzt. Darin dokumentiert sich der rechtsabstrahierende „Teilmengencharakter" der IFRS, der an dieser Stelle durch das europäische Steuerrecht zu ergänzen wäre. So würde es dem europäischen Regulierer obliegen, den Rechtscharakter der obersten Entscheidungs- und Kontrollinstanz festzulegen. Selbst wenn darunter was dem normativen Abgrenzungsleitbild nicht widerspräche - auch Individuen subsumiert werden sollten, würde dies mit IAS 27 konform gehen. Ist diese Instanz erst einmal festgelegt, dient die weite Definition der „subsidiaries“ und „businesses“ dem Vollständigkeitsgebot und der Reduzierung von Selbsteinsteuerungsmöglichkeiten. $\mathrm{Zu}$ berücksichtigen ist allerdings, dass ein rechtsformunabhängig abgegrenzter Konsolidierungskreis daraufhin zu prüfen ist, ob und inwieweit er in die europäische und einzelstaatliche Steuersystematik integriert werden kann.

- Das in IAS 27.12 festgelegte Weltabschlussprinzip kollidiert mit der begrenzten Steuersouveränität des europäischen Regulierers. Solange die Gefahr der Doppelbesteuerung durch veränderte rechtliche Rahmenbedingungen nicht gebannt wird, müssen die fiskalischen Grenzen der EU den Konsolidierungskreis zwangsläufig beschränken. Damit ergibt sich gezwungenermaßen eine Kompromisslösung, die die Wirkung einer Einzelgewinnermittlung nach dem Trennungsprinzip nicht vollständig überwinden kann. Der europäische Regulierer hat in diesem Zusammenhang nicht nur den Konsolidierungskreis auf die EU zu beschränken ${ }^{1}$, sondern auch die Frage zu beantworten, unter welchen Voraussetzungen ein Unternehmen in welchem Staat steuerlich als ansässig gilt. Zudem wäre zu untersuchen, ob und in welcher Beziehung außerhalb der EU befindliche Teile der Unternehmung (Tochterunternehmen außerhalb der EU) anders als ,normale“ fremde Dritte behandelt werden sollen ${ }^{2}$.

- Bei Vorliegen der entsprechenden Voraussetzungen sehen IAS 27.9 und 27.12 im Grundsatz vor, dass die Aufstellung konsolidierter Abschlüsse und die Einbeziehung sämtlicher Tochterunternehmen obligatorisch sind. Diese doppelte Verpflichtung dürfte auch für steuerliche Zwecke geeignet $\operatorname{sein}^{3}$.

- Bei Unternehmensgruppen mit mehrstufigen Eigentumsbeziehungen sieht IAS 27 im Grundsatz die Aufstellungspflicht auch für Zwischengesellschaften im Sinne des sog. „Tannenbaumprinzips“ vor, sofern nicht die Ausnahmeregel in IAS 27.10 greift. Aus

1 Vgl. dies im Hinblick auf IAS 27 ebenfalls fordernd EU-Kommission (Konsultationspapier, 2003) S. 16; Spengel (Einheitliche Bemessungsgrundlage, 2004) S. 110, der zudem komplexe Abgrenzungsfragen wegen des Liefer- u. Leistungsaustausches mit Tochterunternehmen in Nicht-EU-Staaten erkennt.

Vgl. zu diesen Überlegungen Hellerstein/McLure (Company Income Taxation, 2004) S. 206-207.

Vgl. Spengel (Einheitliche Bemessungsgrundlage, 2004) S. 110 in Bezug auf die Einbeziehung. 
Sicht der konsolidierten steuerlichen Gewinnermittlung erscheint dieses Prinzip auch unter den Gesichtspunkten der Steuerlastverteilung entbehrlich.

- Der den IFRS immanente Wesentlichkeits- und Wirtschaftlichkeitsvorbehalt projiziert aus steuerlicher Sicht auf die Notwendigkeit, Aspekte der Durchführungseffizienz bei der Abgrenzung des Konsolidierungskreises im Einzelfall zu berücksichtigen. Ein allgemeiner und nicht weiter konkretisierter Wirtschaftlichkeitsgrundsatz o.ä. kann aber nicht ohne weiteres in die steuerliche Gewinnermittlung übernommen werden ${ }^{1}$. Wenn überhaupt, dürfte nur die Festlegung einer klar definierten Ausnahmeregel von der Einbeziehungspflicht eine steuerlich akzeptable Alternative sein.

- Die Beherrschung als zentrales Verbindungskonzept für eine Unternehmensgruppe nach IAS 27 geht mit dem normativen Abgrenzungsleitbild der konsolidierten steuerlichen Gewinnermittlung durchaus konform. Dies gilt auch für das Abstellen auf die Möglichkeit der Beherrschung und nicht auf ihre tatsächliche Ausübung. Bei ausgedünnten Verfügungsrechten muss der europäische Regulierer jedoch eine Entscheidung treffen, woran er das Verbindungskonzept konkret knüpfen möchte: an die hier präferierten residualen Entscheidungs- und Kontrollrechte oder an das Residualeinkommens- und -risikokonzept. IAS 27 und auch Interpretation SIC-12 sind hier nicht trennscharf und vereinigen letztlich beide Konzepte.

- Das als widerlegbare Vermutung ausgestaltete Konzept der einfachen Stimmrechtsmehrheit erscheint für steuerliche Abgrenzungszwecke überaus sinnvoll. Mit der Vermutung als Grundsatz werden Standardisierungsvorteile generiert, während im Einzelfall rechtssicher begründete Ausnahmen zur verbesserten Annäherung an das normative Abgrenzungsleitbild zugelassen werden. Die in IAS 27 nicht enthaltenen Hinweise zur Berechnung der Stimmrechtsmehrheit erscheinen steuerlich insoweit entbehrlich, wie sich ihre Berechnung aus dem Wesen des Beherrschungskonzeptes ableiten lässt. Zusätzlicher Regulierungsbedarf ergibt sich möglicherweise bei Detailfragen, z.B. wie dazwischen geschaltete, nicht in der EU ansässige Unternehmen der Gruppe bei der Berechnung zu berücksichtigen sind.

- Neben dem Kriterium der Stimmrechtsmehrheit werden in IAS 27.13 und Interpretation SIC-12 weitere Beherrschungssachverhalte festgelegt. Dadurch werden Standardisierungsvorteile des Stimmrechtskriteriums deutlich relativiert. Während sich IAS 27.13 nur auf vier vergleichsweise klar abgegrenzte Sachverhalte beschränkt, ist die zusätzliche Öffnung des Beherrschungskonzeptes durch SIC-12 weit weniger konkretisiert (und im Übrigen auch sehr viel stärker am Residualeinkommens- und -risikokonzept orientiert). Obwohl die normative Bewertung der Beherrschungssach-

1 Vgl. zu einer ähnlichen Einschätzung auch EU-Kommission (Konsultationspapier, 2003) S. 13-14, die - allerdings mit Bezug auf die Wesentlichkeit - auf das Problem verweist, dass unterschiedliche Unternehmensgrößen eigentlich $\mathrm{zu}$ unterschiedlichen Grenzwerten führen müssten, die aber einer gleichmäßigen Besteuerung widersprechen. 
verhalte neben dem Stimmrechtskriterium keineswegs eindeutig und klar erscheint, könnte in einer Beschränkung auf den Sachverhaltskatalog des IAS 27.13 ein tragfähiger Kompromiss für die konsolidierte steuerliche Gewinnermittlung gesehen werden. Aber auch diese Sachverhalte sind mit Ausnahme von IAS 27.13 (b) daraufhin zu prüfen, wie das dort postulierte ,power-Kriterium“ noch stärker in Richtung rechtlich einklagbarer Verträge konkretisiert werden kann.

- Neben der Beherrschung sieht IAS 27 kein weiteres Verbindungskonzept vor. Insbesondere eine zivilrechtliche Anspruchseinheit ist somit als Konsolidierungsvoraussetzung nicht erforderlich. Dies dürfte auch für die Abgrenzung des steuerlichen Konsolidierungskreises gelten. Die Notwendigkeit der zivilrechtlichen Anspruchseinheit ist für Gruppenbesteuerungszwecke letztlich nicht erwiesen. Zudem fehlen die diesbezüglichen Rechtsinstitute in dem Gesellschaftsrecht vieler EU-Mitgliedstaaten.

- Weitere Voraussetzungen für die Einbeziehung in den Konsolidierungskreis existieren nach IFRS nicht und scheinen aus steuerlicher Sicht auch nicht erforderlich. Das betrifft z.B. die explizite Einwilligungserfordernis der Minderheitsgesellschafter wie letztlich sämtlicher betroffener Vertragsparteien, die sich kaum durch die Zustimmung der (beherrschten!) Leitungsgremien der einbezogenen Unternehmen ersetzen lässt. Unter Gesichtspunkten der Durchführungseffizienz ist dieses Erfordernis nicht tragbar. Statt dessen scheint das Vertrauen in die Marktkräfte, also in die individuelle Ausstiegsoption der Betroffenen oder in die Wirksamkeit privatvertraglicher Arrangements gerade bei hochspezifischen Investitionen der durchführungseffizientere Weg. An dieser Stelle wäre regulierungstheoretisch zu prüfen, ob ergänzende gesetzliche Bestimmungen in der EU, ähnlich z.B. den aktienrechtlichen Schutzmechanismen in Deutschland, sinnvoll sind ${ }^{1}$. Nicht erforderlich erscheint auch die Zustimmungserfordernis der Finanzverwaltung zur Gruppenbesteuerung, soweit sie über das Prüfen formaler Gesichtspunkte hinausgeht. Um jede Form der behördlichen Willkür im Ansatz zu unterbinden, scheint - wie in Frankreich - nur der Verzicht auf ein behördliches Genehmigungsverfahren konsequent. Sollte das formale Überprüfen der Voraussetzungen jedoch eines solchen Verfahrens bedürfen, erscheint - wie in den Niederlanden - ein entsprechender Rechtsanspruch auf Genehmigung sinnvoll ${ }^{2}$. Ohnehin betreffen diese Fragen weniger die Konsolidierungsregeln an sich, sondern vielmehr das rechtliche Rahmensystem, in das diese Regeln zu integrieren wären.

1 So bietet es sich z.B. nach Ordelheide (Konzernerfolgskonzeptionen, 1987) S. 985 sogar an, ,den Minderheitsaktionären [weitere, Anmerkung des Verfassers] Rechte einzuräumen, die sie bei Aufnahme eines Unternehmens in einen Konzernverbund in die Lage versetzen, für sie angemessene Zusagen zu erlangen"; vgl. dazu bereits Kap. III.2.5.1.2.

2 Vgl. Kap. IV.1.2.1. 


\section{Stufenkonzept}

- Die Rechnungslegung nach IFRS basiert auf dem „Stufenkonzept“, das für Zwecke der konsolidierten steuerlichen Gewinnermittlung eher ungeeignet erscheint. Hier kann die binäre Form der Abgrenzung besser gerechtfertigt werden, die auch Probleme bei der komplexen Abstimmung unterschiedlicher Gewinnermittlungsmethoden und daraus erwachsender Besteuerungsfolgen vermeidet. Damit reduziert sich der steuerliche Konsolidierungskreis auf die Vollkonsolidierung beherrschter Unternehmen. Hybride Kooperationsformen zwischen der Unternehmung und dem Markt müssten dem Markt zugerechnet und aus dem steuerlichen Konsolidierungskreis ausgeschlossen werden. Die Frage, wie der entsprechende Beteiligungsbesitz in der konsolidierten steuerlichen Gewinnermittlung abzubilden ist, wird dadurch zu einer reinen Bewertungsfrage ${ }^{1}$.

\section{Vorbereitende Maßnahmen}

- Die Notwendigkeit zur Vereinheitlichung der Bilanzierungs- bzw. Gewinnermittlungsgrundsätze ist auch in einer konsolidierten steuerlichen Gewinnermittlung gegeben. IAS 27 gibt hier eine tragfähige Basis vor.

- Die Steuerbilanz II sollte nicht der Neuausübung von Wahlrechten dienen. Die Existenz von Wahlrechten ist aus normativer Sicht ohnehin schwer zu rechtfertigen. Deshalb sind sie nicht nur in der Steuerbilanz I, sondern auch in der Steuerbilanz II und insbesondere noch in jeweils unterschiedlicher Ausübung abzulehnen.

- Eine Fremdwährungsumrechnung ist auch in der grenzüberschreitenden steuerlichen Gesamtgewinnermittlung innerhalb der EU vonnöten, sobald sich eine Unternehmensgruppe über die Grenzen der Euro-Zone erstreckt. Das in IAS 21 festgeschriebene Konzept der funktionalen Währung kann allerdings nicht recht überzeugen und müsste wohl in Richtung eines Methodenmonismus abgeändert werden. Theoretisch konsequenter erscheint hier die Zeitbezugsmethode, einfacher und klarer die Stichtagskursmethode.

\section{Kapitalkonsolidierung}

- Die in IFRS 3 ausschließlich vorgesehene Erwerbsmethode ist mit Ansatz- und Bewertungsaspekten verbunden. Da aber an der grundsätzlichen Eignung der IFRS für die steuerliche Gewinnermittlung gezweifelt wird, ist die Anwendung ihrer Ansatz-

1 Die (in dieser Arbeit nicht im Vordergrund stehende) Antwort hierauf kann auf Grundlage der normativen Anforderungen an die steuerliche Gewinnermittlung gefunden werden. Wird hierbei das Konzept des realisierten Reinvermögenszugangs zu Grunde gelegt, dürfte nur eine Bewertung zu historischen Anschaffungskosten und z.B. keine Equity-Methode (verstanden als Bewertungsmethode) oder gar Zeitwertmethode in Frage kommen. Anders sähe dies nur unter den restriktiven Modellbedingungen des kapitaltheoretischen Gewinns aus. 
und Bewertungskonzeption auch im Zuge der steuerlichen Kapitalkonsolidierung kritisch zu beurteilen. Die Erwerbsmethode sollte hier statt dessen auf geeignete(re) steuerliche Gewinnermittlungsregeln aufsetzen können.

- Die Übernahme der Erwerbsmethode in ein EU-weites Konzept der konsolidierten steuerlichen Gewinnermittlung ist mit den einzelstaatlichen Steuerregeln abzustimmen. So müssen nicht nur die konsolidierungsspezifischen Bilanzierungsaspekte von IFRS 3 (insb. Behandlung der positiven und negativen Unterschiedsbeträge) mit den Einzelgewinnermittlungsregeln harmonieren. Auch Überschneidungen im Anwendungsbereich (beim ,asset deal") sind auszuräumen. Für ein EU-weit geltendes Konsolidierungsmodell folgt daraus die Erkenntnis, dass eine Konsolidierung nicht „so einfach" als Zusatzregulierung die weiterhin existierenden und nicht harmonisierten einzelstaatlichen Regeln ergänzen kann. Dies wird auch durch sonstige technische Schwierigkeiten untermauert, die bei der Regulierung der steuerlichen Konsolidierung in Abstimmung mit den Besonderheiten der nationalen Steuersysteme zu erwarten und zu lösen sind.

- Mit der Erwerbsmethode fände auch die Einzelerwerbsfiktion und die Neubewertung Eingang in die steuerliche Konsolidierung und mit ihr die unter Objektivierungsgesichtspunkten problematische Aufteilung der Unternehmens-Anschaffungskosten auf einzelne Wirtschaftsgüter. Trotz einheitstheoretischer Konsequenz und existierender Parallelen zum (nicht unproblematischen) Teilwert im deutschen Steuerrecht erscheint die „cost allocation“ und die damit einhergehenden Selbsteinsteuerungsmöglichkeiten im Ansatz- und Bewertungsbereich steuerlich kaum tragbar. Dem Regulierer ist deshalb anzuraten, die steuerliche „cost allocation“ in Ergänzung zu den IFRSRegeln soweit wie möglich zu standardisieren und zu objektivieren. Möglicherweise könnte an dieser Stelle eine Differenzierung zwischen den Wirtschaftsgütern, die bereits in der Einzelgewinnermittlung des erworbenen Unternehmens geführt (und objektiviert) wurden, und den erst im Zuge der Akquisition ,angeschafften“ Wirtschaftsgütern sinnvoll sein. In Beschränkung auf die erste Kategorie könnte z.B. erwogen werden, die willkürbehaftete Zuordnung stiller Reserven und Lasten durch eine gleichmäßige Buchwertauf- oder -abstockung der übernommenen Wirtschaftsgüter zu ersetzen ${ }^{\prime}$. Objektivität und auch Durchführungseffizienz ließen sich ebenfalls steigern, wenn die Kapitalkonsolidierung ohne Wertänderung bei den Wirtschaftsgütern einherginge und sämtliche stille Reserven (abzüglich stiller Lasten) im Unterschiedsbetrag aktiviert und über standardisierte Abschreibungsverläufe ergebniswirksam verrechnet würden ${ }^{2}$. Der Umfang der Wertergänzungsrechnung wäre deut-

1 Vgl. z.B. Reis (Körperschaftsbesteuerung des Konzerns, 1996) S. 246 unter Rückgriff auf die deutsche Finanzrechtsprechung; ähnlich Bauer (Besteuerung deutscher Konzerne, 1987) S. 228-234, 246-249, der dies insb. furr den Fall eines negativen Unterschiedsbetrages vorschlägt.

2 Vgl. Ordelheide (Kapitalkonsolidierung, 1984) S. 242, 272. 
lich reduziert. Fraglich ist allerdings, wie stark Objektivierung und Durchführungseffizienz im Vordergrund stehen und die einheitstheoretische Idee der Erwerbsmethode konterkarieren dürfen.

- Der nach IFRS 3 notwendige Ansatz einer Eventualschuld fällt unter die erwähnte zweite Kategorie von Wirtschaftsgütern und ist wegen der Eventualschulden naturgemäß anhaftenden Unsicherheit kritisch zu beurteilen. Unabhängig davon, ob in der fiktiv entgoltenen Übernahme eines Verlustrisikos ein negatives Wirtschaftsgut gesehen wird oder nicht, bedarf es hier der Abstimmung mit den entsprechenden nationalen Steuerregeln zur Einzelgewinnermittlung.

- Die Beurteilung des Goodwill ist aus steuerlicher Sicht gleichfalls schwierig. Der Ansatz desselben im Sinne von IFRS 3 könnte eigentlich nur als Konvention im Umgang mit dem verbleibenden positiven Unterschiedsbetrag aus der Kapitalkonsolidierung gerechtfertigt werden. Ähnlich verhält es sich mit dem negativen Unterschiedsbetrag. Die asymmetrische Behandlung von positivem und negativem Unterschiedsbetrag nach IFRS 3 erscheint hierbei wenig konsistent. Möglicherweise stünde gar die Identifikation des verbleibenden Unterschiedsbetrages insgesamt in Frage, um die aufwendige und ermessensbehaftete „cost allocation“ zu reduzieren. Statt dessen könnte - wie bereits angeführt - die gesamte Differenz aus der Kapitalkonsolidierung einschließlich stiller Reserven und Lasten in einer Art Ausgleichsposten zusammengefasst werden.

- Eine Neubewertung ist in Kombination mit der Ergebniswirksamkeit der Kapitalfolgekonsolidierung nur in Abstimmung mit den nationalen Regulierungen zur Veräußerungsgewinnbesteuerung denkbar. Werden existierende Freistellungsregeln, z.B. nach Art von $\S 8 \mathrm{~b}$ Abs. $2 \mathrm{KStG}$, nicht angepasst, bedarf es kompensierender Mechanismen in der Gesamtgewinnermittlung. Diese reichen von der ergebnisneutralen Form der Konsolidierung bis zu dem Vorschlag, die aufgedeckten stillen Reserven bei der Erstkonsolidierung zu besteuern'. Für die ergebnisneutrale Variante, z.B. nach Vorbild der alten „deutschen“ Methode der Kapitalkonsolidierung, sprechen effizienz- wie gerechtigkeitsgetriebene Argumente der Objektivität, Einfachheit und Klarheit, zumal auch das Problem der Selbsteinsteuerung im Rahmen der „cost allocation“ reduziert würde. Allerdings hat ein EU-weites Gruppenbesteuerungssystem die Kompatibilität mit dem Steuerrecht aller EU-Staaten zu gewährleisten, so dass hier ein Harmonisierungsbedarf auf nationaler Ebene verbleibt - in welche Richtung auch immer.

- Die Goodwill-Folgebewertung nach IFRS 3 und IAS 36 entspricht unter den Modellbedingungen des kapitaltheoretischen Gewinns in geradezu idealer Weise den An-

1 Vgl. Rupp (Ertragsbesteuerung nationaler Konzerne, 1983) S. 59-60; später auch Grotherr (Besteuerung nationaler und grenzüberschreitender Konzerne, 1994) S. 553-556. 
forderungen an eine investitionsneutrale steuerliche Gewinnermittlung. Diese Erkenntnis wird aus Sicht der Reinvermögenszugangstheorie indes deutlich relativiert. Der hier in Rede stehende ,impairment-only approach“ geht mit so gravierenden Objektivierungsproblemen einher, dass die Periodisierung eher einer klaren, einfachen und objektiven Konvention folgen sollte. Insofern müsste eine entsprechende Anpassung für Zwecke der steuerlichen Konsolidierung erfolgen. Dafür bietet sich die gleichmäßige Periodenbelastung in Form einer linearen Abschreibung über einen festgelegten Zeitraum an'.

- Die in IFRS 3 vorgeschriebene Neubewertungsmethode verstößt mit ihrer vollen Aufdeckung stiller Reserven und Lasten gegen das Anschaffungswertprinzip und die Pagatorik. Relativiert wird dieser Verstoß allerdings durch die Parallele zur Sacheinlage und die ,pagatorische Fiktion“ einer ermessensfreien Hochrechnung um die Minderheitenanteile. Wird an der Erwerbsmethode trotz aller Bedenken festgehalten, dürfte die Neubewertungsmethode unter zusätzlicher Berücksichtigung ihrer einheitstheoretischen Konsequenz gegenüber der beteiligungsproportionalen Aufdeckung stiller Reserven und Lasten (Buchwertmethode) eher von Vorteil sein. Dies gilt umso mehr, wenn steuerliche Wirkungen aus der Gesamtgewinnermittlung auch Minderheiten treffen. In diesem Fall hat der Regulierer zusätzlich zu entscheiden, ob er die technisch aufwendige Separation der Minderheiten im Eigenkapital und Ergebnis grundsätzlich unterlässt, um über eine indirekte Form der Steuerlastverteilung Vorteile bei der Durchführungseffizienz zu realisieren ${ }^{2}$. Soll die Gesamtgewinnermittlung indes keinerlei steuerliche Wirkung für die Minderheiten entfalten, erscheint letztlich nur eine strikt interessentheoretische Vorgehensweise auf der Grundlage der Quotenkonsolidierung konsequent.

- Die im Rahmen einer künftigen IFRS-3-Modifikation zu erwartende „full goodwill method" ist einheitstheoretisch konsequenter als die bisher vorgeschriebene Neubewertungsmethode. Wegen schwerwiegender Bedenken, die über diejenigen bei der Neubewertungsmethode noch hinausgehen, konnte ihre steuerliche Eignung nicht belegt werden. Dies gilt auch, wenn die Gesamtgewinnermittlung für Minderheiten steuerliche Wirkung entfalten soll. Wenn aus Sicht des Regulierers die Vorteile der „full goodwill method“ dennoch überwiegen sollten, erscheint zur Ermittlung des „full goodwill“ trotz theoretischer Bedenken nur die einfache und ermessensfreie proportionale Hochrechnung steuerlich opportun.

1 Diese kann sogar als Annäherung an eine investitionsneutrale Ertragswertabschreibung verstanden werden, weil in Abhängigkeit von der Ausgestaltung des Zahlungsstromes nicht auszuschließen ist, dass eine Wertminderung als Ertragswertabschreibung einen linearen Verlauf nimmt; vgl. so z.B. Gröning (Steuerbilanzielle Gewinnermittlung, 2002) S. 159.

2 Vgl. ebenfalls Vorteile der indirekten Methode im europäischen Kontext identifizierend Schäfer/Spengel (Profit Allocation, 2003) S. 18-31. 
- Die vom IASB künftig möglicherweise vorgesehene „fresh start method“ ist letztlich keine Alternative zur Erwerbs- bzw. Neubewertungsmethode, da sie keinen Erwerbsvorgang fingiert, sondern eher von einer Verschmelzung unter Gleichen ausgeht. Das Prinzip dieser Methode ist bereits heute, z.B. dem deutschen Umwandlungssteuerrecht, nicht fremd und dürfte für bestimmte, klar umrissene Anwendungsfälle steuerlich tragbar sein. Vom Prinzip her ergeben sich jedoch ähnliche Objektivierungsprobleme wie bei der Erwerbsmethode. Auch dürfte in der präziseren Konkretisierung der Anwendungsvoraussetzungen, möglicherweise ergänzend zu der noch nicht absehbaren Ausgestaltung einer künftigen IFRS-Vorgabe, eine zusätzliche Aufgabe des Regulierers liegen. Interessant ist auch, die ergebnisneutrale Interessenzusammenführungsmethode (pooling of interests method) auf ihre komparative Eignung für steuerliche Zwecke hin zu überprüfen. Trotz geringerer einheitstheoretischer Konsequenz sind hier Vorteile hinsichtlich deutlich reduzierter Selbsteinsteuerungsmöglichkeiten (insb. die „cost allocation“ fehlt) und verbesserter Übereinstimmung mit einzelstaatlichen Regeln zu vermuten.

\section{Schuldenkonsolidierung}

- Die in IAS 27 festgelegte Schuldenkonsolidierung ist letztlich ein unproblematisches technisches Verfahren zur Eliminierung gruppeninterner Kreditbeziehungen, das auch in einer steuerlichen Gesamtgewinnermittlung notwendig sein dürfte. Aus durchführungseffizienter Sicht ist die Anwendung der steuerlichen Schuldenkonsolidierung aber auf die Fälle zu beschränken, in denen ergebniswirksame Aufrechnungsdifferenzen entstehen.

- Die IFRS-Grundsätze der Wesentlichkeit und Wirtschaftlichkeit fokussieren aus steuerlicher Sicht auf die Notwendigkeit, Aspekte der Durchführungseffizienz bei der Schuldenkonsolidierung auch im Einzelfall zu berücksichtigen. Ein allgemeiner Grundsatz kann hieraus für die steuerliche Konsolidierung kaum abgeleitet werden. Wenn überhaupt, kommt nur eine sehr viel konkretere Regulierung in Betracht, die genau festlegt, unter welchen Voraussetzungen die Schuldenkonsolidierung zu unterlassen ist.

\section{Zwischenergebniseliminierung sowie Betriebsausgaben- und einnahmenkonsolidierung}

- An der grundsätzlichen steuerlichen Eignung der Zwischenergebniseliminierung sowie der Aufwands- und Ertrags- bzw. Betriebsausgaben- und einnahmenkonsolidierung wird nicht gezweifelt. Im Gegenteil: Letztlich handelt es sich hierbei um den Kernbestandteil einer realtypischen Gesamtgewinnermittlung, die über die Vermeidung von Doppel- und Mehrfachbesteuerungen gruppenintern ausgeschütteter Dividenden und einen Verlustausgleich hinausgeht. Angesichts des einheitstheoretischen Leitbildes gilt dies insbesondere auch für ihre obligatorische Anwendung und ihre volle, nicht beteiligungsproportionale Eliminierungswirkung. Aus durchführungsef- 
fizienter Sicht sollte lediglich die Anwendung einer steuerlichen Betriebseinnahmenund -ausgabenkonsolidierung auf die Fälle beschränkt werden, in denen sich Betriebseinnahmen und -ausgaben nicht in betraglich gleicher Höhe gegenüber stehen.

- In IAS 27 fehlt es an der Festlegung technischer Details der Zwischenergebniseliminierung sowie der Aufwands- und Ertragskonsolidierung. Ausgestaltungsfragen dürften sich aber regelmäßig unter Rückgriff auf die einheitstheoretischen Vorgaben beantworten lassen. In Abstimmung mit den staatlichen Einzelgewinnermittlungsregeln wird dennoch zu untersuchen sein, inwieweit der in IAS 27 letztlich nur festgelegte Grundsatz einer im Detail ergänzenden Regulierung bedarf.

- Die IFRS-Grundsätze der Wesentlichkeit und Wirtschaftlichkeit gelten auch bei der Zwischenergebniseliminierung sowie bei der Aufwands- und Ertragskonsolidierung. Eine Übertragung eines allgemeinen Grundsatzes in die steuerliche Konsolidierung verbietet sich jedoch. Da Aspekte der Durchführungseffizienz bei diesen technisch durchaus aufwendigen Konsolidierungstechniken aber möglicherweise ein höheres Gewicht haben als anderswo, ist die Möglichkeit klar definierter Ausnahmefälle zu prüfen. So könnte z.B. die Notwendigkeit gruppendimensionaler Anschaffungs- und Herstellungskosten hinterfragt und der Verzicht der steuerlichen Zwischenergebniseliminierung für bestimmte Wirtschaftsgüter wie Vorräte angesichts der hohen Umschlagshäufigkeit erwogen werden ${ }^{1}$.

1 Vgl. Grotherr (Besteuerung nationaler und grenzüberschreitender Konzerne, 1994) S. 499, 502, der diese Ausnahme allerdings als eine Art Wahlrecht interpretiert und deshalb zur Reduktion der Ermessenspielräume ein Stetigkeitsgebot vorschlägt. Letzteres wäre bei einer ermessensfreien obligatorischen Ausnahmeregel obsolet. 


\section{Kapitel VI}

\section{Fazit und Ausblick}

Die Schaffung einer konsolidierten Körperschaftsteuerbemessungsgrundlage für die grenzüberschreitende Unternehmenstätigkeit innerhalb der EU steht seit dem Jahr 2001 auf der Agenda der Europäischen Kommission. Dieses ehrgeizige Ziel ist in unterschiedlichen Ausgestaltungsvarianten denkbar und geht mit vielen ungelösten Fragen einher. Eine davon steht im Vordergrund dieser Arbeit: Können die IFRS-Konsolidierungsvorschriften für die Ermittlung dieser Bemessungsgrundlage herangezogen werden? Diese Frage ist nicht nur deshalb von erheblicher Relevanz, weil die EUKommission derzeit nach Antworten sucht und dabei in den IFRS „den einzigen verfügbaren neutralen Ausgangspunkt" ${ }^{\text {"l }}$ für eine konsolidierte steuerliche Gewinnermittlung zu erkennen glaubt. Sie hat auch für die gesamte EU-Strategie einer künftigen Unternehmensbesteuerung eine zentrale Bedeutung. Wie die EU-Kommission selbst betont, ist die „Konsolidierung auf EU-Ebene ... das Schlüsselelement aller Lösungsansät$\mathrm{ze}^{\text {“2 }}$. Die „Ausarbeitung von Regelungen für die Konsolidierung“ zählt ihrer Meinung nach „zu den schwierigsten Aspekten der Schaffung einer einheitlichen Steuerbemessungsgrundlage ${ }^{\star 3}$.

Untersuchungsgegenstand und -aufbau werden im Folgenden noch einmal kurz umrissen und mit den zentralen Ergebnissen dieser Arbeit zusammengefasst:

- Unter besonderer Fokussierung auf Konsolidierungsaspekte wird in der vorliegenden Arbeit untersucht, ob und inwieweit die IFRS für eine konsolidierte steuerliche Gewinnermittlung im Rahmen einer EU-Gruppenbesteuerung geeignet sein können. Im Einzelnen wird die Eignung der IFRS zur Bestimmung und Konkretisierung der Konsolidierungspflicht, der Konsolidierungskreisabgrenzung, der vorbereitenden Maßnahmen und der eigentlichen Konsolidierungstechnik analysiert.

- Für diese Untersuchung ist ein mehrdimensionaler Beurteilungsrahmen entwickelt worden, der auf wirkungs- sowie durchführungsorientierten Effizienzüberlegungen, aber auch auf ethisch-verfassungsrechtlich abgeleiteten Kriterien basiert. So hat die steuerliche Gewinnermittlung einem Anforderungsprofil zu genügen, das mit der Entscheidungsneutralität (Wirkungsorientierung), sonstigen Effizienzargumenten (Durchführungsorientierung) sowie der Gleichmäßigkeit bzw. Gerechtigkeit umrissen werden kann. Letztere wird durch das verfassungsrechtliche Legalitätsprinzip ergänzt. Um konsolidierungsspezifische Aspekte besser würdigen zu können, sind zudem Erkenntnisse über die unternehmungsorientierte Abgrenzung der rechnungs-

EU-Kommission (Ergebnisse, 2003) S. 22.

EU-Kommission (Unternehmensbesteuerung, 2001) S. 5.

EU-Kommission (Ergebnisse, 2003) S. 23 [beide Zitate]. 
legenden Einheit generiert und dem normativen Rahmen als Wertungsdimension hinzugefügt worden.

- Eine konsolidierte steuerliche Gewinnermittlung kann aus dem Spannungsverhältnis von normativen Anforderungen und rechtlichen Gegebenheiten erklärt werden. Über die Konsolidierung wird das rechtsformorientierte Trennungsprinzip in die ökonomisch fundierte Einheitstheorie überführt. Am Beispiel der konkreten deutschen Rechtsordnung wird aufgezeigt, dass das rechtsformorientierte Trennungsprinzip die steuerliche Gewinnermittlung dominiert und hiervon allenfalls partielle Ausnahmen existieren. Allerdings rückt die steuerliche Gewinnermittlung im Rahmen der Mitunternehmerbesteuerung durch die fehlende Steuersubjektivität der Personengesellschaft in eine gewisse Nähe zur Konsolidierung.

- Auch eine einheitstheoretisch fundierte Gesamtgewinnermittlung wird durch die Rechtsrealität, insbesondere durch die rechtliche Separation der Unternehmung (Unternehmensgruppe) geprägt. So sind fiskalische Grenzen ebenso zu berücksichtigen wie das Problem spezifischer Risiken für die Vertragspartner der involvierten Unternehmen. Eine gruppeninterne Erfolgslokalisation scheint notwendig. Hierfür bedarf es entweder einer Schattenveranlagung in Form einer parallelen Einzelgewinnermittlung oder einer indirekten Schlüsselung des konsolidierten Gesamtgewinns und der daraus resultierenden Steuerkonsequenzen auf die Unternehmen der Gruppe.

- Das normative Beurteilungsgerüst wird durch die Erfahrungen mit einer konsolidierten steuerlichen Gewinnermittlung auf der Ebene nationaler europäischer Steuerrechtssysteme ergänzt. In Frankreich, Portugal, Spanien und den Niederlanden existieren Gruppenbesteuerungssysteme, die neben der Vermeidung einer Mehrfachbesteuerung gruppenintern ausgeschütteter Dividenden und dem gruppeninternen Verlustausgleich auch Elemente der Zwischenergebniseliminierung sowie sonstiger Formen der Konsolidierung aufweisen. Während das französische Zurechnungsmodell hierfür eine Modifizierung betroffener Einzelgewinnermittlungen vorsieht, finden sich eher klassische Konsolidierungssysteme in Portugal und Spanien. Das niederländische Modell beruht indes auf einer originären Gesamtgewinnermittlung, bei der sich die Konsolidierungsmaßnahmen auf die erstmalige Anwendung und Aufhebung der Gruppenbesteuerung und auf Konsolidierungskreisänderungen beschränken. In allen Systemen beschränken sich die Ergebniswirkungen meist auf die Neutralisierung gruppeninterner Lieferungen und Leistungen, während sonstige Konsolidierungsvorgänge, insbesondere im Bereich der Kapitalkonsolidierung, ergebnisneutral behandelt werden.

- Die Eignung der IFRS zur konsolidierten steuerlichen Gewinnermittlung wird auf Basis der gewonnenen Erkenntnisse in zwei Schritten überprüft. Der erste Prüfungsschritt stellt auf die steuerliche Eignung des IFRS-Systems insgesamt ab und kommt 
zu dem Ergebnis, dass an der grundsätzlichen steuerlichen Eignung der IFRS erhebliche Zweifel verbleiben. Insofern ist eine mittelbare (Maßgeblichkeit!) oder gar unmittelbare Ausrichtung der steuerlichen Gewinnermittlung an diesem Rechnungslegungssystem insgesamt abzulehnen.

- Im Rahmen der insofern notwendigen Suche nach geeigneten steuerlichen Gewinnermittlungsregeln scheint es legitim, einzelne IFRS-Vorschriften in Betracht zu ziehen, sofern ihre steuerliche Eignung im Einzelfall belegt werden kann. Diese Eignung wird im Rahmen des zweiten Prüfungsschrittes, der Einzelanalyse der IFRSKonsolidierungsvorschriften, in Teilen bestätigt. In dieser Einzelanalyse wird aber auch ein erheblicher Anpassungsbedarf festgestellt, so dass die analysierten Konsolidierungsvorschriften nur unter gravierenden Veränderungen in ein steuerliches Regelsystem übernommen werden sollten ${ }^{1}$.

- Vor dem Hintergrund des aufgezeigten Anpassungsbedarfs ist wohl die Aussage der EU-Kommission zu verstehen, dass die IFRS der konsolidierten steuerlichen Gewinnermittlung als Ausgangspunkt dienen können. Mit der Qualifikation als Ausgangspunkt wird aber letztlich nur eine leere Worthülse bemüht, die über die steuerliche Eignung des IFRS nicht viel aussagt. Für eine qualitative Wertung bedarf es stattdessen einer Aussage darüber, wie weit der anzustrebende Endpunkt von dem Ausgangspunkt entfernt liegt. Je größer der entsprechende Anpassungsbedarf bei den IFRS, desto höher wird die Wahrscheinlichkeit, dass andere Regelsysteme durchführungseffizientere Ausgangspunkte markieren.

- Im Rahmen der Einzelanalyse der IFRS-Konsolidierungsregeln wird auch festgestellt, dass eine Konsolidierung im Zuge einer grenzüberschreitenden Gruppenbesteuerung nicht „so einfach" als Zusatzregulierung die weiterhin existierenden und nicht harmonisierten einzelstaatlichen Regeln ergänzen kann. So ist bereits die kategorische Trennung der Konsolidierung von Ansatz- und Bewertungsfragen nicht immer möglich. Dies wird auch durch sonstige technische Schwierigkeiten untermauert, die bei der Regulierung der steuerlichen Konsolidierung in Abstimmung mit den Besonderheiten der nationalen Steuersysteme zu erwarten und zu lösen sind.

Wenn die Europäische Kommission mit ihrem Hinweis auf die IFRS als nützlichen Ausgangspunkt auch Recht behalten mag, so bleibt die Entwicklung eines entsprechenden Gewinnermittlungssystems für die konsolidierte Körperschaftsteuerbemessungsgrundlage von Unternehmensgruppen eine große Herausforderung. Dies gilt insbesondere auch im Hinblick auf eigenständige steuerliche Ansatz- und Bewertungsregeln, die z.B. im Rahmen der ,common consolidated tax base“ (CCTB) europaweit gefunden werden müssten. Der Vorteil der IFRS mag hier weniger in ihrer normativen Eignung als vielmehr in ihrer politischen Durchsetzbarkeit liegen. Schließlich erscheint es er-

1 Vgl. zu den Ergebnissen der Einzelanalyse und dem daraus entstehenden Anpassungsbedarf Kap. V.5. 
folgversprechender zu sein, ein Gewinnermittlungssystem mit internationaler Akzeptanz als fernen Ausgangspunkt zu markieren, als ein normativ geeigneteres System ohne internationale Akzeptanz - ein neues oder ein bestehendes nationales System - im politischen Spiel erst suchen und durchsetzen zu müssen.

Die Strategie der Europäischen Kommission steht aber noch vor weiteren Schwierigkeiten. Dies sind einerseits zahlreiche steuertechnische Detailprobleme und verfahrenstechnische Anforderungen, die ebenfalls nur in Abstimmung mit den divergierenden nationalen Steuersystemen gelöst werden können ${ }^{1}$. Im Vordergrund steht andererseits die Frage der Erfolgslokalisation, die unabhängig von der konkreten Ausgestaltungsvariante beantwortet werden muss. Nach Spengel hängen ,die Erfolgsaussichten der Realisierung einer konsolidierten Besteuerung in Europa vom politischen Standpunkt aus betrachtet vermutlich entscheidend von diesem Sachverhalt ab, da hiermit die zwischenstaatliche Verteilung des Steueraufkommens im Wesentlichen festgelegt wird“"2. Obwohl die Erfolgslokalisation in dieser Arbeit nicht im Mittelpunkt stand, hat sich an mehreren Stellen angedeutet, dass eine Gruppenbesteuerung auf der Grundlage einer einheitstheoretisch konsequenten Gesamtgewinnermittlung wohl eher mit einer indirekten Schlüsselung (formula apportionment) harmoniert. Dem neigt bisher auch die Europäische Kommission $\mathrm{zu}^{3}$. Obwohl bei der Ausgestaltung dieser Schlüsselgröße sicherlich noch Forschungsbedarf besteht, dürften die Aussichten auf eine theoretisch einwandfreie Lösung aber eher gering erscheinen ${ }^{4}$. Treffend hat Mestmäcker auf das vergleichbar schwierige Unterfangen verwiesen, ,zu prüfen, welcher Teil der Leistung eines Rennpferdes auf den Jockey und welcher auf das Pferd zurückzuführen sei“s. Vor diesem Hintergrund bemerkt Schreiber zu Recht, dass es ,nicht um eine richtige, sondern nur um eine praktikable und von den Staaten als fair akzeptierte Aufteilung des

1 Vgl. Sorensen (Company Tax Reform, 2004); Westberg (Consolidated Corporate Tax Bases, 2002), die sich mit der EU-Strategie insg. kritisch auseinandersetzen; kürzer Sørensen (Harmonise, 2002); Spengel (Einheitliche Bemessungsgrundlage, 2004) S. 110; Spengel (Unternehmensbesteuerung in der EU, 2004) S. 146; Spengel/Frebel (Neue Initiativen der EU-Kommission, 2003) S. 790-792.

2 Spengel (Einheitliche Bemessungsgrundlage, 2004) S. 105.

3 Vgl. EU-Kommission (Ergebnisse, 2003) S. 24-28; zuvor bereits EU-Kommission (Company Taxation, 2001) S. 407-415. Vgl. auch Mintz/Weiner (Formula Allocation, 2003); Sørensen (Company Tax Reform, 2004) S. 93, der auf die früher andere Meinung der Kommission hinweist.

4 Vgl. oft mit Zweifeln und keineswegs eindeutigen Lösungen, trotz existierender Erfahrungen insb. in den USA, u.a. Gordon/Wilson (Formula Apportionment, 1986); Hellerstein/McLure (Company Income Taxation, 2004) S. 207-217; Miller (California Practice, 1984); Mintz/Weiner (Formula Allocation, 2003) S. 698-709; Musgrave (Principles for Dividing, 1984); Oestreicher (Konzernbesteuerung in Europa, 2002) S. 348-350; Schäfer/Spengel (Profit Allocation, 2003); Schröer (Erfolgsabgrenzungsparadigmen, 2004); Sorensen (Company Tax Reform, 2004) S. 93-101; Sheffrin/Fulcher (Alternative Divisions, 1984); Sunley (Formulary Apportionment, 2002); Weiner (Formulary Apportionment, 2002); Wellisch (Gewinnaufteilung, 2004); s.a. m.w.N. die umfassenden Überblicke bei Oestreicher (Konzern-Gewinnabgrenzung, 2000); Nientimp (Steuerliche Gewinnabgrenzung, 2003) S. 173-195.

5 Mestmäcker (Verwaltung, 1958) S. 308 der diesbezüglich „Konzernleiter“ der US-Ölindustrie zitiert. 
Gewinns gehen"1 kann. Dies allein dürfte schon schwierig genug sein. Insofern verwundert es nicht, dass die Arbeiten zur Schaffung einer konsolidierten Körperschaftsteuerbemessungsgrundlage bisher nur schleppend vorankommen ${ }^{2}$ und Schneider hier nur „Sirenenklänge ferner Zukunftsmusik“33 erkennt.

Insofern bleibt mit Spannung abzuwarten, welche Entwicklung die Unternehmensbesteuerung in der EU künftig nehmen wird. Die Erfahrungen mit vergleichbar ambitionierten Initiativen der Europäischen Kommission in der Vergangenheit geben keinen Anlass, hier in übermäßigen Optimismus zu verfallen. Bezeichnenderweise hat auch die deutsche Bundesregierung noch vor wenigen Jahren eine über die Organschaft hinausreichende Form der Gruppenbesteuerung trotz Anregung der Wirtschaft explizit abgelehnt ${ }^{4}$. Wie der Rechtsvergleich in dieser Arbeit gezeigt hat, besitzen mit Frankreich, Portugal, Spanien und den Niederlanden nur wenige Mitgliedstaaten in der EU überhaupt Erfahrungen mit einer Gruppenbesteuerung auf der Grundlage einer konsolidierten steuerlichen Gewinnermittlung, so dass politische Vorbehalte auch anderswo zu vermuten sind. Sollten korrespondierende gesellschaftsrechtliche Schutzmechanismen als notwendig erachtet werden, fehlt es zudem auf EU-Ebene, aber auch in den meisten Mitgliedstaaten, an einem entsprechenden Konzernrecht.

Angesichts dieser Vorbehalte ist zu fragen, ob einem so gewaltigen Schritt in Richtung einer Gruppenbesteuerung mit einheitstheoretisch konsequenter Gesamtgewinnermittlung nicht eher politisch durchsetzbare Zwischenschritte vorangehen sollten. Dafür spricht auch das ständig identifizierte Spannungsverhältnis von Einheitstheorie auf der einen und Einfachheit, Klarheit sowie Objektivität auf der anderen Seite. Alternative Vorschläge, die von einem deutlich vereinfachten Konsolidierungsmodell, z.B. nach Art der niederländischen „fiscale eenheid“, in Richtung eines ,einheitstheoretisch modifizierten Trennungsprinzips “5 ${ }^{\star 5}$ unter Umständen nach Vorbild des französischen Zurechnungsmodells, reichen ${ }^{6}$, könnten hier ebenso angeführt werden wie die Forderung, die

1 Schreiber (Unternehmensbesteuerung, 2004) S. 221.

2 Vgl. Spengel (Unternehmensbesteuerung in der EU, 2004) S. 148; zu ersten reservierten Reaktionen der Mitgliedstaaten und ihren Begründungen auch Sørensen (Company Tax Reform, 2004) S. 103104; s.a. o.V. (EU-Finanzminister, 2004) S. 11; o.V. (Mehr Verantwortung, 2004) S. 6.

3 Schneider (Konzernrechnungslegung als internationale Gewinnsteuerbemessungsgrundlage, 2003) S. 664, der diese Aussage aber enger auf die EUCIT- sowie HTB-Alternative bezieht, der konsolidierten steuerlichen Gewinnermittlung in der EU aber auch insgesamt wenig Umsetzungschancen einräumt (S. 669); ähnlich auch Menck/Mutén (Europäische Steuerpolitik, 2003) S. 72-73; Sørensen (Harmonise, 2002) S. 35.

4 Vgl. $B M F$ (Fortentwicklung des Unternehmenssteuerrechts, 2001) S. 47-48.

5 Salzberger (Konzernunternehmung, 1994) S. 228-249.

6 Vgl. u.a. Niemann (Gewinnrealisierung innerhalb des Konzerns, 1968) S. 165; Rupp (Ertragsbesteuerung nationaler Konzerne, 1983) S. 285-304; Scheffler (Besteuerung von inländischen Konzernen, 1991) S. 712-713; Scheuchzer (Konzernbesteuerung, 1994) S. 235-273; Schreiber (Unternehmensbesteuerung, 2004) S. 224. Grotherr (Besteuerung nationaler und grenzüberschreitender Konzerne, 1994) S. 33 spricht hier von der „konzernspezifisch modifizierten Einzelbesteuerung“. 
Equity-Methode für Tochterunternehmen in die Einzelgewinnermittlung zu integrieren ${ }^{1}$. $\mathrm{Da}$ die Einzelgewinnermittlung aber seit jeher Bastion einzelstaatlicher Regulierungen ist, dürfte ein erheblicher Abstimmungs- und Überzeugungsbedarf auch bei diesen Zwischenschritten existieren. Möglicherweise haben aber auch (weiterhin) einzelstaatliche Lösungen ihren Reiz, sofern sie sich im - hoffentlich funktionsfähigen - Wettbewerb der Systeme durchsetzen und eine marktgerechte europäische Lösung markieren kön$n^{2}{ }^{2}$. Sofern dabei Konsolidierungsregeln benötigt werden, vermag diese Arbeit aufzuzeigen, inwieweit einzelne Vorschriften der IFRS hierbei Verwendung finden können.

1 Vgl. Pellens (Gewinnverwendung im Konzern, 1995) S. 101-105, 320 m.w.N., der dies zur Verwirklichung einer „konzernweiten Gewinnverwendungskompetenz“ der Aktionäre des Mutterunternehmens alternativ zum handelsrechtlichen Konzernabschluss vorschlägt; s.a. Forster (Equity-Bewertung, 1993); vgl. bereits Schäfer (Equity-Methode, 1982) S. 160-178, der die Anwendungsmöglichkeiten der Equity-Methode im Einzelabschluss bzw. der steuerlichen Gewinnermittlung untersucht, aber letztlich ablehnt; anders wohl Groh (Mitunternehmerschaft, 1995) S. 385. Zu den Möglichkeiten und Grenzen der Equity-Methode i.R.d. steuerlichen Gesamtgewinnermittlung s.a. Kap. III.1.4.2.

2 Vgl. hierzu treffend Salin (Comment, 1990) S. 204: "Therefore, there is no need for tax harmonization, but there is a need for better tax systems“. 


\section{Literaturverzeichnis}

AAA (American Accounting Association, 1964 Concepts and Standards Research Study Committee), The Entity Concept, in: The Accounting Review, Vol. 40 (1965), S. 358-367.

AAA (American Accounting Association, Committee on Accounting Concepts and Standards), Accounting and Reporting Standards for Corporate Financial Statements, 1957 Revision, in: The Accounting Review, Vol. 32 (1957), S. 536-546.

AAA (American Accounting Association, Financial Accounting Standards Committee), Commentary on the IASB's Exposure Draft on Business Combinations, in: Accounting Horizons, Vol. 18 (2004), S. 55-64.

Ackermann, Ulrich/Maj, Christina, Webbasierte Intercompany Reconciliation, Potentiale zur Effizienzsteigerung der Schuldenkonsolidierung, in: WPg, 55. Jg. (2002), S. 1306-1314.

Addison, Garry, Consolidation concerns, in: Australian CPA, Vol. 72 (Dec. 2002), S. 76-77.

Adler/Düring/Schmaltz, Rechnungslegung und Prüfung der Unternehmen, Kommentar zum HGB, AktG, PublG nach den Vorschriften des Bilanzrichtlinien-Gesetzes, bearbeitet von Forster, K.-H. et al., 6. Aufl., Stuttgart 1995.

AICPA (American Institute of Certified Public Accountants), From the Tax Adviser: Guiding Principles of Good Tax Policy, in: Journal of Accountancy, Vol. 193 (Febr. 2002), S. 70.

Albach, Horst, Grundgedanken einer synthetischen Bilanztheorie, in: ZfB, 35. Jg. (1965), S. 21-31.

Alchian, Armen A., Corporate Management and Property Rights, in: Economic Policy and the Regulation of Corporate Securities, hrsg. von Manne, Henry G., Washington D. C. 1969.

Alchian, Armen A., Some Economics of Property Rights, in: Economic Forces at Work, Armen A. Alchain, Indianapolis 1977, S. 127-149.

Alchian, Armen A./Demsetz, Harold, Production, Information Costs, and Economic Organization, in: The American Economic Review, Vol. 62 (1972), S. 777-795.

Alchian, Armen A./Demsetz, Harold, The Property Rights Paradigm, in: Journal of Economic History, Vol. 33 (1973), S. 16-27.

Alchian, Armen A./Woodward, Susan, Reflections on the Theory of the Firm, in: Journal of Institutional and Theoretical Economics, Vol. 143 (1987), S. 110-136.

Allingham, Michael G./Sandmo, Agnar, Income Tax Evasion: A Theoretical Analysis, in: Journal of Public Economics, Vol. 1 (1972), S. 323-338. 
Alm, James, What is an „optimal" tax system?, in: National Tax Journal, Vol. 49 (1996), S. 117-133.

Arbeitskreis „Externe Unternehmensrechnung“ der Schmalenbach-Gesellschaft für Betriebswirtschaft e.V., International Financial Reporting Standards im Einzelund Konzernabschluss unter der Prämisse eines Einheitsabschlusses für unter Anderem steuerliche Zwecke, in: DB, 56. Jg. (2003), S. 1585-1588.

Arbeitskreis Bilanzrecht der Hochschullehrer Rechtswissenschaft, Zur Fortentwicklung des deutschen Bilanzrechts, in: BB, 57. Jg. (2002), S. 2372-2381.

Aristoteles, Die Nikomachische Ethik, aus dem Griechischen und mit einer Einführung und Erläuterungen versehen von Gigon, Olof (Vollständige dtv-Ausgabe), 5. Aufl., München 2002.

Arlen, Jennifer/Weiss, Deborah M., A Political Theory of Corporate Taxation, in: The Yale Law Journal, Vol. 105 (1995), S. 325-391.

Arrow, Kenneth J., Limited Knowledge and Economic Analysis, in: The American Economic Review, Vol. 64 (1974), S. 1-10.

Arrow, Kenneth J./Debreu, Gérard, Existence of an Equilibrium for a Competitive Economy, in: Econometrica, Vol. 22 (1954), S. 265-290.

Atkinson, Anthony Barnes/Stiglitz, Joseph E., The Design of Tax Structure: Direct versus Indirect Taxes, in: Journal of Public Economics, Vol. 6 (1976), S. 55-75.

Bach, Stefan, Der Cash-flow als Bemessungsgrundlage der Unternehmensbesteuerung, in: Einkommen versus Konsum, Ansatzpunkte zur Steuerreformdiskussion, hrsg. von Smekal, Christian/Sendlhofer, Rupert/Winner, Hannes, Heidelberg 1999, S. 85-122.

Bach, Stefan, Die Perspektiven des Leistungsfähigkeitsprinzips im gegenwärtigen Steuerrecht, in: StuW, 68. Jg. (1991), S. 116-135.

Bachem, Rolf Georg, Berücksichtigung negativer Geschäftswerte in Handels-, Steuerund Ergänzungsbilanz, in: BB, 48. Jg. (1993), S. 967-973.

Baetge, Jörg/Beermann, Thomas, Die Eignung der körperschaftsteuerlichen Organschaft für die Konzernbesteuerung, in: Unternehmensrechnung und -besteuerung (Festschrift Dietrich Börner), hrsg. von Meffert, Heribert/Krawitz, Norbert, Wiesbaden 1998 , S. 265-288.

Baetge, Jörg/Herrmann, Dagmar, Probleme der Endkonsolidierung im Konzernabschluß, in: WPg, 48. Jg. (1995), S. 225-232.

Baetge, Jörg/Kirsch, Hans-Jürgen/Thiele, Stefan, Konzernbilanzen, 6. Aufl., Düsseldorf 2002. 
Baetge, Jörg/Schulze, Dennis, IAS 27: Konzernabschlüsse und Bilanzierung von Anteilen an Tochterunternehmen (Consolidated Financial Statements and Accounting for Investments in Subsidiaries), in: Rechnungslegung nach International Accounting Standards (IAS), Kommentar auf der Grundlage des deutschen Bilanzrechts, hrsg. von Baetge, Jörg et al., Loseblattsammlung, 2. Aufl., Stuttgart 2002.

Ballerstedt, Kurt, Was ist Unternehmensrecht?, in: Festschrift für Konrad Duden zum 70. Geburtstag, hrsg. von Pawlowski, H.-M./Wiese, Günther/Wüst, Günther, München 1977, S. 15-36.

Ballerstedt, Kurt. GmbH-Reform, Mitbestimmung, Unternehmensrecht, in: ZHR, Bd. 135 (1971), S. 479-510.

Ballwieser, Wolfgang, Anforderungen des Kapitalmarkts an Bilanzansatz- und Bilanzbewertungsregeln, in: KoR, 1. Jg. (2001), S. 160-164.

Ballwieser, Wolfgang/Küting, Karlheinz/Schildbach, Thomas, Fair value-erstrebenswerter Wertansatz im Rahmen einer Reform der handelsrechtlichen Rechnungslegung, in: BFuP, 56. Jg. (2004), S. 529-549.

Banks, Jim/Fredrickson, Debra, Intercompany Obligation Regulations Provide a Single-Entity Approach, in: The Tax Adviser, Vol. 28 (1997), S. 202-204.

Barker, Richard, Reporting Financial Performance, in: Accounting Horizons, Vol. 18 (2004), S. 157-172.

Barnard, Chester I., The Functions of the Executive, Cambridge, Mass. $1938\left(16^{\text {th }}\right.$ Printing 1964).

Barth, Mary E./Landsman, Wayne R., Fundamental Issues Related to Using Fair Value Accounting for Financial Reporting, in: Accounting Horizons, Vol. 9 (Dec. 1995), S. 97-107.

Bator, Francis M., The Anatomy of Market Failure, in: The Quarterly Journal of Economics, Vol. 72 (1958), S. 351-379.

Bauer, Klaus, Die Besteuerung deutscher Konzerne: wirtschaftliche Einheit und Konzernsteuerrecht, Regensburg 1987.

Baumgartner, Peter, Irritationen in der Europäischen Union: Der Europäische Gerichtshof prägt das Steuerwesen, in: Neue Züricher Zeitung vom 4.12.2003, URL: http://www.nzz.ch/dossiers/2003/eukonvent/2003.12.04-wi-article98VUF.html (06.07.2004).

Baumhoff, Hubertus, Konzernverrechnungspreise, in: Steuerrecht und steuerorientierte Gestaltung im Konzern, Kölner Konzernrechtstage, hrsg. von Schaumburg, Harald, Köln 1998, S. 331-361.

Baumhoff, Hubertus, Verrechnungspreise für Dienstleistungen, Die steuerliche Einkunftsabgrenzung bei international verbundenen Unternehmen auf der Grundlage des Fremdvergleichs, Köln et al. 1986. 
Baumol, William Jack/Bradford, David F., Optimal Departures from Marginal Cost Pricing, in: The American Economic Review, Vol. 60 (1970), S. 265-283.

Bayer, Hermann-Wilfried, Steuerlehre, Steuerverfassung - Steuergesetz - Steuergericht, Berlin et al. 1997.

Becker, Helmut, Unternehmensbesteuerung als Standortproblem aus deutscher Sicht, in: Grundfragen der Unternehmensbesteuerung, hrsg. von Wassermeyer, Franz, DStJG, Bd. 17, Köln 1994, S. 195-219.

Behrens, Peter, Die Europäisierung des Gesellschaftsrechts, in: GmbHR, 84. Jg. (1993), S. 129-136.

Behrens, Peter, Die ökonomischen Grundlagen des Rechts, Politische Ökonomie als rationale Jurisprudenz, Tübingen 1986.

Berle, Adolf A./Means, Gardiner C., The Modern Corporation and Private Property, 2. Aufl. (revised ed. von 1932), New York 1967.

Berndt, Thomas, FG-Urteil (FG Hamburg, 28.11.2003 - III 1/01, Revision beim BFH anhängig unter I R 5/04) zu „BIAO“: Heranziehung von IAS zur Auslegung der Jahresabschlussrichtlinie, Leitsätze und Kommentar, in: BB, 59. Jg. (2004), S. 1220.

Bernhard, Rolf, Währungsumrechnung und Kongruenz, Kritische Würdigung des Konzeptes der funktionalen Währung nach US-GAAP, Berlin 2001.

Beusch, Karl, Die Besteuerung der Konzerne als wirtschaftliche Einheit in internationaler Sicht, Ein Überblick, in: Festschrift Werner Flume zum 70. Geburtstag, Bd. 2, hrsg. von Jakobs, Horst H. et al., Köln 1978, S. 21-42.

Beusch, Karl, Referat, in: Reichen die Vorschriften des Steuerrechts - unter Berücksichtigung des Gesellschaftsrechts - aus, um Vermögensbewegungen zwischen verbundenen Unternehmen vollständig und befriedigend $\mathrm{zu}$ regeln?, Verhandlungen des Neunundvierzigsten Deutschen Juristentages, Düsseldorf 1972, Bd. II (Sitzungsberichte), Teil Q, München 1972, S. Q 30-Q 45.

Bieker, Marcus, Ökonomische Analyse des Fair Value Accounting, Diss. Bochum 2005.

Bieker, Marcus/Esser, Maik, Der Impairment-Only-Ansatz des IASB: Goodwillbilanzierung nach IFRS 3 „Business Combinations“, in: StuB, 6. Jg. (2004), S. 449-458.

Bieker, Marcus/Esser, Maik, Goodwill-Bilanzierung nach ED 3 "Business Combinations", in: KoR, 3. Jg. (2003), S. 75-84.

Biener, Herbert, Die Konzernrechnungslegung nach der Siebenten Richtlinie des Rates der Europäischen Gemeinschaften über den Konzernabschluß, in: DB, 36. Jg. (1983), Beilage Nr. 19.

Biener, Herbert, Internationalisierung des Bilanzsteuerrechts - Was wird auf uns zukommen?, in: DStZ, 85. Jg. (1997), S. 345-356. 
Biener, Herbert/Berneke, Wilhelm, Bilanzrichtlinien-Gesetz, Textausgabe des Bilanzrichtlinien-Gesetzes vom 19.12.1985 (Bundesgesetzbl. I S. 2355) mit Bericht des Rechtsausschusses des Deutschen Bundestages, Regierungsentwürfe mit Begründung, EG-Richtlinien mit Begründung, Entstehung und Erläuterung des Gesetzes, Düsseldorf 1986.

Bierich, Marcus, Moral und Effizienz in der Marktwirtschaft, in: ZfbF, 47. Jg. (1995), S. 186-196.

Bippus, Birgit E., US-amerikanische Grundsätze der Rechnungslegung von Unternehmen und die Maßgeblichkeit im deutschen Bilanzrecht - keine unvereinbaren Bilanzierungsphilosophien!, in: DStZ, 86. Jg. (1998), S. 637-650.

Birk, Dieter, Das Leistungsfähigkeitsprinzip in der Unternehmenssteuerreform, in: StuW, 77. Jg. (2000), S. 328-336.

Birkholz, Hans, Das neue Aktienrecht in steuerlicher Sicht, in: BB, 21. Jg. (1966), S. 709-716.

Bisani, Fritz, Die Grundlagen der Konzernbesteuerung im Lichte betriebswirtschaftlicher Kritik, Diss. Erlangen-Nürnberg 1962.

Blankart, Charles B., Öffentliche Finanzen in der Demokratie, Eine Einführung in die Finanzwissenschaft, 5. Aufl., München 2003.

BMF (Bundesministerium der Finanzen), Bericht zur Fortentwicklung des Unternehmenssteuerrechts, 7. August 2001, Berlin, URL: http://www.bundesfinanzministerium.de/Aktuelles/Neue/Weitere-Veroeffentlichungen-.393.htm (02.11.2004).

BMF (Bundesministerium der Finanzen), Internationalisierung der Rechnungslegung: Konsequenzen für die deutsche Steuerpolitik, in: Monatsbericht des BMF, 10.2002, S. 63-70.

BMF (Bundesministerium der Finanzen), Schreiben betr. Umwandlungssteuergesetz 1995 (UmwStG 1995); Zweifel- und Auslegungsfragen, vom 25. März 1998 (BStBl. I S. 268).

Boadway, Robin/Bruce, Neil, A General Proposition on the Design of a Neutral Business Tax, in: Journal of Public Economics, Vol. 24 (1984), S. 231-239.

Böcking, Hans-Joachim, IAS für Konzern- und Einzelabschluss! - Replik zum Beitrag von Zabel, IAS zwingend für Konzern- und Einzelabschluss?; zugleich Würdigung der Aussagen der Deutschen Bundesbank zur Umsetzung der Mitgliedstaatenwahlrechte im Rahmen der EU-Verordnung und eine Empfehlung an den Gesetzgeber, in: WPg, 55. Jg. (2002), S. 925-928.

Böcking, Hans-Joachim, IAS für Konzern- und Einzelabschluss?, in: WPg, 54. Jg. (2001), S. 1433-1440.

Bode, Jürgen, Der Informationsbegriff in der Betriebswirtschaftslehre, in: ZfbF, 49. Jg. (1997), S. 449-468. 
Bohl, Werner, IAS/IFRS und steuerliche Gewinnermittlung, Besprechung des gleichnamigen Gutachtens von Herzig, in: DB, 57. Jg. (2004), S. 2381-2383.

Böhm, Steffen, Der Konzerngewinn als Grundlage für Dividendenausschüttung und Steuerbemessung, Ein Vorschlag für eine Neuregelung, Diss. Göttingen 1979.

Bonse, Andreas, Informationsgehalt von Konzernabschlüssen nach HGB, IAS und US-GAAP, Eine empirische Analyse aus Sicht der Eigenkapitalgeber, Frankfurt am Main et al. 2004.

Bonus, Holger/Weiland, Raimund, Die Welt der Institutionen, in: Beiträge zur angewandten Mikroökonomik (Festschrift Jochen Schumann), hrsg. von Dieckheuer, Gustav, Berlin et al. 1995, S. 29-52.

Booth, G. Geoffrey/Broussard, John P./Loistl, Otto, Earnings and stock returns: evidence from Germany, in: The European Accounting Review, Vol. 6 (1997), S. 589-603.

Bores, Wilhelm, Konsolidierte Erfolgsbilanzen und andere Bilanzierungsmethoden für Konzerne und Kontrollgesellschaften, Leipzig 1935.

Bössmann, Eva, Volkswirtschaftliche Probleme der Transaktionskosten, in: Zeitschrift für die gesamte Staatswissenschaft, 138. Jg. (1982), S. 664-679.

Bovermann, Brigitte, Die Umrechnung der Jahresabschlüsse ausländischer Tochterunternehmen für den Weltabschluß in der EG unter dem Aspekt seiner Informationsfunktion, Frankfurt am Main 1988.

Bracewell-Milnes, Barry, Tax Competition: Harmful or Beneficial?, in Intertax, Vol. 27 (1999), S. 86-88.

Brazer, Harvey E., The Report of the Royal Commission on Taxation, in: Journal of Finance, Vol. 22 (1967), S. 671-683.

Brennan, Geoffrey/Buchanan, James M., The Power to Tax, Analytical Foundations of a Fiscal Constitution, Cambridge et al. 1980.

Brief, Richard P./Peasnell, Ken V. (Hrsg.), Clean Surplus, A Link between Accounting and Finance, New York 1996.

Brown, E. Cary, Business-Income Taxation and Investment Incentives, in: Income, Employment and Public Policy, Essays in Honor of Alvin H. Hansen, hrsg. Von Metzler, Lloyd A./Hansen, Alvin H., New York 1948, S. 300-316.

Brücks, Michael/Wiederhold, Philipp, IFRS 3 Business Combinations, in: KoR, 4. Jg. (2004), S. 177-185.

Bruns, Hans-Georg, „Pooling of Interests“ - der Zusammenschluß der Daimler-Benz AG und der Chrysler Corporation, in: DBW, 59. Jg. (1999), S. 831-840.

Buchanan, James M., Constitutional Economics, in: The New Palgrave, A Dictionary of Economics, Bd. 1, London et al. 1987, S.585-588.

Buchanan, James M., Constitutional Economics, Oxford 1991. 
Buchanan, James M., The Constitution of Economic Policy, in: The American Economic Review, Vol. 77 (1987), S. 243-250.

Buchanan, James M./Tullock, Gordon, The Calculus of Consent: Logical Foundations of Constitutional Democracy, Ann Arbor 1962.

Budde, Wolfgang Dieter/Förschle, Gerhart (Hrsg.), Sonderbilanzen, Von der Gründungsbilanz bis zur Liquidationsbilanz, 3. Aufl., München 2002.

Budde, Wolfgang Dieter/Förschle, Gerhart, Realisationsprinzip, in: Lexikon des Rechnungswesens, hrsg. von Busse von Colbe, Walther/Pellens, Bernhard, 4. Aufl., München et al. 1998, S. 595-598.

Bühler, Ottmar, Konzernbilanzen und Konzernbesteuerung, in: Betriebsgrösse und Unternehmungskonzentration, Nürnberger Hochschulwoche v. 16. - 20. Februar 1959, Berlin 1959, S. 229-233.

Bühler, Ottmar, Steuerrecht der Gesellschaften und Konzerne, 3. Aufl., Berlin et al. 1956.

Bundesrat, Drucksache 360/1/90 vom 01.10.1990: Mitteilung der Kommission der Europäischen Gemeinschaften an das Parlament und den Rat über Leitlinien zur Unternehmensbesteuerung (SEK(90)601 endg., Ratsdok. 6128(90).

Bundesrat, Drucksache 96/91 vom 07.02.1991: Vorschlag für eine Richtlinie des Rates über eine Regelung für Unternehmen zur Berücksichtigung der Verluste ihrer in anderen Mitgliedstaaten belegenen Betriebsstätten und Tochtergesellschaften (KOM(90)595 endg., Ratsdok. 4432/91).

Buschmeyer, Klaus-Dieter, Publizität als Korrelat der Haftungsbeschränkung, Köln 1993.

Busse von Colbe, Walther, Aktuelle Fragen der Konzernverfassung aus betriebswirtschaftlicher Sicht, in: Revision und Rechnungslegung im Wandel (Festschrift André Zünd), hrsg. von Helbling, Carl/Boemle, Max/Glaus, Bruno U., Zürich 1988, S. 245-255.

Busse von Colbe, Walther, Der Jahresabschluß des Konzerns, Unter Berücksichtigung des Regierungsentwurfs eines Aktiengesetzes, in: Die Aktiengesellschaft, 5. Jg. (1960), S. 145-148, 181-186.

Busse von Colbe, Walther, Der Konzernabschluß als Bemesungsgrundlage für die Gewinnverwendung, in: Bilanz- und Konzernrecht (Festschrift Reinhard Goerdeler), hrsg. von Havermann, Hans, Düsseldorf 1987, S. 61-77.

Busse von Colbe, Walther, Entwicklungsperpektiven der Rechnungslegung in Deutschland, in: ZfbF, 54. Jg. (2002), S. 159-172. 
Busse von Colbe, Walther, Gefährdung des Kongruenzprinzips durch erfolgsneutrale Verrechnung von Aufwendungen im Konzernabschluß, in: Rechnungslegung, Entwicklungen bei der Bilanzierung und Prüfung von Kapitalgesellschaften (Festschrift Karl-Heinz Forster), hrsg. von Moxter, Adolf et al., Düsseldorf 1992, S. 125-138.

Busse von Colbe, Walther, Internationale Entwicklungstendenzen zur Einheitstheorie für den Konzernabschluss, in: Unternehmensrechnung, Konzeptionen und praktische Umsetzung (Festschrift Gerhard Scherrer), hrsg. von Göbel, Stefan/Heini, Bernhard, München 2004, S. 41-63.

Busse von Colbe, Walther, Prognosepublizität von Aktiengesellschaften, in: Beiträge zur Lehre von der Unternehmung (Festschrift Karl Käfer), hrsg. von Angehrn/Künzi, Hans Paul, Stuttgart 1968, S. 91-118.

Busse von Colbe, Walther, Zur Umrechnung der Jahresabschlüsse ausländischer Konzernunternehmen für die Aufstellung von Konzernabschlüssen bei Wechselkursänderungen, in: Liiketaloudellinen Aikakauskirja (The Finnish Journal of Business Economics), Vol. 21 (1972), S. 306-333.

Busse von Colbe, Walther/Chmielewicz, Klaus, Das neue Bilanzrichtlinien-Gesetz, in: DBW, 45. Jg. (1986), S. 289-347.

Busse von Colbe, Walther/Ordelheide, Dieter, Konzernabschlüsse, Rechnungslegung für Konzerne nach betriebswirtschaftlichen Grundsätzen und gesetzlichen Vorschriften, 6. Aufl., Wiesbaden 1993.

Busse von Colbe, Walther/Ordelheide, Dieter/Gebhardt, Günther/Pellens, Bernhard, Konzernabschlüsse, Rechnungslegung nach betriebswirtschaftlichen Grundsätzen sowie nach Vorschriften des HGB und der IAS/IFRS, 7. Aufl., Wiesbaden 2003.

Calabresi, Guido/Melamed, A. Douglas, Property Rules, Liability Rules, and the Inalienability: One View of the Cathedral, in: Harvard Law Review, Vol. 85 (1972), S. 1089-1128.

Carlson, George N./Galper, Harvey, Water's Edge versus Worldwide Unitar Combination, in: The State Corporation Income Tax, Issues in Worldwide Unitary Combination, hrsg. von McLure, Charles E., jr., Stanford 1984, S. 1-40.

Carman, Paul, Consolidation of SPEs in a World of Securitization - Have INI and ALUMAX changed the Rules?, in: Journal of Taxation, Vol. 97 (Dec. 2002), S. 334-338.

Casson, Mark, The Entrepreneur, An Economic Theory, Oxford 1982 (Reprint, Aldershot et al. 1995).

Casson, Mark, Why are Firms Hierarchical?, in: Journal of the Economics of Business, Vol. 1 (1994), S. 47-76. 
Chetcuti, Jean-Philippe, Corporate Taxation in the EC: The Process of Corporate Tax Harmonisation in the EC, 2001, URL: http://www.chetcuticauchi.com/jpc/research/eu-tax-harmonization.htm (22.10.2002).

Childs, William Herbert, Consolidated Financial Statements, Principles and Procedures, Ithaca (New York) 1949.

Chmielewicz, Klaus, Forschungskonzeptionen der Wirtschaftswissenschaft, 3. Auflage, Stuttgart 1994.

Choate, Gary M./Mason, Donald J., Consolidated Returns and the Single-Entity Theory, in: The Tax Adviser, Vol. 25 (1994), S. 655-668.

Claessens, Stijn/Djankov, Simeon/Fan, Joseph P.-H./Lang, Larry H. P., Disentangling the Incentive and Entrenchment Effects of Large Shareholdings, in: Journal of Finance, Vol. 57 (2002), S. 2741-2771.

Clark, Robert Charles, Corporate Law, Boston et al. 1986.

Coase, Ronald H., The Nature of the Firm, in: Economica, Vol. 4 (1937), S. 386-405.

Coase, Ronald H., The Problem of Social Cost, in: Journal of Law and Economics, Vol. 3 (Oct. 1960), S. 1-44.

Coenenberg, Adolf G., Jahresabschluss und Jahresabschlussanalyse, Betriebswirtschaftliche, handelsrechtliche, steuerrechtliche und internationale Grundsätze HGB, IAS/IFRS, US-GAAP, DRS, 19. Aufl., Stuttgart 2003.

Commons, John R., Institutional Economics, Its Place in Political Economy, Vol. 1, New York 1934 (Reissue, with a New Introduction by Malcom Rutherford, New Brunswick, N. J. 1990).

Coughlan, John W., Guide to Contemporary Theory of Accounts, Englewood Cliffs, N. J. 1965.

Cronos, W., Anpassung des deutschen Rechts an die vierte und siebente EG-Richtlinie - Besorgnisse und Nutzen, Bericht über die Schmalenbach-Tagung 1985 am 22. Mai in Düsseldorf, in: DB, 38. Jg. (1985), S. 1405-1408.

Cyert, Richard M./March, James G., Eine verhaltenswissenschaftliche Theorie der Unternehmung, 2. Aufl., Stuttgart 1995.

Dahlberg, James L., Aggregate vs. Entity: Adjusting the Basis of Stock in a Subsidiary Filing a Consolidated Return, in: Tax Law Review, Vol. 42 (1987), S. 547-567.

Dautzenberg, Norbert, Europäische „Agenda“ für das Ertragsteuerrecht im Jahr 2004: Die Richtlinien vom Juni 2003, in: BB, 59. Jg. (2004), S 17-21.

Dautzenberg, Norbert, Unternehmensbesteuerung im EG-Binnenmarkt, Problembereiche und Perspektiven der Unternehmensbesteuerung im Binnemarkt des EGVertrages - Eine Untersuchung zu Art und Umfang der notwendigen Anpassungen im Ertragsteuerbereich, Bd. 1 und 2, Lohmar et al 1997. 
Dean, Graeme W./Clarke, Frank L., An Evolving Conceptual Framework?, in: ABACUS, Vol. 39 (2003), S. 279-297.

Debatin, Helmut, Die Steuerharmonisierung in der EWG in Form der KonzernBesteuerungs-Richtlinie, in: DStZ, 57. Jg. (1969), S. 146-152.

Debreu, Gérard, A Social Equilibrium Existence Theorem, Proceedings of the National Academy of Science, Vol. 38 (1952), S. 886-893.

Debus, Christian, Haftungsregelungen im Konzernrecht, Eine ökonomische Analyse, Frankfurt am Main et al. 1990.

Demsetz, Harold, Ethics and Efficiency in Property Rights Systems, in: Time, Uncertainty, and Disequilibrium, Exploration of Austrian Themes, hrsg. von Rizzo, Mario J., Lexington, Mass. et al. 1979, S. 97-116.

Demsetz, Harold, Information and Efficiency: Another Viewpoint, in: Journal of Law and Economics, Vol. 12 (1969), S. 1-22.

Demski, Joel S., The General Impossibility of Normative Accounting Standards, in: The Accounting Review, Vol. 48 (1973), S. 718-723.

Deutscher Bundestag, Verhandlungen, 13. Wahlperiode, Drucksache 13/9909 vom 12.02.1998: Entwurf eines Gesetzes zur Verbesserung der Wettbewerbsfähigkeit deutscher Konzerne an internationalen Kapitalmärkten und zur Erleichterung der Aufnahme von Gesellschafterdarlehen (Kapitalaufnahmeerleichterungsgesetz KapAEG).

Deutscher Bundestag, Verhandlungen, 14. Wahlperiode, Drucksache 14/23 vom 09.11.1998: Entwurf eines Steuerentlastungsgesetzes 1999/2000/2002.

Deutscher Bundestag, Verhandlungen, 5. Wahlperiode, Drucksache V/3774 vom 31.01.1969: Vorschlag einer Richtlinie des Rates über das gemeinsame Steuersystem der Mutter- und Tochtergesellschaften verschiedener Mitgliedstaaten.

Deutscher Bundestag, Verhandlungen, 6. Wahlperiode, Drucksache VI/1344 vom 23.10.1970: Schriftlicher Bericht des Finanzausschusses (6. Ausschuß) über die von der Bundesregierung zur Unterrichtung vorgelegten Vorschläge der Kommission für eine Richtlinie des Rates über das gemeinsame Steuersystem für Mutter- und Tochtergesellschaften verschiedener Mitgliedstaaten - aus Drucksache V/3774.

Deutscher Bundestag, Verhandlungen, 7. Wahlperiode, Drucksache 7/3981 vom 18.08.1975: Vorschlag einer Richtlinie des Rates zur Harmonisierung der Körperschaftsteuersysteme und der Regelungen der Quellensteuer auf Dividenden.

Devereux, Michael, P., Debating Proposed Reforms of the Taxation of Corporate Income in the European Union, in: International Tax and Public Finance, Vol. 11 (2004), S. 71-89.

Devereux, Michael/Pearson, Mark, Corporate Tax Harmonisation and Economic Efficiency, London 1989. 
Diamond, Peter A./Mirrlees, James A., Optimal Taxation and Public Production (Part I and II), The American Economic Review, Vol. 51 (1961), S. 8-27, 261-278.

Dirrigl, Hans, Die Bewertung von Beteiligungen an Kapitalgesellschaften, Betriebswirtschaftliche Methoden und steuerlicher Einfluß, Hamburg 1988.

Döllerer, Georg, Besprechung von Niemann, Ursula, Probleme der Gewinnrealisierung innerhalb des Konzerns, Düsseldorf 1968, in: BB, 24. Jg. (1969), S. 371-372.

Döllerer, Georg, Die Beteiligung einer Kapitalgesellschaft an einer Personenhandelsgesellschaft nach Handelsrecht und Steuerrecht, in: WPg, 30. Jg. (1977), S. 81-91.

Döllerer, Georg, Die Steuerbilanz der Personenhandelsgesellschaft als konsolidierte Bilanz einer wirtschaftlichen Einheit, in: DStZ, Ausgabe A, 62. Jg. (1974), S. 211 220.

Döllerer, Georg, Rechtsbeziehungen zwischen der Personenhandelsgesellschaft und ihren Gesellschaftern in der Steuerbilanz, in: Festschrift Werner Flume zum 70. Geburtstag, Bd. 2, hrsg. von Jakobs, Horst H. et al., Köln 1978, S. 43-54.

Döllerer, Georg, Zur Realteilung bei Personenhandelsgesellschaften, Anmerkungen zu dem BFH-Urteil vom 19. Januar 1982 VIII R 21/77, in: DStZ, 70. Jg. (1982), S. 267-272.

Dornfeld, Robert, Die Steuerfähigkeit der Unternehmung, Versuch einer Einordnung der Unternehmung in das System des Steuerrechts, Diss. Köln 1966.

Dörr, Ingmar, Gruppenbesteuerung in Italien, in: DSWR, o. Jg. (2004), Heft 9, S. 248249.

Dötsch, Ewald, Gewinnabführungsvertrag, in: Organschaft: laufende und aperiodische Besteuerung-nationale und internationale Aspekte-Hinweise zum EU-Recht, hrsg. von Herzig, Norbert, Stuttgart 2003, S. 98-118.

Downs, Anthony, An Economic Theory of Democracy, New York 1957.

Dreger, Karl-Martin, Der Konzernabschluß, Grundsätze ordnungsmäßiger Konsolidierung, Konzernrechnungslegung nach Aktienrecht 1965 in Anlehnung an Technik und Praxis in den USA, Wiesbaden 1969.

Drescher, Sebastian, Zur Zukunft des deutschen Maßgeblichkeitsgrundsatzes, USGAAP orientierte Reform des handelsrechtlichen Bilanzsystems, Düsseldorf 2002.

Druey, Jean Nicolas, „Konzernvertrauen“, in: Deutsches und europäisches Gesellschafts-, Konzern- und Kapitalmarktrecht (Festschrift Marcus Lutter), hrsg. von Schneider, Uwe H. et al., Köln 2000, S. 1069-1082.

Dubroff, Harold/Cahill, M. Connie/Norris, Michael D., Tax Accounting: The Relationship of Clear Reflection of Income to Generally Accepted Accounting Principles, in: Albany Law Review, Vol. 47 (1983), S. 354-407.

Dürig, Günter, Art. 19 Abs. III, in: Maunz/Dürig, Kommentar zum Grundgesetz, Bd. III, München, Loseblattsammlung, Stand Februar 2004, hier: Beitrag von 1977. 
Dusemond, Michael, Die Abgrenzung des Konsolidierungskreises im engeren und weiteren Sinne, Unter Berücksichtigung des Entwurfs einer Verlautbarung des IDW zur Konzernrechnungslegung bei Änderung des Konsolidierungskreises, in: DB, 47. Jg. (1994), S. 1733-1741.

Dusemond, Michael/Weber, Claus-Peter/Zündorf, Horst, $\S 301$, in: Handbuch der Konzernrechnungslegung, Kommentar zur Bilanzierung und Prüfung, Bd. II, hrsg. von Küting, Karlheinz/Weber, Claus-Peter, 2. Aufl., Stuttgart 1998.

Easterbrook, Frank H./Fishel, Daniel R., The Economic Structure of Corporate Law, Cambridge, Mass. et al. 1991.

Eberhartinger, Eva, Ertragsteuerliche Konsequenzen der Internationalisierung der Rechnungslegung, Wien 2000.

Eichhorn, Klaus Thomas, Das Maßgeblichkeitsprinzip bei Rechnungslegung nach International Accounting Standards, Lohmar et al. 2001.

Elschen, Rainer, Entscheidungsneutralität, Allokationseffizienz und Besteuerung nach der Leistungsfähigkeit, Gibt es ein gemeinsames Fundament der Steuerwissenschaften?, in: StuW, 68. Jg. (1991), S. 99-115.

Elschen, Rainer, Institutionale oder personale Besteuerung von Unternehmungsgewinnen?, 2. Aufl., Hamburg 1994.

Elschen, Rainer/Hüchtebrock, Michael, Steuerneutralität in Finanzwissenschaft und Betriebswirtschaftslehre - Diskrepanzen und Konsequenzen, in: Finanzarchiv, N. F., Bd. 41 (1983), S. 253-280.

Elvidge, David, Arm's length is the only possible way, in: International Tax Review, o. Jg. (Sept. 1994), S. 17-18.

Emmerich, Volker/Sonnenschein, Jürgen/Habersack, Mathias, Konzernrecht, Das Recht der verbundenen Unternehmen bei Aktiengesellschaft, $\mathrm{GmbH}$, Personengesellschaften, Genossenschaft, Verein und Stiftung, 7. Aufl., München 2001.

Endres, Dieter, Internationaler Vergleich von Konsolidierungs- und Organschaftsvorschriften, in: WPg, Sonderheft (März), 56. Jg. (2003), S. S35-S40.

Endres, Dieter, Konzernbesteuerung in wichtigen Industriestaaten, in: Organschaft: laufende und aperiodische Besteuerung - nationale und internationale Aspekte Hinweise zum EU-Recht, hrsg. von Herzig, Norbert, Stuttgart 2003, S. 461-482.

Epstein, David G./Freer, Richard D./Roberts, Michael J., Business Structures, St. Paul., Minn. 2002.

Erlei, Mathias/Leschke, Martin/Sauerland, Dirk, Neue Institutionenökonomik, Stuttgart 1999.

Ernst \& Young Wirtschaftsprüfungs- und Steuerberatungsgesellschaft m.b.H., Gruppenbesteuerung, Steuerreformgesetz 2005, Wien et al. (Mai) 2004. 
Ernst, Edgar/Gassen, Joachim/Pellens, Bernhard, Verhalten und Präferenzen deutscher Aktionäre, Eine Befragung von privaten und institutionellen Anlegern zum Informationsverhalten, zur Dividendenpräferenz und zur Wahrnehmung von Stimmrechten, Studien des Deutschen Aktieninstituts, Heft 29, Frankfurt am Main 2005.

Eschenburg, Rolf, Der ökonomische Ansatz zu einer Theorie der Verfassung, Die Entwicklung einer liberalen Verfassung im Spannungsverhältnis zwischen Produktivität und Effektivität der Kooperation, Tübingen 1977.

Esser, Maik, Goodwillbilanzierung nach SFAS 141/142, Eine ökonomische Analyse, Diss. Bochum 2003.

EU-Kommission (DG Taxation and Customs Union), (Informal) Summary Report of the Workshop on the application of International Accounting Standards (IAS) in 2005 and the implications for the introduction of a consolidated tax base for companies' EU-wide activities held in Brussels on 18 March 2003, URL: http://europa.eu.int:8082/comm/taxation_customs/taxation/consultations/ias.htm (11.11.2003).

EU-Kommission (DG Taxation and Customs Union), Outline of a possible experimental application of Home State Taxation to small and medium-sized enterprises, Ref.: TAXUD C.1/DOC (04) 1410, Brüssel 24.6.2004.

EU-Kommission (GD Steuern und Zollunion), Konsultationspapier: Die Anwendung der ,International Accounting Standards' (IAS) ab 2005 und ihre Implikationen für die Schaffung einer konsolidierten Steuerbemessungsgrundlage für die grenzüberschreitende Unternehmenstätigkeit in der EU, Brüssel Februar 2003.

EU-Kommission (Generalsekretariat der Kommission der Europäischen Wirtschaftsgemeinschaft), Programm der Steuerharmonisierung, Programm für die Harmonisierung der direkten Steuern, in: Sonderbeilage zum Bulletin 8-1967 der Europäischen Wirtschaftsgemeinschaft.

EU-Kommission, Company Taxation in the Internal Market, Commission Staff Working Paper, SEC(2001) 1681, Brüssel 23.10.2001 (Die Studie liegt nicht in einer offiziellen deutschen Übersetzung vor).

EU-Kommission, Conference on company taxation supports further work on an EUwide consolidated company tax base, MEMO/02/84, Brüssel 30.4.2002.

EU-Kommission, Ein Binnenmarkt ohne steuerliche Hindernisse, Strategie zur Schaffung einer konsolidierten Körperschaftsteuer-Bemessungsgrundlage für die grenzüberschreitende Unternehmenstätigkeit in der $\mathrm{EU}, \mathrm{KOM}(2001)$ 582, Brüssel 23.10.2001.

EU-Kommission, Ein Binnenmarkt ohne unternehmenssteuerliche Hindernisse: Ergebnisse, Initiativen, Herausforderungen, $\operatorname{KOM}(2003)$ 726, Brüssel 24.11.2003. 
EU-Kommission, EU-Steuerumfrage unterstreicht die Notwendigkeit einer einheitlichen Körperschaftsteuerbemessungsgrundlage und des Systems einer einzigen Anlaufstelle im Bereich der MwSt, IP/04/1091, Brüssel 9.9.2004.

EU-Kommission, Finanzdienstleistungen, Erfüllung der Prioritäten von Barcelona und Ausblick: Umsetzung, Siebenter Fortschrittsbericht, Brüssel 3.12.2002.

EU-Kommission, Kommentare zu bestimmten Artikeln der Verordnung (EG) Nr. 1606/2002 des Europäischen Parlaments und des Rates vom 19. Juli 2002 betreffend die Anwendung internationaler Rechnungslegungsstandards und zur Vierten Richtlinie 78/660/EWG des Rates vom 25. Juli 1978 sowie zur Siebenten Richtlinie 83/349/EWG des Rates vom 13. Juni 1983 über Rechnungslegung, Brüssel November 2003.

EU-Kommission, Maßnahmenpaket zur Bekämpfung des schädlichen Steuerwettbewerbs in der Europäischen Union, KOM(97) 564, Brüssel 5.11.1997.

EU-Kommission, Non-Paper der Kommission für die informelle Tagung des Rates „Wirtschaft und Finanzen" am 10. und 11. September 2004: Sitzlandbesteuerung bei kleinen und mittleren Unternehmen, Brüssel 7.7.2004.

EU-Kommission, Rechnungslegungsstrategie der EU: Künftiges Vorgehen, $\operatorname{KOM}(2000) 359$, Brüssel 13.6.2000.

EU-Kommission, Steuern in der Europäischen Union, SEK(96) 487, Brüssel 20.3.1996.

EU-Kommission, Unternehmensbesteuerung: Kommission schlägt einheitliche konsolidierte Bemessungsgrundlage vor, IP/01/1468, Brüssel 23.10.2001.

EU-Kommission, Unternehmensstrategie der Kommission - Häufig gestellte Fragen, MEMO/01/335, Brüssel 23.10.2001.

Euler, Roland, Steuerbilanzielle Konsequenzen der internationalisierten Rechnungslegung, in: StuW, 75. Jg. (1998), S. 15-24.

Europäische Wirtschaftsgemeinschaft, Bericht des Steuer- und Finanzausschusses, Brüssel 1962.

Fama, Eugene F./Jensen, Michael C., Agency Problems and the Theory of the Firm, in: Journal of Law and Economics, Vol. 26 (1983), S. 327-349.

Fama, Eugene F./Jensen, Michael C., Separation of Ownership and Control, in: Journal of Law and Economics, Vol. 26 (1983), S. 301-325.

Fane, G., Neutral Taxation under Uncertainty, in: Journal of Public Economics, Vol. 33 (1987), S. 95-105.

FASB (Financial Accounting Standards Board), Summary of FASB Tentative Decisions on Noncontrolling Interests as of July 27, 2004, last update August 9, 2004, URL: http://www.fasb.org/project/bc_purchmethod.shtml (31.08.2004). 
FASB (Financial Accounting Standards Board), Summary of FASB Tentative Decisions on Business Combinations as of July 27, 2004, last update August 5, 2004, URL: http://www.fasb.org/project/bc_purchmethod.shtml (31.08.2004).

Faß, Joachim, Unterschiedsbeträge aus der Schuldenkonsolidierung und Zwischenerfolgseliminierung, in: BB, 45. Jg. (1990), S. 1203-1310.

FEE (Fédération des Experts Comptables Européens, Direct Tax Working Party), Survey on Group Taxation Domestically and Across Borders within Europe, September 2001 .

Festinger, Leon, A theory of cognitive dissonance, Stanford 1957.

Fezer, Karl-Heinz, Aspekte einer Rechtskritik an der economic analysis of law und am property rights approach, in: JZ (Juristen-Zeitung), 41. Jg. (1986), S. 817-824.

Fischer, Wolfgang-Wilhelm, IAS-Abschlüsse von Einzelunternehmungen, Rechtliche Grundlagen und finanzwirtschaftliche Analyse, Herne et al. 2001.

Fleischer, Holger, Konzernrechtliche Vertrauenshaftung, in: ZHR, 163. Bd. (1999), S. 461-485.

Flume, Werner, Gesellschaft und Gesamthand, in: ZHR, Bd. 136 (1972), S. 177-207.

Flume, Werner, Referat, in: Reichen die Vorschriften des Steuerrechts - unter Berücksichtigung des Gesellschaftsrechts - aus, um Vermögensbewegungen zwischen verbundenen Unternehmen vollständig und befriedigend $\mathrm{zu}$ regeln?, Verhandlungen des Neunundvierzigsten Deutschen Juristentages, Düsseldorf 1972, Bd. II (Sitzungsberichte), Teil Q, München 1972, S. Q 8-Q 29.

Förster, Guido, Finanzielle Eingliederung (unmittelbare und mittelbare Beteiligungen), in: Organschaft: laufende und aperiodische Besteuerung - nationale und internationale Aspekte - Hinweise zum EU-Recht, hrsg. von Herzig, Norbert, Stuttgart 2003, S. 83-97.

Forster, Karl-Heinz, Warum keine Equity-Bewertung im Jahresabschluß?, in: Rechenschaftslegung im Wandel (Festschrift Wolfgang Dieter Budde), hrsg. von Förschle, Gerhart/Kaiser, Klaus/Moxter, Adolf, München 1993, S. 203-211.

Foss, Nicolai J., Evolutionary and Contractual Theories of the Firm: How do they relate?, in: Rivista Internazionale di Scienze Sociali, 105. Jg. (1997), S. 309-337.

Foss, Nicolai J., Evolutionary Theories of the Firm: Reconstruction and Relations to Contractual Theories, Papers on Economics \& Evolution (Max-Planck-Institute for Research into Economic Systems, Evolutionary Economics Unit), No. 9602, Jena 1996.

Fresl, Karlo D., Die Europäisierung des deutschen Bilanzrechts, Wiesbaden 2000.

Friedländer, Heinrich, Der gegenwärtige Stand der Organtheorie, Parallelen zwischen Steuer- und Wirtschaftsrecht, in: StuW, 10. Jg. (1931), Sp. 481-514. 
Frotscher, Gerrit, „Zweistufige Gewinnermittlung“ und Korrektur der verdeckten Gewinnausschüttung, Replik zu dem Beitrag von Prof. Dr. Franz Wassermeyer, DB 2002, 2668, in: FR, 85. Jg. (2003), S. 230-234.

Fülbier, Rolf Uwe, Entwurf eines DRS 4 zur Bilanzierung von Unternehmenserwerben im Konzernabschluss, in: DB, 53. Jg. (2000), S. 1341-1346.

Fülbier, Rolf Uwe, Regulierung der Ad-hoc-Publizität, Ein Beitrag zur ökonomischen Analyse des Rechts, Wiesbaden 1998.

Fülbier, Rolf Uwe, Regulierung, Ökonomische Betrachtung eines allgegenwärtigen Phänomens, in: WiSt, 28. Jg. (1999), S. 468-473.

Fülbier, Rolf Uwe, Wissenschaftstheorie und Betriebswirtschaftslehre, in: WiSt, 33. Jg. (2004), S. 266-271.

Fülbier, Rolf Uwe/Gassen, Joachim, Wider die Maßgeblichkeit der International Accounting Standards für die steuerliche Gewinnermittlung, Erwiderung zu Oestreicher/Spengel, DB 1999, S. 593-600, in: DB, 52. Jg. (1999), S. 1511-1513.

Furubotn, Eirik G., Codetermination and the Modern Theory of the Firm: A PropertyRights Analysis, in: Journal of Business, Vol. 61 (1988), S. 165-181.

Furubotn, Eirik G./Pejovich, Svetozar, Property Rights and Economic Theory: A Survey of Recent Literature, in: Journal of Economic Literature, Vol. 10 (1972), S. 1137-1162.

Gandenberger, Otto, Kapitalexportneutralität versus Kapitalimportneutralität, Allokative Überlegungen zu einer Grundfrage der internationalen Besteuerung, Aufsätze zur Wirtschaftspolitik, Nr. 7, Forschungsinstitut für Wirtschaftspolitik der Universität Mainz, 1983.

Gassen, Joachim, Datenbankgestützte Rechnungslegungspublizität, Ein Beitrag zur Evolution der Rechnungslegung, Frankfurt am Main et al. 2000.

Gassen, Joachim, Rechnungslegung, in: Der Transaktionskostenansatz in der Betriebswirtschaftslehre, hrsg. von Jost, Peter-J., Stuttgart 2001, S. 395-413.

Gassner, Wolfgang, Ansätze zur Reform der Besteuerung von Unternehmensgruppen, in: Besteuerung von Unternehmensgruppen, Bestandsaufnahme und Vorschläge zur Reform der Organschaft im Körperschaftsteuerrecht, hrsg. von Gassner, Wolfgang/Lang, Michael/Wiesner, Werner, Wien 1998, S. 13-27.

Gassner, Wolfgang, Organschaft und Konzernbesteuerung, in: SWK, 65. Jg. (1990), Nr. 14, S. 187-190.

Gassner, Wolfgang, Reform der Konzernbesteuerung in Deutschland und Europa - Österreich ersetzt Organschaft durch Gruppenbesteuerung, in: FR, 86. Jg. (2004), S. 517-520.

Geiger, Uli, Die Ertragsbesteuerung der Konzernunternehmung in den Niederlanden nach dem Konzept der fiskalen Einheit, in: IWB, Fach 5 (Niederlande), Gruppe 2, S. 361-364 (Loseblattsammlung, Lieferung IWB Nr. 20 vom 23.10.2002). 
Geiger, Uli, Die Ertragsbesteuerung der Konzernunternehmung in Frankreich im Rahmen der Zusammenveranlagung nach dem beschränkten Einheitskonzept, in: IWB, Fach 5 (Frankreich), Gruppe 2, S. 1335-1340 (Loseblattsammlung, Lieferung IWB Nr. 2 vom 22.1.2003).

Geiger, Uli, Die Ertragsbesteuerung der Konzernunternehmung in Großbritannien im Rahmen der Einzelveranlagung, in: IWB, Fach 5 (Großbritannien), Gruppe 2, S. 397-399 (Loseblattsammlung, Lieferung IWB Nr. 22 vom 27.11.2002).

Geiger, Uli, Die Ertragsbesteuerung der Konzernunternehmung in Spanien durch Zusammenveranlagung nach dem beschränkten Einheitskonzept, in: IWB, Fach 5 (Spanien), Gruppe 2, S. 277-282 (Loseblattsammlung, Lieferung IWB Nr. 21 vom 13.11.2002).

Gelhausen, Wolf/Mujkanovic, Robin, Auswertung zur Währungsumrechnung im Konzernabschluß, in: DStR, 33. Jg. (1995), S. 1724-1730.

Georgi, Andreas A., Steuern in der Investitionsplanung, Eine Analyse der Entscheidungsrelevanz von Ertrag- und Substanzsteuern, Hamburg 1986.

Gérard, Marcel, Further Research Needed on Comprehensive Approaches, in: CESifo Forum, Vol. 3 (1/2002), S. 38-40.

Gerken, Lüder, Der Wettbewerb der Staaten, Tübingen 1999.

Gerken, Lüder/Märkt, Jörg/Schick, Gerhard, Double Income Taxation as a Response to Tax Competition in the EU, in: Intereconomics, Vol. 36 (Sept/Oct 2001), S. 244-254.

Giannini, Silvia, Home State Taxation vs. Common Base Taxation, in: CESifo Forum, Vol. 3 (1/2002), S. 24-30.

Gilman, Stephen, Accounting Concepts of Profit, New York 1939 (Reprint 1956).

Girnth, Klaus, Ertragsbesteuerung von Konzernen, Diss. Köln 1963.

Goode, Richard, The Economic Definition of Income, in: Comprehensive Income Taxation, hrsg. von Pechman, Joseph A., Washington, D.C. 1977, S. 1-30.

Gordon, Roger/Wilson, John D., An Examination of Multijurisdictional Corporate Income Taxation under Formula Apportionment, in: Econometrica, Vol. 54 (1986), S. 1357-1373.

Görling, Helmut, Die Konzernhaftung in mehrstufigen Unternehmensverbindungen, Frankfurt am Main et al. 1998.

Graf, Hans-Georg, ,Muster-Voraussagen“ und „Erklärungen des Prinzips“ bei F. A. von Hayek: Eine methodologische Analyse, Tübingen 1978.

Groh, Manfred, Die Bilanzen der Mitunternehmerschaft, in: StuW, 72. Jg. (1995), S. 383-389.

Groh, Manfred, Trennungs- und Transparenzprinzip im Steuerrecht der Personengesellschaften, in: ZIP, 19. Jg. (1998), S. 89-95. 
Gröning, Robert, Steuerbilanzielle Gewinnermittlung nach US-GAAP?, Lohmar et al. 2002.

Grossman, Sanford J./Hart, Oliver D., The Costs and Benefits of Ownership: A Theory of Vertical and Lateral Integration, in: Journal of Political Economy, Vol. 94 (1986), S. 691-719.

Grotherr, Siegfried, Der Abschluß eines Gewinnabführungsvertrags als (un-)verzichtbares Tatbestandsmerkmal der körperschaftsteuerlichen Organschaft, in: FR, 77. Jg. (1995), S. 1-14.

Grotherr, Siegfried, Die konsolidierte Konzernbesteuerung in Frankreich und ihre Übertragbarkeit ins deutsche Konzernsteuerrecht, in: AG, 40. Jg. (1995), S. 403415.

Grotherr, Siegfried, Die Reformdiskussion über das steuerliche Organschaftskonzept in der Bundesrepublik Deutschland, in: Besteuerung von Unternehmensgruppen, Bestandsaufnahme und Vorschläge zur Reform der Organschaft im Körperschaftsteuerrecht, hrsg. von Gassner, Wolfgang/Lang, Michael/Wiesner, Werner, Wien 1998, S. 233-268.

Grotherr, Siegfried, Die unterschiedlichen Konzernbesteuerungssysteme in den Mitgliedstaaten der Europäischen Union, Eine steuersystematische Analyse im Hinblick auf Reformüberlegungen beim steuerlichen Organschaftskonzept, in: StuW, 73. Jg. (1996), S. 356-378.

Grotherr, Siegfried, Probleme und Modelle der Besteuerung nationaler und grenzüberschreitender Konzerne in der Europäischen Gemeinschaft, Ein Diskussionsbeitrag im Rahmen der Normativen Betriebswirtschaftlichen Steuerlehre zur Entwicklung von Verfahren der steuerlichen Berücksichtigung des Konzernzusammenhangs unter besonderer Berücksichtigug bestehender Konzernbesteuerungssysteme, unveröffentlichte Habilitationsschrift, vorgelegt dem Fachbereich Wirtschaftswissenschaften der Universität Hamburg, Hamburg 1994.

Grotherr, Siegfried, Übertragung von Konzernrechnungslegungsgrundsätzen ins Konzernsteuerrecht?, in: WPg, 48. Jg. (1995), S. 81-97.

Grotherr, Siegfried/Jorewitz, Gitta, Einflüsse der internationalen Rechnungslegung auf das zukünftige deutsche Bilanzsteuerrecht, in: Die deutsche Rechnungslegung und Wirtschaftsprüfung im Umbruch (Festschrift Wilhelm Theodor Strobel), hrsg. von Freidank, Carl-Christian München 2001, S. 123-153.

Gruber, Thomas, Der Bilanzansatz in der neueren BFH-Rechtsprechung, Stuttgart 1991.

Haase, Florian F., Personengesellschaften als Organträger - Zweifelsfragen bei der Auslegung des $\S 14$ Abs. 1 Nr. 2 KStG n.F., in: DB, 57. Jg. (2004), S. 1580-1584. 
Haase, Klaus Dittmar, Zur steuerlichen Anerkennung des Konzernabschlusses, Unzureichende Erfahrung und sinkendes Steueraufkommen?, in: DB, 21. Jg. (1968), S. 237-238.

Haberstock, Lothar, Die Steuerplanung der internationalen Unternehmung, Wiesbaden 1976.

Hahn, Hartmut, Der Einfluss des Thomas von Aquin auf die Besteuerung nach der wirtschaftlichen Leistungsfähigkeit, in: StuW, 81. Jg. (2004), S. 167-177.

Haig, Robert Murray, The Concept of Income - Economic and Legal Aspects, in: The Federal Income Tax, hrsg. von Haig, Robert M., New York 1921, S. 1-28 (abgedruckt in: Readings in the Economics of Taxation, hrsg. von Musgrave, Richard A./Shoup, Carl S., Chicago et al. 1959, S. 54-76).

Haiß, Uta, Die steuerliche Gewinnabgrenzung zwischen Betriebsstätten im international tätigen Einheitsunternehmen, Diss. Dresden 1999.

Haller, Axel, Das Verhältnis von steuerrechtlicher und 'handelsrechtlicher' Rechnungslegung in den USA, in: DBW, 48. Jg. (1988), S. 723-733.

Haller, Axel, Der Grundsatz der Maßgeblichkeit der Handels- für die Steuerbilanz, Ein wesentlicher Grund für die mangelnde Harmonisierung der Jahresabschlusserstellung in Europa, in: RIW, 38. Jg. (1992), S. 43-48.

Haller, Axel, Die Grundlagen der externen Rechnungslegung in den USA, Unter besonderer Berücksichtigung der rechtlichen, institutionellen und theoretischen Rahmenbedingungen, 4. Aufl., Stuttgart 1994.

Haller, Heinz, Die Steuern, Grundlinien eines rationalen Systems öffentlicher Abgaben, 3. Aufl., Tübingen 1981.

Haller, Heinz, Umstrittene Fragen der „Leistungsfähigkeitsbesteuerung“, in: Finanzwissenschaft im Dienste der Wirtschaftspolitik (Festschrift Dieter Pohmer), hrsg. von Bea, Franz Xaver/Kitterer, Wolfgang, Tübingen 1991, S. 21-40.

Hannemann, Susanne/Peffermann, Petra, IAS-Konzernsteuerquote: Begrenzte Aussagekraft für die steuerliche Performance eines Konzerns, in: BB, 58. Jg. (2003) S. 727-733.

Hansjürgens, Bernd, Für und Wider den Ausgleich von Steuerlastverschiebungen in der EG im Wege des Fiscal Clearing, in: Konjunkturpolitik, 36. Jg. (1990), S. 111130.

Hansmann, Henry, Ownership of the Firm, in: Journal of Law, Economics, and Organization, Vol. 4 (1988), S. 267-304.

Harms, Jens E./Küting, Karlheinz, Perspektiven der Konzernbesteuerung, in: BB, 37. Jg. (1982), S. 445-455.

Hart, Oliver, An Economist's Perspective on the Theory of the Firm, in: The Economic Nature of the Firm, A Reader, hrsg. von Putterman, Louis/Kroszner, Randall S., Cambridge 1996, S. 354-360. 
Hart, Oliver, Firms, Contracts, and Financial Structure, Oxford 1995.

Hart, Oliver/Moore, John, Property Rights and the Nature of the Firm, in: Journal of Political Economy, Vol. 98 (1990), S. 1119-1158.

Hauschka, Christoph E., Entwicklungslinien und Integrationsfragen der gesellschaftsrechtlichen Akttypen des Europäischen Gemeinschaftsrechts, in: AG, 35. Jg. (1990), S. 85-103.

Haussmann, Fritz, Vom Aktienwesen und vom Aktienrecht, Mannheim et al. 1928.

Hayek, Friedrich A. von, Arten des Rationalismus, in: Freiburger Studien, Gesammelte Aufsätze von F. A. von Hayek, hrsg. vom Walter Eucken Institut, Tübingen 1969, S. 75-89.

Hayek, Friedrich A. von, Der Sinn des Wettbewerbs, in: Individualismus und Wirtschaftliche Ordnung, hrsg. von Hayek, Friedrich A. von, Erlenbach-Zürich 1952, S. 122-140.

Hayek, Friedrich A. von, Der Wettbewerb als Entdeckungsverfahren, in: Kieler Vorträge, gehalten am Institut für Weltwirtschaft an der Universität Kiel, Neue Folge 56, hrsg. von Schneider, Erich, Kiel 1968.

Hayek, Friedrich A. von, Die Ergebnisse menschlichen Handelns, aber nicht menschlichen Entwurfs, in: Freiburger Studien, Gesammelte Aufsätze von F. A. von Hayek, hrsg. vom Walter Eucken Institut, Tübingen 1969, S. 97-107.

Hayek, Friedrich A. von, Die Theorie komplexer Phänomene, Nr. 36 der Vorträge und Aufsätze des Walter Eucken Instituts, Tübingen 1972.

Hayek, Friedrich A. von, Die Verfassung der Freiheit, 3. Aufl., Tübingen 1991 (Nachdruck der 2. Aufl., 1983).

Hayek, Friedrich A. von, Grundsätze einer liberalen Gesellschaftsordnung, in: Freiburger Studien, Gesammelte Aufsätze von F. A. von Hayek, hrsg. vom Walter Eucken Institut, Tübingen 1969, S. 108-125.

Hayek, Friedrich A. von, Recht, Gesetzgebung und Freiheit, Eine neue Darstellung der liberalen Prinzipien der Gerechtigeit und der politischen Ökonomie, Band 3: Verfassung einer Gesellschaft freier Menschen, Landsberg am Lech 1981.

Hayek, Friedrich A. von, Recht, Gesetzgebung und Freiheit, Eine neue Darstellung der liberalen Prinzipien der Gerechtigeit und der politischen Ökonomie, Band 2: Die Illusion der sozialen Gerechtigkeit, Landsberg am Lech 1981.

Hayek, Friedrich A. von, Recht, Gesetzgebung und Freiheit, Eine neue Darstellung der liberalen Prinzipien der Gerechtigeit und der politischen Ökonomie, Band 1: Regeln und Ordnung, München 1980.

Hayek, Friedrich A. von, The Muddle of the Middle, in: Philosophical and Economic Foundations of Capitalims, hrsg. von Pejovich, Svetozar, Lexington et al. 1983, S. 89-100. 
Hayek, Friedrich A. von, The Pretence of Knowledge, Nobel Memorial Lecture, December 11, 1974, in: The American Economic Review, Vol. 79 (1989), S. 3-7.

Hayek, Friedrich A. von, The Use of Knowledge in Society, in: The American Economic Review, Vol. 35 (1945), S. 519-530.

Hayek, Friedrich A. von, Wirtschaftstheorie und Wissen, in: Individualismus und Wirtschaftliche Ordnung, hrsg. von Hayek, Friedrich A. von, Erlenbach-Zürich 1952, S. 49-77.

Head, John G., The Comprehensive Tax Base Revisited, in: Finanzarchiv, N. F., Bd. 40 (1982), S. 193-210.

Heintzen, Markus, Verfassungsrechtliche Anforderungen an das Rechnungslegungsrecht für börsennotierte Unternehmen, in: KoR, 1. Jg. (2001), S. 150-154.

Hellerstein, Walter/McLure, Charles E., jr., The European Commision's Report on Company Income Taxation: What the EU can learn from the Experience of the US States, in: International Tax and Public Finance, Vol. 11 (2004), S. 199-220.

Hempe, Richard/Siebels, Renate/Obermaier, Marion, Präzisierung der $\$ 15 a$ EStGAbzugsbeschränkung durch den BFH, Weitere Anmerkungen zum BFH-Urteil vom 14.10.2003 VIII R 32/01, in: DB, 57. Jg. (2004), S. 1460-1463.

Hendriksen, Eldon S./Breda, Michael F., Accounting Theory, 5. Aufl., Homewood, Ill. 1992.

Henning, Steven L./Lewis, Barry L./Shaw, Wayne H., Valuation of the Components of Purchased Goodwill, in: Journal of Accounting Research, Vol. 38 (2000), S. 375-386.

Hennrichs, Joachim, Der steuerrechtliche sog. Maßgeblichkeitsgrundsatz gem. $\S 5$ EStG, Stand und Perspektiven, in: StuW, 76. Jg. (1999), S. 138-153.

Hermann, Friedr. Ben. Wilh., Staatswirthschaftliche Untersuchungen über Vermögen, Wirthschaft, Productivität der Arbeiten, Kapital, Preis, Gewinn, Einkommen und Verbrauch, München 1832 (Nachdruck in 3. Aufl., Leipzig 1924).

Herrmann, Hans Joachim, Reformbedürftiges Konzernsteuerrecht?, Bericht und Stellungnahme zu den Beratungsergebnissen der steuerrechtlichen Arbeitsgemeinschaft des 49. Deutschen Juristentages im September 1972, in: AG, 18. Jg. (1973), S. 37-47.

Herz, Wilfred, Gnadenlos einfach, in: Die Zeit, Nr. 21/2001, URL: http://zeus.zeit.de/ text/archiv/2001/21/200121_steuern.xml (19.8.2004).

Herzig, Norbert, Anmerkung (zum Urteil des Europäischen Gerichtshofes (EuGH) vom 27.6.1996 - Rs. C-234/94; W. Tomberger/Gebr. von der Wettern GmbH), in: DB, 49. Jg. (1996), S. 1401-1402. 
Herzig, Norbert, Besteuerung der Unternehmen in Europa, Harmonisierung im Wettbewerb der Systeme, in: Steuerrecht im europäischen Binnenmarkt: Einfluß des EG-Rechts auf die nationalen Steuerrechtsordnungen, hrsg. von Lehner, Moris, DStJG, Bd. 19, Köln 1996, S. 121-149.

Herzig, Norbert, Einführung, in: Organschaft: laufende und aperiodische Besteuerung - nationale und internationale Aspekte - Hinweise zum EU-Recht, hrsg. von Herzig, Norbert, Stuttgart 2003, S. 3-35.

Herzig, Norbert, Gestaltung der Konzernsteuerquote - eine neue Herausforderung für die Steuerberatung, in: WPg, 56. Jg. (2003), Sonderheft, S. S 80-S 92.

Herzig, Norbert, IAS/IFRS und steuerliche Gewinnermittlung, Eigenständige Steuerbilanz und modifizierte Überschussrechnung, Gutachten für das Bundesfinanzministerium, Düsseldorf 2004.

Herzig, Norbert, Internationalisierung der Rechnungslegung und steuerliche Gewinnermittlung, in: WPg, 53. Jg. (2000), S 104-119.

Herzig, Norbert, Paradigmenwechsel in der Konzernbesteuerung (Gastkommentar), in: DB, 55. Jg. (2002), Heft 46, S. I.

Herzig, Norbert, Steuergestaltung im Binnenmarkt, in: DB, 46. Jg. (1993), S. 1-7.

Herzig, Norbert/Bär, Michaela, Die Zukunft der steuerlichen Gewinnermittlung im Licht des europäischen Bilanzrechts, in: DB, 56. Jg. (2003), S. 1-8.

Herzig, Norbert/Dautzenberg, Norbert, Auswirkungen der Internationalisierung der Rechnungslegung auf die Steuerbilanz, in: BFuP, 50. Jg. (1998), S. 23-37.

Herzig, Norbert/Dautzenberg, Norbert, Steuergestaltung und Steuerharmonisierung im Binnenmarkt, Folgen der Fusionsrichtlinie und der Mutter-Tochter-Richtlinie, in: DB, 45. Jg. (1992), S. 1-7.

Herzig, Norbert/Dempfle, Urs, Konzernsteuerquote, betriebliche Steuerpolitik und Steuerwettbewerb, in: DB, 54. Jg. (2002), S. 1-8.

Herzig, Norbert/Gellrich, Kai M./Jensen-Nissen, Lars, IAS/IFRS und steuerliche Gewinnermittlung, in: BFuP, 56. Jg. (2004), S. 550-577.

Herzig, Norbert/Griemla, Stefan, Steuerliche Aspekte der Europäischen Aktiengesellschaft/Societas Europaea (SE), in: StuW, 79. Jg. (2002), S. 55-77.

Herzig, Norbert/Hausen, Guido, Steuerliche Gewinnermittlung durch modifizierte Einnahmenüberschussrechnung - Konzeption nach Aufgabe des Maßgeblichkeitsprinzips, in: DB, 57. Jg. (2004), S. 1-10.

Herzig, Norbert/Wagner, Thomas, Mindestbesteuerung durch die Begrenzung der Verrechnung von Verlustvorträgen, in: WPg, 57. Jg. (2004), S. 53-64.

Herzig, Norbert/Wagner, Thomas, Zukunft der Organschaft im EG-Binnenmarkt, in: DB, 58. Jg. (2005), S. 1-9. 
Hey, Johanna, Besteuerung von Unternehmensgewinnen und Rechtsformneutralität, in: Besteuerung von Einkommen, hrsg. von Ebling, Iris, DStJG, Bd. 24, Köln 2001, S. 155-223.

Hey, Johanna, Einführung zum KStG, in: Herrmann/Heuer/Raupach, Einkommensteuer- und Körperschaftsteuergesetz, Kommentar, 21. Aufl., Köln 1996 (Loseblattsammlung), hier: Lfg. 196, September 1999.

Hey, Johanna, Harmonisierung der Unternehmensbesteuerung in Europa: Ein Vorschlag unter Auswertung des Ruding-Berichts und der US-amerikanischen ,integration debate“, Köln 1997.

Hey, Johanna, Perspektiven der Unternehmensbesteuerung in Europa, in: StuW, 81. Jg. (2004), S. 193-211.

HFA (Hauptfachausschuss) des IDW, Entwurf IDW Prüfungsstandard: Die Prüfung von Zeitwerten (IDW EPS 315), in: IDW-Fachnachrichten, o. Jg. (2004), Nr. 12/2004, S. 20-28.

HFA (Hauptfachausschuss) des IDW, Stellungnahme HFA 3/76: Zur Bilanzierung von Beteiligungen an Personenhandelsgesellschaften nach aktienrechtlichen Grundsätzen, in: WPg, 29. Jg. (1976), S. 591-594.

Hilton, George W., Regulatory Reform in Transportation: The Basic Behavior of Regulatory Commissions, in: The American Economic Review, Vol. 62 (1972), S. 47-54.

Hiort, Malte J., Einlagen obligatorischer Nutzungsrechte in Kapitalgesellschaften, Problemfall nach Gesellschaftsrecht, Handelsbilanzrecht und Steuerrecht, Frankfurt am Main et al. 2004

Hobbes, Thomas, Leviathan or the Matter, Form, and Power of a Commenwealth, Ecclesiastical and Civil, London 1651 (Reprint 1962).

Hoffmann, A., Die Konzern-Bilanz, Leipzig 1930.

Hoffmann, Wolf-Dieter/Lüdenbach, Norbert, Zur Offenlegung der Ermessensspielräume bei der Erstellung des Jahresabschlusses, in: DB, 56. Jg. (2003), S. 19651969.

Holme, Richard, Groups of Companies, in: Taxation, o. Jg. (24.08.1989), S. 626-630.

Holmstrom, Bengt R./Tirole, Jean, The Theory of the Firm, in: Handbook of Industrial Organization, Vol. 1, hrsg. von Schmalensee, Richard/Willig, Robert D., Amsterdam et al. 1989, S. 61-133.

Hommel, Michael, Neue Goodwillbilanzierung - das FASB auf dem Weg zur entobjektivierten Bilanz?, in: BB, 56. Jg. (2001), S. 1943-1949.

Hommel, Michael/Benkel, Muriel/Wich, Stefan, IFRS 3 Business Combinations: Neue Unwägbarkeiten im Jahresabschluss, in: BB, 59. Jg. (2004), S. 1267-1273. 
Hommelhoff, Peter, Die Konzernleitungspflicht, Zentrale Aspekte eines Konzernverfassungsrechts, Köln et al. 1982.

Hommelhoff, Peter, Konzernrecht für den Europäischen Binnenmarkt, in: ZGR, 21. Jg. (1992), S. 121-141.

Hommelhoff, Peter, Zum Konzernrecht in der Europäischen Aktiengesellschaft, in: AG, 48. Jg. (2003), S. 179-184.

Hommelhoff, Peter, Zwölf Fragen zum Konzernrecht in Europa, in: ZGR, 21. Jg. (1992), S. 422-430.

Hommelhoff, Peter/Hopt, Klaus J./Lutter, Marcus (Hrsg.), Konzernrecht für Europa, Bd. 1: Konzernrecht und Kapitalmarktrecht, München 2001.

Hommelhoff, Peter/Schwab, Martin, Gesellschaftliche Selbststeuerung im Bilanzrecht - Standard Setting Bodies und staatliche Regulierungsverantwortung nach deutschem Recht, in: BFuP, 50. Jg. (1998), S. 38-56.

Hopf, Michael, Informationen für Märkte und Märkte für Informationen, Frankfurt am Main 1983.

Hopt, Klaus J., Der Kapitalanlegerschutz im Recht der Banken: Gesellschafts-, bankund börsenrechtliche Anforderungen an das Beratungs- und Verwaltungsverhalten der Kreditinstitute, München 1975.

Hopt, Klaus J./Will, Michael R., Europäisches Insiderrecht: Einführende Untersuchung - Ausgewählte Materialien, Stuttgart 1973.

Hübl, Leo, Die körperschaftsteuerrechtliche Organschaft und das neue Konzernrecht, in: BB, 20. Jg. (1965), S. 53-57.

Hueck, Götz/Windbichler, Gesellschaftsrecht, Ein Studienbuch, 20. Aufl., München 2003.

Hulle, Karel van, Die Reform des europäischen Bilanzrechts: Stand, Ziele und Perspektiven, in: ZGR, 29. Jg. (2000), S. 537-549.

Hundsdoerfer, Jochen, Die einkommensteuerliche Abgrenzung von Einkommenserzielung und Konsum, Eine einzelwirtschaftliche Analyse, Wiesbaden 2002.

Hundsdoerfer, Jochen, Die Steuerhinterziehung und ihre Integration in betriebswirtschaftliche Entscheidungsmodelle, Eine Wirkungsanalyse, Köln 1996.

IASB (International Accounting Standards Board), Business Combinations (Phase II) - Application of the Purchase Method, Project Summary, revised January 26, 2004, URL: http://www.iasb.org/current/iasb.asp?showPageContent=no\&utility_ catID $=2$ (18.4.2004).

IASB (International Accounting Standards Board), Business Combinations (Phase II) Purchase Method Procedures, Project Update, revised November 1, 2004, URL: http://www.iasb.org/current/iasb.asp?showPageContent=no\&xml=16_10_67 _06012004.htm (5.1.2005). 
IASB (International Accounting Standards Board), IASB Project Timetable, last update March 1, 2004, URL: http://www.iasb.org/current/timetable.asp (18.4.2004).

IASB (International Accounting Standards Board), IASB Update, June 2004.

IASB (International Accounting Standards Board), Project Summary - Business Combinations Phase I, last updated November 18, 2003, URL: http:/www.iasb.org/ current/iasb.asp?showPageContent $=$ no\&utility_catID=2 (18.4.2004).

IASB (International Accounting Standards Board), Project Summary - Consolidation (including Special Purpose Entities), last revised 2004/05/31, URL: http://www. iasb.org/uploaded_files/documents/16_12_spe-ps.pdf (23.7.2004).

IASB (International Accounting Standards Board), Project Summary - Consolidation (including Special Purpose Entities), revised November 23, 2004, URL: http:// www.iasb.org/current/iasb.asp?showPageContent $=$ no\&xml=16_10_67_3105 2004.htm (5.1.2005).

IASB (International Accounting Standards Board), Reporting Comprehensive Income, Project Update, revised September 9, 2003, URL: http://www.iasb.org/uploaded_files/documents/16_19_rci-ps.pdf (7.9.2004).

IASCF (International Accounting Standards Committee Foundation), Annual Report 2003, London 2004, URL: http://www.iasb.org/uploaded_files/documents/8_24_ar2003.pdf (26.08.2004).

IFS (The Institute for Fiscal Studies) Capital Taxes Group, Equity for Companies: A Corporation Tax for the 1990s, IFS Commentary No. 26, London (April) 1991.

Inland Revenue (HM Treasury), Reform of Corporation Tax, A consultation document, London August 2002.

Inland Revenue (HM Treasury), The strength to take the long-term decisions for Britain: Seizing the opportunities of the global recovery, Pre-Budget Report, Presented to Parliament by the Chancellor of the Exchequer by Command of Her Majesty, London December 2003.

Ipsen, Dirk, Zum Erklärungspotential von Williamsons Theorie der Wahl von Governance-Formen, Was lernen wir aus den empirischen Untersuchungen?, in: Institutionenökonomie, Theoretische Konzeptionen und empirische Studien, Frankfurt am Main 2002, S. 67-78.

Isay, Rudolf, Das Recht am Unternehmen, Berlin 1910.

Jachmann, Monika, Besteuerung von Unternehmen als Gleichheitsproblem, Unterschiedliche Behandlung von Rechtsformen, Einkunftsarten, Werten und Steuersubjekten im Ertrag- und Erbschaftsteuerrecht, in: Europa- und verfassungsrechtliche Grenzen der Unternehmensbesteuerung, hrsg. von Pelka, Jürgen, DStJG, Bd. 23, Köln 2000, S. 9-65. 
Jacobs, Otto H. (Hrsg.), Internationale Unternehmensbesteuerung, Deutsche Investitionen im Ausland, Ausländische Investitionen im Inland, bearbeitet von Jacobs, Otto H./Endres, Dieter/Spengel, Christoph, 5. Aufl., München 2002.

Jacobs, Otto H., Das Bilanzierungsproblem in der Ertragsteuerbilanz, Ein Beitrag zur steuerlichen Lehre vom Wirtschaftsgut, Stuttgart 1971.

Jacobs, Otto H., Stand und Entwicklungstendenzen der Betriebswirtschaftlichen Steuerlehre, in StuW, 81. Jg. (2004), S. 251-259.

Jacobs, Otto H./Spengel, Christoph, Ertragsbesteuerung von Konzernen in Deutschland und Frankreich - Eine vergleichende Analyse unter besonderer Berücksichtigung der Behandlung konzerninterner Transaktionen (Teil I und II), in: IStR, 3. Jg. (1994), S. 100-104, 146-151.

Jacobs, Otto H./Spengel, Christoph/Finkenzeller, Martin/Roche, Matthias, Company Taxation in the New EU Member States, Survey of the Tax Regimes and Effective Tax Burdens for Multinational Investors, Study by Ernst\&Young and the Centre for European Economic Research (ZEW), Frankfurt am Main et al. 2003.

Jehnert, Hansgeorg, Der Staat sollte erst bei der Entnahme des Gewinns zugreifen, in: FAZ, Nr. 1 vom 2.1.2004, S. 13.

Jensen, Michael C./Meckling, William H., Theory of the Firm: Managerial Behavior, Agency Costs and Ownership Structure, in: Journal of Financial Economics, Vol. 3 (1976), S. 305-360.

Jeter, Debra C./Chaney, Paul K., Advanced Accounting, New York et al. 2001.

Johansson, Sven-Erik, Income Taxes and Investment Decisions, in: Swedish Journal of Economics, Vol. 71 (1969), S. 104-110.

Johnson, Charles E., A Case Against the Idea of an All-Purpose Concept of Business Income, in: The Accounting Review, Vol. 29 (1954), S. 224-243.

Johnson, L. Todd/Petrone, Kimberley R., Is Goodwill an Asset?, in: Accounting Horizons, Vol. 12 (1998), S. 293-303.

Jonas, Bernd, Abschaffung der Mehrmütterorganschaft und Ersatzlösungen, in: Organschaft: laufende und aperiodische Besteuerung - nationale und internationale Aspekte - Hinweise zum EU-Recht, hrsg. von Herzig, Norbert, Stuttgart 2003, S. 306-320.

Kahle, Holger, Der kapitaltheoretische Gewinn als entscheidungsneutrale Steuerbemessungsgrundlage, in: WiSt, 24. Jg. (1995), S. 214-218.

Kahle, Holger, Europarechtliche Einflüsse auf den Maßgeblichkeitsgrundsatz, in: StuW, 78. Jg. (2001), S. 126-136.

Kahle, Holger, Internationale Rechnungslegung und ihre Auswirkungen auf Handelsund Steuerbilanz, Wiesbaden 2002. 
Kahle, Holger, Maßgeblichkeitsgrundsatz auf Basis der IAS?, in: WPg, 55. Jg. (2002), S. 178-188.

Kahle, Holger, Steuerliche Konsequenzen der Trennung handels- und steuerrechtlicher Rechnungslegung in den USA, in: StuW, 74. Jg. (1997), S. 323-332.

Kahle, Holger, Zur Zukunft der Rechnungslegung in Deutschland: IAS im Einzelund Konzernabschluss?, in: WPg, 56. Jg. (2003), S. 262-275.

Kant, Immanuel, Über den Gemeinspruch: Das mag in der Theorie richtig sein, taugt aber nicht für die Praxis, Königsberg 1793 (in: Immanuel Kant, Werke in zehn Bänden, hrsg. von Weischedel, Wilhelm, Bd. 9: Schriften zur Anthropologie, Geschichtsphilosophie, Politik und Pädagogik, Erster Teil, Darmstadt 1968, S. 125172 (A 201-A 284)).

Kasperzak, Rainer, Netzwerkorganisationen und das Konzept der rechnungslegenden Einheit, in: ZfB, 74. Jg. (2004), S. 223-247.

Kaulmann, Thomas, property rights und Unternehmungstheorie, Stand und Weiterentwicklung der empirischen Forschung, München 1987.

Keitz, Isabel von, Immaterielle Güter in der internationalen Rechnungslegung, Grundsätze für den Ansatz von immateriellen Gütern in Deutschland im Vergleich zu den Grundsätzen in den USA und nach IASC, Düsseldorf 1997.

Kerber, Wolfgang, Zum Problem einer Wettbewerbsordnung für den Systemwettbewerb, in: Globalisierung, Systemwettbewerb und nationalstaatliche Politik, Jahrbuch für neue politische Ökonomie, Bd. 17, Tübingen 1998, S. 199-230.

Ketterer, Thilo, Die Gestaltung der Besteuerung im Konzern bei Divisionalisierung und Internationalisierung, Quantifizierung der Besteuerungseffekte unter besonderer Berücksichtigung der Organschaft, Diss. Bochum 1997.

King, Mervyn A./Fullerton, Don, The Taxation of Income from Capital, A Comparative Study of the United States, the United Kingdom, Sweden, and West Germany, Chicago et al. 1984.

Kirchhof, Ferdinand, Der Weg zur verfassungsgerechten Besteuerung, Bestand, Fortschritt, Zukunft, in: StuW, 79. Jg. (2002), S. 185-200.

Kirchhof, Paul, Das EStGB - ein Vorschlag zur Reform des Ertragsteuerrechts, in: DStR, 41. Jg. (2003), Beihefter 5 zu Heft 37.

Kirchhof, Paul, Der verfassungsrechtliche Auftrag zur Besteuerung nach der finanziellen Leistungsfähigkeit, in: StuW, 62. Jg. (1985), S. 319-329.

Kirchhof, Paul, Empfiehlt es sich, das Einkommensteuerrecht zur Beseitigung von Ungleichbehandlungen und zur Vereinfachung neu $\mathrm{zu}$ ordnen?, Gutachten $\mathrm{F}$ für den 57. Deutschen Juristentag, in: Verhandlungen des Siebenundfünfzigsten Deutschen Juristentages, Bd. I, Teil F, München 1988.

Kirchhof, Paul, Gesetzgebung und private Regelsetzung als Geltungsgrund für Rechnungslegungspflichten?, in: ZGR, 29. Jg. (2000), S. 681-692. 
Kirsch, Hanno, Bedeutung der Maßgeblichkeit bei fortschreitender Internationalisierung der Rechnungslegung, in: Betrieb und Wirtschaft, 58. Jg. (2004), S. 221-227.

Kirsch, Hanno, Berichterstattung nach IAS 1 (revised 2003) über Ermessensspielräume beim Asset Impairment für operative Vermögenswerte und zahlungsmittelgenerierende Einheiten, Verbesserung der Informationsqualität des IFRSJahresabschlusses, in: KoR, 4. Jg. (2004), S. 136-141.

Kirsch, Hans-Jürgen, Die Equity-Methode im Konzernabschluß, Der Charakter der deutschen Regelungen vor dem Hintergrund der internationalen Entwicklung, Düsseldorf 1990.

Kirzner, Israel M., Unternehmer und Marktdynamik, München et al. 1988.

Kirzner, Israel M., Wettbewerb und Unternehmertum, Tübingen 1978.

Kischel, Dieter, Übersicht über die direkten Steuern Portugals, in: IWB, Fach 5 (Portugal), Gruppe 2, S. 77-86 (Loseblattsammlung, Lieferung IWB Nr. 7 vom 12.4.2000).

Kiwit, Daniel/Voigt, Stefan, Grenzen des institutionellen Wettbewerbs, in: Globalisierung, Systemwettbewerb und nationalstaatliche Politik, Jahrbuch für neue politische Ökonomie, Bd. 17, Tübingen 1998, S. 313-337.

Klein, Benjamin/Crawford, Robert G./Alchian, Armen A., Vertical Integration, Appropriable Rents, and the Competitive Contracting Process, in: Journal of Law and Economics, Vol. 21 (1978), S. 297-326.

Kley, Karl-Ludwig, Die Fair Value-Bilanzierung in der Rechnungslegung nach den International Accounting Standards (IAS), in: DB, 54. Jg. (2001), S. 2257-2262.

Knobbe-Keuk, Brigitte, Bilanz- und Unternehmenssteuerrecht, 9. Aufl., Köln 1993.

Knobbe-Keuk, Brigitte, Die beiden Unternehmenssteuerrichtlinien, Insbesondere die Missbrauchsklauseln und die Mängel der deutschen Umsetzung, in: Europäische Zeitschrift für Wirtschaftsrecht (EuZW), 3. Jg. (1992) S. 336-343.

Koch, Hans-Dieter/Schmidt, Reinhard H., Ziel und Instrumente des Anlegerschutzes, in: BFuP, 33. Jg. (1981), S. 231-250.

Kofler, Herbert, Steuerstrukturanpassung durch Steuerwettbewerb und Besteuerungsprinzipien, in: Anpassungsprozesse in Wirtschaft und Recht, Europäische Union: Rechnungslegung und Steuern (Festschrift Hans Lexa), hrsg. von Djanani, Christiana/Kofler, Herbert/Steckel, Rudolf, Wien 1995, S. 499-513.

Kogut, Bruce/Zander, Udo, Knowledge of the Firm, Combinative Capabilities, and the Replication of Technology, in: Organization Science, Vol. 3 (1992), S. 383-397.

Köhler, Hans-Georg, Die Besteuerung von Konzern und Kartell als typische Form von Betriebszusammenschlüssen aus betriebswirtschaftlicher Sicht, Diss. Saarbrücken 1970. 
Kommission Rechnungswesen im Verband der Hochschullehrer für Betriebswirtschaft e.V., Stellungnahme zur Umsetzung der 7. EG-Richtlinie (KonzernabschlußRichtlinie), in: DBW 45. Jg. (1985), S. 267-277.

König, Rolf, Theoriegestützte betriebswirtschaftliche Steuerwirkungs- und Steuerplanungslehre, in: StuW, 81. Jg. (2004), S. 260-266.

König, Rolf, Ungelöste Probleme einer investitionsneutralen Besteuerung - Gemeinsame Wurzel unterschiedlicher neutraler Steuersysteme und die Berücksichtgung unsicherer Erwartungen, in: ZfbF, 49. Jg. (1997), S. 42-63.

König, Rolf, Wirtschaftliche Effizienz und Steuerreformen, Heidelberg 1997.

Koop, Michael J., Zur Gewinnbesteuerung von Körperschaften in der Europäischen Gemeinschaft, Tübingen 1993.

Kosiol, Erich, Pagatorische Bilanz, Die Bewegungsbilanz als Grundlage einer integrativ verbundenen Erfolgs-, Bestands- und Finanzrechnung, Berlin 1976.

Koths, Daniel, Qualifizierung als Organträger, in: Organschaft: laufende und aperiodische Besteuerung - nationale und internationale Aspekte-Hinweise zum EURecht, hrsg. von Herzig, Norbert, Stuttgart 2003, S. 63-82.

Kraft, Cornelia, Steuergerechtigkeit und Gewinnermittlung, Eine vergleichende Analyse des deutschen und US-amerikanischen Steuerrechts, Wiesbaden 1991.

Krause-Junk, Gerold, Steuern IV: Verteilungslehren, in: Handwörterbuch der Wirtschaftswissenschaft, hrsg. von Albers, Willi et al., Bd. 7, Stuttgart et al. 1977, S. 332-356.

Krawitz, Norbert/Klotzbach, Daniela, Anwendungsvoraussetzungen und Aussagefähigkeit der Fresh-Start-Methode bei der Bilanzierung von Unternehmenszusammenschlüssen, in: WPg, 53. Jg. (2000), S. 1164-1180.

Krawitz, Norbert/Leukel, Stefan, Die Abbildung von Unternehmensfusionen in der Rechnungslegung, Rechtliche Möglichkeiten und Analyse ausgewählter Fälle mit deutscher Beteiligung, in: KoR, 1. Jg. (2001), S. 91-106.

Krebühl, Hans-Herbert, Beteiligung an ausländischen Gesellschaften - Möglichkeiten und Grenzen des $§ 8 \mathrm{~b} \mathrm{KStG}$, in: DB, 47. Jg. (1994), S. 496-502.

Krebühl, Hans-Herbert, Konzernbesteuerung de lege ferenda, in: Organschaft: laufende und aperiodische Besteuerung-nationale und internationale Aspekte Hinweise zum EU-Recht, hrsg. von Herzig, Norbert, Stuttgart 2003, S. 595-611.

Krebühl, Hans-Herbert, Reform der körperschaftsteuerlichen und gewerbesteuerlichen Organschaft, in: DB, 48. Jg. (1995), S. 743-748.

Kreile, Reinhold, Zum Vorentwurf einer EG-Richtlinie über die Harmonisierung der steuerrechtlichen Gewinnermittlungsvorschriften, in: DB, 41. Jg. (1988), Beilage Nr. 18. 
Kröner, Michael, Verrechnungsbeschränkte Verluste im Ertragsteuerrecht, Materiellrechtliche Grundlagen und systematische Gestaltungssuche, Wiesbaden 1986.

Kropff, Bruno, Aktiengesetz, Textausgabe des Aktiengesetzes vom 6.9.1965 (Bundesgesetzbl. I S. 1089) und des Einführungsgesetzes zum Aktiengesetz vom 6.9.1965 (Bundesgesetzbl. I S. 1185) mit Begründung des Regierungsentwurfs, Bericht des Rechtsausschusses des Deutschen Bundestags, Verweisungen und Sachverzeichnis, Düsseldorf 1965.

Kroppen, Heinz-Klaus/Rasch, Stephan, Die Reformierung der Unternehmensbesteuerung in der Europäischen Union, Analyse des Berichts der EU-Kommission vom 23.10.2001 (Teil I), in: IWB (Fach 11 (Europäische Gemeinschaften), Gruppe 2, S. 495-506 (Loseblattsammlung, Lieferung IWB Nr. 21 vom 13.11.2002).

Kübler, Friedrich, Gesellschaftsrecht, Die privatrechtlichen Ordnungsstrukturen und Regelungsprobleme von Verbänden und Unternehmen, 5. Aufl., Heidelberg 1999.

Kümmel, Jens, Grundsätze für die Fair Value-Ermittlung mit Barwertkalkülen, Eine Untersuchung auf der Grundlage des Statement of Financial Accounting Concepts No. 7, Düsseldorf 2002.

Kumpf, Wolfgang, Steuerliche Verrechnungspreise in internationalen Konzernen, Möglichkeiten zur Präzisierung des “dealing at arm's length“-Prinzips, Frankfurt am Main 1976.

Kunz, Harald, Marktsystem und Information: ,Konstitutionelle Unwissenheit' als Quelle von ,Ordnung', Tübingen 1985.

Kußmaul, Heinz/Klein, Nicole, Überlegungen zum Maßgeblichkeitsprinzip im Kontext jüngerer nationaler sowie internationaler Entwicklungen, in: DStR, 39. Jg. (2001), S. 546-550.

Küting, Karlheinz, Aktuelle Fragen der Kapitalkonsolidierung (Teil I und II), in: DStR, 33. Jg (1995), S. 192-196, 229-235.

Küting, Karlheinz, Ein erneutes Plädoyer für eine Einheitsbesteuerung, Fortschrittliches Konzernrechnungswesen als Grundlage einheitlicher Konzernbesteuerung, in: DB, 43. Jg. (1990), S. 489-497.

Küting, Karlheinz, Rechnungslegung im Umbruch - Ein Plädoyer für ein Rechnungswesen des Konzerns, in: Das Konzernrechnungswesen des Jahres 2000, hrsg. von Küting, Karlheinz/Weber, Claus-Peter, Stuttgart 1991, S. 3-39.

Küting, Karlheinz, Zur Poblematik des Ausgleichspostens für Anteile in Fremdbesitz im Rahmen des zukünftigen Konzernbilanzrechts, in: ZfB, 54. Jg. (1984), S. 548568.

Küting, Karlheinz/Müller, Wolfgang/Pilhofer, Jochen, ,Reverse Acquisitions' als Anwendungsfall einer ,Reverse Consolidation' bei der Erstellung von Konzernabschlüssen nach US-GAAP und IAS - ein Leitbild für die deutsche Rechnungslegung?, in: WPg, 53. Jg. (2000), S. 257-269. 
Küting, Karlheinz/Wirth, Johannes, Bilanzierung von Unternehmenszusammenschlüssen nach IFRS 3, in: KoR, 4. Jg. (2004), S. 167-177.

Küting, Karlheinz/Wirth, Johannes, Umrechnung von Fremdwährungsabschlüssen vollzukonsolidierender Unternehmen nach IAS/IFRS, in: KoR, 3. Jg. (2003), S. 376-387.

Küting, Karlheinz/Zündorf, Horst, $\$ 312$, in: Handbuch der Konzernrechnungslegung, Kommentar zur Bilanzierung und Prüfung, Bd. II, hrsg. von Küting, Karlheinz/Weber, Claus-Peter, 2. Aufl., Stuttgart 1998.

Küting, Karlheinz/Zündorf, Horst, Die Ermittlung der Minderheitenanteile im Rahmen der Buchwert- und der Neubewertungsmethode des künftigen Konzernbilanzrechts, in: BB., 40. Jg. (1985), S. 1166-1173.

Laffont, Jean-Jacques/Martimort, David, The firm as a multicontract organization, in: Journal of Economics and Management Strategy, Vol. 6 (1997), S. 201-234.

Lamb, Margaret, When is a group a group? Convergence of concepts of 'group' in European Union corporate tax, in: The European Accounting Review, Vol. 4 (1995), S. 33-78.

Lang, Joachim, Besteuerung in Europa zwischen Harmonisierung und Differenzierung, in: Unternehmen Steuern (Festschrift Hans Flick), hrsg. von Klein, Franz/Stihl, Hans P./Wassermeyer, Franz zusammen mit Piltz, Detlev/Schaumburg, Harald, Köln 1997, S. 873-894.

Lang, Joachim, Die Bemessungsgrundlage der Einkommensteuer, in: Besteuerung von Einkommen: Rechtsvergleich Italien, Deutschland und Spanien als Beitrag zur Harmonisierung des Steuerrechts in Europa, hrsg. von Tipke, Klaus/Bozza, Nadya, Berlin 2000, S. 123-151.

Lang, Joachim, Die einfache und gerechte Einkommensteuer, Ziele, Chancen und Aufgaben einer Fundamentalreform, Köln 1987.

Lang, Joachim, Konsumorientierung - eine Herausforderung für die Steuergesetzgebung?, in: Einkommen versus Konsum, Ansatzpunkte zur Steuerreformdiskussion, hrsg. von Smekal, Christian/Sendlhofer, Rupert/Winner, Hannes, Heidelberg 1999, S. 143-166.

Lang, Joachim, Reform der Unternehmensbesteuerung auf dem Weg zum europäischen Binnenmarkt und zur deutschen Einheit, in: StuW, 67. Jg. (1990), S. 107129.

Langlois, Richard N./Robertson, Paul L., Firms, Markets and Economic Change, A Dynamic Theory of Business Institutions, London et al. 1995.

Larbig, Gregor, Perspektiven des europäischen Steuerwettbewerbs, in: Wirtschaftsdienst, 12. Jg. (1998), S. 743-749. 
Lechner, Eduard, Voraussetzungen für eine zusammengefaßte Besteuerung von Unternehmensgruppen in Österreich, in: Aktuelle Fragen der Finanzwirtschaft und der Unternehmensbesteuerung (Festschrift Erich Loitlsberger), hrsg. von Rückle, Dieter, Wien 1991, S. 389-397.

Leffson, Ulrich, Die Grundsätze ordnungsmäßiger Buchführung, 7. Aufl., Düsseldorf 1987.

Lehertshuber, Bonaventura, Unternehmensvertragsrecht und Konzernhandelsbilanz, Frankfurt a. M. 1986.

Lev, Baruch, On the Usefulness of Earnings and Earnings Research: Lessons and Directions from Two Decades of Empirical Research, in: Journal of Accounting Research, Vol. 20 (1989), Supplement, S. 153-192.

Li, David H., Alternative Accounting Procedures and the Entity Concept, in: The Accounting Review, Vol. 38 (1963), S. 52-55.

Linnhoff, Ulrich/Pellens, Bernhard, Ausschüttungspolitik deutscher Konzerne, Eine empirische Untersuchung zum Ausschüttungsverhalten deutscher Konzernobergesellschaften, in: ZfbF, 39. Jg. (1987), S. 987-1006.

Lion, Max, Das Bilanzsteuerrecht, Eine grundlegende Darstellung, 2. Aufl., Berlin 1923.

Lion, Max, Der Einkommensbegriff nach dem Bilanzsteuerrecht und die Schanzsche Einkommenstheorie, in: Festgabe für Georg von Schanz zum 75 Geburtstag, Bd. II (Beiträge zur Finanzwissenschaft, Bd. II), hrsg. von Teschemacher, Hans, Tübingen 1928, S. 273-300.

Lischer, Henry J./Märkl, Peter N., Conformity between Financial Accounting and Tax Accounting in the United States and Germany, in: WPK-Mitteilungen, 36. Jg. (1997), Sonderheft Juni, S. 91-119.

Littmann, Konrad, Ein Valet dem Leistungsfähigkeitsprinzip, in: Theorie und Praxis des finanzpolitischen Interventionismus (Festschrift Fritz Neumark), hrsg. von Haller, Heinz et al., Tübingen 1970, S. 113-134.

Loch, Carsten, Die Proprietary-Theorie, in: DBW, 54. Jg. (1994), S. 272-273.

Lodin, Sven-O./Gammie, Malcom, Home State Taxation, Tax Treaty Aspects, IBFD Research Department, Amsterdam 2001.

Lorensen, Leonard, The Temporal Principle of Translation, in: Journal of Accountancy, Vol. 134 (Aug. 1972), S. 48-54.

Lüdenbach, Norbert/Hoffmann, Wolf-Dieter, Strukturelle Probleme bei der Implementierung des Goodwill-Impairment-Tests, Der Ansatz von IAS 36 im Vergleich zu US-GAAP, in: WPg, 57. Jg. (2004), S. 1068-1077.

Lutter, Bernd/Rimmelspacher, Dirk, Einheitstheorie und Kapitalkonsolidierung mehr Konflikt als Konsens?, in: DB, 45. Jg. (1992), S. 485-491. 
Lutter, Marcus, Der Vorschlag der EG-Kommission für eine neunte Richtlinie zur Angleichung des Konzernrechts, in: ZGR, 14. Jg. (1985), S. 444-465.

Lutter, Marcus, Die zivilrechtliche Haftung in der Unternehmensgruppe, in: ZGR, 11. Jg. (1982), S. 244-275.

Lutter, Marcus, Diskussionsbeitrag, in: Reichen die Vorschriften des Steuerrechts - unter Berücksichtigung des Gesellschaftsrechts - aus, um Vermögensbewegungen zwischen verbundenen Unternehmen vollständig und befriedigend zu regeln?, Verhandlungen des Neunundvierzigsten Deutschen Juristentages, Düsseldorf 1972, Bd. II (Sitzungsberichte), Teil Q, München 1972, S. Q 55-Q 59.

Lutter, Marcus, Entwicklungen und Tendenzen im Konzerngesellschaftsrecht, in: Steuerrecht und steuerorientierte Gestaltung im Konzern, Kölner Konzernrechtstage, hrsg. von Schaumburg, Harald, Köln 1998, S. 61-84.

Lutter, Marcus, Organisationszuständigkeiten im Konzern, in: Festschrift für Walter Stimpel zum 68. Geburtstag am 29. November 1985, hrsg. von Lutter, Marcus/Mertens, Hans-Joachim/Ulmer, Peter, Berlin et al. 1985, S. 825-854.

Lutter, Marcus, Zur Aufgabe eines Konzernrechts: Schutz vor Missbrauch oder Organisationsrecht?, in: Das St. Galler Konzernrechtsgespräch, Konzernrecht aus der Konzernwirklichkeit, hrsg. von Druey, Jean Nicolas, Bern et al. 1988, S. 225-233.

Luttermann, Claus, Unternehmen, Kapital und Genussrechte: Eine Studie über Grundlagen der Unternehmensfinanzierung und zum internationalen Kapitalmarktrecht, Tübingen 1998.

Macneil, I. R., Contracts: Adjustments of long-term economic relations under classical, neoclassical, and relational contract law, in: Northwestern University Law Review, Vol. 72 (1978), S. 854-906.

Mann, Fritz Karl, Zur Frage der steuerlichen Lastenverteilung, Eine Ergänzung und Entgegnung, in: Jahrbücher für Nationalökonomie und Statistik, 124. Bd. (1926), S. 30-40.

Marschak, Jacob, Towards an Economic Theory of Organization and Information, in: Decision Processes, hrsg. von Thrall, R. M. et al., New York et al. 1954, S. 187220.

Mavraganis, George, Corporate Income Tax Harmonization in the Nineties, in: Bulletin for International Fiscal Documentation, April 1993; S. 220-225.

McKenzie, Richard B./Tullock, Gordon, Modern Political Economy, An Introduction to Economics, New York et al. 1978.

McLure, Charles, jr., Defining a Unitary Business: An Economist's View, in: The State Corporation Income Tax, Issues in Worldwide Unitary Combination, hrsg. von McLure, Charles E., jr., Stanford 1984, S. 89-124.

McNulty, John K., Struktur der Einkommensteuer und Reformtendenzen der Besteuerung in den Vereinigten Staaten, in: StuW, 66. Jg. (1989), S. 120-137. 
Mehnert, Angelika/Erbsland, Manfred, Zum Begriff der Regulierung: Gegenstand, Träger und Methoden, Discussion Paper Series des Zentrums für Europäische Wirtschaftsforschung, Nr. 93-04, Mannheim 1993.

Menck, Karl Wolfgang/Mutén, Leif, Europäische Steuerpolitik für mehr Wachstumseffizienz, Die Initiative der EU-Kommission für eine konsolidierte einheitliche Körperschaftsteuerbemessungsgrundlage, IFSt-Schrift Nr. 404, Bonn 2003.

Mennel, Annemarie/Förster, Jutta, Das Steuerrecht im internationalen Vergleich, in: Steuern in Europa, Amerika und Asien, hrsg. von Mennel, Annemarie/Förster, Jutta, Loseblattsammlung (Stand: 49. Ergänzungslieferung), Herne et al. Juni 2003, Allgemeiner Teil.

Meßmer, Kurt, "Steuergerechtigkeit" durch Normenflut, offene und verdeckte Subventionen und Entlastung der Finanzgerichtsbarkeit, in: BB, 36. Jg. (1981), Beilage 1.

Mestmäcker, Ernst-Joachim, Verwaltung, Konzerngewalt und Rechte der Aktionäre, Eine rechtsvergleichende Untersuchung nach deutschem Aktienrecht und dem Recht der Corporations in den Vereinigten Staaten, Karlsruhe 1958.

Meyer, Willi, Entwicklung und Bedeutung des Property Rights-Ansatzes in der Nationalökonomie, in: Property Rights und ökonomische Theorie, hrsg. von Schüller, Alfred, München 1983, S. 1-44.

Milgrom, Paul/Roberts, John, Economics, Organization and Management, Englewood Cliffs 1992.

Mill, John Stuart, Principles of Political Economy with Some of their Applications to Social Philosophy, London 1848 (Faksimile-Ausgabe: Klassiker der Nationalökonomie, Bd. XV und XVI, Düseldorf 1988).

Miller, Benjamin F., Worldwide Unitary Combination: The California Practice, in: The State Corporation Income Tax, Issues in Worldwide Unitary Combination, hrsg. von McLure, Charles E., jr., Stanford 1984, S. 132-166.

Miller, Gary J., Managerial Dilemmas, The Political Economy of Hierarchy, Cambridge, Ma. 1992.

Mintz, Jack M., Company Taxation and the Internal Market, European Company Tax Reform: Prospects for the Future, in: CESifo Forum, Vol. 3 (1/2002), S. 3-9.

Mintz, Jack, Corporate Tax Harmonization in Europe: It's all about Compliance, in: International Tax and Public Finance, Vol. 11 (2004), S. 221-234.

Mintz, Jack/Weiner, Joann Martens, Exploring Formula Allocation for the European Union, in: International Tax and Public Finance, Vol. 10 (2003), S. 695-711.

Mises, Ludwig von, Nationalökonomie: Theorie des Handelns und Wirtschaftens, Genf 1940 (unveränderter Nachdruck, München 1980). 
Möhlmann-Mahlau, Thomas/Gerken, Uwe/Grotheer, Simon, IFRS im Einzelabschluss: Konsequenzen für die Unternehmen und die Rechnungslegung, in: StuB, 6. Jg. (2004), S. 920-925.

Molitor, Bruno, Staatsversagen, in: Hamburger Jahrbuch für Wirtschafts- und Gesellschaftspolitik, 36. Jahr, hrsg. von Kantzenbach, Erhard et al., Tübingen 1991, S. 5569.

Moonitz, Maurice, The Entity Theory of Consolidated Statements, 2. Aufl., Brooklyn 1951 (Reprint 1978).

Mors, Matthias, Roundtable Discussion on the European Commission's Study on Company Taxation, Conference on "Corporate and Capital Income Taxation in the European Union", Mons, 7-8th December 2001, Summary, in: CESifo Forum, Vol. 3 (1/2002), S. 21-23.

Moxter, Adolf, Bilanzlehre, Bd. I: Einführung in die Bilanztheorie, 3. Aufl., Wiesbaden 1984.

Moxter, Adolf, Bilanzlehre, Bd. II: Einführung in das neue Bilanzrecht, 3. Aufl., Wiesbaden 1986.

Moxter, Adolf, Bilanzrechtsprechung, 5. Aufl., Tübingen 1999.

Moxter, Adolf, Zum Verhältnis von Handelsbilanz und Steuerbilanz, in: BB, 52. Jg. (1997), S. 195-199.

Mühlschlegel, Gustav, Die steuerliche Gewinnermittlung für Konzerne, Die Organschaftsbesteuerung in Deutschland, Die konsolidierten Steuererklärungen in den USA, Gewinnermittlung mit Konzernsteuerbilanzen, Diss. Mannheim 1971.

Mülbert, Peter O., Aktiengesellschaft, Unternehmensgruppe und Kapitalmarkt, Die Aktionärsrechte bei Bildung und Umbildung einer Unternehmensgruppe zwischen Verbands- und Anlegerschutzrecht, 2. Aufl., München 1996.

Müller, Christian, Der ,Schleier des Nichtwissens“ und der „Schleier der Unsicherheit“", in: WiSt, 26. Jg (1997), S. 245-247.

Müller, Eberhard, Der Einfluß des Bilanzrichtlinie-Gesetzes auf die Daten zur Steuerung eines Konerns, in: DB, 38. Jg. (1985), S. 241-247.

Müller, Lothar, Die Konzerne im Handels- und Steuerrecht, in: DStR, 13. Jg. (1975), S. 3-18.

Müller, Michael, Reform der Konzernbesteuerung in Österreich, Eine zusammengefaßte Besteuerung von Unternehmensgruppen, Wien 1991.

Müller, Michael, Voraussetzungen einer Gruppenbildung, in: Besteuerung von Unternehmensgruppen, in: Besteuerung von Unternehmensgruppen, Bestandsaufnahme und Vorschläge zur Reform der Organschaft im Körperschaftsteuerrecht, hrsg. von Gassner, Wolfgang/Lang, Michael/Wiesner, Werner, Wien 1998, S. 29-49. 
Müller, Rolf, Konzernsteuerquote - Modephänomen oder ernst zu nehmende neue Kennziffer?, in: DStR, 40. Jg. (2002), S. 1684-1688.

Müller, Welf, Die Ausnahme und die Regel - Ein Lehrstück, dargestellt am so genannten Maßgeblichkeitsprinzip, in: DStR, 39. Jg. (2001), S. 1858-1864.

Müller-Gatermann, Gert, Überlegungen zur Änderung der Organschaftsbesteuerung, in: Steuerrecht, Steuer- und Rechtspolitik, Wirtschaftsrecht und Unternehmensverfassung, Umweltrecht (Festschrift Wolfgang Ritter), hrsg. von Kley, M. D./Sünner, E./Willemsen, A., Köln 1997, S. 457-473.

Musgrave, Peggy B., Principles for Dividing the State Corporate Tax Base, in: The State Corporation Income Tax, Issues in Worldwide Unitary Combination, hrsg. von McLure, Charles E., jr., Stanford 1984, S. 228-246.

Musgrave, Richard A., Criteria for Foreign Tax Credit, in: Taxation and Operations Abroad, A Symposium Conducted by the Tax Institute, December 3-4, 1959, Princeton, N. J. 1960, S. 83-93.

Musgrave, Richard A., The Theory of Public Finance, A Study in Public Economy, New York et al. 1959.

Musgrave, Richard A./Musgrave, Peggy B., Public Finance in Theory and Practice, 5. Aufl., New York et al. 1989.

Müssener, Ingo, Niederlande, in: Steuern in Europa, Amerika und Asien, hrsg. von Mennel, Annemarie/Förster, Jutta, Ordner II, Herne et al. 2002 (47. Lieferung).

Mutze, Otto, Konzernabschluß und körperschaftsteuerliche Organschaft, Erwägungen zur Steuervereinfachung, in: DB, 24. Jg. (1971), S. 1329-1331.

Nef, Robert, Popper contra Hayek?, in In memoriam Friedrich August von Hayek (1899 - 1992), Schweizer Monatshefte für Politik, Wirtschaft, Kultur, 92. Jg. (1992), Sonderheft Nr. 5a, S. 106-109.

Nelson, Richard R./Winter, Sidney G., An Evolutionary Theory of Economic Change, Cambridge, Mass. et al. 1982.

Nenova, Tatiana, The Value of Corporate Voting Rights and Control: A CrossCountry Analysis, in: Journal of Financial Economics, Vol. 68 (2003), S. 325-351.

Neumark, Fritz, Grundsätze gerechter und ökonomisch rationaler Steuerpolitik, Tübingen 1970 .

Neumark, Fritz, Wirtschafts- und Finanzprobleme des Interventionsstaates, Tübingen 1961.

Niehus, Rudolf J., „Auch für Einzelabschlüsse gelten grundsätzlich die IAS“?, Ein Beitrag zu den (möglichen) Grenzen einer „Internationalisierung" der Rechnungslegung im Einzelabschluss, in: WPg, 54. Jg. (2001), S. 737-752.

Niemann, Rainer/Bachmann, Mark/Knirsch, Deborah, Was leisten die Effektivsteuersätze des European Tax Analyzer?, in: DBW, 63. Jg. (2003), S. 123-137. 
Niemann, Ursula, Probleme der Gewinnrealisierung innerhalb des Konzerns, Düsseldorf 1968.

Nientimp, Axel, Steuerliche Gewinnabgrenzung in internationalen Konzernen, Lohmar et al. 2003.

Niskanen, William A., Bureaucracy and Representative Government, Chicago 1971.

Nobes, Christopher, A Conceptual Framework for the Taxable Income of Businesses, and How to Apply it under IFRS, hrsg. von The Association of Chartered Certified Accountants (ACCA), London 2004.

North, Douglass C., Institutions, Institutional Change and Economic Performance, Cambridge 1990.

Northeast, Mark, Coming together, in: Australian CPA, Vol. 73 (Febr. 2003), S. 7071.

Northeast, Mark, Should your group consolidate?, in: Australian CPA, Vol. 72 (March 2002), S. 74-76.

o.V., „Kurs ist falscher Gradmesser für Gehälter“, in: FAZ, Nr. 201 vom 30.8.2003, S. 19.

o.V., Banken scheuen Mühen der Stimmabgabe, in: FAZ, Nr. 14 vom 17.1.2003, S. 19.

o.V., Die Spanier wollen die ersten sein, in: FAZ, Nr. 141 vom 21.6.2004, S. 2.

o.V., EU-Finanzminister verweigern mehr Geld, in: FAZ, Nr. 17 vom 21.1.2004, S. 11.

o.V., Italienische Steuergesetzgebung, 2004, URL: http://www.investinitaly.de/ bdusteur2.htm (24.08.2004).

o.V., Mehr Verantwortung, in: Handelsblatt, Nr. 22 vom 2.2.2004, S. 6.

o.V., Towards a common tax base, in: Business Europe, May $15^{\text {th }}$ 2002, S. 5.

o.V., Wirtschaft fordert einheitliche Steuerbasis in $\boldsymbol{E} \boldsymbol{U}$, in: Handelsblatt, Nr. 76 vom 19./20.4.2002, S. 7.

Oberender, Peter/Cachej, Monty, Wettbewerb der Systeme, Chancen und Risiken für die europäische Integration, in: WiSt, 28. Jg. (1999), S. 577-581.

Oberndorff, Frank, Reform der Konzernbesteuerung, Notwendigkeit, Möglichkeiten und Auswirkungen, Hamburg 1996.

Oberst, Oskar, Beitrag zur Frage der Konzernbilanz, in: ZfhF, 24. Jg. (1930), S. 209234.

Oberst, Oskar, Konzernbilanz und Wirtschaftsprüfer, in: DBW, 26. Jg. (1933), S. 5976.

OECD (Organisation for Economic Co-operation and Development), The Relationship between Taxation and Financial Reporting, Income Tax Accounting, Report by the Working Group on Accounting Standards, Accounting Standards Harmonization, No. 3, Paris 1987. 
Oechsle, Eberhard/Müller, Klaus/Doleczik, Günter, IAS 21: Auswirkungen von Änderungen der Wechselkurse (The Effects of Changes in Foreign Exchange Rates), in: Rechnungslegung nach International Accounting Standards (IAS), Kommentar auf der Grundlage des deutschen Bilanzrechts, hrsg. von Baetge, Jörg et al., Loseblattsammlung, 2. Aufl., Stuttgart 2002.

Oestreicher, Andreas, Konzernbesteuerung in Europa, Zum Vorschlag einer konsolidierten körperschaftsteuerlichen Bemessungsgrundlage für die grenzüberschreitende Unternehmenstätigkeit in der EU, in: StuW, 79. Jg. (2002), S. 342-356.

Oestreicher, Andreas, Konzern-Gewinnabgrenzung, Gewinnabgrenzung, Gewinnermittlung, Gewinnaufteilung, München 2000.

Oestreicher, Andreas/Schmidt, Frank/Spengel, Christoph, Steuerliche Gewinnermittlung nach internationalen Grundsätzen, Eine EDV-gestützte quantitative Analyse der Belastungs- und Wettbewerbswirkungen, in: StuB, 1. Jg. (1999), S. 10351041.

Oestreicher, Andreas/Spengel, Christoph, Anwendung von IAS in der EU - Zukunft des Maßgeblichkeitsprinzips und Steuerbelastung, in: RIW, 47. Jg. (2001), S. 889902.

Oestreicher, Andreas/Spengel, Christoph, International Accounting Standards, Maßgeblichkeitsprinzip und Besteuerung, in: DB, 52. Jg. (1999), S. 593-600.

Oestreicher, Andreas/Spengel, Christoph, Maßgeblichkeit der International Accounting Standards für die steuerliche Gewinnermittlung, International vergleichenden Analyse der wirtschaftlichen Wirkungen eines Übergangs auf die Rechnungslegung nach den IAS, Baden-Baden 1999.

Oestreicher, Andreas/Spengel, Christoph, Replik auf Fülbier, Rolf Uwe/Gassen, Joachim, Wider die Maßgeblichkeit der International Accounting Standards für die steuerliche Gewinnermittlung, in: DB, 52. Jg. (1999), S. 1513-1516.

Ordelheide, Dieter, Anschaffungskostenprinzip im Rahmen der Erstkonsolidierung gem. § 301 HGB, in: DB, 39. Jg. (1986), S. 493-499.

Ordelheide, Dieter, Bedeutung und Wahrung des Kongruenzprinzips („clean surplus“) im internationalen Rechnungswesen, in: Unternehmensberatung und Wirtschaftsprüfung (Festschrift Günter Sieben), hrsg. von Matschke, Manfred J./Schildbach, Thomas, Stuttgart 1998, S. 515-530.

Ordelheide, Dieter, Der Konzern als Gegenstand betriebswirtschaftlicher Forschung, in: BFuP, 38. Jg. (1986), S. 293-312.

Ordelheide, Dieter, Gefährdung der Nominalkapitalerhaltung durch die Währungsumrechnung von Auslandsinvestitionen, in: ZfbF, 46. Jg. (1994), S. 795-818.

Ordelheide, Dieter, Kapitalkonsolidierung nach der Erwerbsmethode (Teil I und II), Zur Umsetzung der 7. EG-Richtlinie in deutsches Recht, in: WPg, 37. Jg. (1984), S. 237-245, 270-274. 
Ordelheide, Dieter, Kapitalkonsolidierung und Konzernerfolg, in: ZfbF, 39. Jg. (1987), S. 292-301.

Ordelheide, Dieter, Kaufmännischer Periodengewinn als ökonomischer Gewinn, Zur Unsicherheitsrepräsentation bei der Konzeption von Erfolgsgrößen, in: Unternehmenserfolg: Planung - Ermittlung - Kontrolle (Festschrift Walther Busse von Colbe), hrsg. von Domsch, Michel et al., Wiesbaden 1988, S. 275-302.

Ordelheide, Dieter, Konzernerfolgskonzeptionen und Risikokoordination, Grundlagen handels- und steuerrechtlicher Erfolgsermittlung für Konzerne, in: ZfbF, 39. Jg. (1987), S. 975-986.

Orth, Manfred, $\S 8$ Abs. 4 KStG: Verlust der wirtschaftlichen Identität verbundener Unternehmen (Teil I), in: Der Konzern, 1. Jg. (2003), S. 378-393.

Orts, Eric W., Shirking and Sharking: A Legal Theory of the Firm, in: Yale Law \& Policy Review, Vol. 16 (1998), S. 265-329.

Osborne, Michael P., FASB Addresses Purchase Accounting Issues in Joint Project with IASB, in: FASB Status Report, Financial Accounting Series, No. 226, Nov. 30, 2001, S. 3, 6.

Otte, Hans-Heinrich, Notwendigkeit und Ausgestaltung einer Konzernbuchführung nach neuem Recht, in: BB, 43. Jg. (1988), S. 661-666.

Ouchi, William G., Markets, Bureaucracies, and Clans, in: Administrative Science Quarterly, Vol. 25 (1980), S. 129-141.

Palmiter, Alan R., Corporations, Examples and Explanations, 4. Aufl., New York 2003.

Pannen, Michael, Meßtheoretische Grundprobleme des Maßgeblichkeitsprinzips, Lohmar et al. 2000.

Pareto, Vilfredo, Manuale di economia politica, Mailand 1906.

Pawelzik, Kai Udo, Die Konsolidierung von Minderheiten nach IAS/IFRS der Phase II („business combinations“), in: WPg, 57. Jg. (2004), S. 677-694.

Pelka, Jörg, Notwendigkeit und Einrichtung einer eigenen Konzernbuchführung, in: Das Konzernrechnungswesen des Jahres 2000, hrsg. von Küting, Karlheinz/Weber, Claus-Peter, Stuttgart 1991, S. 299-329.

Pelka, Jürgen, Rechtsformneutralität im Steuerrecht, Verfassungsmäßigkeit der Steuersatzsenkung für Kapitalgesellschaften, in: StuW, 77. Jg. (2000), S. 389-398.

Pellens, Bernhard, $\$ 312$, in: Münchener Kommentar zum Handelsgesetzbuch, Bd. 4: Drittes Buch, Handelsbücher, §§ 238-342a HGB, München 2001.

Pellens, Bernhard, Aktionärsschutz im Konzern, Empirische und theoretische Analyse der Reformvorschläge der Konzernverfassung, Wiesbaden 1994. 
Pellens, Bernhard, Berücksichtigung der Aktionärsinteressen bei der Gewinnverwendung im Konzern, in: Unternehmenssicherung und Unternehmensentwicklung, hrsg. von Elschen, Rainer, Stuttgart 1995, S. 162-190.

Pellens, Bernhard, Der Informationswert von Konzernabschlüssen, Eine empirische Untersuchung deutscher Börsengesellschaften, Wiesbaden 1989.

Pellens, Bernhard, Die Anwendung der Equity-Methode auf ausländische assoziierte Mutterunternehmen (Teil I und II), in: DB, 43. Jg. (1990), S. 697-702, 747-751.

Pellens, Bernhard, Internationale Rechnungslegung, 4 Aufl., Stuttgart 2001.

Pellens, Bernhard/Basche, Kerstin/Crasselt, Nils, Eignung des IASB-Vorschlags zur Ergebnisspaltung für die Steuerung von Geschäftsbereichen, in: Finanzintermediation-Theoretische, wirtschaftspolitische und praktische Aspekte aktueller Entwicklungen im Bank- und Börsenwesen (Festschrift Wolfgang Gerke), hrsg. von Bank, Matthias/Schiller, Bettina, Stuttgart 2004, S. 599-613.

Pellens, Bernhard/Basche, Kerstin/Sellhorn, Thorsten, Full Goodwill Method, Renaissance der reinen Einheitstheorie in der Konzernbilanzierung?, in: KoR, 3. Jg. (2003), S. 1-4.

Pellens, Bernhard/Bonse, Andreas/Gassen, Joachim, Perspektiven der deutschen Konzernrechnungslegung, in: DB, 51. Jg. (1998), S. 785-792.

Pellens, Bernhard/Fülbier, Rolf Uwe, Ansätze zur Erfassung immaterieller Werte in der kapitalmarktorientierten Rechnungslegung, in: Zur Rechnungslegung nach International Accounting Standards (IAS), Vorträge und Diskussionen zum 15. Münsterischen Tagesgespräch des Münsteraner Gesprächskreises Rechnungslegung und Prüfung e.V. am 10. Juni 1999, Düsseldorf 2000, S. 35-77.

Pellens, Bernhard/Fülbier, Rolf Uwe, Differenzierung der Rechnungslegungsregulierung nach Börsenzulassung, in: ZGR, 29. Jg. (2000), S. 572-593.

Pellens, Bernhard/Fülbier, Rolf Uwe/Ackermann, Ulrich, International Accounting Standards Committee: Deutscher Einfluß auf Arbeit und Regelungen, in: DB, 49. Jg. (1996), S. 285-291.

Pellens, Bernhard/Fülbier, Rolf Uwe/Gassen, Joachim, Internationale Rechnungslegung, IFRS/IAS mit Beispielen und Fallstudie, 5. Aufl., Stuttgart 2004.

Pellens, Bernhard/Gassen, Joachim Die Bereitstellung von Rechnungslegungssystemen - Eine Aufgabe des Staates oder des Marktes?, in: Rechnungswesen als Instrument für Führungsentscheidungen (Festschrift Adolf G. Coenenberg), hrsg. von Möller, Hans Peter/Schmidt, Franz, Stuttgart 1998, S. 633-649.

Pellens, Bernhard/Gassen, Joachim/Richard, Marc, A usschüttungspolitik börsennotierter Unternehmen in Deutschland, in: DBW, 63. Jg (2003), S. 309-332.

Pellens, Bernhard/Sellhorn, Thorsten, Goodwill-Bilanzierung nach SFAS 141 und 142 für deutsche Unternehmen, in: DB, 54. Jg. (2001), S. 1681-1689. 
Pellens, Bernhard/Sellhorn, Thorsten, Kapitalkonsolidierung nach der Fresh Start Methode, in: BB, 54. Jg. (1999), S. 2125-2132.

Pellens, Bernhard/Sellhorn, Thorsten, Minderheitenproblematik beim Goodwill Impairment Test nach geplanten IFRS und geltenden US-GAAP, in: DB, 54. Jg. (2003), S. 401-408.

Pellens, Bernhard/Sellhorn, Thorsten, Neue Goodwill-Bilanzierung nach US-GAAP, Der Impairment-Only Approach des FASB, in: DB, 54. Jg. (2001), S. 713-720.

Peltzman, Sam, Towards a More General Theory of Regulation, in: Journal of Law and Economics, Vol. 19 (1976), S. 211-240.

Penrose, Edith, The Theory of the Growth of the Firm, 3. Aufl., Oxford 1995.

Pfaff, Dieter/Ganske, Torsten, Ent- und Übergangskonsolidierung, in: Handwörterbuch der Rechnungslegung und Prüfung, hrsg. von Ballwieser, Wolfgang/Coenenberg, Adolf G./Wysocki, Klaus von, Stuttgart 2002, Sp. 654-668.

Pigou, Arthur C., The Economics of Welfare, 4. Aufl. (Reprint), London 1952 (Transaction Edition, with a New Introduction by Nahid Aslanbeigui, New Brunswick, N. J. 2002).

Pinkernell, Reimar, Einkünftezurechnung bei Personengesellschaften, Berlin 2001.

Platon, Kriton, Ein Dialog, in: Apologie - Kriton, übertragen, eingeleitet und hrsg. von Hildebrandt, Kurt (Reclam Universal-Bibliothek Nr. 895), Stuttgart 1982.

Pocarno Thomas M./Tran, Alfred V., Relationship of Tax and Financial Accounting Rules in Anglo-Saxon Countries, in: International Journal of Accounting, Vol. 33 (1998), S. 433-454.

Pohle, Wolfgang, Konzernrecht - insbesondere Konzernabschluß - im Entwurf eines Aktiengesetzes, in: AG, 5. Jg. (1960), S. 311-317.

Pohmer, Dieter, Das Verhältnis der Wirtschaftswissenschaft zur Rechtswissenschaft dargestellt am Beispiel der Konzerngestaltungen, in: Das Verhältnis der Wirtschaftswissenschaft zur Rechtswissenschaft, Soziologie und Statistik, hrsg. von Raiser, Ludwig/Sauermann, Heinz/Schneider, Erich, Berlin 1964, S. 57-66.

Pohmer, Dieter, Die betriebswirtschaftliche Problematik der Gewinnrealisation und der Periodenabgrenzung unter dem Gesichtspunkt der Erfolgsbesteuerung, Zugleich ein Beitrag zur Anwendung des $\S 131$ Abs. 1 Satz 3 AO (Teil 1 bis 4), in: WPg, 10. Jg. (1957), S. 461-466, 498-501, 523-529, 551-553.

Pohmer, Dieter, Einige Bemerkungen zu Inhalt und Bedeutung des Leistungsfähigkeitsprinzips, in: Finanzarchiv, N. F., Bd. 46 (1988), S. 135-153.

Posner Richard A., Taxation by regulation, in: The Bell Journal of Economics and Management Sciences, Vol. 2 (1971), S. 22-50. 
Posner, Richard A., Recht und Ökonomie: Eine Einführung, in: Ökonomische Analyse des Rechts, hrsg. von Assmann, Heinz-Dieter/Kirchner, Christian/Schanze, Erich, Tübingen 1993, S. 79-98.

Posner, Richard A., Theories of economic regulation, in: The Bell Journal of Economics and Management Science, Vol 5 (1974), S. 335-358.

Prantl, Johannes, Konzernbildung, Konzernrecht und Minderheitenschutz in Deutschland, Eine ökonomische Analyse, Frankfurt am Main et al. 1994.

Preinreich, Gabriel A. D., Models of Taxation in the Theory of the Firm, in: Economia Internazionale, Vol. 4 (1951), S. 372-397.

Probst, Arno, Die Behandlung der Anteile von Minderheitsgesellschaftern innerhalb der Besteuerung der Konzernunternehmung, Eine steuersystematische Analyse konzerninduzierter betriebswirtschaftlicher Interessenvielfalt, Frankfurt am Main et al. 1997.

Protzek, Heribert, Der Impairment Only-Ansatz - Wider der Vernunft, in: KoR, 3. Jg. (2003), S. 495-502.

Pullen, Michael, Körperschaftsbesteuerung nationaler und internationaler deutscher Konzerne, Eine kritische Analyse aus ökonomischer Sicht, Hamburg 1994.

Putterman, Louis, Ownership and the Nature of the Firm, in: Journal of Comparative Economics, Vol. 17 (1993), S. 243-263.

Raab, Udo H., Öffentliche Transaktionskosten und Effizienz des staatlichen Einnahmesystems, Berlin 1995.

Radbruch, Gustav, Rechtsphilosophie, Studienausgabe (insb. Neuabdruck der Rechtsphilosophie, 3. Aufl., Leipzig 1932) 2. Aufl., hrsg. von Dreier, Ralf/Paulson, Stanley L., Heidelberg 2003.

Rädler, Albert J., The Impact of IAS Accounting on Tax Accounting, in: SWI, 13. Jg. (2003), S. 465-469.

Rahlf, Stefan, IAS-Bilanzierung und Besteuerung, Eine betriebswirtschaftliche Analyse der Steuerfolgen einer Anpassung der handelsrechtlichen Rechnungslegung an die International Accounting Standards unter Aufrechterhaltung des Maßgeblichkeitsprinzips, Berlin 2000.

Rainey, Steven K./Sams, James K., The Final Intercompany Transaction Regulations and International Transactions: A Methodology for Analysis (Part I and II), in: Tax Management International Journal, Vol. 24 (1995), S. 463-473, 507-521.

Raiser, Ludwig, Die Konzernbildung als Gegenstand rechts- und wirtschaftswissenschaftlicher Untersuchungen, in: Das Verhältnis der Wirtschaftswissenschaft zur Rechtswissenschaft, Soziologie und Statistik, hrsg. von Raiser, Ludwig/Sauermann, Heinz/Schneider, Erich, Berlin 1964, S. 51-56.

Rajan, Raghuram G./Zingales, Luigi, Power in a Theory of the Firm, in: Quaterly Journal of Economics, Vol. 113 (1998), S. 387-432. 
Randzio-Plath, Christa, Steuerharmonisierung in der EU, in: Steuerreformen in Deutschland im europäischen Kontext, hrsg. vom Wirtschafts- und sozialpolitischen Forschungs- und Beratungszentrum der Friedrich-Ebert-Stiftung, Abt. Wirtschaftspolitik, Bonn 1999, S. 56-65.

Rasch, Harold, Reichen die Vorschriften des Steuerrechts - unter Berücksichtigung des Gesellschaftsrechts - aus, um Vermögensbewegungen zwischen verbundenen Unternehmen vollständig und befriedigend zu regeln?, Gutachten zum 49. Deutschen Juristentag, Bd. I, Teil G, München 1972.

Rathenau, Walther, Vom Aktienwesen, Eine geschäftliche Betrachtung, Berlin 1918.

Rathenau, Walther, Von kommenden Dingen, Berlin 1917.

Raupach, Arndt, „Gemeinschaftsweite Unternehmensbesteuerung, die den Anforderungen des Binnenmarktes gerecht wird" - Flucht aus dem Chaos in eine Utopie?, in: Gedächtnisschrift für Brigitte Knobbe-Keuk, hrsg. von Schön, Wolfgang, Köln 1997, S. 675-728.

Raupach, Arndt/Burwitz, Gero, Gestaltungsüberlegungen nach Abschaffung der Mehrmütterorganschaft, in: DStR, 41. Jg. (2003), S. 1901-1907.

Rawls, John, Eine Theorie der Gerechtigkeit, Frankfurt am Main 1979.

Reis, Monique, Die Körperschaftsbesteuerung des Konzerns als wirtschaftliche Einheit, Mögliche Altenative zur Einzelbesteuerung?, Frankfurt am Main et al. 1996.

Reiss, Wolfram, Ertragsteuerliche Behandlung von Gesamthandsbeteiligungen und Beteiligungserträgen, in: StuW, 63. Jg. (1986), S. 232-255.

Rheinstein, Max, Einführung in die Rechtsvergleichung, bearbeitet, hrsg. und eingeleitet von von Borries, Reimer, 2. Aufl., München 1987.

Richter, Lutz, Ansätze einer Konzernbesteuerung in Deutschland, Eine betriebswirtschaftliche Analyse spezifischer steuerrechtlicher und zivilrechtlicher Aspekte und Fragestellungen sowie grenzüberschreitender Betrachtungsweisen aus nationaler Sicht im Kontext (eines Entwurfs) des Unternehmenssteuerfortentwicklungsgesetzes (UntStFG), Frankfurt am Main et al. 2003.

Richter, Michael, Die Bewertung des Goodwill nach SFAS No. 141 und SFAS No. 142, Eine kritische Würdigung des impairment only-Ansatzes, Düsseldorf 2004.

Richter, Rudolf, Neue Institutionenökonomik, in: Steuersysteme der Zukunft, Jahrestagung des Vereins für Socialpolitik, Gesellschaft für Wirtschafts- und Sozialwissenschaften in Kassel vom 25. - 27. September 1996, hrsg. von Krause-Junk, Gerold, Berlin 1998, S. 323-355.

Richter, Rudolf, Sichtweise und Fragestellungen der Neuen Institutionenökonomik, in: Zeitschrift für Wirtschafts- und Sozialwissenschaften, $110 \mathrm{Jg}$. (1990), S. 571591.

Richter, Rudolf/Furubotn, Eirik G., Neue Institutionenökonomik, Eine Einführung und kritische Würdigung, 3. Aufl., Tübingen 2003. 
Richter, Wolfram F., Investitionsneutrale Besteuerung: Praktikabilität und Steuergerechtigkeit, Erwiderung zu Haase, BB 1990, S. 112, in: BB, 45. Jg. (1990), S. 760 761.

Ricketts, Martin, The Economics of Business Enterprise, An Introduction to Economic Organisation and the Theory of the Firm, 3. Aufl., Cheltenham et al. 2002.

Riechers, Arndt, Das „Unternehmen an sich“, Tübingen 1996.

Riecker, Andreas, Körperschaftsbesteuerung in der Europäischen Union und das USamerikanische Modell der Unitary Taxation, Baden-Baden 1997.

Ritter, Wolfgang, Reform der Unternehmensbesteuerung aus der Sicht der Wirtschaft, in: StuW, 66. Jg. (1989), S. 319-327.

Robisch, Martin/Treisch, Corinna, Neuere Entwicklungen des Verhältnisses von Handelsbilanz und Steuerbilanz - Anhaltspunkte für eine Tendenzwende?, in: WPg, 50. Jg. (1997), S. 156-169.

Roloff, Otto, Fiskalische Standortkonkurrenz in Europa, in: Steuerreformen in Deutschland im europäischen Kontext, hrsg. vom Wirtschafts- und sozialpolitischen Forschungs- und Beratungszentrum der Friedrich-Ebert-Stiftung, Abt. Wirtschaftspolitik, Bonn 1999, S. 47-55.

Rose, Gerd, Gegenwartsprobleme bei der Besteuerung von Kapitalgesellschaften, in: Steuerberater-Jahrbuch 1965/66, zugleich Bericht über den XVII. Fachkongreß der Steuerberater der Bundesrepublik Deutschland, Köln, 25. bis 27. Oktober 1965, Köln 1966.

Rose, Gerd, Überlegungen zur Steuergerechtigkeit aus betriebswirtschaftlicher Sicht, in: StuW, 62. Jg. (1985), S. 330-344.

Ross, Alf, On Law and Justice, London 1959.

Rousseau, Jean-Jacques, $\boldsymbol{D} u$ contrat social ou principes du droit politique, 1762 (mit: Considérations sur le governement de Pologne, 1772; Nachdruck: Internationale Bibliothek GmbH, Berlin 1922).

Ruding Committee (Committee of Independent Experts on Company Taxation), Report of the Committee of Independent Experts on Company Taxation, Brüssel et al. (March) 1992.

Rüfner, Wolfgang, Fiskus, in: Handwörterbuch der Wirtschaftswissenschaft, hrsg. von Albers, Willi et al., Bd. 3, Stuttgart et al. 1981, S. 302 - 305.

Rüfner, Wolfgang, Grundrechtsträger, in: Handbuch des Staatsrechts der Bundesrepublik Deutschland, hrsg. von Isensee, Josef/Kirchhof, Paul, 2. Aufl., Bd. V: Allgemeine Grundrechtslehren, Heidelberg 2000, S. 485-524 (§ 116).

Ruhnke, Klaus, Konzernbuchführung, Düsseldorf 1995. 
Ruhwedel, Franca, Eigentümerstruktur und Unternehmenserfolg, Eine theoretische und empirische Analyse deutscher börsennotierter Unternehmen, Frankfurt am Main et al. 2003.

Rupp, Reinhard, Die Ertragsbesteuerung nationaler Konzerne, Konzernsteuerbilanz oder Weiterentwicklung der körperschaftsteuerlichen Organschaft?, Frankfurt am Main 1983.

Rutherford, Brian A., An Introduction to Modern Financial Reporting Theory, London et al. 2000.

Saelzle, Rainer/Kronner, Markus, Die Informationsfunktion des Jahresabschlusses dargestellt am sog. ,impairment-only-Ansatz", in: WPg, 57. Jg. (2004), Sonderheft: Wirtschaftsprüfung und Zeitgeist, S. S 154-S 165.

Salin, Pascal, Comment on Vito Tanzi and A. Lans Bovenberg, "Is There a Need for Harmonizing Capital Income Taxes within EC-Countries?, in: Reforming Capital Income Taxation, hrsg. von Siebert, Horst, Tübingen 1990, S. 198-205.

Salzberger, Wolfgang, Die steuerliche Gewinnermittlung einer Konzernunternehmung in der Europäischen Union, Eine betriebswirtschaftliche Analyse, Köln 1994.

Salzberger, Wolfgang, Unitary Taxation - Vorbild für eine Konzernbesteuerung in der Europäischen Union?, in: IStR, 8. Jg. (1999), S. 97-103.

Samuelson, Paul A., Tax Deductibility of Economic Depreciation to Insure Invariant Valuation, in: Journal of Political Economy, Vol. 72 (10964), S. 604-606.

Sapusek, Annemarie, Ökonomische und juristische Analyse der Steuerharmonisierung in der Europäischen Union: Umsatzsteuer, spezielle Verbrauchsteuern, direkte Unternehmensteuern, Teil 1 - 3, Frankfurt am Main et al. 1997.

Schäfer, Anne/Spengel, Christoph, The Impact of ICT on Profit Allocation within Multinational Groups: Arm's Length Pricing or Formula Apportionment, ZEWDiscussion Paper No. 03-53, Mannheim (Sept.) 2003.

Schäfer, Harald, Bilanzierung von Beteiligungen an assoziierten Unternehmen nach der Equity-Methode, Untersuchung über die Anwendbarkeit der Equity-Methode in der Bundesrepublik Deutschland, Thun et al. 1982.

Schaffer, Aljoscha, Die Übernahme internationaler Normen in die deutsche Rechnungslegung, Lohmar et al. 2000.

Schanz, Georg, Der Einkommensbegriff und die Einkommensteuergesetze, in: Finanzarchiv, 13. Jg. (1896), S. 1-88.

Schanz, Georg, Die direkten Steuern Hessens und deren neuste Reform, in: Finanzarchiv, 2. Jg. (1885), S. 235-529.

Schanze, Erich, Hare and Hedgehog Revisited: The Regulation of Markets that Have Escaped Regulated Markets, in: Journal of Institutional and Theoretical Economics, Vol. 151 (1995), S. 162-176. 
Schaumburg, Harald, Grundzüge des Konzernsteuerrechts, in: Steuerrecht und steuerorientierte Gestaltung im Konzern, Kölner Konzernrechtstage, hrsg. von Schaumburg, Harald, Köln 1998, S. 1-59.

Scheffler, Wolfram, Besteuerung der grenzüberschreitenden Unternehmenstätigkeit, 2. Aufl., München 2002.

Scheffler, Wolfram, Gedanken zur Zukunft des Maßgeblichkeitsprinzips, in: DSWR Datenverarbeitung, Steuer, Wirtschaft, Recht, Nr. 6, 2001, S. 151-154.

Scheffler, Wolfram, Grundzüge zur Besteuerung von inländischen Konzernen, in: DBW, 51. Jg. (1991), S. 701-717.

Scheffler, Wolfram, Übersichten zur Reichweite des Maßgeblichkeitsprinzips, in: StuB, 6. Jg. (2004), S. 69-73.

Schenk, Gerald, Konzernbildung, Interessenkonflikte und ökonomische Effizienz, Ansätze zur Theorie des Konzerns und ihre Relevanz für rechtspolitische Schlußfolgerungen, Frankfurt am Main et al. 1997.

Scheuchzer, Marco, Konzernbesteuerung in der Europäischen Union, Bielefeld 1994.

Schiele, Norbert, Unternehmensbesteuerung und Handelsbilanz, Eine ökonomische Analyse der Verknüpfung von Handelsbilanz und Steuerbemessungsgrundlage, Berlin 2000.

Schildbach Thomas, Zeitbewertung, Gewinnkonzeption und Informationsgehalt Stellungnahme zu „Financial Assets and Liabilities - Fair Value or Historical Cost?“،, in: WPg, 52. Jg. (1999), S. 177-185.

Schildbach, Thomas, Bilanzierung zum ,fair value" - Zukunft der Rechnungslegung?, in: Organisation und Personal (Festschrift Rolf Bühner), hrsg. von Wildemann, Horst, München 2004, S. 845-863.

Schildbach, Thomas, Der Konzernabschluß als Ausschüttungsbemessungsgrundlage (Teil I und II), in: WPg, 46. Jg. (1993), S. 53-63, 94-98.

Schildbach, Thomas, Externe Rechnungslegung und Kongruenz - Ursache für die Unterlegenheit deutscher verglichen mit angelsächsischer Bilanzierung?, in: DB, 52. Jg. (1999), S. 1813-1820.

Schildbach, Thomas, IAS als Rechnungslegungsstandards für alle, in: BFuP, 54. Jg. (2002), S. 263-278.

Schildbach, Thomas, Internationale Rechnungslegungsstandards auch für deutsche Einzelabschlüsse?, in: Bilanzrecht und Kapitalmarkt (Festschrift Adolf Moxter), hrsg. von Ballwieser, Wolfgang et al., Düsseldorf 1994, S. 699-721.

Schildbach, Thomas, Zeitwertbilanzierung in USA und nach IAS, in: BFuP, 50. Jg. (1998), S. 580-592. 
Schilling, Wolfgang, Rechtsform und Unternehmen, in: Festschrift für Konrad Duden zum 70. Geburtstag, hrsg. von Pawlowski, H.-M./Wiese, Günther/Wüst, Günther, München 1977, S. 537-553.

Schindler, Joachim, Kapitalkonsolidierung nach dem Bilanzrichtlinien-Gesetz, Frankfurt am Main et al. 1986.

Schmalenbach, Eugen, Dynamische Bilanz, 4. Aufl., Leipzig 1926.

Schmalenbach, Eugen, Finanzierungen, 6. Aufl., Leipzig 1937.

Schmidt, Karsten, Die BGB-Außengesellschaft: rechts- und parteifähig, Besprechung des Grundlagenurteils II ZR 331/00 vom 29.1.2001, in: NJW, 54. Jg. (2001), S. 993-1003.

Schmidt, Karsten, Gesellschaftsrecht, 4. Aufl., Köln et al. 2002.

Schmidt, Karsten, Konzernunternehmen, Unternehmensgruppe und KonzernRechtsverhältnis, Gedanken zum Recht der verbundenen Unternehmen nach $\S \S 15$ ff., 291 ff. AktG, in: Deutsches und europäisches Gesellschafts-, Konzern- und Kapitalmarktrecht (Festschrift Marcus Lutter), hrsg. von Schneider, Uwe H. et al., Köln 2000, S. 1167-1193.

Schmidt, Lutz, Maßgeblichkeitsprinzip und Einheitsbilanz: Geschichte, Gegenwart und Perspektiven des Verhältnisses von Handels- und Steuerbilanz, Heidelberg 1994.

Schmidt, Matthias, Ökonomische Überlegungen zur Rechnungslegungsregulierung bei Vorliegen hybrider Kooperationsformen, in: DBW, 63. Jg. (2003); S. 138-155.

Schmidtchen, Dieter, Jenseits von Maximierung, Gleichgewicht und Effizienz: Neuland für die ökonomische Analyse des Rechts, in: Ökonomische Probleme des Zivilrechts Beiträge zum 2. Travemünder Symposium zur ökonomischen Analyse des Rechts, 21. - 24. März 1990 hrsg. von Ott, Claus/Schäfer Hans-Bernd, Berlin et al. 1991, S. 316-343.

Schmoller, Gustav, Die Lehre vom Einkommen in ihrem Zusammenhang mit den Grundprincipien der Steuerlehre, in: Zeitschrift für die gesamte Staatswissenschaft, 19. Jg. (1863), S. 1-86.

Schmoller, Gustav, Grundriß der Allgemeinen Volkswirtschaftslehre, 1. Teil, 1.-3. Aufl., Leipzig 1900.

Schneeloch, Dieter, Besteuerung und betriebliche Steuerpolitik, Bd. 1: Besteuerung, 4. Aufl., München 2003.

Schneeloch, Dieter, Bilanzpolitik und Grundsätze der Maßgeblichkeit, in: DStR, 28. Jg. (1990), S. 96-104.

Schneider, Dieter, Abschreibungsverfahren und Grundsätze ordnungsmäßiger Buchführung, in: WPg, 27. Jg. (1974), S. 365-376. 
Schneider, Dieter, Betriebswirtschaftliche Gewinnermittlung oder ökonomische Analyse des Bilanzrechts?, in: ZfbF, 35. Jg. (1983), S. 1040-1065.

Schneider, Dieter, Betriebswirtschaftliche Steuerlehre als Steuerplanungslehre oder als ökonomische Analyse des Steuerrechts?, in: Unternehmung und Steuer (Festschrift Peter Scherpf), hrsg. von Fischer, Lutz, Wiesbaden 1983, S. 21-37.

Schneider, Dieter, Betriebswirtschaftslehre, Bd. 1: Grundlagen, 2. Aufl., München et al. 1995.

Schneider, Dieter, Betriebswirtschaftslehre, Bd. 2: Rechnungswesen, 2. Aufl., München et al. 1997.

Schneider, Dieter, Betriebswirtschaftslehre, Bd. 3: Theorie der Unternehmung, München et al. 1997

Schneider, Dieter, Betriebswirtschaftslehre, Bd. 4: Geschichte und Methoden der Wirtschaftswissenschaft, München 2001.

Schneider, Dieter, Das Problem der risikobedingten Anlagenabschreibung, in: WPg, 27. Jg. (1974), S. 402-405.

Schneider, Dieter, Der Unternehmer - eine Leerstelle in der Theorie der Unternehmung?, in: Theorie der Unternehmung, ZfB, 71. Jg. (2001), Ergänzungsheft Nr. 4, S. 1-19.

Schneider, Dieter, Die Anfänge der „Steuerbilanz“ und die Entstehung des Maßgeblichkeitsprinzips, Ein Beitrag zur Betriebswirtschaftlichen Steuerlehre vor der akademischen Betriebswirtschaftslehre, in: Betriebswirtschaftliche Steuerlehre und Steuerberatung, Gerd Rose zum 65. Geburtstag, hrsg. von Herzig, Norbert, Wiesbaden 1991, S. 175-190.

Schneider, Dieter, Die Unhaltbarkeit des Transaktionskostenansatzes für die „Markt oder Unternehmung“-Diskussion, in: ZfB, 55. Jg. (1985), S. 1237-1254.

Schneider, Dieter, Erfolgsermittlung als Rechnungsziel - ein empirischer und wissenschaftsgeschichtlicher Test, in: ZfbF, 30. Jg. (1978), S. 326-347.

Schneider, Dieter, Folgt die Tugend gewinnsteuerlicher Bemessungsgrundlagen den Zahlungsströmen?, Jochen Sigloch zur Vollendung des 60. Lebensjahres, in: StuW, 81. Jg. (2004), S. 293-304.

Schneider, Dieter, Fördern internationale Rechnungslegungsstandards Wettbewerb als Verwertung von Wissen?, in: ZfbF, 52. Jg. (2000), Sonderheft 45, S. 23-40.

Schneider, Dieter, Gewinnermittlung und steuerliche Gerechtigkeit, in: ZfbF, 23. Jg. (1971), S. 352-394.

Schneider, Dieter, Grundzüge der Unternehmensbesteuerung, 6. Aufl., Wiesbaden 1994.

Schneider, Dieter, Investition, Finanzierung und Besteuerung, 7. Aufl., Wiesbaden 1992. 
Schneider, Dieter, Ist die Einkommensteuer überholt? Kritik und Reformvorschläge, in: Einkommen versus Konsum, Ansatzpunkte zur Steuerreformdiskussion, hrsg. von Smekal, Christian/Sendlhofer, Rupert/Winner, Hannes, Heidelberg 1999, S. 114.

Schneider, Dieter, Konzernrechnungslegung nach IAS als Besteuerungsgrundlage?, in: BB, 58. Jg. (2003), S. 299-304.

Schneider, Dieter, Körperschaftsteuerreform und Gleichmäßigkeit der Besteuerung, in: StuW, 52. Jg. (1975), S. 97-112.

Schneider, Dieter, Korrekturen zum Einfluß der Besteuerung auf die Investitionen, in: ZfbF, 21. Jg. (1969), S. 297-325.

Schneider, Dieter, Mängel in der ökonomischen Begründung einer Steuerfreiheit für Kapitaleinkünfte, in: StuW, 77. Jg. (2000), S. 421-430.

Schneider, Dieter, Maß und Ausmaß der Steuervergünstigungen, in: DB, 45. Jg. (1992), S. 1737-1742.

Schneider, Dieter, Maßgeblichkeit der Handelsbilanz für die Steuerbilanz und Besteuerung nach der Leistungsfähigkeit, in: BB, 33. Jg. (1978), S. 1577-1581.

Schneider, Dieter, Meßkonzepte zur Steuerbelastung von Unternehmen, in: WiSt, 19. Jg. (1990), S. 497-502.

Schneider, Dieter, Problemfelder und Methoden des Rechnungswesens allgemein und einer Konzernrechnungslegung als internationale Gewinnsteuerbemessungsgrundlage im besonderen, in: BFuP, 55. Jg. (2003), S. 652-669.

Schneider, Dieter, Realisationsprinzip und Einkommensbegriff, in: Bilanzfragen (Festschrift Ulrich Leffson), hrsg. von Baetge, Jörg/Moxter, Adolf/Schneider, Dieter, Düsseldorf 1976, S. 101-117.

Schneider, Dieter, Reform der Unternehmensbesteuerung aus betriebswirtschaftlicher Sicht, in: StuW, 66. Jg. (1989), S. 328-339.

Schneider, Dieter, Sieben Thesen zum Verhältnis von Handels- und Steuerbilanz, in: DB, 23. Jg. (1970) S. 1697-1705.

Schneider, Dieter, Steuerbilanzen, Rechnungslegung als Messung steuerlicher Leistungsfähigkeit, Wiesbaden 1978.

Schneider, Dieter, Steuergerechtigkeit durch Regelungen gegen Steuervermeidung ein „Gefangenendilemma“ des Steuerrechts, in: StuW, 62. Jg. (1985), S. 345-355.

Schneider, Dieter, Steuerlast und Steuerwirkung, Einführung in die steuerliche Betriebswirtschaftslehre, München et al. 2002.

Schneider, Dieter, Steuervereinfachung durch Rechtsformneutralität, in: DB, 57. Jg. (2004), S. 1517-1521.

Schneider, Dieter, Verbesserung der Allokation durch Besteuerung unrealisierter Vermögenswertänderungen?, in: Finanzarchiv, N. F., Bd. 44 (1986), S. 224-240. 
Schneider, Dieter, Wider Marktpreise als Verrechnungspreise in der Besteuerung internationaler Konzerne, in: DB, 56. Jg. (2003), S. 53-58.

Scholes, Myron S./Wolfson, Mark A., Taxes and Business Strategy: A Planning Approach, Englewood Cliffs 1992.

Schön, Wolfgang, Der große Senat des Bundesfinanzhofs und die Personengesellschaft, in: StuW, 73. Jg. (1996), S. 275-288.

Schön, Wolfgang, Gesellschaftsrecht nach Maastricht, Art. 3b EGV und das europäische Gesellschaftsrecht, in: ZGR, 24. Jg. (1995), S. 1-38.

Schön, Wolfgang, Kompetenzen der Gerichte zur Auslegung der IAS/IFRS, in: BB, 59. Jg. (2004), S. 763-768.

Schönbucher, Sigmar, Die Rechnungslegung wechselseitig verflochtener Unternehmen durch die konsolidierte Bilanz, Diss. Köln 1966.

Schoppe, Siegfried G. et al., Moderne Theorie der Unternehmung, München et al. 1995.

Schredelseker, Klaus, Wider eine individualistisch verkürzte Theorie der Unternehmensbesteuerung, Anmerkungen zu dem Aufsatz von Dieter Schneider: Körperschaftsteuerreform und Gleichmäßigkeit der Besteuerung (StuW 2/1975, 97-112), in: StuW, 52. Jg. (1975), S. 324-326.

Schreiber, Ulrich, Die Bedeutung der US-amerikanischen Rechnungslegung für die Besteuerung von Gewinnen und Ausschüttungen, in: US-amerikanische Rechnungslegung, Grundlagen und Vergleiche mit dem deutschen Recht, 4. Aufl., Stuttgart 2000, S. 49-98.

Schreiber, Ulrich, Gewinnermittlung und Besteuerung der Einkommen in: StuW, 79. Jg. (2002), S. 105-115.

Schreiber, Ulrich, Rechnungslegung im Einzelabschluß nach internationalen Grundsätzen?, in: Unternehmenspolitik und internationale Besteuerung (Festschrift Lutz Fischer), hrsg. von Kleineidamm, Hans-Jochen, Berlin 1999, S. 879-912.

Schreiber, Ulrich, Rechtsformabhängige Unternehmensbesteuerung?, Köln 1987.

Schreiber, Ulrich, Steuerwettbewerb, Steuerharmonisierung und neutrale Unternehmensbesteuerung, in: Rechnungslegung und Steuern international, Tagung des Ausschusses Unternehmensrechnung im Verein für Socialpolitik am 9. und am 10. Mai 1997 in Evelle/Frankreich, hrsg. von Ballwieser, Wolfgang/Schildbach, Thomas, ZfbF, 50. Jg. (1998), Sonderheft Nr. 40, S. 105-144.

Schreiber, Ulrich, Unternehmensbesteuerung im Binnenmarkt, Angleichung der Gewinnermittlung und des Satzes der Körperschaftsteuer?, in: StuW, 81. Jg. (2004), S. 212-226.

Schroer, Achim/Starke, Peter, Abschaffung der Mehrmütterorganschaft durch das StVergAbG - Folgen und Handlungsalternativen, in: GmbHR, 94. Jg. (2003), S. 153-156. 
Schröer, André, Entscheidungswirkungen steuerlicher Erfolgsabgrenzungsparadigmen bei multinationalen Unternehmen, in: ZfbF, 56. Jg. (2004), S. 259-281.

Schroller, Wolfgang, Die Zukunft des Maßgeblichkeitsgrundsatzes im Hinblick auf das Steuerentlastungsgesetz 1999/2000/2002 und die geplante Unternehmenssteuerreform, in: Bilanzierung und Besteuerung der Unternehmen, Das Handels- und Steuerrecht auf dem Weg ins 21. Jahrhundert (Festschrift Herbert Brönner), hrsg. von Poll, Jens, Stuttgart 2000, S. 361-375.

Schubert, Werner/Küting, Karlheinz, Unternehmungszusammenschlüsse, München 1981.

Schuch, Josef, Besteuerung als Unternehmensgruppe: Wahlrecht oder Pflicht?, in: Besteuerung von Unternehmensgruppen, Bestandsaufnahme und Vorschläge zur Reform der Organschaft im Körperschaftsteuerrecht, hrsg. von Gassner, Wolfgang/Lang, Michael/Wiesner, Werner, Wien 1998, S. 75-94.

Schuhmann, Werner, Der Konzernabschluß, Die Bilanzierungspraxis deutscher Konzerne, Wiesbaden 1962.

Schuler, Felix, Der Einfluss des Internets auf die Unternehmensgrenzen, Die Dekonstruktionsthese aus industrie-, institutionen- und informationsökonomischer Sicht, Wiesbaden 2002.

Schulze-Osterloh, Joachim, Handels- und Steuerbilanz, in: ZGR, 29. Jg. (2000), S. 594-603.

Schumpeter, Joseph A., Capitalism, Socialism, and Democracy, 2. Aufl., London 1947.

Schumpeter, Joseph A., Das Wesen und der Hauptinhalt der theoretischen Nationalökonomie, Berlin 1908 (unveränderter Nachdruck/2. Aufl., Berlin 1970).

Schumpeter, Joseph A., Theorie der wirtschaftlichen Entwicklung, Leipzig 1912.

Schweizer, Urs, Eigentumsrechte, Nachverhandlungen und die Theorie der Unternehmung, in: ZfB, 71. Jg. (2001), Ergänzungsheft Nr. 4, S. 35-50.

Schweizer, Urs, Vertragstheorie, Tübingen 1999.

Schwinger, Reiner, Einkommens- und konsumorientierte Steuersysteme, Wirkungen auf Investition, Finanzierung und Rechnungslegung, Heidelberg 1992.

Seer, Roman, Verfassungsrechtliche Grenzen der Gesamtbelastung von Unternehmen, in: Europa- und verfassungsrechtliche Grenzen der Unternehmensbesteuerung, hrsg. von Pelka, Jürgen, DStJG, Bd. 23, Köln 2000, S. 87-126.

Selchert, Friedrich Wilhelm, Internationalisierung der Rechnungslegung und Maßgeblichkeitsprinzip, in: Unternehmenspolitik und internationale Besteuerung (Festschrift Lutz Fischer), hrsg. von Kleineidamm, Hans-Jochen, Berlin 1999, S. $913-$ 933. 
Sellhorn, Thorsten, Ansätze zur bilanziellen Behandlung des Goodwill im Rahmen einer kapitalmarktorientierten Rechnungslegung, in: DB, 53. Jg. (2000), S. 885892.

Sellhorn, Thorsten, Goodwill Impairment, An Empirical Investigation of Write-Offs under SFAS 142, Frankfurt am Main et al. 2004.

Sellhorn, Thorsten, Steuersatz und Verfassungsrecht, Rechtliche Vorgaben für ein politisches Instrument, Wiesbaden 1998.

Selling, Henz-Jürgen, Spanische Konzernbesteuerung aufgrund konsolidierter Jahresabschlüsse, in: RIW, 33. Jg. (1987), S. 291-298.

Sen, Amartya, Soziale Gerechtigkeit und ökonomische Effizienz, in: Philosophie und Politik II, hrsg. von Nida-Rümelin, Julian/Thierse, Wolfgang, Essen 1998, S. 14-26.

Senger, Thomas, Reform der deutschen Konzernertragsbesteuerung, Unter Berücksichtigung grenzüberschreitender Konzernstrukturen im Europäischen Binnenmarkt, Lohmar et al. 1997.

Shackelford, Douglas A./Shevlin, Terry, Empirical tax research in accounting, in: Journal of Accounting and Economics, Vol. 31 (2001), S. 321-387.

Sheffrin, Steven M./Fulcher, Jack, Alternative Divisions of the Tax base: How much is at Stake?, in: The State Corporation Income Tax, Issues in Worldwide Unitary Combination, hrsg. von McLure, Charles E., jr., Stanford 1984, S. 192-213.

Shelanski, Howard A./Klein, Peter G., Empirical Research in Transaction Cost Economics: A Review and Assessment, in: Journal of Law, Economics and Organization, Vol. 11 (1995), S. 335-361.

Shevlin, Terry, Research in Taxation, in: Accounting Horizons, Vol. 13 (1999), S. 427-441.

Shoup, Carl S., The Schanz Concept of Income and the United States Federal Income Tax, in: Finanzarchiv, N. F., Bd. 42 (1984), S. 433-444.

Siebourg, Peter, $\$ 290$, in: Handbuch der Konzernrechnungslegung, Kommentar zur Bilanzierung und Prüfung, Bd. II, hrsg. von Küting, Karlheinz/Weber, Claus-Peter, 2. Aufl., Stuttgart 1998.

Siegel, Theodor, Konsum- oder einkommensorientierte Besteuerung? Aspekte quantitativer und qualitativer Argumentation, in: ZfbF, 52. Jg. (2000), S. 724-741.

Siegel, Theodor, Metamorphosen des Realisationsprinzips?, in: Rechnungslegung, Entwicklungen bei der Bilanzierung und Prüfung von Kapitalgesellschaften (Festschrift Karl-Heinz Forster), hrsg. von Moxter, Adolf et al., Düsseldorf 1992, S. 585-605.

Sigloch, Jochen, Ein Valet dem Maßgeblichkeitsprinzip, in: BFuP, 52. Jg. (2000), S. 157-182. 
Simon, Herbert A., A Behavioral Model of Rational Choice, in: Quaterly Journal of Economics, Vol. 69 (1955), S. 99-118.

Simon, Herbert A., Administrative Behavior, 2. Aufl., New York 1961.

Simon, Herbert A., Models of Man: Social and Rational, Mathematical Essays on Rational Human Behavior in a Social Setting, New York et al. 1957.

Simon, Herbert A., Organizations and Markets, in: Journal of Economic Perspectives, Vol. 5 (1991), S. 25-44.

Simon, Herbert A., Rationality as Process and as Product of Thought, in: The American Economic Review, Papers and Proceedings, Vol. 68 (1978), S. 1-16.

Simons, Henry C., Personal Income Taxation: The Definition of Income as a Problem of Fiscal Policy, Chicago et al. 1938 (Reprint 1980).

Sinn, Hans-Werner, Kapitaleinkommensbesteuerung, Eine Analyse der intertemporalen, internationalen und intersektoralen Allokationswirkungen, Tübingen 1985.

Sinn, Hans-Werner, Tax Harmonization and Tax Competition in Europe, in: European Economic Review, Vol. 34 (1990), S. 489-504.

Sinn, Hans-Werner, The selection principle and market failure in systems competition, in: Journal of Public Economics, Vol. 66 (1997), S. 247-274.

Slemrod, Joel, Tax from Any Angle: Reflections on Multi-Disciplinary Tax Reserach, in: National Tax Journal, Vol. 56 (2003), S. 145-151.

Smekal, Christian/Sendlhofer, Rupert/Winner, Hannes (Hrsg.), Einkommen versus Konsum, Ansatzpunkte zur Steuerreformdiskussion, Heidelberg 1999.

Smith, Adam, An Inquiry into the Nature and Causes of the Wealth of Nations, London 1776 (Reprint, The Modern Library, hrsg. von Cannan, Edwin, New York 1937).

Socher, Karl, Die Österreichische Schule der Nationalökonomie und Austrian Economics, in: WISU, 31. Jg. (2002), S. 122-128.

Söffing, Günter, Besteuerung der Mitunternehmer, 4. Auflage, Herne et al. 1994.

Sørensen, Peter Birch, Company Tax Reform in the European Union, in: International Tax and Public Finance, Vol. 11 (2004), S. 91-115.

Sørensen, Peter Birch, To Harmonise or not to Harmonise?, in: CESifo Forum, Vol. 3 (1/2002), S. 31-35.

Sparfeld, Silvia, Das neue tschechische Konzernrecht, in: IWB, Fach 5 (Teschechien), Gruppe 3, S. 43-52 (Loseblattsammlung, Lieferung IWB Nr. 10 vom 22.5.2002).

Spengel, Christoph, Einheitliche Bemessungsgrundlage für die laufende Besteuerung der Europäischen Aktiengesellschaft, in: Besteuerung der Europäischen Aktiengesellschaft, hrsg. von Herzig, Norbert, Köln 2004, S. 101-117. 
Spengel, Christoph, International Accounting Standards und Unternehmensbesteuerung in der Europäischen Union, Teil I und II, in: IStR, 12. Jg. (2003), S. 29-36, 67-72.

Spengel, Christoph, Internationale Unternehmensbesteuerung in der Europäischen Union, Steuerwirkungsanalyse, Empirische Befunde, Reformüberlegungen, Düsseldorf 2003.

Spengel, Christoph, Rechnungslegung nach IFRS - Konsequenzen für die Besteuerung, in: ZfCM, 48. Jg. (2004), Sonderheft 2, S. 130-140.

Spengel, Christoph, Unternehmensbesteuerung in der $\boldsymbol{E} \boldsymbol{U}$ - quo vadis?, in: Deutsches Steuerrecht im europäischen Rahmen, hrsg. von Lüdicke, Jürgen, Köln 2004, S. 109-155.

Spengel, Christoph/Frebel, Maibrit, Neue Initiativen der EU-Kommission für die Besteuerung grenzüberschreitend tätiger Unternehmen in Europa, in: StuB, 5. Jg. (2003), S. 786-792.

Spiller, Earl A., jr., Financial Accounting, Basic Concepts, Homewood, Ill. 1966.

Stabenow, Michael, Ein ungewisser Vertrag für ein ungewisses Europa, in: FAZ, Nr. 141 v. 21 . Juni 2004 , S. 3.

Stahlschmidt, Michael, Überblick über das Bilanzrechtsreformgesetz, in: StuB, 6. Jg. (2004), S. 993-996.

Steibert, Frank, Der Einfluss des Europäischen Rechts auf die Unternehmensbesteuerung, Eine ökonomische Analyse der Rechtsprechung des Europäischen Gerichtshofes, Frankfurt am Main et al. 2002.

Steiner Jürgen, Gewinnsteuern in Partialmodellen für Investitionsentscheidungen, Barwert und Endwert als Instrumente zur Steuerwirkungsanalyse, Berlin 1980.

Steinhauer, Carsten, Neues Aktien- und Konzernrecht in Italien, in: AG, 49. Jg. (2004), S. R230-R232.

Stieb, Stephan, Portugal, in: Steuern in Europa, Amerika und Asien, hrsg. von Mennel, Annemarie/Förster, Jutta, Ordner II, Herne et al. 2000 (41. Lieferung).

Stigler, George J., The theory of economic regulation, in: The Bell Journal of Economics and Management Science, Vol. 2 (1971), S. 3-21.

Stiglitz, Joseph E./Schönfelder, Bruno, Finanzwissenschaft, 2. Aufl., München et al. 1989 (3. Nachdruck 2000).

Stolk, Jacob Leonard, Die Behandlung multinationaler Konzerne als Einheit im Steuerrecht, Dissertation Nr. 445, Hochschule St. Gallen, Bamberg 1972.

Streim, Hannes, Eigenkapital, in: Lexikon des Rechnungswesens, hrsg. von Busse von Colbe, Walther/Pellens, Bernhard, 4. Aufl., München et al. 1998, S. 202-204.

Streim, Hannes, Grundzüge der handels- und steuerrechtlichen Bilanzierung, Stuttgart et al. 1988. 
Streim, Hannes, Konzernrecht, Wintersemester 2004/2005, Vorlesungsskript an der Ruhr-Universität Bochum, Bochum 2004.

Streim, Hannes/Bieker, Marcus/Esser, Maik, Der schleichende Abschied von der Ausschüttungsbilanz - Grundsätzliche Überlegungen zum Inhalt einer Informationsbilanz, in: Steuern, Rechnungslegung und Kapitalmarkt (Festschrift Franz W. Wagner), hrsg. von Dirrigl, Hans/Wellisch, Dietmar/Wenger, Ekkehard, Wiesbaden 2004, S. 229-244.

Streim, Hannes/Bieker, Marcus/Esser, Maik, Vermittlung entscheidungsnützlicher Informationen durch Fair Values - Sackgasse oder Licht am Horizont?, in: BFuP, 55. Jg. (2003), S. 457-479.

Streim, Hannes/Bieker, Marcus/Leippe, Britta, Anmerkungen zur theoretischen Fundierung der Rechnungslegung nach International Accounting Standards, in: Moderne Konzepte für Finanzmärkte, Beschäftigung und Wirtschaftsverfassung (Festschrift Wolfgang Stützel), hrsg. von Schmidt, Hartmut, Tübingen 2001, S. 177-206.

Streim, Hannes/Esser, Maik, Rechnungslegung nach IAS/IFRS - Ein geeignetes Instrument zur Zahlungsbemessung?: Bewertungsfragen, in: StuB, 5. Jg. (2003), S. 781-786.

Streim, Hannes/Esser, Maik, Rechnungslegung nach IAS/IFRS - Ein geeignetes Instrument zur Zahlungsbemessung?: Ansatzfragen, in: StuB, 5. Jg. (2003), S. 736742.

Streit, Manfred E., Systemwettbewerb im europäischen Integrationsprozeß, in: Festschrift für Ernst-Joachim Mestmäcker zum 70. Geburtstag, hrsg. von Immenga, Ulrich et al., Baden-Baden 1996, S. 521-535.

Streit, Manfred E., Theorie der Wirtschaftspolitik, 4. Aufl., Düsseldorf 1991.

Streit, Manfred E./Wegner, Gerhard, Wissensmangel, Wissenserwerb und Wettbewerbsfolgen - Transaktionskosten aus evolutorischer Sicht, in: ORDO, Bd. 40 (1989), S. 183-200.

Strunk, Günther, Das Ende der Maßgeblichkeit?, Einfluss der internationalen Rechnungslegungsstandards auf die steuerliche Gewinnermittlung, in: StuB, 5. Jg. (2003), S. 397-403.

Sunley, Emil M., The Pros and Cons of Formulary Apportionment, in: CESifo Forum, Vol. 3 (1/2002), S. 36-37.

Sürken, Silke, Abgrenzung der wirtschaftlichen Einheit nach US-GAAP, Frankfurt am Main et al. 1999.

Sweeney, Tim, The inexorable drive towards fair value, in: Accountancy International, Nov. 1998, S. 81. 
Szyperski, Norbert, Einige aktuelle Fragestellungen zur Theorie der Unternehmensrechnung, in: BFuP, 16. Jg. (1964), S. 270-282.

TEI (Tax Executive Institute, International Tax Committee), TEI Comments on International Accounting Standards and European Union Consolidated Tax Base, in: The Tax Executive, Vol. 55 (2003), S. 238-240.

Teubner, Gunther, Recht als autopoietisches System, Frankfurt am Main 1989.

Theisen, Manuel René, Der Konzern, Betriebswirtschaftliche und rechtliche Grundlagen der Konzernunternehmung, 2. Aufl., 2000.

Theisen, Manuel René, Die Gewinnerzielungsabsicht als Besteuerungsmerkmal unternehmerischen Handelns, in: StuW, 65. Jg. (1988), S. 39-45.

Theisen, Manuel René, Die theoretischen Grundlagen der „neuen Methoden“ in betriebswirtschaftlicher Sicht, in: Verrechnungspreise bei Lizenzen und Dienstleistungen, Mit Diskussionsbeiträgen eines Münchener Symposiums, München 1990, S. 21-37.

Theisen, Manuel René, Vorüberlegungen zu einer Konzernunternehmungslehre, in: DBW, 48. Jg. (1988), S. 279-297.

Thiel, Jochen, Maßgeblichkeit und internationale Bilanzierung, in: Weltweite Rechnungslegung und Prüfung, Bericht über die IDW-Fachtagung, 1.-2. Oktober 1997 in Hannover, hrsg. vom IDW, Düsseldorf 1998, S. 91-104.

Tipke, Klaus, Auslegung unbestimmter Rechtsbegriffe, in: Handwörterbuch unbestimmter Rechtsbegriffe im Bilanzrecht des HGB, hrsg. von Leffson, Ulrich et al., Köln 1986, S. 1-11.

Tipke, Klaus, Die Steuerrechtsordnung, Band I: Wissenschaftsorganisatorische, systematische und grundrechtlich-rechtsstaatliche Grundlagen, 2. Aufl., Köln 2000.

Tipke, Klaus, Die Steuerrechtsordnung, Band II: Steuerrechtfertigungstheorie, Anwendung auf alle Steuerarten, sachgerechtes Steuersystem, Köln 1993.

Tipke, Klaus, Resümee, in: Besteuerung von Einkommen: Rechtsvergleich Italien, Deutschland und Spanien als Beitrag zur Harmonisierung des Steuerrechts in Europa, hrsg. von Tipke, Klaus/Bozza, Nadya, Berlin 2000, S. 305-314.

Tipke, Klaus, Steuergerechtigkeit in Theorie und Praxis, Vom politischen Schlagwort zum Rechtsbegriff und zur praktischen Anwendung, Köln 1981.

Tipke, Klaus/Lang, Joachim, Steuerrecht, 17. Aufl., Köln 2002.

Uelner, Adalbert, Der Mitunternehmergewinn als Betriebsvermögensmehrung des Mitunternehmers, in: Jahrbuch der Fachanwälte für Steuerrecht 1978/1979, Aktuelle steuerrechtliche Beiträge, Referate und Diskussionen der 29. Steuerrechtlichen Jahresarbeitstagung, Wiesbaden vom 8. bis 10. Mai 1978, hrsg. vom Deutschen Anwaltsinstitut e.V., Herne et al. 1978/79, S. 300-329. 
Uelner, Adalbert, Ergänzungs- und Sonderbilanzen, in: Probleme des Steuerbilanzrechts, hrsg. von Doralt, Werner, DStJG, Bd. 14, Köln 1991, S. 139-159.

UNICE (Union of Industrial and Employers' Confederations of Europe), UNICE Memorandum on Cross-Border Company Taxation Obstacles in the Single Market, Brüssel 3.4.2000.

Valcárcel, Sylvia, Theorie der Unternehmung und Corporate Governance, Eine vertrags- und ressourcenbezogene Betrachtung, Wiesbaden 2002.

van den Tempel, A. J., Körperschaftsteuer und Einkommensteuer in den Europäischen Gemeinschaften, Kollektion Studien der Europäischen Gemeinschaften, Reihe Rechtsangleichung Nr. 15, Brüssel 1971.

Vanberg, Viktor, Markt und Organisation, Individualistische Sozialtheorie und das Problem korporativen Handelns, Tübingen 1982.

Vogel, Klaus, Harmonisierung des Internationalen Steuerrechts in Europa als Alternative zur Harmonisierung des (Materiellen) Körperschaftsteuerrechts, in: StuW, 70 Jg. (1993), S. 380-388.

Voss, Bernd W., Zur Einheitsbesteuerung verbundener Unternehmen aus betriebswirtschaftlicher Sicht, in: AG, 18. Jg. (1973), S. 326-329.

Wacker, Wilhelm H., Relative Maßgeblichkeit im Rahmen der bilanziellen und pagatorischen steuerlichen Gewinnermittlung, in: Unternehmensrechnung und besteuerung (Festschrift Dietrich Börner), hrsg. von Meffert, Heribert/Krawitz, Norbert, Wiesbaden 1998, S. 231-261.

Wagner, Franz W., „Karlsruher Entwurf zur Reform des Einkommensteuergesetzes“ - Anmerkungen aus der Perspektive ökonomischer Vernunft, in: StuW, 78. Jg. (2001), S. 354-362.

Wagner, Franz W., Aufgabe der Maßgeblichkeit bei einer Internationalisierung der Rechnungslegung?, Eine Anaylse der ökonomischen Wirkungen des Bilanzsteuerrechts, in: DB, 51. Jg. (1998), S. 2073-2077.

Wagner, Franz W., Eine Einkommensteuer muß eine konsumorientierte Steuer sein, in: Einkommen versus Konsum, Ansatzpunkte zur Steuerreformdiskussion, hrsg. von Smekal, Christian/Sendlhofer, Rupert/Winner, Hannes, Heidelberg 1999, S. 15 35.

Wagner, Franz W., Gegenstand und Methoden betriebswirtschaftlicher Steuerforschung, in: StuW, 81. Jg. (2004), S. 237-250.

Wagner, Franz W., Grundfragen und Entwicklungstendenzen der betriebswirtschaftlichen Steuerplanung, in: BFuP, 36 Jg. (1984), S. 201-222.

Wagner, Franz W., Neutralität und Gleichmäßigkeit als ökonomische und rechtliche Kriterien steuerlicher Normkritik, in: StuW, 69. Jg. (1992), S. 2-13.

Wagner, Franz W., Welche Kriterien sollten die Neuordnung der steuerlichen Gewinnermittlung bestimmen?, in: BB, 57. Jg. (2002), S. 1885-1892. 
Wagner, Franz W./Dirrigl, Hans, Die Steuerplanung der Unternehmung, Stuttgart et al. 1980.

Wagner, Franz W./Wenger, Ekkehard, Theoretische Konzeption und legislative Transformation eines marktwirtschaftlichen Steuersystems in der Republik Kroatien, in: Regulierung und Unternehmenspolitik, Methoden und Ergebnisse der betriebswirtschaftlichen Rechtsanalyse, hrsg. von Sadowski, Dieter/Czap, Hans/Wächter, Hartmut, Wiesbaden 1996, S. 399-415.

Wagner, Franz W./Wissel, Harald, Entscheidungsneutralität der Besteuerung als Leitlinie einer Reform der Einkommensteuer, in: WiSt, 24. Jg. (1995), S. 65-70.

Wagner, Ralph, Die Grenzen der Unternehmung, Beiträge zur ökonomischen Theorie der Unternehmung, Heidelberg 1994.

Wald, Abraham, Über einige Gleichungssysteme der mathematischen Ökonomie, Zeitschrift für Nationalökonomie, Bd. VII (1936), S. 637-670.

Wallis, von, Das Konzernrecht des Aktiengesetzes 1965 und das Konzernsteuerrecht, in: AG, 12. Jg. (1967), S. 40-46.

Walras, Léon, Éléments d'économie politique pure ou théorie de la richesse social, Lousanne et al. 1874.

Walter, Norbert, Steuerreform ohne Grenzen, in: FAZ, Nr. 285 v. 8.12.2003, S. 22.

Walz, W. Rainer, Empfiehlt sich eine rechtsformunabhängige Besteuerung der Unternehmen?, Gutachten F für den 53. Deutschen Juristentag, in: Verhandlungen des Dreiundfünfzigsten Deutschen Juristentages, Bd. I, Teil F, München 1980.

Walz, W. Rainer, Ökonomische Regulierungstheorien vor den Toren des Bilanzrechts, in: Ökonomische Analyse des Bilanzrechts, hrsg. von Wagner, Franz W., in: ZfbF, 45. Jg. (1993), Sonderheft 32, S. 85-106.

Walz, W. Rainer, Rechtspolitik und Betriebswirtschaftslehre, Eine juristische Perspektive, in: Regulierung und Unternehmenspolitik, Methoden und Ergebnisse der betriebswirtschaftlichen Rechtsanalyse, hrsg. von Sadowski, Dieter/Czap, Hans/Wächter, Hartmut, Wiesbaden 1996, S. 23-49.

Walz, W. Rainer, Steuergerechtigkeit und Rechtsanwendung, Grundlinien einer relativ autonomen Steuerrechtsdogmatik, Heidelberg et al. 1980.

Walzer, Klaus, Hauptgründe für die Wahl einer Besteuerung nach dem Leistungsfähigkeitsprinzip, in: StuW, 63. Jg. (1986), S. 201-209.

Wassermeyer, Franz, Aktuelle Streitfragen zur grenzüberschreitenden verdeckten Gewinnausschüttung und zur verdeckten Einlage, in: Steuerrecht und steuerorientierte Gestaltung im Konzern, Kölner Konzernrechtstage, hrsg. von Schaumburg, Harald, Köln 1998, S. 363-378.

Watrin, Christian, ,Marktversagen' versus ,Staatsversagen': Zur Rolle von Markt und Staat in einer freien Gesellschaft, Zürich 1986. 
Watrin, Christoph/Sievert, Elke/Strohm, Christiane, Reform der Konzernbesteuerung in Deutschland und Europa, in: FR, 86. Jg. (2004), S. 1-11.

Watrin, Christoph/Strohm, Christiane/Struffert, Ralf, Aktuelle Entwicklungen von Unternehmenszusammenschlüssen nach IFRS, in: WPg, 57. Jg. (2004), S. 14501461.

Watt, George C./Hammer, Richard M./Burge, Marianne, Accounting for the Multinational Corporation, Homewood, Ill. 1977.

Watts, Ross L., Conservatism in Accounting, Part I: Explanations and Implications, in: Accounting Horizons, Vol. 17 (2003), S. 207-221.

WB Ernst \& Young (Wissenschaftlicher Beirat des Fachbereichs Steuer der Ernst \& Young, Wirtschaftsprüfungsgesellschaft), Stellungsnahme zur Abschaffung des Teilwerts, Zugleich ein Beitrag zur Vereinfachung des Steuerrechts, in: BB, 59. Jg. (2004), Beilage 3.

Weber, Alfred, Die konsolidierte Besteuerung von Konzernen in den $\boldsymbol{U S A}$, in: DStZ, 67. Jg. (1979), S. 146-151.

Weber, Claus-Peter/Zündorf, Horst, $\$ 307$, in: Handbuch der Konzernrechnungslegung, Kommentar zur Bilanzierung und Prüfung, Bd. II, hrsg. von Küting, Karlheinz/Weber, Claus-Peter, 2. Aufl., Stuttgart 1998.

Weber, Max, Wirtschaft und Gesellschaft: Grundriss der verstehenden Soziologie, 5. Aufl., hrsg. von Winckelmann, Johannes, 1. Halbband, Tübingen 1976.

Weber-Grellet, Heinrich, Bestand und Reform des Bilanzsteuerrechts, in: DStR, 35. Jg. (1998), S. 1343-1349.

Weber-Grellet, Heinrich, Fairne $\boldsymbol{\beta}$, Aufklärung und Transparenz, Wege zu einer leistungsgerechten Besteuerung, in: StuW, 76. Jg. (1999), S. 311-320.

Weber-Grellet, Heinrich, Maßgeblichkeitsgrundsatz in Gefahr?, in: DB, 50. Jg. (1997) S. 385-391.

Weber-Grellet, Heinrich, Maßgeblichkeitsschutz und eigenständige Zielsetzung der Steuerbilanz, in: DB, 47. Jg. (1994), S. 288-291.

Weide, Klaus-Michael, Harmonisierung der Unternehmenssteuern in der EG, Aachen 1996.

Weiner, Joann Martens, Formulary Apportionment and the Future of Company Taxation in the European Union, in: CESifo Forum, Vol. 3 (1/2002), S. 10-20.

Weizsäcker, Carl Christian von, The Influence of Property Rights on Tastes, in: Zeitschrift für die gesamte Staatswissenschaft, 140. Jg. (1984), S. 90-95.

Wellisch, Dietmar, Maßstäbe zur indirekten Gewinnaufteilung im Rahmen einer neuen Konzernbesteuerung in der EU: Möglichkeiten und Grenzen, in: StuW, 81. Jg. (2004), S. 267-275. 
Wenger, Ekkehard, Einkommensteuerliche Periodisierungsregeln, Unternehmenserhaltung und optimale Einkommensbesteuerung (Teil I und II), in: ZfB, 55. Jg. (1985), S. 710-730 und 56. Jg. (1986), S. 132-151.

Wenger, Ekkehard, Gleichmäßigkeit der Besteuerung von Arbeits- und Vermögenseinkünften, in: Finanzarchiv, N. F., Bd. 41 (1983), S. 207-252.

Wenger, Ekkehard, Warum die Finanzwissenschaft bei der Suche nach einer theoretischen Basis für die Einkommensteuer erfolglos bleiben mußte, in: Einkommen versus Konsum, Ansatzpunkte zur Steuerreformdiskussion, hrsg. von Smekal, Christian/Sendlhofer, Rupert/Winner, Hannes, Heidelberg 1999, S. 37-63.

Wenger, Ekkehard/Hecker, Renate, Der Vorzugsaktionär als bevorzugtes Plünderungsopfer, in: Steuern, Rechnungslegung und Kapitalmarkt (Festschrift Franz W. Wagner), hrsg. von Dirrigl, Hans/Wellisch, Dietmar/Wenger, Ekkehard, Wiesbaden 2004, S. 265-295.

Wentland, Norbert, Die Konzernbilanz als Bilanz der wirtschaftlichen Einheit Konzern, Grundlagen der Konzernrechnungslegung unter Berücksichtigung der Vorschriften des Aktiengesetzes und der Vorstellungen einer 7. EG-Richtlinie, Frankfurt am Main et al. 1979.

Wersig, Gernot, Information - Kommunikation - Dokumentation: Ein Beitrag zur Orientierung der Informations- und Dokumentationswissenschaften, München et al. 1971.

Wessling, Ewald, Individuum und Information: Die Erfassung von Information und Wissen in ökonomischen Handlungstheorien, Tübingen 1991.

Westberg, Björn, Consolidated Corporate Tax Bases for EU-wide Activities: Evaluation of Four Proposals Presented by the European Commission, in: European Taxation, Vol. 42 (2002), S. 322-330.

Weston, Stephen F., Principles of Justice in Taxation, New York 1903 (First AMS Edition, 1968).

Whittington, Geoffrey, Tax Policy and Accounting Standards, in: British Tax Review, 1995, No. 5, S. $452-456$.

Wicksell, Knut, Finanztheoretische Untersuchungen nebst Darstellung und Kritik des Steuerwesens, Jena 1896.

Wiedemann, Herbert, Gesellschaftsrecht, Ein Lehrbuch des Unternehmens- und Verbandsrechts, Bd. I: Grundlagen, München 1980.

Wiethölter, Rudolf, Interessen und Organisation der Aktiengesellschaft im amerikanischen und deutschen Recht, Karlsruhe 1961. 
Williamson, Oliver E., Comparative Economic Organization - Vergleichende ökonomische Organisationstheorie, Die Analyse diskreter Strukturalternativen, in: Betriebswirtschaftslehre und ökonomische Theorie, hrsg. von Ordelheide, Dieter et al., Stuttgart 1991, S. 13-49.

Williamson, Oliver E., Economic Institutions: Spontaneous and Intentional Governance, in: Journal of Law, Economics, and Organization, Vol. 7 (1991), S. 159-187.

Williamson, Oliver E., Markets and Hierarchies: Analysis and Antitrust Implications, A Study in the Economics of Internal Organization, New York et al. 1975.

Williamson, Oliver E., The Economic Institutions of Capitalism: Firms, Marktes, Relational Contracting, New York et al. 1985.

Williamson, Oliver E., The Modern Corporation: Origins, Evolution, Attributes, in: Journal of Economic Literature, Vol. 19 (1981), S. 1537-1568.

Williamson, Oliver E., Transaction-Cost Economics: The Governance of Contractual Relations, in: Journal of Law and Economics, Vol. 22 (1979), S. 233-262.

Willis, Diana W., Financial Assets and Liabilities - Fair Value or Historical Cost?, in: WPg, 51 Jg. (1998), S. 854-860.

Windsperger, Josef, Gleichgewicht und Wissen, Analyse des Hayek'schen Konzeptes, in: Jahrbuch für Sozialwissenschaft, Bd. 34, Göttingen 1983, S. 232-245.

Winnefeld, Robert, Bilanz-Handbuch, Handels- und Steuerbilanz, rechtsformspezifisches Bilanzrecht, bilanzielle Sonderfragen, Sonderbilanzen, IAS/US-GAAP, 3. Aufl., München 2002.

Winter, Sidney G., On Coase, Competence, and the Corporation, in: Journal of Law, Economics, and Organization, Vol. 4 (1988), S. 163-180.

Winterberger, Andreas K., Hayeks Theorie der Gerechtigkeit, in: In memoriam Friedrich August von Hayek (1899 - 1992), Schweizer Monatshefte für Politik, Wirtschaft, Kultur, 92. Jg. (1992), Sonderheft Nr. 5a, S. 99-105.

Wittmann, Rolf, Das Markteinkommen - einfachgesetzlicher Strukturbegriff und verfassungsdirigierter Anknüpfungsgegenstand der Einkommensteuer?, Diss. Augsburg 1992.

Wittmann, Waldemar, Unternehmung und unvollkommene Information, Köln et al. 1959.

Wöhe, Günter, Betriebswirtschaftliche Steuerlehre, Bd. II, 2. Halbband: Der Einfluß der Besteuerung auf Unternehmenszusammenschlüsse und Standortwahl im nationalen und internationalen Bereich, 4. Aufl., München 1996.

Wöhe, Günter, Die Aufgaben der Betriebswirtschaftlichen Steuerlehre und das Postulat der Wertfreiheit, in: Unternehmung und Steuer (Festschrift Peter Scherpf), hrsg. von Fischer, Lutz, Wiesbaden 1983, S. 5-20. 
Wöhe, Günter, Überblick über die Konzernbesteuerung, in: Handbuch der Konzernrechnungslegung, Kommentar zur Bilanzierung und Prüfung, Bd. II, hrsg. von Küting, Karlheinz/Weber, Claus-Peter, 2. Aufl., Stuttgart 1998, S. 325-377.

Wöhe, Günter, Zur Bilanzierung und Bewertung des Firmenwertes, in: StuW, 57. Jg. (1980), S. 89-108.

Wolf, Charles, jr., A Theory of Nonmarket Failure: Framework for Implementation Analysis, in: Journal of Law and Economics, Vol. 22 (April 1979), S. 107-139.

Wolz, Matthias, Die Festlegung von Wesentlichkeitsgrenzen in der deutschen Wirtschaftsprüferpraxis, in: ZfbF, 56. Jg. (2004) S. 122-145.

Wosnitza, Michael/Treisch, Corinna, Leistungsfähigkeitskonzeptionen und steuerliche Behandlung des Existenzminimums, in: DBW, 59. Jg. (1999), S. 351-368.

Wudernitz, Brigitte, Entwicklung der Konzernbesteuerung in den $\boldsymbol{U S A}$, Wien et al. 1996.

Wüstemann, Jens/Duhr, Andreas, Geschäftswertbilanzierung nach dem Exposure Draft $\boldsymbol{E D} 3$ des IASB - Entobjektivierung auf den Spuren des FASB?, in: BB, 58. Jg. (2003), S. 247-253.

Wysocki, Klaus von, Weltbilanzen als Planungsobjekte und Planungsinstrumente multinationaler Unternehmen, in: ZfbF, 25. Jg. (1973), S. 682-700.

Wysocki, Klaus von/Wohlgemuth, Michael, Konzernrechnungslegung, 4. Aufl., Düsseldorf 1996.

Zabel, Martin, IAS zwingend für Konzern- und Einzelabschluss? - Stellungnahme zu Böcking, WPg 2001, S. 1433 ff.; zugleich ein Plädoyer für eine intensivere Diskussion der Vor- und Nachteile kapitalmarktorientierter Rechnungslegungs- und Publizitätsgrundsätze für nicht kapitalmarktorientierte Unternehmen, in: WPg, 55. Jg. (2002), S. 919-924.

Zeitler, Franz-Christoph, Europäische Steuerharmonisierung und direkte Steuern, Erste Überlegungen zum Vorentwurf eines Vorschlags der EG-Kommission für eine Richtlinie über die Harmonisierung der Gewinnermittlungsvorschriften, in: BB, 43. Jg. (1988), Beilage 17.

Zeitler, Franz-Christoph, Rechnungslegung und Rechtsstaat, Übernahme der IAS oder Reform des HGB?, in: DB, 56. Jg. (2003), S. 1529-1534.

Zezschwitz, Friedrich von, Die Bilanzbündeltheorie - ein brüchiger Torso (I. Teil und Schluß), in FR, 25. Jg. (1970), S. 133-140, 158-165.

Zimmermann, Horst/Henke, Klaus-Dirk, Finanzwissenschaft, Eine Einführung in die Lehre von der öffentlichen Finanzwirtschaft, 8. Aufl., München 2001.

Zodrow, George R., Tax Competition and Tax Coordination in the European Union, in: International Tax and Public Finance, Vol. 10 (2003), S. 651-671. 
Zülch, Henning, Die Bilanzierung von Unternehmenszusammenschlüssen nach IFRS 3 und ihre Implikationen für die Bewertungspraxis, in: UM, 1. Jg. (2004), S. 331-339.

Zünd, André, Einheitliche Leitung - Bedeutung und Tauglichkeit des Begriffs, in: Das St. Galler Konzernrechtsgespräch, Konzernrecht aus der Konzernwirklichkeit, hrsg. von Druey, Jean Nicolas, Bern et al. 1988, S. 77-85.

Zündorf, Horst, Quotenkonsolidierung versus Equity-Methode, Zur Einbeziehung von Gemeinschaftsunternehmen in den neuen Konzernabschluß nach neuem Konzernbilanzrecht, Stuttgart 1987. 
Rolf Uwe Fülbier - 978-3-631-75507-5

Downloaded from PubFactory at 01/11/2019 04:02:44AM 


\section{Rechtsquellenverzeichnis}

\section{Inländische (deutsche) Rechtsquellen}

AktG, Aktiengesetz vom 6. September 1965, BGBl. I 1965, S. 1089.

AO, Abgabenordnung vom 16. März 1976, BGBl. I 1976, S. 613, ber. BGBl. I 1977, S. 269.

BewG, Bewertungsgesetz in der Fassung der Bekanntmachung vom 1. Februar 1991, BGBI. I 1991, S. 230.

BGB, Bürgerliches Gesetzbuch in der Fassung der Bekanntmachung vom 2. Januar 2002, BGBI. I 2002, S. 42, 45, ber. S. 2909, erneut ber. BGBl. I 2003, S. 738.

BilReG, Gesetz zur Einführung internationaler Rechnungslegungsstandards und zur Sicherung der Qualität der Abschlussprüfung (Bilanzrechtsreformgesetz) vom 4. Dezember 2004, BGBI. I 2004, S. 3166.

BiRiLiG, Gesetz zur Durchführung der Vierten, Siebenten und Achten Richtlinie des Rates der Europäischen Gemeinschaften zur Koordinierung des Gesellschaftsrechts vom 19. Dezember 1985 (Bilanzrichtlinien-Gesetz), BGBl. I 1985, S. 2355.

BörsG, Börsengesetz in der Fassung der Bekanntmachung vom 21. Juni 2002, BGBl. I 2002, S. 2010.

BörsZulV, Verordnung über die Zulassung von Wertpapieren zum amtlichen Markt an einer Wertpapierbörse (Börsenzulassungs-Verordnung) in der Fassung der Bekanntmachung vom 9. September 1998, BGBl. I 1998, S. 2832.

EStDV, Einkommensteuer-Durchführungsverordnung in der Fassung der Bekanntmachung vom 10. Mai 2000, BGBI. I 2000, S. 717.

EStG, Einkommensteuergesetz in der Fassung der Bekanntmachung vom 19. Oktober 2002, BGBl. I 2002, S. 4210, ber. BGBl. I 2003, S. 179.

EStR (einschließlich EStH), Einkommensteuer-Richtlinien 2003, Allgemeine Verwaltungsvorschrift zur Anwendung des Einkommensteuerrechts vom 15.12.2003 (BStB1. I Sondernummer 2).

GewStG, Gewerbesteuergesetz in der Fassung der Bekanntmachung vom 15. Oktober 2002, BGBl. I 2002, S. 4167.

GG, Grundgesetz für die Bundesrepublik Deutschland vom 23. Mai 1949, BGBl. 1949, S. 1.

HGB, Handelsgesetzbuch vom 10. Mai 1897, RGBl. 1897, S. 219.

KapAEG, Gesetz zur Verbesserung der Wettbewerbsfähigkeit deutscher Konzerne an internationalen Kapitalmärkten und zur Erleichterung der Aufnahme von Gesell- 
schafterdarlehen (Kapitalaufnahmeerleichterungsgesetz,) vom 20. April 1998, BGBl. I 1998, S. 707.

KSTG, Körperschaftsteuergesetz in der Fassung der Bekanntmachung vom 15. Oktober 2002, BGBl. I 2002, S. 4144.

KStR, Körperschaftsteuer-Richtlinien 1995, Allgemeine Verwaltungsvorschrift zur Körperschaftsteuer vom 15.12.1995 (BStBl. 1996 I Sondernummer 1).

PartGG, Gesetz über Partnerschaftsgesellschaften Angehöriger Freier Berufe (Partnerschaftsgesellschaftsgesetz) vom 25. Juli 1994, BGBl. I 1994, S. 1744.

PublG, Gesetz über die Rechnungslegung von bestimmten Unternehmen und Konzernen (Publizitätsgesetz) vom 15. August 1969, BGBI. I 1969, S. 1189, ber. BGBl. I 1970, S. 1113.

UmwStG, Umwandlungssteuergesetz in der Fassung der Bekanntmachung vom 15. Oktober 2002, BGBl. I 2002, S. 4133.

UStG, Umsatzsteuergesetz 1999 in der Fassung der Bekanntmachung vom 9. Juni 1999, BGBl. I 1999, S. 1270.

\section{EU-Rechtsquellen}

EU-Verordnung Nr. 1606/2002, Verordnung (EG) Nr. 1606/2002 des Europäischen Parlaments und des Rates vom 19. Juli 2002 betreffend die Anwendung internationaler Rechnungslegungsstandards, AB1.EG L 243/1.

EU-Verordnung Nr. 2157/2001, Verordnung (EG) Nr. 2157/2001 des Rates vom 8. Oktober 2001 über das Statut der Europäischen Gesellschaft (SE), ABl.EG L 294/1.

Fusionsrichtlinie, Richtlinie 90/434/EWG des Rates vom 23. Juli 1990 über das gemeinsame Steuersystem für Fusionen, Spaltungen, die Einbringung von Unternehmensteilen und den Austausch von Anteilen, die Gesellschaften verschiedener Mitgliedstaaten betreffend, ABl.EG L 225/1.

Konzernrechtsrichtlinie, Vorschlag für eine neunte Richtlinie auf der Grundlage von Art 54 Absatz 3 Buchstabe g) des EWG-Vertrages über die Verbindungen zwischen Unternehmen insbesondere über Konzerne, abgedruckt in Lutter (neunte Richtlinie, 1985) S. 446-465.

Mutter-Tochter-Richtlinie, Richtlinie 90/435/EWG des Rates vom 23. Juli 1990 über das gemeinsame Steuersystem der Mutter- und Tochtergesellschaften verschiedener Mitgliedstaaten, ABl.EG L 225/6.

Richtlinie 2001/86/EG, Richtlinie 2001/86/EG des Rates vom 8. Oktober 2001 zur Ergänzung des Statuts der Europäischen Gesellschaft hinsichtlich der Beteiligung der Arbeitnehmer, ABI.EG L 294/22. 
Schiedsgerichtskonvention, Übereinkommen über die Beseitigung der Doppelbesteuerung im Falle von Gewinnberichtigungen zwischen verbundenen Unternehmen Schlussakte - Gemeinsame Erklärungen - Einseitige Erklärungen, 90/436/EWG, ABl.EG L 225/10.

Siebente EG-Richtlinie, (Siebente) Richtlinie des Rates vom 13. Juni 1983 aufgrund von Artikel 54 Absatz 3 Buchstabe g) des Vertrages über den konsolidierten Abschluß (83/349/EWG), ABl.EG L 193/1.

Verlustrichtlinie, Vorschlag für eine Richtlinie des Rates über eine Regelung für Unternehmen zur Berücksichtigung der Verluste ihrer in anderen Mitgliedstaaten belegenen Betriebsstätten und Tochtergesellschaften (Kom/90/595endg), ABI.EG C 053/30 vom 28.2.1991 (ohne Text), abgedruckt in Bundesrat (Drucksache 96/91, 1991).

Vierte EG-Richtlinie, (Vierte) Richtlinie des Rates vom 25. Juli 1978 aufgrund von Artikel 54 Absatz 3 Buchstabe g) des Vertrages über den Jahresabschluß von Gesellschaften bestimmter Rechtsform (78/660/EWG), AB1.EG L 222/11.

Vorentwurf für eine Richtlinie des Rates über die Harmonisierung der steuerlichen Gewinnermittlungsvorschriften von 1988, abgedruckt in Kreile (Vorentwurf, 1988).

Vorschlag einer Richtlinie des Rates zur Harmonisierung der Körperschaftsteuersysteme und der Regelungen der Quellensteuer auf Dividenden (KOM/75/392endg), ABl.EG C 253/2, abgedruckt in Deutscher Bundestag (Drucksache 7/3981, 1975) S. 1-7.

Vorschlag einer Richtlinie über das gemeinsame Steuersystem für Mutter- und Tochtergesellschaften verschiedener Mitgliedstaaten (KOM/69/6endg), ABl.EG C 039/4 vom 22.3.1969 (ohne Text), abgedruckt in Deutscher Bundestag (Drucksache V/3774, 1969) S. 2-8; die zweite, modifizierte Version ist abgedruckt in Deutscher Bundestag (Drucksache VI/1344, 1970).

Zins- und Lizenz-Richtlinie, Richtlinie 2003/49/EG des Rates vom 3. Juni 2003 über eine gemeinsame Steuerregelung für Zahlungen von Zinsen und Lizenzgebühren zwischen verbundenen Unternehmen verschiedener Mitgliedstaaten, ABl.EU L $157 / 49$.

\section{Ausländische Rechtsquellen}

CGI, Code Général des Impôts [Frankreich].

CTA, Corporation Tax Act, 1976 [Irland].

ICTA, Income and Corporation Taxes Act 1988 (c.1)) [Vereinigtes Königreich]. 
IRC, Imposto sobre o Rendimento das Pessoas Colectivas [Portugal].

KStG, Körperschaftsteuergesetz 1988, BGBl. Nr. 401/1988 [Österreich].

Orden de 15 de julio de 1982 por la que se aprueban las normas sobre formación de las cuentas de los grupos de Sociedades [Spanien].

Real Decreto 1414/1977, de 17 de junio, por el que se regula la tributación sobre el Beneficio Consolidado de los Grupos de Sociedades [Spanien].

TCGA, Taxation of Chargeable Gains Act 1992 (c.12) [Vereinigtes Königreich].

Wet Vpb, Wet op de vennootschapsbelasting 1969 (8.10.1969, Stb. 445) [Niederlande].

\section{Standards des IASB}

IASB Framework, Framework for the Preparation and Presentation of Financial Statements, April 1989.

IASCF Constitution, IASC Foundation Constitution, July 2002.

IAS 1, Presentation of Financial Statements, December 2003.

IAS 21, The Effects of Changes in Foreign Exchange Rates, December 2003.

IAS 22, Business Combinations, September 1998.

IAS 27, Consolidated and Separate Financial Statements", December 2003.

IAS 27 (revised 2000), Consolidated Financial Statements and Accounting for Investments in Subsidiaries, April 1989, reformatted 1994, amended and revised 1998, 2000.

IAS 28, Investments in Associates, December 2003.

IAS 28 (revised 2000), Accounting for Investments in Associates, April 1989, reformatted 1994, amended and revised 1998, 1999, 2000.

IAS 29, Financial Reporting in Hyperinflationary Economies, July 1989, reformatted 1994.

IAS 31, Interests in Joint Ventures, December 2003.

IAS 36, Impairment of Asets, March 2004.

IAS 37, Provisions, Contingent Liabilities and Contingent Assets, September 1998.

IAS 38, Intangible Assets, March 2004.

IAS 39, Financial Instruments: Recognition and Measurement, December 2003, March 2004 revised to reflect Macro Hedging.

IFRS 3, Business Combinations, March 2004. 
IFRS 5, Non-current Assets Held for Sale and Discontinued Operations, March 2004.

\section{Standards des FASB (und der Vorgängerorganisationen)}

APB Opinion 16, Business Combinations, August 1970.

ED (Proposed Statement of Financial Accounting Standards), Fair Value Measurements, in: Financial Accounting Series, No. 1201-100, June 23, 2004.

SFAC No. 7, Using Cash Flow Information and Present Value in Accounting Measurements, February 2000.

SFAS No. 141, Business Combinations, June 2001.

SFAS No. 142, Goodwill and Other Intangible Assets, June 2001. 
Rolf Uwe Fülbier - 978-3-631-75507-5

Downloaded from PubFactory at 01/11/2019 04:02:44AM 


\section{Rechtsprechungsverzeichnis}

\begin{tabular}{|c|c|c|}
\hline \multicolumn{3}{|c|}{ Bundesverfassungsgericht (BVerfG) } \\
\hline 24.01.1962, Urteil & $1 \mathrm{BvR} 845 / 58$ & BStBl. 1962 I, S. 500-506 \\
\hline 20.12.1966, Urteil & $1 \mathrm{BvR} 320 / 57,1 \mathrm{BvF}$ & 70/63 BStBl 1967 III, S. 7-16 \\
\hline 15.07.1969, Beschluss & $1 \mathrm{BvR} 457 / 66$ & BVerfGE, Bd. 26, 1970, S. 327-338 \\
\hline 16.03.1982, Beschluss & 1 BvR 938/81, & BVerfGE, Bd. 60,1982, S. $123-135$ \\
\hline 03.11.1982, Urteil & $1 \mathrm{BvR} 620 / 78,133$ & $\begin{array}{l}78,1104 / 79 \text { u. } 36 \\
\text { BVerfGE, Bd. } 6\end{array}$ \\
\hline 16.11.1982, Beschluss & $1 \mathrm{BvL} 16 / 75$ u. $36 / 7$ & 1983, S. 256-294 \\
\hline 28.11.1984, Beschluss & $1 \mathrm{BvR} 1157 / 82$ & BVerfGE, Bd. 68,1985 , S. $287-311$ \\
\hline 10.02.1987, Urteil & $1 \mathrm{BvL} 18 / 81$ u. $20 / 8$ & BVerfGE, Bd. 74, 1987, S. 182-202 \\
\hline 23.01.1990, Beschluss & $1 \mathrm{BvL} 4,5,6,7 / 87$ & BVerfGE, Bd. 81, 1990, S. 228-242 \\
\hline 22.06.1995, Beschluss & 2 BvL 37/91 & BVerfGE, Bd. 93, 1996, S. 121-165 \\
\hline 2.06 .1995$, Beschluss & 2 BvR 552/91 & BVerfGE, Bd. 93, 1996, S. 165-179 \\
\hline
\end{tabular}

Bundesgerichtshof (BGH)

29.1.2001, Urteil

II ZR 331/00

http://www.bundesgerichtshof.de

\section{Reichsfinanzhof (RFH)}

11.11.1927, Urteil

I A 75/27 RStBl. 1928, S. 52

26.07.1932, Gutachten

I D 2/31 u. III D 2/32 RStBl. 1935, S. 136-140

18.02.1933, Urteil

I A $439 / 32$

RStB1. 1933, S. 647-649

25.09.1934, Bescheid, bestätigt durch Urteil v. 22.1.1935

I A 401/32

03.07.1935, Urteil

VI A $1149 / 33$

Bundesfinanzhof (BFH)

27.01.1956, Gutachten

17.11.1966, Urteil

26.07.1967, Urteil

11.12.1969, Urteil

03.02.1971, Urteil

08.01.1975, Urteil

23.07.1975, Urteil

10.11.1980, Beschluss

25.06.1984, Beschluss

14.11.1985, Urteil

21.04.1988, Urteil

13.09.1989, Urteil
I D $1 / 56 \mathrm{~S}$

I $280 / 63$

I $138 / 65$

IV R 92/68

I R $51 / 66$

I R $142 / 72$

I R $165 / 73$

GrS $1 / 79$

GrS 4/82

IV R $63 / 83$

IV R $80 / 86$

I R $117 / 87$
RStB1. 1935, S. 517-523

RStBl. 1935, S. 1127-1128
BStB1. 1957 III, S. 139-146

BStB1. 1967 III, S. 118-120

BStBl. 1967 III, S. 733-734

BStB1. 1970 II, S. 618-620

BStBl. 1971 II, S. 408-411

BStB1. 1975 II, S. 437-439

BStBl. 1976 II, S. 73-74

BStBl. 1981 II, S. 164-170

BStB1. 1984 II, S. 751-770

BStBl. 1986 II, S. 58-60

BStBl. 1988 II, S. 883-885

BStBl. 1990 II, S. 57-60 
23.10.1990, Urteil

25.02.1991, Beschluss

13.07.1993, Urteil

29.07.1994, Urteil

03.07.1995, Beschluss

02.12.1997, Urteil

13.10.1998, Urteil

20.01.1999, Urteil
VIII R 142/85

GrS 7/89

VIII R 50/92

I R $11 / 94$

GrS 1/93

VIII R 15/96

VIII R 78/97

I R $32 / 98$
BStBl. 1991 II, S. 401-404

BStBl. 1991 II, S. 691-703

BStBl. 1994 II, S. 282-287

BStBl. 1994 II, S. 952-954

BStBl. 1995 II, S. 617-622

DStR 36. Jg. (1998), S. 482-484

BStB1. 1999 II, S. 163-167

BFHE, Bd. 188, 1999, S. 24-27 


\section{Bochumer Beiträge zur Unternehmensführung}

Herausgegeben vom Direktorium des Instituts für Unternehmensführung der Ruhr-Universität Bochum

Band 1 Busse von Colbe, Walther/Mattessich, Richard (Hrsg.): Der Computer im Dienste der Unternehmungsführung (1968)

Band 2 Busse von Colbe, Walther/Meyer-Dohm, Peter (Hrsg.): Unternehmerische Planung und Entscheidung (1969)

Band 3 Anthony, Robert N.: Harvard-Fälle aus der Praxis des betrieblichen Rechnungswesens. Herausgegeben von Richard V. Mattessich unter Mitarbeit von Klaus Herrnberger und Wolf Lange (1969)

Band 4 Mattessich, Richard: Die wissenschaftlichen Grundlagen des Rechnungswesens (1970)

Band 5 Schweim, Joachim: Integrierte Unternehmungsplanung (1969)

Band 6 Busse von Colbe, Walther (Hrsg.): Das Rechnungswesen als Instrument der Unternehmungsführung (1969)

Band 7 Domsch, Michel: Simultane Personal- und Investitionsplanung im Produktionsbereich (1970)

Band 8 Leunig, Manfred: Die Bilanzierung von Beteiligungen. Eine bilanztheoretische Untersuchung (1970)

Band 9 Franke, Reimund: Betriebsmodelle. Rechensystem für Zwecke der kurzfristigen Planung, Kontrolle und Kalkulation (1972)

Band 10 Wittenbrink, Hartwig: Kurzfristige Erfolgsplanung und Erfolgskontrolle mit Betriebsmodellen (1975)

Band 11 Lutter, Marcus (Hrsg.): Recht und Steuer der internationalen Unternehmensverbindungen (1972)

Band 12 Niebling, Helmut: Kurzfristige Finanzrechnung auf der Grundlage von Kosten- und Erlösmodellen (1973)

Band 13 Perlitz, Manfred: Die Prognose des Unternehmenswachstums aus Jahresabschlüssen deutscher Aktiengesellschaften (1973)

Band 14 Niggemann, Walter: Optimale Informationsprozesse in betriebswirtschaftlichen Entscheidungssituationen (1973)

Band 15 Richardt, Harald: Der aktienrechtliche Abhängigkeitsbericht unter ökonomischen Aspekten (1974)

Band 16 Backhaus, Klaus: Direktvertrieb in der Investitionsgüterindustrie - Eine Marketing-Entscheiung (1974)

Band 17 Plinke, Wulff: Kapitalsteuerung in Filialbanken (1975)

Band 18 Steffen, Rainer: Produktionsplanung bei Fließbandfertigung (1977)

Band 19 Kolb, Jürgen: Industrielle Erlösrechnung - Grundlagen und Anwendungen (1978)

Band 20 Busse von Colbe, Walther/Lutter, Marcus (Hrsg.): Wirtschaftsprüfung heute: Entwicklung oder Reform? (1977)

Band 21 Uphues, Peter: Unternehmerische Anpassung in der Rezession (1979)

Band 22 Gebhardt, Günther: Insolvenzprognosen aus aktienrechtlichen Jahresabschlüssen (1980)

Band 23 Domsch, Michel: Systemgestützte Personalarbeit (1980)

Band 24 Schmied, Volker: Alternativen der Arbeitsgestaltung und ihre Bewertung (1982) 
Band 25 Wäscher, Gerhard: Innerbetriebliche Standortplanung bei einfacher und mehrfacher Zielsetzung (1982)

Band 26 Weber, Martin: Entscheidungen bei Mehrfachzielen - Verfahren zur Unterstützung von Individual- und Gruppenentscheidungen (1983)

Band 27 Kroesen, Alfred: Instandhaltungsplanung und Betriebsplankostenrechnung (1983)

Band 28 Plinke, Wulf: Erlösplanung im industriellen Anlagengeschäft (1985)

Band 29 Chamoni, Peter: Simulation störanfälliger Systeme (1986)

Band 30 Arning, Andreas: Die wirtschaftliche Bewertung der Zentrenfertigung - Dargestellt am Beispiel einer Fertigungsinsel (1987)

Band 31 Gebhardt, Günther: Finanzielle Planung und Kontrolle bei internationaler Unternehmenstätigkeit

Band 32 Markiewicz, Michael: Ersatzteildisposition im Maschinenbau - Betriebswirtschaftliche Methoden der Planung und Überwachung (1988)

Band 33 Pellens, Bernd: Der Informationswert von Konzernabschlüssen - Eine empirische Untersuchung deutscher Börsengesellschaften (1989)

Band 34 Mrotzek, Rüdiger: Bewertung direkter Auslandsinvestitionen mit Hilfe betrieblicher Investitionskalküle (1989)

Band 35 Deppe, Joachim: Quality Circle und Lernstatt - Ein integrativer Ansatz (1989, 3. Auflage 1993)

Band 36 Rademacher, Michael: Arbeitszeitverkürzung und -flexibilisierung - Formen und betriebliche Auswirkungen (1990)

Band 37 Kaiser, Klaus: Kosten- und Leistungsrechung bei automatisierter Produktion (1991, 2. Auflage 1993)

Band 38 Müller, Hermann: Industrielle Abfallbewältigung - Entscheidungsprobleme aus betriebswirtschaftlicher Sicht (1991)

Band 39 Schörner, Peter: Gesetzliches Insiderhandelsverbot - Eine ordnungspolitische Analyse (1991)

Band 40 Bentler, Martin: Grundsätze ordnungsmäßiger Bilanzierung für die Equitymethode (1991)

Band 41 Brüggerhoff, Jürgen: Management von Desinvestitionen (1992)

Band 42 Bröker, Erich W.: Erfolgsrechnung im industriellen Anlagengeschäft - Ein dynamischer Ansatz auf Zahlungsbasis - (1993)

Band 43 Frankenberg, Peter: Transnationale Analyse US-amerikanischer und deutscher Jahresabschlüsse - Eine theoretische und empirische Untersuchung (1993)

Band 44 Kleinaltenkamp, Michael: Standardisierung und Marktprozeß - Entwicklungen und Auswirkungen im CIM-Bereich (1993)

Band 45 Pellens, Bernhard: Aktionärsschutz im Konzern - Empirische und theoretische Analyse der Reformvorschläge der Konzernverfassung (1994)

Band 46 Reckenfelderbäumer, Martin: Marketing-Accounting im Dienstleistungsbereich - Konzeption eines prozeßkostengestützten Instrumentariums (1995)

Band 47 Knittel, Friedrich: Technikgestützte Kommunikation und Kooperation im Büro. Entwicklungshindernisse - Einsatzstrategien - Gestaltungskonzepte (1995)

Band 48 Riezler, Stephan: Lebenszyklusrechnung - Instrument des Controlling strategischer Projekte (1996)

Band 49 Schulte, Jörn: Rechnungslegung und Aktienkursentwicklung - Erklärung und Prognose von Aktienrenditen durch Einzel- und Konzernabschlußdaten (1996) 
Band 50 Muhr, Martin: Zeitsparmodelle in der Industrie - Grundlagen und betriebswirtschaftliche Bedeutung mehrjähriger Arbeitszeitkonten (1996)

Band 51 Brotte, Jörg: US-amerikanische und deutsche Geschäftsberichte. Notwendigkeit, Regulierung und Praxis jahresabschlußergänzender Informationen (1997)

Band 52 Gersch, Martin: Vernetzte Geschäftsbeziehungen. Die Nutzung von EDI als Instrument des Geschäftsbeziehungsmanagement (1998)

Band 53 Währisch, Michael: Kostenrechnungspraxis in der deutschen Industrie. Eine empirische Studie (1998)

Band 54 Völkner, Peer: Modellbasierte Planung von Geschäftsprozeßabläufen (1998)

Band 55 Fülbier, Rolf Uwe: Regulierung der Ad-hoc-Publizität. Ein Beitrag zur ökonomischen Analyse des Rechts (1998)

\section{Band 1 - 55 erschienen beim Gabler Verlag Wiesbaden}

Band 56 Ane-Kristin Reif-Mosel: Computergestützte Kooperation im Büro. Gestaltung unter Berücksichtigung der Elemente Aufgabe, Struktur, Technik und Personal (2000)

Band 57 Claude Tomaszewski: Bewertung strategischer Flexibilität beim Unternehmenserwerb. Der Wertbeitrag von Realoptionen (2000)

Band 58 Thomas Erler: Business Objects als Gestaltungskonzept strategischer Informationssystemplanung (2000)

Band 59 Joachim Gassen: Datenbankgestützte Rechnungslegungspublizität. Ein Beitrag zur Evolution der Rechnungslegung (2000)

Band 60 Frauke Streubel: Organisatorische Gestaltung und Informationsmanagement in der lernenden Unternehmung. Bausteine eines Managementkonzeptes organisationalen Lernens (2000)

Band 61 Andreas von der Gathen: Marken in Jahresabschluß und Lagebericht (2001)

Band 62 Lars Otterpohl: Koordination in nichtlinearen dynamischen Systemen (2002)

Band 63 Ralf Schremper: Aktienrückkauf und Kapitalmarkt. Eine theoretische und empirische Analyse deutscher Aktienrückkaufprogramme (2002)

Band 64 Peter Ruhwedel: Aufsichtsratsplanungssysteme. Theoretische Grundlagen und praktische Ausgestaltung in Publikumsaktiengesellschaften (2002)

Band 65 Jens Thorn: Taktisches Supply Chain Planning. Planungsunterstützung durch deterministische und stochastische Optimierungsmodelle (2002)

Band 66 Dirk Beier: Informationsmanagement aus Sicht der Betriebswirtschaftslehre. Theoretische Ansätze und das Beispiel Mobile Business. (2002)

Band 67 Nils Crasselt: Wertorientierte Managemententlohnung, Unternehmensrechnung und Investitionssteuerung. Analyse unter Berücksichtigung von Realoptionen. (2003)

Band 68 Franca Ruhwedel: Eigentümerstruktur und Unternehmenserfolg. Eine theoretische und empirische Analyse deutscher börsennotierter Unternehmen. (2003)

Band 69 Andreas Bonse: Informationsgehalt von Konzernabschlüssen nach HGB, IAS und USGAAP. Eine empirische Analyse aus Sicht der Eigenkapitalgeber. (2004)

Band 70 Thorsten Sellhorn: Goodwill Impairment. An Empirical Investigation of Write-Offs under SFAS 142. (2004)

Band 71 Bernd Slaghuis: Vertragsmanagement für Investitionsprojekte. Quantitative Projektplanung zur Unterstützung des Contract Managements unter Berücksichtigung von Informationsasymmetrie. (2005)

Band 72 Stephanie Freiwald: Supply Chain Design. Robuste Planung mit differenzierter Auswahl der Zulieferer. (2005)

Band 73 Rolf Uwe Fülbier: Konzernbesteuerung nach IFRS. IFRS-Konsolidierungsregeln als Ausgangspunkt einer konsolidierten steuerlichen Gewinnermittlung in der EU? (2006) 


\section{Steuerliche Gewinnermittlung und IAS/IFRS am Beispiel immaterieller Vermögenswerte}

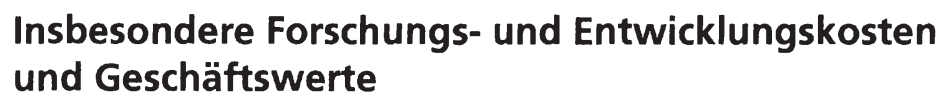

Frankfurt am Main, Berlin, Bern, Bruxelles, New York, Oxford, Wien, 2004.

XLIV, $240 \mathrm{~S}$.

Europäische Hochschulschriften: Reihe 2, Rechtswissenschaft. Bd. 4045

ISBN 3-631-53223-7 · br. €51.50*

Ausgangspunkt der Arbeit ist die zunehmende Kritik am Maßgeblichkeitsprinzip des $\S 5$ Abs. 1 EStG. Die Autorin untersucht die steuerliche Eignung der IAS/IFRS am Maßstab der verfassungsrechtlichen Anforderungen an ein ordnungsgemäßes Steuerbilanzrecht und verdeutlicht dies am Beispiel der Bilanzierung von Forschungs- und Entwicklungskosten sowie Geschäftswerten. Dabei kommt sie zu dem Ergebnis, dass die IAS/IFRS formell und materiell steuerlich ungeeignet sind und de lege ferenda ein eigenständiges Steuerbilanzrecht die bestmögliche Lösung der bestehenden Probleme darstellt.

Aus dem Inhalt: Vergleich der Gewinnermittlung und Bilanzierung immaterieller Vermögenswerte nach EStG und IAS/IFRS · Untersuchung der steuerlichen Eignung der IAS/IFRS

Frankfurt am Main - Berlin - Bern - Bruxelles - New York - Oxford - Wien

Auslieferung: Verlag Peter Lang AG

Moosstr. 1, CH-2542 Pieterlen

Telefax 0041 (0) 32/3761727

*inklusive der in Deutschland gültigen Mehrwertsteuer

Preisänderungen vorbehalten

Homepage http://www.peterlang.de 
Rolf Uwe Fülbier - 978-3-631-75507-5

Downloaded from PubFactory at 01/11/2019 04:02:44AM 
Rolf Uwe Fülbier - 978-3-631-75507-5

Downloaded from PubFactory at 01/11/2019 04:02:44AM 